


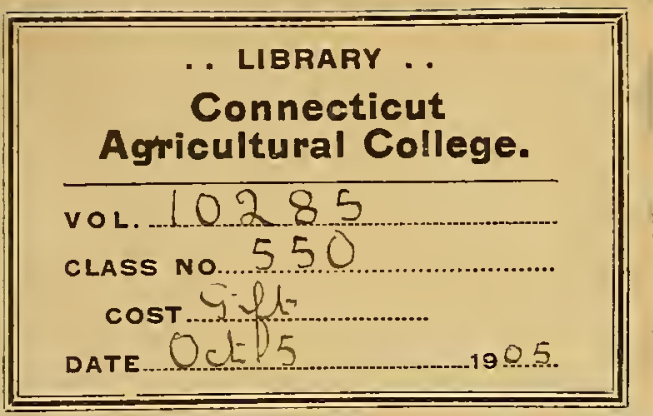





\section{Digitized by the Internet Archive in 2009 with funding from Boston Library Consortium Member Libraries}


. 

DEPARTMENT OF THE INTERIOR

\section{MONOGRAPHS}

Uniteid States Geological Survey

VOLUME XLVII

WASHINGTON

GOVERNMENT PRINTING OFFICE

1904 
10285 
UNITED STATES GEOLOGICAL SURVEY CHARLES D. WALCOTT, DIRECTOR

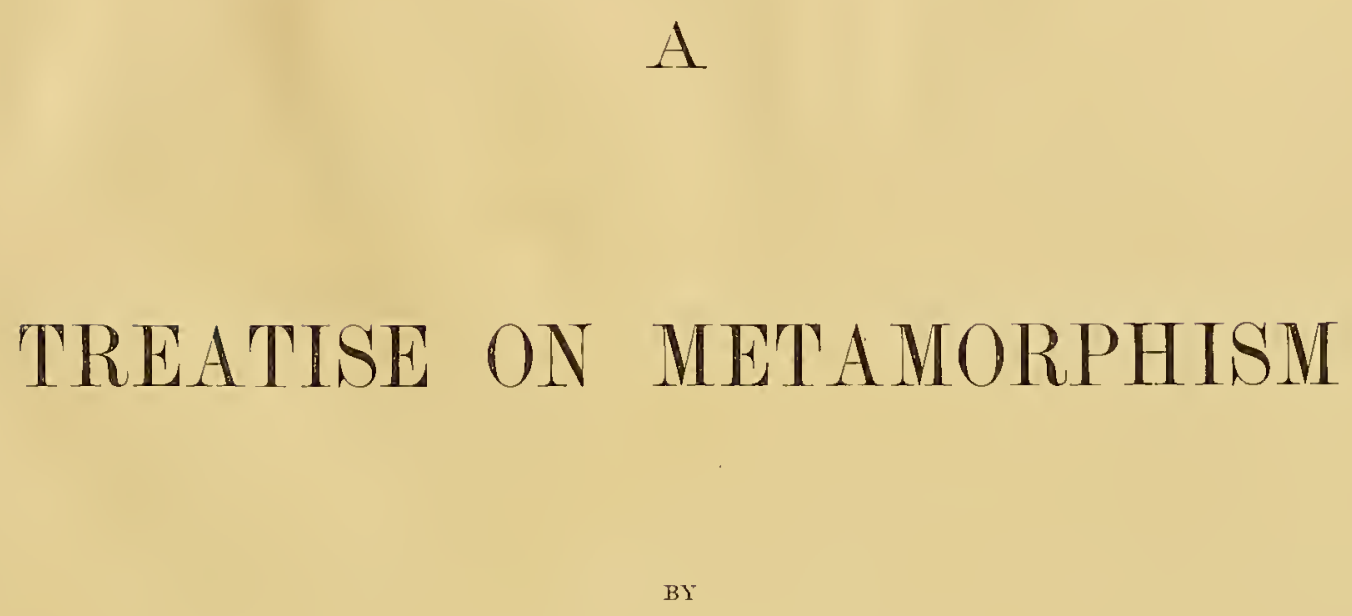

CHARLES RIOHARI VAN HISE

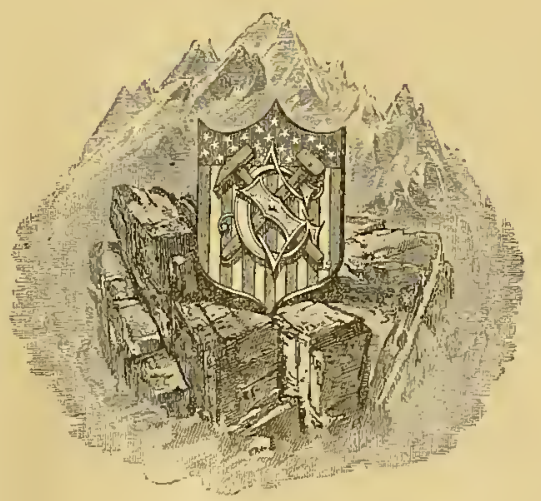

IVASHINGTON

GOVERNMENT PRINTING OFFICE 1904 



\section{CONTENTS.}

Letter of Transmittal .... Page.

Chapter I._Introduction . . .

General nature of alterations..........

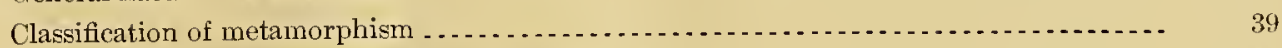

Geological factors affecting the alterations of rocks . .

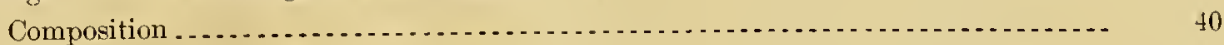

Structures and textures............. 40

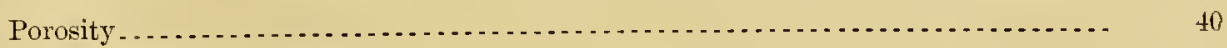

Water and gaseous content.

Climatic and geographic conditions .............. 41

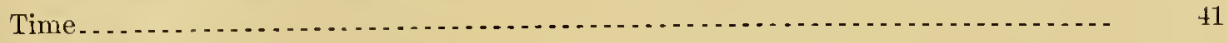

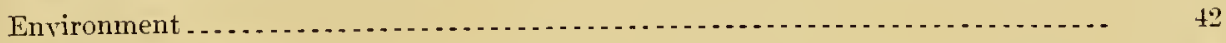

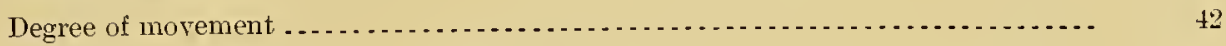

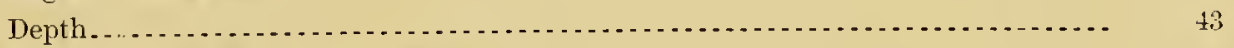

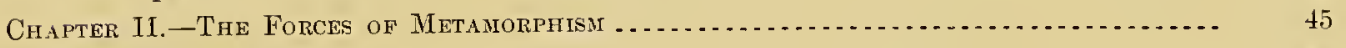

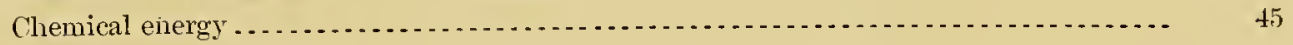

Gravity

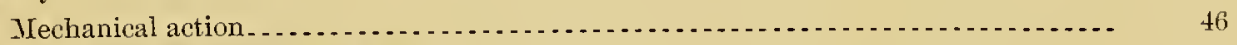

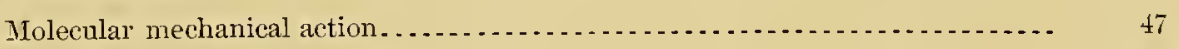

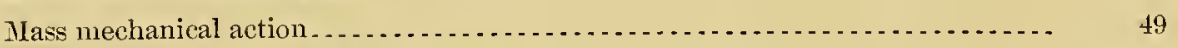

Permanent strain without openings.................................. 49

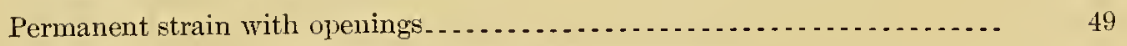

Permanent strain with closing of openings and welding.............. 50

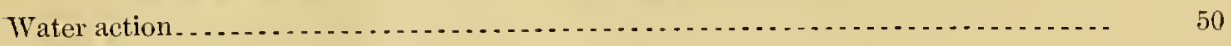

Heat and light.................... 51

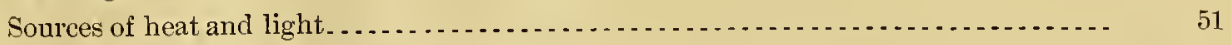

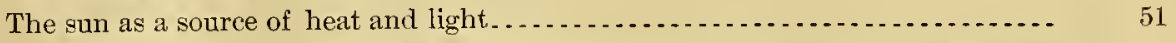

Heat derived from within the earth by conduction or convection through water

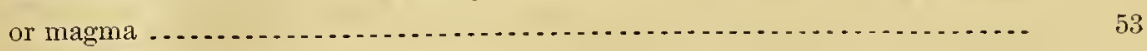

Mechanical action as a source of heat .................. 54

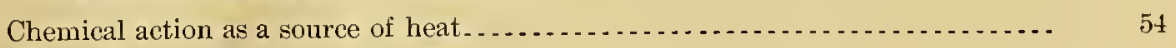

Effects of heat and light on alterations of rocks........... 54

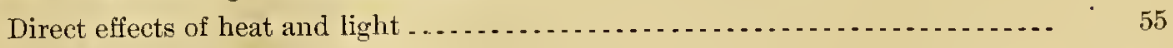

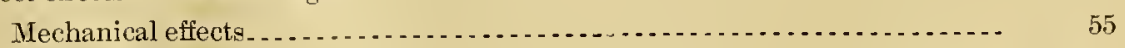

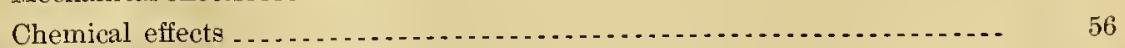

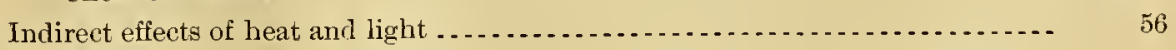

General statements. . . . . 


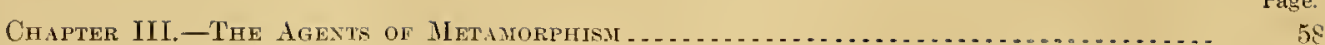

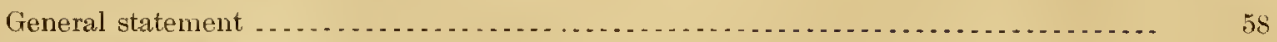

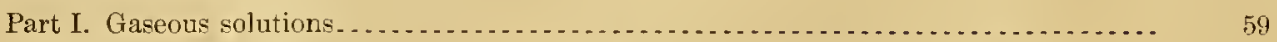

Section 1. Chemical and physical principles controlling the action of gases . . . . . . . 60

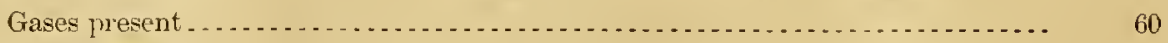

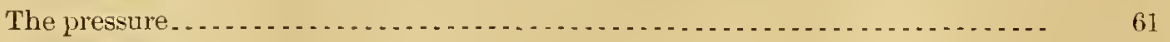

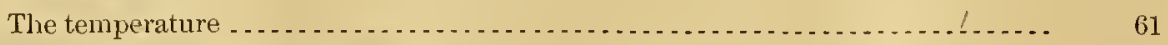

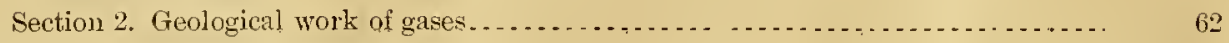

Part II. Aqueous solutions and solids . .

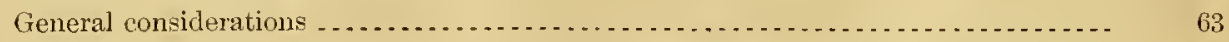

Section 1. Chemical and physical principles controlling the action of ground water.. $\quad 65$

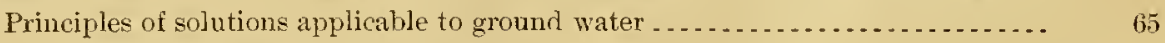

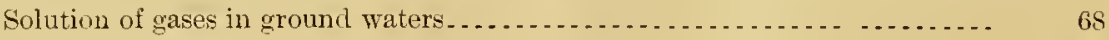

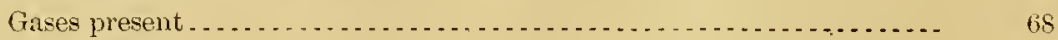

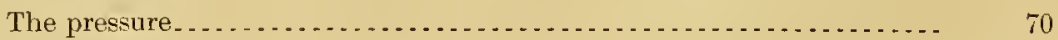

The temperature $\ldots \ldots \ldots \ldots \ldots$ i2

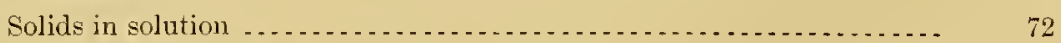

Solution of solids in ground water . .

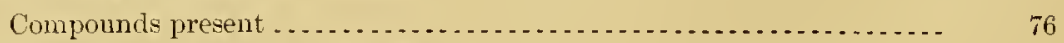

Relations of solution and pressure.......................... 7

Relations of solution and temperature ............................. 79

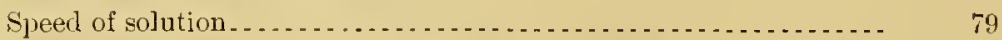

Quantity of material which may be held in solution ............. 79

Relations of solution to absorption and liberation of heat. ....... 81

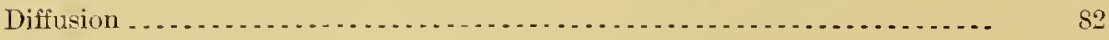

Principles of chemical reactions applicable to ground waters............... $8 \pm$

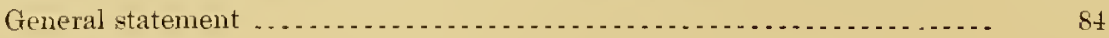

Defunitions

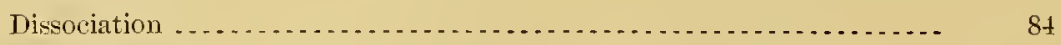

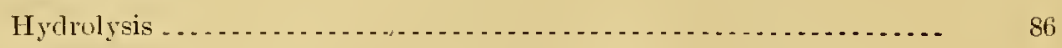

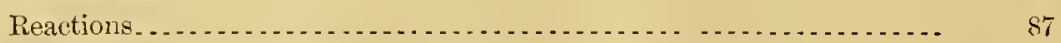

Equilibrium ...

Homogeneous and heterogeneous systems.................... 90

Nature and speed of reactions . . . . .

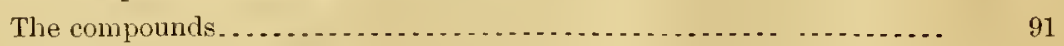

Strength of the solutions......................................... 94

Mechanical action.

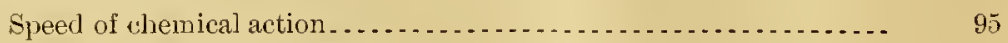

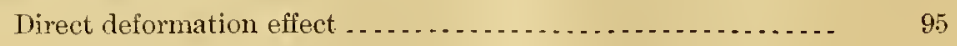

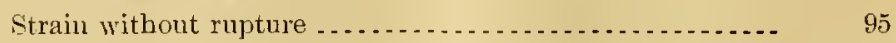

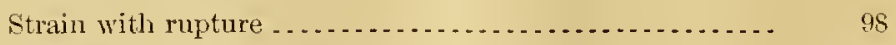

Readjustment of particles...................... Is

Indirect heat effect. . . . . . .

Nature of the chemical reactions. ........................ 100 
Chapter III.-The Agents of Metamorphism-Continued.

Part I1. Aqueous solutions and solids-Continued.

Section 1. Chemical and physical principles, etc.-Continnei.

Principles of chemical reactions applicable to ground waters-Continued.

Tature and speed of reactions-Continued.

Jechanical action-Continued.

Nature of the chemical reactions-Continued.

Smaller rock volume as the result of solution and deposition without change in chemical composition.................

Recrystallization and condensation without change of minerals

Recrystallization and condensation with change of minerals.

Smaller volume as the result of solution and redeposition with change in chemical composition.

Crystallization and condensation of amorphous compounds.

Recrystallization and condensation of crystallized compounds .

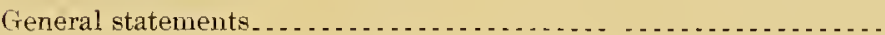

Heat

Relations of chemical action, mechanical action, and heat

Precipitation

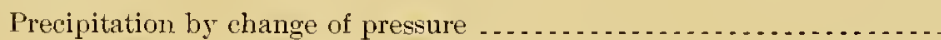

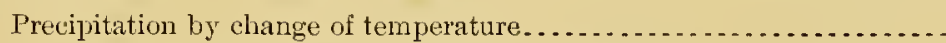

Precipitation by reactions between aqueous solutions ...............

Pracipitation by reactions between aqueons solutions and gases........

Frecipitation by reactions between solutions and solids ............. 120

Section 2. Circulation and work of ground water......................... 123

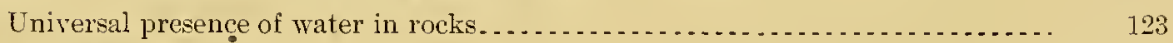

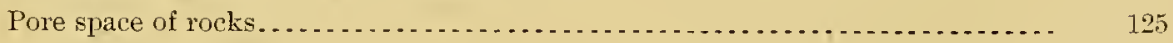

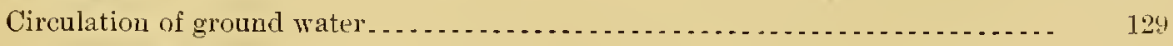

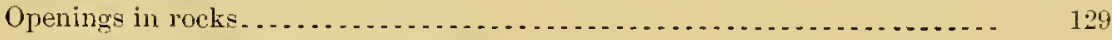

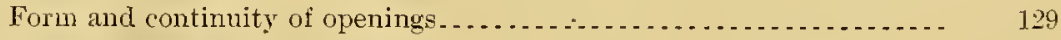

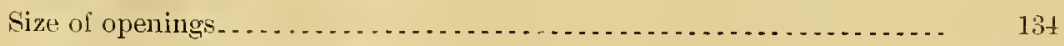

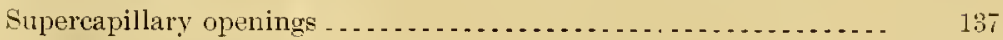

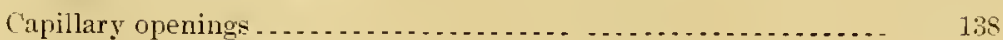

Subcapillary openings ...................................... 143

Percentage of openings, or pore space ....................... $1+6$

Forces producing water circulation ................................... 146

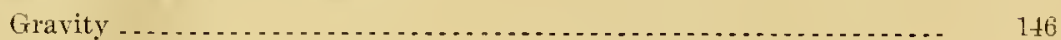

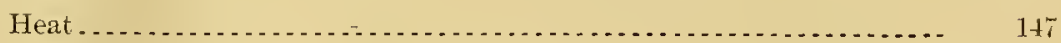

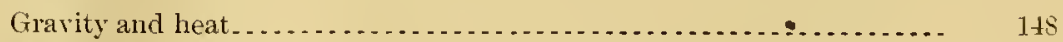

Mechanical action . . .

Molecular attraction . . . . . . . 150

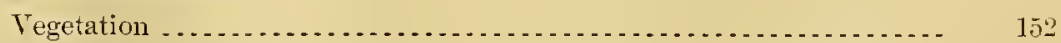

General statements. $\ldots \ldots \ldots \ldots$ 
Chapter III.-The Agents of MEtamorpisil-Continued.

Page.

Part II. Aqueons solutions and solids-Continued.

Section 2. Circulation and work of ground water-Continued.

Circnlation of ground water-Continued.

The factor opposing water cireulation . . . . . . . . .

General statements . . . . .

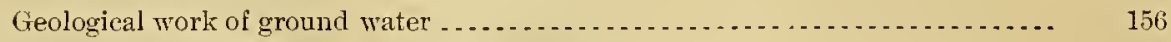

Chapter IV.-The Zones and Belis of Metamorphisu........................... 159

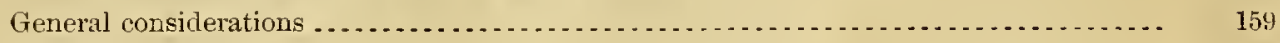

Zone of katamorphism...$\ldots \ldots \ldots \ldots$

Belt of weathering

Belt of cementation ......................

Belts of weathering and cementation contrasted ....

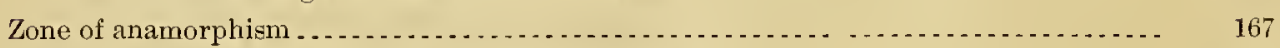

Relations of zones of katamorphism and anamorphism $\ldots \ldots \ldots \ldots \ldots$

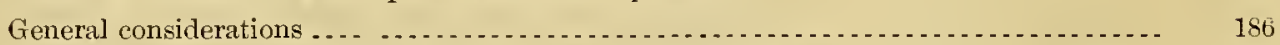

Relations of zones of katamorphism and anamorphism to zones of fracture and flowage .. $\quad 187$

Upper limit of zone of flowage . . . . . . .

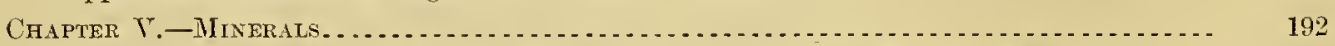

Section 1. Chemical and mineral composition of the known crust of the earth .......... 192

Section 2. General nature of alterations................................... 202

Alteration without change in chemical composition.................... 202

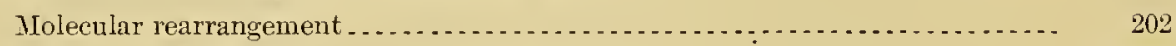

Simple recrystallization. . . . . . .

Alteration with change in chemical composition ........................ 202

Alteration without addition or subtraction of material _............... 203

Alteration with addition or subtraction of material .................... 203

General statements. . . . .

Section 3. Rock-making minerals .

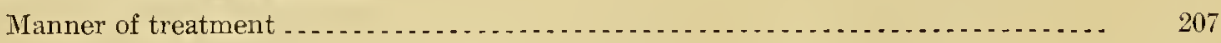

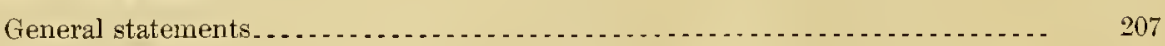

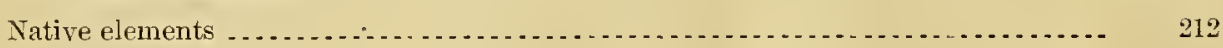

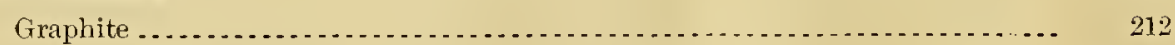

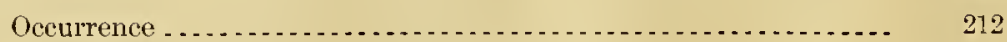

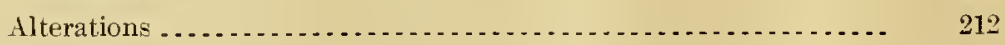

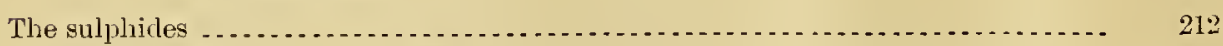

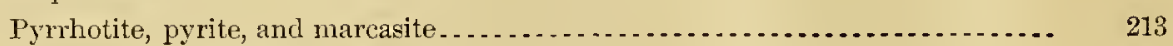

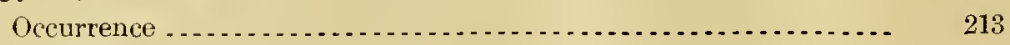

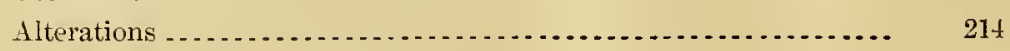

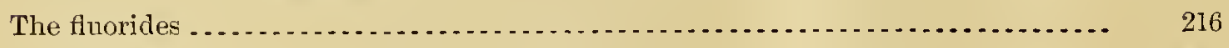

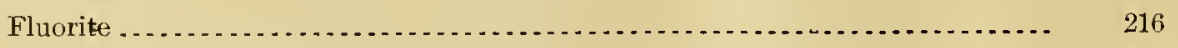

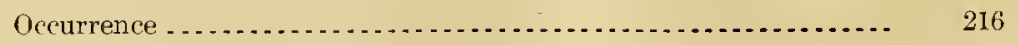

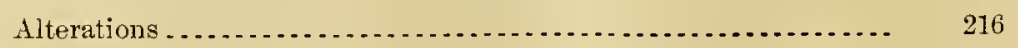

The oxides . . . . . .

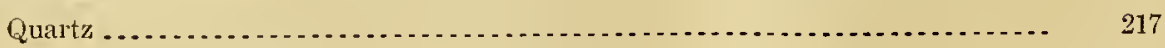

Occurrence $\ldots \ldots \ldots \ldots . \ldots 217$ 
Chapter V.-Minerals-Continued.

Page.

Section 3. Rock-making minerals-Continned.

The oxides-Continued.

Quartz-Continued.

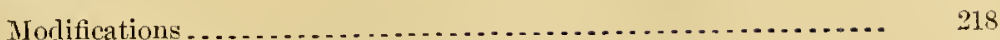

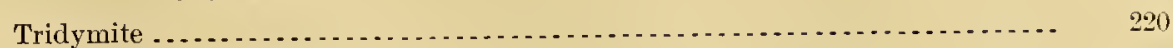

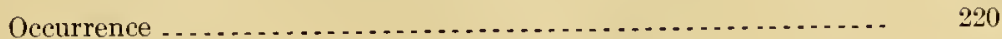

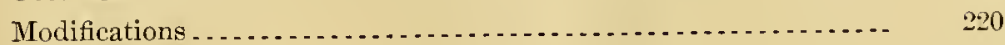

Opal

221

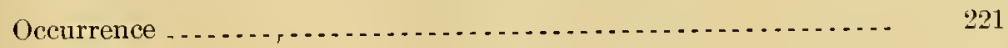

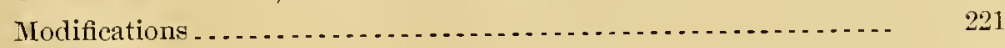

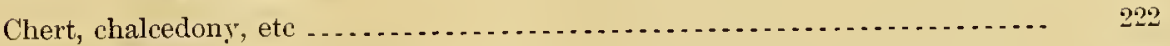

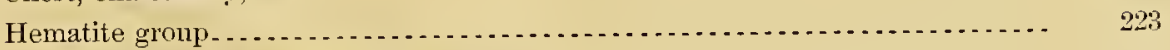

Corundum, hematite, and ilmenite

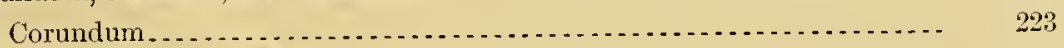

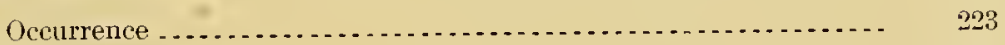

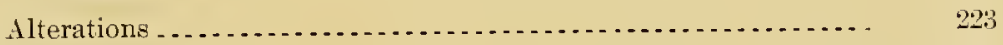

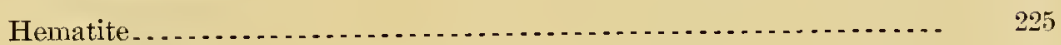

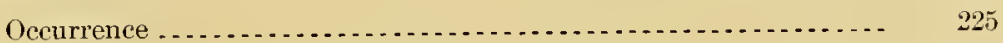

Alterations . . .

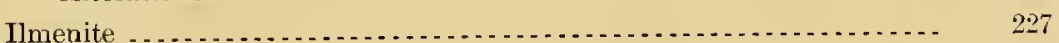

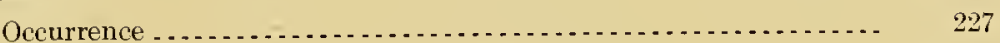

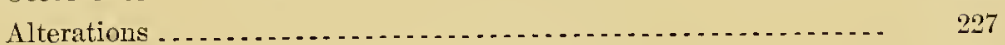

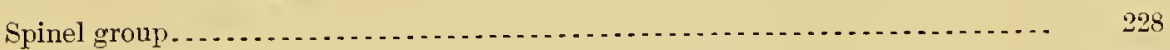

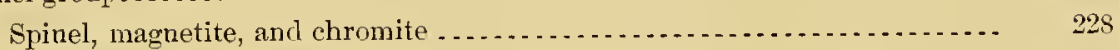

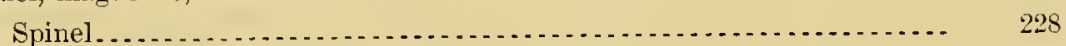

Occurrence $\ldots \ldots \ldots \ldots \ldots \ldots . \ldots 28$

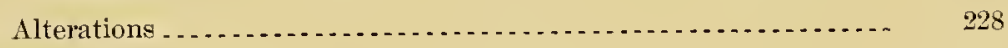

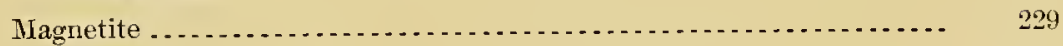

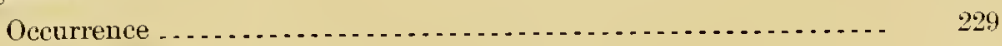

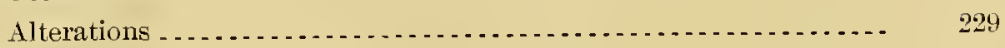

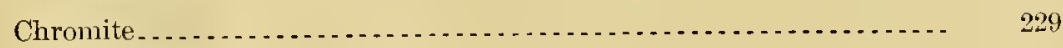

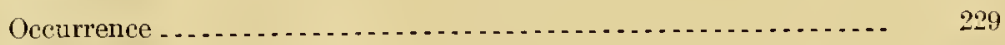

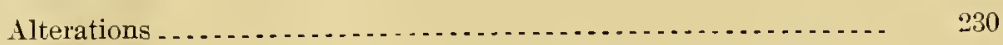

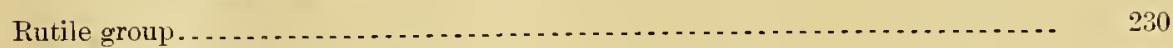

Rutile, octahedrite, and brookite.

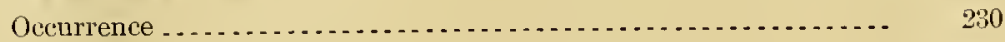

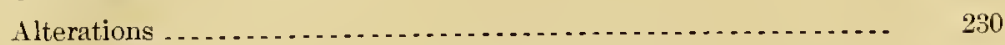

Diaspore group . . . .

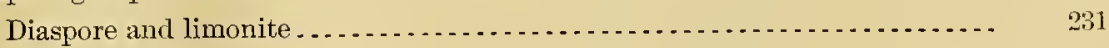

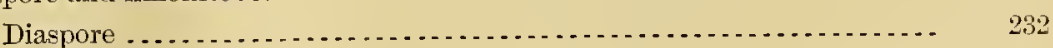

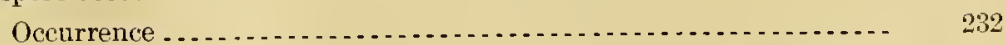

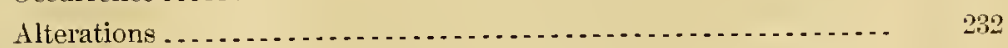

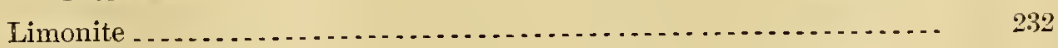

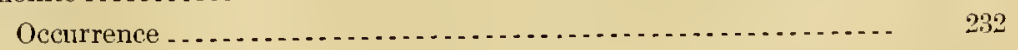

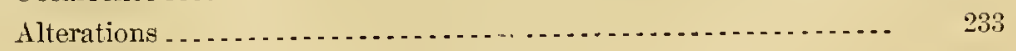


Chapter V.-Minerals-Continuerl.

Page.

Section 3. Rock-making minerals-Contiuued.

'The oxides-Continued.

Brucite group

Brucite and gibbsite

Brucite

Occurrence

Alterations.

Gibbsite

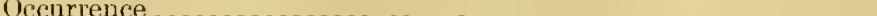

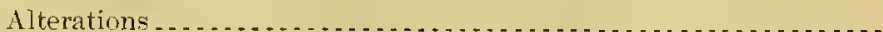

The carbonates. . . . . . . . .

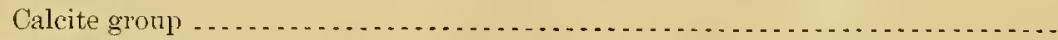

Calcite

Occurrence

(n)

Alterations .

Dolomite

Occurrence

Alterations

Ankerite and parankerite. . . . . . . . . . . . . . . . . . . . . . . . .

Oecurrence

Alterations

Magnesite.

Oecurrence

Alterations

Siderite

Occurrence - - - - - - - - -

Alterations ... . . . . . . . . . . . . . . . . . . . . . . .

Aragonite group

Aragonite

Occurrence

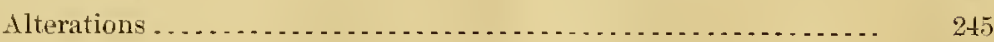

The silicates . . . . . . .

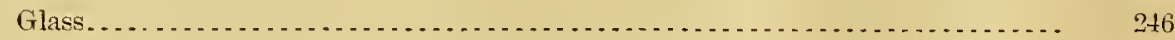

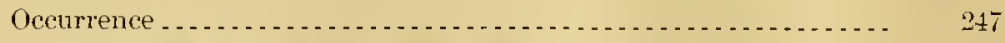

Evidence that devitrification takes place ................. 247

Scale of devitrification .................................. 247

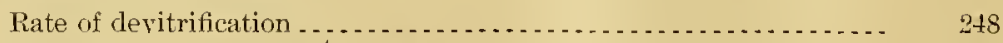

Devitrification in the two zones ........................... 249

Minerals produced . . . . . . . . . .

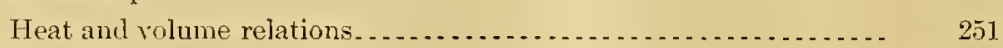

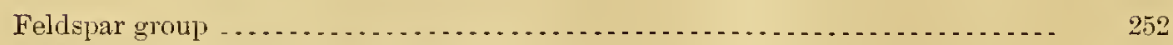

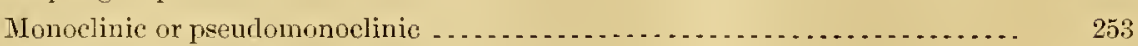

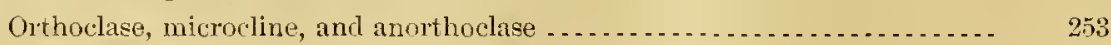

Orthoclase and microcline ................................ 253 
Chapter Y.-Minerals-Continued.

Page.

Section 3. Rock-making minerals-Continued.

The silicates-Continued.

Feldspar grouly--Continued.

Nonoclinic or pseudomonoclinic-Continued.

Orthoctase, microcline, and anorthoclase-Continned.

Orthoclase and microcline-Continued.

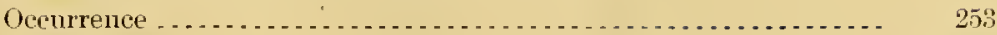

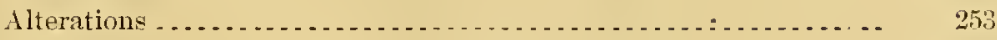

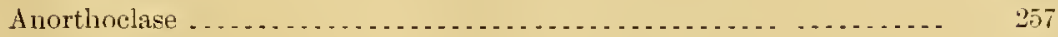

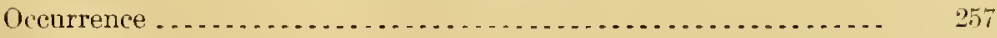

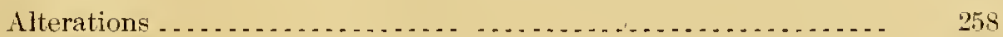

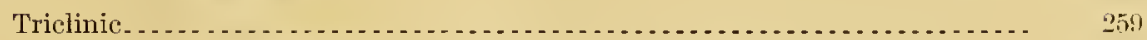

Albite, oligoclase, andesine, labralorite, bytownite, and anorthite ....... 259

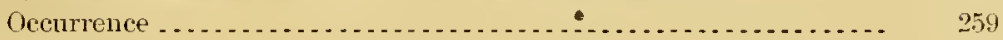

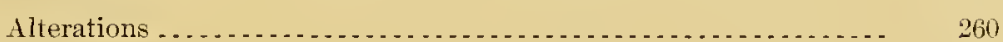

Leucite group.

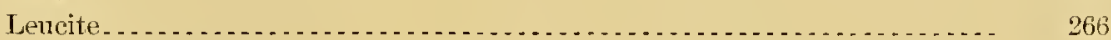

Occurrence $\ldots \ldots 6$

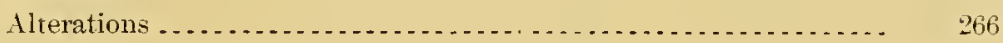

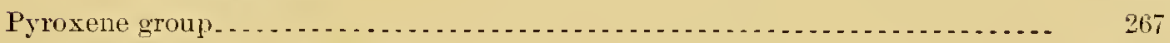

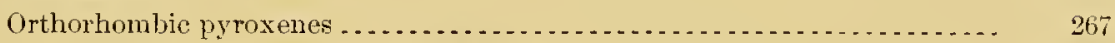

Enstatite, bronzite, and hypersthene ...................... 267

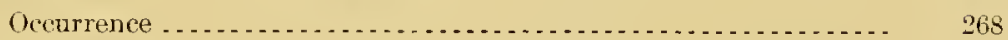

Alterations ...

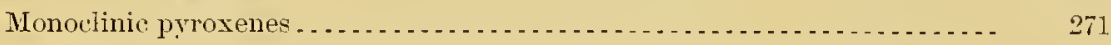

Diopside, sahlite, hedenbergite, augite, acmite, spodumene, wollastonite,

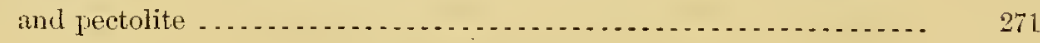

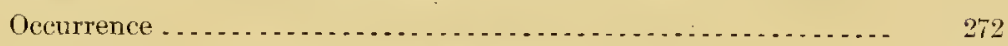

Alterations of the cliopside-augite series. . . . . .

Aiterations of pyroxenes other than the diopside-augite series..... 280

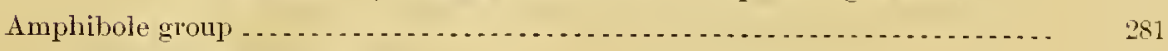

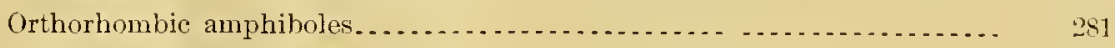

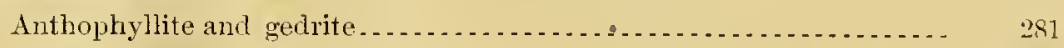

Occurrence . .

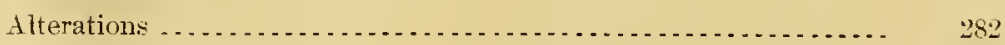

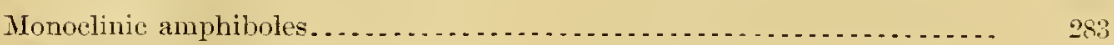

Tremolite, actinolite, cummingtonite, grünerite, hornblende, glaucophane, riebeckite, and arfvedsonite...................... 283

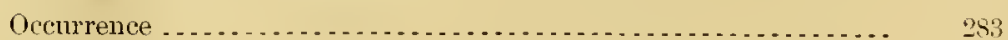

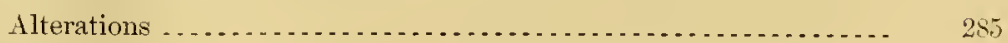

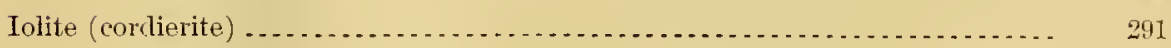

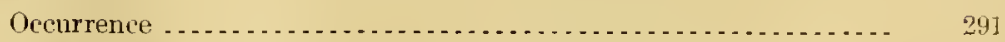

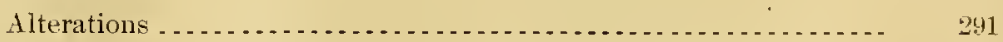

Nephelite group - . . . . . . . . . . . .

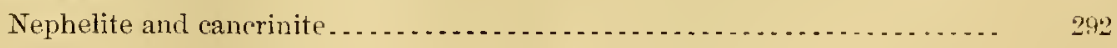


Chapter V.-Minerals-Continued.

Section 3. Rock-making minerals-Continued.

Page.

The silicates-Continued.

Nephelite group-Continued.

Nephelite and cancrinite-Continued.

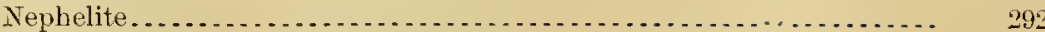

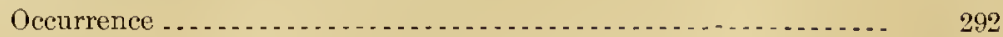

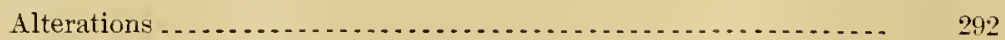

Cancrinite ................ 294

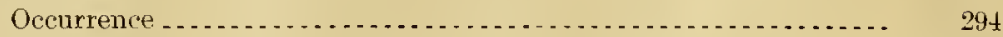

Alterations

Sodalite group

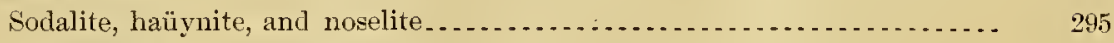

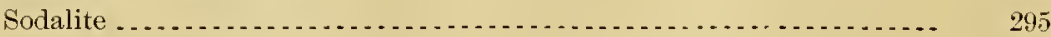

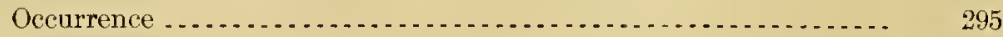

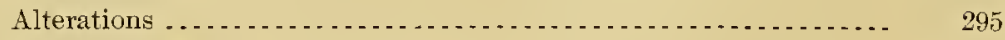

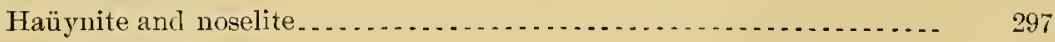

Occurrence

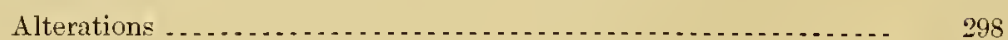

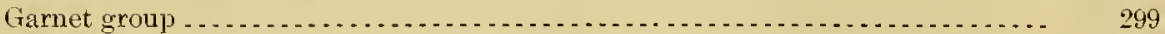

Grossularite, pyrope, almandite, spessartite, melanite, and urarovite...... $\quad 299$

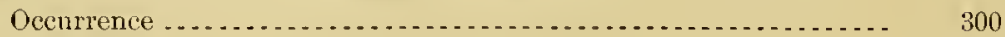

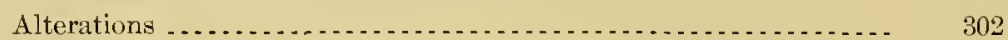

Chrysolite group

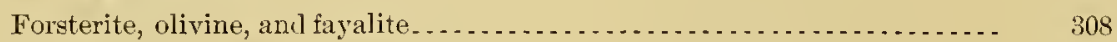

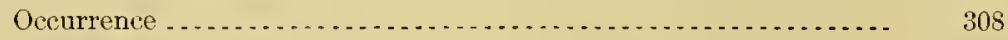

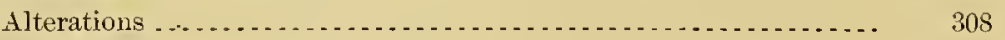

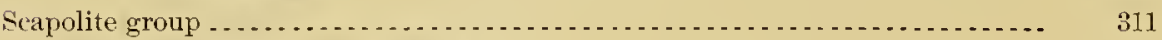

Jeionite, wemerite, and marialite ................................ 311

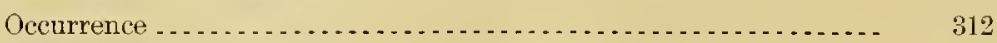

Alterations .................. 312

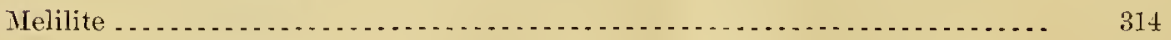

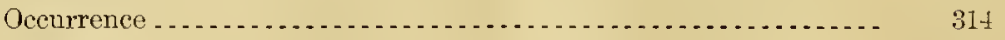

Alterations . .

Gehlenite......

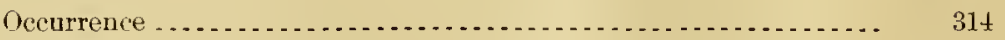

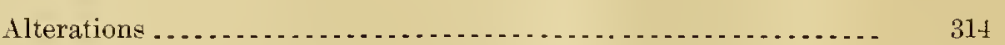

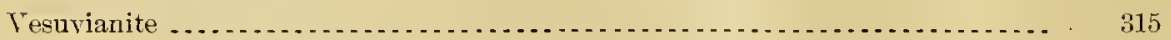

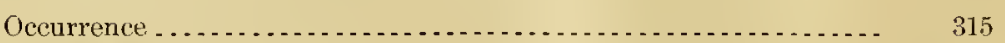

Alterations . . . . 315

Zircon group

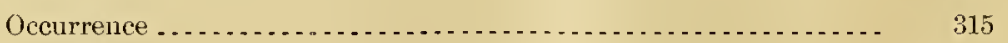

Alterations . . . . . . . . .

Aluninum-silicate grotip . . . . . . . . 316

Topaz, andalusite, sillimanite, and cyanite .......................... 316

Occurrence ............................................... 316

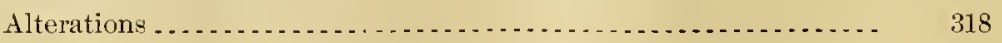


Chapter V.-Minerals--Continued.

Page.

Section 3. Rock-making minerals-Continued.

The silicates-Continued.

Epidote group . . . . . . . . . . . .

Zoisite, epidote, piedmontite, and allanite $\ldots \ldots \ldots \ldots$

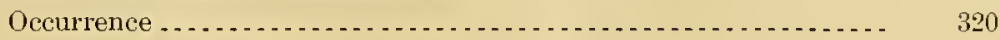

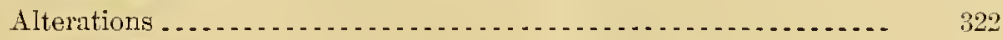

Axinite ....

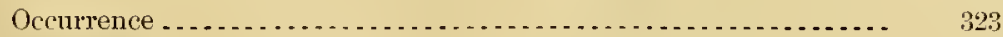

Alterations . . . . . . . . . . . . . . . . . . . . .

Prehnite

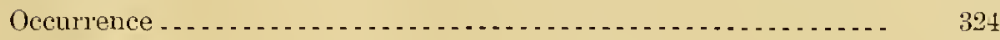

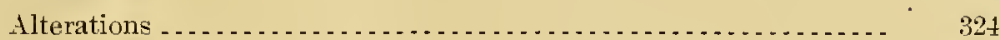

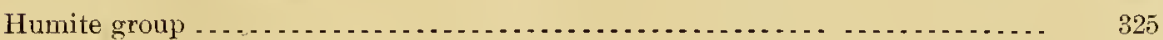

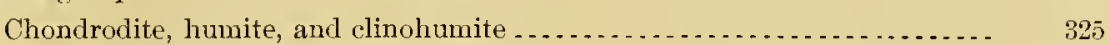

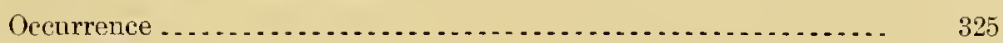

Alterations ..........

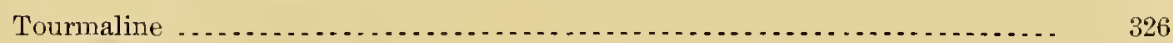

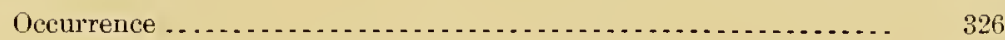

Alterations $\ldots \ldots \ldots$

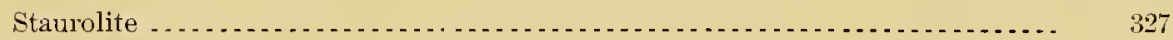

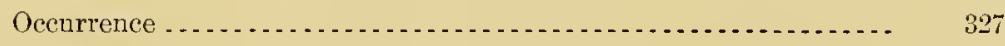

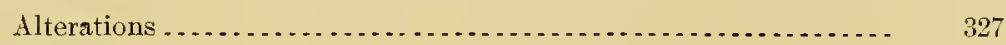

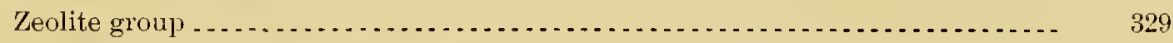

Thomsonite, hydronephelite, natrolite, mesolite, scolecite, analcite, apophyl-

lite, epistilbite, heulandite, stilbite, phillipsite, harmotome, gismondite,

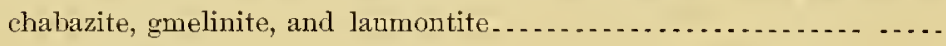

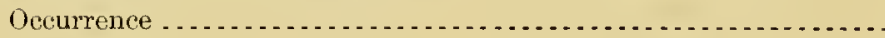

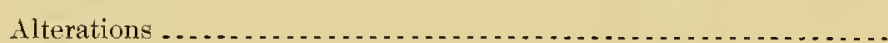

Wica group ...

Muscovite, paragonite, hiotite, and phlogopite .................. 336

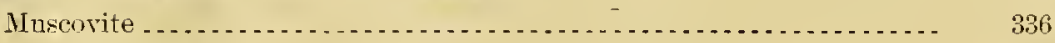

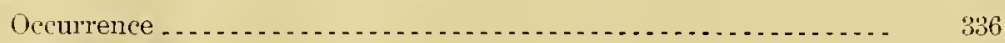

Alterations . .

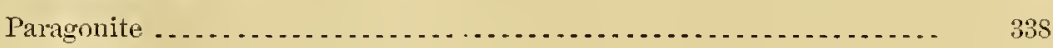

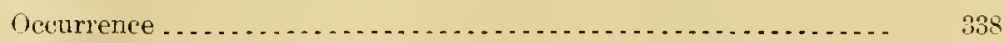

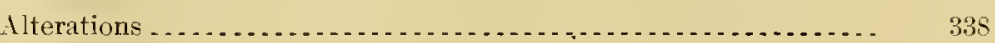

Biotite . 359

Decurrence . . . . 339

Alterations . . . . 339

Phlogopite ........... 343

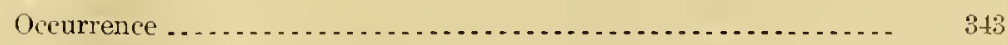

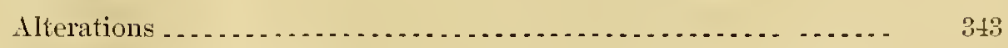

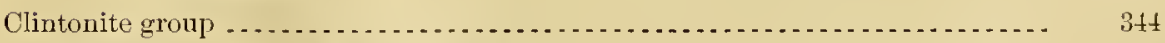

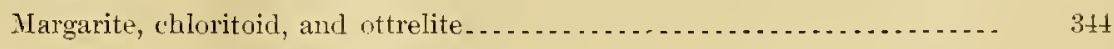

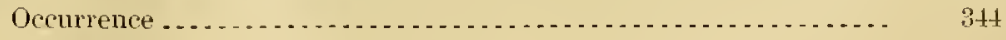

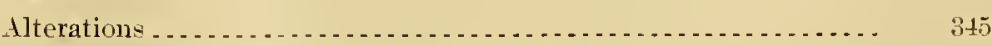


Chapter V.-Minerals-Continued.

Page.

Section 8. Rock-making minerals-Continuer.

The silicates-Continued.

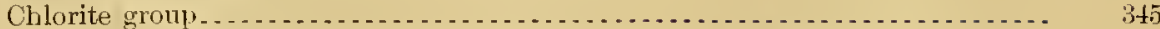

Amesite, corundophilite, prochlorite, clinochlore, and penninite ......... 345

Occurrence . . . . . . .

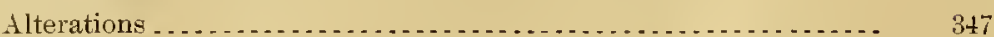

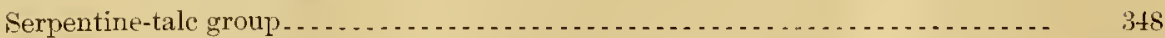

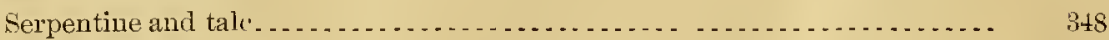

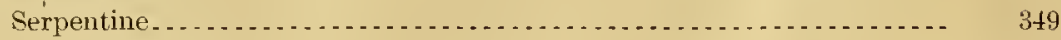

Occurrence

Alterations . . . .

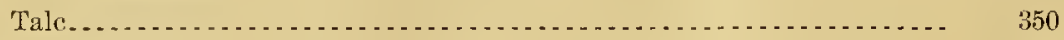

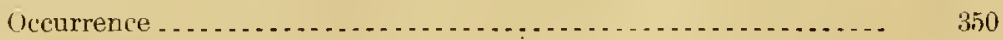

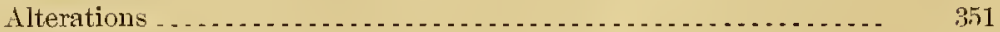

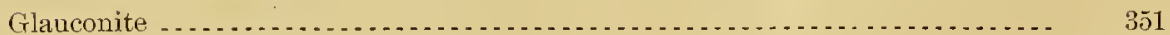

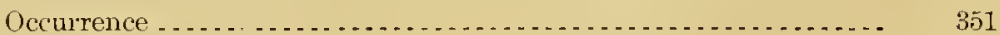

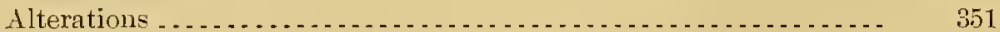

Kaolin group $\ldots \ldots \ldots \ldots$

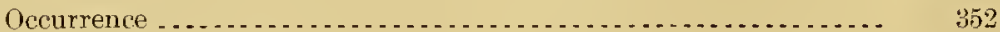

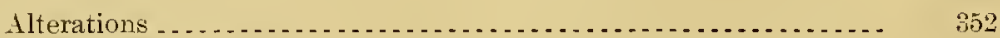

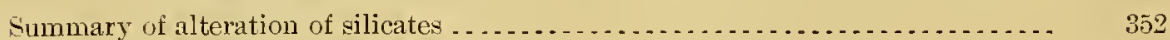

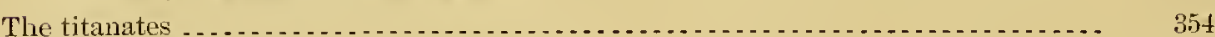

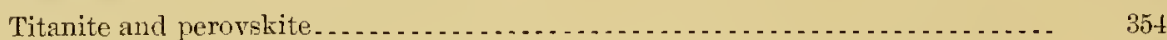

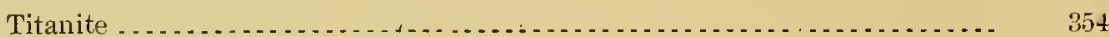

Occurrence . . . . . .

Alterations . . . . .

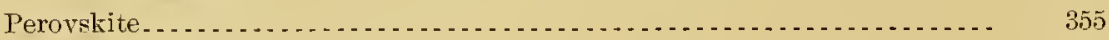

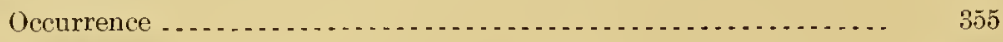

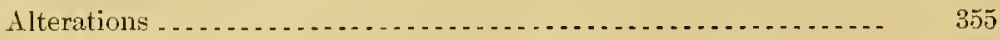

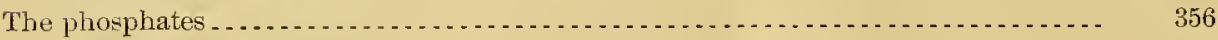

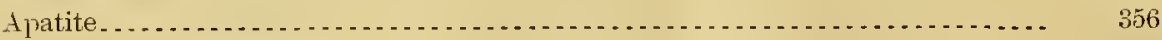

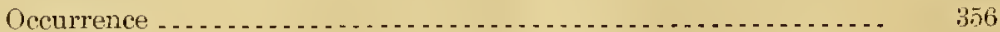

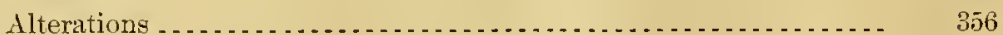

The suiphates. . .

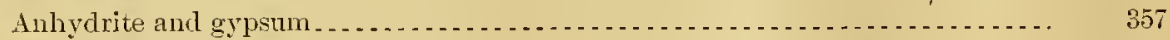

Anbydrite

Occurrence $\ldots \ldots \ldots \ldots \ldots$

Alterations . . . . . . . . . 357

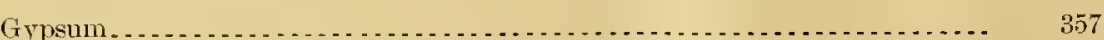

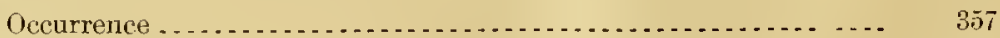

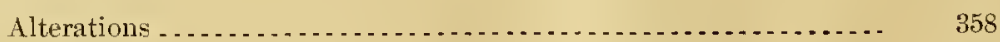

Section 4. General statements. . . .

Physical-chemical factors upon which nature of alterations depends $\ldots \ldots \ldots \ldots \ldots \ldots . . . \ldots 359$

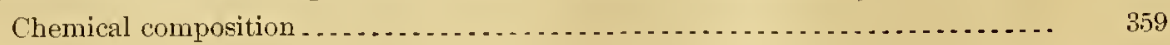


Chapter V.-Jinerals-Contiuued.

Section 4. General statements-Continued.

Physical-chemical factors upon which nature of alterations depends-Continued.

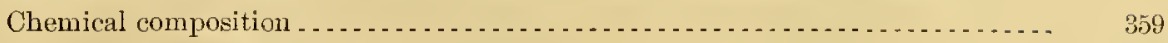

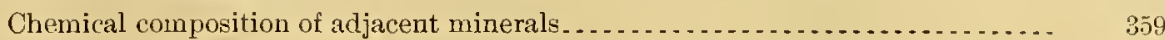

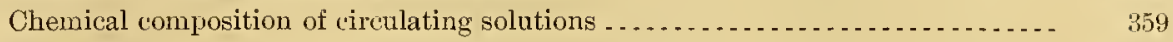

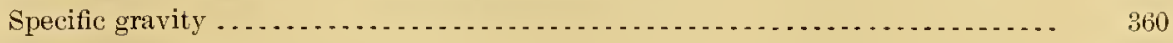

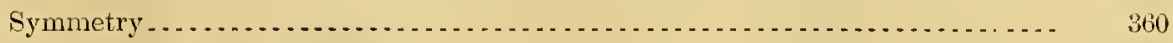

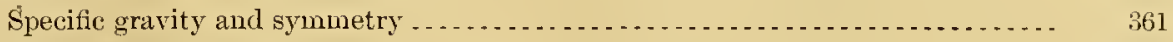

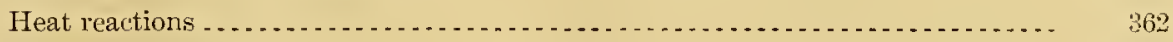

Pressure and volume $\ldots \ldots \ldots \ldots$

Reversible reactions'.

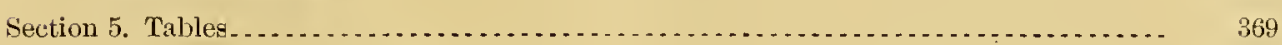

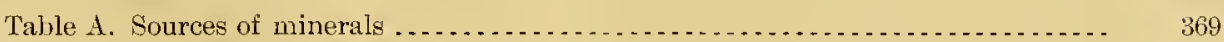

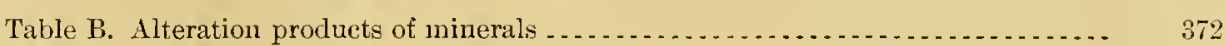

Table C. Chemical reactions and volume changes . . .

Table D. Classification of alterations, with volume changes . . . . . . . $39 \ldots \ldots \ldots \ldots$

Chapter Vi.-The Belt of Weathering $\ldots \ldots \ldots \ldots \ldots \ldots \ldots$

Belt of weathering defined. . . . . .

Form of level of ground water ...................................... 411

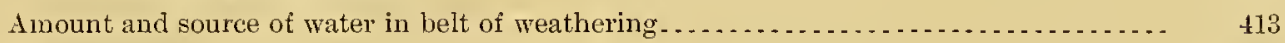

The circulation

Downward movements of water.

Upward movements of water

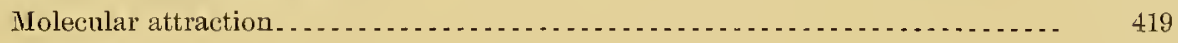

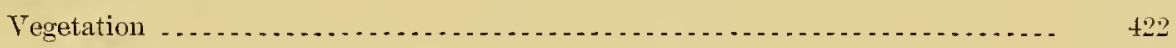

Variation in level of ground water . . . .

Precipitation, seepage, and evaporation .................. 423

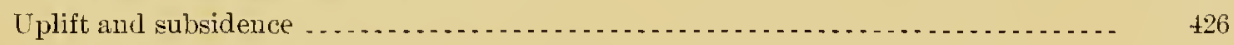

Denudation and valley flling . . . . .

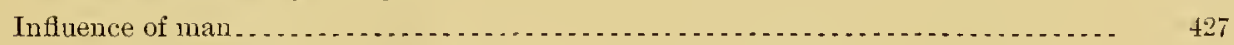

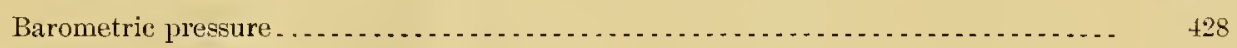

Temperature

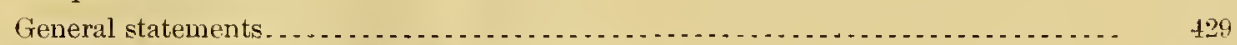

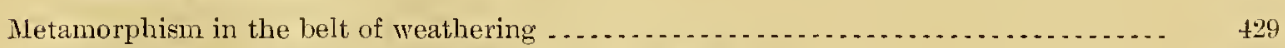

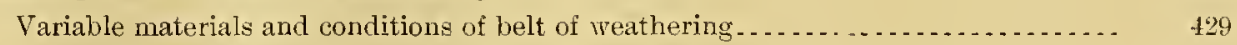

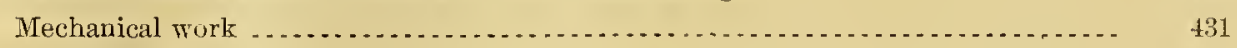

Water, ice, and wind

Change in temperature ........

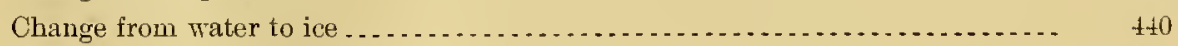

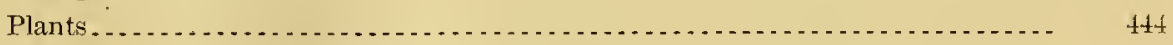

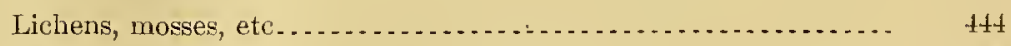

Cacti

Grasses, grains, and vegetables........................... 445

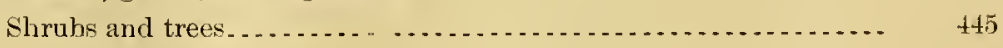


Chapter vi.-The Belt of Weatherisg-Continued.

Page.

Netamorphism in the belt of weathering-Continued.

Mechanical work-Continued.

Animals

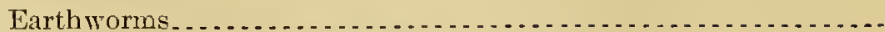

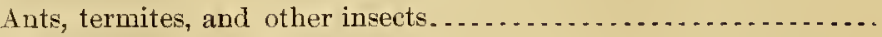

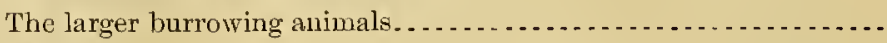

Man

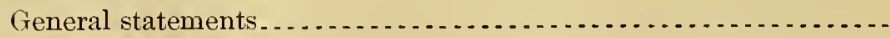

Chemieal work

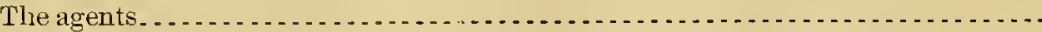

Plants.

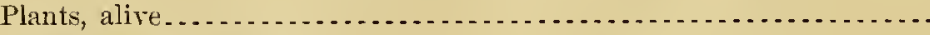

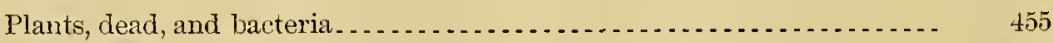

Animals...

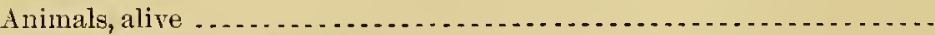

Animals, dead, and bacteria .

Work of solntions . . . . . . . .

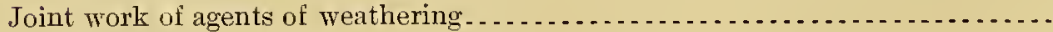

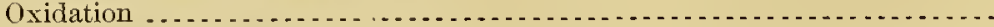

Oxidation of organic compounds. . . . . . . . . . . . . . .

Oxidation of carbon and hydrogen . . . . . . . . . . .

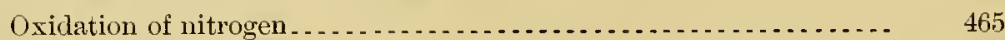

Oxidation of inorganic compounds . . .

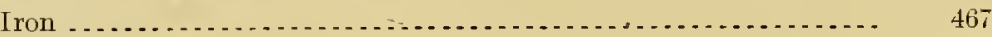

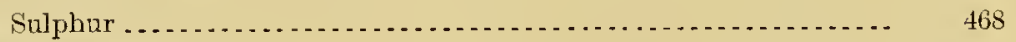

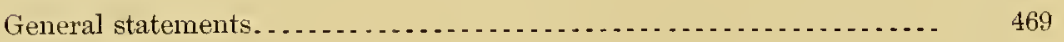

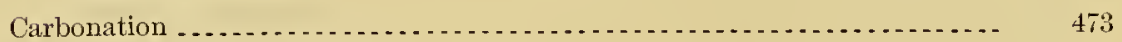

Hydration and dehydration ...................................... 481

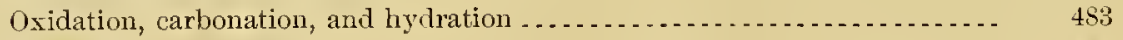

Solntion

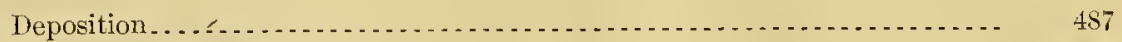

General statements.... . . . . . . . . .

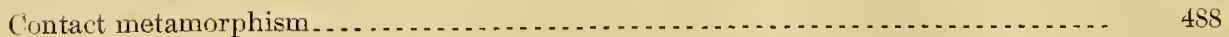

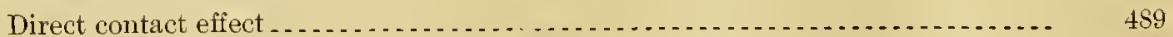

Indirect contact effect, or work of fumaroles and solfataras. ................. 490

Relations of disintegration to lecomposition and solntion ....... . . . . . . . . . . . 494

Regions favorable to prominence of disintegration . . . . . . . .

Arid regions . . . . . . .

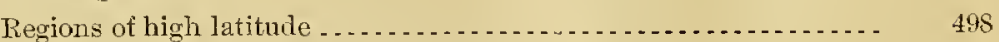

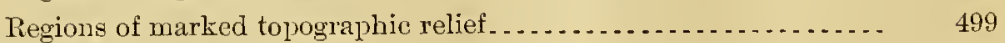

Regions of sparse plants and animals . . . . . ............... 500

Regions near the sea $\ldots \ldots \ldots \ldots$.

Regions favorable to prominence of decomposition . .

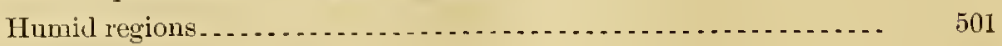

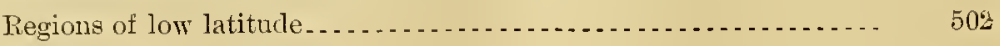


Cinapter Vi.-Tine Belt of Weathering-Continued.

Metamorphism in the belt of weathering-Continued.

Relations of disintegration to decomposition and solution-Continned.

Regions favorable to prominence of decomposition-Continned.

Regions of moderate topographic relief . . . . . . . . . . . . . . .

Regions of abundant plants and animals.................. 503

Regions remote from the sea............................ 504

General statements..................................... 504

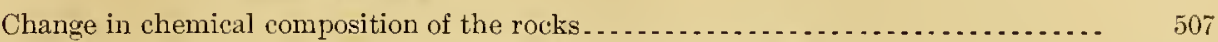

Order of decomposition of the minerals, and the end products.................. 518

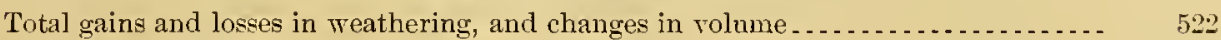

Emphasis and retention of structures and textures.

Obliteration of structures and textures................

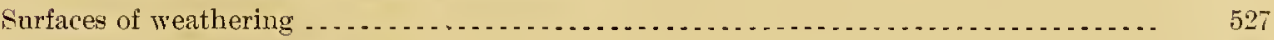

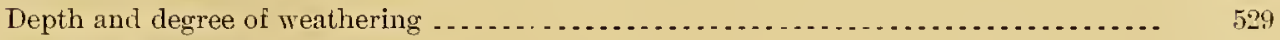

Rate of weathering. . . .

Forces and agents at work in weathering $\ldots \ldots \ldots \ldots$

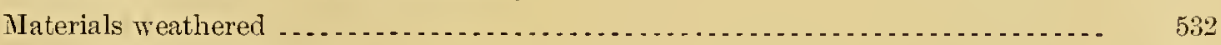

Chemical composition . . . .

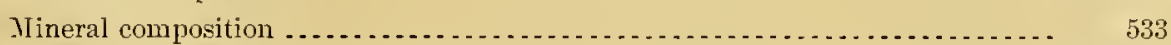

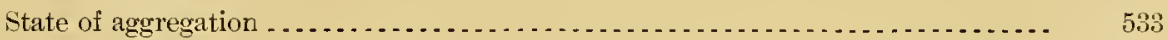

Thickness of the belt of weathering . . . . . . . . .

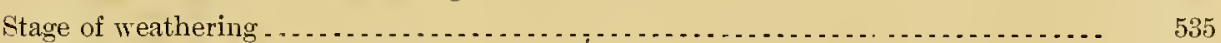

Distribution of dissolved materials . .

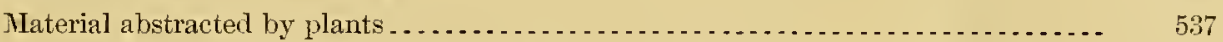

Material transferred to belt of cementation .................................. 538

Material permanently abstracted by run-off. . . .

Naterial dissolved, transported, and reprecipitated in belt of weathering.......... $\quad 539$

Concentration at and near the surface ............................. 543

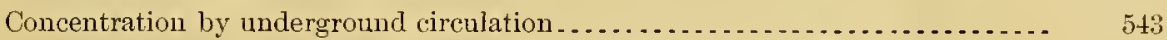

Concentration by circulation mainly confined to belt of weathering........ $\quad 544$

Concentration, by circulation extending into belt of cementation.......... 550

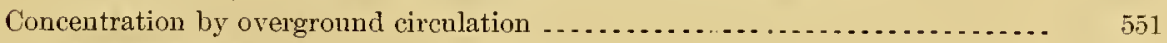

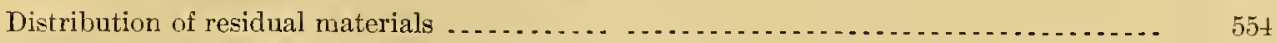

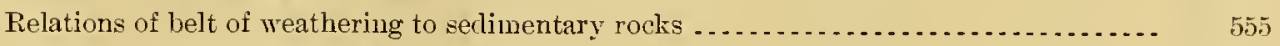

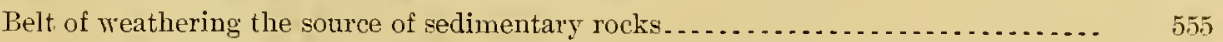

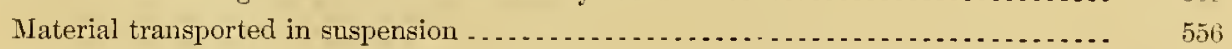

Naterial transported in solution. . . . .

Mlaterial transported in suspension and solution........................... 558

Rocks produced from material of belt of weathering without transportation to the sea . . . . . . .

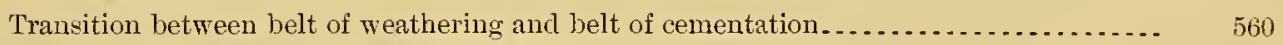

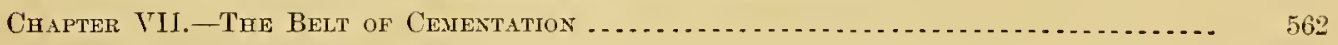

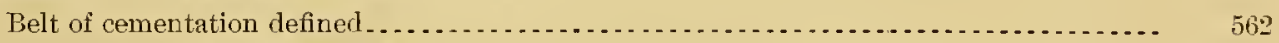

Boundaries of belt of cementation $\ldots \ldots \ldots \ldots$

MION XLVII - 08 - 2 
Chapter YiI.-The Belt of Cenentatiox-Continued.

Conrlition of water in belt of cementation.

Page

566

Amount of water in belt of cementation .

Circulation of water in belt of cementation

Vigor of circulation

Character of circulation.

Linjiting formations. .

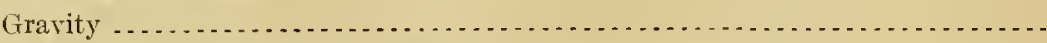

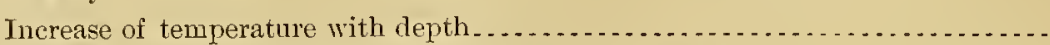

Relative lengths of vertical and horizontal components $\ldots . . .6 \ldots \ldots . . .6$.

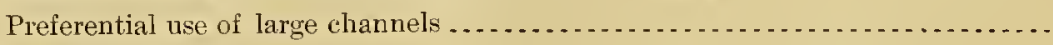

Resultant circulation . . . . . . . . . . .

General statement. . . . . . . . . . . .

Temperature of entering and issuing water, and transfer of heat. . . . . . . . . . . .

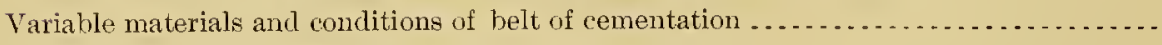

Work in belt of cementation. . . . . . .

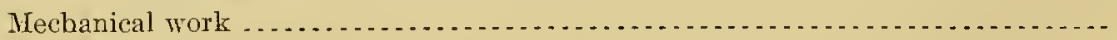

Consolidation... ...

Strain within elastic limit ..................

Strain beyond elastic limit. . . . .

Chemienl work . . . . . . . . . . . . . .

Chemical changes ....

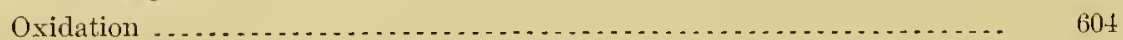

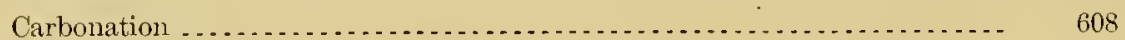

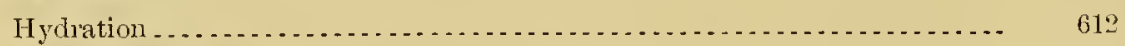

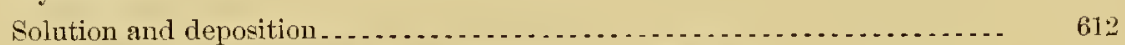

Quantitative relations between solution and deposition ............ 613

Resultant processes . . . . . . . .

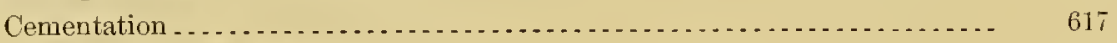

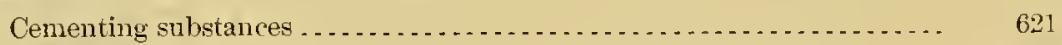

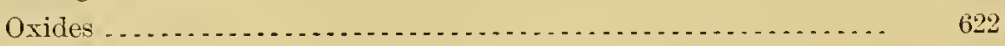

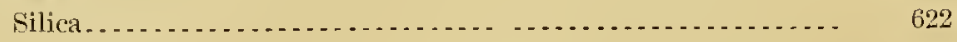

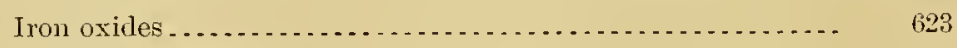

Aluminum oxides . . . . .

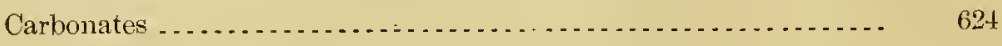

Calcite and dolomite . . . . . .

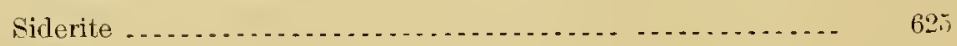

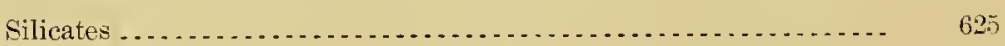

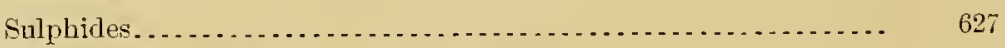

Distribution of elements in cementing minerals................. 627

Distribution of cementing minerials ....................... 628

Causes of cementation .................................... 629

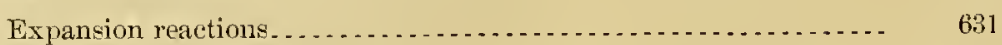

Contributions from igneons rocks ....................... 634

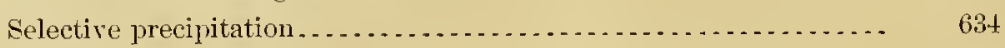

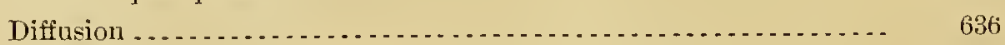

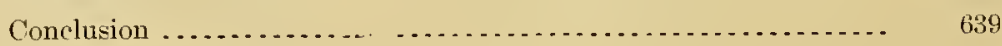




\section{CONTENTS.}

Chapter vil.-The Belt of Cenextation-Continued.

Work in belt of cementation-Contimued.

Chemical work-Continued.

Resuitant processes-Continued.

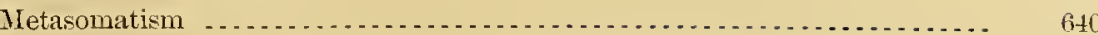

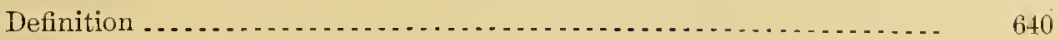

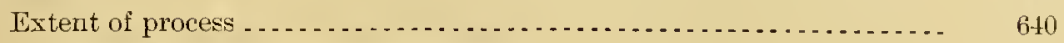

Conditions favorable to metasomatism......................... 641

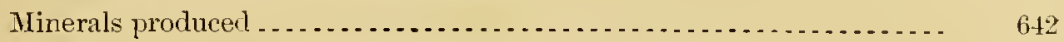

Growth of large individuals and preservation of textures. . . . . . . . . . . 643

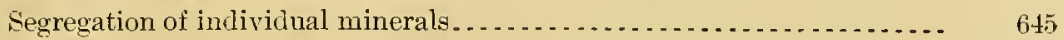

Igneons work. . . . . . . .

Injection . . . . . . . . . . . . . . . .

Combinations and relations of mechanical work, chemical work, and igneous work .. $\quad 653$

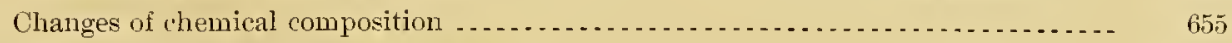

Chapter Vili.-The ZoNe of Axamorphisu $\ldots \ldots \ldots t$

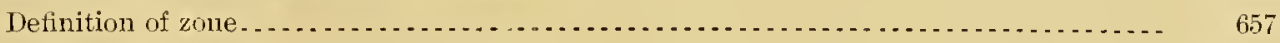

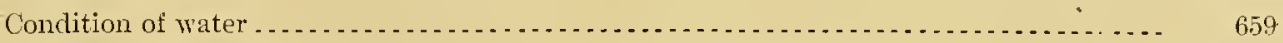

Quantity of water $\ldots \ldots \ldots \ldots \ldots$.

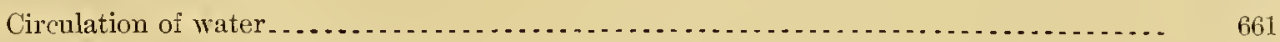

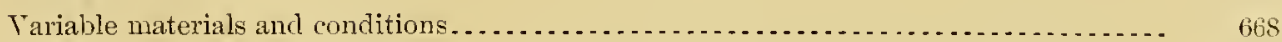

Work in zone of anamorphism . . . .

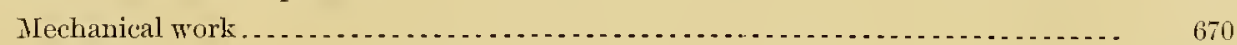

Welding ...

Strain within elastic limit ...

Strain beyond elastic limit. . . . .

Chemical work ...

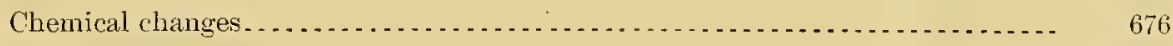

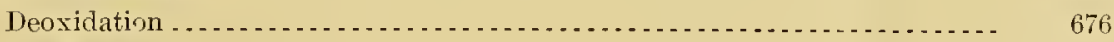

Silication.

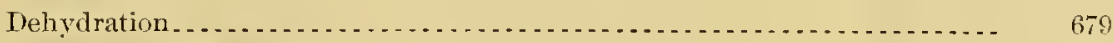

Solution and deposition

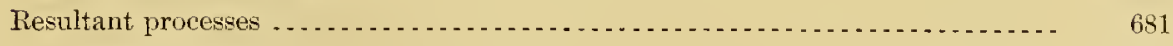

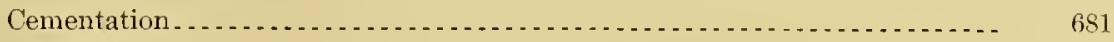

Metasomatism

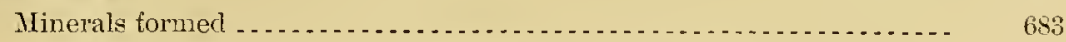

Alterations in connection with mass-mechanical action ............ 685

Recrystallization . . . . . .

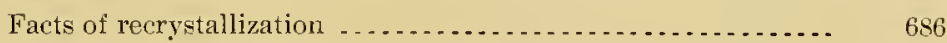

Theory of recrystallization................................. 690

Recrystallization lags behind deformation. . . . . . . $696 \ldots . .66$

Conclusion. . .

Alterations under mass-static conditions . . . . . . . . . . . . . 698

Development of porphyritic textures.......................... 699

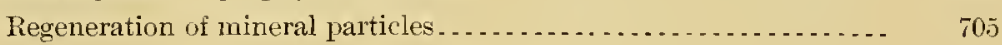


Chapter VIII.-The Zoxe of AxAmorphisu-Continned. Page.

Work in zone of anamorphism-Continned.

Igneous work . . . . .

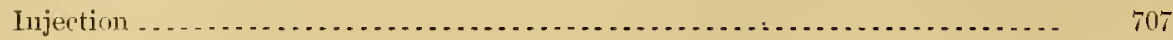

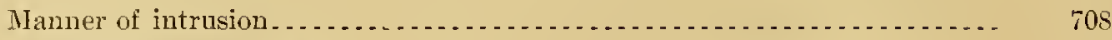

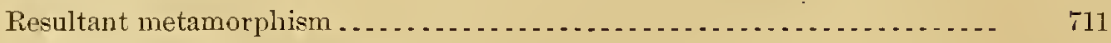

Factors controlling metamorphism ............................. 711

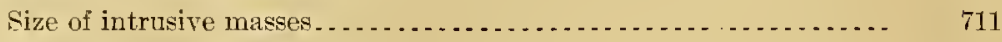

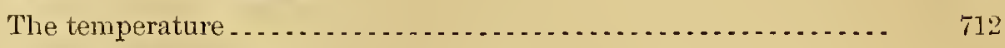

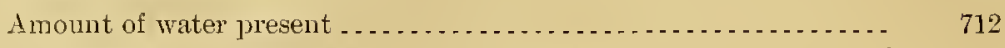

Composition of intrusive and intruded rocks ............... 713

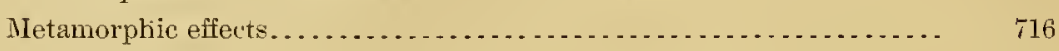

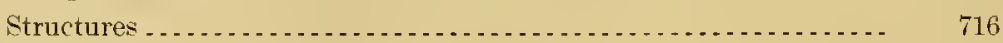

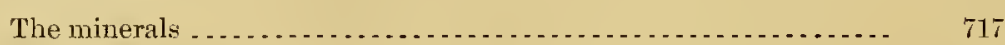

Pegmatites . . . . .

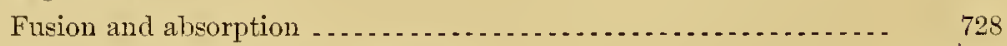

Combinations and relations of the various processes ...........

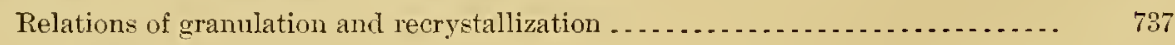

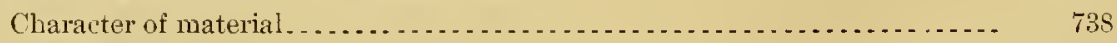

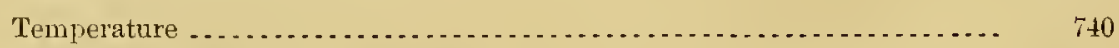

Pressure and rapidity of deformation........................... 741

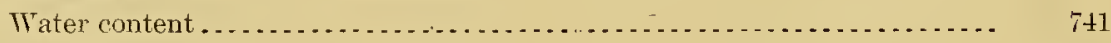

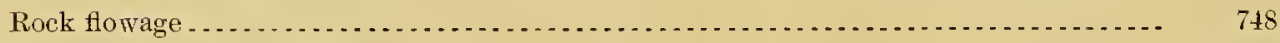

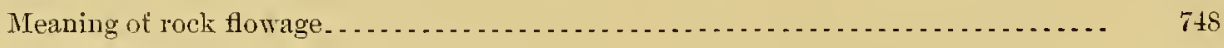

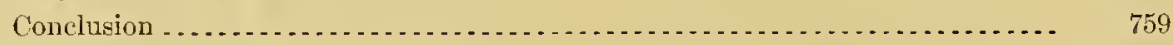

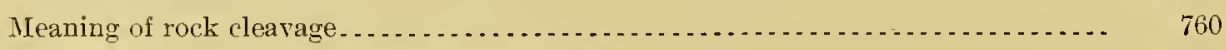

Effect of rock flow on textures and structures . . . .

Rock flowage and mashing .... . . . .

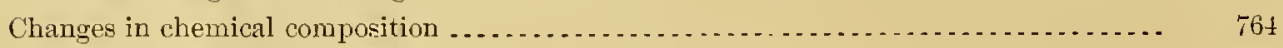

Relations of zone of anamorphism to zone of katamorphism . . .

Comparative energy required for deformation in zones of katamorphism and ana-

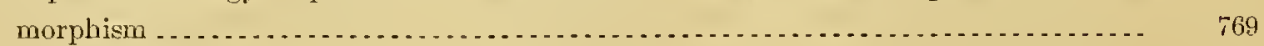

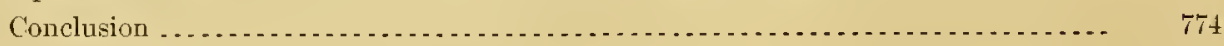

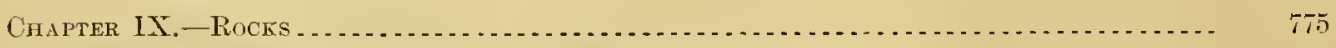

Use of some general terms applied to metamorphic rocks ... $\ldots \ldots \ldots \ldots$

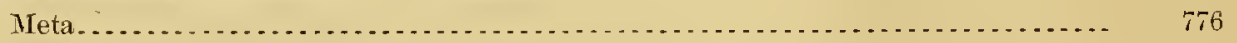

Apo $\ldots 0^{2}$

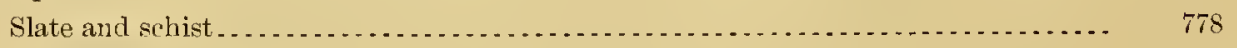

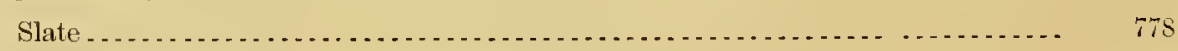

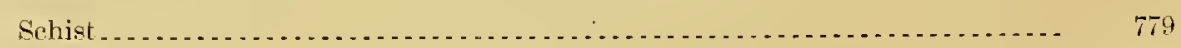

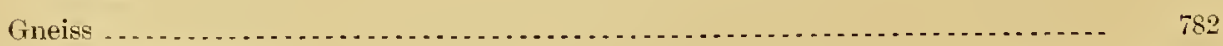

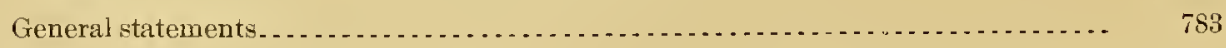

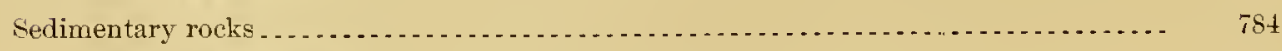

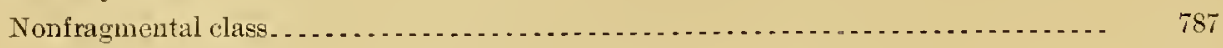

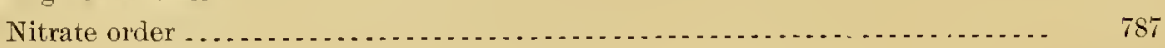

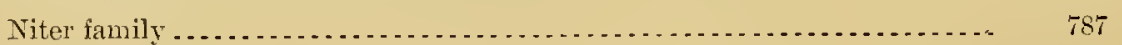


Chapter IX.-Rocks-Continued.

Sedimentary rocks-Continued.

Nonfragmental class-Continued.

Sulphate orler

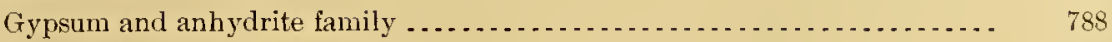

Chloride order ........ 789

Rock-salt family ...

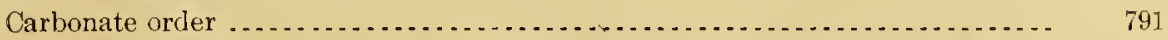

Calcium-magnesium carbonate family and metamorphosed equivalents..... 791

Limestones . . . . . . . . . . . . . . . . . . . . . . . . . . . . . . . . . . . 791

Source of material of limestones............................ 791

Organic precipitates

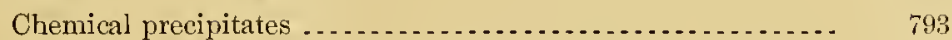

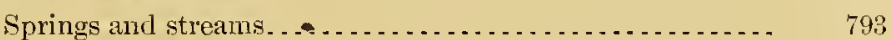

Inland seas with no outlets ......................... 793

Possible chemical precipitates in the ocean or in seas connected with the ocean .......................... 793

Metamorphism of organic and chemical calcium carbonate deposits. _ $\quad 795$

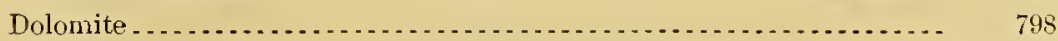

Origin of dolomite . . . . .

Dolomite due to replacement of calcium by magnesium....... $\quad 798$

Conclusion

How and why dolomitization occurs..................... 802

Dolomitization before limestone emerges from the sea . . . . . . 802

Dolomitization after limestone emerges from the sea . . . . . .... 804

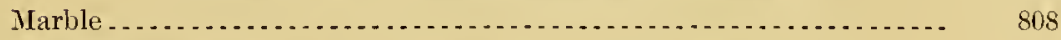

Cherty limestones, cherty dolomites, and cherty marbles.......... 816

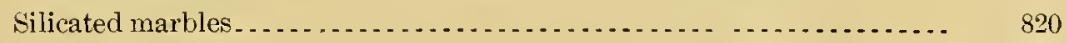

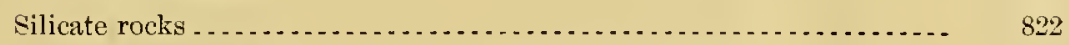

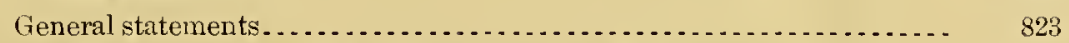

Iron-bearing carbonate family and metamorphosed equivalents......... 823

Siderite, ankerite, and parankerite......................... 823

Origin of siderite, ankerite, and parankerite............... 824

Ferruginous shales, ferruginous cherts, and jaspilites............. 829

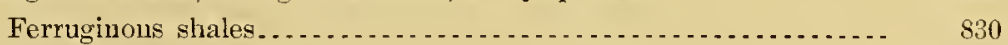

Ferruginous cherts................................... 830

Jaspilites........ $\ldots 31$

Actiuolitic and grüneritic marbles.......................... 833

Actinolite-magnetite-quartz rocks and grünerite-magnetite-quartz rocks. 834

General statements.................................... 811

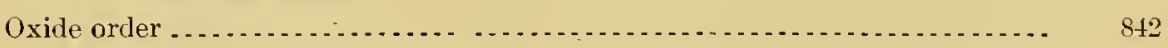

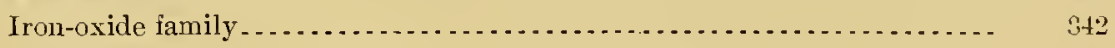

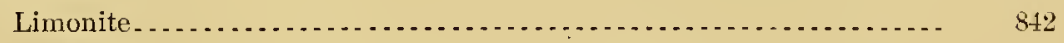

Hematite...... 843

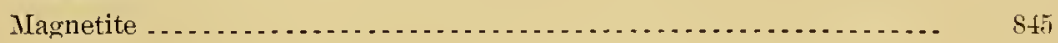


Chapter IX.-Rocks-Continned. Page.

Sedimentary rocks-Continued.

Nonfragmental class-Continnerl.

Oxide order-Continued.

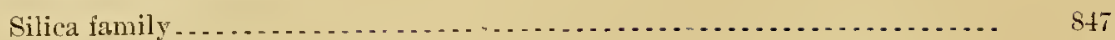

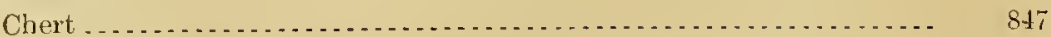

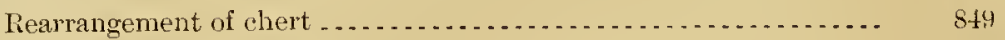

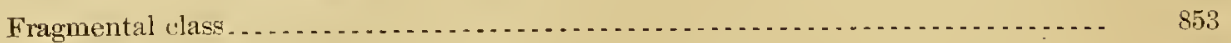

Psephite order. . . . . . . . . .

Pebble, gravel, and bowlder deposits.......................... $85 . .6$

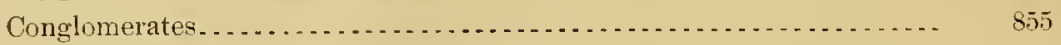

Schist-conglomerate and gneiss-psephite, or conglomerate-schist and psephite-gneiss .......................................... 85

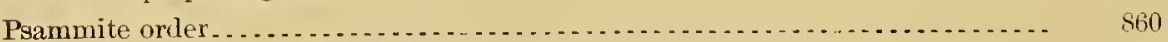

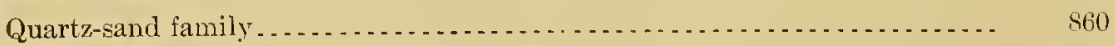

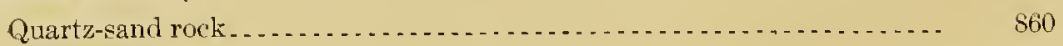

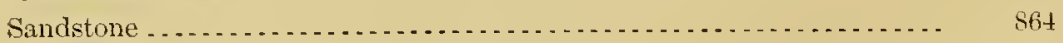

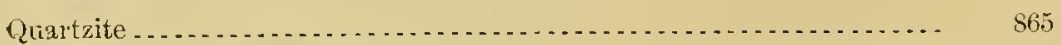

Schist-quartzite or quartzite-schist.......................... 868

Quartz-feldspar-sand family

Quartz-feldspar sand ...................................... 870

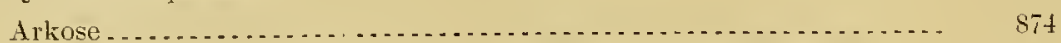

Schist-arkose and gneiss-arkose, or arkose-schist and arkose-gneiss..... 875

Ferromagnesian-sand family ......................

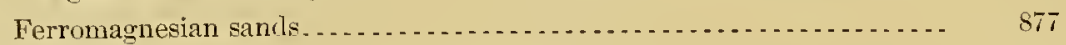

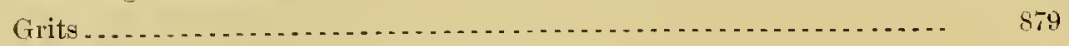

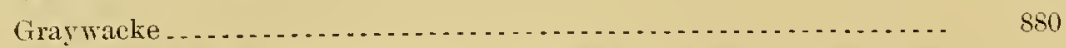

Slate-graywacke, schist-graywacke, and gneiss-graywacke; or graywackeslate, graywacke-schist, and graywacke-gneiss................. $88: 3$

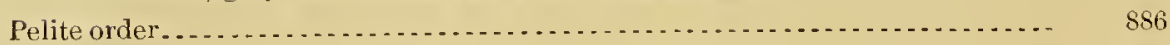

Mud family . . . .

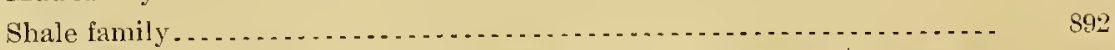

Slate-pelite, schist-pelite, anl gneiss-pelite; or pelite-slate, pelite-schist,

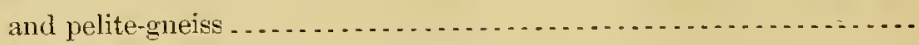

Development of minerals of slates ..........................

Derelopment of minerals of schists aud gneisses. . . . . . . . . . . . . . .

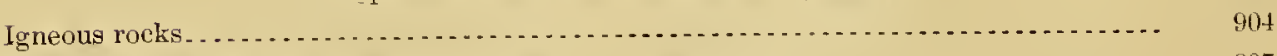

Chapter X.-Tire Relations of Metamorphisu to Stratigraphy . . . . . . . . . . . . . . . 907

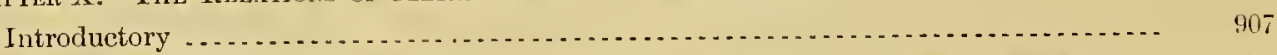

Discrimination between metamorphosed seclimentary and metamorphosed igneous rocks. 408

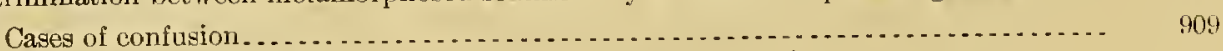

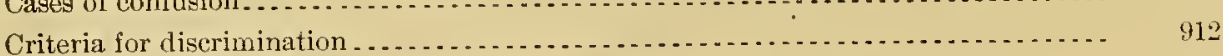

Relations of metamorphic sedimentary rocks to stratigraphy $\ldots \ldots \ldots \ldots \ldots \ldots \ldots$

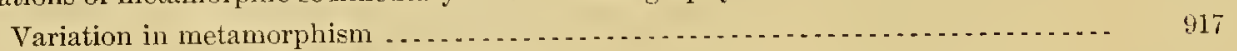

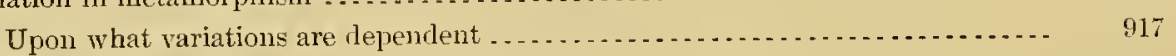

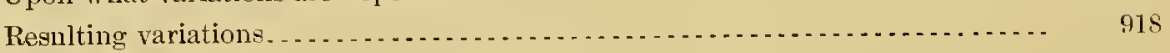


Chapter X.-The Relations of Metayorpinsm to Stratigraphy-Continued.

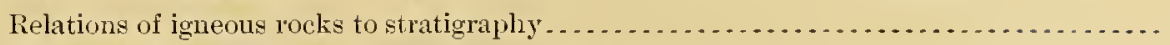

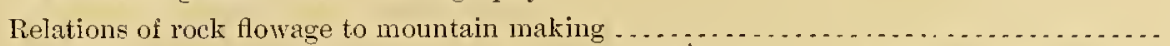

Chapter Xi.-Relations of Metamorphisit to tie Distribution of the Chemical Elemexts.

Composition of the lithosphere

Table of analyses of igneous and crystalline rocks

Table giving symbols, atomic weights, and proportions of the twenty-three most abundant elements in the onter 10 miles of the earth

Pange

Table showing the amounts of the eleven most common oxides of the lithosphere, as estimated in 1891 and 1900

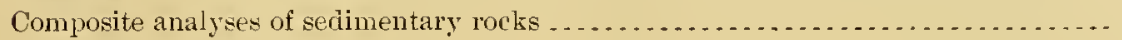

Constituents of meteorites . . . . . . . . . . . . . . . . . . . . . . . . . . . . . . . .

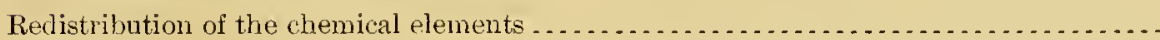

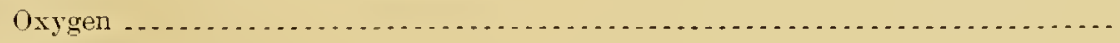

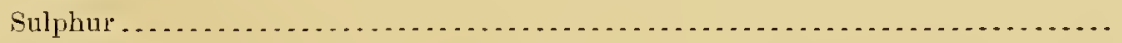

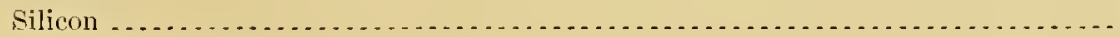

Carljon

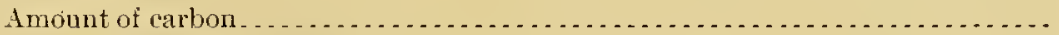

Segregation of carbon . . . .

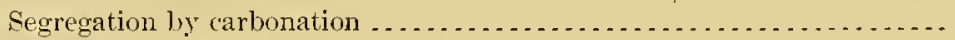

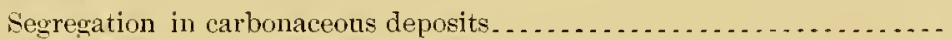

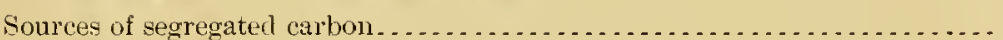

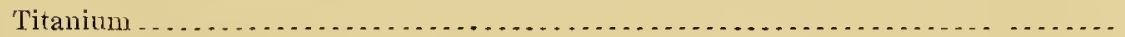

Phosphorus. . . . . . . . . . . . . . .

Chlorine ..

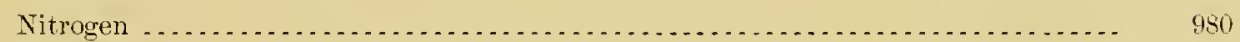

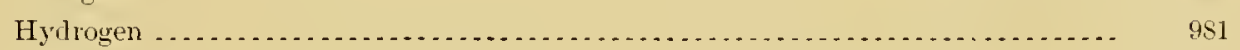

Aluminum

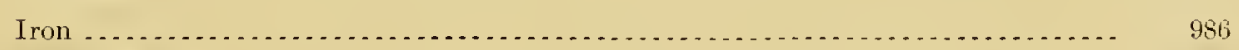

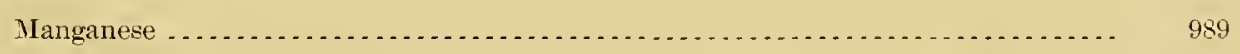

Calcium ...

Magnesium . . . . . . . . . . . . . .

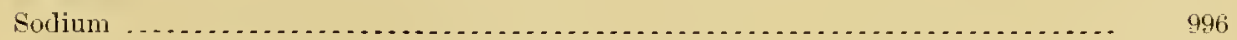

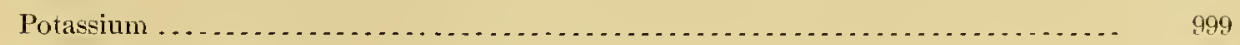

Barium, strontium, cbromium, nickel, lithium, fluorine, bromine . . . . . . . . . . 100?

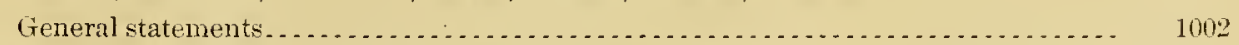

Chapter Xil. -The Relatiosis of Metahorphism to Ore Deposits .................. 1004

Part I. General principles ...... . . . . . . . . . . . . . . . . . . . . . . . . . . . . . . 1004

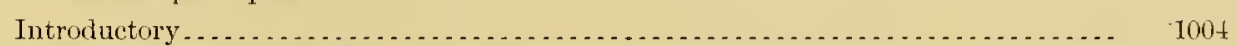

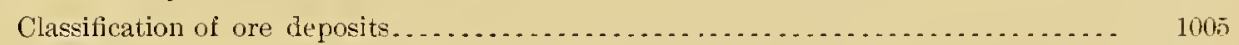

Deformation of the lithosphere.................. 1005

Zone of fracture, or zone of katamorphism . . . . . . . . . . . . . . . . . . . . $100 \overline{1}$

Openings of zone of fracture................................... 1006

Form and continuity of openings. . . . . . . . . . . . . . . . . 1007

Size of openings....................................... 1008

Volume of openings . . . . . . . . . . . . . . . . . . . . . . . . . . . . . . 1008 
Ch.tpter Ail,-The Relations of Metanorphism to Ore Deposits-Continued.

Page.

Part I. General principles--Continued.

Deformation of the lithosphere-Continued.

Zone of fracture, or zone of katanorphism-Continued.

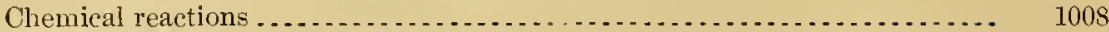

Zone of combined fracture and flowage .............................. 1009

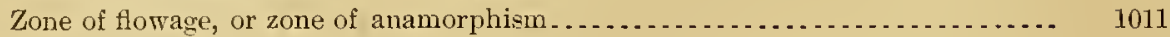

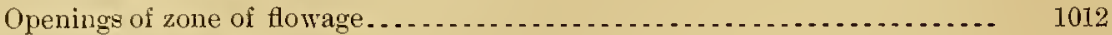

Reactions of zone of flowage..................................... 1012

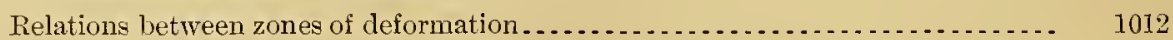

Effects of deformation and chemical changes upon temperature.............. 1013

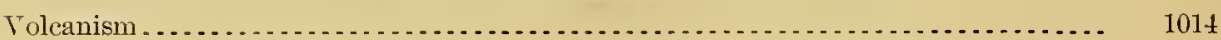

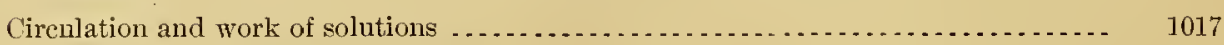

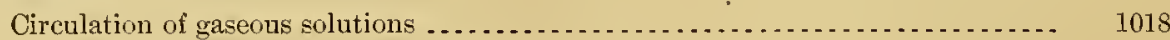

Circulation in belt of weathering . ................................. 1018

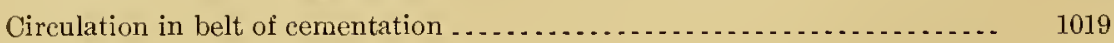

Circulation in zone of anamorphism ............................ 1020

Circulation of aqueous solutions ................................... 10.21

Circulation in zone of fracture, or zone of katamorphism . ............. 1022

Belt of weathering . . . .

Beit of cementation ......................................... 1024

Circulation in zone of combined fracture and flowage ............... 1028

Circulation in zone of flowage, or zone of anamorphism ............... 1029

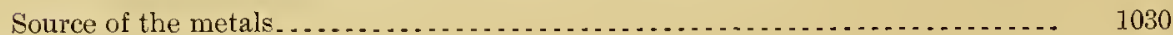

Part II. Segregation of ores . . . . .

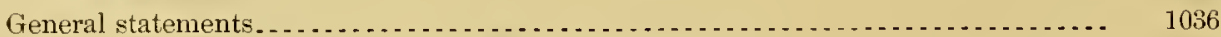

Division A. Ores produced by processes of sedimentation ... . . . . . . . . . . . . . 1037

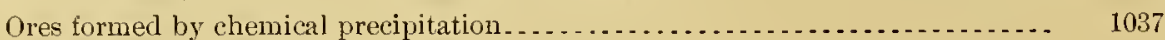

Ores formed by mechanical concentration. . . . . . . . .

Metamorphic alterations of sedimentary ores....................... 1039

Division B. Ores produced by igneous processes $\ldots \ldots \ldots \ldots . . .1043$

Division C. Ores produced by processes of metamorphism .................. 1052

Group A. Ores deposited by gaseous solutions.......................... 1052

Group B. Ores deposited by aqueons solutions . . . . . . . . . . . . . 1058

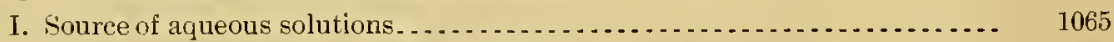

II. Source of metals for ores deposited from aqueous solutions............ 1069

III. Work of aqueous solutions in segregating ores . . . . . . . . . . . . . . . 1072

Subclass 1. Ores precipitated from ascending aqueous solutions....... 1072

Solution of the metals . . . . . . . . . . . . . . .

Transportation of the metals........................... 1075

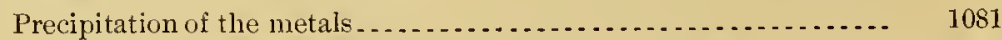

Precipitation by decrease of temperature and pressure........ 1081

Precipitation by mingling of solutions .................... 1082

Precipitation by reactions between solutions and solids ........ 1086

General statements ............................... 1088 
Chapter NII.-The Relations of Metamorphisis to Ore Deposits-Continued. Page.

Part II. Segregation of ores-Continued.

Division C. Ores produced by processes of metamorphism-Continuerl.

Group B. Ores deposited by aqueous solutions-Continued.

III. Work of aqueous solutions in segregating ores-Continued.

Subclass 1. Ores precipitated from ascending aqueous solutions-Cont'cl.

Compounds deposited by ascending solutions................. 1088

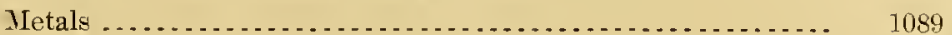

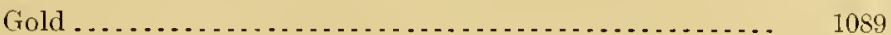

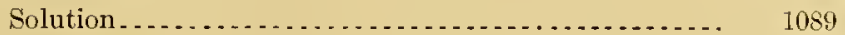

Precipitation . . . . . . . . . . . . . . . 1091

Silver ......................................... 1099

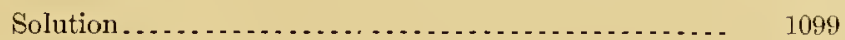

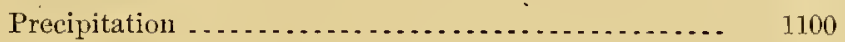

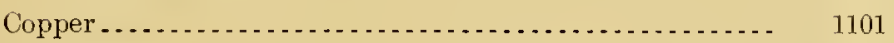

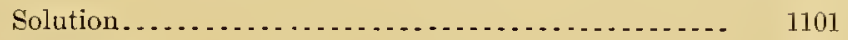

Precipitation ................... 1101

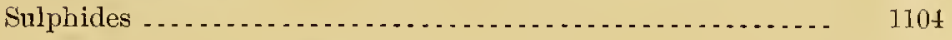

Solution of sulphides . . . . . . . . . . . . . . . 1106

Precipitation of sulphides....................... 1108

Precipitation of sulphides transported as such........ . 1109

Precipitation of sulphicles transported as oxidized salts. 1110

General statements.............................. 1117

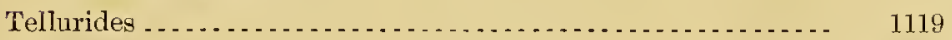

Oxides

Magnetite ... $\ldots \ldots \ldots \ldots \ldots$

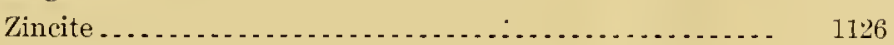

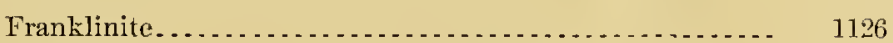

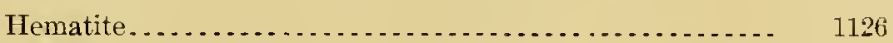

Cassiterite . . . . . . . . . . . . . . . . . . . . . . . . . . $112^{*}$

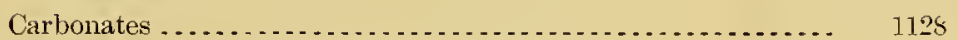

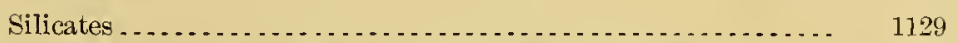

Criteria for discriminating deposits of the deep circulation . . . . . . . 1132

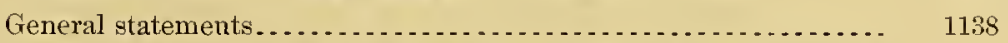

Subclass 2. Ores precipitated from ascending and descending aqueous

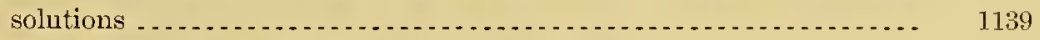

Association of lead, zinc, and irou compounds. . . . . . . . . . . . . . 1144

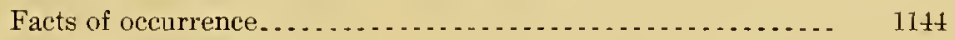

Second concentration ................................ 1147

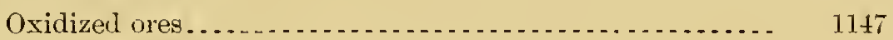

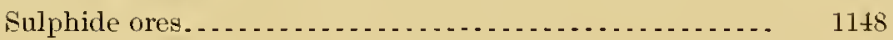

Galena ....................................... 1148

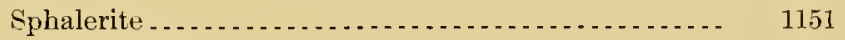

Marcasite and pyrite . . . . . . . . . . . . 1152

General statements . . . . . . . . . . . . 
Chapter Nis.-The Relations of Metanorpinsm to Ore Deposits-Continued. Page.

Part II. Segregation of ores-Continued.

Division C. Ores produced ly processes of metamorphisu-Continued.

Group B. Ores deposited by aqueous solutions-Continned.

III. Wrork of aqueous solutions in segregating ores-Continued.

Subclass 2. Ores precipitated from ascending and rescending aqueons solutions-Continued.

Association of copper and iron compounds................ 1158

Association of silver and gold with base metals............... 1166

silver ........................................... 1166

Gold ............................................. 1169

Concentration by reaction upon sulphides compared with metallur-

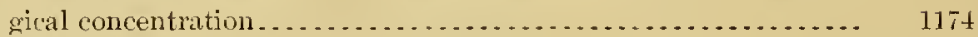

Other reactions of descending solutions.................... 1175

Second concentration favored by large openings near the surface ... 1177

Depth of effect of descending waters. . . . . . . . . . . . . . . . . . 1179

Illustrations of secondary enrichment and diminution of richness with depth .................................... 1182

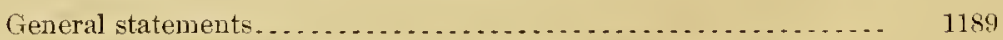

Subclass 3. Ores precipitated from descending aqueous solutions....... 1193

Iron ores . . . . . . . . . . . . . . . . . . . . . . . . . . . . . . . . . . 1193

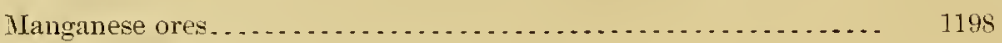

IV. Special factors affecting the concentration of ores ............... 1199

Tariations in porosity and structure. . . . . . . . . . . . . . . . . . . 1200

Distribution and size of openings . . . . . . . . . . . . . . . . . . . . 1201

Complexity of openings ............................ 1202

Preexisting chaunels and replacements .................. 1203

Impervious strata at varions depths . . . . . . . . . . . . . . . . . . . 1207

Pitching troughs aud arches ........................... 1211

General statements................................... 1216

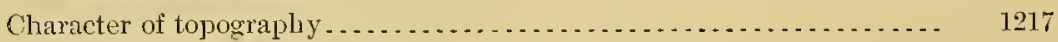

Effect of vertical element. . . . . . . . . . . . . .

Effect of horizontal element........................... $121 \mathrm{~s}$

Physical revolutions. . . . . . . . . . . . . . . . . . . . . . . . . . . 1221

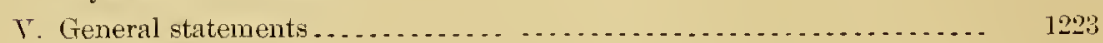

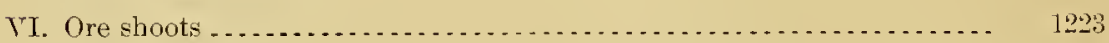

General statements. . . . . . . . . . . . . . . . . . . . . . . . . . . . . 1230

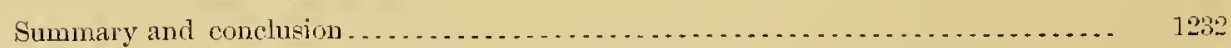

IXDEx ... 


\section{IL L USTRATIONS}

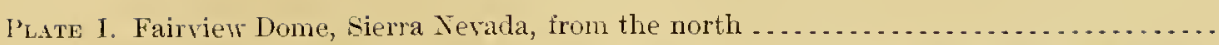

II. L, Parallel reins of calcite, Great Basin; $B$, Biotitic granite, showing garnet surrounded by lenticular areas deficient in iron-bearing minerals ...........

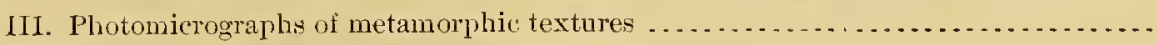

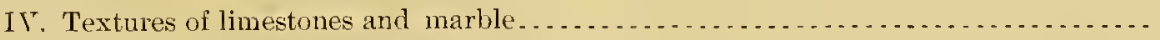

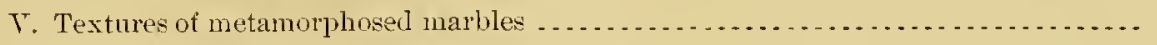

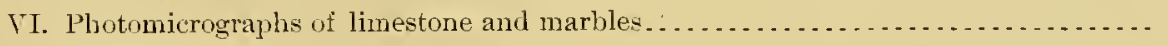

VII. Photomicrographs of iron-bearing rocks . . . . . . . . . . . . . . . . . . . . . . . .

VIII. A, Unaltered Newark conglomerate from Virginia, after Keith; $B$, Schist conglomerate from Felch Mountain district, Michigan.......................

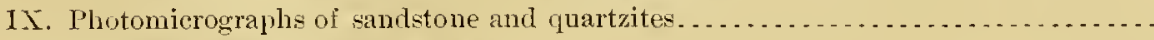

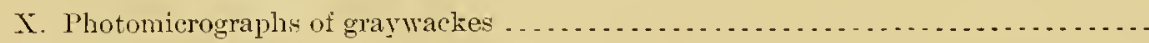

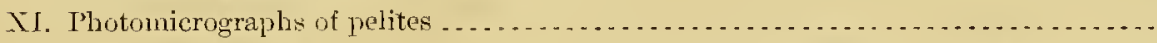

XII. L, Vein quartz, Banner mine, California; $B$, Secondary galend and blende in ores from Missouri

XIII. Iron-ore deposits in pitching troughs . . . . . . . . . .

FiG. 1. Change of rolume resnlting from solution, and relations of solution and pressure ....

2. Quantitative relations between solution and temperature $\ldots \ldots \ldots \ldots \ldots$

3. Triangular cross sections of pore space . . . . . . . . . . . . . . . . . . . . . . . .

4. Spheres packed in the most compart manner possible . . . . . . . . . . . . . . . . . . .

5. Relations of level of ground water to topography and to surface drainage ..........

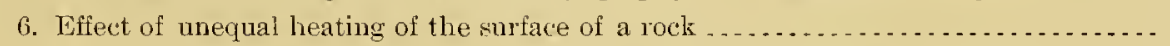

7 . Ideal horizontal section of the flow of ground water from one well to another......

8. Ideal vertical section of the flow of ground water from one well to another .........

9. Ideal vertical section of the flow of ground water entering at one point on a slope and

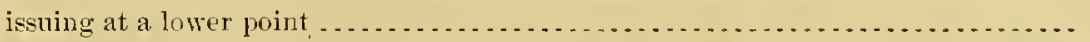

10. Icleal vertical section of the flow of ground water entering at three points and issuing

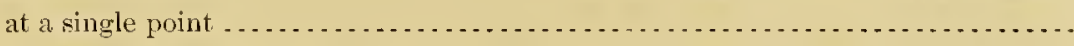

11. Ideal vertical section of the flow of ground water entering at many points along a slope and issuing at a single point at a lower elevation ....................

12. Ideal section illustrating the chief requisite conditions of artesian wells...........

13. Part of a thin section of a qualtz-schist showing liquid- and gas-filled cavities of a secondary nature; Black Hills, sonth Dakota.........................

14. Enlargement of feldspar fragment . . . . . . . . .

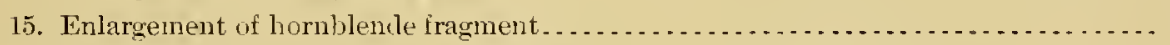

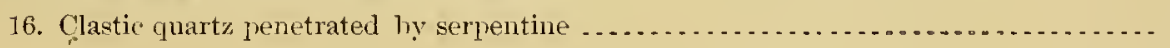


FsG. 17. Granulation of feldspar and gradation between undulatory extinction and granu-

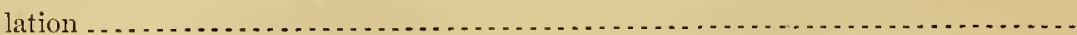

18. Granulation of quartz in a rock in which the feldspar is but little affected ..........

19. Liquid-filled cavities extending across several quartz individuals without change of

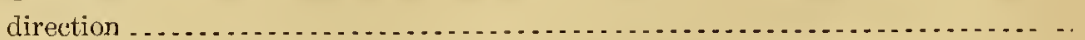

20. Diagram showing possible relation of old and new grains of recrystallized rocks . - . -

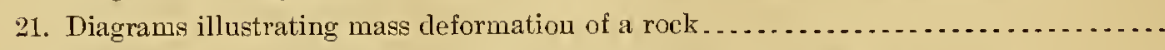

22. Sketch of oval irregular grains of calcite with longer diameters parallel . . . . . . . . . .

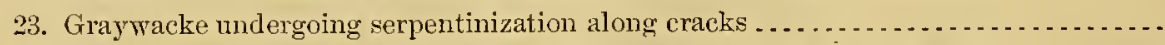

24. Conglomerate deposited in depression produced by erosion of basic dike through gneiss

Page,

25. Diagrams illustrating the manner in which deformation in the zone of flowage may concentrate crustal shortening in the zone of fracture......................

26. Ideal vertical section of the flow of water entering at a number of points on a slope and passing to a valley below through a homogeneous medium interrupted by two open vertical channels, one on the slope and one in the valley .................

27. Ideal section showing underground circulation in which no water anywhere ascends

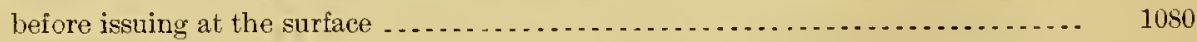

28. Cross section of banded vein near the London shaft, Mineral Point, Colorado ....... 1135

29. Diagrammatic section of Enterprise mine, Colorado, and its blanket pay shoot..... $\quad 1208$

30. Diagram illustrating mingling of circulations of two limestones separated by a shale.

31. Ideal vertical section of flow of underground water in the Galena limestone of the upper Mississippi Valley

32. Ore deposit in limestone beneath impervious shale, Elkhorn mine, Montana . ...... 


\title{
LETTER OF TRANSMIITTAL.
}

\author{
DepartMent of THE INTERIOR, \\ United States Geological Survey, \\ Section of Pre-Cambrian and Metamorphic Geologi, \\ Madison, Wis., Aprit 30, 1903.
}

Srk: I transmit herewith the manuscript of a treatise on metamorphism, to be published as a monograph.

This treatise is an attempt to reduce the phenomena of metamorphism to order under the principles of physies and chemistry, or, more simply, under the laws of energy. The first nine chapters treat of netamorphism; the last three chapters, of the relations of metamorphism to stratigraphy, to the redistribution of the elements, and to ore deposits.

In the preparation of this monograph I have had important assistance from various sources. The late Prof. George H. Williams, of Johns Hopkins University, before his death had begm to accumulate material and notes upon metamorphism. He had made a careful abstract of the most important literature on the subject; also a draft, consisting of about twenty pages of manuscript, of a first cliapter. All of this material Mrs. Williams turned over to me. The summary of literature prepared by Dr. Williams has been of very great service. To this dear friend, the first great teacher of petrology in this country, I dericate this volume.

In the actual preparation of the manuscript I have had the assistance of a number of men, and of a considerable number of advanced stndents. In the earlier work Dr. C. K. Leith aided me mnch by looking up and summarizing literature and by offering many valuable suggestions. Later Mr. W. N. Smith continued this work. To the discriminating judgment of Dr. Leith and Mr. Smith I am greatly indebted. Mr. A. T. Lincoln has made all the numerical computations in reference to the volume relations of original and secondary minerals, and Mr. R. MI. Chapman has verified Mr. Lincoln's work. While these are the men who have assisted me most, a number of gradnate stndents, both at the University of Wisconsin and at the University of Chicago, have helped in various ways. 
Geologists who write in other languages than English will have just eause for complaint because of scant reference to publications on metamorphism in such langnages, but the arduous work of preparing this treatise has taxed my eyes to the utmost without going exhaustively through foreign literature.

If this attempt to treat one phase of the plienomena of geology from the point of view of energy proves successful, I shall hope that it will lead to similar treatment of other parts of this great science.

Very respectfully, your obedient servant,

Charles Richard Van Hise.

Hon. Charles D. Walcott,

Director of United States Geological Survey. 


\title{
A TREATISE ON METAMORPHISM.
}

\author{
By Charles Richard Van Hise.
}

\section{CHA P TER I.}

\section{INTRODUCTION.}

Following Powell, I shall regard the earth as composed of four spheres-the atmosphere, the hydrosphere, the lithosphere, and the centrosphere. ${ }^{a} \quad$ The terms atmosphere and hydrosphere need no definition. The term lithosphere, as here used, will be confined to that portion of the outer part of the earth which is within the limits of observation. How far below the surface observation extends is somewhat uncertain; but it is certain that, in consequence of deformation and denudation, we may observe rocks which have been several thousands of meters below the surface. Clarke suggests that the zone of observation be defined as extending to a depth of 10 miles (16 kilometers) below the level of the sea. ${ }^{b}$ Whatever distance be taken as the limit of the zone of observation, it is certain that such distance is but a very small fraction of the radius of the earth. All the earth below this fraction will be considered as the centrosphere; but no hypotheses are advanced in respect to any essential difference in character between the material of the lower part of the lithosphere and that of the upper part of the centrosphere.

\section{GENERAL NATURE OF ALTERATIONS.}

The data of geology have become so numerous as to be almost ummanageable. Not many decades ago it was possible for a geologist to have a

"Powell, J. W., Physiographic processes: Nat. Geog. Mon., vol. 1, No. 1, 1895, p. 1. 78,1891, p. 34 .

${ }^{6}$ Clarke, F. W., The relative abundance of the chemical elements: Bull. U. S. Geol. Survey No. 
reasonably full and satisfactory knowledge, not only of the known principles of geology, but of the observed phenomena in the parts of the world which had been studied. While by mauy years of work a geologist may still be able to learn the important facts concerning various provinces, it is no longer possible for one man to have anything like complete information as to the local geology of many parts of the world. Not only is this so, but no one geologist can know all the important discovered facts concerning a particular branch of geology. Moreover, in recent year's the accumulation of facts has gone on much faster than the development of geological theory. Nowhere is this more true than in the branch of geology known as petrology, and in petrology it is perhaps more true of the phenomena of the alterations of rocks than of any other. Scarcely a paper on petrology appears that does not contain some account of the alterations of minerals or of rocks, but in most cases there is no serious attempt to arrange the observed phenomena in order under recognized principles. Indeed, there is no general set of recognized principles under which the phenomena can be reduced to order.

Some years ago, finding myself lost in the vast accumulation of data, I began to formulate principles applicable to the alterations of rocks. The result of this work is the present treatise, which is an attempt to reduce the phenomena of metamorphism to order under the principles of physics and chemistry, or, more simply, under the laws of energy. It is but a part of the larger task of reducing to order under the same laws the entire subject of physical geology.

As a result of the derelopment of the science of petrology, especially microscopical petrology, it has been ascertained that changes are continually occurring within the rocks constituting the onter part of the earth. This statement is equally applicable to the most porous rocks at the surface of the earth and to the densest rocks as deep below the surface as obserration gires exact knowledge. All changes, by whatever forces, agents, and processes caused, and in whatever classes of rocks occurring, whether solidified magmas, chemical precipitates, organic deposits, or mechanical deposits, may be called metamorphism.

Metamorphism, as liere used, means any change in the constitution of any kind of rock.

It will be shown that at any given time and place, under any given 
set of conditions, minerals tend to form which remain permanent under those conditions. This tendency is more potent with minerals crystallizing from magmas than with minerals which constitute the sedimentary rocks or with the secondary minerals which form by metamorphism. 'The reason for this is that adjustment to existing conditions is so much more readily accomplished in fluids than in solids; but the tendency to form minerals which are permanent under the existing conditions controls in the solid rocks, although there is a great amount of lag in the process of modification. If adjustment be reached in a given case and if the conditions remain the same, the nimerals formed do not again alter, but may remain the same through eons. This is illustrated by the meteorites, the minerals of which may persist without change during the evolutions of stellar systems. However, when an important change of conditions occurs, as when a meteor gives up its separate existence in the interstellar spaces and joins a planet, as the earth, readjustment begins at once.

Although the changes of conditions upon the earth are not so great as the change when a meteor falls to the earth, the range of conditions upon the earth is large and varied. The conditions may be those of ordinary pressure and temperature at or near the surface of the earth, or they may be those of very high pressure and temperatnre, such as exist well below the surface of the earth. A rock mass may alternately be subject to each of these sets of conditions and to various intermediate conditions. Changes of physical conditions result from surficial transfer of material by epigene agents-bringing rocks to the surface here, burying them there-from igneous intrusions, from orogenic movement, and from other causes. The changes upon the earth are therefore profound, although usually slow.

During the changes the rocks are always modified in the direction of adjustment to the new conditions. Such modification of rocks has led to the idea of adaptation to their environment. As conditions change, species of plants and animals are so rapidly modified that at first sight adaptation seems almost perfect. Indeed, so sensitive are plants and animals to their environment that since the theory of evolution gained ascendancy the fact of approximate adaptation is taken for granted. The variety and complexity of the structures, colors, etc., of life forms resnlting from adaptation to environment is a constant source of wonder. Almost daily some remarkable structure or form is described, and its existence explained by showing how MON XuVII-04-3 
it is advantageous to the animal under the conditions in which it lives. Since adaptation is an assumed law, in those cases where there seems to be lack of adaptation, as where some peculiar structure is present which apparently is not of advantage to an animal or plant, it is believed that the facts are not fully known or that the structure was once useful and is a survival. However, the very idea of surviral shows that to a certain degree the development of plants and animals lags behind their changing environment. Upon a priori grounds it would be certain that this is the case; and the existence of rudimentary organs, such as the muscles for moving the human ear, which at one time may have had a use, is positive evidence of the lag of organic species during their adaptation to changing enviromment.

Likewise it is believed that minerals constantly tend to change to forms that are relatively stable under existent conditions. This, however, is accomplished by granulation or recrystallization or some analogous process, and is adaptation only in the sense that the old particles break up into smaller particles or develop into new mineral particles which conform to the existent conditions. Some minerals are stable under a considerable variety of conditions, and therefore are less sensitive to change than are others. For instance, quartz develops directly from an igneous rock, and it also forms as a deposit from water. It persists under both quiescent and dynamic conditions. Other minerals require rather definite conditions for their existence. Such are leucite and olivine, which abundantly form as original minerals in igneous rocks of certain composition, but which readily change under new conditions to other minerals. However, no mineral persists without reference to its enviromment, and so it may be said that there is a tendency in all mineral substances to form minerals adjusted to the conditions under which they exist. Rocks are composed of aggregates of different minerals. Therefore rocks, like minerals, have a tendency toward adjustment to their enviromment.

Even if the chemical composition of a small mass, say a cubic millimeter, remains exactly the same, the mineral constituents of the mass may greatly change. At the end of the change the original minerals may not be in the same proportions as before and minerals which did not originally exist in the rock may have formed. But the adjustment of rocks is not confined to redistribution of the elements present in a small space. There may be a change in the average chemical composition of rocks. 
Material may be intruded, or may be brought in by water solutions, or may be abstracted by water solutions. By any one of these processes or by any combination of them a considerable change in the chemical composition of a rock may take place.

While it may be safely asserted that all rocks, under all conditions, at all times, are being adapted to their environment, the change in a rock goes on so slowly that its lag behind the change in the environment may be measured by millions of years. Often the lag is so great that the conditions again change before the process of adjustment has made much advancement, and, therefore, before one set of changes is near completion another set is begun. Indeed, a later change in conditions may be a reversal of an earlier change, and, therefore, in the process of adaptation, work done in an early stage may be reversed at a later stage. But even in such a case it is clear that the principle of adaptation applies, just as in the case of many plants and animals, although there may be, in fact, little more than a tendency toward adaptation to existent conditions.

Because the adjustment of rock to environment is so slow, in order that it may be approximately complete it is necessary that a rock remain under substantially the same conditions for a very long time. This has happened in some regions in which important mechanical morements have not occurred for a period or an era and the rocks of which have remained buried to a moderate depth for most of the time. Such were the conditions of the ancient volcanics of certain parts of the Lake Superior region. These have escaped important mechanical movement since the beginning of Paleozoic time. They were buried under Paleozoic sediments to a moderate dejth. Denudation since the beginning of Cretaceous time brought them to the surface. Finally glacial erosion removed a skin of weathered material and exposed the volcanic rocks, approximately adapted to their past environment, that of the belt of cementation under quiescent conditions. (See Chapter VII, pp. 594 et seq.) So far as they have reached the surface they are subject to a new set of conditions; and a new cycle of change, begun at the end of the Glacial epoch, but not far advanced, is in progress.

In considering metamorphism, the fundamental hypothesis of geology will be applied as in other branches of the subject. That is to say, the Huttonian principle, that the present is the key to the past, is 
assumed. Where certain phenomena are now produced by certain eombinations of forces and agents, and by these only, and similar phenomena are fornd in the rocks long since formed, it is assumed that the like phenomena, present and past, are due to essentially the same combinations of forces and agents. For instance, if alterations of a certain kind are now being produced by a complex set of. geological factors, and by these only, where similar alterations are found in ancient rocks it is assumed that they are due to practically the same combination of the forces and agents of alteration.

But the above statement does not imply that the changes are now taking place with the same speed as that with which they occurred in the past, as might have been held by Lyell; nor is it assumed that the varions forces and agents have the same relative valnes. Indeed, it is believed to be highly probable that there have been ehanges in the rate of alteration of rocks and in the nature and effectiveness of the factors producing the alterations.

While the Huttonian principle is of service in the sturly of metamorphism, the alterations of rocks take place so slowly that it does not have nearly the value that it has in the stndy of the work of the epigene agents, such as air and water and ice; nor the value it has in the study of such hypogene agents as voleanoes and earthquakes.

Many of the rock alterations are now taking place under conditions which can not be directly observed, but must be inferred from the records of the change. This statement applies to all changes below a mile in depth, and it is very largely applicable to all but the mere onter film of the rocks, for most excavations and cuttings are not deeper than a few seore or a few hundred feet and the deepest shafts are but little over a mile. Fortunately it frequently happens that in a rock formation now at the surface the results of various stages of change under deep-seated conditions are preserved, so that the eharacter of the alterations and the nature of the forces and agents which have produced them may be inferred from a close study of the different stages of alteration.

In such cases, instead of observing the forces and agents accomplishing certain results, and of reasoning that similar results produced in the past are due to these forces and agents, we observe the results at various stages of development and infer from them the nature of the forces and agents producing them; we then infer that similar forces and agents are at work 
beyond the zone of observation, accomplishing at the present time similar results. This is a complete reversal of the Huttonian method. Hence, in treating of metamorphism we must argue both from the present to the past and from the past to the present. By studying the action of the forces and agents now at work in the zone of observation and the stages of alteration preserved in the rocks brought into the zone of observation we are able to push the boundaries of the known for a certain distance into the domain of the unknown, and infer with considerable certainty the nature of the changes which have taken place in the far-distant past and of those which are now taking place but which we can not directly observe.

It will be generally agreed that the majority of the altered rocks, including a large portion of the schists and gneisses, lave been metamorphosed from aqueous and igneous rocks like those now being produced. This is in accordance with the Huttonian principle. But some may lold that the most ancient of the schists and gneisses, those of the so-called Basement Complex, had a different origin. For instance, it has been held by some that these ancient rocks are direct precipitates in a primeval ocean. On later pages it will be seen that the most ancient schists and gneisses are in all respects like those produced from more recent rocks by the processes of alteration, and therefore that the probable, but not certain, inference is that they were produced from rocks not fundamentally unlike those now being formed by processes of change not radically different from those now at work. But in ascertaining the forces and agents and their method of work in both the ancient and the modern rocks, we must for the most part follow the reversal of the Huttonian principle-i. e., argue from past results as to the nature and method of work of present forces and agents.

Whatever the origin of rocks-whether solidifications from magmas, chemical precipitates, organic deposits, or mechanical deposits-as already noted, they may be altered so as to modify their structures, so as to change their mineral composition, and so as to change their chemical composition. In place of the original characteristic structures of the igneous rocks, such as flowage structure and massive structure, and in place of the original structures of the sedimentary rocks, such as bedding, there may be produced secondary structures, such as cleavage, fissility, joints, slatiness, schistosity, and gneissosity. In place of the original textures of igneous rocks, such as granolitic, porphyritic, ophitic, and poikilitic, and in place 
of the original textures of sedimentary rocks, such as granular and oolitic, there may be produced textmres characteristic of the metamorphic rocks, such as cataclastic, parallel orientation, etc. The alteration may result in the change to minerals all of which may wholly differ from any of the original minerals, or it may take place by recrystallization withont change in mineral character, as in the case of the formation of marble from limestone. Chemical change may result in the addition of constituents, as in the case of oxidation and hydration of compounds already existing, or in the deposition of additional material in the interstices, or in the abstraction of material. Any given mineral may gain additional elements, or a greater proportion of some of the elements; it may lose a part or all of some of its elements, or it may be wholly replaced by another mineral. While the chemical composition of the rock may be greatly affected by such changes, in other cases the alterations may result merely in a redistribution of the elements withont affecting the average composition of the rock, as in the case of marmorization, some cases of devitrification, various cases of metasomatism, etc.

After one set of changes has taken place, or while they are in progress, a change of physical conditions may come about in consequence of which a different set of changes may be set up. Thus rocks may be partly modified under mass-static conditions and subsequently modified under massmechanical conditions. They may be modified near the surface of the earth, and as a result of burial be later modified at nuch greater depth; or they may be modified at great depth, and as a result of erosion be bronght near the surface and there be again modified. 'Therefore one set of changes may be superimposed upon another. In many cases it is certain that rocks have gone through several rery complex sets of modifications. For instance, a rock may be modified under conditions at the surface, afterwards be buried under other strata and thus pass into a deep zone, where it may be modified in a different manner, and still later, as a result of denudation, be bronght to the surface and in the passage undergo successive alterations in intermediate belts, and when it reaches the surface once more be altered by the same forces and agents as at first. Substantially this history has been gone through by the jaspilites of the Lake Superior region. (See pp. 831-833.) Many other rocks have had an equally intricate but very different history. 


\section{CLASSIFICATION OF METAMORPIISM.}

The forces of metamorphism are chemical energy, gravity, and heat and light. The agents of metamorphism are gases, liquids, and organic compounds.

A critical examination of the published classifications of metamorphism shows that the kinds of metanorphism recognized are baserl upon the idea that one force or agent or process is dominant in the production of a particular kind of rock. But in all of the varions kinds of metamorphism ordinarily recognized in classifications, such as thermo-netamorphism, hydro-metamorphism, chemical metamorphism, static metamorphism, pressure metanorphism, dynamo-metamorphism, regional metamorphism, and contact metamorphism, all of the forces above mentioned are required, and also the chief agent, water. There is no metamorphism of a rock without the presence of heat, and hence all metamorphism is partly thermometanorphism; there is no metamorphism without the presence of water solutions, and hence all metamorphism is partly hydro-metamorphism; there is no metamorphism in which chemical action does not enter, and hence all metamorphism is partly chemical metamorphism; there is no metamorphism. without motion, and hence, in an exact sense, all metamorphism is dynamic. In the alterations of rocks the forces of metamorphism in each case produce atomic, molecular, and mechanical changes. ${ }^{\alpha}$ Then it is realized that in all the varieties of metamorphism mentioned chemical action, heat, and dynamic action enter as important factors, and that water is present and active wherever metamorphism occurs, it becomes self-evident that the classifications ordinarily given are not satisfactory. Moreover, the classifications involve different factors not belonging to the same category, some being physical, some chemical, some geological, some referring to an agent, others to a cause. For instance, thermo-metamorphism refer's to heat; hydro-metamorphism refers to the presence of water; chemical metamorphism refers to the action of chemical forces; static metamorphism and pressure metamorphism refer to quiescent conditions; dynamo-metamorphism refers to conditions of motion; regional netamorphism refers to the extent

\footnotetext{
a If this be true, it is clear that a classification of metamorphism into paramorphism, metatrophy, and metataxis, restricting these terms to atomic, molecular, and mechanical changes, respectively, as proposed by A. Irving, is wholly impracticable. Irving, A., Metamorphism of rocks, London. 1889, pp. 4-5.
} 
of the alterations; and contact metamorphism refers to the contiguity of an igneous rock.

As a matter of fact, all of these different kinds of metamorphism are related in the most intricate manner, and certain metamorphic results which have been attributed to one of these forces, agents, or processes could equally well be attributed to another. For instance, in many cases metamorphism known as thermo-metamorphism might just as well be called hydro-metamorphism, or regional metamorphism be called dynamic metamorphism, or contact metamorphism be called thermo-metamorphism or chemical metamorphism.

It follows from the above that a satisfactory classification of metamorphism based upon chemical forces alone, or physical forces alone, or individual processes, is quite out of the question. It appears to me that the only workable classification of metamorphism is geological. (See pp. 43-44.)

GEOLOGICAL FACTORS AFFECTING THE ALTERATIONS OF ROCKS.

The more important geological factors affecting the alterations of rocks are: Composition; structures and textures; porosity; water and gaseous content; climatic and geographic conditions; time; environment; degree of movement; depth. Many physical factors enter into each of these geological factors.

At present only general statements will be made with reference to these factors, but on later pages the effect of each of them will more clearly appear.

composition.-In so far as rocks are composed of minerals which are permanent under the existing conditions, or are composed of minerals which may exist under a wide variety of conditions, this is favorable to stability.

structures and textures.-In so far as there are coarse structures and textures, this is favorable to pemmanency, for it will be seen that fine material is more readily altered than coarse material.

Porosity.-Porosity has a very important influence upon the rapidity of change. In proportion as rocks are porous the agents of alteration, gases and water, may enter and rapidly circulate. In proportion as they are dense, the amount of water present is small and the circulation is slow. 
Hence porosity is favorable to rapid change; density is favorable to stability.

Water and gaseous content._- In proportion as rocks contain water and gas they are readily altered. In proportion as water and gas are absent they are stable.

Climatic and geographic conditions._-The speed of alteration of rocks is affected by their geographical position. The alteration of surface rocks is more rapid in tropical than in arctic regions; it is more rapid in humid than in arid regions; it is more rapid on steep than on gentle slopes; it is more rapid along coasts than in the interior. In short, the nature of the alterations of the upper belt of rocks varies with every varying factor of climate and geography.

Time.-Time is a factor of the very lighest importance in metamorphism. 'Time can not be included among the forces or the agents of metamorphism, but the amount of metamorphism is a function of tre time. Where a given set of forces and agents is at work under a given set of conditions, increase of time increases the metamorphism, but not in a direct ratio, for in proportion as adjustment to environment is approached the alterations decrease in speed. The importance of time in geology can not be too strongly emphasized, for a comparatively weak force or agent working through a great length of time may accomplish an ahnost incredible amount of work. We are accustomed to judge of the efficiency of a force or agent by observations in the chemical or physical laboratory, but the time through which an experiment may be continued in the laboratory is an almost infinitely small fraction of the time through which the forces and agents have been at work in mature. To illustrate, in the chemical laboratory the amount of crystallized silica wlich can be dissolved in water and transported to another place within the time during which an ordinary experiment is carried on is so small as to be unmeasurable, and yet it is certain that in nature water has dissolved and transported to other places enormons quantities of silica. (See Chapter VII, pp. 622-623.) This illustration enforces the fact that the geologist has very much more time at his command than has the chemist or the physicist. If the geologist ignores this fact, and reasons in reference to the potency of forces and agents in metamorphism as a chemist or physicist would in the laboratory in reference to the same forces and agents, be is certain to fall into very serious 
error: The importance of the time factor has been recognized by most geologists with respect to erosion and many of the other geological processes, but it is of even greater importance in metamorphism. Most of the metamorphic processes are very slow indeed, but the amonnt of time available in a single geological period is great, and the metamorphic results are often stupendous.

In general it may be said that in proportion as rocks are old they are likely to have been greatly altered; in proportion as they are young they are likely to have been little altered. While time is a most important factor in the amount of alteration, time alone, without the other necessary conditions for change, is not sufficient to insure important metamorphic results. Further, when the other conditions are very favorable to change, extensive alteration may take place in a comparatively short time, considering this factor from a geological point of view. It follows, becanse of variations in other factors than time, that in some regions very ancient rocks may be little modified and in other regions comparatively young rocks may be greatly modified.

Environment.- In many cases environment may be important. If the rocks surrounding a given rock be porons, this condition readily permits the entrance of the agents of alteration-water and gases-and therefore much more profound change may occur than if the rock were surrounded by comparatively impervious material. This is illustrated by the diabase dikes of the Penokee series of Michigan, which where surrounded by the broken rocks of the iron-bearing formation are completely altered, but which where surrounded by the impervious black slates are comparatively maltered. A further very important factor in envir.mment is the presence of intruded igneous rocks. Igneous rocks, by conduction, may directly heat the adjacent rocks; but of even greater importance is the fact that igneous rocks may furnish solutions to the adjacent rocks or heat the solutions which percolate through them. These ilhustrations show that the alteration of a rock may be greatly affected by the surrounding rocks. Degree of movement.-One of the most important of the factors affecting alterations is movement; indeed, the factor of movement is so important that it has frequently been made a basis for a classification of metamorphism. Changes of rocks take place with comparative slowness under conditions of quiescence and take place with comparative rapidity under conditions of 
movement. Furthermore, the alterations which occur under dynamic conditions are far more profound than those which take place under static conditions. For instance, very ancient sedimentary rocks which have been undisturbed by orogenic movements may be in almost the original condition in which they were deposited. On the other hand, rocks of comparatively recent age which have been in mountain-making areas and been deeply buried may be profoundly modified. Little metamorphosed rocks of great age are illustrated by the St. Peter sandstone of Wisconsin and the unconsolidated Cambrian sands of Russia. Profoundly metamorphosed rocks of comparatively recent age are illustrated by the Eocene and Neocene rocks of the Coast Range of California and the Eocene of the Alps.

Depth-Rocks at or near the surface of the earth are ordinarily under conditions of slight pressure and low temperature. Rocks at sone depth below the surface are under conditions of considerable pressure and temperature. It will be shown that the alterations of a given rock nuder these varying conditions are very different. Therefore depth is a matter of great consequence in the consideration of metamorphism. 'Indeed, depth is believed to be the most important of the influences which determine the character of the alterations of rocks. Therefore the geological factor which in this treatise will serve as the primary basis for a classification of metamorphism is the dominant factor of depth. On this basis metamorphism will be classified into (1) alterations in the zone of katamorphism and (2) alterations in the zone of anamorphism. The zone of katamorphism is subdivided into (a) the belt of weathering and (b) the belt of cementation. The zone of katamorphism may be defined as the zone in which the alterations of rocks result in the production of simple compounds from more complex ones. The zone of anamorphism may be defined as the zone in which the alterations of rocks result in the production of complex compounds from more simple ones. The belt of weathering is the belt which extends from the surface to the level of ground water. The belt of cementation is the belt which extends from ground-water level to the zone of anamorphism.

It is to be noted not only that this classification is geological, but that the factor is one which is miversally applicable. Geological factors of different kinds, such as movement, contact action, etc., are not introdnced. It is therefore clear that the proposed classification follows one law of all 
good classifications, viz, that a factor or factors of the same class shall be used thronghont as a primary basis. While the primary classification of metamorphism will be based upon depth, it is recognized that there are no sharp dividing lines between the zones and belts. In metamorphism, as in every other branch of geology and of science, there is complete gradation between the phenomena of the various classes.

However, it has been seen that depth is not the only geological factor of consequence in metamorphism. It is recognized that various other geological factors enter into the alteration of a given rock. Moreover, these varions factors overlap. In the discussion of the zones of metamorphism the geological factors of subordinate importance will be given proper consideration.

Before considering the general alterations in the zones of katamorphism and anamorphism, and the alterations of the individual minerals and rocks in these zones, it is necessary to consider the forces and the agents of metamorphism from chemical and physical points of view.

It should therefore be recalled that the forces of metamorphism are chemical energy, gravity, and heat and light, and that the agents of metamorphism are gases, liquids, and organic compounds. The rocks are the materials upon which these forces and agents work. The forces of metamorphism are considered in Chapter II, the agents of metamorphism in Chapter III, and the work of these forces and agents upon the rocks in the later chapters. 


\section{CHAPTER II. \\ THE FORCES OF METAMORPHISM.}

As already seen, the important forces of metamorphism are chemical energy, gravity, and heat and light.

\section{CHEMICAL ENERGT.}

When different compounds are brought together molecular interchange may occur between them. As a result the compositions of the compounds are mutually changerl. Such interchange is chemical action. Chemical action usually involves expenditure of chemical energy, which is one of the main original sources of energy; but it will be seen that other forms of energy may be transformed into chemical energy, and chemical action in this way be promoted.

Chemical action may take place between gas and gas, gas and liquid, gas and solid, liquid and liquid, liquid and solid, and solid and solid. Chemical action, or molecular interchange, involves movement between the atoms and molecules. Chemical action therefore never takes place without dynamic action. So far as we know chemical action never takes place without the presence of heat. Under the conditions obtaining in the crust of the earth chemical action is usually promoted by heat and by mechanical action. As chemical action always produces a heat effect, positive or negative, such action may result in the liberation or in the absorption of heat. The heat effect may hasten or retard further chemical action. In so far as chemical action results in the liberation of heat, it usually hastens further chemical action, and therefore promotes metamorphism; in so far as chemical action results in the absorption of heat, it usually retards further chemical action, and therefore stays metamorphism. It is shown (pp. 170-186) that both classes of reactions take place on a very extensive scale.

In consequence of chemical action material may be added to or subtracted from a given mineral. A mineral may alter into two or more other minerals with the simultaneous addition or subtraction of material. Two or more minerals may unite to produce a single mineral. Either of these 
changes may take place withont addition of material, or added material may be derived from some other particle or particles near or remote. Naterial subtracted from any given mineral particle may be added to another mineral particle at a greater or less distance. Illustrating the above are the alterations of feldspar into muscovite and quartz, and of olivine into serpentine, magnesite, magnetite, and quartz. Chemical action is in most cases accomplished through solutions. Therefore its detailed discussion is considered in connection with the agents of metamorphism, gaseous solutions, and aqueous solutions. (See Chapter III.)

\section{GRAVITY.}

Gravity is now the great dominating force of the mniverse. Indeed, it is a main original source of energy. Certainly it is the source of energy which has largely controlled the development of the solar system, including the sun and all the planets and satellites. The transformations of gravity into chemical energy, heat, light, and other forms of energy are important factors in the development of the solar system, including the earth. Moreover, gravity still remains as the great dominating force which controls earth movements, ${ }^{2}$ both vertical and horizontal, and also the circulation of the water, both overground and underground. By earth movements are meant all movements of the solids or rocks of the earth not in solution. In this broad sense the movement of glaciers is an earth movement.

The direct work of gravity in metamorphism may be considered under ' two headings-mechanical action and water action.

\section{MECHANICAL ACTION.}

Rocks may be stressed within the elastic limit, or the stress may extend beyond the resisting power of the material. In either case the rocks are strained. Strain may occur with or without chemical action. Strain is always accompanied by some transfer of energy into heat. When the rocks are strained the molecules are moved with reference to one another. If the strain be within the elastic limit and chemical change does not take place, the molecules are only slightly farther apart or closer together, and when the stress is removed they may return to their original

$a$ Van Hise, C. R., Earth movements: Trans. Wisconsin Acad. Sci., Arts, and Letters, rol. 11, 1898, pp. 512-514. 
positions, or nearly so. If under the stress chemical interchange also takes place between the molecules, when the stress is removed the body may still return to nearly its original form. But if the strain extends beyond the elastic limit the form of the body is notably changed, as when a piece of wrought iron or steel is drawn out or when a piece of cast iron is crushed.

Mechanical action may therefore be considered as molecular or mass. By molecular mechanical action is meant differential movements of the molecules. By mass mechanical action is meant differential movements of large masses of the rocks. Molecnlar morement also frequently involves differential morements of the atoms. Metamorphism by molecnlar movement has generally been called static metamorphism. But molecular mechanical action is always accompanied in some degree by mass mechanical action, though this process may be subordinate: The term "dynamic metamorphism" has usually been restricted to alterations in connection with mass deformation. But mass mechanical action is always accompanied by molecular mechanical action as an important and essential concomitant, although this invariable relation has not always been recognized. Further, as mass movement becomes important molecular movement, instead of becoming less important, is likely to be of even greater consequence. There is therefore gradation between molecular mechanical action and mass dynamic action.

MOLECULAR MECHANICAI, ACTION.

Molecular mechanical action involves various degrees of movements.

Presumably the lesser movements are the cases of change in crystalline form and of strain within the elastic limit. In the change of a substance from one crystalline form to another-as, for instance, of aragonite to calcite- the movement of the molecules may not involve more than a rearrangement of those which are adjacent. In the case of substances strained within the elastic limit, the molecules are simply pressed slightly eloser together or pulled slighlitly farther apart, and yet these rery slight adjustments may have a profound effect upon the physical properties of the materials. For instance, amorphous glass when strained but slightly and well within its elastic limit becomes an anisotropic substance. Lencite crystallizes in the isometric system at high temperatures. As the mineral cools it passes at once into an anisotropic form. The transformation from 
one to the other may be seen by alternately heating and cooling this mineral under the microscope. In the foregoing cases, while we can not doubt that movement occurs, the readjustment is molecular, and it is therefore beyond the power of the microscope to determine its character.

It might at first be supposed that such slight movements as are involved in strains within the elastic limit are unimportant, but it is to be remembered that strains of this kind not only affect every mineral particle, but displace the individual molecules with reference to one another, so that the strained masses are affected throughout. While, therefore, it requires polarized light to detect the strained condition in minerals, it is certain that the effect is pervasive. It will be seen (pp. 95-98) that such state of strain is of fundamental importance in the matter of solution and deposition though the agency of solntions.

In a second class of movements there is molecular interchange between substances by which the compounds are modified in composition. Such interchanges involve chemical action. The motions which occur during chemical changes in solids are commonly for such short distances that the naked eye does not discover the relations of the original and secondary minerals. Such novements are microscopic. Chemical interchange may be mainly accomplished by chemical forces and the movement be an incident of this process. On the other hand, mechanical action may be the inciting canse which leads to chemical action. And, finally, the purely chemical and mechanical forces may interact, each promoting the other. The more important chemical reactions resulting from mechanical action are accomplished through the agency of solutions, and hence are treated in Chapter III. But Prof. Walther Spring ${ }^{a}$ has shown that chemical changes may be induced by mechanical action alone, without the presence of solutions. For instance, when barium carbonate and solid sodium sulphate were mixed in equal molecular proportions and subjected to a pressure of 6,000 atmospheres a change took place by which 80 per cent of the barinm carbonate and sodium sulphate were changed to barium sulphate and sodium carbonate, respectively; and conversely, when barium sulphate and sodium carbonate were mixed together in equal molecular proportions and subjected to a like pressure about 20 per cent was changed

a Professor Spring on the physics and chemistry of solids, review by C. F. Tolman, jr.: Jour. Geol., vol. 6, 1898, p. 323. 
to barium carbonate and sodium sulphate. ${ }^{a}$ In all such changes the fundamental principle controlling is that reactions shall take place which result in smaller volumes. Spring ${ }^{b}$ found that in the case of dry reactions induced by nechanical action time is a very important factor, the reactions taking place much more slowly than when compounds are moist and water is an intermediate agent.

Mass Mrenharcant actrox.

IIass meclanical action (a) may permanently strain the rocks without openings, (b) may strain the rocks with rupture and openings, and (c) may close the openings in rocks and produce welding.

Permanent strain without openings. - In order that permanent strain beyond the elastic limit without openings may take place in the rocks it is necessary that deformation shall occur while the rocks are under a sufficient pressure in all directions to hold the molecules so close together that the molecular attraction is effective. 'This will be true only where the pressure is greater in all directions than the crushing strength of the rocks. It is well illustrated by Adams and Nicolson's experiment on the deformation of marble while under pressure in all directions. ${ }^{\circ}$ The molecules were held close to one another, and the deformed marble retained considerable strengtl.

Later we shall see that the process of readjustment may be mechanical or chemical or partly each. When the process is mechanical the mineral particles are usually granulated-that is, finely fractured. When the process is chemical the particles are recrystallized. Also the process of readjustment may be accomplished by any combination of granulation and recrystallization (See pp. 737-748.) Under natural conditions, in order that the pressure in all directions shall be greater than the crushing strength of a rock, it is necessary that it be in the zone of flowage for that rock.

Permanent strain with openings.-When the rocks are strained beyond the elastic limit and the pressure is not greater in all directions than the crushing strength of the rocks, rupture and openings are produced. The ruptures may be regular or irregular. The regular ruptures may be of great extent

a Nernst, W., Theoretical chemistry, translated by C. S. Palmer, Maemillan \& Co., London, 1895,

5 Spring, op. cit., p. 322

${ }^{c}$ Adams, F. D., and Nicolson, J. T., An experimental investigation into the flow of marble: Philos. Trans. Royal Soc. London, ser. A, vol. 195, 1901, pp. 363-401.

ION XIVII-04-4 
and wide apart, as in the case of faults; or of moderate extent and width, as in the case of joints and bedding partings; or close together, as in the case of fissility. The irregular ruptures may be continuous and the openings wide, as in the case of the coarse breccias; or discontintous and the openings small; or so minute as to affect the individual particles, and thus grade into deformations withont openings or granulation.

Under natural conditions, in order that the pressure shall not exceed the crushing strength of a rock in all directions, it is necessary that it shall be in the zone of fracture for that rock.

Permanent strain with closing of openings and welding.-Mechanical action may close openings in rocks and weld the separated parts. In this case there is a diminution of volume due to bringing the particles closer to one another. In order that welding shall take place there must be sufficient pressure in all directions to bring the particles so close together that the molecular attractions are effective, or the pressure in all directions must be greater than the crushing strength of the rock.

Of course, the pressure required to satisfy the above conditions tor welding depends very greatly upon the character of the material. Moderate pressure may be sufficient to weld material composed of small and weak particles. For instance, moderate pressure of clay may bring many of the minute particles of kaolin so close to one another as to place them within the limits of effective molecular attraction. When the clay is dried the mass becomes harder. This hardening is doubtless due in part to the precipitation of the dissolved material contained by the water and the consequent cementation of the particles, as explained on pages 617-621. In proportion as the particles are coarse, strong, and large, and have relatively few points of contact, the pressure necessary to produce welding increases. To produce deformation with welding of the separated large particles of the strong minerals considerable pressure is necessary.

WATER ACTION,

The morement of water under the force of gravity is of the utmost importance in metamorphism. It is, indeed, the great agent of transportation of material both overground and underground, and is the dominating agent through which metamorphism is accomplished. Its work is fully considered in Chapter III, on "The agents of metamorphism." 
HEAT AND LIGIT.

Heat and light are forms of energy of the first importance. It has already been noted that their ultimate source is largely gravity. Heat is always present as a factor in metamorphism, for nowhere upon the surface of the earth nor within the earth is the temperature absolute zero. Other things being equal, the higher the temperature the more rapidly do alterations of rocks take place. Light also affects all parts of the earth at the surface. In metamorphism heat and light should be considered from two points of view-(1) sources of heat and light, and (2) effect of heat and light upon the alterations of rocks.

\section{SOURCES OF HEAT AND LIGHT.}

Heat and light agential in the alteration of rocks are derived (a) from the sun, (b) from deep within the earth by conduction or by convection through water or magma, (c) from mechanical action, and (d) from chemical action. The heat from all these sources is important; light, howerer, is derived chiefly from the sun, that from the other three sources being of little consequence.

THE SUN AS A SOURCE OF HEAT AND LIGHT.

The lieat and light of the sun are forces of the first order of magnitude in the alterations of rocks. The effect of these forces needs to be considered in four cycles-the cycle of the solar system, that of the seasons, that of the cyclone, and that of the day.

The solar-system cycle is the most important. This cycle involves two factors-the absolute temperature and change in temperature.

As to the absolute temperature, were it not for the heat and light of the sun it is certain that the temperature of the surface of the earth would not greatly exceed that of the interstellar spaces. Probably it would be $-200^{\circ}$ C., or even lower. At the present time the temperature of the surface of the earth averages $10^{\circ} \mathrm{C}$. $\left(283^{\circ} \mathrm{C}\right.$. absolute) or more. Therefore the temperature of all the upper zone of the earth is $200^{\circ} \mathrm{C}$., or more, greater than it would be without the heat from the sun. Were it not for this heat the water in the onter zone of the earth would be congealed, and the atomic and molecular energy would be greatly diminished. As a comparatively slight increase of temperature over that prevalent at the surface of the earth increases greatly the speed of alteration of rocks, it is 
to be presumed that under such low temperatures changes in rocks would be so slow as to be negligible.

How deep below the surface of the earth the heat of the sun produces an effect can not be accurately determined. It is highly probable that it has an important effect to a depth of thousands of meters, probably beyond the limits of the zone of observation. If the sun were not furnishing heat to the earth, and the increment of increase in temperature were the same as at present $\left(1^{\circ} \mathrm{C}\right.$. for 30 meters), and the temperature at the surface were $200^{\circ} \mathrm{C}$. lower it would be necessary to penetrate to a depth of 6,000 meters to reach a temperature as high as that at the surface under the present conditions. Below 6,000 meters the temperature would increase approximately as it does now from the surface downward. However, it is not to be supposed that the effects of metamorphism would be the same as those in the outer 6,000 meters at the present time, for the conditions of pressure would be very different. (See Chapter I, p. 43, and Chapter IV, pp. 15y160.) The assumption that the increment of temperature would remain the same were not the sun giving heat to the earth is only approximately true; but when it is remembered that 6,000 meters is an exceedingly small fraction of the earth's radius, it seems probable that the increment of increase of heat with depth in the outer part of the crust of the earth would not be greatly different, even if the smin had long ceased to be a source of heat; but if it were not for the heat of the sum, the temperature of that part of the lithosphere directly under observation would be so low that all chemical changes would be very slow, if indeed they were not inappreciable.

The absolute temperature at the surface is also dependent upon latitude. The average temperature at the warmest tropical regions is about $300^{\circ}$ C. absolnte, or, stated in the ordinary scale, $27^{\circ} \mathrm{C}$; the average temperature of the coldest polar region where observations have been made (latitude $81^{\circ} 44^{\prime}$ ) is $252.9^{\circ}$ absolute, or, in the ordinary scale, $-20.1^{\circ}$ C. ${ }^{n}$ At intermediate latitudes there are all gradations between these extremes. At any place the temperature may be presumed to increase with depth from these surface temperatures at the rate of $1^{\circ} \mathrm{C}$. per 30 meters.

It would be fruitless to attempt a discussion of the changes of the temperature of the outer part of the earth due to the solar cycle. So far

"Hann, Julius, Handbuch der Klimatologie, J. Engelhorn, Stuttgart, 1883, p. 733. 
as rock alterations now taking place are concerned, the sun may be regarded as furnishing to the earth a miform amount of heat.

The seasonal changes of temperature are very important, at the surface ranging from $30^{\circ} \mathrm{C}$. or less to as much as $80^{\circ} \mathrm{C}$. However, the depth to which the seasonal change produces an effect is not great, probably about 15 meters.

The cyclonic changes of temperature may be very great, ranging from a few degrees to about $70^{\circ}$, but the depth to which these changes extend is slight, probably less than 3 meter's.

The diurnal changes in temperature are scarcely less than the cyclonic, ranging from 0 to $50^{\circ} \mathrm{C}$. or more; but the depth to which the diurnal changes extend is insignificant, probably but a fraction of a meter.

From the foregoing it is plain that the lieat and light derived from the sun are of very great direct importance in the chemical and mechanical changes that rocks undergo. It will also be seen that the various changes of temperature as well as the absolute temperatures are of great consequence. Moreover, the heat and light of the sun exert a very inportant indirect influence upon metamorphism by reason of their being the sole source of the energy which produces plants and animals, and these agents will be seen to have a far-reaching effect upon the alterations of rocks. The effects of the heat and light derived from the sun are fully considered in Chapters VI, VII, and VIII, on "The belt of weathering," "The belt of cementation," and "The zone of anamorphism."

HEAT DERIVED FRONI WITHIN THE EARTH BY CONDUCTION OR CONVECTION THROUGH WATER OR MAGMA.

The amount of heat derived by the crust of the earth from the interior depends upon the conductivity of the various rocks and upon the convectional movements of magma and water.

The heat conductivity of the majority of rocks is between 0.4 and 0.6 , silver having a conductivity of 100 . It is apparent that the conductivity of rocks is very low as compared with that of the metals, but it can not be doubted that there is a steady but slow flow of heat by conduction from the interior of the earth to the zone of observation.

The amount of heat derived by the crust of the earth from intrusions of igneons rocks is very great. So far as this heat passes into the adjacent 
rocks by conduction, the coefficients are the same as in the transfer of heat from the interior of the earth. The transfer of the heat of magma to adjacent rocks is probably largely accomplished by convection. The magmas frequently furnish heated solutions. Ordinary circulating waters approach or come in contact with the igneous rocks; they thus become lieated. The heated waters move through the rocks controlled by the laws of underground circulating waters (see pp. 146-153), and give up a part of their heat to the surrounding rocks. The important metamorphosing effects of the great igneous masses through water convection may extend several miles. Contact metamorphism is sometimes restricted to the very marked effects due to high temperature immediately adjacent to the igneens rock. However, the alterations thus produced by high temperature as the result of direct conduction are probably small, compared with the widespread effects resulting from the dispersal of heat and material by means of underground water's.

MECHANICAL ACTION AS A SOURCE OF HEAT.

It is a well-known principle that when work is done involving strain of solids within the elastic limit, or subdivision of solids, or differential movement between solids in contact, the energy is partly transformed to heat. Hence strain within the elastic limit, subdivision of the rocks, and differential morement betreen rock masses and particles and within the particles raise the temperature of the rocks, and this greatly increases the speed and extent of the chemical reactions. Heat developed by mechanical action is therefore an important factor in the metamorphism of rocks. Indeed, the resnltant metamorphic products are very different under conditions of movement and under conditions of quiescence; but heat is only one of the factors entering into the differences. (See ip. 685-707.)

CHEMICAL ACTION AS A SOURCE OF HEAT.

Chemical action always produces a positive or negative heat effect, and thus promotes or retards metamorphism.

EFFECTS OF HEAT AND LIGHT ON ALTERATIONS OF ROCKS.

The relations between metamorphism and heat and light may be generally stated as follows: The kinetic energy of the molecules of substances, whether in the form of gas, liquid, or solid, is increased by heat and light. 
The speed of metamorphism is therefore largely dependent upon the amount of heat and light present, especially the former.

In rock alteration heat and light produce direct effects and indirect effects.

DIRECT EFFECTS OF HEAT AND LIGHT.

The more important direct effects may be either mechanical or chemical.

Mechanical effects.-The mechanical effects are desiccation, baking, and fusion. At the surface of the earth the heat of the sun frequently results in evaporating the moisture and desiccating the rocks; an attendant result is induration. This process is especially important in the clay sediments, and occurs to the greatest extent in the hot and arid regions, although desiccation is not unimportant in the colder regions. The details of the process especially concern the belt of weathering and are treated in the chapter on that subject. (See Chapter VI, pp. 541-550.) Where igneons rocks as a consequence of volcanism are brought into contact with other rocks the latter may be baked for a longer or shorter distance from the igneons rocks. The process of baking as here used is restricted to modifications similar to those which take place in the baking of bricks; that is, to effects which are mainly due directly to the heat. This process is restricted to the belt above the level of underground water-the belt of weatheringand is therefore treated in detail in the chapter on that subject. (See Chapter VI, pp. 488-494.) Below the belt of weathering the rocks are saturated with water and the heat effects are mainly produced through that agent. Even in the belt of weathering the baking effect is not wholly due to heat, but is partly accomplished throngh the agency of the contained water, precisely as is the transformation of clay to brick by burning; for all rocks under natural conditions contain gas and water, and nsually considerable quantities. During the baking process the original molecules are brought nearer together, but there are also important chemical changes.

Where the masses of the igneous rocks are very great, and especially where adjacent rocks are included in masses of igneous rocks, the rocks may be softened by the heat or even absorbed by the magma. Where the rocks are softened they are likely to be very greatly changed, perhaps recrystallized. Where they are absorbed by the magma they are lost as original rocks and become a part of the magma by which they are absorbed. 
When the modified magma crystallizes it takes the form of an ordinary igneous rock, and may show no evidence of the fact that previously solidified rocks have contributed material.

chemical effects.-In proportion as the temperature is high chemical reactions are likely to take place between solids. This is illustrated by the casehardening of iron. When soft iron is placed in contact with pulverized charcoal and the temperature is raised to a red heat, but not to the point of fusion, some of the carbon unites with the iron, transforming the outer part of it into steel. Thus it is casehardened. Just how the mion takes place between the iron and the carbon is uncertain. It is supposed to be due to the direct union of the solids, but we can not be quite sure that the result is not accomplished through the ageney of a gas. The carbon may be partly oxidized, and thus be transformed to the gas carbon monoxide. This may penetrate the iron, which may rednce the carbon monoxide to carbon again. The reduced carbon may at the instant of reduction unite with the iron, forming the carbide, or steel. While it is certain that high temperature is favorable to the mutual chenical reactions of solids, when the temperature becomes so high as to transform the solids to liquids the chemical reactions are those of liquids rather than those of solids.

\section{INDIRECT EFFECTS OF HEAT AND LIGHT.}

The indirect effects of heat and light are accomplished through the agents of metamorphism-gases, water, and organic forms. The movements of the atmosphere and hydrosphere are the conjoint effect of heat and light and gravity. It has already been noted that the movements of these bodies are the agents which do the main work of epigene transfer of material. Not only do gas and water act as agents of transfer, but they act as agents for chemical changes. It lias already been seen that chemical action may be a direct result of heat. However this may be, it is certain that by far the more important, indeed the dominant, effects which heat and light have upon chemical reactions are accomplished through the agency of gases and water and organic forms. Of the forces heat and light, the former is the important one in the reactions accomplished through the agency of gases and water solutions; but light is very important in the production of organic agencies. The indirect effects of heat and light and all other conjoint forces are considered in comnection with the agents of alteration in Chapter III. 
GENERAI، STATEMENTS.

From the foregoing it is apparent that the effects of chemical energy, gravity, and heat and light are not independent of one another; on the contrary, they are most intricately interlocked. To a considerable degree any one of the forms of energy may be transformed into the others. Consequently the action of one almost always produces an effect upon the action of the others. Moreover, one almost never acts without the action of the others. Frequently all of the forces of metamorphism are important simultaneous factors in the results; again, one or two of the forces may be prominent, or even dominant, the others playing a subordinate part. But, in every transformation of metamorphism, if all the energy factors of the entire system affected be taken into account, some of the energy is changed into the lowest form of energy, heat, and at least a portion of this heat is dissipated. ${ }^{a}$

a Daniell, Alfred, A text-book of the principles of physics, 3d ed., Macmillan Co., New Iork, 1895, p. 51. 


\section{CHAPTER III. \\ THE AGENTS OF METAMORPHISI. \\ GENERAI STATEMENT.}

The agents through which the alterations of rocks take place are gaseous and liquid solutions and organisms. Solutions are the special subject of this chapter. Organisms are influential only in the belt of weathering, and their action is therefore considered in connection with that belt. (See Chapter VI.)

The circulation and work of solutions involve a consideration of the circulation and work of the gases of the earth, of which the atmosphere is the dominant portion, and a consideration of the circulation and work of the water of the earth, of which the ocean is the dominant portion. While the circulation and work of the atmosphere and of overground water may from a purely theoretical point of view be considered as a part of a treatise on metamorphism, the work of these epigene agents is the subject of that division of geology which has been named physiography, and as the work of the atmosphere and overground water is so fully dealt with in comnection with that subject, this branch of metamorphism will not be discussed here at all. But the circulation and work of underground gas and water solutions are of fundanental importance in metamorphism and must be somewhat fully considered.

Gas and water below the surface in the openings of the rocks will be called ground gas and gromnd water, to discriminate them from gas and water above the lithosphere.

Solutions "are homogeneous mixtures which can not be separated into their constituent parts by mechanical means." a The properties of solutions vary continuously and regularly with the concentration. ${ }^{b}$ Under the

"Ostwald, W:, Solutions, translated by M. M. Pattison Muir; Longmans, Green \& Co., London, 1891, p. 1.

${ }^{b}$ Cameron, F. K., Application of the theory of solutions to the study of soils: Rept. No. 64, Field Operations of the Division of Soils, 1899, U. S. Dept. of Agric., 1900, pp. 142-143. 
definition, solutions may be made by mingling gases and gases, gases and liquids, gases and solids, liquids and liquids, liquids and solids, and solids and solids. The solutions resulting from these varions combinations may be gases, liquids, or solids, or partly two or all. Gaseous solutions may be formed by the mingling of gases and gases, of gases and liquids, and of gases and solids. ${ }^{a}$ Liquid solutions may be formed by the mingling of gases and gases, of gases and liquids, of liquids and liquids, of solids and liquids, and of gases, liquids, and solids. Solid solntions may be formed by the mingling of gases and solids, of liquids and solids, of solids and solids, and of gases, liquids, and solids. But however complex the origin and however numerons the components, the compounds with which the geologist has to deal are gases, liquids, and solids. The two common combinations which he has to consider are gaseons solutions and solids, and liquid solutions and solids. The liquid solntions are universally aqueous. The solids are the rocks. The combinations gaseons solutions and solids, and aqueous solutions and solids will be treated under Parts I and II of this chapter:

\section{PART I. GASEOUS SOLUTIONS.}

Since the geological work of gases and vapors can not be practically discriminated, the term gas is here used to cover both gases and vapors.

The gases which are important in rock alteration are oxygen $\left(\mathrm{O}_{2}\right)$, sulphur $\left(\mathrm{S}_{8}\right.$ to $\left.\mathrm{S}_{2}\right)$, water gas $\left(\mathrm{H}_{2} \mathrm{O}\right)$, ammonia $\left(\mathrm{NH}_{3}\right)$, carbon dioxide $\left(\mathrm{CO}_{2}\right)$, sulphurous oxide $\left(\mathrm{SO}_{2}\right)$, boric acid $\left(\mathrm{H}_{3} \mathrm{BO}_{3}\right)$, hydrochloric acid $(\mathrm{HCl})$, and hydrofluoric acid (HF).

Never is one of these chemical compounds at work alone upon the rocks; at the place of action there are always solntions of several gases. Mineralizers in rocks, according to the original definition, are substances which act in the gaseous condition; ${ }^{b}$ but it will be seen (pp. 490-494) that the term has been practically restricted to peculiar gases under special circumstances. Notwithstanding the definition of the term, the action of water solutions containing certain compounds, which if alone would be gaseous, has been spoken of as due to mineralizers. The term mineralizers, if it is to serve any useful purpose, should be definitely restricted

\footnotetext{
a Daniell, Alfred, A text-book of the principles of physics. 3d ed., Macmillan Co., New York, 1895 , p. 330.

b Expression "Agents minéralisateurs" first used by Élie de Beaumont and defined by H. Ste.Claire Deville: Comptes rendus des Séances de l'Académie des Sciences, vol. 52, 1861, pp. 920, 1264.
} 
to the action of some particular compound or compounds, or else to some form of compound, such as gases.

Gaseous solutions require consideration from two points of view-the chemical and physical principles controlling the action of gases and the geological work of gases.

SECTION I. CHEMICAL AND PHYSICAL PRINCIPLES CONTROLLING THE ACTION OF GASES.

The chemical and physical principles controlling the work of gases may be considered under (1) the gases present, (2) the pressure, and (3) the temperature.

Gases present.-The law of greatest importance controlling the chemical action of gaseous solutions is: The properties of a homogeneous mixture or solution of various gases are the sum of the properties of the constituents of the mixture. To illustrate, when carbon dioxide $\left(\mathrm{CO}_{2}\right)$ and oxygen $\left(\mathrm{O}_{2}\right)$ are mixed the properties and activities of each are the same as if the same quantity of each were free from the other and occupied the same space. Therefore, in the belt of weathering, where gases are active, the carbon dioxide and oxygen are both doing their work, the one that of carbonation (see pp. 473-480), the other that of oxidation (see pp. 461-473), as if the other were not present. It is clear, therefore, that the properties of gaseous mixtures are additive.

Slight deviations from this law have been noted under certain conditions, but these mainly concern the exact physics of the gaseous solutions rather than their geological work, and hence are not here considered. In applying the law, howerer, we must be sure that the gases do not unite chemically and produce a new compound. To illustrate, while the law is certainly applicable to the case mentioned, that of a mixture of carbon dioxide and oxygen, it is not certain that this is the case when water gas $\left(\mathrm{H}_{2} \mathrm{O}\right)$ and carbon dioxide or sulphurous oxide $\left(\mathrm{SO}_{2}\right)$ are mixed, for these compounds may unite with water gas, producing carbonic acid $\left(\mathrm{H}_{2} \mathrm{CO}_{3}\right)$ and sulphurous acid $\left(\mathrm{H}_{2} \mathrm{SO}_{3}\right)$ gases. Certainly the law will not apply to a mixture of the gases ammonia $\left(\mathrm{NH}_{3}\right)$ and water, for these gases will largely unite and produce ammonium hydroxide $\left(\mathrm{NH}_{4} \mathrm{OH}\right)$, which may exist in the form of gas. In case a gas be formed by the union of two or more gases, 
the law controlling the action of gases is applicable to the new compound, and to the other gases with which it is mingled but does not unite chemically.

As to the relative importance of the gases, it might at first be thought that the strong acids, such as hydrochloric and hydrofluoric, are of greater consequence than the much less active compounds, carbon dioxide and oxygen; but it should be remembered that carbon dioxide and oxygen are everywhere at work upon the surface of the earth, whereas the presence of the strongly active compounds in more than minute quantities is exceptional. It therefore follows that the action of the universally present weaker agents, such as carbon dioxide and oxygen, is of immeasurably greater geological importance than the action of the stronger but much less abundant gases.

The pressure.-Increase of pressure increases the chemical activity of a gas. This law follows from the fact that the number of molecules which act upon a given space is directly as the pressure. The varying atmospheric pressure may be taken as illustrating this principle. When the pressure increases, say, by .05, this means that 1.05 times as many molecules of gas are actively at work upon a given area as before.

One of the best illustrations of the increased activity of gases in accomplishing chemical work when under pressure is that of carbon dioxide. As shown in another place (pp. 175-176), carbon dioxide is capable of decomposing many silicates at ordinary temperatures; but Struve and Mueller ${ }^{a}$ have shown that when carbon dioxide is under pressure its effect in decomposing silicates is very much greater than under ordinary conditions. This is in accordance with the law of mass action. In proportion as the pressure increases the number of active molecules increases, and therefore the geological work increases in proportion.

The temperature.-The activity of gases increases with increase of temperature. In proportion as the temperature is high, the kinetic molar energy of the molecules of gases is great. The absolute temperature of a perfect gas is believed to be a direct measure of its kinetic molar energy. By molar kinetic energy is meant the energy of trauslation of the molecule of a gas, and not the vibratory or rotary motions of the molecules themselves.

a Iueller, Richard, Untersuchungen über die Einwirkung des kohlensïurehaltigen Wassers auf einige Mineralien und Gesteine: Tschermaks mineral. Uittheil., vol. 7, 1877, p. 47. 
The kinetic energy of a moving body is the product of one-half of its mass into the square of its velocity. When, a gas is very dense its molecules are closely crowded, and on account of the molecular attraction there is an appreciable decrease in the theoretical pressure, which is a measure of the kinetic molar energy. Since the kinetic energy of the gaseous molecular projectiles increases as the squares of the relocities, this may explain why a slight increase of temperature often greatly increases the chemical reactions of the gases in contact with the solids of the earth's crust, for the likelihood of a chemical union depends, among other things, upon the energy with which the particles of a gas come in contact with the minerals of the rocks.

SECTION 2. GEOLOGICAL WORK OF GASES.

The observable geological work of gases is mainly above the level of ground water, or in the belt of weathering. In the belt of cementation, below the level of unclerground water, the rocks are saturated with water solutions. Gaseous substances, if present, would be in solution in water, and their action would therefore fall under water solutions, treated on later pages.

In the belt of weathering oxygen and carbon dioxide are immeasurably the most important of the mineralizers, because they are present in the interstices of the rocks in this belt throughout the land areas. However, in volcanic districts any or all of the geologically important gases may be present and have a very marked metamorphosing effect upon the rocks. But of these gases that of water is of vastly the greatest consequence. The consideration in detail of the effects of these various mineralizers and of their action in conjunction with other agents properly falls in Chapter TI on "The belt of weathering."

In the deep-seated zone of anamorphism water itself is mainly above its critical temperature (see pp. 659-661), and is therefore in the form of a gas. On account of the great pressure the gases are dense. Under these conditions most or all of the substances held in solution would also be in the form of gases. The active substances would be solutions of gases in gases. One would expect that the action of water gas holding in solution other gases under such conditions of pressure and temperature would be different from the action of highly heated water, in that its viscosity would 
be very small. It would therefore have a greater penetrating power than water, and would be more highly energetic in its action. Under these conditions the minutest spaces would be somewhat readily traversed. The rocks of the deep zone in which action of this kind has taken place can reach the surface only by passing through the zone in which water is in the liquid form. Therefore the effects which were produced by the mineralizers in the deepest zone will have been modified by the action of water solutions during the long time the rocks were in the belt of cementation. The details of the effect of water gases in the zone of rock flowage will be considered in Chapter VIII, on "The zone of anamorphism."

All of the gases may act in either of two ways: (1) By their presence they may influence crystallization or recrystallization withont entering into combination. (2) They may enter into the combinations forming oxides, hydroxides, carbonates, sulphates, etc. The first of these actions is spoken of as that of crystallizers, and the second as that of mineralizers. In the metamorphic rocks it is ordinarily difficult to prove the past action of gases, not in water solutions. Occasionally the materials of volcanic cones have been rendered porous and the rocks altered in consequence of the action of gaseous exhalations. In such cases the gases usually have united to some extent with the materials through which they have passed, and in this way furnish evidence of their past action.

PART II. AQUEOUS SOLUTIONS AND SOLIDS.

GENERAL CONSIDERATIONS.

The one liquid throngh which the greater part of the alterations of rocks occur is water solution. Indeed, this is so profoundly true that the water of the earth has been compared with the blood of an organism. And it is certainly true that the transformations of tissues by the blood are scarcely more far-reaching than those of the lithosphere by the agency of water. It has been determined by laboratory experiments that pure water at ordinary temperatures is capable of dissolving all compounds to some extent. Corresponding with this fact, analyses of ground waters show that they contain in solution all of the elements which occur in nature. The solutions may vary from very dilute to rather strong. So far as the gases are dissolved in water, their action is to be treated under water solutions, not under gases. 
In the belt of weathering, above the free surface of ground water, gaseous solutions and liquid solutions work together. In this belt the rocks are not ordinarily saturated with water, but on the average contain a considerable amount of water held by adhesion between the liquid and the solid mineral particles. It is believed that in this belt the gases act upon the rocks chiefly through water solutions. As evidence of this is the small amount of decomposition of the disintegrated rocks in arid regions. (See pp. 496-498.) It therefore appears that the dominant agents of alterations in the belt of weathering are aqueous solutions.

In the belt of cementation below the free surface of ground water the rocks are practically saturated, and in this belt aqueous solutions are the chief agents of alterations.

Water solutions are also a chief agent in the transportation of material from one place to another.

At this point it is necessary to understand that the places of interaction of aqueous solutions and solids are the contacts between the two. It will be seen later that, on account of the molecular attraction between water and rock, a thin film of water adheres to the solid particles with which it is in contact. This film is not in active circulation, yet it is the part of the agent, water, which is immediately concerned in the transfer of mineral material from the rocks to the solutions and from the solutions to the rocks.

The contact film may take material of the rock into solution. From this film the materials taken into solution migrate to other parts of the solution. Probably the migration from the contact film to the free water is largely by diffusion (see pp. 82-83); but, once beyond the contact film, the migration is largely accomplished by convectional movements. Material may be supplied to the contact film by migration of material from the free parts of the solution. From the contact film material may be deposited in the rocks.

In this connection it is interesting to note that in the portions of the solutions near the contact with solids "there is often a concentration of the dissolved material. This phenomenon has been called adsorption." The phenomena of adsorption seem to show with great clearness, not only that the contact film is the active agent in transfer between the free solu-

a Cameron, Frank K., Application of the theory of solutions to the study of soils: Report No. 64, Field Operations of Division of Soils, 1899, U. S. Dept. of Agric., 1900, p. 142. 
tions and the solids, but that in this film the nigration of the dissolved material is to some extent stayed by the molecular attraction of the crystals.

Aqueous solutions as a geological agent require consideration from two points of view - the chemical and physical principles controlling the action of ground water, and the circulation and geological work of ground water. 'Tliese are treated in the following sections I and II, respectively:

SECTION I. CHEMICAL AND PHYSICAL PRINCIPLES CONTROLLING THE ACTION OF GROUND WATER.

The work of ground water, like any other work, requires the expenditure of energy. The energy by which the water accomplishes its work is derived from chemical action, heat, and mechanical action.

In order to comprehend the processes of alteration of rocks it will be necessary to summarize the important conclusions of physical chemistry as to solutions and chemical reactions. The principles here contained are mainly taken from the works of Ostwald and Nernst.

Chemical action will be considered nuder the headings, "Principles of solutions applicable to ground waters," and "Principles of chemical reactions applicable to ground waters."

PRINCIPLES OF SOLUTIONS APPLICABLE TO GROUND WATERS.

While the consideration of the principles of solution logically falls under general chemical action, and, perhaps, ought to be treated as a special case under the general treatment of chemical reactions, it seens adrisable, becanse the subject of solutions is somewhat simple as compared with the interactions of complex chemical compounds, to take up this subject first, after which the general laws controlling chenical reactions will be given.

The water of rocks, whether at ordinary temperatures and pressures or at higher temperatures and pressures, may take any of the substances with which it comes in contact into solution; it inay deposit substances from solution; it may combine with substances forning hydroxides, as in the case of many of the zeolites and limonite; it may part with its hydrogen in exchange for bases, thus at the same time changing the composition of the rock and taking the bases replaced into solution. This is illustrated by the alteration of enstatite to tale. (See Chapter V, p. 268.) There may be MON XIVII- $-04-5$ 
reactions as a result of different substances being taken into solution at different times; there may be reactions as a result of different solutions coming together, and thus mingling; there may be reactions between substances in solution and the solid material with which the water is in contact; there may be reactions as a result of changing temperature and pressure. All these changes are in the nature of chemical action. Therefore by chemical action through solutions is meant the taking of material into solution, the deposition of material from solution, the interchange between materials in solutions, the interchange between materials in solutions and adjacent solids, and, finally, the interchange of the adjacent solid particles, for such an interchinge is usually accomplished through the medium of a separating film of water. In this case the apparently simple reaction between solids is really accomplished by transfers through separating solutions. In all these interchanges the materials pass through a stage of solution.

Salts are combinations of the metals and the acid radicals. Thus $\mathrm{Na}_{2} \mathrm{SO}_{4}$ is a combination of $\mathrm{Na}_{2}$ and $\mathrm{SO}_{4}$, and $\mathrm{KClO}_{3}$ of $\mathrm{K}$ and $\mathrm{ClO}_{3}$. Faraday called these constituents ions. This term will be used as defined by Faraday without any implication that a compound in solution separates into its constituent ions or is dissociated.

According to many chemists ${ }^{a}$ salts in various solutions are at least partly separated into their ions. Such supposed separation has been called electrolytic dissociation. If electrolytic dissociation takes place to a considerable extent, the properties of the compounds are practically the sum of the properties of their separated ions. In its power of dissociation of dissolved salts water is held to exceed all other solvents. Water itself is held to be slightly dissociated, or the $\mathrm{H}_{2} \mathrm{O}$ separates into the ions $\mathrm{OH}$ and $\mathrm{H}$. According to the theory of dissociation the presence of free ions in water solutions is therefore universal. "By the advocates of the theory it is held that it is by the interaction of these free ions that chemical interchanges are accomplished. But dissociation is held to be very imperfect in strong solutions, relatively far advanced in dilute solutions, and in very dilute solutions nearly or quite complete. As the greater portion of

a Nernst, W., Theoretical chemistry, trans. by C. S. Palmer, Macmillan \& Co., London, 1895, p. 307. Ostwald, W., Outlines of general chemistry, trans. by James Walker, Macmillan \& Co., London, 1895 , pp. 266-290. 
underground solutions are very dilute, at least where somewhat free circulation is the rule, if the theory of dissociation be true we may suppose that the salts held in solution are largely separated into their ions. While the theory of dissociation and the explanation of chemical reactions by interchange of free ions (see pp. 84-85) have a strong foothold in theoretical chemistry, they have never gained universal support; and recently the theory has been strongly attacked by Kahlenberg, who not only holds that the theory is unnecessary to explain chemical reaction, but brings together many facts which appear to controvert it. ${ }^{a}$ He has shown, moreover, that instantaneons chemical changes take place in solutions that are
the best of insulators.

Until recently it has not been known how the most important of the geological compounds, the silicates, behave when dissolved. However,
Kahlenberg and Lincoln ${ }^{c}$ have Kahlenberg and Lincoln ${ }^{c}$ have shown that when dilute solutions of silicates are made the silica exists in such solutions in the form of colloidal silicic acid. To illustrate: If a sufficiently dilute solution of sodium silicate be made, but much more concentrated than ordinarily occurs in underground waters, the compound breaks up into $\mathrm{NaOH}$ and colloidal silicic acid. From this fact it wonld not be supposed that the silicic acid is ' a chemically active compound, and it is not active near the surface of the earth at ordinary temperatures and pressures; but on subsequent pages it will be seen that at considerable depth, where the pressure and temperature are much above the normal, silicic acid is a most active compound.

Before the ionic theory of solutions gained recognition it was customary in the published analyses of underground waters to suppose that the bases and acids of the dissolved materials are united in a definite way. For instance, chlorine was ordinarily considered as united witl the potas-
sium, sodium, or calcium. The sulphuric sium, sodium, or calcium. The sulphuric oxide radical $\mathrm{SO}_{4}$ was supposed to be united with the oxides of potassium, magnesium, calcium, and sodium. of iron, magnesium, sodium, and calcium. The aluminum and silica were

a Kahlenberg, L., The theory of electrolytic dissociation as viewed in the light of facts recently ascertained: Bull. Univ. of Wisconsin No. 47, 1901, pp. 299-351; also Jour. Phys. Chem., vol. 5, 1901,
pp. 339-392. $35-392$.

Jour. Phys. Chem., vol. 6,1902 , p. 1 .

$c$ Kahlenberg, L., and Lincoln, $A$. vol. 2,1898 , pp. 88-90. 
nsually regarded as oxides, although in some cases the aluminum was treated as mited with the chlorine. ${ }^{a}$ However, results of recent analyses have ordinarily been given on the basis of ions. ${ }^{b}$

In a solntion, under the law of mass action, each of the bases is to be considered as divided between all acids, and moler the theory of dissociation there are also present in the solutions the free ions of both the bases and the acids. For example, suppose a strong underground water solution to contain three bases and three acid radicals; as, for instance, the bases sodium, calcium, and magnesium, and the radicals of carbonic, sulphuric, and hydrochloric acid; then the following nine compounds are present, $\mathrm{Na}_{2} \mathrm{CO}_{3}, \mathrm{Na}_{2} \mathrm{SO}_{4}, \mathrm{NaCl}, \mathrm{CaCO}_{3}, \mathrm{CaSO}_{4}, \mathrm{CaCl}_{2}, \mathrm{MgCO}_{3}, \mathrm{MgSO}_{4}$, $\mathrm{Mg} C l_{2}$, and also the six free ions, $\mathrm{Na}, \mathrm{Ca}, \mathrm{Mg}, \mathrm{CO}_{3}, \mathrm{SO}_{4}$, and $\mathrm{Cl}$, making altogether fifteen separate combinations of the elements. However, under the theory of dissosiation, if the solutions be so weak that the substances in solution are wholly ionized the nine compounds first mentioned will not be present. If the dissociation theory be rejected, under the law of mass action in all cases all of the nine compounds will be present, but not the free ions.

Under the principles of solntions it is necessary to consider the cases of (1) the solution of gases in ground waters, (2) the solution of solids in ground waters, and (3) diffusion.

SOLUTION OF GASES IX GROCYD WATERS.

The quantity of gases which can be dissolved in underground water depends upon the gases present, the pressure, the temperature, and the solids in solution.

Gases present.-All the natural gases may be dissolved in water or may unite with water. In the latter case the resultant compounds are dissolved. In both cases solutions are formed.

Since below the level of the free surface of underground water it is clear that the gases enter into solntion either by absorption or by combination, it follows that the nore far-reaching effects of these substances in metamorphism are not as gases, but as aqueous solutions. The gases are

a Peale, A. C., Lists and analyses of the mineral springs of the United States: Bull. U. S. Geol. Survey No. 32, 1886, pp. 43, 115, 133.

$b$ Clarke, F. W., and Hillebraud, W. F., Analyses of rocks and analytical methods, U. S. Geol. Survey, 1880-1896: Bull. U. S. Geol. Survey No. 148, 1897. Clarke, F. W., Analyses of rocks, laboratory of the U. S. Geol. Survey, 1880-1899: Bull. U. S. Geol. Survey No. 168, 1900. 
therefore important factors in the a dion of ground waters, but they are of comse only a small portion of the substances which ground waters carry. The more important of these gases which pass into ground waters are: Oxygen $\left(\mathrm{O}_{2}\right)$, carbon dioxide $\left(\mathrm{CO}_{2}\right)$, hydrosulphuric acid $\left(\mathrm{H}_{2} \mathrm{~S}\right)$, sulphurous oxide $\left(\mathrm{SO}_{2}\right)$, hydrochloric acid $(\mathrm{HCl})$, hydrofluoric acid $\left(\mathrm{HF}^{\mathrm{r}}\right)$, boric acid $\left(\mathrm{H}_{3} \mathrm{BO}_{3}\right)$, and ammonia $\left(\mathrm{NH}_{3}\right)$. Sulphur and boric acid as gases occur mainly in connection with volcanic action. If the above-mentioned or other gases mite with the water the laws below given as to solubility do not hold; thus carbon dioxide unites with water, forming carbonic acid $\left(\mathrm{CO}_{2}+\mathrm{H}_{2} \mathrm{O}=\mathrm{H}_{2} \mathrm{CO}_{3}\right)$; sulphurous oxide unites with water, producing sulphurous acid $\left(\mathrm{SO}_{2}+\mathrm{H}_{2} \mathrm{O}=\mathrm{H}_{2} \mathrm{SO}_{3}\right)$; ammonia unites with water, producing anmonium hydrate $\left(\mathrm{NH}_{3}+\mathrm{H}_{2} \mathrm{O}=\mathrm{NH}_{4} \mathrm{OH}\right)$. In some of these cases, for instance, that of ammonia and sulphurous oxide, the water may unite with many times its volume of the gas, with increase of volume; thus water at $0^{\circ} \mathrm{C}$. and atmospheric pressure absorbs 1,050 volumes of ammonia as a result of the union of the two. What portion of $\mathrm{CO}_{2}$ contained in ground water remains as $\mathrm{CO}_{2}$ in solution, and what part unites with water, forming carbonic. acid, is uncertain, but it is definitely known that much of the $\mathrm{CO}_{2}$ contained in the ground water is in the form of the so-called bicarbonatesfor instance, such salts as $\mathrm{Na}_{2} \mathrm{CO}_{3}+\mathrm{H}_{2} \mathrm{CO}_{3}$ or $2 \mathrm{NaHCO}_{3}$-and therefore is united with the water.

When new compounds are formed by the union of the gases with the liquids, the substances held in solution are the new compounds. When these new compounds are gases the laws below given concerning the solution of gases in liquids apply only to the new compound, not to the original gas. Where the compound is a solid-as, for instance, a bicarbonate-the laws for the solution of gases in water do not apply, but such compounds are held under the laws controlling the solution of solids in liquids. (See pp. 72-82.)

In some cases in nature a part of a gas may unite with a substance in solution and make a new compound and a part may unite witl water and be dissolved in this form. If both the compounds be gases the laws for the solution of gases in liquids hold. If the new compound formed be a solid salt the laws for the solution of solids in liquids apply to it, and the laws for the solution of gases in liquids apply to the uncombined gas. This case is illustrated by carbon dioxide, already mentioned. 
The pressure.- "The quantity of a gas dissolved by a specified quantity of a liquid is proportional to the pressure of the gas." a This statement is true of each gas without reference to whether a gas be alone or mixed with other gases. Thus the solubility of each of a number of mixed gases is controlled by the pressure exerted by that gas, not by the total pressure exerted by the mixture. It is therefore clear that under natural conditions the pressnre of that part of any gas which is in the atmosphere and the pressure of that part which is held in solution in the water immediately adjacent are the same when the two are in equilibrium, and the water is therefore just saturated.

So far as ground waters are concerned, there are two cases; first, the waters of the belt of weathering, or those to the level of ground water; and second, those below the level of ground water, or the belt of saturation. In the belt of weathering the pressure is atmospheric. Changes of pressure are barometric. In so far as the atmospheric pressure varies-and this is by fractions up to one-fifteenth-the solubility of the natural gases in the water of the belt of weathering also varies directly as the pressure of each of the gases varies, withont reference to the pressure and solubility of the other gases.

In the belt of saturation, just at the level of ground water, the amount of gases held in solution is proportional to atmospheric pressure; but at greater depths higher degrees of concentration of gases are possible, although it might at first be thought that the atmospheric pressure or vapor pressure at the free surface of the water would determine the concentration of the solution. The pressure which really is determinative as to the amount of gas which may be held in solution is that of a column of water extending to the free surface, plus the atmospheric pressure. Since, however, water is so much heavier than the atmosphere, at considerable depths below the level of ground water the atmospheric pressure may be neglected; and the pressure, and therefore the solubility of underground gases in water, is almost directly proportional to the depth below the level of ground water. For instance, at a depth of only 100 meters below the level of ground water the pressure of the atmosphere is only one-tenth that of the water pressure; at a depth of 1,000 meters it is ouly one

a Ostwald, W., Solutions, translated by M. M. Pattison Muir; Longmans, Green \& Co., New York, 1891, p. 9. 
one-hundredth, and at still gi ater depths the fraction of pressure due to the atmosphere is insignificant.

But in order that saturation for any gas corresponding to the pressure at any given depth shall occur, it is necessary that a sufficient amount of gas shall there exist. Gases may be produced below the level of ground water by the chemical reactions, as by the liberation of carbon dioxide in the process of silication. Later it will be seen (see Chapter VIII, pp. 677-679) that this is one of the fundamental processes of the lower physical-ehemical zone. It follows from the above that at depth the amount of carbon dioxide or other gas in solution per unit of water may be many score times greater than near the surface. The pressure of carbon dioxide at the surface is only about 0.0006 of an atmosphere. The water pressure at a depth of 1,000 meters is almost 100 atmospheres; therefore the amount of free carbon dioxide which may be held in solution, if pressure were the only factor concerned, might be 166666 times as great as that held in solution in the belt of weathering.

But it must be remembered that, as shown below, the increase of temperature due to increase of depth somerwhat reduces this multiple.

It should be remembered also that carbon dioxide combines with water, producing carbonic acid, and the amount of this compound which may be held in solution at the surface of ground water is not dependent upon the pressure of the atmospheric carbon dioxide. But it is evident that deep ground waters, where the pressure is great, may hold a vastly greater quantity of carbon dioxide than can be held in solution near the level of ground water.

As already pointed out, the law which obtains in reference to geological work is that the activity of the carbon dioxide increases in direct ratio with its quantity.

The theoretical conclusion that the action of carbon dioxide wonld be increased by pressure, and consequent greater quantity, has been experimentally verified by Mueller ${ }^{a}$ and Struve, who found that strong pressure increased the action of carbon dioxide in the decomposition of the silicates more than did increase of time.

a Mueller, Richard, Untersuchungen ïber die Einwirkung des kohlensïurehaltigen Wassers auf einige Mineralien und Gesteine: Tschermaks mineral. Mittheil., vol. 7, 1877, p. 47 
The temperature.-Increase of temperature generally results in decrease of solubility of a gas. ${ }^{a}$ Increase in temperature with depth, or because of volcanism, lessens the solubility of gases in ground water, and to this extent works against the effect of increased pressure.

solidsinsolution. - There is still another factor which enters to a slight extent into tlıe solubility of gases. Water holding solids in solution, in most cases, absorbs less of a gas at a given pressure than does pure water. However, the solutions near the surface are ordinarily so dilute that this law is probably not important, but at depth it may be of some consequence in working against the effect of increased pressure.

SOLYTION OF SOLIDS IN GROCND WATER.

Where a solid is placed in a liquid some or all of it dissolves, and thus forms a lomogeneous mixture composed of the two, or a solution.

It has been found that if a liquid be placed in a vessel having two compartments separated by a membrane through which the solvent but not the dissolved substance may pass, when a soluble compound-for instance, sugar-is dissolved in the liquid in one of the compartments, pressure against the membrane is produced. This pressure has been called osmotic pressure, to distinguish it from ordinary gas pressure, known as vapor pressure. According to vals't Hoff, the osmotic pressure "is independent of the nature of the solvent, and in general obeys the laws of gases." That is to say, "the osmotic pressure is proportional to the concentration; the osmotic pressure is proportional to the absolute temperature; the same osmotic pressure can be obtained by equimolecular quantities of the most various substances in the same solvent; the osmotic pressure is exactly the same as the gas pressure which would be observed if the solvent were removed and the dissolved substance were left filling the same space in the gaseous state at the same temperature." c These somewhat sweeping statements need various modifications. For instance, where the solutions are very concentrated the molecules in solution are believed to be so close to

a Ostwald, W., Outlines of general chemistry, translated by James Walker, Macmillan \& Co., London, 2 ed., 1895, p. 121.

$b$ Ostwald, op. cit., p. 121

c Nernst, Wr., Theoretical ehemistry, translated by C. S. Palmer, Macmillan \& Co., London, 1895, pp. 134-137. Ostrald, W., Solutions, translated by II. M. Pattison Muir; Longmans, Green \& Co. New York, 1891, pp. 112-117. 
one another that molecular attraction produces an effect, and in this case the osmotic pressure does not vary directly as the concentration. But, Cameron says, in so far as the molecules in solution are sufficiently separated so that they may act as a gas, "the volume, pressure, and temperature relations are dependent only upon the number of molecules involved." a

Since all of these relations are the same as the laws controlling the behavior of gases, it is held by many physical chemists that when a solid passes into solution it is transformed to a gas. Under this explanation the osmotic pressure is a gaseous pressure. "The kinetic energy of the molecules of the dissolved substance is equal to that of the gas at the same temperature; and, moreover, as the kinetic energies of the molecules of the dissolved subtance and of the solvent must agree, because these molecules are in immediate contact, it follows also that the kinetic energy of the molecules of the liquid must, on the whole, be the same as that of gaseous molecules at the same temperature."

If the above theory be correct, it follows that the solution of solids in liquids is similar to that of gases in liquids; for in both cases the compound when dissolved is in the form of a gas; and the geological work of underground water, whether the solutions be produced by a mingling of gases and water, solids and water, or the three combined, could be considered as a unit. (See pp. 63-64.)

In case a salt dissolved in water be an electrolyte, under the dissociation theory it is separated into ions to some extent. If this be so, the number of dissolved particles is represented by the number of ions plus the number of undissociated molecules. Therefore in very dilute solutions, where the dissociation is held to be complete, the number of dissolved particles and consequently the osmotic pressure is doubled in the case of a salt of a monad acid with a monad base. Thus the law of equal gaseous pressure for equal number of molecules is believed by many to still hold good. For instance, if $\mathrm{NaCl}$ dissociates into the ions $\mathrm{Na}$ and $\mathrm{Cl}$, or $\mathrm{KOH}$ into the ions $\mathrm{K}$ and $\mathrm{OH}$, thus giving twice as many molecules as in the case of a compound which does not ionize, muder the law the osmotic pressure is twice as great as that of the compound which does not dissociate.

aCameron, F. K., Application of theory of solutions to the study of soils: Report No. 6t, Field Operations of Division of Soils, 1899, U. S. Dept. of Agric., 1900, p. 144.

bstwald, op. cit., p. 148. 
The conclusions of ran't Hoff, Ostwald, and others in reference to osmotic pressure being dne to gaseous pressure of the dissolved substances have never been accepted by Mendeléeff, and have recently been strongly opposed by Kahlenberg. Certainly there are many discrepancies between the observations made as to the amount of osmotic pressure and the amount which the pressure should be under the gas law. But, so far as the observations of geology show, I see nothing that controverts or confirms ran't Hoff's theory. In studying the work of underground solutions I lave been unable to discover any criteria which will separate the work of gases in water solutions from the work of solids in water solutions. So far as geology is concerned, solutions of gases in water and solutions of solids in water can not be discriminated. It has been held by some that the presence of fluorite and other minerals is evidence of gaseous action, but, as yet, I have not been able to find valid evidence offered by any author for this conjecture. It may be that gases dissolved in water and solids dissolved in water are held in solution in consequence of chemical affinity, as held by Mendeléeff, or they may be in solution as gases, as held by van't Hoff, but in either case the manner of action of the two is the same, and therefore there is no warrant for attributing the development of fluorite, tommaline, etc., to the presence of "mineralizers" in the sense that these compounds are the products of the action of gases as opposed to water solutions.

When a soluble solid is placed in a liquid solvent it at once begins to dissolve. The temperature and pressure remaining constant, if an excess of the solid be present after a sufficient time there is no further decrease in the amount of the solid present, nor is there any increase. When this state is reached the solution is saturated.

When a solid is in a saturated solution, and therefore constant in amount, even if temperature and pressure remain constant it does not follow that no interchange takes place between the dissolved and solid salt. The kinetic theory of solutions leads to the conclusion that many molecules are released from the solid to the solution, and pass from the solution into the solid, but these amounts balance. This is well illustrated by sugar solutions. If finely pulverized sugar be placed in the bottom of a saturated sugar solution and sugar-covered threads be suspended in the solution, sticks of rock candy will be formed. The crystals of the candy grow at 
the expense of the sugar below, which is being constantly taken into solution and deposited as crystals about the string; and, therefore, although the solution is continuously saturated, there is continuous solution and deposition. Even if no sugar-coated strings were placed in the sugar, after a time it would be found to be coarser grained or to have recrystallized. Thus the constant interchange between a saturated solution and that of an adjacent solid is certain.

The change occurs under the law by which large crystals grow at the expense of small ones. In order that crystals shall grow in a solvent, it is necessary that the solutions shall be saturated or supersaturated at the immediate place of crystal growth. Since underground there is always a superabundance of many materials as compared with the amount of water, we may suppose that at a moderate depth below the surface, and especially in the smaller spaces, where movement is very slow (see pp. 138-146), the solutions are often saturated. It is well known that the growth of larger crystals at the expense of smaller ones, under conditions of saturation and superabundance of material, goes on more rapidly in proportion as the temperature is high and the pressure is great. The principle is taken advantage of in the chemical laboratory in the production, before filtration, of a coarse precipitate by boiling or other means. During the process the finer particles of the precipitate are dissolved and the coarser ones are enlarged at their cost. The growth of the large crystals at the expense of the small ones is due to the fact that the smaller crystals are somewhat more soluble than the larger. The explanation of this change, as given by Ostwald, ${ }^{a}$ lies in the "surface tension which exists on the boundary surfaces between solids and liquids, as on those between liquids and gases-the so-called free surfaces of liquids. This tension acts so that the surfaces in question are reduced in size, with the consequent enlargement of individual crystals (the total amount of precipitate remaining practically unaltered), i. e., with the coarsening of the grains." During the change, for a given volume of solid the lessening of the total surface of the crystals, and consequently the lessening of the surface tension, results from the fact that the surfaces are small in proportion as the individuals are large. For a given volume of a substance the surfaces of the crystals are inversely as their diameters. (See

$a$ Ostwald, W., The scientific foundations of analytical chemistry, translated by George MeGowan, Macmillan \& Co., London, 1895, p. 22. 
p. 98). The increase in the size of the crystals, lessening the surface tension, may be considered as a transfer of potential into kinetic energy. This passes into heat and is dispersed under the apparently general law of the dissipation of energy. Why the tendency to the transformation of all forms of energy into heat and the dissipation of heat should be a law of nature it is not wy purpose here to discuss. But such the law seems to be, and in its application we carry the cansal sequence as far as we are now able.

The growth of large individuals at the expense of small ones in ground water is of the most profound significance in the metamorphism of rocks. It is illustrated by the secondary enlargement of minerals and by the porphyritic erystals which frequently develop in sehists and gneisses, snch as the porphyritic crystals of feldspar, homblende, gamet, stanrolite, etc. (See pp. 643-644, 699-700.)

The above principle in reference to the growth of large crystals at the expense of small ones is very clearly applicable to the growth of segregations of minerals of a certain kind as compared with smaller segregations. If, for instance, at one place there be a mineral aggregate, this, so far as the surface tension and the free surface of liquids are concerned, acts as a unit and tends to draw to itself the material of smaller aggregates or of individual mineral particles. For aggregates which do not have crystal boundaries the form which would be assumed under ideal conditions is spherical. This principle of the growth of large aggregates at the expense of small ones is illustrated by chert nodules. (See pp. 816-818.)

The quantity of a solid which can be dissolved in aqueons solutions depends upon the compounds present, the pressure, and the temperature. When the limit of solubility is reached the solution is said to be saturated.

COIPOUNDS PRESENT.

Theoretically all compounds are soluble to some extent in water. This statement applies to all natural compounds; that is, the minerals of nature are elements, oxides, or salts which are soluble in water. No substance is wholly insoluble in the ground solutions, even at the ordinary temperatures and pressures. This statement is illustrated by the solution of quartz and the more refractory silicates at the surface. ${ }^{a}$ Under surface conditions

a Hayes, C. W., Solution of silica under atmospheric conditions: Bull. Geol. Soc. America, vol. 8, 1897, pp. $214-217$. 
quartz grains are sometimes etched by meteoric waters, and the decomposition and partial solution of the refiactory silicates is universal. Under conditions of deep-water circulation solution of quartz and the refractory silicates may be accomplished with relative rapidity. This is illustrated by the Calumet and Hecla conglomerate, many of the pebbles of which have been partly or even completely dissolved and the space once occupied by them taken by copper."

Since underground solutions always contain a number of componnds, and often many, the influence of one compound upon the solubility of another is of consequence in various ways. For instance, when several compounds are present, a unit quantity of water will not dissolve as much of a given salt as it would if it were alone. But if a number of units of water are each saturated with a single salt, and the solutions are mingled without chemical reaction, the mixture is capable of taking additional quantities of the salts into solution. In other words, a unit of solution simultaneously saturated with each of several compounds contains a greater total of solids than a unit of solution saturated with fewer of these compounds, but less of any individual salt than it would were it saturated with that salt alone. ${ }^{b}$

In the ground solutions the different componnds frequently react upon one another, and therefore important modifications in the above statement are necessary, as is explained nnder "Precipitation," pp. 113-123.

RELATIONS OF SOLUTION AND PRESSURE.

In general, the rolume of the solvent plus that of the dissolved compound is greater than that of the solution. For a given quantity of the solid the contraction is greater the more of the solvent is used." In some cases, however, the volume of the dissolved compound and solvent is less than that of the solution, or expansion results from dissolving the solid. Ammonium chloride in water is an illustration of this case. From the foregoing relations we obtain a rule as to the relations of pressure to solubility. ${ }^{d}$ In the common case in which the volume of the solution is less than that of

a Pumpelly, R., The paragenesis and derivation of copper and its associates on Lake Superior: Am. Jour. Sci., 3d ser., vol. 2, 1871 , p. 34 .

$b$ Ostwald, W., Solutions, translated by M. M. Pattison Muir; Longmans, Green \& Co., New York, 1891, pp. 83,84 .

Ostwald, W., op. eit., p. 82.

aNernst, W., Theoretical chemistry, translated by C. S. Palmer, Macmillan \& Co., London, 1895, p. 567 . 
solvent and solid, pressure increases solubility; for in that case solution tends to bring the molecules nearer together and works in conjunction with the pressure. A mixture of water and ice furnishes an excellent illustration of this principle. At any noment the volume of the water is less than that of the equivalent water and ice. Hence pressure promotes solution and prevents freezing, or in other words, crystallization. In the reverse case, that in which the volmme of the solution is greater than that of solvent and solid, pressure decreases the solubility, the reason being the reverse of that of the previous case.

The above law may be illustrated by fig. 1. A given amount of salt, say $10 \mathrm{cc}$. in volume, may be supposed to be placed in $90 \mathrm{cc}$. of water, and

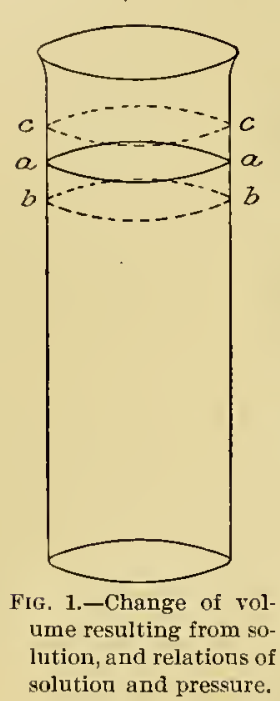
the salt be of such a nature as to saturate the water at that temperature and pressure. Before solution begins the space occupied is 100 cc. After solution this space may be greater or less than $100 \mathrm{cc}$, say $105 \mathrm{cc}$. or $95 \mathrm{cc}$; that is, the water surface instead of being at aa will be at $c c$ or $3 b$. If it be at $b b$, where the volume is less, and the pressure be increased, an additional amount of salt may be added and taken into solution. If it be at $c c$, and the pressure be increased, a part of the salt already in solution will be precipitated from the solution.

It is well known that the solubility of calcium carbonate and of some other carbonates is increased by pressure $^{a}$ It is a fair inference from Barus's work that the solubility of the silicates is also increased by pressure. Barus $^{b}$ found that when soft glass is dissolved in water at temperatures above $210^{\circ} \mathrm{C}$., the volume is 20 to 30 per cent less than the two separately. This glass is one which contains alkalies, alkaline earths, and lead, and therefore is somewhat similar in composition to many natural silicates. The carbonates and the silicates are the dominant compounds in underground solutions. The solubility of many other salts, besides the carbonates and silicates, occurring underground is increased by pressure. Therefore, in the majority of the complex underground solutions

a Lindgren, W., Gold-quartz veins of Nevada City and Grass Valley, California: Seventeenth Ann. Rept. U. 8. Geol. Survey, pt. 2, 1896, pp. 176-178.

${ }^{b}$ Barus, C., Hot water and soft glass in their thermodynamic relations: Am. Jour. Sci., 4 th ser., vol. 9, 1900, p. 173. 
the totals of the salts in solution are in general increased by pressure, and the volumes of the solution are less than those of the salts and solvents separately.

RELATIONS OF SOLUTION AND TEMPERATURE.

The relations of solution and temperature have three phases; first, the speed of solution; second, the quantity of material which may be leeld in solution; third, the relations of solution to absorption and liberation of heat. speed of solution. - The speed of solution is commonly increased greatly by rise of temperature. ${ }^{a}$ A slight increase in temperature may increase the rate of solution out of all proportion to the absolute change in temperature. At temperatures above $100^{\circ} \mathrm{C}$., and especially above $185^{\circ} \mathrm{C}$, the activity of water may increase to an amazing degree. 'The rapid solution of glass, by Barus, ${ }^{b}$ at temperatures about $185^{\circ} \mathrm{C}$. illustrates this. At any temperature solution will continue until the point of saturation is reached, but this state will be attained at high temperatures in but a small fraction of the time required at low temperatures. For instance, to saturate an underground solution with the refractory silicates or sulphides at ordinary temperatures might require months, or even years, while to saturate them at temperatures above $185^{\circ} \mathrm{C}$. might require only an equal number of minutes, or at most, hours. The capacity of water for action at high temperatures combined with pressure, considered above, is adequate to explain the complete recrystallization of great volumes of rock. (See pp. 749-751.)

Quantity of material which may be held in solution.- The effect of temperature upon the quantity of material which may be held in solution does not admit of a simple general statement. ${ }^{c}$ For most substances moderate increase of temperature gives greater capacity for solution; but for many substances there exists a temperature at which there is the maximum capacity for solution, and the amount of material which may be held in solution at higher and lower temperatures is less than this maximum. The quantitative relations of solution and temperature at ordinary pressure between p. 568 .

a Nernst, W., Theoretical chemistry, translated by C. S. Palmer, Macmillan \& Co., London, 1895,

${ }^{b}$ Barus, C., Hot water and soft glass in their thermodynamic relations: Am. Jour. Sci., th ser., vol. 6,1898 , p. 270 , and vol. 9, 1900, pp. 167-168.

c Ostwald, W., Solutions, translated by M. M. Pattison Muir; Longmans, Green \& Co., New York, 1891, pp. 55-77. 
$0^{\circ} \mathrm{C}$. and $100^{\circ} \mathrm{C}$. are shown by fig. 2, taken from Ostwald. ${ }^{a}$ For various substances the maximum capacity for solution lies between $60^{\circ}$ and $140^{\circ}$ C., and for many substances it is probably below $200^{\circ} \mathrm{C}$. It therefore follows, in respect to underground solutions, that a general statement can not be made as to how change of temperature may affect solubility. Howerer, it is highly probable that up to temperatures of $100^{\circ} \mathrm{C}$, and therefore under normal conditions to depths of 3,300 meters, increase of temperature increases the average capacity of underground water to hold material in solution; and it is probable that the average capacity of ground water increases to temperatures considerably above $100^{\circ} \mathrm{C}$., and therefore to depths greater than 3,300 meters. But when water passes downward to the deeper parts of the zone of fracture the increase in temperature may lessen the average capacity for holding material in solution,

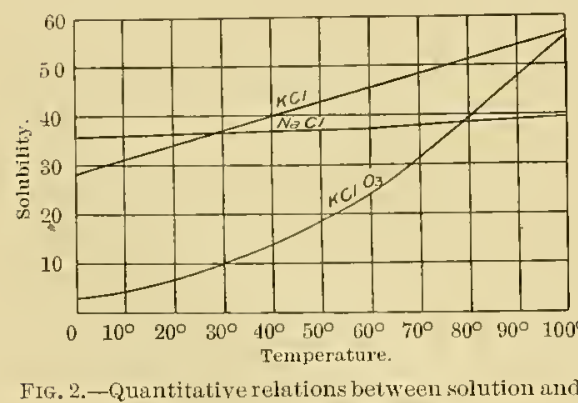
temperature. After Ostwald. provided the joint effect of pressure be barred. But it has been seen that increasing pressure with increasing depth pronotes solubility. It is almost certain that high temperature and pressure combined greatly increase the capacity of water for solution. This is proved by the experiments of Bartus upon the solubility of glass. He has shown that at temperatures above $185^{\circ} \mathrm{C}$. and below $200^{\circ} \mathrm{C}$ it is possible "to impregnate glass with water to such an extent as to make it fusible below $200^{\circ} \mathrm{C}$. The solution occurs with contraction of bulk relatively to the ingredients and increasing compressibility." . . . "If these solutions are sufficiently concentrated they coagulate at ordinary temperature and the congealed aqueous glass is not different in general appearance from common glass. The melting point of the coagulated aqueous silicate frequently lies below $200^{\circ}$ C., probably above $150^{\circ} \mathrm{C}$., depending on the glass." And he concludes that "Glass as a colloid is miscible in all proportions with water." $b$

Since glass is one of the important silicate rocks which occur in nature, these statements are directly applicable to one set of rocks. They may

a Ostwald, W., Grundlinien der anorganischen Chemie, Engelmann, Leipzig, 1900, p. 222.

$b$ Barus, C., Remarks on colloidal glass: Am. Jour. Sei., 4th ser., vol. 6, 1898, p. 270 . See also Am. Jour. Sci., tth ser., vol. 9, 1900, pp. 161-175. 
not be applicable to the same extent to crystallized silicate rocks, but it seems to me highly probable that they apply in large measure to many. In so far as Barus's final conclusion is applicable, there may result all gradations, from solutions in which the water is the dominant constituent to those in which.it is the subordinate constituent. This principle of the increased quantity of material which may be held in solution as a result of combined high pressure and temperature is believed to possess very great significance in alterations in the zone of anamorphism, and to be of importance in alterations in the belt of cementation. (See pp. 602-603, 659-661.)

Relations of solution to absorption and liberation of heat.-As already explained, when material passes into solution the molecules are separated and acquire kinetic energy, and are believed by many to change from the solid to the gaseons form. This process absorbs heat. On the other hand, where the volume of the solution is less than the volume of the solvent and salt separately, the molecules of the solvent and salt combined are brought closer together and lieat is therefore liberated. In the reverse case, where the volume of the solution is greater than that of the solvent and salt separately, the molecules are pushed farther apart, and heat is absorbed. If the compounds in solution separate into ions this process is believed to be nsually attended by liberation of heat. ${ }^{a}$. Whether there is a rise or fall of temperature of the solution will depend upon the relative values of these factors. In the common case where there is decrease in the volume as a result of solution, the heat thus liberated by change in volume plus the supposed heat of ionization are together preponderant, and there is, therefore, liberation of heat and a rise in temperature. However, in the case where there is increase in the volume as a result of solution, the heat thus absorbed and the heat absorbed in changing the salt from the state of a solid to that of a gas is greater than that supposed to be liberated by dissociation. The first two factors are dominant, and there is usually a marked absorption of heat and, consequently, a fall in the temperature of the solntion. This is illustrated by the solution of ammonium chloride in water. The volume is considerably decreased and the fall in temperature is very decided.

a Nernst, W., Theoretical chemistry, translated by C. S. Palmer, Macmillan \& Co.. London, 1895, p. 562 .

MON XxV11-04-6 
DIFFUSION.

It has been seen that the molecules of gases and of solids when dissolved in water are distributed through the solution. When the material dissolved is not evenly distributed the molecules are more abundant here and less abmulant there. If the theory be true that the dissolved solids are gaseous the molecules would exert a greater pressure where more closely packed. Under these conditions molecules where more closely packed move toward places where they are less closely packed. This movement is regarded by many as the explanation of osmotic pressure. Kahlenberg, however, does not accept this explanation, but regards osmotic pressure as due to the "mutual attraction between solvent and dissolved substance." ${ }^{a}$ Without reference to either theory the more important conclusions in reference to diffusion may be summarized.

The force whicb drives the dissolved substances from place to place, and the velocity with which a dissolved substance wanders in a solvent, is proportional to the degree of concentration." Therefore, "the quantity of a salt which diffuses through a given area is proportional to the difference between the concentrations of two areas infinitely near one another." In other words, diffusion is proportional to the difference in strength. The quantity diffused is proportional to the square root of the time of diffusion, and the distance over which a determinate concentration extends is also proportional to the square root of the time of diffusion. ${ }^{d}$ Several salts in a solution diffuse almost independently of one another, each at its own specific rate. $^{e}$ At $20^{\circ}$, according to Ostwald, there is twice as much diffusion as at $0^{\circ}$, and at $40^{\circ}$ twice as much as at $20^{\circ} f$ When a solution is in equilibrium the concentration of the solution varies inversely as the temperature. It follows that when the temperature of the solution varies, equilibrium is obtained not by equal distribution of the solntes, but by unequal distribution. If the temperature be the same throughout a solution with equal

$a$ Kahlenberg, Louis, The theory of electrolytic dissociation as viewed in the light of facts recently ascertained: Bull. Univ. of Wisconsin No. 47, 1901, p. 349.

$b$ Nernst, W., Theoretical chemistry, translated by C. S. Palmer, Macmillan \& Co., London, 1895, pp. 143-144.

c Ostwald, W., Solutions, translated by M. MI. Pattison Muir; Longmans, Green \& Co., New York. 1891, p. 120.

$a$ Solutions, cit., p. 135.

esolutions, cit., p. 139.

$f$ Solutions, eit., p. $13 \mathrm{C}$. 
distribution of the dissolved compounds, a deviation from uniformity in the temperature of the solution will disturb the equilibrium and result in unequal distribution of the dissolved substances. ${ }^{n}$

The values of the coefficient of diffusion (D) of certain substances in water solutions at various temperatures are given by the following table from Nernst: ${ }^{b}$ (The table gives the number of grams of the dissolved substance which will pass in one day through a section of 1 sq. cm. when the difference in concentration of the cross section $1 \mathrm{~cm}$. apart amounts to 1 gram in a cubic centimeter.)

Rates of diffision of certain substances in water solutions at various temperatures.

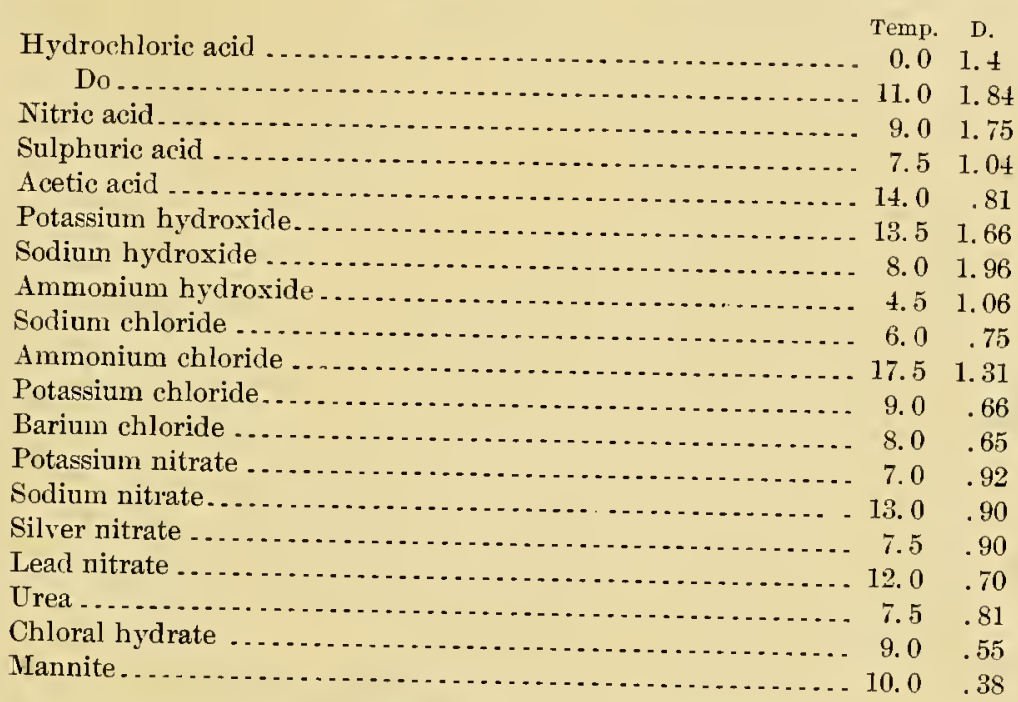

This table shows that diffusion is extremely slow. The slowness with which diffusion occurs is due, according to Nernst, to "the resistant friction experienced by the dissolved substance in its movement through the solvent." ${ }^{\circ}$ This friction is very great, because the molecules themselves are exceedingly small.

Later it will be seen that the process of diffusion is of very considerable importance in the migration of compounds in ground water. (See pp. 636-639.) This is illustrated by the very important process of solution and deposition or recrystallization.

"Ostwald, Solutions, cit., pp. 150-151. p. 144 .

$b$ Nernst, W., Theoretical chemistry, translated by C. S. Palmer, Macmillan \& Co., London, 1895, $c$ Nernst, op. cit., p. 145. 
PRINCIPLES OF CHEMICAL REACTIONS APPLICABLE TO GROUND WATERS.

GENERAL STATEMENT.

DEFINITIONS.

Before taking up chemical reactions it is advisable to give a number of elementary definitions.

"Compounds whose aqueous solutions contain the hydrogen ion (H) are termed acids, and those which contain the hydroxyl ion $(\mathrm{OH})$ bases." a To illustrate, $\mathrm{HCl}$ is an acid; $\mathrm{NaOH}$ is a base. When the hydrogen ion united with one or more nonmetallic elements is mingled in solution with the hydroxyl ion mnited with a metal a double reaction occurs, resulting in the union of the lyydrogen ions with the hydroxyl ions, forming water, and the mion of the nommetallic parts of the compound with the metallic parts. This latter union forms a salt. For example-

$\mathrm{HCl}+\mathrm{NaOH}=\mathrm{NaCl}+\mathrm{H}_{2} \mathrm{O}$.

$\mathrm{H}_{2} \mathrm{CO}_{3}+2 \mathrm{NaOH}=\mathrm{Na}_{2} \mathrm{CO}_{3}+2 \mathrm{H}_{2} \mathrm{O}$.

The acids and salts which contain only a single nommetallic element are called binary compounds. The acids and salts which contain two nonmetallic elements are called ternary compounds. For example, $\mathrm{HCl}$ is a binary acid; $\mathrm{NaCl}$ is a binary salt; $\mathrm{H}_{2} \mathrm{CO}_{3}$ is a ternary acid; $\mathrm{Na}_{2} \mathrm{CO}_{3}$ is a ternary salt. Compounds having the composition of acids, bases, and salts may be separated from solution as solids, and of course all of these solids may pass into solution.

Some salts also contain a certain amount of acid, and such salts are called acid sailts. For instance-

$$
\mathrm{Na}_{2} \mathrm{CO}_{3}+\mathrm{H}_{2} \mathrm{CO}_{3}=2 \mathrm{NaHCO}_{3} \text {. }
$$

"The latter compound is acid sodium carbonate. On the other hand, some salts contain some additional base, and such salts are called basic. For example, $\mathrm{Fe}_{2}\left(\mathrm{SO}_{4}\right)_{3}$ may be united with $\mathrm{Fe}_{2}(\mathrm{OH})_{6}$, producing $\mathrm{mFe}_{2}\left(\mathrm{SO}_{4}\right)_{3} \cdot \mathrm{nFe}_{2}(\mathrm{OH})_{6}$. This compound is basic ferric sulphate.

DISSOCITION.

In explaining chemical leactions the theor'y of dissociation as advocated by Arrhenius, Ostwald, Nerust, and others is followed for the most part.

a Ostwald, W., The scientific foundations of analytical chemistry, translated by George McGowan, Macmillan \& Co., London, 1895, p. 117. 
This theory is firmly placed in the text-books. No opinion is expressed by me as to its correctness. Indeed, I have no right to any opinion on the subject. As already pointed out, this theory has been vigoronsly opposed by Kahlenberg, but as yet that anthor has offered no constructive theory to take its place. I therefore follow the theory of the standard text-books so far as necessary to show how it would apply to the work of ground solutions if it prove to be true; but so far as practicable I make the statements in such form that they will be correct even if the theory of free ions and reactions between such ions is finally abandoned.

Under the theory of dissociation the superiority of water as a solvent for chemical interchanges is regarded as largely due to the fact that the dissolved substances are separated into their ions to a greater degree than in any other solvent. To the fact of active reactions in water, whatever their cause, are very largely due the profound changes which occur in rocks through the medium of water solutions.

Under the theory of dissociation water solutions, acids, bases, and salts separate into their ions. For instance, $\mathrm{HCl}$ separates into the free ions $\mathrm{H}$ and $\mathrm{Cl}$; $\mathrm{NaOH}$ separates into the free ions $\mathrm{Na}$ and $\mathrm{OH}$; and $\mathrm{NaCl}$ into the free ions $\mathrm{Na}$ and $\mathrm{Cl}$. However, in solutions the dibasic acids are supposed to separate into free ions somewhat differently from what might be expected. For instance, it might be expected that $\mathrm{H}_{2} \mathrm{CO}_{3}$ would separate into the free ions $\mathrm{H}_{2}$ and $\mathrm{CO}_{3}$, but it is supposed to separate thus :

$$
\mathrm{H}_{2} \mathrm{CO}_{3}=\mathrm{H}+\mathrm{HCO}_{3} \text {. }
$$

Other dibasic acids are thought to dissociate in a similar nanner. However, if the dibasic acid be very strong the compound ion may again break up. Thus, $\mathrm{H}_{2} \mathrm{SO}_{4}$ is thought to first break up into the free ions $\mathrm{H}$ and $\mathrm{HSO}_{4}$, and the latter to break up into the free ions $\mathrm{H}$ and $\mathrm{SO}_{4}$, so that these would be the ions present in the water. But in the case of the weak acid, carbonic, it is thought that the last change does not take place, and that the free ions remain $\mathrm{H}$ and $\mathrm{HCO}_{3}$.

Ostwald regards the absence of the second stage of dissociation as the explanation of the peculiar characteristics of carbonic acid." Since carbonic acid is, next to silica, the most important rock-making acid, the manner in which it breaks up is of great consequence in metamorphism.

a Ostwald, W., Grundlinien der anorganischen Chemie, Engelmann, Leipzig, 1900, pp. 276-278, 397-398. 
HYDROLISIS. $a$

Under the theory of dissociation, not only do acids, bases, and salts separate into ions in water solutions, but the water itself is believed to dissociate to a very small extent, according to the equation $\mathrm{H}_{2} \mathrm{O}=\mathrm{H}+\mathrm{OH}$; thus simultaneously forming free hydrogen and hydroxyl. If this be true the hydrogen ions and the hydroxyl ions cuexist and water solutions to a small extent contain free acids and free bases at the same time. The excellence of water as an agent for reactions between the substances it holds in solution is held to be partly due to hydrolysis.

When strong bases and acids are in solution the amount of their dissociation is believed to be so much greater than that of water that the dissociation of the latter is of little consequence. But if a very strong base be united with a weak acid the solution will give an alkaline reaction, and this is regarded as showing the presence of free hydroxyl ions or of hydrolysis. For instance, if the strong base, sodium, be united with the weak acid, carbonic, and a water solution be made, it is held that hydrolysis will take place to some extent, thus:

$$
\mathrm{Na}_{2} \mathrm{CO}_{3}+\mathrm{H}_{2} \mathrm{O}=\mathrm{NaHCO}_{3}+\mathrm{NaOH} \text {. }
$$

It is supposed that $\mathrm{NaHCO}_{3}$ breaks up into the ions $\mathrm{Na}$ and $\mathrm{HCO}_{3}$, and the $\mathrm{NaOH}$ into the ions $\mathrm{Na}$ and $\mathrm{OH}$. Therefore, in a solution of $\mathrm{Na}_{2} \mathrm{CO}_{3}$ in water the coexistent ions are thought to be $\mathrm{H}, \mathrm{HCO}_{3}, \mathrm{Na}$, and $\mathrm{OH}$. Since the base, $\mathrm{NaOH}$, is stronger than the acid, $\mathrm{HCO}_{3}$, the separation into the ions is thonght to be the explanation of the alkaline reaction.

Cameron has shown that sodium silicate in solution gives an alkaline reaction, and his explanation is that this compound is hydrolized in a mannei precisely similar to that of sodium carbonate. ${ }^{b}$ Not only do solutions of sodium silicate give alkaline reactions, but Clarke has shown ${ }^{\circ}$ that many natural mineral silicates, when treated with pure water, show an alkaline reaction. The following gave permanent alkaline reactions: Phlogopite, oligoclase, albite, cancrinite, sodalite, analcite, natrolite, pectolite, apophyllite, xgirite. The following gave more or less distinct colorations to the phenolphthalein indicator, but in time faded: Muscovite, lepidolite, ortho-

a Ostwald, W., Grundlinien der anorganischen Chemie, Engelmann, Leipzig, 1900, pp. 254-257.

${ }^{b}$ Cameron, F. K., Application of the theory of solutions to the study of soils: Rept. No. 64, Field Operations of the Division of Soils, 1899, U. S. Dept. of Agric., 1900, p. 169.

c Clarke, F. W., Alkaline reaction of some natural silicates: Jour. Am. Chem. Soc., vol. 20, 1898, pp. $739-742$. 
clase, leucite, nephelite, spodumene, scapolite, laumontite, stilbite, chabazite, heulandite, thomsonite. ${ }^{a}$ If the theory of dissociation be true, this shows that the silicates are hydrolized, thus:

$$
\mathrm{R}_{2} \mathrm{SiO}_{4}+4 \mathrm{HOH}=2 \mathrm{R}(\mathrm{OH})_{2}+\mathrm{H}_{4} \mathrm{SiO}_{4} .
$$

However, according to Kahlenberg and Lincoln, the $\mathrm{H}_{4} \mathrm{SiO}_{4}$ does not dissociate into the radicals $\mathrm{H}$ and $\mathrm{SiO}_{4}$, but forms colloidal silicic acid. ${ }^{b}$ Thus this compound is inert and the reaction reverses only to a small extent and under favorable conditions, and the hydrate of the alkali metal gives an alkaline reaction.

In a similar manner hydrolysis is held to occur in water solutions of the strong base sodium with the weak acid hydrosulphuric, thus:

$$
\mathrm{Na}_{2} \mathrm{~S}+\mathrm{H}_{2} \mathrm{O}=\mathrm{NaHS}+\mathrm{NaOH} \text {. }
$$

Cameron further states that hydrolysis is to be expected in the case of the aluminates and ferrates. ${ }^{c}$ When a strong acid is mited with a weak base the solution gives an acid reaction, and this is also explained by dissociation, the free acid supposed to result from hydrolysis being stronger than the weak base. ${ }^{d}$

Since the three most abundant acids of nature are silicic, carbonic, and hydrosulphuric, all weak, hydrolysis, if true, is a reaction of fundamental importance in metamorphism.

\section{REACTIONS.}

When, after a number of chemical substances are brought together, and especially when they are united by a solvent, interactions between them may occur which after a time appear to cease. When the conditions have become such that there is no increase or decrease in the amount of any one of the chemical compounds, the system is in a condition of chemical equilibrium. ${ }^{e}$ When two substances in solution, $\mathrm{A}$ and $\mathrm{B}$, react upon each other so as to produce two other substances, $\mathrm{C}$ and $\mathrm{D}$, if solutions of $\mathrm{C}$ and $\mathrm{D}$ are mixed they in turn will react upon each other to

a Clarke, cit., pp. 740-741.

${ }^{b}$ Kahlenberg, L., and Lincoln, A. T., Solutions of silicates of the alkalies: Jour. Phys. Chem., vol. 2, 1898, pp. 77-90.

$c$ Cameron, eit., p. 169.

a Ostwald, Grundlinien, cit., pp. 276-278, 397.

e Nernst, W., Theoretical chemistry, translated by C. S. Palmer, Macmillan \& Co., London, 1895, pp. $355-356$. 
produce more or less of the substances $A$ and $B{ }^{a}$ That is, the reaction is reversible to a greater or less degree. To illustrate, if two solutions, one of them containing $\mathrm{IgSO}_{4}$ and the other $\mathrm{Na}_{2} \mathrm{CO}_{3}$, come together, the ions are $\mathrm{Mg}, \mathrm{Na}, \mathrm{SO}_{4}$, and $\mathrm{CO}_{3}$. A part of the $\mathrm{Mg}$ will unite with the $\mathrm{CO}_{3}$, producing $\mathrm{M}_{\mathrm{gCO}}$, and a part of the $\mathrm{Na}$ will unite with the $\mathrm{SO}_{4}$, producing $\mathrm{Na}_{2} \mathrm{SO}_{4}$. Vice versa, if solutions of $\mathrm{Na}_{2} \mathrm{SO}_{4}$ and $\mathrm{MgCO}_{3}$ are mingled in a similar manner, $\mathrm{MgSO}_{4}$ and $\mathrm{Na}_{2} \mathrm{CO}_{3}$ will be produced. The reversible reaction may be briefly expressed thus:

$$
\mathrm{IgSO}_{4}-\mathrm{Na}_{2} \mathrm{CO}_{3} \rightleftarrows \mathrm{IgCO}+\mathrm{Na}_{2} \mathrm{SO}_{4} .
$$

The sign $\rightleftarrows$ means that the equations may be read from left to right or from right to left.

These are the facts: The ions do interchange between compounds whenever a chemical reaction takes place. Just how and why they interchange is another matter, upon which there is not agreement. Under the theory of dissociation the interchange takes place through the medium of the free ions. The free ions of a componud $A$ are held to collide with the free ions of the compound $\mathrm{B}$, and thus produce the compound $\mathrm{C}$ and $\mathrm{D}$, and vice versa. Or, in the specific case above given, of $\mathrm{MgSO}_{4}$ and $\mathrm{Na}_{2} \mathrm{CO}_{3}$, the free $\mathrm{Mg}$ ions collide with the free $\mathrm{CO}_{3}$ ions and produce $\mathrm{MgCO}_{3}$, and the $\mathrm{SO}_{4}$ ions collide with the $\mathrm{Na}$ ions and produce $\mathrm{Na}_{2} \mathrm{SO}_{4}$. From the $\mathrm{MgCO}_{3}$ and $\mathrm{Na}_{2} \mathrm{SO}_{4}, \mathrm{MgSO}_{4}$ and $\mathrm{Na}_{2} \mathrm{CO}_{3}$ are reproduced in a similar manner. Whether the theory of chemicul reactions through free ions be of any value or not, it seems probable that free ions exist for a moment when the interchange takes place. To illustrate, it seems hardly probable that the $\mathrm{Mg}$ is united to the $\mathrm{SO}_{4}$ and the $\mathrm{CO}_{3}$ at the same time. If the $\mathrm{Mg}$ lets go of the $\mathrm{SO}_{4}$ to attach itself to the $\mathrm{CO}_{3}$, for that instant the ion $\mathrm{Mg}$ is free. The same is true of each of the other ions, $\mathrm{Na}, \mathrm{SO}_{4}$, and $\mathrm{CO}_{3}$, at the instant of interchange. Hence the question at issue is the canse of the interchange. Does it take place as the result of contact of free ions produced by dissociation, or does the chemical affinity of the $\mathrm{M} g$ for the $\mathrm{CO}_{3}$ cause a portion of it to leave the stronger acid radical $\mathrm{SO}_{4}$ for the weaker acid radical $\mathrm{CO}_{3}$, etc.? But this is a question for chemists to settle. The problem is stated here because it is one of such fundamental importance in metamorphism.

But whatever the cause, reversible reactions are a certainty, and it will

a Nernst, W., Theoretical chemistry, translated by C. S. Palmer, Macmillan \& Co., London, 1895, pp. $356-357$. 
be seen that certain reactions of the zones of katamorphism are reversed in the zone of anamorphism, and vice versa. But it shonld be remembered that to close the cycle in any case, or, in other words, to make a transformation from left to right and then from right to left, thus completely reversing any reaction, requires the expenditure and dissipation of energy.

The most general law controlling chemical systems is expressed by Le Chatelier as follows: "Every change of one of the factors of an equilibrium occasions a rearrangement of the system in such a direction that the factor in qnestion experiences a change in a sense which is contrasted with the original change." a

Nernst remarks that this law reminds one of the principle of action and reaction. Put in another way, it may be said that any chemical change, by the mere fact of its occurrence, sooner or later renders the conditions less favorable for its continuance. To illustrate, if the increase in volume demanded by the reaction becomes too great, this may stay the reaction. For example, if calcium acetate and copper acetate be placed together in a very strong vessel and but little additional space be left, the reaction resulting in the expansion of volume will go on until the pressure becomes so great as to stay the reaction. ${ }^{b} \quad$ Also, if in a closed vessel a large amount of calcium carbonate be heated it will give off carbon dioxide. But as the amonnt of $\mathrm{CO}_{2}$ increases, and the pressure therefore accumulates, the reaction will be retarded and finally cease. At this stage the $\mathrm{CO}_{2}$ formed unites with the $\mathrm{CaO}$, producing $\mathrm{CaCO}_{3}$, as fast as $\mathrm{CaCO}_{3}$ decomposes and produces $\mathrm{CaO}$ and $\mathrm{CO}_{2}$.

If the heat as the result of a reaction becomes too great, this will stay the reaction. For instance, at low temperatures $\mathrm{CO}$ will completely mite with $\mathrm{O}$, producing $\mathrm{CO}_{2}$; but if the temperature becomes too high, as a result of the change the reaction will be stayed or cease altogether. A case of much greater geological consequence is that of hydration and dehydration. A comparatively low temperature is favorable to hydration of minerals. However, a very moderate temperature-anything above $110^{\circ}$ C.- - at ordinary conditions of pressure is likely to stay the reaction of hydration, or even to reverse this process and produce dehydration.

\footnotetext{
${ }^{b}$ Jones, H. C., On the increasing importance of inorganic chemistry: Science, new ser., vol. 8 ,
} p. 567 .

Nernst, W., Theoretical chemistry, translated by C. S. Palmer, Macmillan \& Co., London, 1895, 
Van't Hoff states the general law controlling chemical systems in another way: "A transformation will take place of itself only in ease it is in a position to do a positive amount of work. If the amount of work done is negative, the transformation can take place of itself only in the opposite sense. If the work done is zero, it can take place in neither sense."

EQuiLimidn.

When the ions of any compound, $A$, unite with the ions of another componnd, $\mathrm{B}$, so as to produce $\mathrm{C}$ and $\mathrm{D}$, just as fast as the ions of $\mathrm{C}$ unite with the ions of $D$ to prodnce $A$ and $B$ the conditions are those of equilibrium, or of chemical statics. When either change takes place faster than the other, these are the conditions of chemical reactions, or of chemical kinetics. ${ }^{b}$ When the two solutions, $\mathrm{A}$ and $\mathrm{B}$, were first mingled, the conditions would be those of chemical kinetics for a time-that is, until a certain amount of $\mathrm{C}$ and $\mathrm{D}$ had been produced. However, when the amount of $\mathrm{C}$ and $\mathrm{D}$ ) is sufficiently great, so that they react upon each other to produce $\mathrm{A}$ and $\mathrm{B}$ as fast as $\mathrm{A}$ and $\mathrm{B}$ react to produce $\mathrm{C}$ and $\mathrm{D}$, the conditions are those of chemical statics, or equilibrium. But it is plain that this does not mean that chemical activity has ceased or that there is real quiescence. Interchange is taking place all the time; but as this interchange is compensatory, no heat effect is prodnced, and the total quantity of each of the compounds present remains the same. The equilibrinm is therefore really dynamic.

HOMOGENEOUS AND HETEROGENEOUS STSTEMS.

A chemical system is homogeneous "when it has the same physical and chemical nature at every point." When this is not the case it is heterogeneous. ${ }^{\circ}$ A solution is therefore homogeneous. If a solid substance be also present, the system is heterogeneous. A heterogeneous system consists "in the intimate association of different complexes, each of which is homogeneous in itself, such as solid salts and saturated solutions." ${ }^{d}$ Each of these complexes is called a phase of the system. "The condition of equilibrium of a heterogeneons system is independent of the relative quantity by weight

$a$ Jones, H. C., On the increasing importance of inorganic chemistry; Science, new series, vol. 8 , 1898 , p. 930.

$b$ Nernst, W., Theoretical chemistry, translated by C. S. Palmer, Macmillan \& Co., London, 1895, pp. 358-360.

$c$ Nernst, cit., p. 357.

d Nernst, cit., p. 391. 
in which each phase is present in the system." ${ }^{a}$ To illustrate, if an excess of salt be in a solution, so that it is saturated, and an additional amount of salt be added, this does not in the least change the quantity of salt held in a given volume of the solution. Therefore the equilibrium in a saturated solution is independent of the amount of undissolved salt in the solution. It follows that in a heterogeneous system "the condition of equilibrium is independent of the relative mass of each of the phases." simple case of heterogeneous equilibrium is that between ice and liquid water, or between liquid water and water vapor. "For a definite external pressure there corresponds a definite temperature at which the two systems can exist beside each other; thus ice and water are coexistent at atmospheric pressure at $0^{\circ}$ C.; and liquid water and water vapor, at atmospheric pressure and at $100^{\circ} \mathrm{C}$. If we change the external pressure, at a temperature which is kept constant, or if we change the temperature, at an external pressure which is kept constant, then the reaction advances" ${ }^{b}$ to equilibrium in one direction or the other. "The process is ended as soon as the expansive force of the evaporating or dissolving substance is held in equilibrium by the gas pressure of the vaporized molecules or by the osmotic pressure of the dissolved molecules, respectively." ${ }^{\circ}$

NATURE AND SPEED OF REACTYONS.

The fundamental principle of chemical dynamics is that chemical action is proportional to the active mass. ${ }^{d}$ 'This is the law of mass action.

The speed of a chemical reaction which occurs under any given conditions depends upon the compounds, the strengtl of the solutions, the mechanical action, and the heat. Hence each of these features requires consideration.

THE COHPOUNDS.

The reactions depend upon the compounds present, or, in other words, upon the nature of the ions composing them; for the conditions under which two ions, A and B, unite may be different from those under which one of these ions will unite with a third, as $\mathrm{A}$ with $\mathrm{C}$, or different from those under which two other ions, $\mathrm{C}$ and D, unite. In order that ions shall unite in solution they must meet or come within the limits of molecular attraction of

a Nerust, cit., pp. 391-392.

$b$ Nernst, cit., p. 393.

$c$ Nernst, cit., p. 403.

astwald, W., Outlines of general chemistry, translated by James Walker, Macmillan \& Co., 2d ed., London, 1895, p. 292. 
one another under certain definite conditions which are peculiar to each substance. Therefore not every time such a meeting occurs are compounds formed. The ratio between meeting and union in the case of any two compounds is a constant, which can be compared with the constant of any other two compounds, each pair of which has its constant. This is merely another statement of the old law that different substances have different affinities for one another, and it is well known that the chemical affinities are developed only when the molecules are in immediate contact with one another:

The ions which are present in ground waters in any given case largely depend upon the character of the adjacent rocks. In a limestone region, for instance, the water may quickly take into solution all the calcium and magnesium it can hold, considering the acids present. Under such circumstances the acid ions will be mainly balanced by the calcium and magnesium. The other substances, such as sodium and potassium, perhaps in more readily soluble forms than the calcium and magnesium, will be largely kept from going into solntion, or if in solution will be partly thrown down, because these substances are obliged to compete for the acid radicals with the vastly greater number of calcium and magnesium molecules. Is it not possible that the agricultural advantage of having calcinm and magnesium abundantly in the soil is largely, or at least partly, dne to the fact that the presence of these soluble substances in abundance prevents the solution and washing out of the elements potassium and sodium which the plants need?

Ostwald divides the bases into strong, moderately strong, and weak. ${ }^{a}$ The alkalies and alkaline earths, with the exception of magnesium, are strong bases; magnesium is a moderately strong base; iron and aluminnm are weak bases-of the two aluminum is the weaker. It follows that, other things being eqnal, in underground sohtions the alkalies and alkaline earths, with the exception of magnesium, largely take possession of the acids. To a less extent this is trie of inagnesium, and to a still smaller degree of iron and aluminum. Thus we have the partial explanation of the relative solubilities of the bases in the belt of weathering. In this belt the alkalies are dissolved to the greatest extent; next in order comes calcium, then magnesium, and finally iron and aluminum. (See p. 518.)

a Ostwald, W., The scientific foundations of analytica! chemistry, translated by George McGowan, Macmillan \& Co., London, 1895, pp. 55-56. 
Ostwald divides the acids into strong, moderately strong, weak, and very weak. The acids $\mathrm{H}_{2} \mathrm{SO}_{4}, \mathrm{HCl}$, and $\mathrm{HNO}_{3}$, are strong acids. The acids $\mathrm{H}_{2} \mathrm{SO}_{3}$ and $\mathrm{H}_{3} \mathrm{PO}_{4}$ are moderately strong. The acids $\mathrm{H}_{2} \mathrm{~S}, \mathrm{H}_{3} \mathrm{BO}_{3}$, and $\mathrm{H}_{2} \mathrm{CO}_{3}$ are weak acids. The acids of silica are rery weak. ${ }^{a}$

The strong acids $\mathrm{H}_{2} \mathrm{SO}_{4}, \mathrm{HCl}, \mathrm{HNO}_{3}$, when present in ground solutions, as they sometimes are, of course take possession of the bases in proportion to their quantity. However, in the crust of the earth strong acids are not abundant on the arerage, although under exceptional conditions, as in roleanic districts, they may be rather plentiful. Also the moderately strong acids $\mathrm{H}_{2} \mathrm{SO}_{3}$ and $\mathrm{H}_{3} \mathrm{PO}_{4}$ are not abundant, although phosphoric acid is rather widespread. Of the weak acids $\mathrm{H}_{2} \mathrm{~S}$ and $\mathrm{H}_{3} \mathrm{BO}_{3}$ are not plentiful. The two great acids of nature are carbonic and silicic acids, and the major contest in the rocks, so far as the acids are concerned, is between the weak carbonic acid and the very weak silicic acid. These two acids are everywhere rery abundant in the rocks. While, therefore, the moderately strong and the strong acids play a relatively important part in proportion to their quantity, one weak and one very weak acid, becanse of their dominant quantity, under the law of mass action play the greatest part in rock alterations; and in the contest the very weak acid, silicic, holds its own against the weak acid, carbonic, partly because its far greater abundance compensates for its relative weakness. The fact of the formation of carbonates and the simultaneous decomposition of the silicates under surface conditions the world over is well known. (See pp. 163, 473-486.) The partial explanation of the phenomena is the relative abundance of carbonic acid nnder the conditions in the zone of katamorphism. As shown in another place (see p. 479), the reaction is also one which liberates heat, and this is a favorable factor in the process.

In the zone of anamorphism, where the pressure is great, the reaction of the rpper zone is reversed. (See pp. 173-178, 677-679.) The replacement of carbonic by silicic acid results in decrease, in volume (see p. 177). Therefore, under the great pressures of the zone of anamorphism, the relative volumes of the original and secondary compounds is a most important, probably dominant, factor in the process. But also it is probable that at the high temperatures and pressures which obtain in the lower zone silicic acid gains strength as compared with carbonic acid. 
It may under these conditions be a stronger acid than at the surface, and if this were the case the reactions would be partly explained. Bearing in this direction is the experiment of Bischof, who has shown that at $100^{\circ}$ C. silicic acid, when present in abundance, may partially replace, carbonic acid of carbonates. ${ }^{\alpha}$

Ostwald's explanation of the varying strength of the bases and acids is based on the varying amount of supposed dissociation.

The velocity of a reaction is proportional to the masses of the active components, and according to Ostwald these are the free ions. Therefore the speed depends npon the number of free ions which are acting. But the number of free ions which are present is dependent upon the degree of dissociation, and in this matter different componnds vary greatly. Therefore the degree of electrolytic dissociation of the various bases and acids determines their respective strengths and is "the measure of the reaction capacities of all substances." ${ }^{b}$

From this it follows that an acid or base which is strongly dissociated is stronger than, or, in other words, is able to largely replace, an acid or base which is but slightly dissociated; for the number of free ions of the stronger compound far exceeds that of the weaker. It therefore becomes important, from Ostwald's point of view, to know the comparative strength, or the relative amounts of dissociation, of the abundant bases and acids which occur in the rocks. According to Ostwald the strong bases and strong acids may be largely dissociated; the moderately strong bases and acids under ordinary conditions are dissociated to a much less extent; the weak acids, carbonic, hydrosulphuric, and boric, are usually not dissociated to the extent of 1 per cent; silicic acid under ordinary conditions is scarcely dissociated at all.

$$
\text { STREXGTH OF THE SOLCTIOSS. }
$$

Satnrated and strong solutions are more active than weaker solutions; for the amount of the active compound increases with the concentration, but not in a simple ratio. Weak solutions are relatively more active than strong solutions, and by those who believe in dissociation this is attributed to their nearer approach to complete dissociation; but the greater relative activity of weak solutions never compensates fully for the greater dilution.

$a$ Bischof, Gustav, Elements of chemical and physical geology, translated by Paul and Drummond, Harrison \& Sons, London, 1854, vol. 1, p. 6.

$b$ Nernst, W., Theoretical chemistry, translated by C. S. Palmer, Macmillan \& Co., London, 1895, p. 440 . 
Although, as just seen, strong bases and acids have a great advantage over weak bases and acids, the quantity of an element present is a very important factor in the final result of the action of the solutions on the solids. If a certain element is abundant in the ground solutions, it may to a large extent replace another element in the solids, an element of the solid going into solution at the same time. This may take place to a large extent even if the element in solution is weaker than the one it replaces in the solid. For instance, the relatively weak base, magnesium, when abundant in solutions, is known to replace the stronger base, calcium, on a large scale in calcium carbonate, thus changing limestone to dolomite. In this reaction, while the abundance of magnesinm is a very important factor, a number of others enter; and therefore its detailed consideration is given under the process of rock dolomitization. (See pp. 802-808.)

\section{MECHAXICAL ACTION.}

It has already been seen that no changes in rocks take place without movements of material, small or great, for long or short distances. Even in the case of a mineral passing from one form to an allotropic form; there is movement of the molecules. In short, wherever there is rearrangement of the elements there must be movements.

Mechanical action alone is one of the processes of metamorphism of the utmost inportance. (See pp. 46-50.) However, the effect of mechanical action in the promotion of chemical action is even more important than mechanical action alone.

Mechanical action influences chemical action in two general ways-the speed is promoted, and the nature of the reaction is modified.

SPEED OF CHEMICAL ACTION.

The speed of chemical action is promoted directly by the deformation, and indirectly by the heat liberated.

DIRECT DEFORMATION EFFECT.

As already shown (pp. 49-50), mechanical action produces deformation in three different ways - by producing strain without rupture, strain with rupture, and readjustment of the particles

strain without rupture.-When material is strained withont rupture, even if the amount of deformation be slight, a great change in the molecular constitution may be involved. This is well shown by a common experiment 
on glass. If a piece of glass, free from stress, be placed under the microscope with crossed nicols, the light is eut off because the glass is isotropic. If, however, the glass be slightly flexed, well within the elastic limit, it immediately becomes anisotropic, and brilliant colors flash out. So far as light is concerned-and this is one of the best agents for giving an insight into the molecular constitution of bodies-the strained glass behaves wholly different from unstrained glass. Evidently when glass is alternately strained and freed from strain it undergoes a profound change in molecular constitution. The greatness of the molecular change in material when strained within the elastic linit is dwelt upon to slow that such changes might greatly affect chemical action; and it will be seen below that the facts correspond to this expectation.

Barns has shown ${ }^{a}$ in the case of metals strained to the point of rupture that a considerable per cent of the energy expended in straining them is potentialized; in "glass-hard" steel 50 per cent, in brass 40 per cent, in copper 25 per cent. A larger percentage of the energy was potentialized in the earlier stages of strain than in the later stages. By stating that energy is potentialized is neant that the mechanical equivalent in lieat of the work done on the metals was only partially developed; the remainder of the energy is stored up in the strained metals. Now, considering a brittle substance which is analogous in physical characters to rocks, Prince Rupert drops, the explosion of a drop when a point is broken shows that a large amount of energy is potentialized, or that the glass is in a high state of strain. The experiments of Barus and the condition of the Rupert drop show that in strained materials energy is probably potentialized. If this be true, must it not be the case that the atoms and molecules of a strained body are in a more than ordinarily favorable condition for chemical action?

Bodies in which energy is potentialized are believed to be in an exceptionally favorable condition for chemical action. For instance, if a strained metal, in which on that account more than the usual amount of energy is stored, be dissolved in an acid, less than the usual amonnt of chemical energy is expended, for the resultant salts in the solution have the same energy of combination in each case. But in the strained metal work has been done, the equivalent of which has not escaped as heat during strain, and is therefore stored energy. Therefore this energy is available

\footnotetext{
$a$ Barus, C., The mechanism of solid viscosity: Bull. U. S. Geol. Survey No. 94, 1892, pp. 107-108.
} 
to assist the chemical reaction. That it is utilized is shown by the fact that the heat of combination of the resultant chemical compound must be the same whatever the condition of the metal. Hence less chemical energy is required for the solution of a strained metal, and the reaction is promoted by the state of the strain.

The validity of this reasoning is dependent upon the principle of the conservation of energy. As a result of my studies in the phenomena of recrystallization, ${ }^{a}$ I became convinced that strained minerals are more readily acted upon by underground solutions than unstrained minerals. (See pp. 690-692.) Barus's experiments already cited suggested the above explanation. I then predicted that experiments would show that strained metals are more readily acted upon chemically than unstrained ones, and asked that this prediction be tested experimentally. This Mr. Hambuechen has done in reference to iron, with the following results:

The application of stress to metals causes an increase in chemical activity, this increase being especially marked after the elastic limit has been reached.

It is possible to get a curve showing the relation of electro-motive force to strain which is similar to that of stress to strain.

There is a definite relation between the electrical potential of iron toward an electrolyte and the amount of energy stored up in the metal through the application of stress. ${ }^{b}$

Thus complete experimental confirmation of this prediction is made so far as iron is concerned; and it can hardly be donbted that this illustrates the general principle above given.

- Applying the above principles to strain and chemical action, it may be said that in so far as minerals are strained either within or beyond the elastic linit, this potentializes energy and puts such minerals into a condition more favorable for chemical reactions than unstrained minerals. All rocks, except at the very surface of the earth, are under stress, and therefore strained to some extent at all times. It is true that the amount of stress may not be great within a few meters of the surface; but with increase of depth the average amount of stress becomes more important. In most cases of ordinary horizontal rocks near the surface it is customary

a Compare Van Hise, C. R., Metamorphism of rocks and rock flowage: Bull. Geol. Soc. America, vol. 9,1898 , p. 300 .

${ }^{b}$ Hambuechen, Carl, An experimental study of the corrosion of iron under different conditions: Bull. Univ. of Wisconsin No. 42 (Engr. ser., vol. 2, No. 8), 1900, p. 255.

MON XLVII-04-7 
to regard them as practically free from stress and strain. However, not infrequently rapid deformation by uplift of an arch or by fracture when a few meters of load is removed, as at the Chicago drainage canal and at the combined lock of Appleton, ${ }^{a}$, shows that such rocks are under very considerable stress, and therefore must be strained.

Not only are rocks generally under stress, but because of the complexity and variability of rock compositions, structures, and textures, wherever rocks are under stress the amount of stress and therefore of strain continually varies with changing direction and changing position. Variable amount of strain is therefore a universal law. In so far as any mineral particle is strained to a greater degree than an adjacent mineral particle of the same kind similarly strained, the particle under greater strain is more rapidly altered by chemical action. In so far as any portion of a mineral particle is strained to a greater degree than another portion of the same particle similarly strained, the part under greater strain is more rapidly altered by chemical action. Finally, for the same mineral particle or some part of the same the strain varies continually during deformation.

From the foregoing it follows that the almost universal state of strain, and the not less nuiversal variability in the amount of strain, are of the most profound significance in metamorphism. (See Chapters VI, VII, VIII.) strain with rupture.-Where deformation produces rupture, another feature enters, also favorable to chemical action. Rupture is favorable to chemical action since thereby the surface exposed to the underground waters is inversely as the average dianeter of the mineral particles. Granulation very greatly increases the surface of action.

Readjustment of particles. - The readjustment of the rock particles with reference to one another can hardly fail to give better opportunities for the chemical action of the ground waters; for during the adjustment the water will necessarily be moving and will come in contact with a succession of mineral particles, and thus promote chemical interchange. Hence I conclude that mechanical action is favorable to metamorphism by chemical action, whether the deformation be strain without rupture, with rupture, or merely readjustment of the rock particles, or, finally, any combination of these.

"Cramer, Frank, On the rock fracture at the Combined Locks mill, Appleton, Wis.: Am. Jour. Sci., 3d ser., vol. 41,1891 , pp. $432-434$. 
INDIRECT HEAT EFFECT,

It is a well-known law that mechanical action develops an equivalent amount of heat, except for the part of the energy which is potentialized. It has alleady been seen that heat is ordinarily favorable to chemical action. Therefore mechanical action promotes chemical action, because it develops heat and raises the temperature. Indeed, the heat developed by mechanical action is frequently one of the most important favorable conditions for metanorphism. It will be shown (Chapter VIII, p. 740) that where mechanical action is strong the complete recrystallization of rocks may occur much nearer the surface than under quiescent conditions. This result is largely attributed to the rise in temperature due to deformation, which results in vastly greater efficiency of the water as an agent of chemical action.

It therefore becomes of the utmost importance to consider to what extent the temperature is raised in the rocks by mechanical action.

The heat, as already intimated, is produced by the transformation of work into heat as a result of straining the rock particles within the elastic limit, by rupturing them, and by their frictional movements over one another. Mallet ${ }^{a}$ has held that the heat thus developed may be sufficient to liquefy rocks by aqueo-igneous fusion. He thus accomts for the crystallized cores of many mountain ranges. He even loolds that the material fused by mechanical action may intrude the adjacent solid rocks. LeConte follows Mallet in this belief. It may be theoretically possible that rock material can be ground so fine as to develop sufficient heat to fuse it. However, as explained (Chapter VIII, pp. 728-732), we have no evidence in the field that this has occurred. It is shown (Chapter VIII, pp. 690-696), that when the temperature of water-saturated rocks rises a certain amount, readjustment occurs, not by mechanical subdivision and grinding of the particles over one another, but by recrystallization. The process is thus chemical, not mechanical, and the expenditure of energy and the consequent development of heat are far less than by the former process. However, it is probable that, as a result of the interior kneading of rocks, the temperature may be materially increased, perhaps several hundred degrees beyond the normal temperature which obtains as a result of the depth of

" Nallet, Robert, Volcanic energy; an attempt to develop its true and cosmical relations: Philos. Trans. Royal Soc. London, vol. 163, 1873, pp. 147-227. 
burial. And it is certain that the temperature can be very materially increased, and therefore that the chemical activity is enormonsly increased.

NATURE OF THE CHEMICAL REACTIONS.

Pressure influences chemical reactions under the following law: If a chemical system be compressed at a constant temperature, there follows a displacement of the equilibrium in that direction, which is associated with a diminution of volume. This law in relation to pressure and chemical activity may be stated in a more general form, as follows: "Those chemical forces are strengthened by compression which condition a diminution of volume; and those chemical forces are weakened by compression which condition an increase in volume." ${ }^{a}$ In other words, so far as pressure influences chemical reactions, changes go on in directions which produce smaller volumes. Therefore pressure at all times and places is influencing chemical reactions in the direction of the production of more condensed systems. It has been seen (Chapter II, pp. 48-49) that pressure alone, without the presence of solutions, may produce reactions under this law. However, in nature, the vast majority of reactions under the law are accomplished through the agency of water. The importance of water in this comnection is well illustrated by Spring's experiments upon the consolidation of clay when dry and wet. By pressure upon moist clay confined in a cylinder he was able to consolidate the clay into a body as compact as a piece of shale-indeed, so compact that it was difficult to scratch it with the finger nail. But using the same pressure upon dry clay he produced a substance so little consolidated that it was easily scratched with the finger nail. In the case of the moist clay, he attributed the consolidation to the escape of the plastic material about the piston, and to the precipitation of material from solution at the moment of escape. ${ }^{b}$ Spring's explanation therefore does not introduce chemical readjustment of the compounds. However, it will be seen that pressure does promote chemical interchange, producing compounds which are, on the average, denser than the original ones. This, as will be shown on the following pages, is believed to be a dominant process for a great many chemical reactions

a Nernst, W., Theoretical chemistry, translated by C. S. Palmer, Macmillan Co., New York, 1895, p. 567.

${ }^{b}$ Tolman, C. F., jr., Professor Spring on the physics and chemistry of solids: Jour. Geol., vol. 6, 1898, p. 323. 
resulting from pressure as the chief motive force; and it may be that chemical interchange is one of the processes which explain the consolidation of the clay in Spring's experiment.

In the rocks a smaller volume may result in either of two ways: Material may be taken into solution and deposited in a more compact form without change in chemical composition, or with change in chemical composition.

SMALLER ROGK VOLUME AS THE RESULT OF SOLUTION AND DEPOSITION WITHOUT CHANGE IN CHEMICAL COMPOSITION.

It has already been explained (pp. 77-78) that pressure promotes solution in case the volume of the solution is less than that of the solvent and solid, and that pressure promotes precipitation in case the volume of the solution is greater than that of the solvent and solid. Thus the soluoility of a salt increases with pressure, provided the dissolving is associated with a contraction of the volume of the solution plus the salt; and, conversely, the solubility decreases if the separation of the salt (from the solution) is associated with a diminution of the volume of the system.a ${ }^{a}$ In ground solutions the general law is that the volume of the solution is less than that of the substances dissolved and the water. It follows from this law that pressure in rocks, the interstices of which are filled with water, promotes recrystallization and condensation.

The production of a smaller rock volume withont change in chemical composition may occur where the recrystallization and condensation take place withont change of minerals, and where the recrystallization and consolidation take place with change of minerals.

Recrystallization and condensation without change of minerals.-As an illustration of the principle, we may consider a stratum of uncousolidated crystallized calcium carbonate over which is a layer of water saturated with calciun carbonate. Inasmuch as the calcium carbonate is porous, the water in the rock is free to move and is under the pressure of the hydrostatic columu above it. The particles of $\mathrm{CaCO}_{3}$ are under this pressure, and also that of the solid above All the water in the crevices and pores small enough to hold water by capillarity is under both the pressure of the water and in part that of the rock. 'This water is saturated under this pressure, and it can hold more substances in solution than the water mider less pressure. An interchange p. 567 .

"Nernst, W., Theoretical chemistry, translated by C. S. Palmer, Macmillan Co., New York, 1895, 
is constantly carried on between the free and the capillary water, and as the capillary water becomes free it is supersaturated and deposits some of its load in the interstices of the rock. But gravity ever pulls the material downward, and although this process is not rapid, it is continuous, and in course of time the particles are cemented. A solidified and recrystallized limestone is produced. Evidently the greater the pressure the more rapid and complete is this change.

Another example of solidification without change in mineral composition is the change of snow or separate ice crystals where mingled with water to solid ice, as at the head of glaciers. Ice has its melting point lowered by pressure. Where the granules are under more than the average pressure some of them melt. The water flows out into the free spaces and is again frozen. Or, as expressed above, under more pressure more of the ice is dissolved in the water than under less pressure. "When the pressure is relieved in the more open spaces the ice is reprecipitated. ${ }^{\text {a }}$ As the process goes on the particles are finally cemented. This process, like that of the recrystallization of limestone, is continuous, and finally the separated snow granules are transformed to continuous ice.

Recrystallization and condensation with change of minerals.-Recrystallization and condensation with change of minerals but without change in chemical composition may take place by precisely the same processes as already given. The resultant minerals, where the inducing cause is pressure, are more compact than the original minerals. Illustrating this principle, pressure induces the transformation of amorphous calcium carbonate to calcite. Similarly, pressure may induce the transformation of many other amorphous substances to crystalline forms. Pressure also induces minerals to change to forms having higher specific gravities. Thus pressure tends to transform tridymite, sp. gr. 2.28-2.33, to quartz, sp. gr. 2.653-2.660; and marcasite, sp. gr. $4.85-4.90$, to pyrite, sp. gr. 4.95-5.10. (See pp. 220-221, 215.)

We may also safely argue that, where the pressure is great, minerals are not likely to crystallize in forms having low specific gravities. Thus under great pressure it is to be expected that silica will crystallize as quartz and not as tridymite. Doubtless this principle explains why quartz is always found in the plutonic rocks, and why tridymite often is

a Le Chatelier, in Theoretical chemistry, by W. Nernst, p. 654. Zeitschr. phys. Chemie, vol. 9, 1892, p. 335 . 
found in the volcanic rocks. The plutonic rocks crystallize under conditions of great pressure, while the volcanic rocks crystallize under conditions of moderate or slight pressure. It would be interesting to know the relations of quartz and tridymite in the matter of depth in the lavas, and therefore in reference to pressure at the time of crystallization.

SNALLER YOLUME AS THE RESULT OF SOLUTION AND REDEPOSITION WITH CHANGE IN CHEMICAL COMPOSITION,

Pressure inducing chemical reactions involving changes in chenical composition may produce crystallization and condensation of amorphous compounds and recrystallization and condensation of erystallized compounds.

Crystallization and condensation of amorphous compounds.- In general the amorphous compounds occupy more volume than their complex crystalline equivalents. "Therefore, since the crystallized state is generally that which takes the smallest volume, pressure aids crystallization." a According to Delesse, in passing from the crystalline to the glassy state, granite decreases in density 9 to 11 per cent, syenite 8 to 9 per cent, diorite 6 to 8 per cent, dolerite 5 to 7 per cent, and trachyte 3 to 5 per cent. ${ }^{b}$ Thus glass occupies from 3 to 11 per cent more volume than the equivalent crystallized rocks. It therefore follows that pressure is one of the potent forces which result in the devitrification of glass. In general it may be said that rocks near the surface, whether original magmas, sediments, or schists and gneisses partly altered in the belt of weathering, very frequently contain amorphous products; whereas rocks which have been altered while deeply buried rarely contain any considerable quantity of anorphous material. It is beliered that the explanation of the difference is largely dne to difference in pressure. At depth where pressure is forceful the amorphous products which occupy more space than their crystallized equivalents either have not formed or if formed at the surface and deeply buried have become crystallized, the pressure being one of the important forces in the process.

Recrystallization and condensation of crystalized compounds.-Pressure may induce chemical action upon crystallized compounds, producing recrystallized products of a different kind and with more compact molecules, and therefore of greater specific gravity. In some cases the recrystallization las occurred

"Tolman, C. F., jr., Professor Spring on the physies and chemistry of solids: Jour. Geol., vol. 6, 1898 , p. 320.

$b$ See Dana, J. D., Manual of geology, American Book Co., 4th ed., 1895, p. 265. 
at least twice. After one set of compounds was produced recrystallization again occurred, producing heavier compounds. The first change may be illustrated by the rearrangement of minerals which constitute mud so as to produce mica, quartz, and feldspar, and the second stage may be illustrated by the development from the latter rock of the still heavier minerals, garnet, staurolite, etc. (See p. 685.) However, the process of recrystallization in nature works in connection with more rapid solution of minerals where strained (see p1. 95-98) and with other forces. Its full cousideration is therefore deferred to Chapter VIII (pp. 686-698).

GENERAL STATEMENTS.

Where pressure is unimportant, as near the surface of the earth, the chemical reactions are ordinarily controlled by other factors than pressure; but as the pressure increases, due to depth below the surface or other causes, it becomes a more and more important factor in the reactions which occur. But it is shown in Chapter VI, on "Weathering," that pressure may be an important factor in chemical reactions comparatively near the surface. This is illustrated by granitic rocks in the District of Columbia, described by Merrill, ${ }^{a}$ which when brought to the surface underwent rapid disintegration, hydration, and expansion. The pressure of a few feet of rock was apparently sufficient to prevent the completion of these reactions, and thus it is clear that the adjustment between chemical reaction and pressure may be very delicate.

However, as explained in Chapter VI, chemical reactions near the surface do extensively take place with expansion of volume, and therefore in spite of some pressure. But it is also shown (Chapter. VIII) that the pressure becomes a more and more potent factor in controlling the reactions; and, finally, that there exists a lower zone of anamorphism in which this is the dominant force. In this zone the chemical changes so take place as to lessen the volume of the compounds, and therefore to produce heavy minerals. Moreover, the reactions which occur in this lower zone are frequently just the reverse of those which take place in the upper zone, where pressure is unable to control, or the reactions in the two zones leverse each other.

a Merrill, G. P., Disintegration of the granitic rocks of the District of Columbia: Bull. Geol. Soc. America, vol. 6, 1895, pp. 322-332. 
HEAT.

Heat is a very important factor in chemical action. In the heat factor two points are involved: first, the general effect of heat; and, second, the effect of change in temperature in consequence of the reactions.

As to the first of these, in the lithosphere the higher the temperature in general the more rapid the alteration. To this law there may be exceptions, but none are positively known to me.

As to the second point, the chemical effect due to the change in temperatme in consequence of a reaction is much more complicated.

In considering whether heat be liberated or absorbed as a result of a chemical reaction it is necessary to take into account the heat changes in solution, the heat changes in precipitation, the heat changes in mixing solutions, and the heat effects of chemical reactions.

"By the heat of solution is meant the quantity of heat produced by the solution of 1 gram molecule of a substance in a large quantity of the solvent." $a$ It has already been seen that in general the volume of the solvent and salt is greater than that of the solution, and that in this case there is usually liberation of heat and consequently rise in temperature; but in exceptional cases the volume of the salt and solvent is less than that of the solution, and in this case there is generally absorption of heat, and consequent fall in temperature. The total effect as to the liberation or absorption of heat depends upon whether the total of the factors, change in volume, change of the solid to its dispersed form in the solution, and the heat factor of dissociation, provided this occurs, is plus or minus. Decrease of volume tends to liberate heat; increase of volume tends to absorb heat. The change from the solid to the dispersed state of solution absorbs heat. The supposed dissociation of a substance into its ions is regarded as attended witl either a liberation or an absorption of heat, though liberation is held to occur more frequently. ${ }^{b}$

In precipitation the heat effect is just the opposite fiom that of solution and is equivalent to the heat effect of the solution of an equal amount of the like salt. "In general, in comparing substances which are chenically analogous and soluble with difficulty, the heat of precipitation (=the negative valne of the heat of solution) is the greater the more insoluble

a Nernst, W., Theoretical chemistry, translated by C. S. Palmer, Macmillan \& Co., London, 1895, p. 503.

$b$ Nernst, cit., y. 562 . 
the substance is." ${ }^{\infty}$ If this law be applicable to quartz and to silicates it is of great importance in metamorphism, becanse these are the substances most largely dissolved and deposited by the ground water, with the possible exception of the carbonates.

As to the heat relations when two solutions are mixed, Ostwald states that in mixing solutions heat is produced by the work between the heterogeneous molecules, and heat is used in separating and spreading out the homogeneous molecules. The sum of these may be positive or negative, but in most cases the former is the case, and hence the two liquids usually become warmer when they are mixed. ${ }^{b}$ Upon the same point Nernst says: "No heat phenomena result from the mixture of salt solutions [provided that no precipitate (and no volatile compound) is produced]."

When chemical reactions occur there is a certain amount of heat of formation of the compounds. "By the 'heat of formation' of a chemical compound is meant the quantity of heat which is given off in the formation of the compound from its respective ingredients." " "The 'heat-toning' of a reaction is equal to the sum of the resulting heats of formation minus the sum of the lieats of formation of the vanished molecules." ${ }^{d}$ In whatever way a chemical result is accomplished, and however many the stages of process of the change, "the energy differences (and therefore the heat differences) between two identical conditions of the system must be the same, independently of the way by which the system is transferred from one condition to the other." $"$

This last is an important law so far as the work of ground waters is concerned, for in most cases we know only the opening and closing stages of the processes of alteration, and can ascertain whether the heat effect of a reaction is plus or minus only by comparing the heat required for the production of the original minerals with that required for the production of the secondary minerals, and their gaseons and fluid by-products.

While the above gives the conclusions as to the heat effect of individual reactions, the reaction which is likely but not certain to obtain at moderate pressure and temperature is covered by the rule of Berthelot. He says, "Every chemical change gives rise to the production of those

\footnotetext{
a Nernst, W., Theoretical chemistry, translated by C. S. Palmer, Macmillan \& Co., London, 1895, p. 504.

bOstwald, W., Solutions, translated by M. M. Pattison Muir; Longmans, Green \& Co., New York, 1891, p. 308.

cNernst, cit., p. $508 . \quad$ dNernst, cit., p. $505 . \quad$ Nernst, cit., p. 496.
} 
substances which occasion the greatest development of heat." ${ }^{a}$ And therefore, "other things being equal, there is the more chance that a substance can be formed, the greater its heat of condensation." ${ }^{\circ}$ While these are the usual rules, they are not broad enough to cover the reactions of metamorphism under all pressures and temperatures. A more general statement of the law as to the relations of heat and chemical reactions is that of ran't Hoff: "On the whole, the preponderating chemical reactions at lower temperatures are the combinings (associations) which take place with a development of heat, while the reactions preponderating at higher temperatures are the cleavings (dissociations) which take place with the absorption of leat." " The meaning of this law may be illustrated by the following reactions: At ordinary temperatures $\mathrm{CO}$ combines with $\mathrm{O}$, producing $\mathrm{CO}_{2}$, with great liberation of heat; at very high temperatures $\mathrm{CO}_{2}$ dissociates into $\mathrm{CO}$ and $\mathrm{O}$, with very great absorption of heat. This illustration makes it clear, as stated by Nernst, that to cover all cases van't Hoff's law must replace that of Berthelot, above given. Still more general laws as to the relations of heat and chemical reactions are the following: "If we heat a chemical system, at constant volume, then there occurs a displacement of the state of equilibrium, and in that direction towards which the reaction advances with absorption of heat." "Those chemical forces which condition a development of heat will always be weakened by an increase of temperature; and, conversely, those which condition an absorption of heat will be strengthened by such an increase in temperature; and it is this fact which, primarily, gives the preceding proposition its universal validity." "If we heat the system, therefore, the reaction which takes place will be accompanied by absorption of heat; if we cool the system, the corresponding reaction will develop heat."

Now that the general laws covering the mutual influences of heat and chemical action have been given, we may consider in more detail their meaning. The speed of the reaction is commonly increased much more rapidly than the increase in absolute temperature. Thus, the speed of reaction of two similar solutions, one of which is at higher temperature

a Nernst, cit., p. 581, quoting Berthelot.

$b$ Nernst, cit., pp. 585-586.

$c$ Nernst, cit., p. 583.

a Yernst, cit., p. 566.

$e$ Ostwald, W., Outlines of general chemistry, translated by James Walker, 2d ed., Macmillan \& Co., London, 1895, p. 312. 
than the other, may be far greater in the solution at high temperature than would be calculated from the relative absolute temperatures of the solutions.

Indeed, the velocity of a chemical reaction commonly increases enormonsly with moderate increase of temperature. The partial explanation of the phenomena lies in the fact that in most cases the reactions themselves, as already seen, develop heat, which immediately reacts to increase the kinetic energy of the remaining molecules, and this again increases the kinetic energy of the molecules, and so on, there being continual action and reaction between the chemical activity and the rising temperature.

Another illustration of the very important way in which increase of temperature increases chemical action is the increased activity of substances which at low temperatures are relatively inert. While at ordinary temperatures carbon dioxide replaces silica in silicates, at temperatures of $100^{\circ} \mathrm{C}$. silica, if present in abundance, may replace carbon dioxide in carbonates. ${ }^{\alpha}$ While this is explained in part by the increase of activity of silicic acid with increase of temperature, it doubtless in part is explained by the law of mass action and the increased volatility of carbon dioxide at higher temperatures.

If the dissociation theory be true, a third factor which may have some effect in producing speed of reaction with increase of temperature is the increase in the amount of hydrolysis with increase of temperature. This is illustrated by ferric chloride, which at low temperatures is regarded as but little hydrolized, but at high temperatures is believed to be hydrolized to a perceptible extent according to the equation:

$$
\mathrm{Fe}_{2} \mathrm{Cl}_{6}+6 \mathrm{H}_{2} \mathrm{O}=\mathrm{Fe}_{2}(\mathrm{OH})_{6}+6 \mathrm{HCl} \text {. }
$$

The presence of the ferric hydroxide is shown by the color of the solution. $^{b}$ In a similar manner, the carbonates and silicates are believed to be hydrolized to a much greater extent at high temperatures than at low temperatures. This is illustrated by calcium carbonate, which in solution at high temperatures gives a strong alkaline reaction of calcium hydroxide, and this is regarded as evidence of strong liydrolysis. It is possible that hydrolysis is an important factor in the reactions which take place in the different zones of metamorphism.

$a$ Bischof, Gustav, Elements of chemical and physical geolngy, translated by Panl and Drummond, Harrison \& Sons, London, vol. 1, 1854, p. 6 .

${ }^{b}$ Ostwald, W., Grundlinien der anorganischen Chemie, Engelmann, Leipzig, 1900, p. 583. 
While in general, speed of chemical change is promoted by rise of temperature, as indicated by the second part of van't Hoff's law, there is a limit to the increase of speed due to action and reaction between chemical change and heat, for when the temperature becomes too high a reverse tendency is set up, since the compounds formed by the chemical reactions frequently can not exist at very high temperatures. In such cases the rate of reaction may cease to increase with increase of temperature, and, indeed, the reactions which obtain at lower temperatures may be reversed.

Just as a slight increase of temperature may enormously increase the speed of chemical reactions, so a slight decrease of temperature may very greatly lessen the speed of reactions. Therefore, if the reaction be one which itself absorbs heat, and thus lowers the temperature, the slight decrease in the kinetic energy of the molecules may greatly retard the speed of the reaction.

At the very moderate temperatures which generally prevail within the outer part of the crust of the earth the heat resulting from the chemical changes does not become so great as to stay the reactions. Therefore, it may be said that the chemical reactions which take place with liberation of heat promote metamorphism, and those which take place with absorption of lieat retard metamorphism. The great importance of these two tenden cies, as applied to rocks, will be shown on subsequent pages in connection with the discussion of the zones of katamorphism and anamorphism.

On subsequent pages it will be seen that in the zone of katamorphism the first part of van't Hoff's law or the rule of Berthelot generally prevails in the alterations of rocks for a considerable distance from the surface. That is to say, on the whole the preponderating chemical reactions are those which take place with the liberation of heat. Moreover, as a consequence of increase of heat with depth, at a very moderate depth the temperature is rather high. Also, igneous rocks give high temperatures to the surrounding rocks and solutions. As a result of any of these causes, water may reach the moderate temperature of $100^{\circ}$ to $200^{\circ} \mathrm{C}$., and such temperatures increase the activity of water in an amazing degree. (See pp. 79-81.) Thus we see that in the zone of katamolplism the heat of chemical action, and that derived from the interior of the earth through conduction and convection by means of magma and water, all work together to increase the speed of chemical action, and therefore to hasten metamorphism. 
However, it will also be seen that in the zone of anamorphism, with pressure as a dominant factor, reactions very generally occur with the absorption of heat under the second part of van't Hoff's law. Thus, in this zone the heat effect of the chemical reactions is to stay metamorphism. But while the reactions which oceur at depth are very generally those which absorb heat, it mnst be remembered that in the zone of anamorphism the amount of heat available, due to increase of heat with depth and to the difficnlty with which the heat escapes from intrusive rocks, is very great. Therefore, notwithstanding the fact that the chemical reactions themselves absorb heat, the temperature is much ligher than in the upper zone. Consequently one wonld expect that the chemical activity would be greater in the zone of ananorphism than in the npper zone of katamorphism; and with these expectations the facts correspond. (See pp. 660-661, 690$692,749-751$.)

RELATIONS OF CIEMICAL ACTION, MECIANICAL ACTION, AND HEAT.

All transformations of material npon the earth, provided all the energy factors be taken into account, involve the expenditure of energy and the dissipation of part of it as heat. If this were not true it wonld be possible to manufactnre an engine by means of which an equal or greater amount of energy is available for work than is expended in driving the engine, and perpetnal motion would be possible. In metamorphism of rocks, in order that the above general statement as to the expenditure of energy shall be true, it is necessary to take into account the chemical force, mechanical force, and heat which promote the transformations. In those cases where a transformation of material does not at first sight appear to demand the expenditure and dissipation of energy, this is due to the fact that some of the energy factors are overlooked.

It has been noted that chenical actions are reversible, and it will be seen subsequently that chemical reactions which take place on a large scale in the zone of katamorphism are reversed in the zone of anamorphism. When a chemical reaction takes place, and later that reaction is reversed and the cycle is repeated, exterior energy must have been expended and dissipated. To illustrate, let us consider the reversible reaction

$\mathrm{Fe}_{2} \mathrm{O}_{3}+3 \mathrm{H}_{2} \mathrm{O} \gtrless \mathrm{Fe}_{2} \mathrm{O}_{3} \cdot 3 \mathrm{H}_{2} \mathrm{O}$.

The reaction may advance from left to right by the expenditure of chemical energy alone, and as a result of the process heat is liberated. 
However, to reverse the reaction or to advance it from right to left requires the expenditure of a greater anount of external energy than the chemical energy expended in the first reaction. In the reaction given the available external energy may be from one of two sources-heat or mechanical action. The ferric hydrate may be broken into ferric oxide and water by heating. Also, if the pressure be very great and water have a chance to escape the same transformation may take place by the expenditure of mechanical energy. Donbtless in nature in many cases both of these forces unite in the process, but whether the dehydration takes place as a result of the expenditure of heat energy alone or mechanical energy alone, or the two combined, a greater amount of energy must be expended than the chemical energy expended in the hydration of the iron. Hence, when hydration takes place in the zone of katamorphism energy is expended. This is potential chemical energy. When dehydration takes place in the zone of anamorphism, reversing the first process, energy is also expended. 'This is either potential mechanical energy or the energy of heat, or the two together. I say potential mechanical energy, for I have held in another place that all earth movements, provided all the factors are taken into account, result in bringing the material moved nearer the center of the earth, and therefore the energy expended is the potential gravitative energy of position. ${ }^{a}$

The reasoning applied to the case of hydration and dehydration of ferric oxide is applicable to every other reversible reaction in metamorphism; hence, when we take all the energy factors into account, at the end of the process energy has been expended. Furthermore, a part of this energy during the process has been transformed to heat and dissipated; for in all transformations of energy there is an inevitable tendency for some of the energy to run down into the lowest form, heat, a portion of which is lost. ${ }^{b}$

In conclusion, therefore, in the zone of katamorphism, while chemical reactions frequently take place which liberate heat and expand the volume, and in the zone of anamorphism chemical reactions take place which absorb leat and condense the volume, in both zones alike when all of the energy

a Van Hise, C. R., Earth movements: Trans. Wisconsin Acad. Sci., Arts, and Letters, vol. 11, 1898, pp. 487, 488, 512-514.

b Daniell, Alfred, A text-book of the prineiples of physies, 3d ed., Macmillan Co., New York, 1895 , p. 51. 
factors are taken into account the reactions take place in such a way as to demand the expenditure of energy and the loss of a part of it.

Where chemical force, mechanical force, and high temperature work together, with an abundance of water, as an agent of metamorphism, the speed of rock metamorphism is very great as compared with the slow alterations which occur at the surface of the earth. For instance, Barus finds that water at temperatures above $185^{\circ} \mathrm{C}$. and under high pressure is capable of very rapidly uniting with glass, forming a new compound, which at these temperatures is liquid, and which he calls water glass. In a retort he combined 210 grams of glass and 50 grams of water in twelve hours at a temperature of $210^{\circ} \mathrm{C}$. into water glass, which was liquid at that temperature, but became a clear solid at ordinary temperatures. ${ }^{a}$

Not only amorphous compounds but crystalline minerals also are acted upon rapidly at such temperatures and pressures. At $180^{\circ}$ C., with pressure sufficient to keep the water in the liquid form, Lemberg ${ }^{b}$ has completély dissolved zeolites in pure water. Under similar conditions it has also been shown that pure water acts rapidly upon powdered anhydrous silicates. For instance, Forchhammer showed that water under these conditions dissolves potassium silicate from powdered orthoclase. ${ }^{c}$

Within the zone of rock flowage temperatures and pressures higher than those with which these experiments have been made are available, and it is therefore to be supposed that in the zone of anamorphism there is rapid transformation of the minerals to forms which are relatively stable under the conditions obtaining at any given time and place. So far as substances have not a compact state of aggregation energy is potentialized. Pressure being a very potent factor, the transformations would of course be into condensed systems, or into minerals having ligh specific gravity and probably complex molecular structure. It is evident that in the forces of chemical action, mechanical action, and heat, and the agent, water, we have adequate causes for the crystallization of amorphous compounds, for the recrystallization of strained minerals, and for the recrystallization of highly

a Barus, C., The compressibility of liquids: Bull. U. S. Geol. Survey No. 92, 1892, pp. 78-84. Ilot water and soft glass in their thermo-dynamic relations: Am. Jour. Sci., 4th ser., vol. 9, 1900, pp. $\mathrm{i} 64-65$.

$b$ Doelter, C., Allgemeine chemische Mineralogie, Wilhelm Engelmann, Leipzig, 1890, p. 189.

c Forchhammer, G., Ueber die Zusammensetzung der Porcellanerde und ihre Entstehung aus dem Feldspath: Poggendorff, Annalen, vol. 35, 1835, p. 354. 
potentialized minerals to lower potentialized forms. These changes are illustrated by the passage of glass to a crystalline form, by the passage of minerals from a strained to an unstrained condition, and by the passage of minerals of low specific gravity to minerals of higher specific gravity.

From solutions, by changing conditions, solids may separate. This process is called precipitation. Since precipitation from ground water solutions is of the utmost importance in metamorphism, it is necessary to consider fully the conditions under which precipitation takes place. It has already been seen that in solutions the ingredient which is present in excess is called the solvent and the ingredients which are subordinate are the substances dissolved. When from solutions the substance in excess, or the solvent, separates, this is called a freezing of the solution. When in the solution the substances dissolved first separate, this is called crystallizing out of the materials dissolved. "The processes of freezing and of crystallizing out are both to be considered from the same point of view; and when we are not dealing with dilute solutions where one ingredient is present in large excess, but with a mixture, where both ingredients are present in about the same proportions, then we would be in actual doubt whether the separation shonld be regarded as a freezing (of the solvent) or a crystallizing out (of the substance dissolved), or perchance of both processes."

The necessary condition for precipitation is supersaturation; for if a solution be not saturated it will take more material into solution; but if a solution be sufficiently supersaturated some of the material must be thrown down or be precipitated. If solids are present similar to the compounds in solution, considerable supersaturation does not occur. This is very frequently the case with ground solutions. Under such circumstances the salts in solution separate out upon the minerals already present, or the minerals grow. At any given pressure and temperature, provided the changes occur slowly, equilibrium is nearly retained by this continuous adjustment. This relation between minerals already present and solutions is one of the most important factors which control the growth of minerals which are present. If, for instance, in a complex solution containing

a Nernist, W., Theoretical chemistry, translated by C. S. Palmer, Macmillan Co., New York, 1895, p. 414. MON XLVII-Ot-8 
various ions there are also various erystalline minerals, the moment that the solution becomes supersaturated with reference to several ions which may unite to produce one of the solids present, this union will take place, the material will be precipitated upon the minerals of that kind, and thus they will grow.

This process of mineral growth applies alike to minerals in maguras and to minerals in sedimentary rocks. If, for instance, in a magma plagioclase and pyroxene individuals once begin to form, they may grow to large size and produce a gabbro. In a sedimentary rock in which quartz and feldspar particles are present and the solutions are of a kind which furnish constituents for their growth, these particles are likely to be enlarged.

Supersaturation, and consequently precipitation, may result in various ways, of which the following are the more important: (1) Precipitation by change of pressure, (2) precipitation by change of temperature, (3) precipitation by reactions between aqueous solutions, (4) precipitation by reactions between aqueous solutions and gases, and (5) precipitation by reactions between sohutions and solids.

\section{PRECIPITATION BX Change OF PRESSURE.}

Change of pressure may result in supersaturation, and therefore in precipitation. Where the volume of the solution is less than that of the solvent and substance dissolved, decrease of pressure is favorable to precipitation. Where the volume of the solution is greater than that of the solvent and substance dissolved, increase of pressure is favorable to precipitation. The volume relations are opposite in the cases of the crystallization of minerals from solutions of ground water and the crystallization of minerals fiom magmas. In the case of substances dissolved in ground solutions the volumes of the solutions are commonly less than those of the solvent and the substances dissolved; therefore decrease of pressure is favorable to precipitation. But in the case of crystallization from magmas the volume of the solution is greater tinan that of the crystallized minerals; therefore pressure is favorable to crystallization.

In another connection it is suggested that under certain conditions water and magma are miscible in all proportions. (See Chapter VIII, p. 723.) In other words, there is every gradation from water containing compounds in solution to magmas containing subordinate amounts of water. If this 
be so, ideally there must be a nentral point in which the volume of the material is thie same whether as a solution or as a solid. In this case pressure would have no effect upon precipitation. However, the precipitation of any part of the material from a solution modifies the character of the remainder of the solution, and it is not to be supposer that a case is likely to occur in which crystallization of material takes place without there being any pressure effect.

Where circulating waters are descending the pressure is increasing, and where ascending the pressure is decreasing. Therefore, in the case of ordinary ground-water solutions the direction of water circulation which is favorable to precipitation is ascension.

PRECIPITATION RY CHAXGE OF TEMPERATURE.

Change of temperature may result in supersaturation, and therefore in precipitation. In general, in gronud solutions increase in temperature increases solubility. (See pp. 79-81.) Therefore decrease in temperature is favorable to supersaturation and precipitation. While this statement is true for most substances at temperatures below $100^{\circ} \mathrm{C}$., and is correct for many substances at temperatures considerably higher than this, at very high temperatures the conditions are reversed for some substances. (See p. 79.) In the common case, that of precipitation with decrease of temperature, the freezing point of the solution is lower than that of the solvent. ${ }^{a}$ Apparently the amount of lowering is proportional to the molecular weights, and is stated by Raoult as follows: "One molecule of any compound when dissolved in 100 molecules of a liquid lowers the solidification point of the liquid by an amount which is nearly constant, viz, $0.62^{\circ}$;" or, the molecular depression, when the solvent is to the solute as $1: 100$, is $0.62^{\circ}{ }^{b}$ In dilute solutions of salts in water, the molecular depression may be larger than this, in which case the substance is regarded by many as dissociated. ${ }^{c}$ It was by the application of the principle of molecular depression that Kablenberg and Lincoln were able to reach the conclusion already given (p. 87), that silica goes into solution as colloidal silicic acid. When the silicates are dissolved and

a Ostwald, W., Solutions, translated by M. M. Pattison Muir; Longmans, Green \& Co., New York, 1891, p. 199 et seq.

$b$ Ostwald, Solutions, cit., p. 208.

$c$ Ostwald, Solutions, cit. p. 214. 
decomposed by hydrolysis into colloidal silicic acid and metallic hydroxides, the latter (or, according to the dissociation theory, their ions) cansed the molecnlar depression, which was unaffected by the colloidal silicic acid.

In precipitation from complex mixtures the substances do not solidify at the same time. The compounds crystallize in such order, and the separated solid is of such a character, that "the freezing point of the remaining liquid is lowered." a After one compound has separated another follows, which again lowers the freezing point, and finally a liquid is left with the lowest freezing point, and this liquid is the last compound to crystallize.

Change in temperature is the rule for underground circulating waters. The waters which are passing to lower levels are, on the average, becoming warmer. Water's which are rising to higher levels are, on the average, becoming colder. Also there are changes of temperature, both positive and negative, due to varying local conditions; for instance, the presence of intruded igneous rocks. Ascending waters are, on the whole, precipitating material, becanse they are losing heat. The increase in the capacity to hold material in solution with rising temperature, and the simply enormous increase in this capacity as the temperature becomes very high, have already been pointed out. (See pp. 79-81.) During the upward journey of the water the temperature continuously falls, and if the journey be long. the total loss of heat is great, and the amount of precipitation is correspondingly large. Since the upward course of the water is likely to be in the larger openings (see p. 583). such as the spaces of porous sandstones, faults, joints, etc., we have the partial explanation of the filling of these openings in the belt of cementation. However, this general statement needs various modifications, dependent upon many variable factors. (See pp. $629-640$.)

\section{PRECIPITATION BY REACTIONS BETIEEN AQUEOUS SOLUTIONS.}

It has already been seen that when solutions containing various salts are mixed the resultant solution will contain all the salts which can be made by the various combinations of their positive and negative ions. (See p. 68.) The first law of precipitation may be stated thus: When any combination of the various ions in a solution can form to a sufficient extent

a Nernst, W., Theoretical chemistry, translated by C. S. Palmer, Macmillan Co., New York, 1895, p. 111. 
to be insolnble in the liquid present, such componnd will be prodnced and precipitated. To illustrate, if a solntion of $\mathrm{BaCl}_{2}$ be added to a solution of $\mathrm{Na}_{2} \mathrm{SO}_{4}$, the ion $\mathrm{Ba}$ can unite with the ion $\mathrm{SO}_{4}$ and produce the insoluble compound $\mathrm{BaSO}_{4}$, which will be precipitated.

The above is a statement of the empirical facts. The explanation of these facts under the theory of dissociation is given by Ostwald as follows: In any given case there is a constant relation between the amount of a compound which can be held in solution and the number of free ions of that compomnd. Upon this statement are based the laws of precipitation from solutions. Says Ostwald:

In solutions a state of equilibrium subsists between the ions of the electrolyte and the nondissociated portion. To take the simplest possible case, if we have a binary electrolyte $\mathrm{C}$, which can break up into ions $\mathrm{A}$ and $\mathrm{B}^{\prime}$, and if $\mathrm{a}, \mathrm{b}$, and $\mathrm{c}$ represent the concentrations of these three constituents in a given solution, then the following simple formula holds good: $a b=k c$.

Now, the two kinds of ions are produced in equivalent quantities, in the above case, hence $a=b$. If, further, the total amount of the electrolyte $=1$, and $\alpha$ represents the ionized portion, then $\mathrm{a}=\mathrm{b}=\frac{\alpha}{\mathrm{v}}$ and $\mathrm{c}=\frac{1-\alpha}{\mathrm{v}}, \mathrm{v}$ being the volume of the solution in which unit quantity (a molecular weight in grammes) of the electrolyte is contained. By carrying out the substitution we get the formula $\frac{\alpha^{3}}{(1-\alpha)}=\mathrm{kv}$, which expresses the state of ionisation of an electrolyte at the dilution $\mathrm{v}{ }^{a}$

In the saturated aqueous solution of an electrolyte we have a complex equilibrium. On the one hand the solid is in equilibrium with the nonionised portion of itself which is in solution, while on the other hand this nonionised portion is in equilibrium with the dissociated part-i. e., with the ions of the same substance. The first equilibrium comes under the law of proportional concentration, or, since we are dealing here with a substance of unalterable concentration on the one hand, the concentration of the nonionised portion in the solution must have a perfectly definite value. For the second equilibrium we have in the simplest case -i. e., when the ions of the compound are monovalent $-\mathrm{ab}=\mathrm{k} \mathrm{c}, \mathrm{a}$ and $\mathrm{b}$ representing the concentrations of the ions and $\mathrm{c}$ the cuncentration of the nonionised portion.

Now, since $\mathrm{c}$ is constant at a given temperature, as we have already seen, ke, and therefore ab, must be constant also. Equilibrium is thus established between a precipitate and the liquid above it when the product of the concentrations of the two ions, into which the precipitate falls, has a definite value. This product may be termed the solubility product for the sake of brevity.

$a$ Ostwald, W., Foundations of analytical chemistry, translated by George IIcGowan, Macmillan \& Co., London, 1895 , p. 59. 
If the electrolyte consists of polyvalent ions in the proportion $\mathrm{mA}: \mathrm{nB}$, the solubility product takes the form: $\mathrm{a}^{\mathrm{m}} \mathrm{b}^{\mathrm{n}}=$ constant. ${ }^{a}$

From the foregoing follows Ostwald's statement of the first law of precipitation, already given: "Whenerer in any liquid the solubility product of a solid is exceeded, the liquid is supersaturated with respect to that solid," and therefore precipitation of the salt follows. Of the various salts which may be precipitated from a solution, that one will be precipitated first whose solubility product exceeds its constant of solubility.

Ostwald illustrates this by the cases already cited: If a solution of $\mathrm{BaCl}_{2}$ be added to $\mathrm{Na}_{2} \mathrm{SO}_{4}, \mathrm{BaSO}_{4}$ will be precipitated. According to Ostwald's view, this happens because the solubility product of the ions in $\mathrm{BaSO}_{4}$ is very small.

The second law of precipitation follows from the fact that "the solubility of one salt is depressed in the presence of another having a common ion." This is equivalent to sayng that "the solubility of each molecular species in a mixture is always smaller than for the particular species when alone." dence, when to a solution containing certain ions a solution is added which has an ion in common with one of those already in the solution, supersaturation and precipitation are promoted. An example of this is the addition of $\mathrm{HCl}$ to a solution of $\mathrm{BaCl}_{2}$. The chlorine ion is common, and if the solution is near saturation before the $\mathrm{HCl}$ is added, $\mathrm{BaCl}_{2}$ will be precipitated. Again, if one arlds a saturated solution of $\mathrm{NaClO}_{3}$ to a saturated solution of $\mathrm{KClO}_{3}$, an abundant precipitate of the latter salt will form.

The above law is a general statement which includes the rule that "The addition to a solution of a liquid which is able to form a homogeneous whole with the solution causes precipitation of more or less of the substance in solution if that substance is insoluble in the liquid which is added." rule is illustrated by the same examples. It follows from this that "in order to precipitate a substance completely from its solution, an addition of an excess of the precipitant is an advantage." $f$

The converse of the second law of precipitation is: The solubility of a salt increases on the addition of a second sail containing no ion in common.

a Ostwald, W., Foundations of analytical chemistry, translated by George McGowan, Macmillan \& Co., London, 1895 , p. 76.

$b$ Ostwald, Foundations, cit., pp. 76-77.

$c$ Nernst, W., Theoretical chemistry, translated by C. S. Palmer, Macmillan Co., New York, 1895 , p. 446.

$d$ Nemst, cit., p. 453.

e Ostwald, Solutions, p. 90.

$f$ Nernst, cit., p. 449. 
To illustrate: "If one adds some $\mathrm{KNO}_{3}$ to $\mathrm{AgBrO}_{3}$, a number of nolecules of $\mathrm{AgNO}_{3}$ and also of $\mathrm{KBrO}_{3}$ will be formed. This will result in a diminution of the number of the nolecules of $\mathrm{AgBrO}_{3}$, which must be replacer from the solid salt," or the solubility will be increased. ${ }^{a}$

Cameron gives two illustrations of this converse which are of great importance in ground solntions:

Gypsum, which is essentially the salt calcium sulphate containing some water, is sparingly soluble in water. But the addition of an electrolyte with no common ion, such as sodium chloride, will considerably increase the solubility of the gypsum. Some experiments made in this laboratory have shown that in moderately strong brines containing only sodium chloride gypsum can be regarded as a soluble salt. The reason for this is readily seen when the snbstances which are formed are considered, both the calcium chloride and the sodinm sulphate being very soluble salts. The transportation of large quantities of lime by the drainage and ground waters in arid regions where these salts are found is readily explicable from this point of view.

Calcium carbonate, so abundant and so important in nature, is dissolved in a precisely similar way; but the ionization of carbonates being relatively small, the effect is not so striking and relatively much less lime is transported in the solution. Treadwell and Renter ${ }^{b}$ have recently published investigntions on this point and find the solubility of calcium carbonate in sodium chloride solutions does not become markedly large until considerable concentrations of the latter salt are reached. The effect of curbon dioxide in forming the more soluble bicarbonate of lime undoubtedly is an important element in this connection, but as the ionization is but little affected by its presence its influence must be small in the presence of snch a salt as sodium chloride. ${ }^{c}$

PRECIPITATIOX BY REACTIONS BETWEEX AQUEOLA SOLVTIONS AND GASES.

Another case of precipitation occurring in nature follows as a result of mixing solutions, one of which is a gas which acts upon the compounds in the aqueons solution, producing ions of a different kind from those before present, and in some cases forming compounds, the solubility of which is so small that precipitation results. Perhaps the most important case of this kind is the mixing of oxygen with a solution containing salts of iron protoxide. As a result of this the irom is elanged from ferrous to ferric form, and the latter is precipitated as a sesquioxide or hydrosesquioxide of iron. In the latter case hydration occurs sinultaneously with oxidation.

" Nerust, cit., p. 450

$b$ Treadwell, F. P., and Reuter, M., Ueber die Löslichkeit der Bikarbonate des Calciums und Magnesiums: Zeitschr. für anorgan. Chemie, vol. 17, 1898, p. 170.

c Cameron, F. K., Application of the theory of solutions to the study of soils: Rept. No. 61 , Field Operations of Division of Soils, 1899, U. S. Dept. of Agric., 1900, pp. 150-151. 
PRECIPITATION BY REACTIONS BETWEEX SOLUTIONS ANI SOLIDS.

"If one pours a solution of $\mathrm{KBr}$ over solid $\mathrm{AgCl}, \ldots$ the bromine existing in the solution will be largely replaced by chlorine, because as $\mathrm{AgBr}$ is much less soluble than $\mathrm{AgCl}$ an equivalent quantity of $\mathrm{AgCl}$ will be changed into $\mathrm{AgBr}$. This is also established by experiment. If one knows the solubilities of $\mathrm{AgCl}$ and $\mathrm{AgBr}$, then for a given concentration of $\mathrm{KBr}$ we may state the point of equilibrium which the system strives to reach." " Hence we conclude that if a salt, $A$, is treated with a saturated solution of another salt, B, a greater or less part of the salt B may separate out, the salt A being taken into solntion at the same time. In this case "the active mass of the solid substance is a constant." ${ }^{b}$ The meaning of this is that if any of a solid salt is present after the reaction has ceased there was sufficient to produce equilibrium between the salt and the solution.

An excellent case illustrating precipitation from solution in nature by the action of a solid, one of the most fundamental importance, is the partial dolomitization of the calcium carbonate of shells and corals by the sea waters, which contain both calcium and magnesium salts. In this case, under the law of chemical equilibrium, there is constant action and reaction between the magnesium salts in solution and the solid $\mathrm{CaCO}_{3}$. The magnesium and calcinm partially interchange, the calcium going into solution by uniting with the ions before combined with the magnesium, and the magnesium simultaneously uniting with the $\mathrm{CO}_{3}$ ion before united with the calciun and thus being thrown down as $\mathrm{HgCO}_{3}$. Thus the calcite is partially dolomitized.

This case of dolomitization well illustrates the principle that simultaneonsly with the precipitation of one element or mineral another element or mineral may be dissolved, one being conditioned upon the other. There are very numerous complicated cases of this kind which need investigation. (See pp. 203-206.)

The solids present exert an important inflnence in precipitation independently of the passage of elements of the solids into the solutions. That is to say, if there be solids present, even if none of the elements of any of such compounds pass into solution, these solids may influence the

a Nernst, W., Theoretical chemistry, translated by C. S. Palmer, Macmillan Co., New York, 1895, p. 452 .

${ }_{b}$ Nernst, cit., p. 450 . 
nature of the precipitation. This statement is applicable both to compounds present in solutions before precipitation begins and to componnds formed by precipitation itself. Once any precipitate begins to form, particles of that precipitate are present and influence further precipitation, precisely as do other solids which were present before the precipitation began. The proof of the influence of the solids present is furnished by the very well-known tendency to the enlargement of mineral particles already existing in preference to the formation of new individuals.

The growth of mineral particles already present is probably connected with the phenomenon of adsorption, described on pages $64-65$. It is there noted that the contact film of solutions with solids contains more than an average amount of material in solution. It may be suggested that this is due to the molecular attraction of the crystal for the molecules in solution, just as the adherent film of the liquid itself is due to the molecular attraction between the solids and liquids. As the particles in solution move about they continually impinge against the solids in the solutions. These particles thus come within the limits of the molecular attraction of the solids and are to a certain extent held, and hence the concentration. It would follow that the adherent films of liquid are likely to become supersaturated in advance of the remainder of the solutions. Under these circumstances the moment supersaturation is reached with reference to the compounds forming a given particle, these materials will be deposited upon the particle, and will grow. Precipitation immediately follows supersaturation of the concentrated film because of the orienting and selecting power of the mineral particle already existing. It is probable in the case of a given mineral that for compounds other than those which can unite to produce the mineral supersaturation can take place to some extent, and that from this slightly supersaturated adherent film this material may escape into the free solution. However, when such solutions become supersaturated in the presence of a mineral which could use them they would be thrown down. By this process is explained the selective power by which each mineral particle is able to take from solution material like itself and add it to itself; and also the fact that particles once formed abstract materials like themselves from solutions in preference to the formation of new particles. ${ }^{a}$ The presence of any

a For explanation of adsorption see Ostwald, W., Grundlinien der anorganischen Chemie, Engelmann, Leipzig, 1900, pp. 387-389. 
mineral species will prevent considerable supersaturation of the solution, so far as the compounds of that species are concerned. The result is that if there be materials in a solution which can mite to produce mineral species which are present they will do so. In this way the minerals control or guide to a considerable extent the character of the solids which are deposited, since when a certain mineral is absent, before that mineral can begin to be precipitated supersaturation must occur with reference to the chemical combination which composes it.

Therefore the mineral species which are present in a solution have an adrantage orer other kinds of minerals which are absent. To a less degree, minerals which are abundantly present have an advantage over those which are sparse. 'To illustrate, if quartz be present and the solutions contain ions of silica, it will be apt to abstract the silica from the solutions the moment supersaturation occurs." In the same rray, if feldspar be present and there are ions of sodium, calcium, aluminum, and silica in proper proportions, these are likely to be grouped together to produce feldspar. Moreover, it appears to be the case that the feldspar may so nearly control that a closely analogous feldspar is produced, and twimning and other phenomena characteristic of the original grains be continued in the secondary growth. The same statements apply to hormblende, tourmaline, calcite, and, in fact, to all minerals in which a secondary growth has been moted. Of course, in a rock in which there are present a large number of mineral particles, the particular mineral which is formed will depend upon the various ions in the solution, their relative proportions, and the relative insolubility of the salts. For instance, toumaline can not form unless the boric acid ions are present; hornblende can not be produced unless there are in the solntion all the bases demanded by that mineral in sufficient abundance. Thus the particular mineral which forms depends upon a complicated adjustment of the mineral particles present, the ions present in the solution, their relative proportion, and the solubility of the mineral particles.

In the above chemical principle lies a partial explanation of the strange fact that minerals are so firmly cemented by material like the dominant original mineiral. In quartzose sandstone the chief cement is silica; in feldspathic sandstone the chief cement is likely to be feldspar; in strongly hornblendic rocks one of the chief cements is hornblende, and so on. Another 
important factor in the process is the extension of the rock masses from the places of solution to the places of deposition. For instance, in any rock which extends from the belt of weathering to the belt of cementation the water at the places of solution (especially the belt of weathering) would obtain material adapted to the enlargement of the minerals of the same rock at the place of deposition (especially the belt of cementation). Consequent upon the two factors above given, rocks in many instances are cemented by minerals like those present before cementation began.

SECTION 2. CIRCULATION AND WORK OF GROUND WATER.

UNIVERSAL PRESENCE OF WATER IN ROCKS.

It has already been explained at the opening of this chapter that water is the great dominating agent through which the greatest trans.ormations are accomplished. Free water is present to some extent in all rocks within the zone of observation. That it is abundant in porous rocks is well known. Water has also the power to slowly penetrate the apparently solid rocks. Between the mineral particles there is space sufficient for water to make its way, and a small amount of water is found in the most massive and relatively impervious rocks.

Besides the free water in rocks, there is always present water in a combined form. The combined water varies from a small fraction of 1 per cent to several per cent. Commonly the combined water does not fall below 0.50 per cent, and seldom is higher than 8 per cent. It therefore appears that all rocks contain water, both in the free and in the combined form. The amounts of each of these are very variable. Bischof many years ago noted the penetration of basalt by water. ${ }^{a}$ The permeation of apparently solid rocks by water is well illustrated by the readiness with which agate, chalcedony, and such materials are affected by a staining solution. When agates are boiled in colored solutions, the liquid makes its way through the minute subcapillary spaces so small that the microscope can not detect them, and the bands are differently tinted, the amount of deposited coloring material depending upon the relative sizes of the minute openings.

a Bischof, Gustav, Chemical and physical geology, translated by Paul and Drummond, Harrison \& Sons, London, vol. 1, 1854, p. 10. 
The water in rocks may completely or partly fill the openings. Where the openings of a rock are completely filled, the rock is saturated. Unless all the openings in a rock are snbcapillary it will remain saturated only so long as it is surrounded or partly surrounded by the saturating liquid. If withdrawn from the saturating liquid, all the water may be drawn off by ordinary physical means except that adhering to the walls of the openings. This residual amonnt of water is called the water of imbibition. The difference between the water of saturation and that of imbibition, which, as will be seen, is the water which may flow somewhat readily, nay be called the water of hygrometricity. In the rocks having subcapillary openings (see pp. 143-146) the attraction extends from wall to wall, and therefore the entire film of water in the spaces adheres to the rock particles, or is water of imbibition. In the rocks having subcapillary pores only, the water of imbibition and satmration is the same.

The next question which arises is as to the source of the ground water. On pages 661-668 reasons are given for the belief that the circulation in the zone of anamorphism, which corresponds to the zone of rock flowage, is very slow indeed. In this deep-seated zone decarbonation, dehydration, and to some extent deoxidation of the rocks take place. It is shown (see pp. 764-766) that witl these exceptions, excluding igneous rocks, the composition of the rocks metamorphosed in the zone of anamorphism closely corresponds with their original composition, contrasting greatly in this respect with the rocks metamorphosed in the zone of fracture. From these and other facts it is certain that the circulation of water in the zone of anamorphism is very slow. However, it is probable that a large portion of the carbon dioxide and water liberated slowly makes its way into the zone of fracture. It is also explained that some water may join the zone of fracture throngh the agency of igneous rocks which enter this zone. But the amount of these supplies of water at any one time is small-indeed, insignificant compared with the amount required to keep up the active circulation which we know exists in the zone of fracture. Since, then, it can not be shown that any considerable fraction of the water of circulation of the zone of fracture is derived from the zone of rock flowage, we can only suppose that this water is derived from precipitation. The subterranean water is therefore predominantly of meteoric origin. 
PORE SPACE OF ROCKS.

The pore space of rocks varies from a small fraction of 1 per cent to 50 per cent or more. The pore space in compact, strong, igneous rocks is exceedingly small. For instance, in fresh, strong granites the percentage of water absorbed by the dry rock raries from 0.08 to 0.20 per cent, which corresponds to a pore space of 0.20 to 0.50 per cent. The more compact limestones also contain very little pore space. Some of them absorb as small an amount as 0.20 per cent by weight of water, which corresponds to a pore space of about 0.55 per cent.

Ordinary compact limestones used for building material, when saturated, contain from 1 to 5 per cent of water by weight, and this corresponds to a pore space of about 2.5 to 12.5 per cent. The more porous limestones are capable of absorbing 10 per cent or more of water by weight. Sandstones are ordinarily very porous, holding from about 2 or 3 to 15 per cent of water by weight. This corresponds to a pore space of from about 5 to 28 per cent Capacity to hold about 10 per cent by weight, and therefore a pore space of about 20 per cent, is very common in sandstones. The extreme of porosity for sandstones yet reported is the Dunnville sandstone of Wisconsin, which, according to Buckley, contains a fraction more than 28 per cent of air space when dry, and therefore when saturated is capable of having 28 per cent of its volume occupied by water. According to Merrill, ${ }^{b}$ chalk may contain as much as 20 per cent by weight of water. Supposing the specific gravity of the chalk to be 2.8, this corresponds to a pore space of about 41 per cent. However, in coherent rocks, pore spaces of more than 25 per cent are rather uncommon.

In unconsolidated rocks where cementation has not taken place at all, and in products of the belt of weathering, the pore space may be even greater than the above amounts. If grains of sand are spherical, of muiform size, and "are arranged in the most compact mannel" possible, each grain will touch the surrounding grains at twelve points." ${ }^{c}$ In this case the pore space will be 25.95 per cent. ${ }^{d}$ If the particles be spherical, of niform

a Buckley, E. R., Building and ornamental stones of Wisconsin: Bull. Wisconsin Geol. and Nat. Hist. Surrey, No. 4, 1898 , p. 225.

$b$ Merrill, G. P., Rocks, rock-weathering, and soils, Macmillan Co., New York, 1897, p. 198.

$c$ Slichter, C. S., Theoretical investigation of the motion of ground waters: Nineteenth Ann. Rept. U. S. Geol. Survey, pt. 2, 1899, p. 306.

a Slichter, cit., p. 310. Becker, G. F., Geology of the quicksilver deposits of the Pacific coast: Mon. U. S. Geol. Survey, vol. 13, 1888, p. 399. 
size, and arranged "so that the lines joining their centers form cubes," a this will be the most open possible arrangement. In this case the pore space will be 47.64 per cent. ${ }^{b}$

King has made a number of experimental determinations of the pore space of unconsolidated sands, of broken rocks, and soils, the material being packed as closely as he was able to pack it. ${ }^{\circ}$ Where quartz sand comprising materials varying greatly in coarseness was used, a pore space as low as 25.43 per cent was obtained." But "well-rounded grains of nearly uniform diameter tend to give a pore space which lies between 32 and 40 per cent. * * For simple sands with angular grains the pore space is much larger than it is for the rounded sands of the same size of grains, and in the case of the crushed glass, whose grains are more angular than those of the crushed limestone, which have a tendency to be cuboidal in form, the pore space is the largest of all."

Seelheim found that clays when allowed to settle in water have a pore space of 50 to $79 \mathrm{per}$ cent, and that there is no sensible reduction of this space under a pressure of 30 meters of water. ${ }^{f}$

In clay loams and clays pore spaces as high as 48 to 52 per cent were obtained by King. ${ }^{g}$ He suggests that the ligh pore space of clays may possibly be partly explained by the angularity of the grains, it being well known that the very fine mechanical sediments are largely composed of angular particles. ${ }^{k}$

It is evident from these experimental results of King's that the grains of sands and soil are not packed by nature in the most compact manner possible; otherwise the pore spaces would run lower, rather than higher, than Slichter's minimum pore space (25.95 per cent); for the natnral grains

a. Slichter, cit., p. 308.

$b$ Slichter, cit., p. 309.

$c$ In order to get the closest packing, the material was added "in small lots at a time and gently tamped with a broad, flat-faced pestle until the vessel was filled. . . . The vessel, after being filled by tamping, was 'struck off' witl a piece of plate glass, then held firmly while with light blows the walls of the tubes were struck gently, but repeatedly, as long as any reduction in rolume conld be produced."-King, F. H., Principles and conditions of the movements of ground water: Nineteenth Ann. Rept. U. S. Geol. Survey, pt. 2, 1899, p. 208.

$t$ King, eit., p. 211.

King, cit., p. 215.

$f$ Seelheim, Zeitschr. für anal. Chemie, vol. 19, p. 387; cited in King, F. H., Principles and conditions of the movements of ground water: Nineteenth Ann. Rept. U. S. Geol. Survey, pt. 2, 1899, p. 78.

$g$ King, eit., pp. 213-215.

$h$ King, cit., pp. 217-218. 
of soil and sand are not spherical in shape, or of uniform size. In so far as the grains vary from regular forms and uniform magnitude the pore space would be less than calculated; but in so far as the method of packing is not the most compact possible the pore space would be greater than calculated. Thus these two factors neutralize each other to a considerable degree, and we are obliged to turn to experiment to ascertain approximately the facts. It is probable that King's experimental results ${ }^{a}$ on sands composed of well-rounded grains of nearly uniform diameters, where the pore space was between 32 and 40 per cent, represent approximately the original pore space in the coarser assorted mechanical sediments. The more porous sandstones, where the pore space, as ascertained by Buckley, ${ }^{b}$ varies from 18 to 28 per cent, have a crushing strength varying from 172 to 413 kilograms per square centimeter; indeed, are strong enough to serve for building stones. It is clear that a considerable amount of cementing material has been added, and that the pore space measured is nuch less than the original space in the sands before cementation. Hence it appears, both from experimental work by King and by deductions from actual measurements of the space in partially cemented sandstones, that the original pore space in clean, well-assorted sands probably varies from onefifth to as much as two-fifths, with a probable average of about one-third.

It is much more difficult to give a statement as to the average pore space of the lavas. Some of these rocks are rather dense and had originally a very small amount of pore space; others are exceedingly vesicular and originally had pore spaces amounting to 50 to 75 per cent, or even more. It is rather probable that where a succession of thin-bedded basic lavas are piled up one on the other, as in the Keweenawan of the Lake Superior region, the pore space averages as much as in ordinary sandstones; but from this maximum the average runs down as the lava flows become thicker and as they become more acid. Therefore the average pore space of the vesicular lavas is probably not more than one-third to one-half as great as in the mechanical sediments.

It is even more difficult to make an estimate of the amount of pore space due to fractures in the rocks, such as faults, joints, fissility, the open-

$a$ King, cit., pp. 147-157.

$b$ Buckley, E. R., Building and ornamental stones of Wisconsin: Bull. Wisconsin Geol. and Nat. Hist. Surv. No. 4, 1898, pp. 393-395, 402-403. 
ings of autoclastic rocks, etc. In the case of some breccias the pore space is certainly as large as in the mechanical sediments, and such breccias in some places are present in considerable volume. From this maximum amount the pore space of course varies to a fraction of 1 per cent.

I am therefore wholly mable to give any general averages of the amount of pore space, taking the world as a whole. But Shaler has estimated that the amomnt of igneous and vein material of certain regions of the New England coast is from 3 to 5 per cent of the superficial area. ${ }^{a}$ Since the volumes are as the cubes of the dimensions, if the amount of vein material were the same in other directions this would involve a filled pore space of from 0.52 to 1.12 per cent.

From the foregoing it is plain that, while it is easy to ascertain the amount of pore space in a given rock, it is very difficult indeed to make any estimate of the average amount of pore space in the zones of katamorphism and anamorphism. It is shown on pages 187-191 that these zones correspond, respectively, to the zones of fracture and flowage. It is certain that the pore space in the zone of fracture is far greater than in the zone of flowage. It is also equally certain that the pore space in the belt of weathering is vastly greater than in the belt of cementation. When these various zones and belts are discussed it will be shown that both the unconsolidated materials and the coherent rocks of the belt of weathering are exceedingly open and have a very large pore space. It will further be seen that in passing downward from the belt of weathering to the belt of cementation there is a sudden diminution in the amount of pore space available, the rocks becoming almost at once far less open. Doubtless on the average the amonut of pore space in the belt of cementation steadily diminishes from the upper to the lower part; and in the zone of anamorphism the pore space is almost certainly but a fraction of 1 per cent.

It is to be remembered that below the comparatively thin belt of weathering, the rocks, with unimportant exceptions, are saturated. Dana estimates the average amount of water contained in the rocks as 2.67 per cent of their weight. ${ }^{b}$ Supposing that the specific gravity of the crust is 2.7, this would mean a pore space of 6.89 per cent of the volume of the rocks; or, if the rocks were saturated, abont 69 . liters of water in every cubic

$a$ Shaler, N. S., The crenitic hypothesis and mountain building: Seience, vol. 11, 1888, p. 281.

${ }^{b}$ Dana, J. D., Manual of geology, American Book Co., 4th ed., 1895, pp. 205, 311. 
meter. Supposing the pore space for the upper part of the zone of fracture to be one-fifth of that suggested by Dana and to diminish to zero at the lower part of that zone, this would give an average pore space for that zone of 0.69 per cent. Supposing that the zone of fracture extends to a depth of 10,000 meters and that the pore space is saturated, the amount of contained water, if concentrated to the exclusion of rock, would make a sheet 69 meters thick, extending throughout the continental areas. This calculation is of course made upon an hypothetical basis (see pp. 569-571), but it shows that the underground water is truly a great subterranean sheet. This subterranean sheet may be compared to the blood of an organism, and the comparison has force to the degree that it is the chief medium through which the transformations of the rocks are accomplished.

CIRCULATION OF GROUND WATEl.

Subterranean water must be considered from two points of viewits circulation and its work.

The actual ground-water circulation depends upon the openings in the rocks, the forces producing water circulation, and the forces opposed to circulation.

OPENINGS IY ROCKA.

The rate and amount of flowage of water is largely dependent upon the openings in rocks. The openings in rocks in reference to flowage need to be considered from the following points of view: The form and continuity of the openings, the size of the openings, and the percentage of openings, or pore space.

FORM AND CONTINUTTY OF OPENINGS.

For a given cross section, in proportion as an opening approaches a circular form-that is, as it approaches a minimum of wall area per unit of volume-the flow increases, because the friction between the moving water and the film of fixed water upon the walls is less per unit volume. In proportion as the openings are continuons in rocks the flow increases.

The openings in rocks include (1) those which are of great length and breadth as compared with their width, and thus are essentially flat parallelopipeds; (2) those in which the dimensions of the cross sections of the openings are approximately the same, and therefore resemble tubes of various kinds; and (3) irregular openings.

MON XLVII-04-9 
(1) The openings which have great length and breadth as compared with their width are those of bedding partings, of faults, of joints, and of fissility. It is recognized that many of the fractures are exceedingly complex. They are, indeed, in many instances a series of parallel or intersecting fractures, forming a zone of brecciation. However, for such a a zone, as a whole, the statement still holds that the openings have great length and depth as compared with their width.

Bedding partings are parallel to the layers. Since ground waters very frequently follow formations, the bedding partings become important factors in the promotion of flowage parallel to the formation This is especially true of the contacts of formations of different character. These contacts are places of maximum differential movements, of consequent complex fracturing, and therefore of important openings and large cireulation.

In position the fault, joint, and fissile openings ordinarily have an important vertical element, or at least traverse the beds. Frequently they are nearly vertical, or traverse layers or formations at right angles. In consequence of this they are very important factors in the vertical movements of ground water.

As to continuity, bedding partings are likely to be the most continuons; faults come next in continuity, joints next, and fissile openings are those that are least continuous.

Bedding partings are likely to be contimuous for long distances, and because of this and their size (considered on pp. 137-138), they are frequently important factors in the flowage of ground water. ${ }^{a}$

Faults may have very great continuity. Thrust faults of 15 kilometers and more along the dip are known; and along the strike faults may extend for even hundreds of kilometers, although ordinarily their extent is much less. From their great persistence and from the fact that they are likely to cut across formations, thus frequently severing and displacing impervious stratia and consequently comecting porous strata separated by impervious strata with one another, faults are of very great consequence in the flowage of ground water.

Joints are less extensive than fanlts, but they may extend across an entire formation, or even across two or more contiguous formations. The

$a$ King, F. H., Principles and conditions of the movements of ground water: Nineteenth Ann. Rept. U. S. Geol. Survey, pt. 2, 1899, p. 126. 
extent of joints along the strike may be many kilometers. While joints are less extensive than faults, they are far more numerous. Probably their number, as compared with faults, more than compensates for their lack of extent. Joints are therefore of very great importance in the flowage of ground water. On the arerage they may be of even greater importance than faults. Joints, like faults, may comnect separated porous strata, but very frequently the joints do not pass throngh the relatively plastic separating impervious strata, and therefore in this respect are of less consequence than faults.

Fissility openings usually have less extent than bedding partings, faults, or joints; and the openings are small. While they doubtless have an important influence in water flowage, they are not of such consequence as bedding partings, faults, or joints.

(2) Openings in which the dimensions of the cross sections are approximately the same are those of the mechanical deposits, including conglomerates, sandstones, soils, tuffs, etc.

The openings of mechanical sediments have a strong tendency to a definite form, and are continuous. The forms of these openings have been fully discussed by Slichter." The openings alternately narrow and widen. At the wider parts their sections are roughly polygonal, the polygons having more than three sides, and these curved. At their narrowest places the cross sections of the openings approximate triangles, and where the grains are of equal size the triangles are equilateral. The form of the tubes at their minimum is due to the contact of three grains in a plane, the space between which is nearly triangular. (Fig. 3.)

Professor Slichter has further shown that there are various possible natural systems of packing of particles. In nature one system of packing may hold for a certain distance, and then be replaced by another system. Within any system of packing all the openings are connected with one another by straight or eurved tubes, triangular at their minimum cross section, and no opening is shut off from any other opening. Slichter has shown that in the various natural systems of packing of the particles there is at least one direction in which the tubes are straight; in other words, there is one direction in which a straight wire may be thrust without coming

a Slichter, C. S., Theoretical investigation of the motion of ground water: Nineteenth Aun. Rept. U. S. Geol. Survey, pt. 2, 1899, pp. 305-323. 
in contact with any grain. (Fig. 4.) In any other than the one direction, where the grains are naturally arranged, the tubes are ordinarily interrupted. In any case the continuity of the tubes in straight lines persists so far as the arrangement of grains is by one system of piling. Slichter has shown that the openings in the directions in which the tubes are not straight may be neglected so far as the flowage of water is concemed; he therefore concludes the quantity of flowage to be dependent upon the continuons straiglit or nearly straight tubes. These of course vary in size, but the water may be reckoned as passing through continuons tubes of the minimum size, made by the cross section between three grains arranged in a plane at right angles to the direction of the tubes. Of course it is understood that any

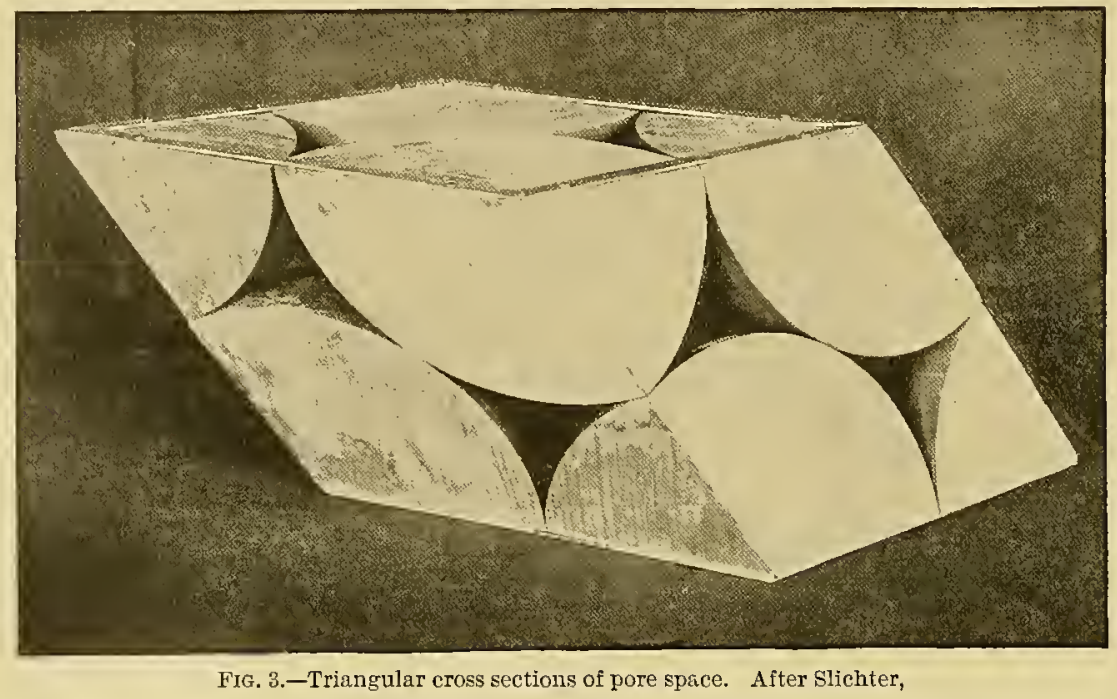

one system of arrangement does not extend indefinitely, and that where one system of packing changes into another there are, ordinarily, bends in the tubes.

Slichter further shows that the amount of space in mechanical sediments before cementation takes place is largely dependent upon the system of packing. It is also dependent upon the regularity of the grains and their variation in size. The more nearly spherical the grains and the more nearly uniform the size, the greater is the pore space.

Ordinarily the continuons tubes of mechanical sediments are limited by the boundaries of a stratum or formation. However, a porous formation may extend for hundreds of kilometers and have a thickness of hundreds 
of meters. 'This is well illustrated by the strata bearing artesian water, many of which certainly transmit great quantities of water for hundreds of kilometers. An excellent illustration of porous strata of this class is the Dakota sandstone. This sandstone yields great quantities of water along' the James River Valley, and the nearest feeding area, so far as known, is in the Black IIills, 400 kilometers distant. The volume of water which issues

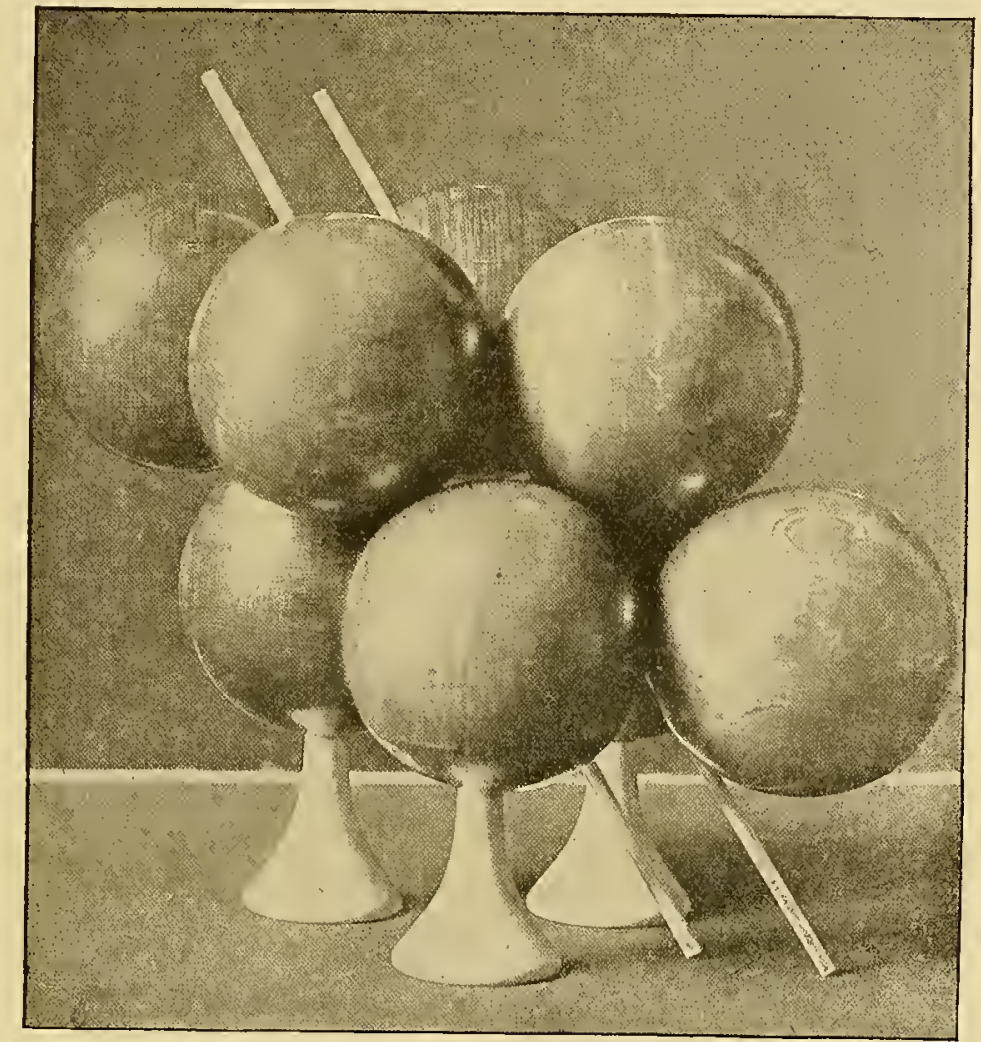

FIG. 4.-Spheres packed in the most compact manner possible, showing contiuuous openings in one direction. After slichter.

from sandstone strata in artesian basins shows how important is the class of openings under consideration.

Since the continuons openings of sediments are commonly limited to a formation, it is plain that such openings are very favorable to the flowage of water along a formation, but are less potent in the transference of water from one stratum or formation to another.

(3) Irregular openings are those of the vesicular lavas and of the 
irregular fractures of rocks. In rocks where the openings are exceedingly irregular in form the flowage of water is limited by the continnous openings, however small they may be.

Irregnlar openings may be of any form. In the lavas they are frequently spherical or ovoid. In the compact rocks they are confined to the very minute, exceedingly irregular interspaces between the mineral particles, which apparently are in perfect contact. As already seen, in the very vesicular lavas the pore space may vary from a small per cent to a very large amount, even to 75 per cent or more. The openings are more likely to be continuous where the pore space is large than where it is small. But even where the pore space is very large the openings of lavas are not nearly so continuous nor the minima of the tubes so large as in sauds. In the igneous rocks and in the rocks metamorphoserl under deep-seated conditions the openings are minute; they are controlled by the form of the grains. They are, therefore, very irregular and discontinuous.

SIZE OF OPENINGS.

The size of the openings is very important in the circulation of ground water. The size of openings must be discriminated from the amount of pore space. The amount of pore space may be the same in two cases, but in one the openings may be very few and large, and in the other very numerous and small. The flowage in the two cases, other conditions being equal, is very different. For a given mass of water the internal friction, both within the moving water and between the moving and fixed water increases very greatly as the openings decrease in size. It is, therefore, necessary to consider the varions classes of openings in reference to size.

Upon the basis of size openings in rocks may be divided into (a) openings larger than those of capillary size, or supercapillary openings; (b) capillary openings, and (c) openings smaller than those of eapillary size, or subcapillary openings.

For water, openings larger than capillary openings, according to Daniell, ${ }^{a}$ may be circular tubes which exceed $0.508 \mathrm{~mm}$. in diameter, or may be sheet openings, such as bedding partings, faults, joints, etc., the widths of which exceed one-half of this, or $0.254 \mathrm{~mm}$. To movement of water in such

a Daniell, Alfred, A text-book of the principles of physies, 3d ed., Macmillan Co., New York, 1895, pp. 315-317. 
openings the ordinary laws of hydrostatics apply. Capillary openings for water solutions include those which, if circular tubes, are smaller than $0.508 \mathrm{~mm}$. in diameter, and those which, if sheet spaces, are narrower than $0.254 \mathrm{~mm}$., and which in either case are larger than the openings in which the molecular attractions of the solid material extend across the space. Such openings in the case of circular tubes are those smaller than $0.0002 \mathrm{~mm}$. in diameter, or', if sheet passages, are below $0.0001 \mathrm{~mm}$. in width. Capillary openings, therefore, include circular tubes from 0.508 to $0.0002 \mathrm{~mm}$. in diameter, and sheet passages from 0.254 to $0.0001 \mathrm{~mm}$. in width. Capillary openings of other forms have a range limited between 0.508 and $0.0001 \mathrm{~mm}$., but no one form has so wide a range as this. To movement of water in openings sucli as these the laws of eapillary flow apply. By subcapillary openings are meant those in which the attraction of the solid molecules extends from wall to wall. These include all tubes smaller than $0.0002 \mathrm{~mm}$. in diameter, and sheet openings smaller than $0.0001 \mathrm{~mm}$. in widtl. For intermediate forms the subeapillary openings have as their maximum limit a range from 0.0002 to $0.0001 \mathrm{~mm}$.

It is not supposed that supercapillary openings, capillary openings, anci subcapillary openings are sharply separated from one another. They grade into one another, and the laws below given which control the flowage in one class of openings are gradually modified until they pass into the laws which control the flowage in another class of openings. For instance, water in circular tubes slightly larger than $0.508 \mathrm{~mm}$. in diameter would to some extent obey the laws of flowage of capillary openings, and water in tubes slightitly less than $0.508 \mathrm{~mm}$. in dianeter would to some extent obey the laws of supercapillary flow. In short, flowage in openings near the dividing line between two classes obeys laws intermediate between those controlling flowage in the typical cases of each class.

The areas of openings of variable size and similar form vary as the squares of their respective diameters. The circumferences of openings of variable size and similar form vary as their respective diameters. It follows, for a given volume of water, that the larger the openings in which it is contained the less is the surface of contact. For instance, if for an opening of any form, of given dianeter, the surface of contact for $1 \mathrm{~cm}$. of length be $1 \mathrm{sq}$. $\mathrm{cm}$., if the cross diameter be doubled, the length remaining the same, the volume of the water is four times as great, but the surface of 
contact is only twice as great. If the diameters be decreased to one-third, the volume of the water is decreased to one-ninth, but the surface of contact to one-third only.

As a consequence of the relation between size of openings and area of contact, it follows that in small openings a given volume of water is capable of performing much more work upon the rocks than in openings of larger size, for the surfaces of contact are the places where chemical interaction between the water and rock takes place. How important is the factor of small size in the amount of work which may be accomplished by ground water can be adequately comprehended only when the surface of action for a given volume of water for small openings is calculated. To illustrate, if the openings are circular tubes of a size at the border line between those of supercapillary and capillary size-that is, tubes $0.508 \mathrm{~mm}$. in diameter-1 cul. cm. of water would have a surface contact with the rocks of about 78.74 $\mathrm{sq} \mathrm{cm}$. If the openings be sheet openings at the boundary between supercapillary and capillary - that is, $0.254 \mathrm{~mm}$. in width-1 $\mathrm{cu}$. cm. of water wonld have a surface contact of about $78.74 \mathrm{sq} . \mathrm{cm}$. If the openings be circular tubes at the border line between those of capillary and subcapillary openings-that is, $0.0002 \mathrm{~mm}$. in diameter-1 cu. cm. of water would have a surface contact of about $200,000 \mathrm{sq}$. cm. If the openings be sheet openings at the border line between those of capillary and subcapillary sizethat is, have a width of $0.0001 \mathrm{~mm} .-1 \mathrm{cu}$. cm. of water wonld have a surface contact of $200,000 \mathrm{sq}$. cm. Therefore $1 \mathrm{cu}$. cm., or 1 gram of water, has a surface contact varying from 0.007874 to 20 square meters in circular capillary tubes; and in sheet passages has a surface contact rarying from 0.007874 to 20 square meters. It has been calculated by Whitney that "the grains in a cubic foot of soil have, on the arerage, no less than 50,000 square feet of surface area." ${ }^{a}$ The magnitude of these numbers shows how important a factor in the work of a given volume of ground water is the size of the openings in which the water is contained.

It follows from the above relations that the area of contact, and therefore the friction between moving water and the fixed film of water adherent to the walls, is inversely as the size of the openings. As will be

a Whitney, Milton, The physical principles of soils in their relations to moisture and crop distribution: Bull. Weather Bureau No. 4, U. S. Dept. of Agric., 1892, p. 14. 
seen, this is a matter of controlling consequence in flowage in small and especially in very small openings.

supercapillary openings. - The flowage of water through supercapillary tubes is controlled by the ordinary laws of hydrokinetics. Ignoring friction, the flowage of water is as the square root of the pressure or head. If $\mathrm{V}=$ velocity, $\mathrm{H}=$ head, and $\mathrm{G}=$ force of gravity, then $\mathrm{V}$ per second $=\sqrt{2 \mathrm{GH}}$. For instance, the velocity resulting from a pressure of 1 atmosphere or a head of $1033.3 \mathrm{~cm}$. would be the square root of $2 \times 981 \times$ $1033.3=1423.8$ cni per second. ${ }^{a}$

This formula is only approximately correct, for the interual friction in supercapillary tubes is dependent upon the viscosity of the solutions, upon the regularity of the openings, upon their length and size, and upon the velocity of flowage. If the openings be not straight, or vary in size, or both, eddies form, which increase the internal friction and decrease the speed of movement. The friction between the moving liquid and that fixed to the walls increases with increase of length, with decrease of size, with ronghness of surface, and with increase in relocity. If the arailable area be great and the movement consequently very slow, the resistance per mit of length due to friction becomes so small as to be almost inappreciable. But even if the openings be large and continuous the formula gives somewhat too high results. If the flow be rapid in long, rough, irregular underground passages, the resistance is sc great as to make the formula above given inapplicable.

Supercapillary openings include the greater number of bedding partings, fault epenings, joint openings, some of the openings of fissility, and the openings in the coarser mechanical sediments, such as coarse sandstones and conglomerates. The distance from an angle to the opposite side of the roughly triangular tubes (fig. 3, p. 132) in sandstones composed of spherical grains of equal size, which average $3 \mathrm{~mm}$. in diameter, somewhat exceeds $0.508 \mathrm{~mm}^{b}$ The average diameter of the pores in the system of closest packing is 43 per cent greater than the minimum section of the triangular pores. $^{c}$ It therefore follows that a sediment composed of grains just large

a Daniell, Alfred, A text-book of the principles of physics, 3d ed., Macmillan Co., New York, 1895, p. 303.

$b$ Slichter, C. S., Theoretical investigation of the motion of ground water: Nineteenth Ann. Rept. U. S. Geol. Survey, pt. 2, 1S99, p. 316.

$c$ Slichter, cit., p. 317 . 
enough to make the pores capillary at the smallest section have supercapillary pores in other parts of the section. ilence, it may be said that sandstones and conglomerates the grains of which exceed $3 \mathrm{~mm}$. in diameter have tubes which are greater than those of capillary size. But the grains in the great majority of sandstones average less than $3 \mathrm{~mm}$. in diameter, and hence the pore openings in sandstones are for the most part capillary, and are considered under the next heading.

It is through openings exceeding those of capillary size-that is, circular tubes larger than $0.508 \mathrm{~mm}$. in diameter and sheet openings greater than $0.254 \mathrm{~mm}$. in diameter-that the rapid circulation of underground water is accomplished. For instance, the openings through which springs of large size issue mainly exceed those of eapillary dimensions.

Capillary openings.—Capillary openings inelude the great majority of the openings of sands and sandstones, many of the openings of fine conglomerates, many of the openings of porous lavas, and many of the openings produced by fracture. As already noted, the superior limit of size of grains of sands and sandstones composed of grains of uniform size, the smallest openings of which are capillary, is $3 \mathrm{~mm}$. in diameter. The inferior limit of size are grains, the diameters of which are six times the maximum diameter of subcapillary tubes, or $0.0012 \mathrm{~mm}$. The majority of the particles of most clays, shales, and slates are much smaller than this, and therefore the openings of these rocks are subcapillary. Hence capillary openings in meehanical sediments range from very fine sands to very coarse sands. Many of the openings of fissility are capillary; but the majority of bedding partings, fault openings, and joint openings are partly supereapillary, although often the walls of such fractures are so close together as to make even these openings eapillary in part.

In eapillary openings the resistance to flow increases very rapidly as a tube diminishes in size. This is due to the fact, already explained, that the area of contact between the moving liquid and that fixed to the wall increases inversely as the size of the openings. Indeed, the friction between the moving and the fixed liquid becomes the dominant factor in the resistance to flowage in eapillary tubes. As openings decrease in size, at the diameter at which this factor controls for a given liquid the openings become of capillary size for that liquid. 
According to Poisenille, the general formula for the flow through a tube of circular section is

$$
f=\frac{\pi a^{4} p}{8 \mu l}
$$

in which $f$ is the discharge in cubic centimeters per second, $a$ is the radius of the tube, $l$ its length, $p$ is the difference in pressure at its ends in dynes per square centimeter, and $\mu$ is the coefficient of viscosity of the liquid. ${ }^{a}$ According to Slichter, "if $A$ is the area of cross section, this formula may be written

$$
f=\frac{A^{2} p}{8 \pi \mu l}
$$

and the mean velocity of the fluid in the tube is given by

$$
v=\frac{p A}{8 \pi \mu l}=(0.03979) \frac{p A}{\mu l} " a
$$

In a triangular tube the flow per second is represented by the formula

$$
f=\frac{p A^{2}}{20 \sqrt{3 \mu l}}
$$

and the velocity by the formula

$$
v=(0.02887) \frac{p A}{\mu l}
$$

"The mean velocity for a circular tube of equivalent area of cross section was found to be about 38 per cent more." ${ }^{b}$. Slichter finds the volume and velocity of flow in an elliptical cylinder to vary but slightly from that of a circular tube. "Even an eccentricity of 0.866 will change the flow by but 10 per cent, and an eccentricity of one-half will reduce the flow by about one-half of 1 per cent. Thus it is clear that a slight change in the shape of the cross section of a tube will change but slightly the flow through it. Analogy warrants us in extending this truth to tubes having other than elliptical sections. For example, we may conclude that the flow through a tube whose section is an oblique triangle is given approximately by the formula for a tube whose section is an equilateral triangle of the same area, even though the shape of the section of the given tube differs slightly, or even materially, from that of an equilateral triangle." ${ }^{\text {"b }}$ Further-

a Slichter, C. S., Theoretical investigation of the motion of ground water: Nineteenth Ann. Rept. U. S. Geol. Survey, pt. 2, 1899, p. 317.

$b$ Slichter, cit, p. 319. 
more, in capillary tubes "the relocity of flow through a tube of variable section will be less than the velocity of flow through a tube having a uniform section equal to the mean section of the first tube, because of the viscosity or internal friction of the expanding or contracting stream."

Daniell expresses a part of the laws of eapillary flow in words, instead of in a formula, as follows: "The flow in capillary tubes is proportional not to the square, but to the fourth power of the radins; the velocity is proportional not to the square root of the pressure, but to the pressure itself. The resistance in capillary tubes varies directly as the velocity; in wide tubes approximately as the square of the velocity. This seems discrepant; but it is due to the formation of eddies in the wider tubes; in a capillary tube the flow is steady."

From the foregoing it follows that the flow in a tube with a radius one-fifth millimeter in diameter is sixteen times as great as in a tube one-tenth millimeter in diameter. Furthermore, in a tube of any definite length, if the pressure be doubled the flow is doubled; if trebled the flow is trebled, etc. Howerer, experimental work by King upon the flowage of water through capillary openings of sandstones and sands gave results showing that under the conditions in which he performer his experiments the flowage increased faster than the pressure. The pressure in the experiments varied from a small fraction of an atmosphere to somewhat more than an atmosphere. The departure from Poiseuille's law varied from less than 1 per cent to more than 50 per cent. ${ }^{c}$ In the experiments the departures seemed to be greater, on the arerage, when rery low pressures were used than when moderate pressures were used. The very variable results may be partly explained by the conditions under which the experiments were performed, but it is entirely possible that the departures are partly to be explained by the relative importance of internal friction dne to viscosity when the rates of movements are slow. (See pp. 141-143.)

Also, according to Poisenille's law, the flowage is inversely as the viscosity. When it is remembered that the viscosity of water decreases rapidly with increase of temperature, it is seen that this is a very important

a Slichter, C. S., Theoretical investigation of the motion of ground water: Nineteenth Ann. Rept. U. S. Geol. Survey, pt. 2, 1899, p. 320.

$b$ Daniell, Alfred, A text-book of the principles of physics, 3d ed., Macmillan Co., New York, 1895 , p. 316.

c King, F. H., Principles and conditions of movements of ground water: Nineteenth Ann. Rept. U. S. Geol. Survey, pt. 2, 1899, pp. 135-157. 
factor. The relative viscosity of water at varions temperatures below $100^{\circ} \mathrm{C}$. is as follows:

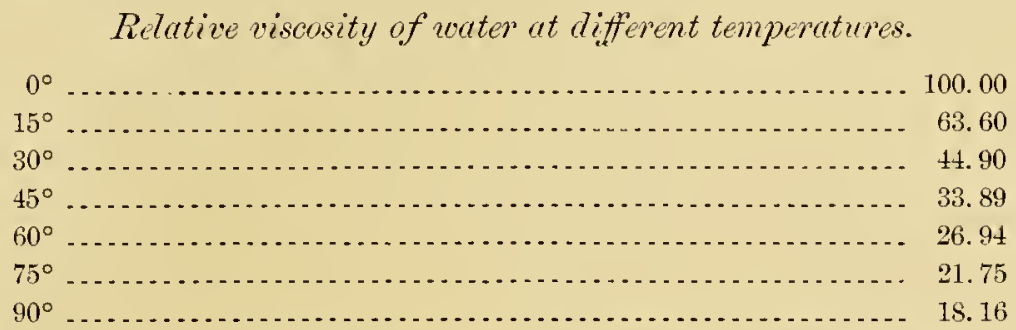

From this table it appears that the viscosity of water at $45^{\circ} \mathrm{C}$. is about one-third its viscosity at $0^{\circ} \mathrm{C}$; ; at $90^{\circ} \mathrm{C}$., less than one-fifth as great as at $0^{\circ} \mathrm{C}$. It therefore follows that temperature is a factor of the greatest importance in the flowage of water through capillary openings in the lithosphere. It is shown (pp. 138, 145-146) that the openings in the lithosphere are largely those of capillary or subcapillary size; hence the importance of the temperature elesnent.

Another factor entering into the flowage of ground water is the influence of the meniscus where the openings are not fully occupied by water. Wolff ${ }^{b}$ has shown that if water be introduced into an empty capillary tube, the meniseus in advance of the column is an important retarding influence, and consequently that the movement is slower than under circumstances where there is no meniscus. This influence is likely to be important in many cases in the belt of weathering, where partial filling is the rule, but is probably of little consequence in the belt of cementation below the level of ground water, where saturation is the rule.

In conclusion, it should be fully understood that the laws of capillary flow, as developed by Poiseuille and others, involve rather rapid movement through the capillary openings. It has already been stated that viscosity of the solutions and friction between the moving and the fixed water are the determinative factors in reference to capillary flow. It is highly probable that where the movements are very slow the friction is minute or inappreciable and that the consequent departures from Poisenille's laws are very great. Apparently in the exceedingly slow movements of many of

"Landolt and Bornstein Tabellen, 1894, p. 28s; supplemented by experimental data furnished by Mr. C. F. Bowen.

$b$ Wolff, H. C., The unsteady motion of riscous liquids: Trans. Wisconsin Acarl. Sei., Arts, and Letters, vol. 12, pt. 2, 1900, pp. 552-553. 
the larger masses of ground water the viscosity of water and the friction becomes almost zero per unit area. Evidence of this is furnished by the fact that artesian water flowing through rocks for hundreds of kilometers, the openings of which are capillary, may have nearly the full pressure due to head. For instance, the artesian water adjacent to Lake Michigan at Chicago at the early wells, before they became so numerous as to interfere when allowed to flow, had a head of 30 meters above the surface, and the feeding area is only about 80 meters above Chicago; ${ }^{a}$ yet the water has traveled underground from 150 to 250 kilometers. The resistance causing the loss of head of 50 meters is to be distributed throngh this distance; therefore the friction per meter must have approached an infinitesinal amount. The same thing is again finely illustrated by the artesian wells of the James River Valley of Sonth Dakota. The water of these wells must have traveled at least from the eastern border of the Black Hills, 400 kilometers. The eleration at the source is 1,500 meters and at the James River 500 meters. The consequent loss of head of considerably less than 1,000 meters is due to resistance throngh the entire distance, and again must be almost immeasurably small per meter. ${ }^{b}$ In all such instances the average movement is exceedingly slow, for it will be shown that to accomplish the first of the above journeys more than a century was perhaps required, and for the second possibly centuries were necessary. (See pp. 585-586.)

But the moment the speed of movement becomes appreciable the resistance promptly runs up. This is shown by the very slow fall of a slanting water table in sands as the result of lateral flowage. The best illustration of this of which I know is that kindly furuished me by J. B. Lippincott, city engineer, of Los Angeles, Cal. The Los Angeles River is mainly fed by ground waters derived from granitic and other sands which are of moderate coarseness, but the openings of which are capillary. The water table rises from the headwaters of the river to a point nortl of Fernando-about 16.1 kilometers-from a little more than 180 meters to a little more than 330 meters, or 9.3 meters per kilometer. Mr. Lippinentt says that from 1896 to 1900 , inclusive, five years, there was practically no rainfall, and

a Leverett, Frank, The water resources of Illinois: Seventeenth Ann. Rept. U. S. Geol. Survey, pt. 2, 1896, pp. 805-806, 811 .

$b$ Darton, N. H., Artesian waters of the Dakotas: Seventeenth Ann. Rept. U. S. Geol. Survey, pt. 2, 1896, pp. 665-670, pl. lxx. 
therefore no addition to the ground waters During that time the water table fell in the granitic sand, on an average, at the rate of 0.38 meter per kilometer per annum. This fall of water during these years in the granitic sands alone, Mr. Lippincott says, is sufficient to account for the entire discharge of the Los Angeles River. A head of 9.4 meters per kilometer in large channels where friction is small would result in the outpouring of the great quantity of water held in the gravels into the Los Angeles River in a very short time. But the openings in the sands are capillary, and the resistance due to friction and to viscosity is such that the watel was very slowly delivered to the river under a head of 9.4 meters per kilometer, the average fall being, as explained, 0.38 meters per kilometer per annum.

Hovement as slow as this must be rapid as compared with the exceedingly slow movement of the ground water in the artesian basins referred to. It follows from these illustrations that the ordinary rates of movement in the belt of cementation are very much slower than were the morements under the conditions in which Poiseuille, King, and others carried on their experiments. It is plain that the laws derived from experiments as given by Poiseuille and King in reference to capillary flow are only rery partially applicable to movements of ground water; indeed, their application is probably limited to the somewhat rapid movements of the water in the capillary tubes above the level of ground water in the belt of weathering where gravity has its full effectiveness, and adjacent to large openings, either natural or artificial.

subcapillary openings.-By subcapillary openings, as already explained, are meant openings smaller than capillary openings. In subcapillary openings the attraction of the solid molecules extends from wall to wall, and therefore in these openings the water is wholly that of the films attached to the walls by molecular attraction. There is no free water, in the sense that the molecules are free to move among themselres, resisted only by the riscosity of the fluid. The ratio of the resistance to movement of water thus attached as films to solids is almost infinitely great as compared with that of free molecules. Water thus attached is as if glued to the walls.

Quincke has determined that the attractive inflnence of glass upon a fluid extends through a silver film $0.00005 \mathrm{~mm}$. thick; or; stated in another way, he finds that the distance through which molecular attraction acts is 
in general $0.00005 \mathrm{~mm} .^{a}$ Platean made the distance through which molecular attraction acts $\frac{1}{17000} \mathrm{~mm} .{ }^{b}$ which amount is slightly greater than Quincke's determination. Since each wall holds a film of water, sheet passages below $0.0001 \mathrm{~mm}$. in diameter are subcapillary. The maximum size for the subcapillary circular openings is twice as great, or $0.0002 \mathrm{~mm}$. in diameter.

The laws of flowage of water through tubes of such small size have not been investigated, so far as I am aware. However, npon theoretical grounds one wotild expect that the flow would be exceedingly, indeed indefinitely, slow even as compared with flow in capillary tubes. This anticipation is fully justified by the observed facts of geology. It is well known that natnral oil and gas may be held in anticlinal arches and domes for long periods of time, even when under great pressure. It is certain in these cases that the escape of oil, or even gas, through the subcapillary openings of the shales is slower than the manufacture of these products in nature's laboratory. The facts as to the retention of oil and gas under shale roofs render it highly probable that flow in subcapillary openings is so slow as to be inappreciable during the time through which an experiment is ordinarily continued; but the flow in subcapillary openings during geological periods is probably of great consequence. (See pp. 892-904.)

It may be anticipated that the slow movement of water in subcapillary openings is greatly influenced by change of temperature. At high temperatures the viscosity of water is an important element in flow, and this rapidly decreases with increasing temperature. That water gas does not obey the law of flow of liquids in subcapillary tubes is shown by the experiment of Daubrée, ${ }^{c}$ in which the vapor of water at a temperature of $160^{\circ} \mathrm{C}$, ind consequently at a pressure of 6 atmospheres, passed through a layer of apparently solid rock $2 \mathrm{~cm}$. in thickness, and gave a pressure on the other side of 1.9 atmospheres. This experiment shows beyond all question that water gas under high pressure and temperature does not adhere to the walls strongly, and has such a small viscosity that it slowly but surely passes throngh subcapillary openings. However, ground water at all temperatures below the critical temperature under ordinary conditions

a Quincke, M., Ueber die Entfernung in welcher die Molecularkrafte der Capillaritat noch wirksam sind: Poggendorif, Annalen, vol. 138, p. 402.

$b$ Plateau, J., Statique des liquides, vol. 1, 1873, p. 210.

¿Daubrée, A., Géologie expérimentale, Paris, 1879, vol. 1, pp. 236-238. 
is held by the pressure in the form of a liquid. But at temperatures higher than $365^{\circ} \mathrm{C}$, or the critical temperature of water, whatever the pressure, the water is in the form of water gas. In this case it may be supposed to have a much greater penetrating power than in the form of liquid, since it can not be considered as adhering to the walls of the openings.

Even if subcapillary openings be rery small and the flow very slow, it does not follow that the water within these minute openings is not an agent through which important geolngical work is accomplished. The water in such spaces is capable of taking into solntion the substances with which it is in contact, of depositing material from solution, of reacting upon the substances by hydration; in short, is capable of performing all the transformations which freely moving water is able to accomplish. Indeed, it has already been seen that all transfers of material between water and rock must take place througl the fixed films of water. (See p. 64.) The transfer of material in subcapillary openings is confined to short distances because there is no free circulating water. The interchanges of material are probably slow, except between adjacent or nearly adjacent mineral particles; therefore it seems highly probable that a given volume of water in the subcapillary openings is far more effective in transforming rocks than an equivalent volume in larger openings. The same reasoning applies here as in the case of the capillary openings as compared with supercapillary openings. The surface of action per unit volume in the subcapillary tubes is vastly greater than in larger openings. As shown on pages 686-698, the above conclusion as to the efficacy of water in subcapillary openings is fully justified by the facts. It is there seen that the ninute amount of water contained in the subcapillary openings is the nedinm throngh which the complete transformation of rocks to schists and gneisses has been accomplished. I therefore conclude that, while it is probable that the actual flow of water and transfer of material in subcapillary openings is comparatively slow, it is certain that most profound alterations of rocks take place through this water as the agent of transformation.

Subcapillary openings include the openings of mechanical sediments the particles of which, if spherical and of uniform size, are not greater than $00012 \mathrm{~mm}$. in diameter. As a matter of fact, many of the openings in HON XLVII-04-10 
which a portion of the particles are larger than this have subcapillary openings, since the larger openings are occupied by grains as small as or smaller than the above dimensions. The great majority of the clays, shales, and slates are largely composed of particles smaller than 0.0012 $\mathrm{mm}$. in diameter and their openings are subcapillary. Minute openings between the grains of the igneans rocks and of the rocks metamorphosed to schists and gneisses are also nsually subcapillary. Where practically all of the openings are subcapillary, whether they be the openings of sedimentary, igneons, or metamorphic rocks, such rocks constitnte practically impervious strata; for the contained water is in fixed films held by molecular attraction, and the circulation, as already explained, is so slow as to be negligible during short time intervals.

PERCENTAGE OF OPENINGS, OR PORE SPACE.

The percentage of openings in the rocks, or the pore space, is a function of the number and the size of the openings. In so far as the openings in rocks are large and numerons, there is a large pore space. It has already been seen (pp. 124-129) that the absolnte amount of openings in rocks, as shown by observation, varies from a small fraction of 1 per cent to over 50 per cent. 'The larger the pore space the more favorable the conditions for circulation, but since the variation in pore space is so great it is evident that the flowage of water dependent upon porosity is very variable. Water passes readily through rocks which contain much pore space; water does not flow to an appreciable extent throngh rocks which have a small fraction of 1 per cent of pore space. Other factors being the same, and the pore space of the same character, the flowage is in direct ratio to the amount of pore space.

FORCES PRODUCING WATER CIRCULATION.

The forces producing circulation of ground water are gravity, heat, mechanical action, molecular attraction, and vegetation. The dominant force, upon which the movement of ground water mainly depends, is gravitative stress.

Gravity.-Gravity ever tends to pull the water downward. And this never-ceasing force at work throughout the zone of water circulation, on the average continuonsly carries the circulating water to lower levels. This condition of affairs is analogous to the work of gravity in earth movements. ${ }^{\alpha}$

a Van Hise, C. R., Earth movements: Trans. Wisconsin Acad. Sci., Arts, and Letters, vol. 11., 1898, pp. $465-516$. 
But in earth movements and water circulation alike, all the elements of the movement must be taken into account. The downward movement of a greater mass of earth or water may result in the upward movement of a lesser mass. The upward movements of water dependent upon downward movements of other water are of relatively greater importance in the water circulation than are the upward movements of rocks consequent upon downward movements of larger masses of material in earth movements.

Indeed, it will be seen that commonly the circulation of a system of ground water in the belt of cementation involves both dowuward-moving and upward-moving masses. In such systems of ground-water circulation gravity is effective in the movement in proportion to the hear. Head is due to the fact that the water entering the ground at a certain level, after a short or long underground journey, issues at a lower level.

Also where there is a difference in the density of the two colnmns due to difference in the amount of material held in solntion, gravity promotes circulation independently of head, the column holding more salts being pulled down and the lighter column driven upward. Probably the amount of material in solution is usually not so great as to make this an important factor in the process, but in salt regions it may be important. The density of the water of the sea as compared with fresh water is 1.02765 to $1.02795,{ }^{a}$ and the density of a saturated solution of sodium chloride at $4^{\circ} \mathrm{C}$., as experimentally determined by Mr. S. H. Ball, is 1.2063 . Of course in actual cases such differences as these are not found, for both columns are sure to have salts in solution; but where springs empty under the sea the first case is approached. In such instances, the increased density of the sea water opposes the head of the lighter stream of relatively pure water.

Heat.-Change in temperature may result in the expansion and contraction of water, and such changes in volume necessarily involve some movement. The volume of water varies as the temperature. Taking the volume of water at $4^{\circ} \mathrm{C}$. as 1 , its volume at $50^{\circ} \mathrm{C}$. is 1.0120 , at $75^{\circ} \mathrm{C}$. is 1.0258 , and at $100^{\circ} \mathrm{C}$. is $1.0432 .^{b}$ Therefore the increase in the temperature of undergromnd water may increase its volume and lessen its density as much as 4 per cent without exceeding its boiling point at atmospheric pressure, and a difference in the density of two columns by 1 per

a Bischof, Gustar, Elements of chemical and physical geology, translated by Paul and Drummond, Harrison \& Sons, London, vol. 1, 1854, p. 97.

$b$ Austin, L. W., and Thwing, C. B., Exercises in physical measurements, Allyn \& Bacon, Boston, 1895 , p. 151. 
cent or more is probably not uncommon. Decrease in temperature may correspondingly increase the density of water.

Gravity and heat.-While change of temperature necessarily involves some movement, its chief effect in water cireulation is as a force subordinate to gravity. In so far as water in a connected descending and ascending system is warmer at its point of issuance than it was when it joined the sea of underground water, this gives gravity an effect in circulation in the same direction as head. This is consequent upon the fact, noted above, that the density of water varies inversely with the temperature.

It is therefore evident that in columns of water of equal length the stress of gravity is greater upon the column having the lower temperature. That the diffence in gravitative stress due to difference in temperature may be sufficient to produce rapid circulation in pipes that are supercapillary is shown by the use of the principle in the hot-water system of heating buildings. Underground, as in the hot-water system of heating, heat is the energy which causes the water to expand, and gives a difference in density. When heat has produced a difference in density of the two columns, gravity is the force which inaugurates and maintains the circulation.

It is believed that underground circulation may be promoted to an important extent by difference in temperature of the descending and ascending columns of water, resulting from heat abstracted from the rocks due wholly to their normal increment of temperature with depth. Later it will be show that the downward-moving water is ordinarily dispersed in many small openings and moves relatively slowly; therefore it may be supposed at any given place to have approximately the temperature of the rocks. The upward movement of water, on the contrary, is shown to be usually in the larger openings and relatively rapid; therefore at any given place its temperature is probably higher than is normal for the rocks at that deptl. The result is a difference in temperature between the descending and ascending columns, the ascending colnmn being the warmer.

In regions where volcanism, or mechanical action, or both, have recently occurred, the difference in density resulting from difference in temperature between the descending and ascending columns is likely to be a much more important influence in the circulation of the ground waters than in regions where the difference in temperature is due to the normal heat of the rocks. Such a region is the Yellowstone Park. 
In some countries the issning waters throughout great regions are very clearly at a higher temperature than the entering waters, and in such regions the difference in temperature must be a very important factor in the underground circulation. In such cases the difference in temperature between descending and ascending waters generally results from a combination of the normal increase of temperature due to depth, from regional volcanism, and from the rocks having a higher temperature than normal becanse of recent orogenic movements. An excellent illustration of such regions is the Cordilleran region of western United States. (See pp. 591592.)

As alreády noted, the expansion of water with increase of temperature is considerable, amounting to over 4 per cent betveen $0^{\circ}$ and $100^{\circ} \mathrm{C}$; that is, a given mass of water occupies a volume 4 per cent greater at the latter than at the former temperature. In other words, if there be an average difference of $100^{\circ} \mathrm{C}$. between the ascending and descending columns, 100 meters of the downward-moving water balances 104 meters of the upward-moving water. If we suppose the descending and ascending columns to be connected, of equal height, and having an average difference in temperature of $100^{\circ} \mathrm{C}$, this would be equivalent to a head of 4 meters per 100 meters for the entire height of the column. Probably the difference in temperature between two columns is not often so great as $100^{\circ} \mathrm{C}$., but if it be sufficient to give a difference in density of 1 per cent, and the ascending and descending columns be the same length, this is ample to give a stress sufficient to orercome friction and viseosity, and give a decided movement to ground water. As an illustration of the principle may be mentioned the water power of the sea mills of Cephalonia, which, according to the Crosbys, is wholly due to difference in temperature between the descending and ascending waters. ${ }^{a}$

Mechanical action.-A third force influencing ground-water cirenlation is mechanical action. Earth movements may close or partly close the openings in the rocks, and in this process squeeze out the water, as in the production of the schists and gneisses from the sedimentary rocks. If the deformation of the rocks be referred to their ultimate canse, gravity, even the circulation of the water resulting from deformation is indirectly due to the stress of gravity.

a Crosby, W. F., and Crosby, W. O., The sea mills of Cephalonia: Tech. Quar., rol. 9, 1896, pp. 6-23. 
Molecular attraction.-The fourth force affecting the movement of ground water is molecular attraction. This attractive force works between the particles of water themselves (cohesion) and between the particles of water and rock (adhesion).

As a result of molecular attraction water may rise against gravity in capillary or hair-like openings, thus saturating the rocks at higher altitudes than it would were it not for this cause; it may creep along the walls of the openings of rocks without extending from wall to wall, and therefore without saturating the rocks.

The rise of water when it fills capillary openings raises the free surface of water above the normal level. This rise of the free surface is explained by the attraction between the water and the walls, and the attraction of the molecules of water for one another. The strong attraction between the surfaces of mineral grains and water has already been alluded to. As a result of this, water tends to rise along a wall or tube. This is dependent upon the fact that there is greater attraction between the molecules of rock and water (adhesion) than between the molecules of water themselves (cohesion). However, the molecular attraction between the particles of water is very great. The strength of the surface tension of a film of pure water is dependent upon cohesion, and is 81.96173 dynes per square centimeter. ${ }^{a}$ When a molecule is surrounded on all sides by free water the attractions in the various directions equalize one another, and so particles are comparatively free to move However, at the surface the upward component of the attraction is zero; hence there is effective tangential and downward attraction. The rise of the water along the walls is due to adhesion. As a result of this attraction a film of water is drawn along the walls. Because of the attraction of cohesion the film of adherent water draws up the next row of molecules away from the walls; these molecules in turn exert an attractive force on the next adjacent molecules, and so on. The attractive force of the surface film of water for the water below draws up the molecules constituting it; this in turn acts upon the film below, and so on. The total effect of the molecular attraction between the walls and

a Daniell, Alfred, A text-book of the principles of physics, 3d ed., Macmillan Co., New York, 1895, pp. 271-279. Ostwald, W., Outlines of general chemistry, translated by James Walker, 3d ed., Macmillan Co., New York, 1895, pp. 107-111. Barker, Geo. F., Physics, Holt \& Co., New York, 1892, pp. 200-211. 
the water and the molecular attraction between the particles of water is to produce an elevation above the normal surface of the water, the upper surface of which is of a shape as though it were an elastic membrane adhering to the walls and being stretched by the weight of the water above the ordinary lerel below.

The height to which water rises above this natnral level is indirectly as the dianeter of the capillary openings. In circular glass tubes $1 \mathrm{~mm}$. in diameter, at $20^{\circ} \mathrm{C}$., pure water rises $3.32 \mathrm{~cm}^{\circ}$ Between plates $1 \mathrm{~mm}$. apart it rises half of this amount. Since the height is inversely as the diameters of the openings, in circular tubes $0.01 \mathrm{~mm}$. in diameter, the height in tubes wonld be $3.32 \mathrm{~m}$. and in sheet openings $1.66 \mathrm{~m}$.

In circular tubes $0.001 \mathrm{~mm}$. in diameter the height in tubes would be $33.2 \mathrm{~m}$., and in sheet openings $16.6 \mathrm{~m}$; and in circular tubes $0.0002 \mathrm{~mm}$. in diameter-that is, openings of a size intermediate between subcapillary and capillary - the water would rise to a height of $166 \mathrm{~m}$., and in sheet openings $83 \mathrm{~m}$. Since many rocks have openings as small as or even smaller than this, capillary attraction may be very important in the position of the ground-water level. (See pp 411-412.) If the openings are inclined the lengths of the openings thus filled are correspondingly great.

The height to which the water rises is independent of the character of the walls, provided the walls are wetted, ${ }^{b}$ and hence the above numbers are applicable to rocks. However, the height to which the water rises diminishes as the temperature increases; hence, the above numbers should be moditied somewhat as the top of the sea of ground water has a temperature below or above a temperature of $20^{\circ} \mathrm{C}$. Ordinarily this modification is of minor importance.

Above the level to which the water may be raised as a continuous. sheet in the capillary openings, the water may still creep along the walls of the openings without filling them. The obstinacy with which a film of water holds to the rock surface has already been explained. This water is that of imbibition ( $p .124$ ). In proportion as the rvater of imbibition varies in amount the water under molecular attraction creeps from areas of greater humidity to areas of less humidity. To the rise of the free surface due to capillarity there is a definite limit; there is no limit to the creep of water along the walls. It is presumable, however, that such movement is rela- 
tively slow, and that the anount of water which is thus transferred for a given surface is small. But in the soils very large surfaces are available for creep, and therefore this process is a very important one, especially in connection with plant growth. The process is one which especially pertains to the belt of weathering and is therefore later considered. (See pp. 412-423.)

The rise of the free surface of ground water abore the normal level saturating the rocks, the creep of water along the walls without saturation, and the flowage of water through small tubes where there is no free surface are generally described under the term eapillarity. However, it is evident that under the term thus used are included three very different things. 'The principles involved in the flow of water through capillary tubes are very different from those which control the free surface of ground water in capillary tubes, and these laws again are different from those which control the creep of water along the walls of openings.

vegetation. - The roots of plants absorb ground water and transport it to the surface. The absorption of water by plant roots canses a relative deficieney of water. This deficiency is remedied by the morement of water from other places toward the roots by the forces already considered. But the influence of roots upon the flow of ground water mainly concerns the belt of weathering. The subject is therefore later considered. (See pp. $417,422-423$.)

General statements.-In conclusion, it may be said that the immediate cause of movements of ground water are five-gravity, heat, mechanical action, molecular attraction, and regetation.

So far as the forces are concerned, the vertical component of the movements of ground water is of far the greatest importance.

But whatever the canse of the flow of ground water, the direction of movement is from places of greater pressure to places of less pressure. A current going in any direction is evidence of an excess of pressure in the rear of the current. Thus water which enters by seepage or through capillary tubes into a larger opening, such as a fissure, must be under greater pressure than the column of water into which it makes its way. Whether the motive force in the morement of the water be difference in gravitative stress or temperature, or any other canse, the excess of pressure resulting in movement is behind the current. 
TIE FACTOR OPPOSIX(i WATER CIRCLLATIOX.

The factor opposing water circulation is internal friction of the water. The internal friction is dependent upon the viscosity of the solutions. The elements entering into viscosity are the concentration of the solutions and the temperature. 'The more concentrated the solutions the greater the viscosity; but as the underground solutions of water are commonly not strong, this is ordinarily not an important element. The viscosity of water decreases very rapidly with increase of temperature. The relative viscosity of pure water at $0^{\circ} \mathrm{C}, 45^{\circ} \mathrm{C}$, and $90^{\circ} \mathrm{C}$. is respectively $100.00,33.89$, and 18.16. (See p. 141.) From these ratios it is apparent that the viscosity of water at $45^{\circ} \mathrm{C}$. is about one-third of that at $0^{\circ} \mathrm{C}$., and at $90^{\circ} \mathrm{C}$. only about one-fifth of that at $0^{\circ} \mathrm{C}$.

It is therefore clear that the higher the temperature the less the viscosity and the less the internal friction. Internal friction due to viscosity results from the variable speeds of different parts of moving water columns and from the friction between the moving and fixed portions. The greater the variations in speed of the moving parts the greater the internal friction due to this cause.

Water usually wets the surface of the rocks. In other words, there is molecular attraction between the water solutions and the minerals composing the rocks. This attraction is so strong that a thin film of water is firmly held by the walls of the openings-so firmly that it may be considered as fixed; at least the only interchange which occurs between it and the passing water currents is that of diffusion, not that of flow. Daniell says the friction between the layer of adherent water and the rock is infinite as compared with the friction within the liquid. ${ }^{a}$ That the friction is between the moving liquid and the fixed film of liquid is shown by the fact that for any liquid the composition of the walls has no effect upon the flowage. ${ }^{b}$ This being the case, it is clear that in the flowage of water through tubes there is no friction of the water against the rock walls. The adherent films of water are the walls of the moving columns, and the internal friction between the water and the walls is that between the fixed films and moving water.

"Daniell, Alfred, A text-book of the principles of physics, 3d ed., Macmilian Co., New York, 1895, p. 306.

$b$ Daniell, cit., p. 316. 
The greater the speed of the moving water the greater the internal friction, becanse of the differential movements both in the moving water and between the moving water and the films fixed to the walls. Where the rate of movement is sufficiently slow the internal friction due to viscosity drops to an almost inappreciable factor. Therefore where the movement is very slow, even if the passages be long and small, the pressure due to head may diminish very slowly. Indeed, nearly the full pressure may be maiutained for long distances-many or even hundreds of kilometers. This principle is of the utmost inportance in the flowage of ground water, and its applications are later developed. (See pp. 585-588.)

GENERAL STATEMENTS.

In general it may be said that in proportion as the driving forces, gravity, mechanical action, etc., are great, circulation is likely to be rapid. In proportion as the opposing force, internal friction, is great, circulation is likely to be slow. In proportion as the openings approach the circular form, circulation is likely to be rapid. In proportion as the openings are continuous, the cireulation is likely to be rapid. In proportion as the pore space is great, circulation is likely to be rapid.

However, of all these varions factors dependent upon the character of the openings, that of size is probably the most important; for rocks which do or do not readily transmit water may have the same proportion of pore space. For instance, if the grains be supposed to be spherical, of the sane size, and arranged in the most compact fashion possible, the unoccupied space is 0.26 of the entire space, without reference to the size of the grains. Thus the relative proportion of the openings in a great bowlder conglomerate and a fine-grained clay may be the same. But the capacity for the transmission of water by the former will be indefinitely greater than by the latter. As illustrating this, an experiment showed that a quartz sand, the water of saturation of which was the same as that of a certain chalk, transmitted water under a certain pressure six humdred times as fast as the chalk. ${ }^{a}$ In the compact soils, the particles of which are exceedingly small (see pp. 138-146), the openings between the particles are of capillary or sub-

a Prestwich, Joseph, Geology, chemical, physical, and stratigraphical, Clarendon Press, Oxford, vol. 1, 1886, p. 159. 
capillary size. In the case of the fine soils and clays the pores may be almost wholly subcapillary, or the water is that of imbibition. In this fact we have the explanation of the retention of soil moisture in fine clays. The moisture is glued to the grains. There is practically no circulation, and the water is removed only by high temperature or high pressure, or the two combined. It follows from the foregoing that, under given conditions with a given pore space, the coarse conglomerates furnish a much larger flow than fine conglomerates, the fine conglomerates a larger flow than the sandstones, and these a vastly greater flow than the soils, clays, and shales.

Bedding, fault, joint, and fissility openings may be so close together that the pore space is very large. Ordinarily fault openings are wider spaced but larger than the joint openings, and joint openings are wider spaced and larger than the openings of fissility. It can not be said which kind of opening gives, on the average, the larger pore space. Since, however, large openings are farorable to rapid flow, for a given pore space the fault openings are likely to give a greater flow than joint openings, and joint openings a greater flow than those of fissility. This follows from the greater size of the fewer openings. To this is to be added the element of greater continuity of the larger openings, as explained on pages 130131. Therefore, with a given pore space the flow may be vastly greater in the case of faults than in the case of joints, and much greater in the case of joints than in the case of fissility.

In this comnection it may be said that the capacity of a rock for imbibition gives a very good idea as to its power of transmission. The water of imbibition, it may be recalled (see p. 124), is the amount which adheres to the walls of the openings. It is evident that in rocks containing the same percentage of water when saturated the power of transmission varies inversely as their capacity for imbibition. If the openings of a rock be very small, but numerous, there is in a cubic centimeter a large surface to which the water can adhere. If the openings be subcapillary, the water of imbibition and saturation are the same and the powers of transmission practically nil. If the spaces be capillary, the water of imbibition is much less and the power of transmission greatly increased. If the spaces be supercapillary, the water of imbibition is slight in amount and the power of transmission very great. 
As already noted, there are two zones of metamorphism, that of katamorphism and that of anamorphism, and the former consists of a belt of weathering and a belt of cementation.

The major pairt of the water entering the ground must finally reach the surface. A small part may be combined with the rocks in the underground course of the water. A small part may possibly penetrate deep within the zone of anamorphism, but it is safe to say that at least 99 per cent of the water entering the ground reappears at the surface in some manner. A very large part of the water penetrating the soil is drawn to the surface after having taken a longer or shorter journey in the belt of weathering. A lesser part of the water joins the sea of ground water and takes a journey of greater or less distance in the belt of cementation before it reaches the surface. This journey may be merely from the top of a small hill to its base, or it may be hundreds of kilometers. An exceedingly small fraction of the water doubtless penetrates the zone of anamorphism, although, as explained (pp. 665-668), the general movement is from rather than to this zone. The underground journeys of water, whether the exceedingly short ones within the belt of weathering or the longer jonmeys in the belt of cementation or the zone of anamorphism, may be resolved into two components, one parallel to the surface of the earth and one at right angles to this surface. The first may be ealled the horizontal component, the second the vertical component. On the average, the horizontal component of the journey is many times longer than the vertical component.

GEOIOGICAL WORK OF GROUND WATER.

From the foregoing it follows that the geological work of ground water is favored by smallness of openings, by length of time, by pressure, and by high temperature. Water enters the rocks mainly through the smaller openings. A very large surface of the rock material is exposed to water action. In so far as the water passes from the smaller openings to the larger openings its geological work is lessened. The geological work may be considered as directly proportional to the time. The smaller the openings the greater the resistance, and therefore the greater the time for a given journey. That the resistance runs up very rapidly as the openings become small, and especially as they become capillary or subcapillary, has 
already been shown. Since the horizontal journey is, on the average, long as compared with the vertical journey, the element of time is of much greater importance in the horizontal component of the journey than in the vertical component. The capacity for geological work is increased by pressure and by temperature. These forces, under ordinary conditions, are a function of depth, and these factors in the work mainly concern the vertical component of movement. During the downward journey the pressure and temperature steadily increase, and the amount of material in solution increases. During the upward journey the pressure and temperature diminish and the tendency for material to pass from solution or to be precipitated increases, and the amount held in solution diminishes.

Pressure and temperature are ever working together according to definite laws. Both increase in efficiency with depth, and they greatly promote the activity of deep ground waters. However, of all the varying factors, varying temperature is the one which is of incomparably the greatest importance. High temperature ordinarily results from depth of penetration; but it has been pointed out that it may result from various other causes, of which chenical action, mechanical action, and the presence of intrusive igneous rocks are the more important. The eapacity which water has for taking and holding in solution various relatively insoluble compounds, and the velocity of chemical reactions, increase enormonsly with increase of temperature. Not only is high temperature favorable to geological work, because of the chemical activity of the water, but, as already pointed out, high temperature greatly decreases its viscosity, and this, as already explainer, is favorable to depth of penetration and flow through minute openings. Since the temperature changes of ground water are commonly dependent upon depth, the vertical component of the movement of underground water is ordinarily far more important than the longer horizontal component.

The underground journey of water may occupy hundreds of years. (See pp. 585-586.) The surface of contact in very small openings is very great. Under these conditions of slow movement and small openings there is sufficient time nearly to establish complete equilibrium between the solutions and the solids with which they are in contact; but it has been seen (pp. 34-35) that rarely or never is the adjustment of a rock to its 
environment complete. In so far as the adjustment is not complete, changes are going on, and the conditions are everywhere those of chemical dynamics, although the chemical action may be so slow that if the operations were conducted in a laboratory it might be concluded that the conditions were those of ehemical statics. This, however, but illustrates the importance of time in geological operations.

Thus far the treatment of the circulation and work of ground water has been general. There are many other factors concerned in the circulation which have not yet been considered, but these are factors special to the different belts and zones. They will therefore be treated in Chapters VI, VII, and VIII, on the belt of weathering, the belt of cementation, and the zone of anamorphism, respectively. 


\section{CHAPTER IV.}

\section{THE ZONES AND BELTS OF METAMORPHISM. \\ GENERAT CONSTDERATIONS.}

The various geological factors which bear upon metamorphism have been briefly discussed in the introductory chapter. It is there held that the geological factor of dominating importance is depth. Upon the basis of depth it is stated that the known crust of the earth is divisible into upper and lower zones of metamorphism; the first is called the zone of katanorphism, and the second the zone of anamorphism. It is further stated that the zone of katamorphism is divisible into two belts, an upper belt of weathering and a lower belt of cementation.

While in the introductory chapter these general statements were made, there was no attempt to show that they are correct. It is one of the purposes of this and the following chapters to furnish evidence of the utility of this classification, and to show that very different metamorphic effects follow from the work of the same forces and agents in the different belts and zones. In the present chapter a brief general statement will be made as to the characteristic reactions of the different zones and belts. This statement is primarily from physical and chemical points of view. The next chapter will treat of the alterations of minerals with reference to the different zones and belts. In succeeding chapters the alterations of the rocks in the belt of weathering, the belt of cementation, and the zone of anamorplism will be taken up in detail. The treatment will be primarily from the geological point of view, but with reference to physical and chemical principles. Finally, the alterations of the individual rocks will be considered. This and the following chapters might be regarded as a consideration of the metamorphism of the crust of the earth from the point of view of the physical-chenical principles developed in Chapter's II and III. 
It has just been stated that the nature of the metamorphism varies greatly with depth. The physical reasons for this are that, as depth increases, temperature and pressure increase. It has been seen in Chapters II and III that where the pressure is moderate chemical reactions are likely to be such that heat is liberated, and this is a fact whether the reactions decrease or increase the volume. It has also been seen that where the pressure is great this is likely to be the controlling factor, and that under such circumstances reactions take place which lessen the volume of the materials. Whether the reactions take place with liberation of heat or with absorption of heat is a subordinate matter; but very commonly the reactions are of a kind that absorb heat.

When the law of chemical affinity controls, and the reactions take place with liberation of heat irrespective of the volume change, the reactions may be said to be chemical-physical reactions. Where pressure is a dominant factor and reactions take place with diminution of volume irrespective of the heat change, the reactions may be said to be physicalchemical. It is because variations in the geological factor of depth result in these contrasting reactions that the lithosphere is divisible into a zone of katamorphism and a zone of anamorphism.

\section{ZONE OF KATAMIORPHISI.}

From the surface of the earth to a very considerable depth below the surface (for strong rocks possibly 10,000 or 12,000 meters under quiescent geological conditions) the rocks as originally formed may contain many openings, as, for instance, those of sandstones, vesicular lavas, etc. Even if not originally porous deformation may fracture the rocks and thus produce many openings. Where the rocks contain openings chemical reactions may take place, increasing the volume of the material without rupturing the rocks and without raising them to a higher position. In the onter lithosphere the pressures and temperatures are moderate. Under such circumstances the reactions which take place are controlled mainly by the laws of chemical affinity, not by the influence of pressure. At low temperatures the fundamental chemical law is that, on the whole, the preponderating chemical reactions are those which take place with the liberation of heat in accordance with the first part of van't Hoff's law. Therefore in this zone the occurrence of a reaction in the alteration of a rock is favorable to further 
alteration; for the heat developed by the first reaction is retained by the adjacent material, at least for a time, and this promotes further reaction, etc. But this tendency, as has been seen, may be reversed if the temperature becomes too high. (See p. 79.)

Since the law of chemical reactions with the liberation of heat is the dominant factor in this upper zone, alterations may take place which work with or against pressure. In the first case both the chemical reaction and the compression in volume result in the liberation of heat. In the second case the heat liberated is that developed by the chemical reaction minus that absorbed as a result of the work done in expanding the volume.

As a matter of fact, near the surface of the earth the very important reactions from the point of view of the nonmetallic elements, aside from solution, are those of oxidation, hydration, and carbonation. Oxidation and hydration commonly involve the addition of material, although the former frequently occurs by substitution of oxygen for sulphur, and therefore by desulphidation. Carbonation frequently involves the addition of material, but more commonly occurs by the substitution of $\mathrm{CO}_{2}$ for $\mathrm{SiO}_{2}$ and the decomposition of silicates. Often the freed silica, or a part of it, remains in situ. All of these reactions are well known to liberate heat. Commonly they decrease rather than increase the specific gravity of the minerals. Since they usually involve addition of material, it is clear that where all the residual material, or a large part of it, remains in sitn the volume of the rocks is considerably increased. However, it will be seen that solution is also a very important reaction in parts of the zone of katamorphism, and where this takes place to a sufficiently great extent the volume of material may be decreased.

The main part of the oxygen and much of the carbon dioxide for oxidation and earbonation is directly or indirectly derived from the atmosphere. Thie water is chiefly that of the ground circulation. It is therefore clear that in the upper zone oxygen and carbon dioxide are being steadily abstracted from the atmosphere and fixed in the rocks, and ground water is steadily becoming fixed by liydration. The amount of oxygen and carbon dioxide thus fixed is great. If it were not for replenishment, it is little short of certain that the carbon dioxide of the atmosphere would have long since become exhausted. But probably the amount of water fixed by hydration is even greater than that of the gases, oxygen yON XLVII-04-11 
and carbon dioxide. Analyses of rocks in the upper zone of metamorphism show that the amount of combined water runs as high as 4.42 per cent in shales (see p. 744), and it probably averages as high as $1.64^{a}$ per cent. When it is remembered that the zone of katamorphism extends to a depth of thousands of meters, it is apparent that the amount of water which is thus fixed in the rocks by the process of hydration is enormons. However, it will be seen that the process of hydration, like that of carbonation, is reversed in the zone of anamorphism.

By the statement that oxidation, carbonation, and hydration are the very important characteristic reactions of the zone of katamorphism it is not meant to imply that the reverse reactions do not take place to some extent. In fact, deoxidation, decarbonation, and deliydration all occur; but oxidation, carbonation, and hydration are greatly preponderant, and indeed dominant over the reverse reactions.

Summarizing so far as the energy factors are concerned, the changes in volume commonly absorb heat, the chemical reactions dominantly liberate heat and only exceptionally absorb heat. The heat liberated by the chemical reactions is certainly very much greater than the sum of that absorbed by the volume changes and that absorbed by the exceptional chemical reactions. Therefore, so far as the rocks of the zone of katamorphism are concerned, the total of the volume and chemical changes results in the liberation of heat and the dissipation of energy.

The minerals formed in the zone of katamorphism are comparatively few in number, with low specific gravities and probably for the most part comparatively simple molecules; hence the propriety of calling this zone the zone of katamorphism, or katamorphic zone. This use of the term katamorphism is parallel to the use of the term katabolism in biology to designate those chemical changes within a living body which result in the production of simple compounds from more complex ones. The zone of katamorphism may therefore be defined as the zone in which alterations of rocks result in the production of simple compounds from more complex ones.

The zone of katamorphism is divisible into two belts, (1) an upper belt of weathering, and (2) a lower belt of cementation. The belts are

$a$ This is the average taken from analyses of shales, sandstones, limestones, and rolcanic and erystalline rocks, given by F. W. Clarke in Bulls. U. S. Geol. Survey No. 78, pp. 36-37, and No. 168, pp. 16-17. 
delimited by the level of ground water. The separation of the belt of weathering from the belt of cementation is therefore based upon the position of an agent of metamorphism. It has been seen that the zone of katamorphism is separaterl from the zone of anamorplism by a reversal of the physical-chemical factors. As one would suppose, the latter distinction is of much more fundamental importance than the former.

BELT OF WEATHERING.

By some it has been proposed to call the belt of weathering that of demorphism; and to call the alterations of all rocks below this belt metamorphism. The fact that the alterations in the belt of weathering are very different from the belts below has been well known for many years. But it has not been generally recognized that the belts of weathering and cementation are delimited by the level of ground water. This is doubtless due to the fluctuations of that level and to a considerable transition band between the two belts (see pp. 423-429, 560-561); but in many places the change in the character of the alterations in passing from the belt of weathering to the belt of cementation is very sudden, and at such places is very clearly connected with the level of ground water.

The belt of weathering is therefore defined to extend from the surface to the level of ground water. In this belt all of the very important reactions characteristic of the zone of katamorphism-viz, oxidation, carbonation, hydration, and solution-are at their maximum activity; but on the whole, of these three reactions the most characteristic, but not the dominant one, is that of the carbonation of the silicates. This reaction takes place on a vast scale, producing carbonates from the silicates, and at the same time setting free silica or colloidal silicic acid. Hydration is the most extensive simple reaction in the belt of weathering. Oxidation is also very important. As will be seen, this reaction is very general in this belt, because not being saturated with water the oxygen of the atmosphere very rapidly makes its way through the porous rocks and continually supplies oxygen to replace that element used in the process of oxidation. The total effect of these chemical reactions is decomposition. While hydration and oxidation are nsual for this belt, under special conditions these reactions may be reversed. In places of luxuriant vegetation and very high humidity deoxidation may take place. In regions of great heat and temporary or 
permanent aridity dehydration may locally occur. As already noted, as a result of oxidation, carbonation, and liydration, the volume of the rocks would be greatly increased if all the compounds formed remained in situ; but the complex process of solution is dominant. . Many of the compounds formed are dissolved in large quantities and transferred by the overground water circulation to the sea, or by the underground water circulation to the belt of cementation below. Consequently the volume of the rocks continnously decreases in the belt of weathering; and finally the resultant material may occupy but a small fraction of the original volume.

In the belt of weathering, in addition to the characteristic chemical reactions, mechanical disintegration is the rule. Thus the complex results of weathering may be classified into disintegration, decomposition, and solution. As a final result of the various mechanical and chemical changes, rocks soften and degenerate. As coherent solids they are destroyed. The processes of the belt of weathering are therefore destructive. The minerals which remain are usually few and simple, and ordinarily are not well crystallized. In the destructive processes all of the agents of metamorphism, both inorganic and organic, are actively at work. The details of these processes are fully developecl in Chapter VI, on "The belt of weathering."

\section{BELT OF CEMENTATION.}

The belt of cementation extends from the bottom of the belt of weathering to the bottom of the zone of katamorphism. On the average this belt is therefore much thicker than the belt of weathering. All of the very important reactions characteristic of the zone to which the belt belongs-viz, oxidation, carbonation, and hydration-take place. Water is everywhere abundantly present in the belt, and hence hydration is the most important of the three reactions. The minerals produced by metasomatic change from the original minerals and those deposited from the solutions are likely to be strongly liydrated. The processes of carbonation and oxidation in the belt of cementation are largely limited by the amount of carbon dioxide and oxygen there contained.

It will be seen (pp. 608-610) that carbon dioxide is derived from several sources and that carbonation is usual throughout the belt, but that the oxygen is limited to that derived from above, and consequently that oxidation 
is usual in only a very limited part of the belt. Not only are the processes of carbonation and oxidation subordinate to hydration, 'but the process of oxidation not infrequently is stopped or reversed in all but the upper part of the belt of cementation. This anomaly is due to the fact that many of the rocks contain organie materials or sulphides or both which have a strong affinity for oxygen. When the oxygen is exhausted from the water derived from the belt of weathering the reducing compounds may act directly as redueing agents or may produce reducing solutions. The demands of these redncing agents for oxygen may abstract this material from highly oxidized compounds, such as ferric oxide, basic ferric sulphate, etc. Deoxidation in the belt of cementation is most commonly the result of the burial of the higher oxide of iron and sulphates with a considerable amomt of organic material in the presence of abundant water. Under these circumstances the ferric compounds may be rednced to ferrous compounds and the sulphates to sulphides.

But it is to be noted that the reduction of these componnds involves simultaneous oxidation of the organic compounds, the resultant products being $\mathrm{CO}_{2}$ and water. The carbon dioxide may escape from the belt or enter into other combinations. For instance, as explained fully in another place, the ferrous compounds largely unite with the carbon dioxide, producing carbonates. Similar reactions may take place with reference to other less abundant metals, as, for instance, manganese, and some metals may even be reduced to the metallic condition, for instance, copper, silver, and gold. These reducing renctions in the belt of cementation, except in the case of iron, are of small consequence from a geological point of view, but they have a most important bearing upon the deposition of ores. (See Chapter XII.) It thus appears that oxidation and deoxidation are both rather important in the belt of cementation.

The changes in the belt of cementation ordinarily prodnce crystalline minerals. Minerals which were partly altered by processes in the belt of weathering may be regenerated. This applies only to those minerals which are adapted to the belt of cementation. The average specific gravity of the rocks is usually lessened.

It has been noted that the most characteristic reaction of the belt of weathering is solution. In contrast with this the most characteristic reaction of the belt of cementation is deposition in the openings of the 
rocks. The material deposited is derived from the belt of weathering or from the alterations within the belt of cementation itself. Much of the material dissolved in the belt of weathering is continuously transferied to the belt of cementation by the downward movement of water. The total amount of material which is thus derived from the belt of weathering is not limited to the thin belt which exists at any given time; for, as a result of denudation, the belt of weathering is constantly migrating downward and encroaching upon the upper part of the belt of cementation; and thus there is never a lack of material for solution in the belt of weathering which may be dissolved and transferred to the belt of cementation. Within the belt of cementation itself the reactions of oxidation, carbonation, and hydration all increase the rolume, provided all the compounds formed, or a large part of them, remain as solids. The material added to the belt of cementation from the belt of weathering, and the reactions within the belt of cementation, fumish an abundant supply of material for deposition in the openings of the rocks, whether these openings be those originally present or produced by orogenic forces. And, as a matter of fact, in the belt of cementation the openings are continuously filled by mineral matter and finally closed; but this does not show that solution may not preponderate over deposition in this belt if the effect upon the original rocks and the openings both be considered. (See pp.612-617.) The mechanical result of the various processes is to indurate the rocks. The processes of the belt of cementation are constructive. The belt of cementation, from a geological point of view, is fully considered in Chapter VII.

\section{BELTS OF WEATHERING AND CEMENTATION CONTRASTED.}

The alterations in the belts of weathering and cementation, while not so fundamentally different as those in the zones of katamorphism and anamorphism, contrast strongly. In the belt of weathering, of the great reactions characteristic of the zone of katamorphism-oxidation, carbonation, and hydration-all are important, but carbonation is most characteristic. In the belt of cementation, of these reactions hydration is most important. In the belt of weathering, solution greatly dominates over deposition. In the belt of cementation solution and deposition are more nearly balanced, but becanse of reactions which increase the volume of the rocks the openings are 
filled. In the belt of weathering, the material continuously decreases in volume due to solution; in the belt of cementation it continually increases in volume due to deposition of material through reactions involving expansion of volume. These changes of volume due to addition or subtraction of material commonly involve decrease in specific gravity. In the belt of weathering the mechanical results are disintegration and softening; in the belt of cementation, cementation and induration. The belt of weathering is therefore especially characterized by solution, decrease of volume, and softening, resulting in physical degeneration. The belt of cementation is especially characterized by deposition, increase of volume, and induration, resulting in physical coherence.

\section{ZONE OF ANAMORPHISM.}

At a variable depth below the surface of the earth the pressure is so great that it can not be supposed that considerable openings permanently exist. The depth at which this condition of affairs is reached depends largely upon the character of the rocks. For the strong rocks, as already noted (p.160), this depth, under quiescent geological conditions, may be as great as 10,000 or 12,000 meters. If openings be originally present in the rocks of the zone of anamorphism, as, for instance, sandstones, vesicular lavas, etc., or be due to fracture while the rocks are not deeply buried, when such rocks become sufficiently deeply buried to be in the zone of anamorphism, it is certain that rock flowage will take place and the openings will be closed, except possibly those of subcapillary size and other miunte openings in which water, carbon dioxide, or other liquids and gases are occluded. In the zone of anamorphism there is great pressure in all directions, and mechanical energy becomes the dominant factor which controls the reactions. Changes consequently take place which diminish the volune of the rocks. 'This volume change increases the specific gravity, and contrasts with the volume clianges of the zone of katamorphism. The fundamental chemical law of energy in reference to heat is subordinate. Reactions take place with the liberation or absorption of heat, depending upon what is deimanded by the pressure. Commonly, the preponderant chemical reactions are those which take place with absorption of heat. The depth at which pressure becomes dominant is variable, depending 
upon the character of the rock and upon whether the conditions are massstatic or mass-mechanical.

It has been seen that at the moderate temperatures of the zone of katamorphism the preponderant chemical reactions are those which take place with the liberation of heat. As the depth below the surface increases, the temperature ever becomes higher; and consequently the temperature may become so high that the tendency for chemical reactions to take place with the liberation of heat is less dominant, and at sufficiently great depths the heat may be so great that this tendency ceases, or is even reversed. Or, using the words of van't Hoff, at high temperatures the preponderating. chemical reactions, or associations, which take place at lower temperatures with the development of heat are replaced by preponderating chemical reactions, or dissociations, which take place with the absorption of heat. ${ }^{n}$ However, at moderate depths in the zone of anamorphism under ordinary conditions the temperatures are not very high. For instance, at a deptlı of 9,000 meters the temperature is probably in the $n$ ighborhood of $300^{\circ} \mathrm{C}$. Therefore, so far as the temperature is concerned, for that part of the crust of the earth within observation the preponderant chemical reactions would probably take place under the first part of van't Hoff's law, rather than under the second part, if it were not for the pressure. But the pressure is the dominant factor which controls the reactions. The rocks in this zone are under so great pressure in all directions that this fact demands chemical reactions which produce diminished volumes irrespective of whether heat is liberated or absorbed by them.

The very important reactions in the zone of anamorphism are silication, or union of silicic acids with bases producing silicates, and dehydration. Deoxidation is subordinate. The process of silication commonly takes place upon carbonates, and consequently involves decarbonation and the liberation of the carbon dioxide, which may escape and thus the volume be decreased. To what extent the pressure is the controlling factor in the production of this reaction is difficult to say. Probably it is the dominant canse, but it is possible that at the temperatures which prevail in this zone silicic acid may be relatively more active than at the lower temperatures of the zone of katamorphism, where carbonic is the stronger acid.

a Nernst, W., Theoretical chemistry, translated by C. S. Palmer, Macmillan \& Co., London, 1895, p. 583. 
As illustrations of the process of silication may be mentioned the formation of wollastonite from pure limestone, of tremolite from dolomitic limestone, of actinolite from ankerite, and of griinerite from siderite. (See pp. 239, 241, 243, 244.) In the impure limestones under deep-seated conditions, where numerous bases are present, various complicated silicates form, such as other pyroxenes and amphiboles, tourmaline, chondrodite, etc.

The process of dehydration involves the liberation of water. This reaction, it is safe to say, is one which is controlled by pressure. The combined water is actually squeezed out of the liydrated mineral particles, transforming them to less hydrous and to anhydrous forms in a manner similar to that in which free water is pressed from a sponge.

Whether or not pressure in the zone of anamorphism is sufficient to deoxidize compounds is uncertain. Certainly it can not be asserted that the pressure is sufficient to squeeze out a part of the oxygen of hematite, thus transforming it to magnetite. So far as deoxidation occurs, probably the oxygen abstracted from the rocks usnally. unites with the elements of organic compounds, thus producing carbon dioxide and water. Tlus the chief products liberated by silication, dehydration, and deoxidation are carhon dioxide and water. These join the interstitial water in the subcapillary spaces and probably slowly escape into the zone of katamorphism above. (See pp. 665-667.) This results in loss of material, and since the specific gravity of the minerals is increased on the average, the volume of the rocks is decreased.

Besides the above processes, condensation may also be accomplished by recrystallization, although this process generally takes place in connection with them. The process of recrystallization produces a rearrangement of the elements in such a way as to form compounds of higher specific gravity. This is well illustrated by the devitrification of glass.

The minerals produced in the zone of anamorphism are numerous, definite, stable, crystalline, of high specific gravities, and probably have complex molecules. The rocks formed are compact and strong. The lower zone may therefore properly be called the zone of anamorphism, or anamorphic zone. This use of the term anamorphism is parallel to the use of the term anabolism in biology to designate those chemical changes in a living body which result in the production of complex compounds from more 
simple ones. The zone of anamorphism may be defined as the zone in which alterations of rocks result in the production of complex compounds from more simple ones.

Summarizing the energy factors in the zone of anamorphism, so far as the volume change is concerned, the result is to liberate heat; so far as the chemical reactions are concerned, heat may be liberated or absorbed, but the latter reaction is more common. In the latter case the heat absorbed is almost certainly much greater than that liberated by decrease of volume. If it were not that a considerable number of the chemical reactions liberate heat, it would be certain that heat is absorbed in the zone of anamorphism But the heat liberated by some chemical reactions must be added to that liberated by decrease of volume. Whether this sum is as great as the heat absorbed by the preponderating chemical reactions is somewhat uncertain; but it is thought to be rather probable, for the compounds immediately concerned in the reactions, that the total effect is to absorb heat and store energy. However, in order to accomplish this, energy must be derived from an ontside source, and when all the factors which in any way affect the reactions are taken into account, including the movement of the superincumbent material, heat is dissipated and energy lost. (See p. 182.)

\section{RELATIONS OF ZONES OF KATAMORPHISM AND ANAMORPHISM.}

We shall now consider the zones of metamorphism together with reference to the energy factors. So far as the chemical reactions are concerned, it has been seen that they may take place with liberation or absorption of heat. So far as heat is liberated energy is dissipated. So far as heat is absorbed energy is stored. The change in volnme may also result in the dissipation or storage of energy. Where increase of volume is preponderant energy may be stored (1) by increasing the volume of the rocks affected by the reaction or (2) by elevating the overlying rocks in order that the space shall be available for the expenditure. In a given case the energy may be stored by (1) or (2) or a combination of them. Where decrease of volume is preponderant energy is dissipated (1) by the decrease of volume of the rock affected by the reaction or (2) by subsidence of the overlying material, or by both. Below the extreme outer film of the earth the factor of elevation or subsidence of the overlying rocks is of vastly greater importance than the volume change, and the relative 
importance of this factor steadily increases with depth. This is more broadly true in the case of increase of volume than in that of decrease of volume; for in the latter case in the zone of katamorphism the strength of the rocks near the surface may prevent subsidence, and the decrease of volume simply produce porosity. A common illustration of that is vesicular dolomite. However, in the zone of anamorphism, when the reactions result in decrease of volume, subsidence occurs and energy is dissipated. The importance of the necessity of lifting the overlying material in order to find more room in the case of increase of volnme is well illustrated by the frequent rapid hydration or slacking, with great expansion and rapid disintegration, which follows when a partly hydrated rock, buried but a few feet, is brought to the surface. ${ }^{a}$ Apparently when buried the tendency for hydration and necessary expansion with liberation of heat was not sufficient to lift the superjacent material. When the necessity of elevating the superjacent material was removed by transfer to the surface the process of hydration and expansion went on to completion with great rapidity.

I conclude from the foregoing that in so far as energy is concerned there are four cases. Chemical reaction may (1) release energy and result in the liberation of heat, or (2) may consume energy and result in the absorption of heat. The change of volume may be (3) by decrease of volume, and result in the release of energy and the liberation of heat, or (4) by increase of volume, and result in the consumption of energy and in the absorption of heat. (1) and (3) will be called plus, and when they are combined the heat developed is equal to their sum; (2) and (4) will be called minus, and when they are combined the heat absorbed is equal to their sum. When (1) and (4) or (2) and (3) are combined heat may be liberated or absorbed, and consequently energy dissipated or stored, depending upon the relative values of the opposing factors.

It has been noted that the three important reactions in the zone of katamorphism are oxidation, carbonation, and hydration; and in the zone of anamorphism are deoxidation, silication, and dehydration.

Since all of the abundant metallic elements except iron are completely oxidized as they occur in the original rocks, the important inorganic compounds which are oxidized in the zone of katamorphism are mainly those

a Merrill, G. P., Disintegration of the granitic rocks of the District of Columbia: Bull. Geol. Soc. America, vol. 6,1895 , p. 332. 
of iron. Iron occurs extensively in the ferrous form, in magnetite, in carbonates, and in silicates. To a considerable extent it occurs as a sulphide. To a small extent it occurs as metallic iroin. In all of these forms it is capable of oxidation. The main result of the oxidation of these compounds, so far as the iron is concerned, is to change the monoxide to ferric oxide. But where it is present as a sulphide it may be changed to a sulphate, and then be thrown down as a basic ferric sulphate. Ferric oxide, hydrous or anhydrous, is an important constituent in the sedimentary rocks, and its presence is, without doubt, largely due to oxidation in the zone of katamorphism. To a far less extent other metals, such as copper, lead, zinc, etc., occur in the native form, in partially oxidized forms, or as sulphides. All these substances may be oxidized. These substances have little importance in general geology, but are of great importance in the production of ores. All of the reactions of oxidation take place with great liberation of lieat and with increase of volume. In the zone of anamorphism partial or complete deoxidation of the highly oxidized compounds may occur. The ferric iron may be reduced to the ferrous form. The sulphates of iron and the other metals may be reduced to sulphides. In most cases the reducing agent is organic matter. The reduction of the metals by organic compounds results in the oxidation of the carbon and hydrogen, thus producing carbon dioxide and water. The carbon dioxide and water largely escape. Where reducing agents are not present the highly oxidized materials produced in the zone of katamorphism commonly remain in this condition even if the material passes into the zone of anamorphism. Deoxidation can not, therefore, be said to be characteristic of the zone of anamorphism to the degree that oxidation is characteristic of the zone of katamorphism: The reducing reactions all take place with great absorption of heat, so far as the metals are concerned, and with decrease of volume. However, since heat is liberated by the oxidation of the carbon and hydrogen, it is probable that the sum total of the heat reaction in deoxidation in the zone of anamorphism is to liberate heat.

In the matter of oxidation and deoxidation, the zone of katamorphism presents a case in which the chemical law of the liberation of heat controls, without reference to change in volume, while in the zone of anamorphism the pressure tending to produce decrease of volume and chemical reactions with the liberation of heat probably work together. 
Another set of reactions, of the most findamental importance and widespread character, which occur in an opposite sense in the two zones of metamorphism are the mutual replacements of carbon dioxide and silicon dioxide. It las already been noted that near the surface, or in the zone of katamorphism, carbonic replaces silicic acid. Deep below the surface, $o r$ in the zone of anamorphism, silicic replaces carbonic acid. Under the conditions near the surface, where the pressure is small and the temperature is low, carbonic is the stronger acid; and under the conditions deep below the surface, where the pressure is great and the temperature is high, silicic is the strongt acid. The importance of the mutual replacement of these compounds $i$. der different conditions makes it advisable to summarize the chemical analogies of silicon and carbon. Silicon is the characteristic element of inorganic compounds; carbon is the characteristic element of organic compounds. How closely analogous are these two elements is shown by the following comparative table:

\section{Chemical relations of siticon and carbon.}

SILICON.

CARBON.

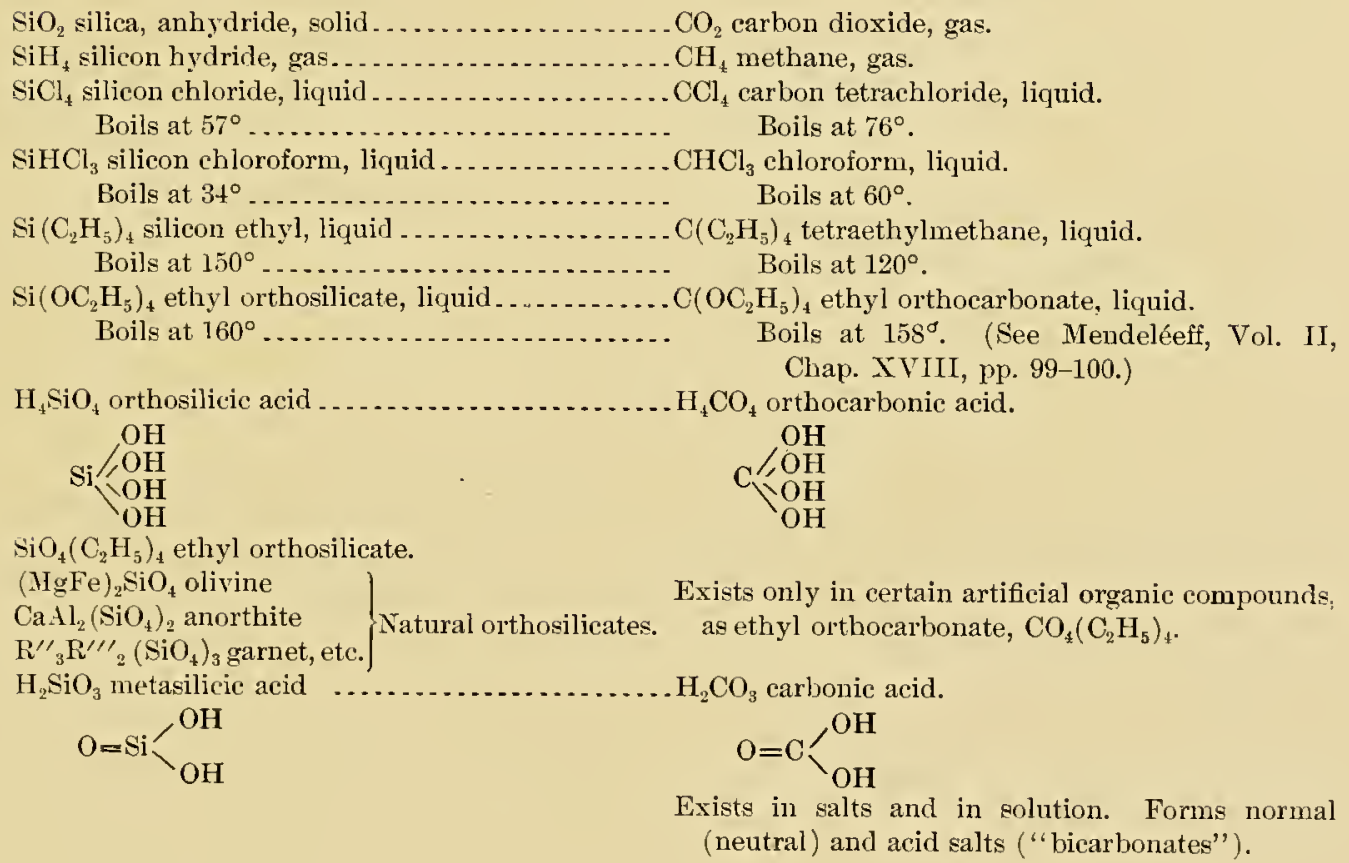

Exists only in certain artificial organic compounds, as ethyl orthocarbonate, $\mathrm{CO}_{4}\left(\mathrm{C}_{2} \mathrm{H}_{5}\right)_{4}$.

$\mathrm{H}_{2} \mathrm{CO}_{3}$ carbonic acid.

$$
\mathrm{O}=\mathrm{C}<\frac{\mathrm{OH}}{\mathrm{OH}}
$$

Exists in salts and in solution. Forms normal (neutral) and acid salts ("bicarbonates"). 
Chemical relations of silicon and carbon-Continued.

SILICON.

CARBON.

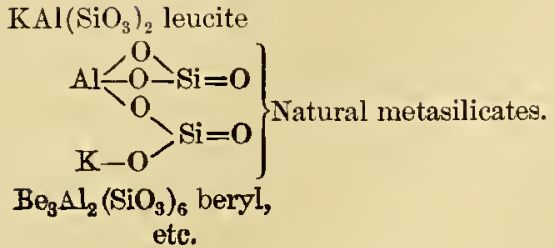

(normal salts)

$\mathrm{O}=\mathrm{C}^{\prime}{ }_{\mathrm{O}-\mathrm{Na}}^{\mathrm{O}-\mathrm{Na}}$

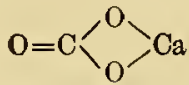

(acid salts)

$\mathrm{O}=\mathrm{C}_{\backslash}^{\prime} \stackrel{\mathrm{OH}}{\mathrm{ONa}}$

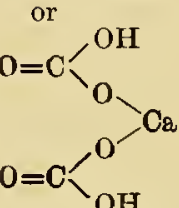

$\mathrm{H}_{2} \mathrm{Si}_{2} \mathrm{O}_{5}$ disilicic or dimetasilicic acid............... $\mathrm{H}_{2} \mathrm{C}_{2} \mathrm{O}_{5}$ dicarbonic or pyrocarbonic acid.

$$
\mathrm{O}=\mathrm{Si}{ }_{\mathrm{O}}^{\mathrm{OH}}
$$

Si : O :: $2: 7$ for basic salts.

$\mathrm{Si}: \mathrm{O}:: 2: 5$ for acid salts.

Not known in free state.

LiAl $\left(\mathrm{Si}_{2} \mathrm{O}_{5}\right)_{2}$ petalite.

$\mathrm{H}_{6} \mathrm{Si}_{2} \mathrm{O}_{7}$ diorthosilicic acid

$$
\mathrm{O}=\mathrm{C}_{\mathrm{O}=\mathrm{C}}^{\mathrm{OH}}
$$

Known only in salts, as $\mathrm{C}_{2} \mathrm{O}_{3}(\mathrm{NaO})_{2}$, produced by heating the acid salt.<smiles>CC(C)O[SiH2]OC(C)(C)C</smiles>

$\mathrm{H}_{4} \mathrm{Mg}_{3} \mathrm{Si}_{2} \mathrm{O}_{9}$ serpentine (normal salt).

$$
\mathrm{Si} / \mathrm{O}-\mathrm{O}-\mathrm{Hg}-\mathrm{OH}
$$

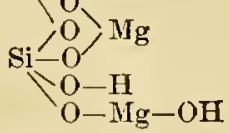

$\mathrm{H}_{2} \mathrm{CaSi}_{2} \mathrm{O}_{6}+\mathrm{H}_{2} \mathrm{O}$ okenite (acid salt).

$\mathrm{H}_{4} \mathrm{Si}_{3} \mathrm{O}_{8}$ polysilicic acid or trisilicic acid ........... The corresponding carbon acid does not exist.

(May be considered as metasilicic acid plus disilicic acid.)

$$
\begin{aligned}
& \mathrm{Si}=\mathrm{OH} \\
& >\mathrm{O} \\
& \mathrm{Si}=\mathrm{O} \\
& \mathrm{Si}=(\mathrm{OH})_{9}
\end{aligned}
$$

(neutral salts of trisilicic acid)

$\mathrm{KAlSi}_{3} \mathrm{O}_{8}$ orthoclase.

$\mathrm{NaAlSi}_{3} \mathrm{O}_{8}$ albite. 
Another close analogy which exists between the carbonates and the silicates is the fact that many salts of both give alkaline reactions, or under the theory of dissociation are hydrolized as explained (pp. 86-87), and that alkalinity increases with the temperature.

The specific volumes of the silicates and carbonates also have very close relations. In general the specific volumes (the molecular weights divided by the specific gravities) of the silicon compound are slightly the greater. The comparative specific volumes of a number of the correlative silicon and carbon compounds are as follows: ${ }^{a}$

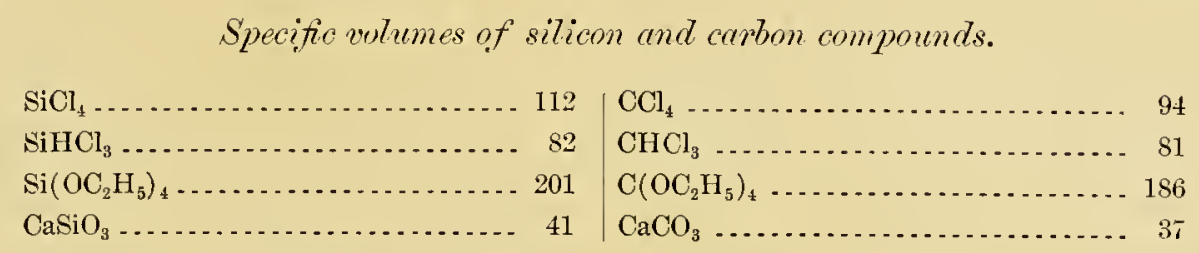

The specific volumes of $\mathrm{SiO}_{2}$ and $\mathrm{CO}_{2}$ are wholly different, but this is explained by the fact that one is a solid and the other a gas.

Since the specific volumes of the carbon compounds are less than those of the silicon compounds, if there be a simple substitution of carbon for silicon the volume is decreased; if silicon for carbon, the volume is increased. However; as a matter of fact, the changes in the rocks are never so simple as this. The volume changes in carbonation with desilication, and in silication with decarbonation in the rocks largely depend upon whether the reacting and resultant compounds are gaseous, liquid, or solid, and whether the products remain as solids or are dissolved and transported elsewhere.

In the zone of katamorphism carbon dioxide replaces silicon dioxide ordinarily with liberation of heat

The fact of the carbonation of the silicates is well known. So far as I know, the importance of this process was first realized by Bischof. $\mathrm{He}$ attributes the general decomposition of the rocks near the surface mainly to the action of carbonic acid, thus producing the carbonates which are found in spring water. He shows by experiment that "the silicates of alkalies, alkaline earths, protoxides of iron and manganese are decomposed

a Mendeléeff, D., The principles of chemistry, translated by Geo. Kamensky, Longmans, Green \& Co., London, 1897, vol. 2, pp. 99-100. 
by carbonic acid at ordinary temperatures." ${ }^{a}$ But he says that, since carbonic acid does not combine with alumina or peroxide of iron, the silicates of these compounds are not decomposed by carbonic acid. ${ }^{b}$ However, we now know that the process of carbonation takes place with all the natural silicates. It will be shown in Chapter. VII that this process of carbonation goes on throughout the entire zone of katamorphism, but it is in the upper of the two belts of the zone of katamorphism, that of weathering, in which the process of carbonation goes on with greatest rapidity and is especially characteristic. Simultaneonsly with the snbstitution of the carbon dioxide for the silica much of the silica separates as colloidal silicic acid, is taken into solution, and is carried downward to the belt of cementation by the percolating waters. In this belt the silica is deposited on an enormous scale. The carbon dioxide is furnished in solution, being mainly derived directly or indirectly from the atmosphere. When carbon dioxide replaces silicon dioxide the volume would be decreased, provided all of the silicic acid were abstracted in solution. But it is probable that the larger portion of the silica set free in the zone of katamorphism by carbonation is deposited in the belt of cementation, and therefore the volume of the zone of katamorphism as a whole, so far as this reaction is concerned, is increased. The deposition of silica in the belt of cementation is probably accompanied by a considerable absorption of heat, under the law that the negative value of the heat of solution is greater the more insoluble the substance.

Carbonation in the zone of katamorphism may taks place without replacing silica, as in the case of the union of carbon dioxide with iron oxide in magnetite, thus producing iron carbonate. In this case the liberation of heat and the increase in volume are both great.

In the zone of anamorphism, and especially under mass-mechanical conditions, silica replaces carbon dioxide in the carbonates on the most extensive scale. So far as I am aware, Bischof was the first to realize that moler proper conditions the process of carbonation of the silicates could be reversed. He shows by experiment that carbonates of calcium, magnesium, and iron are decomposed by silica at a boiling temperature, and cor-

a Bischof, Gustav, Elements of chemical and physical geology, translated by Paul and Drummond, Harrison \& Sons, London, vol. 1, 1854, p. 2.

${ }^{b}$ Bischof, cit., vol. 1, pp. 4-5. 
rectly infers that when any of these carbonates occur with quartz at a sufficient depth within the earth, where a temperature of $100^{\circ} \mathrm{C}$. is reached, this reaction may take place. He calculates that this depth will be 2,440 meter's. He correctly infers that the presence of abundant carbon dioxide in deep-seated waters is probably due to this process of silication. ${ }^{a} \mathrm{We}$ now understand that under conditions of moderate pressure and temperature not only are the carbonates which Bischof mentioned decomposed, but other carbonates may be altered in a similar manner. However, it is noteworthy that the carbonates which Bischof mentioned are those of predominant importance.

The substitution of silicon for carbon would result in increase of volume provided silica were derived from the solutions and the carbon dioxide passed into the solutions. But in the process of silication in the belt of anamorphism little material is available from outside sources. Therefore the most of the silica which replaces carbon dioxide in carbonates must be considered as a solid. It is probable that a large part of the freed carbon dioxide slowly escapes; for at temperatures prevailing in the zone of anamorphism the carbon dioxide is above its critical temperature, and therefore a gas, and probably slowly makes its way through the subcapillary spaces to the zone of katamorphism (see p. 667.) Hence the volnme comparison must be made between the carbonate and replacing silica combined and the resultant silicate. On this basis there is a marked diminution of volume. One of the simplest illustrations of the formation of the silicates with condensation of volume is the development of wollastonite from calcium carbonate and quartz. In this change the volume of the solid remainder is decreased 31.48 per cent. However, this calculated decrease is somewhat too great; for it will be seen (p. 667) that some of the carbon dioxide does not escape, but is retained in the rocks in the form of numerons inclusions.

It appears from the foregoing that in the replacement of silicon dioxide by carbon dioxide in the zone of katamorphism, the chemical law of reactions with liberation of heat dominates over that of pressure; and that in the substitution of silicon dioxide for carbon dioxide in the zone of anamorphism the physical law that pressure demands decrease of volume dominates over the chemical law of reactions with liberation of heat.

$a$ Bischof, cit., vol. 1, pp. 237-241.

IION XLVII $-04-12$ 
The third important case in which the reactions occur in the opposite sense in the zones of katamorphism and anamorphism are hydration and dehydration.

Hydration is a characteristic reaction of the zone of katamorphism, only less important than that of carbonation; moreover, hydration occurs on a great scale both in the belt of weathering and in that of cementation. That hydration occurs extensively deep in the belt of cementation is evidenced by the hydrated minerals which develop in the cavities of the rather deeply buried rocks, such as the amygdules of amygdaloids. Hydration represents, in the words of the first part of van't Hoff's law, "an association which takes place with great liberation of heat." 'This process also results in very considerable increase of volume, provided all or nearly all of the products formed remain in situ.

Dehydration is a characteristic reaction of the zone of anamorphism, only less important than that of silication. When the hydrated minerals formed in the belt of katamorphism pass into the zone of anamorphism by deep burial they are deliydrated. The pressure, or the high temperature, or the two combined, unite to drive off a large part of the water. Dehydration, in the words of the second part of van't Hoff's law, represents "a dissociation which takes place with great absorption of heat" and it takes place with decrease of volume.

Therefore, so far as hydration and dehydration are concerned, in the upper zone the first part of van't Hoff's law, that of chemical reactions with the liberation of heat obtains, but in the lower zone the law of diminution of volume controls, regardless of the heat effect. The first part of this statement is sufficiently evident; the second possibly needs further explanation. To drive off the combined water of rocks at ordinary pressure usually requires a temperature above $110^{\circ} \mathrm{C}$. This temperature mulur mass-static conditions would not be found until a depth of 3,300 meters linl been reached. It is certain that at depths much less than this, anr temperatures lower than this, dehydration takes place on an important scalu: for it will be shown (p. 744) that in the transformation of mudstones to shales there is a loss of about one-half of the combined water. I conclude that under many circumstances the increase in temperature is not sufficient to reverse the reaction of hydration, and therefore the reversal must 
be due to the pressure. However, in the lower part of the zone of anamorphism the temperature is frequently higher than $110^{\circ} \mathrm{C}$., and under such circumstances both the pressure and the temperature may work together to produce dehydration.

The statement that the volume is decreased by dehydration is only true provided the separated water, or a large part of it, escapes; for the volume of the hydrated solid is less than that of the residnal solid plus the separated water; therefore, if the water could not escape, pressure would tend to preserve the combination. Hence, the fact that the reaction does take place in the zone of anamorphism shows that there is sufficient pressure not only to separate the combined water from the rocks, making it free water, but to squeeze the free water from the rocks as one can squeeze the water from a sponge. The effective pressure doing the work is equal to the pressure of the adjacent rocks less the weight of an equal column of water extending to the surface. Thuns, under mass-static conditions, if the rocks have a specific gravity of 2.7 , the effective weight in producing dehydration and driving ont the free water at a depth of 3,300 meters is that of a column of material of this height with specific gravity of 1.7. Under mass-mechanical conditions, where the pressure as a result of thrust may be much greater than that due to weight, the effective pressure tending to separate the combined water is much greater. Consequently, under such conditions dehydration may occur at much less depth than under mass-static conditions. (See pp. 766-768.)

One or two minerals may be mentioned which illustrate the processes of hydration and dehydration in the two physical-chemical zones. Near the surface and to a considerable depth, under mass-static conditions, limonite and other hydrated oxides of iron develop. Deeper down, and especially in connection with mass-mechanical action, limonite is dehydrated, and hematite is produced. As another illustration may be mentioned the somewhat similar compounds, chlorite and biotite. Near the surface and under quiescent geological conditions chlorite forms. Deep below the surface, and especially under mass-mechanical conditions, biotite ordinarily develops. This is nowhere better illustrated than in the Michigamme formation in the Marquette district of the Lake Superior region, where these two minerals directly replace each other under the 1 ins 
stated." In the zone of katamorphism the complex hydrous silicates, such as the kaolins, serpentines, and zeolites form. In the zone of anamorphism these minerals are largely dehydrated, and such minerals as muscovite, andalusite, garnet, stamrolite, etc., are produced.

The physical-chemical principles cited (pp. 45-123) give reasons for the existence of the above reverse sets of reactions in the two zones. We can now give chemical or physical causes why oxidation, carbonation, and hydration take place in the zone of katamorphism, and deoxidation, silication, and dehydration in the zone of anamorphism, and so on for other reactions.

While each of these sets of processes is particularly characteristic of one zone, it is not meant to imply that each reaction may not occur in both zones. But in the zone of katanorphism, oxidation, carbonation, and hydration greatly predominate over the reverse processes. On the other hand, in the zone of anamorphism, deoxidation, silication, and dehydration predominate over the reverse processes.

If all of these sets of processes reversed as preponderant reactions at the same depth, it would be possible to sharply separate the zones of katamorphism and anamorphism. If, for instance, for a given region above a depth of 10,000 meters the sum totals of the oxidation, carbonation, and hydration were greater than the sum totals of reverse processes, the zone of katamorphism would be sharply separated from the zone of anamorphism at this depth. But this is not the case. The reversal of each pair of processes occurs at different deptlis; and, further, the reversal for a given pair of processes is at different depths under different conditions. One of the most important of these is as to whether the conditions are mass-static or mass-mechanical.

Of the three sets of reversing reactions, oxidation and deoxidation, carbonation and silication, hydration and dehydration, the first reverses with the least depth and pressure, the second requires the greatest depth and pressure, and the last a mean depth and pressure. It has already been noted that oxidation very frequently is replaced by deoxidation in the lower part of the zone of katamorphism. It is certain that the process of lydration is very greatly stayed, if it does not altogether cease, and may

a Van Hise, C. R., and Bayley, W. S., The Marquette iron-bearing district of Michigan: Mon. U. S. Geol. Survey, vol. 28, 1897, pp. $444-459$. 
even be reversed in the lower part of the zone of katamorphism. It is therefore apparent that the two zones are not sharply delimited. In general, however, it may be said, that the outer zone to a depth in which oxidation, carbonation, and hydration prepouderate is that of katamorphism, and that the deeper-lying zone, in which the reverse of these processes preponderate, is that of anamorphism. But carbonation and its opposite, desilieation, are the most fundamental reactions of the zone of katamorphism. Silication and decarbonation are the most fundamental reactions of the zone of anamorphism. By these reactions more than by any others, these zones are delimited. The three sets of reversing reactions, oxidation and deoxidation, carbonation and silication, hydration and dehydration, constitute three cycles in metamorphism. The second of these eycles was recognized many year's ago by Bischof (see pp. 176-177), and was called the carbono-silicic cycle.

From the foregoing statement it is clear that the work of the zones of katamorphism and anamorphism are opposed to each other. What the one is doing the other is undoing. At the present time it is therefore possible that in the case of any one of the pairs of opposed reactions, considering both the zones, either one of them preponclerates, or that they are approximately balanced. For instance, the amount of water being fixed in the zone of katamorphism may be greater or less than the amount of water being freed by dehydration in the zone of anamorphism, or the two may be nearly balanced. The same statement may be made in reference to the other reversing reactions. Upon the preponderance of these opposing sets of reactions in the opposite zones depends the answer to the question whether, on the whole, oxygen, carbon dioxide, and water from the atmosphere and hydrosphere are being fixed or freed by metamorphism. This question is eonsidered in Chapter XI.

While the zones of katamorphism and anamorphism are separated from each other by contrasting reactions, all reactions do not reverse in the two physienl-chemical zones. The first part of van't Hoff's law of heat and the law of pressure may work together-that is, in both zones reactions may oecur which, simultaneously with the liberation of heat by ehemical action, also result in liberation of heat by condensation. In so far as there are cases of this kind it is to be presumed that such reactions are common to both zones. As an instance in which heat is probably evolved 
both by the chemical reactions and by the volume change in both zones may be mentioned the devitrification of glass. (See Chapter V, pp. 251-252.) The chenical reaction is presumably under the first part of van't Hoff's law, and the volume is decreased. Another instance of chemical reaction with the liberation of heat and condensation of rolume is the replacement of calcium by magnesium in limestone, thus transforming the rock into dolomite.

It is thought to be certain that the total of all the changes taking place in the whole of the mass of rocks concerned in any given modification of the lithosphere results in the dissipation of energy, and it is believed that such is the fact for each of the physical-chenical zones separately. In the zone of katamorphism the chemical reactions result in liberation of leat; the average rolume reaction results in absorption of heat. It is, however, thought certain that the residnal is in favor of the former. In the zone of auamorphism the arerage of the chemical reactions results in absorption of heat; the average of the rolume reactions results in the liberation of heat. It has already been seen (pp. 170-171) that the amount of energy required for the volume change rapidly increases with depth, and in the lower zone it is thought that the heat liberated from the volume changes is greater than the heat absorbed by the chemical reactions, and therefore that the residual is in favor of the liberation of heat.

Hence, it is concluded that the changes which take place in each of the zones are under the general law of the ruming down of energy into the form of heat which is dissipated, and this accords with the apparent order of the miverse.

A corollary to the foregoing pages is the conclusion that in the upper zone, where pressure is relatively mimportant, on the average, alterations result in the expansion of the volume of the rocks; and that in the deeper-seated zone, where pressure is important or dominant, on the average the alterations result in the contraction of the volume of the rocks. It follows as a further conclusion from this that the tendency of the alterations

a The verification from anthorities of the heat of the chemical reactions and the volume relations for the majority of the changes above mentioned have been very kindly made for me by Mr. A. T. Lincoln. Mr. Lincoln either has found the results used in the works of Thomsen, Ostwald, Mendeléeff, or other standard authorities, or from the data there found has been able to calculate results which answer the specific questions I gave to him. 
in the first zone is, on the average, to produce minerals of lower specific - gravity than the original minerals, while in the deeper-seated zone the tendency, on the average, is to produce minerals of higher specific gravity.

Illustrations of the first rule are the minerals produced by the disintegration and decomposition of rocks near the surface, out of which the sedimentary rocks are built. Some of these are kaolinite (sp. gr. 2.6-2.63), quartz (sp. gr. 2.65), calcite (sp. gr. 2.72), chlorite (sp. gr. 2.60-2.96), serpentine (sp. gr. 2.5-2.65), talc (sp. gr. 2.7-2.8), zeolite (sp. gr. 2-2.4), limonite (sp. gr. 3.5-3.96), etc. All of these minerals and most of the other abundant undecomposed minerals, such as feldspar (sp. gr. 2.55-2.75), which make up great masses of sedimentary rocks, have comparatively low specific gravities.

The second rule is ilhustrated by the change from low to high specific gravity of the minerals where the sedimentary rocks are metamorphosed. As just seen, the minerals which compose the unaltered sedimentary rocks are originally those of low specific gravity. Some of the abundant resultant minerals in the equivalent metamorphosed rocks have considerably higher specific gravities, as, for instance, muscovite (sp. gr. 2.76-3), biotite (sp. gr. 2.7-3.1), pyroxene (sp. gr. 3.2-3.6), and amphibole (sp. gr. 2.9-3.4), and the still heavier minerals, garnet (sp. gr. 3.15-4.3), staurolite (sp. gr. 3.65-3.75), chloritoid (sp. gr. 3.52-3.57), hematite (sp. gr. 4.9-5.3), and magnetite (sp. gr. 5.168-5.180). Less common heavy minerals are audalusite (sp. gr. 3.16-3.2), fibrolite (sp. gr. 3.23-3.24), and chondrodite (sp. gr. 3.1183.24). With the above are the lighter minerals, quartz and feldspar; but even these are quite as heavy as the average of the original minerals.

It is noticeable in the altered rocks that in proportion as deep-seated metamorphism is advanced the heavier of the above minerals appear: In the early stages of the metamorphism of shales, mica develops plentifully, and the rocks become slates. Where the metamorphism is more intense the heavier minerals, garnet and stanrolite, appear; the material of the previously developed micas being absorbed at the places occupied by the garnet and staurolite.

The garnet-, staurolite-, chloritoid-, andalusite-, and tourmaline- bearing schists and gneisses of the Penokee and Marquette districts of Michigan and Visconsin and the Black Hills of South Dakota, produced by the 
alteration of clastic rocks, are perfect illustrations of the above changes. ${ }^{a}$ In these rocks the acid feldspars (sp. gr. 2.55-2.67) have extensively altered into quartz (sp. gr. 2.65) and mica (sp. gr. 2.76-3.01), and therefore have passed into minerals denser on the average than those from which they were derived. Also the heavier minerals, garnet, etc., have developed . on an extensive scale in the more metamorphosed varieties.

When all the minerals formed are taken into account the average is as given. But it is not supposed that there are not exceptions to each of the rules that in the upper physical-chemical zone lighter minerals form and in the lower zone heavier minerals develop. Indeed exceptions are known to both. An illustration of such exceptions in the upper zone is the case already mentioned (see pp. 181-182), the replacement of calcinm by magnesinm. A case of the change from higher to lower specific gravity in the lower zone is the alteration of pyroxene into amphibole. On the average the former is slightly heavier, and yet in the lower zone, under both mass-static and mass-mechanical conditions, pyroxene very generally alters to amphibole. Of course in this transformation a change simultaneously takes place in the chemical composition (and this may have an effect upon the volume of the minerals); for, in general, pyroxene contains a greater proportion of calcium and less proportions of magnesium and iron than the amphiboles. If all of the compounds concerned in the change were taken into account this apparent exception to the rule of the production of compounds of high specifie gravity in the lower zone would probably disappear. In some of the deepest-seated, schists, pyroxene and not amphibole has developed, and it is suspected that sufficiently deep this is the rule. If this be the case the real meaning of the change of pyroxene to amphibole is, in order that pressure shall become the dominant factor for each of the minerals as well as for the average, that the pressure must be very great.

But whatever exceptions may be discovered in the cases of individual minerals, the rules that in the upper physical-chemical zone the alterations, on the average, result in decrease of specific gravity, and that in the lower

a Irving, R. D., and Tan Hise, C. R., The Penokee iron-bearing series of Michigan and Wisconsin: Mon. U. S. Geol. Survey, vol. 19, 1892, pp. 302-331; also vol. 28, 1895, pp. 448-450, 452-454, 456-459. Van Hise, C. R., The pre-Cambrian rocks of the Black Hills: Bull. Geol. Soc. America, vol. 1, 1890, pp. $222-229$. 
zone the alterations result in increase in specific gravity, are believed to hold and to be of fundamental importance in the metamorphism of rocks. This principle of the development of minerals of low specific gravity near the surface and of high specific gravity at depth has a direct application to the crystallization of magmas. From a magma of a given chemical composition there can be little doubt that the greater the depth, and therefore the greater the pressure at which crystallization occurs, the higher the average specific gravity of the rocks. In this treatise no attempt will be made to work out the applications of the rule to individual minerals and rocks, but one illustration in reference to minerals and one illustration in reference to rocks may be cited. It is well known that in the lavas silica frequently crystallizes in the form of tridymite (sp. gr. 2.28-2.33), but that in the deep-seated igneous rocks quartz (sp. gr. 2.65) only is found. It is believed that the explanation of this fact is that near the surface other factors than pressure control the crystallization, and therefore that the less heary form of crystallized silica-tridymite-may be produced; and that in the lower zone pressure is the determinative factor in the crystallization, and therefore that the heavy form of crystallized silica-quartz-invariably results. An illustration in reference to rocks is the presence or absence of glass. Glass has a lower specific gravity than the equivalent crystallized substance. It is well known that where magmas crystallize near the surface glass is a frequent product, and that where magmas crystallize deep below the surface glass is either very subordinate or absent altogether. While other factors besides pressure enter into this result, it is believed that the frequent presence of glass near the surface and the presence of dense crystallized minerals in the equivalent deeper-seated rocks crystallizing from magmas is a rery striking ilhustration of the truth of the principle of the development of minerals and rocks of low density where the pressure is small and of great density where the pressure is great.

"The above conclusions as to the condensation of material at considerable depths has an important bearing upon Reade's theory of monntain making. (Reade, T. Mellard, The origin of mountain making, London, 18s6.) His explanation of the rise of mountains is that the volume of the thick deposits of sediments increases as a consequence of the rise of the isogeotherms. I believe that possible expansion due to this cause is more than compensated in the case of the serliments by the mechanical bringing of the particles closer together as the result of pressure, in many instances to the practical disappearance of the interspaces, and by the condensation of the material itself by the physicalchemical changes ahore explained. The condensation also has a learing upon estimates of crustal shortening. In so far as condensation occurs, shortening of the outer crust of the earth may allow accommodation to a nuclens of decreasing size without crustal corrugation. 
In conclusion of this part of the subject it may be said that in the zone of katamorphism the alterations are mainly controlled by the chemical law that reactions take place with liberation of heat, and this ordinarily results in increase of volume, provided the compounds which form remain as solids. In the zone of anamorphism the reactions are mainly controlled by the physical law that reactions take place with decrease of volume, and this commonly results in chemical reactions with absorption of heat. In the upper zone chemical law is the determinative factor in the reactions; in the lower, physical law. In the ripper zone the important chemical reactions are those of oxidation, carbonation (involving desilication), and hydration; in the lower zone the important reactions are those of deoxidation, silication (involving decarbonation), and dehydration. In the upper zone the minerals are few in number, of low specific gravity, and probably of simple molecular structure; in the lower zone the minerals are numerous, of high specific gravity, and probably of complex molecular stiructure.

If one were to select three words which ronghly represent the characteristics of the alterations in the belt of weathering, the belt of cementation, and the zone of anamorphism, these three words would be, respectively, destruction, construction, and reconstruction.

\section{GENERAL CONSIDERATIONS.}

It is now apparent that a geological classification of metamorphism dependent upon depth carries with it profound chemical and physical significance. Not only is the classification applicable to all parts of the earth, but the alterations of the zones of katamorphism and anamorphism are more fundamentally different than any distinction heretofore made with reference to metamorphism. Also, the alterations of the belt of weathering and the belt of cementation of the zone of katamorphism, again dependent upon depth, are ver'y different so far as the geological facts are concerned, but are closely allied from the chemical and physical point of view, and therefore belong together in a single zone.

It is further to be noted that the classification is based upon one idea throughout. There is no overlapping, although the different belts and zones are side by side and grade into one another.

After the miversal geological applicability of the classification proposed 
is understood and its chemical and physical significance appreciated, one sees how partial, how overlapping, and how variable are the criteria npon which are based such classifications as thermo-metamorphism, hydrometamorphism, dynanic metamorphism, contact metamorphism, regional metamorphism, ete.

\section{RELATIONS OF ZONES OF KATAMORPIISM AND ANAMORPIISM TO} ZONES OF FRACTURE AND FLOWAGE.

In comnection with metamorphism in the zones of katamorphism and anamorphism it may be recalled that the outer part of the surface of the earth may be divided into two zones upon a different basis." It has been shown from the structural point of view that we may divide the rocks of which we have knowledge into an upper zone of rock fracture and a lower. zone of rock flowage. Where the rocks are subjected to deformation while in the upper zone they nainly undergo mass fractures called bedding partings, faults, joints, fissility, etc. The deformation is accomplished but to a slight extent by fracturing of the individual particles and by differential movement between them. In the zone of fracture openings other than those formed by deformation may exist. In the sedimentary rocks are openings between the grains. In the lavas there may be gas openings. So far as the mass-mechanical forces are concerned openings of all of these different classes may persist indefinitely. In the lower zone-that of rock flowage-if openings could be supposed to be produced in any way, the pressure is so great that the rock flows and fills them nearly completely, except that water solutions and gases are to a small extent included in minute cavities. Rock flowage will be subsequently shown to be mainly accomplished by innumerable fractures of the mineral particles, by the recrystallization of the mineral particles, or by a combination of the two processes in any proportion. Mass fractures play but a subordinate part.

UPPER LIMIT OF ZONE OF FLOWAGE.

The depth at which deformation by flowage occurs depends upon many factors, of which the character of the rocks, the temperature, the water content, and the speed of deformation are of consequence. The more

" Van Hise, C. R., Principles of North American pre-Cambrian geology; with an appendix on flow and tracture of rocks as related to structure, by L. MI. Hoskins: Sixteenth Ann. Rept. U. S. Geol. Survey, pt. 1, 1896, p. 589. 
important factors which enter into the character of the rocks are the strength and the mineral composition. The stronger the rock the greater is the depth at which flowage begins. The rocks the materials of which are refractory, as, for instance, those composed of quartz and feldspar, require a greater depth in order that deformation may take place by flowage than those rocks the materials of which are readily acted upon chemically, as, for instauce, calcite.

The higher the temperature the less the depth in order that deformation may take place by flowage. Since the temperature increases normally at the rate of $1^{\circ} \mathrm{C}$. for 30 meters, and since in consequence of orogenic movements and igneous intrusions the increase in temperature with depth is often much more rapid than this, heat is a very important factor in the depth at which rock flowage occur's.

Since rock flowage may be in large measure by recrystallization, and recrystallization is dependent to a large extent upon the amount of water present, the greater the amount of water the more readily does deformation take place by flowage and therefore the less is the depth at which flowage begins.

The speed of deformation is also of very great consequence in limiting the upper part of the zone of flowage. The more rapid the deformation the greater the depth of the zone of flowage; the slower the deformation the more moderate its depth. Speed of deformation, and therefore the time consumed in a given deformation, is of very great importance. It is well known that a stress not sufficient to rupture a material or to appreciably deform it withiu a short time, if applied for a loug time may produce important flowage deformation. The geologist must give this factor of time greater weight than scientists in any other subject. How important it is may be illustrated by the deformation of rock ${ }^{a}$ as a result of placing it in an unusual position. In cemeteries marble slabs have been placed horizontally and supported at the ends; in the course of a score or more of years such slabs are found to luave sagged in the middle a very considerable amount. This is illustrated in the cemetery of Jefferson City, Mo., where a slab about 1.8 meters long, .9 meter wide, and 5.08 centimeters thick,

"Van Hise, C. R., Principles of North American pre-Cambrian geology: Sixteenth Aun. Rept. U. S. Geol. Survey, pt. 1, 1896, p. 594. 
suspended at the ends, has sagger 3.8 centimeters in the middle. ${ }^{a}$ If it had been attempted to bend the slab at the outset to this extent, undoubtedly it would have been ruptured. The change in form without rupture is possible only by rock flowage, through a rupturing and differential movement of the solid particles with reference to one another, or by solution and redeposition-i. e., by granulation or recrystallization, or by the two combined.

On the assumptions (a) that the strength of the rocks is the same as at the surface, (b) that the rocks are all of the same kind, (c) that the temperature is the same as at the surface, (d) that the water present does not make any difference in the character of deformation, (e) that the rocks yield as readily by fracture as by flowage, (f) that the rocks break as readily by fracture when the deformation is slow as when it is rapid, and (g) that the rocks are among the strongest, I have calculated that the maximum depth of the upper part of the zone of flowage under mass-static conditions can not be greater than 12,000 meters. All of these assumptions, except the first, are in favor of great depth for the zone of flowage. It is explained (Chapter VIII, p. 672) that where rocks are under pressure in all directions the rigidity is probably greater than at the surface. Therefore the assumption that the rocks are no stronger below than at the surface might lead to too small a depth. However, the other assumptions wonld give too great a deptl, because the great majority of rocks are not nearly so strong as the strongest, and many of them have only a small fraction of this streng,th; because the temperature increases with increase of depth, with orogenic movements, and with intrusives; because water is present in considerable quantity, and where this agent is available with higher temperatures the rocks are deformed by flowage rather than by fracture (see p. 188); and, finally, because the rocks are ordinarily deformed so very slowly that with a rather moderate pressure the deformation takes place by flowage rather than by fracture. I can see no way to determine to what extent these factors render the maximum depth calculated too great; nor can any estimate be made as to how far the factor (a) renders the maximum depth calculated too small; but I suspect that the various factors giving too great a depth are of far greater consequence than the one factor giving too small

a Winslow, A., An illustration of the flexibility of limestone: Am. Jour. Sci., 3d ser., vol. 43 , 1892, pp. 133-134. 
a depth. Since there is no theoretical way accurately to evaluate these factors and thus to calculate the maximum depth of the upper part of the zone of flowage, one can judge of its real depth only by observation in mountain areas where deep-seated rocks have been deformed when buried under an approximately determinable thickness of rocks and afterwards have been brought to the surface by denudation. From observation data I suspect the maximum depth calculated is much too great, perhaps twice. too great even for the strongest rocks; and for the weaker rocks it is certain that the alterations characteristic of the zone of flowage occur at depths but a fraction of 10,000 or 12,000 meters.

The boundary between the zone of fracture and the zone of flowage is approximately the same as the boundary between the upper and lower physical-chenical zones if indeed it is not identical with it. We may therefore say that the upper physical-chemical zone, the zone of katanorphism, and the zone of fracture are synonymous terms, as are also the lower physical-chemical zone, the zone of anamorphism, and the zone of flowage. The reasons for the correspondence of the zone of fracture with the zone of katamorphism, and of the zone of flowage with the zone of anamorphism, are clear.

To the bottom of the zone of fracture the rocks are strong enough to support themselves, hence there is not pressure in all directions greater than the strength of the rocks, and openings may exist. The reactions may therefore take advantage of these spaces and fill them, thus expanding the volume of the rocks without lifting them or doing the mechanical work of rupturing them. The openings which may thus be utilized vary from those of supereapillary size, such as bedding partings, fault and joint openings, to subcapillary openings between the individual grains. In order to thus fill these spaces, no large amount of work must be done against pressure by the chemical agents, but in proportion as the spaces are filled it is more and more difficult for the reactions to occur requiring expansion of volume, as an increased amount of work must be done against pressure.

However, below the bottom of the zone of fracture, in the zone of flowage, the pressure in all directions is greater than the strength of the rocks. If supercapillary spaces be supposed to be present they would be closed by flow, unless this were prevented by occluded water or some other liquid or a gas which could not escape. If a reaction here occurs which 
demands expansion of rolume, it would be necessary to lift the entire superincumbent mass of rock, and this would require a rast amount of work. This work chemical affinity is usually not sufficiently strong to accomplish, therefore reactions do not take place which give increased volume; but on the contrary, the pressure forces reactions in the opposite sense from those in the upper zone, as a result of which the volume of a material is diminished. If the reactions diminishing volume can be of such a character as to liberate heat, this will oceur; but freqnently, in order to produce a decreased rolume, chemical reactions must take place which absorb heat. In this paper on metamorphism the terms zone of katamorphism and zone of anamorphism are used, as being most serviceable. In strnctural work, howerer, the equivalent terms zone of fracturing and zone of flowage are more serviceable and therefore will there hold their place.

It may be seen on page 167 , also on pages $766-768$, that the passage from the zone of katamorphism to the zone of anamorphism is a gradation and not an abrupt change. The same is true of the change from the zone of fracture to the zone of flowage. (See pp. 187-189.) Therefore, whether the division of the outer crust of the earth into two zones be considered from the metamorphic point of view or from the structural point of view, there is a transition between the two. 


\section{CHAPTER V. MINERALS.}

In the previons chapters I have discussed the forces and agents of alteration, and the general nature of the alterations in the zones of anamorphism and katamorphism, including the two belts of the latter zone. We are now prepared to consider the particular alterations which affect the individual minerals in reference to these forces, agents, zones, and belts.

\section{SECTYON 1.-CHEMICAT AND MINERAL COMPOSITION OF THE KNOWN CRUST OF THE EARTH.}

For convenience the outer part of the crust of the earth of which we have positive knowledge will be called the crust. Clarke, ${ }^{a}$ for the purpose of considering the chemical composition of the outer part of the earth, confines this term "crust" to the part of the earth which extends from the tops of the mountains to 10 miles below sea level. He thinks it fair to assume that we may infer the approximate composition of this small part of the earth by the parts of it which may be observed at or near the surface. ${ }^{b}$ The term "crust" in this treatise will be used in the restricted sense of Clarke. But in so using the term there is no intention to imply that there is any sharp division between the crist and the deeper part of the eartl, to which the term "centrosphere" is applied.

Below is a table which gives the relative proportions of the twenty-one elements composing as much as 0.01 per cent of the crust of the earth as above defined, including the lithosphere, hydrosphere, and atmosphere, and also their atomic weights.

"Clarke, F. W., Relative abundauce of the chemical elements: Bull. U. S. Geol. Survey No. 78, 1891, p. 34.

$b$ Clarke, cit., pp. 34-37.

${ }^{c}$ Clarke, F. W., Analyses of rocks, laboratory of the United States Geological Survey, 1880-1899: Bull. U. S. Geol. Survey No. 168, 1900, p. 15. 
Elements of the earth's crust.

\begin{tabular}{|c|c|c|c|c|c|}
\hline Element. & Proportion. & $\begin{array}{l}\text { Atomic } \\
\text { weight. }\end{array}$ & Element. & Proportion. & $\begin{array}{l}\text { Atomic } \\
\text { weight. }\end{array}$ \\
\hline Oxygen & $\begin{array}{c}\text { Per cent. } \\
47.02\end{array}$ & 15.88 & Manganese . ....... & $\begin{array}{c}\text { Per cent } \\
.07\end{array}$ & 54.57 \\
\hline Silicon ........... & 28.06 & 28.18 & Sulphur ..... & .07 & 31.83 \\
\hline Aluminum & 8.16 & 26.91 & Barium . . . . . . . . . & .05 & 136.39 \\
\hline Iron $\ldots \ldots$ & 4.64 & 55.60 & Strontium ......... & .02 & 86.95 \\
\hline Calcium .......... & 3.50 & 39.76 & Chromium ... & .01 & 51.74 \\
\hline Magnesium _. . . . & 2,62 & 24.10 & Nickel .... & .01 & 58.24 \\
\hline Sodium .. & 2.63 & 22.88 & Lithium ... & .01 & 6. 97 \\
\hline Potassium .......... & 2.32 & 38.82 & Chlorine ... & .01 & 35.18 \\
\hline Titanium . . . . &. \pm 1 & 47.79 & Fluorine..... & .01 & 18.91 \\
\hline Hydrogen .. & .17 & 1.00 & . & $1 \cap 0 \Omega 00$ & \\
\hline Carbon $\ldots \ldots \ldots$ & .12 & 11.91 & & 10. & \\
\hline Phosphorus. . . . . . & .09 & 30.79 & & & \\
\hline
\end{tabular}

From this table it is seen that of the metallic elements aluminum, iron, magnesium, calcium, sodium, and potassium are the only ones which may be called abundant, and that of the nonmetallic elements oxygen and silicon are the only two which are abnndant, althongh carbon, sulphur, and chlorine are very important, aud still others of the nonmetallic elements, such as fluorine and phosphorus, are of considerable consequence. These elements combined, or rarely alone, as they occur in the natural state, are called minerals.

The more important minerals are classified into (1) elements, (2) oxides, (3) salts of the binary acids, and (4) salts of the ternary acids. Of the twenty-one elements above given, only oxygen, iron, nickel, sulphur, and carbon occur in the elemental form, and with the exception of oxygen the amounts thus occurring are insignificant. The free oxygen is mainly contained in the atmosphere, but large quantities are also included in the hydrosphere and lithosphere. The oxides comprise both hydrous and anhydrous minerals. Of the salts of the binary acids, the sulphides are of predominant importance, but the chlorides and fluorides are of some consequence. The salts of the ternary acids are the predominant minerals of the earth's crust. 'They inclucle silicates, carbonates, titanates, phosphates, and sulphates. These compounds are mentioned in the order of their importance; indeed, the silicates are of dominating importance, but MON XLVII-04-13 
next to them stand the carbonates, and the titanates and phosphates are subordinate. Therefore the acids of the silicates and carbonates-i. e., silicic and carbonic acids-are the great rock-forming acids.

The natural combinations of the elements, so far as they occur as important rock-making constituents, their systems of crystallization, chemical formulie, molecular weights, logarithms of molecular weights, specific gravities, logarithms of specific gravities, molecular volnmes (i. e., molecular weights divided by the specific gravities), and logarithms of molecular volumes, are given in tables below alphabetically arranged.

In the tables the chemical formulæ are usually those of the smallest possible molecules. There is no attempt to make the formulæ correspond with the real molecular structure of the minerals, since in the present state of knowledge it is quite impossible to do this. It therefore follows that the molecular weights, molecular volumes, and logarithms of the same in a given case are relative. The table should not be used to compare the absolute molecular weights and molecular volumes of the different minerals, as this would give wholly misleading results. For instance, actinolite, the second mineral in the table, varies in the amount of magnesium and iron so that it may have three special formulie. These formulie as written make the molecular weight of the mean molecule twice that of the smallest and that of the largest molecule four times that of the smallest. This results in similar variations in the molecular volumes and also considerable variations in the logarithms Manifestly there are no such differences as these. Probably the true molecular weights and molecular volumes, and consequently the logarithms, are very close to one another. However, the numbers given in the table serve the purpose, as explained on pages 208-210, of calculating the changes of volumes when the particular varieties of the mineral actinolite represented by the formula are transformed to other minerals. These remarks as between the different varieties of actinolite apply equally well as between other minerals and their different varieties.

The letters D, G, I, and C, following formulæ or specific gravities, signify that the authorities from which the same are taken are, Dana, Groth, Hintze, and Clarke, respectively. 
ROCK-MAKING MINERALS.

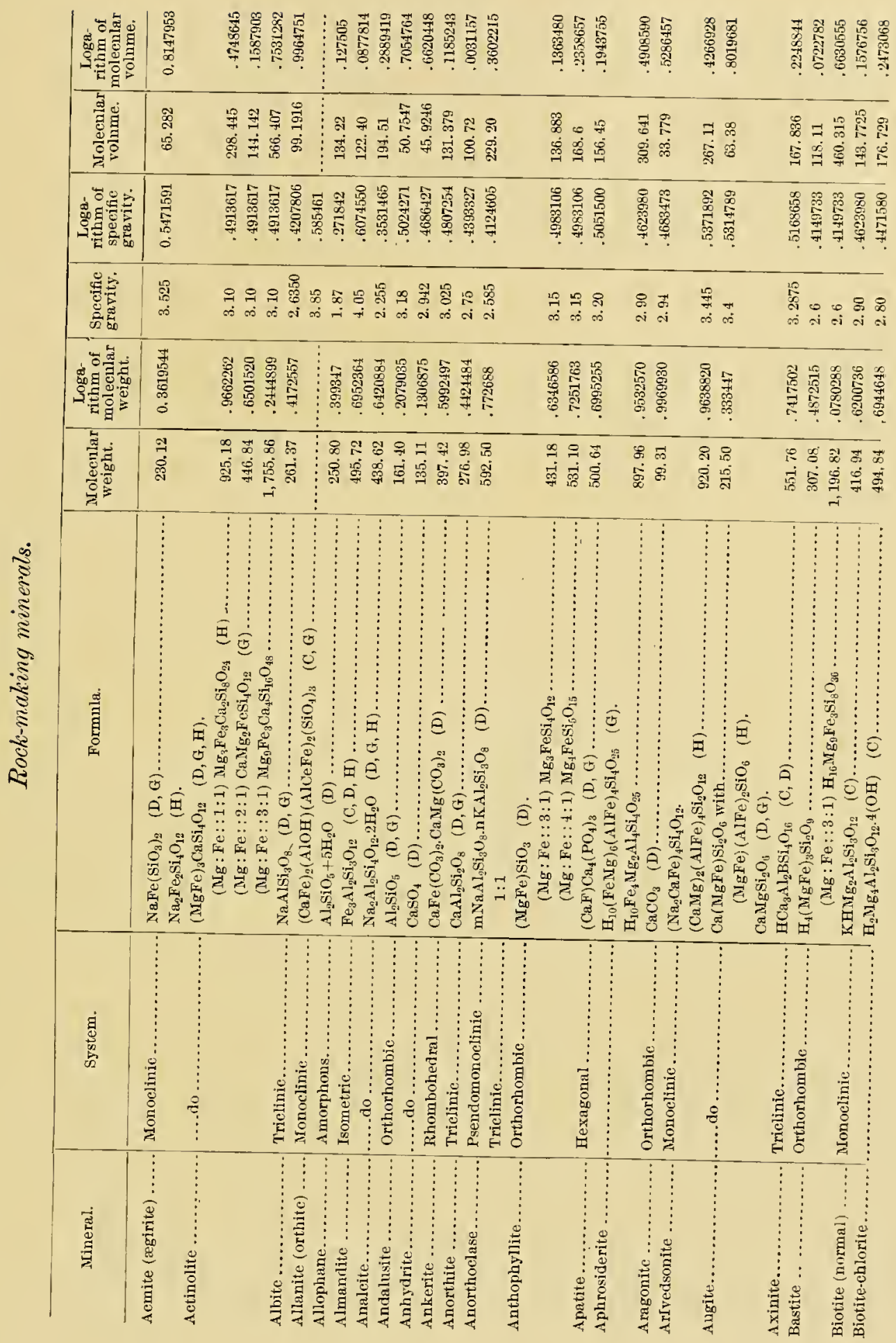




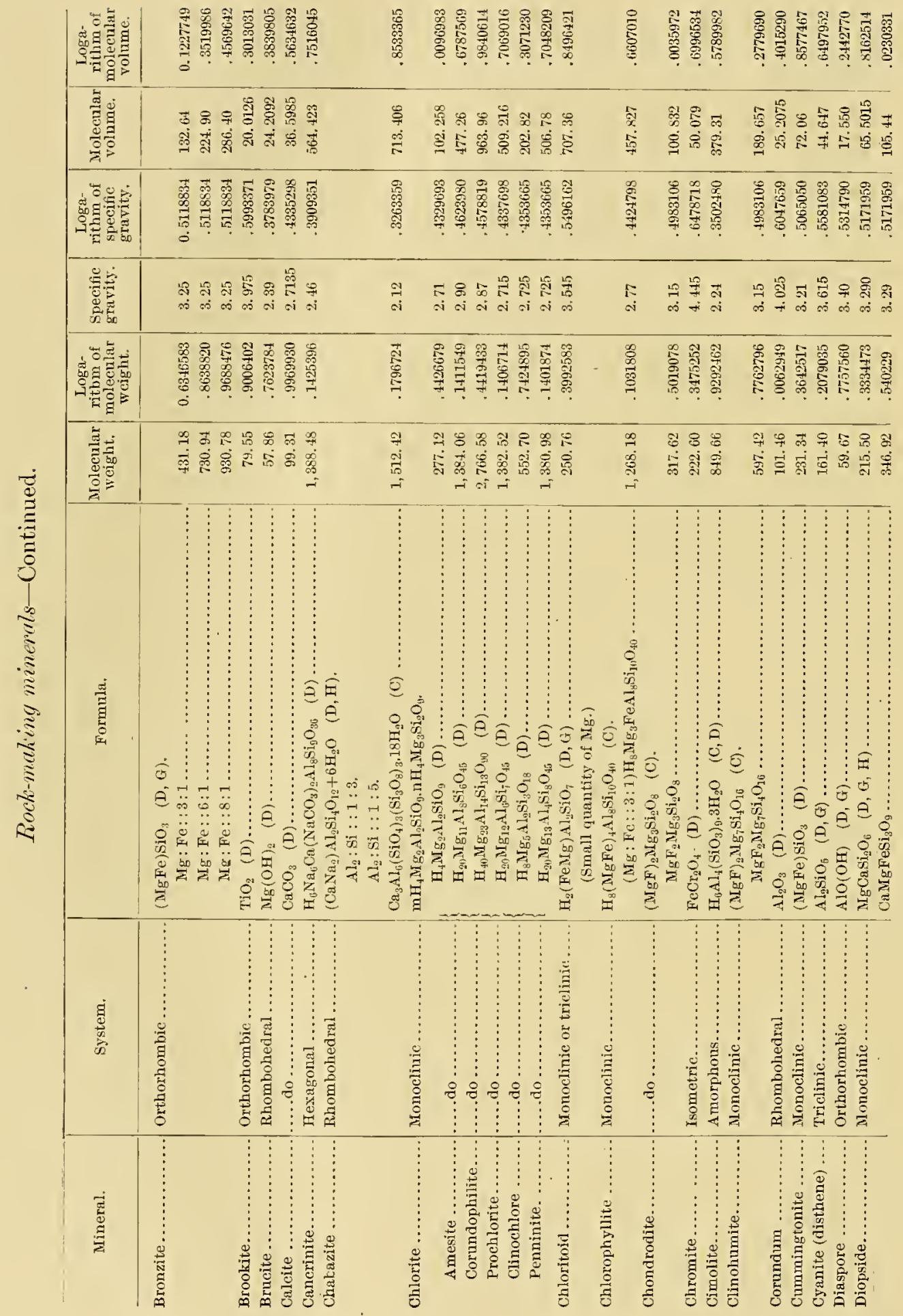


ROCK-MAKING MINERALS.

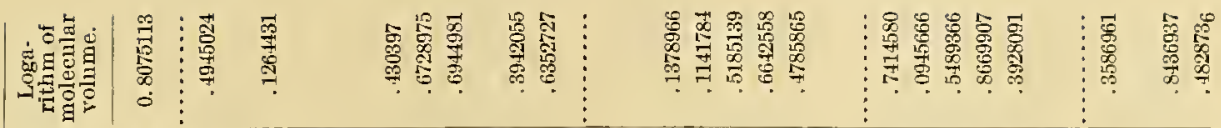

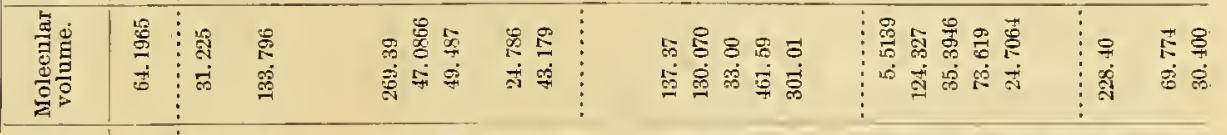

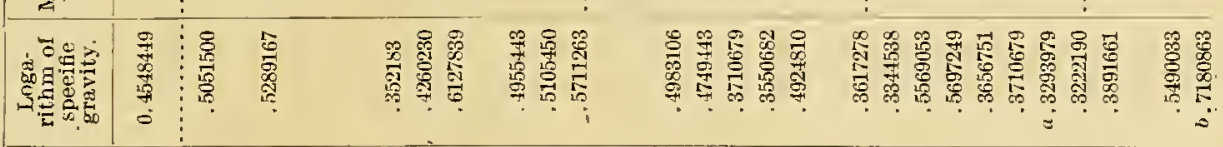

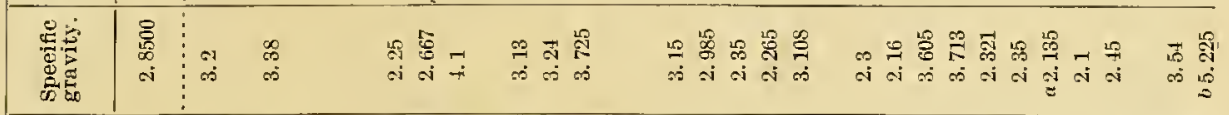

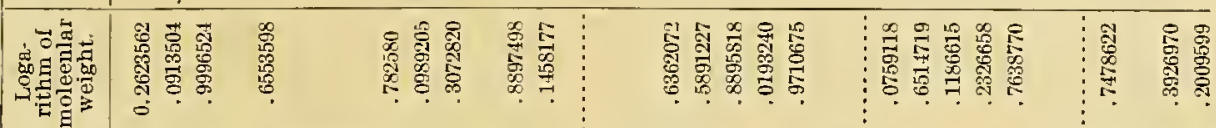

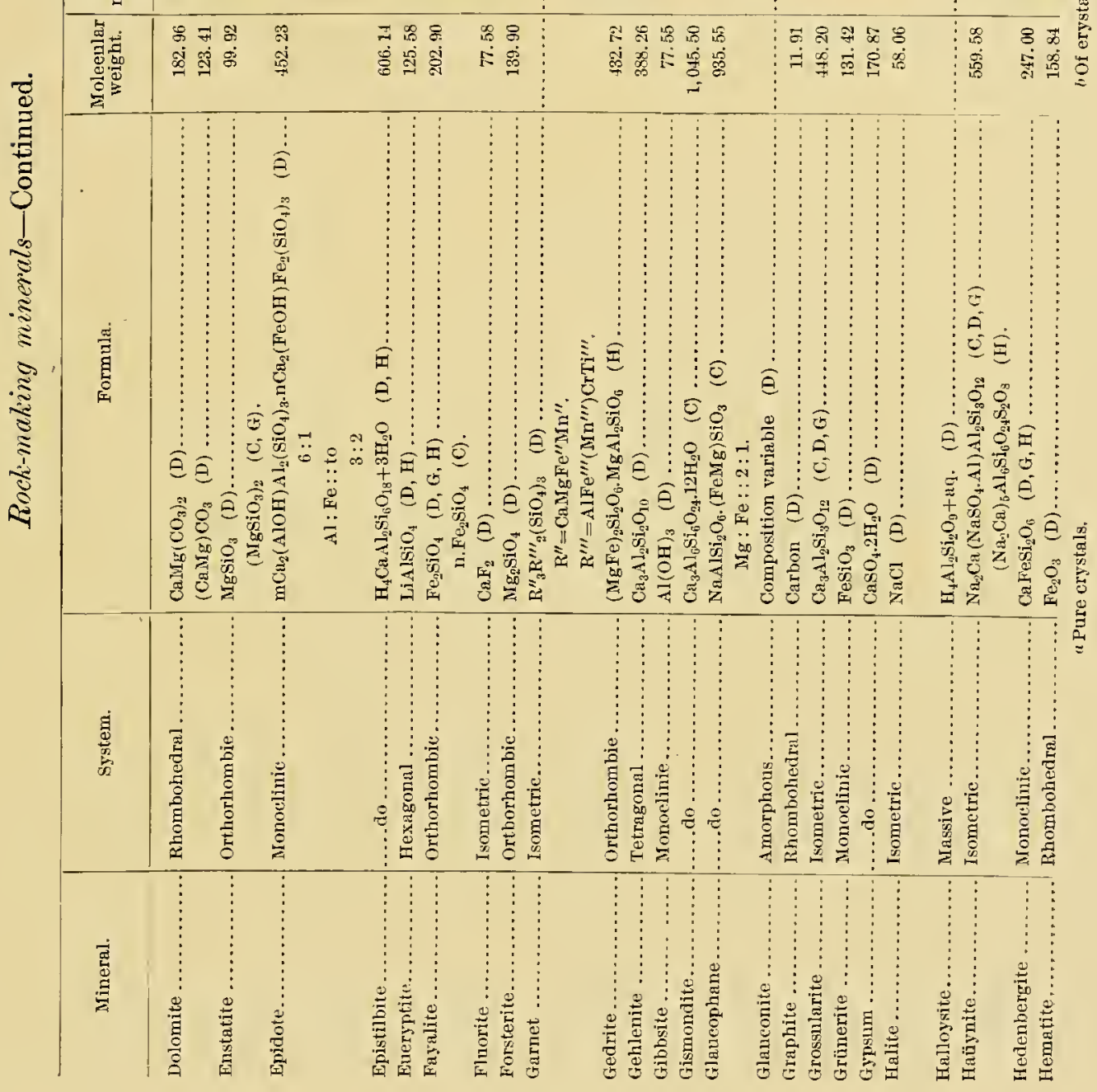




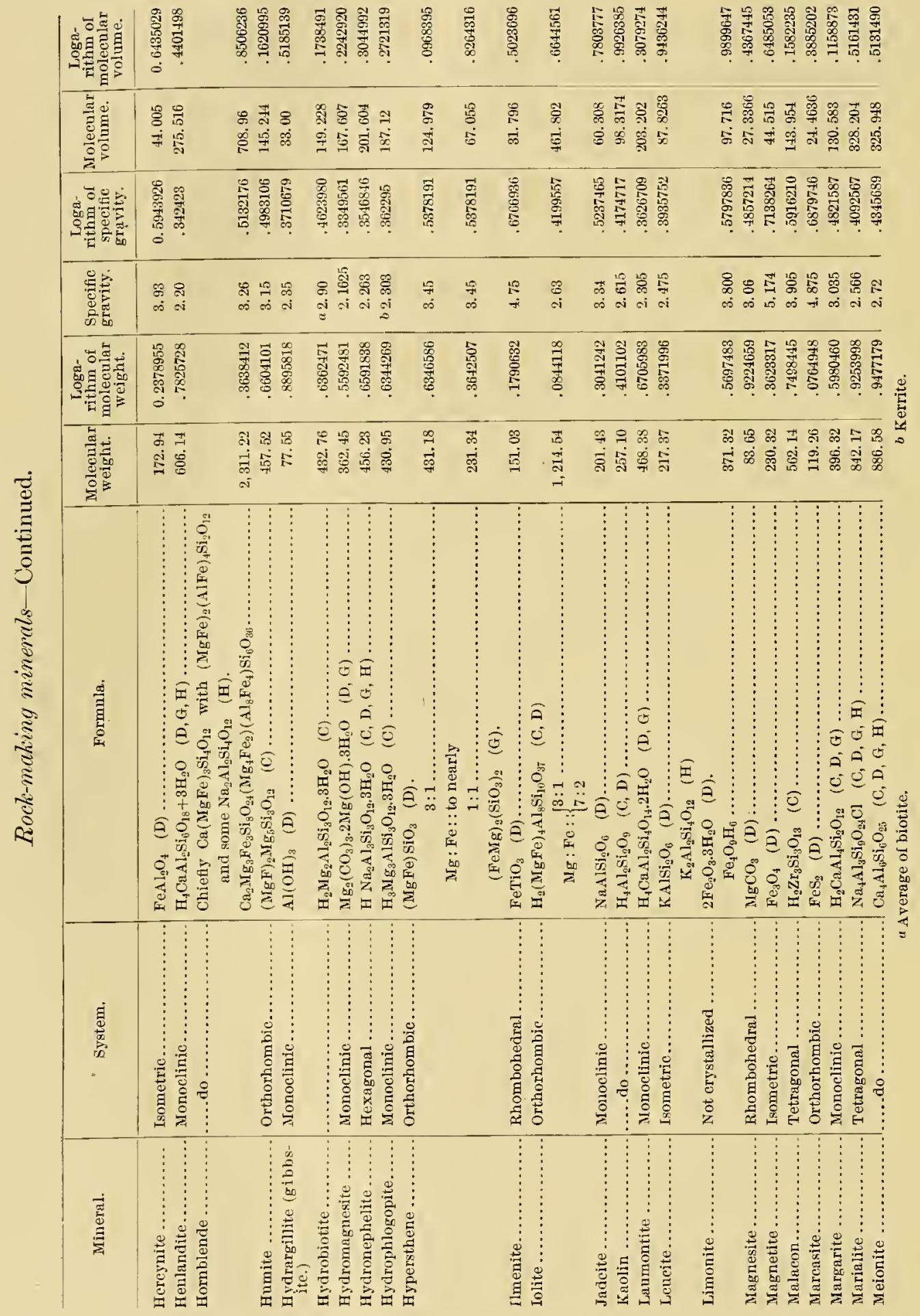


ROCK-MAKING MINERALS.

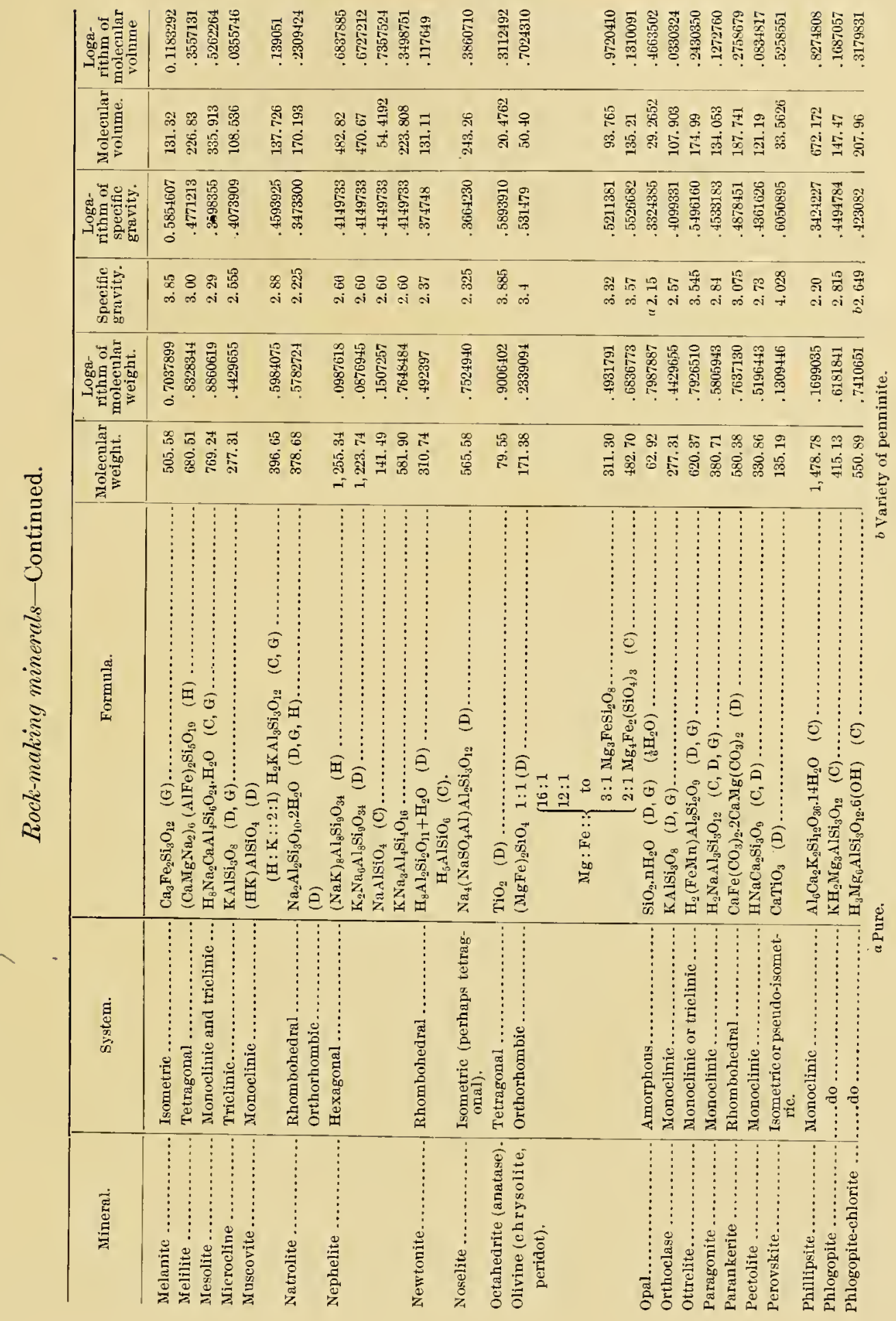


A TREATISE ON METAMORPHISM.

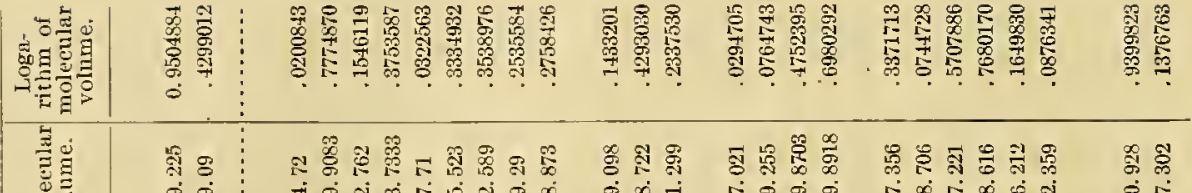

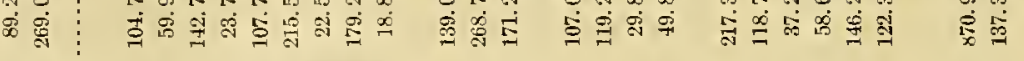

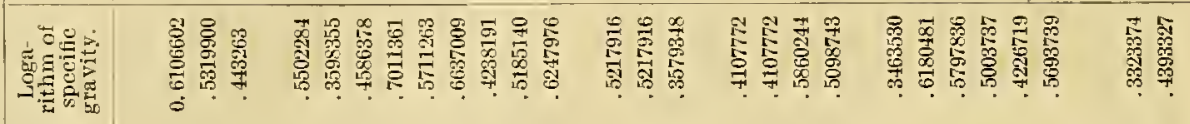

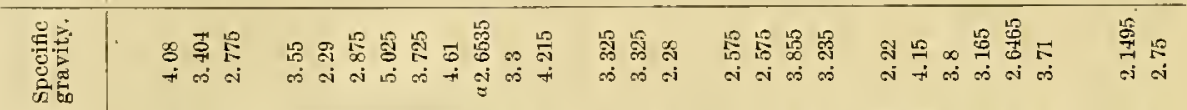

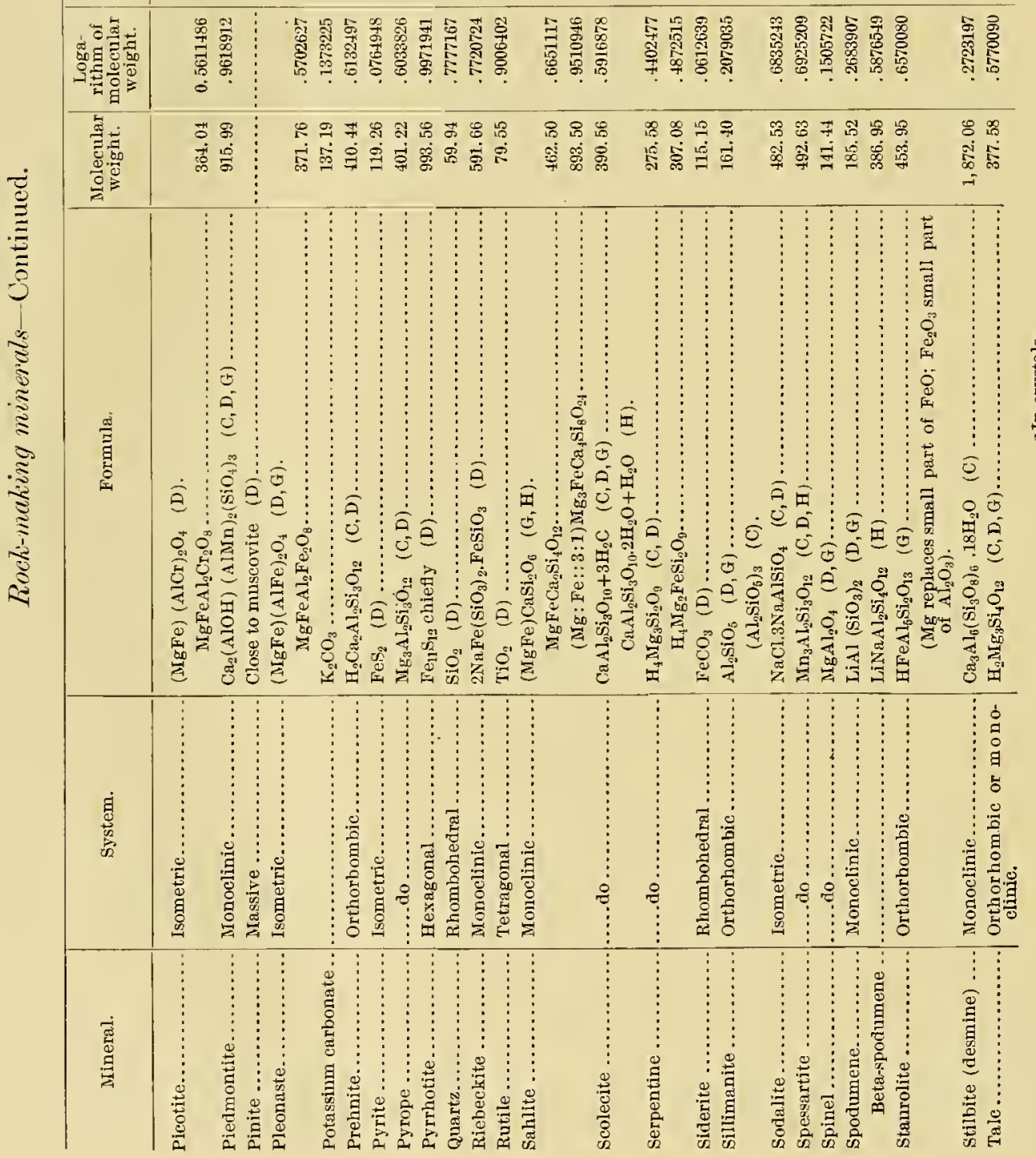


ROCK-MAKING MINERALS.

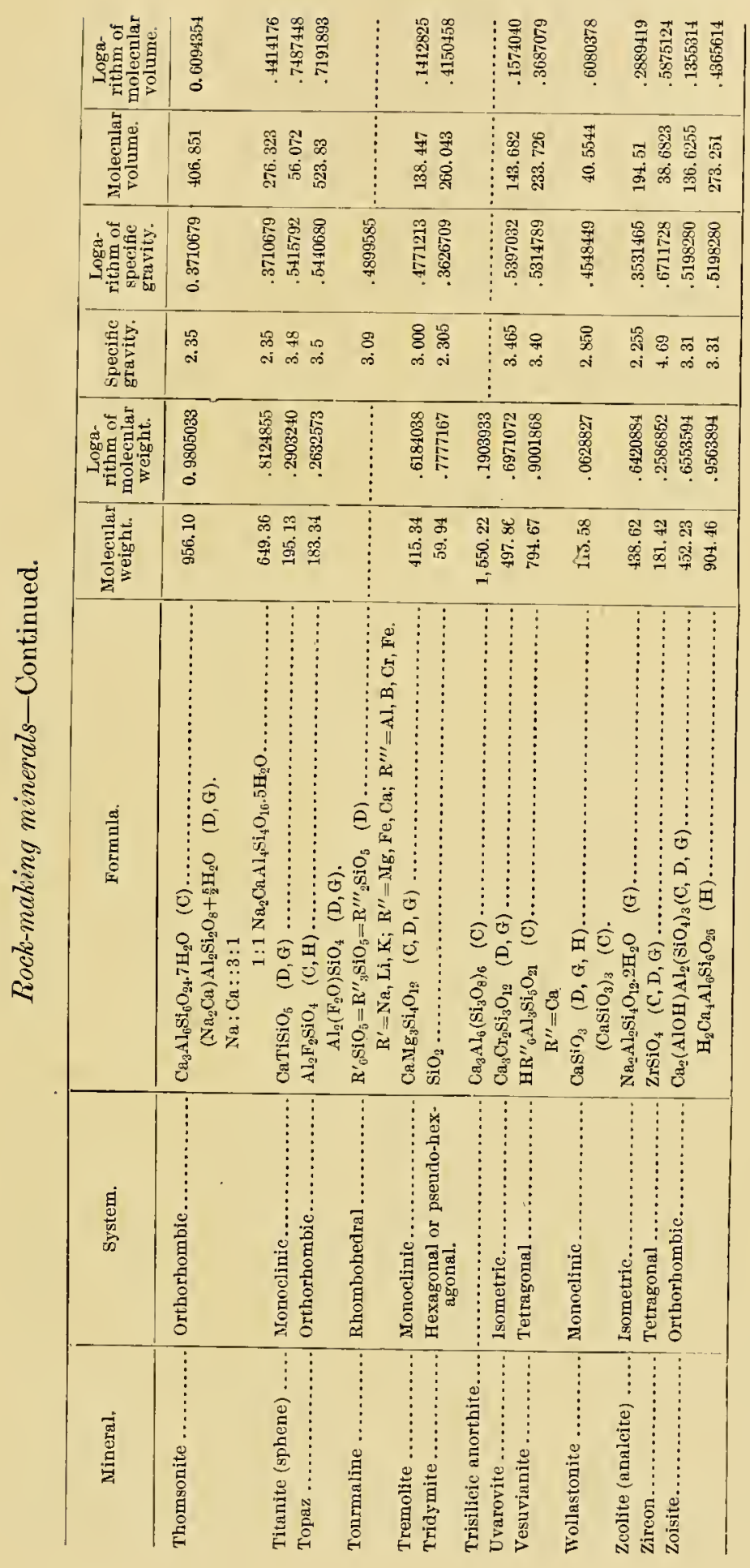




\section{SECTION 2.-GENERAL NATURE OF ALTERATIONS.}

Minerals may be altered (1) without chemical change and (2) with change of chemical composition.

\section{ALTERATION WITHOUT CHANGE IN CHEMICAL COMPOSITION.}

The alterations which occur without changes in chemical composition are (a) molecular rearrangement and (b) simple recrystallization.

\section{MOLECULAR REARRANGEMENT.}

Molecular rearrangement alone means passage from one crystalline form to another crystalline form. Such change of form may result from changed physical conditions, as, for instance, change in temperature or pressure or movement. As an example of molecular rearrangement due to change of temperature may be mentioned leucite, which crystallizes from a hot magma in the regular system, but which changes upon cooling to ordinary temperatures to a complex twinned anisometric form. An example of a change dne to pressure is furnished by orthoclase, which is said for this reason to alter to microcline. ${ }^{a}$ Molecular readjustments such as above are simply changes of form, and are therefore called paramorphism.

\section{SIMPLE RECRYSTALLIZATION.}

Simple recrystallization nsually but probably not always occurs through the medium of a certain amount of water, which is able to take material into solution and deposit it from solution. Changing pressure and comparatively high temperatures are favorable conditions for such recrystallization. Perhaps the most common example of recrystallization without chemical change is that of the transformation of amorphous or finely crystalline calcium carbonate to crystalline or more coarsely crystalline calcium carbonate, such as occurs in limestones and marble. This process has been called marmorosis. Another instance of recrystallization without change in chenical composition which takes place, on an extensive scale, is alteration of flinty or finely crystalline quartz to coarsely crystalline quartz.

\section{ALTERATION WITH CHANGE IN CHEMICAL COMPOSITION.}

Alterations with chemical change may take place (1) without the addition or subtraction of material or (2) with the addition or subtraction

"Dana, J. D., A system of mineralogy, Descriptive mineralogy by E. S. Dana, Wiley \& Sons, New York, 6th ed., 1892, p. 318. 
of material. For either of these changes the presence of water is required in most instances, the alterations taking place through solntion and redeposition, although it is not impossible that solids may act upon one another to an important extent without the help of water.

ALTERATION WITHOUT ADDITION OR SUBTRACTION OF MATERIAL.

In the changes which occur under this case the material moves only short distances. Such changes may be (a) a crystallization of an amorphous substance or (b) interior alteration of mineral particles.

An instance of the crystallization of an amorphous substance is furnished by the devitrification of glass. In this alteration the uniform homogeneous solid glass changes into a heterogeneous crystalline solid, the different mineral particles of which have differing compositions. This involves segregation of the different elements in various proportions into the different minerals. It is therefore clear that the materials lave moved very short distances.

Interior alteration of mineral particles is effected by the change of one mineral into two or more minerals. This is illustrated by the change of pyrope into enstatite, spinel, and quartz; the change of pyrope into hypersthene, spinel, and quartz; the change of spodumene into encryptite and albite; the change of almandite into hypersthene, spinel, and quartz; and the change of titanite into perovskite and quartz.

ALTERATION WITH ADDITION OR SUBTRACTION OF MATERIAL.

The changes which take place with the addition or subtraction of material may vary from those which involve the slightest addition or subtraction to complete substitution. The added material may come from afar or from the adjacent mineral particles. The subtracted material may enter into an adjacent mineral particle or may be transported great distances before entering into a new mineral. Reactions between adjacent minerals may produce new minerals. Two or more minerals may unite to produce a single mineral. For example, olivine and quartz may pass into anthophyllite; nephelite and halite into sodalite; albite and halite into marialite. Or two or more minerals may unite to produce two or more new minerals. For example, rutile and magnetite may pass into ilmenite and hematite; diopside and magnetite into tremolite and calcite; sallite, siderite, and magnesite into actinolite and calcite; augite, siderite, and 
magnesite into hornblende and calcite; or the reverse of this, hornblende and calcite into augite, siderite, and magnesite.

The changes here belonging are by far the most numerous and important of the various classes; iudeed, are vastly more important than all of the other classes together. By far the greater number of reactions written out on the succeeding pages for the alterations of the various minerals fall under this heading.

The more important of these alterations, considered from the point of view of the nonmetallic elements, may be classified into:
(1) Oxidation.
(2) Deoxidation.
(3) Hydration.
(4) Dehydration.
(5) Carbonation.
(6) Decarbonation.
(7) Silication.
(8) Desilication.
(9) Silicification.
(10) Desilicification.

Less important reactions are:
(11) Sulphidation.
(13) Sulphation.
(12) Desulphidation.
(14) Desulphation.
(15) Titanation.
(17) Phosphation.
(19) Chloridation.
(21) Flnoridation.
(23) Boration.
(16) Detitanation.
(18) Dephosphation.
(20) Dechloridation.
(22) Defluoridation.
(24) Deboration.

A number of these reactions are of small consequence so far as the alterations of rocks are concerned; but all are important with reference to the development of minerals, and especially in reference to economic products. This phase of the subject in reference to the metallic products is treated in Chapter XII.

(1) Oxidation is the addition of oxygen. Frequently the added oxygen is substituted for another element, often sulphur.

(2) Deoxidation is the subtraction of oxygen. Often the subtracted oxygen is replaced by another element-for instance, sulphur.

(3) Hydration is the addition of water, producing hydroxides.

(4) Dehydration is the subtraction of water from hydroxides. When carried to completion, anhydrous compounds are formed.

(5) Carbonation is the union of carbonic acid and base, or the substitution of carbonic acid for another combined acid, in either case producing carbonates. The oxide with which carbonic acid most frequentily unites is 
iron oxide. Carbonic acid may replace any of the other ternary rockforming acids, including silicic, ritanic, and phosphoric, and thus become united with any of the important bases. The carbonation of the silicates is of fundamental importance. The carbonation of the titanates and phosphates is unimportant.

(6) Decarbonation is the separation of carbonic acid from a base with. out the addition of other compounds, or with the substitution of another acid for the carbonic. The most frequent substituted acid is silicic.

(7) Silication is the union of silicic acid and base, or the substitution of silicic acid for a combined acid, in either case producing silicates. The only important oxide with which silicic acid unites as a rock-forming constituent is iron oxide. Silicic acid may replace carbonic, titanic, or phosphoric acid, thus becoming united with any of the bases with which it can combine. The silication of the carbonates is of fundamental importance. The silication of the titanates and phosphates is unimportant.

(8) Desilication is the separation of silicic acid and bases withont the addition of other compounds, or with the substitution of another acid for the silicic acid. The most frequent acid substituted is carbonic.

(9) Silicification involves the addition of silica without union with bases. The added silica may or may not replace other compounds.

(10) Desilicification involves the subtraction of free silica. The subtracterl silica may or may not be replaced by other compounds.

(11) Sulphidation is the union of sulphur with a metal forming sulphides. Added sulphur may be substituted for another element, usually oxygen.

(12) Desulphidation involves the subtraction of sulphur. Generally the subtracted sulphur is replaced by another element, usually oxygen.

(13) Sulphation is the union of sulphuric acid with base or the substitution of sulphuric acid for another combined acid, in either case producing sulphates.

(14) Desulphation is the separation of sulphuric acid and base, or the substitution of another acid for the sulphuric.

(15) Titanation is the union of titanic acid with base, or the substitution of titanic acid for another combined acid, in either case producing titanates.

(16) Detitanation is the separation of titanic acid and base, or the substitution of another acid for the titanic. 
(17) Phosphation is the union of phosphoric acid with base, or the substitution of phosphoric acid for another combined acid, in either case producing phosphates.

(18) Dephosphation is the separation of phosphoric acid and base, or the substitution of another acid for the phosphoric acid.

(19) Chloridation is the addition of chlorine, forming chlorides.

(20) Dechloridation is the subtraction of chlorine, destroying chlorides.

(21) Fluoridation is the addition of fluorine, forming fluorides.

(22) Defluoridation is the subtraction of fluorine, destroying fluorides.

(23) Boration is the union of boric acid with base, or the substitution of boric acid for another combined acid, in either case producing borates.

(24) Deboration is the separation of boric acid and base, or the substitution of another acid for the boric.

GENERAL STATEMENTS.

The foregoing processes are seen to be in pairs, in each case one of a pair being the reverse of the other. That is, deoxidation is the reverse of oxidation, dehydration is the reverse of hydration, etc. Moreover, one of the processes of a pair is in several of the cases frequently the complement of that of another pair. To illustrate, the processes of the following pairs are often complementary of each other, viz, oxidation and desulphidation, sulphidation and deoxidation, carbonation and desilication, silication and decarbonation. By complement is meant that one takes place simultaneously with the other, and that the two may really be one chemical reaction. In such a case the change may be considered from either of two points of view. To illustrate, the process of carbonation may be also a process of desilication, and the process of silication may be also a process of decarbonation. In general the process is named on the basis of the substance added rather than that subtracted, for such substance is the active agent which drives off the other and takes it place. It has been shown (pp. 168, 170-181) that for several reactions one of a pair is particularly characteristic for one of the zones of metamorphism. To illustrate, oxidation and its complement desulphidation, carbonation and its complement desilication, and hydration are particularly characteristic of the zone of katamorphism; sulphidation and its complement deoxidation, silication and its complement decarbonation, and deliydration are particularly characteristic of the zone of anamorphism. 
SECTION 3.-ROCK-MAKING MINERALS.

MANNER OF TREATMENT.

GENERAL STATEMENTS.

In this treatise only the principal rock-forming minerals will be considered. The point of view is not that of mineralogy but that of metamorphisur. So far as it seems advisable withont too much repetition, I shall consider each mineral in reference to the following:

(1) Its composition, crystallization, specific gravity, and source, so far as it is a rock-making mineral; but its occurrence in veins will not be considered.

(2) The minerals into which it may pass, giving their crystallizations, specific gravities, and compositions.

(3) The chemistry and physics of the processes of change, including the volume relations.

(4) The natural conditions under which the changes occur, and the causes of the changes.

With many minerals this ontline can be carried out nearly to completion. With others the present state of knowledge is such that it can be only very incompletely done. Consequently there is great variation in the satisfactoriness of the discussion of the different minerals. When the treatment of each of the minerals from these various points of view can be carried out we shall have an interlocking system by which each mineral is considered in its most important metamorphic connections. To a certain extent the plan involves repetitions, but in each case the important facts which concern an individual mineral are brought together. The method of treatment proposed seems advisable, for many minerals are both primary and secondary, and only by considering each mineral from both points of view is it possible to understand the causes of the changes as well as the changes themselves. Ordinarily the latter only are considered. When one of the sources of a mineral is the alteration of another the exact reactions concerned in the change are not given under the former, but may be found by referring to the latter mineral which is mentioned as its source. Ordinarily, however, qualitative statements are made. To illustrate, a source of limonite is siderite. The reactions involved in this change are to be found under siderite, not nuder limonite; but under 
the latter mineral the statement is made that the change generally involves liberation of heat and decrease of volume. But when a mineral is derived by precipitation from a solution, or results by the combination of several minerals, it is necessary to consider the chemistry and physics of the change in commection with the sources, for otherwise this important part of the history of metamorphism of minerals would be omitted.

In discussing the sources of a mineral when it is derived from other minerals the natural conditions of the alterations are not given, but may be found by referring to the minerals from which the one under discussion is derived. But where a mineral is derived by the interaction or union of several other minerals the natural conditions are discussed under the source of the mineral, for otherwise this part of the subject would be omitted.

As this treatise was originally planned it was designed to include the heat and volume changes with the chemical reactions. But with the present state of knowledge of the heat relations in chemical transformations the first has been found impracticable. While very few quantitative results can be given, in many cases it is possible to make a qualitative expression of the heat reaction. To illustrate, the heat of combination of calcium is far greater than that of iron in all analogous compounds in which determinations have been made; but such determinations have not been made with reference to the silicates. Where calcinm is replaced by iron in the alteration of the silicates it is inferred that a considerable amount of heat is absorbed, though the exac amount can not be specified. Vice versa, where iron is replaced by calcium, a considerable amount of heat is liberated. Of course, in each reaction the other chemical combinations which occur simultaneously should be considered, for they constitute i part of the chain, and in obtaining a correct end result their effects are vital. If, for instance, a salt of iron and a salt of calcium interehange acids, no general statement can be made as to the heat reaction. Therefore, if at the same time the iron replaces the calcium the calcium unites with an acid which was before in combination with the iron, the inference above given as to absorption of lieat can not be made.

For the calculation of the volume changes, the equations of the chemical reactions written out by me and the specific gravities of the minerals, taken from the standard Mineralogies, were turned over to Mr. A. T. Lincoln, who made the numerical computations. Subsequently Mr. R. M. Chapman 
repeated the work in order to verify it. The following well-known principle was employed:

The volume of the original compound is to the volume of the compound produced directly as their molecular weights and indirectly as their specific gravities.

Under this general principle are two cases:

Case 1. Where one solid compound alters into another solid compound. This case is illnstrated by the well-known changes of limestone to dolomite. In this change we have $2 \mathrm{CaCO}_{3}$ replaced by $\mathrm{HgCa}\left(\mathrm{CO}_{3}\right)_{2}$. The molecular weight of $2 \mathrm{CaCO}_{3}$ is 198.62. The molecular weight of $\mathrm{MgCa}\left(\mathrm{CO}_{3}\right)_{2}$ is 182.96. The specific gravity of calcite may be taken as 2.7135 ; of dolomite, as 2.85. The compound proportion is therefore as follows:

$$
\mathrm{V}: \mathrm{V}^{1}:: \begin{array}{r}
198.62 \\
2.85
\end{array}: \begin{aligned}
& 182.96 \\
& 2.7135
\end{aligned}
$$

or the volume of the dolomite is 87.70 per cent of that of the calcite; or, therefore, there is a decrease in volume of 12.30 per cent.

Case 2. This has three phases: (a) where two or more solid compounds unite to produce a single solid compound; (b) where a single solid compound breaks up, producing two or more compounds, and (c) where two or more solid compounds unite to produce two or more solid compounds. In this case the method of calculation is slightly different from case 1. The molecular weights of each of the compounds represented in the equations are divided by the specific gravities of the respective compounds. This gives their relative volumes. In phase (a) the volume of the resultant single compound is divided by the sum of the volumes of the producing compounds, and this gives the percentage of change. In phase (b) the sum of the volumes of the resultant compounds is divided by the volume of the original compound. In phase (c) the sum of the volumes of the resultant compounds is divided by the sum of the volumes of the original compounds. These different phases are so similar in method that it is necessary only to illustrate one of them. The first phase is illustrated by the formation of wollastonite by the union of calcite and quartz, the reaction being:

$$
\mathrm{CaCO}_{3}+\mathrm{SiO}_{2}=\mathrm{CaSiO}_{3}+\mathrm{CO}_{2} \text {. }
$$

The molecular weights of the three solid compounds are, respectively, MON XLVII $-04-14$ 
99.3I, 59.94, and 115.58. Their specific gravities are 2.7135, 2.6535, and 2.85 , respectively. The volume of the wollastonite is, therefore:

$$
\frac{115.58}{2.85} \div\left(\frac{99.31}{2.7185}+\frac{59.94}{2.6535}\right)=0.685
$$

That is, the decrease in volume in this case of silication of calcite is 31.5 per cent.

In order to expedite the laborious numerical calculations of the volume relations for the very numerons alterations, $\mathrm{Hr}_{\mathrm{r}}$. Lincoln completed the table on pp. 195-201 by adding the molecular weights, the logarithms of the molecular weights, the logarithms of the specific gravities, the molecular volumes, and the logarithms of the molecular volumes of each of the minerals. These determinations have been carefully verified by Mr. Chapman, and may be used to check the volume changes given in the succeeding pages, and also to make additional rolume calculations.

In calculating the volume relations, mnless otherwise specified, the compounds on both sides of the equations are regarded as solid except those which by themselves independent of the solvents are liquids or gases, such as $\mathrm{H}_{2} \mathrm{O}$ and $\mathrm{CO}_{2}$. All such compounds are supposed to be added in the solutions or to be taken away by the solutions, and therefore are not taken into account in the volume calculations. In general these liquid and gaseous compounds do undoubtedly escape in large measure, although in some cases they are contined as inclusions within the minerals formed. (See p. 678.)

Where $+\mathrm{k}$ is added to the equation, this signifies that heat is liberated; where $-\mathrm{k}$ appears, this means that heat is absorbed by the reaction.

No claim is made that the equations which are written in the following pages exactly represent the changes that take place in the alterations of the various minerals into other minerals Indeed, the probability is that not half exactly represent the facts; for the great majority of the reactions are more complicated than written, and in many cases substances in the solutions or as solids not taken into account are concerned. Since these are the facts, the question may be asked why the equations are written. 'The answer is, first, that at some time the attempt must be marle to give a first approximation to quantitative exactness in the alteration of minerals. The equations found on the following pages represent such an atiempt. Before the appearance of this treatise scarcely more than a seore of minernl 
alterations have been expressed by chemical equations, and in fewer still have the volume relations been calculated. Second, the imprerfect equations herein contained will be sure to lead to closer investigations of the nature of the alterations, and to improved equations representing them. Thus the progress of science will be promoted by the set of equations here given, even if the great majority of them are defective. Third, it is believed that when a more nearly correct set of equations is written it will be found that the large majority of the equations lerein contained substantially represent the facts, and consequenty that the volume clanges are in most cases roughly approximate. Many of them may be changed by a few per cent one way or the other; but the sign of few will be changed, and this is the fundamental point in reference to the zones in which the alterations occur.

The weakest point in the accuracy of the volnme reactions is not found in the chemical equations, but in the inexactness of the specific gravities of the minerals as given in the text-books. For most minerals there is a considerable range of specific gravity given; and with the exception of one or two minerals, such as calcite and quartz, it is impossible to ascertain the exact specific gravity of the pure minerals. Tn the table the mean between the two best determined extremes is given as the best approximation available of the specific gravities of the pure minerals. For most minerals these extremes are taken from Dana's System of Mineralogy.

The facts as to the occurrences and alterations of the varions minerals given in the following pages are largely taken from the standard textbooks of mineralogy and petrology, and especially from Dana's great System of Mineralogy. The information available is especially imperfect as to the manner in which the complex minerals, and particnlarly the complex silicates, break up into simpler compounds in the belt of weathering. As explained fully in the following chapter, this is a general process. For the better known of these changes equations are written, but no attempt is made to express by equations the mamner in which many of the minerals decompose and degenerate, because so little exact information is available upon which to base such equations.

As already stated, only those minerals will be considered which are important rock-making constituents. It is impracticable at the present time to consider the physical-chenistry" of the rarer minerals. 
Following the ordinary classification, the abundant rock-making constituents may be considered under the headings: Native Elements, Sulphides, Fluorides, Oxides, Carbonates, Silicates, Titanates, Phosphates, and Sulphates.

\section{NATIVE ELEMENTS.}

GRAPHITE.

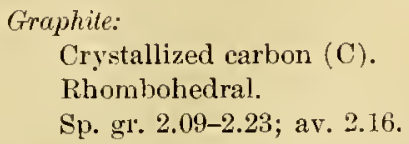

Occurrence._Graphite occurs as a very widely disseminated constitnent in the extremely metamorphosed sedimentary rocks, which in their original condition contained carbonaceous material. It is especially prevalent in scales in the marbles, schists, and gneisses. In some instances the original beds were so heavily carbonaceous as to give considerable layers a large percentage of which is graphite. Such layers are illustrated by the graphitic shales of Worcester, Mass. ${ }^{a}$ Graphite occur's to some extent with the very hard anthracite coals, a part of the carbon having passed over to the graphitic condition. Such graphitic coals occur in the Rhode Island coal field. ${ }^{b}$ The reaction producing graphite as a metamorphic mineral requires great pressure and takes place with decrease in volume. This mineral in the sedimentary rocks is therefore a product of the zone of anamorphism.

Graphite is said to occur as an original constituent in some basaltic rocks. During the alterations of carbonaceous rocks the hydrocarbon compounds, as gases, oils, and bitnmen, wander widely in the solutions. In some cases such compounds are deposited in the openings of original rocks. Later these compounds may be altered to graphite, and yet the carbon not be an original constitnent of the magma from which the rocks crystallized. Alterations.-Alterations of graphite are not recorded, but it is by no means certain that this mineral is not very slowly oxidized under favorable conditions in the belt of weathering.

THE SULPHIDES.

The sulphides which are important as rock-making minerals are pyrrhotite, pyrite, and marcasite. Many other sulphides are important in

a Perry, J. H., Note on a fossil coal plant found at the graphite deposit in mica-schists at Worcester, Mass.: Am. Jour. Sei., 3d ser., vol. 29, 1885, pp. 157-158,

$b$ Shaler, N. S., Woodworth, J. B., and Foerste, A. F., Geology of the Narragansett Basin: Mon. U. S. Geol. Survey, vol. 33, 1899, p. 82. 
OCCURRENCE OF PYRRHOTITE, PYRITE, AND MARCASITE. 213

the genesis of ore deposits. These, however, will be considered only in the chapter on that subject.

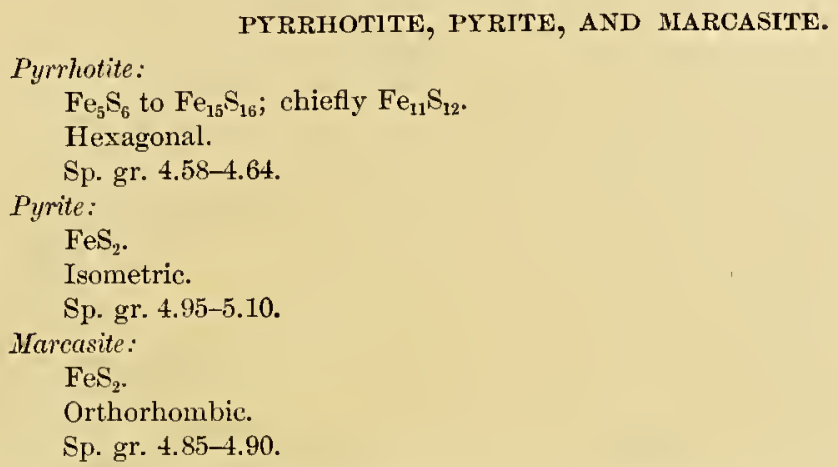

occurrence.-Pyrrhotite, pyrite, and marcasite are very widespread accessory minerals, occurring in rocks of all ages and all kinds. So far as known, these minerals aru not abundant original pyrogenic constituents, although they frequently are found along the contact between intrusive and other rocks, occurring in both the intrusive and the intruded rocks. Pyrrhotite is an original mineral in meteorites. These minerals extensively form in rocks in volcanic districts through the action of solutions of hydrogen sulphide and other sulphide solutions upon iron salts. As secondary minerals . in the sedimentary rocks, and to a less extent in the igneous rocks, the sulphides are extensively formed through the reducing action of organic compounds upon the sulphites and sulphates, especially the latter, and particularly iron sulphate. Such reduction is characteristic of the belt of cementation and the zone of anamorphism; but in the latter zone pyrrhotite or pyrite, rather than marcasite, probably forms.

The reducing agent of the sulphites and sulphates may be either a solid organic compound or one of its gaseous products of decomposition, such as carbon monoxide $(\mathrm{CO})$ and carburetted hydrogen $\left(\mathrm{CH}_{4}\right)$. If the reducing agent be taken as $\mathrm{CO}$, the reaction for pyrite and marcasite may be:

$$
2 \mathrm{FeSO}_{4}+7 \mathrm{CO}=\mathrm{FeS}_{2}+\mathrm{FeCO}_{3}+6 \mathrm{CO}_{2}+\mathrm{k} a
$$

and for pyrrhotite:

$$
12 \mathrm{FeSO}_{4}+45 \mathrm{CO}=\mathrm{Fe}_{11} \mathrm{~S}_{12}+\mathrm{FeCO}_{3}+45 \mathrm{CO}_{2}+\mathrm{k} .
$$

If the reducing agent were taken as carbon, similar results would be obtained, except that the amount of $\mathrm{CO}_{2}$ would be less. This action, while 
ordinarily called a reduction, is reduction so far as the iron sulphate is concerned, but is oxidation so far as the carbon compound is concerned, and hence the explanation of the liberation of leat.

Pyrite, marcasite, and pyrllotite are also doubtless produced by the action of soluble sulphides npon the iron oxides or iron salts. In the change from crystallized $\mathrm{Fe}_{2} \mathrm{O}_{3}$ (hematite) to $\mathrm{FeS}_{2}$ (in the form of pyrite), the volume increases 56.14 per cent.

Alterations. - The first alteration to be considered is that of marcasite into pyrite. In this alteration there is recrystallization, an increase of symmetry, a rlecrease of 2.98 per cent in volume, but no change in chemical composition. The heat effect is undetermined, but probably heat is liberated.

The mineral pyrrhotite by recrystallization passes into pyrite. This change may occur in volcanic districts by the action of hydrogen sulphide upon the pyrrhotite, the reaction perhaps being:

$$
\mathrm{Fe}_{11} \mathrm{~S}_{12}+10 \mathrm{H}_{2} \mathrm{~S}=11 \mathrm{FeS}_{2}+10 \mathrm{H}_{2} \text {. }
$$

In this change the volume is increased 21.13 per cent.

The minerals pyrite and marcasite may by oxidation pass directly into (1) hydrated sesquioxide of iron, of which, ordinarily, limonite (not crystallized; sp. gr. 3.80) is the most common kind; (2) magnetite (isometric; sp. gr. 5.174); (3) ferrous sulphate, which may be removed in solution, or (4) may be decomposed by further oxidation, either at the place of formation or elsewhere, after a longer or shorter time, into hydrated sesquioxide of iron, ordinarily limonite. The reactions for marcasite and pyrite may be as follows, assuming in each case that the sulphur, or a part of it, is also oxidized:
(1) $4 \mathrm{FeS}_{2}+22 \mathrm{O}+3 \mathrm{H}_{2} \mathrm{O}=2 \mathrm{Fe}_{2} \mathrm{O}_{3} \cdot 3 \mathrm{H}_{2} \mathrm{O}+8 \mathrm{SO}_{2}+\mathrm{k}$.
(2) $3 \mathrm{FeS}_{2}+16 \mathrm{O}=\mathrm{Fe}_{3} \mathrm{O}_{4}+6 \mathrm{SO}_{2}+\mathrm{k}$, or $3 \mathrm{FeS}_{2}+4 \mathrm{H}_{2} \mathrm{O}+4 \mathrm{O}=\mathrm{Fe}_{3} \mathrm{O}_{4}+4 \mathrm{H}_{2} \mathrm{~S}+2 \mathrm{SO}_{2}+\mathrm{k}$.
(3) $\mathrm{FeS}_{2}+60=\mathrm{FeSO}_{4}+\mathrm{SO}_{2}+\mathrm{k}$, or $\mathrm{FeS}_{2}+3 \mathrm{O}+\mathrm{H}_{2} \mathrm{O}=\mathrm{FeSO}_{4}+\mathrm{H}_{2} \mathrm{~S}+\mathrm{k}$.
(4) $4 \mathrm{FeSO}_{4}+2 \mathrm{O}+7 \mathrm{H}_{2} \mathrm{O}=2 \mathrm{Fe}_{2} \mathrm{O}_{3} \cdot 3 \mathrm{H}_{2} \mathrm{O}+4 \mathrm{H}_{2} \mathrm{SO}_{4}+\mathrm{k}$.

As shown in Chapter XI, on "Ore deposits," pyrite and marcasite also alter to hematite without oxidation by the reaction of an alkaline carbonate.

The alteration of common pyrrhotite into magnetite and limonite may be written as follows:
(5) $3 \mathrm{Fe}_{11} \mathrm{~S}_{12}+1160=11 \mathrm{Fe}_{3} \mathrm{O}_{4}+36 \mathrm{SO}_{2}+\mathrm{k}$, or
$3 \mathrm{Fe}_{11} \mathrm{~S}_{12}+36 \mathrm{H}_{2} \mathrm{O}+8 \mathrm{O}=11 \mathrm{Fe}_{3} \mathrm{O}_{4}+36 \mathrm{H}_{2} \mathrm{~S}+\mathrm{k}$.
(6) $4 \mathrm{Fe}_{11} \mathrm{~S}_{12}+33 \mathrm{H}_{2} \mathrm{O}+162 \mathrm{O}=11\left(2 \mathrm{Fe}_{2} \mathrm{O}_{3} \cdot 3 \mathrm{H}_{2} \mathrm{O}\right)+48 \mathrm{SO}_{2}+\mathrm{k}$. 
If in the production of the limonite the pyrrhotite passes through the stage of ferrous sulphate the reaction producing the sulphate may be:

(7) $\mathrm{Fe}_{11} \mathrm{~S}_{12}+46 \mathrm{O}=11 \mathrm{FeSO}_{4}+\mathrm{SO}_{2}+\mathrm{k}$, or $\mathrm{Fe}_{11} \mathrm{~S}_{12}+\mathrm{H}_{2} \mathrm{O}+43 \mathrm{O}=11 \mathrm{FeSO}_{4}+\mathrm{H}_{2} \mathrm{~S}+\mathrm{k}$.

The change from the ferrous sulphate to the limonite is the same as in the case of pyrite and marcasite. Where water is present the $\mathrm{SO}_{2}$ produced in the above reactions would unite with water and form $\mathrm{H}_{2} \mathrm{SO}_{3}$, or if further oxidized $\mathrm{H}_{2} \mathrm{SO}_{4}$.

As the end results of alteration are usually limonite or magnetite, the volume relations for these two compounds will be given. In the change of pyrite to limonite the volume is increaser 2.93 per cent; to magnetite, is decreased 37.48 per cent. In the change from marcasite to limonite the volume is decreased $0.14 \mathrm{per}$ cent; to magnetite, is decreased 39.34 per per cent. In the change of pyrrhotite to magnetite the volume is decreased 24.27 per cent; to limonite, is increased 24.68 per cent.

When pyrite and marcasite pass into limonite there is a clange from a crystailine to an amorphous form. In the alteration of pyrite to magnetite the system does not change. In the alterations of pyrrhotite and marcasite to pyrite there are changes from lower degrees of symmetry to the highest degree of symmetry, that of the isometric system. The change from mareasite to prrite occurs especially in the zone of anamorphism, subject to the principle there obtaining that the changes take place with decrease in rolume. The change of marcasite to pyrite is an excellent illustration of the principle that where the pressure is great minerals tend to pass into other minerals having a higher degree of symmetry and a higher specific gravity (see pp. 360-365). The abundance of marcasite as an autogenic constituent in rocks not deeply buried, its absence in the rocks which have been in the lower zone, and the presence of pyrite in these rocks, are thus all explained. Where the pressure is small near the surface mareasite with lower symmetry and lower specific gravity than pyrite may abundantly form. At depth where the pressure is great pyrite of higher specific gravity and higher symmetry forms. If rocks near the surface in which marcasite has formed are buried to a great depth by superimposed strata the marcasite previously formed changes to pyrite.

Similar statements can not be mạde concerning pyrrhotite and pyrite, for these minerals have unlike compositions. Doubtless where the necessary 
chemical reactions can take place there is a tendency in the lower zone for pyrhotite to alter to pyrite.

The natural conditions for the transformation of pyrite, marcasite, and pyrrhotite to limonite are those of abuudance of oxygen and moisture. These conditions are found in the zone of katanorphism, and especially in the belt of weathering. In this belt the process goes on with such rapidity that pyrite, marcasite, and pyrrhotite have generally been completely oxidized where the rocks have been long exposed to the reactions of the belt. The reactions are oxidation and hydration. They take place with great liberation of heat and, for pyrite and pyrrhotite, with some expansion of volume, and these changes may therefore be taken as typical illustrations of alterations of the belt of weathering.

The conditions for the formation of magnetite from pyrite, marcasite, and pyrrhotite are the presence of some oxygen, but not a sufficient amount to fully oxidize the iron, and considerable pressure. Where iron carbonate is present, which also alters to magnetite, oxygen is not necessary. This reaction is of great consequence. (See p. 244.) The alterations of the sulphides to magnetite involve a decrease of volume of 24 to 39 per cent and liberation of heat. Corresponding with this fact, the changes take place in the belt of cementation or in the zone of anamorphism.

\section{THE FLUORIDES.}

Among the fluorides the only important rock-making mineral is fluorite.

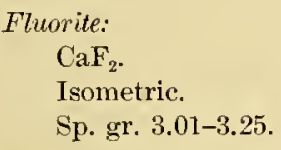

Occurrence.-Fluorite occurs as an accessory constituent, especially in granitic and syenitic rocks. It is also found in other eruptive rocks, and in metamorphic rocks, such as the schists and marbles. It therefore has a somewhat widespread occurrence, but is of very subordinate importance.

Aiterations. - By the action of alkaline waters fluorite alters into calcite (rhombohedral; sp. gr. 2.7135). Supposing the alkaline compound to be sodiun carbonate, the reaction is:

$\mathrm{CaF}_{2}+\mathrm{Na}_{2} \mathrm{CO}_{3}=\mathrm{CaCO}_{3}+2 \mathrm{NaF}+\mathrm{k}$.

The increase in volume of the calcite as compared with the fluorite is 47.66 per cent. 
THE OXIDES.

The more important oxides occuring as rock-building constituents are those of silicon, iron, and titanium. The oxides of silicon are quartz, tridymite, and opal. The important oxides of iron are hematite, magnetite, and limonite. The important oxides of titanium are rutile, octahedrite, and brookite. One oxide of iron and titanium, or else a ferrous titanate, has a widespread occurrence; this is ilmenite.

QUARTZ.

Quartz:

$\mathrm{SiO}_{2}$.

Rhombohedral.

Sp. gr. 2.653-2.654.

occurrence.-Quartz is second in abundance only to the minerals of the feldspar group. According to Clarke, ${ }^{a}$ quartz comprises 12 per cent of the lithosphere. It is very abundant as an original pyrogenic coustituent of the igneous rocks, as an allogenic constituent of the clastic rocks, and as an antogenir mineral in all classes of metamorphosed rocks. The material for secondary quartz may be derived from the alterations of many minerals in situ, or from the decomposition of minerals at some distance. The most widespread of all the alterations which furnish silica to the solutions is that of the decomposition of the silicates by carbonic acid in the belt of weathering, with the simultaneous production of carbonates and quartz, or a solution of colloidal silicic acid from which opal, chert, or quartz may later separate. Such quartz may be extensively deposited from the solutions in the porous rocks of the belt of cementation. It there fills the minute spaces between the individual grains of sedimentary rocks. It occupies spaces in porous tuffs or in vesicular igneous rocks. It fills openings between laminæ, and joint, fault, and breccia openings. The quantity of quartz thus deposited is far greater than that of any other mineral, and not improbably greater than that of all other minerals combiued. By this process the rocks are cemented. (See pp. 617-621.) Not only may the openings be occupied by quartz, but at the time of the deposition of the quartz other minerals may dissolve and their places be taken by the quartz. This process of deposition of silica as quartz is called silicification. (See p. 205.)

"Clarke, F. W., Analyses of rocks from the laboratory of the United States Geological Surver, 1880-1899: Buil. U. S. Geol. Survey No. 168, 1900, p. 16. 
As a metamorphic mineral, quartz is derived from actinolite, anorthite, anorthoclase, anthophyllite, angite, biotite, bronzite, chalcedony, cummingtonite, diopside, enstatite, epidote, garnet, grossularite, homblende, hypersthene, microcline, olivine, opal, orthoclase, plagioclase, prelnite, pyrope, sahlite, scapolites, serpentine, tridymite, and zoisite.

Modifications.-The most frequent and important modification of quartz is by recrystallization. Crystallized quartz is dissolved under conditions of weathering, as are all other minerals. This process is, however, exceedingly slow. As a result of solution the quartz crystals may be corroded. Such corrosion has been described by Hayes." In the belt of cementation, and especially adjacent to trunk channels of circulation, quartz may be extensively dissolved from reins and from the wall rocks. (See pp. 848-849.)

Graunlation and recrystallization of quartz oecur on a most extensive scale in all quartzose rocks which are subjected to mass-mechanical action or other farorable conditious in the zone of anamorphism. These changes involve no heat and volume reactions so far as the quartz itself is concerned, except that as the original minerals may be strained, or the new grains are imperfectly adjusted, the change may involve a slight expansion. But such expansion is followed by an equal contraction when the material is recrystallized into quartz free from strain. In the recrystallization many small individuals may be merged into one large individual. In some instances of recrystallization, where large grains are produced from smaller ones, the large individuals may average more than a million times as great as the small individuals from which they are derived. (See p. 695.) In the production of a comparatively few large individuals from a multitude of small individuals there is probably a release of energy. (See p. 771.) During recrystallization the material otaken into solution may be deposited practically in situ or may travel far and be extensively deposited elsewhere. Often quartz deposited in situ, or nearly so, can not be discriminated from quartz deposited from solutions coming from distant sources, as above deseribed.

A second modification of quartz only less important than that of recrystallization is silication by the mion with bases united with other acids; thus forming silicates. Of such acids carbonic is by far of

a Hayes, C. WI., Solution of silica under atmospheric conditions: Bull. Geol. Soc. America, vol. 8, 1897, pp. 213-220. 
the greatest consequence. Some of the more common minerals in which silication occurs on an extensive scale are calcite, dolomite, ankerite, and siderite, thus producing wollastonite, diopside, tremolite, sahlite, actinolite, and grimerite. The silica may nnite with the bases of varions carbonates producing rarious complex silicates, such as chondrodite, augite, hornblende, garnet, etc. At the same time the material of previous silicates may be absorbed. The heat and rolume reactions in many of these changes may be found under the carbonates mentioned.

In this process of silication of carbonates it is not often possible to identify the remnants of the quartz individuals which furnished the silica for the reactions. But apparently the quartz particles which furnished the silica for the process of silication may be identified in some instances. This is best seen for such fibrous minerals as serpentine, talc, and actinolite, the needles or fibers of which appear to grow into the quartz, in some instances deeply. In such cases it seems clear that the silica of the quartz furnished at least a part of the silica for the silicate, the bases being furnished by the solutions.

One of the best instances of the extensive union of quartz with bases, producing serpentine pseudomorphous after quartz, is that described by Becker." He describes the exteriors of original clastic grains of quartz to be "entirely occupied by felted fibers of serpentine, and long, slender microlites pierce the quartz grain toward its center, like pins in a cushion." This is but one illustration of a very widespread replacement of quartz by serpentine in the Coast Ranges. The growth of actinolite into quartz is illustrated in the Tyler slate of the Penokee district of Wisconsin." "

In instances where the quartz furnishes the silica for the penetrating silicates the migration of the silica is microscopical, and it might be supposed that the reactions occur without the solution of the silica of the quartz; but it seems probable, even in such cases as these, that there is solution of the silica before combination with the bases. In such reactions it is presumed that the bases which unite with the silica were before united with some other acid, and it is only when the previous combination is known that the heat and volume relations of the reactions can be ascertained.

a Becker, G. F., Geology of the quicksilver deposits of the Pacific slope: Mon. U. S. Geol. Survey, vol. 13,1888 , pp. $120-127$.

$b$ Becker, cit., p. 124.

$c$ Irving, R. D., and Van Hise, C. R., The Penokee iron-bearing series of Michigan and Wisconsin: Mon. U. S. Geol. Survey, rol. 19, 1892, p] . 210-215. 
In a third class of changes quartz may be wholly replaced by other minerals, as by magnetite and hematite. Very freqnently the deposition of the new minerals seems to be conditioned upon the solution of the quartz. The replacement of quartz by iron oxide is illustrated in the Lake Superior region in both the iron-bearing and the slate formations. ${ }^{a}$

The most favorable conditions for the solution of silica, especially of that formed by the decomposition of the silicates by carbonation, are furnished by the belt of weathering. The most favorable conditions for the deposition of silica as quartz are those of the belt of cementation. The solution of silica in the belt of weathering of the zone of katamorphism and its deposition in the belt of cementation of this zone is perhaps the best illustration of the principle explained on pages $634-636$, that material dissolved in the belt of weathering may be extensively deposited in the belt of cementation. Recrystallization of quartz mainly takes place in the zone of anamorphism, although it undonbtedly occurs to some extent in the zone of katamorphism, and especially in the belt of cementation. The process of silication takes place almost invariably with decrease in volume, provided all the compounds concerned are solids. Where the carbonates are silicated the decrease in volume ranges from 20 to 40 per cent. Silication occurs upon a great scale in the zone of anamorphism-is, indeed, one of the most distinctive chemical reactions of that zone.

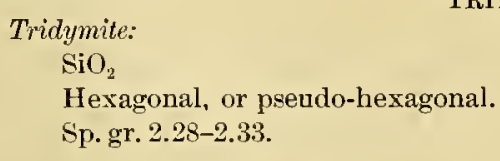

occurrence.-Tridymite usually occurs as an autogenic mineral in cavities in lavas, such as rhyolite, andesite, trachyte, etc.

Modifcations.-Tridymite is dissolved more readily than quartz. The material of tridymite may go through any of the changes which silica of quartz may pass through, with the difference that its recrystallization would result in the production of quartz (rhombohedral; sp. gr. 2.652-2.654) rather than the original mineral, tridymite. The changes of tridymite into other minerals than quartz need not be discussed in detail, since the reactions are the same as with quartz, except that the volume decrease is greater

a Van Hise, C. R., and Bayley, W. S., The Marquette iron-bearing district of Michigan: Mon. U.S. Geol. Survey, vol. 28, 1897, pp. 370, 400-405. 
in the changes of tridymite than with quartz. In the change of tridymite to quartz there is a diminution of volume, amounting to 14.24 per cent, and there is also probably liberation of heat. Energy is therefore potentialized in tridymite as compared with quartz. The change is one which is particnlarly likely to occur in the zone of anamorphism, where pressure is the dominant factor. In the fact that quartz is a denser mineral than tridymite we probably have a reason not only for the passage of tridymite into quartz in the lower zone, but for the absence of tridymite as an original pyrogenic constitnent in the plutonic igneous rocks which erystallized originally in this zone. Under its conditions the denser mineral, quartz, formed.

OPAL.

Opal:

$\mathrm{SiO}_{2} \cdot \mathrm{nH}_{2} \mathrm{O} \quad\left(\mathrm{H}_{2} \mathrm{O} 2\right.$ to 13 per cent; but mostly 3 to 9 per cent. $)$

Amorphous.

Sp. gr. 2.1-2.2.

Occurrence.-Opal, like most other hydrous minerals, is a product of the zone of katamorphism. Opal is a direct deposit from hot springs. In the sedimentary rocks it is abundantly formed from the siliceous skeletons of certain animals and plants, such as radiolaria, sponges, and diatoms. Opal is plentifully deposited in cavities in rocks by subterranean waters. Its most common places of occurrence are the limestones, where it is largely of organic origin, and the porous igneous rocks, especially as anygdules of the anygdaloids, where it is a chemical precipitate.

In general, as a metamorphic product opal may be derived from the same minerals as quartz.

Modifications.-The most frequent change of opal is to quartz (rhombohedral; sp. gr. 2.652-2.654). Frequent intermediate products are chalcedony and chert, which appear to be partly crystalline substances. (See p. 222.) In the passage of opal into quartz, the changes are three: deliydration, reduction of volume, and recrystallization. Supposing the composition of the opal is $\mathrm{SiO}_{2} \cdot \frac{1}{6} \mathrm{H}_{2} \mathrm{O}$, which would be about 6 per cent of water, the decrease of volume would be $22.81 \mathrm{per}$ cent. The change from opal to quartz above given is conmonly accomplished by solution and redeposition or recrystallization. When thé material is taken into solution this silica may be deposited near by or transported elsewhere. It may unite with free bases, producing silicates; it may displace other acids combined with bases, 
as, for instance, carbonic acid, thus also producing silieates. The heat and volume relations of these reactions are discnssed under "Quartz."

The reactions of dehydration, crystallization, and lessening of volume, as seen on pages 167-170, are particularly characteristic of the zone of anamorphism, and it is in this zone that the chinge from opal to quartz probably most extensively occurs. As evidence of this is the frequent occurrence of opal in the zone of katamorphism, and the general absence of opal in the rocks which have been metamorphosed in the lower zone.

CHELT, CHALCEDONY, ETC.

Standing between opal and quartz are numerous varieties of partly crystallized or very finely erystallized silica, of which chert and chalcedony may be taken as the more important kinds. With these substances are frequently small but variable amounts of opal containing combined water: The specific gravities of chert and chalcedony are intermediate between those of opal and quartz, i. e., between 2.15 and 2.65. Their most frequent occurrence is as veins, nodules, belts, and members in carbonate formations. Ordinarily they are derived from organic forms, such as radiolaria, diatoms, and sponges, which lived under conditions similar to those under which the limestone-building animals liver. (See p. 817.)

Chert and chalcedony are derived from opal. The material here included varies from that which is close to opal, having only a few minute crystallized spots, through material which shows more and more evidence of crystallization, to material which contains comparatively little amorphous silica, and thence into fully crystallized silica or quartz. The transition varieties may have the peculiar spotty appearance in polarized light characteristic of ordinary chert or the peculiar radial tibrous polarization of chalcedony or any combination of the two.

The alterations of chert and chalcedony are into quartz, or by combination with bases producing silicates, the same as opal. The chemistry and physics of the change are the same as for opal except that the decrease in volume is less, and therefore they need not be repeated. 
HEMATITE GROUP.

CORUNDUM, IEMATITE, ANU ILMENITE.

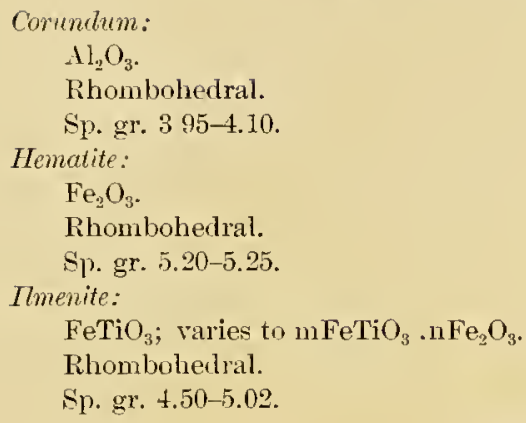

occurrence.-In Canada at one locality corundum occurs as an original constituent of a syenite. ${ }^{a}$ Also, corundun as an accessory mineral has been noted in granite, andesite, and other rocks. Corundum is, therefore, an original pyrogenic constituent of igneous rocks. Corundum occurs along the contact of intrusive basic rocks rich in alumina, especially those containing more than 30 per cent, such as peridotites and pyroxenites. The intruded rocks may be either igneous rocks or gneisses and schists. But where corundum occurs in veins along contacts it is in many cases an aqueo-igneous product (see pp. 720-728) or an aqueous deposit. Corundum is a widespread accessory constitnent in varions micaceous, chloritic, and hornblendic schists and gneisses, and in marble. Corundum, as a metamorphic mineral, is associated with chlorite and corundophilite. It is often associated with other heavy metamorphic minerals, such as andahusite, sillimanite, cyanite, spinel, rutile, etc. As a metamorphic mineral it is derived from andahsite, cyanite, diaspore, gibbsite, sillimanite, staurolite, and topaz.

Alterations. Cormdum alters into diaspore (orthorhombic; sp. gr. 340 ), gibbsite (monoclinic; sp. gr. 2.35), spinel (isometric; sp. gr. 38 ), sillimanite (orthorhombic; sp. gr. 3.235), cyanite (triclinic; sp. gr. 3.615), muscorite (damourite), (monoclinic; sp. gr. 2.88), margarite (monoclinic; sp. gr. 3.035), and zoisite (orthorhombic; sp. gr. 3.31). The reactions for the formation of diaspore and gibbsite are simple reactions of hydration. The reactions for

a Miller, W. G., Economic geology of eastern Ontario; corundum and other minerals: Seventh Rept. Ontario Bureau of Mines, 1897, Toronto, 1898, p. 213. 
the production of the other minerals require the addition of various other constituents-in the case of spinel, magnesia; in the case of sillimanite and cyanite, silica; in the case of the complicated silicates, muscovite, margarite, and zoisite, various bases and a large amount of silica. Therefore in these cases it is clear that the common statement that corundum alters to the minerals muscovite, margarite, and zoisite can have only the meaning that the relations are such that corundum furnishes the alumina for the resultant compound, and that the additional compounds are derived from mother source. It will be assumed in the alterations that the magnesia, lime, and potash are derived from the solid carbonates and that the silica is added as quartz. The equations for the reactions are as follows:

(l) $\mathrm{Al}_{2} \mathrm{O}_{3}+\mathrm{H}_{2} \mathrm{O}=2[\mathrm{AlO}$.(OH) $]+\mathrm{k}$.

(2) $\mathrm{Al}_{2} \mathrm{O}_{3}+3 \mathrm{H}_{2} \mathrm{O}=2 \mathrm{Al}(\mathrm{OH})_{3}+\mathrm{k}$.

(3) $\mathrm{Al}_{2} \mathrm{O}_{3}+\mathrm{IgCO}_{3}=\mathrm{MgAl}_{2} \mathrm{O}_{4}+\mathrm{CO}_{2}+\mathrm{k}$.

(4) $\mathrm{Al}_{2} \mathrm{O}_{3}+\mathrm{SiO}_{2}=\mathrm{Al}_{2} \mathrm{SiO}_{5}+\mathrm{k}$

(5) $3 \mathrm{Al}_{2} \mathrm{O}_{3}+6 \mathrm{SiO}_{2}+\mathrm{K}_{2} \mathrm{CO}_{3}+2 \mathrm{H}_{2} \mathrm{O}=2 \mathrm{H}_{2} \mathrm{KAl}_{3} \mathrm{Si}_{3} \mathrm{O}_{12}+\mathrm{CO}_{2}+\mathrm{k}$.

(6) $2 \mathrm{Al}_{2} \mathrm{O}_{3}+2 \mathrm{SiO}_{2}+\mathrm{CaCO}_{3}+\mathrm{H}_{2} \mathrm{O}=\mathrm{H}_{2} \mathrm{CaAl}_{4} \mathrm{Si}_{2} \mathrm{O}_{12}+\mathrm{CO}_{2}+\mathrm{k}$.

( ) $3 \mathrm{Al}_{2} \mathrm{O}_{3}+6 \mathrm{SiO}_{2}+4 \mathrm{CaCO}_{3}+\mathrm{H}_{2} \mathrm{O}=\mathrm{H}_{2} \mathrm{Ca}_{4} \mathrm{Al}_{6} \mathrm{Si}_{6} \mathrm{O}_{26}+4 \mathrm{CO}_{2}+\mathrm{k}$.

The increase in volume as compared with corundum is, for diaspore (equation 1), 39.25 per cent; for gibbsite (equation 2), 161.83 per cent. The volume of the corundum and the magnesite in passing to the spinel (equation 3) is decreased 29.17 per cent. The volume of the cortundum and quartz in passing into sillimanite (equation 4) is increased 4.38 per cent; into cyanite (equation 4) is decreased 6.59 per cent. If the volume of the corundum be compared with that of the muscovite (equation 5), with that of the margarite (equation 6), and with that of the zoisite (equation 7), there will be great volume increases. If, on the other hand, all the products which unite with the corundum in each case, with the exception of the water, be counted as solid, there would be small increase in the volume for muscovite, a considerable decrease for zoisite, and a small decrease for margarite. On the first hypothesis the increase in the volume in the production of muscovite is 264.25 per cent; in margarite, 159.02 per cent; in zoisite, 261.34 per cent. On the second hypothesis the increase in volume in the production of muscovite is 1.62 per cent; to form margarite the decrease is $1.22 \mathrm{per}$ cent; to form zoisite the decrease is 23.58 per cent.

It is reasonably certain that the passage of corundum to diaspore and gibbsite is a reaction characteristic of the zone of katamorphism, and 
especially the belt of weathering. It is almost equally certain that the passage of cormdum into spinel, sillimanite, and cyanite is characteristic of the zone of anamorplism.

The case, however, is not clear in reference to the muscovite, margarite, and zoisite. The equations as written are those of silicifiation and slight hydration. If these equations be correct, they should ocenr in the lower part of the belt of cementation or in the zone of anamorphism. It is tolerably certain that margarite, zoisite, and muscovite form in the lower part of the belt of cementation; but the zone in which inuscovite characteristically develops is that of anamorphism. It is not at all impossible that the potassium carbonate, and perhaps the calcium carbonate, or even the silica, are added in solution for the margarite and zoisite. In this case there would be a considerable volume increase. Whether the same may be assumed for the muscovite is uncertain. Very likely the materials added to the corundum are in some cases carried in by the solutions, in others are derived from adjacent minerals, and in still others partly from both. Where the lime and potash are derived from minerals adjacent, they may come from other compounds than carbonates, and the silica may have been previously united with other bases. So far as this is so, in considering the variations in volume the minerals from which the elements added to the corundum to produce the muscovite, margarite, and zoisite were derived must be taken into account. It is clearly impracticable in the present state of knowledge to give definite statements as to the volume changes for these minerals.

HEMATTTE.

Occurrence.-Hematite is a pyrogenic constituent in igneous rocks and is an abundant metamorphic mineral. Its most abundant source in the metamorphic rocks is by the dehydration of limonite, a reaction occuring. with the absorption of leat and reduction of volume. A second important source of hematite is from iron carbonate by loss of carbon dioxide and by oxidation, a reaction occurring with the liberation of heat and reduction of volume. Hematite may also be produced by the oxidation of magnetite, a reaction resulting in liberation of heat and expansion of volume. Frequently after this change the hematite has the isometric form of the original magnetite and is called martite. A fourth source of hematite is by the oxidation of the ferrons iron of silicates at the time of their decomposition. MON XLVII-04- 15 
A fifth source is by oxidation of ferrous iron solutions, which may result in the precipitation of hematite. The first reaction occurs most extensively in the zone of anamorphism; the other four occur in the zone of katamorphism, and to these positions the heat and volume reactions correspond. Finally, as shown in Chapter XII, on "Ore deposits," hematite may be formed from pyrite by the action of alkaline carbonate solutions.

In summary, hematite is derived from actinolite, ankerite, anthophyllite, biotite, bronzite, garnet, greenalite, griinerite, hornblende, hypersthene, ilmenite, limonite, magnetite, olivine, parankerite, pyrite, serpentine, and siderite.

Alterations.-The most frequent alteration of hematite is into limonite (amorphous; sp. gr. 3.6-4). The reaction is as follows:

$$
2 \mathrm{Fe}_{2} \mathrm{O}_{3}+3 \mathrm{H}_{2} \mathrm{O}=2 \mathrm{Fe}_{2} \mathrm{O}_{3} \cdot 3 \mathrm{H}_{2} \mathrm{O}+\mathrm{k} \text {. }
$$

In the change the volume is increased 60.72 per cent. A second alteration of hematite is into magnetite (isometric; sp. gr. 5.168-5.18). This may be accomplished by any of the reducing agents furnished by organic compounds. Supposing the reducing agent to be the partially oxidized carbon compound $\mathrm{CO}$, the reaction is:

$$
3 \mathrm{Fe}_{2} \mathrm{O}_{3}+\mathrm{CO}=2 \mathrm{Fe}_{3} \mathrm{O}_{4}+\mathrm{CO}_{2}+\mathrm{k} \text {. }
$$

While a reduction of the oxide of iron occurs a simultaneous oxidation of the organic compound occurs, and the end result is the liberation of heat. In the change the volume is decreased 2.38 per cent. A third alteration of hematite is to pyrite (isometric; sp. gr. 5.025) or marcasite (orthorhombic; sp. gr. 4.875). In the best-known instances siderite (rhombohedral; sp. gr. 3.855) or some other iron-bearing carbonate is simultaneously produced. The reaction may be:

$$
\mathrm{Fe}_{2} \mathrm{O}_{3}+2 \mathrm{H}_{2} \mathrm{~S}+\mathrm{CO}_{2}=\mathrm{FeS}_{2}+\mathrm{FeCO}_{3}+2 \mathrm{H}_{2} \mathrm{O}+\mathrm{k} .
$$

In the change to pyrite and siderite the volume is increased 76.12 per cent, and to marcasite and siderite 78.73 per cent.

The alterations of hematite to limonite occtr in the zone of katamorphism, and especially in the belt of weathering. Corresponding with this position the reaction is with liberation of heat and expansion of volume. The alteration of hematite into magnetite occurs in the belt of cementation and the zone of anamorphism. This agrees with the fact that the reaction 
liberates heat and diminishes the volume. The alteration of hematite to pyrite and marcasite is best known where organic compounds are present to reduce sulphuric acid to hydrosulphuric acid and to furnish carbonic acid to form the carbonates. The reaction is especially characteristic of the belt of cementation, and to this position the expansion of volume and the liberation of heat correspond.

ILMENITE.

Occurrence.-Ihmenite is an abundant pyrogenic constituent of the igneous rocks. It is found both as an allogenic and as an autogenic constituent in metamorphic rocks. As an autogenic constituent the compounds which unite to produce it have not been worked out. As a metamorphic mineral ilmenite is derived from perovskite and rutile.

Alterations.-Ilmenite alters to titanite (monoclinic; sp. gr. 3.48), to rutile (tetragonal; sp. gr. 4.18-4.25), and to octahedrite, or anatase (tetragonal; sp. gr. 3.82-3.95). With these minerals magnetite (isometric; sp. gr. 5.174) or hematite (rhombohedral; sp. gr. 5.225) or limonite (amorphous; sp. gr. 3.80) is simultaneously produced. One of the most frequent reactions in the production of titanite is probably along the following lines:

$$
3 \mathrm{FeTiO}_{3}+3 \mathrm{CaCO}_{3}+3 \mathrm{SiO}_{2}+\mathrm{O}=3 \mathrm{CaTiSiO}_{5}+\mathrm{Fe}_{3} \mathrm{O}_{4}+3 \mathrm{CO}_{2}+\mathrm{k} .
$$

The decrease in volume of the ilmenite, calcite, and quartz in passing into titanite and magnetite, supposing the $\mathrm{CO}_{2}$ to escape, is 22.35 per cent; but the increase in volume of the titanite as compared with the ilmenite alone is 76.35 per cent. The alteration of ilmenite to rutile and octahedrite, with combined magnetite, is as follows:

$$
3 \mathrm{FeTiO}_{3}+\mathrm{O}=3 \mathrm{TiO}_{2}+\mathrm{Fe}_{3} \mathrm{O}_{4}+\mathrm{k} .
$$

In case hematite is produced instead of magnetite the reaction is:

$$
2 \mathrm{FeTiO}_{3}+\mathrm{O}=2 \mathrm{TiO}_{2}+\mathrm{Fe}_{2} \mathrm{O}_{3}+\mathrm{k} .
$$

In case limonite is produced, one and one-half molecules of water are added to both sides of the equation.

The increase in volume of the ilmenite in passing into rutile and magnetite is 6.02 per cent; into octahedrite and magnetite, 11.07 per cent. In case hematite or limonite be produced, the increase in volume is correspondingly greater.

It is certain that titanite forms from ilmenite in the lower zone. In this zone, as explained on pp. 764-765, the $\mathrm{CaCO}_{3}$ and $\mathrm{SiO}_{2}$ can not be supposed 
to have been bronght in from the ontside, and therefore the change takes place with decrease in volume. It is also certain that titanite forms extensively in connection with chlorite, which commonly develops in the belt of cementation. In this case the calcium carbonate and silica may be introduced in solution from an ontside source, under which circumstances the volume is increased.

The alterations of ilmenite to rutile and octahedrite, or any combination of them, certainly occur in the zone of katamorphism, and to this position the heat and rolume reactions correspond. However, I have not found sufficient information on the subject to assert that these reactions do not also occur in the zone of anamorphism.

SPINEL GROUP.

SPINEL, MAGNETITE, AND CHROMITE.

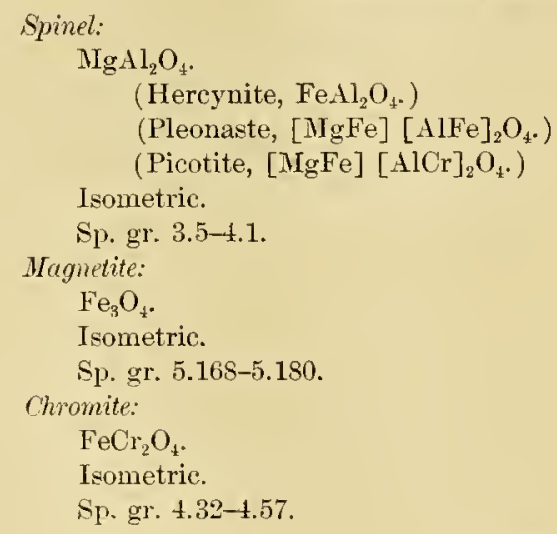

SPINEL.

Occurrence.-Spinel occurs as an original constituent in the igneons rocks, but is much more abundantly present as a secondary constituent in the metamorphic rocks, especially those which are rich in magnesium. In many cases it is secondary to olivine and other minerals rich in magnesium. The more important minerals from which spinel is derived are almandite, biotite, chlorite, corundum, diaspore, garnet, gibbsite, olivine, and pyrope. Alterations.-According to Dana, spinel has been observed as altering to talc (orthorhombic or monoclinic; sp. gr. 2.75), serpentine (monoclinic; sp. gr. 2.575), and mica (monoclinic; sp. gr. 2.88-2.90). However, the character of the alterations and the conditions under which they occur are so little known that I shall not attempt to treat them from the physicalchemical point of riew. 
MAGNETITE

occurrence.-Magnetite is a very abundant pyrogenic constituent in igneous rocks. It is abundantly deposited from solutions, and especially from solutions bearing iron carbonate, according to the reaction:

$3 \mathrm{FeCO}_{3}+\mathrm{O}=\mathrm{Fe}_{3} \mathrm{O}_{4}+3 \mathrm{CO}_{2}+\mathbf{k}$.

Magnetite also extensively forms from siderite in situ. These changes liberate heat and decrease the volume. A third source of magnetite is by incomplete oxidation of pyrite and marcasite, reactions occurring with liberation of heat and diminution of volume. Fourth, frequently siderite and iron sulphide together pass into magnetite with decrease in volume. (See pp. 244, 845.) A fifth way in which magnetite may be produced is by the reduction of hematite by organic compounds, a reaction occurring with the liberation of heat, because of the simultaneous oxidation of the organic compounds, and with diminution of volume. A sixth way in which magnetite is produced is by the incomplete oxidation of ferrous iron of silicates; for instance, olivine and garnet.

In summary, magnetite is derived from actinolite, ankerite, arfvedsonite, angite, biotite, bronzite, diopside, garnet, greenalite, griinerite, hematite, hornblende, hypersthene, ilmenite, marcasite, and pyrite.

Alterations.-Magnetite alters into hematite (rhombohedraI; sp. gr. 5.225), limonite (amorphous; sp. gr. 3.80), and siderite (rhomboherlral; sp. gr. 3.833.88). The reactions are as follows:

(1) $2 \mathrm{Fe}_{3} \mathrm{O}_{4}+\mathrm{O}=3 \mathrm{Fe}_{2} \mathrm{O}_{3}+\mathrm{k}$.

(2) $4 \mathrm{Fe}_{3} \mathrm{O}_{4}+2 \mathrm{O}+9 \mathrm{H}_{2} \mathrm{O}=3\left(2 \mathrm{Fe}_{2} \mathrm{O}_{3} \cdot 3 \mathrm{H}_{2} \mathrm{O}\right)+\mathrm{k}$.

(3) $\mathrm{Fe}_{2} \mathrm{O}_{4}+\mathrm{CO}+2 \mathrm{CO}_{2}=3 \mathrm{FeCO}_{3}+\mathrm{k}$.

In the change the increase in volume is, for (1), 2.44 per cent; for (2), 64.63 per cent, and for (3), 101.30 per cent. The increase in volume in the change from magnetite to siderite-over 100 per cent-is the greatest volume change in which only two minerals are concerned which the calculations of Mr. Lincoln have given, with the exception of the alteration of corundum into gibbsite. (See p. 224.) All of the above changes are well known to occur in the zone of katamorphism, and corresponding with this position they all take place with the liberation of heat, expansion of volume, and decrease in symmetry.

CHROMITE.

occurrence.-Chromite occurs in the igneous rocks, especially those rich in magnesium. It also occurs in the metamorphic rocks, often in connec- 
tion with serpentine. In these positions it is very frequently a secondary product of olivine. The reactions occurring in its production are given under that mineral.

Alterations.-The alteration of chromite into other minerals has not been noted.

RUTILE GROUP.

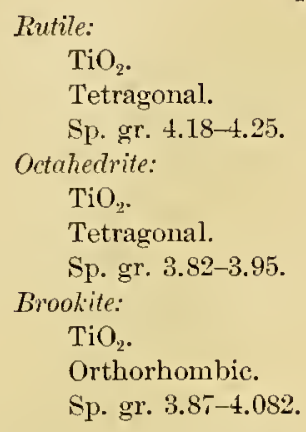

occurrence.-Rutile is a pyrogenic constitnent in igneons rocks, and has a widespread occurrence in the clastic and metamorphic rocks, both as an allogenic and as an antogenic constitnent, in the latter case generally being derived from ilmenite. Rutile is also derived from brookite, ilmenite, octahedrite, and titanite.

Octahedrite in the metamorphic rocks is a secondary alteration of other titanium-bearing minerals, especially of titanite. It is also derived from ilmenite.

Brookite occurs sparingly, both in altered igneous rocks and in sedimentary rocks. In some cases it is secondary to titanite.

Alterations.--Both octahedrite and brookite alter to rutile (tetragonal; sp. gr. 4.18-4.25). In the case of octahedrite the decrease in volume is 7.83 per cent; in the case of brookite the decrease is 5.69 per cent. The heat change is undeternined, but probably the alterations occur with the liberation of heat. If this be the case the alterations involve recrystallization, diminution of volume, and liberation of heat. In the case of octahedrite the symmetry remains the same; in the case of brookite the symmetry is increased.

It may be inferred that such changes as these occur in botls zones, being in all respects analogons to the changes which take place in dolomitization. (See pp. 238-240.) However, the geological occurrences of these alterations have not been given with such definiteness as to enable one to make definite statements as to the actual facts. 
In this commection the experiments of Hautefeuille ${ }^{a}$ are very interesting. He produced rutile, brookite, and octahedrite from the same compounds, but at different temperatures, rutile forming when red heat was used, brookite when the temperature was between that required for the volatilization of cadminm and zinc, and octahedrite when the temperature was a little below that for the volatilization of cadminm. Rutile, the mineral with the highest specific gravity, forms at the highest temperature, and high temperature is especially characteristic of the zone of anamorphism.

Rutile may alter into ilmenite (rhombohedral; sp. gr. 4.75) and into titanite (monoclinic; sp. gr. 3.48). In the change to ilmenite the reactions may be:

(1) $\mathrm{TiO}_{2}+\mathrm{Fe}_{3} \mathrm{O}_{4}=\mathrm{FeTiO}_{3}+\mathrm{Fe}_{2} \mathrm{O}_{3}+\mathrm{k}$, or

(2) $\mathrm{TiO}_{2}+\mathrm{FeCO}_{3}=\mathrm{FeTiO}_{3}+\mathrm{CO}_{2}+\mathrm{k}$.

In (1) the decrease in volume of the ilmenite and hematite as compared with the rutile and magnetite is 1.88 per cent. In (2) the decrease in volume is 34.77 per cent, provided the iron carbonate is present as solid siderite and the $\mathrm{CO}_{2}$ escapes.

In the change to titanite the most probable reaction is:

(3) $\mathrm{TiO}_{2}+\mathrm{CaCO}_{3}+\mathrm{SiO}_{2}=\mathrm{CaTiSiO}_{5}+\mathrm{CO}_{2}+\mathrm{k}$.

The decrease in volume is 28.17 per cent, provided the compounds which unite with the rutile are solids and the liberated $\mathrm{CO}_{2}$ escapes.

Those who have described the changes of rutile to ilmenite and titanite have not indicated whether or not they occur as deep-seated alterations. It may, however, be anticipated that such is the case, for they are changes which involve liberation of heat and condensation of volume, and therefore the kind which normally occur in the zone of anamorphism.

DIASPORE GROUP.

Diaspore:

DLASPORE AND LUUONITE.

$\mathrm{AlO}(\mathrm{OH})$.

Orthorhombic.

Sp. gr. 3.3-3.5.

Limonite:

$2 \mathrm{Fe}_{2} \mathrm{O}_{3} \cdot 3 \mathrm{H}_{2} \mathrm{O}$.

Amorphous.

Sp. gr. 3.6-4.00.

\footnotetext{
a Dana, J. D., A system of mineralogy; Descriptive mineralogy, by E. S. Dana; Wiley \& Sons, New York, 6th ed., 1892, p. 239.
} 
occurrence-Diaspore is especially found in the serpentine- or chloritebearing schists and gneisses and in dolomites. In these rocks it is frequently associated with corundum. Diaspore has been recorded as a constitnent of granite, nepheline-syenite, and basaltic rocks. As noted on other pages, for the alterations of various minerals in the zone of katamorphism, especially the belt of weathering, it may be produced as one of the alteration products of the following minerals: Biotite, cortundum, gibbsite, haiiynite, muscovite, nephelite, noselite, phlogopite, scapolites, sodalite.

Alterations.-No alterations of diaspore are recorded. However, it is probable that where diaspore is deposited in sedimentary rocks and is deeply buried, so as to undergo alteration in the zone of anamorphism, it passes into corundum (rhombohedral, sp. gr. 4.025); or, like corundum, unites witlı other bases to produce such minerals as spinel (isometric, sp. gr. 3.8); sillimanite (orthorhombic, sp. gr. 3.235), and cyanite (triclinic, sp. gr. 3.615); muscovite (monoclinic, sp. gr. 2.88); margarite (monoclinic, sp. gr. 3.035); and zoisite (orthorhombic, sp. gr. 331). So far as the hydrous minerals muscovite, margarite, and zoisite are formed, the water may have been derived from the diaspore, which contains more water, and thus their formation be really a process of dehydration and silication. For these supposed reactions the equations may be:

(1) $2 \mathrm{AlO}(\mathrm{OH})=\mathrm{Al}_{2} \mathrm{O}_{3}+\mathrm{H}_{2} \mathrm{O}-\mathrm{k}$.

(2) $2 \mathrm{AlO}(\mathrm{OH})+\mathrm{IgCO}_{3}=\mathrm{MgAl}_{2} \mathrm{O}_{4}+\mathrm{CO}_{2}+\mathrm{H}_{2} \mathrm{O}-\mathrm{k}$.

(3) $2 \mathrm{AlO}(\mathrm{OH})+\mathrm{SiO}_{2}=\mathrm{Al}_{2} \mathrm{SiO}_{5}+\mathrm{H}_{2} \mathrm{O}-\mathrm{k}$.

(4) $6 \mathrm{AlO}(\mathrm{OH})+6 \mathrm{SiO}_{2}+\mathrm{K}_{2} \mathrm{CO}_{3}=2 \mathrm{H}_{2} \mathrm{KAl}_{3} \mathrm{Si}_{3} \mathrm{O}_{12}+\mathrm{CO}_{2}+\mathrm{H}_{2} \mathrm{O}-\mathrm{k}$.

(5) $4 \mathrm{AlO}(\mathrm{OH})+2 \mathrm{SiO}_{2}+\mathrm{CaCO}_{3}=\mathrm{H}_{2} \mathrm{CaAl}_{4} \mathrm{Si}_{2} \mathrm{O}_{12}+\mathrm{CO}_{2}+\mathrm{H}_{2} \mathrm{O}-\mathrm{k}$.

(6) $6 \mathrm{AlO}(\mathrm{OH})+6 \mathrm{SiO}_{2}+4 \mathrm{CaCO}_{3}=\mathrm{H}_{2} \mathrm{Ca}_{4} \mathrm{Al}_{6} \mathrm{Si}_{6} \mathrm{O}_{26}+4 \mathrm{CO}_{2}+2 \mathrm{H}_{2} \mathrm{O}-\mathrm{k}$.

Supposing that all the compounds in the first member of the equation are solids, and that the liberated $\mathrm{CO}_{2}$ and $\mathrm{H}_{2} \mathrm{O}$ escape, the decrease in volume for cortundum (1) wonld be 28.18 per cent; for spinel (2), 40.39 per cent; for sillimanite (3), 13.52 per cent; for cyanite (3), 22.61 per cent; for muscorite (4), 54.21 per cent; for margarite (5), 14.08 per cent; for zoisite (6), 29.44 per cent. All take place with absorption of heat. Therefore all of these reactions are characteristic of the zone of anamorphism.

LIMONITE.

occurrence-Limonite as a mineral is produced either as an original chemical precipitate or by the alteration of other minerals. It is not, 
so far as known, an original pyrogenic constituent of the igneous rocks. The most important source of bodies of limonite is precipitation from iron-bearing solutions, especially iron carbonate. For iron carbonate the reaction is-

$$
4 \mathrm{FeCO}_{3}+2 \mathrm{O}+3 \mathrm{H}_{2} \mathrm{O}=2 \mathrm{Fe}_{2} \mathrm{O}_{3} \cdot 3 \mathrm{H}_{2} \mathrm{O}+4 \mathrm{CO}_{2}+\mathrm{k} .
$$

A second important source for limonite is the oxidation and hydration of solid iron carbonate in rocks, especially siderite, ankerite, parankerite, and iron-bearing limestone or dolomite. The source next in importance is the oxidation and liydration of pyrite, marcasite, and other sulplides. A fourth important source of limonite is the oxidation and hydration of the ferrous iron of silicates. A fifth source is the hydration of hematite. A sixth but unimportant source is the oxidation and hydration of magnetite. All the reactions involve oxidation or lyydration, or both, and therefore take place with the liberation of heat. In the production of limonite from iron carbonate there is an important contraction of volume; in the other cases the volume of the limonite is greater than that of the compounds from which it is derived. All the above reactions producing limonite occur in the zone of katamorphism, and the controlling factor is the first part of van't Hoff's law, that of chemical reactions with the liberation of heat. Limonite does not develop in the zone of anamorphism.

In summary, limonite is derived from the following minerals: Actinolite, ankerite, anthophyllite, arfvedsonite, biotite, bronzite, epidote, garnet, greenalite, grünerite, hematite, hornblende, hypersthene, ilmenite, magnetite, marcasite, olivine, parankerite, pyrite, pyrhotite, serpentine, and siderite.

Alterations. - The important alterations of limonite are into hematite (rhombohedral; sp. gr. 5.20-5.25) and siderite (rhombohedral; sp. gr. 3.83-3.88). Hematite produced from limonite may be earthy or crystalline. The reaction is-

$$
2 \mathrm{Fe}_{2} \mathrm{O}_{3} \cdot 3 \mathrm{H}_{2} \mathrm{O}=2 \mathrm{Fe}_{2} \mathrm{O}_{3}+3 \mathrm{H}_{2} \mathrm{O}-\mathrm{k} .
$$

The decrease of volume is 37.78 per cent. The change is therefore one of deliydration, reduction of volume, and crystallization. The transformation takes place on a great scale in the zone of anamorphism, that in which pressure controls whether heat is absorbed or liberated.

The second important change of limonite is into iron carbonate. Where this change occurs organic compounds are commonly present and 
decomposing to serve as reducing agents and to furnish abundant $\mathrm{CO}_{2}$ to unite with the iron. The reduction may be by the passage of $\mathrm{CO}$ into $\mathrm{CO}_{2}$, of $\mathrm{C}$ into $\mathrm{CO}_{2}$, or of $\mathrm{C}$ into $\mathrm{CO}$, as follows:

(1) $2 \mathrm{Fe}_{2} \mathrm{O}_{3} \cdot 3 \mathrm{H}_{2} \mathrm{O}+2 \mathrm{CO}+2 \mathrm{CO}_{2}=4 \mathrm{FeCO}_{3}+3 \mathrm{H}_{2} \mathrm{O}+\mathrm{k}$.

(2) $2 \mathrm{Fe}_{2} \mathrm{O}_{3} \cdot 3 \mathrm{H}_{2} \mathrm{O}+\mathrm{C}+3 \mathrm{CO}_{2}=4 \mathrm{FeCO}_{3}+3 \mathrm{H}_{2} \mathrm{O}+\mathrm{k}$.

(3) $2 \mathrm{Fe}_{2} \mathrm{O}_{3} \cdot 3 \mathrm{H}_{2} \mathrm{O}+2 \mathrm{C}+4 \mathrm{CO}_{2}=4 \mathrm{FeCO}_{3}+3 \mathrm{H}_{2} \mathrm{O}+2 \mathrm{CO}+\mathrm{k}$.

So far as the iron is concerned, its reduction and dehydration absorb heat, but the oxidation of the $\mathrm{C}$ or $\mathrm{CO}$ and the union of the $\mathrm{CO}_{2}$ and $\mathrm{FeO}$ both liberate heat, the amount of which is greater than that absorbed, so that in each of these reactions heat is liberated. In all of the reactions the volume is increased 22.27 per cent.

The reduction of the iron of limonite so as to produce protoxide for the formation of iron carbonate may of course be accomplished by carbureted hydrogen, especially methane $\left(\mathrm{CH}_{4}\right)$, rather than by the compounds suggested; but the carbureted hydrogen compounds are so numerous and the resultant compounds so uncertain that no attempt will be made to formulate equations for possible changes with these substances as reducing agents.

The clange of limonite to siderite is one which occurs extensively in rocks bearing organic compounds in the zone of katamorphism. The formation of the abundant siderites which are used as iron ores of Carboniferous and later age are believed for the most part to be thus derived from limonite in the upper zone. The reactions correspond perfectly to this position, being those which occur with liberation of heat and very considerable expansion of volume. The siderite thus formed may later be decomposed into various other compounds, or even reproduce limonite, but the consideration of such changes belongs under "Siderite."

BRUCYTE GROUP.

Brucite: BRUCITE AND GIBBSITE.

$\mathrm{Ng}(\mathrm{OH})_{2}$.

Rhombohedral.

Sp. gr. 2.38-2.40.

Gibbsite (hydrargillite):

$\mathrm{Al}(\mathrm{OH})_{3}$.

Monoclinic.

Sp. gr. 2.28-2.42. 
BRUCITE.

Occurrence-Brucite is one of the minerals which is produced in the upper physical-chemical zone, especially in the belt of weathering. Brucite is produced by the alterations of minerals rich in magnesia, being recorded as secondary to chondrodite, clinohumite, humite, and serpentine. It is especially prevalent in serpentinous rocks and veins. Doubtless in many instances it forms simultaneously with the serpentine and perhaps otler minerals, rather than secondary to them.

Alterations. The one alteration of brucite noted is that of carbonation, into hydromagnesite (monoclinic; sp. gr. 2.145-2.180). The reaction representing the change is-

$$
4 \mathrm{Mg}(\mathrm{OH})_{2}+3 \mathrm{CO}_{2}=\mathrm{MIg} \mathrm{Ig}_{2}\left(\mathrm{CO}_{3}\right)_{3} \cdot 2 \mathrm{Mg}(\mathrm{OH}) \cdot 3 \mathrm{H}_{2} \mathrm{O}+\mathrm{k} .
$$

The increase in rolume is 73.08 per cent. The alteration is therefore one of simple carbonation, and takes place in the zone of katamorphism, especially in the belt of weathering, with expansion of volume and liberation of heat.

GIBBSITE.

Occurrence.-Gibbsite occurs as an accessory constituent in many of the schists and gneisses, especially those which have been subjected to the forces of the upper physical-chemical zone, and particularly in the belt of weathering. As noted on subsequent pages, it may be a result of the alteration of many minerals, the more important of which are as follows: Anorthoclase, andalusite, biotite, cancrinite, corundum, cyanite, epidote, haiiynite, microcline, muscovite, nephelite, noselite, ortlıoclase, phlogopite, plagioclases, pyrope, the scapolites, sillimanite, sodalite, topaz, tourmaline, and zoisite. By reference to the discussion of these minerals and the minerals which simultaneously form, the conditions of its formation may be ascertained.

Alterations.-No alterations of gibbsite are recorded in the standard textbooks, but where sedimentary rocks containing gibbsite are so deeply buried as to pass into the zone of anamorphism it may become partly dehydrated, producing diaspore (orthorhombic; sp. gr. 3.40), or wholly dehydrated, producing corundum (rhombohedral; sp. gr. 4.025); or the aluminum may unite with other componnds, producing the same minerals that are produced by corundum or diaspore. It is believed that these 
alterations from diaspore and gibbsite have taken place on an extensive scale, even if they have not been recorded. There is no doubt about the formation of gibbsite abundantly in the zone of katamorphism, especially in the belt of weathering. To my mind there is as little doubt that the widespread corundum of the schists, gneisses, and marbles is derived in large measure from gibbsite. I am confident that the hydrons aluminum oxides furnish the bases for much of the spinel (isometric; sp. gr. 3.80), sillimanite (orthorlombic; sp. gr. 3.235), and cyanite (triclinic; sp. gr. 3.615) which occur in these rocks. And it is little short of a certainty that gibbsite fumishes alumina for the silicates, muscovite (monoclinic; sp. gr: 2.88), margarite (monoclinic; sp. gr. 3.035), and zoisite (orthorhombic; sp. gr. 3.31). As with diaspore, the reactions protucing all the abovementioned silicates are those of dehydration and silicifiation. The following equations may be written for the above supposed reactions:

(1) $\mathrm{AI}(\mathrm{OH})_{3}=\mathrm{AlO}(\mathrm{OH})+\mathrm{H}_{2} \mathrm{O}-\mathrm{k}$.

(2) $2 \mathrm{Al}(\mathrm{OH})_{3}=\mathrm{Al}_{2} \mathrm{O}_{3}+3 \mathrm{H}_{2} \mathrm{O}-\mathrm{k}$.

(3) $\left.2 \mathrm{Al}(\mathrm{OH})_{3}+\mathrm{NgCO}\right)_{3}=\mathrm{MgAl}_{2} \mathrm{O}_{4}+\mathrm{CO}_{2}+3 \mathrm{H}_{2} \mathrm{O}-\mathrm{k}$.

(t) $2 \mathrm{Al}(\mathrm{OH})_{3}+\mathrm{SiO}_{2}=\mathrm{Al}_{2} \mathrm{SiO}_{5}+3 \mathrm{H}_{2} \mathrm{O}-\mathrm{k}$.

(5) $6 \mathrm{Al}(\mathrm{OH})_{3}+6 \mathrm{SiO}_{2}+\mathrm{K}_{2} \mathrm{CO}_{3}=2 \mathrm{H}_{2} \mathrm{KAl}_{3} \mathrm{Si}_{3} \mathrm{O}_{12}+\mathrm{CO}_{2}+7 \mathrm{H}_{2} \mathrm{O}-\mathrm{k}$.

(6) $4 \mathrm{Al}(\mathrm{OH})_{3}+2 \mathrm{SiO}_{2}+\mathrm{CaCO}_{3}=\mathrm{H}_{2} \mathrm{CaAl}_{4} \mathrm{Si}_{2} \mathrm{O}_{12}+\mathrm{CO}_{2}+5 \mathrm{H}_{2} \mathrm{O}-\mathrm{k}$.

(7) $6 \mathrm{Al}(\mathrm{OH})_{3}+6 \mathrm{SiO}_{2}+4 \mathrm{CaCO}_{3}=\mathrm{H}_{2} \mathrm{Ca}_{4} \mathrm{Al}_{6} \mathrm{Si}_{6} \mathrm{O}_{26}+4 \mathrm{CO}_{2}+8 \mathrm{H}_{2} \mathrm{O}-\mathrm{k}$.

Regarding all the minerals as solid, the decrease of volume for diaspore (1) is 46.82 per cent; for corundum (2), 61.81 per cent; for spinel (3), 60.12 per cent; for sillimanite (4), 43.68 per cent; for cyanite (4), 49.61 per cent; for muscovite (5), 64.99 per cent; for margarite (6), 38.92 per cent; for zoisite (7), 43.06 per cent. The decreases of volume are greater for the corresponding minerals than for diaspore because of the greater amomnt of water in the gibbsite. In all the reactions heat is absorbed. The reactions are therefore typical of the zone of anamorphism.

THE CARBONATES.

The important carbonates which occur as rock-making constituents are the calcite group, including calcite, dolomite, ankerite and parankerite, magnesite, and siderite, and the aragonite group, of which aragonite is the only important rock-making member. 
CALCTTE GROUP.

CALCITE, DOLOHTE, ANKERITE, PARANKEILTE, MAGNESITE, AND SIDERITE.

Calcite:

$\mathrm{CaCO}_{3}$.

Rhombohedral.

Sp. gr. 2.713-2.714.

Dolomite:

$\mathrm{CaMgC}_{2} \mathrm{O}_{6}$.

Rhombohedral.

Sp. gr. 2.8-2.9.

Ankerite:

$\mathrm{CaFeC}_{2} \mathrm{O}_{6} \cdot \mathrm{CaNIOC}_{2} \mathrm{O}_{6} ;\left(\mathrm{CaMgC}_{2} \mathrm{O}_{6}: \mathrm{CaFeC}_{2} \mathrm{O}_{6}:: \frac{1}{2}: 1\right.$ to $\left.2: 1\right)$.

Rhombohedral.

Sp. gr. 2.95-3.1.

Parankicrite:

$\mathrm{CaFeC}_{2} \mathrm{O}_{6} \cdot 2 \mathrm{CaIIgC}_{2} \mathrm{O}_{6} ;\left(\mathrm{CaMgC}_{2} \mathrm{O}_{6}: \mathrm{CaFeC}_{2} \mathrm{O}_{6}: 2: 1\right.$ to $\left.10: 1\right)$.

Rhombohedral.

Sp. gr. 2.95-3.1.

Magnesite:

$\mathrm{IgCO}_{3}$.

Rhombohedral.

Siderite:

Sp. gr. 3.00-3.12

$\mathrm{FeCO}_{3}$.

Rhombohedral.

Sp. gr. 3.83-3.88.

CALCITE.

occurrence.-The chief sources of calcite are (1) organic precipitates, (2) chemical precipitates, (3) by alteration of aragonite, and (4) by carbonation of silicates.

The chief direct source of calcite is organic. Corals and innumerable other kinds of shell animals, especially in the sea, abstract calcium carbonate from the water and build it into their external or internal structures. Calcite as a clemical precipitate may be deposited from the waters of the sea, especially in inclosed lagoons; by the waters of inland lakes, especially those having no outlet; by springs and streams, especially hot springs and desert streams; and by nudergromd. waters in the openings of rocks, snch as the interstices between grains, the cavities of porous igneous rocks, especially anygdules, and in cave, fanlt, joint, and fissility openings. 'The deposited calcite may replace a considerable number of other minerals. As a deposit in the openings of rocks calcite is second in abundance only to quartz. Calcite is an alteration product of a large number of minerals, of which the following are the more common: Actinolite, ankerite, antho- 
phyllite, aragonite, angite, diopside, dolomite, epidote, fluorite, garnet, grossularite, gypsum, haiiynite, hornblende, noselite, parankerite, pyrope, sahlite, scapolites, tremolite, and zoisite.

While the abundant direct sources of calcite are (1), (2), and (3) above, the indirect and ultimate source which has probably furnished the great quantity of calcium carbonate is the carbonation of the silicates. (See pp. 473-480.) This process occurs on a great scale in the zone of katamorphism, especially in the belt of weathering. It is a reaction which takes place with liberation of heat and increase of volume in case the replaced silica separates as quartz in sitn. Many of the individual carbonation reactions of the silicates, as, for instance, wollastonite, diopside, etc., are given under that class of minerals.

Alterations.-The first of the alterations of calcite is recrystallization. Calcite is the most mobile of the abundant rock-making minerals. It responds readily to changes of physical conditions, and is very susceptible to weak chemical agents. A slight stress may produce in it twinning structure. A state of unequal strain favors its solubility. Where the pressure increases, solution increases; where pressure is lessened, deposition takes place. Increase of temperature greatly increases its solubility, and vice rersa. The increase of carbon dioxide in water greatly increases its solubility, and vice versa. Thus it lappens that in rocks where the calcite is almost constantly subjected to changing pressure, temperature, and varying amounts of carbou dioxide it is constantly being taken into solution and, after a greater or less journey, being deposited from solution or carried to the sea to be ultimately precipitated by organic agents. The recrystallization of great masses of calcite, the solution of calcite in the belt of weathering and its partial deposition in the belt of cementation, the formation of caves, cave deposits, etce, are considered later.

The second important change of calcite is partial replacement of calcium by magnesium, often prodncing dolomite (rhombohedral; sp. gr. 2.8-2.9). The generalized reaction is:

(1) $2 \mathrm{CaCO}_{3}+\mathrm{Mg}=\mathrm{CaNg}\left(\mathrm{CO}_{3}\right)_{2}+\mathrm{Ca}+\mathrm{k}$.

Supposing the calcium to be present as a carbonate, and supposing the added magnesium to be a chloride-and this is believed to be a very common case-the reaction would be:

(2) $2 \mathrm{CaCO}_{3}+\mathrm{MrgCl}_{2}=\mathrm{CaMgC}_{2} \mathrm{O}_{6}+\mathrm{CaCl}_{2}+\mathrm{k}$. 
$\mathrm{O}_{1}$ supposing that the magnesium salt is a carbonate, and that this is deposited and an equivalent anount of calcium carbonate is taken into solution, the reaction would be:

(3) $2 \mathrm{CaCO}_{3}+\mathrm{IgCO}_{3}=\mathrm{Ca} / \mathrm{IgC}_{2} \mathrm{O}_{6}+\mathrm{CaCO}_{3}+\mathrm{k}$.

Either of these changes is accompanied by the decrease in volume of 12.30 per cent if the original calcite be compared with the produced dolomite. There might be no diminution in volume, or even an increase in volume, in case less than the molecular weight of calcium salt equivalent to the introdnced magnesium was dissolved. For instance, in an extreme case the reaction might be:

(4) $\mathrm{CaCO}_{3}+\mathrm{MgCO}{ }_{3}=\mathrm{CaMg}\left(\mathrm{CO}_{3}\right)_{2}+\mathrm{k}$,

the $\mathrm{MgCO}_{3}$ being adderl through solutions, and no calcium carbonate dissolved. In this case the expansion in volume over the original calcite would be very great-75.41 per cent. However, the normal case in dolomitization, as noted below, appears to be the molecular replacement represented by the specific equations (2) and (3). The compounds concerned in these reactions are so important that the heat relations have been determined as above given; so it can be asserted positively, from chemical studies, that heat is liberated by them.

The calcium of calcium carbonate may be replaced by' other metals besides magnesium, or calcite may be replaced by an oxide. The most important of the elements which enter into such combinations, and the only one which need be mentioned, is iron. At many localities, partly or wholly occupying the place once held by calcite, iron carbonate is found. For any definite proportion of iron replacing the calcinm, equations may be written paralleling those for the replacement of calcium by magnesium.

The third important alteration of calcite is to wollastonite (monoclinic; sp. gr. 2.8-2.9). This alteration is, indeed, the chief source of wollastonite. The equation is:

(5) $\mathrm{CaCO}_{3}+\mathrm{SiO}_{2}=\mathrm{CaSiO}_{3}+\mathrm{CO}_{2}-\mathrm{k}$.

In the change the volume is decreased 31.48 per cent, provided the silica used is a solid and the carbon dioxide escapes. In case the silicic acid be brought in solution from an outside sonrce, the volume of the solid is increased 10.81 per cent. Between these extremes there are theoretically. 
all gradations, but, as noted below, an approach to the former extreme probably is the common case.

Recrystallization of calcite and dolomitization take place on the most extensive scale at all depths and under both mass-static and mass-dynamic conditions; they are therefore alterations which are common to both physical-chemical zones. By dolomitization it is believed that great masses of calcite have been transformed to dolomite. The evidence of this transformation and the detailed facts in comnection with the change are given under dolomite. (See pp. 798-808.) The fact that dolonite forms in both zones wonld be sufficient evidence that the reactions producing this compound liberate heat, even if this had not been experimentally determined to be the fact. It has been pointed ont before (pp. 181-182) that the formation of dolomite is a typical illustration of an alteration in which both the volume and the chemical changes liberate heat, and which therefore may occur in all zones and belts of the lithosphere.

The change from calcite to wollastonite occurs chiefly or wholly in the very deep-seated rocks, especially in the zone of anamorphism. In this zone, as noted (pp. 764-766), it can not be assmmed that material is added in considerable quantity from an ontside source by circulating water; hence in this zone silica for the change is believed to have been a solid. The reaction is therefore one taking place with the absorption of heat and condensation of volume. The silication of calcite to wollastonite in the zone of anamorphism may be taken as a typical example of the heat and volume cliange of silication of carbonates in that zone.

DOLOMITE.

occurrence.-The chief sonrce of dolomite is believed to be the dolomitization of calcite (see pp. 238-239), but dolomite is also a direct chemical precipitate. Dolomite also forms in subordinate amount by the alteration of ankerite. The ultimate sonrce of the magnesium carbonate for the dolomitization of the calcite is the magnesium liberated by the carbonation of the silicates in the zone of katanorphism, especially in the belt of weathering. The reactions for the decomposition of some of the simple silicates, such as diopside and tremolite, are given under those minerals. The magnesium for the dolomitization need not be directly derived from a silicate, but may be from the solutions of the sea or from 
a previously formed magnesium limestone or dolomite which is in the belt of weathering. Dolomite produced by the carbonation of the silicates or by solution of dolomitic formations is an important chemical precipitate in caves and small crevices in the rocks, the same as calcite.

In summary, dolomite is chiefly derived as a secondary mineral from ankerite, calcite, and parankerite.

Alterations.-An important alteration of dolomite is to diopside (monoclinic; sp. gr. 3.2-3.38). This alteration is a typical example of silication. (See p. 205.) The most probable reaction is:

(1) $\mathrm{IgCaC}_{2} \mathrm{O}_{6}+2 \mathrm{SiO}_{2}=\mathrm{MgCaSi} \mathrm{O}_{6}+2 \mathrm{CO}_{2}-\mathrm{k}$.

The decrease in volume is 40.11 per cent, provided all of the silica entering into the combination was a solid. In case all of the silica were introduced through water solutions there would be an increase in volume of 2.03 per" cent. More important alterations of dolomite are into tremolite (monoclinic; sp. gr. 2.9-3.1) and calcite (rhombohedral; sp. gr. 2.713-2.714), or into tremolite and wollastonite (monoclinic; sp. gr. 2.8-2.9). In the first case the reaction is:

(2) $3 \mathrm{CaNgC}_{2} \mathrm{O}_{6}+4 \mathrm{SiO}_{2}=\mathrm{Mg}_{3} \mathrm{CaSi}_{4} \mathrm{O}_{12}+2 \mathrm{CaCO}_{3}+4 \mathrm{CO}_{2}-\mathrm{k}$.

The decrease in volume, provided the silica is present as a solid, the calcite remains as a solid, and the carbon dioxide escapes, is 25.20 per cent. However, the excess of calcium carbonate may simultaneously change to wollastonite. In this case the reaction would be:

(3) $3 \mathrm{CaIIgC}_{2} \mathrm{O}_{6}+6 \mathrm{SiO}_{2}=\mathrm{Mg}_{3} \mathrm{CaSi}_{4} \mathrm{O}_{12}+2 \mathrm{CaSiO}_{3}+6 \mathrm{CO}_{2}-\mathrm{k}$.

The decrease in volume as compared with the dolomite and quartz of the tremolite and wollastonite is 33.09 per cent. In both of the changes, if a portion of the silica be supposed to be introduced from an outside source the decrease in volume would be lessened, and if all of it were thus supposed to be introduced there would be an increase in volume from the solid dolomite of 9.89 per cent in the case of tremolite and calcite, and 14 per cent in the case of tremolite and wollastonite.

The space once occupied by dolomite, like that occupied by calcite, may be taken by other carbonates or by various oxides. The most important of these are carbonate of iron and oxide of iron. The carbonate may be a replacement, or possibly a substitution, of the iron of some other iron MON XLVII-04- 16 
salt for that of the calcium and magnesium. The oxide of iron is an illustration of a pure replacement, not of an alteration.

The formation of diopside, tremolite, and wollastonite is known to occur in deep-seated rocks, and especially in connection with massmechanical action where the rocks are deformed by flowage. As repeatedly noted, in the zone of anamorphism the circulation of water is reduced to a mininum; and it can not be supposed that important additions are made from the outside, and therefore the silica must be supposed to have been previously present in the rocks. Indeed, we know that silica usually accompanies deposits of calcite and dolomite; hence I conclude that the reactions take place with substantially the decrease in volume above assigned to the changes. In the reactions heat is absorbed. The changes are therefore again typical illustrations of silication in the lower physicalchemical zone.

ANKERITE AND PARANKERITE.

occurrence.-All the compounds from normal ankerite and parankerite to the extremes of composition given above ( $p .237$ ) are included under the general term ferro-dolomite, which I have elsewhere used as covering all the ferriferons compounds standing between dolomite on the one side and siderite on the other. (See p. 823.)

The sources of ankerite and parankerite are the same as siderite, with the difference that at the time of the formation of the iron carbonate, calcinm and magnesium carbonate are present, or formed, and unite with it. Alterations.-The more common alterations of ankerite and parankerite are to limonite (amorphous; sp. gr. 3.80), hematite (rhombohedral; sp. gr. 5.225), and magnetite (isometric; sp. gr. 5.174), the calcium and magnesium carbonates either separating or simultaneonsly undergoing the alterations given under "Calcite" and "Dolomite." Equations may easily be written for any definite compound by which the iron carbonate passes into the minerals mentioned in the same way that siderite does and the calcium-magnesium carbonates separate. The volume changes are in the same direction, and the physical conclitions under which ankerite and parankerite alter to limonite, hematite, and magnetite are the same as those for the alteration of siderite to the like compounds. Therefore the equations and summary of physical conditions will not be here repeated.

Other important alterations of the ferro-dolomites are to sahlite (mono- 
clinic; sp. gor. 3.25-3.4) and to actinolite (monoclinic; sp. gr. 3.00-3.20). Supposing that the magnesium and iron are present in equal quantity in the sahlite, the reaction in the case of normal ankerite is:

(1) $\mathrm{CaFeC}_{2} \mathrm{O}_{6} \cdot \mathrm{CaNIgC}_{2} \mathrm{O}_{6}+4 \mathrm{SiO}_{2}=\mathrm{Mg} \mathrm{IgFeCa}_{2} \mathrm{Si}_{4} \mathrm{O}_{12}+4 \mathrm{CO}_{2}-\mathrm{K}$.

Supposing the silica to be present as a solid, the decrease in volume is 37.27 per cent. In the formation of actinolite from normal ankerite, on the supposition that the iron and magnesium are present in equal quantity in the actinolite, the reaction is:

(2) $3 \mathrm{CaFeC}_{2} \mathrm{O}_{6} \cdot \mathrm{Ca} M \mathrm{IgC}_{2} \mathrm{O}_{6}+8 \mathrm{SiO}_{2}=\mathrm{Mg}_{3} \mathrm{Fe}_{3} \mathrm{Ca}_{2} \mathrm{Si}_{8} \mathrm{O}_{24}+4 \mathrm{CaCO}_{3}+8 \mathrm{CO}_{2}-\mathrm{k}$.

The decrease in volume, supposing the silica to be present as a solid and the $\mathrm{CaCO}_{3}$ as a solid, is 22.62 per cent. Of course, if the ferro-dolomite were one in which the calcium carbonate is not so plentiful, being replaced in equal molecular parts by magnesium and iron, it would not be necessary for any calcium carbonate to form as a result of the reaction. For instance, if the ferro-dolomite were $\mathrm{CaFe}_{3} \mathrm{C}_{4} \mathrm{O}_{12} \cdot \mathrm{CaNI}_{3} \mathrm{C}_{4} \mathrm{O}_{12}$ the reaction would be as follows:

(3) $\mathrm{CaFe}_{3} \mathrm{C}_{4} \mathrm{O}_{12} \cdot \mathrm{Ca} \backslash \mathrm{Cg}_{3} \mathrm{C}_{4} \mathrm{O}_{12}+8 \mathrm{SiO}_{2}=2 \mathrm{Ig}_{3} \mathrm{Fe}_{3} \mathrm{Ca}_{2} \mathrm{Si}_{8} \mathrm{O}_{24}+8 \mathrm{CO}_{2}-\mathrm{k}$.

Using the specific gravity of normal ankerite, the decrease of volume of the actinolite as compared with the ankerite and quartz is 32.72 .

Sahlite and actinolite are both known to form abundantly in the zone of anamorphism. Sallite is found in the marbles of eastern United States. Actinolite is very abundant in the iron-bearing formations of the Lake Superior region. The development of these silicates may be taken as typical illustrations of the reaction of silication in the lower physicalchemical zone, with condensation of volume and absorption of heat.

MAGNESITE.

Occurrence-Magnesite may be a product of the alteration of any of the heavily magnesian rocks. It is especially prevalent in the olivinitic rocks and the chloritic, serpentinous, and talcose schists and gneisses, being a product which is produced by the alteration of original minerals simultaneously with the formation of chlorite, serpentine, and talc. It is also found in dolonite. The more important minerals from which it is recorded as forming are common garnet, olivine, pyrope, and serpentine.

Alterations.-No alterations are recorded for magnesite. There is, lowever, no doubt that this compound does break up in the zone of anamor- 
ism, the carbon dioxide being liberated and the magnesia being furnished for the formation of various dense magnesian minerals, such as enstatite, tremolite, olivine, pyrope, etc. These changes would involve a-diminution of volume and an absorption of heat.

SIDERITE.

occurrence.-The chief source of siderite is believed to be the reduction, dehydration, and carbonation of limonite. (See pp. 233-234.) This change is one occurring with the liberation of heat if the reaction upon the organic compound be taken into account, and increase of volume. A subordinate amount of siderite is also derived from magnetite. This change takes place with liberation of heat and increase of volume. Siderite also forms from ankerite and parankerite, arfvedsonite, garnet, hematite, hornblende, hydrous ferrons silicate, limonite, magnetite, and olivine, and replaces calcite and dolomite.

Alterations.-The important alterations of siderite are into limonite (amorphous; sp. gr. 3.6-4.0), hematite (hexagonal-rhombohedral; sp. gr. 5.225), magnetite (isometric; sp. gr. 5.168-5.18), and griinerite (monoclinic; sp. gr. 3.713 ). The reactions are as follows:

(1) $4 \mathrm{FeCO}_{3}+2 \mathrm{O}+3 \mathrm{H}_{2} \mathrm{O}=2 \mathrm{Fe}_{2} \mathrm{O}_{3} \cdot 3 \mathrm{H}_{2} \mathrm{O}+4 \mathrm{CO}_{2}+\mathrm{k}$.

The decrease in volume is 18.22 per cent.

(2) $2 \mathrm{FeCO}_{3}+\mathrm{O}=\mathrm{Fe}_{2} \mathrm{O}_{3}+2 \mathrm{CO}_{2}+\mathrm{k}$.

The decrease in rolume is 49.11 per cent.

(3) $3 \mathrm{FeCO}_{3}+\mathrm{O}=\mathrm{Fe}_{3} \mathrm{O}_{4}+3 \mathrm{CO}_{2}+\mathbf{k}$.

Very often iron sulphide, as pyrite (isometric; sp. gr. 5.025) or marcasite (orthorhombic; sp. gr. 4.875), unites with the siderite to form magnetite. This reaction is probably of great consequence in forming the heavy beds of magnetite. (See p. 845.) It may be written:

(4) $2 \mathrm{FeCO}_{3}+\mathrm{FeS}_{2}+2 \mathrm{H}_{2} \mathrm{O}=\mathrm{Fe}_{3} \mathrm{O}_{4}+2 \mathrm{H}_{2} \mathrm{~S}+2 \mathrm{CO}_{2}-\mathrm{k}$.

The decrease in volume for the siderite alone to the magnetite, equation ( 3 ), is 50.32 per cent; for siderite and pyrite, 46.67 per cent; for siderite and mareasite, 47.135 per cent.

(5) $\mathrm{FeCO}_{3}+\mathrm{SiO}_{2}+\mathrm{nH}_{2} \mathrm{O}=\mathrm{FeSiO}_{3}+\mathrm{CO}_{2}+\mathrm{nH}_{2} \mathrm{O}-\mathrm{k}$.

The decrease in volume, regarding the silica as a solid, is 32.53 per cent.

The alteration to limonite occurs in the zone of katamorphism, especially 
in the belt of weathering. The alteration to hematite occurs as a somewhat deeper seated change, usually in the belt of cementation of the zone of katamorplism. The alteration to magnetite is especially characteristic of the zone of anamorphisin, but it can not be asserted not to take place in the belt of ceimentation. The alteration to grinerite occurs under deepseated conditions, and is in its heat and volume relations a characteristic reaction of the lower zone. Magnetite and grünerite often form simultaneously. (See p. 284) The series of changes from siderite are very interesting, in that the volume changes are all diminutions, and therefore, so far as this factor is concerned, might take place in either zone. The first three reactions (equations 1, 2, and 3) liberate heat, and hence these reactions in their physical-chemical relations are similar to those of dolomite, discussed on pages 182, 240, and may take place in both zones. But the reaction of equation (4) probably absorbs heat, and that of (5) certainly does. Magnetite having the origin represented by equation (4) is probably, and griinerite is certainly, confined to the zone of anamorphism, where pressure is a controlling factor.

\section{ARAGONITE GROUP.}

The only important rock-making member of this group is aragonite.

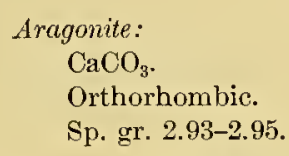

occurrence-A chief source of aragonite is as an organic precipitate. It occurs intimately associated with calcite in numerous marine shells. While abundant, it is very subordinate to calcite as an organic deposit. A second abundant source of aragonite is as a chemical precipitate, frequently in association with beds of iron carbonate and gypsum. It also occurs as a chemical precipitate from ground-water solutions, in openings in rocks, especially at places where the temperature of the solutions is from $30^{\circ}$ to $100^{\circ}$ C. or more. Aragonite is not mentioned as an alteration product of other minerals.

Alterations.-The chief change of aragonite is to calcite (rhombohedral; sp. gr. 2.713-2.714). This is a change involving recrystallization, increase of symmetry, and lowering of specific gravity. The increase in volume is 8.35 per cent. The heat effect of the change has not been found; but it 
seems probable that heat is liberated, for the transformation of aragonite to calcite occurs in both the physical-chemical zones, and I know of no exception to the principle that such reactions take place under the first part of van't Hoff's law (see pp. 107, 181).

The change from aragonite to calcite is so complete in rocks of moderate age that the presence of aragonite in the metamorphosed rocks is almost unknown. The alteration of aragonite to calcite in both zones is of considerable interest, as it presents a somewhat exceptional case. As explained on pages $182-186$, the common rule of clange in the zone of anamorphism is increase in specific gravity and increase of symmetry, provided the rolume change demanded will allow this. However, the change of specific gravity in this case is a decrease rather than an increase, and hence aragonite conforms only to the second of these rules-the first, and usually the controlling rule, for the zone of anamorphism being violated. These facts suggest the conclusion that in this instance symmetry is a more important factor than density-a very exceptional thing. If this be so, the conclusion would follow that the symmetrical arrangement of the molecnles in calcite are those which best resist the changing conditions of mass-static and mass-mechanical action in the lower zone The suggestion occurs to one that, if rocks were very deeply buried, so as to be extraordinarily deep in the lithosphere, pressure might control the form, and calcite alter to aragonite. This, however, is a speculation which has no rerification.

THE SILICATES.

The silicates are the most important of rock-making constituents. They include natural glass and many mineral groups. The groups of rock-making silicates are as follows: Feldspar, lencite, pyroxene, amphibole, nephelite, sodalite, garnet, chrysolite, scapolite, zircon, almminumsilicate, epidote, humite, zeolite, mica, clintonite, chlorite, serpentine-talc, and kaolin. Besides the members of the above groups are a number of important rock-making silicates not so included.

GLASS.

Glass, while not a definite silicate or ordinarily included among the specific minerals, is an important rock-making constituent, and therefore must be treated in connection with the silicates in a treatise on metamorphism. 
Occurrence.-Natural glass is an abundant constituent of the effusive rocks. It is especially prevalent in the more acid ones, but is not confined to them, being not infrequently abundant in the intermediate rocks, such as basalts. A lava or tuff may be almost wholly composed of glass, or glass may constitute but a small part of the background. There are thus all gradations between completely crystalline rocks and glassy rocks. Of the more recent effusive rocks glass not infrequently composes a large part of the flows. An instance is Obsidian Cliff, in the Yellowstone National Park. But in proportion as lavas are old, glass is less and less likely to be found, and in the more ancient lavas is ordinarily absent. The explanation of this absence is devitrification after solidification.

Evidence that devitrification takes place.-That certain rocks now wholly composed of minerals were once glasses is shown by the preservation in perfection of the flow structures and very delicate trichitic, perlitic, spherulitic, and other textures claracteristic of glass.

scale of devitrifcation. - It is also certain that the process of devitrification has taken place in nature on a great scale. As evidence of this may be cited the well-known American instances of devitrified glass in the original Huronian district, described by Willians," the aporhyolite of South Mountain, Pennsylvania, described by Williams and Bascom, ${ }^{b}$ the metarhyolites of the Fox River Valley of Wisconsin, described by Weidman, ${ }^{\circ}$ and the devitrified glasses of the Crystal Falls district of Michigan, described by Clements.?. In the papers of these authors many other instances of devitrification are citer, including European instances.

Not only does devitrification of natural glass take place, but under proper conditions artifical glass devitrifies in a similar manner. Wellknown cases of the devitrification of artificial glass under conditions of weathering are those of the buried ancient glasses of Nineveh and of Rome.

a Williams, G. H., Notes on the microscopical characters of rocks from the Sudbury mining district, Canada: Ann. Rept. Geol. and Nat. Hist. Survey of Canada, vol. 5, Pt. F, Appendix 1, 18901891, pp. $7+-82$.

$b$ Williaur, G. H., The rolcanic rocks of South IIountain, in Pennsylvania and Nlaryland: Am. Jour. Sci., 3d.ser., vol. 44, 1892, pp. $486-490$.

Bascom, Miss Florence, The ancient volcanic rocks of South Mountain, Pennsylvania: Bull. U. S. Geol. Survey No. 136, 1896, pp. $42-61$.

$c$ Weidman, Samuel, A contribution to the geology of the pre-Cambrian igneous rocks of the Fox River Valley, Wisconsin: Bull. Wisconsin Geol. and Yat. Hist. Survey No. 3, 1898, pp. 4-31.

" Clements, J. Morgan, and Smyth, H. L., The Crystal Falls iron-bearing district of Michigan: Mon. U. S. Geol. Surv., vol. 36, 1899, pp. \$7, 101-103, 138. 
In glass found in the lake at Walton Hall, near Wakefield, Bingley ${ }^{a}$ found that the alkalies had been wholly removed by decay. Another case of devitrification largely due to original state of strain is the glass of certain old buildings, such as cathedrals. A well-known instance is that of St. Andrew's Chapter House. ${ }^{b}$

Rate of devitrification.-The rate of devitrification of glass depends, among other things, upor (1) composition, (2) strain or lack of strain, (3) pressure, (4) mass-mechanical action, (5) temperature, (6) moisture.

In any given case of devitrification several and sometimes all of these factors enter, and hence it is impossible to discriminate the effect of each. Very often devitrification has been described as hydro-metamorphism, but by this no more can be meant than that water is usually an important factor in the process.

(1) The rate of devitrification of glass increases with its basicity. This follows from the ready solubility of basic glasses. It has also been determined that glasses rich in soda devitrify faster than those rich in potash. This corresponds with the fact emphasized in another place (see p. 516) that minerals rich in soda are more readily decomposed than those rich in potash.

(2) It is shown in another place that a state of strain in minerals promotes alteration. (See pp. 95-98.) The same is true of glass. It is definitely known that unannealed glass, which therefore cooled irregularly and is in a state of strain, independently of pressure or movemeit may partly devitrify in a few years. For instance, drawn-glass tubing, such as is used in the chemical laboratory, if kept for a few years may devitrify so as to become useless. Another well-known case of devitrification probably due to strain is the glass of certain cathedral windows. As large masses of glass cool under natural conditions, they must often be almost at the extreme of the unannealed condition, and therefore in a high state of strain. So far as glass is in this condition, even without reference to any extraneous pressure or movement, there is a marked tendency toward devitrification. The stage of the process due to this cause is dependent upon the amount of strain and the time.

a Bingley, C. W., On the peculiar action of mudand water on glass, as more especially illustrated by some specimens of glass found in the lake at Walton Hall, near Wakefield: Rept. Twenty-eighth Meeting British Assoc. Adv. Sci., London, 1859, pp. 45-46.

${ }^{b}$ Brewster, Sir David, On the decomposition of glass: Rept. Tenth Meeting British Assoc. Adv. Sci., London, 1841, pp. 5-7. 
(3) Pressure produces a state of unequal strain, and hence is favorable to devitrification.

(4) Mass-mechanical action not only produces a state of unequal strain in minerals, but fractures the material, and this gives a large surface of action for the solutions. It is therefore clear that mass-mechanical action is very favorable to devitrification.

(5) Experiments in the laboratory show that if glass be raiserl to a temperature short of fusion the tendency to devitrification is greatly promoted. It is therefore certain that conditions of dry heat after solidification are favorable to devitrification. As glass occurs in considerable bodies in a state of nature, it must for a long time, perhaps hundreds of thousands of years, have a high temperature due to the residual heat of the magma, and only very gradually assumes the normal temperature corresponding with its depth of burial. It is rather probable that microlites and crystallites, which so frequently occur in glass, largely form during this process of cooling after solidification.

(6) While devitrification of glass may occur without the presence of abundant water, it is probably rare indeed that in nature the process occurs without the presence of some moisture, and in general moisture. is a very important factor favorable to devitrification.

It is therefore clear that each of the above factors may give a condition favorable to devitrification, but in general actual devitrification is due to a combination of two or more of them.

Devitrification in the two zones.- In the zone of katamorphism under ordinary conditions it is probable that the devitrification occurs somewhat slowly. But in areas of regional volcanism, and often in those of local volcanism, the lava flows follow one another in such rapid succession that beds are piled up so deep that the water is held at a ligh temperature. By complex intrusion the entire mass of a cooled glass may again be raised to a high temperature. Orogenic movement if severe may produce a high temperature. Under any of these circumstances the conditions are furnished for tha complete and rapid devitrification of the glass.

'The nature of the devitrification is certainly different in the belt of weathering and the belt of cementation, althongh available descriptions do not furnish data for accurate statements as to the differences. But it is certain that in the belt of weathering the several changes are along the 
lines given on pages 506-527 for that belt, finally resulting in the obliteration of textures and structures and producing an incoherent rock.

In the belt of cementation ordinarily the alterations do not result in the obliteration of the original textures and structures of the glasses. This is sufficiently evident where the alterations occur under mass-static conditions, and even where mass-mechanical conditions prevail. The glass is simply fractured, as explained on pages 601-602, and the individual blocks are altered by metasonatism under mass-static conditions.

So far as we know, glasses originally form only in the zone of katamorphism, and mainly at or near the surface. Therefore a glass can get into the zone of ananorphism only by being buried under succeeding lava flows or tuffs or under sedimentary rocks. Hence, before glass reaches the lower zone, it must lave been subjected for a long time to devitrification in the belt of cementation, and the question arises whether or not a glass would not be completely devitrified before it becomes sufficiently deeply buried to reach the zone of anamorphism. However, if glass ever does reach the lower zone, it is certain that its devitrification will take place rapidly under either mass-static or mass-mechanical conditions. The rocks in this lower zone are everywhere at temperatures exceeding $100^{\circ} \mathrm{C}$; they contain water; hence, even under conditions of absolute quiescence, it is certain that glass could not long exist. The crystallization would be even more rapid under mass-mechanical conditions.

In so far as the glass liad devitrified in the zone of katamorphism, and had produced minerals characteristic of that zone, in the lower zone these minerals would be recrystallized and minerals formed characteristic of the latter zone. If mass-static conditions prevail this recrystallization may take place without obliterating previous textures and structures. However, if recrystallization takes place under conditions of mashing, the original textures and structures are lost, and minerals are prodnced of such kinds and proportions as correspond with the composition of the glass. Horeorer, when the glass passes into the zone of anamorphism, textures and structures may be formed characteristic of the slates, schists, and gneisses. When such alteration is complete it is often impracticable to determine whether the rock was originally glass or not. There can be little doubt that many of the finer-grained schists are derived from rocks which were 
originally partly or wholly glassy. For instance, the Berlin gneiss of central Wisconsin is in ehemical composition the same as that of various associated aporhyolites. The aporhyolites show that they were originally glasses by retaining the characteristic textnres of glass. The Berlin gneiss which was altered under conditions of mashing in the deep-seated zone is entirely devoid of any strneture which ean be attributed to glass, and one can not be certain that it did originally have a glassy base, although this seems probable.

minerals produced.- The minerals which are prodnced by the alterations of glass are very numerons. It has already been noted that glasses form from the most acid magmas, and also from those which are intermediate or basic in character. Furthermore, it has been seen that glass is devitrified in both the upper and the lower physical-chemical zones, and in the mpper zone both in the belt of weathering and in that of cementation. In each of these zones and belts minerals form from the glass which are characteristic of them. It is plain from the foregoing that erery mineral which may be a metamorphic product of an igneous rock of any kind may resnlt from the devitrification of glasses of different kinds under the different conditions which obtain in the zones and belts of alteration.

Heat and volume relations. - The devitrification of glass is a process which probably results in the liberation of heat. This is certainly true for the zone of katamorphism, where oxidation, hydration, and carbonation take place. As to the rolume relations of the change, the devitrification itself by means of which the substance passes from an anorphous to a crystalline condition would decrease the rolnme, provided there were no additions of other compounds. But where devitrification is accompanied by oxidation, carbonation, and hydration there are considerable additions of material. Therefore, in the belt of cementation there can be little doubt that expansion of volume is the rule where glasses are devitrified; but in the belt of weathering, where solution is prominent, doubtless there is diminution in volume with glass as with other compounds. Tn the zone of ananorphism devitrification takes place with decrease of volume, the reactions being controlled by pressure. Whether heat be liberated or absorbed in the zone of anamorphism doubtless depends in large measure upon how far the reactions of the zone of katamorphism have taken place during the time 
the glass was passing throngh that zone. If these had gone far, the undoing of the oxidation, hydration, and carbonation wonld probably absorb heat. But if the glass reached the zone of anamorphism in an anhydrons condition, the crystallization, prodncing a decrease in volume, wonld liberate heat. Thus no general statement can be made as to the heat reaction in the zone of anamorphism.

FELDSPAR GROU1.

The minerals of the feldspar group are the most abundant of the silicates. According to Clarke, "the feldspars comprise 60 per cent of the minerals of the lithosphere. The feldspars include minerals of two classes of symmetry, monoclinic or psendomonoclinic, and triclinic. Those of the first class comprise orthoclase, microcline, and anorthoclase; those of the second class include albite, oligoclase, andesine, labradorite, bytownite, and anorthite.

In chemical composition the feldspars vary from orthosilicates, through metasilicates, to polysilicates. The readiness of decomposition is indirectly proportional to the acidity, the orthosilicates being the most easily decomposed, and the polysilicates being the most difficult to decompose.

The more frequent alterations of the monoclinic feldspars and of the polysilicate plagioclase feldspars are to mica, especially muscovite, and to hydrated silicate of almminum, especially kaolin. In this alteration there is simultaneous liberation of silica, which may separate as quartz. Very frequently also gibbsite is formed at the same time. Where the mica biotite is produced it is necessary that iron and magnesium shall be added. The most common alterations of the orthosilicate plagioclase feldspars are to zeolites, epidote, and zoisite, frequently with the simultaneous formation of another plagioclase and chlorite. Where epidote is produced it is necessary that iron be added from some other source; where chlorite is produced it is necessary that magnesium and iron be added from some other sonree. All the important minerals produced by the alterations of the feldspars, with the exception of quartz and plagioclase, are hydrated, though in varying degrees; hence, in general, water is added during the alteration of the feldspars. From the intermediate plagioclases there may be produced any of the foregoing minerals

a Clarke, F. W., Analyses of rocks, laboratory of the U. S. Geol. Survey, 1880-1899: Bull. U. S. Geol. Survey No. 168,1900 , p. 16. 


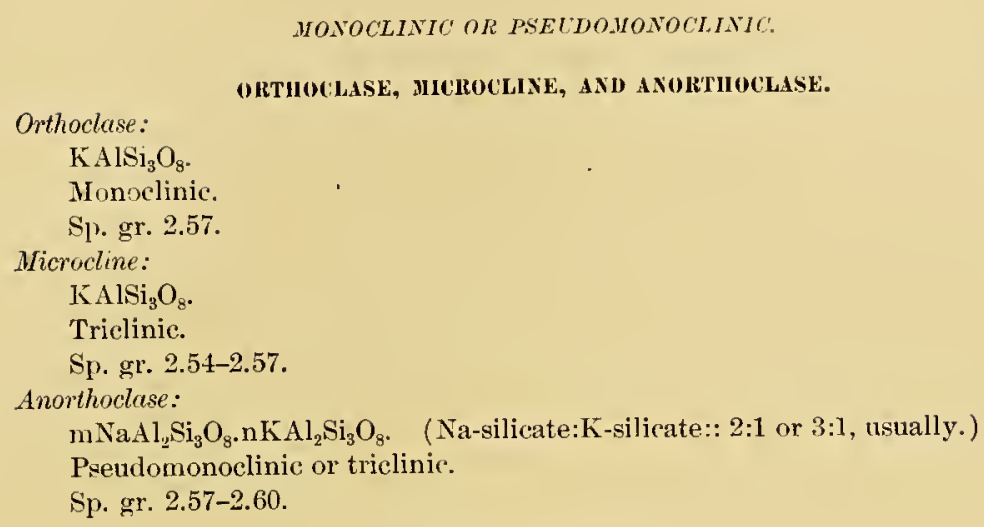

ORTHOCLASE AND MICROCLINE.

Occurrence.-Orthoclase and microcline have a very widespread occurrence as chief pyrogenic constituents. The minerals also are allogenic constituents of the clastic rocks. They further have a very widespread occurrence in the metamorphic rocks, being chief constituents both as allogenic and as autogenic constitnents of the schists and gneisses of both aqueous and igneous origin. In the development of the feldspars as autogenic constituents it is usually necessary that two or more minerals unite, except in the case of the derivation of the acid feldspars from the more basic ones or from leucite. As a metamorphic mineral orthoclase is derived from analcite, henlandite, leucite, laumontite, and stilbite. Microcline is recorded as derived from spodumene.

Alterations. - One of the most important alterations of orthoclase and microcline is to kaolinite (monoclinic; sp. gr. 2.60-2.63). 'The most probable reaction, for reasons given below, is believed to be:

(1) $2 \mathrm{KAlSi}_{3} \mathrm{O}_{8}+2 \mathrm{H}_{2} \mathrm{O}+\mathrm{CO}_{2}=\mathrm{H}_{4} \mathrm{Al}_{2} \mathrm{Si}_{2} \mathrm{O}_{9}+4 \mathrm{SiO}_{2}+\mathrm{K}_{2} \mathrm{CO}_{3}+\mathrm{k}$.

The decrease in volume, supposing the freed silica to separate as quartz, and $\mathrm{K}_{2} \mathrm{CO}_{3}$ dissolved, is 12.57 per cent. If all of the freed silica be dissolved, the decrease in volume would be $54+4$ per cent. In calculating these volume changes and those which follow, the specific gravity of orthoclase is used.

While the ordinary alteration of the potash feldspars to the kaolin group is to kaolinite as indicaterl, the alteration may be to other minerals of this group; for instance, to pyrophyllite (monoclinic (?); sp. gr. 2.8-2.9), halloysite (massive; sp. gr. 2.1), newtonite (rlomboliedral; sp. gr. 2.37), 
cimolite (amorphous; sp. gr. 2.24), allophane (amorphons; sp. gr. 1.87), and perhaps others. The chief differences are in the amomnts of water added and the amount of silica which separates. Pyrophyllite $\left(\mathrm{H}_{2} \mathrm{Al}_{2}\left(\mathrm{SiO}_{3}\right)_{4}\right)$ differs from kaolinite in that less silica is remored and less basic water is added; it therefore might be considered as an intermediate stage in the alteration. Halloysite $\left(\mathrm{H}_{4} \mathrm{Al}_{2} \mathrm{Si}_{2} \mathrm{O}_{9} \mathrm{Aq}\right.$. $)$ differ's from kaolinite only in having water of hydration. Newtonite $\left(\mathrm{H}_{8} \mathrm{Al}_{2} \mathrm{Si}_{2} \mathrm{O}_{11}\right.$. Aq. $)$ differ's from kaolinite in containing twice as much basic water as that mineral, and in being hydrated. Cimolite $\left(\mathrm{H}_{6} \mathrm{Al}_{4}\left(\mathrm{SiO}_{3}\right)_{9} \cdot 3 \mathrm{H}_{2} \mathrm{O}\right)$ differ's from kaolinite in containing more silica, more basic water, and water of hydration. Allophane $\left(\mathrm{Al}_{2} \mathrm{SiO}_{5} .5 \mathrm{H}_{2} \mathrm{O}\right)$ differs from kaolinite in containing less silica and much water. It would be easily possible to formulate equations along the line of that given for kaolinite for each of these minerals and to calculate the rolnme relations. However, this hardly seems necessary since these minerals as secondary products to orthoclase and microcline appear to be very subordinate in amonut.

Another alteration of orthoclase and microcline of some little importance is into gibbsite (monoclinic; sp. grr. 2.3-2.4). The reaction is:

(2) $2 \mathrm{KAlSi}_{3} \mathrm{O}_{8}+3 \mathrm{H}_{2} \mathrm{O}+\mathrm{CO}_{2}=2 \mathrm{Al}(\mathrm{OH})_{3}+6 \mathrm{SiO}_{2}+\mathrm{K}_{2} \mathrm{CO}_{3}+\mathrm{k}$.

The decrease in volume of the gibbsite and quartz as compared with the orthoclase is 6.61 per cent.

Another of the very important alterations of orthoclase and microchine is to muscovite (monoclinic; sp. gr. 2.76-3.0) and quartz (rhombohedral; sp. gr. 2.653-2.654). The reaction is:

(3) $3 \mathrm{KAlSi}_{3} \mathrm{O}_{8}+\mathrm{H}_{2} \mathrm{O}+\mathrm{CO}_{2}=\mathrm{KH}_{2} \mathrm{Al}_{3} \mathrm{Si}_{3} \mathrm{O}_{12}+6 \mathrm{SiO}_{2}+\mathrm{K}_{2} \mathrm{CO}_{3}+\mathrm{k}$.

Provided the silica separates as quartz and the potassium mites with carbonic acid and the potassinm carbonate be removed in solution, the decrease in rolume is 15.58 per cent.

While this reaction may take place under exceptional conditions, it is believed, as explained below, that where muscovite forms from orthoclase one of the rich aluminous minerals often mites with the orthoclase to produce the mica. Supposing the aluminons mineral to be gibbsite, the reaction is:

(4) $\mathrm{KAISi}_{3} \mathrm{O}_{8}+2 \mathrm{Al}(\mathrm{OH})_{3}=\mathrm{KH}_{2} \mathrm{Al}_{3} \mathrm{Si}_{3} \mathrm{O}_{12}+2 \mathrm{H}_{2} \mathrm{O}-\mathrm{k}$.

The decrease in volume of the muscovite as compared with the orthoclase and gibbsite is 2() .81 per cent. 
The alteration may be to hydro-muscovite or damourite (monoclinic; sp. gr. 2.76-3.00). This is believed by most mineralogists to differ from muscovite only in containing more water, but Dana states that a greater content of water in damourite than that contained by ordinary muscovite is not necessary.

From orthoclase and microcline, with the addition of magnesium and iron compounds, biotite (monoclinic; sp. gr. 2.7-3.1) uay be formed. If the hydrogen and potassium be supposed to be present in equal proportions and the same supposition be made with reference to magnesium and iron, and the latter elements are supposed to be present as carbonates, the reaction may be as follows:

$$
\text { (5) } \begin{aligned}
& 4 \mathrm{KAlSi}_{3} \mathrm{O}_{8}+2 \mathrm{MgCO}_{3}+2 \mathrm{FeCO}_{3}+\mathrm{H}_{2} \mathrm{O}= \\
& 2 \mathrm{HKMgFeAl} \mathrm{Si}_{3} \mathrm{O}_{12}+5 \mathrm{SiO}_{2}+\mathrm{K}_{2} \mathrm{SiO}_{3}+4 \mathrm{CO}_{2}+\mathrm{k} .
\end{aligned}
$$

The decrease in volume of the feldspar, magnesinm carbonate, and iron carbonate in passing into the biotite and quartz is 22.64 per cent. But, as with muscovite, the more frequent reaction probably involves gibbsite, thus:

$$
\text { (6) } \quad \mathrm{KAlSi}_{3} \mathrm{O}_{8}+\mathrm{MgCO}_{3}+\mathrm{FeCO}_{3}+\mathrm{Al}(\mathrm{OH})_{3}=\mathrm{HKMgFeAl} \mathrm{Si}_{3} \mathrm{O}_{12}+\mathrm{H}_{2} \mathrm{O}+2 \mathrm{CO}_{2}+\mathrm{k} \text {. }
$$

This greatly simplifies the cquation. The decrease in volume of the biotite as compared with the compounds from which it is derived is 22.33 per cent.

Orthoclase and microcline are said also to alter to epidote (monoclinic; sp. gr. 3.25-3.50); but if this be so calcium and iron must be introduced. The forms in which these compounds are present during the alteration are donbtless variable. If they be assumed to be present as calcium carbonate and iron sesquioxide, the reaction might be as follows:

(7) $4 \mathrm{KAISi}_{3} \mathrm{O}_{8}+\mathrm{Fe}_{2} \mathrm{O}_{3}+4 \mathrm{CaCO}_{3}+\mathrm{H}_{2} \mathrm{O}=2 \mathrm{HCa}_{2} \mathrm{Al}_{2} \mathrm{FeSi}_{3} \mathrm{O}_{13}+6 \mathrm{SiO}_{2}+2 \mathrm{~K}_{2} \mathrm{CO}_{3}+2 \mathrm{CO}_{2}+\mathrm{k}$.

Supposing the $\mathrm{Al}$ is to the $\mathrm{Fe}$ as 2 is to 1 , the decrease in volume of the epidote and quartz as compared with the feldspar, calcite, and iron oxide together is 33.73 per cent. However it is so uncertain as to the forms of the accessory compounds, both before and after reaction, that it is impossible to make a definite statement as to the volume relations.

The alteration of orthoclase and microcline to minerals of the kaolin group and to gibbsite occurs in the zone of katamorphism. The process takeś place on the most extensive scale in the belt of weathering, especially 
in the soil horizon. Wherever the feldspathic rocks are exposed to atmospheric agencies this change steadily goes on, though not so rapidly as with the orthosilicate feldspars. (See p. 519.) But wherever the potash feldspars have been very long exposed to the weathering agencies they have been partly or wholly decomposed, and in some places to a depth of several bundred feet. The change is one of the most important of all those which affect rocks. It is partly because the alterations take place near the surface, where carbon dioxide is abundant, that it is believed that the freed alkali largely unites with carbon dioxide, as given in the reaction. The silica freed in the belt of weathering is in part undoubtedly taken into solution as colloidal silicic acid and carried downward to the belt of cementation. Indeed, the silica for the process of silicification in this belt, which, as explained on page 480, is derived from the decomposition of the silicates, probably in good part comes from the alteration of the feldspars. Under the same conditions in which a part of the feldspar breaks up into kaolinite another part of the feldspar may produce gibbsite, quartz, and potassium carbonate. The potassium carbonate liberated at the time of the formation of the kaolinite and gibbsite is largely dissolved and transported elsewhere, although the soluble potassium compounds are often held in the soil to a cousiderable extent. (See pp. 498, 541-543.)

The alteration of orthoclase and microcline to minerals of the kaolin group and to gibbsite is not, however, confined to the belt of weathering. It takes place on an important scale in the belt of cementation, though not on a scale comparable to that in the belt above. So far as known, kaolinization is not a reaction which occurs in the zone of anamorphism; at least, if it does there take place it is a very subordinate phenomenon. As seen abore, the reaction is one taking place with liberation of heat and frequently with decrease of volume, since much and perhaps the most of the freed silica is taken away in solution. The heat reaction controls, and hence the change is under the rules of the upper physical-chemical zone.

The alteration of orthoclase and mierocline to mica occurs in rocks which have been somewhat deeply buried, and the change has been noted in comnection with both mass-static and mass-mechanical action. Under either of these conditions the alteration may be nearly or quite complete. But it has taken place on the most extensive scale in connection with massmechanical action, where the secondary structures, such as cleavage, are 
produced, and therefore in the belt of rock flowage. In the formation of muscovite and quartz from feldspar by equation (3), as the specific gravity of the separated quartz is somewhat greater than that of the original feldspar, and that of the muscovite is considerably greater than that of the feldspar, the condensation in volume above calculated is accounted for, althongh the alteration is one involving hydration and possibly carbonation. In the zone of anamorphism the wateradded is doubtless largely derived from other minerals, as this is a belt of dehydration, and destruction of previous minerals containing hydroxides. This passage from one mineral to another would involve no increase in the total volume, the controlling consideration. The most doubtful point concerning equaticn (3) is the carbonation of the potassium. It might be supposed that the potassinm mites with a part of the freed silica and with other elements to form potassium minerals. But it is not easy to suggest such minerals, as lencite is not recorded as a metamorphic mineral. The more probable solution of the problem is that potassium and a portion of the silica unite with the almmina of the gibbsite or some other minerals and produce one molecule of mica from one of orthoclase, as suggested in equation (4). This snggestion is rendered especially plausible for the slates, schists, and gneisses derived from sediments, for such rocks usually contain residnal orthoclase and also aluminum hydroxide. (See pp. 232, 235, 898-900.) The reaction of equation (4) produces great decrease in volume, is one of dehydration, and thus absorbs heat; it is therefore a perfect example of the rules of the zone of anamorphism. The same remarks are applicable to equations (5) and (6), respectively, for the production of biotite, as to (3) and (4) for the formation of muscovite, with the addition that the development of biotite involves silication and decarbonation, and therefore still better than muscovite illustrates the reactions of the zone of anamorphism.

The physical-chemical principles for the alteration of orthoclase and microcline to epidote are the same as for the alterations of the more basic feldspars to epidote. As the process occur's much more extensively in connection with the latter minerals, it is discussed under the basic plagioclases. (See pp. 263-264.)

$$
\text { ANORTHOCLASE. }
$$

occursence.-This mineral is subordinate in quantity to orthoclase and microcline. It occurs in both deep-seated and effusive igneous rocks; in INON XLVII $-04-1 \bar{T}$ 
the latter, chiefly in the andesitic lavas. As an allogenic mineral it also is found in the sedimentary rocks. Whether it occurs as an antogenic mineral in the metamorphic rocks has not been determined.

Aiterations.--Both orthoclase and microcline contain some sodium. When the sodium becomes important the mineral is anorthoclase. It naturally follows from this fact that the alterations of anorthoclase are in all respects like those of orthoclase and microcline, with the exception that the freed alkalies are in good part sodinm. The reactions are analogous to those already given for orthoclase, but with the muscovite or biotite the soda-mica paragonite (monoclinic; sp. gr. 284 ) is formed. Supposing the sodium silicate is to the potassium silicate as 2 to 1 , the more important reactions may be written as follows:

(1) $2\left(2 \mathrm{NaAlSi} \mathrm{O}_{8} \cdot \mathrm{KAlSi}_{3} \mathrm{O}_{8}\right)+6 \mathrm{H}_{2} \mathrm{O}+3 \mathrm{CO}_{2}=3 \mathrm{H}_{4} \mathrm{Al}_{2} \mathrm{Si}_{2} \mathrm{O}_{9}+12 \mathrm{SiO}_{2}+\mathrm{K}_{2} \mathrm{CO}_{3}+2 \mathrm{Na}_{2} \mathrm{CO}_{3}+\mathrm{k}$.

(2) $2\left(2 \mathrm{NaAlSi}_{3} \mathrm{O}_{8} . \mathrm{KAlSi}_{3} \mathrm{O}_{8}\right)+9 \mathrm{H}_{2} \mathrm{O}+3 \mathrm{CO}_{2}=6 \mathrm{Al}(\mathrm{OH})_{3}+18 \mathrm{SiO}_{2}+\mathrm{K}_{2} \mathrm{CO}_{3}+2 \mathrm{Na}_{2} \mathrm{CO}_{3}+\mathrm{k}$.

(3) $2 \mathrm{NaAlSi} \mathrm{O}_{3} \cdot \mathrm{KAlSi}_{3} \mathrm{O}_{8}+6 \mathrm{Al}(\mathrm{OH})_{3}=\mathrm{KH}_{2} \mathrm{Al}_{3} \mathrm{Si}_{3} \mathrm{O}_{12}+2 \mathrm{NaH}_{2} \mathrm{Al}_{3} \mathrm{Si}_{3} \mathrm{O}_{12}+6 \mathrm{H}_{2} \mathrm{O}-\mathrm{k}$.

(4) $2 \mathrm{NaAlSi}_{3} \mathrm{O}_{8} \cdot \mathrm{KAlSi}_{3} \mathrm{O}_{8}+\mathrm{IgCO}_{3}+\mathrm{FeCO}_{3}+5 \mathrm{Al}(\mathrm{OH})_{3}=$ $\mathrm{HKMFFeAl} \mathrm{I}_{2} \mathrm{Si}_{3} \mathrm{O}_{12}+2 \mathrm{NaH}_{2} \mathrm{Al}_{3} \mathrm{Si}_{3} \mathrm{O}_{12}+5 \mathrm{H}_{2} \mathrm{O}+2 \mathrm{CO}_{2}-\mathrm{k}$

Supposing the sodium silicate is to the potassium silicate as 3 to 1 , we have:

(5) $2\left(3 \mathrm{NaAlSi}_{3} \mathrm{O}_{8} \cdot \mathrm{KAlSi}_{3} \mathrm{O}_{8}\right)+2 \mathrm{Fe}_{2} \mathrm{O}_{3}+8 \mathrm{CaCO}_{3}+2 \mathrm{H}_{2} \mathrm{O}=$ $4 \mathrm{HCa}_{2} \mathrm{Al}_{2} \mathrm{FeSi}_{3} \mathrm{O}_{13}+12 \mathrm{SiO}_{2}+\mathrm{K}_{2} \mathrm{CO}_{3}+3 \mathrm{Na}_{2} \mathrm{CO}_{3}+4 \mathrm{CO}_{2}+\mathrm{k}$.

The equations corresponding to (3) and (5) under orthoclase and microcline are not written, since their occurrence is very doubtful. The decrease in volume of the kaolinite and quartz as compared with the auorthoclase, equation (1), is 9.56 per cent, or of the kaolinite alone is 52.19 per cent. The decrease in rolume of the gibbsite and quartz as compared with the anorthoclase, equation (2), is 3.30 per cent, or of the gibbsite alone is 68.02 per cent. The decrease in volume of the muscovite and paragonite, as compared with the anorthoclase and gibbsite, equation (3), is 20.04 per cent. The decrease in volume of the biotite and paragonite, as compared with the anorthoclase and gibbsite, equation (4), is 10.91 per cent. The decrease in volume of the epidote and quartz, as compared with the anorthoclase, hematite, and calcite, equation (5), is $28.30 \mathrm{per}$ cent. Equations corresponding with the above and the volume relations can be easily worked out along analogous lines for other ratios of the sodium-bearing and potassium-bearing silicates, but the general results would be the same, so this is hardly worth the while.

The geological positions and physical conditions under which the 
changes take place are identical with the corresponding changes of orthoclase and microcline-i. e., alterations represented by equations (1) and (2) take place in the zone of katamorphism, and especially the belt of weathering. Alterations (3) and (4) occur in the zone of anamorphism, and that of equation (5) is known for the belt of cementation. One general point is clear from the above, that in the anorthoclase rocks we have a source for paragonite in the paragonite-schists and paragonite-gneisses.

\section{TRICLINTC.}

The plagioclase feldspars are a group of triclinic feldspars which range from sodiun-aluminum silicate to calcium-aluminum silicate. The former is a polysilicate and the latter an orthosilicate, hence there is great variation both as to composition and as to acidity. The names, compositions, and specific gravities of the species, as given by Tschermak and Dana, are as follows:

ALITE, OLIOCLASE, ANDESINE, LADRADORITE, BTTOWNITE, AND AYORTHTE.

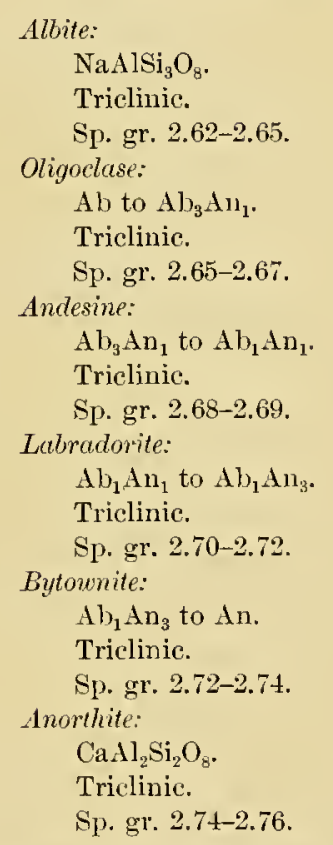

occurrence.-The plagioclases are probably the most important rockmaking constituents, being approached in abundance only by the orthoclase feldspars and by quartz. The plagioclases are present as pyrogenic constitnents in the great majority of igneous rocks. They also occur very 
abundantly as allogenie constituents in the sedimentary rocks. In such rocks the more siliceous plagioclases are more plentiful than the less siliceous plagioclases, becanse of the more ready decomposition of the latter. The plagioclases develop abundantly as antogenic constituents in the metamorphic rocks of both sedimentary and igneous origin. The plagioclase albite is recorded as being derived from analcite, heulandite, laumontite, plagio. clases (with orthoclase), sodalite, spodumene, and stilbite. The plagioclase anorthite is not recorded as being derived from other minerals. But it is seen in the zone of katamorphism that anorthite passes into various zeolites by simple hydration. It can hardly be doubted that when such zeolites pass into the zone of anamorphism by dehydration they are sources of anorthite. Doubtless also anorthite is produced in different ways from the combinations of various minerals, just as it passes into different combinations of minerals. The intermediate feldspars, which are intermolecular mixtures of albite and anorthite, may be derived from any of the minerals from which albite and anorthite are formed.

Alterations.- - In treating the alterations of the plagioclases the only practicable plan is to calculate equations and volume reactions separately for albite and for anorthite. For any of the intermediate feldspars the corresponding equations may be written by multiplying the albite and anorthite equations by the number of molecules of these compounds, respectively, and adding the products. However, the alterations of the plagioclases are so complicated that I have not been able to make the treatment more than very partial.

The species belonging to the more siliceons lalf of the plagioclase feldspars-i. e., albite, oligoclase, and andesine-frequently undergo alterations similar to those of the monoclinic feldspars, producing kaolin (monoclinic; sp. gr. 2.615), gibbsite (monoclinic; sp. gr. 2.35), and quartz (rhombohedral; sp. gr. 2.6535). These alterations may be considered as coming from the albite molecule.

But the more common alterations of the plagioclases are into the zeolites, epidote (monoclinic; sp.gr.3.38), quartz, the scapolites, and paragonite (monoclinic; sp. gr. 2.84), and the less siliceons feldspars into more siliceous plagioclase feldspars. The plagioclases are also recorderl as altering into prehnite (orthorhombic; sp. gr. 2.875) and albite. By pyrochemical methods plagioclase and sodium carbonate at $220^{\circ}$ C. produce the zeolite analcite (isometric; sp. gr. 2.255), and this process is more rapid in propor- 
tion as the feldspars aro less siliceons. The alteration of a given feldspar may be into two or more of the above minerals. Doubtless often orthoclase and plagioclase together pass into other minerals. One snch reaction has been considered by Becke, and is given below.

The less siliceons plagioclases, labradorite, bytownite, and anorthite, alter rarely to kaolin alone, but this mineral nay separate simultaneously with zoisite (orthorhombic; sp. gr. 3.31) or epidote.

The alteration of albite to kaclin and quartz, to gibbsite and quartz, and of albite and gibbsite to paragonite, respectively, may be written as follows:

(1) $2 \mathrm{NaAlSi}_{3} \mathrm{O}_{8}+2 \mathrm{H}_{2} \mathrm{O}+\mathrm{CO}_{2}=\mathrm{H}_{4} \mathrm{Al}_{2} \mathrm{Si}_{2} \mathrm{O}_{9}+4 \mathrm{SiO}_{2}+\mathrm{Na}_{2} \mathrm{CO}_{3}+\mathrm{k}$.

(2) $2 \mathrm{NaAlSi}_{3} \mathrm{O}_{3}+3 \mathrm{H}_{2} \mathrm{O}+\mathrm{CO}_{2}=2\left[\mathrm{Al}(\mathrm{OH})_{3}\right]+6 \mathrm{SiO}_{2}+\mathrm{Na}_{2} \mathrm{CO}_{3}+\mathrm{k}$.

(3) $\mathrm{NaAlSi} \mathrm{O}_{8}+2 \mathrm{Al}(\mathrm{OH})_{3}=\mathrm{NaH}_{2} \mathrm{Al}_{3} \mathrm{Si}_{3} \mathrm{O}_{12}+2 \mathrm{H}_{2} \mathrm{O}+\mathrm{k}$.

The decrease in volume in equation (1) of the kaolin and quartz is 4.89 per cent; in equation (2) the increase for the gibbsite and quartz is 1.58 per cent; in equation (3) the decrease for the paragonite, as compared with the albite and gibbsite, is 18.85 per cent.

Analcite (isometric; sp. gr. 2.22-2.29) may be derived from albite according to the following reaction:

(4) $2 \mathrm{NaAlSi}_{3} \mathrm{O}_{8}+2 \mathrm{H}_{2} \mathrm{O}=\mathrm{Na}_{2} \mathrm{Al}_{2} \mathrm{Si}_{4} \mathrm{O}_{12} \cdot 2 \mathrm{H}_{2} \mathrm{O}+2 \mathrm{SiO}_{2}+\mathrm{k}$.

The increase in volume is 20.82 per cent, supposing the silica separates as a solid.

Natrolite (orthorhombic; sp. gr. 2.20-2.25) may also be derived from albite according to the reaction:

(5) $2 \mathrm{NaAlSi}_{3} \mathrm{O}_{8}+2 \mathrm{H}_{2} \mathrm{O}=\mathrm{H}_{4} \mathrm{Na}_{2} \mathrm{Al}_{2} \mathrm{Si}_{3} \mathrm{O}_{12}+3 \mathrm{SiO}_{2}+\mathrm{k}$.

The increase in volume is 19.95 per cent, supposing the silica separates as a solid.

From anorthite a number of zeolites are derived. Clarke is one of the latest authors who has discussed the relations of the zeolites to the feldspars, and the cliemical alterations given are obtained mainly from his paper., The equations for the more common varieties may be written as follows:

Thomsonite (orthorhombic; sp. gr. 2.3-2.4) is derived from anorthite according to the following reaction:

(6) $3 \mathrm{CaAl}_{2} \mathrm{Si}_{2} \mathrm{O}_{8}+7 \mathrm{H}_{2} \mathrm{O}=\mathrm{Ca}_{3} \mathrm{Al} \mathrm{l}_{6} \mathrm{Si}_{6} \mathrm{O}_{24} \cdot 7 \mathrm{H}_{2} \mathrm{O}+\mathrm{k}$.

The increase in volume is 34.65 per cent.

a Clarke, F. W., The constitution of the silicates: Bull. U. S. Geol. Survey No. 125, 1895, pp. 32-45. 
Gismondite (monoclinic; sp. gr. 2.265) is derived from anorthite according to the following reaction:

(7) $3 \mathrm{CaAl}_{2} \mathrm{Si}_{2} \mathrm{O}_{8}+12 \mathrm{H}_{2} \mathrm{O}=\mathrm{Ca}_{3} \mathrm{Al} \mathrm{S}_{6} \mathrm{Si}_{6} \mathrm{O}_{24} \cdot 12 \mathrm{H}_{2} \mathrm{O}+\mathrm{k}$.

The increase in volnme is 52.76 per cent.

For laumontite (monochinic; sp. gr. 2.305̃) the change does not appear to have been determined with reasonable certainty. It may be supposed to be derived from anorthite by the simultaneons union of freed calcium and aluminum with other compounds, the calcinm perhaps passing into the carbonate and the aluminum into the hydrate. On this hypothesis the reaction is:

(8) $2 \mathrm{CaAl}_{2} \mathrm{Si}_{2} \mathrm{O}_{8}+7 \mathrm{H}_{2} \mathrm{O}+\mathrm{CO}_{2}=\mathrm{H}_{4} \mathrm{CaAl}_{2} \mathrm{Si}_{4} \mathrm{O}_{14} \cdot 2 \mathrm{H}_{2} \mathrm{O}+\mathrm{CaCO}_{3}+2\left[\mathrm{Al}(\mathrm{OH})_{3}\right]+\mathrm{k}$.

The increase in volume is 33.65 per cent, supposing the calcium carbonate to be dissolved and the aluminmm hydroxide to remain as gibbsite. However, Clarke regards lammontite as derived from equal quantities of anorthite and the hypothetical compound trisilicic anorthite ${ }^{a}\left(\mathrm{Ca}_{3} \mathrm{Al}_{6}\left(\mathrm{Si}_{3} \mathrm{O}_{8}\right)_{6}\right)$.

The zeolite phillipsite (monoclinic; sp. gr. 2.20) may be regarded as derived from albite, anorthite, and lencite, as follows:

(9) $\begin{array}{r}6 \mathrm{CaAl}_{2} \mathrm{Si}_{2} \mathrm{O}_{8}+4 \mathrm{NaAlSi}_{3} \mathrm{O}_{8}+6 \mathrm{KAlSi}_{2} \mathrm{O}_{6}+48 \mathrm{H}_{2} \mathrm{O}+2 \mathrm{CO}_{2}= \\ 3\left(\mathrm{~K}_{2} \mathrm{Ca}_{2} \mathrm{Al}_{6} \mathrm{Si}_{12} \mathrm{O}_{36} .14 \mathrm{H}_{2} \mathrm{O}\right)+2 \mathrm{Na}_{2} \mathrm{CO}_{3}+4 \mathrm{AI}(\mathrm{OH})_{3}+\mathrm{k} .\end{array}$

'The lencite is added as a source of the potassinm. The increase in volume of the three compounds in passing into phillipsite is 31.98 per cent.

Heulandite (epistilbite) (monoclinic; sp. gr. 2.20) and stilbite (monoclinic; sp. gr. 2.1495) are regarded by Clarke as derived from the hypothetical compound trisilicic anorthite. Chabazite (rhombohedral; sp. gr. 2.12) is regarded by him as derived from this compound and from normal anorthite. All four, however, may be equally well considered as derived from intermediate plagioclases with carbonation of the excess of calcium and hydration of the excess of aluminum. On these hypotheses the reactions for the four may be written as follows:

(10) $4 \mathrm{NaAlSi}_{3} \mathrm{O}_{8}+3 \mathrm{CaA}_{2} \mathrm{Si}_{2} \mathrm{O}_{8}+21 \mathrm{H}_{2} \mathrm{O}+2 \mathrm{CO}_{2}=$ $3\left(\mathrm{H}_{4} \mathrm{CaAl}_{2} \mathrm{Si}_{6} \mathrm{O}_{18} .3 \mathrm{H}_{2} \mathrm{O}\right)+2 \mathrm{Na}_{2} \mathrm{CO}_{3}+4\left[\mathrm{Al}(\mathrm{OH})_{3}\right]+\mathrm{k}$

(11) $4 \mathrm{NaAlSi}_{3} \mathrm{O}_{8}+3 \mathrm{CaAl}_{2} \mathrm{Si}_{2} \mathrm{O}_{8}+24 \mathrm{H}_{2} \mathrm{O}+2 \mathrm{CO}_{2}=$ $\mathrm{Ca}_{3} \mathrm{Al}_{6}\left(\mathrm{Si}_{3} \mathrm{O}_{8}\right)_{6} .18 \mathrm{H}_{2} \mathrm{O}+2 \mathrm{Na}_{2} \mathrm{CO}_{3}+4 \mathrm{Al}(\mathrm{OH})_{3}+\mathbf{k}$.

(12) $6 \mathrm{NaAlSi}_{3} \mathrm{O}_{8}+6 \mathrm{CaAl}_{2} \mathrm{Ni}_{2} \mathrm{O}_{8}+3 \mathrm{CO}_{2}+45 \mathrm{H}_{2} \mathrm{O}=$ $2\left[\mathrm{Ca}_{3} \mathrm{Al}_{6}\left(\mathrm{SiO}_{4}\right)_{3}\left(\mathrm{Si}_{3} \mathrm{O}_{8}\right)_{3} \cdot 18 \mathrm{H}_{2} \mathrm{O}\right]+3 \mathrm{Na}_{2} \mathrm{CO}_{3}+6\left[\mathrm{Al}(\mathrm{OH})_{3}\right]+6 \mathrm{SiO}_{2}+\mathrm{k}$.

a Clarke, F. W., The constitution of the silicates: Bull. U. S. Geol. Survey No. 125, 1895, p. 42. 
Supposing the sodium carbonate is dissolved and the other componds are solids, the increase in volume for (10) is 37.14 per cent, for (11) is 43.50 per cent, and for (12) is $46.76 \mathrm{per}$ cent.

Scolecite (monoclinic; sp. gr. 2.16-2.40) may be derived from anorthite, according to the following reaction:

(13) $3 \mathrm{CaAl}_{2} \mathrm{Si}_{2} \mathrm{O}_{8}+9 \mathrm{H}_{2} \mathrm{O}+\mathrm{CO}_{2}=2 \mathrm{CaAl}_{2} \mathrm{Si}_{3} \mathrm{O}_{10} \cdot 3 \mathrm{H}_{2} \mathrm{O}+2 \mathrm{Al}(\mathrm{OH})_{3}+\mathrm{CaCO}_{3}+\mathrm{k}$.

The increase in volume is 35.23 per cent, provided the gibbsite separates as a solid and the $\mathrm{CaCO}_{3}$ is dissolved.

Mesolite (monoclinic or triclinic; sp. gr. 2.29), according to Clarke, ${ }^{a}$ is an isomorphous mixture of equal quantities of natrolite and scolecite; therefore tle reaction for this compound may be expressed by the following:

(14) $4 \mathrm{NaAl}_{1} \mathrm{Si}_{3} \mathrm{O}_{8}+3 \mathrm{CaAl}_{2} \mathrm{Si}_{2} \mathrm{O}_{8}+13 \mathrm{H}_{2} \mathrm{O}+\mathrm{CO}_{2}=$ $2\left(\mathrm{H}_{8} \mathrm{Na}_{2} \mathrm{CaAl}_{4} \mathrm{Si}_{6} \mathrm{O}_{24} \cdot \mathrm{H}_{2} \mathrm{O}\right)+6 \mathrm{SiO}_{2}+2 \mathrm{Al}(\mathrm{OH})_{3}+\mathrm{CaCO}_{3}+\mathrm{k}$.

The expansion in rolume is 24.96 per cent, provided the silica and gibbsite separate as solids and the $\mathrm{CaCO}_{3}$ is carried away in solution. If all products are solid the increase in the rolume is 30.19 per cent.

Turning now from the zeolites to other minerals, the plagioclases are recorded as altering into prehnite (orthorthombic; sp. gr. 2.875). Since albite is recorded as simultaneously separating, the most probable reaction is by hydration of the anorthite molecule.

(15) $4 \mathrm{CaAl}_{2} \mathrm{Si}_{2} \mathrm{O}_{8}+8 \mathrm{H}_{2} \mathrm{O}=2 \mathrm{H}_{2} \mathrm{Ca}_{2} \mathrm{Al}_{2} \mathrm{Si}_{3} \mathrm{O}_{12}+4 \mathrm{Al}(\mathrm{OH})_{3}+2 \mathrm{SiO}_{2}+\mathrm{k}$.

Supposing the compounds formed to be solids, the increase in volume is 14.85 per cent.

Another important alteration of the plagioclases is into zoisite (orthorhombic; sp. gr. 3.25-3.37) or epidote (monoclinic; sp. gr. 3.25-3.5), with the simultaneous formation of kaolinite or gibbsite. The reaction for anorthite in the case of zoisite is probably:

$\mathrm{Or}^{*}$

(16) $4 \mathrm{CaAl}_{2} \mathrm{Si}_{2} \mathrm{O}_{8}+3 \mathrm{H}_{2} \mathrm{O}=\mathrm{H}_{2} \mathrm{Ca}_{4} \mathrm{Al}_{6} \mathrm{Si}_{6} \mathrm{O}_{26}+\mathrm{H}_{4} \mathrm{Al}_{2} \mathrm{Si}_{2} \mathrm{O}_{9}+\mathrm{k}$,

(17) $4 \mathrm{CaAl}_{2} \mathrm{Si}_{2} \mathrm{O}_{8}+4 \mathrm{H}_{2} \mathrm{O}=\mathrm{H}_{2} \mathrm{Ca}_{4} \mathrm{Al}_{6} \mathrm{Si}_{6} \mathrm{O}_{26}+2 \mathrm{Al}(\mathrm{OH})_{3}+2 \mathrm{SiO}_{2}+\mathrm{k}$.

The decrease in volume of the solids in (16) is 7.77 per cent, and in (17) is 4.58 per cent.

In the formation of epidote the reactions are of a similar kind, but $\mathrm{Fe}_{2} \mathrm{O}_{3}$ replaces some $\mathrm{Al}_{2} \mathrm{O}_{3}$ of the feldspar molecule. Supposing the 
aluminum is to the iron as 2 to 1 , that the iron is derived from hematite, and that excess of aluminum separates as gibbsite, the reaction for anorthite is:

or

(18) $4 \mathrm{CaAl}_{2} \mathrm{Si}_{2} \mathrm{O}_{8}+\mathrm{Fe}_{2} \mathrm{O}_{3}+6 \mathrm{H}_{2} \mathrm{O}=\mathrm{H}_{2} \mathrm{Ca}_{4} \mathrm{Al}_{4} \mathrm{Fe}_{2} \mathrm{Si}_{6} \mathrm{O}_{26}+\mathrm{H}_{4} \mathrm{Al}_{2} \mathrm{Si}_{2} \mathrm{O}_{9}+2 \mathrm{Al}(\mathrm{OH})_{3}+\mathrm{k}$,

(19) $4 \mathrm{CaAl}_{2} \mathrm{Si}_{2} \mathrm{O}_{8}+7 \mathrm{H}_{2} \mathrm{O}+\mathrm{Fe}_{2} \mathrm{O}_{3}=\mathrm{H}_{2} \mathrm{Ca}_{4} \mathrm{Al}_{4} \mathrm{Fe}_{2} \mathrm{Si}_{6} \mathrm{O}_{26}+4 \mathrm{Al}(\mathrm{OH})_{3}+2 \mathrm{SiO}_{2}+\mathrm{k}$.

The increase of the volume of the epidote, kaolin, and gibbsite as compared with the anorthite and hematite, equation (18), is 3.6 per cent. The increase in volume of the epidote, gibbsite, and quartz as compared with the anorthite and hematite, equation (19), is 6.57 per cent.

The scapolites include marialite (tetragonal; sp. gr. 2.566), meionite (tetragonal; sp. gr. 2.70-2.74), and various isomorphous mixtures. (See pp. 311-312.) The alterations of the plagioclases into these two minerals are given. From these equations those for any definite isomorphous mixture of marialite and meionite can easily be formulated. According to Clarke, ${ }^{a}$ albite changes into marialite, and anorthite into meionite. The reactions may be written as follows:

(20) $3 \mathrm{NaAlSi}_{3} \mathrm{O}_{8}+\mathrm{NaCl}=\mathrm{Na}_{4} \mathrm{Al}_{3} \mathrm{Si}_{9} \mathrm{O}_{24} \mathrm{Cl}+\mathrm{k}$.

Supposing the $\mathrm{NaCl}$ to be in solution, the increase in volume of the solid compound is $10.29 \mathrm{per}$ cent. If the $\mathrm{NaCl}$ be supposed to be a solid, the increase in volume of the solid compound is 1.84 per cent. The change from anorthite to meionite is represented by the following reaction:

(21) $3 \mathrm{CaAl}_{2} \mathrm{Si}_{2} \mathrm{O}_{8}+\mathrm{CaCO}_{3}=\mathrm{Ca}_{4} \mathrm{Al}_{6} \mathrm{Si}_{6} \mathrm{O}_{25}+\mathrm{CO}_{2}+\mathrm{k}$.

If the calcium carbonate be supposed to be present as a solid, the decrease in volume is 3.78 per cent; if it be supposed to be added in solution, the increase in volume is 7.87 per cent.

Becke records the alteration of orthoclase and plagioclase into albite (triclinic; sp. gr. 2.635), zoisite (orthorhombic; sp. gr. 3.31), muscovite (monoclinic; sp. gr. 2.88), and quartz (rhombohedral; sp. gr. 2.6535). His equation for this reaction is as follows: ${ }^{b}$

(22) $\mathrm{x}\left(\mathrm{NaAlSi}_{3} \mathrm{O}_{8}\right)+4\left(\mathrm{CaAl}_{2} \mathrm{Si}_{2} \mathrm{O}_{8}\right)+\mathrm{KAlSi}_{3} \mathrm{O}_{8}+2 \mathrm{H}_{2} \mathrm{O}=$ $\mathbf{x}\left(\mathrm{NaAlSi}_{3} \mathrm{O}_{8}\right)+2\left(\mathrm{HCa}_{2} \mathrm{Al}_{3} \mathrm{Si}_{3} \mathrm{O}_{13}\right)+\mathrm{H}_{2} \mathrm{KAl}_{3} \mathrm{Si}_{3} \mathrm{O}_{12}+2 \mathrm{SiO}_{2}$.

It is impracticable at the present state of knowledge to write reactions representing the changes of the less siliceons plagioclases into more siliceous plagioclases and other minerals, becanse the exact compositions of the original and resultant minerals are not known. The alterations of the

a Clarke, F. W., The constitution of the silicates: Bull. U. S. Geol. Survey No. 125, 1895, p. 29.

${ }^{b}$ Becke, F., Ueber Beziehungen zwischen Dynamometamorphose und Molecularvolumen: Neues Jahrbuch für Mineralogie, ete, vol, 2, 1896, p. 182. 
plagioclases to kaolinite, equation (1), and to gibbsite, equation (2), are by reactions of carbonation and lyydration; the alterations to the zeolites, equations (4) to (14), inclusive, are by reactions of liydration, and (8) to (14), inclusive, also involve carbonation. The alteration to prehnite, equation (15), is a reaction of hydration and desilication. The alterations to zoisite and epidote, equations (16), (17), (18), and (19), are by reactions of hydration. All but (1), (3), (16), and (17) take place with ncrease of volume ranging from 1.58 to 52.76 per cent, provided all the compounds formed remain in sitn. All take place with liberation of heat. The alterations in all particulars are characteristic of the zone of katamorphism.

The development of kaolin is probably more characteristic of the belt of weathering than of the belt of cementation. The development of the zeolites and cpidotes is known to occur on an extensive scale in the belt of cementation, both within the bodies of other minerals and within the openings in rocks. Amygdules and reins of these minerals, with quartz, are of great inportance in cementing rocks. The material for this work is doubtless in large part, though not altogether, derived from feluspathic minerals.

For the intermediate scapolites, equations (20) and (21), the alterations take place with a slight increase in volume for marialite and a slight decrease for meionite, provided all the compounds which enter into them are solids. The reactions are those of silication and decarbonation to some extent, and this involves absorption of heat. The geological occurrences correspond with the physical-chenical facts. The most common of the scapolites which occurs as a secondary product in the altered rocks is wernerite, an isomorphous mixture of meionite and marialite molecules. As stated by Dana, wernerite "occurs in metamorphic rocks, and most abundantly in granular limestone near its junction with the associated granitic or allied rock." ${ }^{a}$ Wernerite is associated with such minerals as pyroxene, amphibole, and garnet, which occur as deep-seated alterations. The formation of wemerite from feldspar is probably, therefore, a deejseated change which occurs in the zone of anamorphism.

The alteration of orthoclase and plagioclase together to albite, zoisite, muscovite, and quartz, equation (22), is a reaction of hydration and desilication. It involves an increase in volume. One would therefore expect the reaction to take place in the zone of katamorphism.

a Dana, J. D., A system of mineralogy; Descriptive mineralogy, by E. S. Dana; Wiley \& Sons, New York, 6th ed., 1892, p. 470. 
LEUCITE GROUP.

Leucite is the only rock-making mineral belonging to this group.

Leucite:

LEUCITE.

$\mathrm{KA} \mathrm{Si}_{2} \mathrm{O}_{6}$.

Isometric.

Sp. gr. 2.45-2.5.

occurrence-Leucite is a common constituent of volcanic rocks, especially the more recent ones. The fact that it is not abundant in the older volcanic rocks is probably due to its ready alteration. It may have been present originally.

Leucite is not known as a constituent of the schists and gneisses derived from the sediments. Lencite has been produced by pyro-chemical methods from analcite and potassium chloride. This is a reversal of the reaction in the case of change of leucite to analcite.

Alterations.-Leucite frequently alter's to analcite (isometric; sp. gr. 2.22$2.29)$; to a mixture of orthoclase (monoclinic; sp. gr. 2.53-2.6) and kaolinite (monoclinic; sp. gr. 2.6-2.63); to a mixtme of orthoclase and muscovite (monoclinic; sp. gr. 2.76-3.0); and to a mixture of orthoclase and nephelite (hexagonal; sp. gr. 2.55-2.65).

The change of leucite to analcite requires a substitution of sodium for potassium; hence sodium carbonate or some other sodium compound must be supposed to be present. Supposing sodium carbonate to be the conlpound, the reaction is:

(1) $2 \mathrm{KAlSi}_{2} \mathrm{O}_{6}+\mathrm{Na}_{2} \mathrm{CO}_{3}+2 \mathrm{H}_{2} \mathrm{O}=\mathrm{Na}_{2} \mathrm{Al}_{2} \mathrm{Si}_{4} \mathrm{O}_{12} \cdot 2 \mathrm{H}_{2} \mathrm{O}+\mathrm{K}_{2} \mathrm{CO}_{3}+\mathrm{k}$.

Ignoring the carbonates, the increase in volume is 10.74 per cent.

The passage of lencite into orthoclase and kaolin is as follows, supposing the freed potassium to unite with carbon dioxide:

(2) $4 \mathrm{KAlSi}_{2} \mathrm{O}_{6}+\mathrm{CO}_{2}+2 \mathrm{H}_{2} \mathrm{O}=2 \mathrm{KAlSi}_{3} \mathrm{O}_{8}+\mathrm{H}_{4} \mathrm{Al}_{2} \mathrm{Si}_{2} \mathrm{O}_{9}+\mathrm{K}_{2} \mathrm{CO}_{3}+\mathrm{k}$.

Supposing the potassium carbonate to be taken into solution, the decreass in volume of the orthoclase as compared with the leucite is 38.57 per cent, and the decrease of the orthoclase and kaolinite together as compared with the leucite is 10.58 per cent.

In a similar way the passage of leucite into orthoclase and muscovite is as follows:

(3) $6 \mathrm{KAlSi}_{2} \mathrm{O}_{6}+\mathrm{CO}_{2}+\mathrm{H}_{2} \mathrm{O}=3 \mathrm{KAlSi}_{3} \mathrm{O}_{8}+\mathrm{K} \mathrm{H}_{2} \mathrm{Al}_{3} \mathrm{Si}_{3} \mathrm{O}_{\mathbf{1 2}}+\mathrm{K}_{2} \mathrm{CO}_{3}+\mathrm{k}$. 
As before, supposing the potassium carbonate to be taken into solution, the decrease in volume of the orthoclase and muscovite as compared with the leucite is 12.43 per cent.

In the passage of lencite into orthoclase and nephelite it is necessary to suppose that a part of the potassium of ths leucite is replaced by sodium. Supposing the nephelite formed to be a pure soda-nephelite, the reaction would be:

(4) $4 \mathrm{KAlSi}_{2} \mathrm{O}_{6}+\mathrm{Na}_{2} \mathrm{CO}_{3}=2 \mathrm{KAlSi}_{3} \mathrm{O}_{8}+2 \mathrm{NaAlSiO}_{4}+\mathrm{K}_{2} \mathrm{CO}_{3}+\mathrm{k}$.

Ignoring the carbonates, the decrease in volume of the orthoclase and nephelite as compared with the leucite is 7.59 per cent.

The reactions above given, except the last, are those of lydration, and the second and third are those of carbonation also. They are, therefore, reactions which are to be expected in the zone of katamorphism. The change of lencite into urtloclase and nephelite gives decrease in volume, witl neither hydration nor dehydration, carbonation nor silication. It is, therefore, to be expected that the change is one which takes place in the zone of anamorphism.

The artificial transformation of leucite into analcite by treatment with soda solutions, and the reverse alteration of analcite into leucite by treatment with potassium solutions, as shown by Lemberg, ${ }^{a}$ is an excellent illustration of the law of mass action and proves the importance of this principle under natural conditions.

PYROXENE GROUP.

ORTHORHOMBIC PYRONENES.

Enstatite:

$\mathrm{IgSiO}_{2}$.

Orthorhombic.

Sp. gr. 3.1-3.3.

Bronzite:

$(\mathrm{MgFe}) \mathrm{SiO}_{3}$ where $\mathrm{Ig}: \mathrm{Fe}:: 8: 1,6: 1$, and $3: 1$.

Orthorhombic. Sp. gr. 3.2-3.3.

Hypersthene:

$(\mathrm{MgFe}) \mathrm{SiO}_{3}$ where $\mathrm{Mg}: \mathrm{Fe}:: 3: 1$, nearly to $\mathrm{l}: 1$.

Orthorhombic.

Sp. gr. 3.4-3.5.

a Lemberg, J., Ueber Silicatumwandhungen: Zeitschr. Deutsch. geol. Gesell., vol. 28, 1876, pp. $536-545$. 
occurrence.-The rhombic pyroxenes are common pyrogenic constituents of igneous rocks rich in magnesium. They are common in the normal diabases, gabbros, and basalts, and are abundant in the norites, peridotites, etc. They also necur in the intermediate, basic, and ultrabasic volcanic rocks, inchuding both lavas and tuffs. A very common associate of the rhombic pyroxenes is olivine. The rhombic pyroxenes also occur in the schists and gneisses, especially those derived from eruptives. In such rocks they are frequently associated with the monoclinic pyroxenes. They further occur as rein materials and are found in meteorites.

As metamorphic minerals, enstatite is derived from pyrope and hypersthene from almandite, biotice, and common garnet.

Alterations.--The most frequent alteration of the rhombic pyroxenes is to talc (orthorhombic or monoclinic; sp. gr. 2.7-2.8). The less frequent alterations are to serpentine (monoclinic; sp. gr. 2.50-2.65), bastite (orthorhombic; sp. gr. 2.50-2.75), actinolite (monoclinic; sp. gr. 3-3.2), and anthophyllite (orthorhombic; sp. gr. 3.1-3.2).

For the sake of simplicity it is assumed that where pure talc or serpentine is produced these materials are derived from enstatite; and that where bastite, actinolite, and anthophyllite are produced these minerals are derived from bronzite or hypersthene. Of course, serpentine or tale may be produced from bronzite or hypersthene, the iron separating as oxide or carbonate. One such possible alteration is written. However, the ordinary alterations of the ferriferous pyroxenes are to bastite, which is iron-bearing.

The change of enstatite to talc is as follows:

(1) $4 \mathrm{MgSiO}_{3}+\mathrm{CO}_{2}+\mathrm{H}_{2} \mathrm{O}=\mathrm{H}_{2} \mathrm{MIg}_{3} \mathrm{Si}_{4} \mathrm{O}_{12}+\mathrm{MggCO}+\mathrm{k}$.

Supposing the magnesium carbonate to be dissolved, the increase in volume is 9.93 per cent. If a ferriferous pyroxene be supposed to alter to tale, iron oxide must separate. Supposing this to be in the form of magnetite (isometric; sp. gr. 5.174), and supposing that the magnesium is to the iron as $3: 1$, or that the mineral is intermediate between bronzite and hypersthene, the reaction may be written:

(2) $3 \mathrm{Mg}_{3} \mathrm{FeSi}_{4} \mathrm{O}_{12}+3 \mathrm{H}_{2} \mathrm{O}+\mathrm{O}=3 \mathrm{H}_{2} \mathrm{NIg}_{3} \mathrm{Si}_{4} \mathrm{O}_{12}+\mathrm{Fe}_{3} \mathrm{O}_{4}-\mathrm{k}$.

Similar equations may be written by which, instead of magnetite, hematite (rbombohedral; sp. gr. 5.225) or limonite (amorphons; sp. gr. 3.80 ) is produced, in which case the expansion of volume would be 
greater. The calculated increase in volume of the talc and magnetite, as compared with the pyroxene, is 14.68 per cent, provided the average specific gravity of broncite be used, and 21.73 per cent provided the average specific gravity of hypersthene be used. Probably the real increase in volume is the arerage of the above, or about 18.20 per cent.

In the case of a hypersthene in which the iron is to the nagnesinm as 1:1 the alteration to tale may be as follows, provided the iron separate as magnetite :

(3) $3 \mathrm{MgFeSi} \mathrm{O}_{6}+\mathrm{H}_{2} \mathrm{O}+\mathrm{O}=\mathrm{H}_{2} \mathrm{Ig}_{5} \mathrm{Si}_{4} \mathrm{O}_{12}+\mathrm{Fe}_{3} \mathrm{O}_{4}+2 \mathrm{SiO}_{2}+\mathrm{k}$.

The increase of volume of the tale, magnetite, and quartz as compared with the hypersthene is 12.84 per cent.

Serpentine is produced from enstatite by the following reaction :

(4) $3 \mathrm{MgSiO} \mathrm{Ig}_{3}+2 \mathrm{H}_{2} \mathrm{O}=\mathrm{H}_{4} \mathrm{Mgg}_{3} \mathrm{Si}_{2} \mathrm{O}_{9}+\mathrm{SiO}_{2}+\mathrm{k}$.

In case the $\mathrm{SiO}_{2}$ is dissolved, the increase in volume is 14.25 per cent; if it separates as quartz (rhombohedral; sp. gr. 2.6535) the increase in volume is 38.36 per cent.

If a rhombic pyroxene be taken in which the magnesium is to the iron as $3: 1$-i. e., stands on the border line between hypersthene and brouziteserpentine might be produced by the following reaction, with the simultaneous separation of hematite and quartz:

(5) $2 \mathrm{Mg}_{3} \mathrm{FeSi}_{4} \mathrm{O}_{12}+4 \mathrm{H}_{2} \mathrm{O}+\mathrm{O}=2 \mathrm{H}_{4} \mathrm{Mgg}_{3} \mathrm{Si}_{2} \mathrm{O}_{9}+\mathrm{Fe}_{2} \mathrm{O}_{3}+4 \mathrm{SiO}_{2}+\mathrm{k}$.

Using the specific gravity of hypersthene, in case only serpentine and lhematite separate as solids, the decrease in rolume is 221 per cent, and if the silica separates as quartz the increase of volume is 33.94 per cent.

Supposing the calcium is to the iron as $1: 1$ and the excess of iron separates as magnetite, the reaction is:

(6) $3 \mathrm{IgFesi}_{2} \mathrm{O}_{6}+2 \mathrm{H}_{2} \mathrm{O}+\mathrm{O}=\mathrm{H}_{4} \mathrm{MIg}_{3} \mathrm{Si}_{2} \mathrm{O}_{9}+\mathrm{Fe}_{3} \mathrm{O}_{4}+4 \mathrm{SiO}_{2}+\mathrm{k}$.

The increase in volume of the serpentine, magnetite, and quartz as compared with the hypersthene is 20.24 per cent.

Other reactions may be written which represent the alterations of bronzites and hyperstlenes, in which the proportions of magnesium and iron are different. Also reactions may be written in which the oxide of iron forms as magnetite or limonite. Where magnetite forms, the increase in volume would be less tlan for hematite, and where limonite forms the increase in volume would be considerably greater. 
If in the formation of bastite, a pyroxene be taken which stands intermediate between bronzite and hypersthene-i. e., in which the magnesimm and iron are as 3:1-and if the same proportions of these constituents be supposed to lold in the bastite, the reaction is as follows:

(7) $3 \mathrm{Mg}_{3} \mathrm{FeSi}_{4} \mathrm{O}_{12}+8 \mathrm{H}_{2} \mathrm{O}=\mathrm{H}_{16} \mathrm{Mg}_{9} \mathrm{Fe}_{3} \mathrm{Si}_{8} \mathrm{O}_{36}+4 \mathrm{SiO}_{2}+\mathrm{k}$.

Using the specific gravity of hypersthene, if the silica be dissolved the increase of volume is $22.77 \mathrm{per}$ cent (if the specific gravity of bronzite be employed, 15.65 per cent); if the silica separates as quartz, 46.87 per cent. Similar reactions may be written which represent the formation of bastites which are richer and poorer in iror, in which cases the volume changes are slightly different.

The passage of feriferous rhombic pyroxene into anthophyllite may be one of pure paramorphism, since in anthophyllite the proportions of magnesium to iron have ranges paralleled by bronzite and hypersthene. Therefore, the only necessary change is a molecular one, a mineral being produced of lower symmetry and lower specific gravity as a result of the alteration. If the specific gravity of hypersthene be used, the calculated increase in volume due to the lower specific gravity of the resultant mineral is 8.70 per cent.

In the formation of actinolite from a rhombic pyroxene, it is necessary that lime and silica be added. Supposing the magnesium is to the iron as 3:1 in both the rhombic pyroxene and actinolite, the equation is as follows:

(8) $3 \mathrm{Mg}_{3} \mathrm{FeSi}_{4} \mathrm{O}_{12}+4 \mathrm{CaCO}_{3}+4 \mathrm{SiO}_{2}=\mathrm{Mg}_{9} \mathrm{Fe}_{3} \mathrm{Ca}_{4} \mathrm{Si}_{16} \mathrm{O}_{48}+4 \mathrm{CO}_{2}+\mathrm{k}$.

The decrease in volume of the actinolite as compared with pyroxene, calcite, and quartz is 7.40 per cent if the specific gravity of hypersthene be used, and if that of bronzite is 10.77 per cent. Similar equations may be written in which the proportions of magnesium and iron are different.

The clianges of the rhombic pyroxenes to talc involve reactions of carbonation and hydration, or of hydration and oxidation, or of all three together. The changes of the rhombic pyroxenes to serpentine and bastite involve hydration alone, or hydration and oxidation. All take place with increase of volume and liberation of heat.

Corresponding with these facts, as a matter of observation the development of serpentine, bastite, and talc from the rlombic pyroxenes takes place in the zone of katamorphism. The development of talc is especially characteristic of the belt of weathering, and serpentine and bastite of the 
belt of cementation, although it can not be asserted that the formation of any of these minerals is confined to either belt.

The paramorphic change of rhombic pyroxene into anthophyllite being one involving lessening of specific gravity and decrease of symmetry, one would expect the change to take place in the upper physical-chemical zone, but I have been mable to ascertain from the literature the facts in this case.

The formation of actinolite from a rhombic pyroxene requires the assistance of calcite and silica. This reaction is one of silication and decarbonation. It occurs with diminution of volume and absorption of heat. As a matter of observation, corresponding with these facts it is well known that the change is a deep-seated one.

MONOCLINIC PIRONENES.

DIOPSIDE, SAILITE, IIEDENBERGITE, AUGITE, MCHITE, SPODUMENE, WOLLASTONITE, AND PECTOLITE.

Diopside:

$\mathrm{CaNIgSi}_{2} \mathrm{O}_{6}$.

IIonoclinic.

Sp. gr. $3.2-3.38$.

Sahlite:

$\mathrm{Ca}(\mathrm{MgFe}) \mathrm{Si}_{2} \mathrm{O}_{6}$.

Monoclinic.

Sp. gr. 3.25-3.4.

Hedenbergite:

$\mathrm{CaFeSi}_{2} \mathrm{O}_{6}$.

Monoclinic.

Sp. gr. 3.5-3.58.

Augite:

$\mathrm{Ca}(\mathrm{MgFe}) \mathrm{Si}_{2} \mathrm{O}_{6}$ with $(\mathrm{MgFe})(\mathrm{AlFe})_{2} \mathrm{SiO}_{6}$.

Monoclinic.

Sp. gr. 3.3-3.5.

Acmite:

$\mathrm{NaFeSi}_{2} \mathrm{O}_{6}$.

Monoclinic.

Sp. gr. 3.50-3.55.

Spodumene:

$\mathrm{LiAlSi} \mathrm{O}_{6}$.

Monoclinic.

Sp. gr. 3.13-3.20.

Wollastonite:

$\mathrm{CaSiO}_{3}$.

Monoclinic.

Sp. gr. 2.8-2.9.

Pectolite:

$\mathrm{HNaCa}_{2} \mathrm{Si}_{3} \mathrm{O}_{9}$.

Monoclinic.

Sp. gr. 2.68-2.78. 
The minerals diopside, sahlite, and augite constitute the so-called diopside-angite series.

occurrence.-The pyroxene group is one of the most widespread and important. One or another variety of pyroxene may occur in almost any rock; but the pyroxenes are much more abundant in the intermediate and basic than in the acidic rocks. Pyroxene is found in the plutonic and volcanic rocks, as an original constituent of the clastic rocks, and as an original and secondary constitnent of the metamorphosed rocks, both of igneous and of aqueous origin. The minerals of the pyroxene group occur extensively in veins.

Diopside occurs in marbles, especially magnesian marbles. Indeed, this is the common form of pyroxene which develops as a secondary constituent during the metamorphism of the magnesian limestones. It also occurs in veins. As a metamorphic mineral diopside is derived from dolomite.

Sahlite occurs in ferriferous magnesian marbles. Like diopside, it is also found in veins. Unlike diopside, it is a common product in many hornblendic schists and gneisses, such rocks probably having been in their original condition calcareous, magnesian, and ferriferous. Sahlite is derived from ankerite and parankerite.

Hedenbergite occurs as a rather common constituent of some nepheline syenites and other basic syenites.

Angite is a common form of pyroxene in the eruptive rocks, both plutonic and volcanic. It occurs in many mechanical sediments. It also is found in metamorphic rocks of both igneous and sedimentary origin, though in the sedimentary metamorphosed rocks it is less common than diopside and sahlite. But augite develops to a considerable extent in the sedimentary rocks which are intermediate between the chemical and mechanical rorks-that is, those which contain abundant calcium carbonate and also are rich in aluminum. Augite is recorded as a metamorphic mineral derived from hornblende.

Wollastonite occurs especially in the metamorphosed calcareous and sedimentary rocks, it being a secondary product produced by metamorphism. It is found abundantly in marbles, and in schists and gneisses which were originally calcareous, especially the calcareous feldspathic schists. It also develops in calcareous inclusions in eruptive rocks, and is found as a contact 
product of igneous and ealcareous rocks. The schists and gneisses containing wollastonite are often garnetiferous and epidotic.

The very frequent development of the above pyroxenes in the sedimentary rocks which are calcareous, rather than amphiboles, is due to the fact that the pyroxenes are richer in calciun than are the amphiboles. Where sedimentary rocks contain magnesium abundantly with the calcium, the amphiboles are likely to form rather than the pyroxenes.

Acmite occurs mainly in the emptive rocks, and especially in those which are rich in alkalies. According to Rosenbusch, it occurs especially in granites, and syenites rich in sodimm, in the elicolite-syenites, phonolites, and leucitophyres. As a metamorphic mineral acmite is derived from arfvedsonite.

Spodumene sometimes occurs as an accessory constitnent in the granites, schists, and gneisses, and in some cases as considerable masses.

Pectolite, while not an abundant mineral, is present as a secondary constituent in many basic eruptive rocks, both plutonic and volcanic. It is, however, especially prevalent in the voleanic rocks, since these are more porons, and pectolite is especially likely to occur in cavities or seams. Occasionally pectolite is found in the metamorphic rocks as a product of apophyllite.

Alterations of the diopside-augite series. - The most common alteration of the nonalmminous diopside and sahlite is into tale (orthorhombic or monorlinic; sp. gr. 2.7-2.8). They also often alter into serpentine (monoclinic; sp. gr. 2.5-2.65). These changes are accompanied by the formation of calcium carbonate, and frequently by the separation of a part of this carbonate as calcite (rhombohedral; sp. gr. 2.7135).

The alnminous pyroxenes, augite, and diallage, under the conditions of the zone of katamorphism, change into chlorite (monoclinic; sp. gr. 2.082.16), with which are usually associated epidote (monoclinic; sp. gr. 3.253.5), this mineral often being embedded in the chlorite and calcite. Under conditions of weathering, any of the minerals of the diopside-angite series may be partly or entirely replaced by quartz (rhombohedral; sp. gr. 2.6535), chalcedony (cryptocrystalline; sp. gr. 2.6-2.64), or calcite. Such replacements are particularly common in the case of the porons andesites and trachytes, and also in tuffs. Not infrequently this replacement of the pyroxene occurs withont the feldspar being greatly affected.

YON XLVII-04-- 18 
However, perhaps the most frequent and characteristic of the alterations of the diopside-augite series is uralitization or change to amphibole (monoclinic; sp. gr. 2.9-3.4). This process is particularly characteristic of the ancient igneous rocks, and especially those which are under comparatively deep-seated conditions, althongh the alteration is by no means confined to deep-seated rocks. It occurs on a great scale under the conditions of the transformation of the igneous rocks into schists and gneisses. During the process of uralitization epidote also very frequently forms. Not infrequently also magnetite (isometric; sp. gr. 5.16-5.18) and calcite separate. In some cases the change is accompanied by the development of a feldspar, such as albite (triclinic; sp. grr. 2.62-2.65). The kind of amplibole which forms depends upon the variety of the pyroxene. From diopside, tremolite (monoclinic; sp. gr. 2.9-3.1) is the ordinary product; from sallite, actinolite (monoclinic; sp. gr. 3.0-3.2) is normally to be expected; from diallage and omphacite (according to Zirkel, ${ }^{a}$ varieties of augite), smaragdite (a variety of homblende) is ordinarily produced; and from ordinary augite, hornblende (monoclinic; sp. gr. 3.05-3.47) is usually dereloped. Finally, it not infrequently occurs that angite changes directly into biotite (monoclinic; sp. gr. 2.90).

The change of diopside to tale may be written as follows:

(1) $3 \mathrm{CaMgSi}_{2} \mathrm{O}_{6}+3 \mathrm{CO}_{2}+\mathrm{H}_{2} \mathrm{O}=\mathrm{H}_{2} \mathrm{MIg}_{3} \mathrm{Si}_{4} \mathrm{O}_{12}+3 \mathrm{CaCO}_{3}+2 \mathrm{SiO}_{2}+\mathrm{k}$.

The increase in volume, supposing all compounds remain as solids, is 48.74 per cent. If only the tale remains, the decrease is 30.13 per cent. Supposing the diopside were one in which a part of the calcium and magnesium were replaceable by iron, so that the calcium and magnesium and iron are present in equal proportion, thus approaching sahlite in composition, and supposing the iron to pass into magnetite, the reaction is-

(2) $3 \mathrm{CaMgFeSi}_{3} \mathrm{O}_{9}+3 \mathrm{CO}_{2}+\mathrm{H}_{2} \mathrm{O}+\mathrm{O}=\mathrm{H}_{2} \mathrm{Mg}_{3} \mathrm{Si}_{4} \mathrm{O}_{12}+3 \mathrm{CaCO}_{3}+\mathrm{Fe}_{3} \mathrm{O}_{4}+5 \mathrm{SiO}_{2}+\mathrm{k}$.

The increase in volume of the talc, calcite, magnetite, and quartz, as compared with the diopside, is 27.88 per cent.

The change of diopside to serpentine may be represented by the following equation:

(3) $3 \mathrm{CaNgSi}_{2} \mathrm{O}_{6}+3 \mathrm{CO}_{2}+2 \mathrm{H}_{2} \mathrm{O}=\mathrm{H}_{4} \mathrm{MIg}_{3} \mathrm{Si}_{2} \mathrm{O}_{9}+4 \mathrm{SiO}_{2}+3 \mathrm{CaCO}_{3}+\mathrm{k}$. 
Supposing all the compounds separated as solids, the increase in volume is 56.32 per cent. If only the serpentine and quartz remain as solids, the increase in rolume is 0.44 per cent.

The change from sahlite to ferriferous bastite, provided that in both compounds the magnesinm is to the iron as $3: 1$, is-

(4) $3 \mathrm{Ca}_{4} \mathrm{Mig}_{3} \mathrm{FeSi}_{8} \mathrm{O}_{24}+12 \mathrm{CO}_{2}+8 \mathrm{H}_{2} \mathrm{O}=\mathrm{H}_{16} \mathrm{Ig}_{9} \mathrm{Fe}_{3} \mathrm{Si}_{8} \mathrm{O}_{36}+16 \mathrm{SiO}_{2}+12 \mathrm{CaCO}_{3}+\mathrm{k}$.

If all the compounds separate as solids, the increase in volume is 56.41 per cent; if the bastite and quartz remain as solids, 1.93 per cent. Supposing the calcium, magnesium, and iron were in equal proportions in the sahlite, and that in the bastite the magnesium were to the iron as $3: 1$, the equation may be written-

(5) $9 \mathrm{CaMIgFeSi} \mathrm{O}_{9}+9 \mathrm{CO}_{2}+8 \mathrm{H}_{2} \mathrm{O}+2 \mathrm{O}=\mathrm{H}_{16} \mathrm{Mg}_{9} \mathrm{Fe}_{3} \mathrm{Si}_{8} \mathrm{O}_{36}+2 \mathrm{Fe}_{3} \mathrm{O}_{4}+9 \mathrm{CaCO}_{3}+19 \mathrm{SiO}_{2}+\mathrm{k}$.

The increase in volume of the serpentine, magnetite, calcite, and quartz, as compared with the sahlite, is 37.50 per cent.

It is, of course, not impossible that serpentine shall develop as one of the products from augite. In this case it doubtless forms from the sahlite molecule of the angite componnd, the sesquioxide compounds passing into some other mineral. It hardly seems advisable to attempt to write equations representing such an alteration.

In writing equations for the alterations of the aluminous pyroxenes into chlorite and epidote it is necessary that certain assumptions shall be made in reference to the relative proportions of the various elements. Moreover, if equations are written which produce chlorite alone, a large amount of the sesquioxide bases must be left over. If an equation be written for the formation of epidote, a large amount of magnesium is unaccounted for. Since it is very common for the minerals chlorite and epidote to form simultaneously, an equation is written on this supposition. In order to give definiteness to the compound, it is supposed that there are twice as many molecules of the diopside part of the angite molecule as of the other part. Furthermore, it is supposed for the diopside molecule that the magnesium is to the iron as $2: 1$; and for the other molecule that the almminum is to the iron sesquioxide as $3: 1$. An epidote is taken in which the aluminum is to the iron as $2: 1$. A chlorite between chinochlore and prochlorite is taken, as such a chlorite is at about the middle of the series. As may be seen by reference to the analyses of augites and epidotes, the proportions taken represent about their 
average compositions. With all these hypotheses, and supposing the extra silica to separate as quartz, the magnesia to separate as magnesium carbonate, and the iron as sesquioxide of iron, the equation maly be written as follows:

$$
\begin{aligned}
& \text { (6) } 6\left[2\left(\mathrm{Ca}_{3} 3 \mathrm{Ig}_{2} \mathrm{FeSi}_{6} \mathrm{O}_{18}\right) \cdot \mathrm{Mg} \mathrm{gg}_{4} \mathrm{Fe}_{2} \mathrm{Al}_{4} \mathrm{Fe}_{3} \mathrm{Si}_{6} \mathrm{O}_{36}\right]+12 \mathrm{CO}_{2}+39 \mathrm{I}_{2} \mathrm{O}+12 \mathrm{O}= \\
& 18\left(\mathrm{HCa}_{2} \mathrm{Al}_{2} \mathrm{FeSi}_{3} \mathrm{O}_{13}\right)+3\left(\mathrm{H}_{20} \mathrm{Hg}_{12} \mathrm{Al}_{6} \mathrm{Si}_{7} \mathrm{O}_{4 \overline{5}}\right)+33 \mathrm{SiO}_{2}+12 \mathrm{Fe}_{2} \mathrm{O}_{3}+12 \mathrm{MgCO} \mathrm{CO}_{3}+\mathrm{k} \text {. }
\end{aligned}
$$

If all the compounds remain as solids the increase in volume is $\mathbf{1 5 . 4 3}$ per cent. If the magnesium carbonate be dissolred the increase in volume is 8.58 per cent.

It is evident that many other equations could be written if other suppositions be made as to the relative proportions of the magnesium to the iron and the aluminum to the iron in the respective compounds, and if other chlorites than the particular one chosen be produced. For the complex silicates, present knowledge is not sufficient to determine whether or not particular equations written accurately represent the alterations which take place, although closer study in the future may possibly determine this. But there is little doubt that substantially the change represented by equation (6) las occurred in many instances, whether it can be verified in an individual case or not, as doubtless have also a multitude of alterations which might be representer by other possible equations. The difficulty is to ascertain in a given instance which of the equations represents a given alteration. It is loped that the quantitative statement of the problem given by equation (6) and following equations will lead to closer study of the compounds which enter into new compounds and the compounds which are produced, and thus to more exact knowledge of the rarious alterations of augite.

According to the above reactions, as would be expecterl from the nature of the compounds, the alteration of diopside and sahlite more fiequently produces talc, serpentine, and bastite, while the alteration of augite more frequently produces chlorite and epidote.

As ahready noted, perhaps the most characteristic of the alterations of the pyroxenes is to the amphiboles. This alteration involves the substitution of magnesium, or maguesium and iron, for calcium. It is supposed that the iron and magnesium are adder in the form of carbonate, and that the liberated calcium separates in the form of carbonate. Parallel equations can, however, readily be written on the basis of any other magnesium compound being arlded and similar iron and calcium compounds being 
produced. It is assumed, further, that the alteration of a pyroxene results in the production of the most closely allied amphibole. Of course this is not always the fact, but it is believed to be usual. Following this assumption, the alteration of diopside is to tremolite, of sahlite is to actinolite, of angite is to horinblende.

The change from diopside to tremolite may be written as follows:

(7) $2 \mathrm{Ca}_{2} \mathrm{IgSi}_{2} \mathrm{O}_{6}+\mathrm{MgCO}_{3}=\mathrm{CaMg}_{3} \mathrm{Si}_{4} \mathrm{O}_{12}+\mathrm{CaCO}_{3}+\mathrm{k}$.

Regarding the magnesinm carbonates as added in solution and the calcinm carbonate as subtracted in solution, the increase in volume is 5.68 per cent. If the magnesimm carbonate be considered as present as magnesite, and the calcium carbonate be considered as present as calcite, the increase in rolume is $10.55 \mathrm{per}$ cent.

The change from sahlite to actinolite, supposing the magnesinm and iron to be present in the salulite in equal proportions, is as follows:

(8) $2 \mathrm{Ca}_{2} \mathrm{IgFeSi} \mathrm{O}_{12}+\mathrm{FeCO}_{3}+\mathrm{IgCO}_{3}=\mathrm{Ca}_{2} \mathrm{Mg}_{3} \mathrm{Fe}_{3} \mathrm{Si}_{8} \mathrm{O}_{24}+2 \mathrm{CaCO}_{3}+\mathrm{k}$.

Supposing the sahlite and actinolite only to be solids, the increase in rolnme is 7.28 per cent. If all the compounds are regarded as solids on both sides of the equation, the increase in volume is 10.81 per cent.

Supposing that in the angite compound there are two of the sahlite molecules to one of the sesquioxide molecule, and supposing that the magnesium and iron are in equal proportions in both the angite and hornblende, the general alteration may be written as follows:

(9) $2\left[\mathrm{Ca}_{2} \mathrm{MgFeSi} \mathrm{O}_{12} \cdot(\mathrm{MgFe})(\mathrm{AlFe})_{2} \mathrm{SiO}_{6}\right]+\mathrm{FeCO}_{3}+\mathrm{MgCO}_{3}=$ $\mathrm{Ca}_{2} \mathrm{Ig}_{3} \mathrm{Fe}_{3} \mathrm{Si}_{3} \mathrm{O}_{24} \cdot(\mathrm{MgFe})_{2}(\mathrm{AlFe})_{4} \mathrm{Si}_{2} \mathrm{O}_{12}+2 \mathrm{CaCO}_{3}+\mathrm{k}$.

But before the volume relations can be calculated it is necessary to assume definite proportions between $\mathrm{Mg}_{\mathrm{g}}$ and $\mathrm{Fe}$, and $\mathrm{Al}$ and $\mathrm{Fe}$, in the second members of the augite and hornblende molecules. If the magnesinum be taken to the iron as $2: 1$ and the aluminum to the iron as $2: 1$, an average case, and only the angite and hornblende be considered as solids, the increase in volume is 4.30 per cent. If all the compounds in both equations are solids, the increase in rolume is 6.14 per cent.

An inspection of the above equations giving the alterations of the diopside-angite series to anphibole shows that the chemical change in the alteration of diopside and sahlite to tremolite and actinolite is relatively greater than in the alteration of angite to hornblende. Moreover, if it be 
supposed that the last half of the augite and homblende molecules are present in greater proportion than given in the equations, the chemical change would be of still less relative importance. This is of interest becanse the alteration of angite to hornblende is a far more common phenomenon thain the alterations of diopside and sahlite to tremolite and actinolite The equations also give reasons for the very frequent occurrence of calcite with uralite. The nature of the alterations is such that calcium carbonate must be produced, and very naturally a portion of this substance frequently separates as calcite.

In the change of augite to biotite it is necessary that potassium be derived from some source. Supposing it to be furnished in the form of potassium carbonate, as a result of the decomposition of some of the potassimm-bearing silicates, the simplest form of reaction may be written as follows:

(20) $2\left[\mathrm{Ca}(\mathrm{MgFe}) \mathrm{Si}_{2} \mathrm{O}_{6} \cdot(\mathrm{MgFe})(\mathrm{AlFe})_{2} \mathrm{SiO}_{6}\right]+\mathrm{K}_{2} \mathrm{CO}_{3}+\mathrm{H}_{2} \mathrm{O}+\mathrm{CO}_{2}=$ $2 \mathrm{HK}(\mathrm{MgFe})_{2}(\mathrm{AlFe})_{2} \mathrm{Si}_{3} \mathrm{O}_{12}+2 \mathrm{CaCO}_{3}+\mathrm{k}$.

Supposing the $\mathrm{IgO}: \mathrm{FeO}: 2: 1$, and the $\mathrm{Al}_{2} \mathrm{O}_{3}: \mathrm{Fe}_{2} \mathrm{O}_{3}: 3: 1$-these ratios being chosen becanse they represent about an average of the analysesand multiplying the above equation by 6 , we have:

(II) $2\left[\mathrm{Ca}_{6} \mathrm{IIg}_{4} \mathrm{Fe}_{2} \mathrm{Si}_{12} \mathrm{O}_{36} \cdot \mathrm{Ig}_{4} \mathrm{Fe}_{2} \mathrm{Al}_{9} \mathrm{Fe}_{3} \mathrm{Si}_{6} \mathrm{O}_{36}\right]+6 \mathrm{~K}_{2} \mathrm{CO}_{3}+6 \mathrm{H}_{2} \mathrm{O}+6 \mathrm{CO}_{2}=$ $2\left(\mathrm{H}_{6} \mathrm{~K}_{6} \mathrm{Mg}_{8} \mathrm{Fe}_{4} \mathrm{Al}_{9} \mathrm{Fe}_{3} \mathrm{Si}_{15} \mathrm{O}_{72}\right)+12 \mathrm{CaCO}_{3}+\mathrm{k}$.

Disregarding all other compounds, the increase in volume of the biotite as compared with the angite is 17.26 per cent.

The alteration of diopside and sallite to talc, serpentine, and bastite, equations (1), (3), and (4), all involve increase in volume and liberation of heat; also they are alterations involving carbonation and hydration. Equations (2) and (5) involve carbonation, hydration, and oxidation. In all except equation (1), even if all of the separated quartz and calcite is dissolved, there is still an increase in volume. They therefore stand as alterations that are typical of all the principles of metamorphism in the zone of katamorphism.

The changes of the pyroxenes, especially angite, to chlorite and epidote, equation (6), involve hydration, carbonation, and oxidation. The change occurs with increase in volume and liberation of heat, even if the resultant oxide of iron and magnesium carbonate be ignored. If these separate as solids, the increase in volnme is considerable. The alteration is, therefore, 
like the change to talc, serpentine, and bastite, one characteristic of the upper physical-chemical zone. The change of pyroxene to the fibrous amphibole known as uralite occurs in the belt of cementation on an extensive scale, and to this position the volume change corresponds.

But the passage of pyroxene into definite amphibole individuals is one of the most common alterations in the zone of anamorphism, and especially under conditions of mashing. The rule for this zone is for alterations to occur which result in minerals of higher specific gravity. The alteration of pyroxene to amphibole seems to be an exception to this rule; for the specific gravity of the pyroxenes ranges between 3.2 and 3.6, while that of the amphiboles varies from 2.9 to 3.4 .

Mainly in consequence of this decrease in specific gravity the increase in volume, as already seen, of all compounds entering into the reactions in the change from diopside to tremolite, equation (7), is 10.55 per cent; of sahlite to actinolite, equation (8), 10.81 per cent; of augite to hornblende, equation (9), 6.14 per cent, supposing that the necessary chemical constituents added to the pyroxene are solid carbonates and the other compounds produced are solid carbonates.

Unlike the previous alterations, these changes do not involve oxidation, hydration, or carbonation; nor, on the other hand, do they involve deoxidation, dehydration, or silication. They are substitution reactions, by which magnesim, or iron, or both take the place of ealcium. They are, therefore, analogous to the dolomitization or ferritization of the limestones; but the volume change is in an opposite sense from those alterations.

But another factor may enter into the problem, the effect of which is hard to estimate. The exchange of the magnesium and iron for calcium is supposed to take place with the separation of a carbonate. If such carbonate were simultaneously silicated, the entire volume change for all the factors concerned would be decrease. It is necessary to consider the volume relations of all the resultant minerals rather than those of the pyroxene and anphibole alone, and hence it may be that in the change of pyroxene to amphibole in the lower physical-chemical zone, if one conld ascertain the entire effect of this alteration in connection with other alterations, the volume would not be expanded but contracted, and thus there be no real exception to the law that the reactions here take place with condensation of volume. 
But, even if this be true, it is freely admitted that the case is not fully covered, for it is very uncommon indeed for the chief resultant mineral of an alteration in the zone of anamorphism to have a lower specific gravity than the minerals from which it is derived with comparatively small chemieal change. Apparently, for some reason the amphiboles are more stable under conditions of moderately deep-seated metamorphism than the pyroxenes. This view is confirmed by the fact that, while the majority of the schists and gneisses are amphibolitic rather than pyroxenitic, in some of the gneisses and schists which have been altered under very deep-seated conditions the pyroxenes are present instead of the amphiboles. The significance of this fact is probably that an unusually ligh pressure is required in order to prodnce the mineral of the highest specific gravity in the case of the pyroxene-amplibole group.

The change from angite to biotite, equations (10) and (11), is one which takes place in the zone of anamorphism especially under conditions of mashing. In this change the volume of the biotite producerl is greater than that of the pyroxene; in the case of the equation (11) 17.26 per cent. However, this case is similar to that of hornblende. Potassium salt must be added from some other mineral and a calcium salt is produced. In order to get the real volume relation of the reaction it would be necessary to know the source of the potassium and the place to which the calcium goes; and as present information does not enable us to determine this, no definite statement can be made as to the total effect of all the changes involved in the alteration of angite to biotite.

Alterations of pyroxenes other than the diopside-augite series.- $-\mathrm{No}$ equations are written for the alterations of wollastonite, hedenbergite, acmite, and pectolite, because the character of the alterations of these componnds has not been described in the standard authorities, althongh there is no doubt that these minerals, like all others, do undergo varions alterations. All these minerals form under deep-seated conditions; and it is to be expected that under the conditions of the zone of katamorphism, especially in the belt of weathering, they would be decomposed; but, if so, the minerals into which they change are unknown.

Alterations of spodumene are recorded. According to Dana, the first stage in the alteration of spodumene is to beta-spodumene (erystallization not determined; sp. gr. 2.644-2.649), in which one-half of the lithium is 
replaced by sodium. The second stage in the process of alteration is the beta-spodumene passing into eucryptite (hexagonal; sp. gr. 2.667) and albite (triclinic; sp. gr. 2.62-2.65), or into muscovite (monoclinic; sp. gr. 2.76-3) and albite, the uniform mixture of which has been known as eymatolite (sp. gr. 2.69-2.70); or spodumene may pass into muscovite and microcline (triclinic; sp. gr. 2.54-2.57). The reactions representing the above changes may be expressed in the manner shown by the equations given below.

The cliange from spodumene to beta-spodumene may be written:

(12) $4 \mathrm{LiAlSi}_{2} \mathrm{O}_{6}+\mathrm{Na}_{2} \mathrm{CO}_{3}=2 \mathrm{LiNaAl} \mathrm{Si}_{4} \mathrm{O}_{12}+\mathrm{Li}_{2} \mathrm{CO}_{3}+\mathrm{k}$.

The increase in volume is 24.72 per cent. Where the beta-spodumene breaks up into encryptite and albite the reaction is:

(13) $\mathrm{LiNaAl}_{2} \mathrm{Si}_{4} \mathrm{O}_{12}=\mathrm{LiAlSiO}_{4}+\mathrm{NaAlSi}_{3} \mathrm{O}_{8}+\mathrm{k}$.

The increase in volume is 0.05 per cent. Where the beta-spodumene passes into muscovite and albite the reaction is:

(14) $6 \mathrm{LiNaAl}_{2} \mathrm{Si}_{4} \mathrm{O}_{12}+\mathrm{K}_{2} \mathrm{CO}_{3}+2 \mathrm{H}_{2} \mathrm{O}+2 \mathrm{CO}_{2}=2 \mathrm{H}_{2} \mathrm{KAl}_{3} \mathrm{Si}_{3} \mathrm{O}_{12}+6 \mathrm{NaAlSi}_{3} \mathrm{O}_{8}+3 \mathrm{Li}_{2} \mathrm{CO}_{3}+\mathrm{k}$.

The decrease in volume is $0.76 \mathrm{per}$ cent. In case the spodumene changes into muscovite and microcline the reaction is:

(15) $12 \mathrm{LiAlSi}_{2} \mathrm{O}_{6}+4 \mathrm{~K}_{2} \mathrm{CO}_{3}+2 \mathrm{CO}_{2}+2 \mathrm{H}_{2} \mathrm{O}=2 \mathrm{H}_{2} \mathrm{KAl}_{3} \mathrm{Si}_{3} \mathrm{O}_{12}+6 \mathrm{KAlSi}_{3} \mathrm{O}_{8}+6 \mathrm{Li}_{2} \mathrm{CO}_{3}+\mathrm{k}$.

The increase in volume is 31.74 per cent.

One would expect reactions (12) and (15) to take place in the zone of katamorphism, but I know of no observations on this point, nor as to the conditions under which reactions (13) and (14) occur.

AMPHIBOLE GROUP.

ORTIORHOMBIC AMPHBOLES.

AYTHOPHYLLITE AXD GLDRITE.

Anthophyllite:

$(\mathrm{MgFe}) \mathrm{SiO}_{3} \mathrm{Mg}: \mathrm{Fe}:: 4: 1,3: 1$, etc.

Orthorhombic.

Sp. gr. 3.1-3.2.

Gedrite:

$(\mathrm{MgFe})_{2} \mathrm{Si}_{2} \mathrm{O}_{6} \cdot \mathrm{MgAl}_{2} \mathrm{SiO}_{6}$.

Orthorhombic.

Sp. gr. 3.1-3.2.

occurrence-Anthophyllite and gedrite occur in the schists and gneisses, both those derived from sedimentary and those derived from igneous rocks. 
They are frequently associated with hornblende and mica. Anthophyllite occupies the same position in the rhombic amphiboles that bronzite does in the rhombic pyroxenes, and gedrite the same position as hypersthene. As already described (p. 270), the bronzites and hypersthenes alter into anthophyllite. It is to be expected that gedrite in a similar manner forms from hypersthene, but this particular alteration is not mentioned in the standard books of reference. Also, as described (p. 310), anthophyllite forms as a secondary product from olivine.

Alterations.-Anthophyllite by hydration passes into talc (orthorhombic or monoclinic; sp. gr. 2.75) or bastite (orthorhombic; sp. gr. 2.6). Also, Lacroix states ${ }^{a}$ that rarely it alters into calcite (rhombohedral; sp. gr. 2.7135). Supposing the magnesium is to the iron as $3: 1$, and that the freed iron separates as hematite (rhombohedral; sp. gr. 5.225), the alteration to tale may be written as follows:

$$
\text { (1) } 2 \mathrm{Mg}_{3} \mathrm{FeSi}_{4} \mathrm{O}_{12}+2 \mathrm{H}_{2} \mathrm{O}+\mathrm{O}=2 \mathrm{H}_{2} \mathrm{Mg}_{3} \mathrm{Si}_{4} \mathrm{O}_{12}+\mathrm{Fe}_{2} \mathrm{O}_{3}+\mathrm{k} \text {. }
$$

The increase in volume of the talc and hematite, as compared with the anthophyllite, is 11.41 per cent. If the iron oxide be supposed to be liydrated into limonite (not crystallized; sp. gr. 3.80), the increase in volume would be still greater. If bastite be produced, and it be supposed that the magnesinm is to the iron as $3: 1$, the same as in the anthophyllite, the equation may be written:

$$
\text { (2) } 3 \mathrm{Mg}_{3} \mathrm{FeSi}_{4} \mathrm{O}_{12}+8 \mathrm{H}_{2} \mathrm{O}=\mathrm{H}_{16} \mathrm{Mg}_{9} \mathrm{Fe}_{3} \mathrm{Si}_{8} \mathrm{O}_{36}+4 \mathrm{SiO}_{2}+\mathrm{k} \text {. }
$$

The increase in volume of the bastite and quartz (rhombohedral; sp. gr. 2.6535 ) as compared with the anthophyllite is $34.09 \mathrm{per}$ cent. If the silica be supposed to be dissolved the increase in volume is 12.09 per cent.

The particular alterations which gedrite nndergoes are not described in the standard text-books; therefore no attempt is made to write equations for changes of this mineral.

The alteration of anthophyllite to talc and iron oxide involves hydration and oxidation. The alteration of anthophyllite to bastite involves hydration and desilication. Both sets of reactions are, therefore, characteristic of the zone of katamorphism; and it is in this zone, especially in the belt of weathering, that the changes occur. 
MONOCLINIC AMPHIBOLES.

The monoclinic amphiboles include the following rock-making minerals:

TREMOLIT, ACTINOLITE, CUMMIGTONITE, GRÜXERITE, HORNBLENDE, GLADCOPIAXF- RIEBECKITE, AND

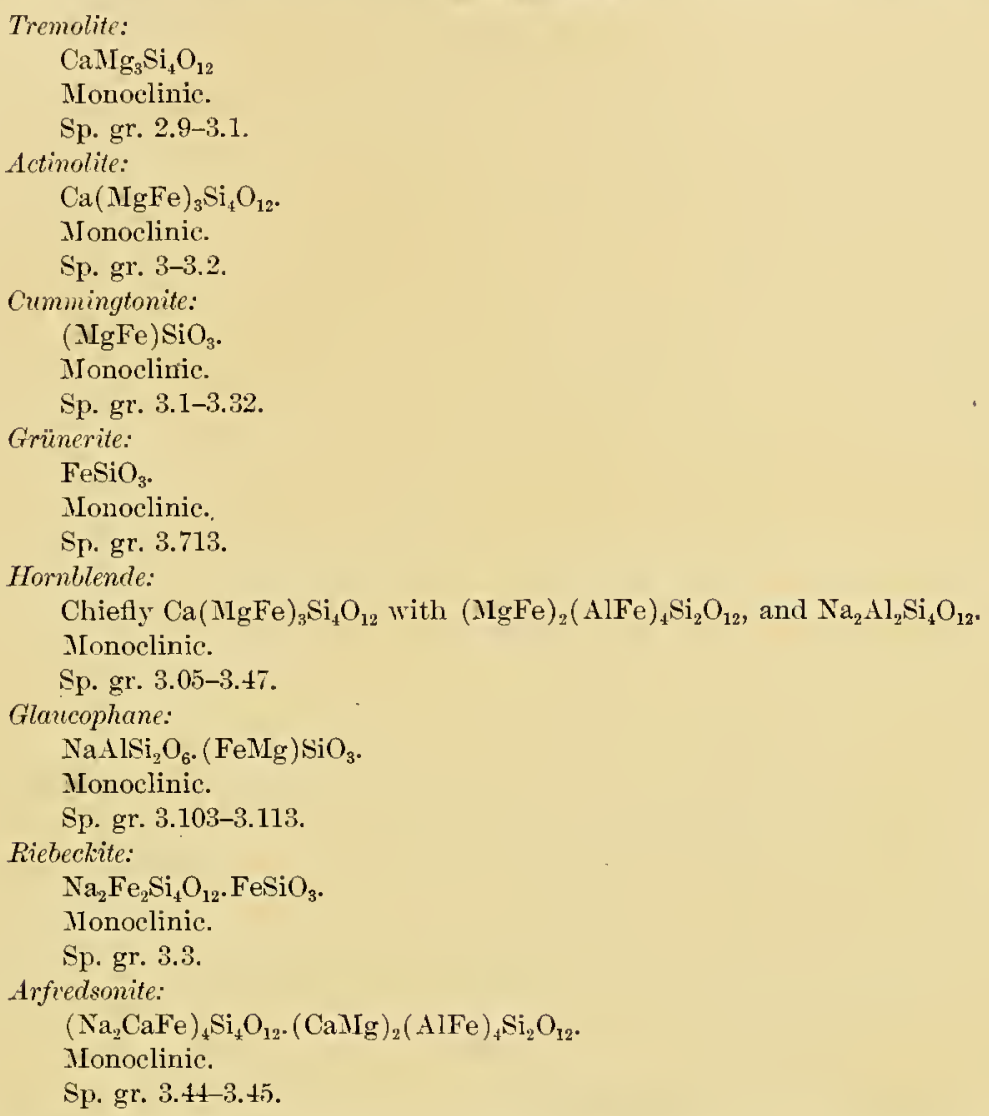

Occurrence.-The monoclinic amphibole group of minerals is one of the most important of the rock-making minerals. Like the pyroxenes, one for'm or another of amphibole may occur in almost any kind of rock, running from the most basic to the most acid, including both plutonic and volcanic rocks, the unmodified sedimentary rocks, and metamorphosed, igneous, and sedimentary rocks. The amphiboles develop extensively as secondary minerals, and especially is this true for the variety of amphibole known as uralite, which, as seen on pp. 274-275, 276-278, is derived from corresponding pyroxenes.

Tremolite and actinolite are rery abundant in the schists metamorphosed from carbonate rocks, especially those rich in magnesium and iron. 
They also occur in the metamorphosed calcareous fragmental sediments. Where iron is not aljundant, as in the marbles, tremolite is the mineral which ordinarily develops. Where ferrous iron is plentiful actinolite normally forms. Where iron is the chief or only carbonate, griinerite ordinarily develops. Tremolite and actinolite also occur as alteration prodncts in igneons rocks, being noted in diabases, gabbros, and more basic rocks. The secondary products frequently take the form of asbestos and jade. They are frequently associated with tale and serpentine in steatiteschists or serpentine-schists. Often, also, tremolite and actinolite are associated with pyroxene, epidote, and chlorite. These amphiboles also occur in veins. Summarizing, as metamorphic minerals, tremolite is derived from diopside, dolomite, and olivine; actinolite fron ankerite, bronzite, hypersthene, olivine, parankerite, and sahlite.

Cummingtonite, the monoclinic amphibole corresponding in composition with the orthorhombic amphibole anthophyllite, occurs in various schists of metamorphic origin. It is not known as an original constitnent of the igneous rocks.

Grïnerite occurs most extensively in comnection with magnetite and quartz, or with quartz alone, thus constituting griinerite-magnetite-quartzschists, or griinerite-quartz-schists. The griinerite in such cases often develops as a secondary prodnct from the alteration of siderite, as explained on page 245. Greenalite, probably having the formula $\mathrm{FeSiO}_{3} \cdot 1 \mathrm{H}_{2} \mathrm{O}$, occurs extensively, as in the Biwabik formation of the Mesabi series of IInnesota. ${ }^{a}$ If such material were so deeply buried as to be altered under the conditions of the zone of anamorphism, dehydration would take place and griinerite would be formed. The mineral also occurs in the garnetiferons micaceous schists; but in some of these rocks the griinerite itself develops from the siderite, as in the case of the pure griinerite-quartz-schists and griineritemagnetite-quartz-schists.

Hornblende is the most abundant of the amphiboles, and has a very widespread occurrence, being found as a principal constitnent in various igneous rocks, including plutonic and voleanic rocks, and among the latter botl in lavas and in tuffs. It also is a constituent of some of the sedimentary rocks. It is a chief constitnent of many of the metamorphosed

a Leith, C. K., The Mesabi iron-bearing district of Minnesota: Mon. U. S. Geol. Survey, vol. 43, 1903, pp. 101-115. 
rocks, especially those of igneous origin. Not infrequently it is also an abundant constituent in the metamorphosed sedimentary rocks. The schists in which the hornblende is the chief constituent, whether of aqueous or igneous origin, are generally known as amphibolites. In many other schists and gneisses which are chloritic and micaceous it is an important constituent. As a metamorphic mineral hornblende has been noted as derived from almandite, augite, melanite, and pyrope.

Glancophane occurs abundantly in certain of the amphibole-schists, especially those which are derived from the débris of basic rocks which were originally rich in sodium. Naturally, such rocks have a somewhat limited occurrence; but where they do oceur abundantly, as in the Coast Ranges of California, glancophane is also very abundant-in fact, is the chief constituent of some of the schists, so that they may properly be called glancophane-schists.

Riebeckite occurs in some eruptive rocks which are rich in sodium and iron, and also in metamorphosed rocks of both sedimentary and igneous origin. Like glaucophane, it may locally ocemr abundantly, but is not a widespread mineral.

Arfvedsonite, a soda-amphibole, very naturally occurs in the sodabearing igneous rocks, especially in elæolite-syenites and nepheline-syenites.

Alterations.-The minerals of the monoclinic amphibole group, of such a wide variety of composition and extensive occurrence, have naturally a large number of alteration products. The more common of these are tale, serpentine, bastite, chlorite, epidote, and biotite. These are frequently accompanied by more or less magnetite, hematite, and limonite. In some cases the amphiboles alter into the zeolites, pinite, and chabazite.

Taking up the individual minerals, tremolite is most frequently transformed into tale (orthorhombic or monoclinic; sp. gr. 2.75), which may be accompanied by calcite (rhombohedral; sp. gr. 2.7135). Actinolite commonly alters into tale or serpentine (monoclinic; sp. gr. 2.575), often with the simultaneous formation of calcite, quartz (rhombohedral; sp. gr. 2.6535), and iron oxide. Cummingtonite commonly alters to bastite (orthorhombic; sp. gr. 2.6). The standard text-books do not describe the alterations of grünerite, although it is believed to alter to the iron oxides. Homblende under weathering conditions ordinarily changes to chlorite (monoclinic; sp. gr. 2.71-2.725), which is often accompanied by epidote 
(monoclinic; sp. gr. 3.38), calcite, quartz, iron oxides, and siderite (rhombohedral; sp. gr. 3.855). Under deep-seated conditions biotite (monoclinic; sp. gr. 2.90) is frequently a product of the alteration of hornblende, and with the biotite epidote may simultaneously form. Rarely serpentine is also produced. While these are the usual alterations of hornblende, in some cases, under conditions of high temperature, hornblende alters into angite (monoclinic; sp. gr. 3.4), with the simultaneous separation of magnetite (isometric; sp. gr. 5.174). Such alteration of the hornblende has been noted, according to Lacroix, both in lavas and in bombs. ${ }^{a}$ In the lava the change is attributed to the action of the magma, being analogous to resorption; but in the bombs it is attributed to heat alone. The alterations of glancophane and riebeckite are not described in the standard text-books. Arfvedsonite under certain conditions changes into an acmite (monoclinic; sp. gr. 3.525) free from calcium. ${ }^{b}$ With the acmite occur limonite (amorphons; sp. gr. 3.80), magnetite, and sometimes lepidomelane (monoclinic; sp. gr. 3.0-3.2). The change of hornblende to augite and the change of arfvedsonite to acmite are the reverse of the process of uralitization.

The alteration of tremolite to talc may be written as follows:

(1) $\mathrm{CaNIg}_{3} \mathrm{Si}_{4} \mathrm{O}_{12}+\mathrm{H}_{2} \mathrm{O}+\mathrm{CO}_{2}=\mathrm{H}_{2} \mathrm{Mg}_{3} \mathrm{Si}_{4} \mathrm{O}_{12}+\mathrm{CaCO}_{3}+\mathrm{k}$.

The increase in volume of the talc and calcite as compared with the tremolite is 25.61 per cent. The decrease in volume of the talc alone as compared with the tremolite is 0.83 per cent.

The alteration of actinolite to talc, supposing the excess of iron to separate as hematite (rhombohedral; sp. gr. 5.225), and supposing that the $\mathrm{Mg}: \mathrm{Fe}:: 2: 1$, is as follows:

(2) $6 \mathrm{Callg}_{2} \mathrm{FeSi}_{4} \mathrm{O}_{12}+4 \mathrm{H}_{2} \mathrm{O}+6 \mathrm{CO}_{2}+3 \mathrm{O}=4 \mathrm{II}_{2} \mathrm{Mg}_{3} 3 \mathrm{Si}_{4} \mathrm{O}_{12}+6 \mathrm{CaCO}_{3}+3 \mathrm{Fe}_{2} \mathrm{O}_{3}+8 \mathrm{SiO}_{2}+\mathrm{k}$.

Supposing all the compounds to remain as solids the increase in volume is 20.33 per cent. If magnetite be formed instead of hematite the increase in volume is somewhat less; if limonite be formed, considerably more. If it be supposed that all the compounds except the talc are dissolved the decrease in volume is 36.51 per cent.

The alteration of actinolite to the variety of serpentine known as bastite may be written as follows:

(3) $\mathrm{Ca}(\mathrm{MgFe})_{3} \mathrm{Si}_{4} \mathrm{O}_{12}+2 \mathrm{H}_{2} \mathrm{O}+\mathrm{CO}_{2}=\mathrm{H}_{4}(\mathrm{MgFe})_{3} \mathrm{Si}_{2} \mathrm{O}_{9}+\mathrm{CaCO}_{3}+2 \mathrm{SiO}_{2}+\mathrm{k}$.

a Lacroix, A., Minéralogie de la France, Paris, 1893-95, vol. 1, pp. 668-669.

$b$ Brögger, W. C., Die Mineralien der Syenitpegmatitgange der Südworwegischen, Augit- und Nєphelin-Syenite: Zeitschr. für Kryst. und Min., vol. 16, 1890, pp. 406-107. 
Supposing that the $\mathrm{Mg}: \mathrm{Fe}:: 2: 1$, the equation is-

(t) $\mathrm{CaNI}_{2} \mathrm{FeSi}_{4} \mathrm{O}_{12}+2 \mathrm{H}_{2} \mathrm{O}+\mathrm{CO}_{2}=\mathrm{H}_{4} \mathrm{Mg}_{2} \mathrm{FeSi}_{2} \mathrm{O}_{9}+\mathrm{CaCO}_{3}-2 \mathrm{SiO}_{2}+\mathrm{k}$.

The increase in volume, supposing all the compounds to separate as solids, is 38.67 per cent. If only the bastite remains as a solid, the decrease in volume is 18.06 per cent.

The alteration of cummingtonite into bastite is as follows:

(5) $3(\mathrm{MgFe}) \mathrm{SiO}_{3}+2 \mathrm{H}_{2} \mathrm{O}=\mathrm{H}_{4}(\mathrm{MgFe})_{3} \mathrm{Si}_{2} \mathrm{O}_{9}+\mathrm{SiO}_{2}+\mathrm{k}$.

Supposing that the $\mathrm{Mg}: \mathrm{Fe}:: 3: 1$, the equation is-

(6) $3 \mathrm{Mg}_{3} \mathrm{FeSi}_{4} \mathrm{O}_{12}+8 \mathrm{H}_{2} \mathrm{O}=\mathrm{H}_{16} \mathrm{IIg}_{9} \mathrm{Fe}_{3} \mathrm{Si}_{9} \mathrm{O}_{36}+4 \mathrm{SiO}_{2}+\mathrm{k}$.

The increase in volume of the bastite and quartz as compared with the cummingtonite is 36.76 per cent; of the bastite alone, 14.2 per cent.

In writing equations for the alteration of hornblende into chlorite and accompanying minerals the soda-bearing part of the molecule will be omitted, since the amount of soda present in ordinary hornblende is small. Supposing that there are eight actinolite molecules in the hornblende to two of the sesquioxide molecules, that the $\mathrm{MgO}: \mathrm{FeO}:: 2: 1$, and the $\mathrm{Al}_{2} \mathrm{O}_{3}: \mathrm{Fe}_{2} \mathrm{O}_{3}:: 2: 1$, that the chlorite produced is on the border line between prochlorite and clinochlore, and that the $\mathrm{Al}: \mathrm{Fe}$ in the epidote as $2: 1$, the reaction may be written as follows:

(7) $8 \mathrm{CaMg}_{2} \mathrm{FeSi}_{4} \mathrm{O}_{12} \cdot 2 \mathrm{Mg}_{4} \mathrm{Fe}_{2} \mathrm{Al}_{8} \mathrm{Fe}_{4} \mathrm{Si}_{6} \mathrm{O}_{36}+21 \mathrm{H}_{2} \mathrm{O}+16 \mathrm{CO}_{2}=$ $2\left(\mathrm{H}_{20} \mathrm{Mg}_{12} \mathrm{Al}_{6} \mathrm{Si}_{7} \mathrm{O}_{4 \mathrm{j}}\right)+2 \mathrm{HCa}_{2} \mathrm{Al}_{2} \mathrm{FeSi}_{3} \mathrm{O}_{13}+4 \mathrm{CaCO}_{3}+12 \mathrm{FeCO}_{3}+24 \mathrm{SiO}_{2}+3 \mathrm{Fe}_{2} \mathrm{O}_{3}+\mathrm{k}$.

Provided all the compounds separate as solids the increase in volume is 25.39 per cent.

It is noticeable that the equation for the alteration of the homblende to chlorite as a chief resultant product demands that epidote, calcite, siderite, quartz, and hematite be produced; and corresponding with this, Lacroix noted all of these minerals as accompaniments of the chloritic alteration with the exception of hematite. ${ }^{a}$ Of course all or a larger part of the iron may pass into the form of iron oxide-magnetite, hematite, or limonite-in which case some oxygen would need to be added to the equation; the amount of $\mathrm{CO}_{2}$ required will be less; and the oxide of iron will replace the iron carbonate partly or wholly. As these modifications can easily be made in the equation, it hardly seems necessary to write out formulæ for them. 
The change of hornblende to biotite requires the addition of potassium. The potassium can be derived from some other mineral. It is perhaps most frequently derived from orthoclase, although it is undoubtedly in many cases deriver from leucite. Supposing it is derived from orthoclase, and therefore is in the form of potassimm silicate, $\mathrm{K}_{2} \mathrm{SiO}_{3}$, and that the actinolite molecule in the hornblende is to the sesquioxide molecule as $2: 3$, the change may be represented as follows:

$$
\text { (8) } \begin{gathered}
2 \mathrm{Ca}(\mathrm{MgFe})_{3} \mathrm{Si}_{4} \mathrm{O}_{12} \cdot 3(\mathrm{MgFe})_{2}(\mathrm{AlFe})_{4} \mathrm{Si}_{2} \mathrm{O}_{12}+3 \mathrm{~K}_{2} \mathrm{SiO}_{3}+\mathrm{SiO}_{2}+3 \mathrm{H}_{2} \mathrm{O}+2 \mathrm{CO}_{2}= \\
6 \mathrm{HK}(\mathrm{MgFe})_{2}(\mathrm{MIFe})_{2} \mathrm{Si}_{3} \mathrm{O}_{12}+2 \mathrm{CaCO}_{3}+\mathrm{k} .
\end{gathered}
$$

In order to ascertain the volume relations it is necessary to make assumptions with reference to the proportions of the $\mathrm{Mg}$ and $\mathrm{Fe}$, and of the $\mathrm{Al}$ and Fe. Supposing the magnesia is to the iron protoxide as $2: 1$, and the alumina is to the iron sesquioxide as $2: 1$, the equation is:-

$$
\text { (9) } \begin{gathered}
2\left(\mathrm{CaIIg}_{2} \mathrm{FeSi}_{4} \mathrm{O}_{12}\right) \cdot \mathrm{Ig}_{4} \mathrm{Fe}_{2} \mathrm{Al} \mathrm{Fe}_{8} \mathrm{Fe}_{4} \mathrm{Si}_{6} \mathrm{O}_{36}+3 \mathrm{~K}_{2} \mathrm{SiO}_{3}+\mathrm{SiO}_{2}+3 \mathrm{II}_{2} \mathrm{O}+2 \mathrm{CO}_{2}= \\
\mathrm{H}_{6} \mathrm{~K}_{6} \mathrm{Hg}_{8} \mathrm{Fe}_{4} \mathrm{Ai}_{8} \mathrm{Fe}_{4} \mathrm{Si}_{18} \mathrm{O}_{72}+2 \mathrm{CaCO}_{3}+\mathrm{k}
\end{gathered}
$$

The increase in volume of the biotite and calcite as compared with the hornblende and quartz is 4113 per cent. It has been noted, however, that the alteration of hornblende to biotite is often accompanied by the separation of epilote; and this is natural, since there is residual calcium in the hornblende not needed by the biotite, which could pass into the epidote. Supposing this residual calcium to pass into the epidote, the reaction may be written as follows:

$$
\begin{aligned}
& \text { (10) } 8 \mathrm{Ca}(\mathrm{MgFe})_{3} \mathrm{Si}_{4} \mathrm{O}_{12} \cdot 18(\mathrm{MgFe})_{2}(\mathrm{AlFe})_{4} \mathrm{Si}_{2} \mathrm{O}_{12}+15 \mathrm{~K}_{2} \mathrm{SiO}_{3}+19 \mathrm{SiO}_{2}+17 \mathrm{H}_{2} \mathrm{O}= \\
& 30 \mathrm{HK}(\mathrm{MgFe})_{2}(\mathrm{AlFe})_{2} \mathrm{Si}_{3} \mathrm{O}_{12}+4 \mathrm{H}\left(\mathrm{Ca}_{2}(\mathrm{AlFe})_{3} \mathrm{Si}_{3} \mathrm{O}_{13}+\mathrm{k}\right.
\end{aligned}
$$

In order to calculate the volume relations it may be supposed that the $\mathrm{Ig} g \mathrm{O}: \mathrm{FeO}$ as $2: 1$, and the $\mathrm{Al}_{2} \mathrm{O}_{3}: \mathrm{Fe}_{2} \mathrm{O}_{3}$ as $2: 1$, the equation being-

$$
\text { (1I) } \begin{gathered}
8 \mathrm{Ca} I \mathrm{Ig}_{2} \mathrm{FeSi}_{4} \mathrm{O}_{12} \cdot 6 \mathrm{Mg} \mathrm{g}_{4} \mathrm{Fe}_{2} \mathrm{Al}_{8} \mathrm{Fe}_{2} \mathrm{Si}_{6} \mathrm{O}_{36}+15 \mathrm{~K}_{2} \mathrm{SiO}_{3}+19 \mathrm{SiO}_{2}+17 \mathrm{H}_{2} \mathrm{O}= \\
10 \mathrm{H}_{3} \mathrm{~K}_{3} \mathrm{Mg}_{4} \mathrm{Fe}_{2} \mathrm{Al}_{4} \mathrm{Fe}_{2} \mathrm{Si}_{9} \mathrm{O}_{36}+\mathrm{H}_{4} \mathrm{Ca}_{8} \mathrm{Al}_{8} \mathrm{Fe}_{4} \mathrm{Si}_{12} \mathrm{O}_{52}+\mathrm{k} .
\end{gathered}
$$

The increase in volume of the biotite and epidote as contrasted with the hornblende and quartz is 30.05 per cent. The increase in volume for equations (9) and (11) would be much less if the $\mathrm{K}_{9} \mathrm{SiO}_{3}$ were taken into account.

Where serpentine also occurs as an alteration product accompanying the chlorite, biotite, epidote, and other products, this mineral is doubtless derived from the actinolite part of the molecule, and an equation may be readily written which represents the simultaneons formation of the bastitic 
form of serpentine by supposing that the number of actinolite molecules is greater than given in the above equations and that such excess of these molecules passes into bastite, according to equation (3).

While the more common alterations of hornblende are to chlorite, biotite, epidote, and accompanying minerals, as above explained, the change of hornblende into angite, just the reverse of that of augite into hornblende described on pages 274-278, does take place, and probably on a great scale at sufficient depth. The equation for one case may therefore be written:

(12) $\mathrm{Ca}_{2} 1 \mathrm{Ig}_{3} \mathrm{Fe}_{3} \mathrm{Si}_{8} \mathrm{O}_{24} \cdot(\mathrm{MgFe})_{2}(\mathrm{AlFe})_{4} \mathrm{Si}_{2} \mathrm{O}_{12}+2 \mathrm{CaCO}_{3}=$ $2\left[\mathrm{Ca}_{2} \mathrm{MgFeSi}_{4} \mathrm{O}_{12} \cdot(\mathrm{MgFe})(\mathrm{AlFe})_{2} \mathrm{SiO}_{6}\right]+\mathrm{FeCO}_{3}+\mathrm{MgCO}_{3}+\mathrm{k}$.

If the $\mathrm{Ig}: \mathrm{Fe}:: 2: 1$, and the $\mathrm{Al}: \mathrm{Fe}:: 2: 1$, the equation is-

(13) $\mathrm{Ca}_{2} \mathrm{Mg}_{3} \mathrm{Fe}_{3} \mathrm{Si}_{8} \mathrm{O}_{24} \cdot \mathrm{Mg}_{4} \mathrm{Fe}_{2} \mathrm{Al}_{8} \mathrm{Fe}_{4} \mathrm{Si}_{6} \mathrm{O}_{96}+2 \mathrm{CaCO}_{3}=$ $2\left[\mathrm{Ca}_{2} \mathrm{MgFeSi}_{4} \mathrm{O}_{12} \cdot \mathrm{Mg}_{2} \mathrm{FeAl}_{4} \mathrm{Fe}_{2} \mathrm{Si}_{3} \mathrm{O}_{18}\right]+\mathrm{FeCO}_{3}+\mathrm{IgCO}_{3}+\mathrm{k}$.

The decrease in volume of the angite as compared with the amphibole is 4.13 per cent.

It is not supposed that the above equations for the alteration of hornblende necessarily represent the actual facts of specific cases. Doubtless in most instances materials from minerals aside from those given enter into the alterations, and the actual changes are more complex than represented. However, the equations very clearly show why it is that the production of chlorite from hornblende demands also the production of other minerals which Lacroix says so generally accompany chlorite. Also, they show why epidote so frequently accompanies biotite secondary to hornblende. The equations may be considered as average cases, which approximate to the alterations that actually occur in many instances. The volume relations calculated from the equations also are probably averages, for the proportions of the elements taken in the equations given are chosen from a consideration of analyses of the various minerals. The equations at least make a quantitative estimate of the relations of the original and secondary minerals, and therefore will lead to closer observations as to the minerals which resuit from the alteration of hornblende, and their relative proportions.

The change of arfvedsonite into acmite is so uncertain in its character that no attempt is made to write out the equations. In order to satisfactorily write equations for this alteration it is necessary to know the composition of the particular arfvedsonite which changes into the particnlar acmite, and what other minerals aside from the acmite are produced in the change. MON XLVII-04-19 
'The alteration of tremolite to talc, equation (1), is that of hydration and carbonation. The alteration of actinolite to talc, equation (2), is that of hydration, carbonation, desilication, and oxidation. The alteration of actinolite to bastite, equations (3) and (4), is that of hydration, carbonation, and desilication. The alteration of cummingtonite to bastite, equations (5) and (6), is that of hydration and desilication. All these changes take place with the liberation of heat and with expansion of volume, provided the compounds which form mainly separate as solids. Whether or not there is an actual increase in the volume as a result of the changes depends, of course, upon the amounts of the secondary material which is dissolved. It is therefore clear that all of these changes are those which are typical of the zone of katamorphism, and especially the belt of weathering. Moreover, some of the changes, like that of actinolite to tale and the accompanying compounds, illustrate all the processes normal to this position; i. e., hydration, carbonation, oxidation, and desilication. The fact that calcite is so frequently found associated with the tales and serpentines secondary to tremolite, cummingtonite, and actinolite, is rendered perfectly clear by the equations; for there is always a residum of calcium which evidently, under the conditions of the upper physical-chemical zone, unites with the carbon dioxide and produces calcium carbonate, which frequently separates as the mineral calcite in large part, but which doubtless is frequently largely or altogether carried away in solution.

The alteration of hormblende into chlorite and accompanying minerals is one of liberation of heat and expansion of volume. It is an alteration also of carbonation, and of oxidation in case some of the ferrous iron be changed to sesquioxide. It is therefore to be expected in the upper physical-chemical zone, and as a matter of fact it occurs there. The change from homblende to biotite is a much deeper seated alteration. It involves hydration, silication, and possibly carbonation, and thus includes an unusual combination of reactions. Corresponding with these facts the change of hornblende to biotite is one which takes place under rather deep-seated conditious, particularly in connection with profound mechanical action. The physics of the interchanges between hornblende and augite are elsewhere discussed (see pp. 279-280); but it may be said that the change of the first to the second involves decrease of volume, and, corresponding with this fact, is known to take place under very deepseated conditions of metamorphism. 
OCCURRENCE AND ALTERATION OF IOLITE.

IOLITE (CORDIERITE).

Iolite (cordierite):

$\mathrm{H}_{2}(\mathrm{MgFe})_{4} \mathrm{Al}_{8} \mathrm{Si}_{10} \mathrm{O}_{37}$.

Orthorhombic.

Sp. gr. 2.60-2.66.

occurrence- - Tolite occurs in a great variety of schists and gneisses. In some cases it is so abmdant as to make the rock a cordierite-gmeiss. It is associated with the very heary metamorphic minerals, such as tommaline, andalusite, sillimanite, garnet, etc. Iolite occurs, likewise, in ejected fragments of volcanoes and as a contact mineral in connection witl dikes; also rarely as an original mineral in igneous rocks.

Alterations.-The most common alteration is simple hydration. Further. changes may remove some of the ferrous iron or introduce alkalies, or both, forming pinite (massive; sp. gr. 2.775). Simultaneously with this an isotropic substance is said to be formed. Iolite sometimes passes into a chlorite similar to tale.

By the hydration of iolite, according to Clarke, chlorophyllite (crystallization not given; sp. gr. 2.77) is formed. ${ }^{a}$ Supposing the $\mathrm{Mg}$ and Fe to be in the same proportions both in the iolite and in the chloronhyllite, the reaction is simple:

(I) $\mathrm{H}_{2}(\mathrm{IgFe})_{4} \mathrm{Al}_{8} \mathrm{Si}_{10} \mathrm{O}_{37}+3 \mathrm{H}_{2} \mathrm{O}=\mathrm{H}_{8}(\mathrm{MgFe})_{4} \mathrm{Al}_{8} \mathrm{Si}_{10} \mathrm{O}_{40}+\mathrm{k}$.

If it be supposed that the $\mathrm{Mg}: \mathrm{Fe}:: 3: 1 \mathrm{in}$ both compounds, the equation is-

(2) $\mathrm{H}_{2} \mathrm{Mg}_{3} \mathrm{FeAl}_{8} \mathrm{Si}_{10} \mathrm{O}_{37}+3 \mathrm{H}_{2} \mathrm{O}=\mathrm{H}_{8} \mathrm{Jgg}_{3} \mathrm{Fe}-\mathrm{Al}_{8} \mathrm{Si}_{10} \mathrm{O}_{40}+\mathrm{k}$.

The decrease in rolume is 0.86 per cent.

The reaction being hydration, one would expect it to involre increase of volume, but the chlorophyllite produced is enough heavier to compensate for this. One would expect the reaction to take place in the zone of katamorphism, but observations on this point are not known to me.

The character of the product which forms simultaneously with pinite being unknown, and the character of the chlorite which forms as a secondary product not being ascertained, it seems hardly worth while to attempt to write equations for these alterations, for they would be largely conjectural.

"Clarke, F. IV., The Constitution of the silicates: Bnll. U. S. Geol. Surrey No. 125, 1895, p. 83. 
NEPHELITE GROUP.

NEPHELITE AXD CANCRINITE.

The nephelite group includes-

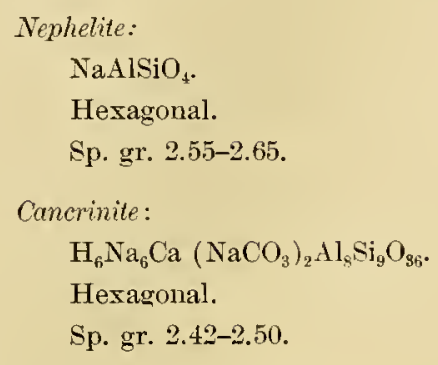

occurrence--Nephelite is a sodium-aluminum silicate. Commonly the sodium is in part replaced by potassium. Nephelite occurs in both ancient and modern igneons rocks, both surface and deep seated. It is abundant in the syenite-schists and syenite-gneisses of certain localities, but is not known in the metamorphosed secondary rocks. This is doubtless due to its ready alteration. Nephelite has been produced artificially at $220^{\circ} \mathrm{C}$. by a reaction between kaolinite and an alkaline carbonate. As a secondary product nephelite forms from lencite, but this alteration is not an important source of the mineral. Nephelite is also probably derived from sodalite.

Alterations.-The most frequently observed alteration of neplelite is to the zeolites, and especially to hydronephelite (hexagonal; sp. gr. 2.263), natrolite (orthorhombic; sp. gr. 2.20-2.25), thomsonite (orthorhombic; sp. gr. 2.3-2.4), and analcite (isometric; sp. gr. 2.22-2.29). Simultaneously with the formation of some of the zeolites diaspore (orthorhombic; sp. gr. 3.3-3.5), or gibbsite (monoclinic; sp. gr. 2.35), or kaolinite (monoclinic; sp. gr. 2.615), or some combination of these, is frequently formed.

The reaction for hydronephelite is-

(1) $6 \mathrm{NaAlSiO}_{4}+7 \mathrm{H}_{2} \mathrm{O}+\mathrm{CO}_{2}=2\left(\mathrm{HNa}_{2} \mathrm{Al}_{3} \mathrm{Si}_{3} \mathrm{O}_{12} \cdot 3 \mathrm{H}_{2} \mathrm{O}\right)+\mathrm{Na}_{2} \mathrm{CO}_{3}+\mathrm{k}$.

The increase in volume is 23.49 per cent.

The alteration next in importance is to vatrolite and gibbsite, or to natrolite and diaspore. The reaction in the former case is:

(2) $6 \mathrm{NaAlSiO}_{4}+7 \mathrm{H}_{2} \mathrm{O}+\mathrm{CO}_{2}=2 \mathrm{Na}_{2} \mathrm{Al}_{2} \mathrm{H}_{4} \mathrm{Si}_{3} \mathrm{O}_{12}+2 \mathrm{Al}(\mathrm{OH})_{3}+\mathrm{Na}_{2} \mathrm{CO}_{3}+\mathrm{k}$. 
Supposing the sodium carbonate to he carried off in solution, the increase in volume would be 24.46 per cent. If two molecules less of water were added, instead of two molecules of gibbsite, two molecules of diaspore would be formed, according to the reaction:

(3) $6 \mathrm{NaAlSiO}_{4}+5 \mathrm{H}_{2} \mathrm{O}+\mathrm{CO}_{2}=2 \mathrm{Na}_{2} \mathrm{Al}_{2} \mathrm{H}_{4} \mathrm{Si}_{3} \mathrm{O}_{12}+2 \mathrm{AlO}(\mathrm{OH})+\mathrm{Na}_{2} \mathrm{CO}_{3}+\mathrm{k}$.

In this case the increase in rolume would be only 15 per cent.

In the production of thomsonite, calcium must replace the sodium. It will be assumed that this calcium is derived from calcium carbonate. The reaction will then be-

(4) $6 \mathrm{NaAlSiO}_{4} \dashv-7 \mathrm{H}_{2} \mathrm{O}+3 \mathrm{CaCO}_{3}=\mathrm{Ca}_{3} \mathrm{Al}_{6} \mathrm{Si}_{6} \mathrm{O}_{24} \cdot 7 \mathrm{H}_{2} \mathrm{O}+8 \mathrm{Na}_{2} \mathrm{CO}_{3}+\mathrm{k}$.

Supposing the calcium carbonate to have been brought in solution and the sodium carbonate carried away in solution, the increase in rolume is 24.60 per cent.

The less common alteration of nephelite to the zeolite analcite, with the simultaneous production of diaspore or gibbsite, is expressed by the following reactions:

(5) $4 \mathrm{NaAlSiO}_{4}+3 \mathrm{H}_{2} \mathrm{O}+\mathrm{CO}_{2}=\mathrm{Na}_{2} \mathrm{Al}_{2} \mathrm{Si}_{4} \mathrm{O}_{12} \cdot 2 \mathrm{H}_{2} \mathrm{O}+2[\mathrm{AlO}(\mathrm{OH})]+\mathrm{Na}_{2} \mathrm{CO}_{3}+\mathrm{k}$

or

(6) $4 \mathrm{NaAlSiO}_{4}+5 \mathrm{H}_{2} \mathrm{O}+\mathrm{CO}_{2}=\mathrm{Na}_{2} \mathrm{Al}_{2} \mathrm{Si}_{4} \mathrm{O}_{12} \cdot 2 \mathrm{H}_{2} \mathrm{O}+2 \mathrm{Al}(\mathrm{OH})_{3}+\mathrm{Na}_{2} \mathrm{CO}_{3}+\mathrm{k}$.

In the first case diaspore is simultaneously formed, and in the second case gibbsite. Supposing the sodium carbonate to be carried away in solution the increase in volume is 5.49 per cent if diaspore be formed, and 19.68 per cent if gibbsite be formed.

Alterations of nephelite to muscovite (monoclinic; sp. gr. 2.88), to hydromuscovite (pinite) (massive; sp. gr. 2.775), and to kaolinite (monoclinic; sp. gr. 2.6-2.63) have also been noticed. Where this alteration takes place the nephelite is probably a potassium-bearing one. Assuming that the amount of potassium is one-third of the sodium, the reaction may be written:

(7) $2 \mathrm{KNa}_{3} \mathrm{Al}_{4} \mathrm{Si}_{4} \mathrm{O}_{16}+4 \mathrm{H}_{2} \mathrm{O}+3 \mathrm{CO}_{2}=2 \mathrm{KH}_{2} \mathrm{Al}_{3} \mathrm{Hi}_{3} \mathrm{O}_{12}+\mathrm{H}_{4} \mathrm{Al}_{2} \mathrm{Si}_{2} \mathrm{O}_{9}+3 \mathrm{Na}_{2} \mathrm{CO}_{3}+\mathrm{k}$.

The decrease in volume of the muscovite and kaolin as compared with the nephelite is 16.50 , provided the sodium carbonate is carried away in solution. The decrease is 13 per cent if the products are pinite and kaolinite. The volume of the muscovite alone is 38.46 per cent less than that of the nephelite. 
Another alteration of nephelite of some importance is to sodalite (isometric; sp. gr. 2.14-2.30) -

(8) $3 \mathrm{YaAlSiO}_{4}+\mathrm{NaCl}=\mathrm{NaCl} .3 \mathrm{NaAlSiO}_{4}+\mathrm{k}$.

Supposing the NaCl to be added in solution, the increase in rolume is 33.14 per cent. If the sodinm chloride be present as solid halite (isometric; sp. gr. 2.1-2.6), the increase in volume would be 15.64 per cent.

While the change is not recorded, it is believed to be highly probable that nephelite during mass deformation under deep-seated conditions may change into feldspar, probably albite (triclinic; sp. gr. 2.62-2.65). This reaction would require the addition of silica, as follows:

(9) $\mathrm{NaAlSiO}_{4}+2 \mathrm{SiO}_{2}=\mathrm{NaAlSi}_{3} \mathrm{O}_{5}+\mathrm{k}$.

Supposing the silica to have been present as quartz (rhombohedral; sp. gr. $2.653-2.654$ ), the decrease in volume wonld be 0.41 per cent.

The formation of the zeolites, and simultaneously the minerals gibbsite or diaspore, equations (1) to (6), are all alterations of hydration, carbonation, and expansion of volume, except that of thomsonite, equation (4), which does not involve carbonation. It is therefore to be expected that these are reactions which take place in the zone of katamorphism, and such is the fact. As a result of the alteration of the nephelites to the zeolites in this zone, a part of the sodium separates and probably goes into solution as sodium carbonate, and thus we have one of the sources of this compound which so frequently occurs in underground waters, especially in volcanic regions. The formation of muscovite and kaolinite from nephelite is a reaction involving hydration and carbonation and decrease of volume, and therefore is characteristic of the zone of katamorphism. The formation of sodalite from nephelite is one which might take place in either physicalchemical zone, only in the upper zone the sodium chloride would probably be added in solntion, while in the lower zone it would probably be derived from solid halite.

CANCRINITE.

occurrence.-Cancrinite is known only in the nepheline syenites.

Alterations.-By Dana it is mentioned as altering to natrolite (orthorhombic; sp. gr., 2.225). The reaction, supposing the excess of alumina passes into gibbsite (monoclinic; sp. gr., 2.35), may be as follows:

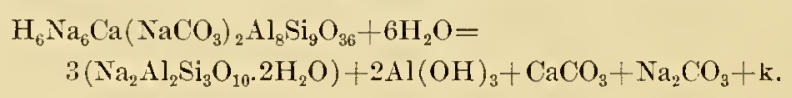


The increase in volume of the natrolite, gibbsite, and calcite (rhombohedral; sp. gr., 2.7135) as compared with cancrinite is 8.64 per cent. The reaction is that of hydration and breaking up of a complex compound into several simpler compounds requiring greater volume, and is therefore typical of the zone of katamorphism.

SODALITE GROUP.

SODALTE, IIÜYXITE, AND YOSELITE.

The sodalite group includes-

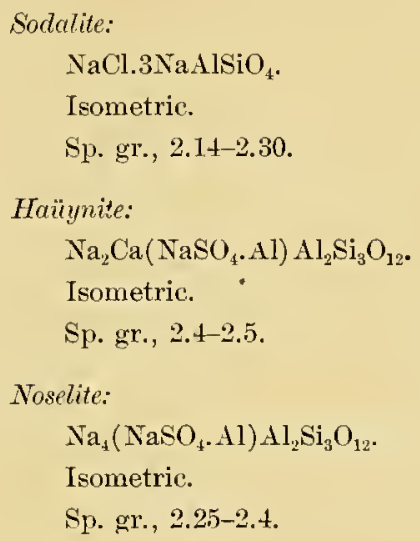

occurrence.-Sodalite is sodium aluminum silicate with some chloride. Sodalite occurs as an original constituent in the igneons rocks, both surface and deep seated. .It is not known in the secondary rocks or their metanorphosed equivalents. In fact, the occurrence of sodalite is almost identical with that of nephelite, which mineral is one of its sources.

Alterations. - The alteration products of sodalite are also identical with those of nephelite, except that nephelite passes into sodalite, and the reverse reaction is not recorded, although, as noted below, it is believed to occur. The alterations of sodalite into minerals similar to those into which nephelite alters is natural, as sodalite is made up of the nephelite molecule with the addition of sodium chloride.

Sodalite alters to the same zeolites as does nephelite, viz, to liydronephelite (hexagonal; sp. gr., 2.263), natrolite (orthorhombic; sp. gr., 2.22.25), thomsonite (orthorhombic; sp. gr., 2.3-2.4), and analeite (isometric; sp. gr., 2.22-2.29). Simultaneously with the formation of some of the 
zeolites, diaspore (orthorhombic; sp. gr., 3.3-3.5) or gibbsite (monoclinic; sp. gr., 2.3-2.4) is frequently formed.

In the production of hydronephelite the reaction is-

(1) $2\left(\mathrm{NaCl}_{3} .3 \mathrm{NaAlSiO}_{4}\right)+4 \mathrm{H}_{2} \mathrm{O}+\mathrm{CO}_{2}=2 \mathrm{HNa}_{2} \mathrm{Al}_{3} \mathrm{Si}_{3} \mathrm{O}_{12} \cdot 3 \mathrm{H}_{2} \mathrm{O}+2 \mathrm{NaCl}+\mathrm{Na}_{2} \mathrm{CO}_{3}+\mathrm{k}$.

Supposing that the sodium chloride and sodium carbonate are dissolved, the decrease in volume is 7.25 per cent.

In the alteration of sodalite to natrolite, gibbsite or diaspore is also produced. The reaction, provided gibbsite be produced, is-

(2) $2\left(\mathrm{NaCl}_{3} 3 \mathrm{NaAlSiO}_{4}\right)+7 \mathrm{H}_{2} \mathrm{O}+\mathrm{CO}_{2}=2 \mathrm{Na}_{2} \mathrm{Al}_{2} \mathrm{H}_{4} \mathrm{Si}_{3} \mathrm{O}_{12}+2 \mathrm{Al}(\mathrm{OH})_{3}+2 \mathrm{NaCl}+\mathrm{Na}_{2} \mathrm{CO}_{3}+\mathrm{k}$.

If two molecules less of water were added, in place of the gibbsite two molecules of diaspore would be produced, according to the reaction:

(3) $2\left(\mathrm{NaCl}_{2} 3 \mathrm{NaAlSiO}_{4}\right)+5 \mathrm{H}_{2} \mathrm{O}+\mathrm{CO}_{2}=2 \mathrm{Na}_{2} \mathrm{Al}_{2} \mathrm{H}_{4} \mathrm{Si}_{3} \mathrm{O}_{12}+2 \mathrm{AlO}(\mathrm{OH})+2 \mathrm{NaCl}+\mathrm{Na}_{2} \mathrm{CO}_{3}+\mathrm{k}$.

Supposing the sodium chloride and sodium carbonate to be dissolved, the decrease in volume in the first case would be 6.52 per cent, and in the second case 13.62 per cent.

In the production of thomsonite the reaction is-

(4) $2\left(\mathrm{NaCl} .3 \mathrm{NaA} 1 \mathrm{SiO}_{4}\right)+7 \mathrm{H}_{2} \mathrm{O}+3 \mathrm{CaCO}_{3}=\mathrm{Ca}_{3} \mathrm{Al}_{6} \mathrm{Si}_{6} \mathrm{O}_{24} \cdot 7 \mathrm{H}_{2} \mathrm{O}+2 \mathrm{NaCl}+3 \mathrm{Na}_{2} \mathrm{CO}_{3}+\mathrm{k}$.

Supposing the calcium carbonate to have been in solution and the sodium chloride and sodimm carbonate to be taken into solution, the decrease in volume is 6.41 per cent.

The alteration of sodalite to analcite and to diaspore may be written as follows:

$$
\text { (5) } \begin{aligned}
& 4\left(\mathrm{NaCl} .3 \mathrm{NaAlSiO}_{4}\right)+9 \mathrm{H}_{2} \mathrm{O}+3 \mathrm{CO}_{2}= \\
& 3\left(\mathrm{Na}_{2} \mathrm{Al}_{2} \mathrm{Si}_{4} \mathrm{O}_{12} \cdot 2 \mathrm{H}_{2} \mathrm{O}\right)+6 \mathrm{AlO}(\mathrm{OH})+4 \mathrm{NaCl}+3\left(\mathrm{Na}_{2} \mathrm{CO}_{3}\right)+\mathrm{k}
\end{aligned}
$$

If six additional molecules of water were added, as in the case of the reaction written for natrolite, gibbsite instead of diaspore would be formed. The reaction is-

(6) $t\left(\mathrm{NaCl}_{3} 3 \mathrm{NaAlSiO}_{4}\right)+15 \mathrm{H}_{2} \mathrm{O}+3 \mathrm{CO}_{2}=$ $3\left(\mathrm{Na}_{2} \mathrm{Al}_{2} \mathrm{Si}_{4} \mathrm{O}_{12} \cdot 2 \mathrm{H}_{2} \mathrm{O}\right)+6 \mathrm{Al}(\mathrm{OH})_{3}+4 \mathrm{NaCl}+3 \mathrm{Na}_{2} \mathrm{CO}_{3}+\mathrm{k}$.

Supposing the sodium chloride and sodium carbonate to be taken into solution, the decrease in volume is 20.77 per cent in the case of diaspore and 10.11 per cent in the case of gibbsite. 
The reaction for the alteration of sodalite to muscovite (monoclinic; sp. gr., 2.76-3) and kaolinite (monoclinic; sp. gr., 2.6-2.63), supposing potassium to replace one-fourth of the sodium of the silicate, would be-

(7) $2\left(4 \mathrm{NaCl} . \mathrm{K}_{3} \mathrm{Na}_{9} \mathrm{Al} \mathrm{l}_{12} \mathrm{Si}_{12} \mathrm{O}_{48}\right)+12 \mathrm{H}_{2} \mathrm{O}+9 \mathrm{CO}_{2}=$ $6 \mathrm{KH}_{2} \mathrm{Al}_{3} \mathrm{Si}_{3} \mathrm{O}_{12}+3 \mathrm{H}_{4} \mathrm{Al}_{2} \mathrm{Si}_{2} \mathrm{O}_{9}+8 \mathrm{NaCl}+9 \mathrm{Na}_{2} \mathrm{CO}_{3}+\mathrm{k}$.

Provided the sorlium chloride and sodium carbonate are dissolved, the decrease in volume is 37.07 per cent.

As in the case of nephelite, it is suspected that sodalite may pass into albite or other feldspar. However, as this change is conjectural, no reaction will be written.

The various reactions above given are analogous, both from a physicalchemical point of view and from a geological point of view, with the corresponding reactions in the case of nephelite. Hence it need only be said that the changes written are those occurring in the zone of katamorphism, in which rock fracture occurs and ground solutions are active. These ground solutions by the changes become bearers of sodium chloride and sodium carbonate.

The relations between the alterations of nephelite and sodalite illustrate very well the law of mass action. In the laboratory, if nephelite be exposed to the "slow action of fused sodium chloride with the addition of vaporized $\mathrm{NaCl}$ " it is changed into sodalite." On the contrary, however, in nature, where water is abundant and the amount of sodium chloride is small, the reverse reaction takes place, and sodium chloride is abstracted. Probably at the same time the neplelite molecule is altered as above indicated. Thus, while observation does not as yet record nephelite as an alteration product of sodalite, it is believed to be highly probable that this mineral is really formed as a stage in the process of alteration of sodalite.

HAÜYNITE AND NOSELITE.

Occurrence-Haïynite is sodiun-calcium-aluminum silicate with some sulphate. Noselite is sodium-aluminum silicate with some sulpliate.

"Dana, J. D., A system of mineralogy; Descriptive mineralogy, by E. S. Dana, Wiley \& Sons, New York, 6th ed., 1892, p. 430 . See also Rosenbusch, Mikroskopische Physiographie, Stuttgart, 1885, p. 284. 
Haüynite and noselite are common in certain igneons rocks, especially those which contain nephelite and leucite. Neither of these minerals is known in the schists and gneisses derived from the sedimentary rocks.

Alterations.-The minerals alter to zeolites, especially to natrolite (orthorhombic; sp. gr. 2.20-2.25), stilbite (monoclinic; sp. gr. 2.094-2.205), and chabazite (rhombohedral; sp. gr. 2.08-2.16). Simultaneously with certain of these alterations calcite (rhombohedral; sp. gr. 2.713-2.714) also forms.

Noselite passes into natrolite according to the following reaction :

(1) $2 \mathrm{Na}_{4}\left(\mathrm{NaSO}_{4} \cdot \mathrm{Al}\right) \mathrm{Al}_{2} \mathrm{Si}_{3} \mathrm{O}_{12}+\mathrm{CO}_{2}+7 \mathrm{H}_{2} \mathrm{O}=$

$$
2\left(\mathrm{H}_{4} \mathrm{Na}_{2} \mathrm{Al}_{2} \mathrm{Si}_{3} \mathrm{O}_{12}\right)+2 \mathrm{Al}(\mathrm{OH})_{3}+2 \mathrm{Na}_{2} \mathrm{SO}_{4}+\mathrm{Na}_{2} \mathrm{CO}_{3}+\mathrm{k} \text {. }
$$

It appears that the change requires the formation of gibbsite (monoclinic; sp. gr. 2.3-2.4) or diaspore (orthorhombic; sp. gr. 3.3-3.5), although these minerals are not recorded as forming contemporaneously with the natrolite. Supposing the gibbsite to separate as a solid, and the sodium sulphate and sodium carbonate to be taken into solution, the decrease in volume is 16.44 per cent.

The parallel reaction for the passage of haiiynite into natrolite and gibbsite is as follows:

$$
\text { (2) } \begin{aligned}
2 \mathrm{Na}_{2} \mathrm{Ca}\left(\mathrm{NaSO}_{4} \cdot \mathrm{Al}\right) \mathrm{Al}_{2} \mathrm{Si}_{3} \mathrm{O}_{12}+2 \mathrm{CO}_{2}+8 \mathrm{H}_{2} \mathrm{O}= \\
2\left(\mathrm{H}_{4} \mathrm{Na}_{2} \mathrm{Al}_{2} \mathrm{Si}_{3} \mathrm{O}_{12}\right)+2 \mathrm{Al}(\mathrm{OH})_{3}+2 \mathrm{CaCO}_{3}+2 \mathrm{NaHSO}_{4}+\mathrm{k} .
\end{aligned}
$$

Supposing the gibbsite and calcite to remain as solids with the natrolite, but the sodium acid sulphate to pass into solution, the increase in volume is 4.99 per cent.

As stilbite is a calcium-bearing silicate, it may be assumed that this forms from haiiynite rather than noselite. The reaction is as follows:

$$
\text { (3) } \begin{aligned}
& 6 \mathrm{Na}_{2} \mathrm{Ca}\left(\mathrm{NaSO}_{4} \cdot \mathrm{Al}\right) \mathrm{Al}_{2} \mathrm{Si}_{3} \mathrm{O}_{12}+36 \mathrm{H}_{2} \mathrm{O}+6 \mathrm{CO}_{2}= \\
& \mathrm{Ca}_{3} \mathrm{Al}_{6}\left(\mathrm{Si}_{3} \mathrm{O}_{8}\right)_{6} \cdot 18 \mathrm{H}_{2} \mathrm{O}+12 \mathrm{Al}(\mathrm{OH})_{3}+3 \mathrm{CaCO}_{3}+6 \mathrm{Na}_{2} \mathrm{SO}_{4}+3 \mathrm{Na}_{2} \mathrm{CO}_{3}+\mathrm{k} .
\end{aligned}
$$

It appears that the reaction for the formation of stilbite thus requires the formation of calcite, and also of gibbsite or diaspore. The equation is written for the former mineral, but could readily be changed to the latter. Supposing the calcium carbonate and the gibbsite, as well as the stilbite, to be solids, and the other compounds to be taken into solution, the increase in volume is $0.460 \mathrm{per}$ cent. 
The reaction for the formation of chabazite from haiiynite is-

(4) $4 \mathrm{Na}_{2} \mathrm{Ca}\left(\mathrm{NaSO}_{4} \cdot \mathrm{Al}\right) \mathrm{Al}_{2} \mathrm{Si}_{3} \mathrm{O}_{12}+24 \mathrm{H}_{2} \mathrm{O}+6 \mathrm{CO}_{2}=$ $\mathrm{Ca}_{3} \mathrm{Al}_{6}\left(\mathrm{SiO}_{4}\right)_{3}\left(\mathrm{Si}_{3} \mathrm{O}_{5}\right)_{3} \cdot 18 \mathrm{H}_{2} \mathrm{O}+4 \mathrm{Al}(\mathrm{OH})_{3}+\mathrm{CaSO}_{4}+\mathrm{Al}_{2}\left(\mathrm{SO}_{4}\right)_{3}+6 \mathrm{Na}_{2} \mathrm{CO}_{3}+\mathbf{k}$.

This reaction again requires the formation of gibbsite or diaspore. Supposing the conpound to be gibbsite, and it and the chabazite to remain as solids, and the other compounds to be taken into solution, the decrease in volume is 7.46 per cent.

The alterations of haiiynite and noselite to the zeolites, calcite, and gibbsite or diaspore are all reactions of hydration and carbonation and liberation of heat. If the readily soluble compounds are dissolved, as is probable, the volume is decreased in most instances. The reactions are therefore characteristic of the zone of katamorphism.

GARNET GROUP.

GROSSULARITE, PXROPE, ALMINDITE, SPESSARTITE, MELANITE, AND UVAROVITE.

The garnet group includes the following rock-making species:

Grossularite:

$\mathrm{Ca}_{3} \mathrm{Al}_{2} \mathrm{Si}_{3} \mathrm{O}_{12}$.

Isometric.

Sp. gr. 3.55-3.66.

Pyrope:

$\mathrm{Ig}_{3} \mathrm{Al}_{2} \mathrm{Si}_{3} \mathrm{O}_{12}$.

Isometric.

Sp. gr. 3.70-3.75.

Almandite:

$\mathrm{Fe}_{3} \mathrm{Al}_{2} \mathrm{Si}_{3} \mathrm{O}_{12}$.

Isometric.

Sp. gr. 3.9-1.2.

Spessartite:

$\mathrm{Nn}_{3} \mathrm{Al}_{2} \mathrm{Si}_{3} \mathrm{O}_{12}$.

Isometric.

Sp. gr. $4.00-4.30$.

Melunite:

$\mathrm{Ca}_{3} \mathrm{Fe}_{2} \mathrm{Si}_{3} \mathrm{O}_{12}$

Isometric.

Sp. gr. 3.80-3.90.

Uvarovite:

$\mathrm{Ca}_{3} \mathrm{Cr}_{2} \mathrm{Si}_{3} \mathrm{O}_{12}$.

Isometric.

Sp. gr. 3.41-3.52. 
Occurrence.-Some form of garnet is a very common mineral in a great variety of the schists and gneisses, including those which are derived from sediments and from all forms of igneous rocks, plutonic and volcanic, both lavas and tuffs. Ordinarily the garnet is a subordinate constituent in these rocks, although in some cases it becomes one of the chief constituents. The mineral has its most ridespread occurrence in the metamorphosed rocks which have altered under the influence of mechanical action, or with the assistance of igneous injections, or both. Not infrequently where garnet is particularly abundant combined contact and mechanical action have assisted in furnishing the conditions favorable to its formation. In many instances the garnet develops after the mechanical action has ceased, showing that it was not the movements themselves but the other favorable conditions resulting therefrom which produced the garnets. It appears, therefore, that the conditions favorable for the extensive derelopment of the mineral are heat, moisture, and high pressure. The mineral garnet is the most important of a group of heavy metamorphic minerals which form under the conditions mentioned. Other minerals which form under similar conditions and are frequently associated with garnet are wollastonite, cordierite, vesuvianite, scapolite, chondrodite, staurolite, andalusite, sillimanite, cyanite, tourmaline, zircon, etc. These minerals are all anhydrous, or nearly so, and mostly of a high specific gravity, many of them having a high symmetry. All of them are formed by the union of silica with bases, and are therefore produced by processes of silication. In many instances this simultaneously involves decarbonation, and this change, as already explained, p. 177, absorbs heat and lessens the volume of the compounds. They are therefore minerals which form normally in the zone of anamorphism.

Garnet thus produced can not in general be said to have been derived from any single mineral. It is ustally the result of the rearangement of material of two or more adjacent minerals. Dana notes ${ }^{a}$ that when garnet is fused, and the matorial recrystallizes, the resultant minerals are usually pyroxene, melilite, monticellite, scapolite, anorthite, nephelite, etc.

This doubtless gives an indication as to some of the minerals which are rearranged under the conditions above described for the developmont of garnet, which are very different from those of dry fusion. Also it is

"Dana, J. D., A system of mineralogy; Descriptive mineralogy, by E. S. Dana, Wiley \& Sons, New York, 6th ed., 1892, p. 447 . 
certain that varions hydrous minerals furnish material for the formation of garnet, and also the limestones and dolomites. As already noted, garnet has a great variation in composition, and in a given case one of the pure species mentioned, or a combination of the molecules of two or more of them, will be formed which can be derived from the elements available. For instance, from an impure limestone, calcium-aluminum garnet, grossularite, is likely to form. In the magnesian rocks, magnesium-aluminum garnet, pyrope, is likely to be produced. In the impure aluminous carbonates of calcium, magnesium, and iron, some combination of two or more of the species grossularite, pyrope, ahmandite, and melanite is likely to be produced.

Garnet may be an original constituent of some of the igneous rocks. If this be so, this source of garnet is comparatively insignificant, as it is very rare indeed that garnet is found in an mnaltered igneous rock. In some of the little altered igneous rocks it is found in lithophyse, but the garnets in this position are apparently the latest products of erystallization, the conditions of their formation being analogous to those producing garnets under the ordinary conditions of rock metamorphism.

Considering the garnets individually, the following statements can be made as to their occurrence:

Grossularite is especially common in the marbles, where it is frequently associated with vesuvianite, wollastonite, diopside, etc. It also occurs in the calcareous schists and gneisses, especially in the calcareous siliceous rocks, such as calcareous quartzites and calcareons novaculites. Grossularite also is associated with common garnet in other schists and gneisses. It is recorded as being derived from melilite and gehlenite.

Pyrope, the magnesium garnet, as wonld be expected, is especially prevalent in peridotites and their derivatives, such as serpentine and tale, since these rocks are rich in magnesium. It also occurs in some basalts.

Almandite, one of the most widespread of the pure garnets, occurs in granites, schists, gneisses, and granulites, and thus is present in both feldspathic and feldspar-free schists. Almandite is also known in certain andesites. It rarely has crystalline forms.

Spessartite occurs in large and small grains in contact rocks, in porphyritic crystals of large size in quartzites, and is abundant in certain whetstone-schists. With topaz, it is known in lithophysæ in rhyolite. 
Melanite is common in basic eruptive rocks rich in alkali. It occurs especially with nephelite and leucite in phonolites, leucitophyres, nephelinites, and tephrites. In connection with contact metamorphism it occurs with wollastonite and fassaite. It is also found in many serpentines.

Uvarovite is at home in the serpentines, particularly those which contain chronite. It is also found in the marbles.

Common garnet, ordinarily a molecular mixture of two or more of the species grossularite, pyrope, almandite, and melanite, is of course more abundant than the pure species. It occurs in such rocks as amphibolites and eclogites, in the metanorphosed diabases and gabbros, in the pyroxenic rocks and their derivatives, and in the schists and gneisses both of igneons and of sedimentary origin.

Alterations.-The minerals into which garnets alter are very numerous, chlorite (monoclinie, sp. gr. 2.71-2.725), tale (orthorhombic or monoclinic, sp. gr. 2.75), and serpentine (monoclinic; sp. gr. 2.575), however, being the more common products. Only the secondary products which occur on an important scale in the rocks will be discussed, mere mineralogical occurrences and pseudomorplis being ignored.

Alterations of grossularite are not described in the standard text-books; but it is known that meionite (tetragonal; sp. gr. 2.72) and zoisite (saussurite) (massive; sp. gr. 3.-3.04) are sometimes secondary products of garnet, and it is natural to suppose that these minerals are derived either from grossularite or from the grossularite molacule of common garnet, since grossularite contains the elements in about the right proportions to produce meionite and zoisite.

Talc and serpentine are minerals which are secondary to garnet, and from their chemical composition ought to be derived from the pyrope molecule, either from the pure garnet or from the pyrope molecule in combination with other garnet molecules. Pyrope is known to alter into chlorite. As chlorite is regarded as a molecular mixture of serpentine and amesite (crystallization not determined; sp. g1. 2.71), equations are written for its alterations into amesite and into average chlorites. Pyrope further alters into enstatite (orthorhombic; sp. gr. 3.2) and spinel (isometric; sp. gr. 3.8), these minerals frequently forming kelyphite rims about the gamet.

Alnandite is recorded as altering into chlorite and into hypersthene (orthorhornbic; sp. gr. 3.45) and spinel, which minerals form kelyphite rims 
about the garnets. It seems probable that in such cases with the almandite there is also present the pyrope molecule, and the reactions for the formation of chlorite, spinel, and lyppersthene, after almandite, as written include the pyrope molecule. In the case of the Spurr mine chlorite, secondary to garnet, the species has been determined to be aphrosiderite ${ }^{*}$ (111assive; sp. gr. 2.90).

Alterations of spessartite, melanite, and uvarovite, as pure species, are not described in the standard text-books

Common garnet most frequently alters into chlorite. Often also it changes into epidote (monoclinic; sp. gr. 3.38) or into hornblende (nonoclinic; sp. gr. 3.26). The mixture of almandite and pyrope altering into aphrosiderite, and into hypersthene and spinel, may be considered as alterations of common garnet. Where epidote is produced it is probable that the molecules from which it is derived are a mixture of grossularite and melanite. Where hornblende is produced it is probable that the molecnles are a mixture of pyrope, almandite, and melanite. In the alterations of the common garnets any of the iron oxides, magnetite (isometric; sp. gr. 5.174), hematite (rhombohedral; sp. gr. 5.225), or limonite (amorphons; sp. gr. 3.80), may be produced.

The change from grossnlarite to meionite may be written as follows:

$$
\text { (1) } 3 \mathrm{Ca}_{3} \mathrm{Al} \mathrm{Si}_{2} \mathrm{Si}_{12}+5 \mathrm{CO}_{2}=\mathrm{Ca}_{4} \mathrm{Al} \mathrm{I}_{6} \mathrm{Si}_{6} \mathrm{O}_{25}+5 \mathrm{CaCO}_{3}+3 \mathrm{SiO}_{2}+\mathrm{k}
$$

The increase in volume of the meionite, calcite (rhombohedral; sp. gr. 2.7135), and quartz (rhombohedral; sp. gr. 2.6535) as compared with the grossularite is 54.62 per cent.

The change of grossularite to zoisite may be written as follows:

$$
\text { (2) } 3 \mathrm{Ca}_{3} \mathrm{Al}_{2} \mathrm{Si}_{3} \mathrm{O}_{12}+5 \mathrm{CO}_{2}+\mathrm{H}_{2} \mathrm{O}=2 \mathrm{HCa}_{2} \mathrm{Al}_{3} \mathrm{Si}_{3} \mathrm{O}_{13}+5 \mathrm{CaCO}_{3}+3 \mathrm{SiO}_{2}+\mathrm{k} \text {. }
$$

The increase in volume of the zoisite, calcite, and quartz as compared with the grossularite is $\mathbf{4 0 . 4 9}$ per cent.

The alteration of pyrope to talc nay be written in two ways, depending upon whether the excess of magnesimm orer that required for the for-

a Pumpelly, Raphael, On pseudomorphs of chlorite after garnet: Am. Jour. Sci., 3d ser., vol. 10, 1875, pp. 1-4. Penfield, S. L., and Sperry, F. L., Pseudomorphs of garnet from Lake Superior and Salida, Colo.: Am. Jour. Sci., 3al ser., vol. 32, 18e6, pp. 307-311. 
mation of tale is regarded as passing into magnesite (rhombohedral; sp. gr. 3.06) or into spinel. The first reaction is-

(3) $4 \mathrm{Mg}_{3} \mathrm{Al}_{2} \mathrm{Si}_{3} \mathrm{O}_{12}+15 \mathrm{H}_{2} \mathrm{O}+3 \mathrm{CO}_{2}=3 \mathrm{H}_{2} \mathrm{Mg}_{3} \mathrm{Si}_{4} \mathrm{O}_{12}+3 \mathrm{MgCO}+8 \mathrm{Al}(\mathrm{OH})_{3}+\mathrm{k}$.

The increase in volume of the tale, magnesite (rhombohedral; sp. gr. 3.06), and gibbsite (monochinic; sp. gr. 2.35) as compared with the pyrope is 75.91 per cent. The second reaction is-

(4) $4 \mathrm{Mg}_{3} \mathrm{Al}_{2} \mathrm{Si}_{3} \mathrm{O}_{12}+6 \mathrm{H}_{2} \mathrm{O}=3 \mathrm{H}_{2} \mathrm{Mg} \underline{\underline{g}}_{3} \mathrm{Si}_{4} \mathrm{O}_{12}+3 \mathrm{MgAl}_{2} \mathrm{O}_{4}+2 \mathrm{Al}(\mathrm{OH})_{3}+\mathrm{k}$

The increase in volume of the talc, spinel, and gibbsite as compared witl the pyrope is 36.84 per cent.

The cluange of pyrope into serpentine is-

(5) $\mathrm{Mg}_{3} \mathrm{Al}_{2} \mathrm{Si}_{3} \mathrm{O}_{12}+5 \mathrm{H}_{2} \mathrm{O}=\mathrm{H}_{4} \mathrm{Mg}_{3} \mathrm{Si}_{2} \mathrm{O}_{9}+2 \mathrm{Al}(\mathrm{OH})_{3}+\mathrm{SiO}_{2}+\mathrm{k}$.

The increase in volume of the serpentine, gibbsite, and quartz as compared with the pyrope is 81.61 per cent.

If amesite (hexagonal plates; sp. gr. 2.71) is produced from pyrope the equation is-

$$
\text { (6) } \quad \mathrm{Ig}_{3} \mathrm{Al}_{2} \mathrm{Si}_{3} \mathrm{O}_{12}+2 \mathrm{H}_{2} \mathrm{O}+\mathrm{CO}_{2}=\mathrm{H}_{4} \mathrm{Mg}_{2} \mathrm{Al}_{2} \mathrm{SiO}_{9}+\mathrm{IgCO}_{3}+2 \mathrm{SiO}_{2}+\mathrm{k} \text {. }
$$

The increase in volume of the amesite, magnesite, and quartz as compared with the pyrope is $62.26 \mathrm{per}$ cent.

In the alteration of pyrope to chlorite, supposing an intermediate chlorite be taken, the reaction is-

$$
\text { (7) } 3 \mathrm{Ng}_{3} \mathrm{Al}_{2} \mathrm{Si}_{3} \mathrm{O}_{12}+8 \mathrm{H}_{2} \mathrm{O}=\mathrm{H}_{16} \mathrm{MIg} \mathrm{Al}_{6} \mathrm{Si}_{5} \mathrm{O}_{36}+4 \mathrm{SiO}_{2}+\mathrm{k} \text {. }
$$

The increase in volume of the chlorite and quartz as compared with the

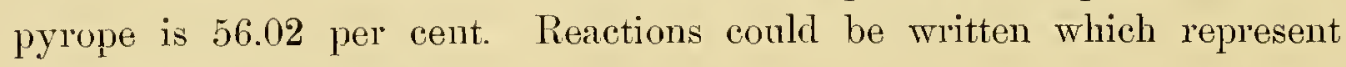
other varieties of elilorite.

The change of pyrope to enstatite and spinel is-

(8) $\mathrm{Ig}_{3} \mathrm{Al}_{2} \mathrm{Si}_{3} \mathrm{O}_{12}=2 \mathrm{Mg} \mathrm{SiO} \mathrm{S}_{3}+\mathrm{MgAl}_{2} \mathrm{O}_{4}+\mathrm{SiO}_{2}+\mathrm{k}$.

The increase in volume of the enstatite, spinel, and quartz as compared with the pyrope is $\mathbf{1 3 . 5 1}$ per' cent.

The alteration of almandite and pyrope to chlorite (aplurosiderite), 
supposing the Fe: $\mathrm{Mg}:: 2: 1$, about the proportion shown by analysis in the case of the Lake Superior chlorite at the Spurr mine," is-

$$
4 \mathrm{Fe}_{3} \mathrm{Al}_{2} \mathrm{Si}_{8} \mathrm{O}_{12} \cdot 2 \mathrm{Mg}_{3} \mathrm{Al}_{2} \mathrm{Si}_{3} \mathrm{O}_{12}+15 \mathrm{H}_{2} \mathrm{O}=3 \mathrm{H}_{10} \mathrm{Fe}_{4} \mathrm{Mg}_{2} \mathrm{Al}_{4} \mathrm{Si}_{4} \mathrm{O}_{25}+6 \mathrm{SiO}_{2}+\mathrm{k}
$$

The increase in volume of the aphrosiderite and quartz as compared with the garnet is 50.98 per cent.

The alteration of almandite and pyrope to hypersthene and spinel, supposing the $\mathrm{Mg}: \mathrm{Fe}:: 1: 1$ in the hypersthene, is as follows:

(10) $\mathrm{Fe}_{3} \mathrm{Al}_{2} \mathrm{Si}_{3} \mathrm{O}_{12} \cdot 2 \mathrm{Mg}_{3} \mathrm{Al}_{2} \mathrm{Si}_{3} \mathrm{O}_{12}=3 \mathrm{MgFeSi} \mathrm{O}_{6}+3 \mathrm{MgAl}_{2} \mathrm{O}_{4}+3 \mathrm{SiO}_{2}+\mathrm{k}$

The increase in volume of the lyypersthene, spinel, and quartz, as compared with the garnet, is 12.66 per cent. If a hypersthene be produced which is less rich in iron, the amount of pyrope molecule in the original garnet must be increased.

The alteration of grossularite and melanite to epidote, supposing an average epidote be produced, in which the $\mathrm{Al}: \mathrm{Fe}:: 2: 1$ is probably-

(11) $2 \mathrm{Ca}_{3} \mathrm{Al}_{2} \mathrm{Si}_{3} \mathrm{O}_{12} \cdot \mathrm{Ca}_{3} \mathrm{Fe}_{2} \mathrm{Si}_{3} \mathrm{O}_{12}+5 \mathrm{CO}_{2}+\mathrm{H}_{2} \mathrm{O}=2 \mathrm{HCa}_{2} \mathrm{Al}_{2} \mathrm{FeSi}_{3} \mathrm{O}_{18}+5 \mathrm{CaCO}_{3}+3 \mathrm{SiO}_{2}+\mathrm{k}$.

The increase in volume of the epidote, calcite (rhombohedral, sp. gr. 2.7135), and quartz, as compared with the garnet, is 40.88 per cent. Similar equations can be written in which the pyrope molecule takes the place of the grossularite molecule in large part. In this case magnesite, instead of calcite, would be produced. Other reactions conld be written for the formation of epidote, in which the original molecule is a combination of grossularite, pyrope, and melanite. The simplest case is as follows:

(12) $\mathrm{Ca}_{3} \mathrm{Al}_{2} \mathrm{Si}_{3} \mathrm{O}_{12} \cdot \mathrm{Mg}_{3} \mathrm{Al}_{2} \mathrm{Si}_{3} \mathrm{O}_{12} \cdot \mathrm{Ca}_{3} \mathrm{Fe}_{2} \mathrm{Si}_{3} \mathrm{O}_{12}+\mathrm{H}_{2} \mathrm{O}+5 \mathrm{CO}_{2}=$ $2 \mathrm{HCa}_{2} \mathrm{Al}_{2} \mathrm{FeSi}_{3} \mathrm{O}_{13}+2 \mathrm{CaCO}_{3}+3 \mathrm{MgCO}+3 \mathrm{SiO}_{2}+\mathrm{k}$.

In this case the increase in volume of the epidote, calcite, magnesite, and quartz, as compared with the garnet, is 39.53 per cent.

The reaction for the passage of pyrope, almandite, and melanite into hornblende may be written in many ways, depending upon the composition of the particular hornblende produced. Taking the case of an average hornblende, in which there are five of the actinolite molecules to two of the

$a$ Penfield, S. L., and Sperry, F. L., On pseudomorphs of garnet from Lake Superior and Salida, Colo.: Am. Jour. Sci., 3d ser., vol. 32, 1886, pp. 307-311.

MON XLVII-04-20 
aluminous molecules, in which the $\mathrm{MgO}: \mathrm{FeO}:: 2: 1$, and $\mathrm{Al}_{2} \mathrm{O}_{3}: \mathrm{Fe}_{2} \mathrm{O}_{3}:: 3: 1$, the reaction is as follows:

(13) $3\left[2 \mathrm{Mg}_{3} \mathrm{Hl}_{2} \mathrm{Si}_{3} \mathrm{O}_{12} \cdot \mathrm{Fe}_{3} \mathrm{Al}_{2} \mathrm{Si}_{3} \mathrm{O}_{12} \cdot \mathrm{Ca}_{3} \mathrm{Fe}_{2} \mathrm{Si}_{3} \mathrm{O}_{12}\right]+4 \mathrm{CO}_{2}=$ $5 \mathrm{Ca} I \mathrm{Ig}_{2} \mathrm{FeSi}_{4} \mathrm{O}_{12} \cdot 2\left[\left(\mathrm{Mg}_{4} \mathrm{Fe}_{2}\right)\left(\mathrm{Al}_{9} \mathrm{Fe}_{3}\right) \mathrm{Si}_{6} \mathrm{O}_{36}\right]+4 \mathrm{CaCO}_{3}+4 \mathrm{SiO}_{2}+\mathrm{k}$.

The increase in volune of the hornblende, calcite, and quartz, as compared with the garnet, is 24.55 per cent.

The alterations of the ferriferons garnets frequently produce iron carbonate or iron oxides. No reactions are written to illustrate these changes; nor would it be easy to express these alterations by reactions without knowing what becomes of the remainder of the garnet material.

Of course, the alterations which are written above, instead of taking place separately, may occur simultaneously. Thus the garnet may be a complex one, which contains molecules of several of the simple garnets, and there would be simultaneously produced a considerable number of secondary minerals. Thus, chlorite and hornblende, chlorite and epidote, or epidote and homblende, might be simultaneously produced. For definite cases such as these, reactions might be written by combining the reactions for the production of the individual minerals.

An examination of the equations as written shows that in almost all cases, simultaneonsly with the production of the minerals which are recorded as secondary to garnet, quartz also appears, and in some cases calcium carbonate also must separate, which may be deposited in the form of calcite. Less frequently siderite and iron oxide form. It is well known that with the minerals chlorite, epidote, hornblende, etc., secondary to garnet, quartz, and calcite are often found, and that with serpentine, talc, spinel, hypersthene, and enstatite, quartz is often found. However, the quartz and calcite are usually not regarded as derived from the garnet and called minerals secondary to them. But the equations clearly show that these minerals should be regarded as secondary to garnet, just as certainly as epidote, chlorite, etc. The almost universal presence of quartz with the minerals mentioned, and the frequent presence of calcite, are thus completely explained. The equations also seem to demand in the alteration to serpentine and tale that gibbsite or diaspore shall be produced. However, some of the alumina may unite with silica and water and form kaolin. The equations suggest that a search be inade for gibbsite, diaspore, and kaolin 
where the serpentines and talcs are secondary to garnet. Of course, in many cases the silica, calcium carbonate, and possibly the excess of aluminum hydrate, may be dissolved and transported elsewhere, and thus their absence wonld be no proof that the compoundş were not really prodnced by the alteration of the garnet.

The alterations of the varions kinds of garnet into different combinations of the following minerals, serpentine, talc, chlorite, epidote, and zoisite, magnesite, and gibbsite (equations 2, 3, 4, 5, 6, 7, 9, 11, 12), are all alterations of hydration, and the majority of them of carbonation and desilication. These reactions are notable in the amount of increase in volume, ranging from 36 to 80 per cent. This increase in volume is a natural consequence of the high specific gravity of the garnet. The alterations of grossularite to meionite, calcite, and quartz (equation 1), and of pyrope, almandite, and melanite to hornblende, calcite, and quartz (equation 13), are alterations of carbonation and desilication. There can be no better illustrations of reactions characteristic of the zone of katamorphism. It will be seen (pp. 683-685) that the development of garnet is a process of the zone of anamorphism where the pressure is great and the temperature probably high. Naturally the extensive destruction of garnet is a process of the upper physical-chemical zone.

The alterations of pyrope to enstatite, spinel, and quartz (equation 8), and of almandite and pyrope together to hypersthene and spinel (equation 10), are common reactions. They do not involve hydration. They do, however, involve desilication. The increase in volume for these changes is comparatively small, 12 or 13 per cent. One would expect that these reactions would take place either in the lower part of the belt of cementation or possibly in the upper part of the zone of anamorphism. 
CHRYSOLITE GROUP.

FORSTERITE, OLIVINE. AND FAYALTE.

The chrysolite group includes-

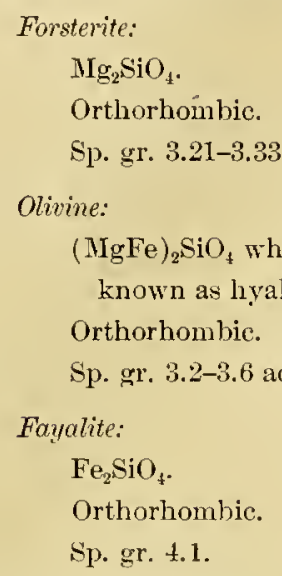

occurrence.-T'schermak considers olivine as an isomorphous mixture of fayalite and forsterite. The occurrence of the three minerals is the same, except that fayalite and forsterite are not nearly so widely known as the intermediate common mineral, olivine. Olivine is an abundant constitnent in intermediate and basic igneons rocks, both plutonic and volcanic, in lavas and tuffs alike. In rare cases in the volcanic rocks fayalite occurs, as, for instance, in nodules in rolcanic rocks and in lithophysæ of the rhyolites of the Yellowstone Park. Forsterite also very rarely occurs in comection with voleanic rocks. Olivine is also an accessory constitnent in the very busic schists and gneisses, such as the amphibolites, pyroxenites, eclogites, etc. Finally, it not infrequently occurs in marbles. In rocks of this class forsterite also rarely oceurs. It therefore appears that the chrysolite group of minerals occurs most abundantly as original constitnents, but are also rather widely found as secondary developments in the metamorphosed rocks, including both the carbonates and the basic schists.

Alterations.-The alterations of fayalite and forsterite are exceptional; therefore the chief alterations which are considered are those which pertain to olivine.

The most common alteration of olivine is to serpentine (monoclinic; sp. gr. 2.50-2.65). This is a change from an anhydrous orthosilicate to a hydrous orthosilicate. Doubtless this explains why serpentine ratler than 
talc develops so generally from the olivines, because talc is a metasilicate. Ordinarily accompanying the serpentine one or more of the following minerals may be foumd: Tremolite (monoclinic; sp. gr. 3.0), actinolite (monoclinic; sp. gr. 3.10), tale (orthorhombic or monoclinic; sp. gr. 2.75), hydrotalcite (hexagonal; sp. gr. 2.04-2.09), magnesite (rhombohedral; sp. gr. 3.06), breumerite (rhombohedral; sp). gr: 3-3.2), siderite (rhombohedral; sp. gr. 3.83-3.88), quartz (rhombohedral; sp. gr. 2.6535), opal (amorphous; sp. gr. 2.15), magnetite (isometric; sp. gr. 5.174), chromite (isometric; sp. gr. 4.445), hematite (rhombohedral; sp. gr. 5.225), and limonite (anorphous; sp. gr. 3.80). One of the most frequent combinations of minerals with serpentine is magnesite, quartz or opal, and magnetite. Frequently the maguetite may partially or completely replace the hematite or limonite. The formation of the serpentine is frequently accompanied by tremolite or actinolite with iron oxide. It is much less frequently accompanied by talc. In some instances the olivine has passed directly into magnesium carbonate and hematite or limonite, but the former commonly being largely removed in solution.

Other alterations of olivine are into anthophyllite (orthorhombic; sp. gr. 3.15) into actinolite, hematite, and spinel (isometric; sp. gr. 3.8), but these are by no means comparable in importance to the change to serpentine.

Beginning with the simplest alteration to serpentine, if an olivine be taken in which the magnesium is to the iron as $3: 1$, and magnetite being the only mineral which accompanies the serpentine, the reaction may be written as follows:

$$
\text { (1) } 3 \mathrm{Ig}_{3} \mathrm{FeSi}_{2} \mathrm{O}_{8}+6 \mathrm{H}_{2} \mathrm{O}+\mathrm{O}=3 \mathrm{H}_{4} \mathrm{Igg}_{3} \mathrm{Si}_{2} \mathrm{O}_{9}+\mathrm{Fe}_{3} \mathrm{O}_{4}+\mathrm{k} \text {. }
$$

The increase in volume of the serpentine and magnetite as compared with the olivine is 29.96 per cent.

Supposing the magnesium is to the iron as $1: 1$ and the iron passes into magnetite, the reaction is-

(2) $3 \mathrm{MgFeSiO}+2+2 \mathrm{H}_{2} \mathrm{O}+\mathrm{O}=\mathrm{H}_{4} \mathrm{Mg}_{3} \mathrm{Si}_{2} \mathrm{O}_{9}+\mathrm{Fe}_{3} \mathrm{O}_{4}+\mathrm{SiO}_{2}+\mathrm{k}$.

The increase in rolume of the serpentine, magnetite, and quartz as compared with the olivine is 15.19 per cent.

If it be supposed that a thind of the magnesium passes into magnesite, and that silica also separates, the reaction may be written as follows:

(3) $3 \mathrm{Mg}_{3} \mathrm{FeSi}_{2} \mathrm{O}_{8}+3 \mathrm{CO}_{2}+4 \mathrm{H}_{2} \mathrm{O}+\mathrm{O}=2 \mathrm{H}_{4} \mathrm{Mg}_{3} \mathrm{Si}_{2} \mathrm{O}_{9}+\mathrm{Fe}_{3} \mathrm{O}_{4}+3 \mathrm{MgC}\left(\mathrm{O}_{3}+2 \mathrm{SiO} \mathrm{O}_{2}+\mathrm{k}\right.$. 
The increase in volume of the serpentine, magnetite, magnesite, and quartz as compared with the olivine is 37.13 per cent. Supposing the $\mathrm{Mg}$ and $\mathrm{Fe}$ are present in equal proportions, the equation stands-

(4) $3 \mathrm{Mg}_{2} \mathrm{Fe}_{2} \mathrm{Si}_{2} \mathrm{O}_{8}+4 \mathrm{H}_{2} \mathrm{O}+2 \mathrm{O}=2 \mathrm{H}_{4} \mathrm{Mg}_{3} \mathrm{Si}_{2} \mathrm{O}_{9}+2 \mathrm{Fe}_{3} \mathrm{O}_{4}+2 \mathrm{SiO}_{2}+\mathrm{k}$.

In this case, the olivine of which nearly corresponds to that of many rocks, the increase in volume is 12.43 per cent.

It would be easy to write other equations for different proportions of maguesium and iron in the olivine, but this seems unnecessary. Also it wonld be easy to write reactions by which other forms of iron compounds than magnetite are produced, such as siderite, hematite, and limonite. If this be done, and the volume reaction calculated, it will be found that the increase in volume is still greater than when magnetite forms.

Olivine is described by Becke as passing into anthophyllite (where $\mathrm{Mg}: \mathrm{Fe}:: 4: 1,3: 1$, etc., orthorhombic; sp. gr. 3.1-3.2). If the proportion of the magnesinm to the iron be taken as $3: 1 \mathrm{in}$ both the olivine and the anthophyllite, the reaction may be written as follows:

(5) $\mathrm{Mg}_{3} \mathrm{FeSi}_{2} \mathrm{O}_{8}+2 \mathrm{SiO}_{2}=\mathrm{Mg}_{3} \mathrm{FeSi}_{4} \mathrm{O}_{12}-\mathrm{k}$.

The decrease in rolume of the anthophyllite as compared with the original olivine and quartz is 1.48 per cent.

Various authors have also described the alteration of olivine into actinolite. Supposing that the magnesium is to the iron as $3: 1$ in both the olivine and the actinolite, and supposing the calcinm to be derived from carbonate and the silica from quartz, the reaction is as follows:

(6) $3 \mathrm{Mg}_{3} \mathrm{FeSi}_{2} \mathrm{O}_{8}+4 \mathrm{CaCO}_{3}+10 \mathrm{SiO}_{2}=\mathrm{Mg}_{9} \mathrm{Fe}_{3} \mathrm{Ca}_{4} \mathrm{Si}_{16} \mathrm{O}_{48}+4 \mathrm{CO}_{2}-\mathrm{k}$.

The decrease in volume of the actinolite as compared with the olivine, ealcite, and quartz, is 13.34 per cent.

In some instances the alteration into actinolite is described as taking place in connection with feldspar as a reaction rim. In this case the calcuim may be supposed to be derived from anorthite, as calcium silicate. The aluminum may be supposed to pass into common spinel and hercynite (isometric; sp. gr. 3.93), which are well known to be alteration products of olivine. The reaction may be:

(7) $4 \mathrm{Mg}_{3} \mathrm{FeSi}_{2} \mathrm{O}_{8}+4 \mathrm{CaAl}_{2} \mathrm{Si}_{2} \mathrm{O}_{8}=\mathrm{Mgg}_{9} \mathrm{Fe}_{3} \mathrm{Ca}_{4} \mathrm{Si}_{16} \mathrm{O}_{48}+3 \mathrm{MgAl}_{2} \mathrm{O}_{4}+\mathrm{Fe} \cdot \mathrm{Al}_{2} \mathrm{O}_{4}-\mathrm{k}$ 
The volume decrease of the actinolite and spinels as compared with the olivine and feldspar is 7.18 per cent.

The reactions in the alterations of olivine into tremolite are parallel with those for actinolite, with the exception that no iron is present, and the mineral therefore probably forms from forsterite. The reaction may be written:

$$
\text { (8) } 3 \mathrm{Ig}_{2} \mathrm{SiO}_{4}+2 \mathrm{CaCO}_{3}+5 \mathrm{SiO}_{2}=2 \mathrm{Mg}_{3} \mathrm{CaSi}_{4} \mathrm{O}_{12}+2 \mathrm{CO}_{2}-\mathrm{k} \text {. }
$$

The decrease in volume of the tremolite as compared with the forsterite, calcite, and silica is 12.29 per cent.

The alteration of olivine to serpentine and the accompanying minerals is the common one. It takes place in the zone of katamorphism on a great scale, both in the belt of weathering and in the belt of cementation. Corresponding with the position in the upper physical-chemical zone, the reactions occur with hydration, oxidation, expansion of volume, and liberation of heat.

The developments of anthophyllite, actinolite, and tremolite from olivine and actinolite, and of spinel from olivine and feldspar, are all deepseated reactions of the zone of anamorphism. Corresponding to this position the change to anthophyllite, equation (5), is a reaction of silication; the changes to actinolite and to tremolite, equations (6) and (8), silication and decarbonation; and the change of olivine and anorthite to actinolite and spinel, equation (7), rearrangement of the silicates into denser silicates; and all take place with diminution of volume and absorption of heat.

SCAPOLITE GROUP.

MEIONITE, WERTERITE, MUd MARLALTE.

The scapolite group includes:

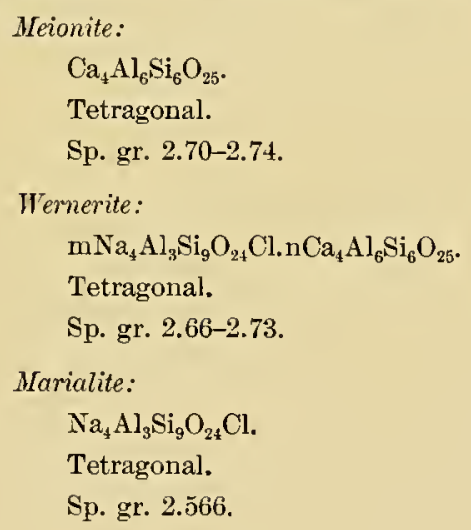


As is well known, the scapolite group is analogous to the plagioclase group, both consisting of sodium-aluminum-silicate molecules and calciumaluminum-silicate molecules, in rarious proportions. Wernerite is a combination of the marialite and meionite molecules in various ratios. Generally the ratios vary between $2: 1$ to $1: 3$.

Occurrence.-Dana summarizes the occmrence of the scapolites as follows: "(1) in volcanic rocks, as in ejected masses on Mte. Somma (neionite); (2) in crystalline limestone, often as the direct result of contact metamorphism; (3) crystalline schists, angite-gneiss, etc.; (4) as an alteration prodnct of a plagioclase feldspar, sometimes on an extensive scale, as with amphibole." a

Alterations.-Dana states that the scapolites are readily alterable. The more common products of alteration are kaolin (monoclinic; sp. gr. 2.6-2.63), tale (orthorhombic or monoclinic; sp. gr. 2.7-2.8), muscovite (liydromuscovite, pinite) (monoclinic; sp. gr. 2.76-3.0), and epidote (the $\mathrm{Al}$ and $\mathrm{Fe}$ varying from $6: 1$ to $3: 2$; monoclinic; sp. gr. 3.25-3.50). It is also recorded that the scapolites alter into biotite (monoclinic; sp. gr. 2.7-3.1). Accompanying varions of these alteration products quartz (rhombohedral; sp. gr 2.653-2.654) separates. Also, it is probable that in connection with some of them, gibbsite (monoclinic; sp. gr 2.3-2.4) or diaspore (orthorhombic; sp. gr. 3.3-3.5) forms, and very likely also calcite (rhombohedral; sp. gr. 2.713-2.714).

In writing ont equations for the alterations to the above minerals, one is handicapped by lack of knowledge as to whether the marialite or the meionite, or a combination of the two, prodnces a given mineral. In this state of affairs the particular molecule is chosen which is most analogous to the compound produced. It seems probable that kaolin and tale together are produced from marialite, according to the reaction:

(1) $2 \mathrm{Na}_{4} \mathrm{Al}_{3} \mathrm{Si}_{9} \mathrm{O}_{24} \mathrm{Cl}+9 \mathrm{IgCO}_{3}+9 \mathrm{H}_{2} \mathrm{O}=$ $3 \mathrm{H}_{4} \mathrm{Al}_{2} \mathrm{Si}_{2} \mathrm{O}_{9}+3 \mathrm{H}_{2} 3 \mathrm{Ig}_{3} \mathrm{Si}_{4} \mathrm{O}_{12}+3 \mathrm{Na}_{2} \mathrm{CO}_{3}+2 \mathrm{NaCl}+6 \mathrm{CO}_{2}+\mathrm{k}$.

The increase of volume of the kaolin and talc, as compared with the marialite, is 7.69 per cent.

It may be that kaolin and calcite are also produced from meionite, as follows:

(2) $\mathrm{Ca}_{4} \mathrm{Al}_{6} \mathrm{Si}_{6} \mathrm{O}_{25}+6 \mathrm{H}_{2} \mathrm{O}+4 \mathrm{CO}_{2}=3 \mathrm{H}_{4} \mathrm{Al}_{2} \mathrm{Si}_{2} \mathrm{O}_{9}+4 \mathrm{CaCO}_{3}+\mathrm{k}$.

a Dana, J. D., A system of mineralogy; Descriptive mineralogy, by E. S. Dana, Wiley \& Sons, New York, 6th ed., 1892, p. 467. 
Supposing all of the $\mathrm{CaCO}_{3}$ to remain as calcite, the increase of volume is 35.40 per cent.

The passage of the scapolites into muscovite may be written as follows: For marialite:

(3) $2 \mathrm{Na}_{4} \mathrm{Al}_{3} \mathrm{Si}_{9} \mathrm{O}_{24} \mathrm{Cl}+\mathrm{K}_{2} \mathrm{CO}_{3}+2 \mathrm{H}_{2} \mathrm{O}+2 \mathrm{CO}_{2}=2 \mathrm{KH}_{2} \mathrm{Al}_{3} \mathrm{Si}_{3} \mathrm{O}_{12}+12 \mathrm{SiO}_{2}+2 \mathrm{NaCl}+3 \mathrm{Na}_{2} \mathrm{CO}_{3}+\mathrm{k}$.

In this reaction, as in the case of the passage of the acid feldspars into muscovite, a large amount of the silica separates. The decrease in volume of the nunscovite and quartz as compared with the marialite is $16.74 \mathrm{per}^{\circ}$ cent, but if the soluble sodium salts be also taken into account the volume is increased.

For meionite the reaction may be-

(4) $\mathrm{Ca}_{4} \mathrm{Al}_{6} \mathrm{Si}_{6} \mathrm{O}_{25}+\mathrm{K}_{2} \mathrm{CO}_{3}+3 \mathrm{CO}_{2}+2 \mathrm{H}_{2} \mathrm{O}=2 \mathrm{~K} \mathrm{H}_{2} \mathrm{Al}_{3} \mathrm{Si}_{3} \mathrm{O}_{12}+4 \mathrm{CaCO}_{3}+\mathrm{k}$.

The increase in volume of the muscovite and calcite as compared with the meionite is 29.42 per cent.

As the composition of epidote is very analogons to meionite, and as it is a calcium-bearing compound, it is thought likely, where epidote is secondary to a scapolite, that it is derived from a meionite molecule. Therefore, supposing that the epidote is one in which the aluminum is to the iron as $2: 1$, and supposing that the iron is derived from ferric oxide $\left(\mathrm{Fe}_{2} \mathrm{O}_{3}\right)$, the reaction may be written as follows:

(5) $\mathrm{Ca}_{4} \mathrm{Al}_{6} \mathrm{Si}_{6} \mathrm{O}_{25}+\mathrm{Fe}_{2} \mathrm{O}_{3}+4 \mathrm{H}_{2} \mathrm{O}=2 \mathrm{HCa}_{2} \mathrm{Al}_{2} \mathrm{FeSi}_{3} \mathrm{O}_{13}+2 \mathrm{Al}(\mathrm{OH})_{3}+\mathrm{k}$.

Supposing the hematite (hexagonal-rhombohedral; sp. gr. 5.225) to have been present as a solid, and the gibbsite to remain as a solid, the decrease in volume is 1.62 per cent. It is thought likely that iron for the reaction is often derived from iron carbonate in solution, combined with simultaneous oxidation. In this case the reaction would be-

(6) $\mathrm{Ca}_{4} \mathrm{Al}_{6} \mathrm{Si}_{6} \mathrm{O}_{25}+2 \mathrm{FeCO}_{3}+4 \mathrm{H}_{2} \mathrm{O}+\mathrm{O}=2 \mathrm{HCa}_{2} \mathrm{Al}_{2} \mathrm{FeSi}_{3} \mathrm{O}_{13}+2 \mathrm{Al}(\mathrm{OH})_{3}+2 \mathrm{CO}_{2}+\mathrm{k}$.

The increase in volume of the epidote and gibbsite as compared with the meionite is 7.55 per cent.

The passage of marialite into kaolinite and talc involves hydration, expansion of volume, and liberation of heat. The change of meionite to kaolinite involves hydration, carbonation, increase in volume, and liberation of heat. The change of the scapolites to nuscovite and accompanying compounds are reactions of hydration, carbonation, increase of rolume, 
and liberation of heat. The change of meionite to epidote is a reaction of hydration and possibly of oxidation.

Corresponding witl these facts the alterations to kaolin and talc are known to take place in the zone of katamorphism, and the same is probably true of the alterations to muscorite and epidote, although the latter reactions may be more characteristic of the belt of cementation than of the belt of weathering.

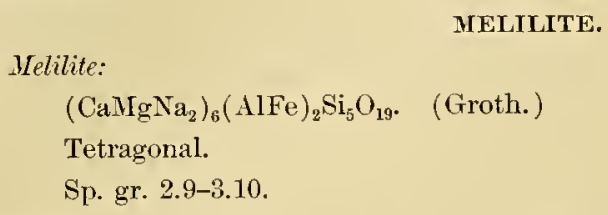

occurrence.-Melilite has a widespread distribution in the lencite and nephelite rocks. Aside from leucite and nephelite the most characteristic associates are augite and perovskite. Some of the rocks in which melilite occurs are leucitophyre, nepheline-syenite, and basalt.

Alterations.-The alterations of this mineral are not recorded, although from its composition there can be no doubt that in the upper physicalchemical zone it decomposes into less complicated silicates.

GEHLENITE.

Gehlenite:

$\mathrm{Ca}_{3} \mathrm{Al}_{2} \mathrm{Si}_{2} \mathrm{O}_{10}$.

Tetragonal.

Sp. gr. 2.9-3.07.

occurrence.-The only accurrence of gehlenite recorded in rocks is as a contact product in limestone.

Alterations.-According to Dana it alters to tale (orthorhombic or monoclinic; sp. gr. 2.75), to fassaite (monoclinic; sp. gr. 2.965-3.291), and to grossularite (isometric; sp. gr. 3.605).

The change to grossularite involves the addition of $\mathrm{SiO}_{2}$, thus:

$$
\mathrm{Ca}_{3} \mathrm{Al}_{2} \mathrm{Si}_{2} \mathrm{O}_{10}+\mathrm{SiO}_{2}=\mathrm{Ca}_{3} \mathrm{Al}_{2} \mathrm{Si}_{3} \mathrm{O}_{12}+\mathrm{k} \text {. }
$$

The decrease in volnme of the grossularite as compared with the gehlenite is 4.42 per cent. If the $\mathrm{SiO}_{2}$ be added as a solid, the decrease in volume is 18.56 .

As gehlenite is so rare, and the manner of the alteration into talc and fassaite is not clear, no attempt is made to write equations for the changes. 
TESUVIANITE.

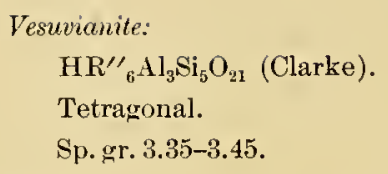

Clarke states that the $R_{6}$ in the typical nineral is replaced by calcium and nagnesium in the proportion of $5: 1$, giving $\mathrm{HCa}_{5} \mathrm{MgAl}_{3} \mathrm{Si}_{5} \mathrm{O}_{21}$.

occurrence.-Vesuvianite occurs in ancient ejections of Vesuvins. It is most abundant in marbles. It is also found in varions gneisses and schists, especially those which are calcareous. It often forms in connection with contact action. It is frequently associated with such other metamorphic minerals as garnet, and also the micas and chlorites.

Alterations.-From the literature it is impracticable to ascertain which particular garnet, mica, or chlorite forms from a certain vesuvianite, and the accompanying minerals which must simultaneonsly form are unknown: it therefore does not seem advisable to attempt to write equations representing the alterations, since they must be so largely speculative.

ZIRCON GROUP.

The only important rock-making mineral of the zircon group is zircon.

Zircon:

$\mathrm{ZrSiO}_{4}$.

Tetragonal.

Sp. gr. 4.66-4.70.

Occurrence.-Zircon is especially common in marble. It also occurs both in massive igneous rocks, such as syenite and granite, and in the schists and gneisses.

Aiterations.-According to Clarke the only alteration described is that of hydration, producing hydrous zircon (malacon) (tetragonal; sp. gr. 3.905), the reaction being:

$$
3 \mathrm{Zr}_{\mathrm{SiO}}+\mathrm{H}_{2} \mathrm{C}=\mathrm{H}_{2} \mathrm{Zr}_{3} \mathrm{Si}_{3} \mathrm{O}_{13} .
$$

The increase in volume in the change is 24.05 per cent. 
ALUMINUM-SILICATE GROUP.

TOPAZ, AYDALUSITE, SILLIMANITE, AN1) CYNITE.

The aluminum-silicate group includes-

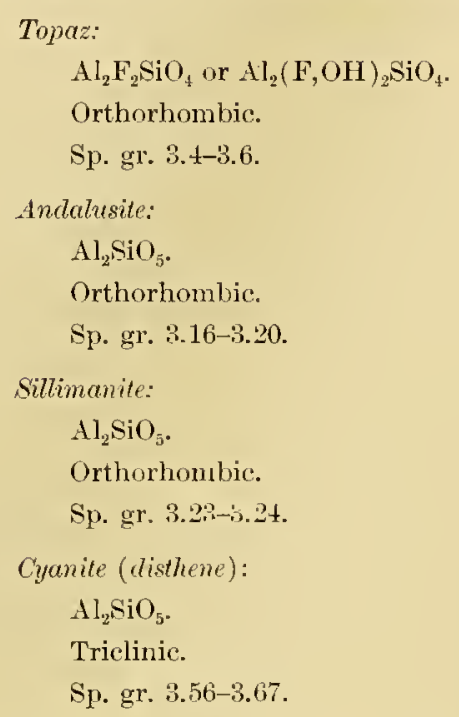

occurrence.-Topaz is a much less common mineral than andalusite, sillimanite, and cyanite. Like them, it occurs in the schists and gneisses of sedimentary origin, especially those in which other fluorine minerals are found, such as tourmaline and beryl. Unlike andalusite, sillimanite, and cyanite, it is sometimes found in cavities in fresh volcanic rocks, as, for instance, rliyolite.

Andalusite is a frequent constituent of the metamorphosed sedimentary rocks, especially of the argillaceous kinds. It often occurs in crystals, including many other minerals in the partly metamorphosed sedimentary rocks; but is also found in large, well-formed crystals in the schists. Frequently in the metamorphosed sedimentary rocks its development has been promoted by the contact effect of igneous rocks, especially the granitic rocks. Its most characteristic associates are sillimanite and cyanite. With the former it frequently has parallel intergrowths. Also it is frequently associated with garnet and staurolite, and not infrequently with tourmaline. Andalusite is rare, if indeed not altogether absent in the metamorphosed igneous rocks.

Sillimanite is a common mineral in the strongly metamory hosed sedimetary rocks, such as schists and gneisses, where it frequently replaces 
andalusite to a large extent. Like andalusite, its development may be promoted by the presence of intrusive rocks, especially granites. In such cases sillimanite frequently develops nearer the intrusive masses than does the andalusite, the sillimanite therefore being the mineral which forms under conditions of more adranced metamorphism. It is frequently associated with garnet and with spinel and stamolite, sometimes with iolite (cordierite). Sillimanite is derived from andalusite, biotite, corundum, cyanite, diaspore, and gibbsite.

The occurrence and associates of cyanite are similar to those of sillimanite; but a very frequent additional associate is corundum, and where formed by the assistance of igneous rocks the cyanite is likely, on the average, to be closer to the intrusive than the sillimanite, although of course they ordinarily overlap. As a metamorphic mineral, cyanite is derived from andalusite, cormudum, diaspore, and gibbsite.

Tremolite, actinolite, and diopside are frequent associates of andalusite, sillimanite, and cyanite, especially of the last two.

The special homos of the aluminum-silicate group of minerals are the metanorphosed argillaceous sedimentary rocks. As is well known, kaolin is one of the chief constituents of such rocks, and doubtless it is from this mineral in large part, under deep-seated conditions, that the aluminum-silicate minerals are formed. If it be supposed that these heary minerals derelop from kaoliu, the process would be one of dehydration and separation of silica. This silica may separate either as quartz or may mnite with other compounds, such as calcium and magnesium or other bases, to form silicates. The breaking up of the kaolin may be represented by the following equation:

(1) $\mathrm{H}_{4} \mathrm{Al}_{2} \mathrm{Si}_{2} \mathrm{O}_{9}=\mathrm{Al}_{2} \mathrm{SiO}_{5}+2 \mathrm{H}_{2} \mathrm{O}+\mathrm{SiO}_{2}+\mathrm{k}$.

Supposing the mineral produced were andalusite, the volume of the andalusite and quartz is 25.40 per cent less than that of the kaolin. If it be supposed that calcium carbonate is present at the same time, and that the freed silica unites with it, the equation may be written:

(2) $\mathrm{H}_{4} \mathrm{Al}_{2} \mathrm{Si}_{2} \mathrm{O}_{2}+\mathrm{CaCO}_{3}=\mathrm{Al}_{2} \mathrm{SiO}_{5}+\mathrm{CaSiO}_{3}+2 \mathrm{H}_{2} \mathrm{O}+\mathrm{CO}_{2}+\mathrm{k}$.

In this case the volume of the andalusite and wollastonite is 32.32 per cent less than that of the kaolin and calcite. If the heavier mineral sillimanite or cyanite be produced the decrease in volume is even greater. 
While for the sake of simplicity wollastonite is supposed to form, the more frequent association of the aluminum-silicate group is with tremolite, actinolite, and diopside. For the first and last of these minerals the freed silica unites with the calcium and magnesimm together, and for the second with the calcium, magnesium, and iron. The equations representing the changes are analogons to (2), and the volume changes are in the same direction.

Alterations.-The standard stated alterations of the aluminum-silicate group are to talc (steatite) (massive; sp. gr. 2.75) and to muscovite (damourite) (monoclinic; sp. gr. 2.88). It is recorded also that topaz and andalusite alter to kaolin (monoclinic; sp. gr. 2.615). Occasionally also andalusite may alter into the heavier mineral cyanite (triclinic; sp. gr. $3.56-3.67)$.

The alterations of the minerals into talc require an entire change of base; that is, from aluminum silicates to magnesium silicates. The reactions being those of the zone of katamorphism, the most probable source of the magnesium is doubtless the carbonate, which may be derived from the decomposition of magnesium rocks such as the pyroxenites, olivinites, etc. The process, however, requires the separation of aluninum either as corundum (rhombolhedral; sp. gr. 4.025), corundophilite (monoclinic; sp. gr. 2.90), diaspore (orthorhombic; sp. gr. 3.40), gibbsite (monoclinic; sp. gr. 2.35), or some other form. Since the reaction takes place in the upper physical-chemical zone, gibbsite will be regarded as the product formed. The change of the aluminum-silicate minerals to muscovite requires the addition of potassium. This is doubtless derived from the liberation of potassium during the decomposition of the potash feldspars, and will therefore be regarded as added as a carbonate. The change from andalusite to eyanite is simply a molecular one, the result being a mineral of great specific gravity. It has already been seen that andalusite is a product of less intense metamorplism, and that more intense metamorphism produces sillimanite and cyanite. The change of andalusite to these heavier minerals is therefore one which requires deep-seated conditions, and is characteristic of the zone of katamorphism.

The equations representing the change of andalusite, sillimanite, and cyanite to talc with gibbsite may be written as follows:

(1) $4 \mathrm{Al}_{2} \mathrm{SiO}_{5}+3 \mathrm{IgCO}_{3}+13 \mathrm{H}_{2} \mathrm{O}=\mathrm{H}_{2} \mathrm{MIg}_{3} \mathrm{Si}_{4} \mathrm{O}_{12}+8 \mathrm{Al}(\mathrm{OH})_{3}+3 \mathrm{CO}_{2}+\mathrm{k}$. 
The decrease in volume of the tale as compared with the andalusite is 32.37 per cent; as compared with the sillimanite, 31.20 per cent; as compared with the cyanite, 23.12 per cent. But if the gibbsite be included as a solid the increases in volume are 97.67 per cent, 101.09 per cent, and 124.71 per cent, respectively.

The change of the three minerals to kaolin may be written as follows:

(2) $2 \mathrm{Al}_{2} \mathrm{SiO}_{5}+5 \mathrm{H}_{2} \mathrm{O}=\mathrm{H}_{4} \mathrm{Al}_{2} \mathrm{Si}_{2} \mathrm{O}_{9}+2 \mathrm{Al}(\mathrm{OH})_{3}+\mathrm{k}$.

The change in volume of the kaolin as compared with the andalusite is a decrease of 3.15 per cent; as compared with. the sillimanite, a decrease of 1.47 per cent; and as compared with the cyanite, an increase of 10.11 per cent. But if the gibbsite be a solid, the increases in volume are 61.87 per cent, 64.67 per cent, and 84.02 per cent, respectively.

The alterations of the same minerals to muscovite (damourite) may be written as follows:

(3) $6 \mathrm{Al}_{2} \mathrm{SiO}_{5}+\mathrm{K}_{2} \mathrm{CO}_{3}+11 \mathrm{H}_{2} \mathrm{O}=2 \mathrm{H}_{2} \mathrm{KAl}_{3} \mathrm{Si}_{3} \mathrm{O}_{12}+6 \mathrm{Al}(\mathrm{OH})_{3}+\mathrm{CO}_{2}+\mathrm{k}$.

The decrease in volume of the muscovite as compared with the andalusite is 9.55 per cent; as compared with the sillimanite, 7.98 per cent; the increase as compared with the cyanite is 2.83 per cent. But if the gibbsite be regarded as a solid, the increases in volume are 55.47 per cent, 58.16 per cent, and 76.74 per cent, respectively.

The alterations of the aluminum-silicate minerals to talc, kaolin, or muscovite, with the accompanying gibbsite, are all reactions of hydration. They involve great increase of volume, from 55 to 125 per cent. To produce the original heary aluminum-silicate minerals in the zone of anamorphism undoubtedly required great condensation of volume. When the reactions are reversed in the zone of katamorphism, there is a correspondingly great expansion of volume. The change of the heavy aluminumsilicate minerals to the much lighter hydrous minerals gives one of the best illustrative cases of typical reactions of the zone of katamorphism.

The change of andalusite to cyanite, as already explained, being a molecular one, involves a volume relation inversely as the specific gravity, and therefore by the change the volume is decreased 12.03 per cent. The change of andalnsite to cyanite is a reaction of the zone of anamorphism. 
EPIDOTE GROUP.

ZOISITE, EPIDOTE, PIEDMONTITE, AND ALLANITE.

The epidote group includes the following minerals:

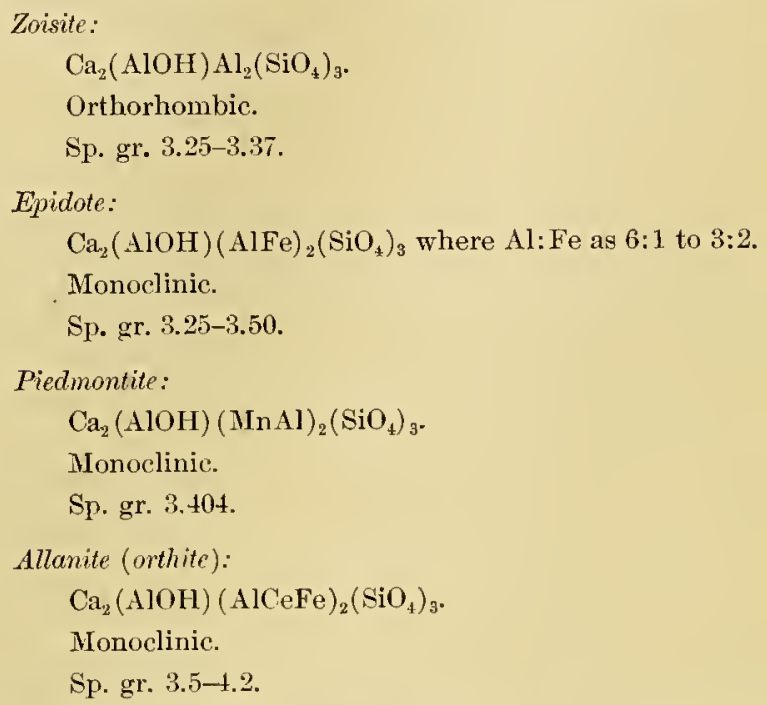

occurrence.-Zoisite is not known as an original pyrogenic constituent of igneous rocks. It is found in the schists and gneisses, especially those containing the amphiboles. Thus it is very common in the amphibolites, glaucophane-schists, eclogites, etc. Zoisite frequently occurs with albite as one of the constituents of the so-called sanssurites, which develop as an alteration of the basic feldspars, especially in gabbros. Zoisite also occurs in the altered granites and other acid igneous rocks, although it is, on the whole, less abundant than in the more basic rocks, but in some localities it is plentiful even in the acid rocks. Zoisite is a very frequent constituent in grits, graywackes, and other sediments of similar composition. In such rocks the minerals were partly altered to zoisite during the formation of the sedimentary rocks, and this zoisite is to be classed with the allogenic constituents of the mechanical sediments. Zoisite further derelops in the altered sedimentary rocks as a frequent and sometimes abundant product of metamorphism. From the foregoing statement of occurrence it is plain that zoisite develops in the zone of katamorphism, and especially in the belt of cementation. As shown under the discussion of the other minerals, it is seen that zoisite may be derived from the following minerals: Corundum, diaspore, gibbsite, grossularite, and the plagioclases. 
Epidote, like zoisite, is rarely if ever a pyrogenic constituent in igneous rocks. It is, however, a secondary constituent in all varieties of metamorphosed igneons rocks, whether plutonic or volcanic, whether lavas or tuffs. It is an allogenic constituent of the sedimentary rocks, and it extensively develops in the sedimentary rocks as a secondary product. It is particularly likely to form in rocks rich in calcium and iron, whether igneous or sedimentary; and thus is especially abundant in those metamorphosed igneous rocks which contain ferriferons varieties of pyroxene and amphibole, and in metamorphic sedimentary rocks which contain a considerable anount of calcium, as, for instance, calcareous schists and gneisses and marble. In the metamorphosed rocks epidote occurs alike in those which have a strongly developed schistose or gneissose structure and in those which have merely undergone metasonatic cliange. It is found as one of the important filling coustitnents of amygdaloids. It frequently develops at the contact of two rocks, especially an igneous rock with other rocks, either igneous or sedimentary. A list of different rock species which contain epidote includes almost every variety of massive, schistose, semischistose, and little altered igneons and sedimentary rocks. Epidote is, in fact, one of the most important secondary constituents of all the silicates. It is an almost constant accompaniment of the chlorites. Wherever the calcium-ironmagnesium-silicate rocks break up, the magnesinm passing into chlorite, a part of the calcium and iron is likely to pass into epidate. The equations for these alterations may be found under the minerals from which epidote is derived. Where epidote becomes so abundant as to be a chief constituent it may give a name to a rock; for instance, epidosite. From the foregoing statements it is apparent that epidote develops abundantly under massstatic and under mass-mechanical conditions. It forms with ease and on a great scale in the belt of cementation of the zone of katamorphism, and it is probable that it develops to some extent in the zone of anamorphism. Whether it forms at all in the belt of weathering can not be stated. Epidote is derived from the following minerals: Anorthoclase, angite, biotite, garnet, hornblende, melanite, microcline, orthoclase, the plagioclases, and the scapolites.

Piedmontite, or manganese-epidote, is apt to replace epidote in those schists and gneisses in which manganese happens to be an important constituent. Thus it is rather common in certain manganese-bearing schists of MON XIVII-OL-21 
Japan, in the manganese-chlorite-sericite-gneisses of eastern United States, and at other localities. In some cases piednontite occurs as nuclei surrounded by ordinary epidote. Piedmontite is occasionally so abundant as to be one of the chief constituents ot rocks.

Allanite occurs as an original subordinate constituent of a great number of eruptive rocks, such as granite, rhyolite, diorite, tonalite, andesite, dacite, and syenite. In short, it is a common accessory in the acid and intermediate eruptives, but is not so characteristic of the basic eruptive rocks. It also occur's in the metamorphic rocks, such as the schists and gneisses, especially those which are calcareous, and it may occur also in the marbles.

Alterations.-Definite alterations of zoisite, epidote, and piedmontite are not recorded. But it is certain in the belt of weathering that zoisite and epidote break up into calcite (rhombohedral; sp. gr. 2.7135), quartz (rhombohedral; sp. gr. 2.6535), iron oxides, kaoin (monoclinic; sp. gr. 2.615), and perhaps gibbsite (monoclinic; sp. gr. 2.35); and piedmontite and allanite alter into other minerals in a similar fashion.

It has already been seen that in the alteration of mica, pyroxene, amphibole, and other minerals chlorite and zoisite are frequent simultaneous products which together use up all the material of the original minerals. It has also been noted that the chlorite and epidote are abundantly developed together in the sedimentary rocks. If the conditions so change that these sedimentary rocks or other rocks in which epidote and zoisite have formed in the zone of katamorphism become so deeply buried as to pass into the zone of anamorphism, it is highly probable that the constituents which form epidote and zoisite and those which form chlorite reunite to produce minerals that are on the average denser, such as mica, amphibole, pyroxene, etc., ont of which they are originally developed. This is believed to be probable from the fact that in the most profoundly metamorphosed sedimentary rocks, those which are true schists and gneisses, little or no epidote and chlorite is contained, unless they have again been subjected to the conditions of the upper physical-chemical zone. Such schists and gneisses, having been derived from and traced into ordinary sedinents, in all probability did originally contain both chlorite and epidote, which have doubtless united to reproduce heavy minerals similar to those from which epidote and chlorite formed originally. 
It is not easy to approach accuracy in writing equations for the alterations of the epidotes in the belt of weathering. In the equations given below it is supposed that the calcium passes into earbonate, that the $\mathrm{Al}(\mathrm{OH})$ goes into gibbsite, that the remainder of the aluninum goes into kaolin, and that the excess of silica separates as quartz. In the epidote the $\mathrm{Al}$ is supposed to be to the $\mathrm{Fe}$ as $2: 1$, and the iron is supposed to pass into limonite (amorphous; sp. gr. 3.8). Upon these suppositions the alterations stand-

For zoisite-

(1) $\mathrm{Ca}_{2}(\mathrm{AlOH}) \mathrm{Al}_{2}\left(\mathrm{SiO}_{4}\right)_{3}+2 \mathrm{CO}_{2}+3 \mathrm{H}_{2} \mathrm{O}=2 \mathrm{CaCO}_{3}+\mathrm{Al}(\mathrm{OH})_{3}+\mathrm{H}_{4} \mathrm{Al}_{2} \mathrm{Si}_{2} \mathrm{O}_{9}+\mathrm{SiO}_{2}+\mathrm{k}$

and for epidote-

(2) $\mathrm{Ca}_{6}(\mathrm{AlOH})_{3} \mathrm{Al}_{4} \mathrm{Fe}_{2} \mathrm{Si}_{9} \mathrm{O}_{36}+6 \mathrm{CO}_{2}+8 \frac{1}{2} \mathrm{H}_{2} \mathrm{O}=$ $6 \mathrm{CaCO}_{3}+3 \mathrm{Al}(\mathrm{OH})_{3}+2 \mathrm{H}_{4} \mathrm{Al}_{2} \mathrm{Si}_{2} \mathrm{O}_{9}+\mathrm{Fe}_{2} \mathrm{O}_{3} \cdot 1 \frac{1}{2} \mathrm{H}_{2} \mathrm{O}+5 \mathrm{SiO}_{2}+\mathbf{k}$.

The increase in volume of all the compounds formed as compared with the zoisite is 66.22 per cent, and as compared with the epidote is 69.08 per cent.

Of course there are many other ways in which the equations could be written. All of the aluminum might pass into gibbsite or diaspore and more quartz form. The iron may pass into hematite in whole or in part, ete. While all this is true, it is believed that the above equations represent correctly the fundamental faet that by hydration and carbonation zoisite and epidote in the belt of weathering pass into simpler compounds.

Similar reactions could be written for the alterations of piedmontite and allanite, but considering the comparative rarity of these compounds this will not be done.

AXINITE.

Axinite:

$\mathrm{HCa}_{3} \mathrm{Al}_{2} \mathrm{BSi}_{4} \mathrm{O}_{16}$. (In some cases part of the $\mathrm{Ca}$ is replaced by Fe and In.)

Triclinic:.

Sp. gr. 3.271-3.294.

occurrence-Axinite occurs as a secondary constituent in basic eruptive rocks, such as the diabases and gabbros. It is found to some extent in the sehists and gneisses, and particularly in those bearing abundant pyroxene and amphibole. It also occurs in altered sedimentary rocks as a product 
formed in connection with the contact action of such rocks as granites, granulites, diabases, and gabbros. In such positions the formation of axinite is usually regarded as assisted by fumarole action.

Alterations.-Apparently the alterations which axinite undergoes in rocks have not been worked out, as they are not recorded in the standard text-books.

$$
\begin{aligned}
& \text { Prehnite: } \\
& \qquad \begin{array}{l}
\mathrm{H}_{2} \mathrm{Ca}_{2} \mathrm{Al}_{2} \mathrm{Si}_{3} \mathrm{O}_{12-} \\
\text { Orthorhombic. } \\
\text { Sp. gr. } 2.8-2.95 .
\end{array}
\end{aligned}
$$

PREHNITE.

occurrence.-Prehnite is almost identical in its occurrence with the zeolites (see pp. 331-333). It is therefore especially prevalent in the basic and intermediate rocks, such as anorthosite, basalt, diabase, gabbro, andesite, diorite, and syenite; also it occurs to some extent in granites and gneisses, where it may be associated with epidote. In the igneous rocks it is especially prevalent in the volcanics, since these are usually more porous. Like the zeolites, it is a very frequent occupant of amygdaloidal cavities, and also of cracks and crevices in the rocks. As already intimated, the most constant associates of prehnite are the zeolites. Prehnite occur's to some extent in the schists and gneisses, including those derived from igneous rocks, such as the amphibolites, and from aqueous rocks, such as the marbles. In some cases it is found in cavities in sedimentary rocks which have been metamorphosed by granitic or granulitic intrusions. As a secondary mineral prehnite is often derived from analcite, laumontite, mesolite, natrolite, the plagioclases, and scolecite. Fused prehnite yields wollastonite and ankerite.

Alterations.-The only alteration which I have been able to note in reference to prehnite is to chlorite (monoclinic; sp. gr. 2.71-2.725). This change requires the substitution of magnesium for calcium. Supposing the chlorite were amesite (liexagonal plates; sp. gr. 2.71), the change might be expressed:

$$
\mathrm{H}_{2} \mathrm{Ca}_{2} \mathrm{Al}_{2} \mathrm{Si}_{3} \mathrm{O}_{12}+2 \mathrm{MgCO}_{3}+\mathrm{H}_{2 .} \mathrm{O}=\mathrm{H}_{4} \mathrm{Mgg}_{2} \mathrm{Al}_{2} \mathrm{SiO}_{9}+2 \mathrm{SiO}_{2}+2 \mathrm{CaCO}_{3}+\mathrm{k} .
$$

Ignoring the carbonates, the increase of volume of the chlorite and quartz (rhombohedral; sp. gr. 2.6535) as compared with the prehnite is 3.27 per cent. The change is one of liydration and desilication, and would be expected to take place in the zone of katamorphism. 
HUMITE GROUP.

CHONDRODTE, HUMTE, AND CLNOHUMITE.

The humite group includes:

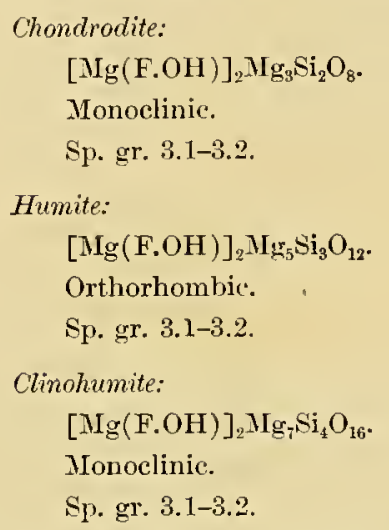

In all the above the hydroxide (OH) replaces a part of the fluorine.

occurrence.-The lumites occur in masses of magnesian limestones and rocks bearing carbonates ejected by volcanoes. Chondrodite has a somewhat widespread occurrence in the marbles of eastern United States. In such cases it is sometimes, at least, a contact mineral. Frequently it is accompanied by spinel.

Alterations.-The incst frequent alterations of the luunites are to serpentine (monoclinic; sp. gr. 2.50-2.65) and brucite (rhombohedral; sp. gr. 2.38-2.4). In the equations for the alterations the liydroxide will be ignored. The reactions may be written as follows:

(1) $(\mathrm{MgF})_{2} \mathrm{Mg}_{3} \mathrm{Si}_{2} \mathrm{O}_{8}+3 \mathrm{H}_{2} \mathrm{O}=\mathrm{H}_{4} \mathrm{Mg}_{3} \mathrm{Si}_{2} \mathrm{O}_{9}+\mathrm{Mg}(\mathrm{OH})_{2}+\mathrm{MgF}_{2}+\mathrm{k}$.

(2) $2\left[(\mathrm{MIgF})_{2} \mathrm{Mg}_{5} \mathrm{Si}_{3} \mathrm{O}_{12}\right]+9 \mathrm{H}_{2} \mathrm{O}=3 \mathrm{H}_{4} \mathrm{Mg}_{3} \mathrm{Si}_{2} \mathrm{O}_{9}+3 \mathrm{Ig}(\mathrm{OH})_{2}+2 \mathrm{MgF} \mathrm{F}_{2}+\mathrm{k}$.

(3) $(\mathrm{MgF})_{2} \mathrm{Mg}_{7} \mathrm{Si}_{4} \mathrm{O}_{16}+6 \mathrm{H}_{2} \mathrm{O}=2 \mathrm{H}_{4} \mathrm{Mg}_{3} \mathrm{Si}_{2} \mathrm{O}_{9}+2 \mathrm{Mg}(\mathrm{OH})_{2}+\mathrm{MgF}_{2}+\mathrm{k}$.

The increase in volume of the serpentine and brucite as compared with chondrodite, from which it is derived, is 30.15 per cent; as compared witls humite, 35.53 per cent; as compared with clinohumite, 38.39 per cent.

The alterations of liumite to serpentine and brucite involve hydration, expansion of volume, and liberation of heat. They are therefore typical reactious of the zone of katamorphism. 
TOURMALINE.

Tourmaline is a complicated aluminum silicate, which may be of any one of four different types or intermolecular growths of these types. According to Clarke, the formulæ for these types are- ${ }^{a}$

Tourmaline:

$\mathrm{NaHR}_{3} \mathrm{Al}_{8} \mathrm{~B}_{3} \mathrm{Si}_{6} \mathrm{O}_{31}$ ( $\mathrm{R}$ in some cases being lithium and hydrogen).

$\mathrm{NaH}_{3} \mathrm{Mg}_{2} \mathrm{Al}_{7} \mathrm{~B}_{3} \mathrm{Si}_{6} \mathrm{O}_{31}$ ( $\mathrm{Mg}$ frequently being replaced by $\mathrm{Fe}$ ).

$\mathrm{NaH}_{4} \mathrm{Mg}_{3} \mathrm{Al}_{6} \mathrm{~B}_{3} \mathrm{Si}_{6} \mathrm{O}_{31}$.

$\mathrm{NaH}_{5} \mathrm{Mg}_{4} \mathrm{Al}_{5} \mathrm{~B}_{9} \mathrm{Si}_{6} \mathrm{O}_{31}$.

Rhombohedral.

Sp. gr. 2.98-3.20.

occurrence-Tourmaline rather frequently occurs in the marbles and in the calcareons schists. It also lias a rather widespread occurrence, although generally not as an abundant mineral, in granites, gneisses, schists, and granulite. In these rocks it frequently occurs in such relations to dikes of igneous rocks, especially of pegmatites, as to suggest that its development is promoted by contact action. Because of the boron, tourmaline las generally been regarded as evidence of fumarole action. Certain it is that boron is not nsually a constituent of the ordinary sediments, and to account for this element, especially where the tourmaline is abundant, as it occasionally is in the schists, would seem to require its introduction from an outside source, either by gaseous or by aqueous solutions.

Alterations.-Mineral specinens of tourmaline are recorded as altering into mica, chlorite (monoclinic; sp. gr. 2.71-2.725), and steatite (massive; sp. gr. 2.794). However, in rocks tourmaline is one of the more permanent minerals, and the chemical additions and subtractions which occur in the alterations are so little known, and the exact nature of the tourmaline from which individual minerals are derived is so uncertain, that it is not thought advisable to attempt to write all the reactions representing these changes. If one assumes a definite tourmaline and a definite mica as being produced from it, it is easy to write a reaction. For instance, supposing that normal biotite (monoclinic; sp. gr. 2.90) is derived from a tourmaline of the composition of the last of the four formula given, that the additional alkalies are added in the forms of carbonates, that the free boric acid

a Clarke, F. W., The constitution of the silicates: Bull. U. S. Geol. Survey No. 125, 1895, pp. 56-57. An alternative form has been proposed by Penfield. 
passes into borax, and that the excess of alumina separates as gibbsite (monoclinic; sp. gr. 2.35), the reaction is-

$$
\begin{aligned}
& 4 \mathrm{NaH}_{5} \mathrm{Mgg}_{4} \mathrm{Al}_{5} \mathrm{~B}_{3} \mathrm{Si}_{8} \mathrm{O}_{31}+4 \mathrm{~K}_{2} \mathrm{CO}_{3}+\mathrm{Na}_{2} \mathrm{CO}_{3}= \\
& \quad 8 \mathrm{HKMg} \mathrm{Ig}_{2} \mathrm{Al}_{2} \mathrm{Si}_{3} \mathrm{O}_{12}+3 \mathrm{Na}_{2} \mathrm{~B}_{4} \mathrm{O}_{7}+4 \mathrm{Al}(\mathrm{OH})_{3}+5 \mathrm{CO}_{2}+\mathrm{k} .
\end{aligned}
$$

The decrease in volume of the biotite as compared with the tourmaline is 6.75 per cent; but if the gibbsite be included the increase of volume is $\mathbf{3 . 9 6}$ per cent.

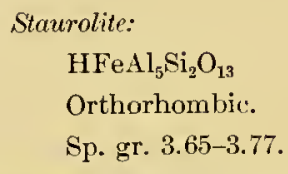

Occurrence.-Staurolite is similar in its occurrence to garnet, but apparently requires more intense metamorphic action for it to begin to form. Its most widespread occurrence is in the schists and gneisses of sedimentary origin. It also develops in profoundly metamorphosed rocks of eruptive origin, but it is not known as an original constituent in any eruptive rock. Like garnet, it may be abundantly developed in the zone of anamorphism in rocks which are cut by intrusives. The conditions favorable to its formation are therefore similar to those which produce garnet (see pp. 300-302) and such minerals as tourmaline, andalusite, sillinanite, and. cyanite, with which it is associated. It is evidently a mineral which derives its materials from various other minerals, the elements being recombined into the more compact form of staurolite under deep-seated conditions.

Alterations. - The only alterations recorded for staurolite are to talc (orthorhombic or monoclinic; sp. gr. 2.75), to chlorite (monoclinic: sp. gr. 2.71-2.725), and to muscovite (damourite) (monoclinic; sp. gr. 2.76-3.0). The first two minerals are essentially magnesian ones, although if the chlorite be aphrosiderite (massive; sp. gr. 2.90) a considerable amount of iron may be present. It is therefore clear that in the change to talc and chlorite magnesium must be derived from some other compounds. As the alterations are those which occur in the zone of katamorphism, it may be supposed that the magnesium is in the form of carbonate, since magnesium carbonate is an almost universal constituent of ground waters in the upper physical-chemical zone. The alteration to muscovite requires an entire loss of the iron and the addition of potassium. It is therefore clear that some 
potassium mineral must also be concerned in this alteration. Staurolite rocks usually contain orthoclase, or at least some potash feldspar. It may be supposed that these potash feldspars break up into kaolin at the same time, thus furnishing the potassium necessary for the change.

The change of staurolite to tale may be written as follows:

(1) $2 \mathrm{HFeAl}_{5} \mathrm{Si}_{2} \mathrm{O}_{13}+3 \mathrm{MgCO} \mathrm{IgCO}_{3}+15 \mathrm{H}_{2} \mathrm{O}+\mathrm{O}=\mathrm{H}_{2} \mathrm{MIg}_{3} \mathrm{Si}_{4} \mathrm{O}_{12}+\mathrm{Fe}_{2} \mathrm{O}_{3}+10 \mathrm{Al}(\mathrm{OH})_{3}+3 \mathrm{CO}_{2}+\mathrm{k}$.

The decrease of the volume of the talc as compared with the staurolite is 44.02 per cent; but if the gibbsite (monoclinic; sp. gr. 2.35) be included the increase in volume of the two is 90.96 per cent.

In the change to chlorite the most aluminous one is chosen, amesite (hexagonal plates; sp. gr. 2.71), since staurolite is so heavily aluminous Moreover, it is supposed that the iron in the chlorite is to the magnesinn as $1: 3$. On these suppositions the reaction may be written:

(2) $2 \mathrm{HFeAl}_{5} \mathrm{Si}_{2} \mathrm{O}_{13}+10 \mathrm{H}_{2} \mathrm{O}+62 \mathrm{IgCO} \mathrm{CO}_{3}=2 \mathrm{H}_{8} \mathrm{MIg}_{3} \mathrm{FeAl}_{4} \mathrm{Si}_{2} \mathrm{O}_{18}+2 \mathrm{Al}(\mathrm{OH})_{3}+6 \mathrm{CO}_{2}+\mathrm{k}$.

The increase of volume of the chlorite and gibbsite as compared with the staurolite is 103.58 per cent

The change of staurolite to muscovite may be written:

(3) $3 \mathrm{HFeAl}_{5} \mathrm{Si}_{2} \mathrm{O}_{13}+\mathrm{K}_{2} \mathrm{CO}_{3}+14 \mathrm{H}_{2} \mathrm{O}+\mathrm{O}=2 \mathrm{H}_{2} \mathrm{KAl}_{3} \mathrm{Si}_{3} \mathrm{O}_{12}+\mathrm{Fe}_{3} \mathrm{O}_{4}+9 \mathrm{Al}(\mathrm{OH})_{3}+\mathrm{CO}_{2}+\mathrm{k}$.

The decrease in volume of the muscovite as compared with the staurolite is 24.96 per cent; but if the magnetite (isometric; sp. gr. 5.174) and gibbsite be included the increase in volume would be 68.08 per cent, and if hematite (rhombohedral; sp gr. 5.225) or limonite (amorphous; sp. gr. 3.8) form, instead of magnetite, the increase would be still greater.

In the above equations it is entirely possible that the magnesiunı may be added in some other form than that given, and the resultant compounds be different. The same thing may be said of the potassium. It is uncertain what becomes of the excess of aluminum. In the equations the aluminum is regarded as passing into the gibbsite. However, the presence of abundant gibbsite is not recorded among the alterations of staurolite, although frequently corundum (rhombohedral; sp. gr. 4.025) occurs in connection with it; but it is by no means certain that this corundum is one of the results of the alteration of the staurolite; indeed, it is more probable that the corundum formed from gibbsite at the same time the staurolite developed. 
In short, the above reactions are probably as unsatisfactory as any that have been written, because the text-books do not record what minerals accompany the talc, chlorite, and muscovite as a result of the transformation of the staurolite. It is certain that in each case some other minerals must be producerl.

ZEOLITE GROUP.

The zeolites are a great group of hydrous silicates about which there seems to be no consensus of opinion as to the species in the group, as to the composition of the species, or as to their classification. Since Groth and Clarke are among the latest authors to discuss this group, their formulæe are used, Groth's being placed first and Clarke's second when he differs from Groth. Groth's formulæ are put into an enpirical form, and the subordinate constituents which may replace the chief bases are omitted. The differences between the formulx given and Dana's also are pointed out. The important rock-making zeolites are as follows, ranged from basic to acid:

THOMSONITE, HYDONEPHELTE, NATROLTE, MESOLTE, SCOLECITE, ANALITE, APOPHYLATE, EPISTILRITE,

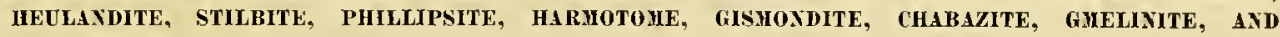
LAVMONTITE.

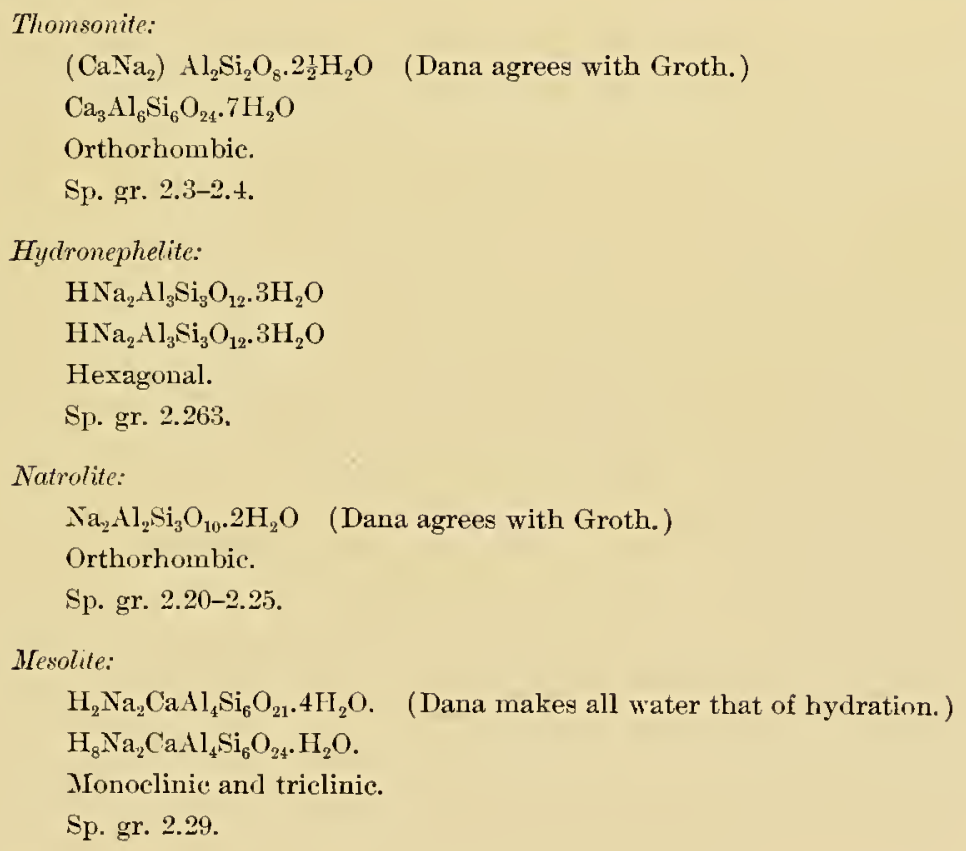


Scolecite:

$\mathrm{H}_{2} \mathrm{CaAl}_{2} \mathrm{Si}_{3} \mathrm{O}_{11} .2 \mathrm{H}_{2} \mathrm{O}$. (Dana agrees with Groth.)

Monoclinic.

Sp. gr. 2.16-2.4.

Analcite:

$\mathrm{Na}_{2} \mathrm{Al}_{2} \mathrm{Si}_{4} \mathrm{O}_{12} \cdot 2 \mathrm{H}_{2} \mathrm{O}$. (Dana agrees with Groth.)

Isometric.

Sp. gr. 2.22-2.29.

Apophyllite:

$\mathrm{H}_{7} \mathrm{KCa}_{4} \mathrm{Si}_{8} \mathrm{O}_{24} \cdot 4 \frac{1}{2} \mathrm{H}_{2} \mathrm{O}$. (Dana agrees with Groth.)

$\mathrm{H}_{14} \mathrm{Ca}_{4} \mathrm{Si}_{6} \mathrm{O}_{23}$.

Tetragonal.

Sp. gr. 2.3-2.4.

Epistilbite:

$\mathrm{H}_{6} \mathrm{Ca}_{2} \mathrm{Al}_{4} \mathrm{Si}_{11} \mathrm{O}_{33} .7 \mathrm{H}_{2} \mathrm{O}$. (Dana varies from both, but is nearer Groth. His formula is $\mathrm{H}_{4} \mathrm{CaAl}_{2} \mathrm{Si}_{6} \mathrm{O}_{18} \cdot 3 \mathrm{H}_{2} \mathrm{O}$.)

$\mathrm{Ca}_{3} \mathrm{Al}_{6} \mathrm{Si}_{8} \mathrm{O}_{48} \cdot 16 \mathrm{H}_{2} \mathrm{O}$.

Monoclinic.

Sp. gr. 2.25 .

Heulandite:

$\mathrm{H}_{4} \mathrm{CaAl}_{2} \mathrm{Si}_{6} \mathrm{O}_{18} .3 \mathrm{H}_{2} \mathrm{O}$. (Dana agrees with Groth.)

$\mathrm{Ca}_{3} \mathrm{Al}_{6} \mathrm{Si}_{18} \mathrm{O}_{48} \cdot 16 \mathrm{H}_{2} \mathrm{O}$.

Monoclinic.

Sp. gr. 2.18-2.22.

Stilbite (desmine):

$\mathrm{Ca}_{4} \mathrm{Al}_{8} \mathrm{Si}_{16} \mathrm{O}_{48} \cdot 18 \mathrm{H}_{2} \mathrm{O}$. (Dana's formula is nearly the same as Clarke's:

$\mathrm{H}_{4}\left(\mathrm{Na}_{2} \mathrm{Ca}\right) \mathrm{Al}_{2} \mathrm{Si}_{\mathrm{B}} \mathrm{O}_{18} \cdot 4 \mathrm{H}_{2} \mathrm{O}$.)

$\mathrm{Ca}_{3} \mathrm{Al}_{6} \mathrm{Si}_{18} \mathrm{O}_{48} \cdot 18 \mathrm{H}_{2} \mathrm{O}$.

Monoclinic.

Sp. gr. 2.094-2.205.

Phillipsite:

$\left(\mathrm{K}_{2} \mathrm{Na}_{2} \mathrm{Ca}\right)_{3} \mathrm{Al}_{6} \mathrm{Si}_{10} \mathrm{O}_{32} \cdot 12 \mathrm{H}_{2} \mathrm{O}$. (Dana's formula is nearly like Clarke's: $\left(\mathrm{K}_{2} \mathrm{Ca}\right) \mathrm{Al}_{2} \mathrm{Si}_{4} \mathrm{O}_{12} \cdot 4 \frac{1}{2} \mathrm{H}_{2} \mathrm{O}$.)

$\mathrm{K}_{2} \mathrm{Ca}_{2} \mathrm{Al}_{6} \mathrm{Si}_{12} \mathrm{O}_{36} \cdot 14 \mathrm{H}_{2} \mathrm{O}$.

Monoclinic.

Sp. gr. 2.2.

\section{Harmotome:}

$\mathrm{Ba}_{3} \mathrm{Al}_{6} \mathrm{Si}_{10} \mathrm{O}_{32} .12 \mathrm{H}_{2} \mathrm{O}$. (Dana varies from each. His formula is $\left(\mathrm{K}_{2} \mathrm{Ba}\right) \mathrm{Al}_{2} \mathrm{Si}_{5} \mathrm{O}_{14} \cdot 5 \mathrm{H}_{2} \mathrm{O}$.)

$\mathrm{Ba}_{3} \mathrm{Al}_{6} \mathrm{Si}_{14} \mathrm{O}_{40} .14 \mathrm{H}_{2} \mathrm{O}$.

Monoclinic.

Sp. gr. 2.44-2.50. 


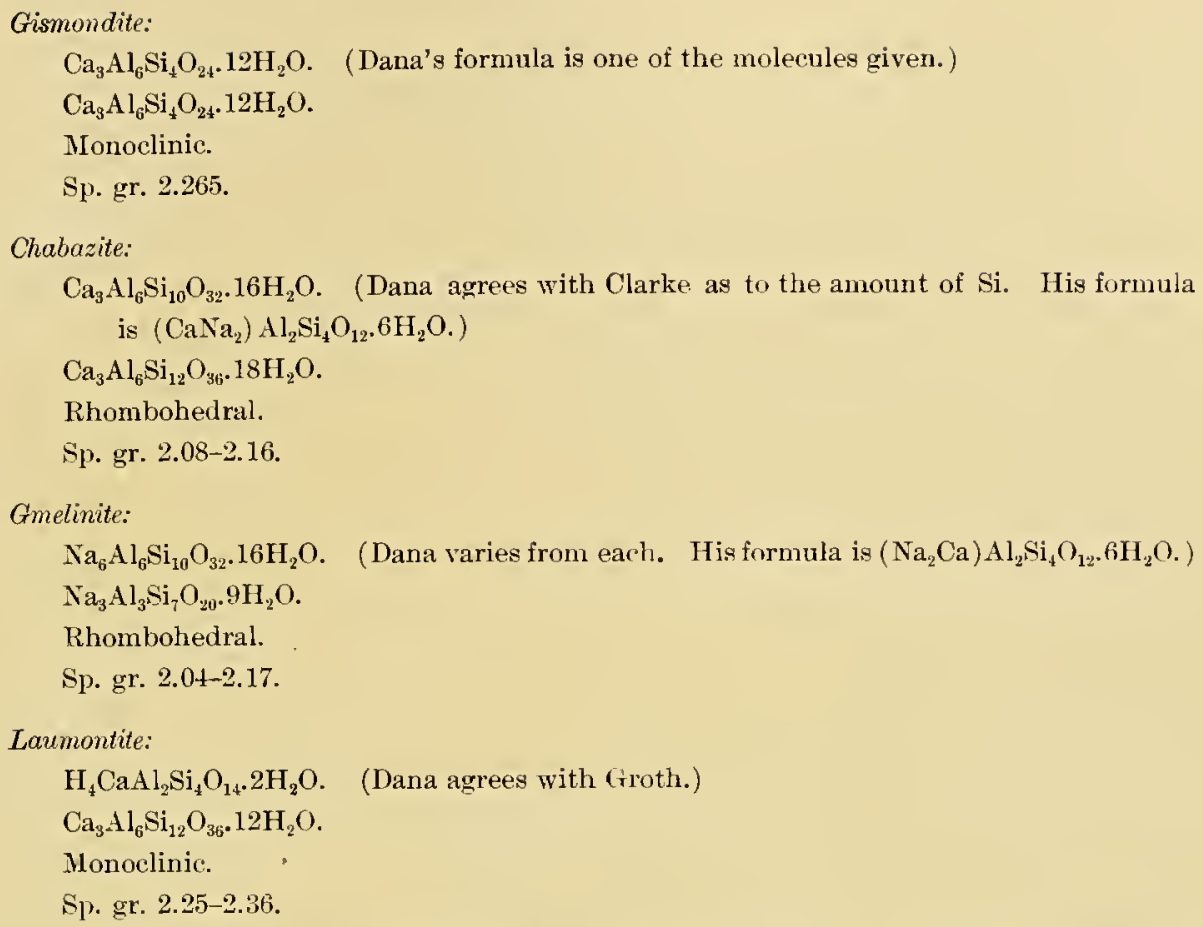

occurrence.-The zeolites are not known as original pyrogenic constituents of igneous rocks. As secondary minerals they are most abundantly found in basic lavas and allied rocks, including botl glassy and crystallized kinds. The zeolites occur in these rocks, both in the ordinary feldspathic varieties, such as basalt and trachyte, and in those containing lencite, nephelite, sodalite, etc., and especially in those which are somewhat resicnlar. The zeolites also develop abundantly in the deep-seated equivalents of the basalts in such rocks as the diabases, gabbros, etc. The zeolites are less prevalent, although far from rare, in the diorite and syenite families, including both the ordinary syenites and nepheline-syenites. Finally, the zeolites are far from uncommon in the more acid rocks, such as those of the granite family. In short, the zeolites may occur in almost any variety of the igneous rocks, but, as already said, are most prevalent in the basic group. In the sedimentary rocks the zeolites may be allogenic constituents separate from other minerals, or an alteration product of partly decomposed minerals. Also, after the deposition of material in the fragmental rocks the zeolites may develop as alteration products. Hence the zeolites are constituents of the altered sedimentary rocks, of the semimetamorphosed 
sedimentary rocks, and of the schists and gneisses of sedimentary origin, which, after becoming schists and gneisses, have been snbjected to agencies of alteration in the zone of katamorphism.

The zeolites develop from many minerals, but especially from the plagioclase feldspars and from the leucites, sodalites, nephelites, etc. From the plagioclases many of the zeolites are produced. The following may be regarded as derived from anorthite: Thomsonite, gismondite, laumontite, phillipsite, heulandite, epistilbite, stilbite, chabazite, and scolecite. The following may be regarded as derived from albite: Analcite and natrolite. Mesolite may be regarded as derived from albite and anorthite together. Since the intermediate plagioclases contain both the anorthite and the albite molecules, all of the above minerals may be derived from oligoclase, andesine, labradorite, and bytownite, as may also mesolite. So far as recorded the derivations of the zeolite minerals from the nephelites, lencites, and sodalites are as follows: Thomsonite from nephelite and sodalite; hydroneplielite from nephelite and sodalite; natrolite from nephelite, sodalite, haiiynite, and noselite; analcite from leucite, nephelite, and sodalite; stilbite from haiiynite and noselite; chabazite from haüynite and noselite. The zeolites are also derived from other minerals as follows: Analcite from laumontite, natrolite from apatite and chabazite, ete.

It is hardly worth while to consider the occurrence of each of the zeolites. It may be said, however, that the calcium-bearing zeolites are most apt to form in the calcareous rocks, and the soda zeolites in the rocks ricl in soda. Thus stilbite, scolecite, and similar minerals are likely to form in the calcareous rocks and limestones, while hydronephelite, natrolite, and analcite, and similar minerals, are especially likely to form from the rocks containing soda feldspars and nephelites, leucites, and sodalites. The sodium-calcium zeolites, such as thomsonite, mesolite, and phillipsite, may occur in the calcareous rocks, such as the limestones, in the igneous soda rocks, such as the nephelite rocks, and in the basalts and similar rocks.

In the rocks in which they occur the zeolites may be found (1) within the mass of the rock as alteration products of the minerals; (2) in amygdules, filling the vacuoles of the igneous rocks; and (3) in other openings of all kinds, such as fiactures, the pores of sediments, etc. 
The development of the zeolites in nearly all cases requires hydration and expansion of volume, as shown under the discussions of the particular minerals from which they form. 'Their formation, therefore, tends to fill up the crevices and cracks in rocks, even if no material be furnisled from an extraneous source. It may be that the zeolitization combined witl other alterations fumishes sufficient material to entirely fill the vacuoles of many amygdaloids without material being furnished from an extraneous source. (See pp. 631-634.) However, it is doubtless the case that much of the material of the zeolites which is deposited in the belt of cementation is derived by solution from the belt of weathering. As shown under the individual minerals from which the zeolites develop, the conditions for the formation of these minerals are those of the zone of katamorphism, both in the belt of weathering and in that of cementation.

In the belt of cementation, in which hydration is perhaps the most characteristic reaction and alterations can take place with expansion of volume, the zeolites form on a great scale. Conforming with these statements are the observations made by Danbrée ${ }^{a}$ that zeolites can be formed experimentally in the presence of abundant water at temperatmes of about $50^{\circ} \mathrm{C}$. Pointing in the same direction is the fact stated by Renard ${ }^{b}$ that phillipsite has extensively formed at the bottom of the sea at temperatures not far from $0^{\circ} \mathrm{C}$.

While the zeolites develop chiefly in the belt of cementation, it is certain that in very humid regions they form in the belt of weathering. But it is also certain that to a great extent the zeolites are also destroyed in the belt of weathering. This is especially the case in hot arid regions.

Alterations.-The most comprehensive statement as to the alterations of the zeolites is that given by Clarke." His statements are as follows: (1) Natrolite alters into prehnite (orthorhombic; sp. gr. 2.875); (2) mesolite alters into prehnite; (3) scolecite alters into prehnite; (4) analcite alter's into albite (triclinic; sp. gr. 2.635), and (5) orthoclase (monoclinic; sp. gr. 2.57) and prehnite; (6) apophyllite alters into pectolite (monochinic; sp. gr. 2.73); (7) heulandite alters into albite, and (8) into orthoclase;

¿ Daubrée, A., Études synthétiques de géologie expérimentale, Pariz, 1879, pt. 1, pp. 199, 205-207.

$b$ Murray, John, and Renard, A. F., Report of the scientific results of the voyage of H. M. S. Challenger, 1873-1876; Deep-sea deposits, London, 1891, pp. 400-411.

$c$ Clarke, F. W., The constitution of the silicates: Bull. U. S. Geol. Survey No. 125, 1895, pp. 32-45. 
(9) stilbite alters into albite, and (10) into orthoclase; (11) chabazite alters into natrolite (hexagonal-rhombohedral (Hintze), orthorhombic (1)ana); sp. gr. 2.225); (12) laumontite alters into albite, (13) into orthoclase and prehnite, and (14) into analcite (isometric; sp. gr. 2.255).

These alterations may be expressed by the following equations, the numbers of the equations corresponding to the numbers of the alterations. In writing these equations, whether Groth's or Clarke's formula is used depends on which is more nearly analogous to the formula of the mineral produced.

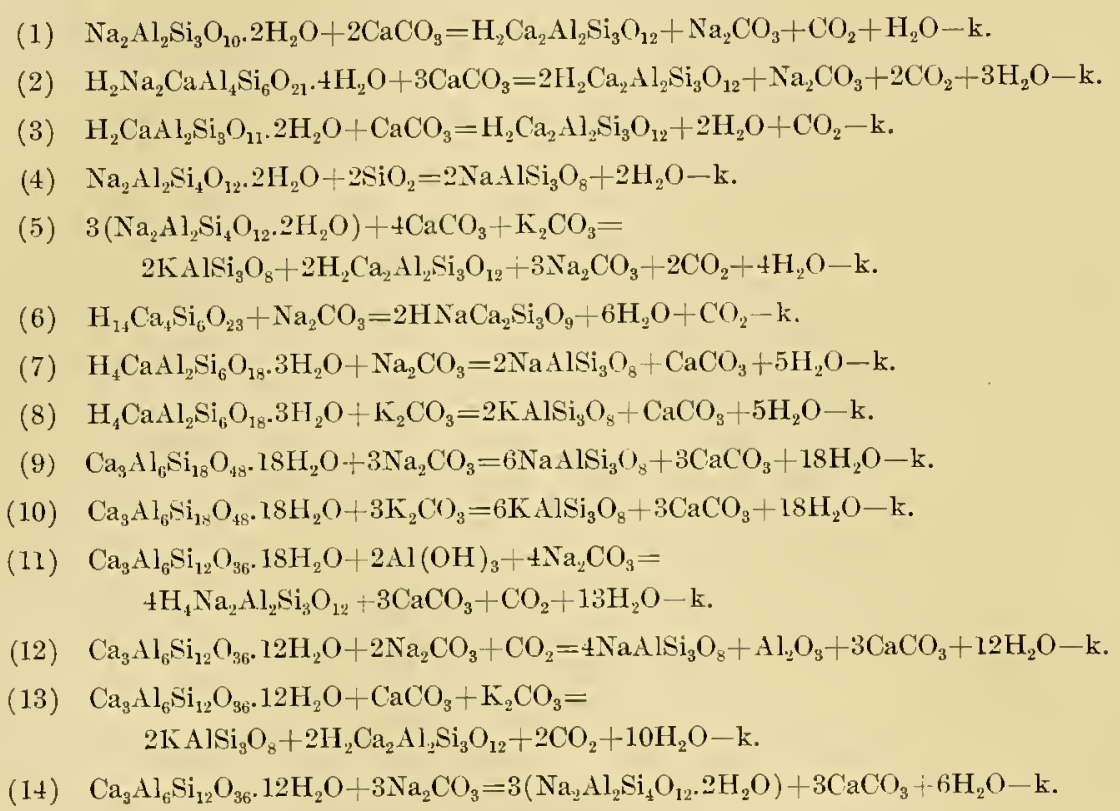

The decreases in volumes are as follows: Prehnite as compared with the natrolite, equation (1), 16.12 per cent; prehnite as compared with mesolite, equation (2), 15.05 per cent; prehnite as compared with scolecite, equation (3), 16.66 per cent; albite as compared with the analcite and quartz, equation (4), 17.25 per cent; orthoclase and prehnite as compared with analcite, equation (5), 14.09 per cent; pectolite as compared with apophyllite, equation (6), 19.48 per cent; albite as compared with heulandite, equation (7), 25.03 per cent; orthoclase as compared with henlandite, equation (8), 18.44 per cent; albite as compared with stilbite, equation (9), 31.67 per cent; orthoclase as compared with stilbite, equation (10), 25.66 per cent; natrolite as compared with chabazite, equation (11), 4.58 per 
cent; albite as compared with laumontite, equation (12), 34.92 per cent; orthoclase and prehnite as compared with laumontite, equation (13), 17.75 per cent; and analcite as compared with laumontite, equation (14), 4.30 per cent.

In calculating the volume relations the carbonates, and in equation (11) the aluminum hydrate, are ignored. If these compounds were taken. into acconut the decreases in volume would in some cases be somewhat more, in others somewhat less. To ignore these side compounds seems the best course, since the added and subtracted salts may be in other forms than those given.

For the most part the alterations, so far as the bases are concerned, are remarkably simple, involving only the interchange between the alkalies, sodium and potassium, or between sodium and the alkaline earth calcium, or the addition of the bases sodium or calcium. They are all reactions of dehydration, partial or complete. Many of them are reactions of decarbonation and one, equation (4), is a reaction of silication. Presumably they all take place with the absorption of heat. While nothing can be ascertained as to the actual conditions under which the changes take place, one would expect them to occur in the zone of anamorphism, for a number of the reactions reverse those of the zone of katamorphisin. In the latter zone the alteration of the feldspars into the zeolites is well known. The reverse changes, those of analcite, heulandite, stilbite, and laumontite into albite and orthoclase, for which equations are written, would be hardly likely to take place in the same zone. At any rate the alterations of the feldspars into the zeolites and the zeolites into the feldspars present a very interesting case of reversible reactions, discussed subsequently. (See pp. 366-369.)

It is further certain that the zeolites as extensively formed in the belt of cementation, in the belt of weathering break up, by carbonation and hydration, into the simpler compounds, such as the carbonates of the alkalies and the alkaline earths, diaspore or gibbsite, kaolin, and quartz. Hypothetical reactions could readily be written for these changes similar to those worked out for zoisite and epidote (po. 322-323); but since so little is known as to the definite minerals which are formed from each zeolite, this is hardly worth while at the present stage of knowledge. 
MICA GROUP.

Muscovite, parakonite, blotite, AND phlodopite.

The mica group includes the following rock-making species:

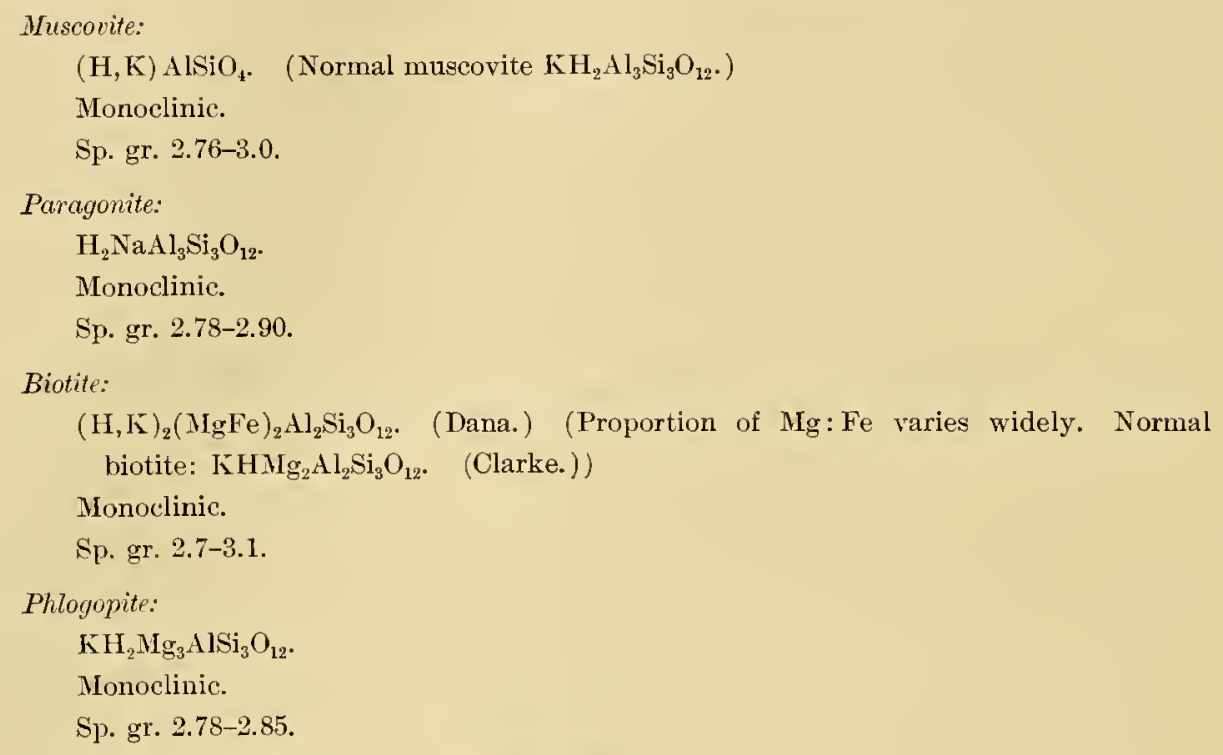

MUSCOVITE.

Muscovite, as already noted, is hydrogen-potassium-aluminum silicate. occurrence.-Muscovite is an abundant constitnent in the plutonic rocks, but is rather rare as a constituent in the volcanic rocks. It is one of the most abundant constituents of the metamorphosed rocks, being a chief mineral in many metamorphosed sedimentary and many metamorphosed igneous rocks. As a secondary constituent, it is derived from many other minerals. The more important of these are feldspar, including both orthoclase and plagioclase, nephelite, sodalite, leucite, the scapolites, spodumene, topaz, andalusite, and cyanite. It is also recorded as a pseudomorph after tourmaline, garnet, beryl, and cordierite. There is little doubt also that muscovite in the metamorphosed rocks is largely formed from the materials of the zeolites. Some of the minerals, such as nephelite, sodalite, and lencite, from which the muscovite is derived, occur only in the igneous rocks. Others of them, such as the zeolites, occur only in rocks of altered or secondary nature. Others of the minerals from which muscovite is derived, such as topaz, cyanite, and andalusite, are chiefly metamorphic constituents. 
Still others from which muscovite is derived, such as the feldspars, may be original constituents of the igneous rocks, or they may be original $\mathrm{or}^{\circ}$ secondary constitnents of the sedimentary rocks. It is therefore clear that muscovite has an unusual variety of sources, and consequently it may be expected in almost any variety of rock except the volcanics. It is, however, a more characteristic constituent of the acidic and intermediate rocks than of the basic rocks.

In summary, muscovite is derived from anorthoclase, diaspore, gibbsite, leucite, microcline, nephelite, orthoclase, plagioclase and orthoclase, scapolites, sodalite, and spodumene. The muscovite damomite is derived from andalusite, corundum, cyanite, sillimanite, staurolite, and topaz.

Alterations. - The minerals to which muscovite alters are not nearly so abundant as those from which it is derived. One of the most frequent alterations is that of hydration, a part of the potassium being replaced by hydrogen; or at the same time it may take up other bases and thus the mineral may pass into vermiculite, a somewhat indefinite compound to which no formula can be assigned. Muscovite also alters into serpentine (monoclinic; sp. gr. 2.50-2.65) and into the steatitic form of talc (massive; sp. gr. 2.7-2.8). Probably simultaneously with the formation of these minerals gibbsite (monoclinic; sp. gr. 2.3-2.4) or diaspore (orthorhombic; sp. gr. 3.3-3.5) forms, although the contemporaneous formation of these minerals is not mentioned. Muscovite also may alter into the soda-mica paragonite (monoclinic; sp. gr: 2.78-2.90).

The reactions by which muscovite passes into serpentine and talc are very uncertain. If the magnesium were supposed to be deriver from a carbonate and all of the silica of the muscovite went into the resultant compounds, the reactions may be written as follows:

For serpentine:

(1) $2 \mathrm{KH}_{2} \mathrm{Al}_{3} \mathrm{Si}_{3} \mathrm{O}_{12}+9 \mathrm{IgCO}_{3}+13 \mathrm{H}_{2} \mathrm{O}=3 \mathrm{H}_{4} \mathrm{Mg}_{3} \mathrm{Si}_{2} \mathrm{O}_{9}+6 \mathrm{Al}(\mathrm{OH})_{3}+\mathrm{K}_{2} \mathrm{CO}_{3}+8 \mathrm{CO}_{2}+\mathrm{k}$.

For talc:

(2) $4 \mathrm{KH}_{2} \mathrm{Al}_{3} \mathrm{Si}_{3} \mathrm{O}_{12}+9 \mathrm{HgCO} \mathrm{IgCO}_{3}+17 \mathrm{H}_{2} \mathrm{O}=3 \mathrm{H}_{2} 2 \mathrm{Ig}_{3} \mathrm{Si}_{4} \mathrm{O}_{12}+12 \mathrm{Al}(\mathrm{OH})_{3}+2 \mathrm{~K}_{2} \mathrm{CO}_{3}+7 \mathrm{CO}_{2}+\mathrm{k}$.

The increase in volume of the serpentine as compared with the muscovite is i6.56 per cent, and the decrease of the talc 25.23 per cent. But if the magnesium carbonate be contributed by solutions, and the gibbsite remains as a solid with the serpentine and talc, the increase in volume of the serMON XLVII-04-22 
pentine and gibbsite as compared with the muscovite is 88.44 per cent, and of the talc and gibbsite 46.69 per cent.

The change of muscovite to paragonite merely requires the substitution of sodium for potassium, and may be written as follows:

(3) $2 \mathrm{H}_{2} \mathrm{KAl}_{3} \mathrm{Si}_{3} \mathrm{O}_{12}+\mathrm{Na}_{2} \mathrm{CO}_{3}=2 \mathrm{H}_{2} \mathrm{NaAl}_{3} \mathrm{Si}_{3} \mathrm{O}_{12}+\mathrm{K}_{2} \mathrm{CO}_{3}+\mathrm{k}$.

The decrease in volume is 2.67 per cent.

Inscovite under deep-seated conditions is a mineral which is practically permanent. In fact, under these conditions, as already indicated, it is produced by the alteration of other minerals. The above alterations of muscovite, resulting in the formation of vermiculite, serpentine, and tale, with gibbsite all occur in the zone of katamorphism, and especially in the belt of weathering. Even under the conditions of the surface belt the processes of change are exceedingly slow. Corresponding with this position, the changes take place with increase of rolume and liberation of heat.

PARAGONITE.

Paragonite is hydrous sodium-aluminum silicate.

occurrence.-Paragonite is not certainly known as an original pylogenic constituent in igneous rocks. It is found especially in the metamorphosed igneons rocks and in the semimetamorphosed and completely metamorphosed sedimentary rocks. In many so-called sericite rocks it is probable that a portion of the micaceous mineral is paragonite rather than muscovite. Paragonite is especially likely to occur in the metamorphic rocks, instead of mnscovite, where the original rocks, either igneous or sedimentary, bear a considerable amount of sodium. Tery frequently associated with paragonite are the heary metamorphic minerals, such as cyanite, staurolite, garnet, tonmaline, etc. In certain places muscovite has been noted as passing to paragonite, and thus the potassium mica is a source for the soda mica.

In summary, paragonite as a metamorphic mineral is derived from anorthoclase, muscovite, and plagioclases.

. Alterations.-Alterations of paragonite are not recorded in the standard text-books. However, there can be little doubt that this mineral undergoes a set of alterations in the zone of katamorphism, and one wonld expect that these alterations would be analogous to those which take place with muscovite. 
BIOTITE.

Biotite is hydrogen-potassium-magnesium-aluminum silicate, a part of the magnesinm frequently being replaced by iron.

occurrence.-Biotite is an original chief constituent of many of the igneous rocks, both plutonic and rolcanic, and ranging from those which are acid to those which are basic. It is a very abundant secondary constituent in the slates, schists, aud gneisses, developing on a great scale in the metamorphosed rocks, both igneons and sedimentary. As a secondary constituent it seems usually not to be derived from a single mineral, as i, freqnently the case with muscovite, but is produced from material furnished by two or more minerals. For instance, it is frequently a reaction product between magnetite and other minerals, the magnetite furnishing the iron for the biotite, the other constituents being derived from such minerals as the pyroxenes, amphiboles, and feldspars. A frequent case is the formation of biotite from the pyroxenes, feldspars, and magnetite. The feldspars and feldspathoids frequently furnish the potassia, parts of the alnmina, and silica. The pyroxenes and amphiboles frequently furnish a part of the magnesia, alumina, and silica. Dolomite is often a source of the magnesia. The oxides and carbonate of iron are the most frequent sources of this element.

In summary; as a metamorphic mineral, biotite is derived from anorthoclase, angite, hornblende, microcline, orthoclase, and the scapolites.

Atterations.-Perhaps the most frequent alterations of biotite are to hydrobiotite (probably monoclinic; sp. gr. 2.90, average of biotite) and to chlorite (monoclinic; sp. gr. 2.80). It also alter's into epidote (monoclinic; sp. gr. 3.25-3.50); rarely it alters into hypersthene (orthorhombic; sp. gr. 3.40-3.50) and sillimanite (orthorhombic; sp. gr. 3.23-3.24); and in some cases it apparently alters into serpentine (monoclinic; sp. gr. 2.575). Its alteration into the above minerals may be accompanied by the separation of quartz (rhombohedial; sp. gr. 2.6535), and if the biotite be ferriferons, by the formation of magnetite (isometric; sp. gr. 5.174), or other iron oxide.

The alteration of biotite into serpentine probably requires the simultaneous production of kaolin (monoclinic; sp. gr. 2.615) and gibbsite (monoclinic; sp. gr. 2.35). Supposing that all the magnesinm of normal biotite 
goes into the serpentine, and that all the silica not required for the production of this mineral passes into the kaolin, the reaction is as follows:

(1) $6 \mathrm{KHMIg}_{2} \mathrm{Al}_{2} \mathrm{Si}_{3} \mathrm{O}_{12}+18 \mathrm{H}_{2} \mathrm{O}+3 \mathrm{CO}_{2}=$

$+\mathrm{H}_{4} \mathrm{Mg}_{3} \mathrm{Si}_{2} \mathrm{O}_{9}+5 \mathrm{H}_{4} \mathrm{Al}_{2} \mathrm{Si}_{2} \mathrm{O}_{4}+2 \mathrm{Al}(\mathrm{OH})_{3}+3 \mathrm{~K}_{2} \mathrm{CO}_{3}+\mathrm{k}$.

Supposing all the serpentine, kaolin, and gibbsite to remain as solids, and the potassimm carbonate to go into solution, the increase in volume is $\mathbf{1 4 . 2 6}$ per cent.

The change of biotite into hydrobiotite nay be written:

(2) $2 \mathrm{HK} M \mathrm{gg}_{2} \mathrm{Al}_{2} \mathrm{Si}_{3} \mathrm{O}_{12}+7 \mathrm{H}_{2} \mathrm{O}+\mathrm{CO}_{2}=2\left(\mathrm{H}_{2} 2 \mathrm{Ig}_{2} \mathrm{Al}_{2} \mathrm{Si}_{3} \mathrm{O}_{12} \cdot 3 \mathrm{H}_{2} \mathrm{O}\right)+\mathrm{K}_{2} \mathrm{CO}_{3}+\mathrm{k}$.

The increase in volume is 3.8 per cent.

The alteration into chlorite, supposing all the alumina and silica to remain in the altered mineral, and the additional magnesia to be added in the form of a carbonate, may be written as follows:

(3) $2 \mathrm{KH}_{\mathrm{H}} \mathrm{g}_{2} \mathrm{Al} \mathrm{Al}_{2} \mathrm{Si}_{3} \mathrm{O}_{12}+4 \mathrm{NgCO} \mathrm{CO}_{3}+5 \mathrm{H}_{2} \mathrm{O}=2\left[\mathrm{H}_{2} \mathrm{Mg}_{4} \mathrm{Al}_{2} \mathrm{Si}_{3} \mathrm{O}_{12} \cdot 4(\mathrm{OH})\right]+\mathrm{K}_{2} \mathrm{CO}_{3}+3 \mathrm{CO}_{2}+\mathrm{k}$.

The increase in volume, supposing the magnesium carbonate is added in solution and the potassium carbonate goes into solution, is 22.92 per cent.

The reaction by which biotite passes into epidote is uncertain. If the ferrous iron of the biotite be changed to sesquioxide during the alteration, and if the proportion of magnesium to iron be supposed to be $3: 1$ in the biotite, and of aluminum to iron 4:1 in the epidote, the reaction may be written:

(4) $6 \mathrm{H}_{2} \mathrm{~K}_{2} \mathrm{MIg}_{3} \mathrm{FeAl}_{4} \mathrm{Si}_{6} \mathrm{O}_{24}+20 \mathrm{CaCO}_{3}+4 \mathrm{CO}_{2}+3 \mathrm{O}=$ $2\left(\mathrm{H}_{5} \mathrm{Ca}_{10} \mathrm{Al}_{12} \mathrm{Fe}_{3} \mathrm{Si}_{15} \mathrm{O}_{65}\right)+6 \mathrm{SiO}_{2}+18 \mathrm{MgCO}{ }_{3}+6 \mathrm{~K}_{22} \mathrm{CO}_{3}+\mathrm{H}_{2} \mathrm{O}+\mathrm{k}$.

The ratios assumed of the magnesium and iron for the biotite, and of aluminum and iron for the epidote, are near means. If it be assumed that the iron of the biotite is not changed to sesquioxide, but that the sesquioxide of iron for the epidote must be derived from another source, the reaction takes a very different form. Under such an assumption the epidote may be produced from normal biotite, and the equation stand as follows:

(5) $30 \mathrm{KHNg}_{2} \mathrm{Al}_{2} \mathrm{Si}_{3} \mathrm{O}_{12}+6 \mathrm{Fe}_{2} \mathrm{O}_{3}+40 \mathrm{CaCO}_{3}+35 \mathrm{CO}_{2}+\mathrm{H}_{2} \mathrm{O}=$ $4\left(\mathrm{H}_{5} \mathrm{Ca}_{10} \mathrm{Al}_{12} \mathrm{Fe}_{3} \mathrm{Si}_{15} \mathrm{O}_{65}\right)+30 \mathrm{SiO}_{2}+\mathrm{I} 2 \mathrm{AlO}(\mathrm{OH})+60 \mathrm{HgCO} \mathrm{Ig}_{3}+15 \mathrm{~K}_{2} \mathrm{CO}_{3}+\mathrm{k}$. 
By adding thirteen molecules of water instead of one, twelve molecules of gibbsite instead of twelve molecules of diaspore (orthorhombic; sp. gr. 3.40) will be produced.

In equation (4), supposing the calciun carbonate to be added in solution and the magnesinm carbonate and the potassium carbonate to be removed in solution and the silica to remain as a solid, the decrease in volume is $\mathbf{1 4 . 8 6}$ per cent.

In equation (5), supposing the biotite and iron oxide to be solids, the calcium carbonate to be added in solution, the magnesium and potassium carbonates to remain in solution, but the epidote, silica, and diaspore to remain as solids, the decrease in volume is 18.45 per cent. If gibbsite instead of diaspore be produced the decrease in volume will not be so much.

If it be supposed that the aluminum passes into spinel (isometric; sp. g1: 3.8) instead of diaspore or gibbsite, and spinel is known to form in connection with biotite, the number of molecules of magnesinm carbonate would be reduced by six in equation (4); that is, to $54.6 \mathrm{Mg} \mathrm{Al}_{2} \mathrm{O}_{4}$ would replace the $12 \mathrm{AlO}(\mathrm{OH})$. No water would need to be added, and five molecules of water would be produced. Finally, only twenty-nine molecules of $\mathrm{CO}_{2}$ would need to be added. Therefore the equation would be:

$$
\begin{aligned}
& \text { (6) } 30 \mathrm{KHVg}_{2} \mathrm{Al}_{2} \mathrm{Si}_{3} \mathrm{O}_{12}+6 \mathrm{Fe}_{2} \mathrm{O}_{3}+40 \mathrm{CaCO}_{3}+29 \mathrm{CO}_{2}= \\
& 4 \mathrm{H}_{5} \mathrm{Ca}_{10} \mathrm{Al}_{12} \mathrm{Fe}_{3} \mathrm{Si}_{15} \mathrm{O}_{65}+30 \mathrm{SiO}_{2}+6 \mathrm{MgAl}_{2} \mathrm{O}_{4}+54 \mathrm{MgCO}_{3}+15 \mathrm{~K}_{2} \mathrm{CO}_{3}+5 \mathrm{H}_{2} \mathrm{O}+\mathrm{k} \text {. }
\end{aligned}
$$

In this case the volume of the resultant epidote, spinel, and silica, would be 14.71 per cent less than that of the biotite and 18.15 per cent less than that of the biotite and hematite.

It is a well-known fact that chlorite secondary to biotite is usually accompanied by epidote and quartz. Comparing the equation (3) for the formation of chlorite with equation (4) for epidote, we see why these two minerals with quartz are frequently formed at the same time. For the formation of chlorite from biotite additional magnesium is needed. For the formation of epidote additional calcium is necessary and magnesium is left over. If instead of magnesium and calcium carbonates being added, as suggested in equations (3) and (4), only calcium carbonate were available, the excess of magnesinm produced by the passage into epidote may go into the chlorite, and thus epidote and chlorite be simultuneously produced. 
Combining these equations, (3) and (4), and supposing the iron oxide to be furnished by hematite, the reaction may be written as follows:

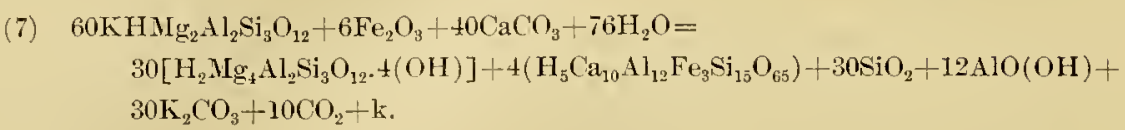

The increase in rolume of the epidote, chlorite, quartz, and diaspore together, as compared with the biotite and hematite, would be 1.81 per' cent.

If biotite alters to hypersthene and sillimanite it may be presumed, in order to furnish the necessary iron for the hypersthene, that the biotite is an iron-bearing one. If the magnesium be to the iron as $3: 1$, and the hypersthene be one in which the same ratio prevails, the reaction may be written as follows:

(8) $\mathrm{H}_{2} \mathrm{~K}_{2} \mathrm{MIg}_{3} \mathrm{FeAl}_{4} \mathrm{Si}_{6} \mathrm{O}_{24}+\mathrm{CO}_{2}=\mathrm{Mg}_{3} \mathrm{FeSi}_{4} \mathrm{O}_{12}+2 \mathrm{Al}_{2} \mathrm{SiO}_{5}+\mathrm{H}_{2} \mathrm{O}+\mathrm{K}_{2} \mathrm{CO}_{3}+\mathrm{k}$.

The decrease in rolume of the hypersthene and sillimanite, as compared with the biotite, is 24.68 per cent.

In the majority of the above reactions a formula for biotite is used which contains no iron. The majority of biotites in nature do contain some iron. If this material be present, simultaneously with the formation of other minerals magnetite (isometric; sp. gr. 5.174), hematite (rhombohedral; sp. gr. 5.225), and the other oxides of iron may be produced. The abstraction of the iron oxides is accompanied commonly by a change in color of the altering biotite from brown to green. The presence of these compounds, howerer, in subordinate quantities will not alter the main conchusions as to the rolume relations above given.

The alterations of biotite, serpentine, kaolin, and gibbsite, into hydrobiotite and chlorite, equations (1) to (3), are all reactions which are known to accur in the zone of katamorphism, corresponding with which position they are all reactions of hydration, and the first two also of carbonation. Where chlorite and epidote form together, the reaction is that of hydration, and doubtless this change also takes place in the zone of katamorphism. The formation of hypersthene and sillimanite from biotite usmally occurs in comnection with contact reactions of igneous rocks; it is, therefore, a reaction requiring high temperature. Also the minerals 
sillimanite and hypersthene do not form at the surface, but at deptl. Corresponding with these physical-chemical facts, the reaction is one of dehydration and reduction of volume.

PHLOGOPITE.

Phlogopite is potassium-hydrogen-magnesium-ahuminum silicate.

occurrence.-Phlogopite has an ocenrrence which is somewhat different from that of biotite. It is especially characteristic of metamorphosed impure carbonates, such as dolomitic marbles. In these rocks it is often associated with pyroxene, amphibole, etc.

Alterations._The most frequent alterations of phlogopite are to hydrophlogopite (monoclinic; sp. gr. 2.303, kerrite) and chlorite (monoclinic; variety of penninite; sp. gr. 2.649). It is also said to alter to tale (orthorhombic or monoclinic; sp. gr. 2.7-2.8). In these last two alterations gibbsite (monoclinic; sp. gr. 2.3-2.4) or diaspore (orthorhombic; sp. gr. 3.40) must simultaneously separate.

The reactions for these changes are as follows:

For lyychophlogopite:

(1) $2 \mathrm{H}_{2} \mathrm{KMg}_{3} \mathrm{AlSi}_{3} \mathrm{O}_{12}+7 \mathrm{H}_{2} \mathrm{O}+\mathrm{CO}_{2}=2\left(\mathrm{H}_{3} \mathrm{Mg}_{3} \mathrm{AlSi} \mathrm{O}_{3} \mathrm{O}_{12} \cdot 3 \mathrm{H}_{2} \mathrm{O}\right)+\mathrm{K}_{2} \mathrm{CO} \mathrm{O}_{3}+\mathrm{k}$.

For chlorite:

(2) $\left.2 \mathrm{H}_{2} \mathrm{~K} \mathrm{Ig}_{3} \mathrm{~A}\right] \mathrm{Ai}_{3} \mathrm{O}_{12}+6 \mathrm{MgCO} \mathrm{IgO}_{3}+7 \mathrm{H}_{2} \mathrm{O}=2\left[\mathrm{H}_{3} \mathrm{Mg}_{6} \mathrm{AlSi}_{3} \mathrm{O}_{12} \cdot 6(\mathrm{OH})\right]+\mathrm{K}_{2} \mathrm{CO}_{3}+5 \mathrm{CO}_{2}+\mathrm{k}$.

For talc and gibbsite:

(3) $4 \mathrm{H}_{2} \mathrm{KMg}_{3} \mathrm{AlSi}_{3} \mathrm{O}_{12}+6 \mathrm{H}_{2} \mathrm{O}+4 \mathrm{CO}_{2}=3 \mathrm{H}_{2} \mathrm{Mg}_{3} \mathrm{Si}_{4} \mathrm{O}_{12}+4 \mathrm{Al}(\mathrm{OH})_{3}+3 \mathrm{IgCO}_{3}+\mathrm{K}_{2} \mathrm{CO}_{3}+\mathrm{H}_{2} \mathrm{O}+\mathrm{k}$.

(4) $2 \mathrm{H}_{2} \mathrm{KMg}_{3} \mathrm{AlSi} \mathrm{O}_{12}+\mathrm{CO}_{2}+4 \mathrm{H}_{2} \mathrm{O}=\mathrm{H}_{2} \mathrm{Mg}_{3} \mathrm{Si}_{1} \mathrm{O}_{12}+\mathrm{H}_{4} \mathrm{Mg}_{3} \mathrm{Si}_{2} \mathrm{O}_{9}+2 \mathrm{Al}(\mathrm{OH})_{3}+\mathrm{K}_{2} \mathrm{CO}_{3}+\mathrm{k}$.

In equations (3) and (4) if diaspore insteal of gibbsite were produced less water would be needed.

Disregarding the carbonates, the increase in rolume for hydrophlogopite, equation (1), is $26.89 \mathrm{per}^{\circ}$ cent; for chlorite, equation (2), is 41.02 per cent. The decrease for talc and gibbsite, equation (3), is 7.79 per cent, and for talc and diaspore 18.27 per cent. The increase in rolume of the serpentine, talc, aud gibbsite, equation (4), is 5.23 per cent.

All of these reactions are those of hydration and solution. They are characteristic of the zone of katamorphism. 
According to Clarke, pemminite, one of the chlorites, is composed of one molecule of biotite-chlorite and one molecule of phlogopite-chlorite; and clinochlore is composed of two molecules of biotite-chlorite and one molecule of phlogopite-chlorite. It is therefore easy to combine the equation given under biotite for the production of chlorite with the one under phlogopite producing chlorite, and thus produce peminite (psendorhombohedral and monoclinic; sp. gr. 2.6-2.85) and clinochlore (monoclinic; sp. gr. 2-2.5). However, as the alterations for the production of chlorite from biotite and of chlorite from phlogopite, reactions of liydration, carbonation, and liberation of heat occur in the zone of katamorphism, it may be said that where pemninite and clinochlore are produced from biotite and phlogopite the physical-chemical reactions are of the same class as those which have been given for hydrobiotite and hydrophlogopite.

CLINTONITE GROUP.

MARGARITE, ('HLORTOID, AND OTTHEITTE.

The clintonite group includes the following rock-naking minerals:

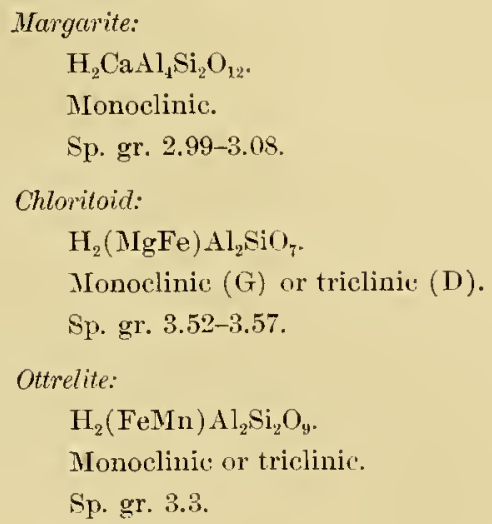

occurrence.-The most common development of margarite is in connection with cortundum. In a number of cases it is recorded that the alumina of the margarite is directly fumished by the cornndum. Margarite is also found as a metamorphic mineral in schists and gneisses, associated with the heary minerals staurolite, tourmaline, etc. As a metamorphic mineral, margarite is also recorded as being derived from diaspore and gibbsite. 
Chloritoid and ottrelite both occur in the slates, schists, and gneisses which are derived from the argillaceous sediments as a product of or comnected with deep-seated, and especially deep-seated regional metamorphism, and often contact action. They are thus heavy minerals which develop from the simpler constituents in the argillaceous sediments in the zone of anamorphism, their formation resulting in condensation.

Alterations.-The only alteration of the clintonite group recorded is that of margarite to dudleyite. However, as no definite formula for this mineral is given, it is not practicable to write an equation representing the transformation.

While no other alterations of the clintonite group are mentioned, there is no doubt that in the upper zone of metamorphism, especially in the belt of weathering, the chloritoids, ottrelite, and margarite are decomposed into simpler compounds, as are the other silicates.

CHLORITE GROUP.

AMESITE, CORUNDOPHILTE, PROCHLORITE, CLINOCHLORE, AND PEXNINITE.

The minerals of the chlorite group, according to Tschermak, may be regarded as isomorphous mixtures of amesite $\left(\mathrm{H}_{4} \mathrm{MIg}_{2} \mathrm{Al}_{2} \mathrm{SiO}_{9}\right)$ and serpentine $\left(\mathrm{H}_{4} \mathrm{Mg}_{3} \mathrm{Si}_{2} \mathrm{O}_{9}\right)$ molecules, although Clarke dissents from this conclusion. Tschermak gives the range of the various orthochlorites as follows:

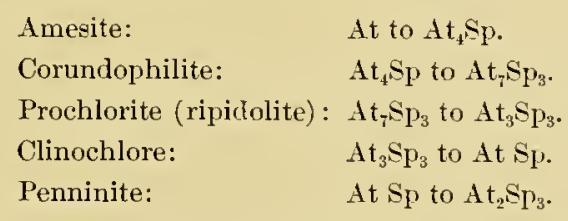

These would correspond to the following compositions:

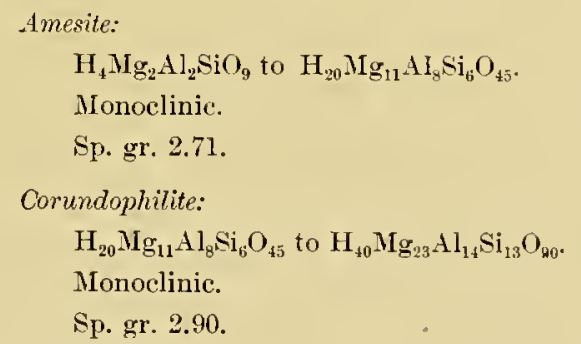




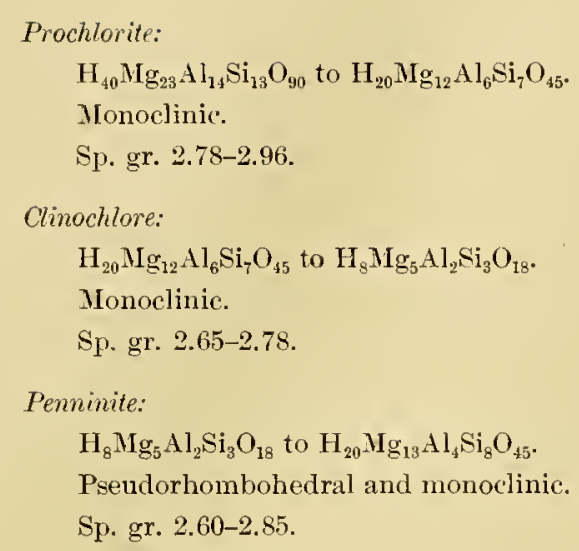

A considerable part of the magnesimm, as shown by the analyses, may be replaced by iron, the analyses of corundophilite showing as high as 15 per cent of monoxide of iron; of prochlorite, from 15 to 25 per cent, rumning even higher than the magnesia. The percentage of monoxide of iron in clinochlore and penninite is usually much less. The alumina may be replaced in part by sesquioxide of iron, although the proportion of this replacement is not nearly so great as that of the magnesia by the iron monoxide, the iron sesquioxide generally not ruming beyond 2 or 3 per cent.

It is apparent that the specific gravities of the chlorites do not regularly grade from lower to higher, as in the feldspars. Donbtless such a regnlar gradation would occur provided the chlorites were pure magnesinm minerals, corresponding to the formulæ above given. The high specific gravities which the intermediate minerals in the gronp, cormondophilite and prochlorite, may have are doubtless explained by their frequent high content of iron monoxide.

occurrence.-Chlorite is the most abundant and widespread of all the secondary silicates. As a secondary mineral it is probably subordinate only to quartz. Chlorite is nowhere known as a pyrogenic constituent of igneous rock. It is very abundant in many of the altered igneons rocks, both plutonic and volcanic, including lavas and tuffs, being especially abundant in the so-called green-schists. Also it is very abundant in many amphibolites. In the altered igneons rocks which are changed under massstatic conditions it is one of the most abundant secondary constituents, being especially prevalent in the basic rocks, such as the greenstones. It is also found in the acid rocks. Chlorite occurs as a plentiful allogenic constituent in all kinds of mechamical sedimentary rocks. It develops as a 
very abundant secondary constituent in the metamorphosed sedimentary rocks, such as slates, schists, and gneisses. Frequently chlorite may accur more abundantly adjacent to intrusive rocks than elsewhere. The most characteristic associated secondary minerals are epidote, serpentine, tale, zeolites, kaolin, magnesite, iron oxides, aluminum oxides, ete.

In the discussion of the individual minerals it has been shown that chlorite is one of the abundant derivation products of the following minerals: Almandite, augite, garnet, hornblende, iolite, prehnite, pyrope, stamrolite, tourmaline, and resuvianite. Being essentially a magnesium-aluminum silicate, it is especially likely to be derived from the heavily magnesian minerals, of which the olivine, pyroxene, amphibole, mica, and gamet groups are the more important. As already seen, corundophilite and prochlorite may contain a large percentage of iron monoxide, and therefore one would naturally expect these chlorites to form from the minerals which also contain a large percentage of iron monoxide, as, for instance, olivine, actinolite, etc. In many cases the mineral from which the chlorite is derived does not contain a sufficient amount of magnesium. In such cases this substance is derived from adjacent minerals, or is brought in in solution. It lias been supposed in such cases that the magnesium is transported as a carbonate. However, the principles of its development would be in no way changed if any other salt of magnesium, such as magnesium chloride, were substituted for the carbonate.

In the discussion of the individual minerals it is shown that chlorite develops especially in the upper physical-chemical zone, and particularly in the belt of cementation. Under conditions of quiescence it derelops at very considerable depth; but in proportion as interior movement occurs it is likely to develop in smaller quantity or not at all, its place as a metamorphic mineral being taken by the magnesian mica biotite.

Alterations. - The alterations of chlorite, like those of other minerals, are largely dependent upon the zones or belts in which the mineral is located. The only definite alteration products of chlorite which are recorded are those which Tschermak has called enophite and berlanite. The first is said by him to be a serpentinous variety of chlorite. No formula for either has been determined, and therefore it is not possible to write equations representing the transformation. Rosenbusch says that the last stage of the alteration of chlorite is into an aggregate of limonite, carbonate, and quartz. This degeneration is especially characteristic of the belt of weathering. As 
usual, no attempt is made to write equations for these degenerative changes; but if one knew definitely the composition of the original mineral and that of the minerals which were produced in a given case, it would be easy to write equations for the change and to calculate the volume relations.

While the alterations of chlorite in the zone of anamorphism are not recorded, it is certain that the chlorite of chloritic rocks under the conditions of the lower physical-chemical zone pass into other constituents, since chlorite is almost always rare or absent in both the sedimentary and the igneous rocks which have recrystallized in the lower zone and have not been later affected by changes in the upper zone.

Therefore in the lower zone chlorite and some of the material of the associated minerals recombine and reproduce minerals from which chlorite was originally derived, or other minerals. There is little doubt that chlorite furnishes a considerable part of the elements for such minerals as the micas, feldspars, amphiboles, pyroxenes, and even the olivines, which develop in the zone of anamorphism, and also it is probable that the chlorite furuishes a part of the constituents for certain of the heavy metamorphic minerals, such as garnet, clintonite, staurolite, tourmaline, etc.

SERPENTINE-TALC GROUP.

SERPENTIYE AND TALC.

The serpentine-tale group includes:

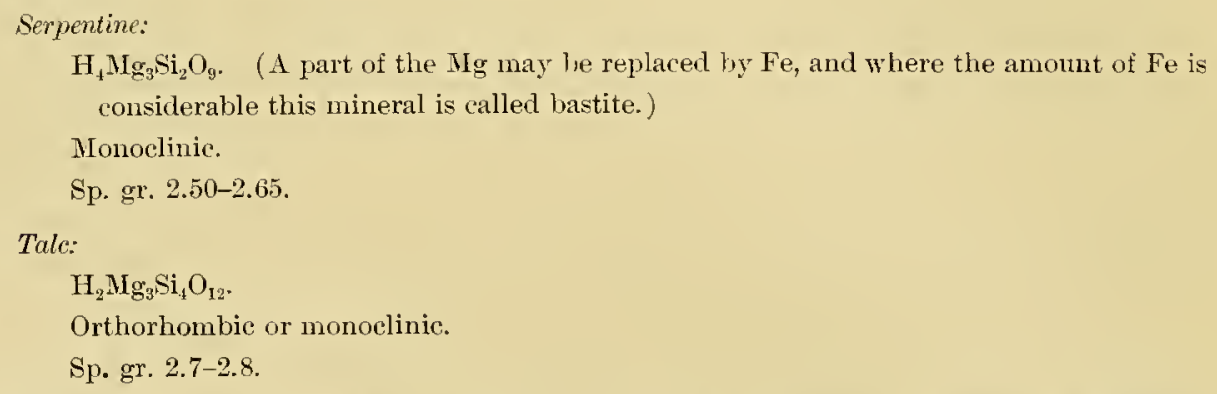

Serpentine and talc, like chlorite, are both hydrous magnesium silicates. Indeed, as has been pointed out, Tschermak regards the serpentine molecule with the amesite molecule $\left(\mathrm{H}_{4} \mathrm{Mg}_{2} \mathrm{Al}_{9} \mathrm{SiO}_{9}\right)$ in variable proportions to constitute the chlorites. Serpentine is more lydrous and more basic than talc. Since the serpentine molecule is similar to some of the chlorites, one would expect that the occurrence of the two would be very similar, and such is the fact. 
SERPENTINE.

Occurrence.-Serpentine occur's in substantially all the varieties of rocks in which chlorite is found, but it is most abundant as a secondary constituent in the igneous rocks which are very heavily magnesian, especially the pyroxenites, peridotites, and similar rocks. Locally it may be so abundant as a secondary constituent in rocks of this class, especially those bearing olivine, as to form serpentine rocks. Serpentine develops very abundantly in the sedimentary rocks which are rich in magnesian constituents, both in detrital material from basic igneous rocks, and in limestones, and in various transition varieties. Serpentine is a product of the zone of katamorphism, including both the belt of cementation and the belt of weathering.

As shown under the discussion of the rarious minerals, it is secondary to actinolite, biotite, bronzite, chondrodite, clinolıumite, diopside, enstatite, hornblende, humite, hypersthene, muscovite, olivine, pyrope, sahlite, and spinel. Of these the most important is olivine, and of second importance are the pyroxenes and amphiboles. In many cases the constituents out of which serpentine is formed are derived not from a single mineral, but from various minerals, in which case the serpentine may replace nommagnesian minerals, as feldspar, or may form in veins.

Alterations.-Serpentine, where long exposed to the conditions of the belt of weathering, is likely to break up into various minerals, of which brucite (rhombohedral; sp. gr. 2.39), magnesite (rhombohedral; sp. gr. 3.06), opal (amorphous; sp. gr. 2.15), and quartz (rhombohedral; sp. gr. 2.6535) are the more important. By hydration and loss of magnesia it passes into webskyite (amorphous; sp. gr? 1.771).

The reaction by which serpentine passes into magnesite, brucite, and quartz may be written thus:

(1) $\mathrm{H}_{4} \mathrm{Mgg}_{3} \mathrm{Si}_{2} \mathrm{O}_{9}+\mathrm{CO}_{2}=\mathrm{MgCO}+2 \mathrm{Mg}(\mathrm{OH})_{2}+2 \mathrm{SiO}_{2}+\mathrm{k}$.

The increase $m$ volume is 13.02 per cent. In case opal or hydromagnesite were formed the increase in rolume would be somervat greater, and the reaction would involve hydration as well as carbonation. It is of course possible that both brucite and magnesite may not always be formed simultaneously. If brucite and not magnesite be formed the equation is--

(2) $\mathrm{H}_{4} \mathrm{NIg}_{3} \mathrm{Si}_{2} \mathrm{O}_{9}+\mathrm{H}_{2} \mathrm{O}=3 \mathrm{MIg}(\mathrm{OH})_{2}+2 \mathrm{SiO}_{4}+\mathrm{k}$. 
The volume of the brucite and quartz is 9.82 per cent greater than the serpentine. If magnesite and not brucite be formed the equation is-

(3) $\mathrm{H}_{4} \mathrm{Mg}_{3} \mathrm{Si}_{2} \mathrm{O}_{9}+3 \mathrm{CO}_{2}=3 \mathrm{MgCO}_{3}+2 \mathrm{SiO}_{2}+2 \mathrm{H}_{2} \mathrm{O}+\mathrm{k}$.

The rolume of the magnesite and quartz is 18.84 per cent greater than that of the serpentine.

Brauns ${ }^{a}$ gives the formula for the derelopment of webskyite as follows:

(t) $3\left(\mathrm{H}_{4} \mathrm{R}_{3} \mathrm{Si}_{2} \mathrm{O}_{9}\right)-\mathrm{BO}+12 \mathrm{aq} .=2\left(\mathrm{H}_{6} \mathrm{I}_{4} \mathrm{Si}_{3} \mathrm{O}_{13}+6\right.$ aq. $)$

Where serpentine contains iron as a base, partly replacing the magnesium, the iron is oxidized and may be lyydrated, thus producing hematite or limonite.

The breaking up of serpentine occurs especially in the belt of weathering, the transformation representing one of the final changes in the degeneration of the silicates. Alterations of serpentine in the zone of anamorphism are not recorded. But the general absence of serpentine in the schists and gneisses of sedimentary origin profoundly metamorphosed in the zone of anamorphism is conclusire eridence that the serpentine which once was in these rocks, and the associated secondary minerals, have recombined to produce heary minerals of the classes from which serpentine and those other secondary minerals were originally produced. One could readily form equations for such alterations by reading the equations by which serpentine is formed from right to left. (See Table C, pp. 375-394.)

TALC.

occurrence.-Tale is practically coextensive in its occurrence with chlorite and serpentine, but in its distribution is more nearly allied to serpentine than to chlorite. Therefore it is found in almost every rariety of rock long subjected to alterations in the belt of weathering; but it is especially abundant in the heavily magnesian rocks. Steatite, which is nearly pure talc, is usually derived from the pyroxenites or peridotites. Howerer, talc is so abundant in many schists as to give them the name talcose, or even talcschists. Also, like serpentine, it occurs abundantly in the dolonite-bearing rocks and in dolomite.

a Brauns, R., Studien über den Palaeopikrit von Amelose bei Biedenkopf und dessen Umwandlungsprodukte: Neues Jahrbuch, supp.-vol. 5, Stuttgart, 1887, 1. 322. 
Tale forms in the upper zone of metamorphism. In this respect it is like chlorite and serpentine. It is especially likely to form under conditions of weathering. The minerals from which tale is derived are as follows: Actinolite, andalusite, anthophyllite, bronzite, cyanite, diopside, enstatite, gehlenite, hypersthene, muscovite, olivine, phlogopite, pyrope, sahlite, scapolites, sillimanite, spinel, staurolite, topaz, and tremolite. The mamer of formation is giren under the various minerals. Of these minerals the more important are the nonaluminous amphiboles and pyroxenes, both orthorhombic and monoclinic. It also forms rather abundantly from olivine, mica, and garmet.

Alterations.-Alterations of talc are not recorded. It appears to be one of the end products of rock alteration in the belt of weathering. However, I have no doubt that when the talc-bearing rocks are buried so deeply as to pass into the zone of anamorplism and there alteration takes place, talc, like chlorite, serpentine, and other minerals, is destroyed, and that from it alone, or from it and other minerals, the classes of heary minerals from which the tale was originally produced are again formed.

GLAUCONITE.

Glauconite:

Essentially a hydrous silicate of iron and potassium. Definite formula unknown. The potassium ranges from 1.85 to 6.56 per cent.

Amorphons.

Sp. gr. 2.2-2.4.

occurrence.-Glanconite occurs in sediments of many- kinds and ages. Where it is so abundant as to give the rock a green color it is known as greensand. Greensands are especially prevalent in the Cretaceous.

Alterations. - Since no definite formula for glauconite can be given it is impracticable to write equations representing the transformations. But since glanconite is almost, if not quite, unknown in the schists and gneisses formed in the zone of anamorphism it seems certain that under the conditions of that zone the glanconite is broken up, its constitnents passing into other minerals. 
KAOLIN GKOUP.

Kaolinite is the only important rock-making mineral of this group. Kaolinite:

$\mathrm{H}_{4} \mathrm{Al}_{2} \mathrm{Si}_{2} \mathrm{O}_{9}$.

Monoclinic.

Sp. gr. 2.6-2.63.

occurrence-Kaolinite is a secondary product in all classes of igneous rocks and occurs as an important constituent in all sedimentary rocks except the pure sandstones and the pure limestones. Kaolinite and quartz are the chief constituents of the clays, and kaolinite is a very abundant constituent of muds and grits.

Kaolinite is a product which forms extensively in the zone of katamorphism in the belt of cementation and in the belt of weathering. It is likely to be prodnced as a result of the decomposition of any of the aluminous minerals. It has been noted as having been produced from the following minerals: Andalusite, anorthoclase, biotite, cyanite, epidote, leucite, microcline, nephelite, orthoclase, plagioclases, scapolites, sillimanite, sodalite, topaz, and zoisite. Of these, undoubtedly the most important are the feldspars, and especially the acid feldspars.

Alterations.- No alterations of kaolinite are recorded. It is certain, however, that where the kaolin-bearing sediments are deeply buried the nineral becomes dehydrated, that such bases as the alkalies and alkaline earths and iron replace the hydrogen, and that various anliydrous silicates or silicates low in hydrogen are producer. It is certain that in the zone of anamorphism the minerals which in the upper physical-chemical zone have broken up into kaolinite as one of the products may recombine to a large extent and reproduce the original minerals.

SUMMARY OF ALTERATION OF SILICATES.

While the important groups of the rock-forming silicates have been treated separately, it may be well in closing the section to class together the groups of the original minerals which have a somewhat similar chemical composition and therefore alter into somervat similar products.

These classes are called by the petrographers (1) the feldspathoid class, (2) the transition class, and (3) the ferromagnesian class. The feldspathoid class includes the feldspar, nephelite, sodalite, leucite, and wernerite groups. The only rock-forming minerals belonging to the 
transition class are those of the muscovite group. The ferromagnesian class includes the pyroxene, amphibole, chrysolite, biotite-phlogopite, and clintonite groups.

(1) In the upper physical-chemical zone, that of katamorphism, the more common alteration products of the feldspathoid class are the kaolins, the zeolites, the epidotes (including both zoisite and epidote proper), diaspore, gibbsite, and quartz. Probably all of these minerals form in both belts of the zone, but the development of the zeolites and the epidotes is more characteristic of the belt of cementation than of the belt of weathering. Indeed, as pointed out under these minerals, under long-continued conditions of the belt of weathering these minerals break up into earbonates of the alkalies and alkaline earths, hydrous and anhydrous, oxides of aluminum and iron, quartz, and, probably, also kaolin. In the zone of anarorphism the more common alteration products of the feldspathoid class are muscovite (damourite) and scapolite. The nephelite, sodalite, and leucite groups alter into the feldspar's.

(2) In the zone of katamorphism muscovite alters into serpentine, tale, and vermiculite (hydromuscovite). In the belt of weathering the serpentine and vermiculite may break up into simpler compounds of the same character as those which form from the zeolites and epidotes.

In the lower physical-chemical zone, that of anamorphism, muscovite is one of the minerals commonly produced, and therefore does not usually alter. But by profornd and deep-seated metamorphism, the material of muscovite may pass into the heavy ferromagnesian minerals, such as garnet, staurolite, etc.

(3) The ferromagnesian silicates may be divided into two great divisions-those which are nonahminous, and those which are aluminous. In the zone of katamorphism the most common alteration products of the nonaluminous ferromagnesian silicates are talc and serpentine. The nonaluminous pyroxenes and amphiboles ordinarily pass into talc; the chrysolites ordinarily pass into serpentine. 'The transformations in these directions are explained by the fact that the pyroxenes, amphiboles, and talc are metasilicates, while the olivines and serpentines are orthosilicates. The metasilicates naturally pass into metasilicates, and the orthosilicates into orthosilicates. In the zone of katamorphism the heavily aluminous ferromagnesian silicates alter into chlorites and epidotes. The pyroxenes and amphiboles which are not heavily aluminous frequently split up into a couHON XLVII-04-23 
bination of chlorite and tale, the aluminous part of the original molecule going to the chlorite and the nonaluminous part into the talc. The development of epidote is largely if not wholly confined to the belt of cementation. But chlorite apparently forms both in the belt of cementation and in the belt of weathering, especially where there is abundant vegetation. Under extreme and long-continned conditions of the belt of weathering the serpentines, chlorites, and epidotes are likely to further degenerate, breaking up into carbonates of the alkalies and alkaline earths, anhydrous or hydrous oxides of aluminum and iron, quartz, and kaolin. Or in the belt of weathering these end products may directly develop from the metasilicates without the serpentines, chlorites, and epidotes as intermediate products. In the zone of anamorphism the pyroxenes change to amphiboles; the pyroxenes and amphiboles both alter to biotite; the olivines change to the amphiboles, anthophyllite, tremolite, and actinolite. The biotite group does not ordinarily alter. But by profound metamorphism the material of the biotites, amphiboles, pyroxenes, etc., may pass into the still heavier class of minerals represented by the garnets, staurolites, etc.

\section{THE TITANATES.}

TITANITE AND PEROVSKITE.

As rock-making constituents only two titanates of importance, titanite and perovskite, are here treated, ilmenite being given under the oxides.

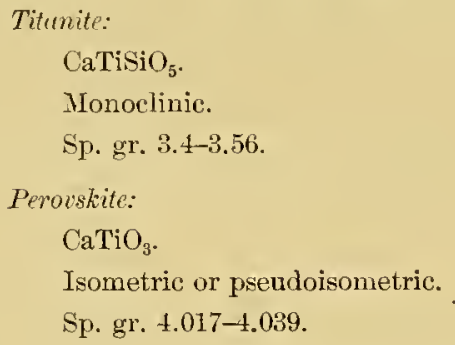

TITANITE.

Occurrence.-Titanite occurs as a rather subordinate but widespread mineral as an original pyrogenic constituent of igneous rocks, and also in the schists and gneisses. So far as observed, titanite as a secondary constituent is derived from ilmenite and rutile. These alterations are discussed under those minerals. 
Alterations._-Titanite alters into rutile (tetragonal; sp. gr. 4.18-4.25), octahedrite (tetragonal; sp. gr. 3.82-3.95), and perovskite (isometric or psendoisometric; sp. gr. 4.017-4.039).

Rutile and octahedrite may be supposed to be produced by the following reaction:

(1) $\mathrm{CaTiSiO}_{5}+\mathrm{CO}_{2}=\mathrm{TiO}_{2}+\mathrm{CaCO}_{3}+\mathrm{SiO}_{2}+\mathrm{k}$.

The expansion of volume is 39.22 per cent for rutile, provided all of the compounds separate as solids, and 42.07 for octahedrite.

Perovskite may be supposed to be produced by the simple breaking up of titanite, according to the reaction:

(2). $\mathrm{CaTiSiO}_{5}=\mathrm{CaTiO}_{3}+\mathrm{SiO}_{2}$

The expansion of volume is 0.14 per cent provided the silica also separates as a solid.

Information as to the natural conditions under which these changes take place is not obtainable from the papers giving the above minerals as secondary to titanite. From the character of the first change one would expect, however, that it would occur in the zone of katamorphism, and especially in the belt of weathering. Under such conditions there would be a reason for the change, for there carbonation of the silicates, with liberation of heat and with expansion of volume, is the rule. As so frequently indicated before, the freed silica may be taken into solution, and if this occur's the volume is decreased. Under what conditions the second reaction is likely to have taken place I can only conjecture from its nature. I should expect it to occur in the zone of katamorphism.

PEROYSKITE.

occurrence.-Perovskite occurs as an original constituent in eruptive rocks, and also in the metamorphic rocks, such as the schists and gneisses. As a secondary mineral it has been observed as a product secondary to titanite. It may be suspected that in the schists and gneisses it forms in the zone of anamorphism by the union of rutile and octahedrite or brookite, with calcium carbonate; but this is a pure conjecture, as the details of its formation are not found in literature.

Alterations.-The mineral does not readily alter into other compounds, although it has been observed to alter into an undeternined substance, and it is said to alter into ihmenite (hexagonal-rhombohedral; sp. gr. 4.75). 
THE PHOSPHATES.

APATITE.

The only important rock-making mineral among the phosphates is apatite.

Apatile:

CaF. $\mathrm{Ca}_{4} \mathrm{P}_{3} \mathrm{O}_{12}$, or $\mathrm{CaCl}$. $\mathrm{Ca}_{4} \mathrm{P}_{3} \mathrm{O}_{12}$, or a mixture of the two.

Hexagonal.

Sp. gr. 3.17-3.23.

Occurrence-Apatite is one of the most widespread, if not the most widespread, of all the subordinate constituents of rocks. It is a common, if not an almost universal, constituent of the plutonic rocks, occurs almost as broadly in the volcanic rocks, and is found in many varieties of unaltered or little altered, sedimentary rocks, such as limestones, shales, sandstones, etc.; and, finally, it is almost everywhere found in the metamorphosed igneous and sedimentary rocks.

Alterations.-The only alteration which is recorded for apatite is to osteolite, which is reported as having the same composition as apatite, except that there has been a loss of part or all of the fluorine or chlorine.

It is certain, however, that in the belt of weathering of the zone of anamorphism apatite is slowly dissolved. This is shown by comparative analyses of the weathered with the unweathered varieties of the same rock. This fact his been frequently noted in reference to the iron ores, because here the presence or absence of phosphorus is of such great importance. It may be stated that in the iron ores it is the general rule that those parts of deposits which have been long subjected to weathering bear a smaller proportion of apatite than the continuations of these same deposits in the belt of cementation.

The depletion of the surface rocks in apatite would seem to furnish an adequate source for the apatite in veins, this mineral being taken into solution near the surface and redeposited deeper down, thus being transported from the belt of weathering to the belt of cementation. 
THE SULPHATES.

ANHYDRTTE AND GYPSUM.

The only important rock-making sulphates are anhydrite and gypsum.

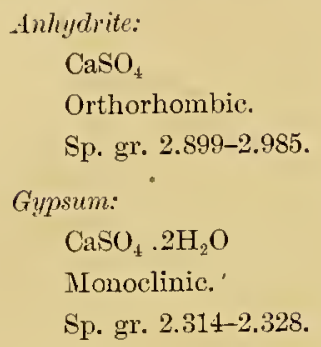

ANHTDRTE.

occurrence.-As explained below, the main sonnce of anlyydrite is by the alteration of gypsum in the zone of anamorphism. Although I do not know the facts, I conjecture that the anhydrite deposits of Switzerland have had such a history.

Alterations. - The chief alteration of anlyydrite is to gypsum (monoclinic; sp. gr. 2.31t-2.328). The reaction is: .

(1) $\mathrm{CaSO}_{4}+2 \mathrm{H}_{2} \mathrm{O}=\mathrm{CaSO}_{4} \cdot 2 \mathrm{H}_{2} \mathrm{O}+\mathrm{k}$

The increase in volume is 60.30 per cent. This alteration is one which takes place in the zone of katamorphism. An interesting case is that of Bex, Switzerland, where the transformation from anhydrite to gypsum has taken place completely to a depth of from 18 to 30 meters, and where below this depth the material is anhydrite. The change of anhydrite to gypsum is with liberation of heat, expansion of volume, hydration, lowering of specific gravity, and lessening of symmetry, and thus stands as a rare example of all the tendencies of the upper physical-chemical zone.

GYPSUM.

occurrence.-The most important source of gypsum is as a chemical precipitate, especially in salt lakes having no outlets. It therefore naturally occurs in association with lalite, calcite, and mechanical detritus. Gypsum also is produced in a subordinate way through fumarole action. The calcium sulphate for the gypsum in either case is produced by the reaction of sulphuric acid or sulphates upon calcium-bearing salts. Com- 
monly the sulphate is formed by the oxidation of a sulphide. A common method is the production of iron sulphate by oxidation of pyrite, marcasite, or pyrthotite, which reacts upon calcium carbonate, thus producing gypsum. The reaction is-

$$
\mathrm{CaCO}_{3}+\mathrm{FeSO}_{4}+2 \mathrm{H}_{2} \mathrm{O}=\mathrm{CaSO}_{4} \cdot 2 \mathrm{H}_{2} \mathrm{O}+\mathrm{FeCO}_{3}+\mathrm{k} .
$$

The derelopment of gypsum by this method is illustrated at many mines. Finally gypsum may be formed by the hydration of "anhydrite. All these methods of formation of gypsum are characteristic of the zone of katamorphism, and especially of the belt of weathering.

Alterations.-An important alteration of gypsum is to anhydrite (orthorhombic, sp. gr. 2.899-2.985). The reaction is-

(1) $\mathrm{CaSO}_{4} \cdot 2 \mathrm{H}_{2} \mathrm{O}=\mathrm{CaSO}_{4}+2 \mathrm{H}_{2} \mathrm{O}-\mathrm{K}$.

The decrease in volume is 37.62 per cent. The other important alteration of gypsum is into calcite (rhombohedral, sp. gr. 2.713-2.714). The reaction is-

(2) $\mathrm{CaSO}_{4} \cdot 2 \mathrm{H}_{2} \mathrm{O}+\mathrm{CO}_{2}=\mathrm{CaCO}_{3}+\mathrm{H}_{2} \mathrm{SO}_{4}+\mathrm{H}_{2} \mathrm{O}+\mathrm{k}$.

The $\mathrm{I}_{2} \mathrm{SO}_{4}$ produced may simultaneonsly react upon some other compound. The decrease in volume is 50.29 per cent.

Unless beds of gypsum have been deeply buried the alteration to anhydrite has not extensively occurred. It is a reaction of diminution of volume, absorption of heat, dehydration, increase in specific gravity, and increase in symmetry, and therefore is one of the very rare cases which illustrate all the tendencies of the lower physical-chemical zone. The change of gypsum to calcite is a reaction with liberation of heat and condensation of volume. The change takes place near the surface, especially in the belt of weathering, where carbon dioxide is abundant, and may also occur in the lower zone. It therefore stands, in its physical-chemical relations, in the same position as dolomitization. (See p. 240.) 
SECTION 4,-GENERAL STATEMENTS.

\section{PHYSICAL-CHEMICAL FACTORS ON WHICH NATURE OF ALTERATIONS DEPENDS.}

As inferences from the foregoing treatment it may be said that the more important physical-chemical factors on which the alteration of an individual mineral depends are (1) the chemical composition of the mineral, (2) the chemical composition of the adjacent minerals, (3) the chemical composition of the circulating solutions, (4) the specific gravity, (5) the symmetry, (6) the heat effect of the reaction, and (7) the pressure and volume.

\section{CHEMICAL COMPOSITION,}

Certain chemical compounds are stable under a great variety of conditions; others are stable only under certain definite conditions; and thus the chemical composition influences the stability of minerals. As an illustration of minerals which have stability under widely varying conditions may be mentioned quartz, which forms alike from a magma and from water solutions, and also at the surface and at great depth. Nephelite and sodalite are examples of minerals which can exist only under a comparatively narrow range of conditions.

CHEMICAL COMPOSITION OF ADJACENT MINERALS.

It has been seen that mineral particles may react upon one another, either through the medium of contained solutions or by direct rearangement under the influence of pressure. Therefore, it is clear that the nature of a mineral which is mainly secondary to another mineral is influenced by the chemical compositions of adjacent minerals.

CHENICAL COMPOSITION OF CIRCULATING SOLUTIONS.

It has already been shown that the secondary minerals are dependent not only upon the adjacent minerals, but upon the material carried by the nnderground solutions. The amount of such material is dependent upon the vigor of the circulation. As explained on pages 507-518, 655-656, 764-766, the material added or abstracted may be great in the zone of karamorphism, but is usually rather limited in amount in the zone of anamorphism. 
SPECIFIC GRAVITY.

Apparently high specific gravity is favorable to stability. This is what one would expect, for high specific gravity involves a comparatively close arrangement of the atoms. Where the atoms are near together the molecular attraction is great, and in order to break up the combination this force must be overcome. This principle is illustrated by dimorphous and trimorphous compounds. Diamond (av. sp. gr. 3.52) is more stable than graphite (av. sp. gr. 2.16), and graphite is more stable than carbon (sp. gr. 1.9, charcoal). Pyrite (av. sp. gr. 5.025) is more stable than marcasite (av. sp. gr. 4.870). Cyanite (av. sp. gr. 3.615) is more stable than sillimanite (av. sp. gr. 3.235), and sillimanite is more stable than andalusite (av. sp. gr. 3.18). Quartz (av. sp. gr. 2.6535) is more stable than tridymite (av. sp. gr. 2.305). This last instance well illustrates the principle; for the symmetry of quartz and tridymite is the same, and this variable factor included in the previous illustrations is excluded. The same is true of andalusite and sillimanite of the aluminum-silicate series. As pointed out on page 112, the more condensed a compound, or, in other words, the higher the specific gravity, the less energy is potentializer. In the chang'e from a lower to a higher specific gravity energy is liberated. In this we have the physical explanation of the greater stability of minerals of high specific gravity. To form minerals of higher specific gravity from those of lower specific gravity releases energy. To reproduce minerals of lower specific gravity from those of higher specific gravity requires the expenditure of energy. An exception to the above rule as to increase of stability with increase of specific gravity is furnished by calcite and aragonite. Calcite (av. sp. gr. 2.7135) is more stable than aragonite (av. sp. gr. 2.94), but in this case the factor of symmetry enters, which is discussed under the next lieading.

SYMMETRY.

Apparently the greater the symmetry the more stable is the mineral likely to be. This principle is illustrated by substances which are dimorphous or trimorphous.

Pyrite (isometric) is more stable than marcasite (orthorhombic). Diamond (isometric) is more stable than graphite (hexagonal), and this is more stable than amorphous carbon. Kelvin suggests ${ }^{\alpha}$ that soft

a Lord Kelvin, Popular lectures and addresses, Macmillan \& Co., London, 1894, vol. 2, p. 428. 
'phosphorus as compared with red phosphorus, and prismatic sulphur as compared with octahedral sulphur, contain potential energy. When the change from the first to the second takes place, energy is evolved, and consequently the second form is more stable. These ehanges are in the direction of higher symmetry, and Kelvin's argunent applies equally well to all the changes in which minerals pass from a lower to a higher legree of symmetry. To reproduce minerals of lower symmetry would require the expenditure of energy. Therefore we have an energy cause why minerals with high symmetry are more stable. They contain less potential energy. Their formation is under the apparent law of the universe of dissipation of energy.

SPECIFIC GRAVITY AND SYMMETRY.

Where specific gravity and symmetry work together, as in a number of the illustrations mentioned, there seem to be no exceptions to the rule of increase of stability with inerease of specific gravity and increase in symmetry.

But in those instances in which the specifie gravity and symmetry are opposed to each other it ean not be predicted which will be the dominant factor. For instance, calcium earbonate erystallizes as ealcite (hexagonalrhombohedral; sp. gr. 2.7135) and aragonite (orthorhonbic; sp. gr. 2.94). The former is the more stable. In this case it seems that symmetry is the dominant factor. In the aluminum silicate which erystallizes as andalusite (orthorhombic; sp. gr. 3.18), sillimanite (orthorhombic; sp. gr. 3.235), and cyanite (triclinic; sp. gr. 3.615), the latter is the most stable. In this case it appears that the specific gravity is the determining factor.

It is believed that when the energy relations of these changes become known it will be found that in each of these cases the more stable molecules contain less potential energy. If this be true, calcite, considering both its specific gravity and its symmetry, contains less energy than aragonite, and cyanite less than andalusite or sillimanite. If this conjecture be true, all compounds are subject to a common law. That mineral forming from a compound is most stable in which the minimum energy is contained.

The relations of symmetry and specific gravity raise some very interesting questions as to the arrangement of the molecules in minerals. Pressure undoubtedly tends to produce the most compact arrangement. 
(See pp. 182-186.) According to Slichter, the most compact possible arrangement of spherical molecules is that which gives a rhombohedral unit having face angles equal to $60^{\circ}$ and $120^{\circ} .^{a}$ One might therefore conchde, other things being equal, that minerals having hexagonal crystaflization would be those which have the closest arrangement of molecules and therefore the highest specific gravity; but plainly there are other factors entering into the problem, for, as already pointed out, aragonite (orthorhombic) has a higher specific gravity than calcite (hexagonal), and cyanite (triclinic) has a higher specific gravity than sillimanite and andahusite (orthorhombic). On the other hand, diamond (isometric) has a higher specific gravity than graphite (hexagonal). This is an especially interesting case, since the cubical arrangement of molecules, the one ordinarily appealed to to explain isometric symmetry, is the most open of all possible arrangements. From the foregoing it appears perfectly clear that besides the manner of the arrangement of the molecular particles the distance of the molecules from one another enters as a very important factor. Also the shape of the molecules, the closeness of the arrangement of their atoms, and the complexity of the molecules themselves doubtless enter as important factors into the density of minerals.

\section{HEAT REACTIONS.}

Other things being equal, within the lithosphere reactions take place which give the greatest liberation of heat. This law is best illustrated at or near the surface, where the reactions nsually occur in accordance with it. The reactions of oxidation, hydration, and carbonation are therefore dominant However, the law of reactions with liberation of heat becomes less and less able to control as the pressure becomes considerable. Where the pressure is great, as noted under the next heading, it determines the reaction withont respect to whether heat is absorbed or liberated, and in many cases the reactions take place with the absorption of heat, so far as the chemical factors are concerned. If all the physical factors also were included, all reactions would take place with the dissipation of energy. (See p. 57.)

a Slichter, C. S., Theoretical investigation of the motion of ground waters: Nineteenth Ann. Rept. U. S. Geol. Survey, pt. 2, 1899, pp. 306-310. 
PRESSURE AND VOLUME.

Pressure lessens the volume and therefore tends to preserve and to produce minerals which have a high specific gravity. Where the pressure is small this factor is relatively inefficient and consequently other factors usually control, and many minerals of low specific gravity form. But even where the pressure is small it is not unimportant, at least retarding reactions which would otherwise occur. This is illustrated by a partially altered rock described by Merrill, ${ }^{a}$ which seemed solid when confined by the surrounding rock, but which when brought to the surface from a depth of a few feet, and thus freed from pressure, rapidly decomposed and disintegrated. Where the pressure is great it is likely to be a determinative force, controlling the reactions. At the depths of the zone of anamorphism the nuiforn production of anhydrous or slightly hydrous minerals of higher average specific gravity than those formed in the zone of katamorphism is clear evidence of the dominance of pressure.

In this commection it will be well to mention the mineral groups, with their specific gravities, which are more characteristic of the zones of katamorphism and anamorphism.

The characteristic products of the zone of katamorphism are: Of the oxides, (1) those of silicon, opal, chalcedony, and quartz (sp. gr 2.1 to 2.654); (2) those of iron, including the hydrous and anlydrous ferricoxides (sp. gr. 3.80 to 5.225); (3) the hydrous aluminum oxides, gibbsite and diaspore (sp. gr. 2.35 and 3.40); of the carbonates, calcite and dolomite (sp. gr. 2.7135 and 2.85); of the silicates, (1) the epidote-zoisite group (sp. gr. 3.25 to 4.20 ); (2) zeolite group (sp. gr. 2.04 to 2.40); (3) chlorite group (sp. gr. 2.60 to 2.96); (4) serpentine-talc group (sp. gr. 2.50 to 2.80); and kaolin group (sp. gr. 2.6 to 2.63). (See pp. 519-520, 621-627.)

The characteristic important mineral groups formed in the zone of anamorphism are as follows: Of the sulphides, pyrite, and pyrrhotite (sp. gr. 5.025 and 4.61); of the oxides, (1) those of silicon, chert, chalcedony, and quartz (sp. gr. 2.6 to 2.654); (2) those of iron, hematite, magnetite, and ilmenite (sp. gr. 5.225, 5.174, and 4.75); (3) those of aluminum, corundum (sp. gr. 4.025); (4) those of titanium, rutile, octaherdrite, and brookite (sp. gr. 4.215, 3.885, and 3.975); of the silicates, (1) the feldspar group (sp. gr.

a Merrill, George P., Rocks, rock weathering, and soils, Macmillan Co., New York, 1897, pp. $252-253$. 
2.54 to 2.76 ); (2) pyroxene group (sp. gr. 2.68 to 3.58 ); (3) amphibole group (sp. gr. 2.9 to 3.713 ); (4) garnet group (sp. gr. 3.41 to 4.30 ); (5) chrysolite group (sp. gr. 3.2 to 4.1); (6) scapolite group (sp. gr. 2.566 to 2.74); (7) aluminmm silicate group (sp. gr. 3.16 to 3.67 ); (8) lunnite group (sp. gr. 3.1 to 3.2); (9) tourmaline (sp. gr. 3.09); (10) staurolite (sp. gr. 3.71); (11) mica group (sp. gr. 2.7 to 3.1); (12) clintonite group (sp. gr. 2.9 to 3.57 ).

The average specific gravity of the mineral groups above mentioned as products of the zone of katamorphism is 2.948 . The average specific gravity of the mineral groups of the zone of anamorphism is 3.488. It thus appears that the average specific gravity of the minerals which develop in the zone of anamorphism is 18 per cent greater than that of the minerals in the zone of katamorphism. This comparison is of course very roughly approximate, since the varions minerals are not present in equal quantities. Probably the percentage is too great, since the heavy sulphides and the very heavy silicates are given equal weight with the abundant but lighter quartz, feldspars, pyroxenes, amphiboles, and micas. The comparison, howerer, shows beyond question that a given mass of material occupies much less space in the lorver physical-chemical zone than in the upper physical-chemical zone.

It is shown under the next heading that many of the reactions written for the minerals of the zone of katamorphism may be read in reverse order when the resultant minerals are buried so deep as to be in the zone of anamorphism. The lighter minerals characteristic of the zone of katamorphism reunite to produce heavier minerals of the zone of anamorphism, such as the feldspars, the micas, the pyroxenes, the amphiboles, the chrysolites, andalusite, etc. Furthermore, where the pressure is great enough these minerals rearrange themselves again in whole or in part so as to produce still heavier minerals, such as garnet, staurolite, tourmaline, sillimanite, cyanite, ete. This great change takes place within the narrow range of less than 10,000 meters.

Since in this mere outer film of the earth a great diminution in the volume of the minerals has taken place, it is thought to be highly probable that, even if the average chemical composition of the interior of the earth be supposed to be the same as the crust, the pressure is such that the minerals may further rearrange themselves into still more compact products, thus probably producing minerals of a different kind and higher specific 
gravity than any with which we are acquainted. Indeed, the interior pressures increase so rapidly with depth that rearlangement might occur again and again. Therefore, even if the average chemical composition be the same deep within the earth as at the surface, in the centrosphere, in consequence of high pressure, there may be a set of silicate minerals which have as high a specific gravity as the average density of the earth, viz, 5.67. If the accepted theory as to the distance between molecules be correct, viz, that molecules of ordinary liquids at the surface of the earth do not occupy more than one-third of the total volume, ${ }^{a}$ there is ample room between them for the condensed rearrangement snggested. From the foregoing it appears that we do not necessarily appeal to a great preponderance of heavy metals deep within the earth to explain its average high specific gravity. It may be very largely explained by the condensation of the material due to pressure. If, as suggested by Chamberlin, the average specific gravity of the material of the earth be that of meteoric falls, the average change in specific gravity would be from 3.69 to 5.67 as a result of pressure. The great increase in the average specific gravity of minerals with increase of pressure in the crust of the earth would seem to make the estimate of the change in arerage specific gravity of the minerals from 3.69 to 5.67 , as a result of the very great pressures deep within the earth, a very modest one.

While I have no doubt that the condensation of the earth material into heavier compounds as a result of pressure is a partial explanation of the high specific gravity of the earth, I by no means urge this as the sole cause. Indeed, it is probable that the segregation of heavy material toward the center and lighter material toward the surface has steadily continued throughont greologieal time, and therefore the difference in composition is a very important factor in the difference in density at the surface and the center: But I do not venture even a guess as to the relative importance of the two factors of condensed compounds and segregation of material in explaining the increase in density of the material of the earth with increase of depth.

"Nernst, W., Theoretical chemistry, trans. by C. S. Palmer, Macmillan \& Co., London, 1895, p. 196. 


\section{REVERSIBLE REACTIONS.}

On the foregoing pages numerous reactions have been written by which the minerals characteristic of the zone of katamorphism are produced; very few reactions have been written by which the minerals of the zone of anamorphism are reproduced. It is certain that when the minerals formed in the belts of weathering and cementation are altered under the conditions of the zone of anamorphism the minerals characteristic of that zone develop; therefore it is believed that many of the reactions for the development of the minerals of the zone of katamorphism are reversible. To illustrate, in the zone of katamorphism olivine may alter into the minerals serpentine, magnetite, magnesite, and quartz, according to the following equation:

$$
3 \mathrm{Mg}_{3} \mathrm{FeSi}_{2} \mathrm{O}_{8}+3 \mathrm{CO}_{2}+4 \mathrm{H}_{2} \mathrm{O}+\mathrm{O}=2 \mathrm{H}_{4} \mathrm{Mgg}_{3} \mathrm{Si}_{2} \mathrm{O}_{9}+\mathrm{Fe}_{3} \mathrm{O}_{4}+3 \mathrm{MIgCO}{ }_{3}+2 \mathrm{SiO}_{2}+\mathrm{k} .
$$

It is believed that when these four minerals are brought together in proper proportions under favorable conditions in the deep-seated zone the reverse reaction occurs, and that the equation may be read from right to left instead of left to right, thus reproducing the olivine.

The above illustration is chosen because the change from left to right involves carbonation, desilication, hydration, and oxidation; and the change from right to left involves silication, decarbonation, dehydration, and deoxidation. Of course, where deoxidation takes place in the zone of anamorphism some reducing agent must be present to utilize the abstracted oxygen. The principle of the reversibility of the reactions in the two opposing zones is actually illustrated in a few cases where the products of the zone of katamorphism have been observed to alter in the zone of anamorphism. For instance, it is recorded (p. 261) that analcite is derived from albite according to the following equation:

$$
2 \mathrm{NaAlSi}_{3} \mathrm{O}_{8}+2 \mathrm{H}_{2} \mathrm{O}=\mathrm{Na}_{2} \mathrm{Al}_{2} \mathrm{Si}_{4} \mathrm{O}_{12} \cdot 2 \mathrm{H}_{2} \mathrm{O}+2 \mathrm{SiO}_{2}+\mathrm{k} ;
$$

whereas we find (p. 334) that analcite alters to albite by the reaction:

$$
\mathrm{Na}_{2} \mathrm{Al}_{2} \mathrm{Si}_{4} \mathrm{O}_{12} \cdot 2 \mathrm{H}_{2} \mathrm{O}+2 \mathrm{SiO}_{2}=2 \mathrm{NaAlSi}_{3} \mathrm{O}_{8}+2 \mathrm{H}_{2} \mathrm{O}-\mathrm{k} \text {. }
$$

In other words, the reaction is exactly reversible; for while the $\mathrm{k}$ is plus in the first equation and minus in the second, it is on opposite sides in the two equations. The feldspars alter into many zeolites, and a number of 
the zeolites alter into the varions feldspars. The above reaction chances to be the only one given for these groups which is exactly reversed. 'This is a consequence of the fact that reactions are written only for recorded alterations. There can be no doubt that practically all the equations representing the recorded alterations of the feldspars (pp. 261-263) into the zeolites, and all the reactions representing the recorded alterations of the zeolites (pp. 333-334) into the feldspars, are reversible. For instance, we have anorthite altering into gismondite as follows (p. 262):

$$
3 \mathrm{CaAl}_{2} \mathrm{Si}_{2} \mathrm{O}_{8}+12 \mathrm{H}_{2} \mathrm{O}=\mathrm{Ca}_{3} \mathrm{Al}_{6} \mathrm{Si}_{6} \mathrm{O}_{24} \cdot 12 \mathrm{H}_{2} \mathrm{O}+\mathrm{k} .
$$

Can one doubt that if gismondite passes into the zone of anamorphism dehydration may take place and anorthite be reproduced?

Another line of evidence pointing to the reversibility of the reactions in the two zones is the frequent recorded association of corundum with diaspore and gibbsite, the latter minerals being secondary to the cormdum. Can it be doubted that these hydrates may be dehydrated in the zone of anamorphism and reproduce corundum? Of course this particular change may not occur alone. At the same time the dehydration takes place the alumina may unite with silica and form andalusite, sillimanite, or cyanite, or the alumina may enter into some other silicate.

Bearing in the same direction are the experiments made by Daubrée upon serpentine. ${ }^{a}$ It is well known that both enstatite and olivine alter into serpentine. Daubrée found that by the fusion of serpentine it split up into enstatite and olivine, according to the following equation:

$$
\mathrm{H}_{4} \mathrm{Mgg}_{2} \mathrm{Si}_{2} \mathrm{O}_{4}+\mathrm{Heat}=\mathrm{MgSiO}_{3}+\mathrm{IIgSiO}_{1}+2 \mathrm{H}_{2} \mathrm{O}+\mathrm{k} .
$$

Finally, my chief reason, in addition to those already given, for belief in the reversibility of the reactions in the two zones lies in the actual compositions of the unmetamorphosed sediments and their metamorphosed equivalents. The ummetamorplosed pelites are composed largely of the lighter hydrous minerals of the belt of weathering and the belt of cementation. It is true that with these, as already explained, there are also considerable, or even dominant, quantities of residual undecomposed anhydrous minerals; but it is certain that the metamorphosed equivalents of these pelites contain none of the minerals which are characteristic of

a Daubrée, A., Expériences synthétiques relatives aux météorites: Comptes rendus des séances de l'académie des sciences, vol. 62 , Paris, 1866, p. 661. 
the belts of weathering and cementation, and the only possible conclusion is that these minerals have recombined and reproduced the heavier minerals of the lower physical-chemical zone. That this is so is shown by the fact that, barring the water and the carbon dioxide which are liberated in the process of alteration, the average chemical compositions of the unaltered pelites and their metamorphosed equivalents are nearly the same.

While it is lield that the reactions are reversible, it is not supposed that this is often exactly the case for a given rock. In order that this shonld even approximately take place, it would be necessary that there be no change of average composition in the zone of katamorphism, and this is never the case. The ininerals formed in the zone of anamorphism depend not only upon the minerals of the zone of katamorphism present, but upon their proportion and many other factors. What is meant by the reversibility of the reactions is that, when compounds produced in the zone of katamorphism from a given mineral are together in proper proportions and conditions in the zone of anamorphism, the original mineral may be reproduced.

If this law of the reversibility of reactions in the two zones be true, the question natually arises why so few of the reversing reactions in the zone of anamorphism have been recorded. The answer lies in the difference in the readiness with which observations may be made in the two zones. The reactions of the belts of weathering and cementation of the zone of katamorphism have been more fully described, because they are constantly taking place at or near the surface under conditions of ready observation. Many of the reverse reactions have not been fully described, because they occur at depth, and because in areas of strong metamorphic action they have been complete. Usually gradatiou from practically complete reactions to very incomplete reactions in the zone of anamorphism is comparatively rapid. But notwithstanding the rery imperfect observations of the zone of anamorphism, the general reversibility of the reactions in the two zones seems as certain as if it were established by observation, and it is believed that it will be established by observation.

If the conclusions of the foregoing paragraphs be correct it is evident that there is an almost entirely neglected field of observation in metamorphism-that by which the minerals of the zone of anamorphism are produced from the minerals of the zone of katamorphism. 
For the reasons given above, I conclude: It is believed that most of the equations which represent the reactions in the zone of katamorphism are reversible in the zone of anamorphism; and so far as there is expansion of volume and liberation of heat in the upper zone, just so far is there condensation of volume and absorption of heat in the lower zone.

\section{SECTION 5. TABLES.}

In order to present compactly the essential facts as to the alterations of each mineral, a set of tables is here given.

Table A gives the mineral sources of each of the minerals.

Table $\mathrm{B}$ gives the minerals to which each mineral alters.

Table $\mathrm{C}$ gives the equations representing the alterations of each of the minerals into other minerals and shows the volume changes.

Table $\mathrm{D}$ classifies the alterations of the minerals under processes and gives their various combinations, with volume changes.

TABLE A.-Sources of minerals.

Acmite is derived from . . . . . . arfvedsonite.

Actinolite is derived from.................... ankerite, bronzite, hypersthene, olivine, parankerite, sahlite.

Albite is derived from ...................... thoclase), sodalite, spodumene, stilbite.

Allophane is derived from ...... ............ anorthoclase, microcline, orthoclase.

Amesite is derived from .................... pyrope.

Analcite is derived from . . . . . . . . . . . . . . laumontite, lencite, nephelite, plagioclases, sodalite.

Anhydrite is derived from .................... . .

Anthophyllite is derived from .............. . bronzite, hypersthene, olivine.

Aphrosiderite is derived from . . . . . . . . . . . . garnet.

Augite is derived from.................. hornblende.

Bastite is derived from . . . . . . ......... actinolite, anthophyllite, bronzite, cummingtonite, hypersthene, sahlite.

Berlanite is derived from .................... chlorite

Beta-spodumene is derived from ...............spodumene.

Biotite is derived from ....................... clase, seapolites.

Biotite-chlorite is derived . . . . . ............ . biotite.

Brucite is derived from ..................... chondrodite, clinohumite, humite, serpentine.

Breunerite is derived from ................... . olivine.

Calcite is derived from....................... diopside, dolomite, epidote, fluorite, garnet, grossularite, gypsum, haüynite, hornblende, noselite, parankerite, sahlite, scapolites, tremolite, zoisite.

Chabazite is derived from haüynite, noselite, plagioclases.

Chalcedony is derived from .................augite, sahlite.

Chlorite is derived from ................ . almandite, angite, biotite, garnet, hornblende, iolite, phlogopite, prehnite, pyrope, staurolite, tourmaline, resuvianite.

MON XLVII-04-_-24 


\section{Table A.-Sources of minerals - Continued.}

Cimolite is derived from..................... anorthoclase, microcline, orthoclase.

Chlorophyllite is derived from ............... iolite.

Chromite is derived from ................... olivine.

Clinochlore is derived from . . . ............. . biotite (with phlogopite).

Corundnm is derived from............... diaspore, gibbsite.

Cyanite is derived from...................... andalusite, corundum, diaspore, gibbsite.

Cymatolite is derived from . . . . . . . . . . . . spodumene.

Damourite is derived from ............. andalusite, corundum, cyanite, microcline, orthoclase, sillimanite, staurolite, topaz.

Diaspore is derived from . . . . . . . . . . . . . . biotite, corundum, garnet (conjectural), gibbsite, haüynite, muscovite, nephelite, noselite, phlogopite, scapolites, sodalite.

Diopside is derived from: dolomite.

Dolomite is derived from ........................

Dulleyite is derived from . . . ...............margarite.

Enophite is derived from ........................

Enstatite is derived from . .

Epidote is derived from ............... cline, orthoclase, plagioclases, scapolites.

Epistilbite is derived from plagioclases.

Eucryptite is derived from . . . . . . . . . . . . . spodumene.

Fassaite is derived from ................... gehlenite.

Garnet is derived from . . . . ............... vesuvianite.

Gibbsite is derived from . . . . . . . . . . . . anorthoclase, andalusite, biotite, cancrinite, corundum, cyanite, epidote, garnet (conjectural), haïynite, microcline, muscovite, nephelite, noselite, orthoclase, phlogopite, plagioclases, pyrope, scapolites, sillimanite, sodalite, topaz, tourmaline, zoisite.

Gismondite is derived from . . ............... plagioclases.

Grossularite is derived from ................. gehlenite.

Grïnerite is derived from . . . . . . . . . . . . . . siderite.

Gypsum is derived from .................... anhydrite.

Halloysite is derived from . . . . . . . . ..........anorthoclase, microcline, orthoclase.

Hematite is derived from ...... . . . . . . . . . garnet, greenalite, grünerite, hornhlende, hypersthene, ilmenite, limonite, magnetite, mareasite, oli-

Hercynite is derived from. vine, parankerite, pyrite, serpentine, siderite.

Heulandite is derived from........... plagioclases.

Hornblende is derived from ................. -augite, garnet.

Hydrobiotite is derived from . . . . . . . . . . . . . . biotite.

Hydromagnesite is derived from . . . . . . . . . brucite.

Hydromuscovite is derived from . . . . . . . . . . nephelite, scapolites, sodalite.

Hydronephelite is derived from ............... nephelite, sodalite.

Hydrophlogopite is derived from .............. phlogopite.

Hydrotalcite is derived from . . . . ............. olivine.

Hypersthene is derived from .................

Ilmenite is derived from . . .................. perovskite, rutile.

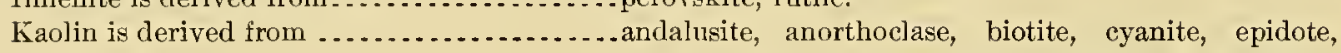
garnet (conjectural), leucite, microcline, nephelite, orthoclase, the plagioclases, the scapolites, silliman-

Lacmontite is derived from. ite, sodalite, topaz, and zoisite. 
Table A.-Sources of minerals-Continued.

Lepidomelane is derived from................ arfvedsonite.

Limonite is derived from ....................... bronzite, chlorites, epirlote, garnet, greenalite, grünerite, hematite, hornblende, hypersthene, ilmenite, magnetite, marcasite, olivine, parankerite, pyrite, pyrrhotite, serpentine, siderite.

Magnesite is derived from . . . . . . . . . . . . . . . garuet, olivine, pyrope, serpentine.

Magnetite is derived from . . .................. ite, diopside, garnet, greenalite, grïnerite, hematite, hornblende, hypersthene, ilmenite, marcasite, olivine, parankerite, pyrite, pyrrhotite, sahlite, siderite.

Malacon (hydrous zircon) is derived from ......zircon.

Marcasite is derived from ... . . .............hematite.

Margarite is derived from . . . . . . . . . . . corundum, diaspore, gibbsite.

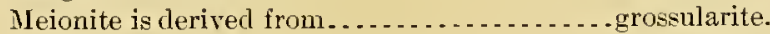

Mesolite is derived from ..................

Mica is derived from . . . . . . . . . . . . . . . . spinel, tourmaline, vesuvianite.

Mlicrocline is derived from ................. sporlumene.

Iuscovite is derived from . . ...............anorthoclase, diaspore, gibbsite, leucite, microcline, nephelite, orthoclase, plagioclase and orthoclase, scapolites, sodalite, spodumene.

See also Damourite.

Natrolite is derived from ................. apatite, chabazite, laäynite, nephelite, noselite, plagioclases, sodalite.

Nephelite is derived from .................. leucite, sodalite (conjectural).

Newtonite is derived from . . . ....................

Octahedrite is derived from ................. ilmenite, titanite.

Opal is derived from ...........................

Orthoclase is derived from .................. . analcite, heulandite, leucite, laumontite, stilbite.

Osteolite is derived from . . . . . . . . . .

Paragonite is derived from . .............. anorthoclase, muscovite, plagioclases.

Pectolite is derived from . . . . . . . . . . . . . apophyllite.

Penninite is derived from ............... . biotite (with phlogopite).

Perovskite is derired from . . . . . . . . . . . . . . titanite.

Phillipsite is derived from . . . . . . . . . . . . . . . plagioclases.

Phlogopite-chlorite is derived from...........phlogopite.

Pinite is derived from ...................... iolite.

Prehnite is derived from ..................analcite, laumontite, mesolite, natrolite, plagioclases, scolecite.

Pyrite is derived from .................... . . . marcasite, pyrrbotite.

Pyrophyllite is derived from................. anorthoclase, microcline, orthoclase.

Quartz is derived from........................... biotite, bronzite, chalcedony, chlorites, cummingtonite, diopside, enstatite, epidote, garnet, grossularite, hornblende, hypersthene, microcline, olivine, opal, orthoclase, plagioclases, prehnite, pyrope, sablite, scapolites, serpentine, tridymite, zoisite.

Rutile is derived from .................... brookite, ilmenite, octahedrite, titanite.

Sahlite is derived from .......................

Scapolites are derived from ................. . plagioclases.

Scolecite is derived from . . . . . . . . . . . . . . plagioclases.

Serpentine is derived from................ actinolite, biotite, bronzite, chondrodite, clinohumite, diopside, enstatite, horublende, humite, byperstbene, muscovite, olivine, pyrope, sahlite, spinel. 
TABLE A.-Sources of minerals-Continued.

Siderite is derived from ................... . arfvedsonite, garnet, hematite, bornblende, limonite, magnetite, olivine.

Sillimanite is derived from . . . . . . . . . . . . andalusite, biotite, corundum, cyanite, diaspore, gibbsite.

Smaragdite is derived from.... . . . . . . . . . . . . diallage.

Sodalite is derived from.....................nephelite.

Spinel is derived from ....................... . . . . olivine, pyrope.

Steatite is derived from ..................... andalusite, cyanite, muscovite, sillimanite, topaz, tourmaline.

Stilbite is derived from . . . . . . . . . . . . . . . . haüynite, noselite, plagioclases.

Talc is derived from . . . . . . . . . . . . . . . actinolite, andalusite, anthophyllite, bronzite, cyanite, diopside, enstatite, gehlenite, hypersthene, muscovite, olivine, phlogopite, pyrope, sahlite, scapolites, sillimanite, spinel, staurolite, topaz, tremolite.

Titanite is deriverl from ....... . . . . . . . . . . ilmenite, rutile.

Thomsonite is derived from . . . . . . . . . . . . nephelite, plagioclases, sodalite.

Tremolite is derised from . . . . . . . . . . . . . . diopside, dolomite, olivine.

Vermiculite is derived from................ muscovite.

Webskyite is derived from ................... serpentine.

Wollastonite is derived from . . . . . . . . . . . . . calcite, dolomite.

Zoisite is derived from.................... corundum, diaspore, gibbsite, grossularite, plagioclases.

\section{TABLE B.-Alteration products of minerals.}

Actinolite alters to ....................... . bastite, calcite, hematite, limonite, magnetite, serpentine, talc, quartz.

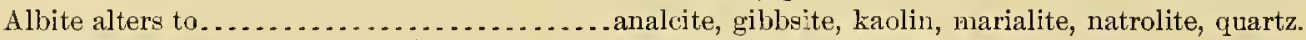

Almandite alters to . . . . . . . . . . . . . . . . . . . chlorite, hypersthene, spinel.

Analcite alters to......................... albite, orthoclase, prehnite.

Andalusite alters to . . . . . . . . . . . . . . . . cyanite, kaolin, gibbsite, muscovite (damourite), sillimanite, talc (steatite).

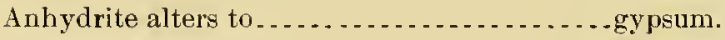

Ankerite alters to ........................ actinolite, calcite, dolomite, hematite, limonite, magnetite, sahlite.

Anorthite alters to ....................... gibbsite, gismondite, kaolin, laumontite, meionite, prehnite, quartz, scolecite, thomsonite, zoisite.

Anorthoclase alters to .................. allophane, biotite, cimolite, damourite, epidote, gibbsite, halloysite, kaolin, muscovite, newtonite, paragonite, pyrophylite, quartz.

Anthophyllite alters to ................. bastite, calcite, hematite, limonite, quartz, talc.

A patite alters to ......................... . osteolite.

A pophyllite alters to ..................... pectolite.

Aragonite alters to ..............................

Arfredsonite alters to .................... acmite, lepidomelane, limonite, magnetite.

A ugite alters to .................................. chite, calcite, chalcedony, chlorite, epidote, hornblende, magnetite, quartz.

Beta-spodumene alters to.................. albite, eucryptite, muscovite.

Biotite alters tỏ . . . . . . . . . . . . . . . . chlorite, diaspore, epidote, gibbsite, hematite, hydrobiotite, hypersthene, kaolin, limonite, magnetite, quartz, serpentine, sillimanite, spinel.

Biotite (with phlogopite) alters to . . . . . . . . penninite, clinochlore.

Bronzite alters to.............. magnetite, quartz, serpentine, talc.

Brookite alters to .................... rutile.

Brucite alters to .................................. 
TABLE B.-Alteration products of minerals-Continued.

Calcite alters to ........................... dolomite, wollastonite.

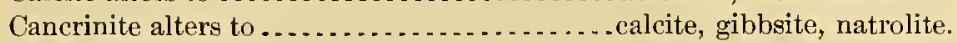

Chabazite alters to...................... natrolite.

Chlorite alters to ............................

Chondrodite alters to .................... . brucite, serpentine.

Clinohumite alters to . . . . . . . . . . . . . . . . . . brucite, serpentine.

Corundum alters to................... diaspore, cyanite, gibbsite, margarite, muscovite (da. mourite), sillimanite, spinel, zoisite.

Cummingtonite alters to bastite, quartz.

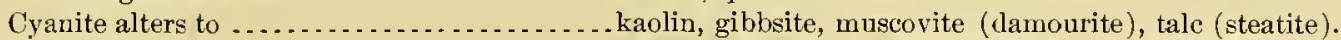

Diallage alters to .................................. chlorite, epidote, feldspar, magnetite, quartz, smaragdite.

Diaspore alters to.................................. spinel, zoisite.

Diopside alters to.................................

Dolomite alters to ............................ calcite, diopside, tremolite, wollastonite.

Enstatite alters to . . . . . . . . . . . . . . . . . quartz, serpentine, talc.

Epidote alters to ........................... galcite, gibbsite, kaolin, limonite, quartz.

Fluorite alters to .............................

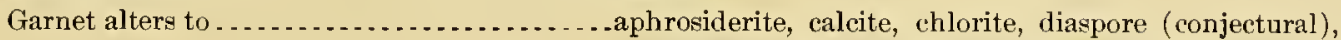
epidote, gibbsite (conjectural), hematite, homblende, hypersthene, iron oxide, kaolin (conjectural), limon. ite, magnesite, magnetite, quartz, siderite.

Gehlenite alters to . . . . . . . . . . . . . . fassaite, grossularite, talc.

Gibbsite alters to.............................. mundum, cyanite, diaspore, margarite, muscovite, sillimanite, spinel, zoisite.

Grossularite alters to . . . . . . . . . . . . . . calcite, meionite, quartz, zoisite.

Grünerite alters to ...........................

Gypsum alters to...........................

Haüynite alters to .............................

Hematite alters to.................... limonite, magnetite, marcasite, pyrite, siderite.

Heulandite alters to . . . . . . . . . . . . . . . . . albite, orthoclase.

Hornblende alters to ............................. bite, biotite, calcite, chlorite, epidote, hematite, magnetite, quartz, serpentine, siderite.

Humite alters to brucite, serpentine.

Hypersthene alters to . . . . . . . . . . . . . . . actinolite, anthophyllite, bastite, hematite, limonite, magnetite, quartz, serpentine, talc.

Ilmenite alters to ............................... titanite.

Iolite alters to $\ldots \ldots \ldots \ldots$. . . . chlorite, chlorophyllite, pinite.

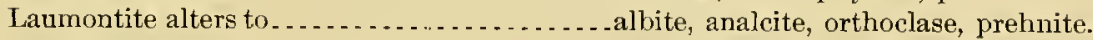

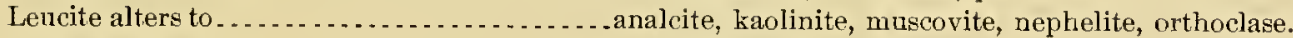

Limonite alters to . . . . . . . . . . . . . . . . . hematite, siderite.

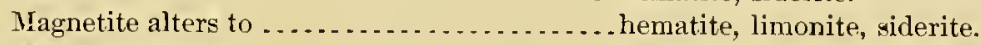

Marcasite alters to............................

Margarite alters to ....................... dudleyite.

Marialite alters to . . . . . . . . . . . . . . . . . biotite, kaolin, muscovite, quartz, talc.

Meionite alters to .......................... biotite, calcite, epidote, gibbsite, kaolin, muscovite.

Mesolite alters to . . . . . . . . . . . . . . . . . . . . . prehnite.

Microcline alters to .......................... allophane, hiotite, cimolite, rlamourite, epidote, gibbsite, halloysite, kaolin, muscovite, newtonite, pyrophyllite, quartz.

Muscovite alters to diaspore, gibbsite, paragonite, serpentine, talc (steatite), vermiculite. 
TABLE B.--Alteration products of minerals - Continued.

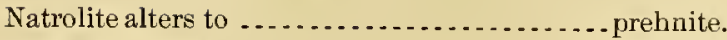

Nephelite alters to ......................... albite (conjectural), analcite, diaspore, gibbsite, hydromuscovite (pinite), hydronephelite, kaolin, muscovite, natrolite, sodalite, thomsonite.

Noselite alters to calcite, chabazite, diaspore, gibbsite, natrolite, stilbite.

Octahedrite alters to .................... rutile.

Olivine alters to ............................. actinolite, anthophyllite, breunnerite, chromite, hematite, hereynite, hydrotalcite, limonite, magnesite, magnetite, opal, quartz, serpentine, siderite, spinel, tremolite.

Opal alters to ..................................... chalcedony, chert, quartz

Orthoclase alters to......................... allophane, biotite, cimolite, damourite, epidote, gibbsite, halloysite, kaolin, muscovite, newtonite, pyrophyllite, quartz.

Parankerite alters to............................. tite, sahlite.

Perovskite alters to. ilmenite.

Phlogopite alters to. ..........................

Phlogopite (with biotite) alter's to............ . clinochlore, penninite.

Plagioclases alter to........................... mondite, heulandite, kaolin, laumontite, mesolite, natrolite, paragonite, phillipsite, prehnite, quartz, scapolites, scolecite, stilbite, thomsonite, zoisite.

Prehnite alters to chlorite, quartz.

Pyrite alters to. .

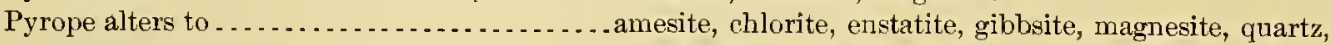
serpentine, spinel, talc.

Pyrrhotite alters to..................... limonite magnetite, pyrite.

Rutile alters to.................................

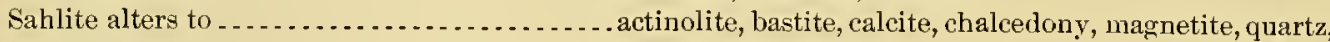
serpentine, talc.

Scapolite alters to ............................. calite, cite, diaspore, epidote, gibbsite, hydromuscovite (pinite), kaolin, muscovite, quartz, talc.

Scolecite alters to ......................... prehnite.

Serpentine alters to . . . . . webskyite.

Siclerite alters to . . . . . . . . . . . . . . . . grünerite, hematite, limonite, magnetite.

Sillimanite alters to Sodalite alters to $\ldots . \ldots \ldots \ldots \ldots$. . . . . . . . albite (conjectural), analcite, diaspore, gibbsite, hydromuscovite (pinite), hydronephelite, kaolin, muscovite, natrolite, nephelite (conjectural), thomsonite.

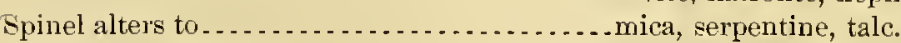

Spodumene alters to....................... albite, beta-spodumene, cymatolite, eucryphtite, microeline, muscovite.

Staurolite alters to ................................

Stilbite alters to................................ orthoclase.

Titanite alters to ...............................

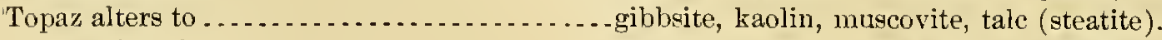

Tourmaline alters to.................. biotite, chlorite, gibbsite, mica, steatite.

Tremolite alters to . . . . . . . . . . . . . . . . . calcite, talc.

Vesnvianite alters to...........................

Zircon alters to..............................

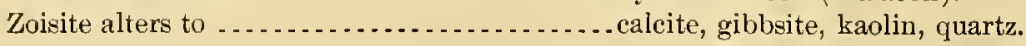


TABLES.

375

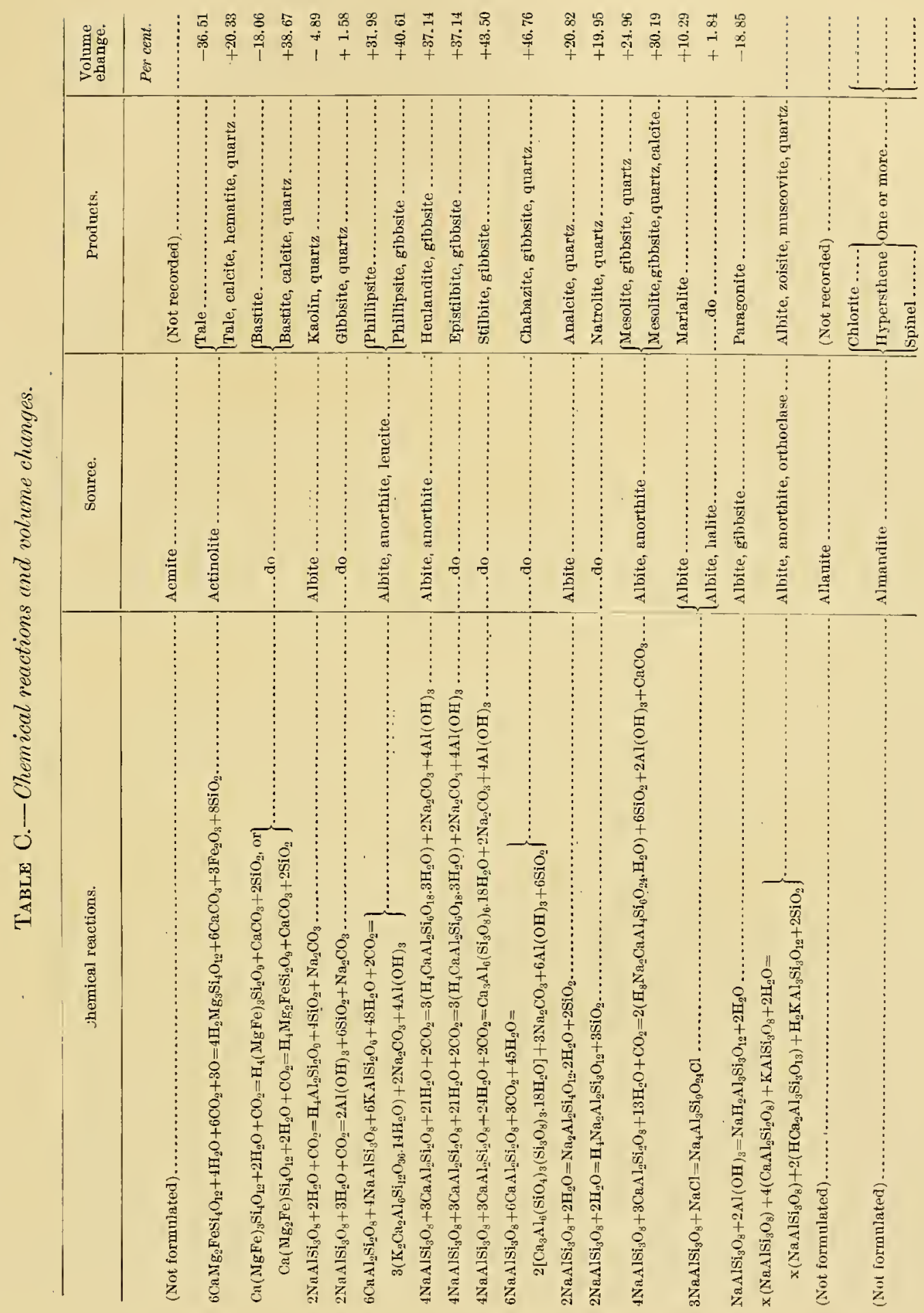




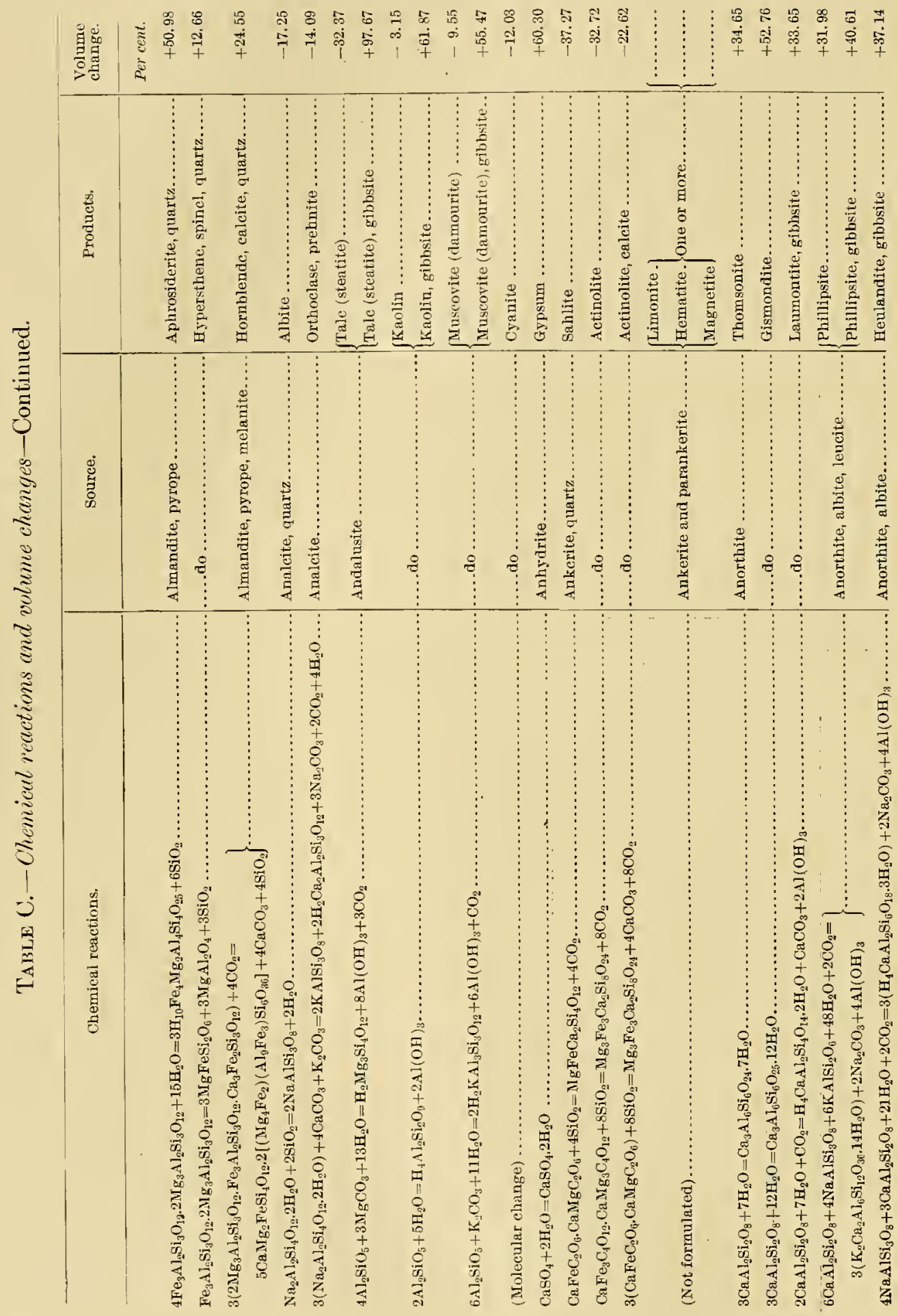


TABLES.

377

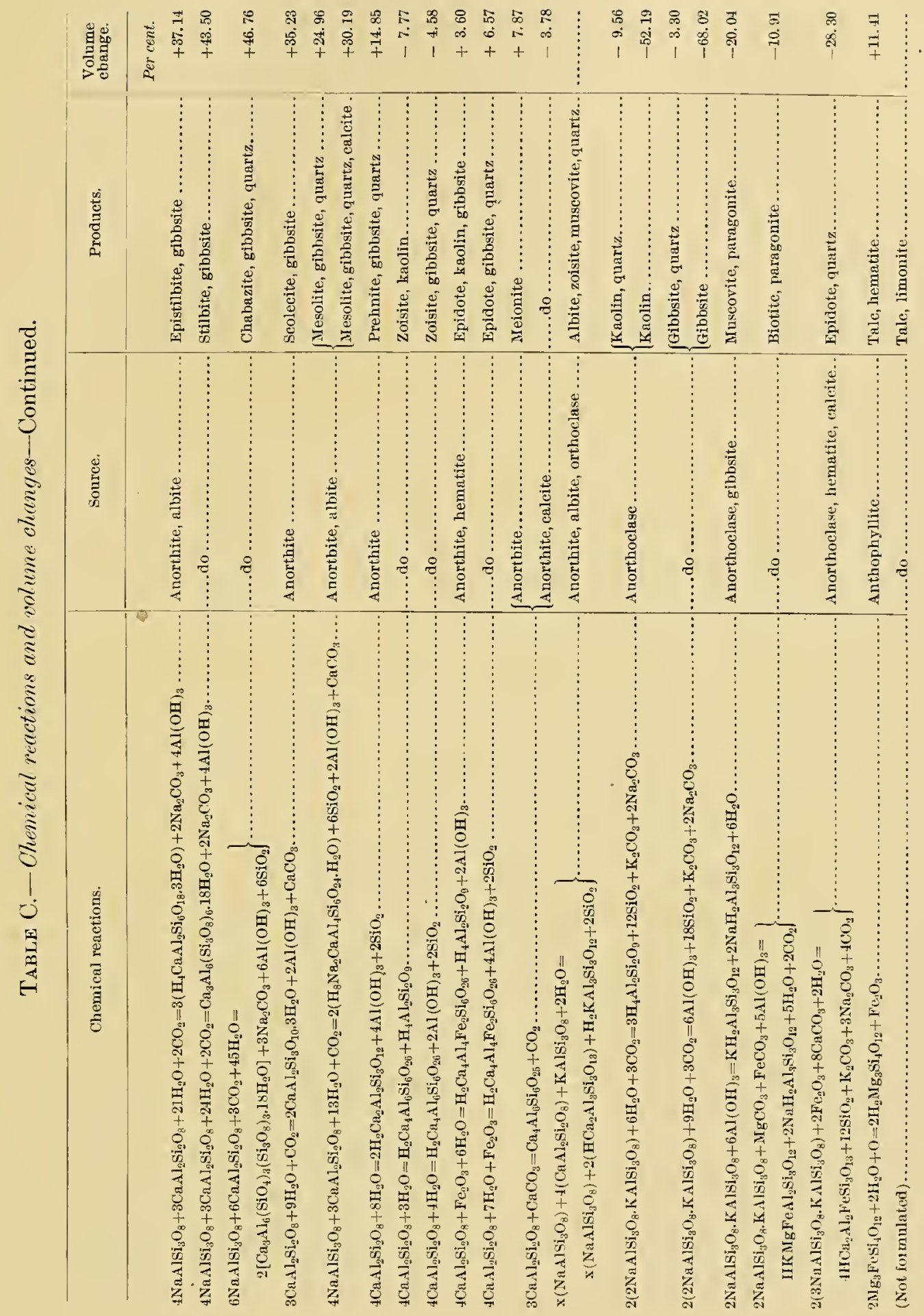


A TREATISE ON METAMORPHISM.

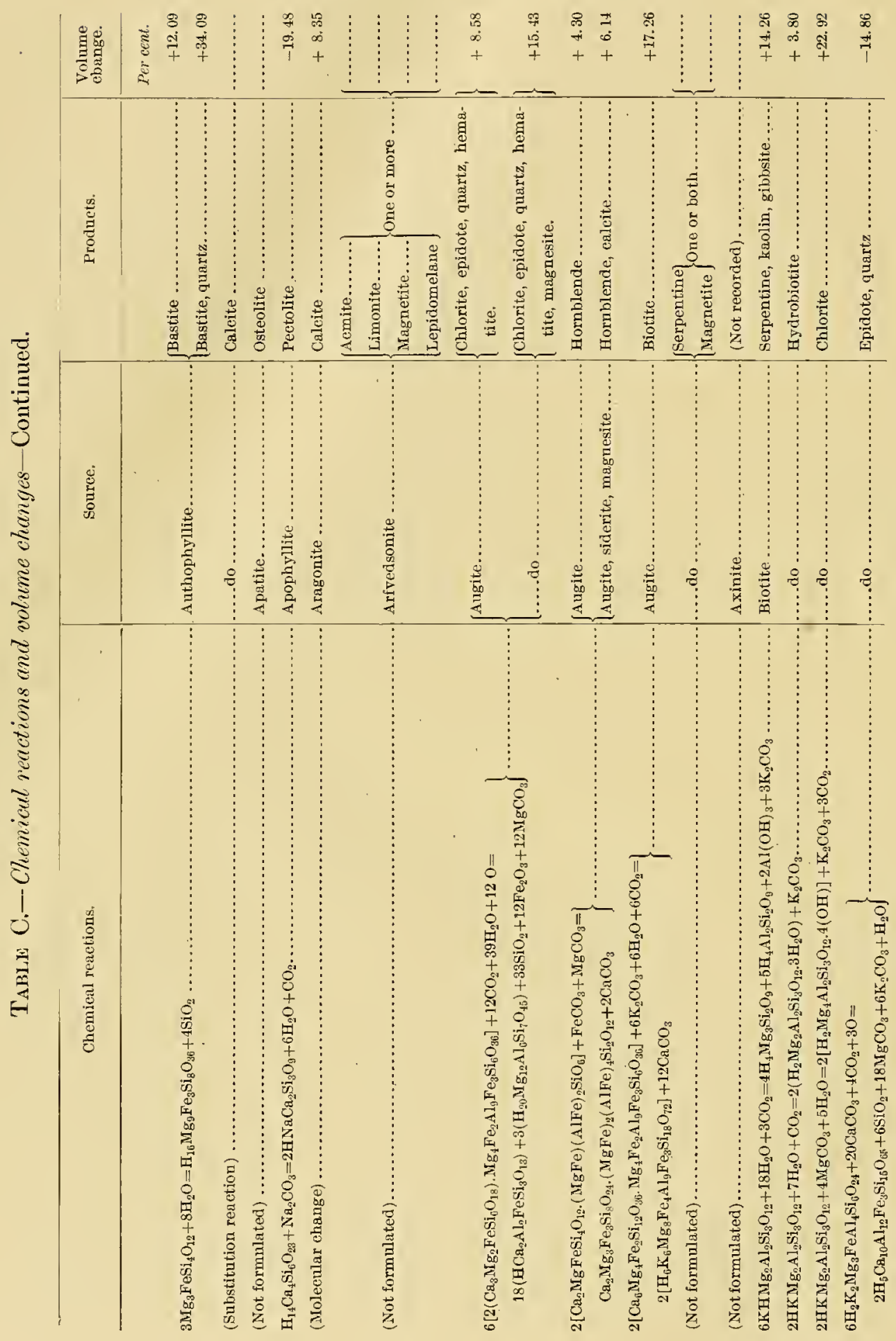


TABLES.

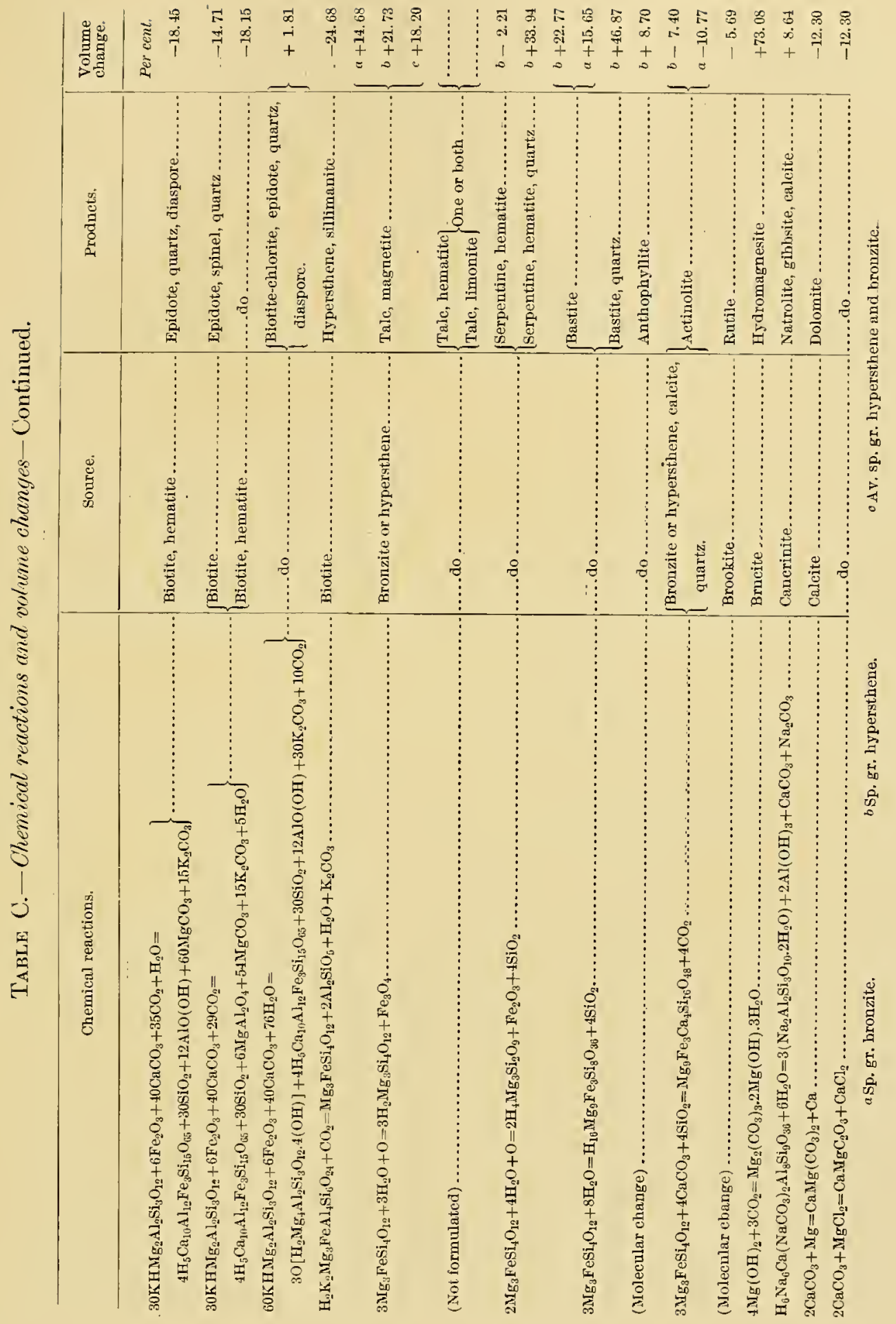




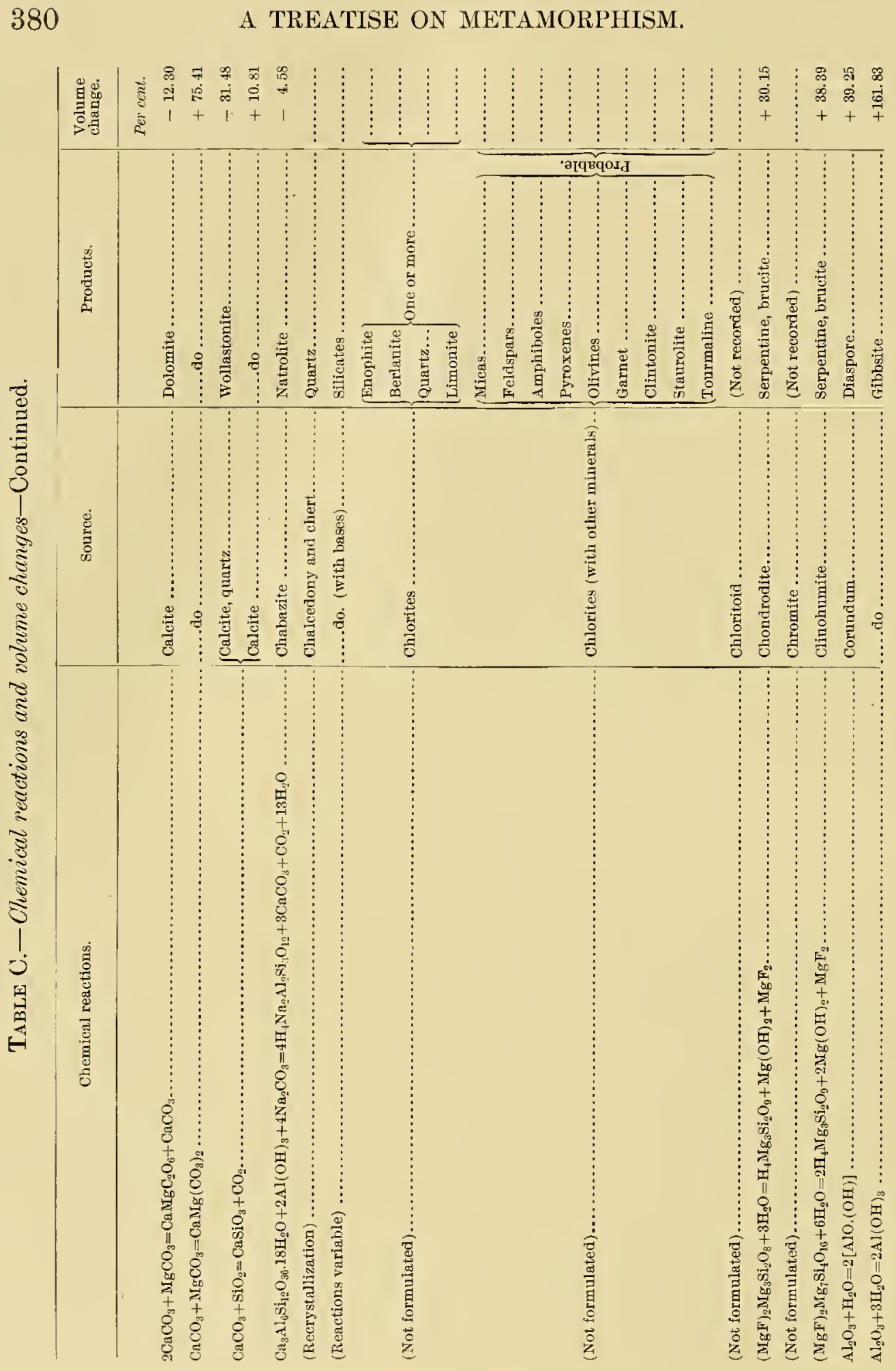


TABLES.

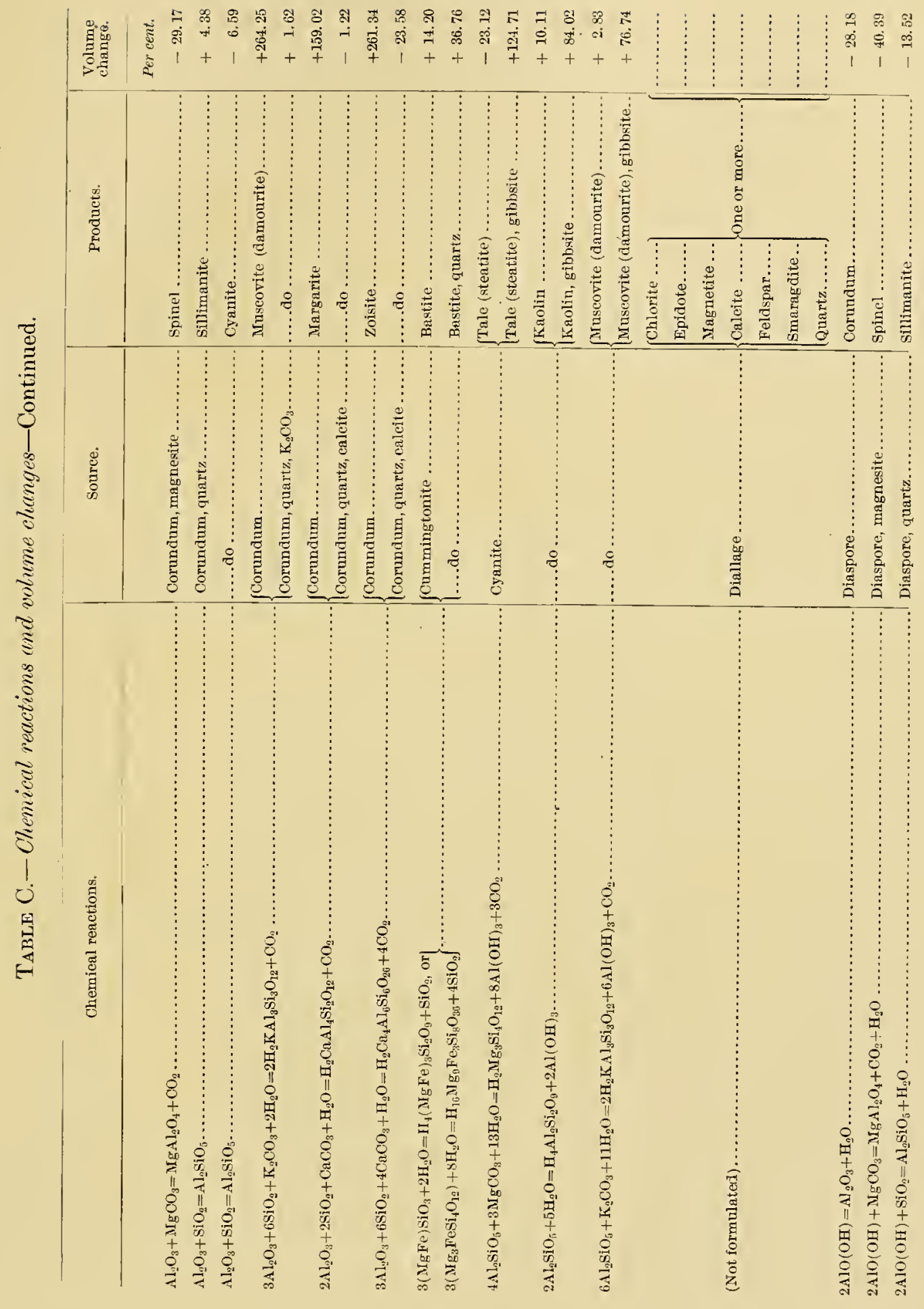




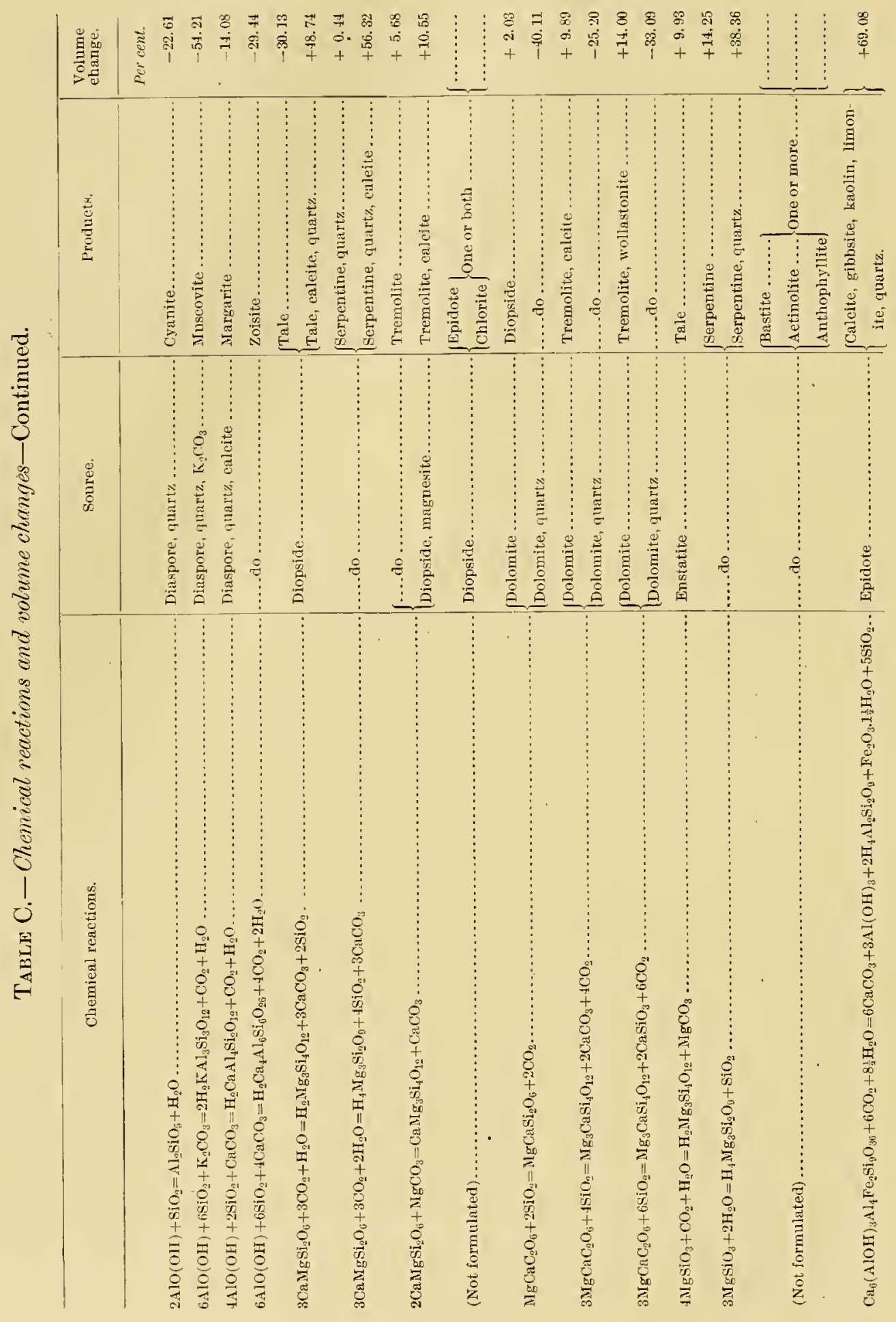


TABLES.

383

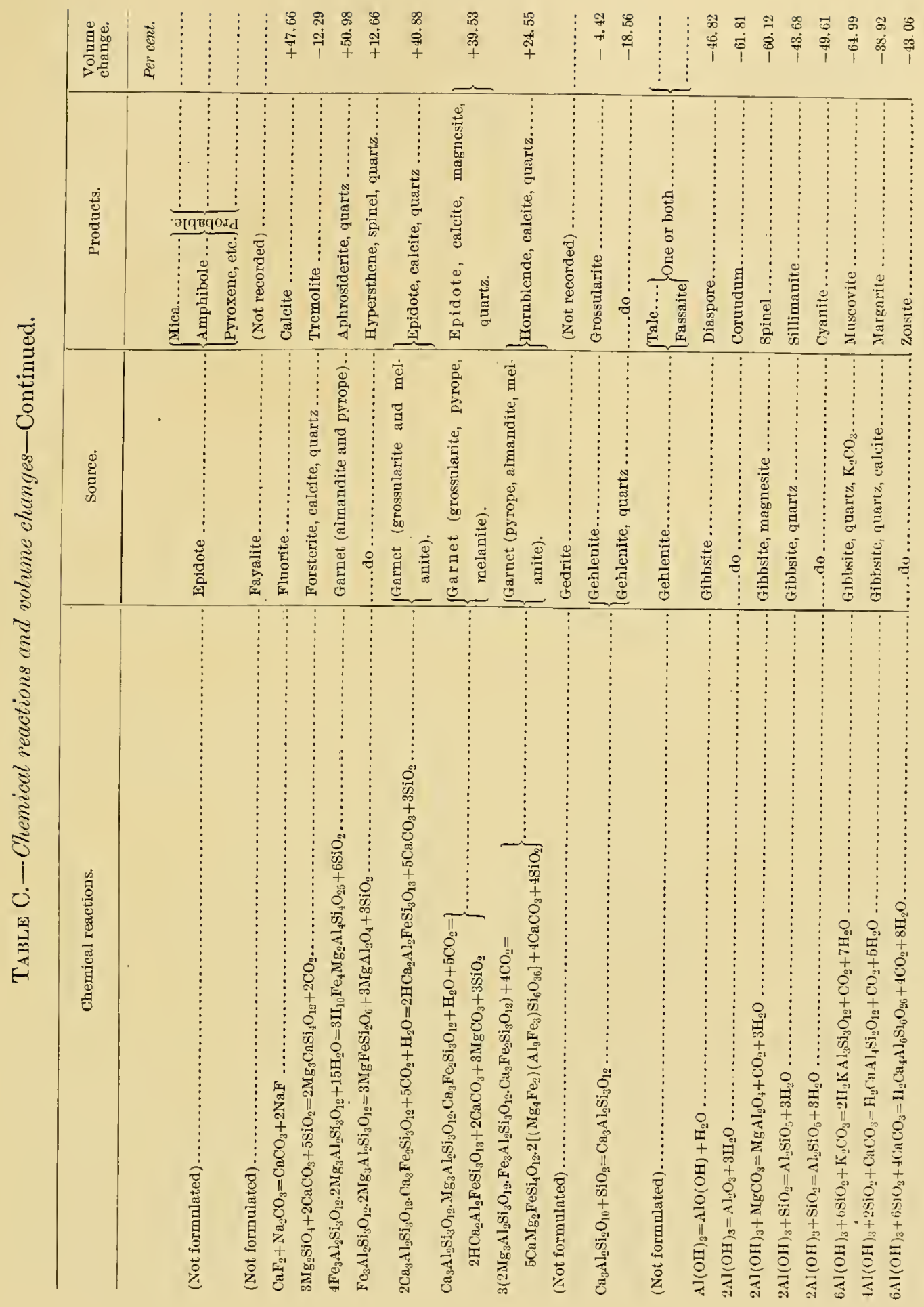




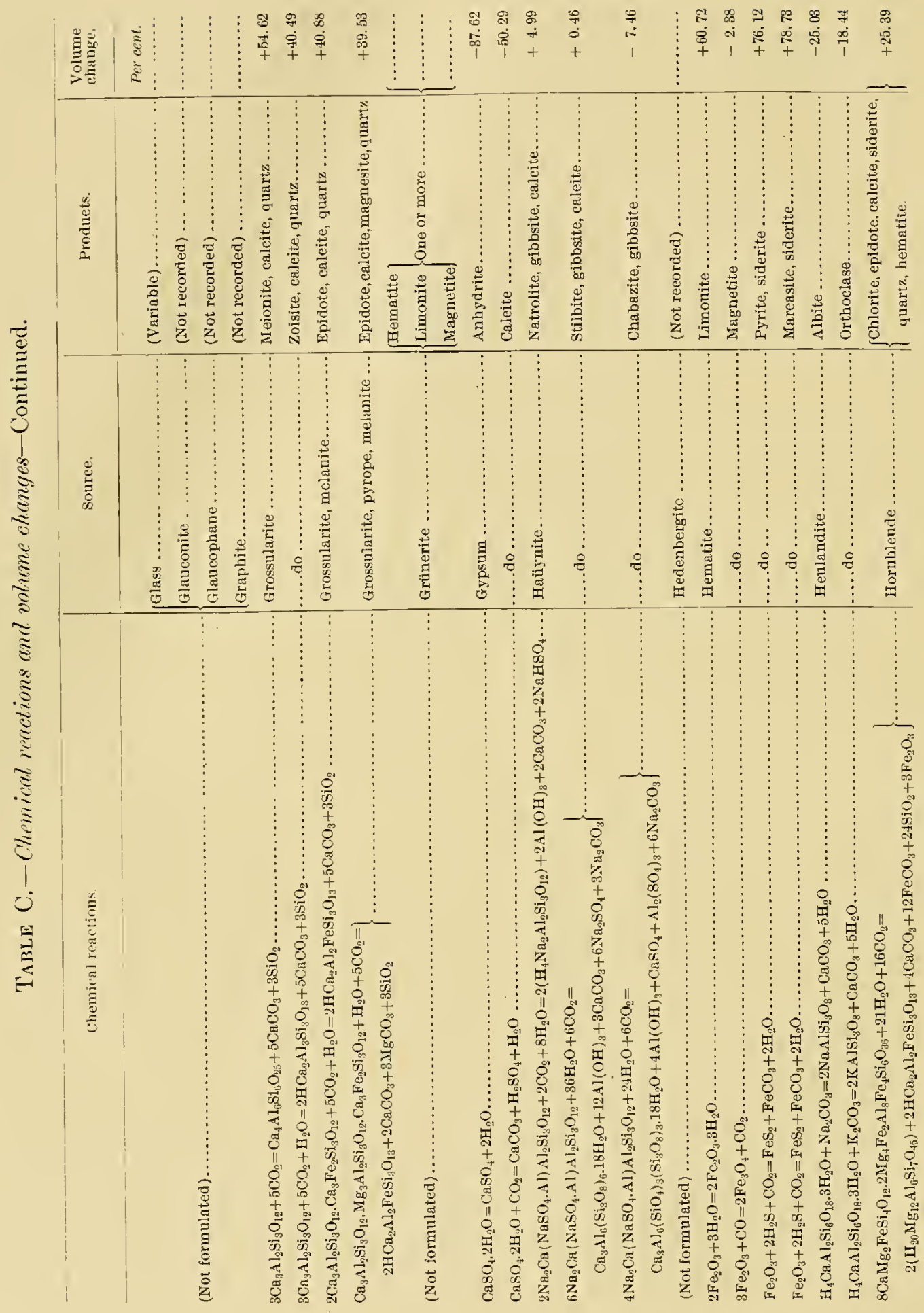


TABLES.

385

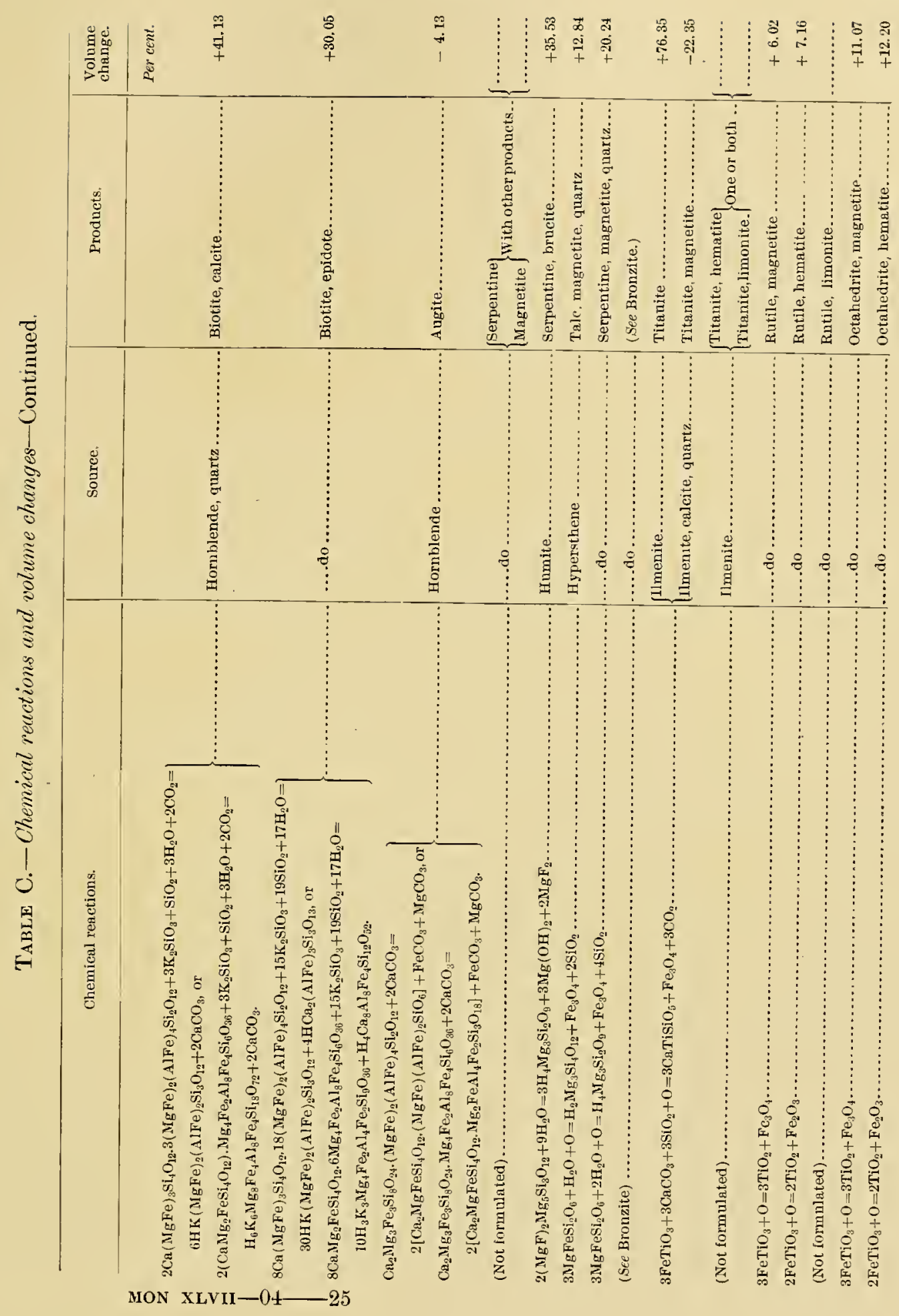


A TREATISE ON METAMORPHISM.

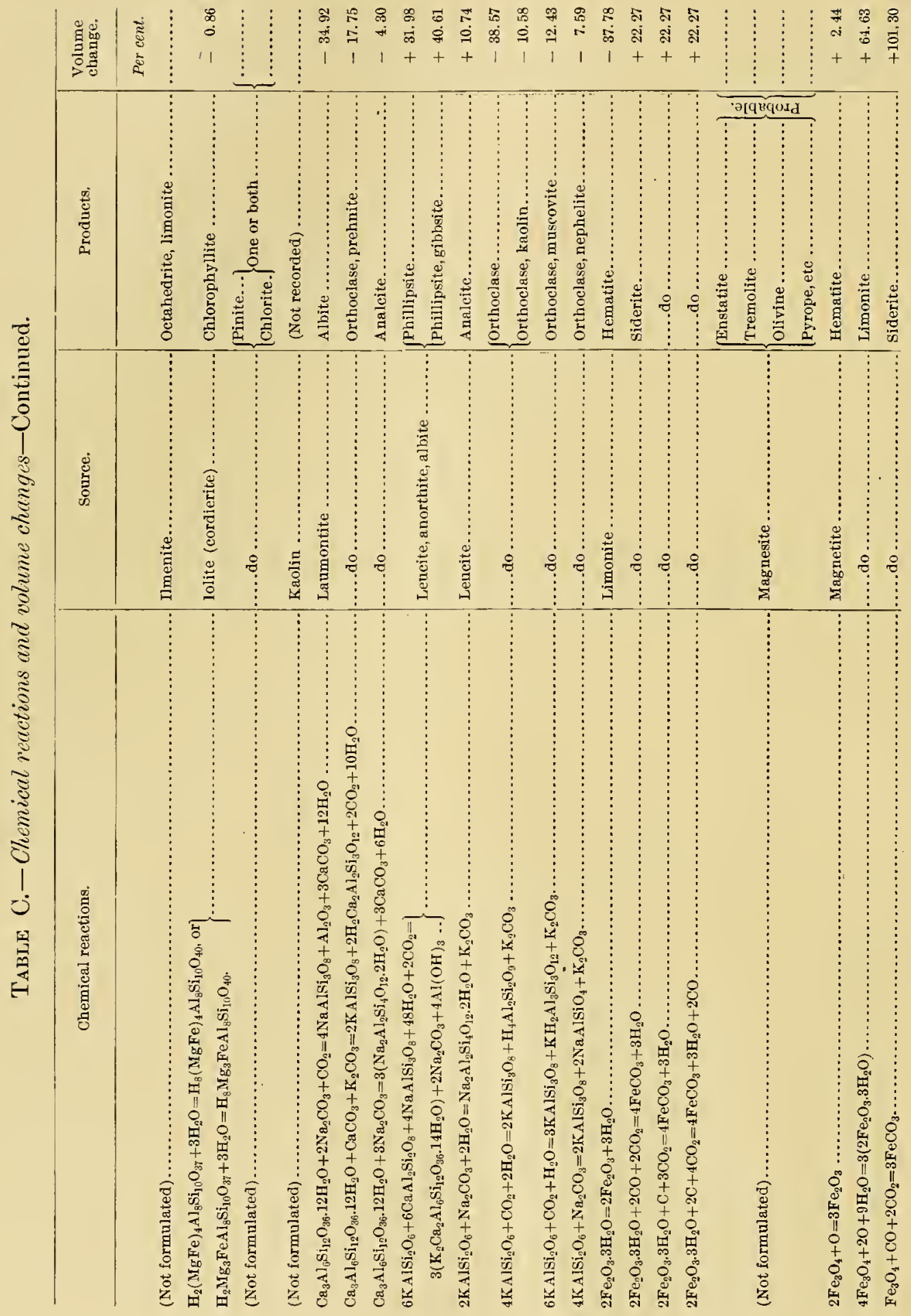


TABLES.

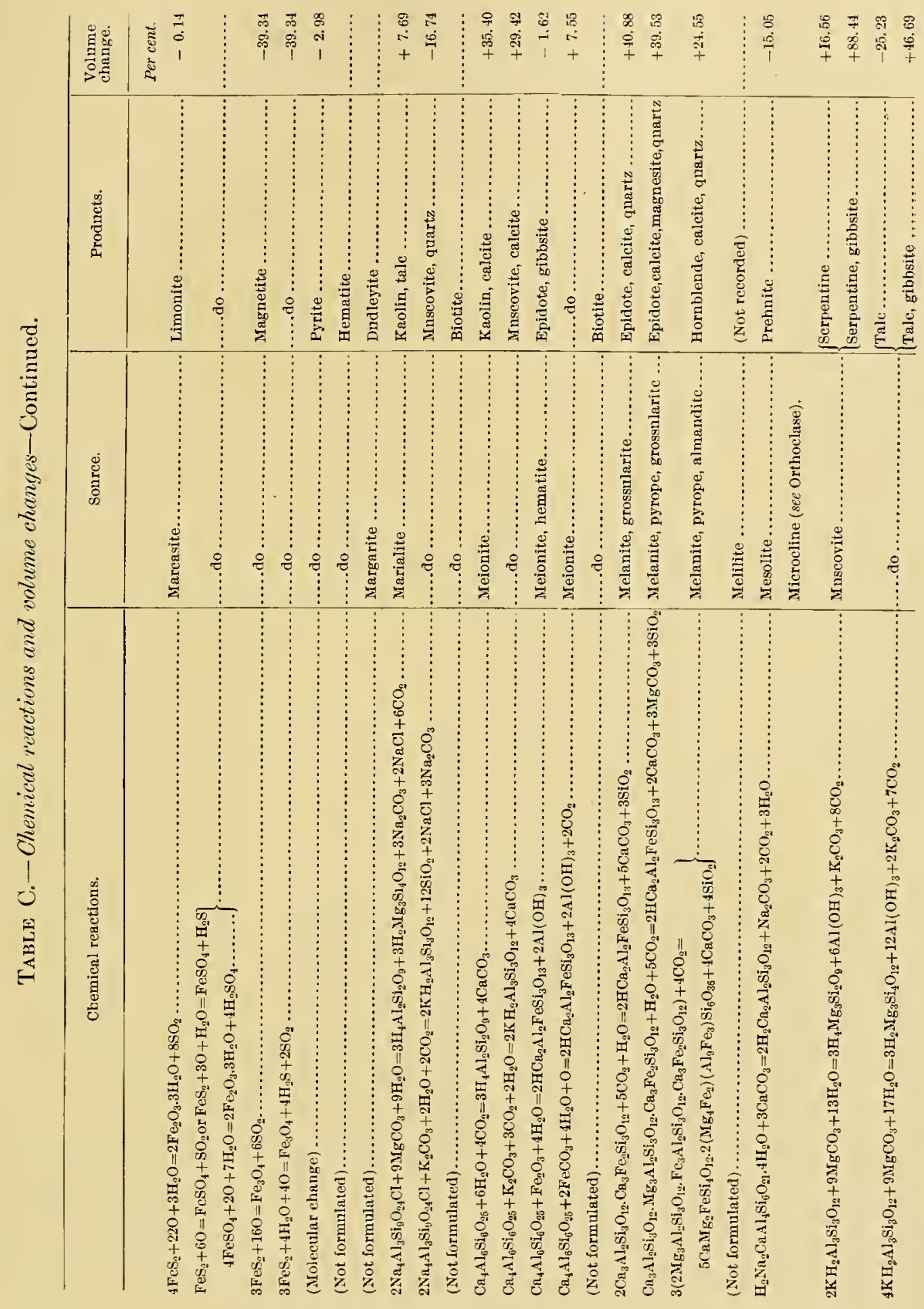




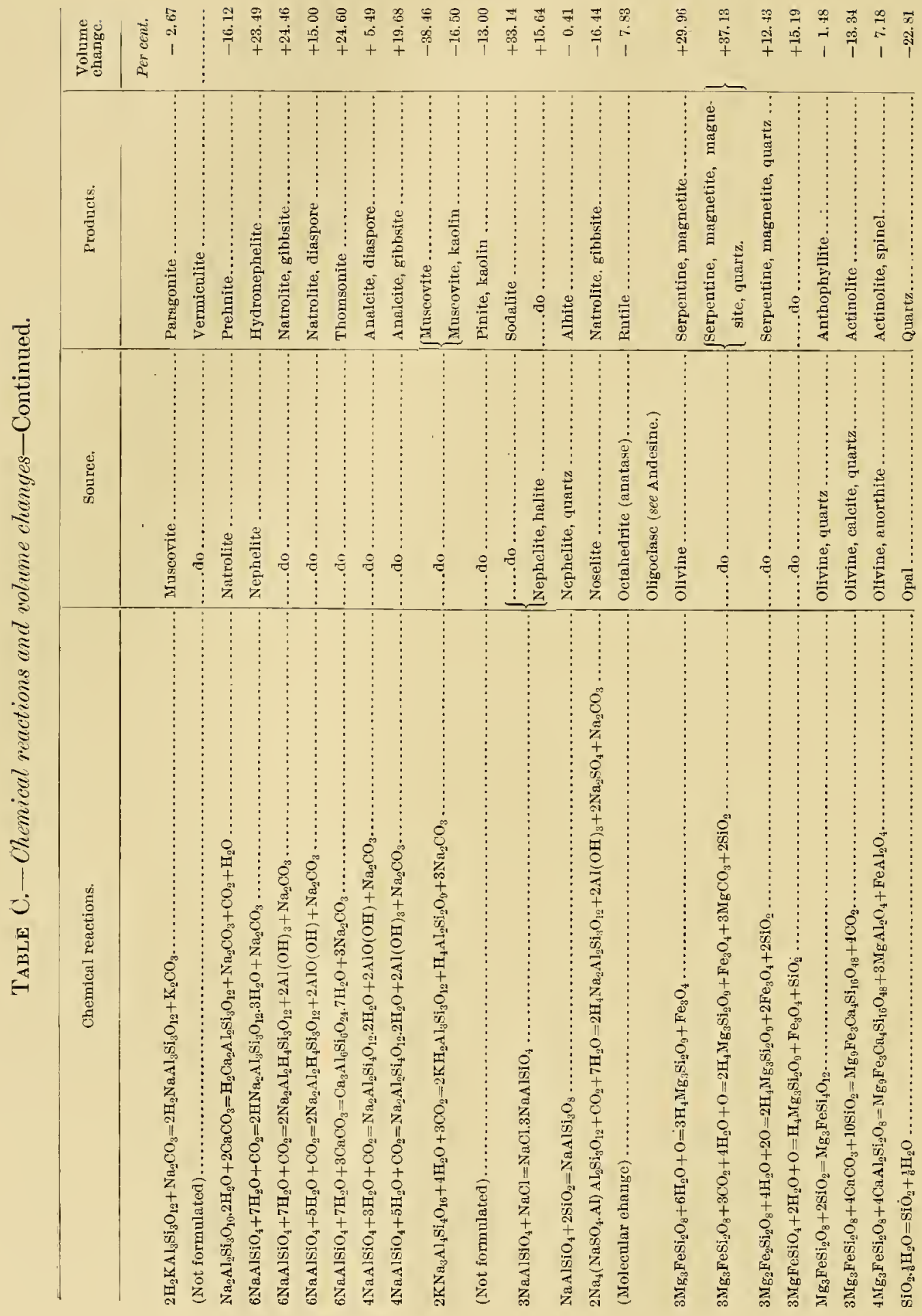


TABLES.

389

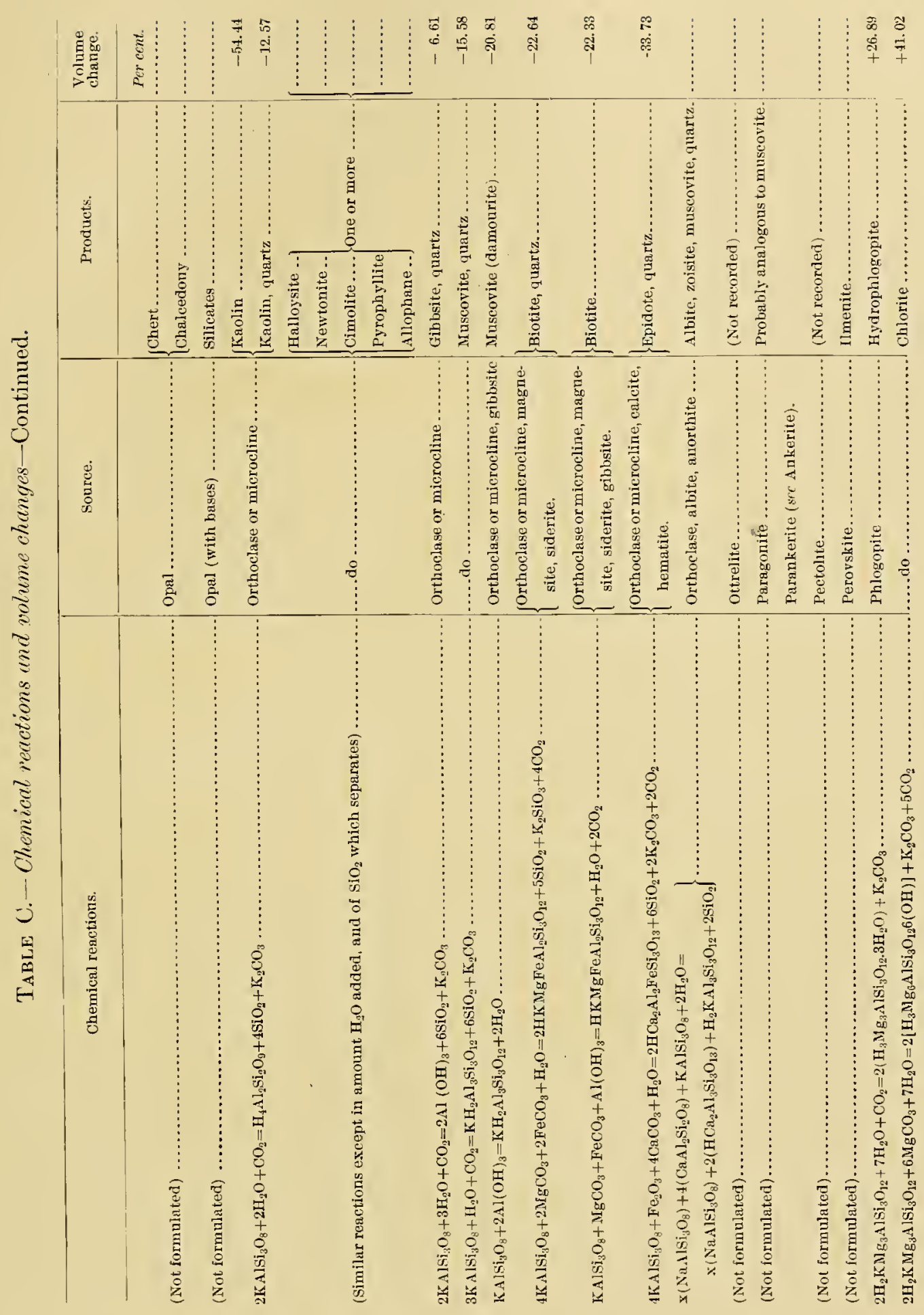




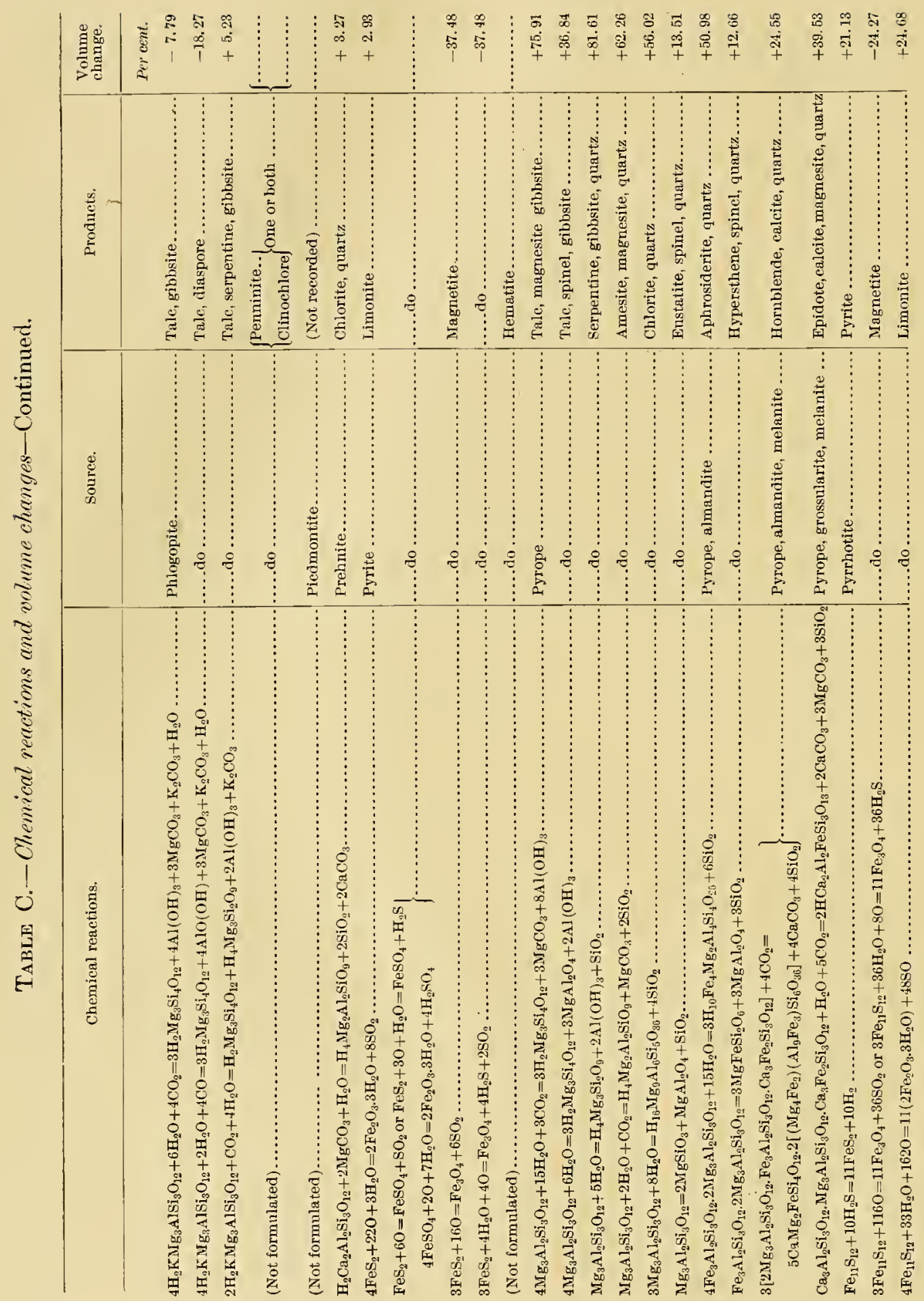


TABLES.

391

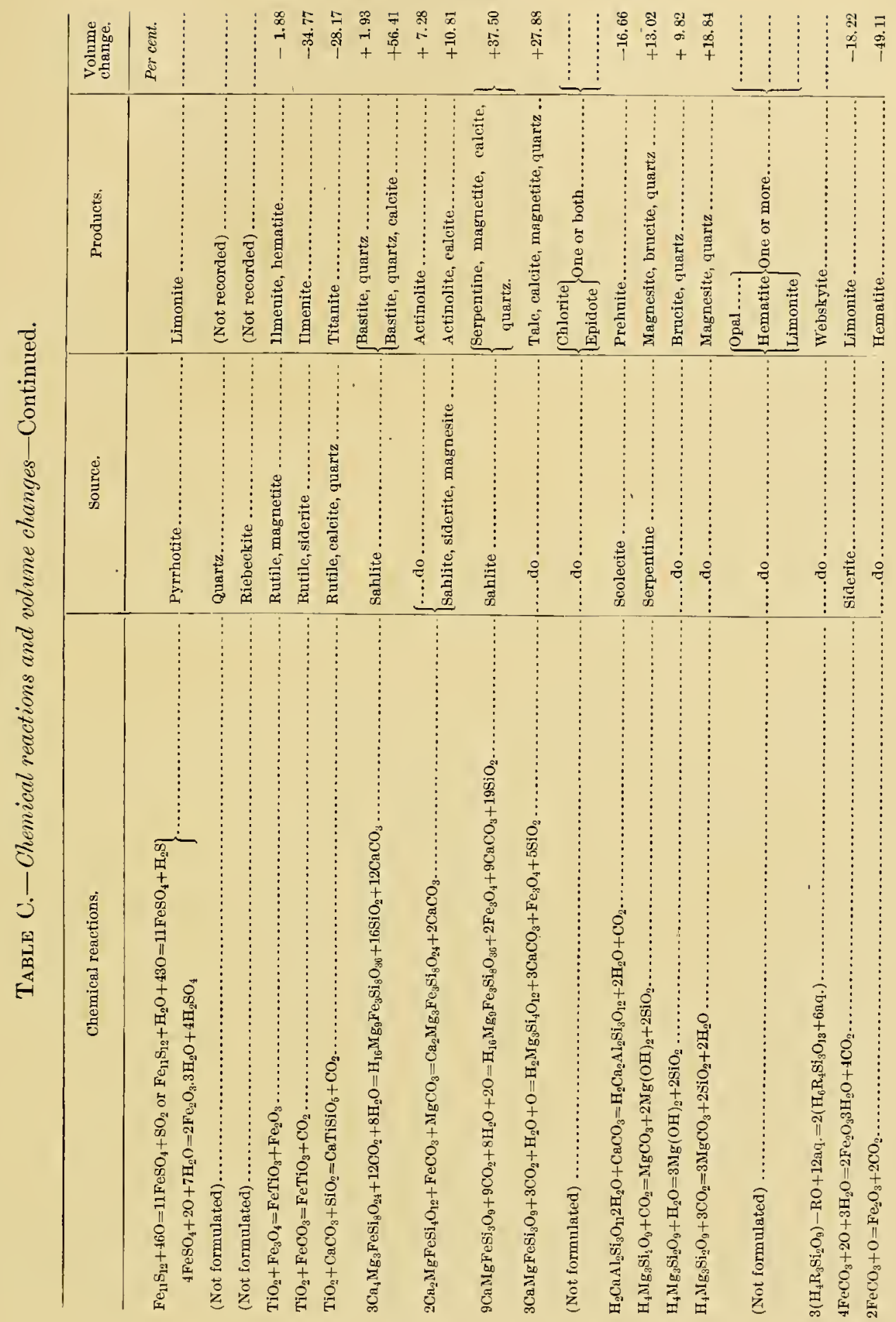




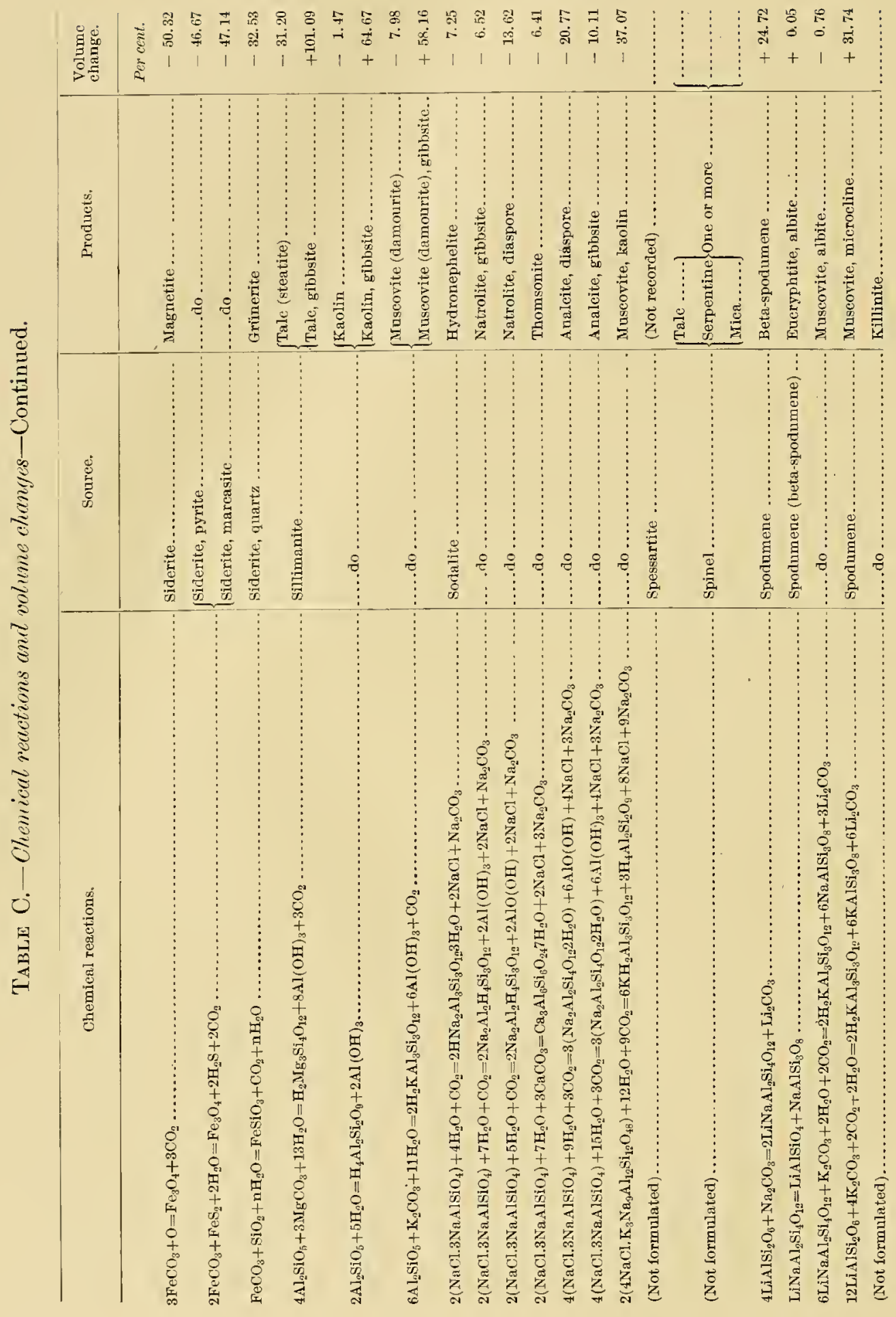


TABLES

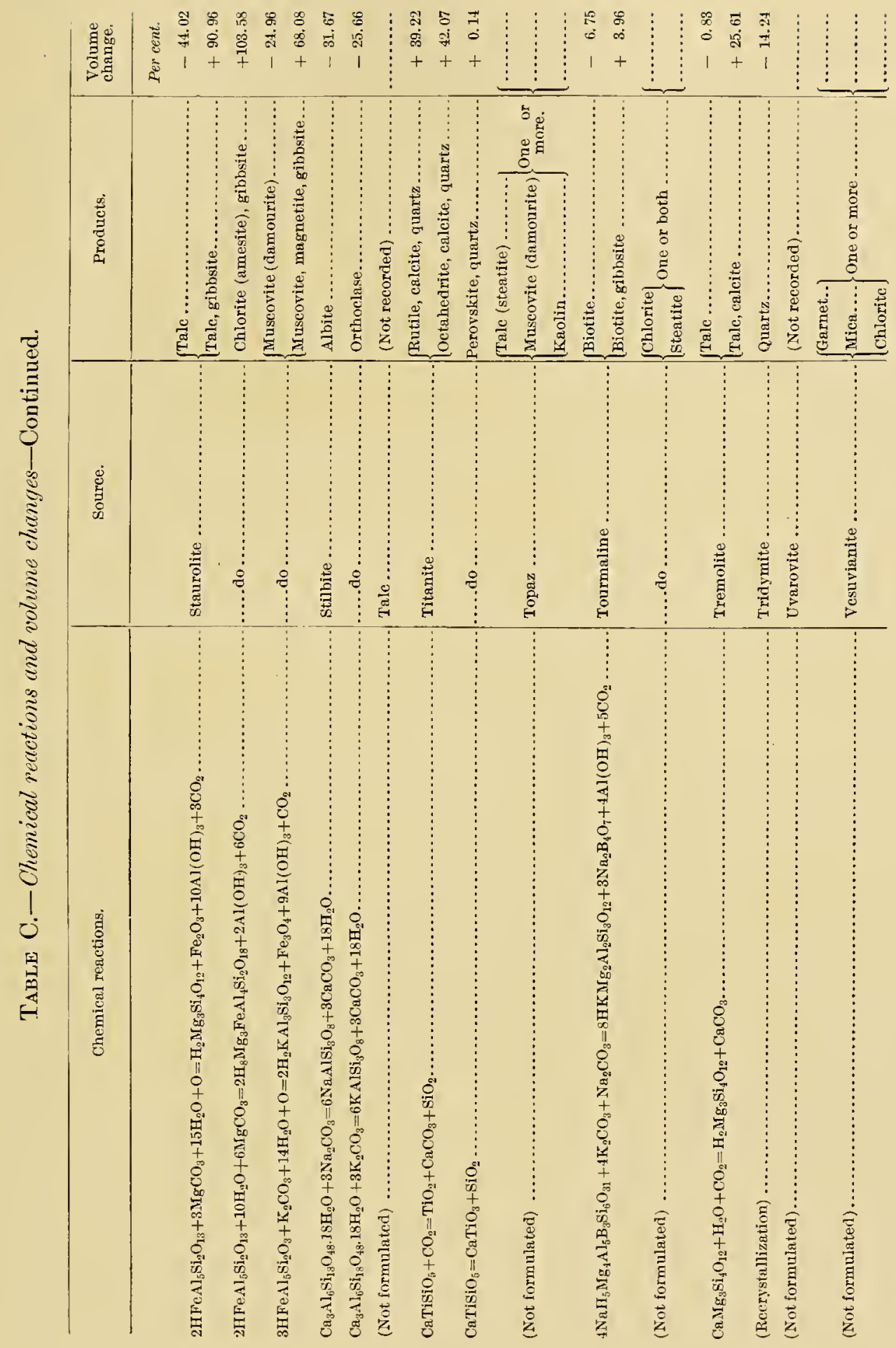




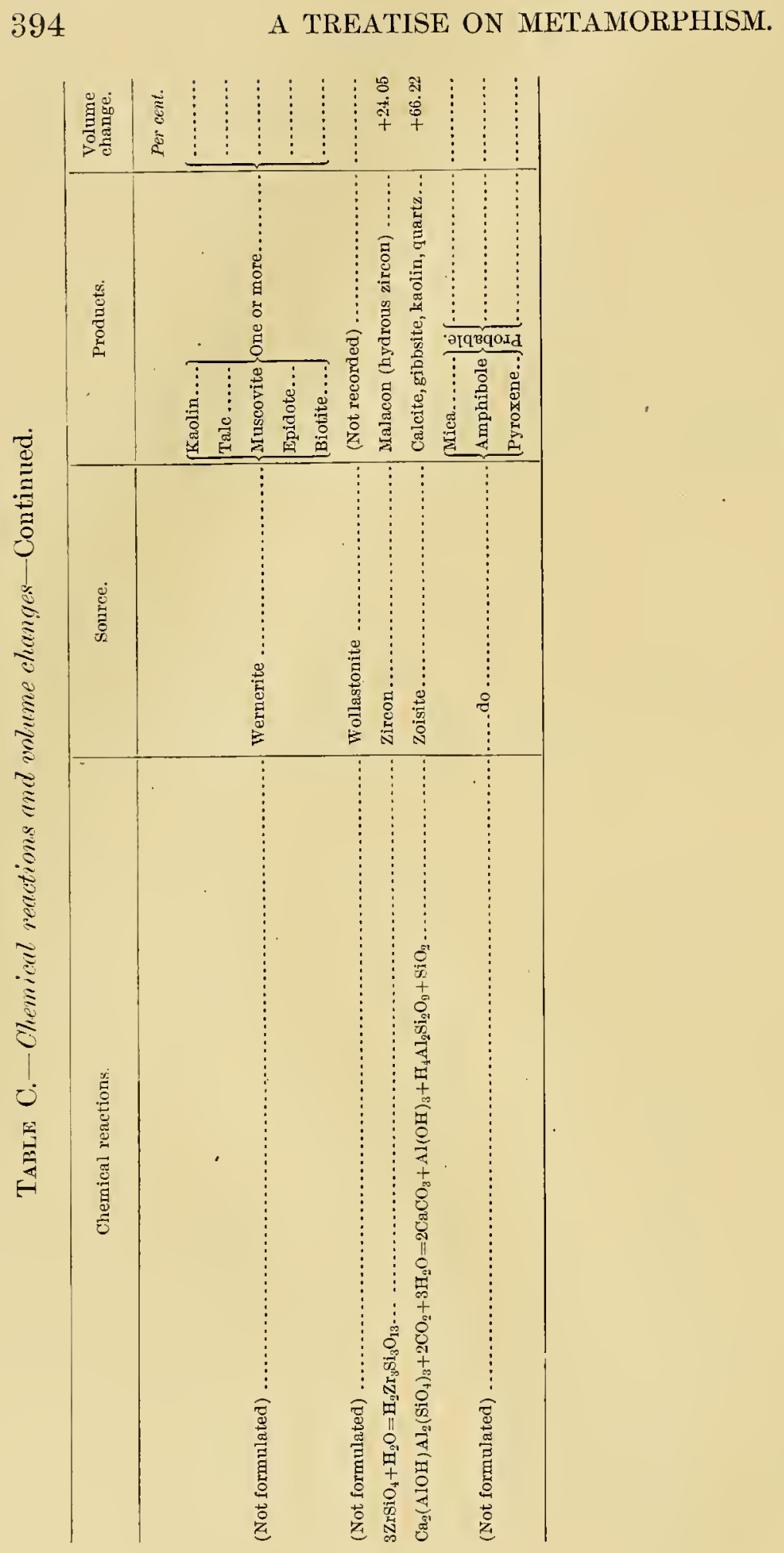


TABLE D.-Classification of alterations, with volume changes.

INDEX TO CLASSIFICATION.

Pã.

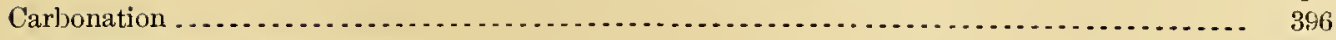

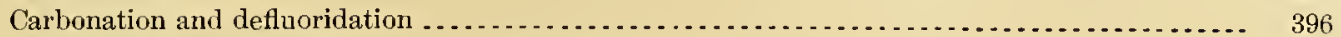

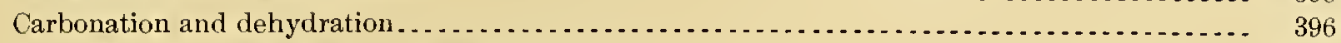

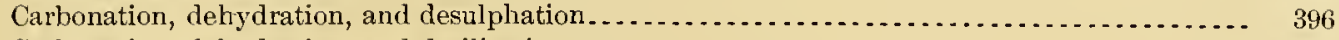

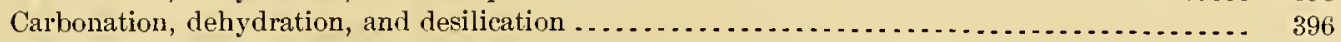

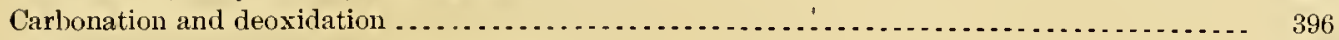

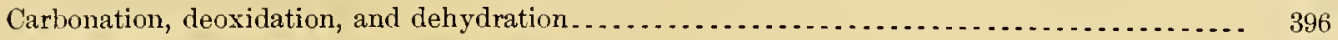

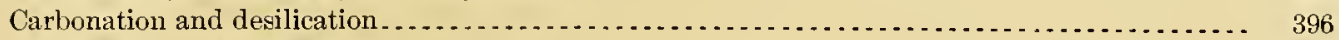

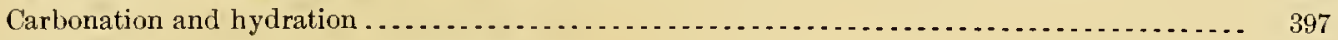

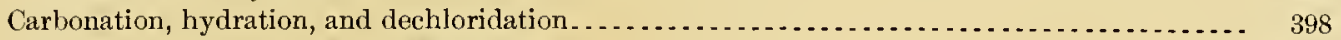

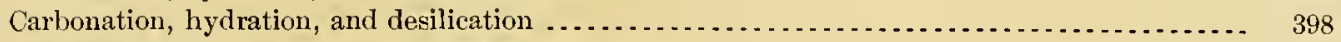

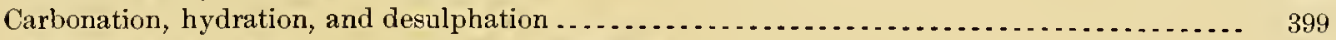

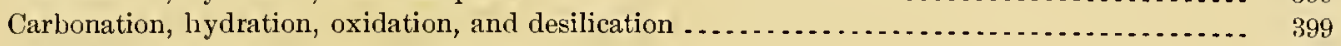

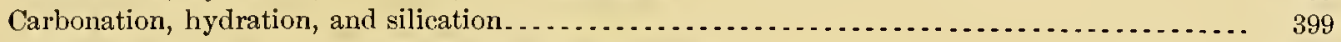

Carbonation, oxidation, dehydration, and desilication ................ 399

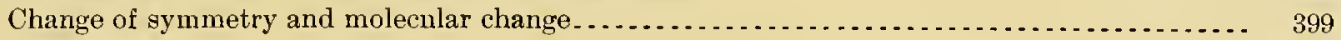

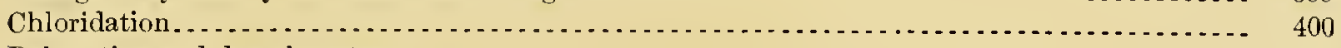

Deboration and decarbonation . . . . .

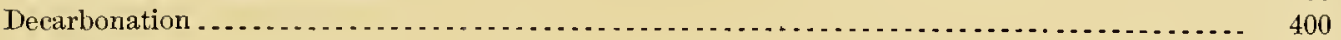

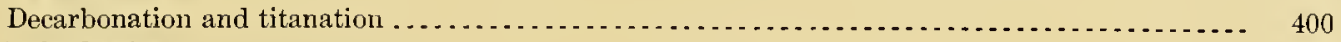

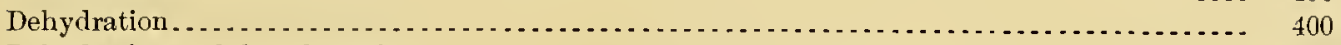

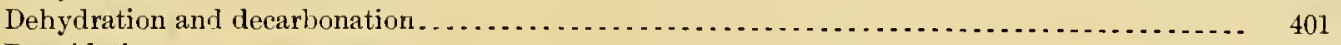

Deoxidation . . . . . . . . . . .

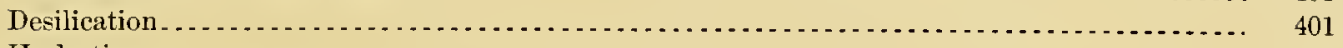

Hydration . . . . . . . . . . . . .

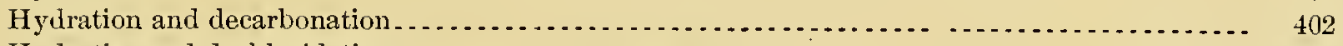

Hydration and dechloridation. . . . . . . . . . . . .

Hydration, dechloridation, carbonation, and desilication . . .

Hydration, dechloridation, and decarbonation ............... 403

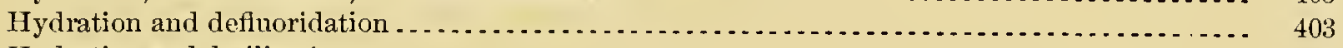

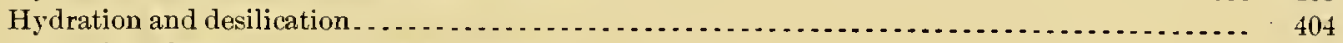

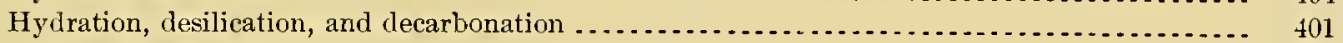

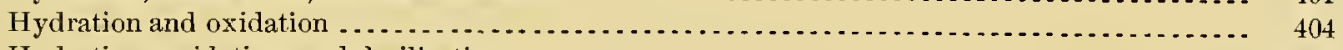

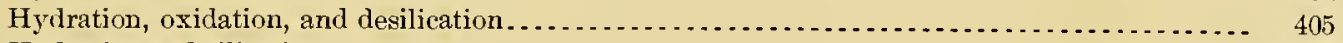

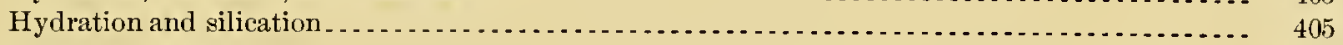

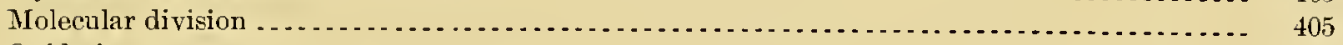

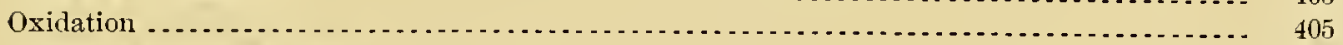

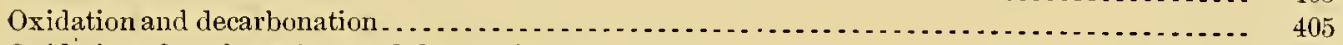

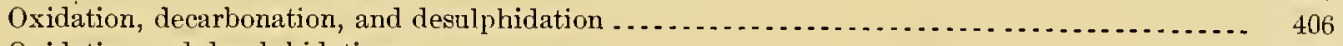

Oxidation and desulphidation. ................

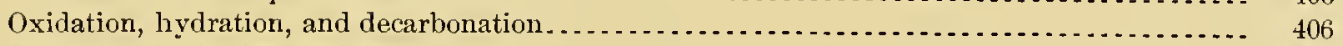

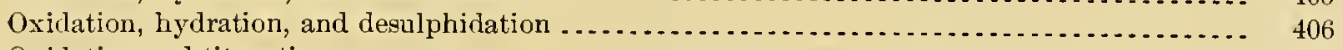

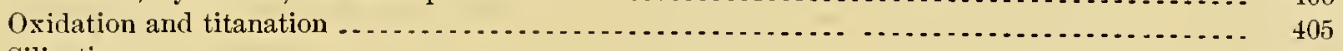

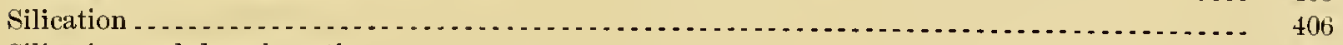

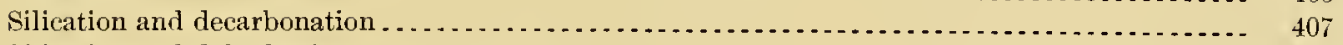

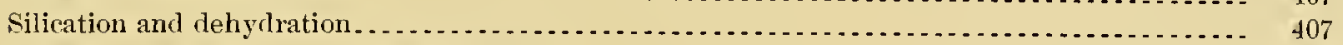

Silication, dehydration, and decarbonation...........

Silication, hydration, and decarbonation.......

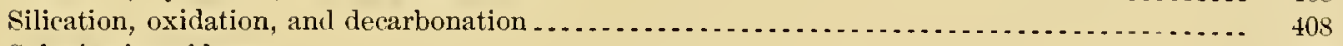

Substitution of bases . . .

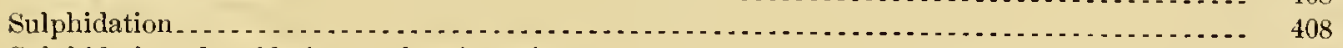

Sulphidation, deoxidation, and carbonation .............. 408 
TABLE D.-Classification of alterations, with volume changes-Continued.

CARBONATION.

Source.
Brucite ...........................

CARBONATION AND DEFLUORIDATION.

\begin{tabular}{|c|c|c|}
\hline Fluorite $\ldots \ldots \ldots \ldots \ldots$ & 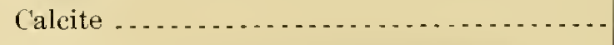 & +47.66 \\
\hline
\end{tabular}

CARBONATION AND DEHYDRATION.

\begin{tabular}{|c|c|c|}
\hline 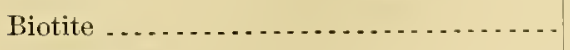 & Hypersthene, sillimanite . . . . . . . . . . . & -24.68 \\
\hline 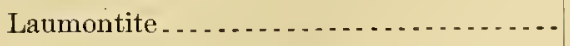 & Albite $\ldots \ldots \ldots+\ldots$ & -34.92 \\
\hline
\end{tabular}

CARBONATION, DEHYDRATION, AND DESULPHATION.

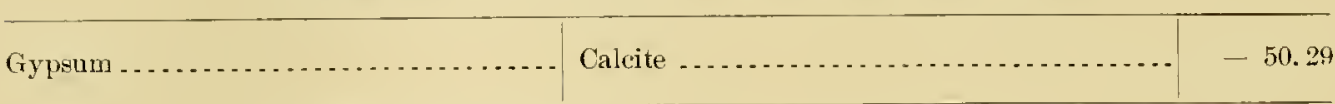

CARBONATION, DEHYDRATION, AND DESILICATION.

\begin{tabular}{|c|c|c|}
\hline Biotite.. .6. & Epidote, spinel, quartz . . . . . . . . . . . . . & -14.71 \\
\hline Biotite, hematite............... & - do & -18.15 \\
\hline 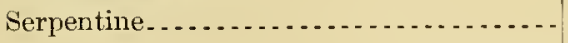 & 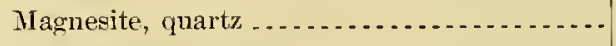 & +18.84 \\
\hline
\end{tabular}

CARBONATION AND DEOXIDATION.

\begin{tabular}{|c|c|c|}
\hline Magnetite ................. & Siderite $\ldots . . \ldots \ldots \ldots$ & +101.30 \\
\hline
\end{tabular}

CARBONATION, DEOXIDATION, AND DEHYDRATION.

\begin{tabular}{|c|c|c|}
\hline Limonite $\ldots \ldots \ldots \ldots \ldots$ & Siderite $\quad \ldots \ldots \ldots \ldots \ldots \ldots \ldots$ & +22.27 \\
\hline
\end{tabular}

CARBONATION AND DESILICATION.

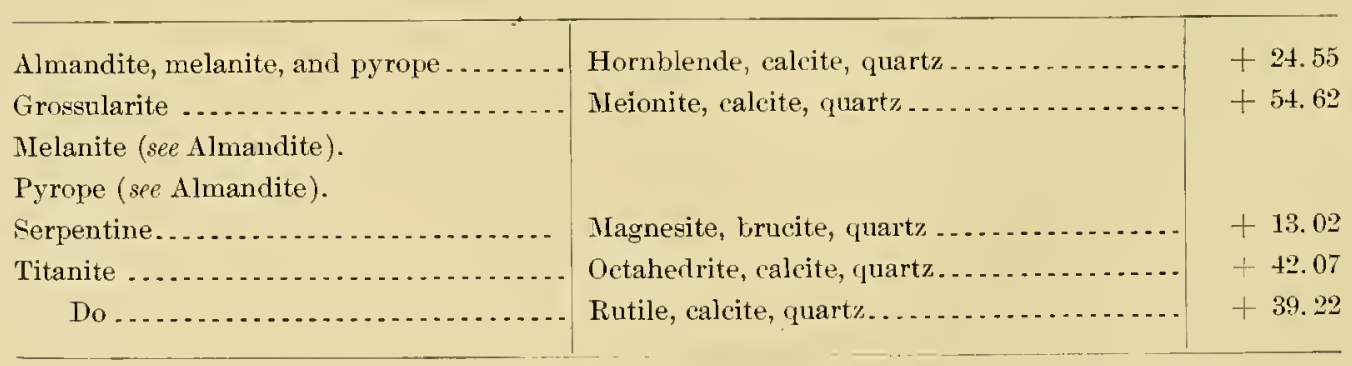


TABLES.

TABLE D.-Clnsification of alterations, with volume changes-Continued.

\section{CARBONATION AND HYDRATION.}

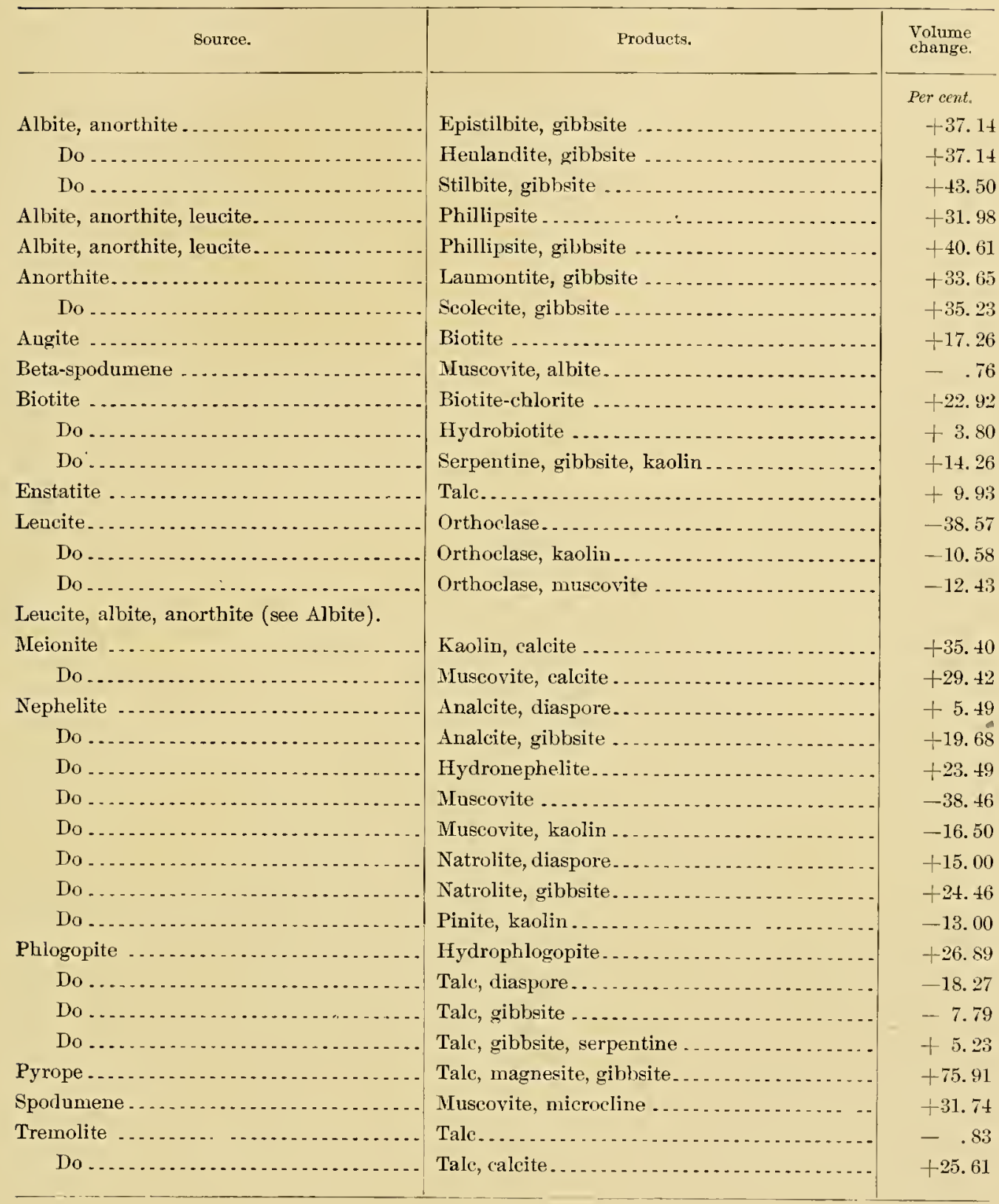


TABLE D.-Classification of alterations, with volume changes - Continued. CARBONATION, HYDRATION, AND DECHLORIDATION.

\begin{tabular}{|c|c|c|}
\hline Source. & P'roducts. & $\begin{array}{l}\text { Volume } \\
\text { change. }\end{array}$ \\
\hline Sodalite .... & Analcite, diaspore ............ . & $\begin{array}{l}\text { Per cent. } \\
\quad-20.77\end{array}$ \\
\hline Do . ........ & Analcite, gibbsite & -10.11 \\
\hline Do . . . . . . & Hydronephelite.............................. & -7.25 \\
\hline Do ........... & Muscovite, kaolin & -37.07 \\
\hline Do .......... & 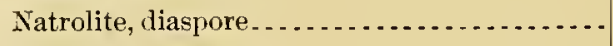 & -13.62 \\
\hline Do $\ldots . . . . . .$. & Natrolite, gibbsite ........... & -6.52 \\
\hline
\end{tabular}

CARBONATION, HYDRATION, AND DESILICATION.

\begin{tabular}{|c|c|c|}
\hline Actinolite ........... & 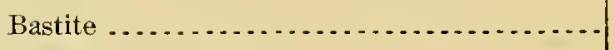 & -18.06 \\
\hline Do & Bastite, calcite, quartz _......... & +38.67 \\
\hline Albite... & 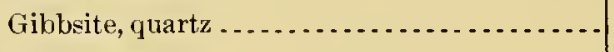 & + 1.58 \\
\hline Do $\ldots . .$. & 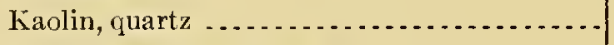 & -4.89 \\
\hline Albite, anorthite .. & Chabazite, gibbsite, quartz $\ldots \ldots \ldots \ldots$ & -46.76 \\
\hline Do ................ & Mesolite, gibbsite, quartz..................... & +24.96 \\
\hline Do & Mesolite, gibbsite, quartz, calcite............ & +30.19 \\
\hline Anorthoclase ....... & Gibbsite $\ldots . .6 \ldots \ldots \ldots \ldots$ & -68.02 \\
\hline Do ...... & Gibbsite, quartz $\ldots \ldots \ldots \ldots \ldots \ldots$ & -3.30 \\
\hline Do. & Kaolin . . . . . . . . . . . . . . . . & -52.19 \\
\hline Do & 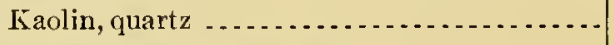 & -9.56 \\
\hline Biotite, hematite ... & Epidote, quartz, diaspore.................... & -18.45 \\
\hline Diopside. & Serpentine, quartz .... . . . . ............. & +.44 \\
\hline (... & Serpentine, quartz, calcite ................ & +56.32 \\
\hline 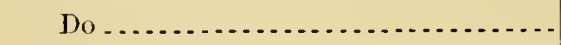 & Talc $\ldots \ldots \ldots$ & -30.13 \\
\hline Do. & 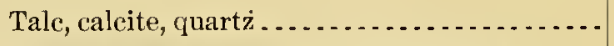 & +48.74 \\
\hline Epidote ......... & Calcite, giblssite, kaolin, limonite, quartz...... & +69.08 \\
\hline 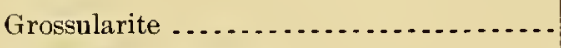 & Zoisite, calcite, quartz $\ldots \ldots \ldots \ldots$ & +40.49 \\
\hline Grossularite, melanite ..... ......... & 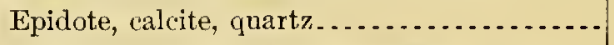 & +40.88 \\
\hline Grossularite, melanite, pyrope ......... & Epidote, calcite, quartz, magnesite ......... & +39.53 \\
\hline Hornblende............ & $\begin{array}{l}\text { Chlorite, epidote, calcite, siderite, quartz, } \\
\text { hematite. }\end{array}$ & -+25.39 \\
\hline Melanite (see Grossularite). & & \\
\hline Orthoclase or microcline.............. & 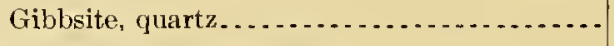 & $-6.6 I$ \\
\hline Do $\ldots$ & 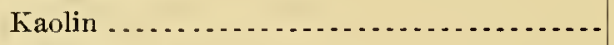 & -54.44 \\
\hline Do. & 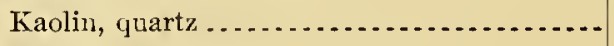 & -12.57 \\
\hline Do & Muscovite, quartz... & - I5. 58 \\
\hline
\end{tabular}


TABLE D.-Classification of alterations, with volume changes-Continued.

CARBONATION, HYDRATION, AND DESILICATION-Continued.

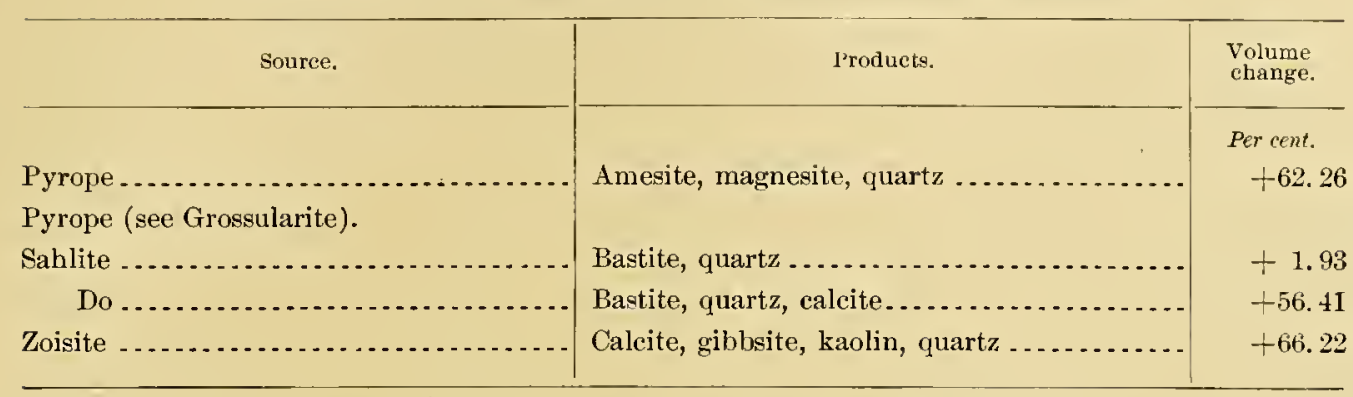

CARBONATION, HXDRATION, AND DESULPHATION.

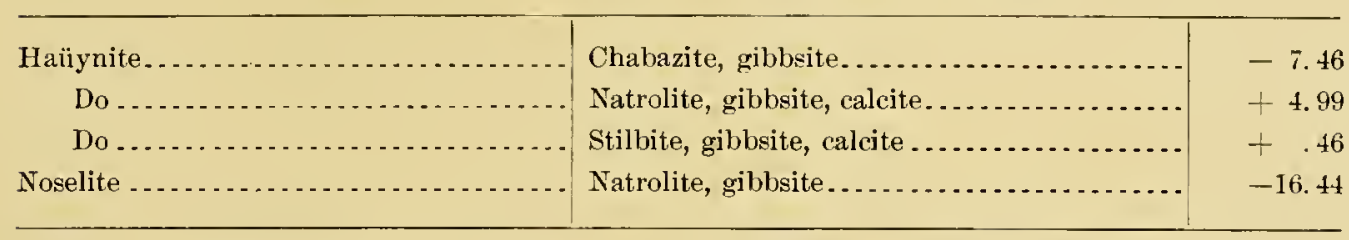

CARBONATION, HYDRATION, OXIDATION, AND DESILICATION.

\begin{tabular}{|c|c|c|}
\hline Actinolite ........... & Tale............ & -36.51 \\
\hline Do .. & Talc, calcite, hematite, quartz $\ldots \ldots$ & +20.33 \\
\hline Augite .. & Chlorite, epidote, quartz, hematite .......... & +8.58 \\
\hline Do ... & Chlorite, epidote, quartz, hematite, nıagnesite. & +15.43 \\
\hline Olivine . . & Serpentine, magnetite, magnesite, quartz..... & +37.13 \\
\hline Sahlite... & Serpentine, magnetite, calcite, quartz .. & +37.50 \\
\hline (n) & Talc, magnetite, calcite, quart $z . \ldots \ldots \ldots . .$. & +27.88 \\
\hline
\end{tabular}

CARBONATION, HYDRATION, AND SILICATION.

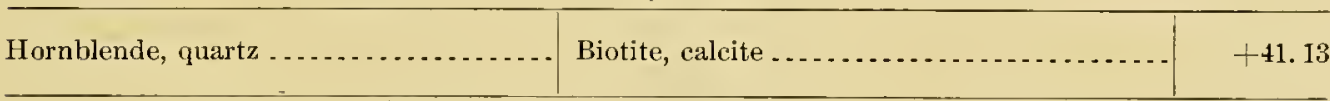

CARBONATION, OXIDATION, DEHYDRATION, AND DESILICATION.

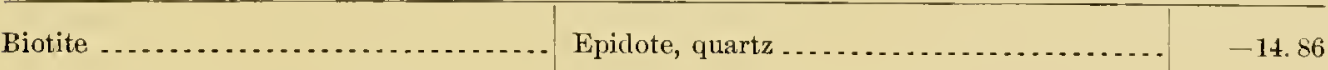

CHANGE OF SYMMETRY AND MOLECULAR CHANGE.

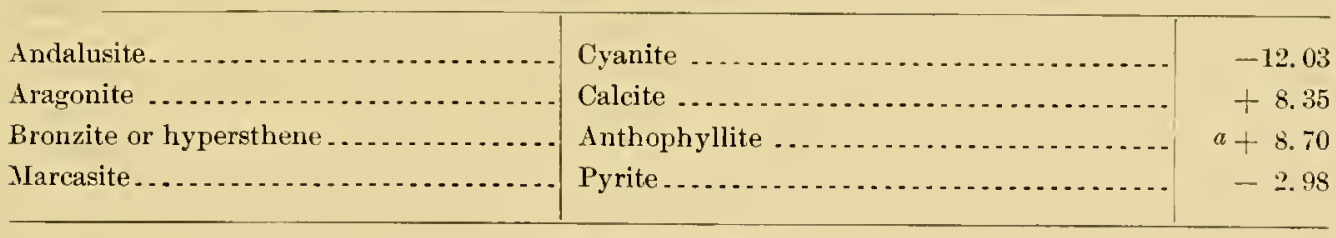


TABLE D.-Classification of alterations, with volume changes-Continued. CHLORIDATION.

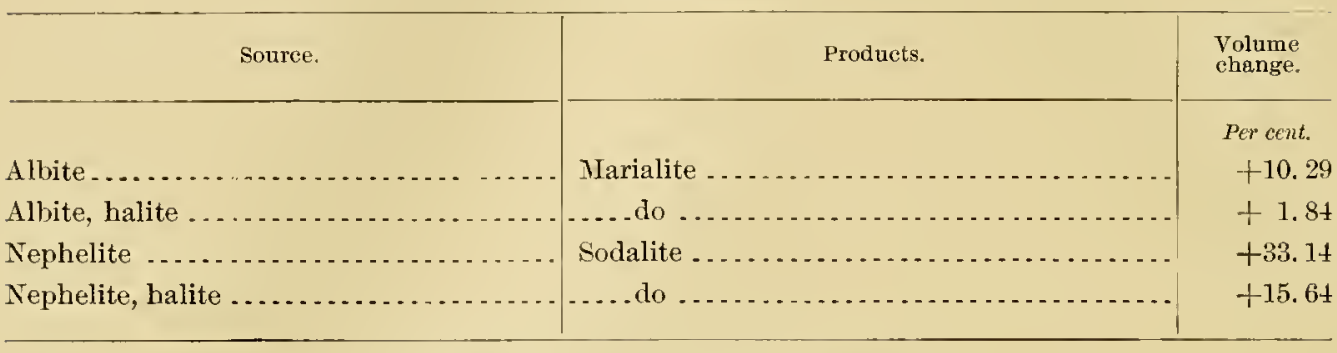

DEBORATION AND DECARBONATION.

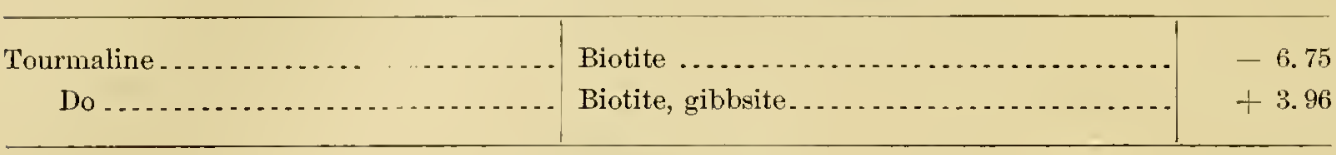

\section{DECARBONATION.}

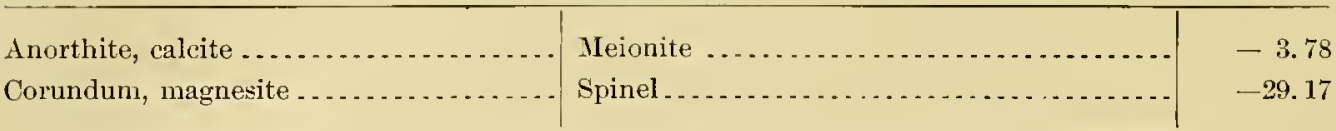

DECARBONATION AND TITANATION.

\begin{tabular}{|c|c|c|}
\hline Rutile, siderite....... & Ilmenite $\ldots \ldots \ldots$ & -34.77 \\
\hline
\end{tabular}

\section{DEHYDRATION.}

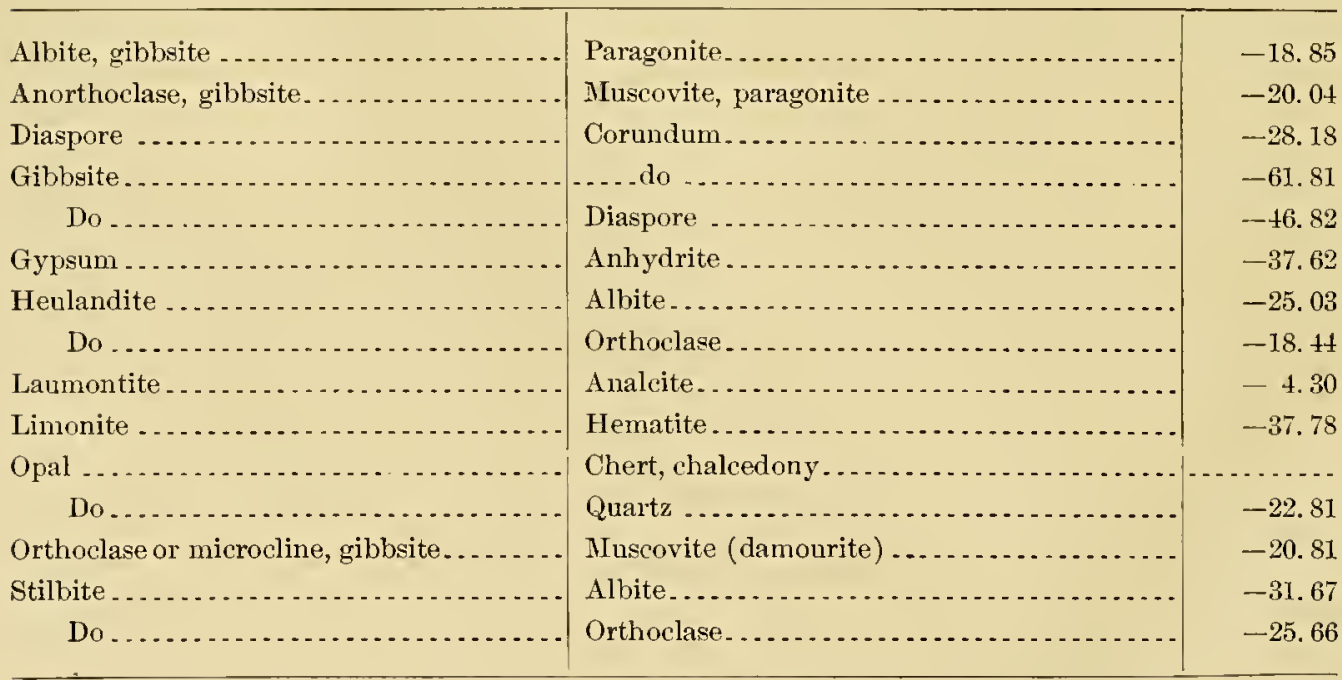


TABLES.

TABLE D.-Classification of alterations, with volume changes-Continued. DEHYDRATION AND DECARBONATION.

\begin{tabular}{|c|c|c|}
\hline Source. & Products. & $\begin{array}{l}\text { Volume } \\
\text { change. }\end{array}$ \\
\hline Analcite . . . . . . . . . . . . . . . . & 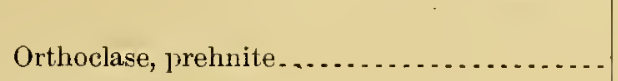 & $\begin{array}{l}\text { Per cent. } \\
\quad-14.09\end{array}$ \\
\hline Anorthoclase, gibbsite . . . . . . . . . . . & 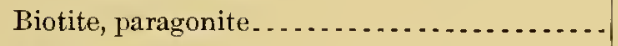 & -10.91 \\
\hline Apophyllite ................ & Pectolite $\ldots \ldots+\ldots$ & -19.48 \\
\hline Chabazite ............ & 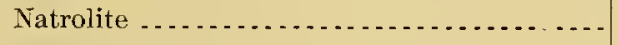 & -4.58 \\
\hline Diaspore, magnesite.................. . . & Spinel . . & -40.39 \\
\hline Gibbsite, magnesite $\ldots \ldots \ldots$ & 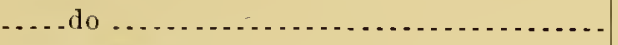 & -60.12 \\
\hline Laumontite . . . . . . . . . . . . . . & Orthoclase, prehnite. .................... & -17.75 \\
\hline Mesolite ...... & Prehnite_........ & -15.05 \\
\hline Natrolite _. $\ldots \ldots \ldots$ & 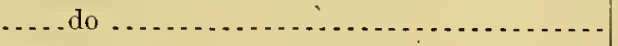 & -16.12 \\
\hline $\begin{array}{l}\text { Orthoclase or microcline, magnesite, sider- } \\
\text { ite, gibbsite. }\end{array}$ & Biotite.. $.6 \ldots \ldots \ldots$ & -22.33 \\
\hline Scolecife.................. & Prehnite. $\ldots \ldots \ldots \ldots$ & -16.66 \\
\hline
\end{tabular}

HYDRATION, DESILICATION, AND DECARBONATION.

\begin{tabular}{|c|c|c|}
\hline Anorthoclase, calcite, ${ }^{\circ}$ ematite. .. & Epidote, quartz $\ldots \ldots \ldots \ldots$ & -28.30 \\
\hline Biotite, hematite. . . . . . . . . . & Biotite-chlorite, epidote, quartz, diaspore... & +1.81 \\
\hline $\begin{array}{l}\text { Orthoclase or microcline, calcite, hema- } \\
\text { tite. }\end{array}$ & Epidote, quartz ... & -33.73 \\
\hline $\begin{array}{l}\text { Orthoclase or microcline, magnesite, sid- } \\
\text { erite. }\end{array}$ & 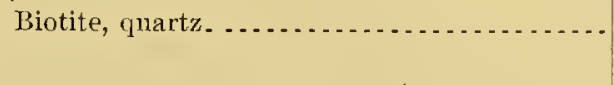 & -22.64 \\
\hline
\end{tabular}

DEOXIDATION.

\begin{tabular}{|c|c|}
\hline Hematite $\ldots . . .6 \ldots$ & 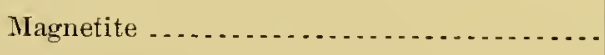 \\
\hline
\end{tabular}

\section{DESILICATION.}

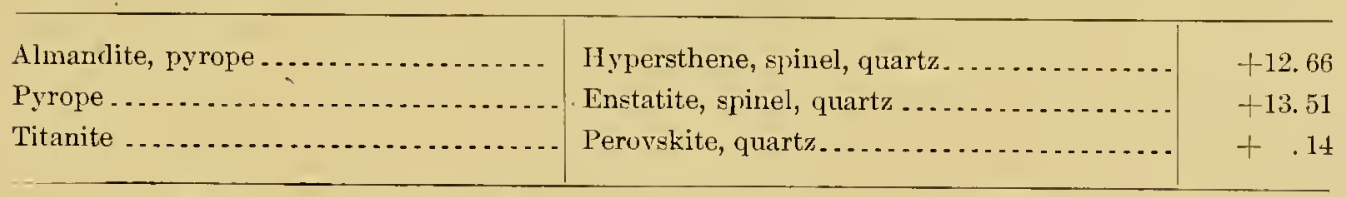

MON XLVII-0 $0 t-26$ 
TABLE D.-Classification of alterations, with volume changes-Continued. HYDRATION.

\begin{tabular}{|c|c|c|}
\hline Source. & Products. & $\begin{array}{l}\text { Volume } \\
\text { changes. }\end{array}$ \\
\hline & & Per cent. \\
\hline Andalusite...................... & Kaolin ..................... & -3.15 \\
\hline 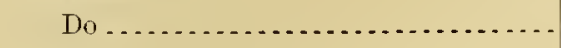 & 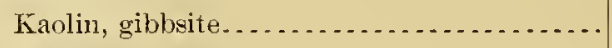 & +61.87 \\
\hline Anhydrite . . . . . . . . & 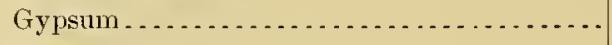 & +60.30 \\
\hline Anorthite .... .................. & Gismondite $\ldots \ldots \ldots \ldots \ldots$ & +52.76 \\
\hline Do.... & Thomsonite. . . . . . . . . . . . . . & +34.65 \\
\hline Do $\ldots . . . . .$. & Zoisite, kaolin . . . . . . . . . . . . . . . . . . & -7.77 \\
\hline Anorthite, hematite................. . & Epidote, kaolin, gibbsite. . . . . . . . . . . . . & t. 3.60 \\
\hline Cancrinite ....................... & Natrolite, gibbsite, calcite. . . . . . . . . . . . - & +8.64 \\
\hline Corundum . . . ..... & 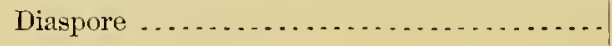 & +39.25 \\
\hline Do.. & Gibbsite............. & +161.83 \\
\hline Cyanite ..................... & Kaolin . . . . . . . . . . . . . . . & +10.11 \\
\hline Do . . & 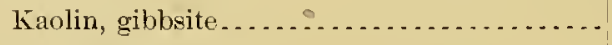 & +84.02 \\
\hline Hematite . . . . . & Limonite . . . . . . . . . . . . . . . . . . & +60.72 \\
\hline Iolite (cordierite) ... & Chlorophyllite $\ldots \ldots \ldots$ & .86 \\
\hline Lencite. ... & Analcite ........................... & +10.74 \\
\hline Meionite, hematite . . . . . . . . . & Epidote, gibusite. . . . . . . . . . . . . . . . & -1.62 \\
\hline Nephelite..... & 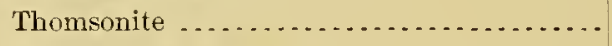 & +24.60 \\
\hline Pyrope. & Talc, spinel, gibbsite ................... & $+36.8 t$ \\
\hline Serpentine... . & Webskyite ..... & ........ \\
\hline Sillimanite ..... & 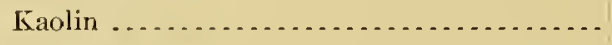 & -1.47 \\
\hline Do.. & 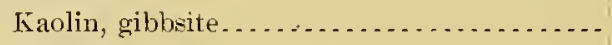 & +64.67 \\
\hline Zircon . - & Malacon (hydrous zircon) ................ & +24.05 \\
\hline
\end{tabular}

HYDRATION AND DECARBONATION.

\begin{tabular}{|c|c|c|}
\hline Andalusite. . . . . . . . . . . . . . . . . . & 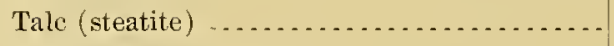 & -32.37 \\
\hline Do . - & Talc, gibbsite . . . . . . . . . . . . . . . . & +97.67 \\
\hline Do $\ldots \ldots \ldots \ldots \ldots$ & Muscovite (daunourite) ................. & -. 9.55 \\
\hline Do ............... & Muscovite, gibbsite..................... & +55.47 \\
\hline Biotite ... & Chlorite . . . . . . . . . . . & +22.92 \\
\hline Cyanite . . . . . . . . . . . . . . . & 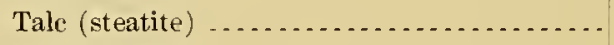 & -23.12 \\
\hline Do $\ldots \ldots \ldots \ldots \ldots \ldots$ & Talc, gibbsite . . . . . . . . . . . . . . . . . . & +124.71 \\
\hline Do $\ldots$ & Muscovite (damourite) .................. & +2.83 \\
\hline Do.......... & Muscovite, gibbsite. . . . . . . . . . . . . & +76.74 \\
\hline Muscovite .... & 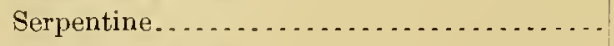 & +16.50 \\
\hline Do $\ldots \ldots \ldots$ & Serpentine, gibbsite . . . . . . . . . . . . . & +88.44 \\
\hline Do . . . . . . . . & 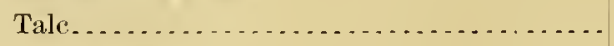 & -25.23 \\
\hline Do & Talc, gibbsite .... & +46.69 \\
\hline
\end{tabular}


TABLES.

TaBLE D. - Classification of alterations, with volume cluanges-Continued.

HYDRATION AND DECARBONATION-Continued.

\begin{tabular}{|c|c|c|}
\hline Source. & Products. & $\begin{array}{l}\text { Volume } \\
\text { change. }\end{array}$ \\
\hline Phlogopite. & Chlorite . - & $\begin{array}{l}\text { Per cent. } \\
+\quad+1.02\end{array}$ \\
\hline Sillimanite.. & Muscovite (damourite) & -7.98 \\
\hline Do $\ldots \ldots . .$. & Muscovite, gibbsite.............................. & +58.16 \\
\hline Do . & 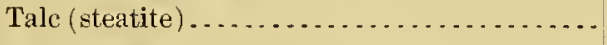 & -31.20 \\
\hline Do ... & Talc, gibbsite...$\ldots \ldots \ldots \ldots \ldots \ldots \ldots \ldots$ & +101.09 \\
\hline Staurolite........ & Chlorite (amesite), gibbsite ................. & +103.58 \\
\hline
\end{tabular}

HYDRATION AND DECHLORIDATION.

Sodalite .................... Thomsonite.................... Th.

HYDRATION, DECHLORIDATION, CARBONATION, AND DESILICATION.

Marialite ..................... $\mid$ Inscovite, quartz . . . . . . . . . . . . .

HYDRATION, DECHLORIDATION, AND DECARBONATION.

\begin{tabular}{|c|c|c|}
\hline 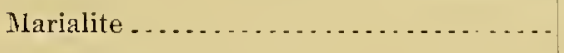 & Kaolin, tale................ & $+\quad 7.69$ \\
\hline
\end{tabular}

HYDRATION AND DEFLUORIDATION.

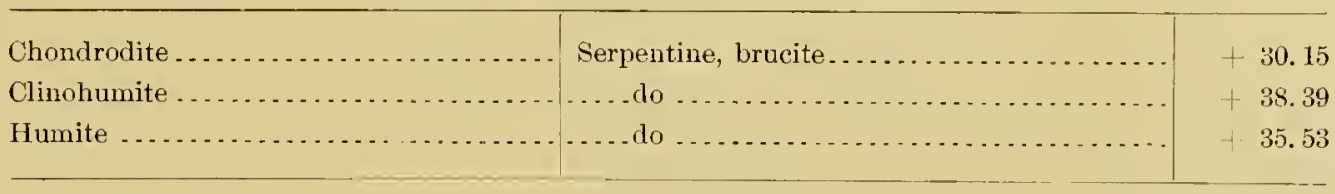


TABLE D. - Classification of alterations, with volume changes-Continued. HYDRATION AND DESILICATION.

\begin{tabular}{|c|c|c|}
\hline Source. & Products. & $\begin{array}{l}\text { Volume } \\
\text { change. }\end{array}$ \\
\hline- & & Per cent. \\
\hline Albite.. & Analcite, quartz ...... & +20.82 \\
\hline Do $\ldots \ldots \ldots \ldots$ & Natrolite, quartz ................ & +19.95 \\
\hline Albite, anorthite, orthoclase ... & Albite, zoisite, muscovite, quartz.. & - ........ \\
\hline Almandite, pyrope ..... & Aphrosiclerite, quartz .... & +50.98 \\
\hline Anorthite ........ & Zoisite, gibbsite, quartz........ & -4.58 \\
\hline Do $\ldots . . . . . . .$. & Prehnite, gibbsite, quartz.... & +14.85 \\
\hline Anorthite, hematite . . & Epidote, gibbsite, quartz ... & +6.57 \\
\hline Anthophyllite ... & Bastite ................ & +12.09 \\
\hline Do $\ldots \ldots \ldots \ldots$ & Bastite, quartz ........... & +34.09 \\
\hline Bronzite or hypersthene $\ldots . . . . . . . .$. & Bastite . . . . . . . . & $a+22.77$ \\
\hline Do. & Bastite, quartz _. & $\begin{array}{l}b+15.65 \\
a+46.87\end{array}$ \\
\hline Cummingtonite & Bastite & $\dashv-14.20$ \\
\hline Do......... & Bastite, quartz . . . . . . . & +36.76 \\
\hline Enstatite ............. & Serpentine. . . . . . . . . . & +14.25 \\
\hline Do $\ldots \ldots$ & Serpentine, quartz ...... & +38.36 \\
\hline Orthoclase (sce Albite). & . & \\
\hline Prehnite. . . . . . . & Chlorite, quartz ........ & +3.27 \\
\hline Pyrope $\ldots . . . . . . . .$. & .... do ................. & +56.02 \\
\hline Do ................ & Serpentine, gibbsite, quartz . . & +81.61 \\
\hline Pyrope (see Almandite). & & \\
\hline Serpentine . - & Brucite, quart\% & +9.82 \\
\hline
\end{tabular}

HYDRATION AND OXIDATIUN.

\begin{tabular}{|c|c|c|}
\hline Anthophyllite & Talc, hematite... & +11.41 \\
\hline Do ..... & Talc, limonite ..... & \\
\hline Bronzite or hypersthene... & Talc, hematite . .......... & - - \\
\hline Do .......... & Tale, limonite $\ldots . . . . . . . . . . . . . .$. & - . - \\
\hline Do $\ldots . . . . .$. & Talc, magnetite $\ldots$ & $\begin{array}{l}b+14.68 \\
a+21.73 \\
c-1-18.20\end{array}$ \\
\hline $\begin{array}{l}\text { Magnetite ... } \\
\text { Olivine ..... }\end{array}$ & 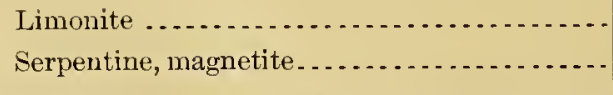 & $\begin{array}{l}+64.63 \\
+29.96\end{array}$ \\
\hline
\end{tabular}


TABLES.

TABLE D. - Classification of alterations, with volume changes-Continued.

HYDRATION, OXIDATION, AND DESILICATION.

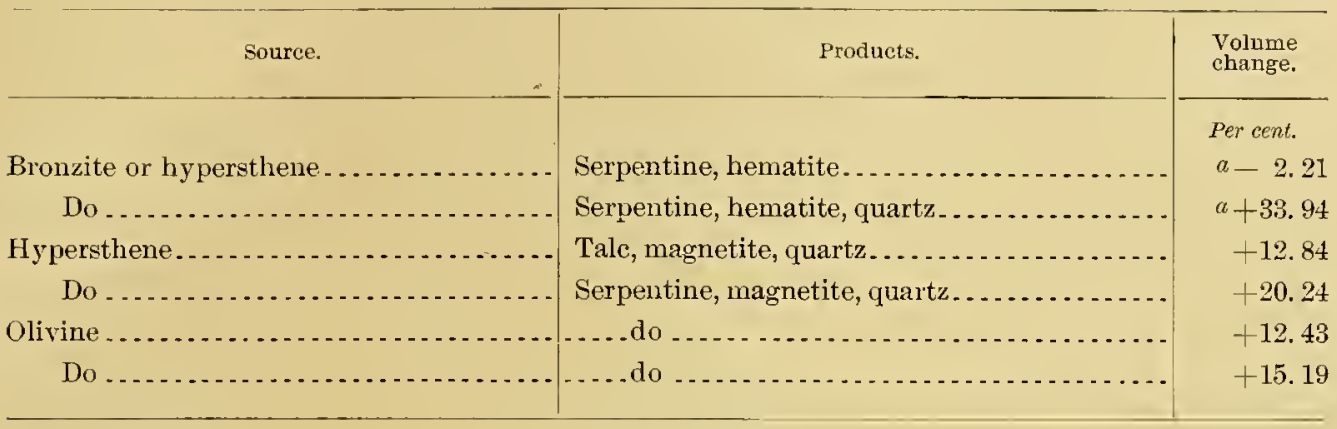

HYDRATION AND SILICATION.

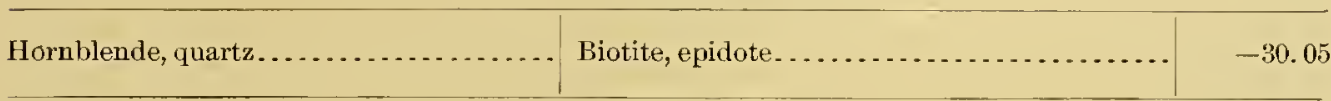

MOLECULAR DIVISION.

Spodumene (beta-spodumene) ......... Eucryptite, albite.................

OXIDATION.

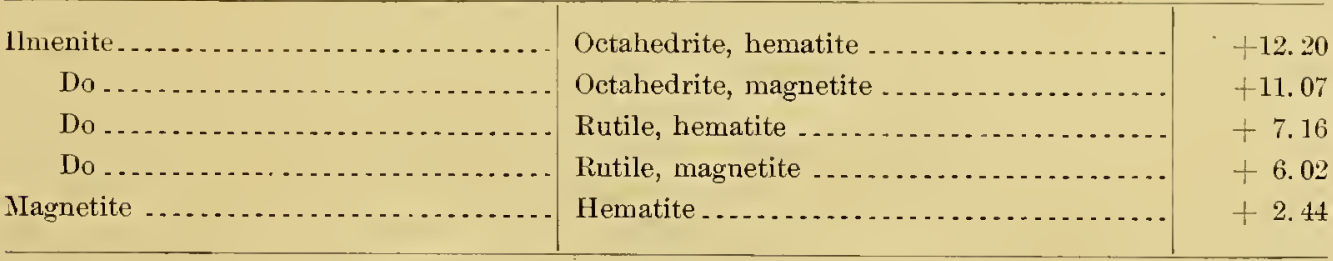

OXIDATION AND TITANATION.

Rutile, magnetite.................. $\mid$ Ilmenite, hematite ................

OAIDATION AND DECARBONATION.

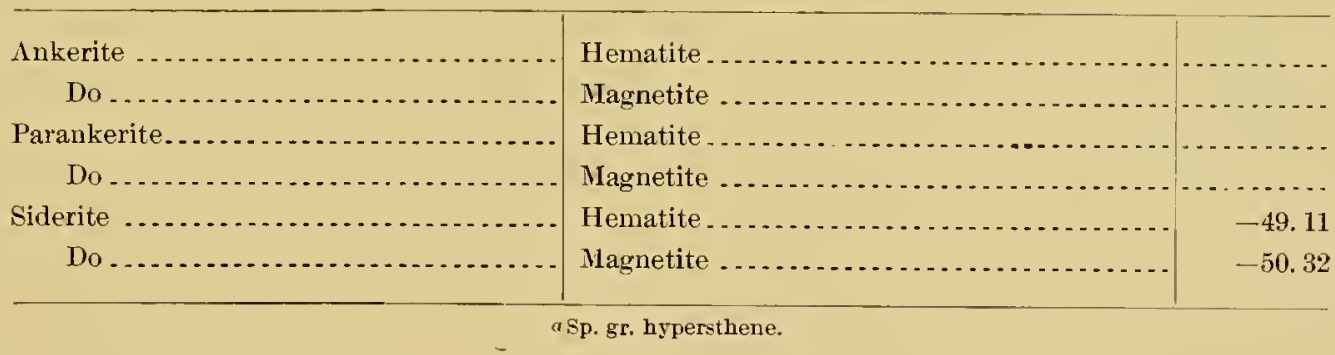


TABLF D.-Classification of alterations, with volume changes - Continued. OXIDATION, DECARBONATION, AND DESULPFIDATION.

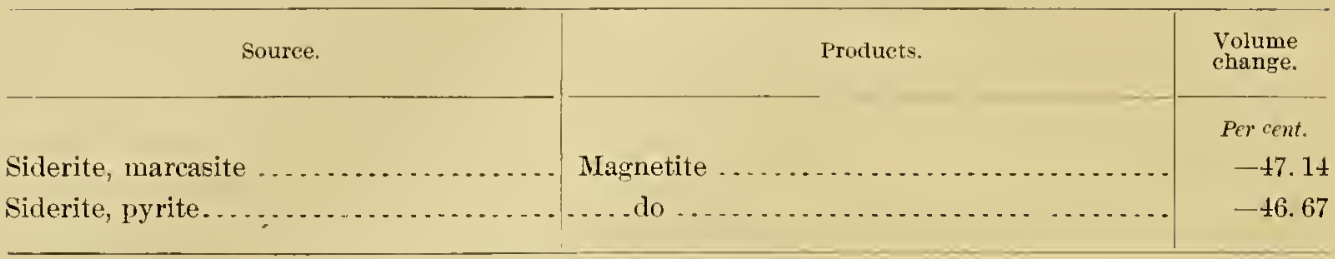

OXIDATION, HYDRATION, AND DECARBONATION.

\begin{tabular}{|c|c|c|}
\hline 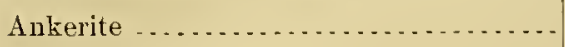 & Limonite.................. & .. \\
\hline Meionite. - & Epidote, gibbsite. . . . . . . . . & +7.55 \\
\hline Parankerite........... & Limonite ............... . . & . . . . . . . . \\
\hline Siderite... . & .... do ....... & -18.22 \\
\hline Stanrolite. . & Muscovite (damourite) & -24.96 \\
\hline Do $\ldots .$. & Muscovite, magnetite, gibbsite ........... . & +68.08 \\
\hline Do $\ldots . . . . .$. & 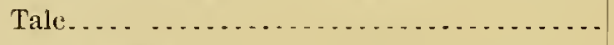 & -44.02 \\
\hline Do.. & 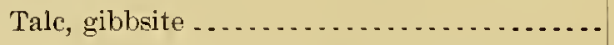 & +90.96 \\
\hline
\end{tabular}

OXIDATION, HYDRATION, AND DESULPHIDATION.

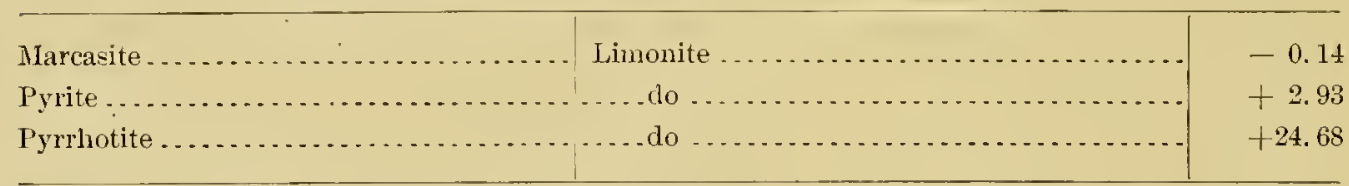

OXIDATION AND DESULPHIDATION.

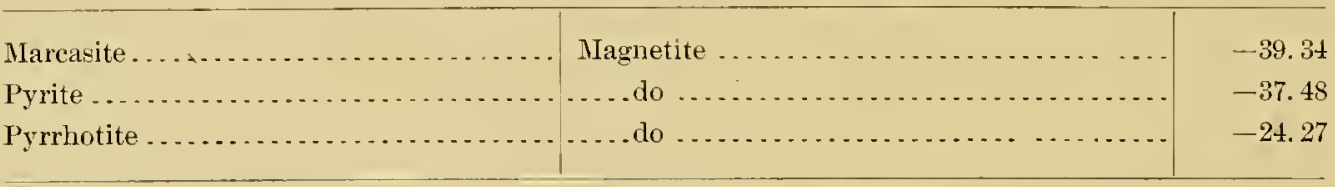

\section{SILICATION.}

\begin{tabular}{|c|c|c|}
\hline 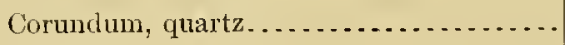 & 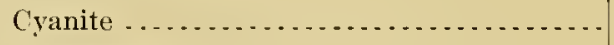 & -6.59 \\
\hline$\ldots \ldots \ldots . . .6$ & Sillimanite....................... & +4.38 \\
\hline Gehlenite... & Grossularite .... & -4.42 \\
\hline Gehlenite, quartz..... & - .... do & -18.56 \\
\hline Olivine, quartz......... & Anthophyllite .......... & -1.48 \\
\hline Nephelite, quartz . . . . . . . . . . . . . & $\ldots \ldots \ldots \ldots \ldots \ldots \ldots \ldots \ldots \ldots$ & -.41 \\
\hline
\end{tabular}


TABLES.

TABLE D.-Classification of alterations, with volume changes-Continued.

SILICATION AND DECARBONATION.

\begin{tabular}{|c|c|c|}
\hline Source. & Produets. & $\begin{array}{l}\text { Yolume } \\
\text { change. }\end{array}$ \\
\hline & & Per cent. \\
\hline Ankerite or parankerite, quartz. & Actinolite . & -32.72 \\
\hline Do . & Actinolite, calcite.- & -22.62 \\
\hline Do .... & Sahlite.... & -37.27 \\
\hline Bronzite or hypersthene, calcite, quartz.. & Actinolite & $\left\{\begin{array}{l}a-10.77 \\
b-7.40\end{array}\right.$ \\
\hline Calcite ...... & Wollastonite.. & +10.81 \\
\hline Calcite, quartz .......... & .... do ............... & -31.48 \\
\hline Dolomite ... . . . . . . & Diopside... . & +2.03 \\
\hline Dolomite, quartz...... & .... do ....... & -40.11 \\
\hline Dolomite ............ & Tremolite, calcite....... & +9.89 \\
\hline Dolomite, quartz ...... & ....do......... & -25.20 \\
\hline Dolomite............. & Tremolite, wollastonite............... & +14.00 \\
\hline Dolomite, quartz ...... & ..... do ...... & -33.09 \\
\hline Forsferite, calcite, quartz . & Tremolite...... & -12.29 \\
\hline Olivine, calcite, quartz ... & ( & $-13.3 \frac{1}{1}$ \\
\hline Rutile, calcite, quartz. . ........ & Titanite.............. & -28.17 \\
\hline Siderite, quartz. . & Grünerite . . . . . & -32.53 \\
\hline
\end{tabular}

SILICATION AND DEHYDRATION.

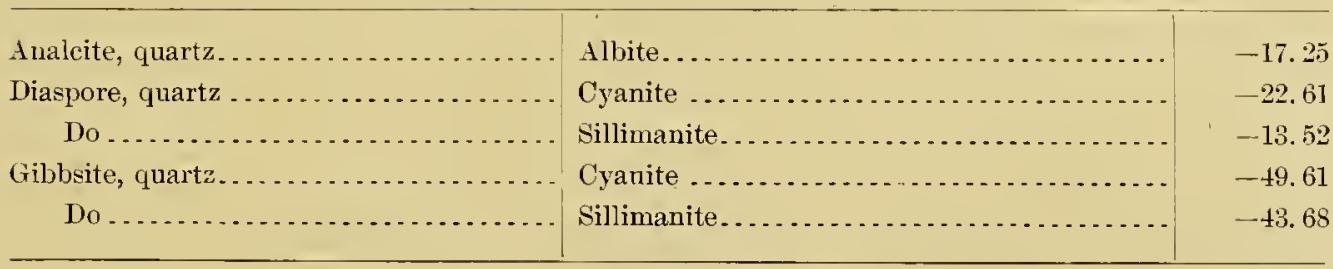

SILICATION, DEHYDRATION, AND DECARBONATION.

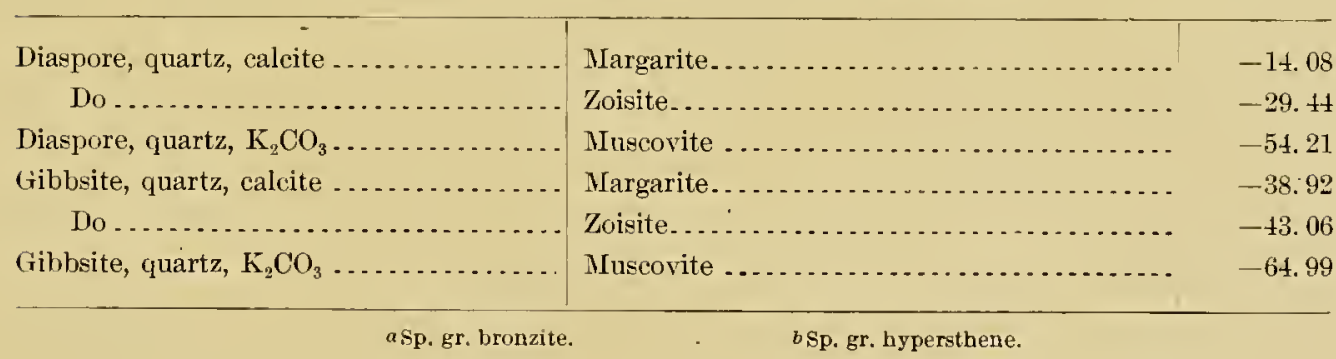


TABLE D.-Classification of alterations, with volume changes-Continued. SILICATION, HYDRATION, AND DECARBONATION.

\begin{tabular}{|c|c|c|}
\hline Source. & Products. & $\begin{array}{l}\text { Yolume } \\
\text { change. }\end{array}$ \\
\hline & & Per cent. \\
\hline Corundum............ & Margarite... & +159.02 \\
\hline Corundum, quartz, calcite & do ............... & -1.22 \\
\hline Corundum . . & Zoisite................. & +261.34 \\
\hline Cornndum, quartz, calcite & .... do & -23.58 \\
\hline Corundun............. & Muscovite (damourite) ........ & +264.25 \\
\hline Corundum, quartz, $\mathrm{K}_{2} \mathrm{CO}$ & . & +1.62 \\
\hline
\end{tabular}

SILICATION, OXIDATION, AND DECARBONATION.

\begin{tabular}{|c|c|c|}
\hline Ilmenite.... & Titanite .. & +76.35 \\
\hline Ilmenite, calcite, quartz . . . . . . . . . . . & Titanite, magnetite ............ & -22.35 \\
\hline
\end{tabular}

SUBSTITUTION OF BASES.

\begin{tabular}{|c|c|c|}
\hline Angite ................ & Hornblende ........ & +4.30 \\
\hline Augite, siderite, magnesite.......... & Hornblende, calcite. .... & +6.14 \\
\hline Calcite ................. & Dolomite ........... & -12.30 \\
\hline Diopside . . . . . . . . . & Tremolite............ & +5.68 \\
\hline Diopside, magnesite ......... & Tremolite, calcite ..... & +10.55 \\
\hline Hormblende ............ & Augite. . . . . . . & -4.13 \\
\hline Lencite... . . . . . . . & Orthoclase, nephelite...... & -7.59 \\
\hline Muscovite ......... . & Paragonite. . . . . . . . . . . & -2.67 \\
\hline Olivine, anorthite $\ldots . . . . . . .$. & Actinolite, spinel..... . & -7.18 \\
\hline Sahlite .............................. & Actinolite.......... & +7.28 \\
\hline Sahlite, siderite, magnesite ................. & Actinolite, calcite ....... & +10.81 \\
\hline Spodumene..... & Beta-spodumene ....... & +24.72 \\
\hline \multicolumn{3}{|c|}{ SULPHIDATION. } \\
\hline & Pyr & +21.13 \\
\hline
\end{tabular}

SULPHIDATION, DEOXIDATION, AND CARBONATION.

\begin{tabular}{|c|c|c|}
\hline Hematite .... & Marcasite, siderite $\ldots \ldots \ldots \ldots \ldots \ldots \ldots . . . . . . . .$. & +78.73 \\
\hline Do $\ldots$ & Pyrite, siderite... & +76.12 \\
\hline
\end{tabular}




\section{CHAPTER VI. \\ THE BELT OF WEA'THERING.}

In Chapter IV general statements were made as to the nature of the alterations of the belt of weathering and the relations of these to alterations in the belt of cementation and the zone of anamorphism. The statements were mainly from the physical-chemical point of view, and no attempt was made to give in detail the facts upon which they were based. It is the, purpose of the present chapter, first, to consider fully the phenomena of the belt of weathering from a geological point of view, and, second, to interpret these phenomena in terms of the physical-chemical principles which have been developed in the previous chapters. However, the two are not separately considered, but are interwoven.

\section{BELT OF WEATHERING DEFINED.}

The belt of weathering has been shown to be a part of the zone of katamorphism. (See Cliapter IV.) From a physical-chemical point of view this belt is one in which the reactions take place with liberation of heat, and with expansion of volume provided all the compounds formed remain in situ.

At a variable depth below the surface of the earth ground water is a -comnected body which fills all of the openings. The position of the surface of this body of water may be called the level of ground water. Above the level of ground water the openings are ordinarily not filled with water. From a geological point of view the belt of weathering is the surficial belt extending from the surface of the earth to the level of ground water. The thickness of this belt varies greatly. Át or near streams, lake, or ocean, and in areas where the surface is not much higher than the adjacent 'bodies of water, the level of ground water may reach near or to the surface, and thus there be for these areas either a very thin upper belt or even none. In regions of average precipitation, moderate elevation, and moderate irregularities of topography the level of ground water is nsually from 3 to 30 
meters from the surface. It is especially likely to be near the surface in regions where there is abundant precipitation and a thick layer of drift or a thick layer of disintegrated rocks. In elevated and irregular regions, especially those in which the precipitation is rather small, the level of ground water is frequently 30 to 90 meters below the surface, and in high desert regions the level of ground water may be 300 or more meter's below the surface.

The above general statements may be illustrated by various regions of the United States. In the humid regions of eastern United States the level of ground water varies from 0 to 27 or 30 meters below the surface. Throughont the greater part of the drift-covered region the sea of ground water is penetrated at a depth of less than 15 meters, although on the higher drift hills the level of ground water may be from 15 to 30 meters

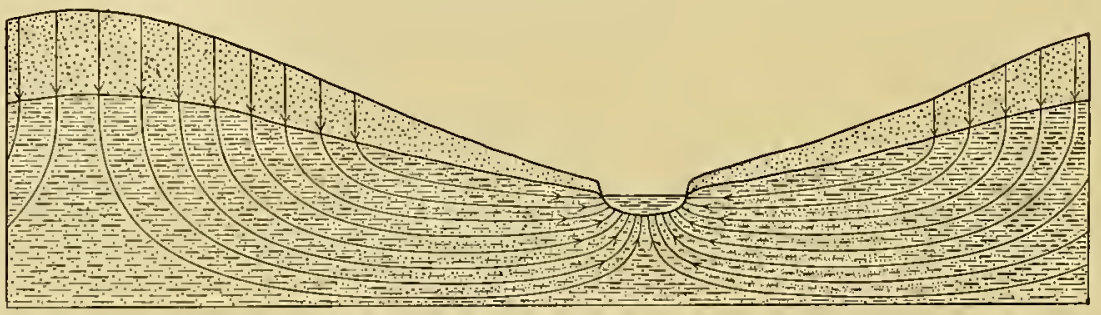

FIG. 5.-Relations of level of ground water to topography and to surface drainage. Lines with arrows are lines of flow. After King.

below the surface. For the disintegrated regions of the southern Appalachians, water is generally reached at a depth of less than 30 meters. For the greater part of the Coastal and Gulf plains water is ordinarily found at a depth of less than 15 meters. In the high limestone region of Kentucky and Tennessee the level of ground water may be 60 to 90 meters below the surface. For the major portion of the western part of the great plateans east of the Cordilleras the level of ground water is from 30 to 75 meters below the surface, althongh adjacent to the streams it is less than this. ${ }^{a}$ In the arid regions cut by deep canyons the level of ground water may be far below the surface. In portions of such regions it is so deep that some anthors have concluded that water wholly fails. But that this is not so is shown by the numerons springs which issue in these regions along the

a Darton, N. H., Preliminary report on the geology and water resources of Nebraska west of the one hundred and third meridian: Nineteenth Ann. Rept. U. S. Geol. Survey, pt. 4, 1899, pl. cx. 
streams at the base of the canyons. For instance, in the Grand Canyon of the Colorado many springs issue near the river and along the side canyons. Some of these are large and are loaded with calcium carbonate. ${ }^{a}$ 'The rule is here, as elsewhere, that the level of ground water starts at the level of the river and rises toward the divide. But in this arid western country, dissected by deep, steep canyous and broken by immmerable fractures, the level of ground water in some places is as much as 1,000 meters or more below the surface.

While there is great variation in the depth of the level of ground water, and ground water is found only at a considerable depth in many regions, on the average the rlepth of ground water in the United States is not greatprobably in the neighborhood of 30 to 50 meters.

\section{FORM OF LEVEL OF GROUND WATER.}

From the foregoing it follows that the form and position of the level of ground water are largely dependent upon the topography, apon the character of the openings in the rocks, upon the precipitation, and upon other factor's. In general, the more accentuated the topography the greater is the difference between the elevation of the surface and the level of ground water. Where from a lowland a steep ridge rises, the level of ground water also rises, but less rapidly and with considerable deviation between the two. Where from a lowland there is a gentle rise, the level of ground water also rises gently, and it more nearly corresponds with the surface than in the case of an abrupt rise. The position of the level of ground water is largely dependent upon precipitation. In hmid regions it is apt to be near the surface; in arid regions it is farther from the surface.

The relations of the level of ground water to topography and to surface drainage are illustrated by fig. $5 .^{b}$ Where the openings in the rocks are numerous and large, there are much greater differences between the surface and the level of ground water than where the openings are few and small. For this there are two reasons: First, the precipitation in a region of large openings more readily makes it way through the openings to the drainage level than in a region where the openings are small, for resistance to movement increases as the openings become small, and therefore on

"Powell, J. W., Explorations of the Colorado River of the West, 1875, p. 94.

${ }^{b}$ King, F. H., Principles and conditions of the movement of ground water: Nineteenth Ann. Rept. U. S. Geol. Survey, pt. 2, 1899 , p. 99. 
account of the slow movement a greater head is necessary in order that equilibrium shall obtain in the sea of ground water between additions from precipitation and subtractions by flowage. Second, the level of the ground water is also dependent upon capillarity. The effect of capillarity is to raise the water surface in the small openings of the rocks above its natural level as found in wells. The amount of this rise is inversely as the diameter of the openings This amount, as shown on page 151, varies from nothing in the largest capillary tubes to 166 meters in circular tubes of limited size between capillary and subcapillary openings, and to 83 meters in similar sheet openings. In circular capillary openings between $1 \mathrm{~mm}$. and $0.001 \mathrm{~mm}$. in diameter the rise varies from $3.32 \mathrm{~cm}$. to 33.2 meters, and in similar sheet openings one-half of this amount. A comparison of the above numbers shows that in openings limiting those of capillary and subcapillary size the rise is five times these larger amounts. When it is remembered that in large classes of sediments, such as fine sands and clays, the openings approach subcapillary size, or even are of subcapillary size, it is evident that the amount which the level of ground water may be raised as a result of capillarity may be a very important factor in determining its position.

While the level of ground water in rocks in which the openings are capillary or subcapillary may be greatly affected by capillarity, in the supercapillary and larger capillary openings this is not an appreciable factor. It follows that there may be great changes in the level of ground water in passing from places where the openings are supercapillary to where they are capillary, and from places where the openings are capillary to where they are subcapillary.

Illustrations of these principles are found in all countries. In fractured limestone regions containing caves the level of ground water may follow approximately that of the drainage of the district, and thus there be a great difference between the topography of the surface and that of the gromdwater level. Where a region is covered with a thick mantle of fine material, as drift, the topography of the ground water may very closely follow that of the surface. A good illustration of an open limestone area is furnished by the Grand Canyon region of Colorado. In this district the topography is much accentuated and the rocks are largely limestone, commonly much 
fractured, and there is therefore great difference between the topography of the surface and that of the level of ground water. In contrast with this may be mentioned the drift-covered regions of North America. Here, even where the topography is only moderately accentuated, the level of ground water may rise rather rapidly. This is illustrated by the rise of that level where one passes from one of the numerous lakes of the region to the adjacent higher lands. A good instance is found at Madison, Wis. About 360 meters from Lake Mendota and 25 meters above its surface, on the slope of a hill, is a well in which the water is, on the average, about 15 . meters above the surface of the lake. ${ }^{a}$

\section{AMOUNT AND SOURCE OF WATER IN BELT OF WEATHERING.}

Under ordinary circumstances the water above the level of ground water is mainly that of inbibition. (See p. 124.) This water is held by the adhesion between the mineral particles and the water. But in the arid regions a large part of the belt of weathering may not contain more than a fraction of the water of imbibition. Whitney explains that not only the surface soil but strata below the soil are often so dry as to be dusty. ${ }^{b}$

However, in contrast with this, for many regions, and for much of the year, the water present is greater than that of imbibition and consequently includes water of hygrometricity. (See p. 124.) Indeed, locally, and for a time, the belt may be nearly or quite saturated with water: The upper belt is therefore characterized by conditions ranging from almost complete dryness, through water of imbibition, to almost complete saturation.

It has been shown in Chapter III that the circulating ground water is almost wholly derived from precipitation, although it is possible that a small fraction of this water is derived from deep within the earth. Before considering the circulation in the belt of weathering, it is necessary to understand how the precipitation is divided among the surface water, the belt of weathering, and the belt of cementation.

In the greater part of the very humid region comprising the southeastern United States the rainfall varies from 100 to $150 \mathrm{~cm}$., but runs up to $175 \mathrm{~cm}$. In this region, according to Newell, the run-off in streams is

a King, F. H., cit., p. 99.

$b$ Whitney, Milton, Conditions in soils of the arid region: Yearbook of the Dept. of Agric., 1894, pp. 159-160. 
about 50 per cent of the total precipitation. ${ }^{a}$ In the humid region 'of the United States comprising the Great Lakes region and a broad belt extending through to central Texas the rainfall varies from 50 to $100 \mathrm{~cm}$. The run-off in this region varies from $12 \mathrm{~cm}$. to nearly $50 \mathrm{~cm}$, or from 25 to 47 per cent, the smaller percentages of run-off corresponding to the lesser rainfalls. In the seniarid portion of the Cordilleran region, where the rainfall is 25 to $50 \mathrm{~cm}$., the run-off varies from 5 to $12 \mathrm{~cm}$., or is from 20 to 25 per cent of the precipitation. In the arid regions, where the precipitation is $25 \mathrm{~cm}$. or less, the run-off varies from 0 to $5 \mathrm{~cm}$, or from 0 to 20 per cent. Thus, according to Newell, the water flowing in the streams varies from 50 per cent or more of the precipitation in the most humid regions of the United States to 1 or 2 per cent in the most arid regions. ${ }^{b}$

All these cases fall under the general rule given by Powell, "that the coefficient of run-off increases with the rainfall;" "and it may be stated generally "that in humid countries the percentage of ron-off to rainfall is larger than in the arid regions; and, of several localities, that one having the greatest mean annual rainfall will, cæeteris paribus, have a run-off disproportionally large to the others." ${ }^{\text {d }}$ However, as pointer ont by Powell, it does not follow from this that the annual run-off of any one basin is directly proportional to the measured annual rainfall, for there are many factors entering into the rum-off besides the amount of the precipitation. Some of these factors are the distribution of precipitation during the year, the temperature and other climatic conditions, the topography, the chemical and physical character of the soil, cultivation, vegetation, etc. Of these secondary factor's that of topography is very important. In proportion as the declivities are steep the rum-off is likely to be large; in proportion as the slopes are gentle the rum-off is likely to be small. It follows from this that the relative run-off is less in large drainage basins than in small ones, because the large drainage basins are apt to have a greater percentage of level land. ${ }^{e}$

a Newell, F. H., Results of stream measurements: Fonrteenth Ann. Rept. U. S. Geol. Survey, pt. 2, 1894, pp. 149-154, pls. v and vi.

$b$ Newell, F. H., Irrigation in the United States, Crowell \& Co., New York, 1902, p. 27.

c Powell, J. W., Second annual report of the irrigation survey: Eleventh Ann. Rept. U. S. Geol. Survey, pt. 2, 1891, p. 27

a Powell, cit., p. 27.

e Newell, F. H., Water supply for irrigation: Thirteenth Ann. Rept. U. S. Geol. Survey, pt. 3, 1893, pp. 13-14. 
This rule is well illustrated by the arid and semiarid regions, where a very large portion of the run-off is that of the precipitation of the mountain regions. Whitney estimates that in the level districts of the arid region of the United States, even where the rainfall is as high as $50 \mathrm{~cm}$., only 10 per cent, or $5 \mathrm{~cm}$, of the rainfall passes into the run-off. ${ }^{a}$

The cultivation of the soil is another of the secondary factors which has an important influence in the amount of run-off. Proper soil cultivation produces a rough surface having many minor depressions arranged in such a way as to have the chamnels follow the contours. Also, cultivation produces numerons large openings in the upper 5 to $30 \mathrm{~cm}$. of the soil. As a result, when precipitation comes the depressions hold the water. From these depressions it makes its way easily into the large openings. The big openings give a large surface from which the water can make its way into the smaller openings of the soil. Therefore, in cultivated soil a much larger portion of the water makes its way into the soil than under natural conditions. The run-off is greatly decreased and the water for circulation in the belt of weathering is greatly increased.

It will be seen later, in considering the belt of cementation, that the run-off includes both the water which never goes below the surface of the ground and that which issues from the belt of cementation. Much the larger part of the water of the belt of cementation passes through the belt of weathering on its way to the belt of cementation. All of the water not included in the run-off has its entire circulation in the belt of weathering. In the United States it follows, from the figures above given, that the entire circulation of about 50 per cent of the precipitation in the more humid regions is confined to the belt of weathering. In the less humid regions from 53 to 75 per cent is confined to this belt. In the semiarid regions from 75 to 90 per cent is confined to this belt. In the arid regions from 90 to 100 per cent of the precipitation has its only ground circulation in the belt of weathering. It is therefore clear that the proportion of the water of precipitation concerned in the circulation of the belt of weathering is much greater than that concerned in the circulation of the belt of cementation; for the belt of weathering has exclusive control of from 50 to 100 per cent of the total precipitation, and nearly all of the water of the belt of cementation first circulates in the belt of weathering.

"Whitney, Milton, Conditions in soils of the arid region: Yearbook of the Dept. of Agric., 1894, pp. $157-159$. 
However, it does not follow that the water present in the belt of weathering at any one time is as great as the amount in the belt of cementation. Indeed, the amount of water in the belt of weathering is only a small fraction of that in the belt of cementation. The explanation of this is that the water contributed to the belt of weathering remains in the belt only a short time-a few minutes, a few hours, a few days, or possibly a few years; while much of the water of the belt of cementation remains in that belt for many years. In the case of the deeper and longer circulations of the latter belt, as shown on pages 585-586, much of the water must have remained underground for centuries. Therefore, while a much larger percentage of the water of precipitation takes part in the circulation of the belt of weathering than in the belt of cementation, at any given time the amount of water at work in this belt is much less than that in the belt of cementation.

\section{THE CIRCULATION.}

It has already been seen (pp. 146-152) that the chief factors which control the movement of the water in the belt of weathering are (1) gravity, (2) mechanical movement, (3) molecular attraction, and (4) plant roots. The special action of these factors in the belt of weathering needs consideration.

The force of gravity is vertical and downward, and therefore, so far as this force is concerned, there is a continual tendency for water to be drawn from above the surface of the ground into and directly through the belt of weathering to the belt of cementation. Where the different parts of the water interfere, as they do in the belt of cementation, there may be superimposed on this vertical movement very important lateral movements, as seen on pages 572-576. But the interference due to hydrostatic pressure comes only when the rocks are saturated. In general the rocks of the belt of weatliering are not saturated; and hence the lateral novements in this belt due directly to gravity are unimportant, except locally and for short periods of time.

In the belt of weathering the effect of mechanical movement controlled by gravity is to steadily make the soils more compact, and thus to decrease the size of the openings and so to promote capillary action. Also, to some extent, mechanical consolidation tends to squeeze out the moisture and so to force it to the surface or to the belt of cementation. 
The influence of molecular attraction is to draw the water from areas of more moisture to areas of less moisture. Since the water falls upon the surface, the first tendency of this force is, like that of gravity, to draw the water from the surface into the soil and downward. However, there are many modifications of this general tendency. Immediately after precipitation molecular attraction works very effectively with gravity in carrying the water downward, but after rainfall has ceased, evaporation near the surface very frequently results in the surface soil containing less moisture than the subsoil or the deeper parts of the belt of weathering. Under these circunstances the force of molecular attraction draws the water from below the surface toward the surface, in opposition to gravity. Also, whenever the belt of weathering is somewhat deficient in moisture, molecular attraction tends to draw water from below the level of ground water into the belt of weathering. These novements are either upward or downward; but whenever local conditions produce lateral variations in moisture, molecular attraction tends to give the water a horizontal component from places of more moisture to places of less moistme.

Wherever roots are present they absorb water from the immediately adjacent soils, and carry it surfaceward. The roots extend both vertically and laterally, and hence the movement of water due to roots is both lateral and vertical. Where roots are present, on accomnt of the absorption of water the soil adjacent to the roots is deficient in amount. As soon as this deficiency appears the force of molecular attraction carries the water from places of more moisture to those places of less moisture, and thus replenishes the supply.

The downward and upward movements of water controlled by the above forces are of such conseqnence that they are entitled to separate consideration.

\section{DOWNWARD MOVEMENTS OF WATER.}

As has been seen, the general forces producing downward movement of water are gravity and molecular attraction; with these forces mechanical movement may cooperate. The results which these forces accomplish are very different under different circumstances. Some of the most important of the variable circumstances affecting the downward movement of water are the irregularities in precipitation and the amount of water in the soil and subsoil.

MON XLVII-6 $04-27$ 
If precipitation comes suddenly and abundantly an upper layer of the soil may become saturated, and this layer be separated from the belt of saturation below by a layer in which the pore spaces are largely occupied by air. The air below the surface layer of saturation prevents the ready passage of the water downward, and if precipitation continnes a large part of the falling water may be prevented by the air from easily making its way into the soil, and consequently joins the run-off. But, as explained later, where the soil is cultivated deeply, so as to leave a considerable percentage of large openings near the surface, and from this supply a temporary reservoir is furnished, a considerably larger proportion of the precipitation may get into the gromend than in uncultivated areas.

The water in an upper saturated layer may make its way downward in two ways, (1) the confined air below slowly escapes, either by upward creep or throngh the rare larger passages which are not filled with water, and the water consequently moves downward; and (2) if the soil particles below the layer of saturation are moistened or contain water of imbibition, the water driven by gravity and capillarity slowly creeps downward along the surfaces of the particles.

If, however, the particles below the upper layer of saturation be entirely dry, this condition exerts a strong retarding influence. Says Whitney: "Water does not readily spread throngh a previously dry soil, because the tension or contracting power of the surface of the water is greater than the attraction of the soil grains, which tends to cause its diffusion through the mass. One may see, therefore, a nearly saturated layer closely adjacent to a perfectly dry and dusty mass." ${ }^{a}$ The explanation of this retardation is expressed differently by Wolff, who attributes it to the elastic meniscus at the front of the moving water. ${ }^{b}$ (See p. 141.)

The above condition of affairs is especially likely to occur in the arid and semiarid regions, where a large part of the belt of weathering is very dry. According to Whitney, even where the amual rainfall is as much as $50 \mathrm{~cm}$, nearly the entire amount may remain within a few meters of the

a Whitney, Milton, Conditions in soils of the arid region: Yearbook of the Dept. of Agric., 1894, p. 160. King, F. H., Principles and conditions of the movement of ground water: Nineteenth Ann. Rept. U. S. Geol. Survey, pt. 2, 1899, p. 93 . Merrill, George P., Rocks, rock-weathering, and soils, Macmillan Co., New York, 1897, pp. 379-380.

$b$ Wolff, H. C., The unsteady motion of viscons liquids: Trans. Wisconsin Acad. Sci., Arts, and Letters, vol. 12, pt. 2, 1900, pp. 552-553. 
surface, and separated from the belt of cementation by a belt of dry soil. This holding of the water of precipitation near the surface, according to Whitney, explains the greater efficiency of water in the production of crops in the semiarid regions than in the humid regions. ${ }^{a}$

In opposition to the above, where the subsoil is moist and where the rate of precipitation is moderate, the water may make its way downward, drawn by gravity and by molecular attraction, without forming an upper barrier of saturated soil which prevents the escape of the air below and the downward passage of the water. Where precipitation continues long and a considerable part of the water makes its way downward into the soil, through the belt of weathering to the belt of cementation, locally the belt of saturation or the level of ground water may rise almost or quite to the surface.

The water which passes to the belt of cementation is carried downward, as already explained, by gravity and molecular attraction. The proportion of the water of the belt of weathering which on the average passes into the belt of cementation is small. In the level arid regions the proportion which thus passes downward may be almost zero, and even in the humid regions only a small fraction of the water which gets into the belt of weathering passes throngh this belt into the belt of cementation.

UPWARD MOVEMENTS OF WATER.

The water which enters the belt of weathering and does not join the belt of cementation is brought to or above the surface (a) by molecular attraction or (b) by vegetation. In either case this water is eraporated. At times of abundant precipitation the evaporation is rery small, but at intervals between precipitation, especially at times of sunshine and in warm climates, the water near the surface rapidly passes into the atmosphere. The water thus brought to the surface, as already intimated, is derived mainly from the belt of weathering, but a portion may come from the sea of ground water.

MOLECULAR ATTRACTION.

The manner in which the water is brought to the surface by molecular attraction, thus overcoming gravity, is fully discussed on pages 150-152. However, the proportion of the precipitation which is thus brought to 
the surface is very difficult to estimate. It is everywhere an important foree, but is more important in proportion as there is lack of vegetation. In the complete desert regions this force acts alone in returning the water to the surface. In such regions practically the entire precipitation may be retumed to the surface by capillarity. This is likely to occur where, on account of sudden and abundant precipitation, a saturated layer forms above a layer not saturated, and especially where the layer below is dry. It has already been explained that under such conditions the water works its way downward with great difficulty, and, remaining near the surface, it is rapidly evaporated.

While much the larger part of the water returned to the surface by molecular attraction is the water of imbibition in the belt of weathering, a portion of the water may be deriverl from the belt of cementation, and thus pass upward entirely through the belt of weathering in reaching the surface. The effect of capillarity in raising the level of ground water above the normal level is spoken of on page 412 and on pages 150-152. It is also explained that, due to the attraction between the molecules of rock and water, water is drawn along the walls of the openings of the mineral particles beyond the height of the free surface.

The amount of water which may be transported uprard a giren distance by molecular attraction is a function of the absolute amount of pore space and the size of the openings. With a given pore space the amount increases with fineness of subdivision to a certain limit. The amount of surface of the particles increases as subdivision increases. Therefore, in finely subdivided material the wall space along which the water can creep is very much greater than in coarse material. To illustrate, it will be readily appreciated that the amount of water which capillarity would carry up from the free surface through a distance of 1 meter in a coarse grained sandstone is small as compared with that which would be transported upward for the same distance through a soil having the same absolute amount of pore space. But where the openings are so small as to be subcapillary the water adheres to the walls, and the amount of water transmitted decreases. Thus, through a fine clay having the same pore space as an ordinary soil, the amount of water transported upward would be less than in the soil.

The quantity of water which may thus move upward from the belt of saturation has been experimentally determined by King for some materials 
under certain conditions. In an experiment carried on for forty days in coarse sands, in which the free surface of water was $15,30,45,60$, and 75 $\mathrm{cm}$. below the surface, King found that the mean eraporation per day was $0.2895,0.282,0.203,0.0864$, and $0.0495 \mathrm{~cm}$, respectively." In the cases of the largest and the smallest numbers, those in which the level of ground water is 15 and $75 \mathrm{~cm}$. below the surface, the amount of evaporation in a year would be 105.6675 and $18.0675 \mathrm{~cm}$., respectively. "Where the movement is vertically upward through a distance of 1 foot $[30 \mathrm{~cm}$.] it has been found by experiment that the rate for a fine sand was 2.37 pounds per square foot [1.16 grams per sq. cm.] per day of twenty-four hours; when the lift was increased to 2 feet $[60 \mathrm{~cm}$.] the movement became 2.07 pounds $[1.01$ grams per sq. cm.]; at 3 feet [90 cm.] it was 1.23 pounds [60 grans per sq. cm.], and at 4 feet $[120 \mathrm{~cm}$. $]$ only 0.91 pounds per square foot $[0.444$ gram per sq. cm.]. A similar trial with medium clay loam gave a movement of 2.05 pounds [1 gram per sq. cm.] for a lift of 1 foot [30 cm.], 1.62 pounds [79 grams per sq. cm.], for 2 feet [60 cm.], 1 pound [0.488 gram per sq. cm.] for 3 feet $[90 \mathrm{~cm}$.$] , and but 0.9$ pound $[0.439$ gram per sq. cm. where the lift was 4 feet $[120$ cm..]."

"The observations show that it [capillary movement] is very rapid at 4 feet $[120 \mathrm{~cm}$.$] ; so rapid, indeed, that were it maintained throughout the$ year it would deliver at the surface the equivalent of 63.85 inches [11.2 cu. cm. per sq. cm.] of water." $b$ With finer but equally porous soils the amount of water thus derived from below the level of ground water may be considerably greater.

By "capillary movement," as used by King, is meant the process, already described, of creep along the walls to the surface above the free surface of ground water, not the raising of the surface in consequence of capillarity, as that term is ordinarily used. (See pp. 150-152.)

Cultivation greatly retards the process of the upward movement of water by molecular attraction. The upper part of the soil is in blocks separated by supercapillary openings. The continuous capillary openings in the soils and the close contacts are broken up. The amount of wall area upon which the water may creep upwird is greatly reduced. The conditions prevent molecular attraction from readily bringing water to the surface, and eraporation is retarded. The intense heat from the sur during 
the day mainly affects the cultivated layer. This contains but little moisture, and consequently evaporation is much slower than in areas where the capillary openings extend uubroken to the heated surface. Consequently. soils cultivated as soon after precipitation as the water has had time to make its way to the subsoil may retain considerable anounts of water a short distance below the surface during long periods of drought.

VEGETATION.

In proportion as vegetation is present, this becomes an important influence working in conjunction with molecular attraction in the circulation of water in the belt of weathering. In another connection it will be shown that roots commonly permeate the soil both laterally and vertically. Ordinary herbaceons plants frequently have roots extending to a depth of 1 to 2 meters, and the roots of trees penetrate to a depth of 5 to 6 meters, or even 9 to 12 meters. The lateral extent of many plant roots is even greater than their vertical extent. In areas of abundant vegetation the upward movement of water is much more largely the result of plant roots than of molecular attraction. According to Merrill, in forested areas the total amount of evaporation and transpiration from the trees amounts to about 75 per cent of the total precipitation. In areas covered by other vegetation the total varies from 70 to 90 per cent, depending upon the character of the plants. ${ }^{a}$ If these figures be correct, they show how important an agent the roots of plants are in the upward transfer of ground waters to the surface. In proportion as the region is arid the volume of the ronts decreases. But even in the deserts the amount of plant life is surprisingly great. Moreover, in deserts the roots are often several times as extensive as the parts of the plants above ground, so that in such regions roots are rery important factors in the circulation of the small amounts of water of the belt of weathering. It is ouly in the comparatively small areas where the deserts are absolute that roots are altogether wanting.

On the average, much the larger quantity of water brought to or above the surface by plants is derived from the belt of weathering. But it is clear that in many areas, and especially in low-lying areas, where the level

"Merrill, George P., Rocks, rock-weathering, and soils, Macmillan Co., New York, 1697, pp. $280-281$. 
of ground water is near the surface, the roots tap this water stratum and carry water from it to the surface.

In summary, while the lateral movements of water in the belt of weathering are of consequence, it is clear that the upward and downward movements are those of dominant importance. Gravity is always at work carrying the water downward; the roots are always at work carrying it npward. Molecular attraction following periods of precipitation works with gravity in carrying the water downward, and at intervals between precipitation works with the roots in carrying the water surfaceward, in opposition to gravity.

Thus, a large proportion of the water of precipitation takes a downward jommey for a certain distance into the belt of weathering, and then retums to the surface. The chief impelling forces for the first part of the journey are gravity and molecular attraction, and the impelling forces in the return jomrney are roots and molecular attraction working against gravity. Where vegetation is sparse or wanting, the upward movement by which water is brought to the surface is chiefly or wholly molecular attraction.

\section{VARIATION IN LEVEL, OF' GROUND WATER.}

Variation in the level of gromnd water is of great importance in rock alteration, since due to this a certain horizon is alternately under conditions of the belt of weathering and under those of the belt of cementation. It follows that the contrasting reactions of these two belts are superimposed upon each other. Variation of the level of ground water has an exceptional importance in connection with ore deposits. (See Chapter XII.)

Variation in the level of ground water depends upon many factors, of which (1) variable precipitation, seepage, and evaporation, (2) uplift and subsidence, (3) denudation and valley filling, and (4) man, produce important results, and (5) barometric pressure and (6) temperature produce inimportant effects.

PRECIPITATION, SEEPAGE, AND EVAPORATION.

The snrface of the ground water rises and falls (a) with climatic change resulting in variations in precipitation, (b) with variations in precipitation running through several years, (c) with seasonal variations in precipitation, and finally (d) with the cyclonic and diurnal variations in precipitation. 
(a) As a result of climatic changes there may be very great variations in precipitation in different epochs in the same region. For instance, there is every reason to believe that in the Great Basin during Glacial time precipitation was abundant, whereas at the present time precipitation is sparse. At the epoch of abundant precipitation there were in this region vast fresh-water lakes, such as Bonneville and Lahontan. At this time of humidity it is highly probable that the level of ground water was comparatively near the surface, while at the present time for much of the region it is a considerable distance below the surface. Similar climatic changes affected much of the western part of the United States and have affected other parts of the world at various periods of geologic time.

(b) Besides these great climatic changes there are in many parts of the the world alternating cycles of several years or a decade, during a part of which there is more than an average precipitation, followed by other years in which the precipitation is less than nomal. At times of abundant precipitation the level of ground water rises; at times of deficient precipitation it falls. The rise and fall in the level of ground water due to such cycles may amount to several meters. It not infrequently happens that wells sunk during the humid part of a cycle have to be sunk deeper during the part of the cycle in which the precipitation is small. During the elosing half dozen years of the nineteenth century California experienced the dry part of one of these cycles. As a consequence of the deficient precipitation vegetation very greatly suffered. During these years in southern California the level of ground water markedly fell at various places from 5 to 10 or even 20 meters. For instance, in the Los Angeles Basin, in the area above where the river emerges from underground, during the years 1895-1899 the level of ground water fell at the rate of between 0.3 and 0.4 meters per kilometer per annum in passing npward from the source of the river. But in southern California the fall in the level of ground water is very largely due to the influence of man. (See pp. 427-428.) Pumping of ground water to the surface for irrigation, and not variation in precipitation, is one of the main causes of this fali.

(c) The greater part of the earth has either one or two seasons of relatively abundant precipitation, followed by one or two less wet or dry seasons; therefore the cycle of seasonal variation is semiannual or annual. 
The variation in the lerel of ground water due to this cause may be exceptionally 2 or 3 meters, but in general is but a fraction of a meter.

(d) 'The cyclonic intervals of varying' precipitation in the north temperate zone are usually from three to seven days. Howerer, in various regions, at varions times, sereral of the cyclonic periods may rapidly follow one another, and give conditions of almost continuous rainfall. In certain regions, as in the Tropics, a chief variation in precipitation is diumal, there being in the region of the doldrums abundant showers almost daily. Ordinarily the rariation in the level of gromed water due to the eyclonic period is but a few centimeters; but locally, and where there is nearly continuous precipitation for a day or more, the level of ground water may rise, due to this variation in rainfall, br amounts as great as a meter, or, very locally, several meters.

The rise of ground water for a given amount of precipitation in any cycle depends not only upon the quantity of the rainfall, but upon the amount of seepage into the soil, and this depends upon many factors. For instance, low declivity, regetation, rough surface, and large openings are favorable to entrance into the soil; while steep declivity, lack of vegetation, and small openings are favorable to large rum-off and evaporation. Where there is a high percentage of seepage a comparatively small precipitation may raise the surface of ground water a considerable amount, for the pore space at the level of ground water may be small. In case the pore space were 10 per cent, a fall of $1 \mathrm{~cm}$. would produce a rise in ground water of $5 \mathrm{~cm}$., provided one-half of it reached the level of ground water through seepage. In many districts increased seepage, due to irrigation, has markedly raised the level of ground water.

In so far as the water evaporated is derired from the belt of cementation, this tends to lower the level of ground water. The annount of this lowering, due to the upward transportation of water through molecular attraction and regetation, is likely to be great in proportion as the level of ground water is near the surface. Where the level of ground water is many meters below the surface the variation due to this cause is probably small. 'The variations of the level of ground water' due to evaporation are considered in connection with precipitation and seepage; for in many regions the abundant precipitation occurs at the same periods of the year 
at which the evaporation is the most rapid. These two factors frequently tend to neutralize each other so far as the level of ground water is concerned, for the effect of precipitation is to raise the level of ground water and the effect of evaporation is to lower that level.

The variations in the level of ground water due to climatic variations in precipitation are the greatest, but the variations of the level of ground water due to seasonal variations in precipitation, or even to cyclonic and diunal variations in precipitation, are far more important than might at first be thought, for these lesser variations largely or wholly compensate for their sualler magnitude by their much greater frequency.

\section{UPLIFT AND SUBSIDENCE.}

Vertical movements of the earth's crust take place as a result of either epeirogenic or orogenic movements, or the two combined. Uplift tends to lower the ground water, and subsidence tends to raise it, in reference to a fixed plane in the rocks. Only regions which have a considerable elevation above the sea have the ground water far below the surface. Regions which are near the level of the sea usually have the ground water near the surface; but this may not apply to interior low-lying deserts.

\section{DENUDATION AND VALLEY FILLING.}

Consequent upon demudation there is a steady downward movement of the level of ground water. This continues, unless compensated for by uplift, mutil base-level is reached, when the ground-water level approximately corresponds, on the average, with the ocean. The result of denudation is continuously to transfer the upper part of the belt of cementation into the belt of weathering, and thus to change the conditions of alteration from those of one belt to those of the other. This steady downward migration, in reference to a fixed plane in the rocks, of the boundary between the belt of weathering and the belt of cementation is the most important of all the changes in the variation of the level of ground water, leading to profomnd geologic and econonic consequences, which are fully discussed elsewhere. Variation in the level of ground water may also result from valley filling. When a valley is filled to a considerable depth, this may result in corresponding rise in the level of ground water. If the valley be again excavated, this may lower the ground water to its former level. 


\section{INFLUENCE OF MAN.}

Man influences the level of ground water in various ways. Probably his most important effect upon this level is by the denudation of the forests, by irrigation, and by cultivation. It is well known that commonly the removal of the forests increases the run-off. It has been explained (p. 415) that bad cultivation may increase the run-off and that good cultivation diminishes it. But, also, cultivation increases greatly the amomit of evaporation. All changes in the quantity of run-off, in the redistribution of the run-off by irrigation, and in the amount of evaporation from the surface, produce an effect upon the level of ground water. In general the effect of cultivation is to lower the level of ground water. This is illustrated in hundreds of localities within the area of the lake plains. In many places where before cultivation began there were shallow lakes, marshes, or swamps in which the ground-water level was at the surface, the ground water is now 5 to 10 meters below the surface. For instance, in central Wisconsin, southwestern Portage County, in the vicinity of Almond and Bancroft, in the gravelly and sandy outwash plains bordering the Wisconsin drift, Dr. Weidman states that in consequence of cultivation the groundwater level has been lowered from 6 to 12 meters, and the level of water in the ponds and lakes lowered from 3 to 4 meters, so that the area of lake and pond waters is not more than 25 to 50 per cent of what it was fifty years ago, when settlement of this vicinity first began. In Clark County, in the area of thick old drift overlying sandstone and crystalline rock, since settlement began forty years ago the level of ground water has been lowered trom 3 to 4 meters.

Man has further modified the level of ground water by drawing upon the sea of ground water. He has sunk innumerable wells from which large quantities of water have been taken. This drawing of the water to the surface lowers the level of ground water. However, the effect was probably comparatively slight until the developments of the last century. During that period great numbers of artesian wells were bored, from which very large quantities of water are taken. The inevitable result of the opening of the numerous ready passages for the ground water to again reach the surface nust be the lowering, at least to a small extent, of the level of ground water at the feeding areas. But probably the most important lowering of the level of ground water is in mining and irrigation 
districts, where within comparatively small areas vast quantities of water are raised to the surface. The ground-water level in many mining areas has been locally lowered scores or even liundreds of meters. From the Comstock locle ellormous quantities of water were pumped. ${ }^{a}$ From a single iron mine in the Lake Superior region 19,000 liters per minute have been raised for considerable periods of time. In the lead and zinc district of Missouri many small pumps located close together have lowered the level of ground water at varions places from 30 to 50 meters. Drafts upon underground water by prumping for irrigation and for city supplies have lowered the level of ground water to a very considerable extent in many of the semiarid regions. An excellent illustration is furnished by sonthern California, where during the last ten years the level of ground water has been lowered at various places over extensive areas from 10 to 30 meters.

Depression of the level of ground water due to pumping rapidly transfers a considerable horizon from the conditions of the belt of cementation to those of the belt of weathering, and thus accomplishes the same effects which are slowly produced by the downward migration of the level of ground water due to other causes.

\section{BAROMETRIC PRESSURE.}

King has shown that barometric pressure may slightly raise and lower the level of ground water. The fluctuations due to this canse are, however, usually but a fraction of a centimeter. ${ }^{b}$

TEMPERATURE.

It has already been seen that increase in temperature decreases the viscosity of ground water. At times of increase of temperature, therefore, the escape of the underground waters throngh springs and seepage is promoted, and the level of ground water is lowered. At times of decrease of temperature the escape is stayed. Also rise of temperature produces increased pressure, dne to the expansion of the gases confined in the soil above the ground water, and King holds this to be the chief cause of increase of flowage with increase of temperature. However; the effect of the temperature factor upon the level of ground water is slight, its most important effect being slight daily oscillations.

a Lord, Eliot, Comstock mining and miners: Mon. U. S. Geol. Survey, vol. 4, 1883, pp. 231-232.

$b$ King, F. H., cit., p. 76.

${ }^{c} \mathrm{King}, \mathrm{F} . \mathrm{H}$. , cit., p. 75. 
GENERAL STATEMENTS.

The variations in the level of ground water where they are considerable are very slow, but in amount they are of great conseqnence. Of the factors which separately, or more commonly by combination, have produced marked variations in the level of ground water, uplift, subsidence, denudation, valley filling, and the influence of man are the most important. The lead and zinc districts of the Mississippi Valley afford excellent illustrations of variations in the level of ground water. In the lead and zine districts of the upper Mississippi Valley, near the close of the Glacial epoch, there was a subsidence and valley filling to the amount of 60 to 90 meters or more. This produced a corresponding rise in the level of ground water, and the transfer of a considerable belt which had been in the belt of weathering to the belt of cementation. Possibly the same thing has happened in the lower Mississippi Valley lead and zine region. For instance, in the Joplin district of Missouri, below the level of ground water, there were large caves before mining began. These caves may have been formed when the level of ground water was at a lower horizon, so that the surrounding ground was in the belt of weathering. At a time when a horizon now in the belt of cementation was in the belt of weathering solution was the dominant process. When the level of ground water rose, this horizon passed into the belt of cementation and deposition and consequent filling of the openings began. As a result in the Joplin district the caves are gigantic geodes lined witlı great crystals of calcite, some of them from 10 to 50 or more centimeters long. By the artificial lowering of the level of ground water by mining processes this belt has been again transferred to the belt of weathering, and reactions characteristic of this belt have been set up.

METAMORPHISM IN THE BELT OF WEATHERING.

VARIABLE MATERIALS AND CONDITIONS OF BELT OF WEATHERING.

Within the belt of weathering there is the greatest variety of materials and conditions. The reactions are therefore of the most extraordinarily complex character. In the belt of rock weathering there is the greatest possible rariety of rocks. In fact, every known variety of rock which exists anywhere mpon the earth may be present. There are in this belt 
original igneons rocks of every variety, from plutonic to volcanic, including both lavas and tuffs; rocks varying from the most dense to the most porous, such as pumice; rocks varying from the most basic to the most acid, and having the most variable mineralogical composition. A second class of rocks which has even a more widespread occurrence in the belt of weathering than the igneons rocks are the sedimentary rocks. These include mechanical sediments of all kinds, chemical and organic sediments of all kinds, and all possible gradations between them. A third class which is present in the belt of weathering is the metamorphosed rocks of igneous and sedimentary origin. These rocks may have been altered either in the zone of anamorphism or in the belt of cementation. Horeover, the amount of alteration is variable; ranging from rocks which lave been but slightly affected to those which have been mashed and gramulated or recrystallized throughout. Fourth, there is every variety of surficial rocks prodnced by the transporting agents of wind, water, and ice. Moreover, all these four classes of rocks are present in the belt of weathering in varions stages of alteration under the conditions of that belt, so that the products vary from those in which the forces of weathering lave prodnced but slight effects to those in which they have produced final results.

Within the belt of weathering all the agents of metamorphism are present. These include gaseons solutions, water solntions, and organic compounds. Oxygen, carbon dioxide, water, nitrogen, and other gases are present in variable proportions. Of these the first three are of greatest. consequence. In lnumid regions, at times of abundant precipitation, the belt of weathering becomes nearly saturated with water, and these gases may be nearly or quite excluded except as they are contained in the water solutions. In desert regions there may be an almost complete lack of water, even that held by imbibition being evaporated by the heat of the sun near the surface. At such places the gases dominate. In the lower part of the belt, in consequence of the variation of the level of gromind water, is a layer which has alternately conditions of saturation and conditions in which water, carbon dioxide, and oxygen are together in important amounts and in varions proportions. Therefore the conditions are those ranging from saturation by water solutions to saturation by gaseous solutions.

It follows from the above that the amount of gaseons solutions is inversely as the amount of water solutions. When the water solutions 
occupy much of the space, this leaves little space for the gases. On the other hand, in so far as water does not occupy the openings in the rocks, this space is taken up by the gases which may exist anywhere in the belt of weathering. Varying amounts of water solutions and gaseous solutions furnish favorable conditions for the gases to pass into the water solutions, in which form they are most effective in rock alteration.

Further, in the belt of weathering there is a great variety of plant and animal life, and consequently the complex action of organic bodies upon the inorganic compounds. These organic forms vary in magnitude from the smallest bacteria to large trees. Moreover, the organic bodies act botl while alive and after death. Therefore reactions of many kinds result from them, involving gases, liquids, and solids.

Furthermore, in the belt of weathering there are great variations in temperature and other physical conditions. The temperature varies from far below $0^{\circ} \mathrm{C}$. in polar regions to $50^{\circ} \mathrm{C}$. or even $60^{\circ}$ or $70^{\circ} \mathrm{C}$. in the sun in some of the arid regions of the Tropics. For much of the globe, as a result of varying temperature, the surface water is alternately in the form of liquid and of ice. Also the conditions are those of variable pressure.

Finally, there are all rariations in topographic conditions. Some areas show very slight relief, while others have the most abrupt slopes. Some areas are near sea level, others are 3,000 or more meters above sea lovel.

The work in the belt of weathering is accomplished by mechanical and chemical agencies. The mechanical work is largely that of disintegration; the chemical work is largely that of decomposition and solution. Disintegration may entirely separate the constitnent minerals from one another, or even subdivide the mineral particles. Decomposition is complete when all of the original minerals lave changed to other minerals. Solution is complete only when all the original minerals are dissolved. 'The ultimate result of the action of the mechanical and chemical agencies is to produce soils.

MECHANICAL WORK.

Mechanical work subdivides the rocks or disintegrates them. Mechanical work is accomplished by the following: (1) Water, (2) ice, (3) wind, (4) change in temperature, (5) change from water to ice, (6) plants, and (7) animaals. 
WATER, ICE, AND WIND.

In the broadest sense wind, water, and ice above the surface are irchded under the agents of the belt of weathering. But this subject is so large that it is ordinarily given a separate treatment under the terms erosion, land sculpture, or physiography. Therefore the work of these three agents will not be here considered or even smmmarized. Howerer, it may be well to recall that these agents are not efficient in the mechanical disintegration of the rocks except as they use rock material as their tools; that is, wind, water, and ice are incapable of rapidly cutting the rocks. When the wind bears sand it may do a considerable amount of cutting; when water bears rock material varying in size from bowlders to silt it may accomplish a vast amount of work. The sane statement is true of ice. All three of these agents, therefore, furnish their energy of motion to rock material as tools of cutting, and thus accomplish mechanical destruction of the rocks. 'This energy is indirectly deriver from the sm and gravity. It should also be said that there appears to be a limit beyond which water, wind, and ice are incapable of finer subdivision of material. Thus Daubrée found that in water there was a limit beyond which mechanical trituration for the hard minerals like quartz ceased, "owing to the bnoyant action of the water, which in the form of a thin film between adjacent particles acted as a cushion and prevented actual contact to the extent necessar $r$ for mutual abrasion." Shaler appeals to the same principle in explaining the endurance of sand grains on the seashore. He says that the grains are held apart by films of interstitial water (this would be water of adhesion), and are therefore prevented from strongly impinging against one another. ${ }^{b}$ Judd says that the small particles of the alluvial deposits of the Nile which have been transported great distances are angular, while the larger particles of the same deposits are subangular or rounded. Judd attributes the rounding of the larger grains to eolian rather than river work; ${ }^{c}$ but this does not lessen the force of the argument as to there being a lower limit beyond which the particles are not rounded by river action.

a Merrill, cit., p. 197. See Daubrée, A., Géologie expérimentale, Paris, 1879, p. 268 et seq.

$b$ Shaler, N. S., Phenomena of beach and dune sands: Bull. Geol. Soc. America, vol. 5, 1894, pp. 208-209.

cJudd, J. W., Report on a series of specimens of the deposits of the Nile Delta, obtained by the recent boring operations: Proc. Royal Soc. London, vol. 39, is85, pp. 213-220. 
Abrasion by wind, and especially by ice, may give a finer subdivision of material than abrasion by water. For instance, it is well known that glacial débris varies in coarseness from great bowlders to a silt so fine that the streans issuing from the glacier's are of whitish color, and it takes many days for the exceedingly finely divided material to settle when a stream has passed into a lake. Chamberlin and Salisbury found, as a matter of observation, that the particles of loess of the Mississippi Valley smaller than $0.1 \mathrm{~mm}$. in diameter are angular. ${ }^{a}$ This accords with the conclusion of Danbrée that particles smaller than $0.1 \mathrm{~mm}$. in diameter are not reduced in size by their mutnal trituration, since the particles of the loess have been carried for long distances in water. However, the particles as originally formed by glacial abrasion may be very much smaller than this. Indeed, Chamberlin and Salisbury state that only 1.3 per cent of the particles of loess of the Mississippi Valley are as large as $0.005 \mathrm{~mm}$. in diameter, and that probably 90 per cent of the particles do not reach half this size. ${ }^{b}$ The loess of the Rhine gave similar resnlts, there being here only seven-tenths of 1 per cent of material over $0.01 \mathrm{~mm}$. in diameter, only 3 per cent between 0.005 and $0.01 \mathrm{~mm}$., while 85 per cent is less than $0.0025 \mathrm{~mm} .{ }^{\circ}$ The lower limit of size of the particles of the loess are not given by any of these writers, but nothing is said which intinates that it goes below the limit of visibility of the microscope.

It thus appears tolerably certain that, however fine the subdivision by any of the mechanical agents, the finest subdivision of material is only accomplished by chemical agents.

For instance, in the residuary soils of the driftless area of Wisconsinmaterial largely snbdivided by chemical agents-less than six-tenths of 1 per cent of the particles are as large as $0.005 \mathrm{~mm}$. in diameter, less than 1.5 per cent are between 0.005 and $0.00285 \mathrm{~mm}$., and abont 98.5 per cent are smaller than $0.00285 \mathrm{~mm}^{d}$ In this ease much of the material is so finely divided that it is stated that "since the visible proportion of exceedingly fine particles was greatly increased with each increase of magnifying power,

"Chamberlin, T. C., and Salisbury, R. D., The driftless area of the upper Mississippi Valley: Sixth Aun. Rept. U. S. Geol. Survey, 1885, p. $2+6$.

${ }^{b}$ Chamberlin and Salisbury, cit., pp. 279-280.

${ }^{c}$ Chamberlin and Salisbury, cit., p. 280.

$d$ Chamberlin and Salisbury, cit., pp. 248-249.

MON XLVII-04-28 
the number at the limit of vision was always great." a It thus appears that in the case of chemical subdivision it is doubtful if the microscope used fully resolved the material into its constituent particles.
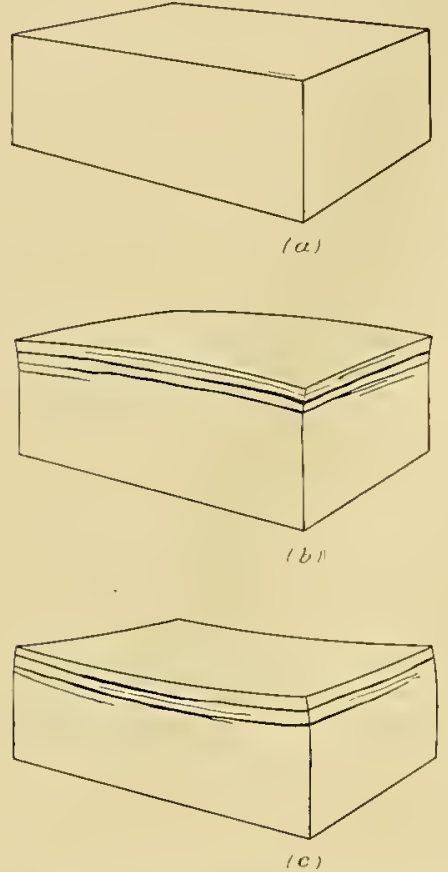

FIG. 6.-Effect of unequal heating of the surface of a rock. (a) shows the eondition of a block of uniform temperature. (b) illustrates the manner in which the ppper portion of a rock surface expands when heated above average temperature; where the difference in temperature is sufficiently great, this results in the splitting off of the upper layers. (c) illustrates the contraction of the upper surface by cooling below the average temperature; where the differeuce in temperature is sufticiently great, this results in the splitting off of the upper lavers.

its length at the coolest period will be from 0.99908 to $0.999 .54 \mathrm{~cm}$., and at the hottest period from 1.00046 to $1.00092 \mathrm{~cm}$. A few inches below the surface it may be assumed that the temperature of the rock is near the mean; consequently, at the coolest part of the day the surface of the rock is shorter than the rock below, and at the hottest part of the day it is

Change in temperature results in the disintegration of the rocks by producing differential expansion and contraction. When the rock surface is affected by any change in temperature, the heat is only slowly conducted and there is differential expansion between the outer part of the rock and the imner part. In other words, powerful shearing stresses are set up, as a result of which flakes of the rock are disrupted from the deeper located solid material (see fig. 6). The surface temperature may be greater or less than the average temperature of the rock, and the process is especially effective when the surface temperature is alternately lower and higher than the average temperature.

The expansion of different rocks per degree centigrade varies from less than $0.000023 \mathrm{~cm}$. to about $0.000046 \mathrm{~cm}$. per meter. When these numbers are multiplied by the number of degrees of change during any period-as, for instance, one day-we have the increment of change in the lengths of the rocks at the surface during the period. Suppose the change for a given day to be $40^{\circ} \mathrm{C}$., and the length of the rock surface be taken as 1 meter at the mean temperature, then

CHANGE IN TEMIPERATURE.

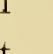

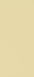


longer than the rock below. When the surface is shorter than the main mass of the rock below, if the elastic limit be surpassed tensile fracture will take place nearly at right angles to the surface. When during the hot part of the day the surface is longer than the average of the rock below, powerful shearing stresses are set up parallel to the surface. If these surpass the elastic limit of the rock, shearing rupture will take place roughly parallel to the surface. When once a rupture is started, it will extend until the rupture feathers out at the surface or until the flake or spall has become long enough to permit the stresses to be relieved by buckling.

The surface scaling of rocks, and parting parallel to the surface exfoliation, are attributed to differential expansion and contraction caused by change of temperature, because the fractures are peripheral. In massive rocks, whatever the topographic forms and shapes, the scaling produced by temperature changes should be ronghly parallel to the surface. For instance, if there be a great dome of granite, the fractures which form should circumscribe it (see Pl. I) as they would circumscribe a sphere, being at any given place parallel to it. In the United States such fracturing is well exhibited by the granite of Dunn Mountain, in North Carolina; by the granite domes of central Missouri; and above all by the great granite domes of the West, such as those in the Sierra Nevada. The scales are ordinarily but a few centimeters in thickness, and are rarely more than 60 cm. thick. Of course, in none of these cases does every fracture occur precisely parallel to the surface; rather, they are inclined to it at small angles in various ways, thus frequently intersecting. However, the correspondence is, in a general way, as given, and therefore the positions of the fractures furnish evidence of their production in consequence of shearing stresses due to changing temperature.

Another reason for believing that the peripheral or zonal scaling and parting are due to changing temperature is the fact that the ruptures occur nearly parallel to the surface without reference to previous structures. Thus it often happens that great slabs, $2 \mathrm{~cm}$. to $5 \mathrm{~cm}$. thick, of schistose or gneissic rocks form, which are diagonal or even at right angles to the structures. 
The changes in temperature are important in proportion as the rate of change and the amount of change are great. It is rapid change of temperature which mainly results in differential expansion and contraction, and therefore this is the factor of final consequence. The temperature changes are (a) diurnal, (b) cyclonic, and (c) seasonal. The amount of the diunal change is cousiderably less than that of the cyclonic, and that of the cyclonic change is considerably less than that of the seasonal; but the rate of change is far greater for the diurnal than for the cyclonic, and this is far greater than the seasonal rate. Therefore the diurnal changes are the most important in the disintegration of rocks, the cyclonic changes of next importance, and the seasonal changes are of least importance.

The diurnal changes range from $0^{\circ}$ to $50^{\circ} \mathrm{C}$. or more. For instance, in Texas the diurnal changes in temperature in the shade are frequently $30^{\circ}$ to $40^{\circ}$ C. ${ }^{a}$ Branner states that in Brazil the diumal change of temperature from the minimum at night to the maximum in the sun frequently amounts to $50^{\circ} \mathrm{C}$, the average appearing to be not far from $40^{\circ} \mathrm{C} \cdot{ }^{b}$ In some desert regions diurnal changes even greater than this have been recorded. Probably even these ranges are not great enough; for the sum beating upon the surface of a rock will raise it to a higher temperature than it will a thermometer in the air. In order to obtain the real effect of the diurnal change of temperature, one ought to sink a thermometer in the exposed rock surface and ascertain its range from the coolest part of the night to the hottest part of the day.

While the diumal range is rery great, probably the diurnal change of temperature and the resultant fracturing is limited to a few inches in depth.

The changes in temperature due to the cyclonic period are greater than those due to the dinmal period, but the period is longer and the rate of change is much less. The cyclonic period produces a variation of temperature which runs over several days; its effect may therefore be felt more deeply than the diurnal range, and it is not improbable that the fractures from a few centimeters to several meters below the surface and parallel to the surface in many massive rocks are largely the result of the cyclonic change of temperature. Such fractures are well exhibited in many granite quarries. The scaling probably mainly due to the diumal and cyclonic

a Fourth Ann. Rept. Geol. Survey of Texas, 1892, p. 144.

${ }^{b}$ Branner, J. C., Decomposition of rocks in Brazil: Bull. Geol. Soc. America, vol. 7, 1896, p. $2 s 6$. 


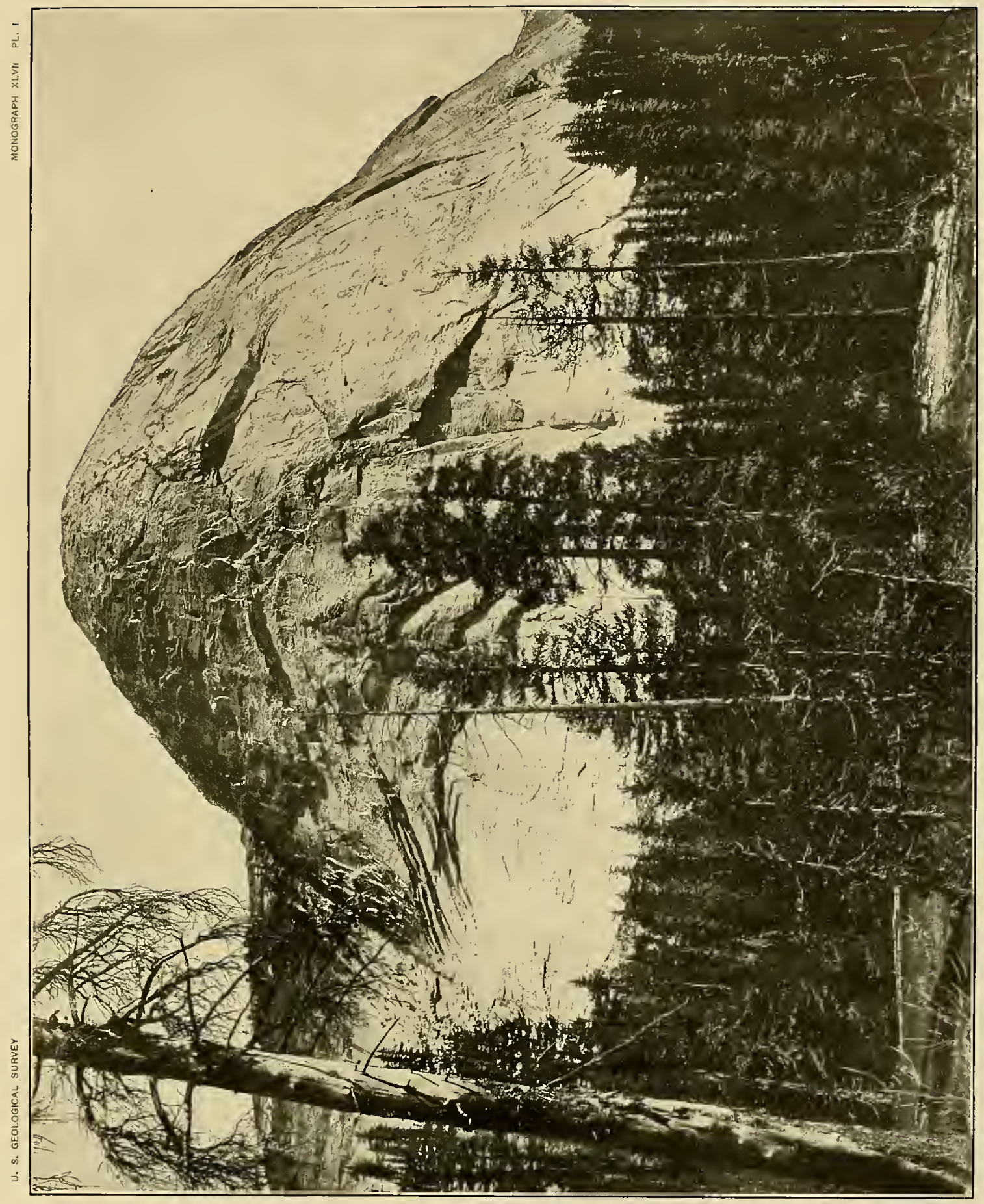



changes in temperature has usually been called exfoliation. Walther, referring to the agency of the sun in producing change of temperature of rocks, has named the process insolation, and of it he gives many instances. ${ }^{a}$

The annual ranges of temperature in various parts of the United States rum from $30^{\circ}$ C., as at San Francisco, to $67^{\circ}$ C., as at Moorehead, Minn. Gannett says that in the interior of Alaska the ammal range is sometimes as great as $80^{\circ} \mathrm{C} .^{b}$ Hahn agrees that the annual range of temperature in some regions is as ligh as $70^{\circ}$ to $80^{\circ} \mathrm{C}$. While the seasonal changes of temperature are therefore greater than the dimnal or cyclonic changes, the times of the changes are far greater, and therefore the rates of the changes far less. While the seasonal change undoubtedly produces some effect in clisintegrating the rocks near the surface, probably the more important effect of the seasonal change is at a greater depth than the diurnal or cyclonic changes. At a depth of 1 or 2 meters, or at most several meters, the dimmal or cyclonic effect must be obliterated. Since the seasonal effect some meters below the surface is produced very slowly, probably this effect is not determined by the maximum range of temperature, but by the range of the hottest season of summer compared with the coldest season of winter, for a long period of time is required in order to produce an effect of differential expansion more than a meter or two below the surface. If January be compared with July, the change in temperature in the arctic regions would be from about $45^{\circ}$ to $60^{\circ} \mathrm{C}$., the change in the temperate regions would be from about $20^{\circ}$ to $45^{\circ} \mathrm{C}$, and the change in the tropical regions would be from about $10^{\circ}$ to $20^{\circ} \mathrm{C}$. If the comparison were made of January and February together with July and August together, these numbers would be but little different. Since the amnual changes of temperature are sinall in the tropical regions, are much greater in the temperate regions, and are very great in the arctic regions, it follows that, so far as the amnual changes in temperature are concerned, the effect is a minimum in the tropics and a maximum in the aretic regions. The seasonal changes of temperature produce an effect to a depth of 12 to 15 meters. Probably the effect which can be discriminated from the dimmal and cyclonic changes is between 3 or 4 to 12 or 15 meters. It seens to me probable that many of the joints

\footnotetext{
a Walther, Johannes, Die Denudation in der Wüste und ihre geologische Bedeutung: Abhandl. Math.-phys. Classe Gesell. Wiss. Leipzig, vol. 16, 1891, pp. 448-453.

b Gannett, Henry, The general geography of Alaska: Nat. Geog. Mag., vol. 12, 1901, p. 191.

${ }^{c}$ Hahn, Juilus, Handbuch der Kilimatology, J. Engelhorn, Stuttgart, 1883, p. 497.
} 
of massive rocks parallel to the surface which may be noted between these limits are the result of seasonal changes in temperature. ${ }^{a}$

The disintegrating effect of changes of temperature is most marked in those regions in which the precipitation is small for at least a portion of each year. The reason for the great activity of the process during dry periods is plain. On account of the low humidity the sun is very effective. For the same reason the radiation is rapid at night. Consequently there are very rapid changes of temperature, and hence very great exfoliation. These conditions of lack of humidity are ideally illustrated in the desert regions. In such areas it is well known that insolation is very rapid. ${ }^{b}$ However, probably insolation is not so rapid in those deserts in which there is no precipitation as in those in which there is occasionally abundant precipitation. The conditions for insolation are furnished by the dry periods extending from one to several years. When the very abundant precipitation, perhaps in the form of cloud-burst, comes it transports the loosened material away from the parent rock and leaves it bare for further insolation. This condition of affairs is well illustrated in the desert regions of the United States. Also insolation may be very rapid in regions which are considered humid, provided a period of each year is dry. This is well illustrated by Brazil, where there are alternately wet and dry seasons. During a dry season insolation loosens the material; during the wet season the water transports the loosened material to the lower ground, and thus exposes the fresh rocks to insolation during the next dry season.

In regions in which the precipitation is plentifully distributed over all parts of the year, insolation is small, for the rocks become covered by vegetation, which prevents the direct action of the sun. In the humid temperate parts of the world are many regions in which insolation is at a minimum, such as the southern Appalachians and the Olympic Mountains.

a Since the abore was put in type Gilbert has said: "In many dome-like granite hills the rock is divided into plates by curved joints approximately parallel to the surface. Some observers call the structure exfoliation; others regard it as an original structure of the granite. Under one view the surface forms determine the structure; under the other the structure determines the surface forms. A study of the High sierra of California in the summer of 1903 has led me to accept the former view, and to believe that the forms of the parting planes are conditioned by the forms of the topography. As to the cause of the phenomenon the following hypothesis is advanced: Formed deep within the crust, the granite was initially subject to compressive stress, which was balanced by internal expansive stress. As the unloading involved in subsequent denudation reduced the compressive stress, the unbalanced expansive stress caused strains which eventually resulted in exfoliation." Gilbert's view has much in its favor for many of the deeper joints parallel to the surface, but it does not exclude the formation of ruptures as above described. Indeed the two causes may work together.

$b$ Merrill, Rocks, rock-weathering, and soils, p. 283 . Walther, cit., pp. 448-453. 
Topography is also an important element in insolation. Where the slopes are steep gravity pulls off the flakes formed, and new surfaces are exposed to the process. Also theoretically the greater the elevation the more the insolating effect, for the sun does not have to pass through so much of the atmosphere and should be more effective in heating, and the heat gained in the day shonld be more rapidly radiated at night. Thus one would expect greater changes in the temperature of the rocks at high elevations than at low elevations, but I am not aware that obscrvations have been made on this point.

Rocks vary greatly in their power to resist the effect of insolation. Sandstones are refractory; limestones and shales are somewhat less so; crystalline rocks, especially those having a large amount of readily cleavable feldspar, are most affected. I suspect the cause of the varying resistance of rocks is a function of their porosity. In proportion as the rocks have many pores, such as sandstones, the expansion and contraction is taken up between the grains, and therefore rupture is not likely to take place. Where, however, the rock is a solid continuous mass, with little or no pore space, when the temperature of the surface is higher than that of the rock below, the expansion can be taken up only by elasticity. When the stresses accumulate beyond the elastic limit, ruptures are produced. (See p. 434.)

Frequently insolation results in burying the erystalline rocks, except the sharpest peaks, beneath débris. Regions which well illustrate the disintegration largely due to change of temperature are southern California and the peninsula of Lower California, described by Merrill ${ }^{a}$ and by McGee; ${ }^{b}$ Egypt, described by Walther; ${ }^{e}$ and Brazil, described by Branner. ${ }^{d}$

Where the rocks become covered with flakes and spalls, this of comrse protects the solid rock below, and thus stays the process of insolation.

Disintegration as a result of insolation can be certainly discriminated in the low-lying regions of the Tropics, in which the temperature never falls below $0^{\circ} \mathrm{C}$. But in all areas in which the temperature frequently falls below $0^{\circ} \mathrm{C}$. the disintegrating effect of insolation is conjoint with that of freezing and thawing, next considered.

a Merrill, George P., Sketch of Lower California: Bull. Geol. Soc. America, vol. 5, 1894, p. 499.

$b$ ITcGee, WV J, The formation of arkose: Science, new ser., vol. 4, 1896, pp. 962-963.

$e$ Walther, cit., pp. 347-569.

a Branner, J. C., Decomposition of rocks of Brazil: Bull. Geol. Soc. America, vol. 7 , 1896, pp. 281-294. 
CHANGE FROM WATER TO ICE.

When water changes to ice it expands 9 per cent. According to Dewar, the decrease in the freezing temperature of water corresponding to an increase of pressure of one atmosphere up to 700 atmospheres is $0.0072^{\circ} \mathrm{C}$. per atmosphere. It follows from this that in order to prevent the change from water to ice taking place at temperatures below $0^{\circ} \mathrm{C}$. very great pressures must be exerted. These pressures are shown by the following table:

Pressures required to keep uater liquid at temperatures below $0^{\circ} \mathrm{C}^{a}$.

\begin{tabular}{|c|c|}
\hline & Atmospheres. \\
\cline { 1 - 1 }$C$. & \\
$-1^{\circ}$ & 138.888 \\
-2 & 277.777 \\
-3 & 416.666 \\
-4 & 555.55 \\
-5 & 694.44 \\
-18 to -20 & 13,000 \\
\hline
\end{tabular}

It follows that where water is in rocks and the temperature is below $0^{\circ} \mathrm{C}$., in general the rocks are not strong enough to resist the change of the water to ice; therefore an expansion of 9 per cent takes place. When this expansion occurs one of two things happens. The water obtains the additional space by pushing aside the material of the soil or rock or by expanding into openings not fully occupied by the water. The latter is especially likely to occur in rocks in which the water is that of imbibition and which therefore are not saturated.

In such cases the space between the particles of the rocks, as, for instance, grains of soil or grains of sand in a sandstone, is so great that the expansion of freezing need not move the grains with reference to one another. In general it may be said that, in proportion as the rocks approach saturation, disruption is likely to occur; in proportion as the amount of contained water becomes small, disruption is not likely to take place.

a See Mousson, A., Einige Thatsachen betreffend das Schmelzen und Gefrieren des Wassers: Ann. der Physik und Chemie, J. C. Poggendorff, vol. 105, Leipzig, 1858, p. 161. 
As shown by Buckley, ${ }^{a}$ the efficiency of the change of water to ice in disintegrating the rocks is largely dependent upon the readiness with which the water from a saturated rock can escape. If the pore spaces are large and continuous, as in sandstones, even where the rocks have been recently saturated, as by a heavy rain, a large part of the water readily and quickly escapes, so the water held long enongh to freeze is mainly that which adheres to the grains or is the water of imbibition. If the pore spaces are not nearly full when the small amount of water is frozen there is room for expansion without disrupting the grains, and consequently there is very little effect in the way of disintegration. Hence a very porons rock where drainage is easy may be comparatively little affected by repeated freezing and thawing. On the other hand, if a rock be fine grained, so that the pore space, while of the same volume as in a sandstone, is very much subdivided, the water of imbibition and that of saturation approximate to each other; the water escapes much more slowly; the pore spaces may be nearly full for some time, and freezing is therefore much more likely to disintegrate the rock. Such rocks are illustrated by the chalks.

Further, in rocks which have a very small anount of pore space, and in which the pore spaces are more or less discontinuous or are subcapillary, so that the water is held firmly, the destructive effect of the freezing of the small amount of water may be very great, because the pore space is full and expansion must cause disruption.

The relation of size and continuity of pore space to disintegration by freezing is well ilhustrated by the resistance of sandstones as compared with granites and limestones. The Dunnville sandstone of Wisconsin has the remarkably large pore space of 28 per cent. Buckley repeatedly saturated specimens of this stone with water and immediately-exposed them to temperatures below $0^{\circ} \mathrm{C}$., but the water so rapidly escaped that the strength of this rock was "proportionally less affected by freezing and thawing than the strong granites and limestones, having low percentages of pore space." In contrast with this is the behavior of Cleopatra's Needle, a granite monolith in Central Park, New York, which, after haring resisted for thousands

"Buckley, E. R., Building and ornamental stones: Bull. Wisconsin Geol. and Nat. Hist. Surrey No. 4, 1898, p. 382.

buckley, cit., p. 382 . 
of years the weathering forces in Egypt, where diurnal temperature changes are great, began so rapidly to disintegrate under conditions of freezing and thawing that it had to be coated with paraffin to exclude water and save it from complete destruction; ${ }^{a}$ but in this case it should be remembered that the effect of change from water to ice is superimposed upon the offect of past centuries of insolation. Perhaps its rapid disintegration was due to minute openings between the grains, formed by insolation, which the water could enter. It is rather probable that stone fresh from the Egyptian quarry would not disintegrate so rapidly.

When water is in large, deep clefts, such as joints, and freezing takes place, the result is to widen the cracks. Furthermore, it is to be noted that at times of alternate freezing and tharving the process is cumulative. After the openings have been somewhat enlarged and the ice melts, the rock does not fully return to its original position, and when freezing again occurs the widening again takes place, and so on. Thus the process may begin with the subcapillary openings and by repeated freezing and thawing widen them to large openings. At each time of expansion the ice acts as a wedge, and besides widening the cracks it may also extend them, and thus the process of freezing and thawing enlarges cracks already formed and also extends them.

In addition to the size and extent of the openings and the amount of contained water, further factors affecting disintegration by freezing and thawing are topography and latitude. In proportion as the slopes are sharp and the elevation is great the effect is likely to be great. 'The disrupting effect is especially strong on cliffs and mountain sides and is slight where the topographic variation is slight. It has already been seen that the depth to which the effect may be produced varies from nothing to a number of meters, and thus it is confined, under the most favorable circumstances, to the mere outer skin of the earth. The great effectiveness of the change from water to ice in disintegrating rocks on steep slopes is due to the fact that the material disrupted is quickly pulled away from the parent rock by gravity or is transported elsewhere by moving water or ice and a new surface is exposed to the action of freezing water.

Illustrations of rapid disintegration due largely to freezing and thawing are afforded by many of the higher mountain slopes, if not by nearly

$\alpha$ For discussion of relations of size of pores to destructive effect by freezing and thawing, see Buckley, cit., pp. 20-25, 382-384. 
every mountainous region of the world the peaks of which extend above the snow line. For instance, the top of Grays Peak, in the Front Range of Colorado, is a mass of disrupted fragments, the solid rock being nowhere exposed. Mount Dana, in the Sierra Nevada, furnishes an illustration of the disintegration of a schistose rock. Here also the top of the mountain is a mass of disrupted blocks, the solid rock protruding only here and there.

As to latitude, it is certain that in the lowlands of the Tropics, where the temperature does not fall to $0^{\circ} \mathrm{C}$, the effect of freezing and thawing is nil. But in the north temperate and frigid regions where there is a long season of alternate freszing and thawing, the effect is very great. The rapidity of the disintegration of rocks in areas like Greenland and Spitzbergen is largely explained by the alternate freezing and thawing. Cushing has described the argillites of the region of Glacial Bay as disintegrating with amazing rapidity. ${ }^{a}$

It is impracticable wholly to discriminate the above-described disintegrating work of freezing and thawing from that of insolation. Insolation is everywhere at work, although, as has been explained, with variable power. It is common to attribute the work of disintegration in temperate and arctic regions wholly to freezing and thawing, but it is plain that the disintegration in such regions is partly the result of insolation.

A further effect of freezing and thawing, fully described by Merrill, is the movement of materials already disintegrated. The movements may affect pebbles and bowlders as well as fine material. As the soil below a pebble or bowlder freezes it expands upward, this being the direction of least resistance. When the soil thaws, the fine material falls back more readily than the bowlders, and thus leaves the pebbles and the bowlders slightly higher than before. ${ }^{b}$

Oftentimes in saturated tough clay soils, after the surface layer of water and soil has frozen, and thus forms a congealed sheet, as the process of downward freezing continues the necessary space required by the expansion in the change from water to ice is obtained by the water breaking through the crust at very numerous points. As the water is slowly squirted up through these pipes it congeals at the points of issue, just as it does when

$a$ Cushing, H. P., Notes on the Muir Glacier region, Alaska, and its geology: Am. Geol., vol. 8, 1891, p. 224. 393-394.

$b$ Merrill, George P., Rocks, rock-weathering, and soils, Macmillan Co., New York, 1897, pp. 
water is frozen while confined in a deep, strong vessel. This squirting upward at the rarious openings produces imnumerable ice pipes. Where a surface sheet of ice liad formed before the restraining frozen sheet of soil and water together were produced the ice pipes may raise it above the surface. In a similar mamner frequently a sheet of the congealed surface soil and vegetation separates from the frozen material below less knit together with roots. This is frequently very destructive to vegetation. As the solidified surface of soil containing the roots of the varions plants is pushed upward the roots are broken and a crop of grain may thus be completely destroyed. The ice, soil, and vegetation may be raised 5 or $10 \mathrm{~cm}$. from the surface. Thus we have a sheet of frozen material above the ground, supported by innumerable minute pillars of ice. When first seen the phenomena appear almost magical. All of the above phenomena are strikingly illustrated in southern United States.

PLANTS.

The mechanical effects of plants in disintegrating rocks is mainly accomplished by means of the roots, which first penetrate the soil and later, at any given place, expand in size. They thus exert very considerable pressure against the surrounding material, and universally, in the case of soil, and frequently, in the case of rocks, push the material aside. In some instances where the roots find lodgment in a crevice of a strong rock they are unable to exert sufficient pressure to widen the openings, and as the roots grow they become flat. Tree roots under such conditions may have become so flat that their breadth is many times their thickness. However, in such cases, it is very certain that the roots exerted great pressure against their confining walls. The plants which first take possession of the rock surface are usually of the smaller kinds. Later larger plants appear, and finally, plants of the largest size may obtain a foothold. The depth to which the action of the roots extends is a function of the size of the plant. The plants may, perhaps, be divided for the present purposes into (a) lichens, mosses, and other small plauts; (b) cacti; (c) grass, grain, and vegetables; and (d) shrubs and trees.

Lichens, mosses, etc.-Lichens, mosses, and other small plants may take possession of the bare rock, sending their tiny rootlets into the minute joints or other fractures, or even into the pores between the grains. They thus 
exert a powerful effect in the disintegration of the rocks and help to form a thin soil, which is gradually taken advantage of by the larger plants.

cacti-Cacti and similar plants may be very effective in breaking up the rocks and producing a soil, becanse able to exist with a small amount of moisture. Storer states that the lava beds of Etna are planted with a prickly pear. The roots of the cacti soon crack the lava and in a few years it breaks up to a sufficient depth to allow vineyards to be planted. By the same sort of action cacti are breaking up the amygdaloidal rocks of the pyramids of old Mexico. ${ }^{a}$ The cacti are very abundant in the semiarid and arid regions, and consequently in such countries produce their most important effect.

Grasses, grains, and vegetables. - Grasses and grains may exist on a very thin soil, but under farorable conditions the roots penetrate to considerable depth. Many of the grasses send their roots into the soil several meters. The roots of the red elover are known to extend a meter into the ground; those of barley, wheat, and oats may penetrate 2 or more meters. In the case of corn, careful experiments have shown that for the depth of 2 meters or more the soil may be permeated with roots, so as to constitute a remarkable tangle, fully occupying all the distance between the hills. But as to size and extent of roots probably the most remarkable of the plants cultivated is alfalfa. It is well known that the roots of this plant often extend to a depth of 6 meters, and the soil is commonly a tangle of alfalfa roots and rootlets to the depth of 3 to 5 meters. Cases are recorded where the roots have been found in sandy soils at river banks at a depth of 15 to 18 meters below the surface. ${ }^{b}$

Shrubs and trees.-Shrubs and trees may extend their roots several or many meters from their base, both laterally and vertically. Of the shrubs, mesquite is one of the more remarkable. This plant in the arid regions sends a tangle of roots several meters below the surface; indeed, the amount of vegetable fiber below the surface is so much greater than that above the surface that the roots are frequently dug out for fuel, as furnishing a better supply than the growth above the surface. Second-growth black oak has been known to extend its roots laterally more than 9 meters beyond its

a Storer, F. H., Agriculture in some of its relations with chemistry, Charles Scribner's Sons, New York, vol. 1, 1887, pp. 130-131.

$b$ Smith, J. G., Leguminous forage crops: Yearbook of the Dept. of Agric., 1897, p. 494. 
base and 1 meter below the surface. Apple trees have been known to send roots 14 meters from their bases. In one case a long-leaf pine in Alabama was found to have extended its roots to a depth of 9 meters, and at this depth the taproot liad a diameter of $20 \mathrm{~cm}$. It is to be presumed that the gigantic trees of western America and the Tropics extend their roots even deeper.

In this comnection it is to be remembered that various kinds of plants work together. For instance, in warm humid regions trees are very numerous. Between the trees are other plants of many kinds. Thus we are lead to the conclusion that wherever the vegetation is luxuriant above the surface of the earth there is almost an equally luxuriant growth below the surface. Wherever there is a cornfield, a wheat field, or a clover field, corresponding with the plexus of stems and leaves above the ground there is another plexus of roots below the ground almost equaling that above the ground in extent, and pervading it throughout with roots varying in size from the most minute hair-like rootlets to the taproots of the plants. Wherever there is a forest the great bulk of trunks and limbs and twigs above ground is almost paralleled below ground by the tangle of roots, grading from the mighty taproot to the minute rootlets.

As the roots grow they thrust the soil or the rock aside. As they decay, openings are left which are taken advantage of by downwardmoving water: Gravity tends to pull the soil or rock together again, and thus finally close the larger openings. But in the meantime others are made by the growing vegetation. Thus where there is abundant plant life the rock material to the depth to which the roots extend is being. constantly moved about.

Therefore, if we would understand the entire work of the plants, wherever we see the foliage of field or forest above the ground we must in our mind's eye see a nearly equal rolume of roots below the surface of the earth, prying the soil apart, splitting the rocks, and, as explained below, acting upon them chemically.

Finally, when large plants, especially trees, fall a further mechanical effect follows. It has already been seen that trees may extend large roots into the ground to a depth of a number of meters, both laterally and vertically. When a tree is overthrown by the wind, or in some other way, a large mass of the soil, subsoil, contained bowlders, and even the solid 
rock, may be lifted 1,3 , or 5 meters above the surface level. When the trees decay the inorganic material again joins the soil, producing a mound. The material of the mound is in a much disintegrated and decomposen state; for it has been in a position to be effectively acted upon by all forces of weathering. How important this effect is can be appreciated only when one travels througl the original forests. In such places there are seen almost everywhere hollows where trees have been uprooted and mounds where the material has fallen to the surface. Where tormadoes have swept through the forests, all the trees in their paths have been orerthrown at once, and it seems as if almost the entire mass of soil and rock to a deptl of several meters had been upturned. This process is well illustrated in the Lake Superior region. The paths of the tornadoes vary from 30 meters to 2 kilometers or more in width. In traveling through the forests of this region one may find the paths of recent tomadoes, those a few years old, and those many years old. Where tornadoes have recently eut through the forests the giant trees have been uprooted and thrown dowu in a tangled mass like jackstraws. Where the tornadoes occurred a few years ago the fallen trees are dead and a tangle of briers, brush, and saplings is between the tree trunks, presenting a smooth surface abore, but the whole making an interwoven mass of live and dead vegetation, which presents all but an impassable obstacle to travel. Still later the fallen trunks show marked decay, and at this time the saplings have become small trees. After many years the great tree trunks and roots are ridges of rotten wood, so decayed that one's foot may pass through them, and the inorganic material held by the roots has fallen to the earth again. The saplings have become trees, but they may be discriminated from the older trees of the adjacent forest. In the final stage of decay one may recognize the path of a tornado by mumberless earth monnds, where the soil and rocks have been lifted up by the roots and fallen back, but the second-growth trees can scarcely be discrininated from those of the adjacent forest.

ANIMIAIS.

Burrowing animals are rery numerous, and they, like the plants, have an important mechanical effect upon the rocks in the belt of weathering. The effect of animals is, however, somewhat different from that of plants, in that the animals frequently move the soil in a definite direction rather than in 
various indefinite directions, as do the plants. The main mechanical effect of the burrowing animals is to bring material from below the surface to the surface. But some animals throw the soil behind them or push it up as they move along. The animals which are mechanically effective upon soil are (a) earthworms, (b) ants, termites, and other insects, (c) larger burrowing animals, and (d) man.

Earthworms.-As shown by Darwin, one of the most important of all the animals in movements of the soil, if not the most important, is the earthworm. ${ }^{a}$ Earthworms are distributed throughoút the world in great numbers. According to Darwin there are at work in many places over 50,000 upon a single acre of soil. The amount of material which the earthworms transport to the surface of the earth in a year is very great. Darwin estimates it as over 18 tons [16 tomneaus] per acre. ${ }^{b}$ Davison states that the amount of eartl turned up by lobworms is sometimes 3,147 tons [2,832 tonneaus] peracre. $^{\circ}$

Ants, termites, and other insects. - According to Bramner, of the burrowing work of insects that of ants and termites is most important. In tropical regions these "are vastly more important as geologic agents than the earthworms of temperate regions." " However, this statement should doubtless be restricted to the mechanical work of turning over the soil and bringing it to the surface. In chemical work the earthworms are probably more important. (See p. 456.) The ant-hills of the Tropics are of great size and incredibly numerous. Branner states that the ants of Brazil live in large, often enormous, colonies. They excavate in the earth chambers with galleries which radiate and anastomose in every direction, and into these chambers and galleries they carry great quantities of leaves. One can get some idea of the extent of these openings from the heaps of earth brought up by the insects. These mounds are often from 15 to 30 meter's long, from 3 to 6 meters across, and from one-third to over 1 meter high, and contain tons of earth. ${ }^{e}$

In another place Branner states in reference to the ant-hills in the forests: "These mounds are from 3 to 14 feet [1 to $4 \frac{1}{2}$ meters $]$ high and

a Darwin, Charles, The formation of vegetable mould, D. Appleton \& Co., New York, 1883, pp. 1-313.

${ }^{b}$ Darwin, cit., p. 165.

c Davison, Charles, Work done by lobworms: Geol. Mag., new ser., vol. 8, 1891, p. 491.

$a$ Branner, J. C., Ants as geological agents in the Tropics: Jour. Geol., vol. 8, 1900, p. 152.

e Branner, J. C., Decomposition of rocks in Brazil: Bull. Geol. Soc. America, vol. 7, 1896, pp. $255-314$. 
from 10 to 30 feet [ 3 to 9 meters] across at the base. The new ones are steeply conical and the old ones are rounded or flattened down by the weather. In many places these mounds are so close together that their bases tonch each other. About the Urucu station the ant-hills are so thick that the country looks like a field of gigantic potato hills." ${ }^{a}$

The termite nests, above the average surface, are sairl by Branner to be from one-third to $3 \frac{1}{2}$ meters in height, and from one-third to 3 meters in diameter. He further says that along the upper Paraguay he has seen "places where the nests are so close together that one could almost walk upon them for severa] hundred yards [one-half a kilometer] at a time, while over many acres of ground no one of the nests was more than 10 feet [3 meters] from another." ${ }^{b}$ Branner further states that innumerable anastomosing galleries are made underground from a depth up to 3 meters or more. "The underground galleries of the saíbas penetrate the soil to great distances. These ants are very injurious to vegetation, and one of the methods used by the planter's to kill them is to blow poisonous fumes into their burrows. I have seen these fumes, blown into one of these openings, issue several hundred, eren 1,000, feet [312 meters] away." c

Even in the temperate regions in favorable locations the number of ant-liils on an acre is very great, and each hill may vary from one to several feet in diameter, and from a few centimeters to a meter in height. Shaler calculates that the ants in a certain field in Massachnsetts transfer annually half a centimeter of material from the subsoil to the surface. He explains the freedom from pebbles of certain sandy soils of New England resting upon a subsoil containing pebbles as due to the upward transportation of the soil by the ants in making their monnds. ${ }^{d}$

Besides ants and termites there are many other small burowing animals, such as beetles and wasps, but these are comparatively unimportant.

The larger burrowing animals. - The larger burrowing animals are very numerons. Of these some of the more important are the prairie dog, rabbit, mole, badger, woodehuck, gopher, and ground squirrel. In many regions

a Branner, J. C., Ants as geologic agents in the Tropics, cit., p. 151.

${ }^{b}$ Branner, J. C., Decomposition of rocks in Brazil, cit., p. 299.

$c$ Branner, J. C., Decomposition of rocks in Brazil, cit., p. 296.

"Shaler, N. S., The origin and nature of soils: Twelfth Ann. Rept. U. S. Geol. Survey, pt. 1, 1891, p. 280. Merrill, George P., Rocks, rock-weathering, and soils, Macmillan Co., New York, 1897, p1. 389-390.

MON XKVII-04-29 
of the West, especially in the great plateaus, colonies of prairie dogs occupy areas extending each from less than an acre to many acres. Throughont one of their towns are burrows and corresponding hillocks in every direction, at intervals from less than a meter to a few meters. Different varieties of gophers and ground squirrels are very widespread. They occur from the Atlantic to the Pacific. In some areas in the West their burrows and mounds are only less numerous than those of the prairie dogs in the dog towns. The mole is scarcely less effective than the prairie dog and ground squirrel. In many areas the ridges produced by his work as he makes his way underground are everywhere intersecting. He works alike in field and in forest; in the South and in the North; in the lowland and high np in the mountains under the snow. In the forests of the momtains, just after the snow has melted, the intersecting ridges are often so thick that a person can scarcely step without crushing one of them. The rabbits in Australia have mnltiplied in an amazing way. Their burrows are innumerable. In Cape Colony there is said to be almost constant morement of the ground due to the various animals. In various parts of the West, especially in the semiarid regions, the ground has been so penetrated with burrowing animals that in riding rapidly great care must be taken lest one's horse break through the crust into the holes. Blake says that in Tulare Valley, California, "mules often break through the thin crust and sink to their shoulders in these holes." a

man.-Finally, man is the most important of all the mechanical organic agents. He has stripped the soil of its protective regetation, including both grasses and forests, for large parts of the world. As a conseguence of this the transporting power of ruming water has been multiplied for these areas many fold. Wherever there are fields the rivulets run turbid to the brooks. Not only is the denuded soil transported seaward with many fold the speed of natural conditions, but in many fields where cultivation is carelessly carried on or is neglected there form gulleys and deep ravines which cut through the subsoil or to the very bottom of the belt of disintegration, or even into the solid rock. A plexus of ravines once formed rapidly deepens and extends, and thus carries on the process of transportation with ever-accelerating speed. 
Marsh, ${ }^{a}$ Shater, ${ }^{b}$ Merrill, ${ }^{c}$ and others have strongly emphasizerl the ravages npon the soil as the result of man's work. They show how even from man's point of riew the present eareless methods of cultivation will in the future work to his disaster. However, for the present purpose I wish to emphasize the fact that as the soil is transported to the streams and to the ocean new material is exposed to the forces of disintegration and decomposition, and thus the process of weathering is accelerated far beyond the speed under natural conditions.

General statements.-In conclusion, we see that the animals, from the earthworm, ant, and termite to the larger burrowing animals, throughout all parts of the earth which are thickly inhabited by animals, are constantly working over the soil to a considerable depth. By the work of these animals there is a constant migration or movenent of material from the soil or subsoil to the surface, where the material is directly exposed to all the weathering agencies. Man has denuded a large part of the surface of the earth of its protecting regetation. Thus, as a consequence of the work of all the animals, the soil is more ready to be canght up by rumning water and transported to the streams. This has other far-reaching consequences in furnishing increased amounts of sediments and salts to the sea, and consequently greatly accelerating the speed of upbuilding of the sedimentary rocks. Hence animals perform a very important mechanical function in weathering the rocks, in promoting their trausportation, and in exposing new surfaces to the weathering forces; and consequently they greatly accelerate denudation and deposition.

\section{CHEMICAL WORK.}

Chemical work is accomplished by all the agents of metamorphism, viz, (I) plants, (2) animals, (3) water solutions, and (4) gaseous solutions. These agents will first be considered and then their joint work.

"Marsh, George P., Man and nature, or physical geography as modified by human actiou, Chas. Scribner \& Co, New York, 1869, pp. 576-577.

$b$ Shaler, N. S., The origin and nature of soils: Twelfth Ann. Rept. U. S. Geol. Survey, pt. 1, 1891, pp. $329-339$. 396-398.

c Nerrill, George P., Rocks, rock-weathering, and soils, Macmillan Co., New York, 1897, pp. 
THE AGENTS.

PLANTS.

Chemical work is done by plants both while alive and when dead.

PLANTS, ALIVE.

The most important chemical action by the nonbacterial plants is that of the abstraction of carbon dioxide from the atmosphere and its reduction and combination with other elements so as to produce the varic s vegetable tissues. The amount of carbon dioxide in the air is exceedingly small, not nore than from about 2.76 to 3 rolumes in 10,000 . Therefore the air in the belt of weathering where plants do not exist can not be presumed to contain more than this proportion of carbon dioxide, except for the very small amount which is brought down by the rain, estimated by Bramer in Brazil to be 0.0065 in 1,000 parts by weight. ${ }^{a}$ However, by the action of the chlorophyll-bearing plants, which inchude all of the large and many of the small plants, and by the action of the "red, brown, and blue-green alga," and by one class of bacteria, ${ }^{b}$ carbon dioxide of the atmosphere is rednced and the carbon is concentrated in the plants mainly as cellulose $\left({ }_{11} \mathrm{C}_{6} \mathrm{H}_{10} \mathrm{O}_{5}\right)$ or woody fiber. This contains 44.4 per cent of carbon. The cellulose produces no marked geological effect so long as the plants are alive; but when dead and acted mpon by bacteria, oxygen, and moisture the cellulose furnishes a number of active acids which prodnce very important geological results. (See pp. 461-465.)

Plants contain combined nitrogen, but the great majority of plants are nuable to obtain their nitrogen from the air; they must use that which is already in a combined state in the soil. A large part of this combined nitrogen is that furnisled by the decay of earlier plants and animals. (See pp. 465-466.) But some combined nitrogen is brought to the soil from the air. For instance, in manufacturing, combined nitrogen often escapes in the form of ammonia, and ammonia may also eraporate from the ocean. But this combined nitrogen was derived from earlier plants or animals, and therefore we have as yet no original source for combined nitrogen.

But it is well known that the nitrogen of the air is to some extent combined with other elements by electric discharge, and thus we have an

"Branner, J. C., Decomposition of rocks in Brazil, eit., p. 305.

$b$ Fisher, Alfred, The structure and functions of bacteria, translated by A. Coppen Jones, Clarendon Press, Oxford, 1900, p. 107. 
original source of combined nitrogen. The combined nitrogen of the air may possibly be absorbed directly from the air by plants, but it is mainly useful when brought down by rain, snow, dew, fog, etc. Howerer, the amount of nitrogen precipitated from the air, including both that which is secondary to plants and animals and that which is originally produced, is very small, only 1 or 2 kilograms per ammun per acre. ${ }^{\alpha}$

We have therefore yet to account for the main original source of combined nitrogen. Recent discoveries have shown that there are certain bacteria that are capable of utilizing the nitrogen of the air. 'The Leguminosæ, such as peas, beans, etc., form numerous nodules ujon their ronts, which becone the hosts of these bacteria, ${ }^{b}$ and finally abstract the nitrogen fixed by the bacteria. Thus the bacteria abstract and the leguminoms plants store nitrogen compounds in the fruits, stalks, and roots. Fxperiments show that where legmminous plants are grown and turned under, the gain in nitrogen for the soil is rapid and the accumulation of combined nitrogen great; and this gain is certainly largely due to the capacity of the bacteria and leguninous plants together to use the free nitrogen of the atmosphere.

Certain bacteria are able to fix free nitrogen without the assistance of other living plants." Whether the plants obtain their nitrogen from the nitrates already in the soil, or, like the leguminous plants, help to produce the combined nitrogen, the material is mainly built into albuminous compounds or proteids.

From the foregoing it follows that there are two original sources of combined nitrogen in the soil-that combined with other elements through the agency of plants, and that combined with other elements through the agency of electricity. Material from each of these sources is built into the body of the plants, as already seen, mainly in the form of proteids. The material so long as it is in this form has no important geological effect, but when plants decay these compounds become the source of the nitrogen acids and salts which are important geological agents. (See pp. 465-466.)

Besides concentrating combined carbon and nitrogen in the belt of weathering, live plants have a direct chemical effect upon the rocks. It is

"Aikman, C. I., Manures and manuring, Wm. Blackwool \& Sons, London, 1894, p. 119.

$b$ Fischer, Alfred, The structure and fumctions of bacteria, trans. hy A. C. Jones, C'larendon I'ress, Oxford, 1900, pp. 88-97.

c Aikman, cit., pl. 96-97. 
well known that plants abstract certain ingredients from the soil, and therefore exert a soluble effect. The inorganic materials which are most abundantly abstracted are potash, soda, magnesia, lime, phosphoric acid, and silica. The relative proportions of these substances in grain and straw, as given by Johnson, are as follows: ${ }^{a}$

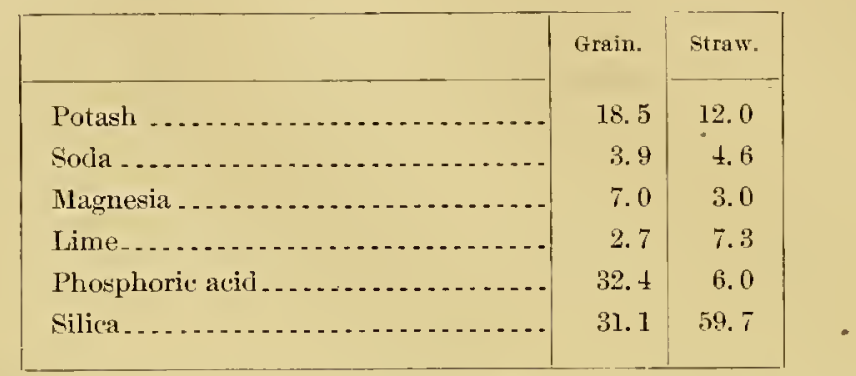

Besides these substances, the plants also abstract such compounds as iron, sulphur, and chlorine in small amounts. The sulphur is absorbed as a sulphate.

Finally, living plants have a further effect upon the rocks. Fresh roots give acid reactions, and as a consequence, where they are in contact with the rocks they corrode them chemically. This is illustrated by the action of lichens and creepers and by the corroded surfaces of rocks where roots are in contact with them. In some cases where the rocks are rather readily soluble, as, for instance, limestone, actual furrows may be produced in the rocks as a result of the solution. ${ }^{b}$ In places where lichens occur the rocks may be softened to a depth of 2 to 4 centimeters." Jolmson states that "on the Schrralbenstein, near Glatz, in Silesia, at a lieight of 4,500 feet [1,368 meters], the granite is disintegrated under a covering of lichens, the feldspar being converted into kaolin or washed away, only the grains of quartz and mica remaining maltered." $d$

Positive evidence that the chemical action of the plants is important is furnished by experiments showing that soils upon which plants have been grown are more soluble after all the parts of the plants have been removed than are similar soils in which no plants have been grown.

a Johnson, S. W., How crops feed, Orange Judd \& Co., Yew York, 1870, p. 364.

bstarer, F. H., Agriculture in some of its relations with chemistry, Charles Scribner's Sons, New York, vol. 1, 1887, pp. 187-188.

c Storer, cit., pp. 130, 131.

¿Johnson, cit., p. 142.

estorer, cit., p. 186. 
PLANTS, DEAJ, AND HACTERIA.

Thus far the work of plants during their uplouilding has been considered. However, there is a class of plants the chief geological work of most of which is the destruction of other plants and animals. Of these the bacteria are by far the most important. The number of bacteria in the soil is almost incredibly great. "Ordinary earth may yield anything from 10,000 to $5,000,000$ per gram, whilst from polluted soil even $100,000,000$ per gram have been estimated." ${ }^{a}$ Certain authors include some of the fungi, and especially the molds and yeasts, mder plants which assist in the destruction of other plants and animals. This assistance seems to be in the way of absorbing compounds of other plants and animals, and building them into new forms which may be more readily attacked by the bacteria. Certain it is that the process of oxidation, both of the chlorophyll-bearing plants and of the fungi, is a bio-chemical one, the main organic agents in which are the bacteria. In this matter the bacteria are one of the most potent factors of all the organic geological agents. Since this process of oxidation of plants and animals is mainly accomplished after death by the living bacteria, the geological work of the bacteria is mainly considered in comnection witl dead plants and dead animals.

When plants die they fall to the earth, and the part above the surface may become buried to a greater or less extent in the soil. The roots of the plants below the surface, nearly as great in mass as the parts above the soil, are buried to a depth, as already seen, from a few centimeters to 10 - meters or more. After this material dies it decomposes or is oxidized.

The oxidation of the carbon, nitrogen, and hydrogen of plants is the conjoint result of bacteria, water, and oxygen. The process of the decomposition of the plants might go on in the presence of moisture and oxygen even if bacteria were not present. However, experiments show that the process of oxidation would be very slow indeed if it were not for the oxidizing bacteria. We have already seen that the bacteria are present in the soil in enormous numbers. The oxidizing bacteria act in different ways. They oxidize the carbon, and with water convert it into carbonic acid; and they oxidize the combined nitrogen of plants into ammonia, nitrons acid, and finally into nitric acid. 
Bacteria, water, and oxygen decompose the iron and other sulphides. They further oxidize the iron of carbonates. While oxidation is the rule for the belt of weathering, under exceptional conditions bacteria, moisture, and vegetation, or the two latter, may deoxidize instead of oxidize compounds, and this may result in the reduction of ferric salts and in denitrification. These processes of oxidation and deoxidation are fully considered on pages $461-473 .^{.}$

\section{ANIMALS.}

The chemical work of animals is accomplished while alive and while dead the same as that of the plants.

ANIMALS, ILIVE.

In chemical work probably the most important of the animals while alive are the earthworms. It has already been seen how great is the number of these animals, and how great is the mechanical work which they accomplish. These animals differ from other animals in that they pass the soil directly through their alimentary canals, so that the active compounds of the body act upon and decompose the inorganic materials. It is impossible to estimate the effect of this repeated passage of the soil through the alimentary canals of the earthworms, but it can not be doubted that it results in dissolving a vast quantity of earth materials and in rendering undissolved parts of the materials more soluble.

The ants and termites carry a large amount of vegetable material from above the surface of the ground to below the surface, and thus introdnce it into the soil, so that when it decomposes the products formed will be most effective in their chemical action. Bramner states: "The quantities of vegetable matter canied inte their burrows is almost beyond belief. I lave seen a full-grown orange tree completely stripped of its foliage within a few hours. In the coffee regions the damage done by them is so serious that the Brazilian Government at one time offered a large premium for a successful formicida or ant exterminator."

A second effect of living animals comes from their constant excreta. These consist in large part of active chemical compounds, of which perhaps

"See Branner, J. C., Bacteria and the decomposition of rocks: Am. Jour. Aci., 4th ser., vol. 3, 1897, pl. $438-442$.

Branner, J. C., Decomposition of rocks in Brazil: Bull. Geol. Suc. America, vol. 7, 1896, p. 297. 
the most important is uric acid. All over the world, above ground and below ground, excreta of all kinds are being added to the soil, or introduced by the burrowing animals below its surface, and the chemical effect upon the inorganic material of the soil can not but be very great.

Man has promoted chemical work in varions ways. It has been pointed out that cultivation exposes the soil to the transportational agencies, and this continually exposes new material to chemical agents. Crops are planted and grown. When the crop matures it is removed, and the soil is again free from its active living plants. Thus there is continual altemation between abundant and sparse plant life, and consequently conditions very favorable for chemical reactions. Further, it is explained on pages $463-465$ that man has oxidized great quantities of the organic nnaterial entombed in the earth during past geological ages, and thus increased the amomnt of the active chemical agent, carbon dioxide, in the atmosphere; and this of course has accelerated to an mknown extent plant growth and chemical action.

ANIMALS, DEAD, AND BACTERIA.

Animals die both below and above ground. When dead their bodies decompose and nltimately produce water, carbon dioxide, nitrates, some free hydrogen and free nitrogen, and some sulphates. This process of change to the ultimate products is accomplished by the bacteria, fungi, oxygen, and water, precisely the same as in the plants. The process is one of oxidation and is considered nnder that heading. (See pp. 461-466.) As with the plants, the process concentrates carbon dioxide, nitrates, and other compounds in the belt of weathering, thus placing important chemical agents in a very favorable position to do active geological work.

WORK OF SOLUTIONS.

It has already been explained that in the belt of weathering there are gaseons solutions, water solutions, and various mixtures of these which are at work npon the rocks. The very important gases are oxygen and carbon dioxide. It has been pointed out (pp. $76-81$ ) that the activity of water solutions is dependent upon (a) the compounds present, (b) the temperature, and (c) the pressure.

(a) The water solutions are likely to contain considerable amounts of the salts formed by the union of the bases and acids which ordinarily occur 
in rocks. In the gromnd water they are ordinarily composed of compounds cousisting of the bases sodium, potassium, calcium, magnesium, iron, and aluminum, and the acids, carbonic, hydrochloric, nitrie, hydrosulphuric, sulphurie, and phosphoric, and also colloidal silicic acid. Nitrous, sulphurons, and organic acids are also present. These bases and acids unite in varions ways to produce many salts, the majority of which are, however, simple salts, such as the carbonates of the alkalies and alkaline earths.

Of these salts the dominant ones are those of sodium, potassium, calcium, and magnesium in the form of carbonates, sulplates, and chlorides. Furthermore, there are present other bases and acids which are omitted because of their subordinate quantity. For instance, in some cases rarious salts of manganese, copper, silver, gold, etc., are present, but the quantities of such compounds are so minute as to have no significance except in connection with ore deposits.

The water, moreover, contains oxygen, carbon dioxide, and other gases in solution. Where the rocks are not saturated by water gaseous solutions also are present and active. Of these oxygen and carbonic acid are the most important active chemical agents

While it is well established, as explained (p. 63), that pure water acts upon all of the compounds which occur in nature, the activity of solutions is very greatly increased by the mineral content. This is true of bases, of acids, and of salts alike. Where bases or acids are present it is well known that the activity of solutions is greatly increased; but it has not been always fully appreciater that the same is true in reference to normal salts.

Therefore all of the above compounds, in all their forms, are actively at work in decomposing the rocks. The amount of work which any one compound does depends upon the strength of its bases or acids, and also upon its quantity, or upon the law of mass action. While if the compounds are present in equal quantity the stronger bases or acids do more work, it is frequently the case that a weaker compound more than compensates for this weakness by its great abundance. Illustrating this is carbonic acid, which, while very weak, is on account of its abundance, one of the most potent agents in the alterations of rocks in the belt of weathering.

(b) The temperature is of very great importance in the activity of the water and gaseous solutions. 
The average annual temperature near the Aretic Circle in northern North America and northern Asia is about $-15^{\circ} \mathrm{C}$.; and from this temperature the average temperature varies to about $-18^{\circ} \mathrm{C}$. in northern Greenland. In the Temperate Zone the average temperature varies from about $-15^{\circ} \mathrm{C}$. in its northein part to about $22^{\circ} \mathrm{C}$ at its sonthern part. The Tropical Zone raries in temperature from about $20^{\circ} \mathrm{C}$. to about $27^{\circ} \mathrm{C}$. In central North America and central Asia the normal a verage temperature is about $5^{\circ} \mathrm{C}$., in southern North America and southern Asia it is from $15^{\circ}$ to $20^{\circ} \mathrm{C}$. For the present purpose the average temperatures, rather than the changes of temperature or the extremes of temperature, are the data of first consequence; for the average action of solutions upon the rocks, extending througl years, is controlled by these average temperatures. In the aretic and north temperate regions, during the time the temperature is below $0^{\circ} \mathrm{C}$, it is highly probable that the decomposition of the rocks practically ceases; as the temperature rises above $0^{\circ} \mathrm{C}$. decomposition begins, and this goes on with increasing speed in proportion as the temperature is high. Therefore, in the above facts as to temperatures we lave in large part the explanation of the slowness of the decomposition of rocks in the arctic regions and the rapidity of the decomposition in the tropical regions.

It is to be noted that the activity of the solutions in the warm climates, as compared with the cold climates is much greater than would be inferred from the absolute temperatures. The temperature of northern Greenland $\left(-18^{\circ} \mathrm{C}\right.$. $)$ is $255^{\circ}$ absolute; that of the Tropies $\left(27^{\circ} \mathrm{C}\right.$.) is $300^{\circ}$ absolute. Thus the ratios of the absolute temperatures between the extreme cold of the aretic regions and the warnth of the Tropics is as 255 to 300 , a difference of less than one-fifth; but it is certain that the activity of the solutions in the Tropics is manyfold greater than in the aretic regions.

While the arerage temperature is the matter of most significance in this comnection, the changes of temperature lave an important effect upon the chemical decomposition of the rocks as well as npon the mechanical disintegration. From the tables given above it appears that while the average temperatures in the aretic regions are very low for certain seasons of the year the temperature for a whole month may average as high as $10^{\circ} \mathrm{C}$, and during the day the temperature may rise as high as $20^{\circ} \mathrm{C}$. At such temperatures it is certain that the process of decomposition of the rocks 
takes place. Thus it appears that at certain seasons the temperature is ligh enough for decomposition to affect the rocks in the most northern and the most southern latitudes. But in polar regions the temperature is such that decomposition takes place for only a small fraction of each year; in the temperate regions the temperature is high enough for decomposition to take place during more than lialf the year; while in the Tropics decomposition is continuous. It therefore appears that in passing from the polat to the tropical zones we pass from a minimun to a maximum of chemical decomposition.

(c) As to the pressure in the belt of weathering, since the ground is not ordinarily saturated by water there is commonly no hydrostatic pressure; and the pressure at which the chemical reactions take place is therefore that of the atmosphere. At sea level the average pressure is that of a column of mereury $760 \mathrm{~mm}$. high, or $1.0333 \mathrm{~kg}$. per sq. cm. From the pressure at sea level the pressure diminishes as the altitude increases, and at the tops of the higher mountains is not more than about one-half of the amount at sea level. Not only is there change of pressure due to elevation, but there is change of pressure due to variable meteoric conditions. As a storm sweeps over an area the pressure is ordinarly low; at the clear intervals between the storms the pressure is nsually high. Commonly the change in barometer from a low to a high is not more than $2 \mathrm{~cm}$. and the average change is probably not more than $1 \mathrm{~cm}$. Infrequently the change is $5 \mathrm{~cm}$., or about one-fifteenth of the total pressure. Very exceptionally the cliange of pressure may be much greater than this. Probably these changes in pressure are so slight as to produce little effect upon the water solutions. But, as already shown (p. 61), the quantity of atmospheric gas acting is directly as the pressure. To illustrate, if the barometric pressure rises from $715 \mathrm{~mm}$. to $760 \mathrm{~mm}$, the proportional increase in the amount of gas action is about one-fifteentl. More frequently, lowever, the variations are from one-thirtieth to one-fiftieth, or eren less.

Since the amount of gas is directly as the pressure, it is evident that, so far as this factor goes, the higher the barometer the greater the activity of the gases at work in the belt of weathering. But since the variations in pressure due to this canse are ordinarily but a small fraction of the total pressure, the variations in effect are not sufficiently great to be appreciable. Since, in reference to the cyclonic periods, the times of ligh pressures are 
usually those of low temperatures, and vice versa, so far as increased pressure produces an effect it compensates to a slight extent for the low temperature, and decreased pressure detracts to a slight extent from the chemical activity resulting from the high temperatures.

JOINT WORK OF AGENTS OF WEATHERING.

As a matter of observation, we know that the most important chemical reactions which take place in the belt of weathering, as a result of the action of the various agents, are (1) oxidation, (2) carbonation, (3) hydration, (4) solution, (5) deposition.

oXIDATION.

One of the reactions of first importance in the belt of weathering is oxidation. Oxidation is the addition of oxygen to other compounds. The source of the oxygen is the atmosphere, of which it composes 23.12 per cent by weight. This oxygen of the atmosphere acts to some extent directly as a gas, but to a far greater extent throngh water solutions, and to the greatest extent through water solutions and organisms combined. Of these organisms bacteria are of the greatest consequence, but the molds and fungi are important.

OXIDATION OF ORGANIC COMPOUNDS.

The chief elements oxidized in the organic compounds are carbon, hydrogen, and nitrogen.

Oxidaticn of carbon and hydrogen. - The most abundant organic componnd is cellulose $\left(\mathbf{n C}_{6} \mathrm{H}_{10} \mathrm{O}_{5}\right)$. Other compounds which contain carbon and hydrogen are the proteids, carbohydrates (starch, sugar, etc.), organic acids, fats, etc. The nltimate oxidation products of all these compounds are carbon dioxide and water. This work of oxidation is almost wholly accomplished through the joint work of bacteria and other microbes (such as the fungi), oxygen, and water. The numbers of bacteria engaged in this work are enormons. Estimates by Wollney, Adametz, Koch, Fullus, and others, of the number of bacteria in one gram of soil connected with the formation of carbonic acid gas alone vary from one-half million to one million.

During the oxidation of cellulose a large number of organic acids are produced. Of these organic acids limmic acid $\left(\mathrm{C}_{60} \mathrm{H}_{54} \mathrm{O}_{27}\right.$, Detmer; $\mathrm{C}_{24} \mathrm{I}_{10} \mathrm{O}_{6}$, 
Thenard) is the most important in the soil. Some of the laboratory properties of humic acid are as follows: It is amorphous; it decomposes at $145^{\circ} \mathrm{C}$; after drying, it requires 13,784 parts of boiling water to dissolve it; when undried, it requires 8,333 parts at $6^{\circ} \mathrm{C}$. and 625 parts at $100^{\circ} \mathrm{C}$. to dissolve it. With humic acid in the soil are various other acids, such as ulnic acid $\left(\mathrm{C}_{18} \mathrm{H}_{14} \mathrm{O}_{6}\right.$ or $\mathrm{C}_{18} \mathrm{H}_{36} \mathrm{O}_{7}$, Berthelot and André), crenic acid $\left(\mathrm{C}_{12} \mathrm{H}_{12} \mathrm{O}_{8}, \mathrm{M}\right.$ ulder $)$, and apocrenic acid $\left(\mathrm{C}_{24} \mathrm{H}_{12} \mathrm{O}_{12}\right.$, Mulder $){ }^{a}$

The hnmic acids are first produced by the oxidation of the cellulose. The other organic acids appear to be produced by further oxidation of the humic acid. Finally, as the process of decomposition continues, humic and the other organic acids by their decomposition are further oxidized and broken up, so that the ultimate products are carbon dioxide and water.

At all stages in the process the acirls are active. The hmmic acid and other organic acids act upon the various inorganic compounds, especially the silicates, forming salts. However, the acids of these salts are broken down to carbonic acid. Also the breaking down of the free humic acid and other organic acids produces carbon dioxide. Therefore the most important result of the decomposition of the cellulose is the production of carbon dioxide. By the process of plant decay carbon dioxide is thus concentrated in large quantities in the belt of weathering-that is, in the place where it can do its most active work. The process of carbonation (explained on pp. 473-480) is consequently largely due to this concentration.

Besides their direct chemical activity, humic and other organic acids have various other important effects in the belt of weathering. As a result of the dark color of humic acid it is an absorbent of the sun's heat. Moreover, it has a higher specific heat than soil, and hence is able to retain a large quantity of heat. Thus, in this way, the presence of humic acid promotes chemical activity. Furthermore, humic acid is hydroscopic, and in sandy soils greatly increases the holding power for water; and it has been noted that the chemical activity in soils is very largely dependent upon the amount of water they hold. Finally, humus in the soils holds ammonia, nitrites, nitrates, and soluble sodium and potassium compounds, in other words, plant foods. 'These plant foods may be held in some cases as

a See also Merrill, George P., Rocks, rock-weathering, and soils, Macmillan Co., New York, 1897, pp. 189-190. 
humates or other organic salts These soluble materials thus held by the presence of the humic acid are important plant foods. Therefore, limmic acid for many reasons furnishes favorable conditions for further luxuriant plant growth, and these plants again react in a powerful way in promoting the alterations of the belt of weathering.

The process of decomposition of the other carbon- and hydrogenbearing compounds, aside from cellnlose, especially the decomposition of the carbohydrates, is describer by Fischer as a fermentation. In this work, as in the decomposition of cellulose, the mold fungi, as well as bacteria, are at work in connection with oxygen and moisture. ${ }^{a}$

While during the history of the earth by far the larger portion of the cellulose formed by organic agencies has been oxidized as above described, from time to time to the present, and in various areas, districts, and regions, this process has been only very partial. As a consequence, the moxidized cellulose has been buried below later sediments, and thus immense quantities of carbon compounds have been entombed within the earth. This is the main source of the coals, oils, yeats, and carbonaceous sediments. It is therefore evident that the total quantity of this entombed organic matter is enormous. By metamorphism of the cellulose these carbon compounds pass into the various forms of coal. After these carbon compounds are formed, as a result of denudation they may again pass into the belt of weathering, and here they are subject to the same oxidizing agencies which are at work upon the original cellulose. But ther are now in a more refractory form than the original cellulose, and while the process is doubtless very slow, there is no doubt that the oxidation of the coal and other similar carbon compounds takes place to some extent in the belt of weathering under natural conditions and thus produces carbon dioxide. But, so far as I know, this process has not been studied, and I can make no definite statements in reference to it. It is probably more rapid than is commonly supposed, and the changes are perhaps accelerated by oxidation of sulphides.

Since man began to use coal, peat, and oil, artificial oxidation of the cellulose and the entomber carbon compounds has taken place upon an immense seale. While this method of oxidation of these carbon compounds was trivial until the middle of the eighteenth century, when coal was first applied to the manufacture of iron, it has since tlat time steadily

" Fischer, Alfred, The structure and functions of bacteria, trans. by A. Coppen Jones, Clarendon Press, Oxford, 1900, pp. 107-115. 
increased in importance. But it is only during the last half of the nineteenth century that the quantity of carbon compounds artificially oxidized has become of importance. In the year 1899 the amount of coal mined and oxidized amounted to 723,287,454 metric tons. At the beginning of the last decade of the nineteenth century, 1890, the production was only 511,518,358 metric tons. ${ }^{a}$ This shows how rapid the increase in the use of coal has been, and therefore a combustion of $1,000,000,000$ metric tons a year is probably very conservative as the estimated average for the present century. Taking 1,000,000,000 metric tons as the amount of coal oxidized per ammum for the future, and supposing the amount of carbon in this coal to average 80 per cent, the quantity of $\mathrm{CO}_{2}$ which passes into the atmosphere would be 2,933,333,000 metric tons per ammum. This is 0.1233 per cent of the total amount of $\mathrm{CO}_{2}$ at present in the atmosphere. (See p. 972.) If this rate of consumption of coal were continued eight hundred and twelve years the amount of $\mathrm{CO}_{2}$ in the atmosphere would be doubled.

It therefore appears probable that within a comparatively short time in the future, as compared with a single geological period, or even an epoch, the anount of $\mathrm{CO}_{2}$ in one of its great reservoirs, the atmosphere, will be increased to an important extent. From this fact rarious geological consequences are likely to follow. One of the most important of these is a higher average of temperature for the globe." According to Arrhenius, "if the carbon dioxide is increased 2.5 to 3 times its present value, the temperature in the aretic regions must rise $8^{\circ}$ to $9^{\circ} \mathrm{C}$. and produce a climate as mild as that of the Eocene period." According to the above computation, the $\mathrm{CO}_{2}$ would be increased by the oxidation of coal alone to three times its present amount in one thousand six hundred and twenty-four years. Certain it is, if Arrhenius be correct, and the coal supplies of the workl are sufficient to meet the demands of man for thousands of years, that a most profound change will take place in the clinate of the world.

"Parker, E. W., Mineral Resources of the United States, 1899; Caal: Twenty-first Ann. Rept. U. S. Geol. Survey, pt. 6, 1901, p. 369.

${ }^{b}$ Chamberlin, T. C., An attempt to frame a working hypothesis of the cause of the Glacial periods on an atmospheric basis: Jour. Geol., vol. 7, 1899, pp. 545-584.

$c$ Arrhenins, Svante, On the influence of carbonic acid in the air upon the temperature of the ground: Philos. Mag., 5th ser., vol.41, 1896, pp. 237-276. Summary in Jour. Geol., vol. 7 , pp. 623-625. 
A further consequence which would follow from an increase in the amount of $\mathrm{CO}_{2}$ in the atmosphere and the warmer climate would be a much more abundant and widespread regetation, and, as pointed out (p. 476), more regetation means that when oxidized more $\mathrm{CO}_{2}$ will be concentrated in the soil, and this concentration will lead to an acceleration in the rate of carbonation. Furthermore, the increase in average temperature of the globe will accelerate all other chemical reactions of the belt of weathering. It therefore appears probable that the artificial oxidation of coal will result in some of the most profound and far-reaching geological consequences which are due to the agency of man.

oxidation of nitrogen.-As already noted, combined nitrogen occurs in various organic compounds, of which the proteids and albuminoids are the more important. The oxidation of this nitrogen, like that of carbon and hydrogen, is a bio-chemical process, being the joint work of microbes, oxygen, and water. Of the microbes, bacteria are by far of the greatest consequence. In the decomposition of the complex nitrogen compounds the nitrogen passes into ammonia, nitrites, nitrates, and, to some extent, free nitrogen. The first stage of the process is the transformation into anmonia. In the case of urea, Fischer gives the reaction as follows: ${ }^{a}$

$$
\mathrm{CO}\left(\mathrm{NH}_{2}\right)_{2}+2 \mathrm{H}_{2} \mathrm{O}=\mathrm{CO}_{3}\left(\mathrm{NH}_{4}\right)_{2}
$$

The second stage of the process is the transformation of the ammonia into nitrites, and the final stage is the transformation of the nitrites into nitrates. Eacl of these stages of work is accomplished by certain bacteria which take no part in the other stages. At the same time the nitrogen is oxidized the carbon and hydrogen of the nitrogen componnds are oxidized into carbon dioxide and water, precisely as in the case of cellulose.

So far as the nitrogenous compounds are concerned, the nltimate geological products which remain in the soil are the nitrates, although in the process some small part of the nitrogen is freed and lost, as already noted. ${ }^{\imath}$

Apparently nitrates are produced on a far vaster scale in the tropical regions than in the temperate regions. Mintz and Marcano state that in

" Fischer, rit., p. 103.

${ }^{b}$ Fischer, cit, pp. 98-106. See, also, Conn, H. W., The story of germ life, D. Appleton \& Co,, New York, 1897, pp. 104, 118; and Aikman, C. M., Manures and manuring, Wm. Blackwood \& Sons, London, 1894, pp. 167-170.

ION XIVI1-04- 30 
places in the valley of the Orinoco the amount of nitrates in the soil amounts to 30 per cent of the mass. The vast amount of these nitrates is loubtless explained by the very great abundance and activity of the bacteria; for it is well known that the ligh temperature of the Tropics, combined with the high humidity of these regions, is very favorable to the action of bacteria. ${ }^{\circ}$ In this connection Schloessing and Miintz state that the maximum activity of the bacteria is at $30^{\circ} \mathrm{C}$, or approximately that of the Tropics.

Much of the combined nitrogen is lost to the belt of weathering in the following ways. In so far as nitrogen is set free by the action of the bacteria and by the passage of the ammonia into the air, it is lost. There are further great losses in the nitrogen compounds by the transportation of the nitrates to the sea by the streams. The quantity of nitrates thus lost has been greatly increased in recent years by the introduction into the streams of serage containing much combined nitrates. Further, as pointed ont by Comm, in so far as the combined nitrogen of the soil is manufactured into powders which are exploded, the combined nitrogen is freed and passes into the atmosphere." 'The ammonia which passes into the atmosphere may be brought back in part to the soil by the rain. The other losses must, however, be compensated by the synthesis of nitrogen componnds from the nitrogen of the air by bacteria and leguminous plants combined. Until very recently the latter process has preponderated, and the crust of the earth has gained in combined nitrogen. Man in recent times has undoubtedly increased the loss in combined-nitrogen, and it is possible, perhaps probable, that the balance is now on the other side, but by care in cultivation, and possibly by manufacture, it will doubtless be possible to continue the process of adding combined nitrogen to the soil faster than it is lost fiom it.

OXIDATION OF IXORGANIC COMPOUNDS.

The most important of the inorganic compounds oxidized are iron and carbon. Other substances subordinate in quantity are also oxidized, but these have small importance from a purely geological point of view. However, from the point of view of ore deposits, and therefore in reference to

" Merrill, George P., Rocks, rock-weathering, and soils, Jacmillan Co., New York, 1897, p. 372.

$b$ Aikman, cit., p. 52.

c Comn, cit., p. 106. 
the needs of man, the metals in subordinate quantity, such as manganese, copper, zinc, lead, etc., have great importance.

Iron.-Since ore deposits are treated in another place, iron is the only metal which will herc be considered. The iron oxidized occurs in the minerals mainly in the form of monoxide. Considerable quantities of it occur as sulphides, and mimportant amounts as arsenides, etc.

Ferrous oxide occurs in the following classes of minerals: Oxides, carbonates, and silicates. Of the oxides, magnetite is the most important. This may be oxidized without hydration into hematite. This change is very well illustrated by the martite ores of the Lake Superior region and by the psendomorphs of hematite after magnetite in the martitebearing schists. Simultaneously with the oxidation of magnetite lydration may take place and thus produce hydrated hematite, limonite, or the other hydrated oxides of iron. The change of magnetite to hematite involves an increase in volume of only $2.5 \mathrm{per}$ cent, but where magnetite is clianged to limonite the increase in volume is large-64 per cent. Iron in the form of carbonate may occur as pure iron carbonate or as iron carbonate in combination with various proportions of magnesium and calcium. The oxidation of the ferrous iron of the iron carbonate may be accomplished by oxygen and moisture. However, in the soil the process usually takes place with the assistance of bacteria. A certain group of bacteria requires various carbonates for its development. ${ }^{a}$ The oxidation of the iron carbonate, wliether with or without bacteria, changes it to ferric oxide. Where the oxidation takes place without lyydration hematite is formed; where with hydration, limonite, or some of the other oxides of iron. Where bacteria are an agent the common product is limonite. The oxidation of the carbonates involves decarbonation, and on account of this fact there is decrease in volune-in the case of hematite 49 per cent, and in the case of limonite 18 per cent. The transformation of the ferrous oxide of the silicates to ferric oxide, either anhydrous or hydrous, occurs simultaneously with processes of carbonation and hydration of the other bases. So far as there is oxidation and hydration of the iron, this would tend to increase the volume; but the amount of increase can not be calculated independently of the conjoint processes. "Laf
$360-362$. 
Of the sulphides of iron, those of marcasite, pyrite, and pyrrhotite are the most important. The oxidation of the iron of these sulphides may be accomplished by oxygen alone, by oxygen and moisture, and finally by oxygen, moisture, and bacteria. With oxygen alone the process is slow; with oxygen and moisture together it is rapid; but oxygen, moisture, and bacteria together furnish the most farorable conditions.

Where oxidation is the only process the compound produced is magnetite or hematite. More commonly, howerer, hydration occurs simultaneously with the oxidation; and under these circumstances linonite and other hydrated oxides of iron are produced. So far as the oxides are formed, this involves desulphidation.

sulphur.-At the same time the iron is oxidized the sulphur united with it may also be oxidized. "There the two are oxidized together and remain united the result is to form iron sulphate. Frequently, however, at the time the iron is oxidized the sulphur or sone part of it separates as hydrosulphuric, sulphurous, or sulphuric acid. The various reactions resulting in these compounds are given on pages 214-216, and need not here be repeated. By reference to the reactions there written it will be seen that certain of them, as already stated, result in the formation of hydrosulphuric acid. Indeed the reactions producing hydrosulphuric acid are very common during the oxidation of pyrite, marcasite, and pyrrotite. In a similar manner the oxidation of the monosulphides of the other metals may result in the production of hydrosulphuric acid.

The sulphur of the hydrosulphuric acid may be later oxidized to sulphurous or sulphuric acid. While the oxidation of hydrosulphuric acid may be accomplished by water and oxygen without the assistance of bacteria, often bacteria are the inciting cause of the change. Where hydrosulphuric acid is abundant the hydrogen only is first oxidized and the sulphur stored in the cells of the bacteria, according to the reaction:

$$
\mathrm{H}_{2} \mathrm{~S}+\mathrm{O}=\mathrm{H}_{2} \mathrm{O}+\mathrm{S}
$$

But finally the stored sulphur is oxidized by the bacteria to sulphuric acid, which reacts upon the bases present and forms sulphates. ${ }^{a}$

In the transformation of the sulphides the rolume change on account of desulphidation produces considerable diminution in volume, provided 
the oxide of irn is not hydrated-with magnetite, 24 to 39 per cent; but in case both oxidation and hydration occur together there is increase in volume of but 3 per cent in the case of pyrite and 25 per cent in the case of pyrrhotite.

GENERAL STATENENTS.

It might be inferred from the foregoing statements in reference to the volume relations that, on the average, there is a decrease in volume in oxidation rather than an increase, as one would naturally expect. In support of this view it has been stated that there is generally a decrease in volume in the processes of oxidation of the carbonates and sulphides, since the process of oxidation simultaneously results in decarbonation or desulphidation. However, much more important than the oxidation of iron in the form of carbonate and sulphide is the oxidation of ferrous iron in silicates, and this process does not necessarily involve subtraction of any material. Since it involves addition of oxygen, the result is to produce an increase in volume provided the separated silica or a considerable part of it remains in situ.

As is well known, and as has been pointed ont heretofore, the process of oxidation involves great liberation of heat; ${ }^{*}$ but the data are not at hand by which the amount of heat liberated can be determined. Concluding in reference to volume and heat relations, it may be said that the process of oxidation perhaps illustrates better than any other the principle that in the zone of katamorphism combinations which take place with the liberation of leat control the reactions rather than the volume relations. Heat is liberated in all the cases of oxidation, and whether there is an increase or decrease of volume is a subordinate factor.

Where the amount of oxygen is sufficient to canse the iron compounds to be transformed to ferric oxide, there are red or yellow soils and subsoils. Excellent illustrations of such regions are the southern Appalachians and the Piedmont Platean, where the crystalline rocks have deeply weathered. As shown by Russell, the red color of this soil is due to a ferruginous clay containing both ferric oxide and alumina, which incrusts the grains of the rocks. ${ }^{a}$ The ferric oxide is produced during the decom-

" Russell, I. C., Subaerial decay of rocks, and origin of the red color of certain formations: Bull. U. S. Geol. Survey No. 52, 1889, N1. It-15. 
position of the parent rocks. Another illustrative region, described by Hayes, is that of Nicaragua east of the continental divide. The red color in this belt is from 3 to 10 meters deep. ${ }^{\alpha}$ Both of these regions are those of rather high temperature and abundant precipitation throughout the year, and therefore abundant vegetation. They therefore well illustrate the conditions under which decomposition of the rocks, including oxiclation, takes place. The very abundant transpiration by the luxuriant foliage (see p. 422) donbtless is a very important factor in preventing the soil from becoming saturated with moisture for any considerable period, and thus the conditions for oxidation are maintained.

One would suppose that in the soil, where oxidation of organic and inorganic matter is active, the amount of oxygen in the gases would be less than in the atmosphere, and observations by Fleck, Letts and Blake and others confirm this conclusion. The amount in the atmosphere is $20.92 \mathrm{per}$ cent by volume, whereas Fleck, as cited by Letts and Blake, finds that at a depth of 2 meters the mininum is 16.33 per cent and the maximum 19.39 per cent; at 4 meters the minimum is 15.67 per cent and the maximum 16.79 per cent; at 6 meters the minimum is 14.94 per cent and the maximum 14.85 per cent. $^{b}$ These last numbers are only a little nore than two-thirds the full amount of oxygen of the atmosphere. It appears that as depth increases, and therefore as the air of the soil is further removed from its source of supply-the oxygen of the atmosphere-there is a steadily decreasing amount, and this fact must be explained by the consumption of oxygen by the oxidation of organic and inorganic matter.

In some cases the amount of oxygen is little more than half as great as that in the air. The defieieney varies directly, although not in simple ratio, with rapidity of oxidation and with the depth below the surface where the process takes place. ${ }^{c}$

While oxidation is the normal process in the belt of weathering, under certain conditions deoxidation may take place. Under such circumstances gray or white soils and subsoils are formed. This is illustrated by the western division of Nicaragua, where Hayes states that the clays are blue,

a Hayes, C. W., Report of the Nicaragua Canal Commission, Appendix II, Geologic Report, 1899 , pp. $128-129$.

$b$ The last number must be a misprint. Letts, E. A., and Blake, R. F., The carbonic anhydride of the atmosphere: Scientific Proc. Royal Dublin Soc., vol. 9, new ser., pt. 2, p. 215.

CAikman, C. M., Manures and manuring, Blackwood \& Sons, London, 1894, p. 100. 
the iron being in the ferrous form. ${ }^{a}$ This is a region of less humidity than the eastern region, and here dry seasons alternate with rery wet seasons. According to Hayes, during the dry season each year the soil cracks deeply, and a large amount of organic material falls into these cracks. During the wet season the soil swells and fills the cracks, and the organic matter becomes incorporated with the soil. This material acts as a reducing agent and prevents the further oxidation of the iron, or reduces any part of the iron oxide which has become ferric oxide to the ferrous state.

While this explanation is plansible, it seems incomplete. In the eastern division the soil is continuously in contact with numerous dead and dying roots of the abundant regetation, and the question naturally arises whether the difference is not due to saturation of the soil of the western division, as explained below, the cracks being utilized by the water.

Deoxidation of the iron may occur in regions where the water of the soil is so abundant as to approach saturation, and plants are abundant. Under such conditions the large amount of oxygen required to decompose the plants is not able to enter from the air with sufficient rapidity, and lience the oxidation of the plants abstracts oxygen from ferric oxide, and this reduces the iron to the ferrous condition. This reduction of ferric salts results from the demands of the abundant oxidizing bacteria for oxygen where organic matter is being rapidly decomposed. Consequently the process of deoxidation of iron compounds commonly takes place only by the oxidation of organic constituents. So far as the inorganic constituent is concerned, there is absolute loss of oxygen by the process.

Examples of deoxidation of iron compounds are fumished by the so-called cumnlous deposits, where abundant regetation near the water level accumulates and does not completely decay. Instances of such deposits are the sphagnum mosses of marshes, bogs, lakes, and the margin of the ocean, which result in the accumulation of peat; and the swamps, for example, cedar, spruce, mangrove, etc. Probably the same conditions obtained in the past, especially at the coal-forming periods, for the underclays of coal beds are alınost always gray or white, the iron luaving been almost completely reducerl to the ferrous form.

The iron reduced to the ferrous condition and that already in the ferrous condition in the silicates is in the most favorable form to unite 
with carbon dioxide, as explained under "Carbonation;" and thus may be produced a great quantity of iron carbonate, which may join the sea of ground water and furnish the material for chalybeate springs and for siderite deposits, as explained on pages 824-829. The clay ironstones and the siderite, often associated with the coal beds and frequently in the coal itself, are illustrations of such siderite deposits. Thus the association of deposits of iron carbonate with coal deposits is explained, and also-as developed on pages 842-846-there is in this iron carbonate thus former the source from which other iron-ore bodies are concentrated.

Another example of deoxidation is furnished by the nitrates, which may be reduced to nitrites, or even to free nitrogen when the conditions of the belt of weathering are those of abundant vegetation and very high humidity. ${ }^{a}$ The reduction of the nitrites is effected by definite bacteria. It is highly probable that the oxygen abstracted in the cleoxidation of nitrates, like that abstracted from ferric iron, is nsed by the oxidizing bacteria in decomposing the organic matter.

Under conditions similar to those in which ferric iron is reduced to the ferrons form and nitrates are reduced, sulphates may also be reduced to sulphides. This is usually accomplished mainly by organic material where abundant to serve as a reducing agent; but also in this reduction, as in various other processes, bacteria may play a part. ${ }^{b}$

Finally, where the moisture is too abundant the oxidation of the plants themselves is greatly delayed, and may be permanently stayed. The best illustration of the lag in decay of plants and deoxidation of the ferric salts, nitrates, and sulphates is found in the marshes where water entirely covers the soil, and thus makes the oxidation very slow indeed. Where the plants fall below the surface of the water the plant decay may be very partial, and hence there may be produced peat or coal beds. But in this connection it should be recalled that where, as a result of great humidity, the decay of plants is slow and deoxidation takes place the conditions approach those of the belt of cementation. In swamp areas the thickness of the belt of weathering is practically reduced to zero; the roots of vegetation reach below the level of ground water, and'under these circumstances the reactions which take place in connection with organic matter are those of the belt of cementation rather than those of the belt of weathering. 
It has been shown that in the belt of cementation oxidation is much less prevalent than in the belt of weathering, and indeed that, on the whole, deoxidation, especially where organic material is prevalent, is the rule. Therefore, the reversal of the ordinary process of oxidation in the belt of weathering usually takes place only where this belt is grading into or is under conditions which are approaching those of the belt of cementation and below.

It has already been stated that the direct source of the oxygen for the process of oxidation is the atmosphere. It is apparent from the foregoing that a vast amount of oxygen is now being demanded for this process, and the amount of oxygen which has thus been consumed during geological time is beyond computation. But it will be seen under "The zone of anamorphism" that there are also processes which restore oxygen to the atmospliere. Which of these processes, oxidation or deoxidation, is, on the whole, preponderant and what are the possible sources of supply for oxygen can best be considered after all the reactions in each of the belts are considerod, and therefore this subject is taken up in Chapter XI.

(ARBOSATION.

The process of carbouation may be defined as the union of carbonic acid witl bases, forming carbonates. Since the carbonates are not known as original minerals in the igneous rocks, we must look in other directions for the source of the carbon dioxide for the process of carbonation. The immediate reservoir for this carbon dioxide is undoubtedly the atmosphere, but the amount in the atmosphere is very small, only 0.045 per cent by weight, and the quantity now in the atmosphere is, as will be seen subsequently, insignificant as compared with that which must have been abstracted from the atmosphere during past geological ages by the process of carbonation. Either the atmosphere must have once contained vastly more carbon dioxide than at present, or else it must have been contimuously replenished in this compound, or partly both. These questions can be best discussed after the reactions of both the zone of katamorphism and the zone of anamorphism have been considered, and their consideration is deferred to Chapter XI.

It has been explained that from the atmospheric reservoir the plants absorb carbon, dioxide, reduce it, and build it into their bodies. Further- 
more, it has been seen that oxidation of organic materials by bacteria and oxygen in the belt of weathering produces carbon dioxide abundantly. This process, therefore, concentrates in the upper part of the belt of weathering a large amount of carbon dioxide, and this carbon dioxide is available for the process of carbonation. The fact of the concentration of carbon clioxide in the npper part of the crust of the earth was noted by Bischof many years ago. In the waters of his laboratory well at Bonn he found three times as much carbonate of lime as in the Rhine near by Also, free carbonic acid often collects above the water of wells. Facts like these, and the large amounts of carbonic acids in mines Bischof explained by the oxidation of organic matter, including coal. ${ }^{a}$

The importance of the process of concentration of carbon dioxide in the belt of weathering through the oxidation of organisms can be appreciated only by comparing the amount of this material in the atmosphere with the amount in the gases of the belt of weathering where vegetation is present.

The amount of carbon dioxide in rain water, according to Fischer, arries from 0.22 to 0.45 per cent of the volume of the water, or only 0.00044 and 0.00089 per cent by weight. ${ }^{b}$

It has already been noted that the amount of the carbon dioxide in the atmosphere by weight is abont 4.5 in 10,000 . The amount present in gases of the soil is far greater than this, as shown by the following table by Boussingault and Lewy: ${ }^{c}$

Table showing the amount of carbon dimxide in the air of belt of weathering.

\begin{tabular}{|c|c|}
\hline & $\begin{array}{c}\mathrm{CO}_{2} \text { in } 10,000 \\
\text { parts by } \\
\text { w'eight. }\end{array}$ \\
\hline Air from sandy subsoil of forest......... & 38 \\
\hline Air from loamy subsoil of forest......... & 124 \\
\hline Air from surface soil of forest............ & 130 \\
\hline Air from surface soil of vineyard......... & 146 \\
\hline Air from pasture soil ........ & .270 \\
\hline Air from soil rich in humus. . & 543 \\
\hline
\end{tabular}

"Bischof, Gustav, Elements of chemical and physical geology, Harrison \& Sons, London, 1854, vol. 1, p. 239. (Translated by. Paul and Drummond.)

b Merrill, George P., Rocks, rock-weathering, and soils, Macmillan Co., New York, 1897, p. 179.

c Merrill, cit., p. 178. 
Fleck, as cited by Letts and Blake, found in the soil at a depth of 6 meters by rolume a minimum amount of carbon dioxide of 4.22 per cent, and a maximum amount of 7.96 per cent; at 4 meters, a minimum amount of 4.11 per cent and a maximum amount of 5.56 per cent; at 2 meters, a minimum amount of 2.99 per cent and a maximum amount of 2.91 per cent (the last number must be a misprint). ${ }^{a}$

These figures show that the amount of earbon dioxide in the ordinary air is insignificant in comparison with the anount in soils in regions of luxuriant regetation. In such regions the carbon dioxide is from thirty to more than one hundred times more abundant than in the atmosphere. This large amount is mainly furnished by the decomposition of vegetation, although, as shown by Briggs, even dry soils have the power to absorb carbon dioxide from the atmosphere.

The process of carbonation is dominantly accomplished by the substitution of carbonic for silicic acid. The negative side of this process is desilication. To a very small extent carbonation is accomplislied by the substitution of carbonic acid for other acids-for instance, phosphoric acid. Also carbonates are produced on a considerable scale by the union of carbon dioxide with the oxides which were not united with other acids, as, for instance, ferrous oxide in magnetite.

Mueller has experimentally ascertained that carbon clioxide in water at ordinary temperatures and pressures is capable of attacking many minerals. Of the oxides, he experimented with magnetite; of the silicates, he experimented with orthoclase, oligoclase, hornblende, /olivine, serpentine, and muscovite. He also experimented upon a number of phosphates, including apatite. While all of the silicates experimented with were attacked to some extent, there was great variation in the rate of action. For instance, orthoclase is attacked more readily than oligoclase; hornblende and serpentine are attacked more rapidly than the feldspars, and olivine is the most readily attacked of all the silicates tested. The process of carbonation formerl carbonates of sodium, potassium, calcium, magnesium, and iron. Alumina also went into solution. The liberated silica partly went into solution, but partly also separated as quartz. Magnetite was the most

"Letts, E. A., and Blake, R. F., The carbonic anhydride of the atmosphere: Sci. Proc. Royal Dublin Soc., vol. 9, pt. 2, 1900, p. 215 .

"Cameron, Frank K., Soil solutions, their nature and functions, and the classification of alkali lands: Bull. U. S. Dept. Agric. No. 17, 1901, p. 17. 
resistant of all the minerals and rocks tester. Apatite was found to be as readily solnble as the more soluble silicates. Perhaps one of the most interesting results in reference to the silicates is the comparative readiness with which the hydrous silicate, serpentine, is attacked. From this fact Mneller makes the point that this silicate does not represent an end prodnct of alteration. ${ }^{\text {. }}$

Jolmstone later experimented upon the micas, including muscorite, biotite, and lepidomelane, and found that they are attacked by water solutions of carbon dioxide. ${ }^{b}$ As one would expect from the above reactions, Struve ${ }^{c}$ found that water containing carbon dioxide at ordinary pressure attacked basalt, phonolite, gneiss, granite, clay slate, and porphyry.

Combining the experimental fact that carbon-dioxide solntions deconpose the silicates and the observed fact of the abmulance of $\mathrm{CO}_{2}$ where vegetation is plentiful, one would expect that the process of carhonation wonld be more rapid in regions of abundant regetation than elsewhere. Belt many years ago made observations which confirm this expectation. He says that the decomposition of rocks in tropical America is largely confined to the forest regions, and ascribes it to the action of water charged with acids derived from the decomposing regetation. " Where vegetable matter is abundant it has also been observer that the amount of dissolved silica contained in underground water is much greater than where vegetation is sparse or absent.e This observation is direct evidence that the reactions of carbonation and desilication are correlative, and are very largely due to the concentration of carbon dioxide in the belt of weathering by the oxidation of organic matter.

Since the reaction of carbon dioxide upon the silicates and other compounds forms carbonates, in a soil there may be present both sedimentary and secondary carbonates. Now, it has been shown experimentally by Bischof that the alkaline carbonates are capable of decomposing the silicates at

a Iueller, Richard, Untersuchungen ueber die Einwirkung des kohlensäurehaltigen Wassers aul einige Hineralien und Gesteine: Tschermak's mineral. Mittheil., vol. 7,1877 , pp. 25-48, especially pp. 39, 46-48. See Merrill, G. P., Rocks, rock-weathering, and soils; Macmillan Co., New York, 1897, Pl. 192-193.

$b$ Johnstone, A., Ou the action of pure water and of water saturated with carbonic-acid gas on the minerals of the mica family: Quart. Jour. Geol. Soc. London, vol. 45, 1889, pp. 363-368.

$c$ Struve, F. A. A., Ueber die Nachbildung der natïrlichen Heilquellen, Pogg. Ann. vol. 7, 1 l1. $3+1-372-429-450$.

a Belt, 'Thomas, The naturalist in Nicaragua, 1874; cited in Nerrill, p. 175.

e Hunt, T. Sterry, Chenical and geological essavs, 1875, lp. 149-152. 
ordinary temperatures and pressures. ${ }^{a}$ A great variety of silicates were thus decomposed. The alkaline silicates and carbonates of sodium, potassium, calcium, magnesium, and iron were formed. Not only do the alkaline carbonates decompose silicates in the belt of weathering, but other carbonates accomplish the same result. This has been shown by observations on the alterations in the soil by Hilgard. ${ }^{b}$ Of these other carbonates, that of calcium has been found to be the most important. Hilgard states that the decomposition of the silicates is much more active in calcareous soils than in noncalcareous soils that are otherwise similar. He says "this is seen when we contrast the analyses of calcareous clay soils of the humid region with the corresponding noncalcareons ones of the same. In the former the proportions of dissolved silica and alumina are almost invariably much greater than in the latter, so far as such comparisons are practicable without assured absolute identity of materials."

Since the carbonate sediments are mainly or. solely produced by the process of carbonation of the silicates of an earlier period, Hilgard's statement is equivalent to saying that the process of carbenation to-day is promoted by the carbonation of past geological ages.

It is well known that soils containing carbonates are fertile, and therefore are favorable to abundant regetation. This is well illustrated by the limestone soils. As already seen, vegetation promotes carbonation, and thus prodnces carbonates. It therefore appears that there is constant action and reaction through regetation and carbonation in promoting the process of carbonation. 'Tegetation results in the process of carbonation, and this produces the carbonates. Carbonates in turn result in further carbonation and furnish favorable conditions for regetation. Carbonation provides carbonates, and therefore promotes vegetation. The relations of the three may be represented by the following diagram, the arrows indicating the directions of action and reaction.

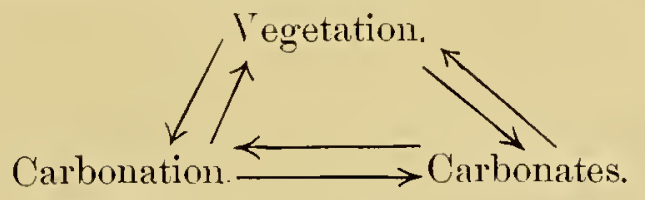

"Bischof, G., Elements of chemical and physical geology, translated by B. H. Paul and J. Drnmmond, Harrison \& Sons, London, 185t, rol. 1, pp. 8-11.

"Hilgard, E. W., Report on the relations of soil to climate: Bull. Weather Bureau, U. S. Dept. of Agric., No. 3, 1892. pp. 36-38: cited, Merrill, p. 371.

c Hilgard, cit., p. 37. 
The process of carbonation with the liberation of silicic acid is continnous, cumnlative, and takes place on a vast scale. Notwitlsstanding this, there is, as already seen (p. 474), only a comparatively small amount of carbon dioxide in the belt of weathering at any one time-from 38 to 500 parts in 10,000. Carbonates may be present; if so, they represent the action of earlier carbon dioxide. The continuous process of carbonation may be understood when the law of mass action and the time factor are considered. Under the law of mass action an acid anywhere existing will unite with some of the bases present. The compounds thus produced are in part transported elsewhere by underground and overground drainage. The carbon dioxide used is resupplied by the oxidation of organic material, and thus the reacting agent contimes its work; and so the process goes on unceasingly through geological time.

While this cumulative process goes on without cessation in the humid regions where the carbonates are largely removed by solution, in the semiarid and arid regions the carbonates, especially the alkaline carbonates, may become so abundant in the soil as to be unfavorable to regetation, and thus eheck the process. (See p. 543.) Where the alkalies, especially sodium carbonate, exceed a certain very small amount, vegetation can not exist, and the region becomes a desert. ${ }^{a}$

"The amount of soluble salts which plants can stand depends upon the character of the salt, the character of the soil, and the kind of plant. Hilgard states that few plants can bear as much as 0.1 of 1 per cent of sodium carbonate, or about 3,500 pounds per acre to a depth of 1 foot [ahout $3.9 \mathrm{~kg}$. per sq. meter to depth of $30 \mathrm{~cm}$.]; of sodium chloride, about 0.25 per cent; and of sodium sulphate most plants can grow with 0.45 to 0.50 per cent present, and are affected by even less salts in the sandy lands than on heavy clay or gumbo lands."

The process of carbonation with desilication just described may take place without other reactions with a number of ninerals. (See p. 396.) The change involves an increase in volume ranging from about 13 per cent

a Means, Thos. H., and Gardner, Frank D., A soil survey of the Pecos Valley, New Mexico; Field operations of Div. of Soils, U. S. Dept. of Agric., 1899, No. 64, 1900, pp. 53-58.

$b$ Whitney, Milton, and Means, Thos. H., The alkali soils of the Yellowstone Valley: Bull. Div. ol Soils, U. S. Dept. of Agric., No. 14, 1898, p. 10. 
to over 50 per cent. But carbonation with or without desilication occurs on far the most extensive scale in connection with hydration. When the great majority of the abundant silicate minerals are carbonated they are also hydrated. (See pp. 397-399.) Finally carbonation with desilication occurs rather extensively in connection with both oxidation and hydration. (See p. 399.) In all these combinations, provided all the compounds formed remain as solids, there is an increase in volume. This increase rarely falls below 5 per cent; it runs as high as 75 per cent, or even higher, but the more common range is between 15 and 50 per cent. It is well known that the processes carbonation, carbonation combined with hydration or oxidation, and carbonation combined with both hydration and oxidation, liberate much heat, but the data are not at hand from which the amount can be calculater.

The process of carbonation just considered is one of paramount importance in the belt of weathering. Although the process is not so extensive as hydration, if one were to pick out a single chemical process especially characteristic of this belt and of great significance in geology it would be carbonation. Carbonation has continued through all geological time since land areas first arose above the sea. Moreover, it has continued in all the land areas of the globe; but the process is very slow in the frigid zones, becomes of importance in the temperate zones, and is of great consequence in the torrid regions. In the warm regions the process is rapid in proportion as there is high humidity and consequently abundant life. In the arid regions carbonation is comparatively slow.

There is no reason to suppose that the carbonates existed as original rocks or as original minerals of the igneous rocks. If this be so, all the carbonate formations which now exist and which have existed at any time in the past have been produced by carbonation. The precipitation of carbonates in the sea is accomplished largely through organic agencies. These carbonates are essential to the existenre of great classes of sea animals, and certain it is had not these carbonates formed by the process of carbonation and been contributed to the ocean, the evolution of life upon the globe would have followed entirely different lines from those that have been followed. 
Notwithstanding the rast scale and doninant importance of the process of carbonation, it is mainly accomplished, as has already been seen, through the small amount of carbon dioxide continuously concentrated in the belt of weathering by means of organic material. It is therefore clear that a very slow but continuous action, extending over the globe throughout geological time, has produced stupendons results. But the positive side of the process of carbonation is of scarcely less importance than the negative side. It has been pointed out that carbonation largely takes place through the decomposition of the silicates or by desilication. The siliea set free, as already noted, largely separates as colloidal silicic acid. The amount of silica thus liberated approximates to the molecular equivalent of the carbon dioxide which unites with the bases combined with silica; or, since the molecular weights of carbon dioxide and silica are 44 and 60.4, there is about one and one-third times as much silica released from the silicates as there is carbon dioxide combined in the carbonates. The stupendous results of the process of carbonation are therefore matched by the results of the process of desilication. As will be seen subsequently, while a portion of the silica of the colloidal silicic acid is precipitated in the belt of weathering, probably by far the greater part of it is carried by the ground water's to the belt of cementation, and is there largely precipitated.

While carbonation, with correlative desilication, is of such fundamental importance in the belt of weathering, under exceptional conditions silication may oceur. Where silica is very abundant and in a readily soluble form, the law of mass action may be so effective as to result in the formation of abundant silicates rather than carbonates. This has not been observed as a general process in the belt of weathering, doubtless because of the lack of close observation. However, in many cases in ore deposits above the level of ground water the silicates of the metals are formed. So far as I know, this is better illustrated in the lead and zinc district of Missouri than elsewhere. Here silica as chert, partly amorphous, is very abundant. The zine was originally in the form of sulphide. As the level of ground water descended owing to denudation, and the sulphide arose into the belt of weathering, the zine sulphide was decomposed, the zinc being oxidized. Simultaneonsly with this process it united, upon a somewhat extensive scale, with the silica, producing silicate of zinc. 
HYOLTIOS AND DEHYDRATIOS.

By hydration is meant the union of water with chemical compounds, thus producing hydrous minerals. The water for hydration is derived mainly from the hydrosphere. Hydration stands as the most extensive reaction in the belt of weathering. In its importance in this belt as a geological process it is second only to carbonation. Indeed, it has been supposed by some geologists that hychation is the dominant reaction of the belt of weathering, the process of carbonation being wholly ignored. The list of important hydrous minerals formed comprises many silicates and oxides and some carbonates, sulphates, etc.

As a matter of observation, all of the so-called anhydrous silicate minerals of the igneous, sedimentary, and metamorphic rocks which have long remained in the belt of weathering are shown by analysis to have become more or less hychated. But more important than this, the new minerals which develop in the belt of weathering are usually strongly hydrated. Of these in the silicate class the kaolin, serpentine-talc, chlorite, and zeolite groups are examples. Of the oxides the most important are those of aluminum and iron, the former occurring as gibbsite or diaspore; and the latter commonly as limonite, but not infrequently as göthite or some other hydraterl oxide.

In many cases in the dense rocks inydration goes on to a certain stage and then ceases or at least becomes rery slow. This is due to the fact that the process of hydration involves expansion of volume and therefore makes it necessary that the superjacent material be elevated if the process continnes. Such partly hydrated rocks below the surface when brought to the surface, and therefore relieved from pressure, may continue to rapidly hydrate nearly or quite to the completion of the process with great expansion of rolume. In many cases the process is so rapicl that the term slaking is applicable. This slaking has been observed by Merrill in the granitic rocks of the District of Columbia, ${ }^{a}$ and by Derby in the sedimentary rocks from railway cuttings of Brazil. ${ }^{b}$ In both of these places the rocks when exposed at the surface soon break into powder, although in position they are perhaps so strong' as to require blasting. 'These facts make it clear that the process of hydration is largely dependent upon the pore space in the rocks. Where

"Merrill, (teorge P., Rocks, rock-weathering, and soils, Macmillan Co., New York, 1897, 1. 18s.

"Derby, O. A., Decomposition of rocks in Brazil: Jour. Geol., vol. 4, 1896, pl). 529-5 40.

MON XLTH1-04-31 
there is large pore space and abundant room, so that hydration may take place without lifting the rocks, it is probable that with sufficient time the process may go on to completion in all parts of the belt of weatlering. However, in proportion as the rocks are dense and contain small pore space the process of hydration at an early stage is likely to be retarded or altogether stayed, because of the necessity demanded for more space and because the chemical affinity of rocks for water is not strong enough, at least in the later stages of the process, to overcome considerable pressure.

While hydration is the rule for the belt of weathering, in regions in which the temperature is high and which are not continuously hunid dehydration may take place. Dehydration probably occurs on the largest scale in regions of high temperature in which dry and wet seasons alternate. During the wet season hydration occurs, and at the dry times dehydration occurs. This process is well illustrated by iron. As is well known, ferric iron in the belt of weathering is ordinarily hydrous, and this gives a yellow color. In regions of high temperature where the lumidity is low for at least a portion of the year the soil is likely to be red, the iron being in the form of hematite rather than göthite or limouite. Such regions are illustrated by the Desert Ranges of sonthern California, in which dark red is the doninant color. But dehydration also takes place to some extent in such humid regions as the southern Appalachians. Crosby, Dana, and Russell attribute to dehydration the bright-red color of the surface soil in this region as compared with the less brilliant color of the subsoil. ${ }^{a}$ This region, although one of large precipitation, is apt to be dry in late summer and autumn, the season when conditions are favorable to dehydration. In the subsoil the process is naturally less marked. The dehydration of iron is well known, because the process involves a change of color. Under the conditions in which dehydration of iron takes place, it is certain that many of the other hydrates which form in the belt of weathering are also dehydrated to a greater or less extent. It is well known that the process of dehydration of many minerals begins at temperatures lower than $110^{\circ} \mathrm{C}$. Indeed, it is certain that the dehydration of limonite and other hydrous oxides of iron begins as low as $100^{\circ} \mathrm{C}$, and that if this temperature be maintained even during the insignificant time in which an experiment is 
earried on in a laboratory, dehydration is very appreciable. ${ }^{a}$ These temperatures are not reached under natural conditions, but in liot regions where water is not plentiful it is probable that partial deliydration of such componnds as the zeolites, colloidal silicic acid, ete., takes place on a considerable scale. Doubtless the process in reference to these minerals has not been commented upon becanse ordinarily there is no accompanying change in color. To illustrate, the table on pages 375-394 shows that aluminum lydroxide, as gibbsite and diaspore, forms on a vastly greater scale in the belt of weathering than ferric hydroxide. It is highly probable that, under the same conditions in which dehydration of iron occurs, delyydration of aluminum hydroxide also takes place to some extent. The same statements may be made in reference to the other hydrous minerals which lose their water or a part of it at a low temperature, as, for instance, the zeolites.

It has already been stated that hydration is the most extensive reaction of the belt of weathering. This is at once found by reference to the classified tables of alterations, page 402. It is there seen that a number of the important oxides and many of the more important silicates may be altered by simple liydration. The process of liydration, as explained in Chapter IV, from a physical-chemical point of view, involves expansion of volume and the liberation of heat. The amount of heat liberated is great, as shown in Chapter V. Whether hydration occurs alone or occurs combined with the other processes, there is an increase in volume. In simple liydration the volume increase ranges from a very small per cent to as high as 160 per cent, as in the alteration of cornudum to gibbsite. Commonly the increase in volume is less than 50 per cent. The quantity of heat liberated in the process of hydration is great, but the average amonnt can not be quantitatively stated.

OXIDATIOX, CARBONATION, AYD HYDRATIOX.

As already noted, oxidation, carbonation, and hydration may each take place separately, but cominonly two or three of these processes are simultaneonsly at work on the same rocks, and even on the individual mineral particles. No average can be given as to the amount of increase

( Leith, C. K., The Mesabi iron-bearing district of Minnesota: Mon. U. S. Geol. Survey, vol. 43, 1903 , p. 262. 
in volume as'a consequence of the combination of these three reactions, but doubtless in most cases the increase in volume, where the processes are complete, is 15 to 50 per cent or even more.

It is of importance to note that the oxygen, carbon dioxide, and water added to the rocks in the belt of weathering are not directly derived from other rock materials, but are in large measure derived from the atmosphere and hydrosphere. As already noted, the oxygen is directly derived from the atmosphere; the carbon dioxide comes from the atmosphere mainly through the intermediary action of vegetation and other organic matter, and water is derived directly or indirectly from the hydrosphere. The depletion of the atmosphere and hydrosphere in oxygen, carbon dioxide, anid water is continuons, and through geological ages wonld doubtless seriously encroach npon the supplies of these materials were it not for the compensatory reversing reactions largely nccurring in the zone of anamorphism. (See pp. 366-369.)

soLutrox.

Concurrently with the processes of oxilation, carbonation, and hydration, the underground waters of the belt of weathering take compounds into solution. The process of solution is not only concurrent with these other processes, but is promoted by them. This follows from the fact that the dominant processes of carbonation and hydration transform the compounds into more soluble forms. The change of ferrous to ferric iron by oxidation has a reverse effect, but the quantitative value of this reaction is small compared with that of carbonation and hydration.

It has already been explained that all natural compounds are soluble in pure water, but the solution would he slow if this were the only solvent. It has been seen that in the underground solutions of the belt of weathering there are continually produced organic acids, earbonic acid, nitric acid, sulphuric acid, and hydrosulphuric acid. These produce corresponding saltscarbonates, nitrates, sulphates, and sulphides. Also the presence of these salts favors solution. Besides these salts chlorides are present. The active acids of the solutions nnite with the bases of the minerals. But in this process the acids with which the bases were mited in the minerals are displaced, and these acids may also pass into the solutions and become active constituents. The oxygen, carbonic acid, nitric acid, sulphuric' acid, and hydrosulphuric 
acid have been accounted for by processes in the belt of weathering. But the source of the hydrochloric acid, producing the chlorides, has not been explained. This subject is considered on pages 789-790.

The amounts of the compounds which are taken into solution by ground waters depend very largely upon the number and anounts of the above active chemical agents or solvents. Also the amounts of the compounds which are taken into solution depend upon the relative proportions of the elements present, and the manner in which they are conpounded. If all the important bases occurring in the rock-naking minerals were equally abundant the stronger-bases would be taken into solution to a larger extent than the weaker bases. Therefore there would be dissolved more sodium and potassium than calcium and magnesiun, more calcium or magnesinm than iron, more iron than ahminum. And as a matter of fact, the percentages of the compounds dissolved are in this order. But the amount of alkalies in the rocks is much less than that of the alkaline earths, iron, or aluminum, and consequently the total amount of the former elements dissolved nay be less than the latter-indeed, is commonly much less than the amount of the dissolved alkaline earths. Further, the greater the proportion of bases present as compared with the acids-i. e., the more basic the compounds-the more readily the minerals are decomposed and the greater the amount of bases which are dissolved. If the acids were present in equal quantity there would be dissolved a greater amount of the salts of the stronger acids than of the weaker acids. Thus there would be a greater quantity of sulphates, nitrates, and cllorides than of the carbonates. Since, however, in the solutions carbonic acid is so much more plentiful than any other active acid, carbonates greatly predominate. The only acid in solution which can be compared with carbonic acid in abundance is silicic acid, produced by the decomposition of the silicates. However, the liberated silicic acid, as explained on pages 115, 176, separates in a colloidal state, and in that form is exceedingly inactive and, notwithstanding its great quantity, does comparatively little work. The great power of the weak acid, carbonic, in the solutions shows that the law of mass action is of great consequence in the relative amonuts of the compounds formed and taken into solution.

The above general statements are ver'y well illustrated by T. Mellard Reade's estimate of the amount of salts which are abstracted from each 
square mile of area. ${ }^{a}$ He calculates that throughout the entire globe there is remored annually in solution 96 tons (about 86 tonneaus) of material per square mile, which he divides as follows: Calcium carbonate, 50 tons (45 tomneaus); calcium sulphate, 20 tons (18 tonneaus); sodium chloride, 8 tons ( 7.2 tomneaus); silica, 7 tons (6.3 tomeaus); alkaline carbonates and sulphates, 6 tons (5.4 tomneaus); magnesium carbonate, 4 tons (3.6 tonneaus); oxide of iron, 1 ton ( 0.9 tonneaus). The order of the larger of these amounts is much what one would expect. The strong, abundant base, calcium, is largely united with the weak abundant acid, carbonic. The strong acids, such as sulphuric and hydrochloric, are largely united with the alkaline metals, sodium and potassium, but a residuum is left over which is supposed to be united with the calcium.

We now know that in solutions all the bases are united with all the acids except so far as dissociation occurs, according to the various factors of strength, mass, and solubility, and we can see that it would have been better to have estimated the various compounds as oxides or elements rather than as salts. But it would still be true that the most abmndant salt is calcium carbonate, that that standing next in abundance is probably calcium sulphate, and that those standing next in abundance are the alkaline sulphates and chlorides.

We conclude from the foregoing that in the belt of weathering all the elements in the minerals are being dissolved all the time, but with greatly varying rates, depending upon the strength and abundance of the active compounds in solution and upon the solubility of the rarious minerals upon which the solvents are acting. While the more readily soluble substances are dissolved many times more rapidly than those wlich are usually spoken of as insoluble, even those substances which are least soluble may be taken into solution on a large scale. For instance, silica in the form of quartz is regarded as exceedingly insoluble, yet it is certain that in the iron-bearing formations of the Lake Superior region quartz has been dissolved on an enormous seale. Also the evidence is conclusive that such extremely refractory substances as hematite and limonite are dissolved. (See pp. 548-549.) While all minerals in the belt of weathering are soluble, after a sufficient length of time the constituents remaining undissolved are, of course, those which are relatively insoluble.

a Reade: T. Mellard, Chemical denudation in relation to geological time. Also Merrill, cit., p. 194. 
Consequent upon these various reactions, combined with solution, material is continuously abstracted from the belt of weathering, and thus the openings tend to increase in size. This does not appen in the case of the unconsolidated materials at the surface, for gravity brings the particles together as fast as material is dissolved; but in the rocks which have sufficient strength to hold together, the openings are often numerous and large, and constitute a considerable percentage of the volume of the rocks. The best illustrations of rocks with large openings are the limestones, which, above the level of ground water, are commonly intersected with numerous open joints, are often porous throughout, and not infrequently contain caves. On account of the contimuons abstraction of material by the ground waters the belt of weathering might be called the belt of solution.

DEPositiox.

Later it will be seen that concurrently with solution, farored by it and in direct proportion to it, deposition is constantly going on. Thus it will be seen that the substances dissolved in greatest quantity are those deposited in greatest quantity. As just noted, in limestone regions solution takes place on an enormous seale. But while this is going on deposition of $\mathrm{CaCO}_{3}$ is occurring on a large scale; for instance, in caves travertine, stalactites, and stalagmites are forming. Where evaporation is not easy, solution will be the rule; where evaporation is easy, deposition. Thus a cave inay be simultaneously enlarged at the bottom and decreased in size at the top. Solution and deposition are correlative processes, but in the belt of weathering the first is dominant. The absolute amount abstracted, estimated by Reade at 96 tons per annum per square mile, represents the difference between the results of solution and deposition.

GENERAL STATEMENTS.

On the preceding pages it has been seen that the processes of oxidation, carbonation, hydration, and solution are characteristic of the belt of weathering, and that all take place on a great scale. However, it has also been seen that to some extent the reverse of these processes-deoxidation, silication, dehydration and deposition-also occur. This is what one would expect from the laws of pliysical chemistry. All chemical reactions are reversible; and while the first set of the above processes greatly 
dominates over the reverse set, all the above sets of reactions take place on an important scale in the belt of weathering, although the belt is characterized by the one set rather than the other.

\section{CONTACT METAMORPHISM.}

Contact metamorphism is a term used to cover the mutual effects of intrusive and intruded rocks. The effect upon the intruded rocks is known as exomorphic and that upon the intrusive rock as endomorphic. The first is of greater consequence. In considering the exomorphic effect, ordinarily there has been no well-defined attempt to estimate the relative importance of the direct and indirect action of the igneous rocks. The direct effect is due to the heating of the intruded by the intrusive rock. The indirect effect is due to the increased activity of the gaseous and liquid solutions cansed by the intrusive rocks.

The gaseons and liquid solutions adjacent to igneous rocks differ from ordinary solutions in two respects. First, at the time of the crystallization of magmas, gases and liquids emanate from the igneous rocks. The chief constituent of these emanations is, of course, water, but associated with the water are other compounds. By the circulation of the gaseous and liquid solutions the material emanating from the igneous rocks may pass into the surrounding rocks. A second and still more important indirect effect is that of heating the solutions of the surrounding rocks. In Chapter: III, on "The agents of metamorphism," it has been explained that solutions gain marvelously in their metamorphic power by heat, and adjacent to igneous rocks the temperature may reach or even surpass that of the critical temperature of water. While by conduction high temperature progresses from the magma, by convection, where the circulation is vigorous, solutions having a high temperature are carried over wide areas. In this treatise contact metamorphism is considered in three places, for the nature of the contact action, like that of other forms of metamorphism, is very different in the different belts and zones. Therefore the subject of contact metamorphism is considered under the belt of weathering, the belt of cementation, and the zone of anamorphism. In this chapter only the first part of the subject is considered; the other parts may be found under the heading "Injection," on pages 646-652. 
In the belt of weathering contact metamorphism comprises (1) the direct contact effect and (2) the indirect effect through gaseons solutions. 'This second is ordinarily called the action of fumaroles and solfataras.

\section{DIRECT CONTACT EFFECT.}

The direct contact effect is produced by condnction of the leat of the magna into the surrounding rocks. The temperature of the rocks immediately adjacent to the igneous rocks may become very high-indeed, approach that of fusion, and possibly reach a fusion temperature locally. Under these circumstances the complex mixtures of minerals characteristic of the belt of weathering, including the hydrates, silicates, and other forms, are likely to be baked, and thus indurated. The hydrous minerals may be dehydrated, and thus to this extent the ordinary reactions of the bet of weathering are reversed. The zeolites, serpentines, talcs, chlorites, etc, where dehydrated, are destroyed. Limonite may be changed to hematite, grpsum to anhydrite, etc. From the carbonates the carbon dioxide may be driven off or calcination take place, and thus lime and magnesia be produced. This gives the rocks an alkaline reaction, so that contact action on such rocks in the belt of weathering is sometimes called "caustic" action.

The general contact effects of dry heat have been called, depending upon the degree of action, baking, fritting, and vitrification. Irving gives the following illustrations of these processes:

Sandstones are decolorized and often fritted to a glistening enamel-like or porcelanic mass; in other cases, where the cement is of a calcareo-argillaceons nature, this is melted into a glass; clay and mud are converted into porcelanite or brick, with marked change of color in many cases; tufts and phonolites are so fiur vitrified as to acquire a character resembling that of obsidian; brown coal is altered into seam coal or anthracite, and these in other cases into a substance more resembling graphite, while in others (probably under less pressure) the coal is converted into coke, the rarious shades of metatropic change of brown coal into anthracite, carbon-glance, bituminous conl, and black coul being observed in some cases in the same section through several meter's of the mass; a prismatic structure is dereloped, not only in clays and marls, but even in sandstones, in brorn coal, in seam coal, and in dolomite; limestones are altered into crystalline marble, often with complete effacement of their stratitication and even of all traces of their fossils: the finer varieties of grauwacke and its associated shales are converted into hornstone, as in the classical region of the Brocken. 
Of these metatropic changes by the action of dry heat under pressure that of the formation of marble has been experimentally verified years ago by G. Rose and nore recently by Richthofen and others."

Usually all of the direct dry heat contact effects are very limited ir: amount, extending only short distances from the igneous rocks. Ordinarily the direct effect is modified by indirect effects In many of the cases mentioned by Irving, where the material when modified was not in the belt of weathering, it is highly probable that the results were not accomplished by dry leat alone, but with the assistance of gases and vapors. Commonly the rocks which are being baked, fritted, or fused are in the midst of gases and vapors, including, of course, abundant water vapor and oxygen. Also, as in the cases mentioned by Irving, in many instances which have been given of the effect of dry heat alone the material when altered was below the belt of weathering; but as the different cases of metamorphism attributed to dry heat have not been studied in reference to the different zones and belts of metamorphism, and it is therefore impossible to discriminate with certainty the cases which are truly due to dry heat alone from those in which heat works in conjunction with gases and vapors, or even in conjunction with water, in so far as the gases and vapors are present, we have the indirect effects considered below mingled with the direct contact effects.

INDIRECT CONTACT EFFECT, OR WORK OF FUMAROLES AND SOLFATARAS.

It has been said that the indirect contact action is due to gaseous solutions. The action of such solutions may extend much farther than the direct contact effect. The belt of weathering may be permeated locally with hot gaseous solutions. The work of these gaseous solutions is essentially of the same nature as that of ordinary gaseous solutions, discussed on the previous pages (see pp. 59-63); but the gaseous solutions adjacent to igneous rocks usually contain a greater quantity of the active chemical agents than do ordinary solutions; and, moreover, their temperature is much higher than normal. This gives a combination of conditions which results in much more rapid alteration than the average of the belt of weathering and alteration of a different kind. The exceptional regions in which these unusual conditions obtain are volcanic In volcanic regions

a.Irving, A., Chemical and physical studies in the metamorphism of rocks, Longmans, Green \& Co., London, 1889, p. 76. 
the so-called fumarolic and solfataric ${ }^{a}$ actions may occur on an extensive scale. In such regions fumarole is generally applier to the gases at the higher temperatures, and solfatara to the gases at moderate temperatures, although this distinction is not everywhere applied. Fumarolic and solfataric action is therefore largely the work of gaseous solutions, although liquid solutions are also at work to an important extent. The gases may be widely dispersed through the porous rocks, but in many cases they move chiefly along large definite channels, from which they spread for various distances along smaller and less definite openings.

Of the gases of fumaroles and solfataras, water vapor is dominant. In many districts it is emitted in enormous quantities from the orifices. Probably the gas next in abumdance to steam is sulphurous oxide $\left(\mathrm{SO}_{2}\right)$. Other important gases are chlorine $\left(\mathrm{Cl}_{2}\right)$, hydrochloric acid ( $\left.\mathrm{HCl}\right)$, hydrofluoric acid $(\mathrm{HFl})$, hydrosulphuric acid $\left(\mathrm{H}_{2} \mathrm{~S}\right)$, sulphuric acid $\left(\mathrm{H}_{2} \mathrm{SO}_{4}\right)$, carbon dioxide $\left(\mathrm{CO}_{2}\right)$, oxygen $\left(\mathrm{O}_{2}\right)$, and hydrogen $\left(\mathrm{H}_{2}\right)$. Boric acid $\left(\mathrm{H}_{3} \mathrm{BO}_{3}\right)$, is sometimes plentiful; nitrogen $\left(\mathrm{N}_{2}\right)$, is abundant; and hydrocarbons occur. The proportions of these gases are very different in different localities. In many cases the differences seem to be a function of the temperatures of the fumaroles and solfataras. In the very hot fumaroles chlorine, hydrochloric acid, and hydrofluoric acid are likely to be abundant. At lower temperatures sulphurous oxide and hydrosulphuric acid are rery common, and at still lower temperatures oxygen, carbon dioxide, and nitrogen are abundant. In the hot fumaroles, associated with the strong acids characteristic of them, are also found many of the compounds characteristic of fumaroles and solfataras of lower temperatures, although these may be overlooked. With all classes of fumaroles and solfataras water vapor is dominant, but it is frequently more markedly dominant at the lower than at the higher temperatures.

The source of the gases of fumaroles and solfataras is a complex question of which I shall not attempt to give an adequate discussion. It is to be presumed, as pointed ont on pages 931-937, that the ultimate source of the various products formed in the belt of weathering is the material of the original magmas. However, later it will be more fully explained that several of the rarer elements of the igneous rocks are locally concentrated in the belt of weathering by rarious processes. To what extent the active gases of the rolcanoes are derived from the original magmas and what part from the later concentrations of these I shall not here consider. 
The source of the most abundant vapor emitted during volcanic action has been much discussed. Some have held that the water is derived from the original magnas, never having been at the surface, while other's have held that it is derived from the water of the surface and underground circulation. It may be in part derived from each. Clilorine, hydrochloric acid, hydrofluoric acid, and hydrosulphuric acid are undoubtedly largely formed by the action of hot water upon chlorides, fluorides, and sulphides. Sulphurous and sulphuric oxides are produced by the action of the oxygen upon the sulphides. These may unite with water and produce sulphurous and sulpluric acid. To what extent the above chlorine, fluorine, and sulphur compounds are derived directly from the magmas and to what extent from later segregatious containing au unusual amount of these elements it is not my purpose here to discuss. The hydrogen of fumaroles and rolcanoes is usually regarded as due to the decomposition of water: ${ }^{a}$ This may be accomplished by ferrous oxide according to the following equation:

$$
\mathrm{H}_{2} \mathrm{O}+2 \mathrm{FeO}=\mathrm{H}_{2}+\mathrm{Fe}_{2} \mathrm{O}_{3} .
$$

The immediate source of a part of the hydrogen is probably hydrosulphuric acid, the hydrogen being liberated as this acid decomposes and the sulphur separates. But since the $\mathrm{H}_{2} \mathrm{~S}$ is probably produced, as already explained, by the action of $\mathrm{H}_{2} \mathrm{O}$ on sulplides the hydrogen is indirectly derived from the water. It is shown that carbon dioxide is extensively liberated by the process of silication in the zone of anamorphism. (See pp. 677-679.) It is natural to suspect that this liberated carbon dioxide largely makes its way to the surface at places where there is active upward circulation. Volcanic districts are certainly such places. Hence it is believed that much of the carbon dioxide issuing in comnection with fumaroles and solfataras is that liberated by silication. Where carbonates are present as rocks adjacent to volcanoes another portion of the carbon dioxide is donbtless derived by the action of the strong acids upon these carbonates, salts of the strong acids being produced and the carbon dioxide liberated. No opinion is expressed as to the relative abundance of these two sources of carbon dioxide.

As would be expected, the ordinary reactions of the belt of weathering take place in regions of fumarolic and solfataric action the same as else193-197.

$a$ Geikie, Sir Archibald, Text-book of Geology, Macmillan \& Co., London, 1893, 3d edition, pp. 
where. Indeed, these reactions probably take place at a greatly accelerated rate. Therefore in areas of fumarolic and solfataric action oxidation, carbonation, lydration, and solution are important reactions, but ordinarily this is not recognized because of the more striking action of the exceptional compounds which are present in unusual abundance. That oxidation takes place on an extensive scale is shown by the yellow, red, or brown colors of the altered rocks due to limonite, hematite, and magnetite which extensively form from the monoxide of iron. Hydration in commection with fumaroles and solfataras has been to a considerable extent overlooked. Delesse found that dry steam at a pressure of five atmospheres had no appreciable action upon minerals. Barns found that the diabase of the Comstock lode, containing fresh feldspar, was not kaolinized by the longcontinued action of steam at $100^{\circ} \mathrm{C} .^{a}$ However, it is rare that steam is dry in the actual case of fumaroles and solfataras, and therefore, as would be expected at high temperatures, the process of hydration goes on at a great rate. Carbonation also takes place on a scale scarcely less extensive than hydration. In consequence the formation of sodinm carbonates is very common and in some places it is found in large quantities.

However, it is not by these common products but by the exceptional products that fumarolic and solfataric action is especially distinguished. The chlorine and hydrochloric acids form chlorides, of which sodium chloride $(\mathrm{NaCl})$, potassium chloride $(\mathrm{KCl})$, ammonium chloride $\left(\mathrm{NH}_{4} \mathrm{Cl}\right)$, iron chloride $\left(\mathrm{FeCl}_{3}\right)$, copper chloride $\left(\mathrm{CuCl}_{2}\right)$, manganese chloride $\left(\mathrm{MnCl}_{2}\right)$, and other chlorides lave been observed. Through the action of sulphuric acid various alums ale formed, of which potassium-aluminum sulphate and sodium-aluminum sulphate are the more common. By action upon calcium-bearing compounds sulphuric acid forms gypsum. By action upon the alkali-bearing componnts the snlphurie acid forms Glauber's salt, or sodium sulphate, and potassium sulphate. The action of hydrosulphuric acid upon the various compounds may form various sulphides, or it may be decomposed without action upon other substances, in which ease it liberates hydrogen and deposits sulphur. The hydrofluoric acid attacks the various compounds, forming various fluorides, of which fluorite is the best known. The boric acid forms borates. Of these varions sub-

\footnotetext{
"Barus, C., On the thermal effect of the action of aqueous vapor on feldspathic rocks: School of Mines Quart., vol. 6, 1884, pp. 1-23.
} 
stances formed, some are volatile and may be sublimed. Among these aramonium sulphate, sulphur, and boric acid are well known.

While any of the minerals present may be acted upon, on the average the silicates are decomposed on a far greater scale than other compounds; for silicates are the dominant salts present which the active agents find to work upon. Besides producing the varions compounds above mentioned, which are especially characteristic of fumarolic and solfataric action, the relatively insoluble residual products of the silicates are extensively produced, such as kaolin, etc. While these chemical reactions are taking place, concurrently with and depending upou them the rocks are softening, and the result is to produce a whitish or yellowish earth, frequently stained red where irou oxide is abundant. So long as the fumarolic and solfataric action continues, mingled with this residnal material are many of the solnble compounds mentioned above; but after funarolic and solfataric processes cease, the soluble salts are rapidly leached out by the ground water circulation and there remains the residual, relatively insoluble compounds characteristic of the belt of weathering.

In summary it may be said that fumarolic and solfataric action is not so different from the ordinary reactions of the belt of weathering as might be supposed. The reactions are essentially the same. All of the reactions characteristic of the belt of weathering occur, but at a more rapid rate than ordinarily. Moreover, the local concentration of numerous strong acids makes their action of relatively greater importance than under the ordinary conditions of the belt of weathering. Finally, in the case of fumaroles and solfataras the process of decomposition is wholly chemical, whereas ordinarily in the belt of weathering organic compounds play an important part.

In a strict sense fumarolic and solfataric action, so far as it is the action of gases, is that of mineralizers, as defined by Nammann. However, fumarolic and solfataric action as here considered is not that which is ordinarily known as the action of mineralizers; hence $I$ have avoided the term.

RELATIONS OF DISINTEGRATION TO DECOMPOSITION AND SOLUTION.

The mechanical work of weathering is the physical snbdivision of the material; in other words, is disintegration. The chemical work of weathering is decomposition and solution. The process of disintegration promotes the chemical work of decomposition and solution, because, as disintegration 
goes on, the surfaces exposed to the action of the chemical agents become larger. If a mass of material, of whatever size, be divided into any number of parts with similar forms, the total area of the new surfaces will be equal to that of the original surfaces multiplied by the square root of the number of parts. For instance, if a given mass of rock be divided into a hundred parts, with forms similar to the original mass, the surface is increased ten times, and therefore the area subjected to chemical action is increased tenfold. Hence, in so fab as the rocks are broken mechanically, they give greater surface of action, and this surface of action increases directly as the comminntion increases. It follows that the finely comminnted material is much more readily decomposed than the coarser material. Longhridge has shown that the amount of soluble material in soils is, on the average, larger in proportion to the comminution, thus contirming the conchision that increase in the surface is favorable to chemical action. ${ }^{a}$

But decomposition reacts upon disintegration. In proportion as the material becomes decomposed it is more readily broken up. In so far as the material is chemically altered, and especially in proportion as it is dissolved, the rock is weakened and thus the forces of disintegration rendered more effective. The mechanical and chemical forces therefore act and react upon each other, each one increasing the effectiveness of the other; hence disintegration greatly accelerates decomposition and solution, and decomposition and solntion accelerate disintegration.

This action and reaction between the mechanical and chemical work is well illustrated by the experiments of Daubrée, ${ }^{b}$ who found that various minerals and glass when mechanically triturated in a rotating cylinder are very readily acted mpon by pure water, carbonated water, and water containing sodium chloride. In this way he prodnced a very fine, impalpable mud, which when dried resembled argillite and contained a high percentage of alkalies. It is clear from the above that the greatest effects in the way of weathering are produced by combination of the mechanical and chemical processes. Where, by theaction and reaction of the mechanical and chemical agents, the subdivision has gone to such a stage that the particles are

a Loughridge, R. H., On the distribution of soil ingredients among the sediments obtained in silt analysis: Am. Jour. Sci., vol. 7, 187t, p. 17. Merrill, George P., Rocks, rock-weathering, and soils, Macmillan Co., New York, 1897, pp. 365-366.

Daubrée, A., Géologie Expérimentale, Paris, 1879, pt. 1, pp. 268-279. AIso, Merill, George P., Rocks, rock weathering, and soils, Macmilian Co., New York, 1897, p. 197. 
exceedingly minute, the surface exposed to action is enormous. As illustrating this, Whitney has calculated that there are 22 billion grains of sand and clay in a gram of residual subsoil from a limestone, and that the surface of these particles has an area of 5,000 square centimeters. This is an extreme case, but Whitney estimates the number of grains in ordinary soils to vary from 2 billions to 15 billions per gram. ${ }^{n}$

In an early stage of the process of subdivision disintegration usually plays the dominant part. As the material becomes finer chemical action becomes more important. When the particles become minute, chemical action is dominant in producing subdivision. As shown on pages 432-434, it may well be doubted whether the exceedingly minute subdivision of the residual clays from limestones could be accomplished by the mechanical agents of weathering alone.

It has been seen that the mechanical work of weathering is accomplished by wind, water, ice, change from water to ice, change in temperaature, plants, and animals. The chemical work is accomplished by plants, animals, and solutions. The various factors in this mechanical and chemical work interlock in a most complex fashion. An increase in the amount of work of one of the factors may increase or decrease the amomnt of work of another factor. Moreover, the kind of roork accomplished by one factor is so different from that of another factor that it is difficult or impossible to make quantitative comparisons between them. Thus it is impossible to compare the mechanical work of disintegration with the chemical work of decomposition.

The particular combination of agents and forces most actively at work at a given place is largely dependent upon humidity, latitude, elevation, and life. There are very numerous permutations and combinations of these, so that the number of variations in the rate of weathering are indefinitely great.

REGIONS FAVORABLE TO PROMINENCE OF DISINTEGRATION.

The regions farorable to prominence of disintegration are those of (a) aridity, (b) high latitude, (c) marked topographic relief, (d) sparseness of plants and animals, and (e) nearness to the sea.

Arid regions.-It has already been seen (pp. 438-439) that in arid regions the mechanical stresses dne to rapid change in temperature and to the wind

a Whitney, Milton, The soils of Maryland: Bull. Maryland Agr. Exp. Sta. No. 21, 1893, pp. 8, 33-57. 
are potent inflnences in breaking up the rocks. By insolation the rocks may be coarsely subdivided; by the wind, bearing sand, they may be finely snbdivided-both with very little chemical action. In many dry regions the rainfall is largely concentrated into a small part of the year. In some regions this rainfall may occur as severe local storms. Under these circumstances the disintegrated prodncts are stripped from the rocks by the running water, thus exposing new surfaces to weathering. The transported material may be carried to the sea or may be accumnlated in the lower levels between the steep slopes. The former case is illustrated by the sedimentary rocks which are now forming in the Gulf of California. IIcGee describes the granitic and other rocks of southern California as being simply split apart and broken into their individual grains, which are transported at rare times of abundant rainfall by the process which he calls sheet-flood erosion and deposited in the Gulf of California with scarcely any chemical change Such rocks may have very nearly the average chemical composition of the original rocks from which they are derived. $^{\alpha}$

Very frequently the disintegrated material of arid regions does not reach the sea, but accumulates in the lower areas. Hilgard notes that the soils of such regions are "predominantly sandy or silty, with bnt a small proportion of clay, unless derived directly or indirectly from preexisting formations of clay or clay shales." Moreover, he notes that the soil and the subsoil are substantially the same. The deficiency of clay-that is, kaolinis explained by the lack of the decomposition of the feldspars. The deficiency of clay is no less marked in these soils than the abundance of alkalies and alkatine eartlis. Hilgard finds the proportions of these elements in arid and humid regions to be as follows: ${ }^{b}$

\begin{tabular}{|c|c|c|}
\hline & $\begin{array}{c}\text { Arid region } \\
\text { (per cent). }\end{array}$ & $\begin{array}{l}\text { Humid region } \\
\text { (per cent). }\end{array}$ \\
\hline Potash & 0.825 & 0.187 \\
\hline Soda. & .251 & .071 \\
\hline Lime . . . . . . . . . . . . . . . & 1.645 & .112 \\
\hline Ilagnesia ...... & 1. 384 & .209 \\
\hline
\end{tabular}

a McGee, W·J, The formation of arkose: Science, new ser., vol. 4, 1896, pp. 962-963.

${ }^{b}$ Hilgard, E. W., Relations of soil to climate: Bull. Weather Bureau No. 3, U.S. Dept. Agric., 1892, p. 17.

$c$ Hilgard, eit., p. 30 . MION XLVII--04- 32 
The soils of the arid regions investigated by Hilgard therefore contain from four to fourteen times more of the elements potassium, sodium, calcium, and magnesium, than do those of the humid regions. This difference is doubtless due in part to lack of decomposition of the original compounds; but it is also due in part to the fact that the decomposed materials of the arid regions have not been leached as they have been in the humid regions. As shown in another place (pp. 541-543), the soluble constitnents resnlting from the decomposition of the original minerals are largely retrined.

In conclusion, we see that aridity or low humidity is generally favorable to mechanical rather than to chemical work. In arid regions the process of disintegration is rapid, and that of decomposition and solntion is slow. The total rate of weathering in arid regions, including mechanical and chemical work, is probably, on the average, less rapid than in humid regions.

Regions of high latitude. - First, regions of high latitude are those of low temperature. It has already been seen that the disinpting effect of change from water to ice is an important factor' in the disintegration of rocks. 'This . process is applicable only to those regions in which the temperature falls below $0^{\circ} \mathrm{C}$., and to such regions for only those parts of the year in which the temperature alternately passes above and below the zero mark. These conditions at low altitnde do not occur at all in the 'Tropics. They occur' in winter only in the parts of the temperate zones near the Tropics. 'They occur in spring and autumn in the cooler parts of the temperate zones and in the frigid zones. However, in passing from low to high latitude the length of time during each year in which the conditions are those of alternate freezing and thawing increases; also the range above and below zero increases. Hence the disintegration due to freezing and thawing increases as the latitude increases from those parts of the temperate zones near the Tropics to the far northern and sonthern lands. Second, regions of high latitude are those of extensive glaciation. The glaciers are most powerful disintegrating agents, producing débris ranging in size from great bowlders to the minute particles which whiten the waters issuing from them, and all this with scarcely a trace of decomposition. Third, in regions of ligh latitude there are great changes in temperature which work by differential expansion, as explained on pages $438-439$, and thus help to disintegrate the rocks. Absence of decomposition in comnection with disin- 
tegration at high latitudes also follows from the low temperature, because very unfavorable to chemical action and to abundant organisms.

Therefore in regions of high latitude the rocks are ordinarily broken down and not greatly changed chemically. The exceedingly rapid and extended disintegration of the rocks in regions of high latitude is well illustrated by such comtries as Greenland, Spitzbergen, Franz Josefs Land, etc. As in the arid regions, the sedimentary rocks formed in regions of high latitude may be composed of disintegrated materials, chemically essentially like the naterials from which the rocks are derived. As in the arid regions, where mechanical materials from different sources are mingled, they represent the average composition of the original rocks rather than any one original rock.

Regions of marked topographic relief.-Regions of marked topographic relief are usually regions of considerable elevation. In such regious the mechanical forces work under most favorable conditions. Gravity pulls the material down the steep slopes. The range in temperature is great; water alternately freezes and thaws; glaciers are prevalent. Consequently material is split or gromud from the solid rocks and is carried by gravity in great quantity to lower levels.

The remarkable effect of elevation and sharp relief in disintegration is especially well illustrated in high mountain ranges. In such regions great and small masses are split from the cliffs by the disintegrating forces and agents or are carved from the valley floors by the glaciers, and are transported to a lower level by water or by ice with scarcely appreciable chemical change The cirques at the heads of glaciers give excellent illustrations of the very great rapidity of disintegration due to the combination of the above causes. The Matterhor'n, with its sharp triangular peak and the great cirques at its base, is a most impressive illustration of such disintegration. The peaks of the High Siemas and the Canadian Rockies afford many fine illustrations of the same process.

Penck suggests that the average altitude of mountains in any given region for a given kind of material is limited by the fact that disintegration increases so rapidly as the height increases that for any given area there is a height where the forces of disintegration degrade the mountains as fast as the forces below are able to lift them. ${ }^{a}$

"Penck, A., Morphologie der Erilsherfliche, J. Engelhorn, Stuttgart, 1894, pt. 2, pp. 334-335. 
Also the low temperature is unfavorable to chemical action and to life, and transportation follows closely upon disintegration. The result, therefore, of marked topographic relief is rapid disintegration with comparatively little decomposition.

Regions of sparse plants and animals. - That sparseness of plants and animals is favorable to disintegration without decomposition has already been shown, since it has been made clear that decomposition is largely dependent upon the action of plants and animals and their by-products. The sparsen life may be due to low temperature, low humidity, or other causes.

Regions near the sea.-Nearness to the sea or to a large river is favorable to disintegration with subordinate decomposition, since the material is transported only a short distance before it is deposited below the water. But this relation is not so important as one might at first think. The amount of decomposition is far more dependent upon whether the conditions are favorable for this process before the material reaches the large streams than upon distance from the sea.

When the material once gets permanently below the surface of the water, it passes to a considerable extent from the conditions of the jelt of weathering to those of cementation. While oxygen and living organisms nay still act upon the material, they are not nearly so effective as under the conditions of the belt of weathering; hence, the process of decomposition is much retarded. This is well illustrated by the material brought down by the Nile and deposited in its lower reaches. According to Judd, the deposits of the Nile delta consist of fresh, unaltered, rounded, angular and subangular grains of the original minerals of the rock, such as the feldspars, hornblende, augite, quartz, etc. This material, he says, has been derived from the desert sands, which lie on eitler side of the Nile Valley and are stvept into it by the wind. ${ }^{\alpha}$ As has been seen (pp. 496-498), desert conditions are favorable to disintegration without decomposition; hence the sands contributed to the upper Nile are little decomposed, and the long river journey does not greatly increase the amount of decomposition.

While decomposition largely ceases when the material is transported by streams, disintegration does not cease, for the particles grind against one another or over the bottom, and thus comminution goes on; and therefore the

"Judd, J. W., Report on a series of specimens of the deposits of the Nile delta, obtained by the recent boring operations: Proc. Royal Soc. London, vol. 39, 1885, pp. 213-220. 
longer the journey the farther this process contimnes. However, as shown on pages 432-434, there appears to be an inferior limit in size, beyond which attrition ceases; that is, the particles become so fine that they are floated and have not sufficient weight and momentum to materially grind one another. This conclusion is further supported by the fact, given by Judd, that the small particles of the alluvial deposits of the Nile which have been transported great distances are angular, while the larger particles of the same deposits are subangular or rounded. However, he attributes the rounding of the larger grains to eolian rather than river erosion; but this does not lessen the force of the argument as to there being a lower limit beyond which the particles are not rounded by river action. Further evidence in the same direction is the angular character of the loess of the Mississippi Valley. Chamberlin and Salisbury found that the loess of that valley, much of which must have been floater for long distances, probably hundreds of miles, is wholly composed of angular particles which show no evidence of wear. For the most part these loess grains are less than 0.005 mm. in diameter, althongh in some places 1 per cent or more exceed this diameter, and a few grains are nearly $0.1 \mathrm{~mm}$. in diameter.

REGIONS FAVORABLE TO PRONINENCE OF DECOMPOSITION.

The regions favorable to decomposition are those of humidity, low latitude, moderate topographic relief, abundance of plants and animals, and remoteness from the sea.

Humid regions. - It is clear that humidity is one of the reqnisite conditions for regions of rapid decomposition, since chemical action is very slow in the absence of water. In humid regions, as alrearly shown, the belt of weathering always contains a large and variable amount of water, and water is essential for vigorous chemical action. Hydration is one of the chief reactions of the belt of weathering, and in humid regions there is abundance of the necessary compound for the process.

High humidity may occur at any latitude 'and at any elevation. At low latitudes and low elevations the temperature is high and life is abundant, and these conditions are especially favorable to chemical work.

As evidence of decomposition in the humid regions, Hilgard contrasts the soils of stch regions with those of the arid regions, and finds that in the humid regions the soils are usually loams with a clay subsoil. The presence 
of clays, of which kaolin is the chief constitnent, proves the extensive decomposition of the silicates, especially the feldspars.

It is rather probable that decomposition is most rapid in regions of moderate humidity, where there is moisture sufficient to carry on decomposition, solution, and transportation of the disintegrated material with considerable rapidity, and for animals and plants to be reasonably abundant, but not sufficient to produce extraordinarily luxuriant regetation, which may practically stop mechanical transportation on all but the steepest slopes, and thus produce a protective covering of decomposed materials. (See p. 503.)

While humidity is very favorable to decomposition, it must be remembered that running water is the greatest of the eroding agents, and therefore that humidity is also very favorable to disintegration.

Regions of low latitude.-Regions of low latitude are those of ligh temperature. Warmth is favorable to chemical decomposition. The great increase in the activity of chemical agents in consequence of increase in temperature has already been explained on pages 61-62, 78-81, and hence in warm regions the chemical agents which are at work in the belt of weathering have a potency which they do not approach in cold regions. Therefore the usual deep belt of decomposition in the tropical and semitropical regions and the general absence of such a belt in the colder regions is partly explained by high temperature.

Consequent upon high temperature as one essential factor is abundant life, which still further favors decomposition, as explained below. In regions of high temperature the range of temperature may be great, and therefore disintegration due to this canse be a concurrent process. But in such regions the temperature does not often fall below zero, and hence the disintegrating effect of freezing and thawing is nil, or nearly so.

Regions of moderate topographic relief.-Regions of small topographic relief generally have gentle slopes, and gentle slopes are farorable to retention of moisture and unfarorable to rapid transportation. Moreover, regions of small relief usually have low elerations and are farorable to high temperature, and consequently to abundant life. Hence, regions of small elevation are those of marked decomposition.

If the elevation be slight the level of ground water may be at a very small depth below the surface, or even reach the surface, and thus decom- 
position be stayed. But areas of very low relief are farorable to decomposition of the narow belt extending to and somewhat below the level of ground water. This is well illustrated by Florida. In that region the original refractory minerals havo been decomposed and the soluble material abstracted; and the relatixely soluble minerals, snch as the calcium carbonate of the limestones, lave been wholly abstracted, leaving for a large part of the region a mantle of insoluble residual nuterial, corresponding in composition almost perfectly with the nltimate products of weathering. (See pp. 520-521.)

In contrast with low regions are regions where the altitudes are great and the slopes steep. Disintegration and transportation may go on so rapidly as to give little opportunity for decomposition.

Thus the most favorable conditions for most rapid but not complete decomposition are limited both by very low and by very high altitudes. Therefore, the most favorable topographic conditions for rapid decomposition are those of moderate relief. Excellent illustrative regions are southeasteru United States, Nicaragua, and large parts of Brazil. These are all regions of moderate elevation and continuous moderate slopes.

Regions of abundant plants and animals. - Plentiful plant and aminual life is very favorable to decomposition. Abundance of plants and animals is conditioned by high humidity and high temperature. Regions of abundant life are therefore the warm, moist regions of the Tropics and the sub-Tropics. It is not too much to say that abundant animals and plants and their by-products are the sources of most of the active compounds, which, working throngh abundant water solutions favored by high temperature, do the great work in the decomposition of the rocks. As alleady pointed out, the process of carbonation, one of the chief reactions of the belt of weatlering, is largely conditioned on the carbonic acid concentrated by the decomposition of plants and animals.

While the work of life is fundamental in the decomposition of the rocks, where life is too abundant this may stay the progress of weathering. Abundant plant life gives a protective covering to the decomposed rocks, which is effective in proportion to its luxuriance. The plant covering, where very luxuriant, as in many parts of the warm regions, very greatly retards, and may almost wholly stop, the mechanical work of disintegration and transportation. Therefore, under these conditions, in very humid 
regions decomposition frequently outruns transportation, and a thick layer of decomposed material accumulates. Finally, there may be produced a thick, nearly permanent, belt of weathered material which is protected from mechanical transportation by vegetation and protects the rocks below from decomposition. Such appear to be the conditions in Nicaragua along portions of the proposed route of the ship canal. Hayes says that in parts of Nicaragua, notwithstanding the complete decomposition of the rocks and the abundaut rains, the streans are clear. ${ }^{a}$ The process of weathering must therefore be very slow, being almost wholly limited to solution.

Regions remote from the sea.-In so far as the material is remote from the sea it is long exposed to the forces of weathering before it is finally floated or deposited in the sedimentary rocks, and thus in proportion as the material is transported far before permanently reaching the water it is likely to be decomposed.

General statements. - While in the previous pages an attempt has been made to consider separately humid regions, regions of low latitude, regions of moderate topographic relief, regions of abundant plants and animals, and regions remote from the sea, in speaking of one it has been necessary to some extent to consider one or more of the others. In regions which combine several of these factors decomposition is at a maximum. It is only when the materials of the belt of weathering in regions of high latitude, high altitude, and aridity, in which life is sparse, are compared with the materials of the belt of weathering in humid regions, regions of low latitude, low altitude, and abundant life, that the efficiency of the latter combination of conditions in the decomposition of rocks can be fully appreciated. It has been seen that where the former set of conditions obtain, weathering consists in rapid change of temperature, change of water to ice, and the work of glaciers splitting or grinding the rocks into fragments; but that the particles in chemical and mineral composition are substantially the same as the original rock, although, of course, decomposition does always take place to some extent. But in warm humid regions, in which plant life and animal life are abundant, the solid rocks are not only disintegrated, but the material is rapidly decomposed. This decomposition may extend from a few meters to a depth of 90 meters in the subtropical and tropical regions. A result of high humidity and high temperature are the wonderfully luxuriant

a Hayes, C. W., Report of the Nicaragua Canal Commission, Appendix II, Geologic Report, Baltimore, 1899, p. 112. 
forests of the Tropics, such as those of Brazil and central Africa. The difficulties of traversing such a region are almost incredible. The forests are a tangle of vegetation, which it is possible to penetrate only by cutting one's way. Under such conditions the rocks in the belt of weathering are continnously acted upon in the most powerful way, under the most favorable conditions of humidity and temperature, by the chemical products furnished by the plants and animals, alive and dear. No one can realize the abundance of plant and animal material, dead and alive, both above and below the soil, in a dense forest region withont traveling through one. The soil for many feet below the surface seems to be mainly composed of regetation. The individuals vary from great trees, through plants of medium size, to the smaller plants, such as the mosses, fungi, and finally the bacteria. To a large extent the living plants are feeding on the dead and decomposing ones. At the surface the quantity of organic material is at a maximum. Normally the quantity steadily decreases from the surface to a depth of 12 to 15 meters, where it becomes unimportant. Thus there is every gradation between places at the surface where the organic material occupies the larger part of the space to a place below the surface where the inorganic material ocenpies all the space.

One who has studied regions where life is dense will readily believe that great geological consequences follow from the chemical activity of compounds produced by animals and plants, both alive and dead. It is not too much to say that life is an essential factor in far the larger part of the chemical work of decomposition and solution of the rocks.

Of the plants. the minute bacteria are among the most important. Of the animals, earthworms are perhaps the most important The prodigious numbers of these compensate for their smallness. They furnish a striking. illustration of the principle that small numerons agents may be more potent than large and more conspicuous but less numerous ones.

From the foregoing it is plain that living and dead plants and animals interact with one another and with the rocks in the production and maintenance of the soil. As shown on pages 452-453, chlorophyll-bearing plants, and especially one group of them, the leguninosie, working in conjunction with bacteria, are the agents which collect carbon and nitrogen from the atmosphere and place them in the soil in a combined state. Dead plants and animals are the materials npon which living bacteria, oxygen, and water work to produce carbonic, nitric, and sulphuric acids. These form carbon- 
ates, nitrates, and sulphates in great abundance within the soil, and thus the processes of carbonation, nitration, and sulphation of the minerals of the rocks are rapid. The carbonates, nitrates, and sulphates furnish food for the chlorophyll-bearing plants. The plants are food for the animals. After a time these plants and animals die, decompose, and thus supply additional material to carry on the process of decomposition of the rocks. Therefore there is action and interaction between the chlorophyll-bearing plants and the bacteria, and between these and the animals alive; interaction between these plants and animals dead and bacterial plants alive, and interaction between all live and dead plants and animals and the rocks. Decomposition of rocks produces plant food; the food builds the plants: the plants build the animals; these in turu, both while alive and after death, produce decomposition of the rocks, and so round indefinitely.

It is now clear. why it is so difficult to produce a good soil where such a soil does not exist, and why a soil once formed may be retained indefinitely by proper tillage. Where the soil is good and vegetation is abundant, the complicated machine is in full motion and is able to produce new soil as fast as the old soil is transported elsewhere by wind or water.

The cycles above considered do not include the whole case. The full geological cycle does not occur in the belt of weathering alone. As fully explained elsewhere (pp. 538-539, 612 et seq.), a portion of the salts dissolved during the decomposition of the rocks in the belt of weathering is transported to the belt of cementation and there precipitated; another portion goes to the sea. It is only when these portions are followed that a full comprehension of the complicated and far-reaching geological effect of weathering throngh plants and animals may be obtained. Here it will only be remarked that of the salts of the sea, calcinm carbonate is produced by carbonation of the silicates, but this process is mainly dependent upon the plants. Thus the work of the plants furnishes the material for the hard parts of sea animals; these hard parts are the source of the great limestone formations; as a result of geological revolutions limestone formations built below the sea are raised and becone land areas; upon these limestones soils of umusual fertility are formed, and this results in luxuriant plant and animal life, thus completing a cycle, one among the many geological cycles connected with plants and animals.

While life is especially potent in chemical work, the power of life in mechanical work is considerable. 
CHANGE IN CHEMICAL COMPOSITION OF THE ROCKS.

So far as the change in the average chemical composition of rocks in the belt of weathering is concerned, solution is largely the final determinative factor: althongh, as has been seen, the amount and nature of the material dissolved are dependent upon all the many factors heretofore considered. By comparing the original chemical composition of rocks with the chemical composition of the partly disintegrated and decomposed equivalent rocks, one is able to obtain an approximate idea of the relative losses of the elements. In order to compare the losses which the various elements have undergone as a result of solution and transportation, it is necessary to suppose that some one element is insoluble and is not abstracted at all. Usually iron and aluminum have been chosen as the insoluble constituents. With these as a standard in most cases, but in some cases other elements, Merrill made the following calculations as to the losses of the elements for varions rocks:

Supposing the amount of iron to remain constant, for a disintegrated and partly decomposed granite in the District of Columbia the original composition and the losses of the constituents are as follows:

TABLE I. - Ammlyses of fresh and altered grunite.

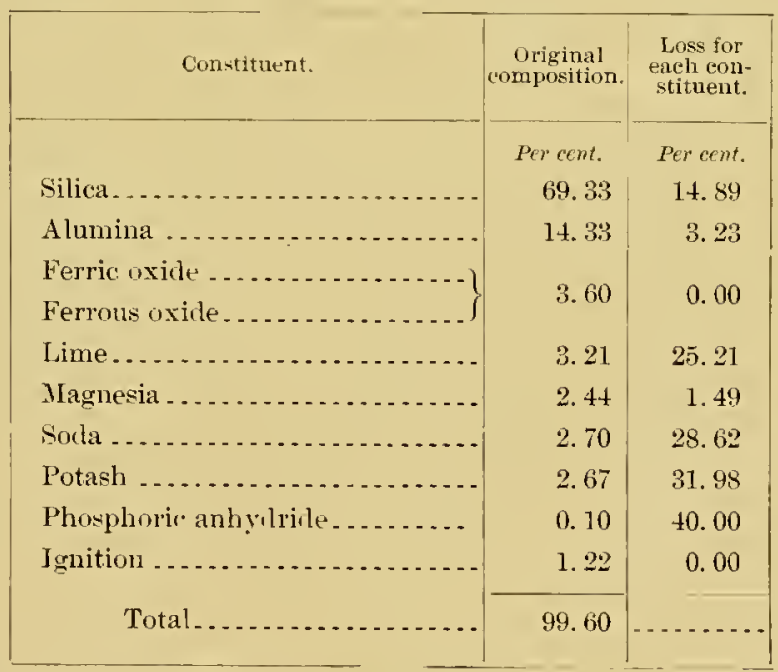

a Merrill, George P., Rocks, rock-weathering, and soils, Macmillan Co., New York, 1897, pp. 209-23:. 
Supposing the amount of aluminum to be constant (except in Table III, analysis 2, fresh diabase from Venezuela, in which iron is supposed to be constant), the original composition and the losses of the various elements for the following rocks are as follows:

TABLE II.-Analyses of fresh and altered gneiss and syenite.

\begin{tabular}{|c|c|c|}
\hline \multirow{2}{*}{ Constituents. } & $\begin{array}{l}\text { Fresh gneiss } \\
\text { (Virginia). }\end{array}$ & $\begin{array}{c}\text { Fresh } \\
\text { syenite } \\
\text { (Arkansas). }\end{array}$ \\
\hline & \multicolumn{2}{|c|}{ Original composition. } \\
\hline Silica ......... & $\begin{array}{l}\text { Per cent. } \\
\quad 60.69\end{array}$ & $\begin{array}{r}\text { Per cent. } \\
59.70\end{array}$ \\
\hline Alumina . . . . . & 16.89 & 18.85 \\
\hline Ferric oxide .... . & 9.06 & 4.85 \\
\hline Lime........... & 4.44 & 1.34 \\
\hline Mlagnesia . . . . . . . & 1.06 & .68 \\
\hline Potash ....... & 4.25 & 5.97 \\
\hline Soda $\ldots \ldots \ldots$ & 2.82 & 6.29 \\
\hline Phosphorie acid.......... & .25 & ..... \\
\hline Ignition ............... & .62 & 1. 88 \\
\hline Total_ & 100.08 & 99.56 \\
\hline \multirow{2}{*}{ Constituents. } & $\begin{array}{c}\text { Decomposed } \\
\text { gneiss. }\end{array}$ & $\begin{array}{l}\text { Decomposed } \\
\text { syenite. }\end{array}$ \\
\hline & \multicolumn{2}{|c|}{ Loss for each constituent. } \\
\hline Silica_....... & $\begin{array}{l}\text { Per cent. } \\
52.45\end{array}$ & $\begin{array}{c}\text { Per cent. } \\
62.18\end{array}$ \\
\hline Alumina ..... & 0.00 & 0.00 \\
\hline Ferric oxide ........... & 14.35 & 86.17 \\
\hline Lime............ & 100.00 & 87.90 \\
\hline Magnesia . . . . . . . . . & 74.70 & 82.10 \\
\hline Potash ........... & 83.52 & 81.85 \\
\hline Soda $\ldots . . . . . . .$. & 95.03 & 97.11 \\
\hline Phosphoric acid ........... & 0.00 & $\cdots$ \\
\hline 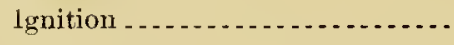 & 0.00 & \\
\hline
\end{tabular}


TabLE III.-Analyses of fresh and altered diabase and basalt.

\begin{tabular}{|c|c|c|c|c|}
\hline & $\begin{array}{l}\text { Fresh dia- } \\
\text { base (Mass- } \\
\text { achusetts). }\end{array}$ & $\begin{array}{l}\text { Fresh dia- } \\
\text { base (Vene- } \\
\text { zuela). }\end{array}$ & $\begin{array}{l}\text { Fresh basalt } \\
\text { (Bohemia). }\end{array}$ & $\begin{array}{l}\text { Fresh basalt } \\
\text { (France). }\end{array}$ \\
\hline & \multicolumn{4}{|c|}{ Original composition. } \\
\hline & Per cent. & Per cent. & Per cent. & Per cent. \\
\hline 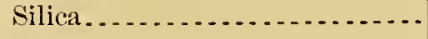 & 47.28 & 49.35 & 43.61 & 48.29 \\
\hline Alumina. .................... & 20.22 & 15.30 & 12.26 & 13.25 \\
\hline Ferric oxide ............... & 3. 66 & $\ldots \ldots \ldots$ & 3.51 & 0.00 \\
\hline 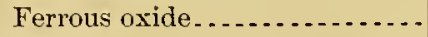 & 8.89 & 12.28 & 12.16 & 16.66 \\
\hline 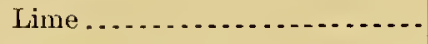 & 7.09 & 9.60 & 11.37 & 7.33 \\
\hline Magnesia ................. & 3.17 & 7.38 & 9.14 & 7.03 \\
\hline Mlanganese oxide.............. & .77 & $\ldots . . .$. & ..... & $\therefore \ldots \ldots$ \\
\hline Potash $\ldots \ldots \ldots \ldots \ldots$ & 2.16 & .85 & .81 & 1.81 \\
\hline Soda .......... & 3. 94 & 1.98 & 2.72 & 2.71 \\
\hline \multirow{5}{*}{$\begin{array}{l}\text { Phosphoric acia } \\
\text { Ignition } \ldots \ldots \ldots\end{array}$} & .68 & 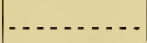 & $\ldots \ldots \ldots$ & $\ldots \ldots$ \\
\hline & 2.73 & 3.25 & $\mathrm{H}_{2} \mathrm{O} 4.42$ & 4.92 \\
\hline & 100.59 & 100.00 & 100.00 & 100.00 \\
\hline & $\begin{array}{l}\text { Disinte- } \\
\text { grated dia- } \\
\text { base. }\end{array}$ & $\begin{array}{c}\text { Decomposed } \\
\text { diabase. }\end{array}$ & $\begin{array}{l}\text { Decomposed } \\
\text { basalt. }\end{array}$ & $\begin{array}{c}\text { Decomposed } \\
\text { basalt. }\end{array}$ \\
\hline & \multicolumn{4}{|c|}{ Loss for each constituent. } \\
\hline & Per cent. & Per cent, & Per cent. & Per cent. \\
\hline 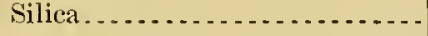 & 18.03 & 42.40 & 32.99 & 65.56 \\
\hline 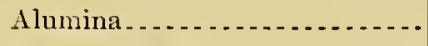 & 0.00 & 21.38 & 0.00 & 0.00 \\
\hline Ferric oxide.. & 18. 10 & 0.00 & 50.17 & 88,84 \\
\hline Ferrous oxide $\ldots$ & & & (5) 11 & $0.0 x$ \\
\hline Lime $\ldots . . . . . . . . . . . . .$. & 25.89 & 83.23 & 84.53 & 47.24 \\
\hline Magnesia . .... & 21.70 & 61.37 & 74.10 & 96.38 \\
\hline Manganese oxide . . . . . . . . & 41.57 & $\ldots . .$. & - & $\ldots-\ldots$ \\
\hline Potash ....... & 29.15 & 45.88 & 6169 & $\int 83.34$ \\
\hline Soda $\ldots \ldots \ldots \ldots$ & 12.83 & 95.37 & 01.09 & 74.41 \\
\hline Phosphoric acid . . . . . . . . . & 11.39 & - & & - \\
\hline 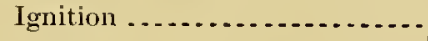 & 0.00 & 0.00 & $\ldots$ & 0.00 \\
\hline
\end{tabular}


TABLE IV.-Analyses of fresh and altered diorite, pyroxenite, and argillite.

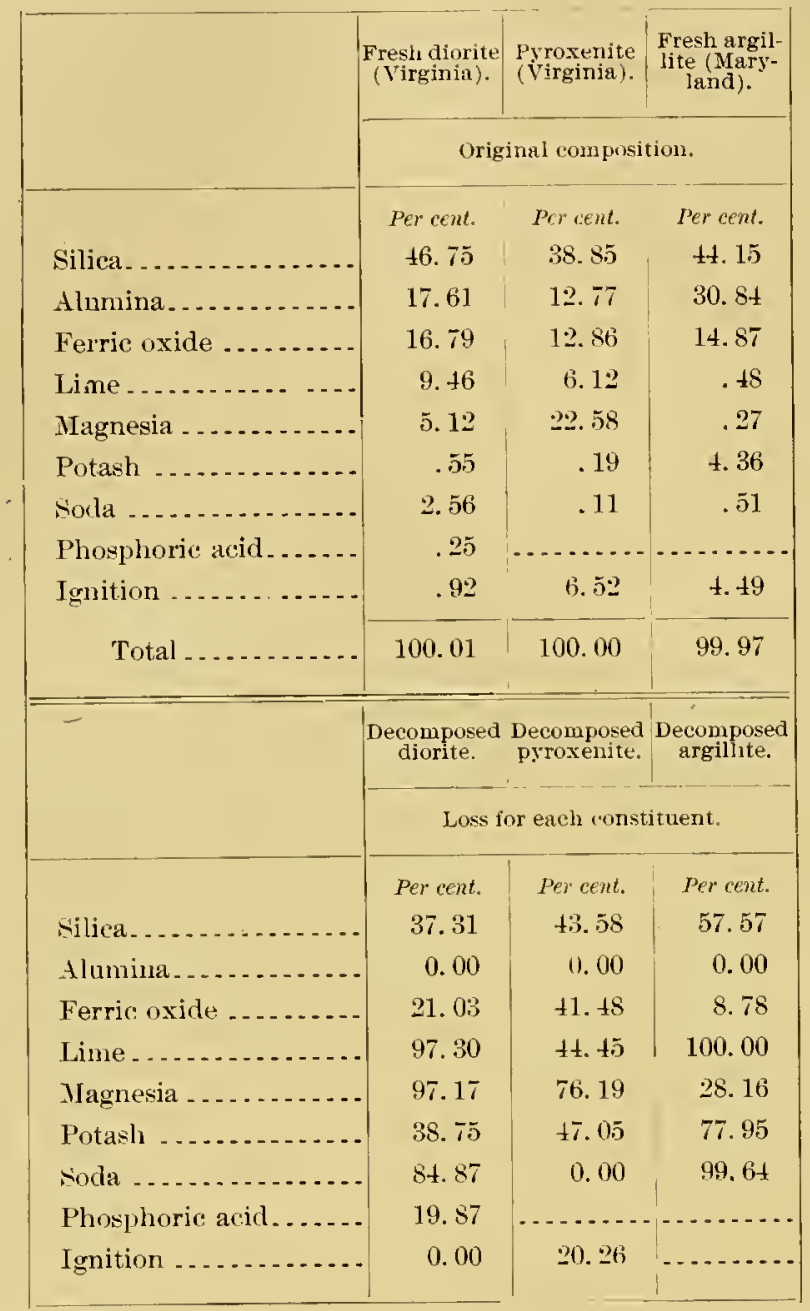

One of the best cases of complete decomposition known to me is that of the diabase of the iron-bearing formation of the Penokee-Gogebic district. In this rock in its most altered form not one restige of any original mineral was discovered with the microscope. While the analyses of this rock are here inserted, it was largely altered below the level of ground water, but at a point where abundant descending waters from the belt of weathering were converged, and where therefore the conditions were intermediate between those of the belt of weathering and those of the belt of cementation. The 
analyses of the fresh diabase and the decomposed rock are given in columns 1 and 2. Supposing the alumina to have remained constant, the losses of the other constituents are as given in columu 3 .

TABLE V.-Analyses of fresh and altered diabase. ${ }^{a}$

\begin{tabular}{|c|c|c|c|}
\hline & 1 & 2 & 3 \\
\hline $\mathrm{H}_{2} \mathrm{O}$ at $105^{\circ} \ldots \ldots$ & 0.15 & 0.29 & 00 \\
\hline $\mathrm{H}_{2} \mathrm{O}$ at red heat ....... & 2.34 & 13.54 & 0.00 \\
\hline $\mathrm{CO}_{2} \ldots \ldots \ldots \ldots$ & .38 & .38 & 58.06 \\
\hline $\mathrm{SO}_{3} b \ldots \ldots$ & .03 & $\ldots \ldots . . . .$. & $\ldots \ldots \ldots$ \\
\hline $\mathrm{P}_{2} \mathrm{O}_{5} \ldots \ldots$ & .13 & .14 & 54.83 \\
\hline $\mathrm{SiO}_{2} \ldots \ldots \ldots \ldots$ & 47.90 & 41.60 & 63.57 \\
\hline $\mathrm{TiO}_{2} \ldots \ldots \ldots$ & .82 & 3.79 & 0.00 \\
\hline $\mathrm{Al}_{2} \mathrm{O}_{3} \ldots$. & 15.60 & c 37.20 & 0.00 \\
\hline $\mathrm{Fe}_{2} \mathrm{O}_{3} \ldots \ldots \ldots$ & 3.69 & 3.21 & 63.51 \\
\hline $\mathrm{Cr}_{2} \mathrm{O}_{3} \ldots \ldots \ldots$ & Trace. & .......... & 100.00 \\
\hline $\mathrm{FeO} . . .$. & 8. 41 & .30 & 98.51 \\
\hline $\mathrm{NiO}(\mathrm{CoO}) \ldots \ldots . . .$. & .10 & $\ldots \ldots \ldots$ & 100.00 \\
\hline $\operatorname{MnO} \ldots \ldots \ldots$ & .17 & .08 & 80.26 \\
\hline $\mathrm{BaO} \ldots . . .$. & .05 & Trace. & $99.00+$ \\
\hline $\mathrm{CaO} \ldots \ldots \ldots \ldots$ & 9.99 & .23 & 99.04 \\
\hline $\operatorname{IgO} \ldots \ldots \ldots \ldots$ & 8.11 & .02 & 99.90 \\
\hline $\mathrm{K}_{2} \mathrm{O} \ldots \ldots \ldots$ & .23 & $\ldots \ldots$ & 100.00 \\
\hline $\mathrm{Na}_{2} \mathrm{O} \ldots \ldots \ldots \ldots$ & 2.05 & .07 & 98.57 \\
\hline Total ........... & 100.15 & 100.85 & \\
\hline
\end{tabular}

a Irving, R. D., and Van Hise, C. R., The Penokee iron-bearing series of Michigan and Wisconsin: Mon. U. S. Geol. Survey, vol. 19, 1892, p. 357.

$b \mathrm{SO}_{3}$ ealcnlated from $\mathrm{BaO}$ found, as this latter probably exists as $\mathrm{BaSO}$

$c \mathrm{Al}_{2} \mathrm{O}_{3}$ is probably a little high, owing to alkali retained by titanic acid. 
Upon the supposition that no potash is lost in the case of a phonolite, the original composition and the losses are as follows:

TABLE VI.-Analyses of fiesh and altered phonolite.

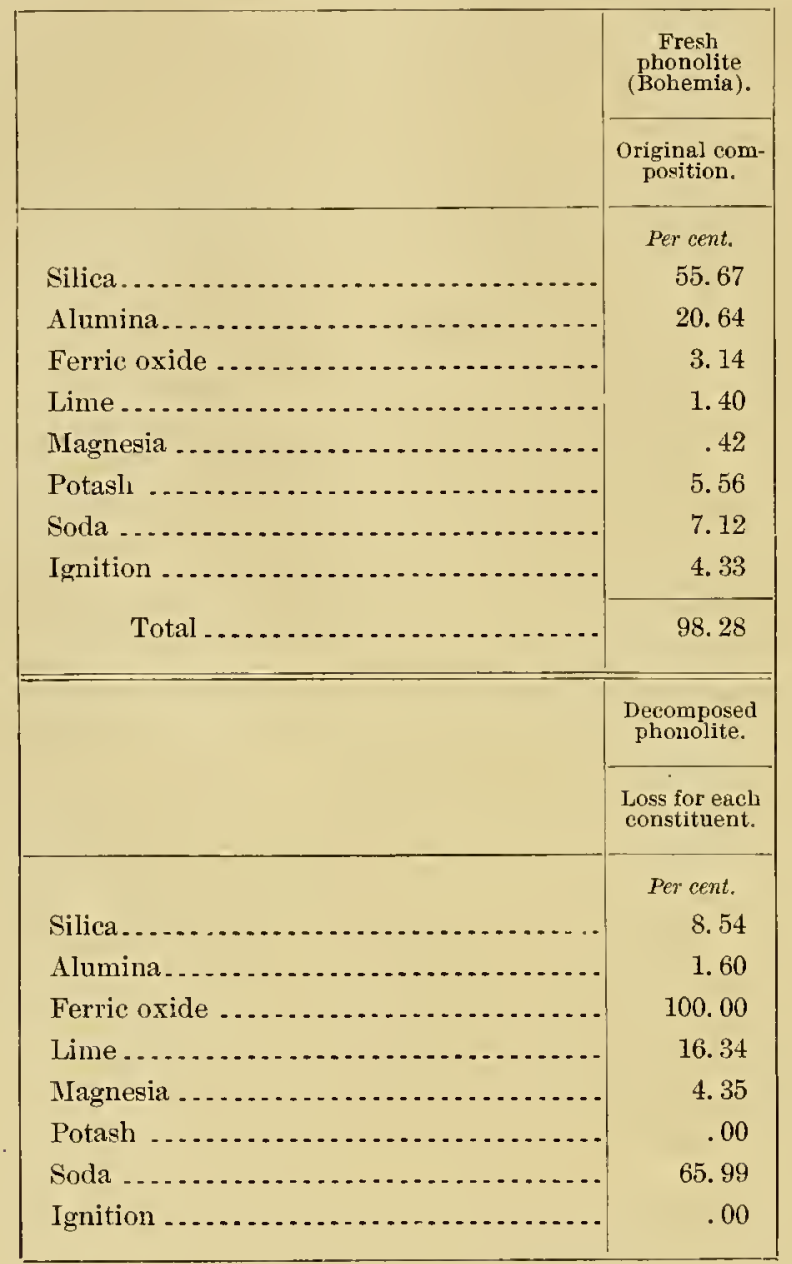


Supposing the amount of silica remains constant in a limestone, the original composition and the losses are as follows:

TABLE VII.-Analyses of fresh and altered limestone.

\begin{tabular}{|c|c|}
\hline & \multirow{2}{*}{\begin{tabular}{|c}
$\begin{array}{c}\text { Fresh } \\
\text { limestone } \\
\text { (A rkansas) }\end{array}$ \\
$\begin{array}{c}\text { Original com- } \\
\text { position. }\end{array}$
\end{tabular}} \\
\hline & \\
\hline & Per cent. \\
\hline Silica .... & 4.13 \\
\hline Alumina ..... & 4.19 \\
\hline Ferric iron. . . . . . . . . & 2.35 \\
\hline Manganic oxide ..... & 4.33 \\
\hline Lime. . . . . . . & 44.79 \\
\hline Magnesia ... . & .30 \\
\hline Potash $\ldots \ldots \ldots \ldots \ldots$ & .35 \\
\hline Soda $\ldots \ldots \ldots$ & .16 \\
\hline Water.......... & 2. 26 \\
\hline Carbonic acid ...... & 34.10 \\
\hline \multirow[t]{4}{*}{ 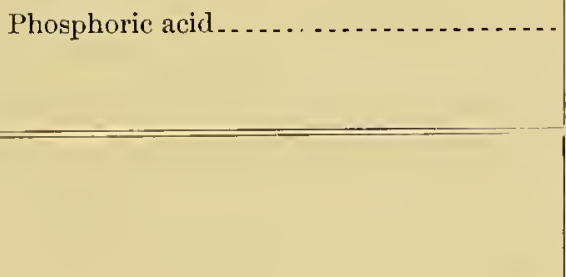 } & 3.04 \\
\hline & 100.00 \\
\hline & Residual clay. \\
\hline & $\begin{array}{l}\text { Loss for each } \\
\text { constituent. }\end{array}$ \\
\hline & Per cent. \\
\hline Silica........... & 0.00 \\
\hline Alumina ........ & 11.35 \\
\hline Ferric iron...... & 89.56 \\
\hline Manganic oxide.................... & 57.59 \\
\hline 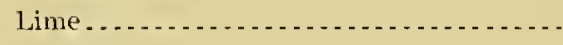 & 98.93 \\
\hline Magnesia .... & 89.38 \\
\hline Potash . . . . . . & 66.37 \\
\hline Soda & 53.26 \\
\hline Water..................... & 41.63 \\
\hline Carbonic acid . . . . . . . & 100.00 \\
\hline Phosphoric acid ......... & 89. 76 \\
\hline
\end{tabular}

While in the foregoing tables, with the exception of one rock spoken of as disintegrated, the altered forms of the rocks are ciassed as decomposed, it must be understood that these terms are relative. In the so-caller MON XIVII-04-3 33 
decomposerl rocks the processes of decomposition have gone to different stages. In but few of the rocks analyzed has the process nearly approached completion. Also the rock which is spoken of as disintegrated has been partially decomposed. This is conclusively shown by the fact that there is great variability in the calculated losses for the varions elements. If the rock had simply been mechanically disintegrated the composition of the alteved rock would have been the same as that of the original rock.

In the tables the varions elements-iron, aluminum, potassium, and silicon-are chosen in different cases as constant in amount. This shows that the supposition that any element is fixed in. amount is erroneous. Evidently in each case in making the calculations the method has been to choose the element in which the loss has been the least, and by this to gange the loss of the other elements. For any one of these elements it is highly probable that the loss in most instances is as great as or greater than the loss of this element where other elements are chosen as the standard.

For instance, when aluminum is taken as fixed the loss of the potassium ranges from 29 to 83 per cent. It is highly probable that in the case of the phonolite, where potassium is taken as fixed, the loss of this element is at least as great as the minimum, and it may equal the maximum. Therefore the percentages of loss of the other elements of the phonolite, given on page 512 , are greater than estimated. On the average alnminum is the least soluble of the elements, and in those cases where it can be used as the standard the underestimates for the other elements may not be large; but the occasional very considerable loss of ahmina in some instances-for example, a limestone (Table VII, p. 513), where the loss is over 11 per centshows that even where this element is taken as fixed there may be very considerable losses of it, and consequently corresponding underestimates of the losses of the other elements. For instance, in a diabase (colmmn 1 of Table III, p. 509) the aluminum is taken as fixed and the loss of the iron oxide is calculated at 18.1 per cent. In column 2 of the same table the iron oxide is supposer to be fixed and the loss of the aluminum is calculated at 21.38 per cent. The facts probably are that there were heavy losses of iron and aluminum in both rocks, and that in each case the calculated loss is much too small. 
It is therefore clear that even the large losses of the elements repre: sented by the above tables are much too small. The amount of the error in a given case for a certain element is large in proportion as the element is relatively insoluble. For instance, in the phonolite, where the potassinm is considered fixel, the loss in alumina is given as 1.60 per cent; but if the loss of the potassinm is, for instance, 30 per cent-and it is probably more than this-the loss of the alumina was more than 30 per cent. But in the case of the sodium, the loss of which is calculated as 66 per cent, this amount may be considerably too small, but it can not be more than 100 per cent; hence the relative error is much less in this case. For instance, in the diabase (Table V) the loss of sodium, 98.57 per cent, is almust, and of potassium, 100 per cent, is quite, correct. Where the losses are given as small in the foregoing tables, therefore, it is probable that the calculated amounts are but a fraction of the real losses; but where the losses are given as large, the errors, while very considerable, are probably not so great proportionally, and the calculated amounts give a rough approximation to the minimum percentage of depletion of the rocks in these elements.

In order to show the caiculated comparative losses of the six important elements, aside from aluminum, the following table is compiled for those rocks in which the calculation has been made upon the supposition that the aluminum is fixed.

Table showing calculated percentage losses of important elements on the supposition that the aluminum is constant.

\begin{tabular}{|c|c|c|c|c|c|c|c|}
\hline & Potash. & Soda. & Lime. & $\begin{array}{l}\text { Mag- } \\
\text { nesia. }\end{array}$ & Silica. & $\begin{array}{c}\text { Iron } \\
\text { oxide. }\end{array}$ & $\begin{array}{l}\text { Alu- } \\
\text { mina. }\end{array}$ \\
\hline Gneiss (column 1, Table II, p. 508) .. & 83.52 & 95.03 & 100.00 & 74.70 & 52.45 & 14.35 & 0.00 \\
\hline Syenite (column 2, Table II, p. 508) ..... & 81.85 & 97.11 & 87.90 & 82.10 & 62.18 & 86.17 & 0.00 \\
\hline Diabase (column 1, Table IIL, p. 509) ... & 29.15 & 12.83 & 25.89 & 21.70 & 18.03 & 18.10 & 0.00 \\
\hline Diabase (column 3, Table $\mathrm{r}$, p. 5]1).. & 100.00 & 98.57 & 99.04 & 99.90 & 63.57 & 87.81 & 0.00 \\
\hline Basalt (column 3, Table III, p. 509) .. & 61. & & 84.53 & 74.10 & 32.99 & 50.17 & 0.00 \\
\hline Basalt (column 4, Table III, p. 509).. & $83 . \overrightarrow{34}$ & 74.41 & 47.24 & 96.38 & 65.56 & 88.84 & 0.00 \\
\hline Diorite (column 1, Table IV, p. 510) & 38.75 & 84.87 & 97.30 & 97.17 & 37.31 & 21.03 & 0.00 \\
\hline Pyroxenite (column 2, Table IV, P. 510) & 47.05 & 0.00 & 44.45 & 76.19 & 43.58 & $41 . \pm 8$ & 0.00 \\
\hline Argillite (column 3, Table IV, p. 510$) \ldots$ & 77.95 & 99.64 & 100.00 & 28.16 & 57.57 & 8.78 & 0.00 \\
\hline Average & 67.70 & 70.31 & 76.26 & 72.27 & 48.14 & 46.30 & 0.00 \\
\hline
\end{tabular}
and $\mathrm{Na}$.

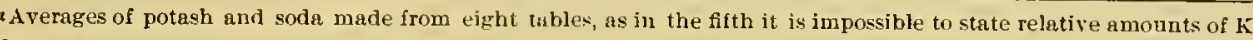


From the above table it appears that the order of loss, reckoned by quantity, begiming with the greatest, is: Lime, magnesia, soda, potash, silica, iron oxide, alumina. Of the two alkalies, more of the soda is dissolved than the potash. Of the alkaline earths, while on the whole the lime is dissolved in greater amount, in some rocks more magnesia is dissolved than lime. One of the unexpecter things showu by this table is the fact that the percentage loss in silica is more than one-half as great as the average losses of the alkalies and alkaline earths. When it is remembered that the arerage amount of silica in the original rocks is 48.7 per cent, and that the average of the alkalies and alkaline earths together is but 17.5 per cent of the total, it is clear that the loss of the silica is about the same as the entire losses of the alkalies and the alkaline earths togetleer.

This is a very interesting conclusion, since it shows that a very erroneons impression prevails in reference to silica. It has been generally supposed that the rocks in the belt of weathering are not much depleted in this compound. On account of the extreme insolubility of crystallized silica or quartz, it has been supposed that the silica of a rock is exceedingly insoluble. For instance, Merrill says: "Silica, even in its most soluble for'm, requires 10,000 times its weight of water for solutiou." " Doubtless, under ordinary cireumstances, quartz is but sparingly soluble, although, as shown in another place (see p. 848), even this form of silica is dissolved to some extent. But in the majority of instances a large part of the silica is present as a silicate, although of course quartz is also abundant. When the silicates are broken up by carbonation there is every reason to believe that the greater portion of the freed silica separates as silicic hydroxide or colloidal silicic acid, which is readily soluble. That this reaction takes place has already been shown (see p. 480) and that the silicic hydroxide is dissolved and abstracted from the rocks is shown by the tables already given. In the rocks in which the silica is largely as silicate and the almuina is taken as constant the calculated losses of silica are high-in gneiss, 52.45 per cent; in syenite, 62.18 per ceut; in decomposed diabase and basalt, 18.03 to $65.56 \mathrm{per}$ cent; in diorite, 37.31 per cent; in pyroxenite, 43.58 per cent, and in argyllite, 57.57 per cent. The average of these numbers is 48.14 per cent. It should also be remembered that these are underestimates, because they are based upon the

a Merrill, George P., Rocks, rock-weathering, and soils, Macmillan Co., New York, 1897, p. 238. 
erroneous supposition that the alumina is not dissolved at all. Since in some of these rocks a part of the silica was present as quartz and the rocks are not completely decomposed, it-is certain that much more than half of the silica of the silicates decomposed in the belt of weathering went into solution and was carried elsewhere by the underground solutions. The number of instances given is large enough to make it probable that they represent approximately the average fact as to the soluble nature of the freed silica in the belt of weathering. It is therefore no inference, but a fact proved by analyses, that the freed and dissolved silica of the bett of weathering furnishes an enormous and adequate supply of this componnd for the induration of the rocks of the belt of cementation, explained on pages $617-640$.

Another notable thing shown by the table on page 515 is the small range in solubility of the various elements. With some exceptions the usual range for all the important elements except iron is not greater than a ratio of 1 to 2 . But in the case of iron the amount dissolved varies greatly and irregularly. Disregarding the wider variations and considering only the thoroughly decomposed rocks in which the variations in the amounts of the other elements are not great, the amount of iron dissolved varies from 14.35 to 88.84 per cent, a ratio of more than 1 to 6 . Doubtless this great variability in the amount of iron dissolved is dependent upon the fact that the iron occurs in both the ferrous and the ferric forms. The former is much more readily soluble. When the iron is mainly ferrous one would expect that a large proportion would be dissolved; where ferric, a small proportion.

In conchusion it may be said that, in order to comprehend the amounts of the losses of the various elements in the bett of weathering, it is necessary that the amount of loss of the supposed fixed substances should be known, and the methods of calculation used, although a line of attack giving approximate results fails to convey a correct impression. Doubtless in many cases the supposed fixed element is reduced to one-half or even to one-third of the original amount. If this be true, it is evident that the percentages of losses given fall far below the facts. It is, of course, impossible that more than 100 per cent of any constituent shall be lost; but from this it does not follow that the rolume of the residual material may not be an exceedingly small fraction of the original material. For instance, if in a given rock the losses of all the various elements were exactly proportional, the conclusion from the analyses would be that there had been no loss, and yet 0.90 or 0.99 
of the constituent might have been alstracted, and thius the amount of residual material left be but 10 per cent or 1 per cent of the original amount. Doubtless even the latter shrinkage sometimes occurs in the case of the limestones. It is therefore manifest that all that the foregoing tables show is that the losses calculated for the elements are at least as great as given, and in many cases they are in all probability much greater. Probably more accurate calculations than have been made are possible by taking as the constant constituents the very difficultly decomposable accessory minerals. For instance, where zircon is present and is uniformly distributed through the rock the assumption that this mineral is constant would undoubtedly lead to closer approximation to trutl than has been obtained on the hypothesis that the iron or aluminum, or both, are constant.

But in order fully to solve the problem of the amount of losses of the varions elements, in addition to the facts given in the tables, we need to know the original mass of the material as compared with the resultant mass. If we could combine these data we could give a quantitative estimate of the loss of each of the elements due to solution in the belt of weathering. But as long as one of the two necessary factors of the problem is not ascertained, we know only that the losses of material are much greater than any method of calculation yet made would lead us to believe.

ORDER OF DECOMPOSITION OF THE MINERALS, AND THE END PRODUCTS.

From the relative amounts of losses of the various elements, as given on page 515, one may infer the relative rate of decomposition of the minerals. The alkalies sodium and potassium commonly occur together; the same is true for the alkaline earths calcium and magnesimm; but neither of these rules is invariable. One would expect the heavily alkaline minerals to be decomposed most rapidly; next in order the alkaline earth minerals; next in order the ferromagnesian minerals; and lastly and least rapidly the heavily aluminous minerals. Of course this statement is only of the most general kind, since most of the abundant minerals may have as bases more than one of these groups. But in proportion as the alkali end of the series dominates, the minerals are soluble; in proportion as the aluminous end of the series is dominant, they are insoluble.

We thus have the explanation of the order of decomposability of the silicates. Among the common anhydrons minerals, nephelite-leucite minerals are the most readily decomposed Second in order of decomposability 
are the olivines and similar minerals. The third group is the pyroxenes and amphiboles. Fourth is the biotite-muscovite group. The fifth and most difficultly decomposable important group is the feldspars. Still more difficultly decomposable are some of the subordinate silicates. Of these garnet, staurolite, tom'maline, andalusite, fibrolite, cyanite, and zircon are probably the more inportant. The decomposition of these minerals is a relatively slow process. The order given is that of relative decomposability. Gamet alters somewhat readily; zircon very slowly indeed.

While the above statements hold in a general way, besides the constituent elements, another very important factor enters into the rate of decomposition, viz, the acidity of the mineral. Thus the feldspars vary from orthosilicates to trisilicates. On this account the orthosilicate anorthite decomposes more readily than the trisilicates albite and orthoclase, notwithstanding the fact that alkalies are absent in the first and abundant in the second. For the same reason some of the basic feldispar's decompose under some circumstances more readily than certain of the more acid pyroxene-amphibole and biotite-muscovite groups

The more abundant relatively insoluble products of the first stage of the alteration of the anhydrous silicates may be classified into bydrous silicates and oxides. The hydrous silicates comprise (1) the kaolin group, (2) the serpentine-talc group. (3) the chlorite group, (4) the hydro-mica group, (5) the zeolite group, and (6) the epidote group. The oxides include (1) the gibbsite-cormudum group, (2) the quartz group, and (3) the ferric iron group.

Under long-continued farorable conditions of the belt of weathering many of these hydrous silicates, which forn in the belt of weathering or which migrate into the belt of weathering from the belt of cementation, are further modified and changed to simpler compounds. The hydrous silicates thus further altered comprise serpentines, chlorites, zeolites, and epirlotes. These silicates, it may be noted, are minerals rer'y characteristic of the belt of cementation. The serpentine alters into magnesite, quartz, iron oxide, and other componnds. The chlorite passes into gibbsite, magnesite, iron oxide, and quartz. The epidote passes into gibbsite and quartz. It is probable that the zeolites pass into kaolin, gibbsite, carbonates, and quartz. Of course, under the conditions of the belt of weathering, the carbonates, including most of the magnesite, are dissolved and removed. 
Of the oxides in the original rocks, quartz is that of dominant importance; but hematite and magnetite are of consequence. Quartz is only slowly dissolved. Hematite may become slowly hydrated. Magnetite may be oxidized and hydrated. All of the iron oxides are very slowly soluble.

It therefore appears that the important end products in the belt of weathering, whether the original compounds are silicates, hydrous or anhydrous, or are oxides, are inclurled in the following groups: (1) Kaolin group, (2) tale group, (3) gibbsite-cormudum group, (4) quartz group, (5) ferric iron group, hydrous or anhydrous. These are the minerals which have become adapted to their enviromment and may therefore persist indefinitely, so long as the conditions remain those of the belt of weathering. The elements which constitute this group are but six in number. In order of probable abundance they are as follows: Oxygen, silicon, aluminum, iron, magnesium, hydrogen.

A sixth unimportant group is formed by the very difficultly decomposable minerals already mentioned-stamrolite, tommaline, andalusite, cyanite, fibrolite, and zircon, and to these should probably be added the additional rare difficultly decomposable minerals, such as diamond, casiterite, gold, silver, xenotime, monazite, ete.

The quartz is largely that which was originally present in the rocks as quartz. Watson notes this fact for the granitic rocks of Georgia. While the total loss of silica in the rocks varies from 10 to nearly 80 per cent, the residual products contain quartz granules similar to those in the original rocks, with little or no evidence of corrosion. ${ }^{a}$ The loss is due to the decomposition of the silicates and the abstraction of the greater part of the liberated silica, as explained on pages 516-517. For the most part the other important minerals of the end series are secondary.

The foregoing minerals, by the processes of decomposition and solution, are concentrated in the belt of weathering in varions proportions. Under one set of conditions one group of them may be dominant and others entirely subordinate. Ordinarily, for instance, the rare difficultly decomposable minerals mentioned are not noticeable, but if the original rocks contain an unusual anount of them they may become rather important. In some cases a single one of these minerals may become important or dominant. An excellent illustration of such a case is that of Iron Mountain,

a Watson, Thos. I., Weathering of granitic rocks of Georgia: Bull. Geol. Soc. America, vol. 12, 1901, p. 99. 
Missouri. Here the country rock is quartz-porphyry, in which are veins of iron oxide. The quartz-porphyry was disintegrated, decomposed, and largely removed, while the iron oxide was concentrated on the surface of the mound, producing a residual mass composed largely of nodules and bowlders of ferric oxide in a matrix of residual clay.

Where the conditions for solution and removal of the soluble material are not favorable, in addition to the end products above given there may be found important amounts of many other relatively soluble minerals. This condition of affairs, as explained on pages 497-498, frequently occurs in arid and semiarid regions, where in the residual soils are found considerable quantities of carbonates, sulphates, chlorides, and nitrates of the alkalies and alkaline eartlis.

These ultimate products of weathering are found to the exchusion of other compounds only where the process is complete, and this is very exceptional. Even under very favorable conditions of weathering the limit of disintegration is never attained and decomposition is nsually far from complete. The end products of weathering are found as preponderant constituents only in the soils and subsoils in humid warm regions, which are permeated by plants; and even in these soils it is rare indeed to find all the constituents fully changed to the ultimate products above given. In proportion as the process of weathering is incomplete, other minerals and compounds are present; and it has already been seen that all kinds of rocks may exist in all stages of disintegration and decomposition. Hence the chemical composition of the rocks of the belt of weathering may vary most widely. Ordinarily the undecomposed or partly decomposed materials are prominent-or even predominant. The undecomposed minerals are likely to be present in the order of their refractoriness. Therefore, the end compounds above given adapted to the belt of weathering may vary from a rery subordinate quantity to an amount which vastly preponderates over all other constituents. While this is true, it is perfectly clear that the sum total of the processes of weathering tends toward mineralogical and chemical simplicity. The end products of weathering comprise but a few of the mirieral species, and these species are simple compounds of a few elements. ${ }^{a}$ Hence the propriety of the assignment of this belt to a zone of katamorphism.

a Merrill, George P., Rocks, rock-weathering, and soils, Macmillan Co., New York, N. Y., 1897. pp. 265-266. 
TOTAL GAINS AND LOSSES IN WEATHERING, AND CHANGES IN VOLUME.

The processes of oxidation, carbonation, and hydration involve great additions of material and expansion in volume, provided all of the compounds formed remain. Of these expansions in volume, that due to hydration is the greatest. The added material is of course oxygen, carbon dioxide, and water. The increases in volume due to the processes of oxidation, carbonation, and hydration and their varions combinations have been worked out for each of the minerals (see Chapter $V$ ), and the results are bronght together in Table D on pages 395-408. It is seen there that the expansion of volume with most of the silicates dne to these processes and their combinations usually varies from about 20 to 60 per cent, but in some cases is 80 per cent or more.

However, the processes of oxidation, carbonation, and hydration are accompanied by solution of great quantities of materials, and consequently the amount and the volume of the residual solid compounds are usually far less than those of the original componnd becanse of the abstraction of a large proportion of the majority of the elements originally present and their transfer" to the surface water's or to the belt of cementation.

As already fully noted, the calculations as to losses of elements thus far made liave been upon the supposition in a given, case that one element is constant; but in most cases, as already explained, it is highly probable that a considerable portion of these elements also has been dissolved.

On this hypothesis Merrill has brought together a number of computations upon the total losses of various rocks at different stages of weathering. The calculated losses vary from 13.47 to 97.635 per cent. Supposing the iron constant, disintegrated and partly decomposed granite from the District of Columbia has lost 13.47 per cent; supposing the aluminum constant, a disintegrated and partly decomposed diabase from Medford, Mass., has lost 14.93 per cent; a diorite from Albemarle County, Va, 37.51 per cent; an argillite from Harford County, Md., 40.83 per cent; a diabase from Spanish Guiana, Venezuela, 39.51 per cent; a basalt from Kammer Bull, Bohemia, 43.96 per cent; an altered pyroxenite, now soapstone, from Harford County, Md., 52.46 per cent; a syenite from Arkansas, 55.28 per cent; a basalt from Crouzet, France, 60.12 per cent; an altered pyroxenite, 
now soapstone, from Fairfax County, Ta., 77.95 per cent; and supposing the silica constant, a Carboniferous limestone from Arkansas has lost 97.635 per cent.

Watson ${ }^{\text {a }}$ has calculated the losses of various disintegrated and decomposed granites from Georgia, inclnding granite, porphyritic granite, and granite-gneiss, and has found that the loss for the entire rock varies in different cases from 7.68 to 71.82 per cent $^{b}$ The losses are in all cases higher on the assumption that the $\mathrm{Fe}_{2} \mathrm{O}_{3}$ is constant than on the assumption that the $\mathrm{Al}_{3}$ is constant."

So far as I am aware, computations have not been made as to the addition of the constitnents oxygen, carbon dioxide, and water in the processes of weathering. Until this is done it is impossible to make approximately accurate quantitative statements as to the total anounts of original material and weathered material. It is still less practicable to make quantitative statements as to the relative volumes of the original and altered materials, since in this matter are involved not only the additions and subtractions of materials, but the specific gravities of the original and secondary materials and their states of aggregation. Undoubtedly the specific gravities of the resulting minerals are less, on the average, than the specific gravities of the original minerals. Also, the state of aggregation is in almost all cases less compact. Therefore, for a given amount of material the rolume of the weathered products is greater than that of the original material. But notwithstanding the addition of material. the lessened specific gravity, and the looser state of aggregation, the losses of the original elements are so great, where decomposition has gone far, that there is no question that the rolume of the resultant material is often diminished.

Among the cases of diminished volume, that of the formation of residual clay from limestone undoubtedly represents the maximum. The dominant constitnent of the rock, calcium carbonate, has been almost wholly dissolved and removed. The few feet of residual material at the surface of limestones represents the alteration products of the noncalcareous

$a$ Watson, Thos. L., Weathering of granitic rocks of Georgia: Bull. Geol. Soc. America, vol. 12, 1901, pp. 93-108.

$b$ Watson, cit., p. 101.

$c$ Watson, cit., pp. 106-108. 
impurities. Whitney estimated that to make 1 meter of residual clay in Wisconsin requires 35 to 40 meters of limestone and shale. ${ }^{a}$ This involves a diminution of volume of more than 95 per cent. The shrinkage of limestone is scarcely less strikingly shown by underground solution, as a result of which the surface becomes uneven and pitted and frequently honeycombed by caves. The process may go so far as to result in the irregular sinking of the surface. This condition is especially well illustrated by the limestone of Kentucky and by the honeycombed limestones of Lake Huron, described by Bell. ${ }^{b}$

In line with the above is the explanation by Rutley of the slight thickness and lenticular character of many beds of Paleozoic limestone. ${ }^{\circ} \quad \mathrm{He}$ holds that the underground waters have dissolved much the greater portion of the limestones, and that these slight layers or lenses are but remnants of the original formations.

From this maximum diminution of volume represented by limestone there are of course all gradations to no diminution, and doubtless in some cases there is actnal expansion of volume. If expansion of volume occurs it would be likely to be in rocks where the minerals are mainly silicates. From the figures given by Merrill and by Watson, it appears that the losses of the original elements in acid, intermediate, and basic igneous rocks vary from 14 to nearly 80 per cent. These losses, as already pointed ont, would be partly compensated for by the addition of oxygen and water. Moreover, on account of the lower specific gravity of the secondary minerals and the looser state of aggregation, there would be considerable expansion of volume. Hence it appears probable that the decrease in volume in the case of the weathering of these igneous rocks commonly does not exceed 50 per cent, and from this the decrease may run down to zero, or even expansion of volume may take place, especially in early stages of alteration.

EMPHASIS AND RETENTION OF STRUCTURES AND TEXTURES.

The first effect of weathering upon structures and textures is to emphasize them so that they may be readily seen. Structures which may not be visible in fresh rocks may be strongly marked upon the weathered

a Hall, James, and Whituey, J. D., Geology of Wisconsin, vol. 1, 1862, pp. 121-125.

${ }^{b}$ Bell, Robert, Honeycomber limestones in Lake Huron: Bull. Geol. Soc. America, vol. 6, 1895, pp. 297-304.

c Rutley, F., The dwindling and disappearance of limestones: Quart. Jour. Geol. Sor., August, 1893, pp. 380-381. 
surfaces. Textures which the eye can not diseover become elearly apparent. Any variation in the hardness or solubility of the rock is shown by a ridgy structure. As a consequence, every variation in original and secondary structures and textures may be shown on a weathered surface. So nice is weathering in its selective power in disintegration and solution, that when the different unaltered rocks can not be discriminated the weathered forms are easily separable.

Some cases will be mentioned illustrating the above general statements. Frequently the rocks which when muweathered appear to be massive, in the belt of weathering develop a strongly marked cleavage or fissility-cleavage in the lower part of the belt of weathering and fissility in the upper part. This effect is so marked that often it is difficult to believe that the weathered and unweathered portions of the rock belong to the same formation. The unaltered rock may be so massive that it has only a rift which ean scarcely be called cleavage. The weathered portion may be split up into leaf-like layers, scores of them within the breadth of an inch, so that the rock at once would be called a schist, while one would not think of applying the term schist to the massive phases.

In comection witl the emphasis of schistosity, micaceous minerals are likely to become very conspicuous. In the weathered portion of some rocks it seens as if the mica is one of the most abundant of the ninerals, while in the unweathered portion it is scarcely noticeable. Excellent illustrations of this are found in various places on the Piedmont Plateau. Perhaps one of the best is at Washington, D. C. Here the unveathered rock at various places is a very massive appearing, slightly cleavable granite or a somewhat dense schist, whereas the partly weathered portions are fissile mica-schists.

Where mechanical forces have not displaced the particles with reference to one another, a rock may be completely weathered in the sense that none of the original minerals remain, and yet perfectly retain the original struetures and textures. This is beautifully illustrated by the decomposed diabase dikes in the Penokee distriet, which still perfectly retain the textures of diabases, and yet in composition some of them approach very closely to kaolin. Every original mineral has been completely altered. Other similar instances described by Merrill ${ }^{a}$ are the decomposed gneisses and

a Merrill, George P., Rocks, rock-weathering and soils, Macmillan Co., New York, 1897, p. $26 t$. 
schists of the Piedmont Plateau which, where so soft as to be readily removed with the pick and shovel, still show all their textures and structures. Russell describes the Triassic conglomerate near Wadesboro, N. C., as showing every detail of the original rock, and yet it is so "completely decomposed that when moist it can be cut with a pocketknife through pebbles and matrix alike, as easily as so much potter's clay." ${ }^{a}$ Potter describes the feldspar-porphyry of Iron Mountain as "so soft that it can easily be whittled away with the penknife or scratched with the finger nail; at the same time the original porphyritic structure of individual crystals scattered through the mass is beautifully preserved, and is even frequently more distinctly visible than in the original rock, owing to stronger contrasts of color in the kaolinized material." ${ }^{\circ}$ The so-called tallow rock of the lead and zinc district of sonthwestern Missouri shows all the textures and structures of the original chert, yet is easily pared like tallow with the penknife.

\section{OBLITERATION OF STRUCTURES AND TEXTURES.}

In proportion as the mechanical forces are important in connection with decomposition the original structures and textures are apt to be destroyed because of the differential movement of the particles. Structures and textures are likely to be long preserved in cases of decomposition alone," but are destroyed by decomposition and disintegration combined, since these act together at and very near the surface.

The final stage in the process of weathering is the destruction of all textures and structures and the production of soils and subsoils. Near the surface, after the various minerals are broken apart they are mixed with one another indiscriminately by the mechanical forces of freezing and thawing and by the work of plants and animals (see pp. 440-451), and they are decomposed by the chemical forces. Finally no definite structures and textures remain. The character of the surface soil is modified by its organic content. It may contain from a small percentage of organic material to a predominant amount of that material, as in the case of the peat

a Russell, I. C., Subaerial decay of rocks, and origin of the red color of certain formations: Bull. U. s. Geol. Survey No. 52, 1889, p. 16.

$b$ Potter, W. B., The iron-ore regions of Missouri: Jour. United States Assoc. Charcoal Iron Workers, vol. 6,1885, p. 25.

c Jerrill, George P., Rocks, rock-weathering, arid soils, Marmillan Co., New York, 1897, pp. 264-265. 
deposits. There is every gradation from the fresh rocks deep below the surface, which do not well exhibit their structures and textures, through those in which structures and textures are brouglit out with great clearness by the process of weathering, to completely disintegrated and partly decomposed rocks constituting the soils, in which no structures and textures remain. The gradations of the process may be very well seen at many localities where there are sufficiently deep cuts on the Piedmont Plateau of the United States.

\section{SURFACES OF WEATHERING.}

Weathering is only one of the complex processes which have an influence upon the surface features of the land. Transportation and erosion are quite as important in this respect as weathering, or even more important. But certain features of the surface are largely due to difference in the rate of weathering. Wherever the rocks are heterogeneons they differ in their power to resist weathering. The more resistant rocks commonly constitute the elevations, and the less resistant rocks the minor features. This is true of both the major and the minor features. Illustrations of this principle of varions kinds will be mentioned. One of the most common illustrations are elevations or ridges formed by dikes, which are often more resistant than the surrounding rocks. In other cases dikes are less resistant than the intruded rocks, and where the dikes once were may be found deep, narrow-walled depressions or chasms, which may be necupied by streams or, if along the shore, by the water of the ocean or lake. Basic dikes in the resistant gneisses furnish frequent instances of this. Beautiful illustrations are seen on the coast of New England, especially Maine. ${ }^{a}$

Another interesting case of an irregular surface due to weathering is produced by bowlders of disintegration. The process of rock decay follows along the planes of weakness, and especially along fractures, such as joints. When a rock is cut by varions sets of intersecting joints the process of weathering goes on more rapidly at the corners of the rectangular blocks than on the sides, thus producing round masses which

a Lord, E. C. E., On the dikes in the vicinity of Portland, Me.: Am. Geologist, vol. 22, 1898, p. 338. Bascom, F., On some dikes in the vicinity of Johns Bay, Maine: Am. Geologist, vol. 23, 1899, pp. 275-280. 
frequently simulate to a remarkable degree bowlders produced by water or ice erosion. "

On the Piedmont Plateau, at nany places where there are good sections exposed, as in railroad cuts, one may see hundreds of these roundish bowlder-like masses in the midst of soft disintegrated material. Erosion carries away the soft material faster than the bowlder-like masses. The latter therefore accumulate at the surface, and finally produce a surface which presents the appearance of a "Felsenmeer." Such a surface has strewn over it innumerable bowlder-like masses, small and large, from those less than a foot to those many feet in diameter. Some of the largest masses are dome-like and of such magnitude that the name "mountain" has been applied to them; for instance, Dumn Mountain, in North Carolina. These masses, small and great, are at the surface simply as a consequence of fracturing, differential weathering, and differential erosion.

Bowlders of disintegration and mountains of disintegration have been described by Bramner ${ }^{b}$ as also occurring on a most extensive scale in Brazil. They are beautifully illustrated by the granitic mountains of southern California and other arid regions of the United States.

'The innumerable bowlder's in the till of the glacial deposits of America and Europe are believed by some to be largely bowlders of disintegration which were produced before the advance of the ice sheets. This explanation premises that before the time of the continental ice sheet the glaciated regions were weathered in a manner somewhat similar to that of the Piedmont Plateau.

In minor details the nature of the minerals present controls the character of the surface. In general, any surface long exposed to weathering is roughened, owing to difference in the solubility of the minerals, or to imperfect cementation, or to these and other causes combined. The minerals which protrude are usually those which are relatively insoluble. The order of solubility, and therefore of disappearance, is that given on pages 518-521. Very numerous illustrations might be giren of the roughening of the surface of rocks as a result of the variable rate of solution of the constituents. One of the best illustrations is furnished by the nepheline

"Becker, G. F., Geology of the quicksilver deposits of the Pacific slope: Mon. U. S. Geol. Survey, vol. 13, 1888, pp. 68-72.

$b$ Branner, J. C., Decomposition of rocks in Brazil: Bull. Geol. Soc. America, vol. 7, 1896, pp. $269-280$. 
syenites. The nopheline-syenite of the Wausan district of central Wisconsin has a peculiar, deeply pitted appearance, due to the complete solution of the nephelites at the surface.

A further case of irregular surface is furnished by the cherty limestones; the calcite is dissolved more rapidly than the quartz, and thus the weathered surface presents a series of ridges and hollows, giving a very rough, ridgy surface.

\section{DEPTH AND DEGREE OF WEATHERING.}

The belt of weathoring has already been defined as extending from the surface to the level of ground water, and locally to some distance below the level of ground water. (See pp. 409-411.) Furthermore, it has been seen that the level of ground water varies from 0 to more than 300 meters below the surface.

Whatever the thickness of the belt of weathering, the conditions throughout this belt are favorable for oxidation, carbonation, hydration, and solution, and therefore for the chemical reactions of decomposition. But the conditions are far more favorable for decomposition at the surface than at the lower part of the belt of weathering. Disintegration is much more limited in extent. It is at a maximum at the surface, but decreases rapidly with depth, and at $\mathbf{1 0}$ meters below the surface is scarcely appreciable. While it is clear that reactions of weathering extend throughout the belt as defined, it is equally certain that the processes are at their maximum efficiency at or near the surface, and decrease in efficiency as depth increases. But in some cases the processes are very important to the bottom of the belt, êven where of very considerable thickness. This is illustrated by limestone regions, in which minor openings or even extensive caves may form abundantly quite to the level of ground water, although this may be 100 or 200 or more meters below the surface.

As to degree or stage of weathering, rocks are ordinarily spoken of as "weathered" where they are very appreciably affected by the peculiar weathering processes. As already explained, there are all gradations, from no weathering to complete weathering. Both extremes are very rare, although it is common for geologists to speak of "complete weathering" without telling what they mean thereby. In regions where the conditions for weathering" MOX XLVII-0 $0 t-3 t$ 
are favorable and the forces and agents of weathering lave been long at work, greater or less thicknesses of material in varions stages of weathering lave accumulated.

Some of the regions will be mentioned in which the weathering pro cesses are far advanced. Perhaps one of the most striking illustrations of advanced weathering is furnished by various limestone regions. The destruction of limestones located in the belt of weathering occurs both at the surface and below the surface. Below the surface the process is mainly that of solution, and in many regions the same statement applies to the surface reactions. Solution below the surface is the chief canse of the porous, cellular, and cavernous character of limestone formations above the level of ground water. As a result of solution at the surface, residual clays are formed. Residnal clays in limestone regions vary in thickness from a few centimeters to 7 meters or more. Chamberlin and Salisbury give the average thickness of the residual clay of the driftless area of the upper Mississippi Valley as more than 2 meters. ${ }^{a}$ Whitney estimates the thickness of the clay in this same area as 3 meters ${ }^{b}$ This he believed to correspond to an original thickness of from 105 to 120 meters of limestone and shale.

In regions of noncalcareous rocks arlvanced decomposition may extend to the depth of a score or more of meters. The comparatively late coast ranges of California at many places are much weathered. The weathering affects all the rocks, but to a different depth. The Montara granite in many places is disintegrated to a depth of 6 to 10 meters. The complete disintegration and advanced decomposition of the rocks of the Piednont Platean, from Pemsyivania to Georgia, is well known to have extended from a depth of 2 or 3 meters to nearly 30 meters. In Georgia, according to Spencer, ${ }^{\circ}$ decomposition has gone on to some extent at a depth of 60 meters. Herrill says that in many places the Sierra Nevada gramodiorites are disintegrated and partly decomposed to a depth of 60 meters. $^{d}$ Belt states that the igneons rocks of Nicaragna are decomposed

aChamberlin, T. C., and Salisbury, R. D., Driftless area of the upper Mississippi Valley: Sixth Ann. Rept. U. S. Geol. Survey, 1885, p. 254.

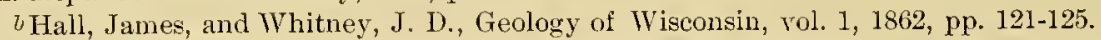

oSpencer, J. W., The Paleozoic group of norlhwestern Georgia: Geol. Survey Georgia, 1893, pp. $22-24$.

d Merrill, George P., Rocks, rock-weathering, and soils, Macmillan Co., New York, 1897, p. 274. See also Merrill on extent of weathering, pp. 276-278. 
to a depth of 60 meters. ${ }^{a}$ The Transval granites, according to Furlonge, ${ }^{b}$ are decomposed to a depth of 60 meters.

From maximum amounts of weathered material illustrated by the above regions there are all gradations to amounts almost inappreciable. Excellent illustrations of such regions are the areas of the Northern Hemisphere over which the latest ice incursion has taken place. Glaciated quartzites may retain the glacial striations with marvelous delicacy, microscopic strice being perfectly preserved. Such igneous rocks as the granites, gabbros, and peridotites, and other families usmally show only a mere skin of appreciably decomposed material, ordinarily but a fraction of an inch in thickness. 'The readily soluble limestones usually present planed, grooved, and striated surfaces which show comparatively little evidence of modification. The minimum weathering effects are fonnd on the solid rocks which have a thin veneer of drift or soil. Where this reneer is thick enough to bury the rock surface below the frost line, the only weathering effects ordinarily produced are slight stains of decomposition on the surface and along the joints and other fractures. Where the topographic forms are more rugged, so that the rocks are more exposed to weathering, there has been pronounced disintegration, and the decomposition has also gone farther. While the latest drift shows much more evidence of weathering than the solid rocks, below the soil the weathering effect's are surprisingly slight. The pebbles and bowlders commonly show planing, grooving, and strix, and scarcely any evidence of decomposition. The marvelous freshness of this drift, which has been exposed to the weathering forces under favorable circumstances for thousands of years, perhaps tens of thousands of years, is to me the best evidence of the slowness of the complex process of weathering.

A comparison of the small amount of weathering in the glaciated regions with the great amount in some other regions gives one an idea of the vast amount of time required for deep and advanced weathering. Even if the most conservative estimate as to the length of time since the last ice invasion were used as a measure of the rate of weathering, it would follow that to have accomplished such weathering results as are exhibited

"Belt, Thomas, The naturalist in Nicaragua, p. 86 .

$b$ Furlonge, W. H., Notes on the geology of the Dekaap gold fields in the Transvaal: Trans. Am. Inst. Min. Eng., vol. 18, 1890, p. 337. 
in the southern Appalachians, Nicaragua, and Brazil must have taken several or many hundreds of thousands of years. The process of decomposition was of conrse more rapid in these regions than in the colder northern regions, but even allowing for this the time required for the work accomplished must have been great.

\section{RATE OF WEATHERING.}

The rate of weathering depends upon all the factors that have heretofore been given. These factors may be classified under the forces and agents at work in weathering, the materials weathered, the thickness of the belt of weathering, and the stage of weathering.

\section{FORCES AND AGENTS AT WORK IN WEATHERING.}

The rate of weathering is rapid in proportion as the temperature is high; the humidity is great; erosion by wind, water, and ice is active; and plants and animals are abundant. All these statements lave been so fully developed on previous pages that they will not be further amplified here.

MATERIALS WEATHERED.

The rate of weathering as dependent upon the material involves a consideration of the chemical composition of the rocks, the mineral composition, and the closeness of aggregation.

CHEMICAL COMPOSITION.

In general the more basic a rock the more rapid the rate of weathering, and the more acid a rock the less rapid the rate of weathering. As to individual elements, the following statements may be made: The richer a rock is in alkalies the more rapid is the rate of weathering. With a given quantity of alkalies, the greater the proportion of sodium the more rapid the alteration, and the greater the amount of potassium the less rapid the alteration. The greater the amount of alkaline earths the more rapid is the alteration. With a given quantity of alkaline earths, the greater the proportion of ealcinm the nore rapid the alteration, and thie greater the proportion of magnesium the less rapid the alteration. The greater the amount of iron the more rapid is the alteration. The greater the amount of alumina the less rapid is the alteration. Where the iron and ahnminum 
mutually replace each other, the greater the proportion of alnminum the more rapid the alteration. The greater the amount of silica the less rapid is the alteration.

MINERAL COMPOSITION.

The readiness of the alteration of minerals is largely a direct consequence of the character and the chemical composition. With a given chemical composition, the greater the proportion of glass the more rapid the alteration, and the greater the proportion of crystallized minerals the slower the alteration. Among the crystallized minerals, the greater the proportion of the easily decomposed minerals the more rapid the alteration.

The order of decomposition of the common anhydrous minerals from the easiest to the hardest, as given on pages 518-521, is (1) nephelites and leucites, (2) olivines, (3) pyroxenes and amphiboles, (4) biotite-muscovite group, (5) feldspars, (6) ganrnets, staurolite, tourmaline, andalusite, cyanite, and (7) hematite, magnetite, and quartz.

STATE OF AGGREGATION.

Fine-grained rocks weather less rapidly than coarse-grained ones. This is a consequence of the closer interlocking of the mineral particles of the fine-grained rocks, and of the fact that the differential expansion and contraction by change of temperature is less with fine particles than with coarse particles. The more open the aggregation the more rapid the alteration; the closer the aggregation the less rapid the alteration. This follows from the fact that openings give ready access to the agents of alteration, and the border of every opening is a place of attack for the chemical agents, and therefore all classes of openings promote decomposition. The openings in rocks are divided into pore spaces between the mineral particles, sheet openings, and irregular openings (see p. 129). Pore spaces are generally in the mechanical sediments, the lavas, and the tuffs; therefore mechanical sediments, lavas, and tuffs alter much more rapidly than the plntonic igneous rocks and the compact metamorphic rocks. Sheet openings are of varions kinds, such as faults, joints, bedding partings, and fissility. All these openings serve as channels through which the waters may readily pass and extend the decomposing effect. In general, along a fault or a joint, decomposition extends more rapidly downward than in the adjacent solid rock. Where 
the openings are fine and close, as in the case of fissility, the process extends downward uniformly and much more rapidly than where this structure is absent.

As examples of very fine- and close-grained rocks which weather less rapidly than other rocks of similar chemical and mineral composition may be mentioned the Berlin rhyolite-gneiss and the Niagara limestone of Wisconsin. The former has a maximum crushing strength of $3,304 \mathrm{~kg}$. per sq. cm. and the latter a crnshing strength of $2,812 \mathrm{~kg}$. per sq. cm. ${ }^{a}$ These are probably the highest errushing strengths yet recorded for such rocks. While altogether unlike in composition and origin, they are alike in their remarkable uniformity, fineness, and eloseness of grain. Many of the marbles are not more porous than the limestone mentioned, but the mineral particles are much larger, and in this difference probably lies the explanation of the very unusual strength and slow weathering of this limestone.

From the above there follows the conclusion that in proportion as the aggregation is coarse and open the rate of weathering is rapid; in proportion as it is fine and close the rate of weathering is slow. These general statements need modification with reference to disintegration through freezing and thawing (see pp. 441-442).

\section{THICKNESS OF THE BELT OF WEATHERING.}

Since the entire belt of weathering is affected by the reactions characteristic of that belt, the greater the thickness of the belt the more effective the process of weathering. It has already been explained that, other things being equal, the level of ground water is likely to be a considerable depth below the surface in proportion as the elevation is great. It therefore follows that the rate of weathering is greater in elevated than in low regions. This is partly a direct consequence of the fact that the weathering agencies have a greater volume of material upon which to work. But probably eren more important than this is the rapid removal of weathered material in elevated regions. Material disintegrated and partly decomposed by the weather is removed by erosion as rapidly as formed, and therefore continuously exposes new surfaces to the agencies of weathering.

a Buckley, E. R., Building and ornamental stones of Wisconsin: Bull. Wisconsin Geol. and Nat. Hist. Survey No. 4, 1898, pp. 360-363. 
While the above is true, if one were to confine his attention entirely to the decomposing effect of the weather and exchude disintegration, it is probable that there is a limit beyond which increase in elevation decreases the lecomposing effect. As explained on pages 499-500, 502-503, great elevation gives conditions unfavorable for the existence of life, and life is one of the necessary agents in rapid decomposition.

While the reactions of weathering are taking place throughout the entire belt above the level of ground water, the process is at its maximum efficiency near the surface and rapidly decreases in efficiency with depth. This is largely due to the fact that life is confined to the upper few meters and therefore the decomposing effects of life rapidly diminish with depth.

It is a corollary from the relation of the thickness of the belt of weathering and the rate of the process that geological periods in which there are extensive land areas at a ligh elevation above the sea are periods in which the processes of weathering are most rapid. These processes are essential to the rapid formation of all classes of sediments, including the limestones. The relations between weathering and sedimentation are discussed on pages 555-560.

\section{STAGE OF WEATHERING.}

Where the rocks in the belt of weathering are fresh, and therefore have not been adapted to their environment, the processes of weathering are active. And, per contra, where the processes of weathering have transformed the rocks to minerals adapted to the belt of weathering the processes are slow. For instance, the conditions are favorable for rapid weathering in glaciated regions where all the weathered products have been recently removed, and where, therefore, the rocks and minerals are not adapted to the belt in which they are found. In such areas as the Piedmont Platean, on the contrary, where in some places the minerals have been very largely transformed to those characteristic of the belt of weathering, and are therefore permanent under the conditions of that belt, the processes of weathering are very slow.

Probably where weathering is in an early but not the earliest stage the processes are at their maximum activity. Where by changes of physical conditions rocks have been brought into the belts of weathering, at first the conditions are very unfarorable for the existence of life, and the great rôle 
which life plays in weathering has already been pointed out. But when the processes of weathering have gone so far that a good soil has formed and abundant life has taken possession of the little weathered rocks, the conditions for weathering, including disintegration and decomposition, are probably most favorable.

\section{DISTRIBUTION OF DISSOLVED MATERIALS.}

We have seen that all the elements of the rocks are dissolved, but with exceedingly variable rates, and that in consequence of this there is a concentration in the belt of weathering of a fer minerals and fewer elements. Where only the end products of weathering are present the important elements there concentrated are but six in number-oxygen, silicon, aluminum, iron, magnesium, and hydrogen. Before taking up the question of what becomes of the dissolved materials, it is advisable to recall the elements dissolved, their relative rates of solubility, and the fact that under ordinary conditions of weathering and erosion but a portion of any of the elements in the belt of weathering are rapidly dissolved.

It has been seen (p. 518) that the common bases are taken into solution in the following order:

(1) The alkalies. Of these the sodium minerals are more readily decomposed than the potassium ones and hence a much greater amount of sodium than potassium is dissolved.

(2) The alkaline earths. Of these the calcium minerals are certainly more readily decomposed than the magnesium minerals, and therefore calcium is taken into solution in much greater quantity than magnesium.

(3) Iron, especially that in the ferrous.form.

(4) Altuminum, which, while dissolved to a less extent than the other bases, is dissolved in large amounts.

It has also been seen (p. 485) that the dominant acids which go into solution are silicic and carbonic. Common subordinate acids in solution are hydrosulphuric, sulphuric, nitric, hydrochloric, and phosphoric. In volcanic districts hydrofluororic and hydrobromic acids are frequently present.

Within the zone of observation by far the greater quantity of the substance is carried as carbonate, and, as is well known, the salts are usually not carried as normal carbonates but as bicarbonates. ${ }^{a}$

"Letts, E. A., and Blake, R. F., The carbonic anhydride of the atmosphere: Sci. Proc. Royal Dublin Soc., new series, vol. 9, pt. 2, 1900, p. 160. 
It must also be recalled that the dissolved silicic acid is in the colloidal state, and in the belt of weathering is an inactive chemical agent, and therefore is not united with the bases in solution. The acids in the solutions in combination with the bases therefore do not include silicic acid. Of the remaining acids carbonic is that of dominant importance.

It is further to be recalled that the amounts of the various bases and acids which may be taken into solution are dependent not only upon their relative strengths, but also upon the amounts present and upon the combinations in which they exist.

We are now prepared to take up the question as to what becomes of the materials dissolved in the belt of weathering. These materials are abstracted by plants, transported to the belt of cementation, permanently abstracted by the run-off, and dissolved, transported, and reprecipitated in the belt of weathering.

\section{MATERIAL ABSTRACTED BY PLANTS.}

Considerable quantities of the soluble constituents produced in the belt of weathering are absiracted by the plants and built into their bodies. Of the bases, the plants take greater quantities of the alkalies than of the alkaline earths. They take only minute amounts of iron and aluminum. The acids abstracted by plants in important amounts are nitric, phosphoric, and silicic. In this connection it should be remembered that under ordinary conditions the amount of alkalies available is less than that of the alkaline earths, and that the amounts of nitrates and phosphates available are far less than the amount of silicic acid. Therefore, even if the amounts of these compounds abstracted by the plants were the same, this would result in the abstraction of a considerable portion of the alkalies and the nitric and phosphoric acids, while the major portion of the alkaline earths, of the iron and aluminum, and of the silicic acid would remain.

The distance of the transfer of material in the belt of weathering by means of plants is limited by the depth to which roots extend. It has been noted (pp. 445-446) that the roots of ordinary grains and grasses extend into the soil 1 or 2 meters, and that the roots of larger plants may extend to a depth of 10 meters. The vertical transfers are therefore to be measured by these distances. The amount of material transferred by plants is a direct function of the iuxuriance of the vegetation. Luxuriant regetation occurs 
where humidity is high, and hence it is in the humid regions that vertical transfers of material through the ageney of plants is greatest in quantity.

It will be remembered that by far the greater portion of the plants either decay or are used by animals, which in turn ultimately decay. At the time of decay the mineral material dissolved by the plants either passes into the rum-off and is transported to the sea or else joins the soil, to be there again redistributed. Probably the latter is the larger portion. Therefore much of the soluble material abstracted by life from the belt of weathering is but temporarily held. The only permanent loss to that belt is the portion which gets into the streams and thence into the sea.

Since the part of the vegetation above ground to a large extent decays at or near the surface, the permanent effect of the vegetation in the transportation of the dissolved material is to bring it from a depth of one to several meters below the surface near or to the surface.

The roots decaying in situ to some extent redistribute the material and transfer it toward the surface, but not to so great a degree as the portion of the plants above the ground with the help of the roots.

\section{MATERIAL TRANSFERRED TO BELT OF CEMENTATION.}

A large amount of material which is dissolved in the belt of weathering is carried downward by the descending waters and joins the subterranean sheet below the level of ground water. It will be shown below and in the following chapter (pp. 612-617) that the material which joins the belt of saturation is again subdivided, a part being precipitated in the belt of cementation and a part joining the surface waters and thus being transporterl to the sea.

\section{MATERIAL PERMANENTLY ABSTRACTED BY RUN-OFF.}

A considerable amount of the soluble material of the belt of weathering joins the run-off. In times of abundant rain water flows over the surface. This water takes up the soluble material with which it comes into contact. The amount dissolved is especially likely to be considerable if abundant rains follow a time of drought, for it will be seen below that in times of deficient rain capillarity brings the soluble salts to the surface where they can be readily abstracted by the run-off. From seepage waters and springs the streams receive large quantities of water from the belt of 
cementation, containing soluble material derived directly or indirectly from the belt of weathering. In so far as the streams empty into lakes with no ontlet the material is not permanently lost to the belt of weathering, but rejoins it, as will be shown below. But the vast majority of streams reacl the ocean and the dissolved material of the rum-off is contributed to the mother water. The material thus contributed is the source of the salts of the sea.

MATERIAL DISSOLVED, TRANSPORTED, AND REPRECIPITATED IN BELT OF WEATHERING.

A portion of the compounds dissolved in the various ways in the belt of weathering is transporterl to other parts of the belt and precipitated. The salts which are reprecipitated depend upon (a) the abundance of the compounds, (b) their relative and changing solubility, and (c) the humidity of the region.

(a) The more abundant a compound is in a solution the more likely is it to be reprecipitated. This law is almost self-evident, for the more material there is in solution the more likely, under the changing conditions which obtain in the belt of weathering, are the solutions to become supersaturated and thus precipitation take place. The supersaturation may result from any of the canses given on pages 113-123. This principle of precipitation of the abundant compounds is one of the utmost importance in metamorphism. It applies not only to the belt of weathering but to all belts and zones, and is correlative with the principle already explained, that the more abundant a substance is the more likely it is to be dissolved. Both are but special cases of the law of mass action. (See p. 94.)

Botlı of these principles are well illustrated by the solution and precipitation of calcium carbonate in the limestone regions, altlough the relative solubilities of the compounds present also enter into the result. Where the dominant material is calcite or dolomite, or any combination of these, these materials preponderate in the underground solutions. Also to an equal degree they preponderate in the precipitates. The extensive solution of limestone has already been considered. (See pp. 485-486). But wherever there is a minute cavity, a cleft, a cave, or an opening of any other kind in limestones in the belt of weathering, there calcite, aragonite, or dolomite, or some combination of these, may be precipitated. The small 
cavities may be lined with crrstals of nearly the composition of the surrounding rock, thus producing geodes; the joint, fault, and irregular openings may be partly or completely filled with carbonates, producing veins; but geodal filling and veins commonly form in the belt of cementation. In the caves the floor is ordinarily covered with stalagmites and from the roof stalactites depend. The precipitation of the carbonate in the openings is commonly caused by the lessened pressure, by the escape of some of the dissolved carbon dioxide, or by evaporation, any one of which or any combination of which may produce a condition of supersaturation and consequent deposition.

Another compound which is very abundantly precipitated in the belt of weathering is silica, as opal, ehert, or quartz. This again is largely a consequence of its abundance, but also is a function of its solubility. (See p. 480.) By the decomposition of the silicates silicic acid, probably largely as colloidal silicic acid, is set free in almost incredible quantities. (See pp. 480, 516-517.) The larger amount of this material probably joins the belt of cementation, and thus is a source of the silicification which is so dominant a process of that zone. (See pp. 622-623.) But by chemical change, which is a factor in its precipitation as well as in its abundance, a very considerable amount is partly or completely dehydrated and thrown down in the belt of weathering as opal or quartz. Like calcite and dolomite, it is deposited in the belt of weathering in geodal cavities, in caves, and in veins, and as siliceons sinter.

(b) The more insoluble a compound is, the more likely is it to form a precipitate in the belt of weathering. This is ahnost self-evident, and only needs cases illustrating the principle. The best illustrations are furnished by the iron and aluminum oxides and their mixtures. It has already been seen that these are the two compounds which are most frequently taken as constant in weathered rocks, and on this hypothesis are used to determine the amount of loss of the other constituents. Much of the iron in the original compounds is in the ferrous form, but under the conditions of the belt of weathering it is oxidized to the ferric form, and much of it simultaneously precipitated. On account of the insolubility of the oxide of iron and oxide of aluminum, as compared with other constituents, a large amount of iron, as hematite, limonite, and other hydrated forms, and of alumina, both hydrous and anhydrons, and of mixtures of iron oxide and aluminum oxide, bauxite, aceumulates at the surface. It is well known 
that iron is abundantly transported as a carbonate, and aluminum as a sulpliate, as in the natural alums. Also, both the alumina and the ferric oxicle may be partly transported to the places of precipitation as aluminates and ferrates. ${ }^{a}$

What proportions of these materials have been dissolved and precipitated and what parts are simply residual undissolved substance is probably not usually determinable, but in many places solution and reprecipitation appear to be the chief cause of the concentration. Not infrequently these concentrates are so rich in iron and alumina as to be ores. This phase of the matter is much more fully developed on pages $842-846$ and pages 983-989.

As much less abundant important insoluble compounds which accumulate under the same principle as iron oxide may be mentioned the manganese oxides, pyrolusite, manganite, etc. The abundant precipitation of quartz in the belt of weathering, as explained on page 540, while largely due to its plentifulness, is also controlled in an important degree by its relative insolubility.

Still another set of compounds which well illustrate the principle are the phosphates. It is well known that the manufactured soluble phosphates used as fertilizers largely "revert" or are transformed to relatively insoluble phosphates, and as such are precipitated in the soil. ${ }^{b}$

(c) To a certain point the less humid a region the more likely are precipitates to form in the belt of weathering. The reason for this is obvious. If the amount of rainfall be so small that it is largely brought to the surface by capillary and other forces, as explained on pages 419-423, and evaporated, the material it holds in solution will be precipitated; but if a region be so arid that there is not sufficient precipitation to dissolve material abundantly, it can not be abundantly precipitated. Indeed, it has been seen (pp. 496-498) that in regions of extreme aridity disintegration is the rule and decomposition takes place only to a small extent. Therefore we conclude that the climatic conditions for abundant precipitation of minerals in the belt of weathering are those of moderate rainfall for a certain period of the year, with aridity for the remainder of the year.

a Cameron, F. K., Application of the theory of solutions to the study of soils: Rept. Div. of Soils, U. S. Dept. Agric., No. 64, 1899, p. 169.

$\checkmark$ Wyatt, Francis, The phosphates of America, Scientific Pub. Co., New York, 1892, pp. $22-26$. 
In the arid regions not only are the relatively insoluble compounds precipitated in the belt of weathering, but the readily soluble compounds may likewise be thrown down, such as the salts of the alkalies and alkaline earths. These elements may be combined with any of the acids which exist in the soils. Thus there may be precipitates of such soluble salts as the alkaline carbonates, and even the alkaline chlorides and nitrates. The more abundant salts precipitated are sodium, potassium, calcium, and magnesium carbonates, sulphates, and chlorides. Nitrates and borates of the bases mentioned are also locally abundant. In any given case the bases and acids unite in such a manner as to produce the most insoluble compounds. Therefore the carbonic acid first unites mainly with the alkaline earths and is thrown down as calcium and nagnesium carbonates. Where sulphuric acid is present it mites mainly with calcium, producing gypsum. The hydrochloric and nitric acids are left for the alkalies. Frequently the salts and acids may not be present in proportion to combine as above. For instance, after the alkaline earths are exhansted by the sulphuric and carbonic acids there may be residual carbonic acid which will necessarily unite with the alkalies. Or again, on the contrary, the sulphuric and carbonic acids may not be sufficiently plentiful to exhaust the alkaline earths, and under such circumstances chlorides of calcium and magnesium may form. This is well illustrated by the calcium chloride deposits of the borders of Great Salt Lake, where locally there is as much as 40 per cent of this material. ${ }^{a}$

The compounds are likely to be precipitated in the openings of the rocks, where evaporation may occur. Such openings are, of course, by far. the most abundant in the soils at and near the surface, and decrease in abundance with depth. Therefore it is in the soils that the greatest amount of precipitation takes place, but below the soils are found joint cracks, bedding partings, caves, etc, and in such openings deposits of the various compounds mentioned are built up. While in these openings the precipitation is largely dependent upon the abundance of the solutions and their evaporation, and also upon the abundance of the various salts and their relative solubilities, in exceptional cases the reactions may not be simple chemical ones, but be largely or' wholly dependent upon animal life. This is illustrated by certain caves where abundant phosphates and nitrates are

(6) Gardner, F. D., and Stewart, John, A soil survey in Salt Lake Valley, Utah, Rept. Dir. of Soils, U. S. Dept. Agrie., No. 64, 1899, p. 113. 
attributed to the excrement of bats. ${ }^{a}$ But, as already said, the preponderant precipitates of the belt of weathering form in the soil.

The accumulation of particles at and near the surface in the soil is a matter of great geological and agricultural importance, and therefore this case will be especially considered.

CONCENTRATION AT AND NEAR TIE SURFACE.

The abundance of alkalies throughout the soils of the semiarid regions of the United States and other parts of the world is well known. The soil for large areas is impregnated with considerable amounts of alkaline salts. Of these salts sodium and potassium chlorides, carbonates, and sulphates are the most important. Where the amount of alkaline carbonates and sulphates in the soil exceeds one-half of 1 per cent crops can not be grown. ${ }^{b}$ Where more than one-tenth of 1 per" cent is as carbonate or as "black alkali" crops can not be grown. But locally in arid regions, as, for instance, at places near Salt Lake, the amount of sodium carbonate is as much as 10 per cent. ${ }^{c}$ In some regions nitrates of the alkalies are not less important than the chlorides, sulphates, and carbonates. The comntry most noted for abundance of nitrates is Chile, where there are extensive deposits. Muntz and Marcano believe that these nitrates were produced by the action of nitrifying bacteria in the humid regions, that the salts have been transported by water to the area where now found, and that the evaporation of this water has resulted in the deposition of the nitrates. ${ }^{d}$

The concentration of soluble products in the soil is accomplisled both by underground and by overground circulations.

CONCENTRATION BY UNDERGROUND CIRCULATION.

The concentration of considerable quantities of soluble material at and near the surface may be accomplished by the circulation of the ground water. This circulation may be confined to the belt of weathering or may inclucle the circulation in the belt of cementation.

a Hess, WWm. H., Origin of nitrates in cavern earths: Jour. Geol., rol. 8, 1900, pp. 129-134. Nichols, H. W., Nitrates in cave earths: Jour. Geol., vol. 9, 1901, pp. 236-243.

b Heans, T. H., and Gardner, F. D., A soil survey in the Pecos Valley, New Mexico: Rept. Div. of Soils, U. S. Dept. Agric., No. 64, 1899, pp. 53, 74.

c Garkner, F. D., and Stewart, John, A soil survey in Salt Lake Valley, Utah: op. cit., p. 113.

aComptes rendus Acad. Sci., Paris, vol. 101, 1885, pp. 65-68. See, also, Merrill, George P., Rocks, rock-weathering, and soils, Macmillan Co., New York, 1897, pp. 372-373. 
CONCENTRATION BY CIRCELATION MAILY CONFINED TO BELT OF WEATHERING.

It has been seen (pp. 419-423) that of the water which enters the belt of weathering a considerable portion returns to the surface through molecular attraction and regetation and is evaporated. During the journey of water downward and npward, in the onter belt of water circulation, it takes material into solution.

When the water, the circulation of which is wholly confined to the belt of weathering, or which is derived from the belt of cementation by molecular attraction, nears the surface evaporation begins, and finally a state of saturation is reached. Ordinarily saturation occurs only within a few inches of the surface, and especially in the outer inch or half inch. For instance, in a case of segregation of saline incrustation at Washington, D. C., Cameron states that practically all of the salt was in the surface inch, the larger part of it being in the top eighth inch. ${ }^{a}$ As a result of the abore processes the soluble materials in the onter part of the earth are taken into solution in large quantities and brought near or to the surface and there deposited. (See pp. 539-543.)

It lias been seen (pp. 417-419) that the downward movement of the water is due both to gravity and to molecular attraction, and that the upward movement is due largely to molecular attraction, working against gravity. It is well known that the soil, even in humid regions, is relatively rich in soluble constitnents. This is undoubtedly in large part explained by the fact that the solnble products are mainly produced by the process of decomposition, and are more largely mannfactured within the soil than elsewhere, as so fully set forth on previous pages. The material there manufactured is strongly held by the water of imbibition. But Means suggests in this connection that the failure of the downward-moving water in humid regions to remove the excess of soluble material is due to the fact that the downward movement is mainly in large openings, the force being gravity, and is therefore rapid, and consequently only a relatively small amount of material is taken into solution, while the upward movements are in the smaller openings, mainly under the influence of molecular attraction, and consequently this upward-moving water is loaded with material. ${ }^{b}$

a Means, Thos. H., On the reason for the retention of salts near the surface of soils: Science, new series, vol. 15, 1902, p. 33.

b Ieans, cit., pp. 33-35. 
The upward transfer of material, while largely due to the water which does not pass beyond the belt of weathering, is also partly due to water which under the influence of molecnlar attraction passes upward from the sea of gromud water. The amount of such water increases in proportion as the surface of ground water is near the surface. It has already been pointed out (pp. 419-422) that when the ground water is comparatively near the surface a very large amount may thus migrate upward and be evaporated. This material carries with it all the salts which it had in solution in the belt of cementation and such as it may take into solution during its upward movement above the level of ground water. Locally, as a result of over-irrigation, seepage from irrigation ditches or unusual precipitation for several years, the level of grom water may be raised. A layer of the belt of weathering may be thus encroached upon. This belt is likely to contain a large amount of soluble material. To illustrate, Hilgard states that "The investigations of the California station have shown that in the arid region few uplands normally contain less than from 2,000 to 2,500 pounds [900 to 1,300 kilograms] of soluble salts per acre in 4 feet [1.22 meters] depth, and much more has been found in the silty substrata of the Salton Basin in southern California even to 22 feet [6.7 meters] depth." When the level of ground water is raised this material is abundantly dissolved by the water. If the rise continues so that the level of ground water is within 3 meters or less of the surface, a very large amount of salts may be carried upward to the surface from the belt of cementation by molecular attraction. ${ }^{a}$

The solutions carry more of the readily soluble compounds than of the difficultly soluble ones, and therefore the substances transferred in greater amounts are the alkalies and the alkaline earths. In humid regions the material thus transferred to the surface layer is largely taken into solution at times of abundant precipitation and carried downward again. Therefore, if there be no change in the composition of the compounds, there is little accumulation of such material near the surface. But in the semi-arid and arid regions, where the belt of weathering is comparatively rich in alkalies and alkaline earths, the material carried upward during the long periods of drought may not be compensated by downward transfer at the rare occasions of abmondant precipitation. Consequently the upper part of the soil may become exceedingly rich in salts of the alkalies and alkaline earths,

"Hilgard, E. W., The rise of alkali salts to the soil surface: Science, new series, vol. 15, 1902, pp. $314-315$. MON XLVII-04-35 
especially the former. Indeed, the surface may thus become saturated witl these salts.

The process of migration of alkalies to the surface is well illustrated in varions irrigated districts. Before irrigation the soil may have contained only a sufficient amount of alkalies to be very fertile. In many districts, by irrigation for some years, so large a quantity of alkalies has been brought to or near the surface as to injure vegetation or even to make crop growing impossible. Where the water used is sweet, these effects follow from overirrigation. Where more than a sufficient amount of water is used a part of it passes to some deptl below the surface. Between the times of flooding a part of this is brought to the surface by capillarity, carrying with it various dissolved salts. Also by continual seepage from canals at higher levels water passes below the surface, and by capillarity is brought to the surface in the cultivated areas, carrying with it dissolved salts. As the water evaporites these salts are precipitated in the soil. This process is cumulative, and after a number of years, as already stated, the quantity of alkalies may become so great as to lead to the abandonment of formerly productive tracts. This process is well illustrated in San Joaquin Valley, California, and in Salt Lake Valley, Utah. At the latter place alone Whitney states that of the 50 square miles once irrigated about 10 square miles, or one-fifth, has become unfit for agriculture. ${ }^{*}$

Where the waters used for irrigation are themselves very rich in alkalies, as, for instance, in Pecos Valley, New Mexico, the accumulation of alkalies in the soils is prevented in a different way, namely, by very abundant use of water with considerable intervals between and by thorough underdrainage. By this method the salts which are precipitated between the periods of irrigation by evaporation are dissolved by the abundant waters at the time of irrigation, and thus accumulation of the alkalies in the soil is prevented. ${ }^{b}$

While the more readily soluble constituents are of far more importance as precipitates at or near the surface than the less soluble salts, the latter are precipitated in the soils. Of these difficultly soluble compounds silica and ferric oxide are perhaps the only ones of sufficient importance to require mention.

Many sandstones which have long been exposed to the weather have a

a Whitney, Milton, Field operations of the Division of Soils: Rept. Div. of Soils, U. S. Dept. Agric., No. 64, 1899, p. 25.

$b$ Whitney, Milton, cit., pp. 22-24. 
thin outer layer or crust of quartzite. Sections of such material show that it is a true cementation quartzite. (See pp. 865-868.) Casehardening also occurs in many other kinds of rocks, for instance, granite. In the production of casehardening the waters have penetrated to a greater or less depth, and throngh capillarity have been brought back to the surface as a result of drying of the onter surface.

During the journey of the water silica is dissolved, probably mainly in the colloidal form. This $\mathrm{H}_{4} \mathrm{SiO}_{4}$ is doubtless largely that liberated from the silicates during the process of carbonation. (See pp. 473-480.) Probably the solntions do dissolve some silica from chert and quartz and bring it to the surface, but the amount of this is probably small as compared with that transported in the colloidal form. It therefore appears that the process of surface cementation, so far as the cement is silica, is a correlative of the process of carbonation.

Very near the outer surface of the rock the water evaporates, the silica is dehydrated, and quartz is deposited. In this case chemical change takes place. The silica is thrown down in a very difficultly soluble form; so that even in humid regions the falling water is mable to dissolve the quartz and carry it downward. This process may continue until the sandstone, which may be loose or almost incoherent below the surface, is a quartzite at the surface. 'The casehardened layer may be a mere outer' film but a fraction of a centimeter in thickness, perhaps one-half to one-fourth of a centimeter. In other instances the casehardening may extend to a depth of a centimeter, or even several centimeters. Ordinarily the maximum induration is at the surface, and the transitions between the inclurated and soft parts of the rocks are somewhat rapid. This fact gives positive evidence that evaporation and conséqnent deposition are at a maximum at the surface.

Casehardening has been observed in many parts of the world. It is beautifully illustrated at many points in the arid region of western United States. In arid regions the hardened film has frequently been smoothed by the wind-blown sand, so as to present a polished surface. Such polished hardened films are known as "desert varnish." While more common in arid regions, casehardening lias been found in humid regions. For instance, the phenomena are well exhibited by the Potsdam and St. Peter sandstones of Wiscousin."

a Wadsworth, M. E., Some instances of atmospheric action on sandstone: Proc. Boston Soc. Nat. Hist., vol. 22,1853, p. 202. 
Surface induration, while most common as the result of the deposition of silica, is not limited to this compound. The upward-moving solutions carried by molecular attraction may, under favorable circumstances, contain iron salts in solution. When the solutions approach the surface evaporation takes place and the iron salts are thrown down, usually as limonite or hematite. If precipitated as limonite, this compound may be later dehydrated and hematite be formed. Where the iron salts are transported as carbonate, oxidation takes place at the time of precipitation. While it is not necessary to suppose that the iron is always transported as carbonate, since limonite and hematite are so insoluble it is natural to suppose that in most cases the iron is transported in some other form than the oxide, and is chemically changed when precipitated. By the above processes we have surface induration due to iron oxide cement. This is beantifully illustrated at various places in the desert regions of western United States. One of the best localities known to me is that of the rolcanic rocks of the Colorado Desert east of Needles along the line of the Santa Fe Railway. The desert is strewn with bowlders of disintegration, of a light-colored lava. The part of these bowlders embedded in the sand has its normal color; the part above the sand line is a rich reddish brown, due to hematite, the iron of which has been brought to the surface in solution and has there been oxidized and precipitated.

Another interesting case of the segregation of iron oxide at the surface is furnished by quartzite bowlders in the Potsdam sandstone of the driftless area of the Baraboo district of Wisconsin. Here, locally, in consequence of weathering processes. the sand matrix has been carried away and the quartzite bowlders have accumnlated at the surface. The quartzite is ferruginous, containing hematite, which gives purplish and brownish tones to the nuweathered rock. The centers of the bowlders still show these colors; the border's are rich yellow-brown, or red, due to limonite and hematite, the color being much more marked than in the centers of the bowlders or in the massive quartzite, and plainly showing an unusual proportion of the iron oxide. Between the onter surfaces of the bowlders aud the central cores of unaltered quartzite are frequently bands, from two to five centimeter's broad, almost white, which fade off into the heavily ferruginous onter parts of the bowlders and to the less ferruginous cores. It is very clear in these cases that the iron oxide once in this lighter middle 
band has been taken into solution, transferred to the surface, and there deposited. It is a depleted area, and correlative with it is the surplus of iron oxide at and near the surface. This case is interesting, since the iron, both in its original form and where segregated, is an oxide. It is therefore clearly shown that iron in the form of hematite is soluble in the belt of weathering. Whetler actually carried in that form or whether reduced and changed to carbonates or other salts at the time of transfer is uncertain.

In a similar manner other cements besides silica and iron oxide may be brought to the surface and deposited. These processes, while most prominent at the surface, are not limiterl to it; they take place to a considerable extent along the major openings of the rocks near the surface, such as joints. Crosby has noted the induration of Pikes Peak granite along the joints. Surface induration of granite, rhyolite, and other rocks has been noted, the casehardening materials ordinarily being the three most common ones-silica, iron oxide, and calcite. ${ }^{a}$

In connection with casehardening it is interesting to note the influence of the so-called quarry water contained in stones taken from the quarry. This is the water of imbibition. As this water is evaporated the material in solution is deposited between the grains near the surface and thus helps to cement them. The very considerable induration thus produced by the quarry water is evidence that this water is rich in mineral solutions. In this deposition of material we have the explanation of the great advantage of dressing sandstones and other porous rocks before the quarry water is lost by evaporation.

From the previous pages it appears that capillarity is most effective in transferring soluble material from below the surface to the surface in semiarid and arid regions. But if in regions which are ordinarily known as humid there are seasons of drought, great quantities of soluble material may be segregaterl at the surface by capillarity. So far as this material is thrown down in a readily soluble form it is likely to be largely taken into solution at times of abundant rainfall and again carried below the surface. But if at the time of precipitation chemical change takes place, so that the material is transformed to a relatively insoluble form, as, for instance, the dehydration of colloidal silicic acid forming quartz, or the oxidation of iron

a Merrill, George P., Rocks, rock-weathering, and soils, Macmillan Co., New York, 1897, pp. $25+-256$. 
carbonate, forming liematite or limonite, its solution is very slow, and thus the upward transfer of the compounds at the time of drought may more than compensate for the solution at periods of humidity, and actual segregation of certain materials at the surface take place.

Furthermore, it is to be noted that in humid regions regetation is abundant, and therefore the upward transfer of material through the agency of life is at a maximum. This compensates in part for the relative inefficiency of capillarity in humid regions as compared with that in arid regions. It therefore appears that whether a region be arid or humid the vertical transfer of soluble material through the agency of life and by capillarity takes place effectively.

CONCENTRATION BY CIRCULATION EXTENDING INTO BELT OF CEMENTATION.

It has been pointed ont, on pages 128,156 , that waters continuously join the belt of cementation and continuously issue from it. In general the waters which issue from the belt of cementation are not saturated, but not infrequently the waters of springs as they near or reach the surface precipitate material by lowering of the temperature, by evaporation, or by chemical change.

Perhaps one of the most common deposits thus produced is limonite. The iron precipitated is usually carried underground as carbonate, bnt when it reaches the surface, where oxygen is abundant, oxidation takes place, the carbon dioxide is liberated, the ferric oxide unites with water, and limonite is thrown down. Thus bog deposits of iron ore are built up. Another deposit which is not infrequently prodnced is calcium carbonate. This may be thrown down as a resnlt of lessening pressure and temperature, or by evaporation. Snch deposits are known as tufa or travertine. They are found in many parts of the world. One of the best illustrations is furnished by the travertine deposits of the Yellowstone National Park, at Mammoth Hot Springs and on Terrace Mountain. The latter represents the deposit of springs now dead. A third class of deposits thus built up by issuing spring water is siliceous sinter. These are best illustrated by the deposits of geyserite in the Yellowstone National Park. It is interesting to note that the travertine and the siliceons sinter deposits in the Yellowstone Park are in the same region, and one in which the spring waters are hot. To the latter fact may be attributed the magnitude of the deposits. 
Such waters were capable of taking more calcium carbonate and silica into solution than ordinary cold undergrom waters. An interesting fact in connection with these deposits is the correlation of their character with the rocks adjacent. As pointed ont by Hague, the calcareous deposits of Mammoth Hot Springs and 'Terrace-Mountain are adjacent to sedimentary rocks which contain abundant calcium carbonate to serve as a source of supply." The geyserite deposits of siliceous sinter, on the other hand, are in a region of rolcanic igneous rocks, mostly rhyolite, and where there are no sedimentary rocks. Here calciun carbonate is not available, but silica is very abundant in matural glass and in crystallized minerals. These silicates are decomposed by the processes of weathering. Colloidal silicic acid is thus formed, which is readily taken into solution by the hot waters and abundantly brought to the surface. There dehydration, partial or complete, takes place and the geyserite deposits are built up.

In these cases it is clear that the major portion of the material deposited was derived from the solid rocks through which the hot solutions circulated, rather than from the magmas which heated the water, as maintained by some. (See pp. 1033-1034, 1071-1072.)

CONCENTRATION BY OVERGROUND CIRCULATION.

The waters of streams and lakes always contain soluble material derived from the soil dissolved by the rum-off and from the lower part of the belt of weathering and the belt of cementation by the issuing spring waters. The material dissolyed by the run-off may form in the soil by the processes of weathering or be bronght to the surface by means of life or by the underground circulation. The amount of this material is comparatively small in humid regions, but is relatively large in arid regions. In some arid regions the amounts held by the surface water's may be so great as to unfit them for domestic purposes, or even for purposes of irrigation, since, as already noted, a comparatively small amount of alkali is sufficient to prevent plant life.

The best illustrations of overground concentration are furnished by basin regions, where there is no permanent run-off. In the United States the Great Basin is the one of dominant importance. Southern California also contains basins of great extent. Into the Great Basin a large number of

" Hague, Arnold, Geological history of Yellowstone National Park: Trans. Am. Inst. Min. Eng., vol. 16,1888 , pp. $795-796$. 
streams flow, some of them of considerable size, for instance, the Bear, Ogden, and Weber river's. The smaller streams which flow into the basin for the most part rise on the mountain slopes of the Wasatch and Sierra Nevada, which wall the Great Basin on the east and the west. Within the Great Basin there are many mountain ranges, some of them of great size. The greater of these are the Humboldt and the Inyo ranges. On these basin ranges many streams rise and flow down upon the floor of the basin. The precipitation in the Great Basin region is mainly in the winter and spring. At times of abundant precipitation and rapid melting of the snow many ephemeral streams form npon the floor of the basin itself. The streams, small and great, all fail to reach the ocean; the larger of them flow into the permanent lakes of the basin, such as Great Salt Lake, Mono Lake, and Winnemucca Lake, but by far the greater number flow into the ephemeral lakes. These lakes, which are numbered by hundreds, are shallow; they may be many miles across in early spring and entirely disappear before autumn. Also, the permanent lakes, like Great Salt Lake and Winnemncea Lake, greatly expand at the time they receive the large contributions from the streams and shrink during the summer and autumn. All the streams bring their contributions of soluble materials to the lakes and, in addition, the usual amounts of mechanical sediments. Hence there is mingled in the Great Basin lakes the greatest variety of materials. The salts of alkalies, the salts of the alkaline earths, and lesser amounts of other soluble salts are all commingled with one another and with the mechanical sediments.

When the waters of the ephemeral lakes are evaporated, all the materials held in solution and in suspension are thrown down. In the larger of the ephemeral lakes there is a distinct tendency for the chemical and mechanical sediments to be deposited in alternate layers. Within a short time after the flood season of spring the mechanical sediments are largely laid down. During the dry season the lake evaporates and the chemical sediments are precipitated. These sediments, while perhaps partly dissolved by the water's of the lake of the succeeding flood season, are largely buried under the mechanical sediments of that year. Upon these mechanical sediments follows the next layer of chemical sediments, and so on.

It is difficnlt for one who has not traveled in the Great Basin region to appreciate the vast amount of alkaline material deposited by the ephemeral 
lakes. In journeying across the desert of Nevada in summer or autumn a person is rarely out of sight of one or more areas, small or great, varying in size from a fraction of an acre to luundreds or even thousands of square miles, covered with the almost snow-white chemical deposits of the evaporated lakes, which glare with intense light under the brilliant sun.

The permanent lakes, like Great Salt Lake, continually receive supplies of material in solution and are constantly being evaporated. When such lakes were first formed the salts steadily accumulated until the water became saturated. After a state of saturation is reached each year at the flood season chemical deposition may and usually does cease and solution even may take place to some extent. After the flood season the mechanical sediments quickly subside. During summer and autnmn evaporation greatly exceeds the influx of water; the lakes shrink; the solutions become supersaturated and chemical precipitation follows. Along the borders of the permanent lakes chemical and mechanical precipitates are interstratified the same as in the ephemeral lakes; but in the central areas of these lakes, beyond the depth to which plentiful mechanical sediments are carried, the chemical precipitates, comparatively little contaminated with mechanical material, are steadily built up. It is well known that the annual rainfall is not uniform, but that there are periods extending over a number of years of more than and less than the average rainfall. It is in the dry parts of the cycles that the thick deposits of chemical sediments are largely built up. The formation of such deposits is now also promoted in many lakes by the use of the water in irrigation.

As already noted, the abundant chemical sediments are the alkalies and alkaline earths, carbonates, sulphates, and chlorides. The order in which the materials are deposited depends upon the relative amounts of these substances and upon their relative solubilities. In consequence of difference in solubility there is a more or less marked tendency for the bases first to unite with the acids so as to produce the most insoluble compounds. Thus the calcium and magnesium unite with carbonic acid to produce marl and tufa. The calcium unites with sulphuric acid to produce gypsum. But always before one substance is completely precipitated one or more others begin to be thrown down, and consequently there is a mingling of precipitates. This is especially true of those compounds which are closely allied chemically, such as the calcium and magnesium carbonates, the sodium and potassium chlorides, ete. While there is a tendency for 
the most insoluble compounds first to be thrown down, these relatively insoluble compounds may be very sparse in quantity, and therefore more soluble salts be first precipitated. While all the above complications make the result very uncertain, still there is usually a marked tendency to stratification, each stratum being composed dominantly of one compound or of two closely allied compounds. Thus a stratum may consist mainly of marl, another mainly of gypsum, another mainly of common salt, and so on.

By great changes in the humidity of a region and some changes perhaps in the topographic conditions a basin lake may become smaller or wholly disappear, thus baring its deposits to the ordinary forces of erosion. Such lakes are Lake Bomeville, described by Gilbert, and Lake Lahontan, described by Rnssell. The chief chemical deposit of Lake Bomneville, according to Gilbert, was a white calcareons marl. However, this marl is very impure, containing a large amount of silicates and silica, in one case as much as 74 per cent. $^{n} \quad$ The chief chemical deposits of Lake Lahontan, according to Russell, are a calcareous white marl and tufa. The white marl, like that of Bonneville, is impure, containing about 30 per cent of silica, alumina, and iron, of which 22 per cent is silica. The tufa deposits are mainly calcium carbonates, although small amounts of magnesium carbonates and other constituents are contained. ${ }^{b}$ It appears that Lakes Bonneville and Lahontan did not become saturated with the salts of the alkalies. In the case of Bomneville this stage was not reached until it had shrmink to Great Salt Lake.

By still more radical topographic revolntions and changes in meteorological conditions than those experienced by Bonneville and Lahontan, deposits of salt lakes may become deeply buried below other sediments, and thus we have the explanation of the salt, the gypsum, and other similar deposits of various parts of the world.

\section{DISTRIBUTION OF RESIDUAL MATERIALS.}

The distribution of the dissolved material in the belt of weathering is of very great importance, but the distribution of residual material which at no time goes into solution is of no less importance. The concentration

a Gilbert, G. K., Lake Bonneville: Mon. U. S. Geol. Survey, vol. 1, 1890, p. 202.

$b$ Russell, I. C., Geological history of Lake Lahontan: Mon. U. S. Geol. Survey, vol. 11, 1885, pp. 152-153, 203. 
of this material and its transportation, separation and deposition by the epigene agents of erosion ought, perhaps, to be considered here; but this is a subject so large and complicated that it is ordinarily given a separate treatment in physiography; therefore no attempt will be here made even to summarize this part of the cycle of the movements and alterations of the material of rocks. The residual undissolved material of the belt of weathering is a source of the mechanical sediments and the partial source of the combined mechanical and organic or chemical sediments.

This residual material is deficient in the elements which have been taken in solution in large amounts; it is therefore complementary to the dissolver material. It follows that the residual material which is the source of the mechanical sediments is likely to be deficient, to a varying extent, in the alkalies and the alkatine earths, and of these it is much more likely to be deficient in sodium and calcium than in potassium and magnesium. This is true without taking into account the mechanical sorting. So far as there is mechanical sorting, there may be deficiencies or excesses of other elements. But it may here be suggested that the deficiency in certain elements, as compared with the original rocks, furnishes an adequate reason why the mechanical sediments, when metamorphosed, do not reproduce mineral combinations like those of the original rocks. The metamorphosed equivalents of the mechanical sediments will naturally be deficient in minerals rich in sodium and in calcium, such as sodalite, nephelite, anorthite, etc.

\section{RELATIONS OF BELT OF WEATHERING TO SEIIMENTARY ROCKS. \\ BELT OF WEATHERING THE SOURCE OF SEDIMENTARY ROCKS.}

The materials transported to the sea in suspension and in solution by overground and undergromnd waters, and subordinately by the wind and ice, supply the materials for the sedimentary rocks. These materials are almost wholly derived, directly or indirectly, from the belt of weathering. The main source of the sedimentary rocks is therefore the belt of weathering. The material derived from the belt of weathering is transported in suspension and in solution. 


\section{MATERIAL TRANSPORTED IN SUSPENSION.}

The dominant constitnents of the sedimentary rocks transported in suspension are the minerals produced in and adapted to the belt of weathering and the slowly decomposable minerals. The first class comprises the kaolin group, the serpentine-talc group, the chlorite group, the zeolite group, quartz, iron-oxide minerals, and aluminum-oxide minerals. Of the second class the minerals of dominant importance are quartz and the acid feldspars. Quartz is included in both classes, and is the mineral of greatest abundance in the sedimentary rocks; second to it is feldspar. With the abundant minerals there are present, of comse, very subordinate amounts of the very difficultly decomposable minerals, such as garuet, staurolite, tourmaline, zircon, etc.

'The readily alterable minerals are usually rare or' subordinate in quantity in the sediments. The group of minerals most readily alterable, the feldspathoids, including mephelite, lencite, and sodalite, are rarely, if ever, found in the sedimentary rocks. Minerals of the olivine group are also rare in the sedimentary rocks. The ferromagnesian group of minerals, including the pyroxenes, amphiboles, and biotites, are more difficultly decomposable and are frequently found; still, they alter with such readiness that they are generally subordinate in quantity, although locally abundant. While where decomposition has been important the above are the dominant minerals in the mechanical sedimentary rocks, in many sedimentary rocks the materials are but slightly decomposed, disintegration being the chief process of destruction of the original rocks. In mechanical sediments derived from disintegrated material, as already pointed out, all or nearly all the original minerals may be present. Where disintegrated materials are dominant the rocks produced by their consolidation are conglomerates, arkoses, and grits. As would be expected, there is every gradation between rocks in which decomposed material is important and rocks in which disintegrated material is dominant. Therefore, sedimentary rocks may be built up of materials which, in chemical composition, stand anywhere between decomposition products and disintegrated products, and which vary from the mineralogical simplicity of the former to the mineralogical complexity of the latter. Since the chemical analyses of such materials vary greatly, as shown by the analyses given on pages 507-515, it is usually possible, by the analysis of a sedimentary rock, to obtain a rough idea as to the stage of 
decomposition. In cases where both the decomposed and the undecomposed materials are abuudant the mineralogical complexity is even greater than in the ordinary original rocks.

Even where decomposable minerals are largely altered and the abundant minerals are few, by different combinations of these few minerals a wide variety of sedimentary rocks may be produced. This is due to the opposing processes of mingling of the materials in streams and separation of them by waves and currents. Where material is deposited at the mouth of a great and rapid river all the minerals are intermingled; where the material is contributed to the sea no faster than it can be sorted by the waves and the currents the different minerals are separated. Between thorough assorting and no assorting there are all gradations. In proportion as the material is unassorted the combinations of different minerals and of different-sized particles built into a deposit is varied; in proportion as the process of assorting is advanced a deposit is likely to be built up of a single mineral or of a combination of two or more minerals having approximately the same size and the same specific gravity, or at any rate which are floatable to the same degree. Where the materials are slowly contributed to the sea and are long subjected to the waves, the nearly perfect assorting, both as to mineral material and as to size, is remarkable. As an illustration of nearly perfect assorting may be mentioned the St. Peter sandstone of Wisconsin. This sandstone is almost wholly composed of quartz grains, analyses showing it to have 96.74 per cent of silica ${ }^{a}$ Moreover, the variation in diameter of the great majority of the grains is less than by ratios of $2: 3$ (pp. 861-862).

\section{MATERIAL TRANSPORTED IN SOLUTION.}

It has been pointed out that the material transported in solution is mainly composed of the more soluble compounds, viz, salts of the alkalies and the alkaline earths. The ocean as a whole is not saturated with the salts derived from the belt of weathering, nor is there any evidence that it has been so at any time in the past, although locally inclosed seas and lagoons do become saturated, and in this case chemical precipitation may occur precisely as in inland lakes, described on pages 551-553. But the dominant precipitation of material from solution in the ocean is not through the process of chemical precipitation, but through the agency of life. As is, 
well known, by far the most abundant of all the constituents thus precipitated is calcium carbonate. The corals and other shell animals abstract this material from the water and build it into their hard parts. As the animals die this material is deposited, and thus great limestone formations are built up, and doubtless have been in the past. No adequate reason has been given for the belief that great seas connected with the ocean have become saturated by calcium carbonate so as to build up limestone formations by chemical precipitation, although, as already intimated, chemical precipitation of calcium carbonate has locally occurred. While the chief precipitation of calcium carbonate is through the agency of life, chemical replacement works in conjunction with organic precipitation. No sooner is a deposit of calcium carbonate formed than the other salts of the sea begin to act upon it, under the laws of heterogeneous systems, and thus modify the deposit. Calcium is taken in solution and is replaced by the other bases, especially by magnesium. (See pp. 798-802.)

\section{MATERIAL TRANSPORTED IN SUSPENSION AND SOLUTION.}

Commonly the material transported in suspension and that transported in solution are built into deposits which are largely separated from each other; but not infrequently both classes of material are laid down together, and this causes additional variety in the sedimentary rocks. We thus have sediments built up of all proportions of materials mechanically transported and materials chemically transported. It therefore appears that the sedimentary rocks may have a wider variety of chemical composition and of mineral composition than any of the igneous rocks. But while this is possible, the rule for the great sedimentary formations is simplicity; and this is due to the tendency toward simplicity in the belt of weathering and to the processes of assorting. The first great process of assorting in the belt of weathering is the subdivision of material into insoluble compounds transported in suspension and soluble compounds transported in solution. As already pointed out, the mechanical sediments are commonly assorted by waves and currents, and the chemical sediments are assorted by life; and thus the dominant formations of the sedimentary rocks are simple, both chemically and mineralogically. This is especially true of the two kinds of formations, sandstones and limestones. The shales, arkoses, graywackes, and conglomerates represent the varieties of sedimentary rocks in which there is greater complexity. 


\section{ROCKS PRODUCED FROM MATERIAL OF BELT OF WEATHERING WITHOUT TRANSPORTATION TO THE SEA.}

While by far the larger part of the material prodnced by the processes of weathering is transported to the sea, either in suspension or solution, the weathered material may be buried under other deposits without transportation to the sea. 'l'he weathered material not carried to the ocean may be classified into residuary and transported material. Such deposits may be from a few meters to hnndreds of meters, or, in the case of the transported material, even a thousand meter's in thickness. After a deposit of residuary or transported material has accumulated, the sea may transgress over the region so quietly as not to disturb the larger part of the weathered rock. As an example of the burial of residuary material under marine deposits may be mentioned the Coastal Plain of the United States. Here the deeply disintegrated pre-Cretaceous rocks have been overridden by the ocean, and upon them have been laid down the Coastal Plain deposits. If the sea should now advance over the Piedmont Platean somewhat rapidly part of the deeply disintegrated and decomposed belt there occurring might be buried under marine deposits without disturbance.

Weathered material may be transported a greater or less distance, but not to the sea, and thick deposits be built up. This is well illnstrated by the deposits of the Great Basin region of the United States. Here the weathered material, instead of being transported to the sea, continuously accumulates in the lower areas. This has gone on until there are hundreds or a thousand or inore meters of weathered rock material, which has accumnlated between the mountains. Some of this material is deposited by the streams; other parts are deposited by the ephemeral lakes; others by the permanent lakes. (See pp. 551-554.) The result is the building of great sedimentary deposits, in which there is local assorting. When the sea next encroaches upon this Great Basin area there may be buried below the marine deposits a great mass of weathered material, which differs radically from the ordinary marine deposits in that there has been comparatively little abstraction of soluble salts, and which therefore must have nearly the same average chemical composition as the original rocks from which they are derived, but not the same mineral composition.

The residuary or transported material, when sufficiently deeply buried, whether below the sea or by upbuilding, as in the Great Basin area, passes 
into the belt of cementation, and may even pass into the zone of anamorphism. It may be metamorphosed in those positions, and produce rocks different in character from ordinary metamorphosed sedimentary rocks, becanse the material has a different chemical composition. It is pointed out in mother place (see pp. 831-833) that the jaspilites of the Lower Huronian of the Marquette district represent a weathered belt, which has been overridden by the Upper Huronian seas, deeply buried by later sediments, and metamorphosed under the conditions of the zone of anamorphism.

\section{TRANSITION BETWEEN BELT OF WEATHERING AND BELT OF CEMENTATION.}

Before taking up "The belt of cementation," it will be well to call attention to the fact that the belts of weathering and cementation are not sharply separated, but there is a transition between them. In many cases the explanation of the transition is partly that locally strong downward currents carry solution as a preponderant process well below the level of gromnd water, and partly that a considerable quantity of oxygen may be carried some distance below the level of ground water and produce reactions characteristic of the belt of weathering. In other cases the level of ground water rises and falls, as explained on pages 423-429, and therefore there is a belt in which the conditions are alternately those of the belt of weathering and the belt of cementation. While in general the transition from one belt to the other is somewhat gradual, in some instances it is rather abrupt. An excellent illustration of an abrupt change is that given by Culver in the case of the diabase in Minnehaha County, S. Dak. ${ }^{a} \quad$ This rock is thoroughly disintegrated and apparently much decomposed to a depth of 6 or 8 meters, that is, to the bed of the stream which marks the linit of ground water. Says Culver: "The limit of decomposition seems to be marked by the position of the stream; the rock in its bed is firm and apparently maltered."

As an illustration of a transition belt of considerable width may be cited the iron-ore deposits of the Lake Superior region. Many of these deposits exten'd from the surface to a depth of 200 to 500 or more meters, but at the greater depths they usually become gradually smaller and less rich in hematite. The level of ground water is rarely deeper than 30 meters.

a Culver, G. E., and Hobbs, William H., On a new occurrence of olivine-diabase in Minnehaha County, South Dakota: Trans. Wisconsin Acad. Sci., Arts, and Letters, vol. 8, 18s5-1891, pp. 206-207. 
These iron-ore deposits consist mainly of hematite with some linonite, and occasionally some magnetite, with silica as the main impurity. In passing downward the silica is likely to become somewhat more abundant, and finally the ores become too lean for working. As explained in another place, these ores have been precipitated in pitching tronghs on impervious basements by downward-percolating waters which bear oxygen, often at places where the rocks have been much fractured by orogenic movement and are therefore very open and porous. Simultaneously with the precipitation of the iron oxide silica is dissolved. (See pp. 1193-1197.) It appears, therefore, in the case of these ore deposits, that oxidation and solution, both reactions characteristic of the belt of weathering, have locally extended for 300 meters or more into the belt of cementation.

MON $\mathrm{XLVII}-03-36$ 


\section{CHAPTER VII. \\ THE BELT OF CEIENTATION.}

BELT OF CEMENTATION DEFINED.

The belt of cementation, like the belt of weathering, belongs to the zone of katamorphism. The belt has been discussed from the physicalchemical point of view in Chapter IV. From this point of view its definition is very similar to that of the belt of weathering. It is a belt in which the reactions take place with liberation of heat and expansion of volume, or come under the first part of van't Hoff's law. From a geological point of view the condition of affairs is very different in the belt of cementation from that in the belt of weathering, and it is primarily the purpose of this chapter to consider the belt of cementation from this point of view, but, as heretofore, the geological treatment is subject to the. general principles which have been developed in the previous chapters.

Geologically the belt of cementation may be defined to include that part of the zone of katamorphism which is below the belt of weathering. It has as its lower limit the zone of anamorphism, the zone in which permanent openings, whether produced by fracture, original sedimentation, or any other cause, are of subcapillary size. It is bounded above by the belt of weathering, the lower limit of which is the level of ground water. All of the classes of openings described on pages 129-146 are found in this belt. But whatever the nature of the openings, whether cracks and crevices produced by mechanical action, such as those of joints, faults, bedding partings, and fissility, or the openings originally present in the rocks, such as pore spaces of the mechanical sediments and the vacuoles in volcanic rocks, they are usually filled with water.

The belt under cliscussion is named the "belt of cementation" because cementation is the most obvious and probably the most important single process of the belt. But it is by no means the only process; it will be seen 
that metasomatism, injection, consolidation, and fracturing are important, and some of them scarcely less so than cementation. The geological evidence clearly shows that no sooner are openings produced in this belt, or rocks containing openings transferred to this beit, than deposition of material in the openings begins and continues until the separated parts are firmly cemented. Since cementation is only one of the processes which occur, the name "belt of cementation" is less fortunate than the name for the belt at the surface, the belt of weathering, for weathering is a general term properly covering many, if not all, the processes which take place within the belt to which it is applied; but as there is no comprehensive term available, the name "belt of cementation" has been chosen. with hesitation, on the basis of naming the belt by the most obvions and characteristic of the processes which take place within it. In many respects the name "belt of induration" would be a good one, since under quiescent conditions the rocks are hardened by the various processes at work. The process of cementation also hardens or indurates many of the rocks. This name would cover both of the chemical processes, cementation and metasomatism, and the igneous process of injection, but it is contradicted by the mechanical process of fracturing. It is more comprehensive than the name "belt of cementation," but is inaccurate in that induration is not always characteristic of the belt. "The name "belt of saturation" well covers the fact that the openings are commonly filled by water solutions, but this is also true of the exceedingly minute openings of the zone of anamorphism. Furthermore, the term "belt of saturation" would be likely to be understood to imply that the solutions in the belt are always saturated with the compounds with which they are in contact, and this is far from the truth. Certainly the term "belt of cementation" is the one which seizes as distinctive the most characteristic and obvions feature, evidences of which are seen in the field in all major openings, and which are equally evident through the microscope in minor openings.

The geological evidence that cementation is the miversal law for the part of the zone of fracture in which the rocks are usually saturated with water seems to be conchnsive. In mining operations the world orer it has been found that there is a tightening of the ground when the level of ground water is reached. Above that level the rocks are likely to be open and porous, giving the freest circulation to the waters of the belt of weathering; 
but below that level the rocks are usually much less porons, although it does not follow that the water circulation may not be inportant and rapid. Fine illustrations of the sudden lessening of the pore space at water level are furnished by the lead and zine districts of the Mississippi Valley. This lessening of the pore space is partly due to the solution of material above the level of ground water, rather than to cementation below it. But observations below the level of ground water show that cementation is as certain as is solution above. Sandstone formations, as is well kuown, are cemented mainly by silica, althonglı calcium carbonate, iron oxide, etc., are subordinate cementing constitnents. Wherever sandstones are found which have long been below the level of ground water, cementation has taken place, either by enlargement of the old grains or by independent deposition between the grains, or by the two combined. All stages of this process are seen, from those in which the grains have simply built out crystal facets that sparkle in the sun, to rocks so firmly cemented as to be perfect quartzites, in which fracture breaks through the cement and across the old grains rather than around them. ${ }^{a}$ The pore spaces of arkoses, tuffs, and other rocks which have long been below the level of ground water, are shown by ninicroscopical examination to have been also closerl; but often the cements are more variable than in the case of quartzites, frequently including feldspar, pyroxenes and amphiboles, calcite, and varions other minerals.

That cementation is the miversal rule for the porous rocks below the level of ground water was ascertained only by microscopical study, but in the field may be seen evidence of cementation of the larger fractures. The filling of ancient joints, recementing the separated joint blocks, the filling of fanlt openings, thus producing true veins, and the cementing of the fragments of breccias are all well-known phenomena. Where rocks have been broken and buried deep enough to be below the level of ground water and have remained there long, it is found to be an almost universal rule that the filling of these larger openings has begur; and usually, so far as the older openings are concerned, the process has been practically completed, althongh recent earth movements may have produced openings which have not been closed.

The openings which are being filled in the belt of cementation vary in size from minute pores between the grains to great caves. Interesting

a Irving, R. D., and Van Hise, C. R., On secondary enlargements of mineral fragments in certain . rucks: Bull. U. S. Geol. Survey No. 8, 1884, pp. 1-56. 
instances of very large openings below the level of ground water are furnished by the caves in the lead and zinc district of Missouri. Here, in consequence of extensive pumping operations, the level of ground water has been lowered from a few meters to 45 to 60 meters. At various places below the level of ground water caves of considerable magnitude have been found, some nearly 60 meters in length and with rooms 12 to 15 meters in width. These caves are lined with crystals of calcite. The faces are perfectly clear. It is almost certain that the erystals continned to grow until the level of ground water passed below them. The caves are, in fact, like gigantic geodes with great scalenohedral crystals, some of them a half meter or nrore in length, projecting everywhere from the walls. No stalactites or stalagmites are found, or any of the other peculiar phenomena so characteristic of caves above the level of ground water in the belt of weathering. These caves, before transferred from the belt of cementation by the lowering of the level of ground water, were being filled, and had the process continued sufficiently long there would have been formed great masses of crystalline calcite analogous to the masses of that mineral which are sometimes elsewhere found.

Concluding from the geological facts observed, it seems perfectly clear to me that the fundamental fact of the part of the zone of fracture between the level of ground water and the zone of anamorphism is that cementation is the most characteristic process, and therefore the one which properly gives its name to the belt.

\section{BOUNDARIES OF BELT OF CEMENTATION.}

It has been explained (pp. 409-411) that in different areas the level of ground water is at different depths from the surface, varying from zero to 300 meters, and exceptionally to a thousand meters.

It has been shown that the level of the upper surface of the ground water is not horizontal, but undulating, and that the undulations of the level of ground water roughly follow the topography, as shown by the fact that upon many hills and mountains wells reach water of saturation at the very moderate depths of a few meters to 50 meters. A topographic map of a region is to a certain extent a map of the level of ground water, but the latter shows less accentuated contours. The elevation of the contour of the ground water at a given place is less than the elevation of the 
surface contour by the depth of the level of ground water. It has also been seen (pp. 411-413) that the surface of ground water rises and falls from a few centimeters to a number of meters, and that therefore the apper boundary of the belt of cementation is somewhat variable.

The lower limit of the belt of cementation is the lowest horizon at which there may exist abundant openings in the rocks of supercapillary and capillary size. It has already been pointed out (pp. 190-191) that to this linit the rocks are self-supporting, but below it the rocks are not sufficiently strong to support themselves, so that if openings were supposed to be proluced they would be closed by flow. It has heen calculated that for the strongest rocks the bottom of the belt of cementation may be as deep as $10,000 \mathrm{or}^{\circ}$ possibly 12,000 meter's, although for most rocks under ordinar'y conditions the bottom of the belt of cementation is believerl not to be nearly so low. With the same kind of rock the bottom of the belt of cementation is at different depths under different conditions. For instance, when earth movements are rapid the belt might extend considerably deeper than when they are slow. The belt of cementation, extending as it does from the level' of ground water to the bottom of the zone of fracture, is much broader than the belt of weathering.

\section{CONDITION OF WATER IN BELT OF CEMENTATION.}

The question whether hydrostatic pressure increases sufficiently fast with depth to prevent the water from passing into the form of gas needs to be answered. If the arerage temperature at the surface be assuned to be $0^{\circ} \mathrm{C}$. - and in the arctic regions the average temperature is probably lower rather than higher than this-and if the increment of increase of temperature be taken as $1^{\circ} \mathrm{C}$. for every 30 meters, the critical temperature of water, $365^{\circ} \mathrm{C}$, is at a depth of 10,950 meter's. If the average temperature at the surface were supposed to be $25^{\circ} \mathrm{C}$., about the maximum for the tropical regions, in order to reach a temperature of $365^{\circ}$, the critical temperature of water, a depth of 10,200 meters would be required.

At any given place the water is subject to the pressure of the superincumbent columm of water. Supposing the temperature of the water were $100^{\circ} \mathrm{C}$, or just at the boiling point, at the surface of the earth (the most

"Van Hise, C. R., Principles of North American pre-Cambrian geology: Sixteenth Ann. Rept. U. S. Geol. Surtey, pt. 1, 1896, pp. 591-5!t. 
unfavorable assumption to holding the water as a liquid), the water would be a liquid in the belt of cementation, as is shown by the following table based upon this supposition, column (1) being temperatures, column (2) being pressures necessary to hold water as a liquid at these temperatures, column (3) being depth in meters at which the pressures wonkd be produced, column (4) being the depth which would be required to produce the temperatures on the supposition that the increment of the increase of temperature is $1^{\circ} \mathrm{C}$. for every 30 meters, and column (5) being the actual temperatures which exist upon this supposition at the depths represented by column (3).

Relations of pressures, temperatures, and depths in ground water.

\begin{tabular}{|c|r|r|r|r|}
\hline (1) & \multicolumn{1}{|c|}{$(2)$} & $(3)$ & $(t)$ & $(5)$ \\
Temperatures. & $\begin{array}{c}\text { Pressures cor- } \\
\text { responding to } \\
\text { temperature } \\
\text { of column 1. }\end{array}$ & $\begin{array}{c}\text { Depth neces- } \\
\text { sury to pro- } \\
\text { duce pressure } \\
\text { of column 2. }\end{array}$ & $\begin{array}{c}\text { Depth neces- } \\
\text { sary to pro- } \\
\text { duce tempera- } \\
\text { turc of col- } \\
\text { umn 1. }\end{array}$ & $\begin{array}{c}\text { Temperatures } \\
\text { actually ex- } \\
\text { isting at pres- } \\
\text { sures and } \\
\text { depths of col- } \\
\text { umns 2 and } 3 .\end{array}$ \\
\hline${ }^{\circ} \mathrm{C.}$ & Atmospheres. & Meters. & Heters. & $\circ \mathrm{C}$ \\
120 & 2.0 & 20 & 600 & 100.66 \\
180 & 10.0 & 100 & 2,400 & 103.33 \\
225 & 25.0 & 250 & 3,750 & 108.33 \\
265 & 51.0 & 510 & 4,950 & 117.00 \\
310 & 99.0 & 990 & 6,300 & 133.00 \\
340 & 148.0 & 1,480 & 7,200 & 149.33 \\
365 & 205.5 & 2,055 & 7,950 & 168.33 \\
\hline
\end{tabular}


A fuller table, showing the relations of temperature and pressure between $225^{\circ}$ and $365^{\circ} \mathrm{C}$, at intervals of $5^{\circ} \mathrm{C}$., is given below.

Relations of temperatures and pressures of water.

\begin{tabular}{|c|c|c|c|}
\hline $\begin{array}{l}\text { Tempera- } \\
\text { tures. }\end{array}$ & $\begin{array}{l}\text { Pressure neces- } \\
\text { sary to hold } \\
\text { water as liquid. }\end{array}$ & $\begin{array}{l}\text { Tempera- } \\
\text { tures. }\end{array}$ & $\begin{array}{l}\text { Pressure neces- } \\
\text { sary to hold } \\
\text { water as liquid. }\end{array}$ \\
\hline${ }^{\circ} \mathrm{C}$ & Atmospheres. & ${ }^{\circ} \mathrm{C}$. & Atmospheres. \\
\hline 225 & 25.1 & 300 & 86.2 \\
\hline 230 & 27.5 & 305 & 92.2 \\
\hline 235 & 30.0 & 310 & 99.0 \\
\hline 240 & 32.8 & 315 & 106.1 \\
\hline 245 & 35.5 & 320 & 113.7 \\
\hline 250 & 39.2 & 325 & 121.6 \\
\hline 255 & 42.9 & 330 & 130.0 \\
\hline 260 & 46.8 & 335 & 138.8 \\
\hline 265 & 50.8 & 340 & 147.7 \\
\hline 270 & 55.0 & 345 & 157.5 \\
\hline 275 & 59.4 & 350 & 167.5 \\
\hline 280 & 64.3 & 355 & 178.2 \\
\hline 285 & 69.2 & 360 & 188.9 \\
\hline 290 & 74.5 & 365 & 200.5 \\
\hline 295 & 80.0 & & \\
\hline
\end{tabular}

From these tables it is seen that the hydrostatic pressure at various depths is normally far in excess of that required to hold the water in the form of a liquid, or, looked at in another way, for any given depth the temperature is not sufficiently high to allow the water at that depth and pressure to exist in the form of a gas.

It therefore appears perfectly clear that where the increase in temperature with depth is normal the water remains as a liquid to its critical temperature, i. e., $365^{\circ} \mathrm{C}$, and that the depth of the zone of water circulation is, therefore, about 10,000 or 11,000 meters. In another place (pp. 189-190), it has been shown that this approximates to the greatest depth at which continuous crevices and cracks can long exist in the earth. It therefore follows that in the belt of cementation the water is normally in the form of a liquid to the bottom of the zone. Where magma is intruded in the lithosphere the temperature may become so high that this statement will not hold. But this is the exceptional, not the usual case. Furthermore,

a Preston, Thomas, The theory of heat, Macmillan \& Co., London, 1894, p. 385. 
it is conceivable that as a result of deformation itself the temperature of the rocks may become so ligh as to convert the water present into the form of gas, but, from investigations upon metamorphism, it is believed to be probable that this condition of affairs rarely obtains, since, as shown on pages $690-692$, long before the critical temperature of water is reached solntion and deposition of rock material, or recrystallization, readily takes place, and in this change the work converted into heat is far less than in mechanical granulation.

In conchision the general statement may be made that in the belt of cementation water is commonly in the form of liquid, and only exceptionally in the form of gas.

\section{AMOUNT OF WATER IN BELT OF CEMENTATION.}

It has already been suggested that the belt of cementation might be called the belt of saturation. 'This implies that the openings in the 'Jelt of cementation normally are filled with water solutions; therefore, the answer to the question as to the amount of openings in the belt of cementation approximately answers the question as to the amount of water there contained. It las been seen that in the belt of weathering the openings vary from a small amount to 40 or 50 per cent or more. In the belt of cementation the amount of pore space varies from zero to a maximum as high as 28.28 per cent, the actual amount of pore space found by Buckley in the Dunnville sandstone of Wisconsin. ${ }^{a}$ The mechanical sediments, especially sandstones which have not been much cemented, contain very large amounts of pore space. The volcanic fragmental rocks also furnish considerable pore space. The very dense rocks, especially the plutonic igneous rocks, have a very small amount of pore space unless they have been fractured. Wherever the rocks have been deformed above the zone of anamorphism fractures of all classes are produced, including joints, faults, bedding partings, fissility, and brecciation fractures. The amounts of openings which are thus produced may vary from a fraction of a per cent to as large a per cent as in the porous sandstones, as, for instance, in breccias. But the openings which originally existed in the rocks or which have been produced by deformation are in all stages of cementation. Also

a Buckley, E. R., Building and ornamental stones of Wisconsin: Bull. (ieol. and Nat. Hist. Survey Wisconsin No. 4, 1898, table v, p. 403. 
in all probability the amount of pore space gradually decreases in passing from the upper to the lower part of the belt of cementation. All of the foregoing uncertain factors make any estimate of the water of the belt of cementation little better than a guess. On page 128, assuming there is

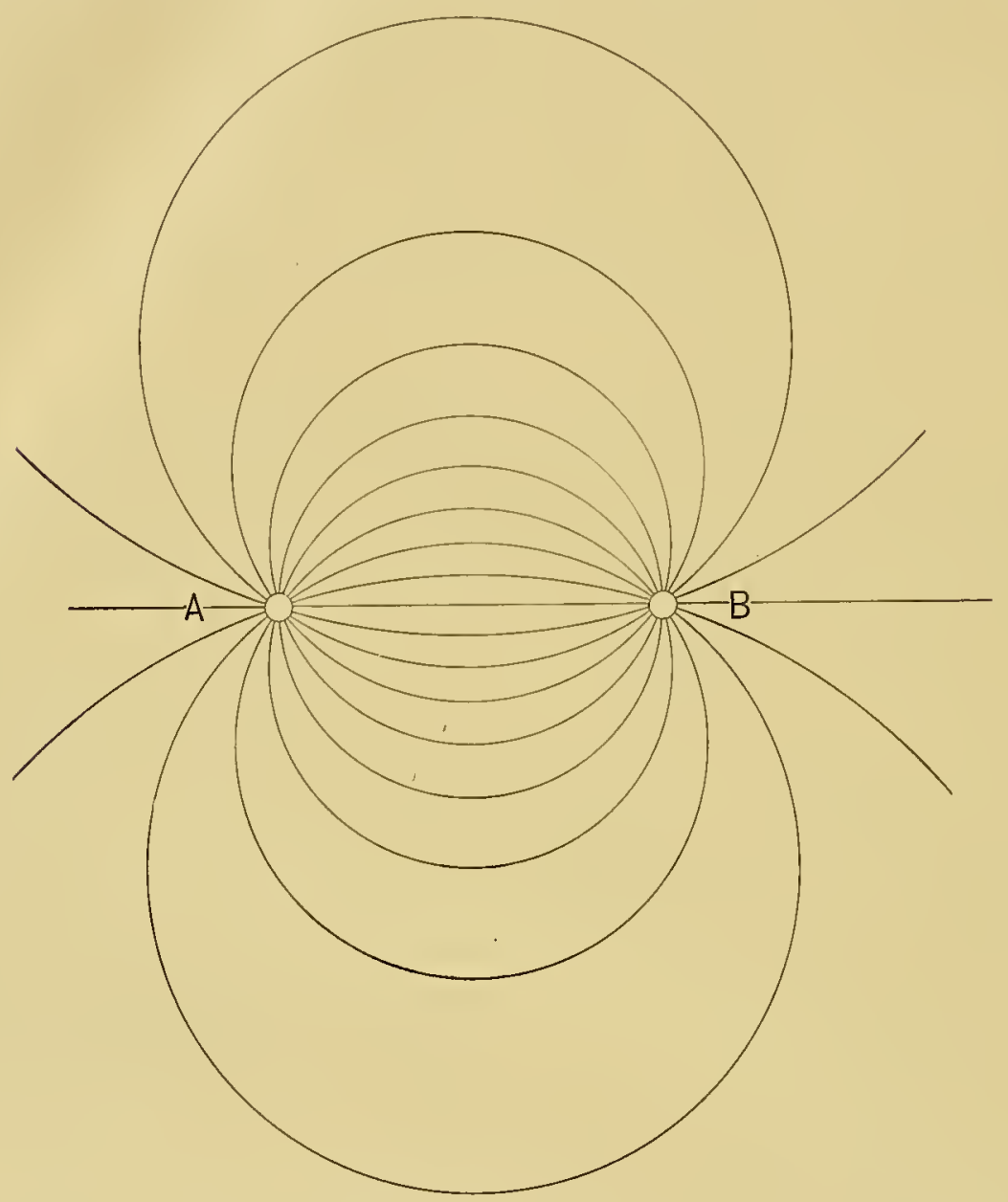

FiG. 7.-Ideal horizontal scetion of the flow of ground water through a homogeneons merlium from one well to another.

present only one-fifth as much as Dana's estimate of 2.67 per cent by weight as the average amount of water in the upper part of the belt of. comentation, supposing that from this amount it gradually decreases to zero at the bottom of the belt, and assuming the belt to extend to a depthi of 10,000 meters, I have calculated that the amount of water in the belt, if concentrater in a stratum, would make a sheet 69 meters thick. How- 
ever, it may be that this estimate is too small, and that the anount of water of the belt of cementation may be two or three times this amount.

\section{CIRCULATION OF WATER IN BELT OF CEMEN'TATION. VIGOR OF CIRCULATION.}

The vigor of the circulation in the belt of cementation is best shown by the amount of work which has been accomplished in cementation of rocks

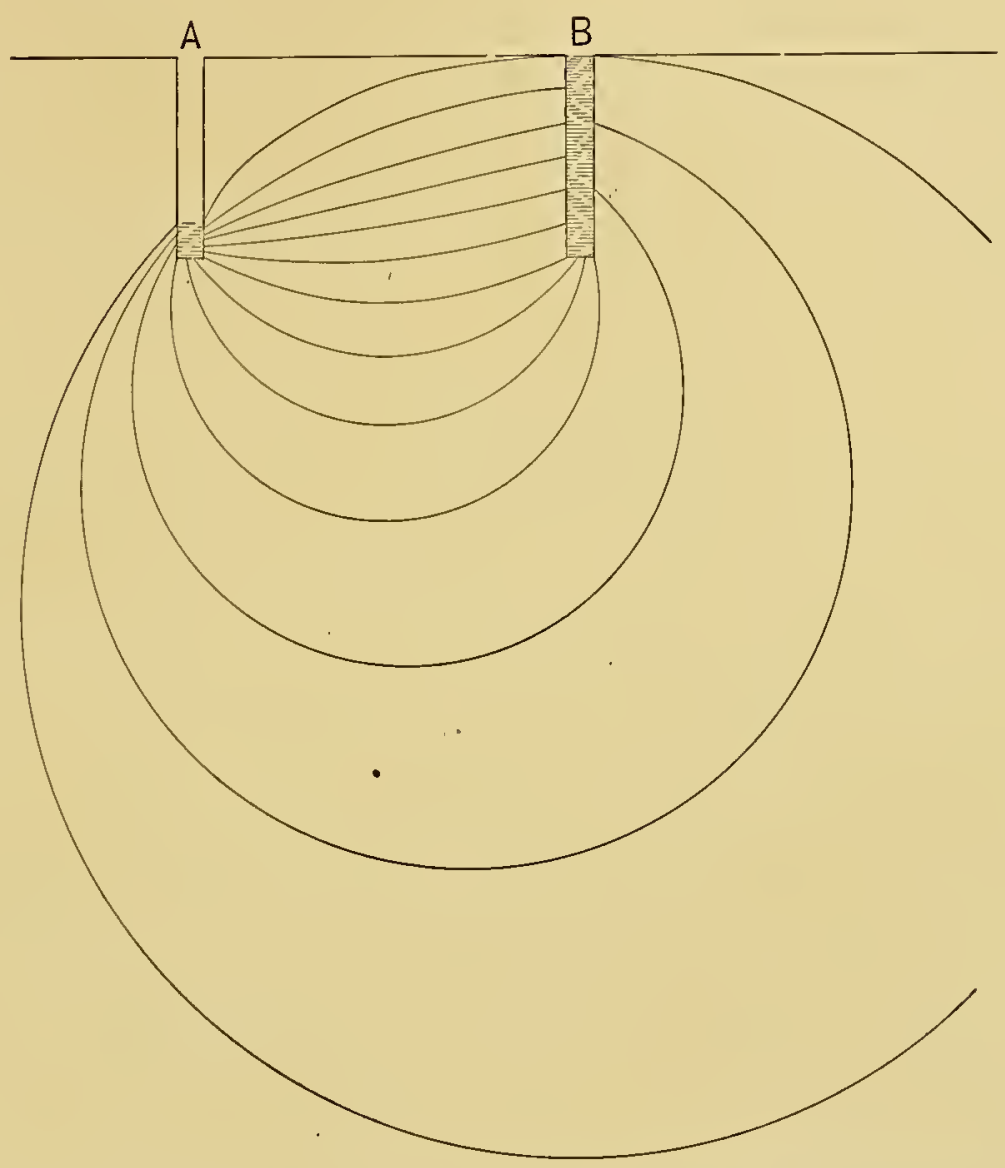

F1G. \$.-Ideal vertical seetion of the flow of ground water through a homogeneous medium from one well to another.

by gromud waters. It is shown in another place that great sandstone formations, which must originally have had a pore space of from 32 to 40 per cent, lave been completely cemented by the rleposition of silica. (See pp. 865-868.) It is further shown that the amount of silica thus deposited is 
enormous- to be measured in tens of thonsands, and probably hundreds of thousands of cubic kilometers. The amount of silica which the waters of mineral springs carry is, on the average, less than 2 parts in 100,000. In only a few cases is the amount greater than 10 parts in 100,000, although in one case, that of San Bernardino spring of California, the amount runs as high as 22 parts in $100,000 .^{a}$ Supposing the amount of silica deposited by underground waters to be as high, on the average, as 1 part in 100,000 (and the amount deposited is invariably less than that in solution), it would be necessary to believe that over 260,000 times as much water must have circulated through the sandstone formations as the enormous amount of quartz which has been deposited. The amount of silica assumed to be deposited by underground water's may be too great or too small, but it is certain that many thousand times as much water as deposited quartz has circulated through the rocks.

\section{CHARACTER OF CIRCULATION.}

It has already been explained that the complex movements of ground water may be resolved into two components, horizontal or lateral movements and vertical movements. In order to understand the work done by underground water in its journey, it is first necessary to know the path which it follows. On this point the recent analytical work of Prof. C. S. Slichter gives the desired information. ${ }^{b}$. According to Professor Slichter's analysis, the flowage of water from one place to another through a homogeneous medium, say from $A$ to $B$, is not by a direct path, but by a large number of diverging paths from A during the first part of the journey, and by a large number of converging paths to $B$ during the latter part of the journey. This may be illustrated by supposing the water to be poured into a well, A, and to flow to a well, B. The horizontal course of the water is represented by fig. 7, and the vertical course by fig. 8. These conclusions apply equally well to any porous rock, such as a soil or sandstone in which the spaces are distributed in a somewhat uniform manner.

It is apparent that Slichter's conclusions have far-reaching consequences as to the flowage of ground water. In the passage of the water from the

a Peale, A. C., Mineral springs of the United States: Bull. U. S. Geol. Survey No. 32, 1886, 1'p. $156,187,192,195,212,213$.

$b$ slichter, C. S., Theoretical investigation of the motion of ground waters: Nineteenth Ann. Rept. U. \&. Geol. Survey, pt. 2, 1899, pp. 297-384. 
top or slope of a hill to a point of issue at the foot of a hill, supposing these to be the only points of entrance or issuance of the water, and supposing the spaces to be uniform, the rertical course would be represented by the lines of fig. 9 and the horizontal course would be represented by the lines of fig. 7 .

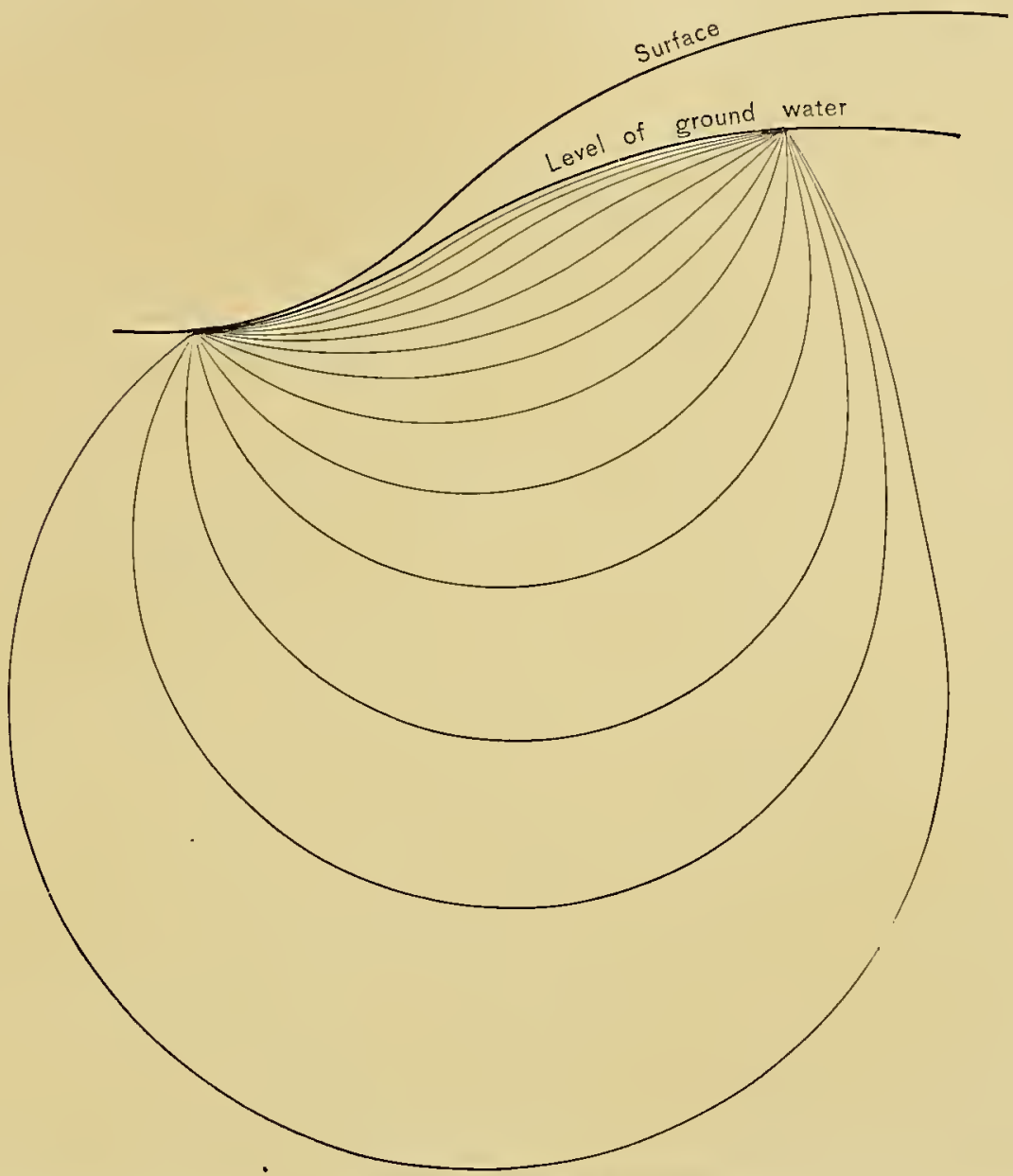

FIG. 9.-Ideal rertical section of the fow, through a homogeneous medium, of ground water entering nt nue pnint on a slope and issuing at a lower point.

In an actual case of ground-water flowage the water does not enter the ground at a single point, but at every point of a slope. As a simple case, we may suppose that the water entering on a slope reaches the surface again at the level of a stream in an adjacent valley. To get an idea of the complexity of the flow in this ideal case we may arbitrarily select a number of points where the water enters and trace out its course. We may plat by 
different kinds of lines the vertical components of the flowage of the water which enters at each place independently of the water that enters at other places. (Fig. 10.) In the figure we have a series of intersecting lines representing the vertical components of movement.

It is not supposed that water actually follows paths similar to those represented by the figure, for there is mutual interference of the water

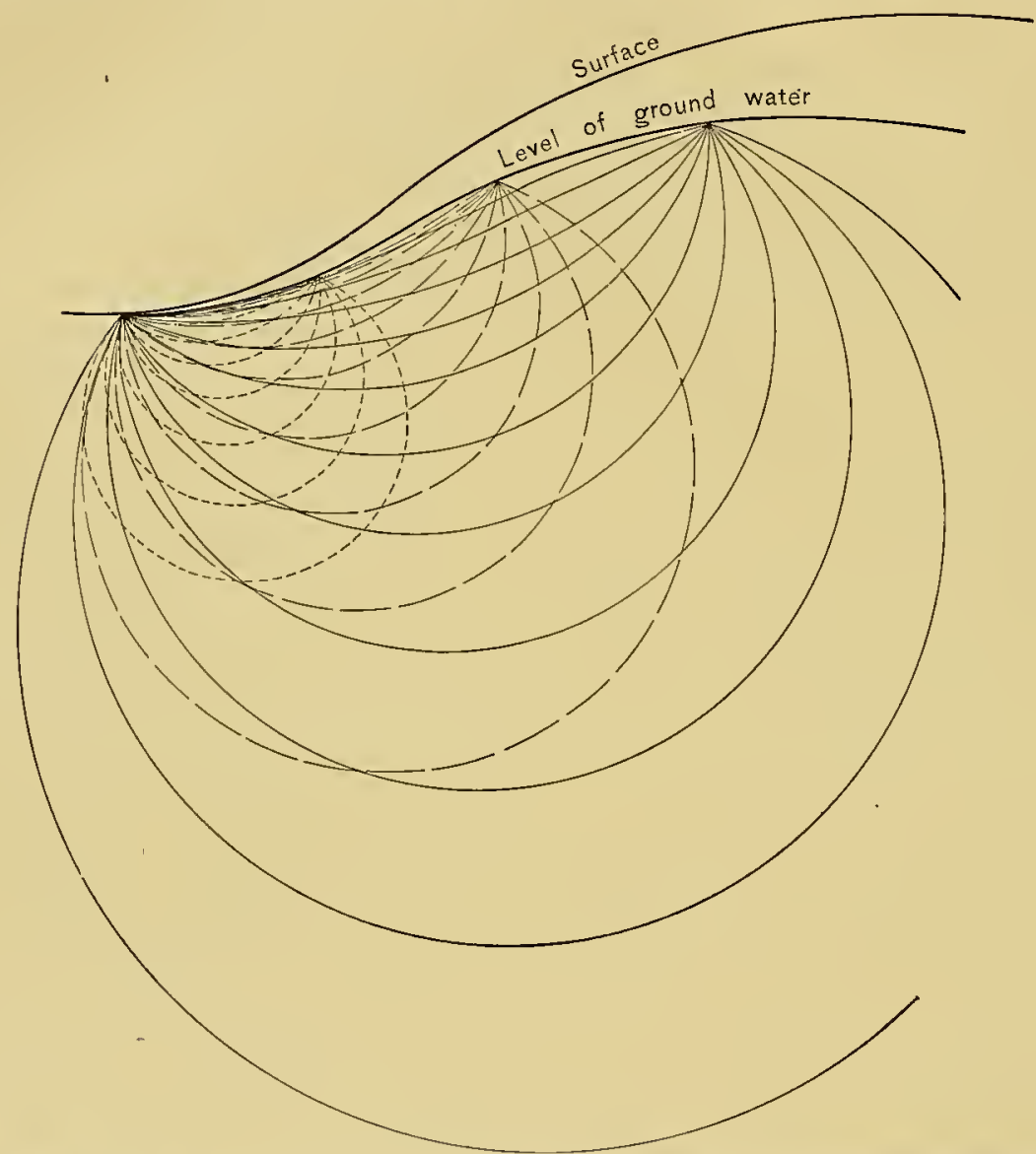

FIG. 10.-Ideal Tertical section of the flow, through a homogeneons medinm, of ground water entering at three points and issuing at a single point, cach system of flow being independent of the others.

entering at the various points. As a result of this the water entering the opening nearest the exit would take a more direct conrse than the average ' of that platted; but, as a conseqnence of this, the water from the next opening up the slope would take a more indirect course, on the average, than that platted, and so on. The total result would be to give an average course for the water which may be represented by combining the inde- 
pendent curves. (Fig. 11.) The effect, so far as the geological action of the underground water is concerned, would be approximately the same whether the course of the water were that represented by fig. 10 or that represented by fig. 11. This statement, applicable to a few points of entrance and one of exit, is equally applicable to a great number of points of entrance and one of exit. The statement can be further extended to

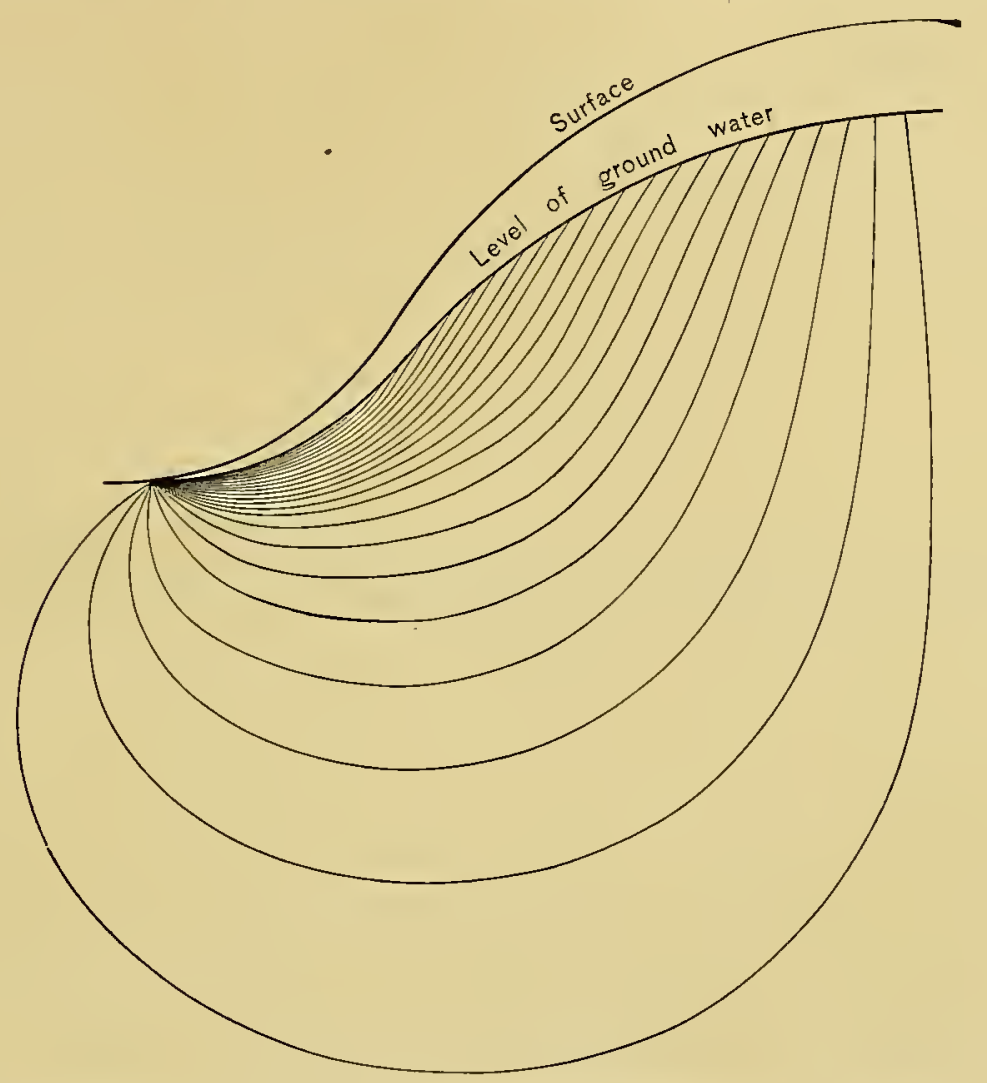

FIG. 11.-Ideal vertical section of the flow, through a homogeneous medium, of ground water entering at many points along a siope and issuing at a single point at a lower elevation.

an indefinitely great number of points of entrance distributed along the contours of the slope as well as up the slope and to many points of exit at or near the level of the valley.

Disregarding the lateral movement after the water reaches the level of ground water, the sea of ground water at a given place might be considered as a column moving downward as rapidly as the increment of ground water is added from above. However, the lateral movement which is super- 
imposed upon the vertical movement carries it sooner or later to some point where upward movement is taking place. Thus the amount which continues downward is an ever-decreasing fraction of the amount of precipitation which joins the sea of ground water.

Thus far the discussion of the flowage of ground water has been carried on as if it were through a homogeneons porous medinm extending indefinitely in all directions in which the pressure and the temperature are the same thronghout. It is needless to say that such are not the conditions of natural systems of underground flowage. Under' natural conditions there are many other factors which very greatly modify the nature of the flowage. Among these are limiting formations, gravity, increase in temperature with depth, the relative lengths of the vertical and horizontal components, and preferential use of large and continuous chamnels.

\section{LIMITING FORMATIONS.}

It has been shown (pp. 190-191) that the bottom of the belt of cementation corresponds with the bottom of the zone of fracture. It has been explained that to the bottom of the zone of fracture supercapillary or capillary openings may exist. Below the bottom of the zone of fracture the openings in the rocks are subcapillary and therefore practically impervions to a rapid circulation. The bottom of the zone of fracture is the lowest possible boundary of efficient circulation. But there is no theoretical reason why a ground-water system may not utilize the entire zone of fracture to its lower boundary. Indeed, the well-known hydrodynamical principle that the entire available cross section is utilized by flowing currents demands that the circulation extend to the bottom of the zone of fracture. This generalized statement conforms well with the lines of flow in a homogeneons medinm as determined by Professor. Slichter. (See figs. 7 and 9.) It therefore appears highly probable that, in any system of ground-water circulation, where there is no impervious rock nearer the surface than the bottom of the zone of fracture the entire zone of fracture is searched, although waters joining and departing from the underground sea disappear and appear at its surface. While this is true, other things being equal, the more direct route is utilized to a greater degree than the more indirect ronte, and therefore the remotencorners of available space have relatively 
small circulations The principle of the distribution of the flowage of water orer the entire available area is well illustrated by the case of water flowing horizontally into a beaker from one side and overflowing the beaker on the other side. The movement of the water is not confined to the liquid near the surface, but all portions of the water in the beaker, from the top to the very bottom, take part in the flowage, although, of course, the rate of morement is much more rapid at the top than at the bottom. ${ }^{\text {" }}$

While the circulation may extend to the very bottom of the zone of fracture, in many cases before that depth is reached a stratum is met all the openings of which are subcapillary. As shown on pages $143-146$, such a stratum is practically inpervious, and therefore becomes a practical limit of circulation in that direction. Such impervions strata may be only a few meters below the level of ground water, and thus the circulation be exceedingly shallow. From such a position an impervious stratum may be at various depths to the bottom of the zone of fracture.

While one system of circulation may thus be of very limited depth, it

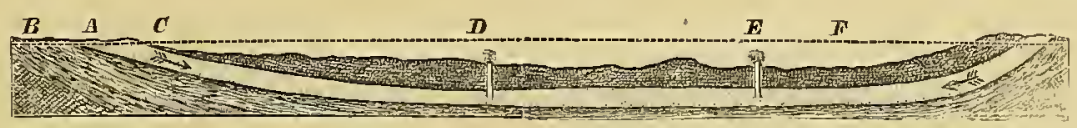

FIG. 12-Ideal section illustrating the chicf requisite conditions of artesian wells. A, a porous stratum; B and C, impervious beds below and above $A$, acting as confining strata: $F$, the height of the water level in the porous bed $A$, or, in other words, the height of the reservoir or fountain head; D and $E$, flowing wells springing from the porons water-filled bed A. After Chamberlin.

does not follow that other systems of circulation are not utilizing the other parts of the zone of fracture below the first circulation; for very frequently a belt below, which contains openings and is available for flowage, may elsewhere reach the surface and have a feeding area. Indeed, such are the circulations of many systems which are limited above by impervious strata. One of the simplest of such systems is represented by fig. 12. There are an indefinite number of variations of the systems of underground cireulations, dependent upon various conbinations of pervious and impervious strata. In some instances there may be several superimposed or adjacent systems, the relations of which are exceedingly complex. Some of the cases are of general geological interest. A number have been discussed by

a Slichter, C. S., Theoretical investigation of the motion of ground waters: Nineteenth Ann. Rept. U. S. Geol. Survey, pt. 2,1899 , p. 331.

HON XLVII-04-37 
Chamberlin and others in connection with artesian waters; ${ }^{a}$ but the best illustrations of complex systems have been worked out in connection with ore deposits, and in the chapter on that subject a number are discussed.

GRAVITY.

Thus far the full effect of gravity upon the character of the circulation has not appeared. The discussion has been carried on as if the movement of the ground water were controlled by simple pressure. But gravity is ever pulling the water downward. This force, in the early part of the journey, accords with the downward movement produced by head, and the result is that the water follows a deeper course than it would if moving through a homogeneous medium, in a manner similar to that of an electric current.

INCREASE OF TEMPERATURE WITH INCREASE OF DEPTH.

It has been repeatedly stated that the normal increase of temperature with increase of depth is $1^{\circ} \mathrm{C}$. for each 30 meters. It has been pointed out (pp. 140-141) that the viscosity of water decreases as the temperature increases, and that the flowage of water is relatively rapid in proportion as it has low viscosity. Indeed, in capillary openings it has been shown (p. 139) that the flowage is inversely as the viscosity. When it is remembered that the pore spaces of the ordinary mechanical sediments are of capillary size, it is seen that this principle is very important in the flownge of ground water. At a depth of 1,350 meters, supposing the increment of temperature to be normal, the ground waters would have a temperature of $45^{\circ} \mathrm{C}$. greater than at the surface. At a deptlı of 2,700 meters the ground waters would have a temperature of $90^{\circ}$ C. greater than at the surface. The viscosity of water at $45^{\circ} \mathrm{C}$. is only about one-third as much as at $0^{\circ} \mathrm{C}$, and at $90^{\circ} \mathrm{C}$. is only one-fifth as much as at $0^{\circ} \mathrm{C}$. (See p. 141.) In the lower part of the zone of fracture the temperature of water varies between $100^{\circ} \mathrm{C}$. and the critical temperature of water, $365^{\circ} \mathrm{C}$. (See pp. 566-5ti9.) If we suppose that at temperatures above $90^{\circ} \mathrm{C}$. the viscosity decreases at

a Chamberlin, T. C., Artesian wells: Geol. of Wisconsin, 1873-79, vol. 1, 1883, pp. 690-691; also vol. 2, 1878, pp. 149-152. Leverett, Frank, The water resources of Illinois: Seventeenth Ann. Rept. U. S. Geol. Survey, pt. 2, 1896, pp. 802-803. Hill, R. T., Geography and geology of the Black and Grand prairies, Texas: Twenty-first Ann. Rept. U. S. Geol. Survey, pt. 7, 190], pp. 398-401. 
the same average rate as between $0^{\circ} \mathrm{C}$. and $90^{\circ} \mathrm{C}$, at a depth of 9,000 meters, where the temperature is probably about $300^{\circ} \mathrm{C}$. greater than at the surface, the viscosity would be only about one-twentieth of that at the surface. From the foregoing it appears that in capillary openings in the part of the zone of fracture below 1,350 meters, with a given head, the flowage of water for capillary tubes of a definite size would vary from about three times to about twenty times faster than at the surface. These numbers are not accurate, because water at the surface usually has a higher temperature than $0^{\circ} \mathrm{C}$., but the error is not so great but that the conclusion follows that increase of temperature with depth is a very important factor, tending to promote a circulation in the deeper parts of the zone of fracture, for water follows the lines of least resistance; therefore, ground water, on the average, follows a deeper path than it would were the temperature and viscosity uniform.

RELATIVE LENGTHS OF VERTICAL AND HORIZONTAL COMPONENTS.

The vertical component of the jomrney of ground waters in the belt of cementation may be considered as confined to the zone of fracture, and is probably measured by 10,000 meter's, or at most by 12,000 meter's. The lateral component, on the other liand, may vary from a few meter's to hundreds or even a thousand or more kilometers. There can be little doubt that, on the average, the horizontal component is much greater than the vertical component. No limit can be assigned to the horizontal norement of water. It is known that the nearest sonrce for artesian waters may be many kilometers from the wells. For instance, in the. James River Talley, Dakota, the Dakota sandstone yields abundant water. The nearest place at which this sandstone ontcrops is several hundred kiloneters distant, and it therefore appears highly probable that the horizontal movement of the ground water is measured by hundreds of kilometers, while its rertical jom'ney is probably less than 1,000 meter's. Doubtless in this case the horizontal distance which the water has journeyed is far greater than the average, but still the average jomrney is probably one of considerable length.

The length of the horizontal component of the journey has much to do with the depth of the circulation. Where the horizontal component is 
comparatively short, not many times longer than the rertical component, there is a strong tendency for the circulation to be relatively shallow. Where, however, the horizontal component is very great, the relatively short distance between the bottom and top of the zone of fracture of a porous stratum is of comparatively little conseruence. In such cases the circulation through the deeper channels, provided they are equal in area and size to the shallow chamnels and the water is of the same temperature, night be practically the same as through the shallow ones. For instance, in the case already citer of the Dakota sandstone of the James River Talley, its thickness, about 100 meters, is insignificant compared with the horizontal joumey of hundreds of kilometers. Therefore, in such a case, if the sandstone were equally porons throughout and of the same temperature, for the greater part of the joumey there would be no appreciable difference between the amount of flow in the upper and that in the lower part of the sandstone, although in the very early and very late stages of the jouney the upper part of the sandstone would have a greater flow. Where the horizontal joumer is long, it is possible, on account of increase of temperature, giving decreased viscosity, that the cireulation is more rapid through the lower part of a frrmation than through the upper part. This would almost certainly be true if all parts were equally porous. But if this were so, sooner or later the more rapid flowage would carry the process of cementation of the lower part of the formation farther than the higher part: and as the openings became partially closed, this would tend to lessen the amount of the deeper circulation.

PREFERENTIAL USE OF LARGE CHANXELS.

A very important factor in the flowage of ground water is the great variation, in any natural system of underground flow, of the area of available space and the rate of movement. In nature the points of entrance for ground water are indefinitely numerous, and the places of exit comparatively few. The water falls upon the ground everywhere and enters the innumerable pores. After a longer or shorter underground course, perhaps passing under many subordinate hills and valleys, it escapes to the surface as a spring or by seepage, nearer the drainage level than where it entered the ground. The water began its journey through an almost infinite number of openings; it issues at many openings, but these are few compared with the rast number of those at which it entered. 
This conclusion is based on the following facts: Openings in rocks are never of uniform size. It has been seen that the resistance to flow in capillary openings is far greater than in supercapillary openings. In small supercapillary openings the resistance is greater per unit of flow than in larger ones. Thus there is a strong tendency for the water starting through innumerable small openings to converge into larger and larger openings, because these are the lines of least resistance. Of cotrse, water may go long distances underground without finding larger openings than those near the surface, as in some sandstones; but if large openings exist, they are fully utilized. Finally, when a single opening or a gronp of openings larger than the arerage reach the surface at a lower altitude than the average level of entrance of the water, there is a spring.

This reasoning is confirmed by experimental work of King, who finds that the flow in the Amherst sandstone of Wisconsin is faster along than across the bedding planes. The openings along the bedding planes are larger than those between the grains. The first are largely utilized in flowage along bedding and the second must be utilized in flowage across bedding planes. ${ }^{t}$

From his experimental work King holds "that the morements of ground water across long distances must take place in considerable measure throngh passageways larger than those which depend upon the pore space fixed by the diameters of the grains which constitute the beds themselves."

While I believe that in proportion as openings are large they are much more fully utilized than a similar area of distributed openings of small size, we nust remember that the movement of the widely dispersed deep water is often excessirely slow, and that under these circumstances the resistance in the capillary tubes per muit distance is reduced to a very small, alnost an infinitesimal, amount. (See pp. 141-142.) Therefore capillary openings between the grains in the cases of great sandstone and similar formations may be the chief channels of circulation for large quantities of water and for long distances. That such openings are the chief channels through which the water actually flows in the deeply buried sandstones bearing artesian water's is indicated by the fact brought out by

a King, F. H., Principles and conditions of the movement of ground water: Nineteenth Ann. Rept. U. S. Geol. Surver, jt. 2, 1899, p. 126.

$b$ King, cit., p. 249. 
Slichter, that the pressure a short distance from the bottom of a well is commonly as great while the well is flowing as it is at the mouth of the well when the flow is stopped." If the flowage was mainly, or even largely, throngh supercapillary openings, this would not be the case.

Large openings are favorable to a somewhat direct course; small openings are faviable to a circnitous route. As the openings decrease in size, a more circuitous route must be taken, for to pass a given volume of water from one point to another it is necessary that a wide range of openings be ntilized. It has been pointed out (pp. 569-570) that the openings of the belt of cementation are relatively large in its upper part and probably diminish in magnitude as deptl increases. So far as this is true, therefore, large channels for trunk circulation are, on the average, most numerous near the level of gromd water, and dininish in number and size as depth increases. From this, and the principle that the ground water tends to utilize the larger openings to the greatest extent, it follows that the abundant circulation tends to follow a relatively shallow course.

The direct course of water in large openings is illustrated by limestone regions where there are mumerous large joints and sometimes caves within which the water is quickly concentrated. In such instances the flowage of water is rery largely in the upper part of the zone of fracture.

\section{RESULTANT CIRCULATION.}

Summarizing, it has been seen that the movement of water in a homogeneons medium is similar to the movement of a current of electricity through a homogeneous medium, in that it utilizes the entire available cross section. But by the water the more direct course is utilized to a much greater extent than the less direct course. For the actual underground circulation this general statement must be modified in various ways. The circulation is limited wherever a formation is met in which the openings are subcapillary. Gravity and increase of temperature with depth tend to cause the water to take a deeper course than it otherwise would. On the other hand, the preference of water for the larger openings, and the greater abmudance of openings of large size near the surface, tend to.give the water a shallow course. Therefore the influence of gravity and temperature and that of large openings oppose each other. Which of these two opposing

a slichter, C. S., Theoretical investigation of the motion of ground waters: Nineteenth Ann. Rept. U. S. Geol. Survey, pt. 2, 1899, pp. 363-364. 
factors is the more important is nncertain, but probably the existence of larger fractures near the surface is more important than the effect of gravity and temperature.

It has been seen that during the first part of the underground journey of water the vertical component is downward, and that during the latter part of its journey the vertical component of much of it is upwarl. It follows that, on the average, the downward movements of water are through the smaller, and the upward movements through the larger, openings in the rocks. Of course, where large openings are available for the downwardmoving water they are fully utilized, and therefore to a greater extent than a similar area of smaller openings. But even if this be true, the statement still holds that, on the average, the larger openings are more extensively used by the mpward-moving water than by the downward-moving water. From the foregoing it appears that a system of circulation of ground water has a very close analogy to a tree of peculiar character.

The points of entrance of water are the ends of the indefinite number of twigs; these twigs mite into a branch; the branches mite to produce a larger branch; the larger branches unite into a trunk; and at the end of a trunk is a spring. The analogy of an underground drainage system to a tree is even closer than that of a surface system; for in a system of underground water circulation three dimensions are concerned to an important extent, while in a surface system of drainage the movement of the water is approximately confined to a plane. But, from what has gone before, it is clear that the tree of ground water has a peculiar shape. 'The twigs and branches have an important downward component; the larger branches of the tree may be considered as approximately horizontal; and the trunk usually has an upward component, which may be slight but is often important. Thus twigs, branches, and trunks together ordinarily make a great $U$. Where the water issues near the places of entrance the sides of the $U$ are rather close together. Where there is great lateral movement of the water the sides of the $U$ are very far apart. Such a system of ground water is somewhat similar to that of a surface system of drainage.

Ordinarily where the water first enters the underground sea the area of available space is exceedingly great and the rate of morement is very slow. As the water gather's in the larger openings the speed increases, and in the final trunk chamels the water may lave a very rapid movement, as 
shown by springs. These facts are important in connection with the variation in the size of the openings. The earlier movements are in the capillary openings, where the resistance to rapid flow would be great; but here the movement is slow, and consequently the friction is very small. (See p. 581.) As the water passes into the supereapillary branch and trunk channels, the important factor in friction is not that between the moving water and the adherent films, but the internal friction. The total friction in these larger channels is almost indefinitely snall as compared with the friction of the same amount of water moring at the same rate through the same area subdivided among capillary openings; for the area of contact, and therefore the friction between the moving liquid and that fixed to the walls, is inversely as the size of the openings. (See pp. 136-137.)

An undergromd circulating system is ideally illustrated in many arid and semiarid regions. In the United States it is especially well illustrated in the Great Basin and in sonthern California. In these regions the early parts of the courses of many streams are in mountain gorges, where usually considerable streams are above ground. As the streams leave the gorges and pass ont to the plains their conrses are over their own deposits, consisting of great alluvial fans of material, coarse and fine, which is called "wash." The streams at these places commonly pass underground, and there, as shown by drilling for water, follow somewhat definite chammels. Lorrer in the course of the drainage systems a large part of the underground water frequently issnes in a series of springs, or by seepage on a large scale, and continues its course above ground. The gravel and coarse sands furnish a close approximation to a homogeneous medium and ideally illustrate the laws of flowage given on pages $129-152,572-576$. Such an underground circulation as the above differ's from an overground system in that the boundaries of the water courses are indefinite, in that the movement as compared with the morement overground is exceedingly slow, and in that the mudergronnd cross sections are necessarily much larger. The work of Professor Slichter shows that the gromd water of the Arkansas River flows in gravels at a rate not greater than 3 to 5 meters a day. ${ }^{a}$ Supposing the rate of movement of the overground streams to be 10 kilometer's an hour, or 240 kilometers a day, and supposing the rate in the underground streams in the Great Basin or

" Slichter, C. S. The motions of underground waters: Water-Sup. and Irr. Paper No. 67, U. S. Geol. Survey, 1902, p. 43 . 
in southern California to be four times as great as the most rapid rate in the Arkansas sands-that is, 20 meters a day-the overground rate would be 12,000 times as fast as the underground rate. When it is remembered that underground about three-fourths of the space is occupied by sand and gravel, and that the openings present are more or less irregular, at the maxinum the available openings are not more than one-fourth the entire space. It follows that, in order to accommodate the underground water, the channel would have to be 48,000 times larger than at the surface. This number may be an overestimate, but certainly an underground channel through sand and gravel to accommodate a certain amount of water must be many thousand times larger than an orerground channel with the same slopes which accommodates the same amount of water.

While many streams in the semiarid and arid regions normally have an underground course as above describer, at occusional times of flood, which may be for a brief season each year or may occur only once in a number of seasons, the mountain streams are of such increased volume that the nuderground circulation is not sufficient to dispose of the water, in which case there is for a time also an overground circulation, which usually follows approxinately the same general course as the ground waters. It is at these times of flood that the fans of the wash are built up and the overground channels determined. Such circulations are ideally illustrated by the Santa Ana, San Gabriel, San Antonio, and other streams of southern California.

Excellent illustrations of underground flowage are furnished by artesian systems. For instance, in $W$ isconsin the Potsdam sandstone is an artesian water-bearing stratum. This sandstone is 200 to 250 meter's thick. The annual precipitation in the district of its outcrop is approxinately 50 centimeters. Supposing that one-half the rainfall enters the sea of ground water in the sandstone, this would give an additional increment every year of 25 centineters. If the pore space of the sandstone be supposed to be $16 \frac{2}{3}$ per cent, in order that the increment added shall find space in the sandstone without raising the water level it is necessary to suppose that the water of the previous year shall have moved downward 150 centimeters. In other words, the rertical flowage per anmum is only 150 centimeters, or $1 \frac{1}{2}$ meter's. Suppose the dip of the sandstone to be 2 meters per kilometer; it would follow that the lateral movement of the 
water, in order that the new water shall have room to enter the sandstone without raising the water level, should be three-fourths of 1 kilometer per annum. If the dip of the artesian-bearing strata were steeper the lateral movement would be much less. The above case, however, is approximately that of the Potsdam sandstone of Wisconsin. Since the average lateral morement of the water can not be supposed to be more than three-fourths of 1 kilometer per annum, the water which enters the artesian circulation at a distance of 150 kilometers from Chicago should, on the average, issue from the wells at Chicago 200 years after it enters the sea of ground water in Wisconsin.

In so far as the openings in the porous stratum are not of uniform size, the movement will be more rapid through the larger openings, and so far as this takes place the water rising in the artessan wells would remain underground for a less time than calculated; but, on the other land, the remainder of the water which did not follow the larger openings would travel at a slower rate than calculated, and thus remain underground a longer time; and thus, so far as difference in porosity is concerned, the average would be as calculated.

The average lengtll of time during which the water remains in the ground would probably be longer, perhaps much longer, than calculated, for all the premises are made so as to give the minimum time. For instance, the calculation is made upon the supposition that the porous stratum is homogenous and that there is no leakage through the overlying imperrious structure, whereas it is certain that there is leakage. In so far as there is leakage the lateral movement would be slower and the calculated length of time should be increased.

Also the annual rainfall which enters the sea of ground water in the belt of cementation is not so great as 25 centimeters, for a considerable portion of the water which goes underground is evaporated from the belt of weathering. In so far as the amount is overestimated the length of time calculated-two hundred years-should be increased.

The above result as to length of time which water remains underground in an artesian circulation is not so surprising when we compare it with the exceedingly slow flow already mentioned for the underground water in the sands of the Arkansas River and of the alluvial cones of sonthern California, in which the descent of the level of ground water is many times 
greater per kilometer than the gradient for the artesian water, as figured by dividing the difference between the head and the point to which the water would rise by the horizontal distance. Where the sandstone is perforated by artesian wells near Lake Michigan the water rises with a pressture which is a large fraction of the pressure due to head.

If, for instance, the city of Chicago be taken, the nearest point at which the Potsdann sandstone outcrops is abont 150 kilometers, and the water for the Chicago wells is probably mainly derived from points 150 to 250 kilometers from Chicago. The average eleration of the catchment area above Chicago is 80 meters. The water of the early artesian wells at Chicago, before they were so numerous as mutnally to interfere when allowed to flow, rose to an altitude of abont 30 meters above the surface; ${ }^{a}$ or, there is a loss, in the entire distance of 150 kilometers or more, of only about 50 meters of pressure. This small loss of hearl, which may be attributed to friction between the water and the sandstone, and within the water, is to be distributed through this entire distance. It follows that in the capillary openings of this sandstone the friction of the water is almost zero, else the pressure at the wells would not so nearly equal the pressure due to head. Of course the moment the wells are allowed to flow, and especially if there be a number of contiguons wells which are allowed to flow, the pressure rapidly drops. This is not due to friction through the major course of the water, where the novement is slow, but is due to friction adjacent to the wells, where the water is moving rapidly toward them. This is shown by the fact that at a distance of from 100 to 200 meters from a well the pressure is commonly as great while the well is flowing as it is at the month of the well when the flow is stopped. ${ }^{b}$ Indicating the same thing is the fact that the flow of a well may be greatly increased by shattering the rock at the bottom of the well, thus producing supercapillary openings into which the water may issue from the capillary openings. If the area of these supercapillary openings be many times that of the cross section of the well, the chief source of friction is that of moving water in the well itself; for the water has a chance to slowly ooze from the capillary into the supercapillary tubes without rapid motion, and to make its way to the well tube through

a Leverett, Frank, The water resources of Illinois: Seventeenth Ann. Rept. L. S. Geol. Survey, pt. 2,1896 , pp. $805-806,811$.

$b$ Slichter, C. S., Theoretical in restigation of the motion of ground waters: Nineteenth Ann. Rept. U. S. Geol. Survey, pt. 2, 1899, pp. 363-36t. 
many supereapillary chanuels of much greater cross section than the well. The rapid movement is restricted to the section of water in the well, and there the friction is great. This Wisconsin ilhnstration is typical of natural systems of ground water flow; for, as shown on page 583, a natural system of flowage simulates a tree. At the ontset there are an indefinite number of minnte openings throngh which the water slowly moves to the branch openings. In the branch openings the movement is faster. The branches mite into the trunk channels, and in these the movement of the water is rapid.

The analogy to a tree has been suggested in order to get definitely in mind the general character of the circulation of ground water. But the analogy must not be pushed too far. A tree commonly has but a single, continnous, solid trmnk, although willows and other trees have many trunks. Very frequently, indeed commonly, the trunk channels of ground water cireulation are very complex. While a main watercourse may exceptionally occupy a single open passage, ordinarily it occupies a number of interlocking passages. These may be the parallel openings of a complex fanlt, the smaller numerous openings of a zone of fissility, or the more open places of sandstones or conglomerates. In short, a trunk channel of ground water differs from other channels only in that because the openings are larger than the average, they are places where there is more circulation.

Thus far the discussion has not taken into accomnt the geological work of the circulation itself. But the character of the circulation is being continually affected by the material deposited.

Later in this chapter it will be explained that under quiescent conditions the process of deposition of mineral material in the openings of the belt of cementation continues until the openings are practically closed. In proportion as this process is advanced the openings become smaller and the circulation slower. In many great, almost perfectly cemented formations, as the process neared completion, the movement of the ground water must have become exceedingly slow, and finally practically ceased. After a formation has been once cemented, orogenic movements may again produce fractures within it, and thus form new openings throngh which an underground circulation may again be set up. 
GENERAL STATEMENT.

In conclusion of this part of the subject, while the lessened viscosity with depth, slow movement, and long journey are all very favorable to a deep circulation, I have little doubt that in porous strata laroge openings near the surface and the more direct course of a shallow journey result, on the average, in much larger flowage in the upper part of the belt of cementation than in the lower part.

TEMPERATURE OF ENTERING AND ISSUING WATER, AND TRANSFER OF HEAT,

Before taking up the work of ground water in the belt of cementation it is necessary to consider the relative temperatures of the water which enters and departs from the sea of underground water. Is the water which joins the belt of cementation colder or warmer than that which issues from it?

At a certain definite distance below the surface, in most regions from 12 to 15 meters, seasonal variations in temperature are eliminated; the thermometer discloses no difference between the temperature of winter and that of summer. The thermal conductivity of the rocks is so low and the amount of water which passes to the belt of cementation is relatively so small that the great variations of temperature of the atmosphere, of the rocks at the surface, and of the meteoric water, emphasized on pages $433-444,458-460$, at the depth of a few meter's all merge into a temperature uniform for a given locality, but of course variable in different localities, and especially with latitude.

When the rain falls upon the soil it may be warmer or colder than the surface of the earth, but the part that sinks into the soil is subdivided between the pores of the rocks and comes into most intimate contact with them, so that when the water at the surface is warmer than the rocks it is cooled; when colder than the rocks it is warmed. Thus the two quickly assume nearly the same temperature. Doubtless downward-moving water is one of the most important of the agents which determine the fixed average annual temperature of the rocks a short distance below the surface. The reason for this belief is the high specific heat of water as compared with rocks. However, the relative influence of the heat given by water and that due to other climatic factors, such as latitude, altitude, etc., need 
not here be discussed. For the present purpose the important point is that for any locality at a very moderate distance below the surface the water and the rocks have a common and practically invariable temperature.

It is highly probable that the point at which there is no appreciable annual change of temperature is not deeper, on the average, than the level of ground water. If this be so we may consider the ground water as entering the belt of saturation at a fixed temperature. Assuming this, in order to answer the question whether the water is colder or warmer when it issues from the belt of cementation than when it entered the belt, it is necessary to consider in what manner the water may gain or lose heat during the interval.

For the following reasons it appears highly probable that, on the average, the water gains heat during its underground journey:

(1) Earth movements are general for the lithosphere, and in many regions these are of the most intense character. So far as earth morements take place, to a very large extent the energy of the mechanical action finally passes into heat. Where the movements are forceful the amount of heat thus producerl is considerable. The cireulating underground water in contact with the rocks necessarily absorbs some of this heat.

(2) It has been shown that the dominant chemical reactions that take place in the belt of cementation are those which liberate heat. Of all the reactions characteristic of the belt of cementation it has been pointed out that hydration is the most important, and this process liberates a large amount of heat. The chemical reactions therefore furnish heat which the percolating waters must certainly absorb, in part at least.

In the lower zone, that of anamorphism (see p. 167), it has been pointed out that the dominant chemical reactions take place with absorption of heat. But where these reactions take place it is only through the expenditure of mechanical energy which liberates heat to a greater extent than that absorbed by the chemical reactions. That is, as a result of mechanical action and chemical action together, as fully developed on pages $110-113$, there is a residuum of heat liberated to be absorbed by the water, and therefore if the reactions of the zone of anamorphism affect the temperature of the water of the belt of cementation at all it must be by addition of heat.

(3) Very large quantities of heat are brought into the belt of cementation by intrusive igneous rocks. The intruded rocks are partly cooled by 
twe transmission of their heat to the surrounding rocks and by conduction to the surface, but the underground circulating water in contact with the igneous rocks and in contact with the other rocks heated by them absorbs a large amount of the heat, probably a unch larger amount than that transmitted to the surface through conductivity.

(4) After the water joins the sea of ground water its vertical component is at first downward. Because of the normal increment of increase of temperature- $1^{\circ}$ C. in 30 meters-the descending water gradually absorbs heat from the rocks. During the ascent the water tends to give heat to the rocks, because it is passing from rocks of higher to those of lower temperature. But the upward movement of the water is of shorter duration, is in larger openings, and is more rapid than its downward movement (see pp. 582-584); therefore it seems probable that in consequence of normal increase of temperature due to depth, more heat is transmitted to the water than is abstracted from it.

When we combine all four of these factors it follows to a certainty that the water in its journey absorbs heat, on the average, and therefore issues from the belt of cementation at a higher temperature than it enters it. Hence it appears perfectly clear to me, from general reasoning, that during the circulation of ground water it abstracts heat from the rocks.

So far as I know, no attempt las been made to prove this general statement by observation; but it appears to be highly probable that it could be proved by careful experiments. $\Lambda t$ the crests of elevations in various regions temperatures should be taken at the level of ground water. In the same regions the average temperature of the water issuing from springs should be observed. The two sets of data should be compared. While no general observations have been made along these lines, in some regions of recent orogenic movements and volcanism observation does clearly show that the temperature of the issuing water is higher than that of the entering water. This is well illustrated by the Cordilleran region of western United States. This is a region of comparatively recent epeirogenic and orogenic movements and of volcanism. Gilbert and others ${ }^{a}$ have shown that, scattered throughout this vast region, accupying nearly one-third of the

a Gilbert, G. K., Volcanic rocks and mountains, with localities of thermal springs in the United States: U. S. Geog. Surv. W. 100th Mer., vol. 3, 1875, pp. 145-155. Howell, E. E.. Thermal springs: ibid., pp. 256-257. Stevenson, J. J., Mineral springs: ibid., pp. 478-487. 
United States, are many springs the temperatures of which vary from $30^{\circ}$ to $100^{\circ}$ C. For instance, in the Yellowstone Park are a great number of hot springs and geysers, the temperatures of which approximate $100^{\circ} \mathrm{C}$. That a rast anomit of heat is brought to the surface by the mnderground circulation of this district can not be doubted. The number of springs in the Cordilleran region which are known as lot is very small as compared with those which are simply warm. The warm springs, according to Gilbert, ${ }^{a}$ may be considered as those having a temperature between $18.3^{\circ}$ and $37.7^{\circ} \mathrm{C}$. ( $\left(65^{\circ}\right.$ and $100^{\circ} \mathrm{F}$.) or practically blood heat According to Gilbert, ${ }^{b}$ the water of all the foregoing springs exceeds the mean anmul temperature of the air by $8.3^{\circ} \mathrm{C} .\left(15^{\circ} \mathrm{F}\right.$.).

Although we have no data by which to verify the statement, I have no doubt whatever that the number of springs the temperature of which is slightly but measurably above the mean annual temperature exceeds many times the total number of all springs the temperatures of which are so notably above the normal temperature of the region as to be called warm or hot. Finally, it is lighly probable that the amount of water which escapes through notable springs is small as compared with that which reaches the drainage of the valleys throngh small openings and seepage. The movement of this water is relatively slow, and it may be presumed that it is at but a slightly higher temperature at the point of issue than the average temperature of the rocks of the surface. But it is to be remembered that a slightly higher temperature of issuing water over that of the entering water through the vast number of springs of very moderate temperature, and through seepage, is probably of far greater quantitative importance than the marked increase of temperature in the comparatively few warm and hot springs. This illustrates the old principle that widespread small forces and agents may be of more importance, sometimes incomparably more, than the more conspicuous but more circumscribed forces and agents.

In other regions of recent orogenic movements and volcanism essentially the same facts prevail as in the Cordilleran region of America; and therefore observation, so far as it has gone, confirms the general reasoning given on pages 590-591, that water issues from the belt of cementation at a higher temperature than it enters it.

Aside from the matter of metamorphism, this conclusion has a bearing upon the refrigeration of the earth. The heat of the earth produced by 
mechanical action, produced by chemical action, transferred to within the zone of fracture by volcanism, and derived from the interior by conduction, so far as it escapes is largely transferred by means of water. If this conclusion be true the question immediately arises as to the effect upon the temperature gradient.

Barus states that, because of the chemical action of water in the pores of rocks, heat is liberated; and that we may consider the zone of circulation as a furnace. From this he concludes that the temperature gradient observed is probably not high enough, on the average, or the "observed rate of increase of temperature with depth is too large." a The reasoning applied to heat developed by chemical reactions would apply to that produced by mechanical action in the zone of fracture and to that introduced by volcanism. But in Barus's statement the fact that the water is in circulation is altogether neglected. This makes the case much more complicated than Barus supposed. The water is in circulation, and, as already shomn, is constantly abstracting heat from the earth. Therefore it appears that, aside from volcanism, from the zone of fracture heat is being transferred to the surface in two ways-by conduction and by the convectional circulation of water. I snspect that the heat convectionally transferred by circulating waters is as great as or greater than that lost by conduction. The amount thus transferred by conrection may more than compensate for that developed within the zone of fracture by mechanical and chemical action and by volcanism.

The above suggestions are offered to show that the problem of the heat gradient is much more intricate than has been supposed, and that the heat problem of the earth can not be treated as a simple one in which conduction is the only factor to be handled. The problem is so complicated by chemical action, by mechanical action, by igneous intrusions and extrusions, and by the water circulation in the zone of observation, that any conclusion as to the loss of heat of the earth and the depth to which cooling extends which ignores these disturbing factors is of very little value, to say the least.

\footnotetext{
"Barus, Carl, The compressibility of liquids: Bull. U. S. Geol. Survey No. 92, 1892, 1"\}. S3-84. HON XLV1I-Ut-38
} 


\section{VARIABLE MATERIALS AND CONDITIONS OF BELT OF CEMENTATION.}

Within the belt of cementation the materials and conditions are variable, but not nearly so variable as in the belt of weathering. The materials within the belt of cementation include all the classes which exist in the belt of weathering (see pp. 429-430); that is, igneous rocks, sedimentary rocks, surficial rocks, metamorphosed rocks, and their variations and gradations; but ordinarily the alteration products are not nearly so complex in the belt of cementation as in the belt of weathering, and therefore the alteration forms of the belt are much less varied than those of the belt of weathering.

Water solutions are the main active agents at work in the belt of cementation. Gaseous solutions and organic compounds, which are so important within the belt of weathering, play a comparatively small part. The water solutions may contain any of the bases and acids which occur in the belt of weathering. (See pp. 457-458.) They may also contain gases in solution, of which oxygen and carbon dioxide are the more important, but others are of considerable consequence. In the belt of cementation the temperature varies with depth and also varies greatly in consequence of mechanical action and igneous intrusions. A great range of temperature is much more common than in the belt of weathering, but the speed of change at any place is slow, so that for a long time at any one place the temperature is relatively constant. The work of the belt of cementation is accomplished by mechanical and chemical agents, precisely as in the belt of weathering, but the character of the work performed is very different from that of the belt of weathering.

\section{WORK IN BELT OF CEMENTATION.}

The rocks in the belt of cementation are modified by mechanical work, by chemical work, and by igneous work.

\section{MECHANICAL WORK.}

The mechanical work of the belt of cementation occurs in commection with deformation. The mechanical work of wind, water, and ice, of changes in temperature, of plants and animals, so important in the belt of weathering, plays no part. The chief force producing deformation is gravity 
acting directly or indirectly through orogenic movements and intrusives. The direct pressure due to gravity increases with depth. It is therefore increasing at areas where loading is taking place by sedimentation or igneous accumulations, and is decreasing in areas where demulation is going on. Heat is also a force producing mechanical effects. As a result of denudation, by which process the rocks approach nearer the surface; by sedimentation, by which process rocks pass deeper below the surface; by mechanical and chemical action, and by the intrusion of igneous rocks, the temperature is changed. Increase of temperature expands the material affected, and therefore induces compressive strains and tends to decrease the openings within the rocks. Decrease of temperature produces the opposite effect.

The mechanical work of deformation includes the processes of consolidation, strain within the elastic limit, and strain beyond the elastic limit. Each of these processes is considered in tmrn.

CONSOLIDATION.

Mechanical consolidation is a process by which the separated parts of a rock are brought closer together through pressure. The pressure may be due to the weight of the superincumbent rocks, to the lateral thrust of orogenic movements, to the lydrostatic pressure of igneous rocks, and to mineral growth during cementation and metasomatism. The very idea of the zone of fracture, to which the belt of cementation belongs, implies that the rocks and mineral particles are sufficiently strong to be self-sustaining.

In proportion as the rocks show openings, and especially in proportion as they are incoherent, mechanical consolidation is likely to produce an important effect. The incoherent rocks comprise the mechanical sediments and tuffs in their original condition. The colerent rocks comprise both of the above classes which have been more or less cemented and the massive rocks which may have openings dne to various canseś.

For the present purposes the mechanical sediments are of two general classes, the silts and muds, and the coarse sands and grits. The first of these classes is the one which is most affected by mechanical consolidation. In many eases the mineral particles of the fine-grained silts and muds appear to be separated by water. In such a rock pressure gradually squeezes ont this water, bringing the mineral particles into contact. At the same 
time the mineral particles are mechanically readjusted in reference to one another. In consequence of the two the volume of the material may be considerably decreased. The process of consolidation ma continue until finally the particles are brought so close together that they cohere. As explained by Becker, ${ }^{a}$ when the films of water between the particles become very thin, they may become an important factor in the colherence of the rocks. The molecular attraction of the water films and the adjacent particles, or their adhesion, and the cohesion of the molecules of the films may be sufficient to give the rocks a certain amount of strength. As the process of squeezing out the water goes on, many of the particless are brought so close together as to be within the sphere of molecular attraction independently of the separating films of water. So far as this is true the particles are welded by the pressure. 'The welding and the adherent influence of the water films may give the muds and silts marked colnerence.

During the process of consolidation, as the water escapes the pressure to which it is subject gradually becomes less. Therefore if saturated or nearly so, during its escape it may deposit a portion of the material in solution, and hence cementation dependent upon mechanical consolidation may promote induration.

In proportion as the particles of the mechanical sediments become large and clean the process of mechanical consolidation becomes less important, for the points of contact rapidly decrease in number as the sediments become coarse, and where they are very coarse such contacts are so few that the rocks gain little strength as a result of close contact and the adherent effect of the films of water. Moreover, as shown by Professor Slichter, ${ }^{b}$ coarse mechanical sediments deposited by water are usually arranged in a somewhat compact manner. This natural arrangement, while not the most compact possible, is so compact that experiments show that subsequent mechanical disturbances sufficient to displace the grains in reference to one another ordinarily result in decreasing the compactness of the packing, and therefore in increasing the rolume of the rocks.

The tuffs are somewhat intermediate in character between the coarse and the fine mechanical sediments. They ordinarily include both classes

a Becker, Geo. F., The torsional theory of joints: Trans. Am. Inst. Min. Eng., vol, 24, 1895, p. 131.

$\checkmark$ Slichter, C. S., Theoretical investigation of the motion of ground waters: Nineteenth Ann. Rept. U. S. Geol. Survey, pt. 2, 1899, p. 305. 
of material in the same rocks. If originally arranged under air, they have a very much less compact arrangement than they or the ordinary sediments do if arranged nuder water. Thus many tuffs are in a condition in which mechanical adjustment of the particles by pressure may give a considerably more compact arrangement. Also, since between the coarse particles there are many fine particles, the number of points of contact between the particles may be sufficient to give considerable coherence by welding, and the strength is further increased by the adherent power of the water films, precisely as in the case of the muds and silts. Therefore it is probable that to a considerable extent tuffs may be consolidated by pressure.

In general in the zone of fracture the coherent rocks are sufficiently strong to support themselves, and mechanical consolidation is relatively unimportant. However, the openings produced by rather rapid movements may be subsequently gradually closed by the steady pressure of "gravity or thrust. In the massive rocks containing no openings mechanical consolidation has no appreciable effect.

\section{GTRAIN WTTHIN ELASTIC LTMT.}

All substances subjected to stress are more or less strained, and the amount of the strain is proportional, although not directly proportional to the stress. The rocks throughout the belt of cementation are all subjected to stress, and therefore to strain; for none are free from the weight of the superincumbent material, and in general they are subjected to compressive or tensile stresses parallel to the surface of the earth. It has been seen that in the belt of cementation the direct stress of gravity, and its indirect effect through orogenic morements, is sufficient to mechanically consolidate the rocks and to fracture them in the most extensive manner. It is clear that in a given case of rupture, before fracture took place the rocks must have been strained to the elastic linit. Therefore the amount of the strain within the belt of cementation varies from an insignificant quantity to strain to the elastic limit of the rocks under the conditions in which they exist. It would be generally agreed that the intensity of the strain is rery important at moderate depths. But it is commonly supposed that rocks near the surface, and especially in little disturbed regions, are not under considerable strain: but that this conchsion is erroneous is shown by observations which have been made by a-number of nen. Niles has 
shown a a high state of strain in the granite quarry at Monson, Mass. Before the quary was opened it would not have been supposed that the rocks were subject to any unusual amount of stress, but when the quarry was opened the rocks were found to be in such a state of strain that frequent ruptures spontaneously took place, or occurred with very slight assistance by the quarrying operations. Before quarrying began the rocks were prevented from lateral expansion, but after an excavation was made they were freed from pressure on one side, and this loss of restraint led to the rupturing already mentioned. That the Monson granite is elastically compressed is shown by the fact that when a great mass is cut off from the sides of the quarry it expands so that the bisected drill holes do not match. Also elastic compression is shown by the expansion at various times during: the quarrying, anticlinal arches thus being formed by the elevation of layex along horizontal planes of rupture. Johnston had previously described ${ }^{b}$ similar spontaneons movements in the sandstone strata at Portland, Conn. Niles has also given ${ }^{c}$ evidence of very important strain in the sandstone at Berea, Ohio, in the limestone of Lemont, Inl., and in quarries in Connecticut.

At rarious places in the Galena limestone of the Fox River Valley, Wisconsin, after excavation has been made, the layers have been found to be under such elastic strain that they have released themselves by expansion, forming anticlinal arches, in places $40 \mathrm{~cm}$. in height. ${ }^{d}$ Gilbert has described ${ }^{e}$ post-Glacial anticlinal arches at various places in the Devonian shale of New York and northwestern Ohio and in the Trenton limestone of New York. It thus appears that the rocks in the upper part of the belt of cementation may be in a state of strain near or even to the elastic limit at many places throughont extensire regions. The condition of mechanical strain can be discovered only by quarying processes, and by observations such as are given above. When a specimen is taken from a quarry in which

$a$ Niles, W. H., Peculiar phenomena observed in quarying: Proc. Boston Soc. Nat. Hist., vol. 1t, 1871, pp. 1-8.

$b$ Johnston, John, Notice of some spontaneous morements occasionally observed in the sandstone strata in one of the quarries at Portland, Conn.: Proc. Am. Assoc. Adr. Sci., 8th meeting, 185t, pp. $283-286$.

c Niles, W. H., The geological agency of lateral pressure exhibited by certain movements of rocks: Proc. Boston Soc. Nat. Hist., vol. 18, 1876, pp. 272-284.

dCramer, Frank, On a recent rock flexure: Am. Jour. Sci., 3d ser., vol. 39, 1890, pp. 220-225. Also, Cramer, Frank, On the rock fracture at the combined locks mill, Appleton, Wis.: ibid., 3d ser., rol. 41,1891 , pp. 432-434.

Gilbert, G. K., Post-Glacial anticlinal ridges near Ripley and Caledonia, New York: Am. Geol., vol. 8,1891 , pp. 230-231. 
the rocks are much strained, by that process it is largely relieved from strain, and a slide of it placed under the microscope may show little or no evidence of its former state of strain.

It therefore appears probable that a high state of strain is the common condition for the great mass of the rocks constituting the belt of cementation. It has been explained on pages 95-98 that in proportion as mineral particles are in a state of strain they are likely to be acted upon chemically by the ground solutions. Therefore the very general and marked state of strain in the rocks of the belt of cementation is probably a very important factor in their alteration. This is especially true of metasomatism. By that process, as explained on pages 690-692, the rocks may be released from strain, the mechanical energy producing the strain being utilized in promoting recrystallization. It is difficult or impossible to prove the importance of state of strain in metasomatism except by general reasoning, based upon the experimental facts referred to in Chapters III and VIII. But it is my confident belief that the general state of strain is one of the most important of the inciting causes of alteration.

STRAIN BEYOND ELASTIC LIMIT.

Strain beyond the elastic limit results in fracture. The belt of cementation belongs to the zone of fracture. It has been seen in the previous sections that deformation may be accomplished to a considerable extent by differential movement of the particles of incoherent rocks and by strain within the elastic limit. Where the rocks are coherent marked deformation in the belt of cementation is largely accomplished by fractures and by movements along the fracture planes. In the very partially indurated rocks fracturing may consist in the rupturing of the particles from one another, aud adjustment come by differential morements between the particles. But in the coherent rocks the ruptures are wider spaced than the individual grains. In the weaker coherent rocks the surfaces of rupture are more or less irregular, ordinarily breaking around rather than cutting through the grains. This form of rupture is well illustrated by sandstones. The strongly coherent rocks usually show clean-cut fractures which cut the mineral particles.

When rocks in the belt of cementation are strained beyond the elastic limit there is a marked tendency for the ruptures to follow planes more or 
less closely, and for the planes to be in parallel sets. In a given case there may be one or more of these parallel sets; commonly there are as many as three. In such instances the rocks are broken into parallelopiped blocks. In some instances there are as many as six or more parallel sets of ruptures, and by them the rocks are cut into various irregular forms.

The spacing of the different sets of ruptures is very variable. For instance, if there be three sets of ruptures, the distances between the fractures in one set may be several or many times' as great as between those of another set. The spacing of all the sets in one case may be much wider than that of any set in another case. The fractures may be very far apart, as with widely separated faults or joints, or they may be very close together. In some instances the different sets of ruptures are so close together that it is scarcely possible to find an umruptured parallelopiped a centimeter in diameter. Ruptures of this kind are very well illustrated in the slates and graywackes of the Wausan district of Wisconsin. However, in the belt of cementation the ruptures are not so close as to cut all, or even any considerable proportion, of the mineral particles. Between the amount of rupturing necessary to produce particles a fraction of a centimeter across and that necessary to affect every mineral particle there is a very wide gap. In general, near the surface the ruptures are likely to be widely spaced, with considerable differential movement along the firactures. As depth increases, so that the rocks are subject to the weight of the superincumbent material, the ruptures are likely to be closer together. When the depth become so great that the fractures affect the individual mineral particles, the zone of anamorplism, or rock flowage, has been reached.

The fractures produced in rocks must take place as a result of tensile or compressive stresses." Where the rocks are homogeneous and the fractures are by tensile stresses, they take place normal to the force. Where the fractures are by compressive stresses - and this is probably much more common-the ruptures are inclined to the direction of maximum compressive stress. Ignoring the effect of the stress, and supposing the rocks to be homogeneous, the ruptures would occur in sets at angles of $45^{\circ}$ to the maxinum stress. However, since the stress itself gives additional strength

a Becker, G. F., Finite homogeneous strain, flow, and rupture of rocks: Bull. Geol. Soc. America, rol. 4, 1893, pp. 48-49. Van Hise, C. R., Principles of North American pre-Cambrian geology: Sixteenth Ann. Rept. U. S. Geol. Survey, pt. 1, 1896, pp. 668-678. 
in the direction of compression, the inclinations of rupture are inclined at angles less than $45^{\circ}$ to the direction of greatest compressive stress.

The actual direction of fracture depends not only upon the direction and nature of the stresses, but upon the character of the rocks. The directions of rupture are greatly influenced by the variable strength of the rocks, by the rock structures and textmes, and by the difference in size and strength of the constituent particles. Because of these varying factors force is transmitted with unequal efficiency in different directions. Consequently the direction of the maximum stress is not the same throughout a rock mass, but varies firom place to place. This variability both in the nature of the rock and in the direction of the stresses gives very great irregularity of rupturing. Because of these variable factors no comprehensive statement can now be made as to the directions of ruptures in rocks; but certain special conclusions are evident. Where the rocks are heterogeneous the ruptures are likely to take place to a greater extent in the weaker rocks. Where there are contacts of strong and weak rocks ruptures are likely to take place at the contact planes, for these are planes of weakness. Where there are regular structures, such as bedding, gneissosity, schistosity, cleavage, the ruptures are likely to follow these planes of weakness. Where in a rock the particles have variable strength, weaker particles suffer more than the stronger ones. In the rupture of mineral particles fractures are likely to follow cleavage planes, since these are planes of weakness. All these factors result in giving ruptures which vary greatly from positions at right angles to tensile stresses and from $45^{\circ}$ to the maximum compressive stresses.

It follows from the foregoing that the determination of the precise direction and nature of the forces which produced rupture in any individual rock is a most difficult matter.

After ruptures are produced differential movements may result in the rubbing of the parts adjacent to the fractures against one another. At such places the individual mineral particles may be granulated. However, this fracturing of the mineral particles is largely confined to thin layers along the walls of the openings. This fracturing of the particles is in many respects like the fracturing of mineral particles in the zone of anamorphism. (See pp. 673-675.) The matter is not further considered here.

From the foregoing it follows that deformation accomplished by fracture in the belt of cementation results in breaking up the rocks into great 
masses by faulting, into blocks by jointing, into layers by fractures along bedding planes and other planes of weakness, into narrow slices by fissility, and into irregular fragments by brecciation. It has furthermore been seen that deformation produces comparatively unimportant changes in the size of the masses between the fractures. In these masses the original structures and textures are unaffected. But it will be explained under cementation, metasomatism, and injection, that the ruptures furnish conditions very favorable for these processes. Everywhere the ruptures give ready passages for the circulating ground water; everywhere they give ready entrance to intrusives. In consequence, the openings are closed by cementation and injection. Moreover, from the openings the water, frequently heated and loaded with material, is able to make its way for short distances in the subcapillary openings between the grains, and thus metasomatic processes are greatly pronoted. Where the spacing of the fractures is small metasomatism may modify the unbroken masses throughout. Where the spacing of the ruptures is somewhat wide the metasomatic alterations may not extend all the way from one passage to another, and thus leave the interiors of the masses unaffected. Therefore there is very great variation in the amount of metasomatic alteration in passing from the walls of the openings to the interiors of the large unbroken masses. This has been fully worked out in connection with ore bodies, which commonly form along widely spaced, simple or complex, large openings. Lindgren especially has shown ${ }^{a}$ how metasomatic processes greatly affect the walls of the fissures. The effect gradually dies out in passing away from the openings, but may be marked for some distance.

\section{CHEMICAL WORK.}

The chemical work in the belt of cementation needs consideration from two points of view-the chemical changes and the resulting processes.

\section{CHEMICAL CHANGES.}

The chemical work within the belt of cementation is accomplished mainly by water solutions. Water is here the great agent of metamorphism, but the igneous rocks are second only to water solutions. They

$a$ Lindgren, Waldemar, Metasomatic processes in fissure veins: Trans. Am. Inst. Min. Eng., val. 30, 1901, pp. 578-692. 
are of vastly greater importance than in the belt of weathering. At the surface or within the belt of weathering, igneous rocks rapidly lose their heat, and thus produce a comparatively short-lived effect. Within the belt of cementation the igneons recks retain their heat for a very long time. By their introduction they produce both a direct effect, due to their own action, and-far more important-an indirect effect by heating the solutions, and thus very greatly increase their efficiency both as to speed of reaction and as to quantity of material which can be held, as is fully explained elsewhere. . (See pp. 79-81.)

The range of temperature at which the solutions work is from $0^{\circ} \mathrm{C}$. to the critical temperature of water, which, as we have seen (pp. 566-569), is $365^{\circ} \mathrm{C}$. The amount of work which the solutions accomplish in a given time at very high temperatures is almost indefinitely greater than that which is accomplished at lower temperatures. (See p. 79.)

The pressure at which the solutions work varies from that of an atmosphere to the pressure of a column of water to the bottom of the zone of fracture. Supposing the bottom of this zone of fracture to be at a depth of 10,000 meters, the maximum pressure would be 1,000 kilograms per square centimeter. Therefore the range of pressure upon the solutions within the belt of cementation is very great.

By observation we know that in the belt of cementation the important chemical reactions which take place as a result of the action of the various agents are oxidation, carbonation, hydration, and solution and deposition. These reactions are the same as those in the belt of weathering. Just as in the belt of weathering, the reactions of oxidation, carbonation, hydration, and possibly solution preponderate over the reverse reactions. However, the relative importance of these various reactions in the two belts is very different.

All of these reactions, as has been seen, are of very great consequence in the belt of weathering. Oxidation and carbonation are of much less consequence in the belt of cementation; but this statement can not be made of hydration, solution, and deposition. Hydration, because of the decreased prominence of oxidation and carbonation, becomes the chief one of these three processes in the belt of cementation. Solution and deposition are both of fundamental importance; but the first, solution, does not dominate as it does in the belt of weathering. All of these reactions have been fully 
considered in Chapter VI on "The belt of weathering," and they will here be taken up only so far as their work is different in the belt of cementation from that in the belt of weathering. The modifications are easily made for oxidation, carbonation, and hydration and their reversals, but are complicated for solution and deposition.

In the upper part of the belt of cementation, that near the level of ground water, the active agents in, the solutions are very similar to those in the belt of weathering, and therefore the reactions are closely allied to those of the belt of weathering. But as depth below the belt of weathering increases, the distinctions between the reactions which are of controlling importance in the two belts becomes more and more clear, and for the major part of the belt of cementation the relative importance of reactions is very different from that in the belt of weathering. The depth to which all the reactions of the belt of weathering extend into the belt of cementation depends very largely upon whether the waters for the particular area are ascending or descending. At places where large amounts of descending waters are converged, and where the variations of topography are marked, so as to give a very high head, all the reactions of the belt of weathering may be quantitatively important to depths of $800 \mathrm{or} 1,000$ meters or more, although such depths as these are very unusual. But where the descending currents are driven by a low head, some of the reactions of the belt of weathering may extend only to a very moderate deptlı into the belt of cementation. In areas where the water currents are ascending, and so continue to the belt of weathering, some of the reactions of the latter belt may extend scarcely at all into the belt of cementation. Oxidation, carbonation, hydration, and solution and deposition commonly do not take place separately, but occur at the same time upon the same materials; although, as pointed out on page 611, in the upper part of the belt of cementation, carbonation and oxidation are to some extent exclusive of each other. But for the purposes of analysis it is necessary to treat each separately.

bxideitiox.

Ordinarily when water passes from the belt of weathering into the belt of cementation it contains oxygen in solution. The amount of this oxygen may be as great as can be dissolved under atmospheric conditions of pressure and temperature, or the water may be saturated. From this the 
amount varies to almost nothing. Also, in consequence of atmospheric pressure, oxygen may be forced into the sea of ground water to some extent. The favorable conditions for abundant oxygen in the water when it joins the belt of cementation are a very porous belt of weathering and absence of luxuriant regetation. Under such conditions the atmosphere circulates somewhat freely through the belt of weathering, and as oxygen is exhansted in the belt by the processes of oxidation it is resupplied to the solutions by the atmosphere.

It is seen (pp. 609-610) that the sonrces of carbon dioxide are abundant, and therefore that the process of carbonation is almost universal in the belt of cementation. The situation is very different with oxygen. Practically the only oxygen supplied is that which is carried down by solutions from the belt of weathering and that which makes its way into the water of the belt of cementation at the level of ground water in consequence of atmospherie pressure. It naturally follows that, as the waters move downward and the process of oxidation continues, the amount of oxygen available becomes less and less. Commonly the oxygen is practically exhansted at very moderate depths. Therefore, while oxidation takes place within the belt of cementation wherever oxygen is available, for much of the belt there is no oxygen arailable for this process and hence oxidation does not occur. This general reasoning is plainly confirmed by observation. The waters of the upper part of the belt of cementation are commonly oxidlizing, while the deeper waters of the belt rarely contain oxygen. According with this general observation, Lepsins has made exact experimental tests of the amount of oxygen in waters derived from bore holes, and he finds that with increase of depth there is a gradual and somewhat uniform decrease of oxygen container in the ground waters. ${ }^{a}$ Bischof many years ago verified the depletion of oxygen as the result of oxidation by determinations of the relative amounts of oxygen and nitrogen in springs. He found in cold springs that the oxygen is not so great in proportion to the nitrogen present as in the atmosphere, and in warm springs this deficiency is even more marked, and he correctly explains this deficieney as dne to the "partial combination of this gas with oxidizable substances."

a Berichte Deutich. chem. Gesell., vol. 18, 1885, p. 2487.

$b$ Bischof, Gustav, Elements of chemical and physical geology, translated by Paul and Drummond, Harrison \& Sons, London, 185t, vol. 1, p. $23 \%$. 
Under ordinary circumstances oxygen is practically exhansted in the early part of the journey, so that it is rather unusual for marked oxidation to extend more than a few meters below the level of ground water. But where, becanse of marked relief, there are large and strong downwardmoving currents through open and porous rocks, the process of oxidation may extend to a very considerable depth into the belt of cementation. This has been especially noticed in mining regions, where ore deposits are commonly located along joints, faults, or other trunk channels where there are numerous and large openings. One of the best illustrations of oxidation extending to a considerable deptl is that furnished by the iron ores of the Lake Superior region. Here, as fully explained in the chapter on ore deposits, the process of oxidation has extended on a very great scale to the depth of 100 meters, in mines has produced great ore bodies to a depth of 300 meters, and exceptionally has gone on to an important extent to a depth of 500 to 700 meters. As an instance in which oxidation has extended to a great depth may be mentioned the San Juan district of Colorado. Here in some of the mines oxidation is marked to a depth of 600 meters, and is occasionally noticeable to a depth of 1,000 meters. In contrast with such regions as these are others in which the water ascends almost or quite to the surface. In such instances oxidation scarcely extends below the level of ground water: An excellent illustration of this is furnished by the Missouri-Kansas lead and zinc district.

The oxygen is chiefly utilized in the oxidation of iron, sulphur, and organic material. In the upper part of the belt, where oxygen is abundant, large amounts of hematite and limonite nay be produced by the oxidation of the ferrous particles, but for the greater part of the belt of cementation, where oxygen is somewhat deficient, the ferrous oxide is oxidized only to the form of magnetite, since this requires, per unit of iron, only two-thirds as much oxygen as to produce hematite and limonite.

The sulphur is mainly united with the iron as pyrite and marcasite. At the same time the sulphur is oxidized the iron also is oxidized. Where the oxygen is abundant there may be produced ferrous sulphate, or ferric oxide and sulphuric acid; but where oxygen is not abundant, as in the major portion of the belt, magnetite and sulphurous acid are more likely to be formed.

Where the oxygen is utilized in the oxidation of organic material carbon dioxide and water are producerl, and these compounds join the 
circulating ground water. In many cases the major portion of the oxygen is thus utilized. In so far as this takes place the process leaves no direct evidence of itself by the existence of oxides. So far as suphuric acid is formed the same is true. The carbonic acid and the sulphuric acid may remain in part in the belt of cementation in carbonates and sulphates. So far as this occurs the oxidized compounds remain in the belt, but not as substances which we ordinarily think of as evidences of the process of oxidation.

After the oxygen of the waters of the belt of cementation is exhausted organic and other compounds, such as sulphides, are likely to be taken into solution, which renders the waters reducing, as explained on page 165 . The waters under impervious strata which take a long underground journey are especially likely to be in this condition, for such a journey furnishes ample time for the complete consumption of the oxygen contained in the solutions. The above is illustrated by the deep artesian waters of many parts of the world. Excellent cases are those furuished by the artesian waters of the Potsdam sandstone of Wisconsin and the Dakota sandstone of the James River Valley, Dakota. The waters which issue from the Potsdam formation along Iake Michigan are of a reducing character, containing, as noted by Chamberlin, some hydrogen sulphide.

Where the waters become reducing deoxidation of the compounds with which they come into contact may take place.

One form of deoxidation is of sufficient consequence to require mention. While of no great quantitative importance, it is important from the point of view of the metallic ores. It has been explained under "The belt of weathering" (pp. 468-469) that the sulphides are continuously oxidized to sulphites or sulphates. A part of the sulphurous and sulphuric acid mited with the original elements, or with other elements, joins the belt of cementation. After the oxygen is exhausted and organic compounds are present the sulphites and sulphates may be reduced to sulphides by the direct action of the organic matter, or by these componnds after passing into the solutions.

The process of reduction, or deoxidation, of the sulphates involves the oxidation of the organic material, and thus this reaction, from one point of view only, is reduction. From the other point of view it is oxidation. p. $5+7$.

a Chamberlin, T. C., The ore deposits of southwestern Wisconsin: Geol. of Wisconsin, vol. 4, 1882, 
Thus the process of deoxidation or rednction, so far as it takes place, involves the passage of the oxygen abstracted to the reducing agents or their oxidation. Moreover, the sum total of the heat effect, taking into account both the reduction and the oxidation, is to liberate heat. Hence the reaction is one normal for the zone of katamorphism. The sulphides formed may be precipitated and serve as one of the subordinate cementing substances. The formation and precipitation of sulphides will be much more fully considered in Chapter XIl, on "Ore deposits."

We have just seen that deoxidation, so far as it takes place, is explained by oxidation of some other compound. But oxidation by the oxygen originally derived from the surface and present in the solution does not involve the deoxidation of some other compound. It therefore follows that the process of oxidation in the belt of cementation overbalances that of rednction in the belt by the amount of axygen which is carried into the belt of cementation by the entering waters, and is abstracted from it by the union of the oxygen with the compounds enconntered during its undergromnd joumey.

It has been explained on page 467 that the process of oxidation of inorganic compounds involves increase of volume varying under ordinary cireumstances from a small amount to as much as 64 per cent. But by the oxidation of the carbonates carbon dioxide is liberated, and this may give a considerable decrease in the volume of the product, amounting in some instances to as much as 50 per cent.

In summary, it is clear that oxidation is a reaction characteristic of the belt of cementation, but that in this belt it has no such importance as in the belt of weathering. In the belt of cementation oxidation goes on but to a very limited extent. While in the upper part of the belt great masses of highly oxidized rocks are locally found, as in the case of iron ores, for the major part of the belt the evidences of oxidation are not apparent, it being evidenced perhaps to the greatest extent by magnetite.

CaRBonation.

The water which passes from the belt of weathering to the belt of cementation carries dissolved carbon dioxide precisely as it does oxygen. The quantity thus carried varies from an exceedingly small amount to sufficient to produce saturation. 
It has been fully explained on pages 473-475 that carbon dioxide is produced in large quantities in regions of abmind vegetation, where the process of oxidation of carbon goes on on a great scale in the belt of weathering. Therefore, the conditions for abundant carbonic acid in the waters joining the belt of cementation are those of luxuriant vegetation. It has just been explained that the conditions favorable for the transportation of abundant oxygen to the belt of cementation are those of open soil and lack of regetation. Hence, the waters which carry carbonic acid plentifully to the belt of cementation are not likely to carry oxygren plentifully. Where one is abundant the other is likely to be deficient It has just been explained that the process of oxidation may take place upon carbonates. Also, by oxidation of organic matter which has been so deeply buried as to be within the belt of cementation, carbon dioxide is formed. In so far as these occur carbon dioxide is produced by the reactions within the belt of cementation itself, and thus is added to the ground solutions. It thus appears that the occurrence of one of the chemical processes within the belt of cementation, that of oxidation, by its very action produces another active agent, carlyon dioxide, and therefore promotes the second of the important reactions of the belt of cementation, that of carbonation.

The third source of carbon dioxide for the belt of cementation, as is fully explained in the following chapter (pp. 677-679), is the process of silication, with simultaneous decarbonation as a prominent and often a dominant reaction. Some of the liberated carbon dioxide is permanently retained in the zone of anmorphism as occluded gas and liquid. (See p. 678.) But the temperatures of the zone of anamorphism are above the critical temperature of carbon dioxide. This compound is therefore originally a gas, and is capable of making its way through very small openings. Doubtless a considerable amount of it escapes from the zone of anamorphism and enters the belt of cementation. Thus is largely explained the abundant carbonic acid which is frequently found in the waters of deep mines rising from a still deeper source.

It therefore appears that the waters of the belt of cementation have four important sources of carbon dioxide-from the belt of weathering, from the decomposition of carbonates of the belt of cementation through oxidation, from the oxidation of organic material within the belt of cemenMON XLVII $-0 \pm-39$ 
tation, and from the silication of carbouates in the zone of anamorphism. Therefore, the carbon dioxide for carbonation in the belt of cementation is contributed by the belt of weathering above, by the zone of anamorphism below, and by the belt of cementation itself.

Bischof fully realized the very great abundance of carbonic acid in "a numerons class of springs which are abundantly distributed over the surface of the earth, especially in districts where extinct volcanoes or basaltic rocks occur:" a He also notes that "carbonated springs which evolve abundance of this gas are likewise met with in the midst of sedimentary formations." "The locations of a very large number of carbonated springs scattered through extensive regions are mentioned. ${ }^{c}$ Bischof further says that the carbonated springs "are always situated at the lower part of momitain declivities or at the deepest points of valleys, generally near brooks;" while "fresh-tvater springs issue at points still higher above the bottom of the valley, and sometimes at tolerably considerable

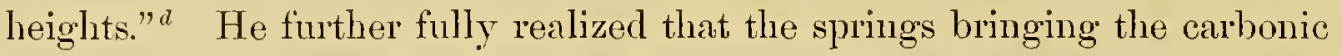
acid abundantly to the surface are deep-seated waters which have arisen from considerable depths. ${ }^{e}$ Finally, Bischof attributes the abundance of carbonic acid in the waters of deep springs and those which come from deep borings to the silication of the carbonates. However, he recognizes that the carbonic acid found in the waters of wells is also produced in part by the oxidation of organic material. ${ }^{f}$ Bischof therefore many year's ago correctly gave two main sources of carbon dioxide for the water of the belt of cementation.

It has been fully explained on pages 160-161 that, under the conditions of the belt of cementation, where the rocks support themselves and openings exist, the reactions take place which liberate heat. Carbonation of the silicates and oxides belongs to this class. (See pp. 475-480.) It therefore follows from general reasoning that the carbon dioxide abundantly supplied to the waters of the belt of cementation will react upon various compounds and produce carbonates. Of the compounds upon which it acts

a Bischof, Gustav, Elements of chemical and physical geology, trans. by Paul and Drummond, Harrison \& Sons, London, 1854, p. 217.

$b$ Bischof, cit., rol. 1, p. 217.

¿Bischof, cit, vol. 1, pp. 218-241.

a Bischof, cit., rol. $1, \mathrm{p} 223$.

e Bischof, cit., vol. 1, pp. 228-230.

$f$ Bischof, cit., vol. 1, p. 239 . 
the silieates are undonbtedly those of dominant importance. The action of carbonic acid upon the silieates results in the production of carbonates of the bases and the liberation of silica, which nay remain in situ as quartz or go into solution as eolloidal silicie aeid. Monoxides of iron and manganese originally present in this form or produced by the oxidation of sulphides may unite with the earbon dioxide and form earbonates.

Since the carbon dioxide of the belt of cementation is derived from above, from below, and, by reactions of oxidation, from within the belt, one would expeet earbonation to take place throughout the beit of cementation. In the upper part of the belt of cementation the main source of supply of earbon dioxide is that from the belt of weathering; but, as has been noted, wliere the earbon dioxide is abundant oxygen is apt to be deficient, so that where one finds aetive carbonation in the upper part of the belt of eementation one would not expect to find aetive oxidation.

The majority of the carbonates formed, and those originally present in the belt of cementation, are rather soluble. Commonly, therefore, the waters issuing from the belt of cementation contain very large amonnts of carbonates and earbon dioxide. Average amounts of carbonates given by Peale from many mineral springs from various portions of the United States are as follows: ${ }^{a}$

\begin{tabular}{|c|c|c|}
\hline North Atlantic States. : . & $\begin{array}{l}\text { rains per gallon. } \\
-. \quad 32.88\end{array}$ & $\begin{array}{c}\text { Milligrams per liter. } \\
56.27\end{array}$ \\
\hline South Atlantic States... & .. 13.70 & 23.45 \\
\hline North Central States . - & 45.35 & 77.62 \\
\hline South Central States.. & 18.30 & 31.32 \\
\hline Western States... & 139.59 & 238.90 \\
\hline
\end{tabular}

Carbonic acid is a very mueh less active agent than oxygen. The process of earbonation therefore takes place slowly, and the carbonie acid does not all succeed in getting united with the bases. In many instances the amount which has failed to mite with the bases is large. This is illustrated by the abundance of nneombined carbon dioxide in the waters of many of the famous springs of the world, as those of Carlsbad and Shasta, and also by the great abundance of uncombined carbon dioxide noted in connection with the rising waters of many mines.

It has been explained under "The belt of weathering" that the increase in volume in the process of carbonation of the silicates, provided

a Peale, A. C., Lists and analyses of the mineral springs of the Inited States: Bull. I'. S. Genl. Survey No. 32, 1886, 1p. 1-235. 
the liberated silica remains in sitn, varies in most cases from 15 to 50 per cent. If, therefore, the carbonates produced and the silica liberated be deposited, there is great increase in volume.

While in the belt of cementation carbonation unquestionably dominates over decarbonation, doubtless it frequently happens during earth movements that the pressure is so great that silication and decarbonation take place.

\section{HYDRATION.}

It has been stated that the belt of cementation might almost equally well be called the belt of satmation. Water is everywhere present. The process of lıydration is one which involves a great increase of volume, but openings exist which may be utilized by the process without overeoming the strength of the rocks or gravity. Therefore the conditions are ideal for liydration, and this everywhere oceurs. Indeed, it is in the belt of cementation that the great group of hydrous silicates form most abundantly. The belt of cementation is the home of the hydromicas, of the chlorites, of the zeolites, of serpentine, of the epidotes, and of limonite and gibbsite. Kaolin and tale also form there, although they are more especially characteristic of the belt of weathering. The increase in volume in these processes of hydration, provided all the compounds remain in sitn, varies in most cases from 20 to 50 per cent. While, as already explained, oxidation and carbonation are important in the belt of cementation, the process of lydration occurs on a vastly greater scale, and the chief change in volume in this belt is due to this process.

Just as decarbonation may take place under conditions of exceptional pressure in the belt of cementation, so dehydration may, and certainly does, occur, although this is so subordinate to the process of hydration as almost to be negligible.

SOLETION ANI) DEPOSITION.

Both solution and deposition are processes of great importance in the belt of cementation. We have already seen that deposition occurs on so great a scale as to make the filling of the cavities and consequent cementing of the rocks the rule. While at first thought it might be supposed that solution is subordinate, a close analysis shows that this process is not less important than deposition, and, indeed, it may more than balance deposition. 
QUANTTATIVE RELATIONS BETWEEN SOLUTION ANN DEPOSITION.

It has been fully explained that the belt of weathering at any given time represents the partly disintegrated and decomposed material above the level of ground water. During the long-continued erosion of a region the belt of weathering steadily migrates downward. 'Thus the forces of weathering continually find new material at the bottom of the belt upon which to work. Therefore, as denudation goes on, there is always a belt of a certain thickness in which weathering processes are taking place. These inchude solution as a dominant process. It has further been noted that the material abstracted from the belt of weathering is divided into two parts, one of which goes to the overground circulation and thence to the sea, the other of which passes through the belt of weathering into the belt of cementation below. Each unit of water which passes downward through the belt of weathering into the belt of cementation carries with it in solution a certain amount of material. As a consequence of continuous downward migration of the belt of weathering, it is certain that an increment of material is continuousiy added to the belt of cementation from the belt of weathering.

If this increment which the sea of underground water continually receives were deposited in the belt of cementation, it would furnish a sufficient supply of material for the cementation of that belt. Much of this material is certainly deposited in the belt of cementation, but in that belt solution is also taking place, and the question therefore arises whether or not more material is deposited than is dissolved in the belt of cementation. This question is not easy to answer, but we know certain data which have an important bearing upon it.

One of the fundamental conclusions worked out in Chapter III, on "The agents of metamorphism," is that the quantity of water which passes through the belt of weathering and enters the sea of underground water is substantially equal to that which emerges from this sea through springs and through seepage and joins the rmoff. If we knew the relative amounts of material contained in solution in the waters entering and issuing from the belt of cementation, we could auswer the third question-i. e., whether more material is dissolved or deposited in the belt of cementation. But the only possible way to get this information is by numerous analyses. 
In rarions regions the amounts of salts should be determined in the solutions near the bottom of the belt of weathering and in the solutions issuing from the belt of cementation. Such a comparative analytical study has not been made, and we must therefore have recourse to general reasoning for a probable answer to the question of the relative amounts of the salts entering and issuing from the belt of cementation.

It might be concluded that the actual fact of widespread consolidation due to filling the openings of the belt of cementation, so fully emphasized in the opening pages of this chapter, is evidence that the amount of material contained in the water issuing from the belt is not so great as that which joins it through percolation. But there are considerations which render this view very doubtful. As shown by numerous analyses, it is certain that large amounts of materials are contained in the spring and seepage waters which issue from the belt of cementation. From general considerations, if the character of the compounds transported be ignored, one would expect that this amount would be greater than that which entered the belt. These considerations are as follows:

As water passes throngh the belt of weathering and enters the belt of cementation it may not have been sufficiently long in the belt of weathering and in close enough contact with the various compounds to become saturated. Doubtless in many cases of fine soils containing plentiful soluble compounds, where vegetation is abundant and percolation is slow, saturation for many of the compounds may be approached or even attained. But where there are coarse and thin soils underlain by fissured or porons material, it is highly probable that the descending waters are far from saturated when they leave the belt of weathering and join the belt of cementation. After the waters join the belt of cementation they take a longer or shorter journey before issuing at the surface. It has been explained (pp. 584-586) that the general movement of the ground water is exceedingly slow. In many instances also its journey is long-in some areas hundreds of kilometers. In this connection it may be recalled that it was calculated that the waters which issue at Chicago probably entered the ground in central Wisconsin somewhere from one hundred and fifty to two hundred and fifty years before This factor of time, therefore, is of fundamental consequence in the rork of the water of the belt of cementation, and it would be strange if the water which has taken a considerable 
journey in a formation, even if but a small fraction of that in the case mentioned, should not become saturated with the compounds with which it is in contact.

The journey of the water in the belt of cementation involves a component parallel to the surface and a vertical component. As a result of the component of the movement of ground water parallel to the surface there is a tendency for material to be taken into solution and to be abstracted by the water. For a given depth the pressure and the temperature are, on the arerage, the same. The longer this course the nearer will the water approach to saturation with the compounds with which it is in contact, because of the time factor. If the journey be long, the state of saturation may be attained at a comparatively early stage, after which the additions and subtractions of material may be presumed, on the arerage, to neutralize each other, although in a given instance the total amount of material held in solution would vary greatly, depending upon the character of the rocks with which the water is in contact.

Under normal conditions, so far as the vertical component is concerned there is steadily increasing pressure and temperature during the downward movement, and steadily decreasing pressure and temperature dùring the upward movement. If the places of entrance and issue were at the same level, these two factors might be considered to neutralize each other, but the descending column is necessarily the longer; therefore the balance of the two processes is in favor of solution rather than deposition. Also, unless the water has become saturated during its descent solution will continue during its ascent until saturation is attained, and if the vertical component be short, this may not occur before the entire ascent has been made.

Finally, the temperature of the entering and issuing water is of great consequence in the matter of relative quantities of dissolved and deposited materials. Even if the temperature were precisely the same at the entering and issuing points this would favor solntion, for increase in temperature as the water descends very greatly accelerates the process of solution, and as the water ascends precipitation takes place only when saturation is reached, and then only to an extent sufficient to prevent supersaturation.

But into this matter of temperature another very important factor enters. It has been shown on pages 589-592 that, on the average, the temperature of the issuing water is higher than that of the entering water. 
It has been fully explained on pages 79-81 how important a slight increase in temperature is, not only in respect to the speed with which material is dissolved, but in respect to the quantity which may be taken into solution before saturation is reached. This small average additional increment of heat in the issuing water over that of the entering water is very favorable to the presence in the issuing water of larger amounts of material than was contained by the entering water:

Therefore it appears that, in proportion as the underground journey of the water in the belt of cementation is slow, in so far as it has a horizontal course, in so far as it enters at a ligher elevation than it issues, and in so far as it issues at a higher temperature than it enters, it should contain more material in solution per unit mass when it issues than when it enters. From all these points of view it is to be expected that ground waters contain more material in solution when they issue from the belt of cementation than they contained when they entered that belt, and that waters which have taken a journey of considerable length in a uniform formation will have reached a state of almost complete equilibrium between themselves and the surrounding rocks, or will be saturated.

But another important factor enters into the matter. It is not to be supposed that during the underground journey the materials which are held in solution are the same. Throughout the journey there are various chenical interactions. Much of the material brought from the belt of weathering is deposited; there is solution of material at a certain place, and later deposition of it elsewhere; there is interaction between the solutions and solids; there is interaction between the mingled solutions from different sources.

It is the uncertainty as to the average effect of these varions chemical reactions that leaves us in doubt as to the end result; that is, whether or not the solutions of all systems of circulation are, on the average, richer in material when they emerge from the belt of cementation than when they entered it. For instance, if a solution containing oxygen were mingled with a solution in which iron was the chief base, hematite or limonite would be precipitated, and the solution would be depleted in material even if the temperature of the water were higher at the end than at the beginning of the journey. Again, colloidal silicic acid is readily soluble even at low temperatures, but the acid has a marked tendency to decompose into water and silica, though the reaction is a slow one. So far as it takes place in the 
belt of cementation, there is precipitation of quartz and reduction of the amount of material held in solution, even if the temperature be higll. Indeed, it is not improbable that high temperature is favorable to the dehydration of silicic acid. ${ }^{a}$ Because of the uncertainty of the effect of the chemical reactions, one can not say whether more material emerges with the solutions than enters with them. Were it not for the enormous quantity of colloidal silicic acid contributed by the belt of weathering and the dominant importance of quartz as a cement (see pp. 622-623), probably solution due to the causes above assigned would overbalance deposition. But in the present state of knowledge I must leave unanswered the question as to which of the processes, solution or deposition, is preponderant in the belt of cementation. Both are of the utmost consequence.

Concluding, we now see that the unity of the belt of cementation and the belt of weathering from a physical-chemical point of view is perfect. Both are belts of oxidation, carbonation, hyclration, and solution and deposition. Both are belts of reactions with liberation of heat and expansion of volume. The contrast between the two belts is largely due to the variable quantitative value of each of these processes in the two belts and the resulting condition in which the rocks are left-disintegraterl and softened in the one and cemented and indurated in the other.

\section{RESULTANT PROCESSES.}

The processes resulting from the chemical clanges are cemertation and metasonatism.

$$
\text { CEIENTATION. }
$$

By cementation is meant the binding together of the rock particles by deposition of material as minerals in the interstices of the rocks. In the previous chapter on "The Belt of Weathering," we ascertained the source and character of the materials which joinerl the sea of ground water and which are therefore available for cementation in the belt of induration. It is clear that there are constantly being added from the belt of weathering to the continuous sheet of water in the belt of cementation the following compounds: Sodium, potassium, calcium, magnesium, iron, aluminum, as carbonate, sulphate, nitrate, phosphate, chloride. With these there are also

a Mendeléeff, D., Principles of chemistry, trans. by George Kamensky, Longmans, Green \& Co., London, 1897, vol. 2, p. 112. 
abundant colloidal silicic acid and lesser proportions of the rarer bases and acids, such as manganese, hydrofluoric, and boric. In the following section on metasomatism it will be shown that dning the alterations of the materials of the belt of cementation equal or greater amounts of these compounds are added to the solntions. A portion of the great amount of material which joins the sea of ground water from the belt of weathering and from the alterations of the minerals of the belt of cementation is there precipitated as minerals and the rocks are cemented. Hence the name, "belt of cementation."

It will be remembered that the openings in rocks comprise those between the mineral particles, and especially the grains of sediments, the vacuoles of igneons rocks, the regular openings of fissility, joints, and faults, and the irregular openings from those of the fractures of the individual mineral particles to those of breccias. Further, it will be recalled that the amount of openings varies from a small fraction of 1 per cent to 75 per cent, that in the mechanical sediments and the porous lavas a pore space of 20 to 40 per cent is common, and that the quantitative importance of the fault, joint, and fissile openings is great. (See pp. 124131.) Therefore the amount of material which is required to fill the openings of great formations, thousands of meters in thickness and extending over areas of hundreds or thousands of square kilometers, is vast. Yet it is rather rare, if not unknown, for a rock which has been deeply brried and approaches the surface by denudation not to have the older openings of all kinds almost entirely filled.

In proportion as the process of cementation advances it necessarily follows that the openings become smaller, the circulation of the water is retarled, material is transported in smaller quantity, and the process becomes slower. This lessening of speed continnes from the first, and when cementation is near completion it must be exceedingly slow. Notwithstanding this the process, as has been explained, has been practically completed for great thicknesses of rocks over extensive areas. The time required for the work must have been great, and yet for completion muder favorable conditions it is certain that it does not require geological eras. This is shown by the complete cementation of formations of Eocene age In such instances the process must have been completed and a sufficient time have elapsed for erosion to bring the cemented rock 
to the surface since early in Tertiary time. The best illustration known to me of a completely cemented great formation of Tertiary age is the San Juan breccias of Colorado. This formation is 1,500 meters thick; it was very porous, and yet every ancient opening not of microscopic size, from great fissures to pores between the particles of ash, is completely filled.

Of course, after cementation has been partially or wholly completed orogenic movements may occur which produce a new set of openings, and a vigorous circulation be set ap in the new openings. This would give new trunk channels for circulation and thus assist in the cementation of partially closed old openings.

In judging of the nearness to completion of the process of cementation when the rocks were at a considerable distance below the surface, openings which have been produced by later orogenic movements when the rocks were nearing the surface must be ignored. Commonly such openings are not closed.

It is explained on pages 595-597,646-648 that the openings in the rocks are to some extent closed by pressure, and locally are closed by injection. So far as these processes take place the space left to be filled by the process of cementation is decreased; but the residual actually observed to have been filled by the process of cementation is enormous.

In the cementation of the openings between the mineral particles the new mineral material may be added in two different ways. It may attach itself to the old grains of like mineral character, or it may be deposited as independent interstitial material. If mineral particles be fractured, it may heal them with the same or some other mineral.

When interstitial mineral material attaches itself to an old mineral of like character, the two being in optical continuity, the mineral is said to have been enlarged. The principle explaining the enlargement of old mineral particles rather than the derelopment of new smaller mineral particles is essentially the same as that explained on pages 74-76, that large individuals grow at the expense of small ones. Where there are old nuclei which can be used the solutions deposit material upon these; for if independent particles begin to form, these muder the principle above referred to would be likely to be again dissolved and deposited upon the old larger particles. The enlargement process is far more important for quartz than for any other mineral, although enlargements of feldspar, homblende, angite, biotite, 
calcite, garnet, and tourmaline have been observed, some of them frequently. In a clastic rock the process of enlargement means that the component grains are minerals still and have the structure and potency of minerals. These minerals, originally produced in igueous or metamorphic rocks, are taken from their original positions and deposited in a secondary rock. The beds are buried by overlying formations. Mineral-bearing solutions pass throngh the new rock and each mineral fragment chooses from the solutions material like itself. This it attaches to itself in optical contimnity, even thongh the time interval between the first and second growtlis be indefinitely long. In the early stages of this renewed growth crystal faces are often rebuilt. (Pl. IX, A.) If the growth continues, the enlargement of a particle meets similar enlargements from other grains. By

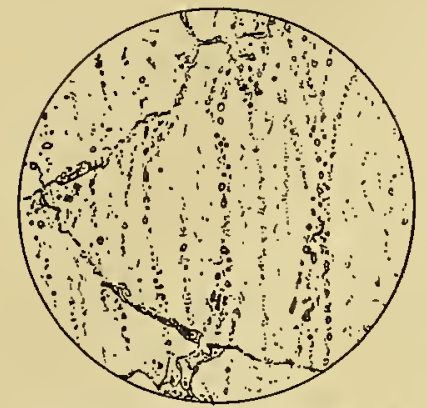

FIG. 13.-Part of a thin section of a quartz-schist showing liquid- and gas-filled cavities of a secondary nature. Black Hills, Solth Dakota. further growth these interlock and finally fill up all the interspaces and perfectly indurate the rock. (Pl. IX, B.)

This process of enlargement is of greatest importance in the mechanical sedimentary rocks. Its magnitude in these rocks is fully explained on pages 865-868. The process is also important in the volcanic fragmental rocks, including both coarse tuffs and ashes; and, finally, the process does take place, although it is of subordinate importance, in massive igneous rocks. The cracks within and between the grains may be cemented by substances the same as or different from the materials cemented. If the cementation be imperfect secondary gas- or liquid-filled cavities may be formed. Often the broken fragments are somewhat displaced, but occasionally, in the case of parallel fractures, the particles are broken apart and left very nearly in their original relative positions, in which case the liealing may be so perfect that the fact that the rock has been fractured may be shown only by the gas- or liquid-filled cavities and by the secondary inclusions. Thus are explained many of the inclusions in cavities which are so frequently noticed to occur along regular parallel planes. (See fig. 13.)

In all cases where the process of cementation has gone far the depos ited minerals interlock, and in the larger spaces they may have a coarsely crystalline texture. The quantity of cementing material varies in different 
cases from a relatively unimportant amount to predominance. The cementing minerals may permeate the rocks through and through, and fill all the interspaces, microseopic and macroscopic. The result is in many instances to give a most extraordinarily complex structure, the places between the original minerals being filled, the parallel fractures being emphasized by the parallel inpregnation, and the whole being intersected by larger masses of holocrystalline interlocking mineral materials, some of which are parallel to the original structures, some of which are diagonal to them, and some of which are parallel for a certain distance and then cut across them. The material filling the larger crerices often has distinct veinlike forms. (Pl. II, $A$.) When examined carefully the material deposited parallel to laminated rocks may be found to follow the folia very closely, or it may be found to follow along them for some distance, then break across one or more, and then follow them again. In proportion as the cementing material follows the lamine the cement bands are likely to be of approximately the same width. In proportion as there is a tendency for the material to break across the folia the veins usually are of nuequal size.

The cementing minerals filling the openings of fissile rocks are usually different or in different proportions from the minerals of the adjacent laminæ, and hence there is a tendency to preserve and emphasize the laminated arrangement. Where sets of parallel joints are filled, for a similar reason a parallel structure is produced. Where there are intersecting sets of parallel joints the parallel structures of cementation may form simultaneously in two or three directious. It therefore follows that where the openings are of the sheeted parallel kind, in general the process of cementation results in a regular alternation of parallel layers of different kinds, the structures of which have no definite relations to the original bedding.

CEMENTIYG SUBSTAYES.

The more important cements of rocks may be divided into oxides, carbonates, silicates, and sulphides.

The most important oxides are silica, iron oxide, and alımin'ın oxide. The more important carbonates are calcite, dolomite, and siderite. The silicates inchude both the hydrous and anhydrous silicates, but the former are by far the more important. The only sulphides which are geologically 
important are marcasite and pyrite, but from the point of view of ore deposits many other sulphides are of great consequence.

In addition to these, there are many subordinate minerals deposited in the belt of cementation; indeed, almost every mineral which occurs in rocks may there form, but the amounts are so small that they will not be considered here.

OXIDES.

silica.-Silica may be deposited as opal, chalcedony, or quartz. In the process of precipitation it may fill any of the classes of openings which exist in rocks. But the greatest quantity of this material is deposited between grains of sediments, and especially between the grains of quartzose sand. Sandstone formations are one of the most abundant of the sedimentary deposits. It has been shown on pages 124-126 that the original pore space of such formations probably varied from one-tifth to two-fifth of the volume, with a probable average of approximately one-third. The ordinary quartzites which have not been modified by mechanical action are completely indurated by the deposition of quartz between the grains, in orientation with the original grains, or as independent material, or the two combined (Pl. IX.) The volume of quartzite of this class now existing upon the earth is very great. (See pp. 865-868.) In reaching a judgment as to the amount of quartz which has been precipitated in sand, it must be remembered also that many sandstone and quartzite formations produced in past geological times have been destroyed by the forces of erosion and redeposited.

One of the reasons why quartz is so very extensively deposited in quartzose sandstone is furnished by the principle (see pp. 120-12\%) that, other things being equal, material in solution is precipitated where there are nuclei of the same composition upou which it may be deposited. The innumerable rounded grains of quartz in the sands furnish the necessary nuclei which promote the precipitation of silica.

But quartz is deposited not only between the grains of quartzose sands; to some extent it is deposited between the grains of all other porous mechanical sediments, although the anount thus precipitated is subordinate. A vast amount of quartz is also deposited in the vacuoles of volcanic rocks as amygdules. Further, silica is deposited in the innumerable openings of the fissile rocks, in the numberless joints, and along the numerous faults 
and openings in the brecciated rocks. The amount thus deposited is only second to that deposited in the sediments. Finally, as shown in the succeeding section on metisomatism, there are very extensive replacement deposits of quartz. There is no means by which the amount of replacement silica can be measured, but the quantity is certainly very great.

The foregoing facts give us some idea of the vastness of the amount of siliceous material which is deposited in the belt of cementation. Certainly the amount is to be measured in thousands and probably in hundreds of thousands of cubic kilometers. An adequate source of this silica is that liberated by the process of carbonation in the belt of weathering. (See p. 480.)

Iron oxides.-1ron oxide is extensively deposited between the grains of mechanical sediments, and therefore is an important cementing agent Irón oxide is also deposited in the other classes of openings in rocks, and also as a replacement product. Iron oxide is deposited as magnetite, hematite, limonite, and other hydrated oxides.

A very large amount of the iron is precipitated as hematite or limonite or other hydrated oxide. This precipitation is likely to occur where oxygen is abundant. These conditions are likely to obtain wlere solutions from different sources are united in some main channel of rescending ground water. No better illustration of precipitation of iron oxide by this process can be given than the great henatite deposits of the Lake Superior region, which are precipitated by the mingling of waters bearing iron carbonate and those bearing oxygen. (See pp. 1194-1197.)

Magnetite is deposited in the belt of cementation as a very widespread constituent. The explanation of the precipitation of some magnetite is: In the belt of cementation there is usually a deficiency of oxygen. If the iron be supposed to be carried in the form of carbonate, the reaction for the precipitation of magnetite may be written as follows:

$$
3 \mathrm{FeCO}_{3}+\mathrm{O}=\mathrm{Fe}_{3} \mathrm{O}_{4}+3 \mathrm{CO}_{2} .
$$

Other methods by which magnetite is precipitated are considered on pages 845-846. Where iron is thrown down as magnetite it is ordinarily found in crystals. As illustrations of this may be mentioned formations in the Lake Superior region, some of which are of economic importance, as, for instance, the magnetite of the Michigamme, Republic, and other mines 
along the Republic trougin. However, the magnetite thus deposited in solid bodies is entirely subordinate to the vast amount which is disseminated through the rocks of the adjacent formations-the quartzites, slates, and tuffs. Extensive deposition of magnetite is illustrated by the Michigamme schist of the Iarquette district and by the Hemlock rolcanic formation of the Crystal Falls district. ${ }^{a}$

It will be remembered that hematite and limonite are very abundantly precipitated in the belt of weathering as well as in the belt of cementation, but magnetite very rarely forms in the belt of weathering. It therefore appears that magnetite cement is especially characteristic of the belt of cementation.

Aluminum oxides. - The aluminum oxides which are deposited as cementing substances are gibbsite, diaspore, and perhaps corundmm. Both of the hydrous minerals are known to be rather frequent cementing constituents where the rocks are of an intermediate or basic character. Usually they have not been regarded as important cementing minerals, but $I$ suspect they are rather more plentiful than has been supposed. My reason for this belief is the frequency with which aluminum hydroxide is a by-product in the common alterations of such minerals as the feldspars, feldspathoids, micas, and other minerals. (See pp. 375-394.)

CARBONATES.

The important carbonate cements are calcite, dolomite, and siderite. Calcite and dolomite.-Calcite and dolomite are treated together, since without chemical analyses it is usually impracticable to discriminate between the two where deposited in rocks. Also, there are various gradations between calcite and dolomite. In general, it may be saic that these minerals are deposited in all the kinds of openings in rocks. They are more likely to be extensively deposited in the calcareous rocks than in the siliceous rocks, since in such rocks the solutions are sure to contain abundant carbonates, and there are crystals of calcite and dolomite to serve as nuclei for deposition. The calcium carbonate and magnesium carbonate may be deposited upon calcite and dolomite, respectively, thus enlarging these minerals precisely

a Van Hise, C. R., and Bayley, W. S., The Marquette iron-bearing district of Michigan: Mon. U. S. Geol. Survey, vol. 28, 1897, pp. 444-152. Clements, J. Morgan, and Smyth, H. L., The Crystal Falls iron-Dearing district of Michigan: MIon. U. S. Geol. Survey, vol. 36, 1899, pp. 150-152。 
as quartz is enlarged. The deposition of magnesium carbonate in many cases involves the solution of an equivalent amount of calciun carbonate, in which case the process is that of metasomatism, fully considered on pages $640-646$.

The quantity of calcite and dolomite deposited between the grains of sediments, the vacuoles of igneous rocks, the openings of fissility, joints, and faults, while very great, is vastly less than that of quartz.

siderite.-The iron in solution may be partly or largely precipitater in the form of siderite, ankerite, or ferrodolomite. These compounds all form somewhat extensively in the minor interstices in rocks, and oceasionally they may form veins of such magnitude as to be worked as iron ore.

SILTCATES.

The silicates which are most abundantly precipitated as cements are hydrous, but anhydrous silicates are also deposited. The important cementing silicates include, in order of abundance, the (1) zeolites and prelmite, (2) chlorites, (3) epidotes, (4) serpentine and talc. The zeolites and prehnite are sodinm-aluminum silicates, calciun-ahuminum silicates, sodium-calcium aluminum silicates, and potassium-calcium silicates. The chlorites are magnesium-aluminum silicates when pure, but ordinarily the magnesium is partly replaced by iron. The epidotes comprise zoisite (calcium-altminum silicate) and epidote (calcium-aluminum-iron silicate). Serpentine and tale are magnesium silicates. As to the degree of hydration, the minerals may be divided into three classes: The zeolites and prehnite, the chlorites and serpentine, and epidote and talc. The bases of all of the above compounds are those which abundantly enter into the solutions. Hydration, as already shown, is one of the most important of the chemical processes which result in the liberation of heat. Probably the dominant factor in the precipitation of these hydrous compounds is the chemical law obtaining in the zone of katamorphism that, other things being equal, those compounds form by which the greatest amount of heat is developed and liberated.

The anhydrous silicates which are somewhat abundantly deposited in the belt of cementation are feldspar, homblende, and nica, the order given being that of relative abundance. These materials mar be deposited as independent constituents in the interstices of the rocks, and they may also IION XLVII- $0 t- \pm 0$ 
be deposited in optical orientation upon nuclei of like minerals. Feldspar enlargements have been found in many arkoses. Perhaps the best knowu instance is that of the Keweenawan sandstone of Lake Superior, the cementation of which is mainly accomplished by the deposition of feldspar upon

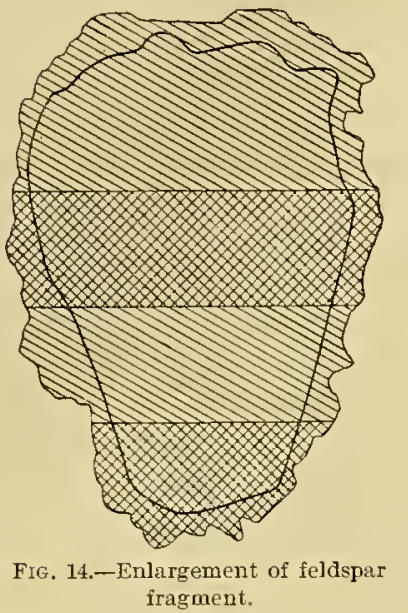
worn grains of that mineral. ${ }^{a}$ The grains are of different kinds of feldspar, orthoclase, and various plagioclases. The material deposited in each case is in optical continuity with the old material, even to the extension of the twinning lamellæ. (See fig. 14.) An excellent instance of the enlargement of horublende is that of the hornblende crystals of the volcanic tuffs of Kekekabic Lake, in northeaster'n Minnesota. ${ }^{.}$The relations of the cores and additions of hornblencie are identical with those of the feldspar's, even to the extension of the twinning lamellæe. (See fig. 15.)

The enlargement of feldspar and hormblende furnish the best ilhustrations known of the principle so strongly emphasized on pages 120-122, that mineral nuclei already present are able to abstract from solutions materials like themselves, and thus control the combinations of the elements when precipitated. In this principle probably lies the partial answer to the question why, in the cases cited of feldspar and hornblende enlargements, the material was not deposited between the grains as hydrous minerals. The formation of hydrous compounds would have developed more heat, but the power of the nuclei of old minerals to control the precipitation appears to more than have overbalanced the chemical law that in the belt of cementation reactions commonly take place which liberate the greatest amount of heat.

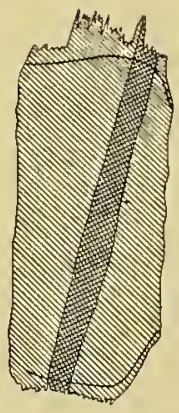

FIG. 15.-Enlargement of hornblende fragment. But another factor which fiequently enters into the precipitation of such anlyydrous minerals as feldspar, horublende, and mica is the abundance and the proper proportions in the solutions of the elements out of which they can be made. Rocks in which feldspar, hormblende, etc.,

a Van Hise, C. R., Enlargement of feldspar fragments in certain Keweenawan sandstones: Bull. U. S. Geol. Snrvey No. 8, 188t, pt. 2, pp. $4+47$.

$b$ Van Hise, C. R., Enlargements of hornblende fragments: Am. Jour. Sci., 3d ser., vol. 30, 1885, pp. $231-235$. 
are deposited usually contain these same minerals in abundance, and in many cases the formations extend to the surface. The materials for the solutions may have been derived from the same minerals in the belt of weathering, or from a part of the belt of cementation above the places of deposition in case the waters are descending, and below the places of deposition in case the waters are ascending.

SULPHIDES.

The only important sulphide cement is that of iron. Iron is somewhat extensively thrown down as pyrite or marcasite. This may be precipitated by means of hydrosulphuric acid; it may be produced by the reduction of iron sulphate by means of organic reducing agents in the solutions or the rocks. These and other methods of precipitating sulphides are fully considered on pages 1108-1118. The quantitative importance of the cementing sulphides in the belt of cementation, from a geological point of view, is small, but from the point of view of ore deposits they are of the greatest consequence. (See pp. 110t-1105.)

DISTRIBITIOX OF ELEMENTS IX CEMENTIXG IINERALS.

From the foregoing it appears that the elements added to the solutions from the belt of weathering and from the belt of cementation itself are distributed between the rarious minerals as follows:

The sodium passes into the silicates as zeolites, and may produce any one of the following sodium-bearing minerals of this group: Thomsonite, hydronephelite, natrolite, mesolite, gmelinite, analcite, phillipsite. The potassium passes into silicates as zeolite, being a constituent of apophyllite. The calcium passes into the carbonates and silicates. As a carbonate it is a constitnent of calcite, dolonite, ankerite, and parankerite. As a silicate it enters into the zeolites and epidotes. The zeolites containing calcium are thomsonite, mesolite, scolecite, apophyllite, stilbite, phillipsite, gismondite, chabazite, and launontite. Both epidote proper and zoisite contain calciun. The magnesium may enter into carbonates or silicates. As a carbonate it is a constitnent of dolomite, ankerite, and parankerite. As a silicate it is a constituent of all the chlorites, of serpentine, and of talc. The iron may pass into oxide, carbonate, silicate, or sulphide. As an oxide it is a constituent of magnetite, hematite, and limonite. As a carbonate it is a constituent of ankerite, parankerite, and siderite. As a silicate it is a constituent of epidote and chlorite. As a sulphide it is a constitnent of 
pyrite and marcasite. The almmina passes into the hydroxides and silicates. As a lyclroxide it is a constituent of diaspore and gibbsite. As a silicate it is a constitnent of all the zeolites except apophyllite, of all the chlorites, and of the epidotes.

The carbon of carbonic acid enters as a constituent of the carbonates above mentioned. The silicon of silicic acid enters into quartz, opal, and the silicates above mentioned. The sulphur of hydrosulphuric acid enters as a constituent of the sulphides.

\section{DISTRIBLTIOS OFE PEHENTINA YLIERALS.}

It is rery noteworthy that the cementing minerals have a strong tendency to be like the compounds which are cemented. Thus the sands are transformed to sandstones and fually to quartzites by silicenus cement. Where nearly pure limestones and dolomites hare been fractured, the dominant cementing minerals are calcite and dolomite. If, however, the limestone be a very cherty one, the cementing material may be largely chert. Where the porous rocks are largely silicates, as in the case of the amygdaloids, the cementing materials are mainly silicates, including the zeolites, epidotes, chlorites, etc., bnt also with these are usually associated important amounts of quartz and carbonates, me being correlative with the other; for carbonation of the silicates, forming carbonates, liberates silicic acid, which may separate as quartz.

These phenomena are beantifully illustrated by the amygdaloids of the Keweenawan series described by Pumpelly ${ }^{a}$ and Irring, ${ }^{b}$ and by the Crystal Falls volcanics described by Clements.

In inany cases not only are the silicates cemented by silicates, but the cementing minerals are like the dominant minerals cemented. For instance, the feldspathic sandstones may be cemented by feldspar, as in the case of the Kerreenawan sandstones of Eagle Harbor.' There hornblende is abundant the cementing material may be largely hornblende, as in the case of the Cacaquabic tuffs of northeastern Minnesota.

\footnotetext{
"Pumpelly, Raphael, Hetasomatic derelopment of the copper-bearing rocks of Lake Superior: Am. Acad. Arts and Sci., vol. 13, 1878, pp. 253-309.

$\checkmark$ Irving, R. D., The copper-bearing rocks of Lake Superiur: Mon. U. S. Geol. Survey, vol. 5, 1883, pp. 87-91, 134-139.

cClements, J. Morgan, and Smyth, H. L., The Crystal Falls iron-bearing district of Michigan: Mon. U. S. Geol. Survey, vol. 36, 1899, pp. 73-154.

UVan Hise, cit., Bull. $\mathrm{S}$.
} 
CALSES OF CEMENTATION.

It has already been explained (see p. 156) that the amount of gromnd water which reaches the surface by springs and by seepage for a given period is approximately equal to the amount which is added to the sea of grome water. It is well known that all issuing waters contain material in solution; and it has been shown that the amount of such material may be greater than that which the solutions contained when they entered the belt of cementation. Notwithstanding the foregoing conclusion, it is an mdeniable fact, as fully shown in the previous pages, that cementation is the rule for the part of the zone of fracture below the level of ground water. If more material be dissolved in this belt than is deposited by the circulating waters, what is the explanation of the apparently contradictory fact of deposition to the extent of complete cementation?

Before attempting to answer this question, it is advisable to recall the amount of opening's which may be present in the belt of cementation. It has been shown that the coarse mechanical sediments frequently have an original average pore space as great as one-third; that in the thinly bedded lavas this amount is often equaled, and that the openings produced by mechanical action are great. It follows, as already clearly shown, that the amount of deposited cementing material is vast. Therefore we must not only fumish a canse which will result in the deposition of material in the pore spaces, but we must show that the causes assigned are quantitatively adequate to perform the great work.

In this comnection it is well to restate the principles of precipitation worked out on pages 113-123. Mentioned in order of probable importance, precipitation is due (1) to the mingling of solutions from different somrces, (2) to reactions between the solutions and the wall rocks, (3) to decrease in temperature, and (4) to decrease in pressire. The compounds are precipitated from the solutions in proportion as they are relatively insoluble and in proportion as they are abundant.

The law of chemistry that when compounds of different kinds come together substances form (if possible) which are insoluble in the liquids present, explains the importance of the first and second causes of precipitation. It has been shown that decrease in temperature is also very important, and that probably the importance of this factor in comnection with decrease 
of pressure has not been sufficiently appreciated. The experimental work of Barus ${ }^{a}$ shows that at temperatures above $185^{\circ} \mathrm{C}$. water and soft glass are miscible in all proportions. Further, it is held that water and rock are miscible in all proportions at proper temperatures and pressures. (See p. 723.) These conclusions throw new light upon the importance of the third and fourth causes of precipitation. If these conclusions as to the miscibility of water and rock be true, at the high temperatures and pressures which prevail in the deep seated eirculation the water must be very rich in mineral content. It is clear that ascending waters which continuonsly fall in temperature and pressure must throw down great quantities of this material before they reach the surface. It is notable that large channels are most favorably situated with reference to all of these canses of precipitation, for in the large channels mingling of solutions is most likely to take place, along them reactions with the wall rock are important, and in them solutions are most likely to be ascending. (See pp. 582-584.) Therefore all the causes for precipitation combine to explain the great amount of material deposited in the large openings.

While all of these statements are undoubtedly true, in view of the fact already pointed out, that waters issuing from the belt of cementation may contain more material in solntion than those entering that belt, none of them, nor their combinations, explain the general cementation in large and small openings alike. Before we can satisfactorily assign causes for general cementation it is necessary also to recall the cementing minerals and to indicate their relative importance. Of the substances deposited in the belt of cementation quartz is undoubtedly the one which dominates over all others. The one great process in the belt of cementation is silicification. Of very great importance is the deposition of the silicates and carbonates. Botl of these classes of minerals are deposited on a great seale, but which of these is quantitatively the more important it is hard to say. It has been noted that of the various silicates deposited the important ones are the zeolites, the chlorites, the serpentines and talcs, and the epidotes. The deposition of oxide of iron, as hematite, limonite, etc., and of aluminum, as gibbsite and diaspore, is rather important, but quantitatively very subordinate to that of the classes of minerals already mentioned.

a Barus, C., Hot water and soft glass in their thermo-dynamic relations: Am. Jonr. Sci., 4th ser., vol. 6, 1898, p. 270; and vol. 9, 1900, pp. 167-168. 
We are now prepared to suggest causes which may combine to explain the apparently contradictory facts that a vast amount of openings in the belt of cementation is cemented and that emerging waters may contain more material in solution than entering waters; or that, of the two processes of deposition and solution, the latter is the preponderant one.

EXPANSION REACTIONS.

The first cause which will be given for cementation-and I believe the one of greatest importance-is that of expansion reactions. It has been explained (p. 603) that the chief reactions of the belt of cementation are oxidation, carbonation, and hydration, and that of these three the latter is of greatest consequence. Further, it has been seen that, provided all of the compounds formed remain as solids, the average volume increase in consequence of these reactions varies from 15 to 50 per cent or more. So far as these expansion reactions take place-and they undoubtedly occur on a most extensive scale-they tend to fill the openings, and thus cement and consolidate the rocks.

In the following section it is explained that the process of metasomatism, or change of the minerals within the body of the rocks, has taken place upon a vast scale in the belt of cementation. Indeed, in extensive ancient formations, especially in rocks of a porons character, it has frequently happened that, with the possible exceptior of quartz, scarcely a vestige of any original mineral remains. Many of the rocks, especially the igneous rocks, are largely or almost wholly composed of silicates. Even in the acid rocks the amount of quartz and otleer compounds, aside from the silicates, together is rarely as great as 50 per cent, leaving 50 per cent or more of silicates.

We shall now consider the expansion due to alteration of a rock which contains 50 per cent of silicates. If we snppose the silicates to be completely altered by the processes of oxidation, carbonation, and hydration, and that in these processes the expansion is 25 per cent-which is less rather than more than the average amount-if all of the materials were deposited the resultant expansion wonld be sufficient to furnish material to fill pore spaces to the amount of $12 \frac{1}{2}$ per cent of the total original solids of the rock. Therefore, in the case of an igneons rock of exceptional acidity and exceptional porosity, the expansion reactions would be aldequate to entirely fill the openings of a rather porous rock. But it may be said that many of the 
rocks, especially the lavas, contain more pore space than $10 \mathrm{or} 12$ per cent. This is especially likely to be true of the basic igneous rocks, of which the basalts may be taken as illustrative. But in basalt there is ordinarily no quartz. Practically the entire mass of the rock is composed of silicates, and the complete alteration of these compounds would furnish a sufficient amount of material, supposing the oxidation, carbonation, and hydration to produce an expansion of volume of 25 per cent, and all the compounds formed remain in situ, to fill a pore space of one-fifth the volume of the rock.

As an illustration of the very considerable amount of enlargement in volume by metasomatisin in the belt of cementation a specific ease may be given. For this purpose we may take a rock of intermediate composition. The amplibole-gabbro of Beaver Creek, Big Trees quadrangle, California, the mineralogical composition of which has been determined by Cross, Iddings, Pirsson, and Washington, will serve the purpose. ${ }^{a}$ Columns (1) to (3) are taken from these author's:

Table showing relative volumes of original and altered rocks in belt of cementation.

\begin{tabular}{|c|c|c|c|c|}
\hline $\begin{array}{c}\text { (1) } \\
\text { Mineral. }\end{array}$ & $\begin{array}{c}(2) \\
\text { Formula. }\end{array}$ & $\begin{array}{c}(3) \\
\text { Per cent. }\end{array}$ & $\begin{array}{c}(4) \\
\text { Volume } \\
\text { ratio. }\end{array}$ & $\begin{array}{l}\text { (5) } \\
\text { Volume of } \\
\text { resultant } \\
\text { products. }\end{array}$ \\
\hline Orthoclase & $\mathrm{K}_{2} \mathrm{Al}_{2} \mathrm{Si}_{6} \mathrm{O}_{16} \ldots$ & 1.11 & 0.8743 & 0.9705 \\
\hline Albite.... & $\mathrm{Na}_{2} \mathrm{Al}_{2} \mathrm{Si}_{6} \mathrm{O}_{16} \ldots \ldots$ & 23.06 & 1.2082 & 27.8611 \\
\hline Anorthite .... & $\mathrm{CaAl}_{2} \mathrm{Si}_{2} \mathrm{O}_{8} \ldots \ldots \ldots$ & 43.92 & 1.3465 & 59.1383 \\
\hline Diopside ..... & $\mathrm{CaMgFeSi}{ }_{3} \mathrm{O}_{9} \ldots \ldots$ & 13.10 & 1.2788 & 16. 7523 \\
\hline Hypersthene & $\mathrm{MgFeSi}_{2} \mathrm{O}_{6} \ldots$ & 3.92 & 1.1284 & 4.4233 \\
\hline Olivine...... & $\mathrm{Mg}_{2} \mathrm{Fe}_{2} \mathrm{Si}_{2} \mathrm{O}_{8} \ldots$ & 7.75 & 1. 1519 & 8.9272 \\
\hline Magnetite ... & $\mathrm{Fe}_{3} \mathrm{O}_{4} \ldots \ldots \ldots$ & 2.55 & 1.0000 & 2.55 \\
\hline Ilmenite..... & $\mathrm{FeTiO}_{3} \ldots \ldots$ & 1.67 & 1.0000 & 1.67 \\
\hline Apatite .... & $\mathrm{Ca}_{3} \mathrm{P}_{2} \mathrm{O}_{8} \ldots \ldots$ & 1.55 & 1.0000 & 1.55 \\
\hline Pyrite..... & $\mathrm{FeS}_{2}$ & .20 & 1.0000 & .20 \\
\hline Undetermined. & (........ & 1.37 & 1.0000 & 1.37 \\
\hline Total. & $\cdot$ & 100.20 & & 125.4127 \\
\hline
\end{tabular}

Supposing that the orthoclase by hydration and carbonation passes into kaolin and quartz, the decrease in volume is 12.57 per cent (p. 389). Supposing that the albite passes into analcite and quartz by simple hydration,

a Cross, Whitman, Iddings, J. P., Pirsson, L. V., and Washington, H. S., Quantitative classification of igneous rocks, Univ. of Chicago press, 1903, p. 199. 
the increase in volume is 20.82 per cent (p. 375). Supposing that the anorthite by hydration passes into thomsonite, a zeolite with only a moderate anomut of water, the increase in volume is 34.65 per cent (p. 376). Supposing that the diopside by carbonation, lydration, and oxidation passes into talc, quartz, magnetite, and calcite, the increase in volume is 27.88 per cent (see sallite, p. 391). Supposing that the hypersthene by hydration and oxidation passes into tale, magnetite, and quartz, the increase in volnme is 12.84 per cent (p. 385). Supposing that the olivine by liydration and oxidation passes into serpentine, magnetite, and quartz, the increase in volume is 15.19 per cent (p. 388). Since the percentages of the other constitnents are small, they will be supposed to remain unaltered. In the above table, column (4) is the volume ratio and (5) the volume of resultant products.

It thus appears that the supposed reactions of hydration, carbonation, and oxidation of the amphibole gabbro result in an increase of volume of 25.21 per cent. It is to be noted also that the calculation is made upon a conservative basis. It might be supposed, for instance, that the anorthite, the most abundant mineral in the rock, passed into gismondite, which would increase its volume by 52.76 per cent rather than 34.65 per cent. Also, if the conditions were very favorable for oxidation the iron would pass to hematite and perhaps to limonite. If all these suppositions were made in favor of getting the maximum volume, this would make the rolume increase considerably greater than calculated.

While the scoriaceous upper parts of lava beds may contain a pore space greater than 20 per cent, such a proportion of openings is comparatively rare for any considerable thickness of lava beds. It is well known that the amygdules of amygdaloids are ordinarily filled with quartz, with the zeolites, with chlorites, with epidotes, serpentine, and other hydrous silicates, and with carbonates; in other words, with the minerals mentioned on pages 621-627 as especially likely to be formed in the belt of cementation. That from the anhydrous silicates, hydrous silicates shonld form and fill the openings is to be expected. That the bases should unite with carbon dioxide is natural. But what is the source of the quartz? So far as carbonation of the silicates has taken place-and the presence of plentiful carbonates shows that this is an important reaction-silica, probably mainly in the form of colloidal silicic acill, is liberated. The precipitation of this 
silica from the solutions forms the abundant chalcedony and quartz of the amygdules.

It therefore appears probable that, in the alteration in the bolt of cementation of the porons rocks containing abundant silicates, expansion reactions characteristic of the belt of cementation may be entirely adequate not only to account for the filling of the openings, but possibly to furnish additional material to the ground solutions.

CONTRIBUTIONS FROM IGNEOUS ROCKS.

Expansion reactions, however, are not the only cause of cementation. In a subsequent section upon igneous rocks it is seen that injections locally produce profound metamorphic effects. It is there explained that the chief of these is the increased action of solutions due to the heat of the magma. But, as is well known, magma when solidifying gives off water. This water is sure to be very rich indeed in mineral content. The material thus contributed to the ground water solutions is certainly a source of material for cementation. This source is of importance, for volcanism is a widespread geological process. So far as material of this origin is available it explains the cementation of rocks notwithstanding the probability that solutions emerging from the belt of cennentation contain more material than when entering this belt.

SELECTIVE PRECIPIXATION.

But it is clear that the explanation thus far offered by no means fully covers the matter of cementation for all rocks. Indeed, it does not fully include the most important of the cases of cementation. It has been seen that the dominant cement of the belt of cementation is quartz. In many instances (see pp. 622, 865-866) the transformation of the great sand formations to sandstones and quartzites is wholly, or almost wholly, accomplished by the deposition of quartz. Probably 90 per cent or more of the fractures of rocks produced by deformation, such as joints, faults, bedding partings, etc., are cemented by quartz. The cementation by silicates, carbonates, etc., may be fully accounted for by the expansion reactions above given; but what is the source of the great quantity of silica for silicification? In order to answer this question we need to recall that the most distinctive process of the belt of weathering is carbonation; that there, by the process of carbonation of the silicates on a vast scale, colloidal silicic acid is set 
free. This material is taken into solution by the descending waters and transmitted to the belt of cementation. As already pointed out, by the processes of denudation and downward migration of the belt of weathering, an abundant increment of silicic acid is ever contributed to the belt of cementation. If this naterial could be there deposited, this would account for the very general cementation by quartz. It has been seen that the silica largely separates from silicates as colloidal silicic acid. This compound is unstable, and tends to slowly decompose into water and silica. During the long and very slow journey of the water in the belt of cementation there is ample time for this process. It is likely that the principle that insoluble products are apt to be precipitated has a bearing at this point. Quartz is an extremely insoluble compound, and therefore tends to separate from the solutions bearing colloidal silicic acid. In the precipitation of the silica from the solutions the previous almost miversal presence of quartz is also of great importance; for it has been shown (pp. 120-122) that the presence of a mineral of a certain kind favors the abstraction of like material from a solution and the addition of that material to the nuclei. Hence a large part of the most abundant substance contributed by the solutions from the belt of weathering is precipitated in the belt of cementation. As already pointed out, an additional supply of silica is furnished by the carbonation of the silicates within the belt of cementation. Finally, silica is furnished by emanations from intrusive rocks. Thus is explained the miversal dominance of quartz as a gangue and cementing material, and the formation of great masses of sandstones and quartzites by this cementation process, as fully explained (pp. 864-868).

It is highly probable that the solutions are partly or fully compensated for the silica abstracted by the addition of calcium, magnesium, sodium, potassium, iron, etc., obtained by alteration of the minerals within the belt of cementation. It has been noted (pp. 609-610) that carbon dioxide is added to the belt of cementation in four ways. This carbonic acid unites with bases, producing carbonates. Further, it has been explained (pp. 624-625) that carbonates are very important compounds added to the belt of cementation. Thus the solutions of the belt of cementation have two sources of these compounds. It is therefore to be expected that undergound solutions which issue at the surface and in springs would bear as their most abundant compounds the carbonates of the alkalies, alkaline earths, and iron, 
and with this expectation analyses of waters of springs fully accord. With the carbonates are also salts of other acids, such as hydrochloric, hydrosulphuric, and others, and also various salts of other subordinate metals.

From the foregoing it appears that during the circulation of water in the belt of cementation the processes of precipitation and solution are selective. Quartz and the hydrous silicates are the dominant precipitates. Carbonates of the alkalies and alkaline earths are the dominant salts which come to the surface. The above precipitations and solutions are precisely what should be anticipated from the laws of chemical precipitation given (pp. 113-123). The compounds which, on the average, are thrown down to the greatest extent are those which are least soluble and most abundant. The compounds which are retained in solution to the greatest extent are those which are most soluble and least abundant. However, of the more soluble and less abundant compomds a portion is precipitated. The conditions under which we should expect partial precipitation of these compounds are those of lessening temperature and pressure. These are the conditions of the ascending colmmns of water. It has already been seen that the ascending columns are likely to be the main water chamels. Hence is explained the precipitation of the comparatively soluble carbonates of the alkaline earths and other minerals which form in the trunk channels.

By these various processes the larger openings are filled with deposits, some of which contain a sufficient quantity of valuable minerals to constitute ores. But where one large opening contains valuable minerals in sufficient quantity to be of service to man, millions are filled with quartz, lyydrous silicates, calcite, dolomite, and other gangue minerals. It thus appears that the deposition of much of the ores is but a special phase of a general geological process of great consequence. This idea will be fully developed in Chapter XII.

DIFFUSION.

Other factors besides those already considered enter into the cementation of openings. Of these, diffusion is important. Before considering the influence of diffusion, it is necessary to recall some of the points already developed. After the water enters the belt of cementation it first has a downward movement, and usually later an upward movement. 
Siperimposed upon these rertical movements are lateral movements. During the downward course under normal conditions the temperature and the pressure steadily increase; during the upward course they steadily decrease. But there are irregular variations in temperature and pressure due to orogenic movements and to igneous intrusions. Increase of temperature and pressure increases the capacity of water to hold material in solution. The amount of material required to produce saturation is therefore exceedingly variable for different portions of the underground circulation. Equilibrium in the solutions extending between two places depends not upon the absolute quantity of material contained, but upon the relative approach to saturation at the various intermediate points. Material migrates by diffusion from places where the approach to saturation is nearest to places where it is less near, and this might be from a cool dilute solution to a warmer stronger solution. The conditions of equilibrium are therefore not those of uniform concentration, or in many cases even approximately so, for often the temperature and the pressure are different in horizontal columus from those in vertical columns, and rary greatly in vertical columns if they are of great altitude. Low temperatures and pressures obtain near the surface, and high temperatures and pressures obtain at depth. Consequently as depth increases more material may be held in solution before reaching a state of saturation; and because of this the conditions of equilibrium are those of greater concentration in the lower than in the upper parts of the columns. Moreover, the experimental work of Barus, ${ }^{\text {s }}$ showing the wonderful dissolving power of water on glass at high temperatures and pressures, but still at temperatures which obtain in the lower part of the zone of fracture, shows that the differences in the amount of material held in solution may be rery great-may, indeed, vary by ratios as great as $1: 100$ or $1: 1,000$.

From the foregoing it follows that if there were uniform concentration, with rariable temperatures and pressures in the underground solutions, the material would diffuse from high levels to low levels and thus produce equilibrium. Where the currents are noving downward, but with decreasing slowness on account of the lateral movement of the water, which continually carries a part off to one side (see pl. 572-576), the lower

a Barus, Carl, The compressibility of hot water and its solvent action on glass: Am. Jour. Sci., 3d ser., vol. 41, 1891, pp. 110-116. 
part of the column, because of its contact with the rocks for a greater time, would be more likely to be near the point of saturation than the ligher parts; and thus there is a tendency for upward diffusion against the current. Diffusion is so slow that this movement might be thought to be of so little consequence as to be negligible; but it has been seen that the average downward movement of water in the belt of cementation is exceedingly slow, the rate of movement frequently not being more than a meter per annum. Therefore it is rather probable that upward diffusion against the downward-moving currents is a matter of consequence in maintaining the approximate equilibrium of the undergromud solutions, and therefore in promoting continuous and uniform precipitation throughout the belt.

During the upward movements which are characteristic of the later parts of the jonmey of the water currents diffusion may also work against the movement. This would be true if at the place where the upward movement began saturation had not been attained. At some higher point, as a result of the lessening temperature and pressure, saturation would be reached, and thus the coefficient of saturation would be higher. Hence there would be diffusion downward, or from places where there is less material in solution to places where there is more material in solution.

So far as the lateral movement of water is concerned, if variations in temperature and pressure be ignored, there is diffusion from areas of greater concentration to areas of less concentration. But the farther the water has gone, and the longer therefore it has been in contact with the rocks, the nearer are the solutions to saturation; hence there is a tendency for diffusion to take place against the currents. But where the temperature and the pressure are unequal, due to igneous rocks or orogenic movements or both, this condition of affairs may be reversed.

This factor of diffusion in comnection with movements of the underground currents apparently explains some of the anomalous features of the belt of cementation. The downward movement may be presumed to be generally so slow that diffusion keeps the solutions approximately at equilibrium, and the process of cementation goes on subject to the laws of the expansion reactions and selective precipitation. But at places where the downward currents move so fast that diffusion does not maintain 
equilibrium by movement of the dissolved material in a direction against the current, the descending waters continuously take material into solution; or, if not that, at least deposit little or no material; and thus a formation or an area in a formation below the level of ground water may not be cemented or indurated. In this manner may be explained the streaky cementation and induration of sandstones and quartzites, and very frequent preponderant solution below the level of ground water where there are strong descending currents (see p. 604). In places where the downward movement was slow and regular, cementation and induration are in an adranced stage or complete; while at places where there was rapid descending movement of the waters there was little deposition, and the material is but feebly or not at all cemented.

Besides the greater movements of diffusion connected with general currents of ground water, diffusion is mquestionably of great inportance in the short movements of the ground water in the subcapillary openings between the single mineral particles or aggregates of mineral particles and between the adjacent capillary and supercapillary openings in which the main water currents travel. In the subcapillary openings, during the metasomatic processes, the water becomes satmrated with material. Even if the water within the subcapillary openings itself does not move, the material in solution slowly migrates by diffusion toward the larger openings containing circulating waters, and vice versa. Therefore the materials of the small openings and those of the main water currents meet. The latter may carry not only recently acquired material, but material obtained long before, perliaps at great distances, or even from the belt of weathering above. As a result of this meeting selective precipitation takes place.

$$
\text { CONCLUSION. }
$$

From the foregoing pages I conclude that cementation is cansed by the expansion reactions, by contributions from magmas, by selective precipitation, and by diffusion, and that these processes are adequate to explain the process, notwithstanding that the water's issuing from the belt of cementation contain large quantities of material in solntion. In the actual precipitation in the openings of rocks these different factors work together, not separately. 
The material precipitated is derived from three sources--that carried by the waters passing from the belt of weathering into the belt of cementation, that contributed by igneous emanations, and that which passes into solution within the belt of cementation. While at any one time the belt of weathering may not be of great thickness, as a consequence of denndation, there is steady addition of new material to this belt, and therefore a constant supply of material. If all of this material could be deposited in the belt of cementation it would undonbtedly be adequate for the work. The same is true of the material which passes into solution within the belt of cementation itself. But doubtless if the belt of cementation har only one of these sources, cementation would be very imperfect. It is only by the combination of the important sources of material that an adequate supply is obtained to furnish the issuing solutions the abundant materials which they carry and yet leave a sufficient residum for cementation.

\section{METASOMA TISM.}

DEFINITION.

Metasomatism may be defined as the process by which original minerals are partly or wholly altered into other minerals, or are replaced by other minerals, or are recrystallized with or without mineral changes, or one or more of these together. In the alteration of a mineral into other minerals, or in its replacement by other minerals, there may be addition or subtraction of certrin constitnents. As a result of the changes, the new rock may gain or lose variety in the minerals composing it. Either by the substitution of constituents, or by the loss of constituents, and therefore concentration of other constituents, a resultant rock may have a predominant mineral.

EXTEXT OF PROCESS.

In rocks changed by metasomatism under mass-static conditions all stages of alteration may be seen, from comparatively fresh rocks, in which the changes are incipient in the minerals most readily alterable, to those rocks in which all alterable minerals have been transformerl by metasomatism into others which are permanent under the prevailing conditions.

Throughont extensive areas important formations are so altered that no original mineral remains. That the recrystallization of great masses of 
sedimentary and igneous rocks may go far toward or quite to completion under mass-static conditions is so well known that the fact need not here be emphasized. One of the best illustrative American localities is that of the Keweenawan series of the Lake Superior region. As shown by Pumpelly ${ }^{a}$ and Irving, ${ }^{b}$ the more porous lavas of this series lave in many cases largely recrystallized. The less porous ones, show extensive alterations. In various regions even great dense igneous masses have been profoundly affected or completely recrystallized throughout by metasomatic change.

However, as subsequently seen, the rocks which have recrystallized under mass-static conditions are easily discriminated from those which have been recrystallized under mass-mechanical conditions.

\section{CONDITIONS FATORAELE TO METASOMATISH.}

Since the changes are produced mainly through the medium of water, the presence of a considerable amount of water, and especially conditions favorable to its circulation, are very favorable to metasomatic changes. It follows that in proportion as the rocks are porous metasonatism is likely to be rapid. But if there be sufficient time, in order to produce profound changes, there is no necessity for circulation of ground water's beyond that necessary to provide water for the development of the hydrated minerals which form in the belt of cementation so as to keep intact the minute amount of water in the small openings. If these conditions obtain, a veiry small amount of water may be the medium through which the rocks are completeìy altered and recrystallized. Even the subcapillary openings may be penetrated by solutions and the unstable minerals transformed throughout. But in dense rocks under mass-static conditions, where the spaces bearing water are all subcapillary, the changes are exceedingly slow. Even in the pre-Cambrian rocks, in the larger dense masses, such readily alterable minerals as nepheline and olivine are found. Olivine occurs extensively in the pre-Cambrian rocks of the Lake Superior region. Thronghout extensive masses in this region the less alterable minerals, augite and basic feldspar, are apparently almost perfectly fresh. The

a Pumpelly, Raphael., Metasomatic development of the copper-bearing rocks of Lake Superior: Proc. Am. Acad. Arts and Sci., vol. 13, 1878, pp. 253-309.

${ }^{b}$ Irving, R. D., The copper-bearing rocks of Lake Superior: Mon. U. S. Geol. Survey, vol. 5, 1883, pp. $87-91$.

MON XLVII-0t- 41 
small masses of dense rocks, especially those which are in the midst of porons rocks, are much more altered.

Porosity is also farorable to metasomatism because the necessary space is available for the expansion reactions of the belt of cementation without lifting the rocks. This necessity for more space is an important restraining factor in the alteration of the dense rocks.

In so far as the minerals are in a state of strain, this is favorable to solution and redeposition, and therefore, in proportion as this condition obtains, metasomatism is rapid. In so far as the mineral particles are finely divided, they furnish a large area for the attacking solutions, and therefore, in proportion as this condition obtains, metasomatism is rapid. Other things being equal, the higher the temperature the more rapid is metasomatisn. Since normally the temperature increases $I^{\circ}$ C. for 30 meters in depth, metasomatism is likely to be much more rapid in the middle and lower parts of the zone of fracture than in the higher parts. The process of metasomatism may be greatly promoted by increase of temperature due to intrusives, as explained on pages 648-649.

Metasomatism is rapid in proportion as the rocks are composed of readily alterable minerals. Of these leucite, nephelite, olivine, etc., are readily alterable; the pyroxenes, amphiboles, and micas occupy an intermediate position; and quartz and the acid feldspars are very slowly alterabie monder the conditions of the belt of cementation, although, as has been explained in a previous chapter (see p. 519), the feldspars are somewhat readily attacked in the belt of weathering.

Finally, the extent to which metasomatism has taken place is a direct function of the age of the rocks. The older a formation the more likely are the changes to be far-reaching.

\section{MINERALS PRODUCED.}

The dominant ninerals produced by metasomatism are the same as the cementing minerals (see pp. 621-627), and this is what should be expected; for it is to be remembered that the solutions pass through the rocks slowly, and that the minerals deposited in the openings and those deposited in the body of the rock are alike the joint result of the reactions between the solutions and solids. 
If this be so, it can not but follow that the minerals precipitated from the solutions in openings will be essentially the same as those produced by the changes within the mineral particles, although their relative proportions may be very different; for it is certain that the changes in the body of the rock are largely accomplished by solution and redeposition, although the material may be deposited very close to the place at which it was taken into solution.

GROWTH OF LARGe INDIVIDLAS WITH PRESERTtiox OF TEXTURes.

One of the most distinctive features of metasomatism in the belt of cementation is the growth of large mineral individnals with the preservation or emphasis of original textures and structures.

The formation of large individuals is a result of the physical-chemical law explained on pages 74-76, under which large individuals form at the expense of smaller ones. In rocks altered by metasomatism in the belt of cementation the more than average growth of certain individuals may be recognized in the very unequal size of the inineral particles and in the enlargement of the old individuals. The general unevenness in the magnitude of mineral particles in rocks altered by metasomatism in the belt of cementation is so well known that the point need not be emphasized.

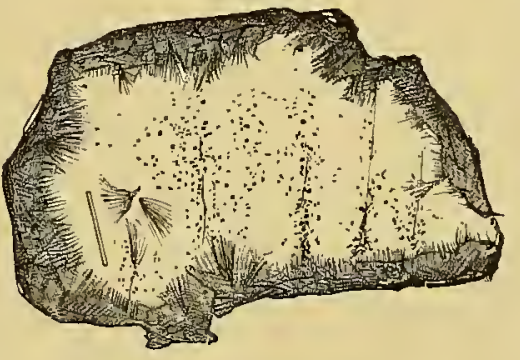

FIG, 16.-Clastic quartz penetrated by serpentine. After Becker

While certain individuals may grow to much more than average magnitude, many others break up into very numerous smaller individuals of different kinds; for instance, the change of feldspar to quartz and mica. (See Pl. III, A.) The growth of large individuals at the expense of small ones explains the numerous interpenetrations of minerals in the recrystallized locks. As a result of the disturbance of equilibrium from any cause, a change may take place. One mineral may grow. At the same time the adjacent mineral may be dissolved. The growth of one in many cases is apparently conditioned by the solution of the other. Cases of this are the growth of magnetite into quartz, and the secondary penetration of needles of actinolite and serpentine into quartz. (See fig. 16.) 
The enlargement of mineral particles has been described as occurring in quartz, feldspar, hornblende, augite, garnet, tourmaline, and other minerals, by Sorloy, ${ }^{a}$ Becke, ${ }^{b}$ Lrving,${ }^{,}$myself, ${ }^{d}$ Williams, ${ }^{e}$ Hobbs, ${ }^{f}$ Whittle,${ }^{g}$ and others. (See figs. 14 and 15.)

However profound the alterations of metasomatism by molecular mechanical action under mass-static conditions, the original textures and structures of the rock may not be greatly affected. It may be that all of the original minerals composing a rock are completely changed and yet the original igneous or other textures be perfectly preserved. The case is parallel to that of petrifaction of a wood in which no particle of the woody fiber remains and yet the textures of the original organic tissue are almost perfectly preserved. The modifications are mainly changes of substance, not changes of form. 'Thus all the textures characteristic of igneous rocks, such as granolitic, ophitic, porphyritic, etc., may be almost completely preserved in a rock which has altered throughout. This is illustrated by the dolerite dikes in the iron-bearing formation of the Penokee series of Michigan and Wiseonsin. These dikes in the black impervious slates are little altered dolerites, but their continuations in the iron-bearing formation do not contain one vestige of any original mineral, but are ferruginous, hydrated, aluminum silicates, which in composition correspond very closely to kaolin. ${ }^{h}$ Yet the texture in the altered rock and in the dolerite is the same.

Indeed, not only may there be no tendency to destroy textures and structures which were originally present, but there may be a tendency to

"Sorby, H. C., On the structure and origin of noncalcareous stratified rocks: Proc. Geol. Soc. London, 18s0, p. 62 .

${ }^{b}$ Becke, F., Eruptivgesteine aus der Gncissformation des niederösterreichischen Waldviertels: Tschermaks mineral. Mlittheil., vol. 5, pt. 2, 1883.

c Irving, R. D., and Van Hise, C. R., Enlargement of quartz fragments and genesis of quartzites: Bull. U. S. Geol. Survey No. 8, pt. 1, 1884, pp. 11-43.

a Tan Hise, C. R., Enlargements of feldspar fragments in certain Keweenawan sandstones: Bull. U. S. Geol. Survey No. 8, pt. 2, 1884, pp. 44-17. Van Hise, C. R., Note on the enlargement of hornblendes and augites in fragmental and eruptive rocks: Am. Jour. Sci., 3d ser., vol. 33, 1887, pp. 385-388.

e Williams, G. H., The greenstone-schist areas of the Menominee and Marquette regions of Michigan: Bull. U. S. Geol. Survey No. 62, 1890, p. 173.

$f$ Hobbs, Wm. H., Phases in the metamorphism of the schists of the southern Berkshire: Bull. Geol. Soc. America, vol. 4, 1893, pp. 173-176.

$g$ Whittle, C. L., Some dynamic and metasomatic phenomena in a metamorphic conglomerate in the Green Mountains: Bull. Geol. Soc. America, vol. 4, 1893, pp. 156-158.

$h$ Irving, R. D., and Van Hise, C. R., The Penokee rron-bearing series of Michigan and Wisconsin: Mon. U. S. Geol. Survey, vol. 19, 1892, pp. 357, 358. 
emplasize them. This emphasizing of old textures and structures results from the fact that solntions work along openings and surfaces of weakness. At any place in which water is present in more than the average amount, or is more than usually active, there may be greater than average solntion and deposition, and thus emphasis of the old texture or structure. Common cases are the emphasis of perlitic cracks and bedding planes.

However, where large individuals alter to many small particles, or undergo a secondary enlargement with needle-like terminations, or are altered in varions other ways, the original textures may become much less definite than they were originally, although the process of modification rarely goes so far as to obliterate original textures.

As a result of the preservation or emphasis of original textures and structures during metasomatism in the belt of cementation, it may happen that somewhat extensive changes in a rock are overlooked or ignored. Those who are most familiar with the recent little modified rocks are inclined to explain the phenomena they see in them as original. Those who have been working among the ancient and therefore more modified rocks are inclined to explain similar phenomena as the result of alteration. In each case the phenomena must be studied in the field and in the laboratory, taking into account all the evidence, in order to ascertain the actual trutlı; for it is certain that such phenomena as amphibole surrounding. pyroxene cores and pegmatitic textures may be due to primary crystallization or to secondary alteration, and the appearance in the two cases be much the same, if not identical.

\section{SEGREGITIOY OF INIVIDLAL IINERALS}

Under exceptional conditions, by alteration or substitution or the two combined one mineral may very largely or wholly replace the minerals previously occupying a certain space. The space thus taken may vary from an insignificant amount to a considerable area for the entire thickness of a formation. In the latter case the process of metasomatism is often given a name dependent upon the mineral which replaces the other minerals, or that into which the other minerals alter. If, for instance, the segregating compound be silica, the process is called silicification; if it be serpentine, it is called serpentinization; if it be chlorite, it is called chloritization, etc. 
Probably the most common of the rarious segregations is that of silica. This perhaps most frequently takes place in limestones, producing cliert or quartz masses. According to Hinde, ${ }^{a}$ silicification has extensively occurred at Spitzbergen and Axels Island, where formations once largely carbonates, aggregating 250 or more meters in thickness, are composed almost entirely of chert.

Cases of extensive serpentinization are those of the metamorphosed sandstones and igneous rocks in the Coast Range of California, described by Becker, where serpentine is said to replace quartz, feldspar, and apatite on an extensive scale. ${ }^{b}$

IGNEOUS WORK.

The igneous work of the belt of cementation is all comprised under "injection."

\section{INJECTION.}

By injection is meant the penetration of a rock by a molten magma. In the belt of cementation the injecting rocks make their way chiefly by following fiactures, such as fanlts, joints, bedding planes, fissility planes, irregular fractures of brecciation, etc. The injected material therefore fills the larger crevices, such as those produced by faulting, jointing, bedding, fissility, or brecciation, and to some extent it may penetrate the interspaces between the individual grains-for instance, those of the ordinary sedimentary rocks. But it is probable that pure igneous injection between the mineral particles of the dense rocks does not usually penetrate a great distance from a continuous mass of the magma. Not only do the injecting masses utilize the openings already formed, but they force the walls apart and extend the openings, thus making possible intrisire masses of large size. The intrusive masses vary in size from great laccoliths many kilometers in extent and thousands of meters in thickness, throngh numerous great dikes or sills, many of which may be a hundred or more meters in thickness and many kilometers in extent, through dikes and sills of small size, to minute lamina between the fissile leaves or to stringers between the grains.

a Hinde, G. J., On the chert and siliceous schists of the Permo-Carboniferous strata of Spitzbergen: Geol. Mag., new ser., dec. 3, vol. 5, 1888, pp. 241-251. Reviewed in Am. Jour. Scı., 3d ser., vol. 36, 1888 , p. 73 .

$b$ Becker, G. F., Geology of the quicksilver deposits of the Pacific slope: Mon, U. S. Geol. Survey, vol. 13,1888, pp. 122-125. 
Injection by occupying the opening's of the rocks indurates them. In these respects the process is similar in its results to cementation. The injection nagma is a solntion which crystallizes. This is a freezing of the solution. (See p. 113.) In cementation the solids crystallize from the solutions. It is believed, as will be seen (pp. 723-728), that the process of injection passes by gradation into cementation. The forms which injections take are often similar to those of the reins produced by cementation, and rock masses formed by either process may have the same relations to the previous structure of the rock.

Injecting materials comprise magmas of all kinds. Injections follow parallel and irregular fractures alike. Where the injections are in plane parallel openings, such as those of faults, joints, and fissility, the rock may take on a banded character. These bands may be large and wide apart, as is often true of injections along faults; smaller and closer together, as is frequent along joints; or very narrow and very close together, as is occasionally the case along planes of fissility. The banded rocks produced by injection may have an added complexity, due to the fact that many of the dikes follow one or more sets of fractures diagonal to the previous structure as well as parallel to it. Where the injections are in rocks with original irregular fractures, such as brecciation, this results in great complexity of structure.

The Sierra Nevada grauite furnishes an admirable example of a rock which has been injected in a complicated manner. This granite is cut by several sets of intersecting joints. Many of these joints have been taken advantage of by the later injecting granite; and in the magnificent exposures in the region the dikes may be seen in parallel sets, intersecting other parallel sets of dikes. One of the localities in which the phenomena may be particularly well seen is the Yosemite Valley. Here there are at least six sets of intersecting joints. At some places two or three of these sets of joints have been taken advantage of by the entering material.

In some regious, after one set of fractures has been taken advantage of by injection material, succeeding orogenic movements have produced other sets of fractures, which have again been injected, and in some regions there may be found evidence of several distinct periods of fracturing and injections Complicated injection is particularly likely to occur adjacent to great laccoliths within the zone of fracture. 
Not only do igneous intrusions follow the various openings of rocks, such as those of joints, faults, fissility, brecciation, etc., and thus close them, but they produce a metanorphic effect upon the injected rocks. This contact effect may be confined to a centimeter or two adjacent to the intrusive or it may extend to a distance of several kilometers, depending upon many factors considered below. Furthermore, the contact effect, whether confined within narrow limits or affecting an extensive area, may be either slight or profound.

As already stated on page 488, the contact effect of the injecting upon the injected rock is known as the exomorphic effect, and that of the injected rock upon the injecting rock as the endomorphic effect. As has been fully explained on pages 489-494, the exomorplic effect is produced in two ways-by the direct contact action of the igneous rocks due to rise of temperature, and by indirect action through heated solutions. The exomorphism is ordinarily at a maximum immediately adjacent to the intrusive, and it decreases in amount, either rapidly or gradually, with distance from the intrusive. The eliange immediately adjacent to the injecting rock is often very marked. The rocks may be greatly indurated; the colors may be changed, etc; and these physical changes are commonly accompanied by changes of chemical and mineral compositions.

The modifications of the intruded rocks immediately adjacent to the intrusive rocks are commonly attributed to direct contact action, but the change in chemical composition shows that solutions are also an important factor in the result, and therefore that there is indirect action. Indeed, in the belt of cementation the two are never independent, and it is impracticable to separate direct and indirect exomorphism and measure their quantitative importance. While this is true, it will be seen that contact metamorphism in the belt of cementation is only in small measme direct, and in very large measure indirect.

As fully explained on pages 490-494, in the belt of weathering the exomorphic effect is accomplished throngh gaseous solutions; in the belt of cementation the exomorphic effect is accomplished mainly through liquid solutions. In the latter belt, as in the belt of weathering, the solntions are modified in two ways-by the actual emission of water and associated materials from the igneous rocks to the solutions, and by the simple 
heating of the solutions by the igneous rocks. In the belt of weathering the range of action of the gaseous solutions is somewhat limited. (See pp. 430-431.) In the belt of cementation the range of action of the liquid solutions may be far more extensive and the total result vastly greater. Indeed, I believe it would be difficult to. overestimate this indirect effect.

The solutions are the great agents which permeate all the openings of the rocks, great and small, travel great distances from the source whence they derived their lieat and dissolved materials, and in their journey everywhere alter the rocks.

To illustrate, the waters of hot springs, such as those of the Yellowstone Park, derive their heat from igneous rocks at considerable distances from the points where the water's issue, and throughout the journey the activity of these solutions is very greatly enhanced, and therefore exomorphism is greatly accelerated.

The amount of contact action and the distance to which it extends depend mainly upon (a) the porosity of the intruded rock, (b) the efficiency of the water circulation, (c) the composition of the intrusive and intruded rock, (d) the size of the intrusive masses, (e) the length of time of intrusion, (f) the temperature of the intrusive, and $(g)$ the depth of the intrusion.

(a) A most important factor in the extent and amount of contact metamorphism is the porosity of the intruded rock. If the rock be nouporous the contact effect is usually limited to a somewhat narnow belt adjacent to the intrusive. If the intruded rock be broken by faults, joints, planes of fissility, and especially if the indiridual masses between the larger openings are porous, as in the case of sandstones, the contact effect for a given intrusive mass may extend many times farther and be many times more effective than in a nonporous rock.

Chemical change is greatly facilitated by the perviousness of the intruded rock. A porous róck, such as a sandstone or a fissile rock, has openings in which may be deposited great additions of materials different from the unmorlified rock, and thus change its chemical composition. For instance, a quartzose sandstone may have large additions of feldspar or amplibole, as in the Wausau district of Wisconsin. On the other hand, an impervious rock, such as a mudstone or shale, may be but little changed, as the solutions can not readily penetrate this rock and carry with them 
constituents of a different composition. Of course an impervions rock may be considerably changed in chemical composition immediately adjacent to the intrusive, but the change is not likely to extend far. (See e.)

(b) If circulating underground waters are in rapid motion in the intrnded rock-and this of course depends, among other things, npon the porosity - the contact effect will extend widely and the alterations be great, for the rapidly moving percolating waters derive both heat and soluble material from the igneous rocks, or the heated rocks adjacent to them, and this material and the heat are carried far and therefore produce great effects.

(c) The amount of contact action depends upon the compositions of the intrusive and intruded rocks. The general law in this connection is that the exomorphism and endomorphism tend to make the rocks approach each other in chemical composition. Therefore the amount of change is likely to be great in proportion as the difference in composition of the intrusive and intruded rocks is great. If they be practically the same in chemical composition, the intereliange of constitnents throngh the solutions is not likely to greatly modify the composition of either. But if, on the other hand, the two rocks differ greatly in composition, each will be likely to gain constitnents from the other and be modified in chemical and nineral composition. Each furnishes to the other materials in which it is deficient. Thus, if an intrusive rock in which feldspar and bisilicates are abunlant, but in which quartz is absent, intrudes a rock rich in quartz, but one in which feldspar and bisilicates are absent, the intruded quartzose rock will be likely to gain feldspar and bisilicates, while the intrusive rock will be likely to gain silica, and may gain an amount sufficient to canse the silica to separate as quartz. An excellent example of the addition to the intruded rock from the intrusive is furnished by the adinoles and spilosites of the Crystal Falls district of Michigan described by Clements. ${ }^{a}$ These metamorphosed slates contain very much more potassiun than the average slate of the district. The igneous rock is rich in potassium and this element, therefore, must lave been derived from that sonrce.

In producing the above effects intrusive rocks are likely to cause important change in proportion as they are mobile and in proportion as they contain a large amount of occhuded water. Indeed, to a certain extent

$a$ Clements, J. Morgan, A contribution to the study of contact metamorphism: Am. Jour. Sci., 4th ser., vol 7, 1899, pp. 85-90. 
these two factors are mutual; for the greater the amount of occluded water the greater the mobility of the magma. The greater the mobility the nore extensive the intrusion is likely to be and the more minute the openings which may be entered. Further, magmas which contain a large amount of occluded water at the time of crystallization emit this water loaded with salts, and this material is added to the intruded rocks and increases the exomorphism.

(d) Other things being equal, the greater the mass of the intrusive the farther its effects are likely to extend and the more potent they are likely to be. While there is a tendency for the metamorphism to be proportional to the size of the intrusives, the small metamorphic effect upon the adjacent rocks which large intrusive masses, such as the great dikes or even the laccoliths, frequently show is astonishing. In many eases the intruded rocks seem to be searcely modified at all by masses of the largest size in the belt of cementation. An excellent illustration of great intrusive masses with little or no apparent metamorphism is furnished by the extensive sills, from 10 to 100 or more meters thick, in the Animikie slates northwest of Lake Superior. But, as explained below, comparatively small masses of intrusive rocks may, for various reasons, result in profound modification.

(e) An inportant factor in the extent of metamorphism is the length of time through whish flow continues along a certain opening. If magmatic flow continues long through an opening, the quantity of passing. magma is great and the contact effect is likely to extend far and to be profound. This is a general consequence of the large amount of heat and emanations which may be furnished to the surrounding rocks and solutions by the long-continued intrusions. Long-continued flow of lava to higher levels or to the surface may take place through small openings, and a large intrusive mass may quiskly form. Therefore a comparatively narrow igneous mass may be accompanied by profound contact action, because the changing mass funishes to the intruded rock a continuous supply of heat and material to the solutions for a long time; while accompanying. great masses of igneous rocks which simply occupied an area, comparatively little contact action may occur. The latter case is illustrated by the Henry Mountain laccoliths " and the great dolerite sills, some of them

"Gilbert, G. K., Report on the geology of the Henry Hountains: IT. S. Geog. and Geol. Surv., Rocky It. Region, I880, pp. 5I-98. 
hundreds of feet in thickness and many miles in extent, in the Animikie series of the north shore of Lake Superior. ${ }^{a}$

(f) The higher the temperature of the intrusive the greater the amount and extent of the contact effect. The temperatures of lavas as they reach the surface vary greatly, ranging from 700 to $1,100^{\circ} \mathrm{C} .{ }^{b}$ Other things being equal, it is evident that those magmas which have the higher temperatures are more effective in metamorphism, for two reasons. In the first place, they furnish a larger amount of heat to the surrounding rocks and solutions; and in the second place, they have greater mobility and therefore are more likely to extend far and enter minute openings.

(g) Other things being equal the greater the depth of the intrusion the greater the contact effect. One of the chief reasons for this is that rocks are very poor conductors of heat, and therefore the direct and indirect effect upon the intruded rocks continnes for a longer time with a gradually broadening zone of action. Indeed, it is highly probable that the larger masses of the intrusive rocks in the middle and lower parts of the belt of cementation, of Tertiary age, have not yet cooled. The solutions of very greatly increased metamorphic efficiency on account of this heat have been at work for millions of years.

Finally, the pressure is much greater where the intrnsives are deep seated, and this promotes metamorphism. This matter of the incrense of the metamorphic power of intrusives with depth can not be too strongly emphasized. Indeed, in cases of widely extended and profound exomorphic effect the intrusives are almost invariably deep seated. As the depth of the intrusives increases, we gradually pass from the belt of cementation, which we are now considering, to the zone of anamorphism, to be considered in the following chapter. It will there be seen (pp. 711-736) that in that zone, where the intrusives are of still greater depths than in the belt of cementation, the contact effects are of -the most profound character. But it can not be too strongly insisted upon that these effects are not mainly due to the direct heating effects of the intrusive rock, but to the indirect effect upon the solutions in heating them and furnishing materials to them. I repeat, the solutions are the important direct agents which produce far-reaching and profound metamorphism in the belt of cementation.

a Lawson, A. C., The laccolitic sills of the northwest coast of Lake Superior: Bull. Geol. and Nat. Hist. Surv., Minnesota, No. 8, 1893, pt. 2, pp. 24-48.

$b$ Geikie, A., Textbook of geology: Macmillan \& Co., London, 1893, pp. 225-226. 
COMBINATIONS AND RELATIONS OF MECHANICAL WORK, CHEMICAL WORK, AND IGNEOUS WORK.

For the sake of clearness of analysis, each of the mechanical processes of consolidation-strain within the elastic limit, and fractming; the chemical processes of cementation and metasomatism; and the igneous process of injection-has been treated separately. As a matter of fact, any one of the processes may be dominant in an individual case, as, for instance, the cementation of a sandstone to quartzite. Commonly, however, they do not occur independently in the rocks, but two or more take place simultaneously. The joint work of different combinations will be briefly considered in order to make clear the interaction of the processes.

The mechanical, chemical, and igneous processes often occur together, one frequently promoting the other. The chemical processes are promoted by the mechanical processes. Fracturing gives water a much larger surface of contact; it promotes water circulation; it allows easy injection. The mechanical processes induce a state of strain in the mineral particles where it does not fracture them. Therefore fracturing very notably promotes cenentation, metasomatism, and injection. Indeed, in the belt of cementation, where the rocks are massive and originally contained no openings, cementation, metasomatism, and injection would take place with difficulty and slowly if it were not for mechanical action.

It has been explained that the processes of oxidation, carbonation, and hydration, characteristic of the belt of cementation, can take place only with expansion of volume. Where there are no openings available, in order that these reactions shall occur, it is necessary that much material shall be dissolved to compensate for this expansion; and in the massive rocks the water circulation is so slow that the material can be dissolved and transported from the belt of cementation only very slowly indeed. This, therefore, is the explanation of the small amount of alteration in the belt of cementation where the rocks are not porous and have not been fractured.

However, where the massive, originally nomporous rocks have been fractured, the fracturing increases the total volume of the rocks by the amount of the openings produced. Later the openings are closed by cementation, metasomatism, and injection, and thus there is absolute increase in the volume of the material. This increase has been estimated 
by Shaler, as already noted (p. 127), to be 3 to 5 per cent of the superficial area at certain places along the New England coast, ${ }^{a}$ and this corresponds to an increase in volume from 0.52 to 1.12 per cent. Where one set of openings which originally existed or has been produced by fracturing has been closed by cementation, metasomatism, and injection, a new set of ruptures may form, thins further increasing the volume of the rocks, and these openings may again be closed by cementation. Of course, in such rocks as were originally very porons-for instance, the sandstones and amygdaloids-the alterations of the belt of cementation may take place

- with no gross expansion of the volume of the rocks, the necessary spaces being found in the original openings.

The conditions favorable to cementation and metasomatism are usually the same; therefore the two processes naturally occur together. In some cases, such as cementation of a pure quartz sand, cementation may take place without marked metasomatism; but this is exceptional. Metasomatism is almost invariably accompanied by cementation, and usually where the former process is important the other is sure to be of consequence. Where injections occur it has been seen that, besides closing the openings, an extended and profound exomorphic effect is produced. Further, it has been seen that this is especially likely to be true when the exomorphism is indirect or the work of solntions. But the alterations accomplished by the. solutions as an agent are cementation and metasomatism. Therefore, where injection is an important metamorphosing inflnence, cementation and metasomatism are exceedingly active and widely extended. The underground waters are heated. These heated waters dissolve a large amount of the material of the injected and injecting rock; they receive a further contribution furnished by the solutions emanating from the injected rock. Solntions thus enriched travel for a greater or less distance, but ultimately a portion of the material is deposited, thus cementing the rocks. Just as injection promotes cementation it promotes metasomatism, and for the same reasons. The solntions are heated and rich in mineral materials, and therefore the mineral particles present in the injected rock are modified. It follows from the foregoing that the chief indirect exomorphic effects are. accomplished by cementation and metasomatism.

a Shaler, N. S., The crenitic hypothesis and mountain building: Science, vol. 11, 1888, p. 281. 
Irving further points out ${ }^{a}$ that, after an igneous rock has solidified, as it continues to cool it contracts, and therefore at the contact of the igneous rock with the intruded rocks openings are likely to be produced. Frequently the contraction openings are not confined to the contacts, but extend into both the injecting and the injected rock. Such openings, being within the intrusive rocks or near the contacts of the intrusive and intruded rocks, furnish trunk channels which are likely to receive solutions from both the injecting' and the injected rocks. 'Thus are explained the rery frequent trunk channels for circulation and rein formation within and adjacent to igneous rocks. The openings along the borders of igneous rocks and within them are of very great consequence in connection with ore deposits. (See p. 1116.)

Concluding, it is clear that while one or two of the processes of cementation, metasomatism, and injection may occur without the other one ${ }^{\circ}$ two, it is rarely that one works alone. Of the processes, that which is most likely to occur without the others is cementation. Metasomatism rarely, if ever, takes place withont cementation. Cementation and metasomatism may take place on an extensive scale without injection. Injection is invariably accompanied by cementation and metasomatism.

\section{CHANGES OF CHEMICAL COMPOSITION.}

The amount of change in the chemical composition of the rocks in the belt of cementation is likely to vary with the porosity. Where the rocks are dense, chemical analyses appear to show that the average composition of the rocks does not greatly change, except by oxidation, carbonation, and hydration. The oxygen and carbon dioxide are added directly or indirectly from the atmosphere, and the water from the hydrosphere. In the opening pages of Chapter II it has been explained that all chemical changes involve molecular mechanical action, even where the average chemical composition remains the same. There may be interchange on a great scale between the minerals within short distances (for instance, glasses may wholly devitrify), but in the dense rocks the migrations of material are ordinarily contined within somewhat narrow limits and the average change in chemical composition is not great.

${ }^{a}$ Irving, A., Chemical and physical studies in the metamorphism of rocks, Longmans, Grcen d Co., London, 1889, pp. 82-84. 
In the porous rocks, such as sandstones, extrusive igneous rocks, especially the vesicular lavas and porous tuffs, and much fractured rocks, where there is comparatively rapid circulation of water, the migration of materials for considerable distances may be important. The addition or subtraction of material at any place may be large; for instance, simply filling the pore spaces may require the addition of 20 to 40 per cent of the rolume of the rocks. (See pp. 569-570.) Also alterations extend through the minerals originally present. Therefore the chemical compositions of the rocks for extensive areas may be much changer. Excellent illustrations of the transportation of material for long distances and its replacement of other material, thus changing the composition of the rocks, are furnished by the segregation of individual minerals, described on pages 645-646. One of the best illustrations of extensive change in chemical composition is furnished by the silicification of limestone formations. (See pp. 646, 816-820.) Perhaps there is no more conclusive case of replacement than the very numerous instances of partial and complete substitution of copper for porphyry pebbles and bowlders, described by Pumpelly, ${ }^{a}$ in the Calumet and Hecla conglomerate. Other illustrations of replacement are furnished by many of the ore deposits.

a Pumpelly, Raphael, The paragenesis and derivation of copper and its associates on Lake Superior: Am. Jour. Sci. for Sept., Oct., and Nov., 1871, vol. 2, pp. 188-198, 243-258, 347-355. 


\section{CHAPTER VIII.}

\section{THE ZONE OF ANAMORPHISM.}

\section{DEFINITION OF ZONE.}

In Chapter IV the zone of anamorphism lias been treated from a physical-chemical point of view. It is there shown that this is a zone in which there is great pressure in all directions, and that this is the dominaut factor controlling the reactions, so that changes take place which diminish the volume of the rocks. The chemical law of energy is subordinate to the dominant physical demand of pressure for reactions which lessen the volume. Chemical reactions therefore take place with liberation or absorption of heat, as demanded by the pressure; but in large measure pressure demauds that chemical reactions take place with absorption of heat, such as silication, dehydration, deoxidation.

It is the purpose of the present chapter to consider the zone of anamorphism from a geological point of view. The zone of anamorphism is bounded above by the belt of cementation of the zone of katamorphism. It has no assignable boundary below. The depth of the upper surface of the zone of anamorphism is very variable, depending upon many factors, among which the strength of the rocks and the speed of deformation are very important. It is not practicable to assign a minimum limit to this depth, but it is highly probable that in many cases the upper surface of this zone is not at greater depth than 1,000 to 2,000 meter's, for rocks have been modified by the reactions characteristic of the zone which have apparently not been buried to a greater depth than this. By making assumptions so as to give a maximum depth for the belt of cementation, the upper surface of the zone of anamorphism is calculated to be at a depth not greater than 10,000 to 12,000 meters. $^{a}$ (See pp. 189-190.)

"See Van Hise, C. R., Principles of North American pre-Cambrian geology: Sixteenth Ann. Rept. U. S. Geol. Survey, pt. 1, 1896, p. 593. 
It has been said that no lower limit can be given for the zone of anamorphism. The alterations certainly obey the physical laws of the zone of anamorphism to the depth at which observation is possible as a result of deformation and denurlation. How the rocks behave at greater depths is only to be judged by inference. So far as one can foresee the action of the laws of energy, it appear's highly probable that the reactions of the zone of anamorphism extend to a very great depth. But in this treatise the zone of anamorphism is restricted to the lower part of the lithosphere of which we have observational knowledge, and, following Powell, I apply to the unknown depth below it the term "centrosphere."

The zone of anamorphism differs in an important respect from that of katamorphism, in that the openings are in general those of subcapillary size. This follows from the fact that the pressure in all directions is greater than the crushing strength of the rocks, and if large openings conld be supposed to exist they would be closed by the flowage of the rocks. While the general fact of the subcapillary size of the majority of the openings in the zone of anamorphism is beyond doubt, it can not be stater that somewhat larger openings do not exist. So far as there are openings which are filled with liquid that can not escape, the above reasoning does not apply, for the inclosed liquid successfully resists the closing of the cavities. By general reasoning one is not able to deternine how large such liquid-filled openings are, but observation indicates that they are small, in general so small that they are observed only by the microscope, and in no cases known to me are they larger than capillary size.

One modification of the above statements should be made in reference to openings in the rocks in which the alterations are mainly those of the zone of anamorphism. During periods of very rapirl deformation large fractures may extend much deeper than under ordinary conditions, for whether rupture takes place by major fractures or by flowage is largely dependent upon the speed of the movement. This principle can not be better illustrated than by the deformation of marble at the surface. Where a marble slab is rapidly cleformed at the surface, it is ruptured. Where, howerer, a similar slab is laid horizontally, being supported only at the ends, so that gravity steadily tends to bend it, the slab bends very slowly with permanent set. This is ilinstrated in cemeteries by slabs long suspenderl in the manuer described. Julien cites a number of instances of the bending of marble 
slabs at the surface without rupture, the most notable being that of an upright marble slab, 3.35 meters long, $22.8 \mathrm{~cm}$. wide, and $6.35 \mathrm{~cm}$. thick, in one of the doors of the Alhambra, Spain, which, throngh the settling of the material of the wall, had attained a curvature of $76.2 \mathrm{~mm}$. $^{\text {" }}$

From these illustrations it appears that a strong force rapidly applied may deform a rock by fracture, whereas a very moderate force slowly applied may deform it by flowage. This principle probably has great geological significance in metamorphism. Where the deformation is very rapid the zone of fracture and the alterations of the zone of katamorphism may extend to great depth. Under such circumstances igneous injection and cementation may go on, but as soon as the earth movements cease, or lessen in speed, the openings are gradually closed by rock flowage under the laws of the zone of anamorphism. Thus a great zone or belt of rocks is alternately under conditions of the belt of cementation and under conditions of the zone of anamorphism, according as deformation is fast or slow. This subject will be further considered on subsequent pages, especially in the section on pegmatization. (See pp. 720-728.)

\section{CONDITION OF WATER.}

In considering the condition of water in the zone of anamorphism the temperature is of the utmost importance. It has been explained on page 566 that above a temperature of $365^{\circ} \mathrm{C}$., the critical temperature of water, water can exist only as gas. Supposing the increment of increase of temperature with depth to be $1^{\circ} \mathrm{C}$. for 30 meters, this temperature wonld be reached at a depth of 10,950 meters, even if the temperature be $0^{\circ} \mathrm{C}$. at the surface. It has been explained that the upper surface of the zone of anamorphism is probably in most cases at a deptly not greater than one-half of 10,950 meter's. It therefore is clear that in the upper part of the zone of anamorphism the water may be in the form of leated liquid, not as water gas. Disregarding igneous rocks and orogenic movements, where the critical temperature is not reached, even if the water were at temperatures far above the boiling point at the surface, the water would be held in the form of liquid by the pressure, as fully explained on pages 566-569. In so far as the water is in the form of liquid, nothing further need be said

aJulien, A. A., The durability of building stones, etc.: Tenth Census of United States, 1880, vol. 10, 1884, pp. 366-367. 
in reference to it, for the laws controlling its movements and metamorphic action are precisely the same as those governing the heated water of the belt of cementation. (See pp. 566-646.) But at depths greater than abont 11,000 meter's the water must be supposed to be gas. Moreover, in consequence of igneous intrusions and orogenic movements, the critical temperature is probably frequently attained over extensive areas at depths much less than this. Therefore it is highly probable that for much of the zone of anamorphism the water is in the for'm of gas, not liquid.

The general statement may be made that, for the greater part of the zone of anamorphism, water is in the form of water gas, but that for considerable portions of the upper part of the zone the water is in the form of liquid. Thus, in this matter the zone of anamorphism is in direct opposition to the zone of katamorphism, where the water is dominantly in the form of liquid and only exceptionally in the form of gas.

The probable action of water gas in the zone of anamorphism should be considered. What are the differences between the circulation and work of water in the form of liquid at high temperatures and under great pressures and the circulation and work of water gas at such temperatures and pressures? At the pressures existing in the zone of anamorphism it is certain that the gas would be dense. At the depth of 10,950 meters the pressure per square centimeter of a hydrostatic columm of water to the surface would be 1,095 kilograms, or 1,060 atmospheres.

The density of water gas at atmospheric pressure and $100^{\circ} \mathrm{C}$. is 0.0006 of the density of water at $4^{\circ} \mathrm{C}$. Assuming, for purposes of calculation, that, under the temperatures and pressures given, water gas acts as a perfeet gas, H. C. Wolff has calculated for me that at a pressure of 1,060 atmospheres and at the critical temperature of water $\left(365^{\circ}\right)$, the density of the gas would be 2.32 times the density of water' at $4^{\circ} \mathrm{C}$, a result almost certainly too great, but still indicating that the gas is very dense.

In a ver $y^{\circ}$ dense gas the molecules attract one another, ${ }^{a}$ and in so far as this is true the gas approaches a liquid. It is certain that superheated water at high temperature has a low viscosity and remarkable chemical power, as shown on pages 79-81, 105-110, 140-141. In so far as the water gas in the openings of the zone of anamorphism is less dense than the liquid p. 185 .

"Nernst, W., Theoretical chemistry, trans. by C. S. Palmer, Macmillan \& Co., London, 1895, 
in the openings, this would reduce its chenical activity; but the fact that the viscosity of the gas is probably less and its temperature higher may render a small quantity of water in the form of gas as potent $\mathrm{r}^{\circ}$ even more potent in the transformation of rocks than in much larger amount as liquid.

\section{QUANTITY OF WATER.}

The quantity of water in the crystallized rocks of the zone of anamorphism is certainly small as compared with that in the belt of cementation. It has been explained that the openings of the zone are normally of subcapillary size, although some of them are is large as capillary openings. The quantity of water is therefore. limited to the space which may be furnished by these openings, mless it be supposed that under the extraordinary pressures and high temperatures which prevail in this zone the water gas finds a place between the molecules of the crystallizerl minerals, and this lyypothesis can not be proved. Ignoring this possibility, it is probable that the amount of free water in the forms of liquid and gas in the zone of anamorphism is in most cases less than 1 per cent.

\section{CIRCULATION OF WATER.}

Before the question as to the circulation of the water in the zone of anamorphism can be satisfactorily discussed, it is necessary to answer the question as to the probable sources of the water. The certain sources of water in the zone of anamorphism are (a) the water mechanically contained in the rocks at the time they passed into the zone, (b) water produced by dehydration of hydrous minerals, and (c) water from igneous intrusions.

(a) The sediments as originally formed commonly contain large quantities of water in their interstices. As explained on pages 124-127, this amount by volume is frequently 25 per cent or more. By deep burial the sediments pass into the zone of anamorphism. In most cases it is highly probable that before this takes place the larger portion of the original water has been lost as a consequence of consolidation and cementation. But it is not likely that all of the water is lost, and therefore the sedimentary rocks as they pass into the zone of anamorphism probably carry with them mechanically mingled water. As to the quantity of this water, no certain knowledge is available; but I suspect that in the majority of cases it is small, possibly less than 1 per cent. Doubtless the rocks' of the centro- 
sphere which pass into the lower part of the lithosphere also contain some mechanically mingled water, but it is rather probable that the amount is very small.

(b) It has been noted that dehydration is one of the most important reactions of the zone of anamorphism. Water is thus set free within the zone of anamorphism. Dehydration is therefore a certain source of water. It is explained elsewhere (pp. $742-744,895-896$ ) that in muds the combined water is about 8 per cent, in slales is only about 4 per cent, in slates about 3 per cent, and in schists about 1.50 per cent. The process of metamorphism by which a mud is transformed to a schist requires the squeezing out of least 6.5 per cent of water by weight. If the conclusion be true that in general in the zone of anamorphism the quantity of free water is less than 1 per cent, the process of dehydration is eapable of producing more water than is present at any one time. Dehydration is thrrefore an important source of water. Indeed, water of hydration is probably a main reservoir of this essential agent for the recrystallization of the rocks in the zone of anamorphism.

(c) It will be explained under "Injection" that igneons intrusion is one of the important processes which modify the zone of anamorphism. It is. well known that when a magma makes its way to the surface it may contain a considerable amount of oceluded water. The amount of this water is greater in many cases than the amount ordinarily contained in the crystallized deep-seated equivalents of these magmas. If this be so, the process of erystallization of intruded magma in the zone of anamorphism may release water within the zone, and thus furnish another important source of this agent witlin the zone itself. How important this source of supply is, is more or less conjectural, but I suspect that it is important, as will be more fully explained under "Pegmiatization." But it is necessary to say here that where there are great complex intrusive masses in the zone of anamorphism the central masses crystallize like igneous rocks. Often pegmatites and veins form peripherally to this central mass. In their crystallization water is believed to be a very important agent, and it is rather probable that this agent, or at least a large part of it, is that liberated during the crystallization of the large igneous masses.

In addition to the above sources of water, water may have passed from the belt of cementation downward into the zone of anamorphism, or from 
the centrosphere upward into the zone of anamorphism. But it is probable, as will be seen below, that these are not important somrces of water. I suspect that, on the arerage, the mechanical water and the water of dehydration are the main sources of water supply of the zone of anamorphism. MY reason for this belief is that rocks which, containing large quantities of combined water, like the sediments or the porons lavas, are readily recrystallized in the zone of anamorphism, as fully explained on pages 741-748; whereas great masses of igneons rocks in which there is a deficiency of combined water are very frequently not recrystallized, but granulated. The fact that massive igneous rocks containing little combined water do not readily recrystallize is rather clear evidence that sufficient water to do this work is not driven downward from the belt of cementation, or upward from the centrosphere into the zone of anamorphism.

We are now prepared to consider the circulation of the water in the zone of anamorphism. It has been seen that the available openings are mainly those of subcapillary size. It is through these openings that the water must circulate, unless it he assumed that under the high pressures and temperatures obtaining in parts of the zone of anamorphism the water can make its way through the intermolecular spaces of the solid crystallized minerals. This has been held by some geologists. It has been pointed out that water is certainly occlnded within magmas; but this is a rery different thing from the existence of free water between the molecules of a crystallized substance. While the possibility of the transmission of water in this manner is not denied, it is a mere hypothesis; and therefore the only openings which we know to be arailable for water circulation are those of subcapillary size, with possibly a relatively few of capillary size' between the mineral particles.

The movement of the water through these openings must be slow because of their subcapillary size. It has been explained on page 143 that in openings of this kind the attraction of the mineral particles extends from wall to wall, and the filns are strictly adherent and therefore not free water at all. But as the temperature becomes high the riscosity of the water becomes much less, the molecular attraction between it and the rock is decreased, the adherent film is less fixed, and its mobility is therefore very greatly increased. Also, in so far as the temperature of the water exceeds its critical temperature, it is in the form of a gas; between a gas 
and the rock particles molecular attraction is not so important as between rock particles and a liquid; therefore, so far as the water is gaseous, there are probably no strongly adherent films in the openings. The gas, as already explained, is very dense; gas is very mobile; therefore, so far as the water is in the form of gas, it wonld be likely to very effectively make its way from places of great pressure to places of less pressure. With a given amount of water per unit volume the water gas would move from places of higher temperature toward places of lower temperature, for with a given amount of gas occupying the same volume, the higher the temperature the higher the pressure.

As to what extent the water is in the form of liquid and to what extent it is in the form of gas we know so little that $n^{2}$ attempt is made to discuss the movement of the two separately. The statement below is true for both aqueous solutions and gaseous solutions of the zone of anamorphism. Where the term water is used in the succeding paragraphs there is no implication as to which state the compound is in.

Disregarding the possible trans:nission of water through the intermolecular openings, all of the subcapillary and capillary openings would be taken advantage of at every farorable opportunity, and favorable opportunities would be furnished at times of orogenic movement. In the zone of anamorphism during earth movements the mineral particles either are broken and move differentially with reference to one another, or else are recrystallized, or the two combined. In any case there is a constant readjustment of the rock material by which the positions of the minute openings are constantly changed. Where the movements are rapid, supercapillary openings temporarily extend downward from the belt of cementation. (See pp. 658-659.) During orogenic movement the pressures vary greatly from place to place; indeed, at the same place they vary from moment to moment. This results in very variable pressure upon the water solutions within short distances. Therefore, during orogenic movements, when the rock material itself is in motion, the water is in most active movement. The activity of the water in connection with deformation would be further likely to be promoted by the fact that locally the movements would raise the temperature above the critical point if it were not so already, and thus the water would be in the form of water gas, and hence have the high mobility of that form. 
As to the direction of circulation for a given depth, it can be said that the movements would be from places of greater pressure and higher temperature to places of less pressure and lower temperature. It seems probable that the water would move laterally from places of intense orogenic movement to places of less strong orogenic movement. It seems probable that water would move away from places of igneous intrusions, because these produce high temperatures and pressures.

But the water movements of greatest geological interest are the vertical movements. Does water make its way downward from the belt of cementation or upward from the centrosphere into the zone of anamorphism?

It has been explained that the water at the upper part of the zone of anamorphism is under great pressure and at high temperature. It might be supposed, under these circumstances, that the water would make its way downward into the rocks below. This has been a favorite hypothesis of those who have explained the water contained in magmas issuing from volcanoes as of surface origin. The experinental work of Daubrée has been appealed to in support of this view. Daubrée showed that water gas at a temperature of $160^{\circ} \mathrm{C}$. penetrated through a slab of fine-grained sandstone 2 centimeters thick, and produced a pressure upon the other side of 1.9 atmospheres (1,963.2 grains per sq. cm.). ${ }^{a} \quad$ However, it is to be remarked that an essential point in this experiment is that the amount and pressure of water gas are very much less upon the side of the rock to which the water makes its way than upon the other side, for to hold water as liquid at a temperature of $160^{\circ} \mathrm{C}$. a pressure of about six atmospheres is required. If there were no water in the zone of anamorphism there is little doubt that the water would make its way from the belt of cementation into the zone of anamorphism until equilibrium were reached. The force tending to carry this water downward is that of gravity, and is equal to the pressure of a column of water from the bottom of the belt of cementation to the surface. But before we can assume that this pressure is sufficient to drive the water into the zone of anamorphism we must be certain that the pressure in that zone is not as great as or greater than in the lower part of the belt of cementation.

We have seen that water may be present in the zone of anamorphism from at least three sources. This water is under the high pressure of the

a Daubrée, A., Études Synthétiques de Géologie Expérimentale, pt. 1, Paris, 1879, pp. 236-241. 
plastic rocks, and in large part above the critical temperature of water. It is a characteristic of the zone of anamorphism that the rocks are not sufficiently strong to sustain themselves, and that consequently no large and continuous openings are present; therefore the imprisoned water is not subject to the hydrostatic pressure of a column of water reaching to the surface only, as is that of the belt of cementation, but to the weight of the rock columm to the surface, which is approximately 2.7 times as much as the pressure of an equivalent column of water. It has been seen that in much of the zone of anamorphism the water is above its critical temperature, and therefore that the enormous expansive force of this gas is tending to drive the water from the zone of anamorphism to the belt of cementation. In the experiment of Daubrée ${ }^{a}$ the water gas traveled from a place of greater pressure to a place of less pressure. So far, therefore, as this experiment is applicable to the case under discussion it indicates that the water would be driven from the zone of anamorphism to the belt of cenentation. From a consideration of physical principles, therefore, we conclude that water does not pass from the belt of cementation to the zone of anamorphism, but probably is driven by the superior pressure and the expansive force of the gas from the zone of anamorphism to the belt of cementation.

This conclusion, reached by physical reasoning, is fully confirmed by the facts of observation. It lias already been pointed out that, in the zone of anamorphism, in the transformation of a shale to a schist the amount of combined water is reduced from 4 to 1.50 per cent. But the amount of free water in the zone of anamorphism is only a fraction of 1 per cent. This liberated water must have escaped either above or below. That the relative pressures in the zone of anamorphism and the belt of cementation are such as to make the movement upward has already been seen, and there can be little doubt that much or most of the water freed by dehydration goes in this direction. This seems to me highly probable from the fact that the amount of combined water in the recrystallized rocks lessens as the intensity of the metamorphism increases. Where the rocks have been metamorphosed under moderately deep-seated conditions, such minerals as chlorite may be found; where the metamorphism was deeper seated, biotite and muscovite, containing less water, are abundant; but where the metamorphism is most profound, and where apparently the pressure has 
gone to the extreme recognized by observation, muscovite and biotite may be destroyed, with the production of such heary anhydrous minerals as garnet, staurolite, etc. Therefore the water apparently does not make its way downward, or if it does it is water occluded between the solid molecules rather than water combined with them; but as already stated, there is no evidence that water can exist in important quantity in such positions. From the above facts, since the amount of water apparently decreases with the intensity of the metanorphism, or practically, disregarding local irregularities, with depth, and the freed water must escape somewhere, I conclude that the probable general movement of the water present or produced by dehydration and from magmas in the zone of anamorphism is npward into the belt of cementation.

This conclusion is confurmed by other facts in connection with metamorphism. It has been stid, and will be fully explained, that silication of carbonates, forming silicates and releasing earbon dioxide, is one of the chief reactions of the zone of anamorphism. ${ }^{a}$ In the rocks metamorphosed muder deep-seated conditions inclusions of liquid and gaseous carbon dioxide in the cavities are very common. When formed all of the occlnded carbon dioxide was probably a deuse gas, because above its critical temperature. Under surface conditions, below critical temperature and with the high pressures of the gaseons portions, the carbon dioxide largely condenses to a liquid. It is a fact that water's rising from a deep-seated source almost invariably carry large quantities of carbon dioxide. It seems highly probable that much of the carbon dioxide brought up by the rising deep-seated waters is a portion of that earbon dioxide liberated by the process of silication of the carbonates. If this be true, it is further probable that the upward movement of the carbon dioxide was accompanied by water or water gas, for there is no reason why one should go up and the other down.

Therefore it seems to me that the principles of pliysics and the facts of observation both lead to the conclusion that, so far as the vertical circulation of water between the zone of anamorphism and the belt of cementation are concerned, the transfer is upward, from the former to thise latter:

u See Le Conte, Joseph, Genesis of metalliferous veins: Am. Jour Sci., 3d ser., rol. 26, 1883, p. y. 
The next question of importance is the probable movement of water between the zone of anamorphism and the centrosphere. We know nothing. as to the average comparative amount of water in the openings of the lower part of the zone of anamorphism and in the openings of the centrosphere below, nor do we know the pressures and temperatures to which the water is subjected. If the amount of water in the centrosphere be as great as it may be supposed to be from the quantity in the extrusive lavas, it is pressing upward toward the surface, driven by the enormous pressure and high temperature to which it is subjected. Are the quantities of water in the crystallized zone of anamorphism, combined with the pressures and temperatures there, sufficient to give to the water an equally strong tendency to move downward? Whether water makes its way into the zone of anamorphism from the centrosphere below, or moves in the reverse direction, would depend upon the relative force of these two tendencies. Since we know nothing of the quantity of water in the centrosphere, but little as to the condition of the material of that zone, little of the temperatures there prevailing, and absolutely nothing as to a change in the condition of the material in passing from the lithosphere to the centrosphere, I do not venture to express an opinion as to whether or not water travels upward from the centrosphere into the zone of anamorphism. So far as the analogy between the zone of anamorphism and the belt of cementation has any weight, it indicates an upward rather than a downward movement The permanence of the ocean might be addnced as evidence of the gradual although slow movement of water from the centrosphere to the zone of anamorphism, and from the zone of anamorphism to the belt of cementation, and thence to the surface, rather than a reverse movement. But this movement may be accomplished mainly by volcanism rather than by circulation through the solid rocks.

\section{VARIABLE MLATERIALS AND CONDITIONS.}

The rocks of the zone of anamorphism include various classes: (1) All kinds of plutonic igneous rocks may be found in the zone of anamorphism. Indeed, the lower zone is especially the zone of the plutonic igneous rocks. It is in this zone that the great batholiths form. Chemically they vary from the most basic to the most acid, and mineralogically they are correspondingly variable. (2) All kinds of sedinentary and all kinds of rolcauic rocks may pass into the zone of anamorphism by deep burying. 
As sediments are buried under later sediments, the earlier sediments join the lower zone. Volcanic rocks may join the lower zone either by burying beneatl later voleanic rocks or by burying below sediments, or both combined. During their downward movement to the zone of anamorphism they undergo the alterations of the belt of cementation. (3) Any of the products of the belt of weathering may be included within the zone of anamorphism. This may follow as a consequence of the transgression of the sea upon a weathered area and subsequent deep burial under sediments. To illustrate, the rocks of the Piedmont Platean of the United States and of Brazil are disintegrated to a depth varying from a meter to 90 meters. If the sea transgresses over these regions in the future, as it has in the past, without very active erosion, the weathered zone may be buried beneath later sediments, or volcanics may be poured over the weathered rocks and thus protect them. By deep burying, as a result of volcanism or sedimentation, or the two combined, the entire weathered zone may thus join the lower zone. Finally, it is to be remembered that the weathered rocks which join the lower zone by burying necessarily pass through the belt of cementation, or have undergone the modifications of that belt at least to some extent, before joining the zone of anamorphism.

From what has gone before it is clear that there are considerable variations in the conditions of the zone of anamorphism. The pressure and the temperature vary greatly, depending upon depth, deformation, and igneous intrusions; the quantity of injection raries greatly, the igneons materiai being here very abundant or preponderant and there altogether absent; the quantity of water, while absolutely small, has a wide ratio of range, being many times more abundant under some conditions than under others. Since this agent, although present in small quantity, is a chief agent of transformation, this variation in the quantity of water is very important.

Therefore the conditions are exceedingly varied in the zone of anamorphism. Excluding the effects of intrusives, the changes of conditions generally take place rather gradually, and changing from one set of conditions to another a considerable vertical depth or a greater lateral distance is commonly required. In this respect the conditions contrast with those of the zone of katamorphism. The contrast is especially marked with the belt of weathering, where the rariations in conditions are great and 
sudden, but less marked witl the belt of cementation, where the rariations in conditions are somewhat gradual, and therefore approximate in this respect those of the zone of anamorphism.

\section{WORK IN ZONE OF ANAMIORPIISM.}

As in the zone of katamorphism, the work from a physical-chemical point of view may be divided into mechanical work, chemical work, and igneous work.

MECHANICAL WORK.

Mechanical work comprises welding, strain within the elastic limit, and strain beyond the elastic limit.

\section{WELDING.}

Welding is the cohering of the rock particles in consequence of pressure which brings them so close together that they are within the limit of molecular attraction of one another. It has been explained that within the zone of anamorphism the pressures in all directions are greater than the crushing strength of the rocks, and that if openings could be supposed to be prodnced they would necessarily be closed because of the incapacity of the rocks to support themselves. This pressure is so great that the particles are brought within the limits of molecular attraction, and therefore are welded for the same reason that metals weld under proper conditions. That this conclusion, based upon physical reasoning, is certainly true, is shown by the invariably strong cohesion between the mineral particles of rocks which have been in the zone of anamorphism; and recently this conchision, founded upon physical reasoning and observation, has been confirmed by the experiments of Adams and Nicolson. ${ }^{.}$They have ascertained that when dry marble is deformed under pressure in all directions greater than its crushing strength, no supercapillary openings form, and the deformed rock has strength only a little short of that of the original marble. Since the deformation was carried on while the rock was dry, the coherence of the rock particles can not be attributed to the action of water, but must be due to true molecular attraction or welding. The rock was therefore deformed under conditions similar to those which often obtain in the zone of anamorphism.

addams, F. D., and Nicolson, J. T., An experimental investigation into the flow of marble: Philos. Trans. Royal Soc. London, ser. A, vol. 195, 1901, pp. 363-401. 
In the zone of anamorphism, in consequence of pressure in all directions greater than the crushing strength of the rocks, and the resulting invariably close contact of the mineral particles, the process of welding is of far greater consequence than in the belt of cementation, although it has been shown that in the latter belt welding does take place under favorable conditions. (See pp. 595-597.) In short, while welding is an exceptional process in the zone of katamorphism, it is a universal process for the zone of anamorphism.

The deptlı at which welding occurs is different for different substances. Such plastic substances as coal and clay may be welded at very moderate depth, while the strong and refractory rocks, such as quartzites, require a very considerable depth.

STRAIN WITHIN ELASTIC LIMIT.

Within the zone of anamorphism all the mineral particles of all rocks are in a high state of strain at all times. Where the conditions have been quiescent for a long time and the mineral particles have readjusted themselves to the conditions, it may be supposed that the stresses are approximately equal in all directions, and therefore that the conditions approach those of hydrostatics. Under such circumstances the pressure would be the same in all directions within a mineral particle, and the only tendency would be to elastically condense it. The strain would be one of simple compression; or putting it in physical terms, negative lomogeneous dilatation. ${ }^{\infty}$ The molecules of a given mineral particle, as, for instance, one of quartz, are pressed together by virtue of the elasticity of the mineral, and a given particle occupies less space than under surface conditions, where the pressure is slight. Where the hydrostatic pressure is very great, recrystallization may follow, by means of which the minerals pass into more condensed molecules, as is fully explained under "Metasomatism," and especially in comnection with the development of porphyritic crystals. (See pl. 699-705.)

Strain within the elastic limit in which the pressure is equal in all directions is very exceptional, if it ever exists. Almost invariably the pressure is unequal in different directions. The difference in the amount

a Hoskins, L. M., Flow and fracture of rocks as related to structure, appendix to Van Hise, C. R., Principles of North American pre-Cambrian geolngy: Sixteenth Amn. Rept. U. S. Geol. Survey, pt. 1, 1896, p. 860. 
of the pressure in the different directions varies from zero to the elastic limit of a mineral particle under the conditions in which it exists. The difference between the stresses in the different directions where they are great in all directions has been called by Darwin the "stress-difference." It has been assumed by Darwin that if a mineral particle or a rock be subjected to stress in all directions, when the stress-difference between the maximum and mininum pressure is as great as the strength of the particle or rock at the surface, deformation by rupture will take place. But this by no means necessarily follows. It is highly probable that a greater stress-difference is required for deformation when the rocks are under pressure in all directions than when the pressure in one direction is zero, as at the surface. Hallock found ${ }^{b}$ that when a solid of a certain composition, readily plastic under ordinary conditions, was subjected to a pressure of 6,000 atmospheres in cylinders on one side of which were placed coins and tacks, the plastic substance, instead of flowing around the coins, pressed them against the surface of the cylinder so as to fit it perfectly. MLoreover, the coins and the steel tacks were forced against the cylinder so strongly that their impressions were left on the steel holder so as to be seen and felt. From this experiment Haliock concludes that "in general for one and the same substance, over considerable ranges of condition, the rigidity diminishes as the intermolecular distances increase." Or, reversing this generalization to accord with his experiment, the rigidity increases as the intermolecular distance decreases. Now in the zone of anamorphism, where great pressure obtains in all directions, the molecules are brought closer together than at the surface, and probably therefore a much greater stress-difference is required to reach the elastic limit of mineral particles in rocks in the zone of anamorphism than at the surface. How much greater the stress-difference must be it is impossible to conjecture.

This statement applies only to mechanical deformation. In so far as change in form takes place through solution and deposition, or by recrystallization, the above rule does not apply; and this is probably a fact of

aThomson, W., and Tait, P. G., Treatise on natural philosophy, Cambridge Univ. Press, London, edition of 1890 , pt. 2 , p. 423.

$b$ Hallock. Williau, The flow of solids; or, liquefaction by pressure: Am. Jour. Sci., 3d ser., vol. 34, 1887, pp. 277-281.

c Hallock, cit., p. 278. 
most profound significance in the metamorphism of rocks, for it will be fully explained under "Metasomatism" that in so far as mineral particles are strained, and especially as they are under unequal strains, in different directions, solution and redeposition is likely to accomplish deformation. (See pp. 690-692.) The materials are dissolved and mineral particles of different shapes are deposited in an unstrained condition. To accomplish this it is not necessary that the stress difference shall equal or even approach that of the elastic limit of the minerals and rocks.

We conclude that strain within the elastic limit, either with or without a stress difference, but almost universally with a stress difference which for much of the zone of anamorphism often exceeds the crushing strength of the rocks at the surface, prevails throughout the zone, affecting every mineral particle, small and great.

Where the stress difference surpasses the elastic limit of the rocks under the conditions in which they exist, ruptnre may take place, and this leads us to the next section.

\section{STRAIN BEYOND ELASTIC LINITT.}

Strain beyond the elastic limit in the zone of anamorphism results in disruptive deformation, as in the belt of cementation. But the ruptures are very different in the two. During deformation in the zone of anamorphism every particle, small or great, takes part in deformation, and it is this fact which gives a fundamental difference between fractming in the zone of anamorphism and in the belt of cementation, since in the latter belt between the fractures are blocks, small or great, which do not take part in the movements. In this belt but a small number-in many cases an almost infinitesimal fraction-of the mineral particles are actnally ruptured, whereas in the zone of anamorphism strain beyond the elastic limit breaks all particles. If a slide be made from rocks deformed in the zone of anamorphism not one square centimeter can be found in which movement has not taken place. Not only so, but no mineral-particle has escaped the effect of the deformation. Where strain has extended beyond the elastic limit, under the microscope the deformed mineral particles are seen to give evidence of the above facts by their undulatory extinction and their gramulation. (See fig. 17.)

This contrast in the nature of mechanical deformation between the zone of anamorphism and the belt of cementation is of great significance, IION XLVII- $04-43$ 
and yet it has almost altogether escaped notice. What stronger mechanical contrast ean there be than escape from rupture of all but a very small number of the minerals of a rock and the participation in fracturing of all the mineral particles of a rock? But we shall see that in the zone of anamorphism deformation is largely accomplished by chemical processes, whereas in the belt of cementation deformation is mainly accompanied

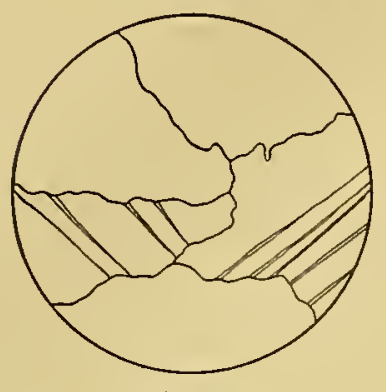

(a)

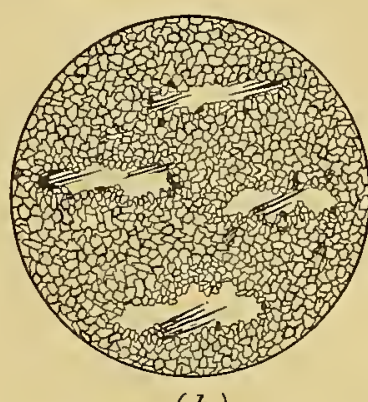

(b)

FIG. 17.-Granulation of feldspar, and gradation between undulatory extinction and granulation. (a) normal anorthosite; (b) granulated anorthosite. After Adams.

more readily granulated than others. For instance, in many rocks containing quartz and feldspar the former mineral nay be grannlated while the latter mineral is but little affected. (See fig. 18.) The granulation of a particle may be peripheral or extend throughout the particle. At a stage of cleformation, when the smaller particles are granulated thronghout, the larger particles may suffer only peripheral granulation; in a more advanced stage the larger particles may be granulated throughout; and in some cases of extreme deformation the largest bowlders of conglomerates are mashed into thin layers not recognizable as clastic fragments, each being composed of a multitude of particles. The degree of subdivision by graulation in eases of extreme defor-

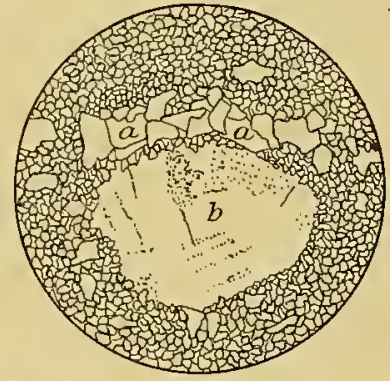

Frg. 18.-Granulation of quartz in a rock in which the feldspar is but little affected. $(a-a)$ granulated quartz; (b) feldspar. After Adams. mation is not usually realized. It should be recalled in this connection that the volumes of particles are as the cubes of their diameters. Very often the diameters of the granulated particles are not more than .1 the diameters of the original fragments; rather frequently they are not more than .01, and in some cases they may not be more than .001 of the originals. This means a subdivision of the original particles into $1,000,1,000,000$, 
and 1,000,000,000 particles, respectively. One of the best ilhustrations of mechanical granulation is that of the anorthosite described by Adams. ${ }^{a}$ Mr. S. H. Ball has compared the size of the grains of the original anorthosite and the granulated anorthosite in two specimens furnished by Dr. Adams, and found that, on the average, one feldspar grain of the original rock is broken iuto 70,000 grains.

By granulation the volume is sure to be somewhat increased, for it is not possible that the broken particles of a grain shall fit so closely as they did when all were parts of one crystallographic unit. The subcapillary openings between the particles may be very small, but they are not so minute as to be ignored. Also, not infrequently small capillary openings form between the granules, and these considerably increase the volume.

Miigge ${ }^{b}$ has shown that ice crystals may be mechanically deformed by differential movement along gliding planes without the destruction of the crystals. Adams and Nicolson ${ }^{\circ}$ have shown by experiment that the same process may occur in calcite crystals; and they thus largely explain the deformation of many of the marbles. This process is essentially mechanical strain beyond the elastic limit. In so far as gliding takes place, deformation may occur without diminution in size of the mineral particles, and hence it contrasts very strongly with gramulation. It is notable that in the experimental deformation of marble by gliding, the mineral composing the rock is one in which there are numerous gliding planes, and how important this process may be in reference to other. minerals is more or less conjectural. Doubtless it is of some consequence in such minerals as have good gliding planes-for instance, the micas; but probably it is of little consequence with the greater number of the rockmaking minerals, such as quartz, feldspar, the pyroxenes, and ampliboles.

\section{CHEMICAL WORK.}

The chemical work of the zone of anamorphism, like that of the belt of cementation, must be considered from tro points of view-the chemical changes and the resultant processes.

a Adams, F. D., Report on the geology of a portion of the Laurentian area lying to the north of the Island of Montreal: Ann. Rept. Geol. Surv. Canada, new ser., vol. 8, 1896, pt. J, pp. 31-85.

$b$ Mlügge, O., Ueber die Plasticitüt der Eiskrystalle: Neues Jahrbuch für Mineralogie, etc., Jahrgang, 1895, vol. 2, pp. 211-228.

c Adams, F. D., and Nicolson, J. T., An experimental investigation into the flow of marble: Philos. Trans. Royal Soc. London, series A., vol. 195, 1901, pp. 363-401. 
CHEMICAL CHANGES.

The chief chemical changes in the zone of anamorphism comprise deoxidation, silication, dehydration, and solution and deposition.

It is commonly true that the reactions of deoxidation, silication, dehydration, and solution and deposition do not ocen separately, bnt two or more together; yet, in order to clearly understand their effect, each is considered separately.

\section{DEOXIDATION.}

Many of the sedimentary rocks contain organic material. In some cases, at least, the deep-seated igneous rocks contain metallic iron, and often they contain sulphides, among which bisulphide of iron is the most important. The zone of anamorphism is deep below the surface, so that oxygen can not get into it from the surface of the earth. Indeed, it has been shown that the oxygen which passes downward with the surface waters is nsually exhansted before it has gone far into the belt of cementation. It follows that the solntions of the zone of anamorphism are reducing, and the conditions those of deoxidation. Therefore highly oxidized compounds are likely to be partly reduced. Ferric oxide is the most important of snch compounds. This compound may be rednced to the ferrosoferric state, forming magnetite, or to the ferrous state, in which form it is in a favorable condition for silication. The amount of reducing agents which are present in the zone of anamorphism is very variable. For instance, the sediments may have almost no organic matter or they may have a great, even a predominant, quantity. Where redncing agents are abundant little or none of the iron is likely to remain as ferric oxide. Where, on the other hand, organic material is sparse and there are large quantities of ferric oxide this may permanently remain in this state. Where deoxidation occurs there is a decrease in volume, but in most cases the amount is small.

In the above paragraph it is supposed that deoxidation takes place only if a reducing agent be present. There is no evidence that the pressure may be so great that oxygen is squeezed out becanse of the demand for decreased volume, although such a reaction is theoretically possible if the pressure were high enough. 


\section{SILICA TYON.}

In Chapter IV (p. 168) silication has been defined as the mion of silica with bases so as to produce silicates. In that chapter the close analogy between the silicates and the carbonates has been pointed out, as well as one of the most fundamental facts of metamorphism, their mutual interchange. (See pp. 173-177). In the chapters on the zone of katamorphism it las been seen that the carbonation of the silicates is one of the processes of fundamental importance, and in the belt of weathering the one which has the most far-reaching effects. It has further been explained that in the zone of anamorphism this process is reversed, silica replacing carbon dioxide of the carbonates and producing silicates. While silica in the zone of anamorphism unites with bases not previously combined with carbon dioxide, it is probable that silication of this kind is unimportant. It is certain that much of the free silica which unites with bases in the zone of anamorphism simultaneously drives off carbon dioxide. There are a number of silicates which are formed by the direct silication of a single mineral. To illustrate: silication of calcite forms wollastonite; silication of dolomite forms tremolite and wollastonite; silication of ankerite forms sahlite and actinolite; silication of siderite forms griunerite. Frequently silication requires two or more minerals to produce the new silicate. As instances, we have, the silication of rutile and calcite together, producing titanite; of hyperstliene and calcite, producing actinolite and anthophyllite; of olivine and calcite, producing actinolite; and of dolomite and siderite, or ferrous dolomite, producing anthophyllite. Silication usually does not oceur alone, but takes place in comnection with deoxidation or dehydration, or both. As a case where we have silication with dehydration may be mentioned the silication of gibbsite, producing sillimanite and cyanite. A case of silication with deoxidation and dehydration is the formation of grünerite from limonite. But usually the instances of silication combined with deoxidation or dehydration, or both, are so complex that it is impossible to state what particular combinations of minerals are deoxidized, dehydrated, or both, and silicated in order" to produce a definite silicate.

It will be seen in Chapter IX, when rocks are considered, that this process of silication takes place on a vast scale. Indeed, no sooner does a carbonate pass from the zone of katamorphism to the zone of anamorphism 
than silication of the carbonates, with decarbonation, takes place. In many of the ancient formations the process of transformation has been complete; in others it is far advanced, and it is uncommon to find any carbonate formation that is buried in the zone of anamorphism in which the process has not taken place to an important extent.

It has been explained (pp. 665-667) that a portion of the carbon dioxide and water freed by silication probably escapes to the belt of cementation and thence to the surface. It will be seen on pages 970-971 that one of the important sources of carbon dioxide for the process of carbonation is the vast quantity which comes to the surface through ground waters. Illustrating this is the startling case furnished by Lecoq, who says that the mineral springs in Auvergne district annually give off 7,000,000,000 cubic meters of carbon dioxide; ${ }^{a}$ and the immeasureably greater amount which reaches the surface for the world as a whole is mainly carbon dioxide freed by the process of silication in the zone of anamorphism. This idea, that the carbon dioxide which reaches the surface from subterranean sources is that derived from the carbonates produced in previous geological ages, was first suggested by Bischof.

However, a part of the carbon dioxide and accompanying water does not escape, and this is believed to largely explain the innumerable cavities partly filled with water and carbon dioxide which are so generally found in the sedimentary rocks metamorphosed in the zone of anamorphism. Such inclusions are comparatively rare, although not unimportant, in the original igneous rocks. (See p. 969.) Silication is thus offered as a cause which explains a large proportion of the liquid carbon dioxide inclusions in the rocks.

Commonly when the silicated rocks liave reached the surface, so that thin sections may be cut, liquid carbon dioxide and water do not entirely fill the cavities, a part being occupied by the gases of these compounds. Doubtless in the deep-seated zone where the rocks were altered the carbon dioxide and often the water were above their critical temperature, and were altogether in the form of gas. Possibly if accurate measurements were made of the volumes of water, liquid carbon dioxide, and water and carbondioxide gas, and the total volume of many of the openings in a rock, so as

a Blake, R. F., and Letts, E. A. The carbonic anhydride of the atmosphere: Sci. Proc. Royal Dublin Soc., new series, vol. 9, pt. 2, 1900, p. 159.

$b$ Bischof, Gustav, Elements of chemical and physical geology, translated by Paul and Drummond, Harrison \& Sons, London, vol. 1, 1854, pp. 237-241. 
to get average determinations, this might enable one to arrive at alternative conclusions as to the pressures and temperatures under which the alterations took place. If a given temperature were assumed, the pressure, and therefore the depth, could be calculated. If, on the other hand, pressure were assumed, the temperature could be calculated.

Silication involves decrease in volume, varying from a very small amount to 40 per cent or more. In the silication of the carbonates, if the freed carbon dioxide be supposed to escape, the decrease in volume is usually between 20 and 40 per cent, and averages fully 30 per cent. In so far as there are cavities that are filled with the water and carbon dioxide which have been liberated by the processes of silication and dehydration but have not escaped, the above determinations as to diminution of volume are too great. No estimates of the volumes of these inchions in the metamorphic sedimentary rocks have been made, but the average amount would probably be comparatively small, possibly less than 1 per cent; although in certain of the schists and gneisses the amount would be much greater than this.

\section{DEHYDRATTON.}

It has been seen in the previous chapters (Chapters IV to VII) that hydration is one of the most important and characteristic of the reactions which occur in the zone of katamorphism. By that process alone or combined with others a large number of hydrated minerals are formed. The most important of these comprise the hydrous silicates and the hydrous oxides. The hydrous silicates include the kaolin group, the serpentine-tale group, the chlorite group, the hydromica group, the zeolite group, and the epidote group. The oxides include the aluninum-oxide group, of which gibbsite is the most important, and the iron-oxide group, of which limonite is the most important. In the zone of anamorphism all these minerals are dehydrated; but in general one can not assert that from a definite one of them some other definite mineral is produced, for commonly during the time of dehydration other alterations also take place, and commonly the materials of two or more minerals mite to produce a new mineral. However, in some cases the alteration is that of simple dehydration; as, for instance, hematite is formed from limonite, anhydrite is produced from gypsum, quartz is formed from opal, corundum develops from gibbsite. By the process of simple dehydration there is usually a very considerable decrease in volume, rumning from 20 to 40 per cent. 
It is believed that the process of dehydration is largely caused by pressure. In other words, water is actually separated from its combination and made free water by the pressure, and the freed water is squeezed out of the rocks as water from a sponge. Undoubtedly, also, the increase of temperature with depth promotes dehydration. Withont exhaustive experimental work it is impossible to give any quantitative estimate of the relative importance of pressure and temperature in producing dehydration. While it is certainly true that moderate pressures and temperatures together rapidly produce dehydration of the more hydrous minerals, ordinarily pressure and temperature are not sufficiently great to drive off all water. Apparently liberation becomes more and more difficult as the water increases in amount. Dehydration is always incomplete, and commonly does not reduce the combiner water below 1.5 per cent. (See pp. 742-744.)

It is probable, as explained on pages 665-667, that the larger part of the freed water escapes upward to the belt of cementation, but some part of it is confined in the altered rocks. Thus dehydration explains a large portion of the water inclusions in the metamorphosed rocks. Of course the water inclusions of original igneons rocks are explained differently, although in an analogous manner. The water, or a part of it, occluded in the magmas, separates at the moment of crystallization, and such part as can not escape is included by the crystallizing minerals.

SOLUTIOY AND DEPOSITION.

Solution and deposition are essential concomitants of the chemical reactions of deoxidation, silication, and dehydration, as well as of all other important chemical changes. Cementation, next considered, involves deposition. In metasomatism, subsequently treated, recrystallization is the change of greatest consequence, and this is accomplished almost wholly by solution and deposition.

Whether solution is preponderant in the zone of anamorphism, or the reverse process, deposition, it is difficnlt to say with certainty. But if intrusives be ignored, probably solution is slightly preponderant. Elsewhere it is shown that there is no evidence of transfers of material into the zone of anamorphism by the water solutions. (See pp. 665-668, 764-766.) By deoxidation, silication, and consequent decarbonation, and by deliydration, the solids constantly lose material. The water as a whole moves from the 
zone of anamorphism to the belt of cementation (see pp. 665-667), and takes with it the freed materials and all the other compounds it can hold. Hence, under normal conditions, solution probably somewliat overbalances deposition; but where igneous instrusions occur the above reasoning is inapplicable.

RESULTANT PROCESSES.

The processes resulting from the chemical changes comprise cementation and metasomatism.

\section{CEMENTATION.}

Cementation in the zone of anamorphism is of far less importance quantitatively than in the belt of cementation. The openings are mainly confined to those of microscopic size--i. e., to the capillary openings between the mineral particles and to the innumerable subcapillary openings. There are in this zone no large openings. The laws of deposition within the minute openings are the same as in the belt of cementation, and will therefore not be repeated. However, the minerals produced are those characteristic of the zone of anamorphism rather than those of katamorphism.

The list of these minerals is deferred to the next section on metasomatism, since that process is far more important than cementation. While the quantity of cementing material in the zone of anamorphism is small, it is not unimportant, at least so far as the strength of the rocks is concerned. If after deformation the new openings between the particles were not occupied by mineral material, the rocks would be rather weak. When, however, these particles are cemented by deposition, they may become as strong as or stronger than they were before deformation.

That cementation actually does take place in the minute openings between the grains is shown by the experimental work of Adams. IVhen marble was deformed without water the modified rock was weaker than the original marble, but where water was present, under great pressures and at ligh temperatures, in one case the deformed rock was actually stronger than the original marble, thus showing that cementation caused the grains to cohere more strongly than when simple welding was the cause of cohesion, as in the case of deformation where water was absent. ${ }^{a}$

a Adams, F. D., and Nicolson, J. T., An experimental investigation into the flow of marble: Plilos. Trans. Royal Soc. London, ser. A, vol. 195, 1901, pp. 370-385. 
It lias been seen (pp. 663-664) that the migration of water through the discontinuous minute openings is exceedingly slow. Therefore the transfer of material in any considerable amount and for great distances is very slow. It follows that the process of cementation is confined to the deposition of material in the minute microscopic spaces, and, ignoring injections, that this material is mainly if not wholly derived from the body of the adjacent rock. In this respect there is a marked contrast between the zone of anamorphism and the belt of cementation. It has been pointed out on pages $617-619,656$, that in the latter belt the material deposited may be great in quantity and derived from points remote from deposition. It follows that, so far as the process of cementation is concerned, the chemical composition of the rocks is little changerl in the zone of anamorphism; whereas, as has been shown on pages $655-656$, in the belt of cementation the chemical composition may be greatly changed by this process.

\section{METASOMLATISW.}

Metasomatism in the zone of anamorphism may take place in various ways, the same as in the belt of cementation. A mineral may recrystallize without change in chemical composition, as, for instance, the alteration of tridymite to quartz. 'Two or more minerals may unite to form a single mineral, as, for instance, the union of calcite and quartz, producing wollastonite. A mineral may change into two or more minerals, as, for instance, kaolinite into andalusite and quartz, but this class of reactions is much more common in the belt of cementation. One mineral may be replaced by another, as, for instance, the substitution of magnetite for quartz. Two adjacent minerals may react upon each other, producing a third mineral, as, for instance, bytownite and olivine, producing amphibole. ${ }^{a}$ But more frequent than any of these simple reactions are complex changes by which the materials from a number of minerals rearrange themselves to produce more than one new mineral. These various reactions between the minerals are mainly accomplished, as usual, through the medium of the water solutions.

There are important differences between metasomatism in the zone of anamorphism and metasomatism in the belt of cementation. In this zone

a Williams, Geo. H., The gabbros and associated hornblende rocks occurring in the neighborbood of Baltimore, Md.: Bull. U. S. Geol. Survey No. 28, 1886, p. 52. 
the water solutions are in minute openings, in small quantity, and cireulate slowly; therefore, it can not be supposed that any considerable amount of material is contributed from an outside source except by injection. This subject is more fully discussed later. (See pp. 764-766.) The reactions which occur are in the direction of deoxidation, silication, and dehydration, instead of in the direction of oxidation, carbonation, and hydration. The minerals formed comprise practically all of the important heavy anhydrous minerals.

MLNERATS FORMED.

Among the minerals formed in the zone of anamorphism are the following :

The carbon minerals are anthiracite, graphite, or diamond.

The abundant sulphides are pyrite and pyrrhotite. Marcasite, having lower symmetry and lower specific gratvity than pyrite, is rare or altogether absent, although abundant in the belt of cementation.

The important oxides are those of silicon, iron, aluminum, and titanium. Silica is found in the form of chert, chalcedony, or quartz. Tridymite is not known. Tridymite alters to quartz because of the higher specific gravity of the latter mineral. Iron oxide occurs in hematite, magnetite, and ilmenite. Aluminum oxide occurs as corundum. Titanium oxide is found as rutile, octahedrite, and brookite. The two latter are rare as compared with rutile. This is probably explained by the fact that the latter mineral occupies less volume. The absence of the hydrons oxides, such as limonite, gibbsite, brucite, etc., is explained by the general fact of dehydration characteristic of the zone of anamorphism.

The carbonates, aragonite, magnesite, dolomite, siderite, ankerite, and parankerite are extensively recrystallized; but the processes as a whole tend to destroy them, forming silicates. Ordinarily, where the carbonates were in large volumes, the process of silication and decarbonation is incomplete.

The most important sulphate is anhydrite. Gypsum does not occur, because the process of dehydration destroys it. Titanate as titanite, and phosphate as apatite, occur.

Practically all the important anhydrous silicates are abundant. These comprise the feldspars, the pyroxenes, the amphiboles, the nephelitesodalite-leucite group, the garnets, the olivines, the scapolites, the epidotes, 
allanite, chondrodite, andalusite, sillimanite, cyanite, staurolite, tourmaline, the micas, chloritoid, and ottrelite; and of course various subordinate silicates, such as axinite, melilite, gehlinite, vesuvianite, zircon, piedmontite, topaz, etc. The only silicates which bear appreciable amounts of water are the epidotes, staurolite, and the micas. The ordinary compression conditions of the zone are not strong enough to completely dehydrate these minerals. It therefore appears that the most profound conditions of metamorphism with which we are familiar are not sufficient to drive off all of the water from all the minerals.

It has been explained that the hydrated, carbonated, and highly oxidized minerals produced in the zone of katamorphism may, when buried, pass into the zone of anamorphism. It has also been explained on pages 366-369 that in these two zones the reactions are reversed. However, it by no means follows that when a rock altered in the belt of weathering or the belt of cementation has passed into the zone of anamorphism the minerals originally present in the rock will be reprodnced in their original proportions. Indeed, it is certain that this will rarely, if ever, occur. The reason for this is that in the zone of katamorphism, and especially in the belt of weathering, there may have been great changes in the chemical composition of the rocks. For instance, it has been pointed out that the rocks are very much depleted in alkalies and alkaline earths in the belt of weathering, and that in the belt of cementation the addition of silica is very common. It is therefore clear that when rocks of changed chemical composition pass into the lower zone the minerals which were originally present before the rocks were altered in the zone of katamorphism may not all be reproduced, nor will those there formed develop in the same proportion as originally. Furthermore, the sediments are likely to be deficient in certain elements as compared with original igneous rocks. One element which is especially deficient in these is sodinm. It naturally follows that when a sedimentary rock is transferred to the zone of anamorphism by burying, such soda minerals as leucite, nephelite, and sodalite are rarely, if ever, produced, simply becanse of a deficiency of one of the elements out of which they may be made. But even where unchanged igneous rocks are recrystallized in the zone of anamorphism the minerals are not preserver in the same proportion, for it has been explained that pressure tends to produce molecules which are heavy, and consequently 
such minerals as garnet, stamolite, and other heavy minerals form by the metamorphosis of many of the igneous rocks without any necessary change in average chemical composition.

Not only may such changes as those given occur, but there may be repeated changes. These are especially likely to occur with changes in the pressure conditions. Under the law that the greater the pressure the heavier the minerals formed, there may be repeated recrystallizations of the rocks. Ninerals produced at an early stage under conditions of moderate temperature and pressure are destroyed and minerals of higher specific gravity are prodnced. Thus a mud may change to shale, thence to slate, thence to mica-slate, thence to andalusitic micaceons schist, thence to garnetiferous, staurolitic, and cyanitic micaceons schist or gneiss. In proportion as the pressure is great and the temperature high, the tendency is to produce heavier and heavier minerals. Thus a rock which had become more and more deeply buried may be recrystallized, or partly so, a number of times, minerals of higher and higher specific gravity successively appearing. It is entirely possible that in the deeper part of the lithosphere and within the centrosphere unknown minerals are produced which are heavier than any formed in the part of the lithosphere which has reached the surface as the result of denudation. In this connection it is noteworthy that the majority of the heavy silicate minerals developed in the zone of anamorphism are those which, so far as they have been artificially produced, have been formed either under igneous conditions or, if water were present, under conditions of very high pressure and temperature. The latter is notably the case for amphibole, pyroxene, quartz, and adularia, which were obtained by Chrustschoff from aqueous solutions heated to a temperature of $550^{\circ} \mathrm{C} .^{a}$

Metasomatism in the zone of anamorphism may take place nnder mass-mechanical or mass-static conditions. The modifications under these two sets of conditions are so different that it will be necessary to consider them separately.

ALTERATIONS IN CONYECTION WITH MSS-MECHANTCAL ACTION.

It has been seen that where deformation in the zone of anamorphism is accomplished by rupture alone the result is ever to subdivide the rock particles. (See pp. 673-675.) It was there indicated that under other

a Chrustschoff, K. von, Ueber künstliche Hornblende: Neues Jahrbuch, vol. 2, 1891, pp. 86-90. 
circumstances deformation is mainly accomplished, not by mechanical subdivision, but by the chemical action of recrystallization. The fundamental idea of this process is that as the rock is deformed it takes the new form necessary by means of solution and redeposition of the rock material. But this process is accompanied by strain within and beyond the elastic limit of the minerals. In considering recrystallization these facts also are necessarily taken into account. In order to make this clear the facts of recrystallization will first be considered, and then the theory.

RECRYSTALLIZATION.

Facts of recrystallization.-One would expect, from the section on strain beyond the elastic limit, that the more profound the kneading the finer would be the granulation of the altered rock, but this is not the case. Many of the most profoundly deformed rocks, instead of being extremely fine-grained, are somewhat coarsely crystalline.

This anomaly was long a puzzle to me. In examining the deformed rocks, I found that under certain conditions the more profound the deformation the finer the granulation; but in tracing the process to the extreme, I found that there was always a limit beyond which the particles did not become more finely granulated. On the contrary, at a certain stage a reverse tendency appeared, and the particles, instead of becoming smaller, gradually became larger. This increase in coarseness of the mineral particles may be followed through all stages to the coarse schists and gneisses.

In the granulated rocks the mineral particles everywhere show strongly the strains of undulatory extinction, but the mineral particles of many of the coarse schists and gneisses show no more than slight strain shadows. The coarse, perfect schists and gneisses, nearly free from strain shadows, are always found to be those which have been deeply buried and profoundly deformed or which are adjacent to great intrusive nrasses, or both. It is therefore clear that those rocks represent the most advanced stages of metamorphism.

It is generally agreed that the schists and gneisses of this character have been recrystallized throughout, and therefore strongly contrast with those rocks which have been granulated. However, the granulated and recrystallized rocks are not separated sharply from each other (see pp. 
766-768); on the contrary, there is every gradation between the two. The original rock may have varied greatly in the coarseness of its constituent particles. If one passes from a place of granulation to a place of recrystallization, one may find that recrystallization of the matrix begins while gramulation of the larger particles is still going on. In an intermediate stage the matrix may liave completely recrystallized and the granulation of the coarser particles be still incomplete. As a consequence, the mineral particles of the matrix are increasing in size at the same time the larger particles are decreasing in size.

At a certain stage the larger grains are granulated into particles which average about the same magnitude as those which have erystallized out of a fine-grained and perhaps irresolvable matrix, and, moreover, the grains which have formed from the matrix approximate uniformity of size. Thus there is a marked tendency toward uniformity in the size of the grains of the metamorphosed rocks, and this tendency is ordinarily dominant in the schists and gneisses so long as mass deformation continues. (Pl. XI, C.) This statement is more nearly accurate in reference to the particles of each mineral than to particles of different minerals. This tendency toward uniformity controls notwithstanding the principle that under ordinary conditions large minerals grow at the expense of smaller ones (see Chapter III, pp. 74-76); for under mass-mechanical conditions a large grain, whether original or produced by umeven growth, is especially exposed to the mechanical stresses, and therefore is granulated in part or put into a state of strain, and thus is more readily attacked by the solntions. Some of the properly oriented smaller particles may themselves grow at the expense of the larger ones or of the small ones not properly oriented or happily placed. Thus is explained the characteristic miformity in the size of the particles of the schists and gneisses which have not been modified since mass-mechanical action ceased. However, in some cases, where the mineral particles are properly óriented, the tendency for large individuals to grow at the expense of smaller ones may control, and porphyritic textured schists and gneisses be produced. (Pl. III, C, D.)

Such an occurrence is beautifully illustrated by the albite-schist of Hoosac Mountain, Massachusetts, described by Wolff. ${ }^{a}$ Here there are

\footnotetext{
a Pumpelly, Raphael, Wolff, J. E., and Dale, T. Nelson, Geology of the Green Mountains in Massachusetts: Mon. U. S. Geol. Survey, vol. 23, 1894, pp. 59-63.
} 
numerons porphyritic, simple twinned albites, with a close approximation to definite orientation, the two greater dimensions of the crystals lying in the planes of schistosity. Similar phenomena in reference to feldspar are shown by some of the augen-gneisses. Not infrequently porphyritic mica and chloritoid show approximately similar orientations. In some cases porphyritic staurolites have their greater dimensions arranged approximately in the schistose planes. In such cases as these the fortunate positions of the porphyritic crystals are such that the tendency for large individuals to grow at the expense of small ones is sufficiently strong to prevent the usually dominant tendeney to destroy large individuals, and thus to prevent the production of the even-grained texture which is normally characteristic of the schists produced during mass-mechanical movement.

In the case of an isometric mineral, such as garnet, which has no cleavage and an isometric habit, it may be possible for porphyritic crystals to develop during mass-mechanical movement, although it is believed not to be common at least for undistorted crystals, for such growth would imply that minerals of this kind are able to grow as far against the greatest pres. sure as in the direction of least pressure.

The second characteristic feature of the recrystallized slaty, schistose, and gneissose rocks is that the mineral particles show a marked tendency toward regular orientatiou. This orientation may consist in the particles having major, mean, and minor diameters in approximately conmon directions, or in certain species having their crystallographic axes in nearly common directions, as a result of which the like cleavages of all the particles of a given mineral are approximately in the same plane, or in the two combined. (PI. XI, C.) Orientation, where marked, gives the rocks a cleavage.

The most important of the minerals the particles of which show similar erystallographic orientation are the micas, especially biotite and muscovite. With these minerals similarity of orientation is usual. Another set of minerals the particles of each of which frequently show a marked tendency toward similar crystallographie orientation are chlorite, amphibole, and feldspar. Other less important minerals are known to show the same phenomena. Of course, it is understood that the crystallographic orientation is in no case perfect, but with the micas it may approach perfection. From the extreme of regularity of orientation shown by mica in 
the typical schists to the random orientation of some of the minerals in the same rocks there are gradations; also there are gradations from the schists recrystallized under mass-mechanical conditions to rocks recrystallized under mass-static conditions where none of the minerals show a marked tendency to similar crystallographic orientation.

In many cases the similar orientation of mineral pasticles in a typical schist or gneiss may have been greatly disturbed by subsequent deformation near the surface, and therefore in the zone of fracture. Under such conditions shearing fractures may be produced parallel to the slatiness or schistosity, and the shearing motion between the layers may largely destroy the original regularity of the orientated particles.

The particles of some of the mineral constituents of igneous rocks which liave not been recrystallized show a tendency toward parallel crystallographic orientation. With this structure are other structures characteristic of rocks crystallized from a magma. I know of but few instances where unaltered igneous rocks so closely resemble the recrystallized schists and gneisses that there is great trouble in distinguishing them.

In the production of the characteristic textures and structures of the slates, schists, and gneisses, the original textures and even the structures may be destroyed, whether they be those of sedimentary or those of igneons rocks. In passing from an area metanorphosed under mass-static conditions to an area altered during mass-mechanical action, often all stages of destruction of the original textures and structures and the development of new textures and structures may be seen. In an intermediate stage the larger particles or more refractory minerals may show the textures of the original rock, the matrix of the same rock, however, having the texture of a slaty or schistose rock. In instances of extreme alteration nuder massmechanical conditions no trace of the original textures remains, even where the rocks were coarse conglomerates or coarse porphyritic, igneons rocks; and the secondary structures may traverse the directions of the original structures and the latter may be wholly obliterated.

Thus metanorphism under mass-mechanical action stands in sharp coutrast to metamorphism during mass-static conditions, in so far as textures and structures are concerned. In metamorphism during mass-mechanical action there is a tendency to destroy old textures and to produce a characteristic texture, the more important features of which are mineral particles MON XLVII $-04-44$ 
of uniform size and parallel orientation, and there is a tendency to destroy old structures and to produce a characteristic slaty or schistose structure. In metamorphism under mass-static conditions original textures and structures are usually preserved, although they may be somewhat modified or emphasized by the unequal size and lack of orientation of the newlydeveloped mineral particles.

Theory of recrystallization.-Where recrystallization occurs in the deep-seated zone the temperature is considerably ligher than at the surface, because of the increase of temperature due to depth, because of heat resulting from mechanical action, and in many districts because of heat derived from intrusive igneous rocks. Water occupies all the openings, including those of subcapillary size. Moreover, this water has about the temperature of the adjacent rocks, and is therefore extremely active. Taking the ordinary gradient, the temperature at a depth of 3,000 meters would be $100^{\circ} \mathrm{C}$; at 6,000 meters, $200^{\circ} \mathrm{C}$; and at 9,000 meters, $300^{\circ} \mathrm{C}$. At these temperatures the material wonld ordinarily be water and not steam, for, ignoring the rock pressure, the pressure of the superincumbent column of water is more than sufficient to prevent it from passing into the condition of a gas. But in consequence of the heat of mechanical action or of igneous intrusion, or both, the temperature at a given depth may be so high that the water may, at least locally and for short times, be in the form of a gas. During the mass movements of rocks water as liquid makes its way between the rock particles much more readily than under conditions of quiescence. (See p. 664.) Therefore the water, on account of high temperature and comparatively free movement, is in a most favorable condition for work.

It has been pointed out (p. 98) that during orogenic novements the rock pressures vary from place to place and from moment to moment. This results in great variation in the pressure upon the contained water. When the pressure increases, solution takes place; when it decreases, deposition occurs. Therefore, in consequence of changing pressure during orogenic movement the conditions are favorable for alternate solution and deposition. Since the pressure continuously varies throughout long periods of orogenic movement, it is probable that this is a factor of very considerable importance in the recrystallization of the rocks.

Another factor which is of great importance in recrystallization is the potentialized energy which exists in mineral particles in consequence of a 
state of strain. It has been seen on pages 95-98 that state of strain is very favorable to ehemical aetion. This follows from the principle of the conservation of energy. So far as minerals are in a state of strain, energy is potentialized. This conclusion has been fully verified by Barus, ${ }^{a}$ who showed experimentally that when metals are strained a large amount of energy is potentialized; and, finally, Hambuechen ${ }^{b}$ has shown experimentally that strained metals are much more easily acted upon ehemically than unstrained metals. Therefore the experimental work of Barus and Hambuechen together has completely demonstrated that a state of strain in substances is favorable to chemical action.

It has been shown (pp. 671-673) that all nineral particles in the zone of anamorphism are in a high state of strain. It has been further noted that the stresses may vary from equality in all directions to those so mequal as to approach or surpass the elastic limit of the rock under the conditions in which it exists. Therefore, the mineral particles may be strained within the elastic limit to the point of granulation; and with the latter the forner occurs, for even where the original mineral particles are broken the individual granules ordinarily show strain shadows in polarized light. The condition of unequal stress and strain is especially characteristic of massmeehanical action. (See pp. 670-672.)

It follows from Barus's and Hambuechen's work that in this interior state of strain of the mineral particles, and especially in unequal strain, we have a cause for reerystallization. The simplest illustration of the effect of a state of strain is perhaps furnished by glass. It is well known that unannealed glass is in a strained condition. This is best illustrated by Prince Rupert's drops. When a point is broken the glass explodes, breaking into powder, showing that a large amount of energy is potentialized. Unamealed glass, even in the laboratory and without the presence of water, slowly releases itself from strain by reerystallization. Corresponding with this fact it is to be expected that ancient natural glasses, beeause of their unannealed condition, would lave released themselves from strain by recrystallization; and such are the facts.

We conclude from the above that the state of strain, and especially unequal strain combined with high temperature in the presence of water, is

a Barus, C., The mechanism of solid viscosity: Bull. U. S. Geol. Survey, No. 94, 1892, p). 107-108.

${ }^{b}$ Hambuechen, C., An experimental study of the corrosion of iron under different conditions: Bnll. Univ. of Wisconsin No. 42, 1900, p. 255. 
a sufficient cause to produce recrystallization of rocks. As soon as movement begins, equilibrium is disturbed and the processes of solution and deposition or recrystallization set to work rapirlly to adjust the minerals.

'The amazing power' of heated water in solution and deposition, or in recrystallization, has already been pointed out on pages 79-81, and it may be recalled that Barus has shown that above $200^{\circ} \mathrm{C}$. glass and water are miscible in all proportions. ${ }^{a}$ At temperatures as high as or higher than this, which undoubtedly prevail in the deep-seated zone of deformation, recrystallization can go on with comparative rapidity. At any moment the substances are present almost wholly as minerals. However, superheated water is in the capillary and subcapillary spaces between the particles, and through this as a medium adjustment by solution and deposition goes on continnously during the deformation. At any given moment only an exceedingly small part of the material is in solution; but under the molecular theory of solids all materials in a state of strain, or subject to unequal pressure, or not in a compact state, will be more ready to part with their molecules than the minerals not so conditioned. Thus, from all mineral particles which are under one or all of these conditions, particles are filed off or solution is constantly taking place. Simultaneously with this, from the solutions there is deposition of material in more compact molecules than those dissolved at the places where the pressnre on the mineral particles is less than the average.

Two minerals that excellently illustrate the process are quartz and mica. The first recrystallizes somewhat readily and the second develops on an extensive scale in the schists and gneisses. That quartz occurs abundantly in flat individuals in the schists is well known. Moreover, it is knowh in some cases that the flat individuals are largely the equivalent of individual crystals which have had a nearly spherical form. As illustrations of flat grains of this mineral are the quartzes of the quartz-porphyries described by Futterer $^{b}$ (PI. III, B) and of the schists from the Black Hills ${ }^{c}$ (PI. XI, $C$ ), which I have describer. 'The many flat particles have exactly the appearance they would have had if the material could have been pressed out and

a Barus, C., Remarks on colloidal glass: Am. Jour. Sci., 4th ser., vol. 6,1898, p. 270 . See also Am. Jonr. Sci., th ser., vol. 9, 1900, pp. 167-168.

b Futterer, Karl, Die "Ganggranite" von Grosssachsen, nul die Quartzporphyre von Thal im Thüringer Wald. Heidelberg, 1890, pp. $27-47$.

$c$ Van Hise, C. R., The pre-Cambrian rocks of the Rlack Hills: Bull. Gerl. Soc. America, vol. 1, 1890, pp. $222-226,244$. 
had recrystallized anew as a single individual and subsequently had been somewhat strained. In some cases the flat individuals have a somewlat. curved form. (Pl. III, B; also, see p. 753.) The phenonena are believed to be due to solution and deposition, or recrystallization, as already explained. The particles of the quartz not fortumately oriented or at places of great strain are taken into solution and transported to fortmately oriented individuals or those less strained, and redeposited; or, the material dissolved from the more strained part of a ?rin ma be deposited on another part of the same grain where the strain is less. Thus the quartz of a given flat granule may be largely the same quartz as that of the original grain, but it has been dissolved and redeposited in part, perhaps repeatedly.

Were the quartz grains to be granulated the volume of the rock would be increased. (See pp. 674-675.) But by the process of solution and deposition above described the form of the grain is clanged and no increase in volume results. Therefore, in the zone of ananorphism, where pressure is the dominant force, recrystallization rather than granulation takes place where it can, for by so doing the volume remains the same even if the grains remain of the same average size, and heavier minerals are not formed; and the volume is decreased where many grains merge, as eited below, and where heavier minerals are produced.

Micas, especially biotite and nusco vite, are very abundant in the slates, sclists, and gneisses. Moreover, in proportion as ti.e rocks approach typical schists and gneisses the particles of these minerals are large, of approximately uniform size, and oriented crystallographically. (Sec Pl. XI, C.) In the original pelites, from which the micaceous schists most extensively form, the micas are not abundant constituents. Even in the psammites, where allogenic micas accur, the particles are large, more or less irregularly arranged, often somewhat decomposed, and are readily discriminated from the regularly arranged, fresh micas of the schists. These facts are so well known that nearly all petrographers who have studier thin sections of the schists have regarded the micas as authigenic. Chemical analyses show that soils, muds, clays, and shales contain the elements out of which mica may develop." Many of these elements occur in hydrated compounds, such as kaolinite, zeolite, chlorite, and limonite. In the schists which develop

aClarke, F. W., and Hillelorand, W. F., Analyses of rocks and analytical methods: Bull. U. S. i ienl. Survey No. 148, 1897, pp. 277-301. 
from such sediments these minerals may be altogether abseut, their places being largely taken by the micas and other minerals. It is clear that during the metamorphism of the rocks these minerals are taken into solution, and from such solutions the new minerals, containing little water, are deposited. The solution and deposition give the material a less hydrated and more compact form. During the process, at numerous places mica nuclei oriented by the differential stresses (see pp. 671-673) begin to form. The minute nuclei, once formed, serve as cores upon whiclı the material which is continuously taken into solution may be deposited. The mineral particles grow somewhat uniformly, being subject to the same laws in this respect as original particles. (See pp. 120-123.) By studying a series of thin sections from any of the districts in which the rocks of a formation vary from little altered material to coarse schists, all stages of the process may be seen, from that in which the original hydrated minerals are abundant and mica is absent to that in which the former are absent and mica is abundant.

In the foregoing we apparently have the explanation of the large average size of the mineral particles which constitute the schists formed at considerable depth during mass-mechanical action. They are continuous growths during deformation by solution and redeposition.

As excellent illustrations of rocks showing all or many stages of recrystallization of quartz and the development of mica may be cited the schists and gneisses which I have deseribed in the Penokee-Gogehic and Marquette districts of Michigan and in the Black Hills of Sonth Dakota." (Pl. III, $A, D ; \mathrm{Pl}$. XI, B,C.)

As a beantiful illustration of the transition from finely crystalline to coarsely crystalline rocks may be cited the iron-bearing formation of the Marquette district of Michigan. ${ }^{b}$ The deformation of this formation was mainly by recrystallization. In the eastern part of the district granulation and widely spaced fractures occurred to some extent, but the temperature was not high enougl for reerystallization, or else some other essential con-

alrving, R. D., and Van Hise, C. R., The Penokee iron-bearing series of Michigan and Wisconsin: Mon. U. S. Geol. Survey, vol. 19, 1892, pp. 305-345. Tan Hise, C. R., and Bayley, W. S., The Marquette iron-bearing district of Michigan: Mon. U. S. Genl. Survey, vol, 28, 1897, 44t-459. Van Hise, C. R., The pre-Cambrian rocks of the Black Hills: Bull. Geol. Soc. America, rol. 1, 1890, pp. $222-229$.

$b$ Van Hise and Bayley, cit., Mon. 28, pp. 336-375. 
dition was lacking. In the western part of the district, while the rocks were probably not more deeply buried, the deformation was much more profound, and probably because of this the temperature reached $180^{\circ} \mathrm{C}$. or more. As a consequence the mineral particles grew to a large size. At places in the eastern part of the district, where the conditions were least favorable for recrystallization, the quartz granules in the jaspilite average about $0.01 \mathrm{~mm}$. in diameter. In the westem part of the district, where the conditions were most favorable, the quartz particles in the coarsest jaspilite average about $1 \mathrm{~mm}$. in diameter. Moreover, they show little strain. These particles therefore average about a million times greater than those of the eastern part of the district, and hence to form one new individual the material of a million old particles was utilized. This illustration gives conclusive evidence of the capacity of quartz to accommodate itself to the most intense deformation by recrystallization.

The explanation suggested by Adams ${ }^{a}$ for the deformation of the quartz of the leaf gneisses of the original Lanrentian district is movement along gliding planes, as advocated by Miigge ${ }^{b}$ in reference to ice crystals. However, this explanation is inadequate to explain the phenomena above described, and similar phenomena for other minerals, for two reasons: First, the greater dimensions of the flat new individuals always corresponding to the secondary structures in the slates and schists, are wholly independent of the orientation of the original particles, and therefore independent of their gliding or other definite planes. If gliding harl taken place, it must have occurred along definite crystal planes. Second, as shown on pages 686-688, the particles of the metamorphosed schists are very frequently, and in the case of the metamorphosed sediments commonly, much larger than the original particles. In many instances the particles average so much larger that à multitude of old particles are built into a single new particle. ln those cases where different mineral particles merge to form new particles of larger size, gliding along any set of definite planes can not possibly explain the process; this can be due only to solution and deposition, or recrystallization, as already explained. But it does not follow from the above that where

"Adams, F. D., Report on the geology of a portion of the Laurentian area lying to the north of the Island of Montreal: Ann. Rept. Geol. Surv. Canada for 1895, vol. 8, pt. ., 1897, p. 48.

$b$ Mügge, O., Ueber die Plasticität der Eiskrystalle: Neues Jahrbuch für Mineralogie, etc., Jahrgang 1895, vol. 2, p. 212. 
recrystallization is the dominant or preponderant process, gliding may not occur as a subordinate simultaneous process, especially with such minerals as calcite, which, as Adams ${ }^{a}$ has shown, is especially likely to be deformed by movement along gliding planes.

In the theory of recrystallization we have an explanation of the general unifornity in size of the particles of any definite mineral in a rock metamorphosed at depth during mass-mechanical action: The larger grains of any mineral have smaller areas of contact for the solutions to work on, and therefore granulation plays a large part; the smaller particles lave larger areas of contact for the solutions to work on, and consequently recrystallization merges them, producing larger particles. Therefore, the tendency of granulation and recrystallization together is to produce uniform-textured rocks.

Rccrystallization lags behind deformation.-In the deep-seated zone adjustment may not lag far behind the disturbing forces. However, in all cases there is apparently some lag. In the most regularly laminated of the schists, close exannination usually reveals a slight undulatory extinction, and therefore a state of unequal strain in the minerals, showing that recrystallization las not exactly kept pace with deformation, or else that the schists have been somewhat deformed since recrystallization.

Where such subsequent deformation has not taken place, the amomt of strain shadows and granulation is thought in many cases to be a measure of the amount that molecular readjustment lags behind the disturbing movément. In the typical schists strain is in many cases scarcely perceptible. In other cases all of the mineral particles show marked strain shadows. In still other cases the strain shadows are accompanied by more or less of granulation, and this phase of the rocks grades into the ordinary granulated rocks. Thus there are all gradations between molecular rearljustment or recrystallization almost pari passu with deformation, and readjustment almost wholly by granulation.

Evidence that recrystallization does nearly keep pace with deformation in the case of the schists consists partly in the absence of marked strain structures, for it is to be supposed that if recrystallization did not nearly keep pace with deformation the result would be that the mineral particles

a Adams, F. D., and Nicolson, J. T., An experimental investigation into the flow of marble: Philos. Trans. Royal Soc. London, ser. A, vol. 195, 1901, pp. 363-401. 
would show important strain shadows or even granulation. The texture characteristic of the schists (described on pp. 688-690) is itself further evidence of continuous recrystallization during deformation. It is a texture peculiar to the schists. If the minerals were not readjusted in a continuous fashion they must have become granulated by the mechanical forces. If they lad become fused into a magma, from that state the material would have recrystallized with textures peculiar to the igneous rocks. The regular arrangement of the mineral particles, with thein longer axes in definite planes is just what would be expected if the contained water were taking material into solution and depositing it largely at the borders of the mineral particles, and thus continuonsly building then ont laterally.

Further evidence that recrystallization may nearly keep pace with deformation is found in the porphyritic minerals which frequently occur in the schists Some of the more common of these minerals (nentioned on page 700) are garnet, staurolite, andalusite, feldspar, hornblende, chloritoid, chlorite, and mica. Such porphyritic minerals ordinarily show no pereeptible strain. They frequently lie with their longer axes or readiest cleavage across the schistosity. 'This is true even of mica and chloritoid, the cleavage of the porphyritic constitnents cutting directly across the cleavage of the abundant small individuals of mica which accord with the schistosity. It is maintained (p. 702) that such minerals have developed mainly under static conditions after mass movement ceased. These porphyritic minerals seem to be evidence that the differential stresses of static conditions are ordinarily not sufficient to control the orientation of the mineral particles; that in order to do this the differential stresses must be sufficient to produce actual movement throughout the mass of the rocks. If this be so we must suppose tlat the orientation of the minerals producing schistosity occurred during the movement itself, or, in other words, that recrystallization nearly kept pace with the movements.

During movement, in some cases the tendency for large individuals to grow at the expense of snaller ones may control, and properly oriented individuals grow to a porpliyritic size. For instance, porphyritic feldspar's may show a marked tendency toward arystallographic orientation, the cleavages of the feldspars corresponding with the cleavages of the rocks. 
This is beautifully illustrated by the albite-gneiss of Hoosac Mountain, ${ }^{a}$ by augen-gneiss of the French Broad River, and at various other localities.

The argument that orientation of mineral particles in rocks is primarily due to unequal stress in different directions during crystallization applies equally to the cases of the parallel crystallographic orientation of individuals which occasionally occur in rocks crystallizing directly from magmas. Feldspar is not infrequently oriented in such rocks, and the phenomena is known in reference to other minerals.

conclusion-From the foregoing it is concluded that the development of the schists is to be explained as a process of chemical action induced by mechanical action, resulting in the constant solntion and deposition of the material, or its recrystallization, so as to accommodate it to the changing form of the mass.

AKTERATIONS UNDEI MASS-STATIC CONDITIONS.

It has just been shown that metasomatic recrystallization largely induced by mass-mechanical action is the most important process in the development of the schists. However, recrystallization may and does take place under mass-static conditions, by means of which minerals are produced characteristic of the zone of anamorphism. The canse for recrystallization under mass-static conditions is the demand of the pressure for less volume. If the minerals be recrystallized or made over into those which have a higher average specific gravity, the volnme is lessened and work is done. Changes are likely to be important in proportion as the temperature is high and the pressure great. It naturally follows that recrystallization under mass-static conditions is important where the rocks are very deeply buried, or where orogenic movements have occurred, or where igneous rocks have been intruded, and especially where two or all of these are combined. If a rock has recrystallized during mass-mechanical action or igneous intrusion, and therefore has developed into a schist, under succeeding mass-static conditions recrystallization is particularly likely to recur, for the orogenic movement or the intrusive produces a higher temperature in the rocks than would obtain at the same depth under static conditions.

"Pumpelly, Raphael, Wolff, J. E., and Dale, T. Nelson, Geology of the Green Mountains in Massachusetts: Mon. U. S. Geol. Survey, vol. 23, 1894, pp. 59-63. 
Under mass-static conditions the textures which are produced by recrystallization are very different from those formed by crystallization during mass-mechanical action. It has been seen that under mass-mechanical conditions schists form, the distinctive textures of which are uniformity of size of the mineral particles, and especially the similar orientation of certain minerals. Under mass-static conditions, where the pressure conditions approximate to hydrostatic, schists do not ordinarily develop. The rearrangement takes place so as to form more condensed molecules, without producing either uniformity of size or regularity of arrangement of the mineral particles. During the development of the mineral particles they ordinarily interfere with one another and interlock, producing a complex texture often more intricate than that formed by the mutual interference of minerals when crystallizing from a magma.

Commonly, the old mineral particles, if large, break up into a great number of other mineral particles of varying size. If, on the other hand, the original particles are very small, they are apt to coalesce so as to produce larger mineral particles; but usually the magnitude of the resultant mineral particles is not great. To the above extent there is a tendency toward uniformity of size, but it does not go so far as to result in approximate miformity. Indeed, a very notable characteristic of the texture of rocks recrystallized under mass-static conditions is the unequal size of the mineral particles. This results from the fact that there is no movement to prevent the full operation of the law of growth of large individuals at the expense of small ones. In this particular the conditions contrast with those of mass-mechanical action in which large individuals are especially exposed to strain and rupture, and are therefore likely to be destroyed.

This process of the growth of large indiriduals at the expense of small ones develops a porphyritic texture. This process is of such significance that it needs to be especially considered, as does also mother process closely allied to it, that of the regeneration or rejuvenation of old mineral particles of large size which are adapted to their environment.

DEVELOPMENT OF PORPHYRITIC TEXTURES.

Where the mass-static conditions farorable to recrystallization continue long, some of the mineral particles may grow to great size as compared with their fellows, and thus a porphyritic textmre is produced. The pressure 
conditions demand diminution of volume, and the large mineral particles are apt to be those of high specific gravity. The more important dense porphyritic minerals are feldspar, garnet, staurolite, tournaline, andalusite, sillimanite, eyanite, mica, chloritoirl, and lormblende. The minerals also exhibit a marked crystal habit, and not infrequently as they grow they maintain crystal forms. Often the porphyritic minerals show a distinct zonal texture, comparable in every way to the zonal texture sometimes shown by minerals in igneous rocks. The zonal texture is frequently seen in minerals having a varying composition, as, for instance, garnet; and is rare or has not been observed in minerals having a rather definite chemical composition, as, for instance, staurolite. It is believed that the zonal texture of the minerals is often due to varying composition, during their growth, of the mineral solutions or adjacent minerals, or both. In some cases there may have been actual cessation of growth and later a renewed growth. In such instances the renewed growth is analogous to the process of enlargement of fragmental mineral particles.

Single porphyritic individuals may be larger than hundreds of individuals of the background. Those a centimeter in diameter are very abundant, while those two or even several centimeters in diameter are not infrequent, and occasionally they are many' centimeters across.

As the large porphyritic individuals form at the expense of many small mineral particles, they either absorb the material of which the surromding minerals are composed, and thus grow by their destruction, or else absorb a part and inclose a part. The minerals mentioned differ in capacity to absorb the other minerals which before occupied the space they now occupy. In propurtion as they lack capacity to absorb the constituents of prior minerals, they lave the capacity to grow around and inclose them, so that a single individual may be a large, reticulating, honeycombed mass, which incloses a large amount of other material. (Pl. III, C.) ln some cases the inclosed material may be several times as great in quantity as the host. As minerals conspicunus for their capacity to include other minerals may be mentioned andalusite and staurolite; occupying an intermediate position are garnet aud feldspar: while toumaline usually does not contain any considerable quantity of the prior minerals.

A large variety of minerals may be included by the porphyritic constituents, but the dominant inclusion is quartz. Andalusite and garnet are 

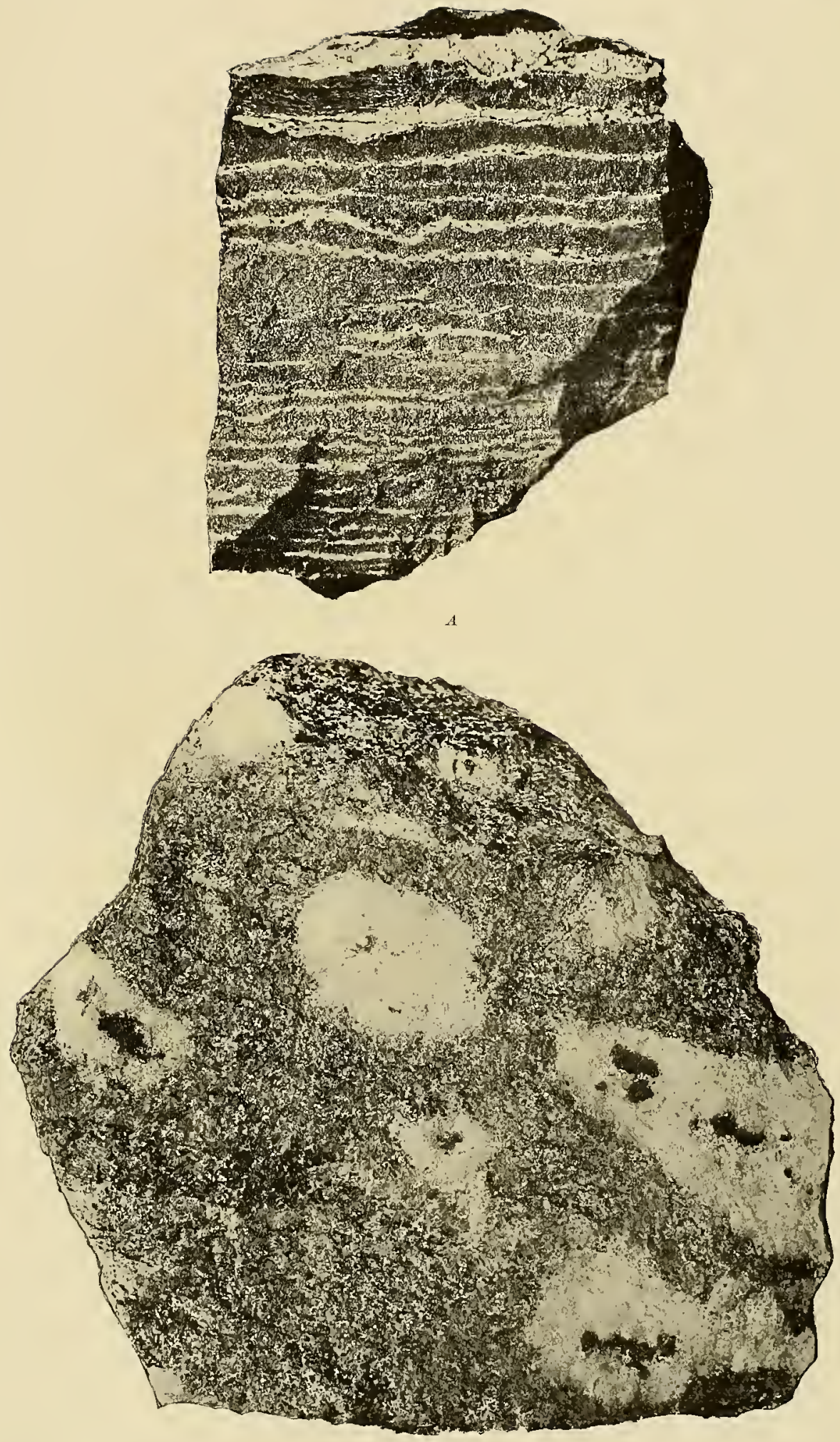

T:

A. PARALLEL VEINS OF CALCITE, GREAT BASIN. B. BIOTITIC GRANITE SHOWING GARNET SURROUNDED BY LENTICULAR AREAS DEFICIENT IN IRON-BEARING MINERALS. 

orthosilicates; stamrolite and tourmaline are subsilicates. They are therefore unable to absorb a large anount of silica, and hence the explanation of the abundant inclusions of quartz. The inclusion of quartz is finely illustrated by some of the garnetiferous and stanrolitic schists. In the staurolites the quartz frequently seems as abundant as in the background, but the micas and other minerals are usually absent, although they may be abundant in the background. The garnet and staurolite have partly or wholly absorbed the micas, chlorites, feldspars, and other minerals, which are largely composed of the same elements as themselves, and have built them into their bodies, thus making denser minerals.

The evidence of this consists in the absence of inclusions of the ironbearing constituents of the schists in garnet and stanrolite, and the presence of abundant quartzose particles. While frequently the iron-bearing minerals extend without apparent diminution in amount to the garnets and staurolites, in some cases around the garnets are aureoles or lenticnlar areas of material which are markedly deficient in the iron-bearing minerals. This I first observed at Bristol, Comn. (See Pl. II, B.) Here is a biotitic granite blotched by white spots, consisting of quartz and feldspar with 110 mica, the larger of them $2 \mathrm{~cm}$. wide by $8 \mathrm{~cm}$. long, in the cores of which are large crystals of garnet The same thing is beautifully illustrated by the almandite in a mica-schist of Hampshire County, Mass. The acid minerals, such as quartz and feldspar, outside or inside the garnets which conld not be absorbed have arrangements characteristic of the schists.

The above occurrences give beautitul illustrations of the principle of the development of the large heavy mineral particles from the material' of small and light ones. They also give positive evidence that the work is done by solution and redeposition. The transportation of the material of a mica flake to a garnet or staurolite must be done by solntions

Commonly the porphyritic minerals do not show any orientation. But in the schistose rocks containing porphyritic minerals it is usually true that the minerals constituting the background have laminar forms, and often similar erystallographic orientation. These minerals of the background often stop abruptly at the junction with the garnets, staurolites, tourmalines, etc., without any deviation whatever or tendency to peripheral arrangement abont the porphyritic ninerals. The micas may be seen with perfect arrangements extending to the exact junction of the porphyritic 
individuals with undiminished transverse dimensions, but with various fractions of the average length of those of the background which have not been interfered with by the porphyritic minerals. In short, the appearance, so far as the minerals of the background are concerned, is precisely that which would be produced if one could cut ont from a fully developed schist an outline for a porphyritic mineral and subsequently insert that mineral with extreme nicety. (Pl. III, D.)

The minerals included in the porphyritic individuals have the same appearance, and have their gramules arranged according to the same system, as the like minerals in the background of the schist.

Where in the schists the porphyritic constituents have crystal habits, and are not arranged with their greater dimensions parallel with the sehistosity of the groundmass, the evidence seems conclusive that such porphyritic crystals developed under mass-static conditions. The case seems especially conclusive when readily cleavable porphyritic minerals, such as mica, chlorite, and chloritoid, in well-defined crystals, occur with their elearages diagonal or perpendicular to the dimensional arrangement and cleavage of similar minerals of the background. Such cases are beantifully illustrated by the Hudson schist of New York and by the Michiganme schist of the Upper Huronian of the Lake Superior region. Such porphyritic constituents with random orientation formed after the movenent ceased during which the minerals with parallel orientation were formed and the schistose structure developed.

The conditions favorable to the development of porphyritic crystals are those already mentioned as favorable to recrystallization under massstatic conditions, viz, the presence of water, high pressure, and high tenıerature. Where those conditions obtain to an exceptional degree porphyritic constituents are common. These conditions are likely to obtain to an unusual degree after either powerful orogenic movements or great batholithic intrusions, or, still more commonly, the two combined. This is illustrated by the porphyritic crystals of nearly every variety, including mica, chloritoid, andalusite, garnet, staurolite, and tourmaline, in the schists adjacent to the great Black Hills ${ }^{a}$ granite batholith, and by the inany

a Van Hise, C. R., The pre-Cambrian rocks of the Black Hills: Bull. Geol. Soc. America, vol. 1, 1890 , pp. $222-230$. 
PLATE III 


\section{PLA T E I I I.}

\section{PHOTOMICROGRAPHS OF METAMORPHIC TEXTURES.}

1. Uneren texture developed by metasomatic alteration of feldspar to quartz and mica. From biotite-slate of Penokee-Gogebic district, Michigan.

$B$. Thin section of mashed quartz-porphyry, showing the quartzes elongated by recrystallization, while the adjacent feldspar is little affected. After Futterer.

C. Albite-schist, showing secondary porphyritic albites which include other mineral constituents of the rock and their longer axes parallel to the prevailing schistosity. From Hoosac Mountain, Massachusetts. After Leith.

D. Porphyritic chloritoid developed after rock flowage has ceased. The chloritoid includes the other constituents of the rocks with their longer diameters parallel to the prevailing cleavage. From Black Hills, Sonth Dakota. After Leith.

704 

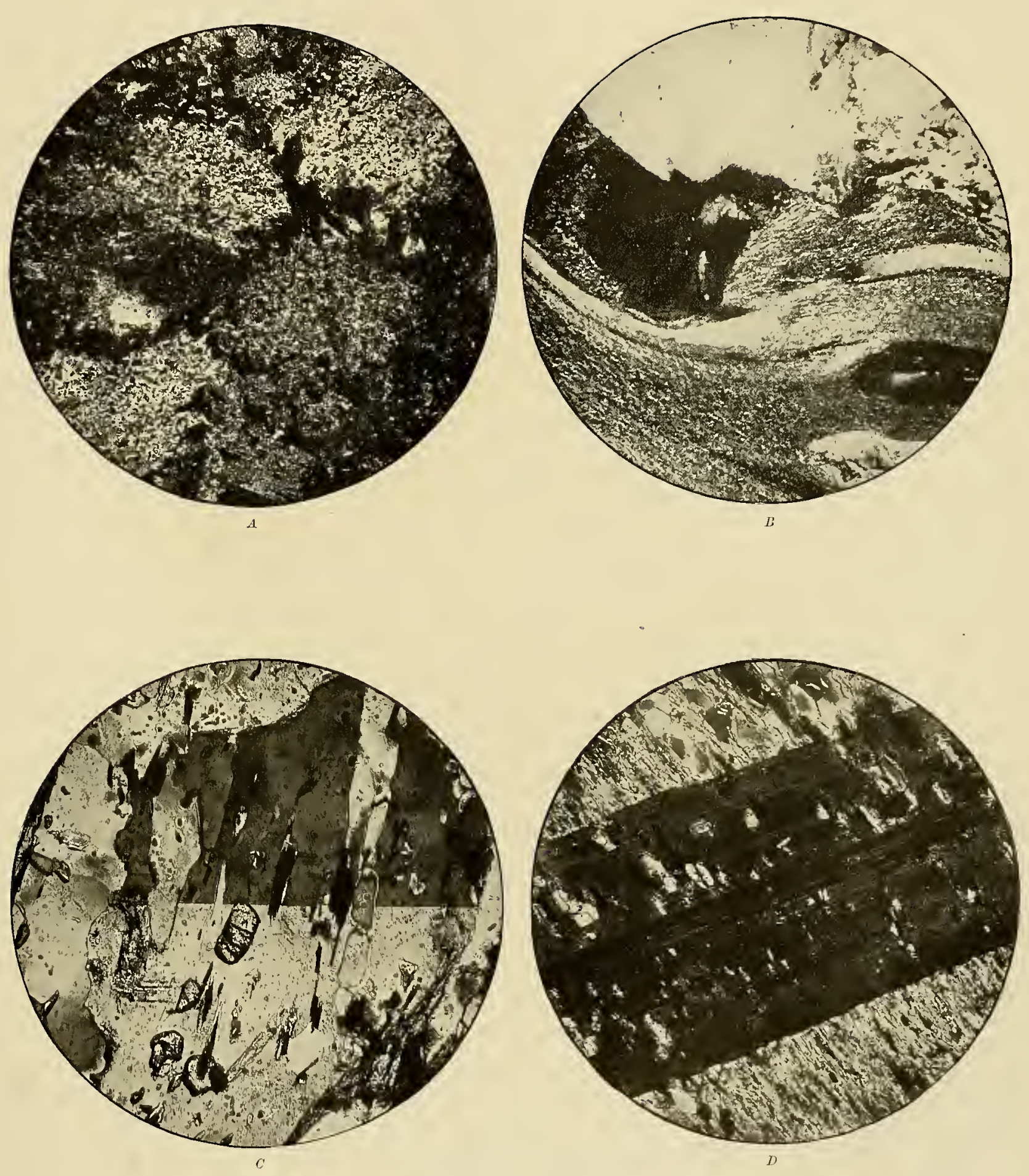

porphyritic constituents in the schists and gneisses adjacent to the great granite batholiths of western Massachusetts."

Occasionally there may be present in schistose rocks porphyritic minerals which show a marked tendency toward sinilar crystaltographic or dimensional orientation, or both.

To instances of orientation of porphyritic eonstituents the arguments above given in reference to the nsual development of porphyritic minerals under mass-static conditions after movement has ceased are not applicable. This case is discussed on pages 687-688.

REGENERATION OF MINERAL PARTICLES.

The regeneration ${ }^{b}$ or rejuvenation in the zone of anamorphism of large mineral particles which have been partly altered in the belt of weathering or the belt of cementation is closely analogous to the growth of porphyritic minerals. Such partly destroyed large minerals are sometimes regenerated at the expense of the small ones for the same reason that the porphyritic: minerals form. As an illustration of the process, the feldspars may be cited. In the belt of weathering they are likely to become clondy in consequence of kaolinization, development of chlorite, zeolite, deposition of iron oxide, etc. In the belt of cementation they may become clondy, in consequence of zeolitization or other alterations. When such altered feldspars pass into the lower zone the reactions may be reversed; new fetdspar is produced, which is controlled in its orientation by the residual maltered feldspar; the alteration products are absorbed by this new fetdspar or else dissolved; thus the clondy appearance disappears, and the feldspar once more becomes clear and fresh-i. e., is regenerated or rejuvenated.

This process of regeneration is especially likely to occur where the rocks pass from the zone of katamorphism into the zone of anamorphism

a Emerson, B. K., Porphyritic and gneissoid granites in Massachusetts: Bull. Geol. Soc. America, ml. 1, 1890, pp. 559-561.

$b$ Wolff, J. E., Metamorphism of clastic feldspar in conglomerate-schist: Bull. Mus. Com. Zool. Harvard College, whole ser., vol. 16, 1891, pp. 173-183. Weidman, S., A contribution to the geology of the pre-Cambrian igneous rocks of the Fox River Valley, Wisconsin: Bull. Wisconsin Geol. and Nat. Hist. Surv., No. III, 1898, pp. 20-24. Whittle, C. L., Some dynamic and metasomatic phenon1ena in a metamorphic conglomerate in the Green Mountains: Bull. Geol. Soc. America, vol. 4, 1898, pp. 155-164. Hobbs, W. H., Phases in the metamorphism of the schists of southern Berkshire: Bull. Geol. Soc. America, vol. 4 , 1893, pp. 167-178.

MON XLVII-O) +5 
by burying without orogenic movement. Where recrystallization during orogenic novements occurs the process of rejuvenation is less likely to take place, but may oceur in the more resistant minerals which escape destruction. As is well known, feldspar is one of the most resistant minerals mnder deepseated conditions of deformation, and hence many of the original partly altered particles of this mineral may be rejuvenated during the time in which other minerals are recrystallized. Of course, if the deformation is severe the borders of the original feldspars are likely to be gramulated or recrystallized, and during extreme orogenie movements there may be complete recrystallization of the feldspar.

The facts that under certain conditions feldspars are destroyed by kaolinization, chloritization, zeolitization, etc., and under other conditions are rejuvenated or newly developed, have been known for some time. We can now assign reasons for the reversal of these reactions. Feldspar is not adapted to the zone of katamorphism, and especially to the belt of weathering, and it is destroyed by the reactions demanded by the chemical and physical forces there obtaining; whereas feldspar is adapted to the zone of anamorphism, and the chemical and physical forces there at work reproduce it.

The nature of the process of rejuvenation has been illustrated by feldspar becanse this is the best known case, but other minerals may be rejuvenated in a similar manner. ${ }^{a}$

a Lepsius has anticipated a number of the points of the previous pages, as is shown by the following quotations and summary from the Geologie von Attika (Ein Beitrag zur Lehre vom Metamorphismus der (resteine), Dietrich Reimer, Berlin, $1893,196 \mathrm{pp.}$ With tables and atlas.

"Die Mineralien in den Gesteinen können nur umkrystallisiert werden, wemn ihre Moleküle flüssig werden; dies kann auf dreierlei Weise geschehen:

1. Durch Schmelzung in der Glühhitze und zwar für unsern Fall bei Gegenwart von Druck, also durch die eben besprochene Druckschnelze.

2. Durch Lösungsmittel auf chemischem Wege, und zwar in unsrem Falle bei Gegenwart von Druck und bei einer Temperatur, die höher ist als die mittlere Temperatur der Erdoberfläche, die jedoch im allgemeinen nur bis zu einigen hundert Grad Celsius und wohl nicht über $500^{\circ}$ steigen wird.

3. Durch hohen Druck auf mechanischem Wege, das ist riejenige Art von Druckrerflüssigung, welche durch die Springschen Versuche illustriert wurde.

Betrachten wir jetzt die zweite Möglichkeit, die Verflüssingung der Moleküle durch Lösungsmittel auf chemischem Wege; diese Art der Verflüssigung und Auskrystallisierung aus der chemischen Lösung scheint mir am besten die von aus beobachteten Vorgänge bei der Metamorphose der Gesteine aufzuklïren." (P. 183.)

Holds that the schistose Silurian and Tertiary rocks when metamorphosed were buried to a depth of about 12,500 meters, which with a specific gravity of 2.5 would give a pressure of 3,125 atmospheres. (P. 187.) 
IGNEOUS WORK.

The igneous work of the zone of anamorplism is comprised under "Injection."

\section{INJECTION.}

Injection in the zone of anamorphism probably occurs on a much greater scale than in the zone of katamorphism. The field evidence for this view is found in the vast amount of intrusive igneous naterial in the areas where deep denudation has exposed rocks which have been within the zone of anamorphism. For instance, in the extensive areas of the Canadian pre-Cambrian, in the Paleozoic of New England, and in the cores of the great mountain masses of the world intrusive rocks constitute a large percentage of the total material exposed. Indeed, over considerable districts intrusive igneous material composes 25 to 50 per cent of the area. These facts accord with what one would expect, for as magma struggles toward the surface the quantity which is unable to accomplish the task naturally increases from the surface toward the source.

Holds that recrystallization takes place, producing coarser crystals, because of the fact that the larger crystals have less surface for action than the small crystals, and therefore that, if solution and precipitation are occurring, the small crystals will be dissolved and the large crystals grow. (P. 188.)

Holds that where the pressure is great the chemical reactions will take place in such a sense as to produce a diminution of volume, and cites Caillete and Praff's work as showing that certain reactions can be greatly hindered and finally ceased altogether by a pressure of from 40 to 80 atmospheres. (P. 190.)

Holds that crystallization is not possible without solution, and explains that through crystallization under pressure the large crytals grow at the expense of the small ones. In this connection states, "ist dieser zweite Krystall kleiner als der erste, so kann er nach dem oben angeführten Gesetze aufgelöst werden, und kümnen alsdann seine Moleküle allmählich mittels des Lösungwassers zu dem grösseren Krystall binüberwandern." (P. 193.)

"Neben der Zeitbauer sind die für die Grösse der Krrystalle bestimmenden Faktoren: die Höhe der Temperatur, mittelbar die Stärke des Druckes, sowie natürlich auch die grössere oder geringere Löslichkeit der Mineralien in überhitztem Wasser und die absolute Quantitat, in welcher die betreffenden Moleküle in den ursprünglichen Sedimente vorhanden waren. Daher wïchst die Grösse der Krystalle auch mit dem stïrkeren Druck; jedoch geschieht überhaupt kaum eine Umkrystallisierung, wenn ein mechanischer Druck allein ohne chemische Lösung wirken sollte; umgekehrt wird die Lösungsfïhigkeit des Wassers erhöht durch den Druck." (P. 193.)

"Bei der Entstehung von metamorphen Gesteinen wirken also vier Ursachen zusammen: Wasser als chemisches Lösungsmittel der in deu Gesteinen vorhandenen Substanzen; höhere Temperatur, um das Wasser zu erwïrmen; mechanischer Druck, um das überhitzte Wasser in flüssiger Form in den Gesteinen festzuhalten und dessen Lösungsfähigkeit zu erhöhen; endlich auch eine lange Zeitdauer, wïhrend welcher die chemischen Umsätze in den Gesteinen vor sich gehen können." (P. 194.) 
The manner of intrusion in the zone of anamorphism differs in many respects from that in the zone of katamorphism. In the latter zone it has been explained that the igneous rocks mainly follow fractures. In the lower zone no large fractures can be supposed to exist continuously. In some way the magma must mike its way through rocks which normally have no large openings.

The progress of the igneous rocks is therefore a matter of far greater difficulty. In consequence of earth movements the material may make its way (1) en masse, without breaking across the structures of the intruded rocks to a great extent: (2) by breaking across the structures of the intruded rocks and by following along planes of weakness such as cleavage, bedding, and contacts; and (3) by fusion and albsorption of the intruded material.

(1) It is probable, indeed certain, that all three of the above processes occur to some extent, hut it is believed that the movements en masse, without extensive breaking across the intruded rocks, are of great consequence. As evidence of this may be cited the fact that in general, adjacent to the great batholiths, the injected rocks have peripheral structures, as if they had been driven aside en masse br the eartl stresses in comnection with epeiorogenic and orogenic movements. It is believed that the magmas transmit the thrusts they receive substantially under the laws of liydrostatics, and consequently make their way by raising up and pushing aside the material previonsly occupying the space, without necessarily breaking through it on a large scale. Under such circunstances, if the intruded rock be sedimentary, the bedding of the sediment is peripheral to that of the great intrusive masses. Materials of other kinds are similarly arranged. The intrusive acts in reference to the rocks as would a hemispherical or lenticular mass raised against a piece of flexible but tightly stretched leather. The leather ronghly adjusts itself to the shipe of the hemisphere or lenticule.

Also, as will be seen, high pressure, temperature, and water result in the recrystallization of the rocks adjacent to intrusive masses, and during this process they are shortened in a direction normal to the intrusion and sometimes lengthened in a direction peripheral to it. Thus room is made for the entering mass. Often the result, so far as the relations of the 
masses are concerned, is as if a solid body were poshed up against a sheet of rubber. The rubber would be thimed and extended above the mass and on the sides. Therefore a consequence of recrystallization is to carry the entering magma nearer to the surface.

The rleep-seated intrusives, producing uplift of the intruded roeks, form mountains at the surface. Such mountains have been called subtuberant by Russell and others. ${ }^{a}$ When later erosion removes the capping rocks the igneous masses below are seen. Intrusive igneous masses of this class are exposed on a great scale in this country, in the Cordilleras, in the Black Hills, northwest of Lake Superior in Canada, and in New England. The intrusive masses may be nearly spherical, lenticular, or many times longer than broad. The larger of them have minor diameters of many kilometers and major diameters of 50 to 100 kilometers, or even more. When the magnitnde of these masses is appreciated it is easy to miderstand how the great interior earth stresses result in eoncentrated upward motion at some area, as a consequence of which the magma, either liquid or potentially liquid, slowly but with tremendons power oozes up toward the surface, carrying with it and pushing aside the superincumbent rocks.

(2) Next in importance to raising the intruded roeks and pushing them aside in the lower zone is the breaking across or the following of the structures or planes of weakness of the intruded mass. During the great movements resulting in mass intrusion the rocks which are thrust aside are cut and injected parallel to their struetures on a large scale, as a necessary correlative of the greater process above described. Returning to the illustration of the leather, this material stretehed against a hemisphere is wrinkled on its sides nnless it be as extensible as rubber. Similarly, as a great nnass of igneous rock is intruded and pushes the rocks up and aside, they are wrinkled, unless we assume greater flexibility than is warranted by the facts. Commonly, therefore, subtuberant intrusion demands close corrugation on the sides. Further, I have held in another place that great periods of intrusion are also periods of rapid orogenie movements. ${ }^{b}$

When the deformation of a rock mass is rapid, fractures may extend much deeper into the earth than they would under normal conditions.

a Russell, I. C., Volcanoes of North America, Macmillan Cu, New York, 1897, pp. 103-105. Also, On the natmre of igneous intrusions: Jour. Geol., vol. 4, 1896, p. 189.

${ }^{b}$ Van Hise, C. R., Earth movements: Trans. Wisconsin Acad. Sci., Arts, and Letters, vol. 11, 1898, pp. $493-494$. 
(See pp. 658-658.) I have said that it is characteristic of the zone of flowage that no large openings can be supposed to exist continuously. It does not therefore follow that at times of rapid movement extensive fractures may not be temporarily formed. If these were at a place of subtuberant intrusion, or were adjacent to any magma, material would break away from the central mass, intrude itself into the openings and fractures, wedge the walls apart, and thus we should have intrusives for a considerable belt peripheral to the central mass which are analogous in their forms to the intrusives characteristic of the belt of cementation-that is, intrusives along fractures; and this would be so even if the rock alterations of the place were, on the average, those characteristic of the zone of anamorphism rather than of the zone of katamorphism. We lave here really the case of an intermediate belt of combined fracture and flowage, fractures extending deep at times of rapid deformation, although the normal conditions are those of flowage. Thus from the great central masses of igneous rocks smaller masses extend in varions directions to rarions distances, some being subordinate subtuberant masses, and others taking advantage of the temporary fractures and thus forming dikes There is a marked tendency for these subordinate masses to follow planes of weakness, as, for instance, the contacts between rocks of different character, the bedding of sedimentary rocks, or other structures such as the planes of clearage in schistose rocks. Intrusives of this kind nsually have greater dimensions parallel to the structures followed than in the transverse directions. The tendency of the injections to follow clearage is very marked indeed. Parallel to the planes of cleavage in the slaty and schistose rocks intrusions may be very close together and snrall, there being perhaps a considerable number within the breadth of an inch; or the intrusives along clearage planes may be larger and far apart, or they may be any combination of these. All these phenomena are well illustrated by the Hudson schist of New York City, especially at New Rochelle, and by the gneisses at many places upon the Piedmont Plateau.

(3) Finally, the upward progress of the great masses of magma is also doubtless made in part by the fusion and absorption of the material with which it is in contact, although the evidence that such absorption has taken place on a great scale is lacking. That absorption does take place in a minor way, however, is certain. (See "Fusion and absorption," pp. 728-736.) 
It is natural to expect that the rocks surrounding great batholiths of igneous rocks, and those intinately associated with the abundant and numerous branch batholiths and dikes, would be profoundly modified, and such is the fact. Conditions for profound and far-reaching modification are perhaps most favorable in connection with batholithic injection and conjoint orogenic movements, and to this fact is probably due the classification of certain kinds of metamorphism as contact metamorphism. But it must be remembered that, with the one exception, the forces and agents at work are essentially the same as those in other parts of the zone of anamorphism, the difference being, merely, that under the conditions of batholithic intrusion these forces and agents are particularly potent. During an intrusion the orogenic forces and the thrust transmitted by the magma both act upon the rocks, and thus the mechanical processes are at work. The temperature is abnormally high; hence the solutions are especially potent. To some extent, as pointed out on page 662 , the magma itself may furnish water, and thus the surrounding rocks contain more than an average amount of water; and this is the most important agent in recrystallization. Therefore about great batholiths are usually zones of profound netamorphism.

\section{FACTOIS CONTROLLIXG METAMORPHISM.}

The factors of alteration to be especially considered in this connection are the size of the intrusive masses, the temperature, the anount of water present, and the composition of the intrusive and intruded rocks.

The size of the intrusive masses is of the first importance in the amount of metamorphism. 'The smaller of the deep-seated irregular masses are ordinarily called stocks; those of intermediate size, bosses; and those of the largest size, batholiths. We know of no down ward limit for any of these. Oftentimes they undoubtedly increase very rapidly in magnitude with depth, although this fact can not be directly observed. Frosion may have extended only deep enough to expose a very small area of a batholith, and yet for long distances about that place the subtuberant mass may be only a short distance below the surface, and the rocks exposed therefore be well within the limit of its influence. This must be a common case, for it 
is certain that the batholiths of great magnitude which now show a large area must at an earlier stage of erosion have been in the position just described with reference to the surrounding rock. Therefore, while metamorphism is a function of the size of the intrusive masses, it is not a function of the size of the masses exposed. When the masses are small and do not rapidly expand in size below, the appreciable metamorphic effect may extend only a few centimeters or a few meters; but the metamorphosing effect of the great batholiths, some of them scores of kilometers in diameter, may extend from a kiloneter to many kilometers.

THE TEMPERATURE.

The temperature effect depends largely upon the size of the intrusive mass, and to a less extent upon its temperature. The greater the size of the intrusive mass and the higher its temperature the larger the amount of leat it is able to furnish to the surrounding rocks and the farther that heat penetrates by conduction and convection. In the natter of heat the intrusives in the zone of anamorphism are in a vastly more advantageous position than those of the belt of cementation. In the latter belt the rocks are comparatively near the surface. There is a somewhat rapid circulation of the water, so that the heat is dispersed, slowly to be sure, but witl relative speed as compared with the zone below; but in the zone of anamorphism the great store of heat of an intrusive mass is so far below the surface, and the circulation is so slow, that it is a sustained factor in increasing the temperature of the surrounding rocks, certainly for geological epochs, and frequently in the case of the larger masses for geological periods. Thus there is ample time during high temperature for the alterations to take place. IIoreover, the heat through conduction and convection slowly disperses itself from the central mass over a very wide area and produces a metamorphic effect upon the rocks far beyond the distance to which the materials of the nagma can possibly penetrate.

AMOUNT OF WATER PRESENT.

The amount of water, as fully explained in other connections (see pp. 741-748), is of the utmost importance in determining whether the metamorphisin is by granulation or by recrystallization. In proportion as water is abundant recrystallization is likely to take place. Where the intrusive 
masses are introduced into sedimentary, volcanic, or other rocks, which have passed through the zone of katamorphism, they already contain a reservoir of water in hydrated minerals which can be released by dehydration. This supply is usually ample to entirely recrystallize the rocks. But as nearly as we can ascertain from observation, the magmas thenselves contain a considerable store of water, as pointed ont on page 662. At the time of erystallization of a magma a portion of this water escapes and passes slowly into the surrounding rocks, and thus in magmas we have a second reservoir, which supplements the first; so that adjacent to masses of igneous material in the zone of anamorphism there is commonly an amount of water such that recrystallization readily takes place.

COMPOSITION OF INTRUSIVE AND INTRUDED ROCKS.

The absolute and relative compositions of the intrusive and the intruded rocks are both of importance in reference to the alterations whicl take place. So far as observation can determine, it seems to be a fact that the alterations are more widespread in connection with batholiths of granite and syenite and other acid rocks than with basic rocks. Possibly the apparently greater contact effect may not be due so much to the chemical composition of the crystallized intrusive as to a greater than average amount of occhded water (see pp. 720-728), and to the high temperatures which are frequent accompaniments of acid magmas.

The character of the intruded rock has much to do with the nature of the alteration. In so far as rocks are composed of minerals which are easily recrystallized, this process is more likely to take place; whereas rocks which are difficult to recrystallize under the same conditions may be comparatively little altered. The presence of hydrous minerals which may be dehydrated and furnish water, and fineness of grain are very favorable to recrystallization.

As to the mutual effect npon the chemical composition of the intrusive and the intruded rocks, the law in the zone of anamorphism is the same as that in the belt of cementation, viz, that the joint endomorphic and exomorphic effect is to make the intruded and intrusive rocks approach each other in composition. Under the law of mass action each gains from the other elements in which it is deficient. One of the commonest illustrations of this law is furnished by the large amounts of feldspar which frequently 
develop in a schist adjacent to an intrusive, when the continuations of the schist formations remote from the intrusive contain little or no feldspar. Such are the facts about the Black Hills batholiths (see p. 724) and at many places abont the New England granite batholiths.

Another excellent illustration is furnished by the Rib Hill quartzites of central Wisconsin, adjacent to a great intrusive batholith of augite-syenite. The center of the quartzite mass contains no feldspar. As the masses of syenite are approached feldspar and hornblende appear in the quartzite. These minerals increase in amonnt as the syenite is approached, and close to that rock the quartzite is so thoronghly impregnated with feldspar which has developed in and between the grains as to make many of the hand specimens of the rock difficult to discriminate from a granite.

There is much difference between the zones of anamorphism and katamorphism in the extent to which interchange of material takes place between the injected and the injecting rocks. It has been seen that in the belt of cementation, in consequence of the porosity of that zone, the material of the magma, both by direct injection and by transmission through water, may profoundly affect the average chemical composition of the intruded rock for great distances from the intrusire mass. Thile these changes do not take place on an extensive scale to any such distance from the intrusive in the zone of ananorphism, we must not go too far in minimizing the importance of the exomorphic effect of intrusive rocks in this zone. The short distance to which magma can furnish material to the injected rock is compensated to a large extent by the great scale of the intrusions. As has been explained, there are in the zone of anamorphism innmmerable batholiths, bosses, and stocks, and in temporary fractures intimate intrusions for extensive areas. Hence the conditions favorable for endomorphic and exomorphic effects without transportation of material to a great distance from an intrusive are widespread and important. The quantity of solutions is small, and they make their way very slowly through the subcapillary openings. The consequence is that, where there is a great simple mass of intrusive witl few offshoots, the chemical compositions of the two rocks are affected for only a short distance from each other; but where the intrusive and intruded rocks are intimately mingled there may be a profound modification in the chemical composition of both rocks over an extensive area, each approaching the chemical composition of the other. This general statement requires some amplification. 
As just noted, where the contacts are sharp one does not need to go far in order to obtain rocks the chemical composition of which corresponds to that of the intruded and intrusive masses, although the intrusive may be affected to a greater distance by the absorbed material than are the intruded rocks, since in a magna the elements are more rapidly distributed than the r are in the solid rock, in which the water is very small in amount and moves very slowly. Howerer, even in the case of the intruding magma, Becker" and others have shown that the process of diffusion is comparatively slow, a very long time being required for the chemical composition of the intrusive to become greatly affected at a considerable distance from the contact with the intruded rock.

Where, however, the intruded and intrusive rocks are intimately mingled there may be profound modification of the chemical composition of both rocks. A case of this alrearly given is that of parallel injection into slates, schists, and gneisses. In such a case the modification may be so great that the chemical composition of the intruded rock, if sedimentary, may vary greatly from that of ordinary sediments, and the intruded rock nay differ considerably in composition from the main mass of inirusives. Such rocks as these are the so-called iujection gneisses (See pp. 725-727.) These rocks are usually coarsely or finely bauded, and may be aqueous and igneous in any proportion, or igneous rocks of two kinds in any proportion, provided the intruled rock was a schistose igneous one.

Another case of intimate mingling of the two rocks is that where numerous fragments of the intruded rock are caught by the intrusive. By subsequent movement such fragments may make their way into the magma for some distance from its border, and their partial or complete absorption may affect the chemical and mineral composition of the intrusive for considerable or even long distances from the outside of the intrusive.

In closing this part of the subject it should be noted that the above statements as to the rather short distances to which chemical changes are usually limited does not contradict the statement already made, and more fully developed later, that the metanorphic effect of great intrusives often extends far from the intrusive maisses.

\footnotetext{
"Becker, George F., Some queries on rock differentiation: Am. Jour. Sci., 4th ser., vol. 3, 1897, pp. $27-31$.
} 
The metamorphic effects accomplished in connection with intrusions are both structural and mineral. It has already been noted (p. 712) that the effects of great masses of intrusive rocks naly extend for several wr many kilometers. It is by the study of areas adjacent to batholiths that the contact effects are best appreciated. About a great batholith there are commonly various zones of metamorphism which grade into one another. This is true both of the structures which are formed and of the miuerals which develop.

STRUCTURE:

It has aheady been indicated that as batholiths are intruded the rocks are deformed by being pushed aside. The deformation is mainly accomplished by recrystallization, as described on pages 690-696. Juring the process the majority of rocks take on a slaty or schistose structure. Cleavage developing normal to the pressure is peripheral to the batholith or circumscribes it. The contact effect naturally dies out as the distance increases from the intrusive. Near the intrusive the recrystallized rock may be a coarse-grained gneiss or schist; farther away from the intrusive it may become an ordinary slate; and still fiuther away a slaty cleavage may not be found muless it had been previously developed in some other way. Between these three zones there are gradations.

In America peripheral structures in gneisses, schists, and slates lare illustrated by the Carboniferous batholiths of New Eugland, described by Emerson; ${ }^{a}$ by the Algonkian batholiths of the region northwest of Lake Superior, described by Lawson $;^{b}$ by the grauite batholith of the Black Hills, described by Van Hise; ${ }^{c}$ and by the batholiths of Vanconver, described by Dawson. ${ }^{d}$

If a previous regional cleavage exists in an area intruded by a batholith, this older cleavage is reenforced if it correspond to the new direction of cleavage, and tends to be obliterated if it be diagonal or perpendicular

a Emerson, B. K., Porphyritic and gneissoid granites in Mlaswahusetts: Bull. Geol. Soc. Amerin'a, vol. 1, 1890, pp. 559-561.

$b$ Lawson, A. C., The laccolitic sills of the northwest cuast of Lake Superior: Bull. Ceol. and Nat. Hist. Surv. Minnesota, No. 8, 1893, pt. 2, pp. 24-48.

$c$ Van Hise, C. R., The pre-Cambrian rocks of the Black Hills: Bull. Geol. Soc. America, vol. 1, 1890, pp. 206-212.

d Dawson, George M., Report on a geological examination of the northern part of Vancouver Islanıl and adjacent coasts: Rept. Geol. and Nat. Hist. Surv. Canada for 1886, pt. B, 1887, pp. 1-129. 
to it. All of the abore relations may obtain about a single batholith, as in the case of the Black Hills granite already mentioned. At places where the new clearage develops at right angles to the old cleavage, the older may be completely obliterated near the batholith. Farther away from it the old and new clearage may both be present and intersect each other, and still farther away the old clearage may be dominant. ${ }^{a}$

THE MINERALS.

The minerals which form depend upon the intensity of the metamorphism. To illustrate, closest to the Black IIills granite batholith is a gneiss containing abundant quartz, mica, feldspar, garnet, staurolite, homblende, and toumaline. Farther from the granite is a schist containing quartz and mica, comprising both muscovite and biotite, with staurolite and garnet. Farther out is a schist in which the stamolite is absent and garnet is present. Still farther away is an ordinary slate in which there are small flakes of mica, but in which there are no garnets or staurolite. Similar illustrations are furnished by the batholiths of Massachusetts, described by Emerson; but these have, in addition to the minerals above mentioned adjacent to the granite, cranite: somewhat farther ont in the schists, sillimanite; and still more remote in the ordinary slate, andalusite. The three minerals mentioned furnish a particularly good illustration of the metamorphic effect with reference to position. since they have precisely the same chenical composition. Also these minerals furnish a perfect illustration of the principle, expounded in Chapter IV (pp. 182-186), that in proportion as the metamorphic effect is profound and the pressure great, minerals of high specific gravity develop. The specific gravities of andalusite, sillinanite, and cranite are, respectirely. 3.18, 3.235, and 3.615, and this is their order observer in approaching the intrusives.

In a given case the different mineral zones are not sharply defined, but grade into one another. Noreover, the most intensely metamorphosed area may contain all the minerals developed by the feebler metamorplic processes This may be explained on the suppositjon that as the metamorphic wave passes away from the central batholith the conditions were first those of mild metamorphism, later those of moderate metamorphism, and finally those of serere motamorphism. Also adjacent to the

$$
\text { a Van Hise, cit., pp. 232-234. " Emerson, cit., pp. 559-561. }
$$


intrusive mass as it cools, following the severe metamorphism, the conditions are those of moderate and mild metamorphism. As the metamorphic wave passes out from the newly intruded batholith the minerals first developed may later be transformed into other minerals requiring more intense metamorphic power, and thus early minerals may be partly or wholly obliterated by transformation into the minerals of more intense metamorphism. Under such circumstances the facts might be discovered by partial change or by pseudomorphs. The phenomena are finely illustrated about the batholiths of western Massachusetts. According to Emerson-

The zonal character of the contact metamorphosis around these batholites is interesting, especially in aluminous sediments. The first wave of heat develops the easily formed minerals, fibrolite and chiastolite: stronger heat, stanrolite and garnet; then the first influx of the alkaline waters from the granite forms pseudomorphs of these in muscovite, and with increasing heat feldspars develop. So the highly altered rocks nearest the intrusive mass hare often passed through all the stages one passes over in going from the onter zone inward. Thus, in the Carboniferous argillite in Harvard one finds masses of interlaced prisms of andalusite, of the largest size and finest pink color, inclosing crystals of fibrolite in abundance (the two not orientated to each other), and the whole in every stage of change to coarse muscovite. This preserves three stages which were plainly passed orer in succession, and nearer the granite large feldspars are interspersed. In the Hattield argillite, a zone of delicate chiastolite is succeeded inwardly by a zone where the chiastolites are changed to a mixture of muscovite and minute twins of staurolite (the mass still retaining the shape and black cross of the chiastolite) by the influence of greater heat and alkaline solutions; and nearer the granite the whole changes to sericite schist, chlorite schist, and finally bornblende and feldspar appear near the contact with the hornblende granite. ${ }^{a}$

In Europe at many localities a zonal arrangement of the metamorphic minerals peripheral to intrusive masses has been observed. The minerals commonly developed and the order of their arrangement are in general similar to the instances above given. Four well-known instances are those furnished by the Vosges, the Erzgebirge, the Hartz, and the Tyrol. In the Vosges, granite intrucles the Steiger Schiefer. ${ }^{b}$ Says Rosenbusch:

Die gesammte Contactzone der Steiger Schiefer an den Granititen lässt sich demnach gemäss der wesentlichsten Entwicklungsglieder in 3 ammähernd concentrische Partialzonen zerlegen, welche etwa zu bezeichnen wären als:

(1) die Zone der Fleck-, Frucht- oder Knotenschiefer mit unverïnderter Seliefergrnndmasse oder Lnotenthonschefer:

a Emerson, B. K., Porphyritic and gneissoid granites in Massachusetts: Bull. Geol. Soc. America, vol. 1,1890 , pp. $560-561$.

${ }^{b}$ Rosenbusch, H., Die Steiger Schiefer und ihre Contactzone an den Granititen von Barr-Andlau und Hohwald, R. Schultz \& Co., Strasshurg. 1877. no. 178-250. 
(2) die Zone der Fleck-, Frncht- oder Knotenschiefer mit deutlich gröber krystallin entwickelter Schiefergrnndmasse oder Thotenglinmerschiefer; felse."

(3) die Zone der ITornfelse, speciell der weitans vorwiegenden Andalusithorn-

In the Erzgebirge granite intrudes phyllite. Dalmar summarizes as follows:

Sonach lassen sich also innerhalb der fortschreitenden Reihe von Umwandlungen, welche die Phyllite im Contact mit den Granitstöcken erlitten haben, folgende vier Stadien unterscheiden:

(1) Das Stadium der Fruchtschiefer mit unveränderter Schiefermasse.

(2) Das Stadium der Fruchtschiefer mit Krystallinisch veränderter Schiefermasse.

(3) Das Stadium der schieferigen Glimmerfelse.

(t) Das Stadium der Andalusitglimmerfelse und Andalusithornfelse. ${ }^{b}$

In the Hartz granite has intruded the sedimentary rocks, and here Lossen finds three contact zones. Says Lossen:

Im Allgemeinen aber doch sehr wohl ausgeprägte, concentrisch um den Granit verlaufende Steigerung'szoneu der nach dem Eruptivgestein hinwachsenden Umbildung: die Aeussere Knotenschieferzone, die mittlere Hornfelszone und die innere Zone der Glimmerschiefer- ilhnlichen Hornfelse gegliedert werden. ${ }^{c}$

Near Monzoni in the Predazzo district of Tyrol is a set of zones characterized in passing from the intrusive by a succession of garnet, augite, serpentine, and brucite. ${ }^{d}$ This is a very interesting case, because the first two minerals are those which ordinarily develop in the zone of anamorphism, whereas the third and fourth minerals commonly develop in the zone of katanorphism. So far as I kuow this is unique. It suggests, if all these minerals be original, that near the intrusive mass the pressure was sufficient to require reactions giving decrease in volume, and therefore the conditions were those of the zone of anamorphism; whereas at a greater distance the pressure was not so great but that reactions could take place with increase of volume, and therefore the conditions were those of the zone of katamorphism. Howerer; before this can be regarded as established it must be shown that the serpentine and brucite developed simultaneously with the garnet and angite, and are not later alteration products.

"Rosenbusch, cit., pp. $17 \overline{7}-178$.

$b$ Dalmer, K., Erlïuterungen zor geologischen Specialkarte des Königreichs Sachsen: Section Kirchberg: Leipzig, 1884, Blatt 125, pp. 26-27.

c Lossen, K. A., Erlüuterungen zur geologisehen Specialkarte von Preussen und den Thüringischen Staaten: Blatt Harzgerode, Berlin, 1882, p. 45.

a Teller, F., and John, C. von, Geologisch-petrographische Beiträge zur Kenntniss der dioritischen Gesteine von Klausen in Suidtyrol: Jahrbuch k.-k. geol. Reichsanstalt, 1882, XXXII, 589-684. Irving, A., Metamorphism of rocks: Longmans, Green \& Co., London, 18̨s9, p. 80. 
One additional American illustration is given. Grant describes the derelopment of contact minerals adjacent to the great basal gabbro of northeastern Minnesota. ${ }^{\alpha}$ This is an interesting case, since the intrusive rock is basic and since it is in contact with several different formationsAnimikie slates, Animikie iron-bearing member, green-schists, greenstones, and granites. The prominent contact minerals dereloped in the slates are feldspar, biotite, and muscovite, with occasional graphite, cordierite, and liypersthene. The important contact minerals in the iron-bearing member are magnetite, amphibole, augite, hypersthene, and olivine. In the metamorphosed greenstones augite and hypersthene are found in considerable amounts. Besides the distinctive minerals developed, all of the rocks are completely recrystallized for a distance varying from a hundred ineters to several hundred meters from the intrusive rock.

Concluding this part of the subject, it is evident that the development of the metamorphic minerals occurs largely while intrusion is taking place and morement is still going on, which explains the marked tendency for the development of slates, schists, and gneisses. Following the intrusions of the great batholiths and the orogenic morements connected with them the mass conditions are static, yet the conditions may be very farorable for recrystallization. The temperature may still be high and the solutions active, and under such circumstances the conditions are very favorable for the development of porphyritic crystals which have no relation in their orientation either to the batholiths or to the slates, schists, or gneisses. Hence it follows that within these rocks peripheral to the batholiths we find the best illustrations of secondary porphyritic erystals. Moreover, the porphyritic crystals which appear are dependent upon the intensity of the metanorphism. The order of the heary porphyritic crystals in relation to the batholiths is that above mentioned, viz., near the batholiths are apt to be the heary silicates, tourmaline, stanrolice, and cyanite; more remote from them, garnet and sillimanite; and still more remote, andahnite. Of course these overlap and are intermingled, as already explained.

PEGMATITES.

The complex processes in connection with the intrusive batholiths and their offshoots may, and indeed do, produce masses of rocks which

"Grant, U. S., Contact metamorphism of basic igneous rock: Bull. Geol. Soc. America, vol. 11, 1900, pp. 503-510. 
may be called pegmatites. So far as my observation goes, many of the more complex phenomena of pegmatization which can not be explained by igneons injection alone are in regions in which the rocks have been buried to a very considerable depth. They commonly form in the lower part of the zone of fracture, in the zone of combined fracture and flowage, or in the part of the zone of flowage in which continuous fractures may exist temporarily The phenomena occur to a great extent in the lower zone in connection with offshoots from the deep-seater batholiths-i. e., injection dikes which have made their way along planes of rock weakness, such as contacts or cleavage planes. Probably a strictly logical arrangement would require that the treatment of pegmatites be deferred until the relations of the zones of anamorphism and katamorphism are considered, but the relations of pegmatites to deep-seated intrusives are so elose that, for the sake of continuity, the subject is dealt with here.

Pegmatization has been variously explained as the result of true igneous injection, of aqueo-igneous action, and of water impregnation or cementation. Brögger has strongly enforced the idea that many pegmatite veins are true igneous injections. ${ }^{a}$ In support of this idea he cites the undoubted frequent association of pegmatitic veins with intrusive masses of acid rock, the fact that many of the pegmatitic veins behave like other eruptives, and that their structure is that of igneous rocks.

Williams is in substantial agreement with Brögger in assigning an essentially eruptive origin for the greater number of the pegmatite dikes of the Piednnont Plateau. ${ }^{b}$ In favor of this view he cites (1) the likeness in chemical and mineralogical composition of the granite masses to the pegmatites, although it is stated that the pegmatites are usually somewhat more acid; (2) the fact that the size and abundanee of pegmatites are directly proportional to their nearness to eruptive granite masses; (3) that in composition the pegmatites are independent of the rocks which surround them, and (4) that they do not show the drusy or symmetrical character of reins. While Williams thus lolds to the igneous origin of the pegmatites, he thinks they show a greater activity of mineralizing agencies than the normal granite. In conclusion of his discussion, he says: "The writer therefore

a Brögger, W. C., Syenitpegmatitgünge der südnorwegischen Augit-und Nephelinsyenite: Zeitsch. für Kryst., vol. 16, 1890, pp. 215-235.

$\checkmark$ Wrilliams, G. H., The general relations of the granitic rocks in the middle Atlantic Piedmont Platean: Fifteenth Ann. Rept., U. S. Geol. Survey, 1895, pp. 675-68t.

HON XLVII-04 46 
interprets those pegmatites which by their mode of occnrrence and association strongly indicate an igneous character as the products of the residual and therefore most acid portion of a granite magma highly charged with water and other mineralizing agents. Such a siliceous material, in a state intermediate between fusion and solution, has been injected into fissures and there crystallized into very coarse-grained aggregates, not necessarily throngh any great slowness of this process, but rather in virtue of the aid to crystallization afforded by the abundance of mineralizers present." a

While Williams and Brögger strongly emphasize the igneous side of pegmatization, they both agree that some of the pegmatites which show a comb structure are essentially the result of aqueous processes. ${ }^{b}$

Standing at the other extreme is Hunt, who maintains a strictly aqueous origin for pegmatites. ${ }^{\circ}$ In an intermediate position, ascribing an aqneo-igneous origin to pegmatites, are Élie de Beanmont, Scheerer, Lehmann, Credner, Reyer, and Crosby and Fuller. Scheerer in 1847, according to Hunt, "Conceives the congealing granitic rocks to have been impregnated with 'a juice,' which was nothing else than a highly heated aqneons solution of certain mineral matters. This, unler great pressnre, oozed out, penetrating even the stratified rocks in contact with the granite, filling cavities and fissures in the latter, and depositing therein crystals of quartz and of hornblende, the arrangement of which shows them to have been of successive growth." ${ }^{d}$ Reyer, following Scheerer, regards the pegmatites as "Exsudate der erstarrenden Granitmasse." But of all the anthors writing upon pegmatites Lehmann, ${ }^{f}$ followed by Crosby, ${ }^{g}$ makes the closest approximation to the view which I hold in reference to pegmatites. Lehmam conceives that as a result of crystallization of the parent mass and the concentration of the water in the residual uncrystallized part, a gelatinons magma rich in silica is formed. "Between such a gelatinous magma and a saturated aqueons solntion a large number of consecutive intermediate stages can be imagined." ${ }^{\prime}$ However, Lehmann insists that no part of the

$a$ Williams, G. H., The general relations of the granitic rocks in the middle Atlantic Piedmont Plateau: Fifteenth Ann. Rept. U. S. Geol. Survey, 1895, p. 684.

$b$ TVilliams, eit., p. 679.

$c$ Hunt, T. Sterry, Chemical and geological essays: Osgood \& Co., Boston, 1875, pp. 191-219.

a Hunt, cit., p. 189.

e Reyer, E., Theoretische Geologie: Schweizerbart'sche Verlagshandlung, Stuttgart, 1SSs, p. 101.

$f$ Lehmann, Johannes, Untersuchungen üher die Entstehung der altkrystallinischen Schiefergesteine: Bonn, 1884, pp. 24-58.

$g$ Crosby, W. O., and Fuller, M. L., Origin of pegmatite: Tech. Quar. vol. 9, 1896, pp. 326-356.

${ }^{h}$ Crosby, W. O., and Fuller, M. L., citing Lehmann, cit., p. 345 . 
water is atmospheric, but is wholly eruptive water. Crosby and Fuller, however, think it is possible that a portion of the water required "for the more perfect hydration and liquefaction of the residuum of the magma may be derived from extraneous sources." a

It seems to me that to explain adequately all the facts of pegmatization described in various regions of the world, we must conclude that all three processes have been at work-in some cases igneous injection, in some cases aqueo-igneons action, in other cases pure water cementation, and in still other cases combinations of two or all of these processes. It is further believed that there is no sharp separation between these processes, but that, on the contrary, there are all gradations between the three. That is, it is thought highly probable that, under sufficient pressure and at a high temperature, there are all gradations between heated waters containing mineral material in solution and magma contcining water in solution. In other words, under proper conditions water and liquid rock are miscible in all proportions. This possibility, first published by me in $1896,{ }^{b}$ in precisely the above words, has received almost conclusive experimental verification at the hands of Barns. As noted on page 80, Barus has shown that at temperatures below $200^{\circ} \mathrm{C}$, and at high pressure, soft glass and water are actually miscible in all proportions.

From the water solutions true cementation takes place; from the rock solutions, true injection. Pegmatization comprises these and the intermediate processes. It is not to be expected that under great pressure and at high temperatures there is any sharp line of demarcation between the processes of aqueous cementation and igneous injection. At the surface it is usually easy to sharply separate aqueous from igneous action, but deeper within the earth even the strongest rocks are latently plastic. At great pressure heateri waters must have power to absorl a quantity of material far beyond that at the surface of the earth. Truly liquid rock is highly impregnated with water. It therefore is probable that at considerable depths we have, on the one hand, material which all would call water solution, and on the other hand material which all would eall liquid rock, with no sharp division line between the two. If this be so, there are all

${ }^{a}$ Crosby, W. O., and Fuller, M. L., Origin of pegmatite: Tech. Quar., vol. 9, 1896, p. 348.

$b$ Van Hise, C. R., Principles of North American pre-Cambrian geology: Sixteenth Ann. Rept. U. S. Geol. Survey, 1894-95, pt. 1, 1896, p. 687. 
stages of gradation between true igreous injection and aqueous cementation, and all the various phases of pegmatization may thus be fully explained.

This idea of continuity was first suggested to me by the phenomena observed in the schistose rocks surrounding the intrusive core of the Black Hills. Remote from the intrusives the sedimentary rocks are slates; adjacent to it they are schists and gneisses. The core rock is a great batholith of granite, $11 \mathrm{~km}$. broad and $18 \mathrm{~km}$. long. Besides this central mass there are, to the southwest, a number of smaller masses, from 2 to $6 \mathrm{~km}$. long, which may be comnected below with the greater mass. From the central mass great quartz-feldspar dikes radiate. In passing away from the core the dikes become smaller and have a less typical form; at the same time the material assumes the appearance which we ordinarily denominate pegmatitic. These veins might be considered true igneous injections. Still farther away the pegmatitic masses begin to have vein-like charactersthat is, there is a rough concentration of the material in different layers parallel to the walls. Still farther away a true banded-vein structure is found. Yet farther away feldspar becomes less and less important in the veins and the quartz more abundant, until remote from the granite the impregnating material is mainly quartz. Within the intruded rock, adjacent to the granite, there is also an extensive development of feldspar, giving the rock a banded appearance and changing it from a schist to a gneiss. If one examined only the outer zone, in which the quartz cementation series occur, one would not doubt that they are ordinary deposits from ground water; if one examined the dike-like masses of the inner zone adjacent to the great granite mass, one would not doubt that they are true igneous injections; but in passing back and forth between the two, one observes that there is every gradation between them, and is driven to the conclusion that true igneous injection was predominant adjacent to the granite, that in the central zone aqueous and igneous agencies were about equally important, and that in the outer zone aqueous agencies were predominant. It is impossible to believe that the larger dikes - plainly offshoots of the central batholith - are not igneous injections; it is equally impossible to believe that quartz veins remote from the granite are dikes, or that the ordinary granite magma has penetrated to considerable distances between the individual grains of the schist and thus impregnated it with feldspar.

From the foregoing it is clear that under the general term pegmatite 
are included the results of three somervhat distinct phases of action, which, however, grade into one another; first, pegmatization mainly aqueous; second, pegmatization mainly igneous, and third, aqueo-igneous peginatization.

The first case is illustrated in the Marquette district of the Lake Superior region, ${ }^{a}$ where at certain places in the Michigamme formation there is a great development of feldspar within the interstices of the schists. In the crevices minute pegmatitic veins of quartz and feldspar occur. No adjacent intrusive in this formation has been discovered even by the closest detailed study. In this case it seems clear that pegmatization has taken place during the metamorphism of the rocks, in connection with mechanical action, without the assistance of any extraneous igneous material, and is therefore essentially aqueous.

The second of these cases is illustrated by the pegmatites described by Brögger in southern Norway, in which igneous injection satisfactorily explains all the phenomena. It is to be noticed that in this region the process of pegmatization occurred at a maximum depth of 600 meters, while much of it occurred at a depth varying from 30 to 100 meters.

The third phase of peginatization, which combines both aqueous and igneons agencies, is far the most extended and important. By it are formed the great class of the rocks which are usually spoken of as pegmatized. This phase may affect massive igneous rocks, massive sedinientary rocks, and their metamorphic equivalents. It occurs in both acid and basic rocks. In all, the effects may be most complex, ranging from the formation of great pegmatite dikes to the development of individual crystals of feldspar, quartz, and other minerals anywhere within the intruded masses.

But this phase of pegmatization is most extensive and best illustrated by rocks in which there is a gneissic or schistic structure, since, as pointed out on page 710, cleavage furnishes planes of weakness which are readily taken advantage of by the imneons rocks. The relations are best studied where intrusive and intruded rocks are of different colors; for instance, where there is a dark-colored schist intruded by granite. In such rocks will be seen a background of schist. Parallel to the folia are innumerable

a Van Hise, C. R., and Bayley, W. S., The Marquette iron-bearing district of Michigan: Mon. U. S. Geol. Survey, vol. 28,1897 , pp. $447-148$.

${ }^{b}$ Brögger, W. C., Syenitpegmatitgünge der südnorwegischen Augit- und Nephelinsyenite: Zeitsch. fïr Kryst., vol. 16, 1890, pp. 215-235. 
cementation-injection bands of lighter color. These bands vary from those as thin as leaflets, being perhaps but a single row of crystals, to those of considerable width. There may be many such bands within the space of a centimeter, or a single one may be many meters àcross. Frequently parts of the injected material are in dike-like masses of rarying size, which cut the schistosity at various angles. At numberless places the leaf-like bands of pegmatitic-looking material parallel to the schistosity are found to be connected directly with the dike-like masses cutting the schistosity.

The dark schistose bands are found to show exomorphism in various degrees by the injecting material. Besides recrystallization, the modification consists in the derelopment of various new minerals, the material of which is derived in part at least from the intrusive. Clear evidence of this is the frequent addition of minerals, or a large increase in the amount of minerals, in the pegmatized rock of the kinds found in the adjacent intrusive. Not only may the main mass of unpegmatized schist show a deficiency of certain minerals as compared with the pegmatized areas, but if within the pegmatized area there be any considerable belt of schist not affected by the pegmatite masses it may exhibit a similar deficiency. The endomorphic effect upon the injection bands follows the same rule. The more intimate the intrusion and pegmatization the greater the endomorphism. The smaller bands of injection material gain proportionally more material from the schist than do the larger ones.

The intrusive rock, which is the final inciting cause of the third phase of pegmatization may vary from acid to basic, but pegmatization in connection with granite and other acid intrusives has been most closely studied. The process of granitization described by Michel Lévy ${ }^{a}$ comprises the particular form of pegmatization produced by this rock. The pegmatization known as granitization has been studied more closely than other forms because of its prevalence, because the light color of the granite renders it easily distinguishable, and perhaps because acid magmas supply more water and heat than basic ones.

It seems to me that the third phase of pegmatization described above can be conceived of only as an aqueo-igneous process. In many instances the larger masses of cutting material are truly igneous dikes containing a

a Lévy, A. Michel, Sur l'origine des terrains eristallins primitits: Congrès géologique international, 4th sess., London, 1888, pp. 117-129. 
little water. On the other hand, the intimate penetration of all parts of the rocks, down to the openings between the mineral particles, by the pegmatizing material can be accomplished only by very mobile solutions which are more nearly allied to water than to magma; but such water is very rich in mineral material. Between these extremes are all gradations.

The aqueo-igneous pegmatites, especially the pegmatitic schists and gneisses, in all their phases may be seen in any of the regions of America in which there are great batholithic intrusions. They are illustrated equally well in the Cordilleras, the Lake Superior region, Canada, and eastern United States from Maine to Alabama. All these regions afford innumerable perfect illustrations of the process. Even the most extreme pegmatization is illustrated at many places. One of the best instances known to me is that of Rib and Mosinee hills, central Wisconsin. These hills of quartz rock are surrounded by a great batholith of augite-syenite many kilometers in diameter. Within the quartz rock adjacent to the syenite feldspar has so extensively developed as to change the rock from a nearly pure quartz rock to one in which feldspar is an important constituent. A more extensive and no less perfect illustration of pegmatization, as well as of almost every other phase of the process, is furnished by the Hudson schist in the upper part of Central Park, New York, and even better at New Rochelle, adjacent to Long Island Sound. Williams's accurate description of the phenomena exhibited in Maryland shows this to be an admirable case of pegmatization. ${ }^{a}$

In summary, pegmatization, when it occurs on a great scale, nsually is found in comection with great intrusive masses in which there have been long-continued composite intrusions. No great batholith is the result of a single simple intrusion. The introduction of such masses went on irregularly throngh a very long time. Pegmatitic masses are not the result of a distinct epoch of erruption, but usually are produced in connection with the closing phases of igneous activity. The pegmatites very fiequently cut the igneous rocks intruded in an earlier stage of the igneous epoch. After the main masses of igneous rock have crystallized they continue to contract as they cool, and are thereby fractured. This occurs while they are still very hot, and gives ready access to the pegmatizing material. Also the surround-

$a$ IVilliams, G. H., The general relations of the granitic rocks in the middle Atlantic Piedmont Platear: Fifteenth Ann. Rept. U. S. Geol. Survey, 1895, pp. 657-684. 
ing rocks which have been long affected by the batholiths become highly heated as a result of direct conduction and in consequence of convection through water. The occluded water which undoubtedly exists in the parent mass, at the moment of crystallization is in large measure expelled. As crystallization continues the residual magma gradually becomes more watery. Thus a considerable part of the water, the presence of which is evidenced by the character of the pegmatites, is derived from the magma itself. Doubtless the pegmatite dikes in immediate connection with the great parent masses of igneons material, which closely resemble ordinary igneons dikes, largely and perhaps predominantly derive their water from the igneons rock itself.

As the pegmatites close to the central mass solidify, a large portion of the water is expelled and travels outward to help form the pegmatitic rock having a more distinetive vein character; but in many and perhaps most cases the water in the outlying pegmatite dikes and reins, which more and more assume the character of ordinary veins, has been largely derived from the surrounding rocks. We thus have completely explained the variations from the true igneons dikes by imperceptible gradations to materials which have the unmistakable characters of aqueons mineral veins.

This injection-cementation theory of pegmatization gives an adequate explanation of the extreme coarseness of erystallization which the pegmatites frequently exhibit. The rocks in which the pegmatites form, both the parent crystallized igneous mass and the surrounding rocks, are highly heated, and hence during the closing pegmatitic stages, even if the masses be small, the temperature falls so slowly that there is ample time for the formation of very coarse crystals. Also it is well known that there is no limit to the size to which the crystals may grow from water solutions. The separation of the crystalline material in many pegmatite veins is more nearly analogous to crystallization from a solution than to the solidification of a solvent (see p. 113), and this analogy, so far as it exists, is favorable to very coarse crystals.

FUSION AND ABSORPTION.

In connection with metamorphism in the deep-seated zone where igneous rocks are among the agents, the question of the fusion of the intruded rocks should be considered. It has been held by Mallet and by others that heat produced by mass-mechanical action is a sufficient canse to pro- 
duce aqueo-igueous fusion, and that such supposed fused material is the source of molten material for volcanoes. ${ }^{a}$ Mallet supposes that the material is mechanically divided so fime that a sufficient amount of heat is developed by this work and by friction between the particles to fuse the rock. However, he does not tell how fine this must be, although he speaks of reducing a rock to an absolute powder. What is meant by an absolute powder is not apparent, but one might suppose it means a powder the particles of which are of molecular size.

The conclusions herein contained concerning recrystallization and rock flowage have an important bearing upon the hypothesis of aqueo-igneous fusion. It has appeared that if water be present when the material, as a result of the mechanical subdivision, or for any other cause, reaches the very moderate temperature of $185^{\circ} \mathrm{C}$, the adjustment is accomplished mainly by recrystallization, and that fusion is not necessary to account for the plasticity of the rocks. Probably a much higher temperature is required for aqueo-igneous fusion than for recrystallization. Barus has failed to secure aqueo-igneous fusion of the silicates at a temperature of $600^{\circ} \mathrm{C} .{ }^{b}$ and at temperatures much lower than this it is certain that recrystallization goes on very rapidly.

So far as the typical schists and gneisses themselves are concerued, it is certain that they are not the products of aqueo-igneous fusion. They have the peculiar textures and structures characteristic of these rocks. (See pp. 779-783.) Every magma crystallizes according to the laws of magmas, and produces textures and structures which are characteristic of such crystallization. The textures and structures of the two classes of rocks are very different. There is no evidence that the great masses of the magmas are formed by the fusion of the crystallized rocks in consequence of mech unical action. But it does not follow that various rocks, including the schists and gneisses, may not be fused by contact with intruded magmas. It has been seen in connection with injection that profound metamorphic effects are produced upon the intruded rocks, the ordinary metamorphic forms being slates, schists, and gneisses. It has been held that the phenomena of pegmatization may be exptained by crystallization

a Mallet, Robert, Volcanic energy; an attempt to develop its true and cosmical relations: Philos. Trans. Royal Soc. London, vol. 163, 1874, pp. 147-227.

b Powell, J. W., Report of the Director: Fourteenth Ann. Rept. U. S. Geol. Survey, pt. 1, 1893, pp. 161-162. 
from materials between water solutions and trne magmas. Dur.ng pegmatization, in proportion as the conditions approach those of a magma, the textures and structures may depart from those of slates, schists, and gneisses and approach those of igneous rocks. Thus there nay be all gradations between the textures and structures characteristic of the slates, schists, and gneisses and those characteristic of the igneons rocks. In some regions there occur remarkable combinations of textures and structures characteristic of varions rocks; for instance, the clastic rocks, the schists, and the igneons rocks.

When once a rock, whether a sediment, a crystallized igneons rock, or a metamorphic rock, has become a magma by fusion, whether it be by aqueo-igneons fusion or by dry fusion, the resultant material is a true magma. The crystallized rock which forms from'it by cooling has all the characteristics of an igneous rock. The textures and structures formed are those of the igneous rocks. The textures and structures of the fused sedimentary, original igneons, or metamorphic rocks are totally destroyed, and the newly formed rock is to all intents and purposes a new igneous rock. If rocks rlerived by the fusion of previous solid rocks have again erystallized on a large scale, it is most difficult to prove this. The contacts between the fused and unfused portions of the material wonld be similar to those between ordinary intruded and intrusive rocks. The only way which I can suggest to show fusion and recrystallization on a large scale is to prove that the rock supposed to be fused and recrystallized possesses the chemical composition of the rock from which it is believed to have been derived. For instance, a fused and recrystallized shale should possess the textures and structures of an igneous rock, but the essential chemical composition of a sedimentary rock. This criterion of chemical composition as applied to the red granular rock (meta-rhyolite) of Pigeon Point leads to the conclusion that it is probably an independent intrusive, rather than the result of the fusion of the Animikie rocks by the gabbro. ${ }^{a}$ (See pp. 732-733.)

But while it has not been shown that fusion and reerystallization have taken place on a great scale, varions cases have been described in which the evidence seems clear that to some extent intruded rocks have been fused.

There can be no question that fusion of fragments included within igneous rocks does take place. Very numerons inclusions which are found

a Bayley, W. S., The eruptive and sedimentary rocks on Pigeon Point, Minnesota, and their contact phenomena: Bull. U. S. Geol. Survey No. 109, 1893, p. 118. 
adjacent to great batholiths show various stages of absorption. Frequently the partly absorbed resiclual fragments are profoundly metamorphosed, being perhaps completely recrystallized, and frequently greatly changed in chemical composition from that of the parent rock.

It is certain that the absorption of fragments must react upon the chemical composition of the absorbing rock. In so far as rocks fused and absorbed by a magma differ from it in chemical composition, they must change the chemical composition of that magma. Where the rock absorbed is igneous, and therefore has the composition of igneous rocks, the modified magma has a composition intermediate between two nagmas. Where the material has the composition of a sediment, this changes the chemical composition of the magma toward that of the sediment. For instance, if a considerable portion of limestone or dolomite be absorbed, the rocks become very rich in calcium or calcium and magnesium. If a considerable portion of shale or slate derived from mudstone be absorbed, the igneous rock would be likely to be deficient in the alkalies, especially sodium; it might be deficient in the alkaline earths; and it would probably be high in aluminum, thus becoming intermediate in chemical composition between igneous rocks and the mudstone series. If a sediment intermediate between the limestone series and the mudstone series, as, for instance, calcareous shale or slate, were absorbed by magma, while there might not be any deficiency in the alkaline earths, there would be a cleficiency in the alkalies, and probably the aluminum would be abnormally high.

If a rock were fused by contact with a magma without absorption by it or mingling with it, it would, of course, have approximately the composition of the original solid rock, and therefore that of a sedimentary, igneous, or metamorphic rock, as the case might be. Doubtless the compositions of such rocks would be somewhat modified by the exomorphic effect of the igneous rocks. (See pp. 713-714.) If any considerable mass of solidified rock were fused as a result of contact with igneous rocks, it is natural to suppose that for a zone of variable width the two would become mixed, and thus there would be a gradation in chemical composition between the fused rock and a normal magma.

While it is beyond dispute that all of the above cases occur, petrographers have been inclined to believe that none has taken place on a great scale. It may well be doubted whether the excess of heat in molten magma, beyond that required to keep it liquid, is sufficient to perform the vast 
amount of work required tor the liquefaction of a great mass of solidified rock. Work must be doue in fusing the material, and work must be done in expanding the material. Besides raising the temperature to the fusion point, all the latent heat of fusion must be supplied. The heat required for the process of fusion of rocks in a furnace is very great. Ordinarily a magma has a temperature only slightly in excess of that required to hold it in the liquid form. Therefore, that it could furnish a sufficient amount of heat to liquefy immense masses of solid rocks seems highly improbable. And it has already been seen that it can not be assumed that the necessary heat is furnished by orogenic movements, although this may be a helpful factor.

While fusion of solidified rocks of the lithosphere on a great scale, either by magina or by orogenic movement, or the two combined, is to be proved, it is certain that fusion has locally occurred. One of the clearest instances of fusion or semifusion in America is that on Pigeon Point, described by Bayley." At this place is a metarhyolite, called keratophyre, on one side of which is a great mass of gabbro, and on the other side of which are the slates and quartzites of the Animikie series. The keratophyre has all the characteristics of an eruptive rock younger than the gabbro. In a position between the keratophyre and the gabbro is a coarse-grained red rock, which is intermediate in character between the two and grades into each of them. It is therefore regarded as a product formed by the intermingling of the gabbro and rhyolite magmas, the gabbro having been actually fused for a short distance from the keratophyre. For a distance of about 9.5 kilometers, with a few interruptions, the contact rock has a width of from 30 to 90 meters, and for one continuous stretch of nearly 3 kilometers it has an average width of fully 60 meters. If this rock, which is intermediate in composition between the metarhyolite and the gabbro, and which grades into each, and yet has the textures and strtictures of an igneous rock, really represents the result of the action of the quartz-keratophyre on the gabbro, as it appears to do, it is one of the best known cases of actual fusion of one rock by another.

Between the metarhyolite and the slates and quartzites of the Animikic there is another contact belt which extends for about the same length as the

a Bayley, W. S., The eruptive and sedimentary rocks on Pigeon Point, Minnesota, and their contact phenomena: Bull. U. S. Geol. Survey No. 109, 1893, pp. 1-121. 
contact between the quartz-keratophyre and gabbro, and has an even greater wilth, averaging perhaps 90 meters, and being in some places as wide as 150 meters. But only a comparatively small part of this belt, that nearest the rhyolite, has the textures and structures of an igneous rock, and seems to have been completely fused and recrystallized into slates and quartzites. The fusion metamorphism prodnced by the metarhyolite is correlated with the enormous masses of intrusive granite which occur in the Keweenawan series above the Animikie. The Pigeon Point dike of this rock donbtless is located at one of the passages through which the material of some of these larger masses made their way toward the surface. In this connection it is notable that subsequent intrusive trap dikes cut all of the other rocks of Pigeon Point with sharp contacts, and no sign of metamorphosing effects.

Bayley states that the metarhyolite itself may be the product of the action of the gabbro upon the slates and quartzites. If this snggestion is correct the Pigeon Point locality is a still more remarkable case of the production of a rock by fusion of sediments. But that the rhyolite has been produced from the slates can not be considered as determined. Indeed, the analyses of the rhyolites and of the slates and quartzites are different from each other in various important respects. While the amount of silica and alnmina in the two rocks is substantially the same, the alkalies are nearly twice as abundant in the rhyolite as in the sedimentary rocks. Also, the iron is more than twice as abundant in the sedimentary rocks as in the igneons rocks. Nor can it be supposed that the surplus of alkalies and the deficiency of iron in the rhyolite can be explained by the gabbro, it modifying the composition of the fused slates and quartzites so as to produce a magma of the composition of the rhyolite; for if any considerable portion of gabbro magma had been added the silica content would have fallen and the alumina wonld have gone up. Furthermore, the gabbro is scarcely richer in alkalies than the slates and quartzites; hence, on the theory that the red rock was formed by the fusion of the slate and quartzite by the gabbro, one wonld have to explain why the quantity of alkalies in the red rock is about twice as great as in either of its possible sonrces. Thus the analyses seem to stand in the way of the conchusion that the granular red rock (metarhyolite) is really a result of the fusion of the Animikie slates and quartzites by the gabbro. ${ }^{a}$

a Clarke, F. W., and Hillebrand, W. F., Analyses of rocks and analytical methods: Bull. U. S. Geol. Survey No. 148, 1897, pp. 106-110. 
Cases of claimed fusion of vastly greater magnitude than that at Pigeon Point are described by Lawson, Barlow, and other members of the Canadian survey. Lawson ${ }^{a}$ has held that the great batholithic masses of granite and gneiss, some of them many kilometers in diameter, in the region of Rainy Lake and Lake of the TVoods, northwest of Lake Sriperior, have been produced by the fusion of the sedimentary and volcanic series, which he has called Keewatin and Coutchiching. He has called this a case of subcrustal fusion. Similar statements have been nade by Barlow in reference to the batholiths of granite in the Original Huronian district; $^{b}$ and the same thing has been said with reference to the granite and gueiss of the Original Lanrentian district. However, no adequate evidence has been offered to support any of these conchusions. Composite chemical analyses have not been made of the Keewatin and Contchiching rocks and the granites and gneisses supposed to be formed by their fusion, in order to compare their compositions and thus to determine whether the granites conld possibly have been derived from the Keewatin and Coutchiching rocks by subcrustal fusion. All of the phenomena along the contacts of the granitic rocks and the Keewatin and Contchiching are such as may be found at various parts of the world where batholiths of igneous rock have intruded other rocks. Many fragments of the intruded rocks are inchuded in the intrusive. At many places there is a border belt in which the two are intermingled in the most confused way, and, furthermore, in the intruded rocks pegmatization has occurved adjacent to the batholith. The phenomena might possibly lead one to infer the derivation of the intrusive rocks from the intruded rocks by the fusion of the latter, and subsequent action as an intrusion of the magma thus formed, but I do not so initerpret them.

I have gone over the Rainy Lake and Lake of the Woods region in the field, and have visited and closely studied the specific localities described by Lawson as giving evidence of subcrustal fusion. At every one of these localities the phenomena are precisely those which generally occur where great intrusive batholiths penetrate other rocks. For instance, at the Narrows of Kaiarskons Lake, which is cited by Lawson ${ }^{c}$ as one of the best

a Lawson, A. C., The internal relations and taxonomy of the Archean of central Canada: Bull. Geol. Soc. America, vol. 4, 1890, pp. 185-186.

$b$ Barlow, A. E., Relations of the Laurentian and Huronian rocks north of Lake Huron: Bull Geol. Soc. America, vol 4, 1893, pp. 313-332.

c Lawson, A. C., Report on the geology of the Rainy Lake region: Ann. Rept. Geol. and Nat. Hist. Survey of Canada, for 1887-88, new ser., vol. 3 , pt. 1, 1889, p. 32. 
instances giving evidence of subcrustal fusion, the granite cuts the hornblendic schist in a most intricate fashion. However, in most cases the contacts between the two rocks are knife-like in their sharpness, and this is true whether the granite dikes and veins are large or small. At one place a few feet square the granite and schist are so confused as to make it possible that the hornblende-schists were locally softened. The granite near the contact contains numerous fragments of the schist. The lornblendic schist generally retains its typical texture and structure directly to the contact with the granite. The phenomena are clearly those of complex intrusion, with no evidence whatever that the granite has crystallized from the fused lornblendic schist. Similar phenomena were found at other localities cited by Lawson as evidencé of subcrustal fusion.

This eảse has been dwelt upon because it is the one in America where it has been most strongly claimed that immense masses of igneous rocks have been produced by the fusion of older solidified rocks. The relations seem to me, however, to be clearly those which are characteristic of great batholithic intrusions in the rocks of the zone of anamorphism.

Another instance where in America it las been claimed that fusion metamorphism has taken place on a great scale is that described by Fmerson. It is well known that in eastern Massachusetts there are numerous great batholiths of granite intrusive in the Paleozoic strata. Concerning these batholiths Emerson makes substantially the following statements:

The Quiney granites of eastern Massachusetts do not alter the Cambrian schists and do not absorb any material from them. Several other granite bands cxtending across Worcester County contrast with the Quincy band in the following particulars: They are often coarsely porphyritic, while the Quincy granites are not. They are microcline granites. The Quincy granites are orthoclase granites. They contain biotite, or biotite and muscovite instead of biotite and hornblende or glaucophane.

These granite batholiths are also contrasted with the Quincy rock in having a broad peripheral layer, which has all the peculiarities of pegmatite in some cases, and grades into black albitic granites, or even quartz-diorites.

These differences are largely due to the fact that in the Worcester district the granites have fused much of the surronnding schist into their composition. This was proved by finding characteristic inclusions of the schist in great numbers and of every size in the granite, and also by tracing these inclusions into smaller and smaller filaments, until they faded from sight, and finding with the microscope far beyond this point in the fresh granite clear traces of the schists. Where the schist contains pyrite, garnet, fibrolite, cordierite, or graphite, the granite becomes more ferruginons and garnetiferous. The amber conrse fibrolite of the schist appears dissolred and 
recrystallized as a white, silky bucholzite, or fazer-kiesel in the granite, and the graphite scales are inclosed in all the constituents of the granite over many square miles.

Over the whole surface of the great Hubbardston batholith of perfect coarse porphyritic granite. 51 kilometers long and 10 kilometer's wide, it was possible to map the areas once occupied by the different schists, which formerly mantled orer the granite mass, by means of the indestructible constituents of the former schists, by the portions which had melted into the mass of the granite, by the filaments still remaining unabsorbed, and by the different aspect of the granite, dependent largely upon the great increment of iron. Using the first two criteria especially, this donble mapping of the region was carried out in the sheets prepared for the United States Geological Survey.

The region extending for several kilometers south from Mount Wachusett, and that north and south of Brookfield, in the Hubbardston batholith, furnish abundant exposures for the study of the phenomena here described."

The statement of facts which Emerson makes seems clearly to lead to the conclusion that the granites of the Worcester district have actually fused the metamorphosed schists to some extent. However, the changes in chemical and mineral character of the granites adjacent to the schists may be partly dne to the transfer of material from the injected rock by solutions. Until the facts for this district are given in detail, including chemical analyses of the different phases of the granites, it will be impossible to say how far the intruded schists have been absorbed by the granite; and certainly the assumption that the differences between the Worcester granites and the Quincy granites are due to absorption of schistose material by the former requires much more evidence than las ret been offered.

COMBINATIONS AND RELATIONS OF THE VARIOUS PROCESSES.

The processes of welding, strain within the elastic linit, strain beyond the elastic limit, cementation, metasomatism, and injection rarely occur separately. Commonly several of them take place at the same time, and in many instances all of them unite in the metamorplism of a rock. In the previous pages, for the sake of clearness in analysis, each process has been considered by itself, so far as this was possible, so that the effect of each could be clearly appreciated. This natural tendency to consider each process separately, and the tendency to regard a certain process under consideration as the sole cause of metamorphism, have led to the artificial classification into dynamic metamorphism, contact metamorphism, etc

\footnotetext{
$a$ Emerson, B. K., Difference in batholithic granites according to depth of erosion: Bull. Geol. Soc. America, vol. 10, 1899, pp. 499-500.
} 
The mechanical process of welding can not take place without strain within the elastic limit. Strain beyoud the elastic linit can not occur without strain within the elastic limit and welding. Therefore, where the former occurs all the mechanical processes are involved. The chemical processes of cementation and metasomatism do not occur separately; where one takes place the other is sure to be active. These processes, together, go on with or without injection. But injection, which involves both mechanical and chemical factors, never takes place without involving one or two or all of the other processes. Where it takes place on a large scale it is sure to include all the mechanical processes. Moreover, under such circumstances the exomorphic alterations involve the chemical transformations of cementation and metasomatism on a great scale.

From the foregoing it follows that in most instances of alteration in the zone of anamorphism it is impracticable to state the relative importance of the mechanical processes among themselves or of the chemical processes among themselves. However, the chemical processes, as a group, and the mechanical processes, as a group, can be better compared. As has been noted, the mechanical processes where important usually produce granulation, and the chemical processes where important result in recrystallization; but also mechanical action promotes chemical action. The importance of the relations of these two classes of processes demands full consideration.

RELATIONS OF GRANULATION AND RECRYSTALLIZATION.

In a rock the same mineral may be partly granulated and partly recrystallized. Even the individual grains of a mineral may exhibit the two processes in varions proportions. In this case the fracturing may be along the borders of the individuals, may extend entirely across them, or may granulate them thronghout. The simultaneous solutions and depositions may occur along the borders of the original or the secondary granules, or within the spaces produced by the fracturing, or may regenerate the old mineral particles throughout. Any of the deposited material may occur as independent individuals or as enlargements of original grains or mechanical gramules. Thus, in the different particles of the same mineral in a given rock granulation or recrystallization may be the dominant process. If this be so, the same is true, to an even greater extent, of the particles of different minerals. 
Whether granulation or recrystallization is preponderant in a given place in the zone of anamorphism depends upon many factors. Some of these factors are, the character of the material and water content, temperature, pressure, and rapidity of deformation.

CHARACTER OF MATERIAL.

The degreee to which grantlation and recrystallization takes place depends to a considerable extent upon the character of the material. The character of the material involves both mineral composition and coarseness.

In the same rock mass certain minerals may be mainly recrystallized and others mainly granulated or even retain their integrity. For instance, it is well known that quartz suffers gramulation and recrystallization much more readily than feldspar. This is illustrated by the recrystallization of the flat individuals of quartz in the quartz-porphyry described by Futterer ${ }^{a}$ (Pl. III, $B$ ), in which the feldspars have been little affected.

I shall make no attempt to compare the various minerals with one another with reference to ease of recrystallization. There are all gradations, from calcite, which can be easily recrystallized in the laboratory by the passage of water through finely powdered material under very moderate pressure, to the more refractory minerals, such as feldspar.

Since some minerals when strained recrystallize much more readily than other minerals, it follows that a formation composed chiefly of one class of minerals may be deformed mainly by granulation, and an adjacent formation composed of another set of minerals may be deformed mainly by recrystallization. One formation may thus show complete granulation or other important strain effects, while the recrystallization of the adjacent formation, becanse of the greater mobility of its mineral particles, nearly keeps pace with the deformation. One rock may recrystallize so as to show the textures and structures of the schists and gneisses with more or less residual strain effects, while an interlaminated rock recrystallizes so' readily as to take on a granolitic texture after movement has ceased. As an illustration of this are the closely associated gneisses and marbles of the Adirondacks and of the Hastings series of Canada. The gneisses, besides having their characteristic textures and structures, show marked residual strain, while at

"Futterer, Karl, Die "Ganggranite" von Grosssachsen, und die Quartzporphyre von Thal im Thüringer Wald, Heidelberg, 1890, pp. 27-47. 
various localities interstratified with these are coarse marbles with granolitic textures showing no other strain effects than those of polysynthetic twinning and similar phenomena, which may have been developed by the slight stresses to which the material was subjected in section cutting in the laboratory.

The coarser the particles the more likely is granulation to be of importance. The finer the particles the more likely is recrystallization to be dominant. The finer the particles originally or by granulation the greater is the surface cxposed to the action of the solutions. The dissolving power of water, when not nearly saturated, is alnost directly in proportion to the area upon which it can act. If the grains of a rock be broken by granulation into particles having radii 0.1 of those of the original grains, each small grain will have 0.001 the volume of an original grain, and the total surfaces of the fewer original grains will be to the total surfaces of the more numerous grains as $1: 10$. If the gramulation goes so far as to give the gramules radii averaging only 0.01 of those of the original grains, each small grain will have 0.000001 of the volume of the original grains, and the total surfaces of the original grains will be to the total surfaces of the granules as $1: 100$. A good illustration of mechanical granulation is furnished by the anorthosites described by Adams. ${ }^{\alpha}$ Mr. S. H. Ball has compared the size of the grains of the original anorthosite and the granulated anorthosite in two specimens, the result showing that, on the average, the ratio of the diameters of the feldspar grains of the original rock to the diameter of the granulated grains is 1:40, or one feldspar grain of the original rock is broken into about 64,000 grains.

Ultimately, even under conditions otherwise favorable to granulation, finer subdivision does not continue, for so large a surface is exposed to the action of the solutions that the process of adjustment is accomplished by recrystallization at least to such an extent that the gramules do not, on the average, decrease in size. In this fact of increased surface of action for the solutions by granulation we have the explanation of the fact that granulation is not known to produce particles the average of which is near the limit of observation with a moderate power of the microscope.

An excellent example of the influence of the character of the material

adams, F. D., Report on the geology of a portion of the Laurentian area lying to the north of the Island of Montreal: Ann. Rept. Geol. Surv. Canada, new ser., vol. 8, 1895, pt. J, pp. 85-134. 
upon the gradation and relations between granulation and recrystallization is furnished by the Algonkian rocks of the Black Hills. ${ }^{a}$ There conglomerates, quartzites, slates, schists, and gueisses occur in intimate relations to one another, due largely to varying character of material. Nearly every phase of deformation, from that in which granulation is the dominant process to that in which recrystallization is the dominant process, is there represented.

\section{TEMPERATTRE}

Low temperature is farorable to granulation; ligh temperature is favorable to recrystallization. If Barus's experiments upon the solubility of glass ${ }^{b}$ be a guide as to the silicates, the temperature of $185^{\circ} \mathrm{C}$. is more nearly crucial between the processes than any other. Below $185^{\circ}$ C. granulation is likely to be prevalent, especially if the deformation be rapid. Above $185^{\circ} \mathrm{C}$., if sufficient water be present, recrystallization is probably so rapid that the mechanical strains do not go far before they are largely obliterated by recrystallization.

Temperature increases with depth: the less the depth the greater the tendency to deformation by granulation, and the greater the depth the greater the tendency to recrystallization. But it must be remembered that the mechanical work of deformation itself develops heat, which can escape only by conduction or convection. Therefore, during mountainmaking periods, temperatures sufficient for recrystallization mar exist much nearer the surface than under quiescent conditions, and consequently recrystallization takes place rapidly at no great depths.

Furthermore, the temperature is raised by intrusive igneous rocks. The heat of the intrusives is conveyed to the adjacent rocks, both by conduction and by convection through water. Hence the presence of igneous rocks is farorable to recrystallization. This has already been dwelt upon. The numerous broad zones of schists and gneisses in which recrystallization is complete about great batholiths, with schistosity everywhere parallel to the sides of the intrusives, have been described. (See pl. 716-717.)

a Van Hise, C. R., The pre-Cambrian rocks of the Black Hills: Bull. Geol. Soc. America, vol. 1, 1890, pp. 21t-230.

$b$ Barus, C., Hot water and softglass in their thermo-dynamic relations: Am. Jour. Sci., 4th ser., vol. 9,1900 , pp. 161-175; rol. 6,1898, p. 270. 
The identical character of the schists surrounding batholiths and those produced in connection with regional mechanical action is explained by the foregoing pages. The necessary conditions for the production of recrystallized schists are movement under sufficient pressure, moderate temperature, and presence of water. These conditions are produced in the two cases in different ways.

\section{PRESSURE AND RAPIDITY OF DEFORMATION.}

The less the pressure the more likely is the deformation to be accomplished by granulation. 'The greater' the pressure the more likely is the deformation to be accomplished by recrystallization. The pressure increases with depth, with mechanical action, by igneous intrusions, and possibly from other causes.

To a certain point, the more rapid the deformation the more likely is the adjustment to be by granulation. The limit beyond which this does not apply is reached when the mechanical process develops such an amount of heat that the readjustment is by recrystallization rather than by granulation. The slower the deformation the more likely is the readjustment to be by recrystallization.

\section{HATER CONTENT.}

Absence of water is favorable to granulation; presence of water is farorable to recrystallization. If a series be so dense, or is of such origin, that it contains comparatively little water, even if other conditions be farorable, deformation by gramulation rather than by recrystallization may occur. Another series, which is in every other respect under similar conclitions, but which contains a fair amount of combined water that may be liberated by dehydration to serve as a medium for the process, may be adjusted by recrystallization and form coarse schists. This principle is believed to explain the difference in the character of the deformation of the different formations for many districts. It is a vell-known fact that in the same district different rock masses composed of similar minerals deformed in the zone of anamorphism vary greatly in the character of the alteration, some formations yielding by granulation, others by recrystallization. In general the sedimentary rocks contain a considerable percentage of combined water, and therefore when deformed are recrystallized. The same is true of the porous igneous rocks, such as lavas and tuffs. In contrast with these are 
the massive igneous rocks, and especially the plutonic rocks, which contain little combined water, and when deformerl are apt to be granulated rather than recrystallized. One of the best districts to illustrate the principle is the Original Lanrentian area described by Adams. ${ }^{a}$ In this district are the anorthosites, the Grenville sedimentary series, and the Basement gneiss of igneous origin. Adams's careful deseriptions show that the most fundamental point of difference between the three classes of rocks in their response to deformation is in reference to recrystallization and granulation. The sedimentary rocks of the Grenville series have been completely recrystallized and are typical schists. ${ }^{b}$ The igneous gneisses are largely deformed by granulation, but "the granulation has perhaps been effected, in part at least, by recrystallization." " The anorthosites have been almost wholly deformed by granulation. ${ }^{.}$Corresponding exactly with these facts are the amounts of contained water. Analyses of three recrystallized Grenville gneisses give an average water content of 1.46 per cent. $^{e}$ An analysis of one partly granulated and partly recrystallized gneiss of igneous origin gives 0.70 per cent of water. ${ }^{f}$ An analysis of grannlated anorthosites gives only 0.51 per cent of water. ${ }^{g}$

The frequent granulation of the massive igneous rocks does not contradict the conclusion (pp. 712-713) that in many cases water as a source of recrystallization may be derived from the plutonic rocks during recrystallization. The very fact that water is given off during this process leaves the plutonic rocks deficient in combined water. When later mass movements take place with only a very small amount of combined water present, granulation is likely to occur, and, as already noted, somewlat in proportion to the amount of the residual water; for; as shown by the ilhnstrations already given, the anorthosites, containing a small amount of water, under mass movement have been granulated to a greater extent than the granites, which contain somewhat greater amounts of combined water.

As examples of recrystallized schists of igueous origin may be men-

a Adams, F. D., report on the geology of a portion of the Laurentian area lying to the north of the Island of Montreal: Ann. Rept. Geol. Surv. Canada, vol. 8, 1895, pt. J, p. 184.

$b$ Adams, cit., pp. 49-66.

$c$ Adams, cit., p. 45 .

a Adams, cit., p. 106.

$e$ Adaus, cit., p. 58.

$f$ Adams, cit., p. 43.

$y$ Adams, cit., p. 130. 
tioned the schists and gneisses of the Basement Complex of the Marquette district of Michigan. Two analyses of the Kitchi schists showed, respectively, 2.51 and 2.70 per cent of water above $100^{\circ} \mathrm{C}^{.}{ }^{n}$ A micaceous schist gave off 2.04 per cent of water above $100^{\circ} \mathrm{C} .^{b}$ A Palmer gneiss gave off 2.33 per cent of water above $100^{\circ} \mathrm{C} .^{\circ}$ Partial analyses of two other micaceous schists from the same locality as the micaceous schist above referred to, which show a cataclastic or gramulated structure, unfortunately do not include water determinations.

The foregoing analyses of recrystallizerl schists from the Archean and Algonkian may be taken as typical of the recrystallized schists of all ages the world over. This is shown to be evident by running through the various analyses of the recrystallized schists in any of the published tables of analyses. Such tables show that the recrystallized schists average more, rather than less, than 1.50 per cent of combined water, and in many cases that they contain more than 2 per cent of water.

In Clarke and Hillebrand's book of analyses, ${ }^{a}$ besides those mentioned, are found three other analyses of recrystallized gneisses. The analyses are of typical gneiss, derived from basic granite at Washington, D. C., with a water content (at and above $110^{\circ}$ C.) of 1.97 per cent, and two plagioclase gneisses from the Sierra Nevada, with a water content (at and above $110^{\circ}$ C.) of 1.71 and 1.47 per cent, respectively. These analyses, with those already quoted, cover all the schists and gneisses cited in Clarke and Hillebrand's book which, from the available descriptions, can be ascertained to be certainly recrystallized. They are here included to show that in this bulletin there is no exception to the rule laid down, viz, that when rocks are deformed in the zone of anamorphism, which contain a sufficient amount of combined water to serve for recrystallization, this process is dominant rather than granulation.

It is to be noted that the water contents of the schists and gneisses mentioned are amounts given off above $100^{\circ} \mathrm{C}$., and in most cases above $110^{\circ} \mathrm{C}$; ; in other words, the water is combined water. This point is of importance as showing that, after the metamorphism of the rocks to schists

$a$ Van Hise, C. R., and Bayley, W. S., The Marquette iron-bearing district of Michigan: Mon. U. S. Geol. Survey, vol. 28, 1897, p. 168.

b Mon. 28, cit., p. 202, anal. v1.

c Mon. 28, cit., p. 217.

a Clarke, F. W., and Hillebrand, W. F., Analyses of rocks and analytical methods: Bull. U. S. Geol. Survey, No. 148, 1897, pp. 88, 215. 
or gneisses, 1.50 per cent or more of water remained. The percentages of combined water after metamorphism are, of course, no measure of the amount of water, free and combined, contained by the rock before and during the metamorphosing process. It is highly probable that the amount of combined water in the later stages of the process, in the case at least of the sedimentary rocks, is lower than in the earlier stages of the process, consequently water is driven off during the process, thus renewing the water films in the subcrpillary spaces, and furnishing a medium for solution and redeposition. (See Chapter III, p. 145.) This is inferred from the analyses of pelites in their various stages of alteration from soils and elays to shales, slates, schists, and gneisses. Sixteen analyses given by Clarke and Hillebrand of soils and clays from Pennsylvania, Florida, and Colorado gave an average loss of water at or above $100^{\circ} \mathrm{C}$. of 7.15 per cent. Six analyses of clays and soils from Virginia gave an average loss of water above $110^{\circ} \mathrm{C}$. of 8.61 per cent. Forty-four analyses of clays and soils from Massachusetts, South Carolina, Alabama, Missouri, Colorado, Nevada, and California gave an average loss of water upon ignition of 8.10 per cent. $^{a}$ Twenty slates and shales from Vermont, Colorado, ard California gave an average of 4.42 per cent of water above $100^{\circ} \mathrm{C}$.' Fourteen slates and shales from Vermont, New York, Kentucky, Georgia, and Alabama gave an average of 4.34 per cent of water above $110^{\circ} \mathrm{C} .^{b}$ The original mudstones from which the shales and slates were produced may be presumed to have contained at least as much water as do soils and clays. The shales and slates are rocks partly metamorphosed during mass-mechanical action, and they certainly lost about one-half of the combined water during the change.

It is well known that shales and slates, when profoundly metamolphosed during mass-mechanical action, produce schists or gneisses. Since most of the schists contain less than 2 per cent of water, this agent was again reduced to one-half or one-third of the amount present when the rocks were in the stage of shales and slates. Therefore the pelites in their original form contain in combination not only a sufficient amount of water to satisfy the requirements as to combined water in the completely metamorphosed schists, but an excess of water, which may be steadily given off

a Clarke, F. W., and Hillebrand, W. F., Analyses of rocks and analytical methods: Bull. U. S. Geol. Survey, No. 148, 1897, pp. 287-301.

${ }^{b}$ Clarke and Hillebrand, cit. pp. 277-286. 
during the process of metamorphism, and thus constantly furnish a supply of the medium through which recrystallization can take place. The same is certainly true of many other rocks the materials of which have been subject to the processes of alteration in the zone of katamorphism, and which therefore contain hydrous minerals. The most important exceptions are the pure silica and the pure carbonate rocks.,

The steadily lessening amount of combined water with increasing metamorphism is illustrative of the facts already explained on pages 178-180, that the deep-seated zone of recrystallization is one of dehydration. In opposition to this, the alterations under conditions of small depth are those of hydration. Many of the rocks metamorphosed under such conditions contain as high or higher percentages of water than the soils and clays the water contents of which bave been quoted. If later such hydrated rocks, whether of igneous or of aqueous origin, were subjected to alterations in the zone of anamorphism, recrystallized schists or gneisses would be developed.

In the above no account is taken of the mechanically mingled water. This is uudoubtedly always present in important amount in all of the sedimentary and in many of the igneous rocks, and is an additional supply of the agent of transformation. The amount of this mechanical water has already been diseussed. (See Chapter III, pp. 124-127.) It varies from a fraction of 1 per cent of the volume in the densest rocks to as high as 50 or more per cent in the more open soils and clays. At the outset of the process of change the mechanically included water is often an abuudant source of the agent of metamorphism; but when the rocks become compacted by pressure, or cemented, or both, this water is largely removed. This is likely to take place in large measure in the zone of katamorphism; consequently, when the rocks reach the zone of anamorphism the amount of mechanical water is usually much reduced. It follows that the originally mechauically mingled water; while probably of importance, can not be depended upon as an adequate supply for recrystallization in the zone of anamorphism. Indeed, it is believed that the water freed by dehydration is the most reliable source of water for recrystallization in the zone of anamorphism. (See pp. 662-663.)

The facts presented on the preceding pages give strong support to the idea that presence of water at the beginning of the process of metamorphism 
is necessary in order that recrystallization shall readily occur. If the massive original rocks at the beginning of the mass movements do not contain water sufficient for recrystallization to take place, it doess not appear that they are likely under normal conditions to gain sufficient water from an outside source. But where intrusives are introduced on an extensive scale, this sonrce of water may make good the deficiency, so that recrystallization may occur. Apparently the amount of water present during recrystallization must be great enough for at least 1 per cent to be left as combined water; for in the deformed igneous rocks containing less than 1 per cent of water gramulation is frequent, and the schists and gneisses formed by recrystallization usually contain between 1 and 2 per cent of water. But doubtless in proportion as rocks are deep seated, so that the

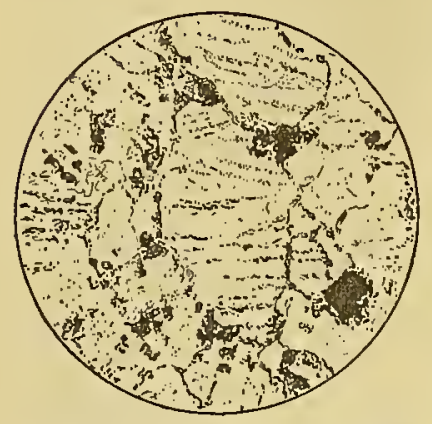

FIG. 19.-Liquid-filled cavities extending across several quartz indiriduals without change of direction. From Black Hills quartz-schist. pressure is great and the temperature high, a decreasing amount of water suffices for recrystallization.

While the minerals of the rocks are steadily dehydrated during the process of recrystallization, not all of the water driven off escapes; a small part of it is caught within the recrystallizing material; and thus are explained the almost infinite number of minute microscopic water inclusions contained in the schists and gneisses. In some instances the water bubbles are arranged along planes of fracture, in which case they appear in the sections as rows of bubbles which frequently extend continuously across many individuals. (See fig. 19.) The arrangement of continuous rows of water bubbles across many minute individuals has been taken as evidence that the minerals are original, whereas it is plain that the correct interpretation is that the bubbles themselves are probably secondary inclnsions, as I have fully explained in another place. ${ }^{a}$

Liquid carbon dioxide is frequently associated with the water inclusions. It is believed that in most cases this material is a portion of the carbon dioxide given off by the decomposition of the carbonates during silication. Another and probably larger portion of the carbon dioxide escapes

a Van Hise, C. R., The pre-Cambrian rocks of the Black Hills: Bull. Geol. Soc. America, vol. 1, 1890, p. 218. 
with the freed water, and is squeezed npward to the belt of cementation. (See pp. 177, 667.)

The foregoing facts seem to show that whether granulation or recrystallization occurs in the zone of anamorphisin in a given district in rocks of a certain chemical composition does not depend npon whether the rocks are igneous or aqueous, but, other things being equal, mpon whether sufficient water is present, by means of which recrystallization can occur. As this is more frequently the condition in the sedimentary rocks than in the igneons rocks, the sedimentary rocks are more frequently recrystallized than the igneons rocks, though in many instances reci'ystallization, rather than granulation, has been the process of modification for the igneons rocks.

The experimental work of Adams and Nicolson ${ }^{a}$ upon the deformation of marble seems to me to be fully confirmatory of the above conclusions as to the influence of water in determining whether grannlation or recrystallization occurs. They deformed marble nnder conditions of the zone of flowage, both dry and wet, at a temperature of about $300^{\circ} \mathrm{C}$. The marble deformed while dry, "if not quite as strong, is at least very nearly as strong as the original rock," as shown by tests of its crushing strength, whereas the marble deformed at the same temperature in the presence of steam at a pressure of 460 pounds per sqnare inch was "not weaker, but actually somewhat stronger than the original rock." ${ }^{\circ}$ While they conclude that "the presence of water was not observed to exert any inflnence," they say: "It is just possible, however, that there may have been a deposition of infinitesimal amounts of calcium carbonate along very minute cracks or fissures, thus contributing to maintain the strength of the rock. No signs of such deposition, however, are visible."

It seems to me that the increased strength of the rock deformed in the presence of steam is positive evidence of the influence of water. When it is remembered that the mineral experimented upon was one which is readily deformed by movement along gliding planes, and therefore one in which for deformation without granulation recrystallization is not necessary, and that the time through which the experiment was

a Adams, F. D., and Nicolson, J. T., An experimental investigation into the flow of marble: Philos. Trans. Royal Soc. London, series A, vol. 195, 1901, pp. 363-401.

$b$ Adams and Nicolson, cit., p. 379.

$c$ Adams and Nicolson, cit., p. 385.

a Adams and Nicolson, cit., p. 399.

$\epsilon$ Adams and Nicolson, cit., p. 385. 
continued was but a minute fraction of the time of the action of water under natural conditions, the experiment seems to me to furnish the strongest possible confirmation of the conclusion already expressed as to the importance of the presence of water during the recrystallization of rocks.

\section{ROCK FLOWAGE.}

\section{MEANING OF ROCK FLOWAGE.}

If the conclusions of the foregoing pages be true, the real meaning of rock flowage, at least as deep as observation extends within the earth, follows as a corollary. It is apparent that the process of rock flowage is very different from the flowage of a liquid or that of a malleable solid, although it involves elements which occur in these processes.

In discussing the subject of rock flowage it will be necessary to repeat the substance of certain things which have already been said. This is necessary in order to bring the different elements which enter into rock flowage into juxtaposition in proper relations to one another. I have previonsly maintained that deformation at considerable depth is accomplished by rock

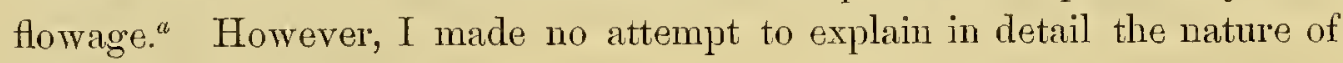
the interior movements.

All of the different processes which have been described are involved in rock flowage. That is to say, the mechanical processes of strain within the elastic limit, gliding, gramulation, and welding, and the chemical processes of cementation and metasomatism resulting in recrystallization, all enter into the result. In the foregoing pages each of these processes has been separately discussed and their relations have been pointed out. Various combinations of the foregoing mechanical and chemical processes explain rock flowage. Commonly in rock flowage the chemical process of recrystallization is dominant; but this, as has been explained (pp. 690-692), is promoted by the simultaneous mechanical strains. But in many eases of rock flowage the evidences of chemical and mechanical processes are about equally marked, and in some instances of considerable importance mechanical processes have been dominant.

I shall first consider the slates, schists, and gneisses, which are typical examples of rocks that have been deformed by rock flowage, and are also

$a$ Van Hise, C. R., Principles of North American pre-Cambrian geology: Sixteenth Ann. Rept. U. S. Geol. Survey, pt. 1, 1896, pp. 593-595, 636-643. 
the class of rocks in which the process has taken place on the most extensive scale. It will be remembered that slates, schists, and gneisses are rocks in which many of the mineral particles show parallel orientation and in which the major portion of the mineral particles now show slight or no strain effect. (Pl. XI, C.) It is evident that these are rocks which have nearly perfectly accommodated themselves to the deformation through which they have passed. The accommodation, as already explained, is accomplished by continuous solution and deposition, or by continuous recrystallization. While the adjustment during deformation at any moment was nearly as complete as though the rock were a magma, and while it may nowhere show even a microscopic opening, it is evident that the flowage is wholly different from that of a liquid. At no time was the rock a liquid; on the contrary, it was at all times almost wholly a erystallized solid. At no time was more than an almost inappreciable fraction of it in liquid form-that is, dissolved in water-yet at all times it was adjusting itself by means of the small percentage of water contained in the capillary and snbcapillary openings, this being the chief agent of deformation working through solntion and deposition, or recrystallization. In order that such a continuous process shall bs adequato to explain rock flowage, it is necessary only that it shall be sufficiently rapid to keep pace with the deformation. Probably one's first thought is that it is not possible that the process can be sufficiently rapid to account for the phenomena. Howerer, the experiments of Barns on the solution of glass give us a basis upon which we can make a quantitative calculation.

- Barus has shown ${ }^{a}$ that a temperature of $185^{\circ} \mathrm{C}$. is critical so far as the solution of glass by water is concerned. At temperatures lower than this the rate of solution by water is very slow. However, at temperatures of $185^{\circ} \mathrm{C}$. and above, solution of the silicates of glass goes on with astonishing rapidity. Barus dissolved, in capillary tubes, a sufficient amount of glass to cause an apparent contraction of volume of the water amounting to 13 per cent of the water present in 42 minutes, and 18 per cent in an hour.

This illustrates the fact that the activity of water at a very moderate temperature is amazing and one need not be surprised at its potency in the alteration of rocks deep below the surface of the earth. Temperatures higher than $185^{\circ} \mathrm{C}$. exist at moderate depth, and therefore it is reasonable

$a$ Barus, C., The compressibility of liquids: Bull. U. S. Geol. Survey No. 92, 1892, pp. 78-84. 
to suppose that a small amonnt of water may be the medium of rapid and most profound modification of the rocks.

We have already seen (pp. 690-691) that during the process of deformation the material, if not dissolved, may be strained even to the point of granulation by the mechanical processes; also it has been seen that, so far as strain occurs, or the particles are small, the minerals are in a state in which solution is easier than for unstrained or larger mineral particles. But it is probable that the solution of mineral particles and the deposition of the material in an unstrained crystallized condition is considerably slower than the solution of amorphons glass; for, among other reasons, it can not be supposed that the same amount of energy is potentialized in the mineral particles as in the glass. But the further the strain goes before fracture the more energy is potentialized, or if fractures occur smaller particles are produced. Moreover, the contained water is in suall capillary or subcapillary spaces, and therefore a given volume is acting upon a much larger surface than in the capillary tubes used by Barris in his experiments. In so far as granulation occurs, the surface of action is still further increased. All these conditions are favorable to solution and redeposition; therefore, the greater the straining and resultant granulation, the more rapid the process of recrystallization; hence, in the deep-seated zone, when water is present in sufficient amount, mechanical disintegration never gets far in advance of solution and redeposition. (See pp. 696-698.)

At temperatures above $185^{\circ} \mathrm{C}$., if it be supposed that in the capillary and subcapillary spaces within the rocks the speed of solution, of minerals is 0.1 of that of glass, as ascertained by Barus, water would dissolve its own volume of minerals in about five hours. If the deep-seated rocks be supposed to contain 2 per cent of water by volume-that is, less than 1 per cent by weight-the entire mass of rocks might be dissolved in abont 250 bours, or little more than ten days, provided deposition went on at the same rate as solution. The percentage of water premised is known to be lower than the amount ordinarily found in the recrystallized schists and gueisses (see pp. 742-743), and the rate suggested seems reasonable; but if the speed of solution and deposition be decreased to 0.1 of that suggested, or to 0.01 of that of the solution of glass, still the entire mass of the rock might be dissolved and redeposited in about 100 days. Make the rate 0.1 of this, or 0.001 of that of the solution of glass, and still recrystal- 
lization might be complete in about 1,000 days, or three years. If it be supposed that a mountain-making period occupied 150,000 years-and this is probably less rather than more than the time required for most mountainmaking movements-during this period at the slow rate suggested the rocks could be recrystallized 50,000 times by 1 per cent of water, and this number certainly seems adequate to fulfill the requirement that at any given moment the rock shall exhibit but a slight strain effect.

Of course it is not thought probable that any rock has completely recrystallized 50,000 times. Indeed, it is well known that many of the rocks in which recrystallization is complete, in so far as the finer particles are concerned, contain many larger particles which have not been completely recrystallized. Perhaps one of the best instances of this is furnished by the schist-conglomerates. The typical schist-conglomerates contain a schist matrix, embedded in which are numerous large fragments. In many of these the matrix is completely recrystallizer, but the fragments, unlike the matrix, show important strains, which not infrequently pass to the point of partial granulation with partial recrystallization. To explain the phenomena exhibited by the perfect schists which hrvo dereloped during a continuous process of deformation it does not seem necessary to suppose that complete recrystallization is necessary. If the case of a large grain of quartz or feldspar in a recrystallizing rock be taken, we may suppose the process to go on somewhat as follows: Because of the lack of homogeneity of the rock the stresses are irregularly distributed. At the most exposed places upon the mineral particles the conditions are favorable for solution, for the following reasons: The particles are there greatly strained, perhaps to the point of granulation; and, so far' as strain exists, or small granules are formed, these conditions are favorable to solution. At the places of great strain the material is therefore taken into solution and transported to the parts of the particles less strained or to other particles. At such places the conditions are favorable to deposition, on account of the relatively large size of the residual original grains as compared with the granules. (See pp. 74-76.) The mineral particles, where least strained, separate from the solution materials like themselves and attach them in orientation with the cores in an unstrained or little strained condition. The process of growth is analogous to that of mineral growth by secondary enlargement. The entire process is similar in several respects to that of 
tho continuous solution and deposition of calcium carbonate in the chemical laboratory when water is passed through a layer of this material under pressure. Where the pressure is greatest, in the upper part, the grains are taken into solution; at the place of escape, where the pressure is least, the material is deposited from solution and the grains increase in size, or grow.

During the deformation of the rocks this process of solution and deposition of the mineral particles is continuous.

If it be supposed to go on to a stage in which an original particle is one-half or one-third as thick as it was originally, it is not necessary to suppose that the central part of the mineral particle has been recrystallized. This is illustrated by fig. 20. A spherical grain is supposed to have changed to the superimposed spheroidal grain. The

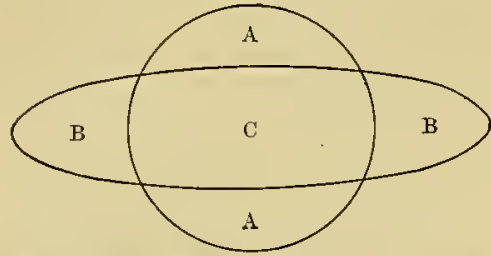

Fre. 20.-The possible relation of old and net grains of recrystallized rocks. common portion $\mathrm{C}$, or a large portion of it, may be an uncrystallized part of the old grain, but the material AA has been dissolved and added to the borders at $\mathrm{BB}$. Corresponding to this explanation, some of the flat quartz grains of the slates and schists of the Black Hills of Dakota show residual cores. ${ }^{\text {t }}$

Since in most cases the stresses are unequal in three dimensions, there is a direction of greatest pressure; at right angles to this is a direction of mean pressure; and at right angles to these two, a direction of least pressure. During the process of recrystallization, at any given moment there is maximum shortening in the direction of greatest stress, maximum elongation in the direction of least stress, and shortening or elongation in the direction of mean stress. Consequently the shape of the modified particle may be that which would be produced if a plastic grain were rolled out, the sides being confined in one direction, but with liberty to elongate in another direction in the same plane; or it may be that which would be produced if a roundish cake of dough were flattened between two boards, and consequently elongated in all directions at right angles to the direction of greatest pressure; or, finally, the mean stress may approach so closely to the maximum stress that there is shortening in two directions and elongation in a single one only, in which case a fibrous structure is produced. But from my

"Van Hise, C. R., The pre-Cambrian rocks of the Black Hills: Bull. Geol. Soc. America, rol. 1, 1890, p. 224. 
study of the slates, schists, and gneisses I am inclined to believe that shortening in one direction and unequal elongation in the direction at right angles to this is the most common case, though my thin sections give illustrations of all the cases. The particles are arranged with their greater, mean, and minor diameters corresponding to least, mean, and greatest pressures. In proportion as the movement involves shearing motion or scission," the mineral particles are rotated from a position in which the direction of greatest elongation is at right angles to the direction of greatest pressure, although at any given time the mineral particles tend to develop with their longer axes at right angles to the inaximum pressure.

In some cases the direction of greatest pressure varies within exceedingly short distances. This is illustrated by large rigid particles, such as feldspar, gamet, and other refractory minerals, which act as transmitters of pressure to more than an average extent. Adjacent to the rigid mineral particles the direction of greatest pressure is modified from point to point, thus deviating from the average for the rock. New minerals forming may curve about the rigid granules. This is beautifully illustrated by the flat, curved quartzes adjacent to feldspar in the quartzporphyry described by Futterer. (Pl. III, $B$; see p. 738.) In this case the flat individuals lack orientation and show undulatory extinction independently of subsequent strain.

The above process of flattening by recrystallization is general; and therefore we conclude that while recrystallization is constantly occuring in the deformation of rocks, at any given time a large number of the mineral particles retain their integrity, and are nuclei which at any moment orient the material being deposited. In many rocks evidence may be seen that this has happened. The old mineral particles, represented by the cores, are partly altered, and in consequence of this may be discriminated from the freshly added material; or the cores show a border of iron oxide or other mineral; or the old and new materials have slightly different compositions, and this may be discovered by a difference in the color, refraction, or extinction, or in some other way. Finally, all of the old mineral particles may be regenerated or recrystallized.

a Becker, G. F., Finite homogeneous strain, flow, and rupture of rocks: Bull. Geol. Soc. America, vol. 4,1893 , pp. 24-25.

MON XLVII $-04-48$ 
Therefore a given portion of a definite mineral particle in a slate, schist, or gneiss may not have been recrystallized at all, or, on the other hand, may have recrystallized several or many times. It is believed that ordinarily the recrystallization is far advanced or complete for all parts of a typical schist, although this is far from the case in the semicrystalline schists or imperfectly schistoso rocks. Where deformation is mainly accomplished by recrystallization the process may be called recrystallization flowage or chemical flowage.

Of course, during this rearrangement it is not supposed that the identical molecules which are taken from the more severely stressed parts of a grain are necessarily deposited at the places of less stress upon the same grain. Undoubtedly there is great interchange of material between the particles by means of the solutions. It is, however, thought probable that in many cases of deep-seated deformation, where the passage of solutions is difficult and slow, much of the identical material which is taken from a grain at one place is added to it at another place.

When new individuals are produced in any way, as by granulation, or by deposition as new mineral particles, perhaps as different species from any originally in the rock, they are subject to the same laws as the original mineral particles. Many have a tendency to form with dimensional orientation, which usually carries with it similar crystallographic orientation. However, it is only rarely that the orientation of the particles of a given mineral approximates exactness. One mineral-for instance, mica-may be well oriented, whereas such minerals as quartz or calcite may not be oriented.

In proportion as the minerals readily respond to the forces of recrystallization, or are mobile, they do not gain or retain a regular arrangement. After mass movement has ceased the temperature may be high enough and the heat be held long enough for the solutions to completely recrystallize the minerals under mass-static conditions, and therefore orientation may be lost. In proportion as minerals do not readily recrystallize or stubbornly resist the force of recrystallization, the minerals once oriented retain their regularity of arrangement.

The most mobile of the important minerals is calcite. As explained by Adams and Nicolson, ${ }^{a}$ the mobility of this mineral is doubtless partly

a Adams, F. D., and Nicolson, J. T., An experimental investigation into the flow of marble: Philos. Trans. Royal Soc. London, series A, vol. 195, 1901, pp. 363-401. 
due to movement along gliding planes. Quartz is also somewhat mobile. Therefore these minerals in marble and in recrystallized quartzite frequently lack regularity of arrangement. However, in some cases even calcite may show well-developed dimensional and to some extent similar erystallographic orientatiou. The usual almost complete lack of regular arrangement for calcite is illustrated by most of the marbles from the Laurentian Mountains to Alabama. The complete recrystallization of quartz to a coarse granolitic-textured rock, the individuals wholly lacking orientation, is illustrated by the quartzites of the Wausau district of central Wisconsin.

In the process of recrystallization of rocks it is not supposed that every large mineral particle retains a nucleus for lateral growth; indeed, it is certain that in a rock some large particles of a mineral may retain the modified integrity above described, while other particles of the mineral may be wholly destroyed. It is believed that orientation of the mineral particles in reference to the varying stresses has an influence upon their preservation. If the original particles happen to be in such positions that they would develop as authigenic minerals under the differential stresses, this is thought to be favorable to the preservation of their nuclei and to growth. It is believed that in proportion as the particles vary from such positions the mineral particles are likely to be destroyed. The effect of position with reference to the principal stresses upon the persistence of a given particle is probably great in proportion as the mineral has a tendency to be influenced in its dimensional arrangement and crystallographic orientation by the stress differences which exist during deformation. To ilhustrate: The position of the axes in reference to the greatest pressure in mica, which shows a marked tendency to parallel arrangement, would be a more important factor in its preservation than in quartz, which only rarely shows regular arrangement. ${ }^{a}$

In the foregoing nonrotational distortion has been assumer. In case the deformation includes a rotational element, during the recrystallization each of the particles would be similarly rotated, as well as flattened or recrystallized, or both; and consequently the direction of the maximum compression, and therefore the nost favorable direction of elongation of the mineral particles, would change in reference to them. At any stage

aVan Hise, C. R., Principles of North American pre-Cambrian geology: Sixteeuth Ann. Repht. U. S. Geol. Survey, pt. 1, 1896, p. 635 . 
of the process there would be a tendency to retard the growth of the mineral particles which had formed at an earlier stage. Another effect of rotation would be to decrease the regularity of the similar arrangement of the mineral particles as compared with those produced during nonrotational distortion; for at any stage the new mineral particles would form in positions somewhat different from those of the particles formed at an earlier stage. I suspect that in rotation with reference to the forces during development lies the principal cause of imperfect arrangement of the cleavagemaking mineral particles of the slates, schists, and gneisses. This point is more fully developed by Leitl. ${ }^{a}$

While in the slates, schists, and gmeisses many mineral particles are able to maintain themselves, a vastly greater number are probably destroyed by the process of recrystallization. This is certainly true in those very numerons instances in which the average size of the mineral particles of the metamorphosed rocks is much greater than the average size of the particles in the unaltered rocks. It has been pointed out (pp. 674-675) that in many instances hundreds or thousands or even a million or more of particles may be required to produce a single individual. From such cases there are all gradations to those where the particles of the recrystallized rocks are not larger than those of the unaltered rocks, and through these to those in which the particles of the recrystallized rocks are smaller than those of the unaltered rocks. In proportion as the particles of the original rocks are large, an increasing proportion of them, or of parts of many of them, is likely to be preserved in the recrystallized rock. In proportion as the particles of the unaltered rock are small, a decreasing proportion of them is likely to be preserved in the recrystallized rock, although in the latter case the absolute number of mineral particles preserved and enlarged may be as great as or greater than in the former case.

On pages 751-753 the modifications of the forms of the original particles have been considered. Substantially the same principles apply to newly formed mineral particles. With or without a nucleus, a mineral particle begins to grow. Because of the differential stresses the molecules which first segregate to form minerals that have strong crystal habit orient themselves in such positions that their shortest axes are in the direction of maximum pressure, their longest axes are in the direction of minimum pressure, 
and their mean axes are in the direction of mean pressure. When once the mineral particles have oriented themselves in this way, they continue to grow according to their crystal labits, the most rapid growths being in the direction of greatest pressure. This dimensional arrangement controlling the orientation of mineral particles forming in rocks during conditions of unequal stresses has been formulated by Leith as a result of his detailed

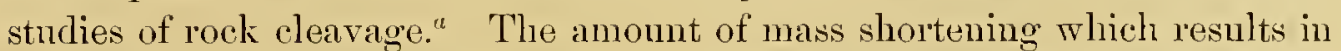
the regular arrangement may be comparatively slight, and yet the differences in the dimensions of the mineral particles be great. For instance, Leith's measurements show that the common ratio between the least and greatest diameters of the mica flakes of mica-schists is, on the average, about $1: 10^{b}$ It does not follow, as has been thought by some, that this involves the shortening of the rock mass by 0.9 . Indeed, it is perfectly conceivable that the rock mass may be but slightly shortened, perhaps by 0.1 , and yet produce mineral particles the shortest dimensions of which are only 0.1 as great as their longest dimensions. During recrystallization of a rock the material of those minerals which have strong crystal habit rapidly attaches itself to the borders of the particles and but slowly to the sides.

The above conchusion seems to be completely confirmed by the constancy of the ratios between the greatest and least diameters for a given mineral. Leith has ascertained that in mica the ratio varies from 100:65 in the case of biotite to $100: 10 \mathrm{in}$ muscovite, with an average of $100: 20$ for biotite and 100:14 for muscovite; in horublende from 100:40 to $100: 25$; in feldspar from $100: 75$ to $100: 50 .^{\circ}$ In the case of each mineral these ratios are practically the same whether the rock be a slate, a finegrained schist, or a coarse-grained gneiss. The full range of variation in the ratios of a mineral can be found in the same rock in each of the different stages of metamorphism. If the ratios between the least and greatest diameters of the mineral particles were taken as evidence of the amount of shortening of a rock, we should reach a different conclusion for each mineral and the same conclusion for all stages of metamorphism. Such a conchusion is absurd, and the independence of the dimensional ratios of the orienting minerals aud the amount of rock shortening is perfectly established. Therefore, so far as new mineral particles are produced with similar 
dimensional arangement, these give no basis to estimate the amount of shortening of the rock.

The case of flattened original fragments is very different. In so far as the resultant material or flattened orules can be iclentified with original forms, as, for instance, where conglomerate pebhles and fossils are deformed, these distorted objects give a means of determining the amount of the mass shortening.

In proportion as the conditions are unfavorable for recrystallizationthat is, as mineral particles are refractory, as they are coarse grained, as the deformation is rapid, as the depth is small, as the temperature is low, as the water content is small-granulation occurs instead of recrystallization. This is sufficiently evident, without amplification, from the discussion already given. (See pp. 737-748.)

In the imperfect slates, schists, and gneisses, which are widespread rocks, adjustment during deformation is accomplished in part by the process of recrystallization just described, but also in part by the mechanical processes. Of these, granulation with differential movement of the gramules and welding of the granules is of first importance. Strain within the elastic limit is of very considerable moment. The deformation of the mineral particles by movement along gliding planes may be of occasional importance, especially in certain classes of rocks, such as marbles.

The cataclastic rocks do not usually show slaty or schistose structures. In these rocks the process of flowage is mainly mechanical. It is chiefly accomplished by the multitudinous fracturing of the solid particles, by differential movements between the minute particles, and by the welding of the differentially moved hodies. With this process as a main one, there is sure to be marked strain within the elastic linit in all the particles, both original and secondary; and thus this is a rather important factor in the process. Finally, gliding is more important than in the case of recrystallization-flowage. But it may perhaps be doubted whether even in the typical gramulated rocks the process of flowage is wholly mechanical. In all rocks there is a small amount of water present, and even in the instances of apparently perfect granulation probably solution and deposition, or recrystallization, has taken place to some extent. Where deformation in the zone of anamorphism is mainly accomplished by granulation and differential movement of the particles, the process may be called gramulation-flowage, or mechanical flowage. 
The illustrations of the perfect schists produced mainly by recrystallization, and of the imperfect schists produced by recrystallization and mechanical strains combined, are so well known that they need not be mentioned. The best illustration known to me of flowage mainly by granulation is afforded by the anorthosites of the Original Laurentian, described by Adams. ${ }^{a}$

So far as the mass deformation is concerned, the rock flowage may be mainly by recrystallization, mainly by gramulation and other mechanical processes, or by any combination of them. In all alike there is minute interior adjustment of the particles so as to change the mass form of the rock. It makes no difference, so far as the resultant form is concerned, whether the elrange is accomplished mainly by the differential movements of the molecules, as in the recrystallized schists, or by the differential movements of granules, as in the cataclastic rocks, or by the tro combineed.

CONCLUSION.

Rock flow is mainly accomplished through continuous solution and deposition-that is, by recrystallization of the rocks through the agency of the contained water. The recrystallization is largely induced by mechanical strains. Rock flow is partly accomplished by direct mechanical strains. At the beginning of the process of flow, during the process, and at the end of the process, the rocks, with the exception of an inappreciable amount, are crystallized solids. At any moment only an infinitesimal quantity is fluid-that contained in the minute quantity of water present. Yet the solids respond to deformation like plastic bodies, not only not losing erystalline character, but usually acquiring mineral particles of fair magnitude, becanse the water is ever changing the position of the crystallized material, dissolving a substance here and depositing it there. By this process, combined with the mechanical strains, there is continuons adjustment or adaptation of the mineral particles to their environment, as demanded by the deformation of the rock.

This is rock flow. In this conclusion nothing is said as to the condition of material below that part of the earth which is called the lithosphere, nor as to the meaning of flow in this part of the globe-i. e., the centrosphere.

addams, F. D., Report on the geology of a portion of the Laurentian area lying to the north of the Island of Montreal: Ann. Rept. Geol. Surv. Canada, new ser., vol. 8, 1895, pt. J, pp. $103-131$. 


\section{MEANING OF ROCK CLEAVAGE.}

The conclusions of the foregoing pages show clearly the meaning of rock cleavage. I have already held that this structure is largely accordant with the cleavage planes of minerals the particles of which have crystallographic orientations; that these particles are mainly authigenic, and therefore that rock cleavage is a capacity to part largely due to the actual cleavage of similarly oriented mineral particles. ${ }^{a}$ As the cleavage of mineral particles has long been known to be a molecular structure, it follows that the cleavage of rocks is also largely a molecular structure. I have also explained that the similar crystallographic orientation is frequently, indeed usually, accompanied by an arrangement of the mineral particles with their longer diameters in the same plane as the cleavage, aud that this dimensional arrangement is a factor in rock cleavage, althongh less important in most cases than that of the crystallographic orientation of the mineral particles. ${ }^{b} \quad$ Leith has shown that the dimensional arrangement dependent upon mineral habit is the factor which controls the similar crystallographic arrangenent.

Where similar dimensional and crystallographic orientation prevails with a number of the important cleavable minerals, and a similar dimensional arrangement without crystallographic orientation prevails with other important minerals, cleavage is perfect. The ruptures take place by taking advantage of the cleavage of the mineral particles or by partings between their longer dimensions, and both these factors give easier rupturing than transverse to the cleavage. Since rock cleavage is fully discussed by Leitl in the publication referred to above, no detailed discussion is here made, but it is mentioned in order to put this part of the subject in proper relation to rock flowage.

EFFECT OF ROCK FLOW ON TEXTURES AND STRUCTURES.

As soon as rock flowage, combining mass and molecular movements, is inaugurated, the interior movements begin the destruction of the original textures and structures. With comparatively little flowage the original

$a$ Van Hise, C. R., Principles of North American pre-Cambrian geology: Sixteenth Ann. Rept. U. S. Geol. Survey, pt. 1, 1896, pp. $633,635$.

$b$ Van Hise, cit., p. 635.

c Leith, C. K., Rock cleavage. 
textures of some rocks may be wholly destroyed. For instance, such rocks as quartzose sandstones, composed dominantly of a single mineral, which retain their structures for indefinite periods if there be no marked deformation even when buried under a thousand or more meters of other rocks, when deformed in the zone of anamorphism, rapidly lose all clastic textures. In place of the original textures, whether those of sedimentary or those of igneous rocks, in consequence of flowage there appear the peculiar textures of the slaty, sclistose, gneissose, and cataclastic rocks.

But while there is a marked tendency to obscure and finally to obliterate textures and structures by flowage, the extent to which this goes is very variable. The larger the texture or structure the less likely it is to be destroyed. Since structures involve larger masses than textures, the former may not be much obscured at a stage when the textures are wholly gone.

During rock flowage, even if there be perfect granulation or recrystallization, or some combination of the two, the resultant rock may preserve the larger textural and structural mits of the original rock. This is more likely to be true of granulation than of recrystallization. In rocks composed of a number of minerals, even where granulation is complete, the aggregate of mineral particles resulting from each original mineral particle is commonly preserved as an elongated or flattened disk, the different granules not being mingled to any considerable extent with those of the granules of the associated minerals. For instance, the many granules from a large feldspar grain of anorthosite may constitute an oval area little or not at all mingled with the granules of the adjacent pyroxene. Again, the innumerable granules of a flattened pebble of a conglomerate may be sharply separated from the granules of the adjacent matrix, so that the pebble is easily discriminated.

In proportion as recrystallization takes place the textures are likely to become more rapidly obscured. The solutions transport material for short distances from one mineral particle to another, and thus the products become intermingled. For instance, adjacent feldspar and pyroxene may produce reaction minerals different from each. But even where recrystallization occurs the process must go to an extreme before the flattened pebbles of a coarse conglomerate are wholly lost. Even when the matrix is a coarse schist or gneiss the flattened clisks of the pebbles are often 
recognizable in a section transverse to the greatest elongation. But where the metamorphism is extreme the pebbles may be so greatly flattened as to allow the solutions to mingle the materials of the pebbles and matrix, and thus the pebbles be wholly lost.

But even with most extreme metamorphism by recrystallization the larger structures are usually preserved, although the process may occasionally go so far as to make the strata or even the beds indistinguishable; but it rarely, if ever, goes so far as to obliterate formations. Excluding igneous action, interstratified sedimentary formations of, for instance, sand, mud, and limestone, have rarely been so profoundly metamorphosed as to make them indistinguishable. The composition of a formation is the most prominent feature by means of which the original nature of a rock can be recognized. Where there are metamorphic formations having the approximate chemical compositions of sands, muds, and limestones, we may be sure that such formations are sedimentary. Rock flowage may wholly obliterate the clastic textures, and even the bedded structures; but there is not sufficient kneading and intermingling of the materials to obliterate major structures. That this should be so is precisely what we would expect when we understand that rock flowage is accomplished not by recrystallization from fusion, but by recrystallization and by granulation of the individual mineral particles, the rocks remaining solids throughout the transformations.

ROCK FLOWAGE AND MASHING.

In another place 1 have proposed the term "mashing" to describe the process of mass deformation in the zone of rock flow." It has been seen that rock flow involves the universal participation of the mineral particles. The preceding study shows that this participation may be by recrystallization or by granulation, or by the two combined; but in the field, where microscopical work is not usual, it is difficult or impracticable in many cases to discriminate between these two processes. Therefore it is very convenient to have a word which will cover deformation by rock flowage without reference to the detailed effects upon the mineral particles, and for this purpose it has seemed to me, that the word "mashing" expresses

a Van Hise, C. R., Principles of Torth American pre-Cambrian Geology: Sixteenth Ann. Rept. U. S. Geol. Survey, pt. 1, 1896, pp. 69t-696. 
better than any other the macroscopical point of view of the zone of flow. Without further exposition, which would involve repetition, I propose the term "mashing" to cover mass deformations of all kinds in the zone of rock flow

The term "mashing," thus used, includes much of the process which has usually been described under the terms "dýnamic metamorphism" and "shearing:" The term "dynamic metamorphism" is objectionable for many reasons; it will here simply be said that fracturing in the belt of cementation is equally dynamic metamorphism; but the effects in the two zones of flowage and fracture contrast so sharply that they should not be confused. The term "shearing" has been used in a very loose and most objectionable manner. Most authors who have used it mean differential movement along a certain set of parallel planes, but apparently most geologists who have thus used the term do not recognize that shearing parallel to one plane is invariably accompanied by shearing in other planes. Nor is it generally understood that when rocks are compressed by shortening without rotation this is possible only by shearing along all sets of diagonal intersecting planes. In short, in all cases which have been described as shearing and as shortening there is maximum shearing along two sets of intersecting planes and maximm shortening and elongation in the two directions half way between the two sets of shearing planes. Further, as the term "shearing" is ordinarily used, it seems to be assumed that there results a structure parallel to the one set of shearing planes, whereas this may or may not be true. " Therefore, to aroid errors implied by the terms "dynamic metanorphism" and "shearing," the term "mashing" is introduced, and from this term the implications which attach to the others have been excluded.

In this connection it should be noted that mashed rocks and their constituent portions, such as pebbles and minerals, are frequently spoken of as stretched. For the most part, this term can not be applied to rocks in the same manner that it is applied to india rubber or steel. In general, the facts upon which the statements as to stretching are made are simply that the rocks show evidence of being longer in a certain direction than they were originally. However, it does not follow from this that the rocks

a Hoskins, L. M., Flow and iracture of rocks as related to structure; appendix to Van Hise, C. R., Principles of North American pre-Cambrian geology: Sixteenth Ann. Rept. I. S. Geol. Survey, pt. 1, 1896, Pp. 860-866. 
have been stretched. Most rocks and minerals when stretched quickly pass their elastic limit, rupture takes place, and the dissevered parts are drawn away from each other, often witlont deformation of the separated masses. The elongations of rocks and portions of rocks are in most cases explained not by pulling or stretching, but by compression or mashing in a direction transverse to that of the elongation, but this process does produce tensile stresses, which often disserer the mineral particles. But the use of the word "stretching" in reference to such rocks implies that tensile stress is the dominant force. The term "stretching" should be dropped, except in those instances where it is shown that tensile stress has been the primary canse of deformation.

\section{CHANGES IN CHEMICAL COMPOSITION.}

If injection be excluded, changes in the chemical composition of the rocks during metamorphism in the zone of anamorphism are not nearly so great as they are in the zone of katamorphism. It has been explained that in the latter zone, both in the belt of weathering (see Chapter-VI, pp. 507-518) and in the belt of cementation (see Chapter VII, pp. 655-656), the chemical composition of the rocks may be very-greatly modified. Indeed, the changes of chemical composition are most profound in the belt of weathering, and are very important in the belt of cementation. The great changes in these belts are dne to rapid and continuous circulation of water, by means of which large quantities of material are transported from one place to another. It has been explained that in the zone of anamorphism the amount of water present is very small and its circulation exceedingly slow. It follows that the water is not capable of transporting large quantities of material considerable distances and thus making great changes in the chemical composition of the rocks through extensive areas. In this we have the explanation of the relative constancy of the chemical composition of the equivalent unmetamorphosed and metamorphosed rocks of the zone of anamorphism. While chemical changes do not greatly modify the average composition of masses of rocks, it has been explained (pp. 682-685) that there is important migration of material for short distances, and therefore profound interior readjustment of the elements in different mineral combinations.

Excluding injection, the chief chemical changes applying to the rock masses as wholes are those of deliydration and decarbonation. Deoxidation 
also occurs. The water and carbon dioxide eliminated from the chemical combinations are largely squeezed out of the zone of anamorphism (see pp. 665-667), but a subordinate amount may remain as inclusions in the minerals developed. (See pp. 667-678.) The absolute losses of these compounds is considerable. The loss of liydrogen, oxygen, and carbon dioxide increases somewhat the percentage of the other elements, but does not affect their relative proportions. Excluding hydrogen, the relative proportions of the bases are substantially the same before and after alteration. The replacement of carbon dioxide by silica reduces the amount of carbonates, increases the quantity of silicates, and lessens the amount of free quartz; but the absolute quantity of silica remains the same. In discriminating the metamorphosed sedimentary from the metamorphosed igneous rocks, it will be shown on pages 914-915 that in many cases the proportions of the important chemical elements furnish the best criteria for separating the two classes of rocks.

While in the absence of intrusives there is small change in chemical composition of the rocks in the zone of anamorphism, there may be great changes in the chemical composition where injection is an important factor in the metamorphism (see pp. 711-720), for by injection material different in chemical composition from the injected rock may be intruded in various amounts and in various degrees of division for extensive areas. (See pp. 708-711.) The chranges in chenical composition of the rocks where injection is important may be as great as or greater than in the belt of cementation.

The difference in the amount of chemical changes in the rocks in the belt of cementation and in the zone of anamorphism under ordinary conditions, and the difference in the amount of change in the latter zone where injection is absent and where it is present, explain some of the differences of opinion which are prevalent among geologists. One geologist says that metamorphism does not alter the composition of the rocks; another says that metamorphism greatly alters the chemical compositions of the rocks. Each has a part of the truth. Probably the facts with which each is familiar verify his point of view, but each makes a mistake in supposing that a narrow set of facts covers the entire field. The truth of the matter is, as explained, that there are profound changes in the chemical composition of the rocks in the belt of weathering, great changes in the belt of cementation, and considerable changes where intrusion is important in the zone 
of anamorphism. But the alterations in the zone of anamorphism where intrusives are absent do not result in great changes in the chemical composition.

RELATIONS OF ZONE OF ANAMORPHISM TO ZONE OF KATAMORPHISM.

It has already been intimated that the zones of anamorphism and katamorphism are not sharply separated, and that there is a gradational belt between them. This gradational belt follows of necessity from the varying character of the rocks and from the varying forces and agents at work. One rock is of a chemical and mineral composition which readily alters; another is of a composition which alters with difficulty. One rock is weak; another is strong. At one place the conditions are mass-static, or those of quiescence; at another they are mass-dynamic, or those of movement. In one place igneous rocks may be absent; in another, abundant. In one place the temperature at a given depth may be low; at another, relatively high. The amount of water has the widest range. Hence it is inevitable that there should be no sharp bounding plane, between the zones of katamorphism and anamorphism.

The weak or readily alterable rock may be changerl by the reactions of the zone of anamorphism, while a stronger and more refractory rock below may be altered by the reactions of the zone of katamorphism. Horeover, the same rock in the same position, becanse of varying conditions, may be altered by the reactions of the zone of katamorphism and at a different time by those of the zone of anamorphism. It follows that there is a belt of considerable width in which we may have at one time, under one set of conditions, the reactions of hydration, carbonation, and oxidation, with expansion of volume; and at another time, under another set of conditions, the reactions of dehydration, silication, and deoxidation, with diminution of volume. Neither oxidation nor deoxidation is prominent in the intermediate belt.

We therefore have in an intermediate belt the metamorphic results of the belt of cementation, or those of the zone of anamorphism, or various combinations of the two. In one place we may find the metamorphic effects of the belt of cementation superimposed upon those of the zone of anamorphisin; in another we may find those of the zone of anamorphism superimposed upon those of the belt of cementation.

In order to understand more fully the phenomena in this transition 
belt, we may consider the metamorphism of an imaginary rock of homogeneous character; composed of a single mineral which extends from the surface to an indefinite depth. Near the surface the rock is broken into blocks by faults and joints. There is no marked deformation of the individual particles, except in thin layers along the fractures. The textures of the rocks are for the most part preserved. Deeper down the fractures are closer together, and at sufficient depth the layers may be no thicker than leaves. Still deeper down every particle takes part in the deformation. This is the belt in which granulation is prominent, although with it there may be some recrystallization. Still deeper down recrystallization becomes important, and finally dominant. In the intermediate belt fracture and flowage do not exclude each other; both oceur to varying extent in different positions at the same time.

The transition above described for a single fornation composed of a single mineral takes place at different depths for different formations and for different minerals of the same formation, and hence it is that in heterogeneous formations all the phenomena discussed under both the zone of katamorphism and the zone of anamorphism may ocen together.

At a given depth the stronger or less readily recrystallized rocks may be largely deformed by fracture, and the weaker or more readily recrystallized rocks be largely deformed by flowage. The result is that original textures and structures may be more or less preserved in the former, while in the adjacent layers original textures and structures may be entirely destroyed and the rocks become slates or schists. It very often happens that the alternating beds which show original textures and structures and those in which they are obliterated are not more than a few inches thick.

In the intermediate belt many of the beds are deformed by combined mass fractures and fractures of the individual mineral particles, so that in the same rock in which joints, faults, fissility, etc., and the alterations attending these phenomena oceur, there are also found, between the major fractures, all grades of deformation by interior movement, from the earliest stages of peripheral granulation of the grains to complete granulation or recrystallization, extending throughout the mineral particles. Thus we have all combinations of macroseopic and microscopic fractures and recrystallization.

In some places the intermediate belt is broad; in other places it is narrow. The phenomena of the belt may be seen in aqueous and igneous rocks alike. Many illustrations of each might be given. 
As typical cases of sedimentary formations altered in tha intermediate belt may be mentioned the IVewe and Siamo slates of the Lower Marquette series, the Goodrich quartzite, and the eastern half of the Michigamme formation of the Upper Marquette series, all in the Marquette district of Michigan. ${ }^{a}$ Within these formations almost every one of the multifarious reactions described, both within the zone of katamorphism and within the zone of anamorphism, are beautifully illustrated. Indeed, it was a study of these formations which first suggested to me the idea of a combination of the phenomena of different alterations near the surface and at depth, and the very great difference in the alterations which often occur at the same depth inder mass-static conditions and under mass-dynamic conditious.

In Calaveras Creek, a short distance below Calaveras Talley, south of San Francisco, in the Coast Ranges of California, may be seen all stages of transition between a brecciated igneous rock and a schist. The first was deformed under the conditions of spaced fractures. The second was deformed by granulation and recrystallization. In passing from the breccia to the schist one first finds about the blocks of igmeous rock which have their characteristic textures mere films of schist. Farther toward the schist is found an intermediate stage in which unmashed blocks lie in a schistose background or matrix. But a short distance from this place is the completely altered schist, in which no ummashed fragments remain. Every stage of the transition is seen. The alterations within the blocks are those of the zone of katamorphism. (See pp. 160-167, 187-191, 599-6()气.) Withiu the films and larers of schists constituting the matrix in which the blocks rest and in the main mass of schist the alterations are those of the zone of anamorphism. (See pp. 167-170, 187-191, 657-659.)

These cases of the combination of the phenomena of metamorphism of the zone of katamorphism and those of the zone of anamorphism are but typical of almost innumerable illustrations. The phenomena in any one case are very complex and intricate. Detailed consideration of any single instance wonld require much space, and it is yet too early to attempt to classify the different cases of various combinations of the alterations of the zones of anamorphism and katamorphism.

a Yan Hise, C. R., and Bayley, W. S., The Marquette iron-bearing district of Michigan: Mnn. U.S. (Geol. Survey, vol. 28, 1S97, pp. 1-608. 


\section{COMPARATIVE ENERGT REQUIRED FOR DEFORMATION IN ZONES OF KATAMORPFISM AND ANAMORPHISM.}

The question of the amount of energy required to produce deformation in the zone of katamorphism, in the intermediate zone, and in the deepseated zone of anarnorphism is of great importance.

The energy for rock deformation may be divided into two partsenergy for mechanical work and energy for chemical work. The mechanical work is of three kinds-the subdivision of the rocks, the transfer of the material in order to produce a changed form, and the friction between the parts of the subdivided rocks during the trausfer.

The most useful comparison as to the amount of energy spent in the different zones is upon the hasis of average mass deformation. By arerage mass deformations I mean the strains necessary to change the shape of unit masses of rock in a nearly similar way, so that the exterior forms are practically the same. To illustrate: A cubic foot of rock may be supposed to be divided into ten horizontal slices and sheared parallel to these slices, so as to produce, ignoring the minor corners, a roughly rhomboidal mass (fig.

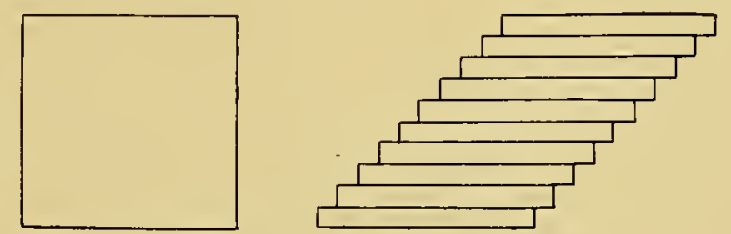

FIG. 21.-Illustrating mass deformation of a rock. 21). If instead of ten there were a hundred slices, the approximation to a rhomboidal mass would be closer; if a thousand, closer still; and so on, until the slices became of infinitesinal thickness, when the mass would be rhomboidal. In all of these strains the mass deformation averages about the same.

It is perfectly clear in the case of this hypothetical deformation that the amount of work in rupturing is directly as the number of slices. The arerage mass deformation is substantially the same, and the energy required for change of form-in other words, for transfer of material-is mearly coustant. The total amount of differential movement or shear is practically the same in all cases, and therefore the friction is nearly constant. Hence, in the case of the illustration, the energy for the deformation is almost directly as the number of slices. But in the case of the crust of the earth, supposing the fracturing to become closer as depth increases, the energy MON XLVII $-0 t- \pm 9$ 
required for a given mass deformation wonld increase with depth for two reasons: (1) More energy is required for the finer subdivision; and (2) the load increases with depth, and therefore the energy required to overcome friction also increases with depth. The energy required for the similar transfers of material remains practically the same at all depths.

It has already been seen that near the surface the dominant deformations are relatively wide-spaced fanlts and joints; that with increase of depth the spacing between the faults and joints decreases until the fracturing is that of fissility and finally of granulation.

It is therefore clear that the amount of energy required for fractures a considerable distance apart, such as prevail where faults or joints, or both, are the dominant deformations, is much less than where the fractures are close together-as, for instance, in fissility. Furthermore, it is clear that the amount of energy required for the slicing of fissility is much less than that required for granulation of the individual particles, for in the latter case a mass equivalent to a fissile leaf must be broken into a multitude of particles. Probably the ratio between the energy required for breaking a rock into fault or joint blocks near the surface and that required for producing fissile leaves deeper down is not greater than the ratio between the energy required to produce fissility and that required to prodnce granulation thronghout at a still greater depth. No general ratio between the amount of energy spent in deformation by faults and joints and deformation by granulation can be given, but it is certain that the amount of energy used in extreme cases of the latter may be indefinitely greater than that required for the former.

Since it is certain that in passing from the surface to considerable depth there is a passage from deformation by faulting or jointing, or both, to deformation by granulation, it is certain that to a deptl of many hundred meters there is a steady and very rapid increase in the amount of energy required for a given mass deformation.

At sufficient depth, as has been seen, granulation is more and more replaced by recrystallization, and finally this process is dominant. It wonld be very interesting to know exactly the relative amounts of energy required for the two processes of granulation and recrystallization.

As already noted, the energy required for granulation is wholly mechanical, and includes three factors-(1) that required for the subdivision 
of the rocks, (2) that required for transfer of material, and (3) that required to orercome friction.

The energy factors in recrystallization are four in number:

(1) Energy is continuously used in straining minerals during deformation, but it is impossible to determine the amount of straining which takes place, for eviclence of the strain is continuonsly obliterated by solution and deposition. If the mechanical stresses did not continnonsly produce a state of strain, and thus disturb the equilibrium, it is probable that the rate of the process of solution and deposition wonld be very slow. It is this constant mechanical work in producing strain that keeps the process of recrystallization going.

(2) Energy is required for the transfers of materials by solution.

(3) Energy is required to overcome the viscosity of the solutions, or, stated in a different way, energy is required to overcome the friction of the molecules against the water during their movements.

(4) As a result of solution and deposition in the lower zone, the minerals prodnced are, on the average, more compact than before the process. In so far as a nore compact condition results energy is liberated. On the other hand, the dominant chemical reactions of deoxidation, silication involving decarbonation, and dehydration all demand a large amount of energy. The energy thus consumed is probably greater than that liberated by condensation. It is therefore thought to be probable that the process of solution and deposition consumes energy. In the rare cases in which the minerals are equally compact before and after the process, and no chemical change takes place, as in the recrystallization of a limestone, the energy of solution and that of deposition balance.

We may now compare the energy demanded for ench of the different factors in the two processes of granulation and recrystallization. 'The three factors entering into granulation are paralleled by the first three of the four factors mentioned below entering into recrystallization. (1) It appears probable that the energy required to prodnce granulation is greater than that required to produce a state of strain during recrystallization. (2) The energy required for the actual transfer of the material by granulation and by solution may be supposed to be the same. (3). Tlie energy required to overcome friction during granulation is certainly vastly greater than the energy required to overcome the friction of the molecules against the water 
during the transfer of the material. (4) As a result of the solution and redeposition, energy is consumed.

Therefore the energy required to accomplish granulation, on account of the greater work of subdivision and the much greater work necessary to overcome friction, is almost certainly greater than the eneryy required for recrystallization.

If one premises that when the conditions are such that either granulation or recrystallization might occur the process takes place which requires the less expenditure of energy, this furnishes additional support to the above conclusion; for wherever the conditions are such that recrystallization can replace granulation, this occurs.

In the artificial deformation of dry marble in the experiments performed by Adams and Nicolson, ${ }^{a}$ the deformation was accomplished by gliding and granulation. When the deformation was made in the presence of steam, the adjustment was, to a small extent, by recrystallization. ${ }^{b}$ (See pp. 747-748.) - If the conditions conld be so varied as to accomplish the deformation by recrystallization mainly, it would be interesting and important to compare the amount of work done upon the mass during deformation under these different conditions; for if this conld be done it would be possible, at least in this case, to make an estimate of the relative energy demanded by deformation throngh gramulation and throngh recrystallization. Doubtless this would be a difficult task. It would be necessary to separate the total work done in the machine into the parts which were required for the deformation of the rock mass and that required for the deformation of the surrounding iron, and in one case also to estimate the energy furnished by the water. If it were possible to make the determination, I anticipate from the analysis of the previous pages that the energy required for deformation throngh recrystallization wonld be less than that required for deformation through granulation.

The question naturally arises, If less energy is required for recrystallization than for granulation, why did the latter process occur extensively during mountan making in various regions? The answer is plain. Recrystallization can not take place except where the proper conditions of temperature and moisture are present. If the nucleus of the earth be shrinking, the lithosphere must be reduced in size to accommodate itself to this nuclens.

A Alams, F. D., and Nicolson, J. T., An experimental investigation into the flow of marble: Philos. Trans. Royal. Soc. London, ser. A, vol. 195, 1901, Pp. 376-382.

${ }^{\circ}$ Adams and Yicolson, eit., pp. 382-385. 
This implies crustal deformation which extends to the surface, and therefore to places where the conditions are not such that recrystallization can take place.

From the foregoing considerations, I believe that the amount of work done, in order to produce the same mass deformation of the rocks, increases to a certain depth and then decreases until the belt of the perfect schists is reached. How far down this holds I am unable to conjecture, but believe it is probable that it does so at least as deep as the zone in which the schists formed by recrystallization develop, and that it may continue much farther.

The deformation of this deep-seated zone may or may not require the elevation of the superincumbent mass. Where the superincumbent mass is not elevaterl it is concluded that the energy required for deformation by recrystallization per unit mass is probably less than that required for deformation by granulation, and may be less than that required to produce the spaced fractures which occur near the surface. Where the deformation is of the kind which requires the elevation of the superincumbent material, energy is needed, not only to do interior work of deformation, but to elevate this material. Where these conditions obtain it may be that the amount of energy required to produce the deformation steadily increases with depth on account of the energy required for lifting the load in addition to that required for the interior deformation.

So far as I know, the region in America which best illustrates all the phenomena fron deformation by widely spaced. thrust faults and by joints to the interior deformation of recrystallization is the Southern Appalachians. In the Great Valley the Paleozoic rocks are little deformed except by thust faults and joint folds. Eastward, deeper into the mountains, the faults and joints become closer together, and are finally replaced by numerous closely distributed fractures. At the sane time the rocks show more and more evidence of metamorphism, first by granulation, and second by recrystallization. In the cores of the mountains are rocks which have largely or completely recrystallized, being slates, schists, and gneisses, with welldeveloper cleavage. In the valley we fint the alterations to affect but a small part of the mass of the rocks now exposed. The deeper we go into the mountains the larger is the proportion of the material which was affected by the alterations, and in the schists in the core the entire mass was morlified, both in a mechanical and in a chemieal way. In this passage it becomes clear that for a certain distance the amount of energy required for deformation per unit mass increased, but this tendency may have been 
reversed in the deepest seated zone. However, since this latter zone is a region of uplift, and the work required for the raising of the superincumbent strata must be added to that required for the interior deformation of the rocks which we now see, no positive statement can be made as to whether the total energy increased or decreased per mit mass in the deformation of the deeper seated rocks.

The conclusions of the previous pages concerning the energy required for a given mass deformation at different depths gives a possible explanation of the concentration of superficial deformation found in mountain ranges. If the energy of deformation be less at the depth at which the slates, schists, and gneisses develop than in more superficial belts, it is possible that the more rigid outer shell of the earth may shear over the mucleus in the zone at which the schists develop, the deformation being widely distributed. Such shearing for a considerable area may require less expenditure of energy than wonld be demanded for the similar deformation of the rocks above; but during the earth movements, as a result of cooling and other changes, the superficial material must certainly be deformed and shortened, ${ }^{a}$ and at such places deformation is concentrated and mountain ranges are formed. This subject is, however, better discussed in Chapter $\mathrm{X}$, mnder the heading "Relations of rock flowage to mountain making."

CONCLUSION.

The energy requi.ed to produce a given mass deformation increases downward to the bottom of the zone where deformation is chiefly by fracture. In deformation by recrystallization the energy required to produce a given mass deformation is probably less and may be much less than that in the lower part of the zone of fracture. By observation we see that recrystallization does take place wherever that process can occur. We have shown that the amount of water present in the rocks wherever recrystallization takes place is adequate to accomplish the process. In the fact that less energy is required for recrystallization than for granulation lies the most fundamental answer to the question why recrystallization rather than deformation by fracture takes place wherever the conditions are such that the former process can occur. Nature is a great economist, and expends the minimum amount of energy to accomplish her work.

"Van Hise, C. R., Estimates and causes of crustal shortening: Jour. Geol., vol. 6, 1898, pp. 41-64. 


\section{CHAPTER IX.}

ROCKS.

In the preceding chapters I have considered the forces and agents of metamorphism, the divisions of the lithosphere into zones of metamorphism upon a physical and chemical basis, the alterations of each of the important rock-making minerals in reference to the zones in which they occur, and the general nature of the alterations of rocks in the belt of weathering, the belt of cementation, and the zone of anamorphism. It now remains to consider the metamorphism of individual rocks, but for a number of reasons it is impossible to do this part of the work satisfactorily at the present time.

In papers upon metamorphism there has in general been no attempt whatever to consider the subject from the points of view set forth in the previons chapters. The usual practice has been to describe the metamorphism of a given region or district and give various conjectures as to the causes of the alterations, often with little or no reference to the different belts and zones of metamorphism. To some extent the belt of weathering has been recognized as having distinctive reactions. The general neglect of the principles of pliysics and chemistry in the consideration of metamorphism renders it impossible in most cases to interpret the descriptions of the phenomena from the points of view discussed in this volume. If the principles of metamorphism set forth in the foregoing chapters are well founded they should be considered in the study of individual instances. If these principles be recognized it will be comparatively easy to describe a given case of metamorphism in reference to them. When this work is done for a sufficient number of districts it will then be possible to write a satisfactory chapter upon the metamorphism of individual rocks.

A second insuperable difficulty preventing a systematic treatment of the metamorphic igneons rocks is the statis of the classification of these rocks. At the present time there is not only no consensus of opinion concerning 
a classification of such rocks, but there is not even an approximation to a consensus of opinion as to the principles upon which a classification should be based. Until the original igneous rocks are satisfactorily classified it is quite impossible satisfactorily to consider their metamorphosed equivalents. The sitnation in reference to the original sedinentary rocks is somewhat more fortunate. There is rather general agreement as to the principles upon which the classification of the sedimentary rocks is to be based, and upon the main classes, orders, and families of rocks which shall be recognized. I shall therefore attempt to consider the metam rphism of each of the main divisions of the altered sedimentary rocks, but shall not make a similar attempt for the igneous rocks.

\section{USE OF SOME GENERAL TERMS APPLIED TO METAMORPHIC ROCKJ.}

The more important of the terms generally applied to metamorphic rocks are the prefixes meta and apo, and the general names "slate," "schist," and "gneiss."

META.

The prefix meta is used in this treatise in a general way to indicate any kind of alteration of any kind of rock. This usage of the prefix corresponds with the definition of the term "metamorphism" as given in Chapter I, page 32, where metamorphism is defined as meaning all kinds of alterations of all rocks by all forces, agents, and processes. In the sense proposed we may say meta-sandstone, meta-shale, meta-arkose, metadolerite, etc. We may even apply the prefix meta to a rock already metamorphosed which has nudergone a second set of changes, as, for instance, meta-graywacke and meta-quartzite. Thus used it means that a rock which had first been transformed to a graywacke or quartzite, respectively, was afterwards again metamorphosed.

\section{APO.}

The prefix apo is here used as a qualifier to indicate metasomatic cnanges in rocks in which the original textures and structures are largely preserved. This usage of apo accords with the underlying idea of the term as proposed by Doctor Bascom." She proposed to call a rhyolite which has

a Bascom, Florence, Aporhyolite of South Mountain, Pennsylvania: Bull. Geol. Soc. Ameriea, vol. 8,1897 , pp. 393-396. 
all the textures of glass, but which has been completely devitrified, aporhyolite. In her original definition she restricted the term to this single alteration, but later she enlarged the meaning ${ }^{a}$ so as to include not only devitrified glasses but alterations of all rock in which the original textures and structures are preserved.

The prefix apo thus nsed discriminates rocks which have been metamorphosed under mass-static conditions and retain their original textures and structures from those which have been metanoryhosed under massdynamic conditions, so as to destroy or partly destroy the original textures and structures and to produce slaty, schistose, or gneissic structures. A rock to which apo is prefixed may differ greatly from the original rock in both chemical and mineral composition.

The term epi was proposed by Giimbel ${ }^{b}$ as a prefix for rocks which have undergone a change in mineral composition, and which by this change have come to have the same mineral composition as another rock. Thus a diabase the pyroxene of which has changed to amphibole, and which, therefore, has the mineralogical composition of diorite, he calls an epidiorite. The term diabase itself was originally applied to an altered dolerite, which has as an importaut constituent secondary chlorite. Applying the method which is proposed to be here followed, the rock which Grimbel calls epidiorite would be called apodolerite. This name is much more satisfactory than that of Giimbel, since it gives the original nature of the rock, and tells that a part or all of its minerals have altered, but that it retains its original textures and structures. Therefore the name apodolerite gives a better understanding of the history and relations of the rock than does the name epidiorite.

In a mamer similar to the above apo may be prefixed to any rock altered under mass-static conditions, when it is desired to call attention to the rock from which it was derived. Thus quartzite is an aposandstone; graywacke is an apogrit, etc. The term apo thus used supplements the terms schist and gneiss, its usage being structural in a negative sensethat is, applied to metamorphic rocks in which the textures and structures have not changed.

a Bascom, Florence, Volcanics of Neponset Valley, Massarhusetts: Bull. Geol. Soc. America, vol. 11,1900 , pp. 121-122.

v Gümbel, K. Wilheln von, Geologie von Bayern, Kassel, 1888, wol. 1, p. 125. 
SLATE AND SCHIST.

Slate and schist are here used as general terms which are applicable to all rocks having a well-defined cleavage in which the cleaved plates are essentially like one another. I have explained in another connection that cleavage in rocks is due to the arrangement of the mineral particles with their longer diameters or readiest cleavage, or both, in a common direction, and that this arrangement is cansed, first and of most importance, by parallel development of new minerals; second, by the flattening and parallel rotation of old and new mineral particles; and third, and of least importance, by the rotation into approximately parallel positions of random original particles. ${ }^{a} \quad$ Subsequently Leith has shown that parallel slicing may also be a subordinate factor. In a slate or schist the cleavage may or may not be parallel to an original structure such as bedding; but usually it intersects the original structures. Clearage is fully discussed by Leith. ${ }^{b}$ His work shows that cleavage ultimately rests upon a parallel dimensional arrangement of the mineral particles, but for some minerals this dimensional arrangement carries with it mineral cleavage, and the cleagrage of these minerals is nsually the controlling factor in rock cleavage. Horeover, he argues that the dimensional arrangement is mainly cansed by recrystallization. His work while advancing in an important way the theory of cleavage also confirms my own view in showing that rock cleavage is mainly due to the actual cleavage of mineral particles produced by recrystallization, and subordinately due to the easy separation between mineral particles in the direction of their greater dimensions.

The production of slate and schist requires recrystallization during mass-dynamic action. Previons textures and structures are partly or wholly obliterated. In these particulars slate and schist contrast with those rocks to which the term apo may be prefixed.

SLATE.

Slate is defined to include those cleavable rocks the cleavage pieces of which are like one another and the mineral particles of which are for the most part so small as to be invisible to the naked eye. The typical example is furnished by the roofing slates, which, so far as the eye can see, are gray

$a$ Van Hise, C. R., Principles of North American pre-Cambrian geology: Sixteenth Ann. Rept. U. S. Geol. Survey, pt. 1, 1896, p. 635.

$b$ Leith, C. K., Rock cleavage. 
or black, homogeneons, aphanitic rocks, which may readily be parted into thin plates which are indistinguishable from one another. The microscope shows that the cleavage of these rocks is due to the carses above given.

The foregoing definition of slate is purely structural. It involves no implication as to the minerals which compose the slate. It says nothing as to whether the rock from which a slate is derived is sedimentary or igneous. If it be desired to ignore the origin of a slate and to indicate its mineral composition, this may be accomplished by prefixing mineralogical qualifiers. For instance, if a slate be composed of mica and quartz as the chief constituents, it is a mica-quartz-slate. If it be desired to emphasize the slaty structure, and at the same time to indicate the original rock from which the slate is derived, the name of this rock may be prefixed. For instance, if a slate be derived from mud, it may be called a pelitic slate or pelite-slate; if a slate be derived from dolerite, it is a doleritic slate or dolerite-slate, etc. If it be desired to emphasize the original rock from which the slate is derived, and only secondarily to indicate that the rock has a slaty structure, this may be done by placing the word slate in the first position; as, for instance, slaty pelite or slate-pelite, and slaty dolerite or slate-dolerite. Finally, mineralogical qualifiers may be prefixed to the above compound names, as mica-quartz-pelite-slate or mica-quartz-slate-pelite.

SCHIST.

Schist is defined to include those cleavable rocks the cleavage pieces of which are like one another and the mineral particles of which are for the most part so large as to be visible to the naked eye. 'The thin cleavage plates of a schist which are like one another are called folia, and the rock is spoken of as foliated. The most important of the cleavage-making minerals is mica, and a typical example of a schist is one composed of mica and quartz in which mica is the chief cleavable mineral. Such a rock may therefore be called a mica-quartz-schist. There is great variation in the approach to perfection of the arrangement of the minerals. For instance, the plates of mica may be almost perfectly straight and parallel or they may be curved or even crenulated. The closest approximation to the above definition of schist is that given by Geikie. According to this anthor, "A rock possessing a crystalline arrangement into separate folia is in English termed a schist." " It is to be noted that the definition of schist given is

a Geikie, Archibald, Text-book of Geology, Macmillan \& Co., London, 3d ed., 1893, p. 178. 
purely structural, and to its structural meaning the term will be rigidly confined in this treatise.

However, the term schist has been widely used both in a structural sense and as the name of definite rocks; and indeed this double usage is found even in Geikie, whose definition restricts the term to a structural meaning. Illustrations of the use of the term schist both as the name for a definite rock and with a structural signification are furnished by the terus mica-schist, chlorite-schist, and hornblende-schist as generally used. In the case of mica-schist, the term means that the rock is a schistose mica-quartz rock. As here proposed such a rock should be called a mica-quartz-schist. The omission of the term quartz from the name of this rock arose naturally, since this is one of the most abundant varieties of schists, and since in it mica is so conspicuous and quartz so inconspicuous. After it was discovered that quartz is usually equally or more important than mica in most schists, usage came to imply the presence of quartz in the rock called mica-schist. But as the study of rocks continued, other schists were found in which the conspicuous constituent is not mica, but chlorite or hornblende; and such rocks were immediately called chlorite-schists or hornblende-schists, the implication being that quartz was the remaining chief constituent However, when close microscopical studies were begun, they showerl that in the chlorite-schists and hornblende schists quartz might or might not be an abundant constitnent, its place being taken by feldspar or other minerals, and thus chlorite-schist or horublende-schist, as used by most English-speaking. geologists, means a schistose rock eontaining chlorite or hornblende and other unnamed minerals. Thus the original scheme broke down. The German petrographers soon saw this, and where schistose rocks were found in which feldspar was an important constituent they proposed to call the rock a gneiss, since feldspar was recognized as an important constituent in the rocks which had before been called gneiss. When the English and American geologists ascertained that a schist, as they use the term, might contain various combinations of minerals, they were inclined to return strictly to a structural sense, as indicated by the quotation from Geikie already made. But as yet this plan has not been carried ont consistently in reference to individual rocks, and the usage of combining a structural meaning with mineralogical implications is still common. It seems to me that clear discrimination can be obtained only by restricting the term schist to the 
structural meaning as advocated. Illnstrating the usage, if a rock which has the structural characters of schists as here defined be composed of hornblende and plagioclase as chief constituents, it is a hornblende-plagioclaseschist. If the plagioclase be definitely determined, as, for instance, labradorite, such a rock is a hornblende-labradorite-schist; and of course the classical mica-schist is mica-quartz-schist, as already stated.

The schists in which it is not desired to direct the attention to their origins, or the origins of which are not known, are thus satisfactorily discriminated by mineralogical qualifiers. If the origin of a given schist be known, and it is desired to indicate this, the term is used in precisely the manner in which it is proposed to use slate, viz; by combining schist with the names of rocks from which it has been derived. In doing this either the schistose character or the origin of the rock may be emphasized. If it be desired to emphasize the schistose character, and at the same time to indicate the original rock from which the schist is derived, the name of this rock may be prefixed. For instance, if a schist be derived from arkose, it is an arkose-schist. If a schist be derived from a gabbro, it is a gabbroschist. If it be desired to emphasize the original rock from which the schist is derived, and only secondarily to indicate that the rock has a schistose character, this may be done by placing the word schist in the first position; as, for instance, schistose arkose or schist-arkose, schistose gabbro or schist-gabbro. Finally, if it be desired to combine the chief minerals with the compound names which indicate the schistose character and the origin of the rock, this may be done. For instance, a rock may be said to be a mica-quartz-feldspar-arkose-schist.

The usage above advocated is very advantageous in handling the metamorphosed rock masses, since the mineral character of a given schist may be correctly indicated without any reference to its origin, or the origin of the schist may be very accurately indicated. If the term schist be used with a combined structural and mineralogical meaning, as is ordinarily done, such usages are impossible. For instance, if schist means the presence of a certain mineral, as quartz, it can not be applied to a rock which has a schistose character as here defined and which does not contain quartz. For example, one could not say peridotite-schist. Considering all the foregoing facts, the advantage of restricting the term schist to a purely structural usage is so great that all wineral implications for the term should be dropped. 
GNEISS.

The term gneiss is defined to apply to a banded rock the bands of which are petrographically mulike one another and consist of interlocking mineral particles. The bands in different gneisses are of variable thickness, ranging from a fraction of a centimeter to many centimeters. Also there is a similar range in thickness of the different bands of the same gneiss. The lithological dissimilarity of the bands of gneiss constitutes a fundamental distinction between gneisses and the slates and schists, which are comparatively homogeneons. Usually the gneisses have a cleavage parallel to the banding, but this cleavage is by no means so general or distinctive as in the slates and schists, and not infrequently a parallel arrangement of the mineral particles resulting in cleavage is almost wholly lacking. This is especially likely to be the case with the gneisses of igneous origin. It has been explained that the slaty and schistose structures are mainly dependent upon recrystallization during mashing. (See pp. 688-690, 748-759.) Where a parallel arrangement of the mineral particles is marked in gneiss this is likely to be largely due to the same cause. But the parallel orientation of some of the mineral particles of a part of the original gneisses formed from magmas is due to differential stress during the primary crystallization of the rocks.

The use of the term gneiss advocated in the preceding paragraph approximates closely to the practice of American and English geologists in recent years. But gneiss, like schist, has been extensively used with a dual meaning, comprising structural and mineralogical factors. For instance, in Germany the word gneiss has been used generally to designate rocks which have the structure either of schists or of gneisses, as defined in the foregoing pages, and which have a quartz-feldspar background with one or more other constituents. In this sense the terms mica-gneiss and hornblendegneiss mean rocks having either a schistose or a gneissose structure, as here defined, and a quartz-feldspar groundmass in which are respectively mica and hornblende. The dual significance of the term gneiss has arisen naturally from the fact that many of the gneisses, especially the abundant ones first studied, have as chief constitnents quartz and feldspar, and with these minerals one or more other constituents. The minerals quartz and feldspar common to them were taken as distinctive of the gneisses, and the names of the other minerals were prefixed as qualifiers. But precisely as is the ease 
with schists, the ter'm gneiss was extended to banded rocks many of which do not have this definite mineral groundmass. This became apparent only when the microseope was applied to thin sections of rocks.

Since, as a matter of fact, it has been found that the rocks which have been called gneiss have a very great variety of mineral constituents, and not necessarily any of the constituents originally supposed to be implied by the name, it is no longer possible to nse the term gneiss with a dual signification and at the same time to have clear discrimination. I therefore propose to confine the term gneiss strictly to its structural sense, including all finely banded crystalline rocks, whether of igneous or of aqueous origin. Thus defined, the term gneiss may be applied precisely as are the terms slate and schist. Mineralogical qualifiers may be prefixed; the name of the rock from which the gneiss is derived may be prefixed; the word gneiss may be prefixed to the name of the original rock; and, finally, names denoting the mineral composition, the name of the original rock, and the term gneiss may be combined. For instance, we may say mica-quartz-feldspar-gneiss, dioritegneiss, granite-gneiss, gneissoid diorite, gneiss-diorite, gneissoid granite; gneiss-granite, and finally mica-quartz-feldspar-gneiss-granite, ete.

GENERAL STATEMENTS.

It has been seen that all of the terms which have been discussedmeta, apo, slate, schist, and gueiss-may be united with petrographical names and with mineralogical qualifiers in various ways. For additional refined discrimination geographical qualifiers may be used.

Under the usages advocated the character of a metamorphosed rock may be designated very loosely and broadly either in a structural or in a petrographical sense, may be discriminated with a moderate degree of accuracy, or may be designated very accurately. The following usages illustrate the various stages of gradation from loose to accurate designation: An original maltered rock may be granite, diorite, syenite, limestone, sandstone, etc. If we wish to indicate that the rock has been altered without saying anything as to the nature of the alteration, we may prefix meta to these terms. If alteration has taken place, but the original texture of the rock is retained, we may prefix apo to any of the names. If alteration has taken place so as to produce new structures, we may prefix to the names the words slate-, schist-, or gneiss-, or the adjectives slaty, 
schistose, or gneissose. If we wish to designate the minerals of which the rocks are composed. we may prefix the names of the minerals to any of the previous names, as, for instance, mica-hornblende-schist-syenite, or mica-hormblende-syenite-schist. Still further accuracy is obtained by prefixing a geographical name, as Aurora granite. A final stage of accuracy is obtained by combining all of these devices, as Amrora mica-quartz-feldsparschist-granite, or Aurora mica-hornblende-syenite-gneiss. Of course ordinarily the rock will be designated by the simpler terms, but somewhere in a paper all of the qualifiers can be put together, so as to give in a single compound name its most accurate designation.

The elasticity of this plan, by which it is possible to make loose, approximate, and very fine discriminations, is noteworthy. In the field it may not be possible to give the mineral composition or the origin of the rocks and an expression on these points can be avoided. But so far as the facts are known they may be expressed in the notes if desired. Thus all grades of knowledge of the metamorphic rocks can be indicated without implying more than is known. When additional knowledge is gained and further refinement is possible, these refinements may be expressed.

In preparing reports in the office it is very often advantageous to be able to throw large groups of rocks together which have common structures or textures without reference to their mineral composition or origin. In another part of the text it may be desirable to indicate the mineral character of the different rocks. In other parts of the text it may be desirable to indicate exactly the origin of the rocks. All these wants are very nicely met by the proposed usage of the terms meta, apo, slate, schist, and gneiss.

\section{SEDIMENTARY ROCKS.}

The sedimentary rocks may be divided in accordance with the ordinary classification into nonfragmental or nonclastic and fragmental or clastic.

The nonfragmental rocks may be divided into five orders-nitrates, sulphates, chlorides, carbonates, and oxides. The only inportant nitrate is niter. The important sulphates are gypsum and anhydrite. The only important chloride is rock salt. The carbonates may be divided into two families-the calcium-magnesium carbonate family and the iron-bearing carbonate family. The oxides are divided into tro families-the iron-oxide family and the silica family. 
Following Naumam and Haiiy ${ }^{a}$ the fragmental rocks are divided into

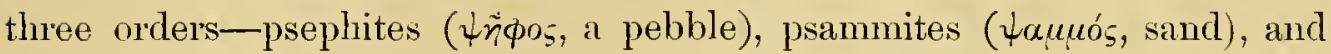
pelites ( $\pi n \lambda o_{5}$, clay). The psephites include the fragmental rocks which contain abundant fragments coarser than peas. Frequently the matrix of the psephites is psammitic. The psammites, following Rosenbusch, ${ }^{b}$ are defined as including the sedimentary rocks which are composed of particles under the size of peas and larger than dust. The pelites are composed of the minnte particles, from those of the size of dust down.

The unconsolidated psephites, depending upon the coarseness, may be called pebble, gravel, or bowlder deposits. Since the psephites are unassorted material, the order includes but this one family and their metamorphosed equivalents.

The psammite order comprises three families-quartz sands, quartzfeldspar sands, and ferromagnesian sands, and the metamorphosed equivalents of each.

The pelite order includes but one family-the muds, and their metamorphosed equivalents.

The foregoing classification may be represented in tabular form as follows:

Classitication of sedimentary rocks.

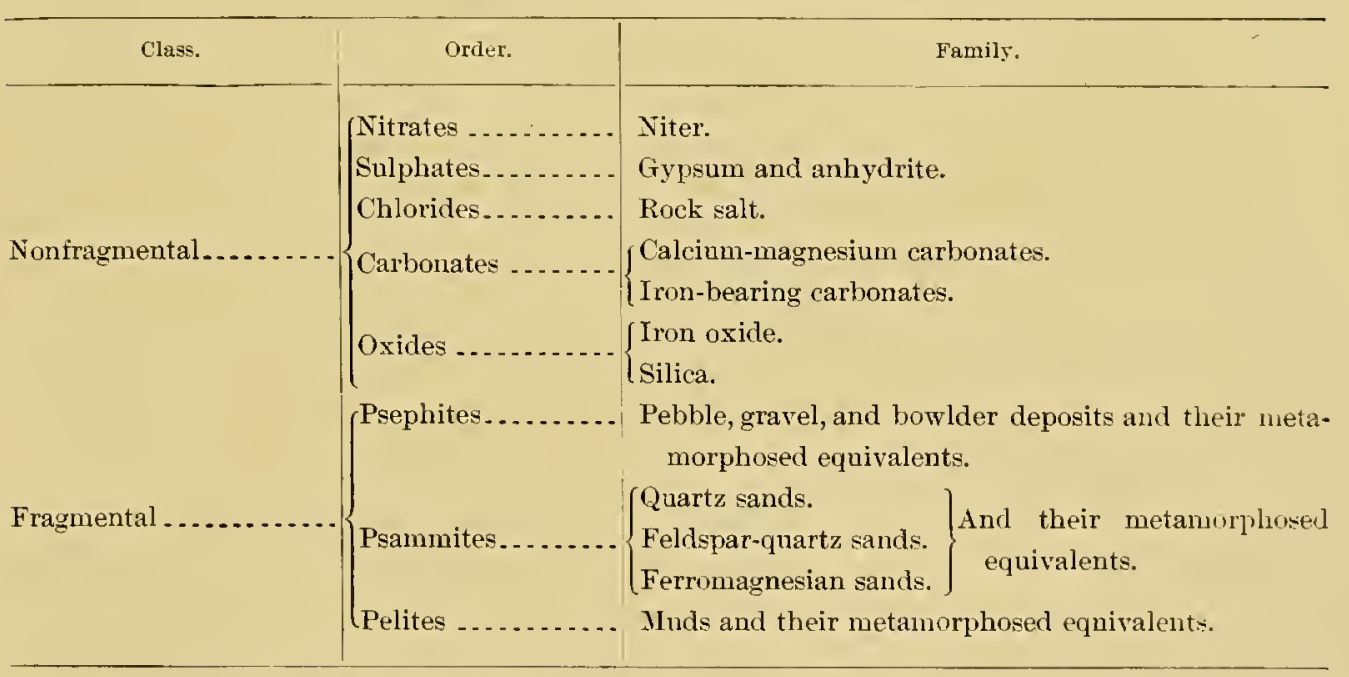

a As cited by Zirkel, F., Lehrbuch der Petrographie, Leipzig, 1893, vol. 1, pp. 493-504.

${ }^{b}$ Rosenbusch, H., Elemente der Gesteinslehre, Stuttgart, I898, pp. 386-389.

MON XLVII-04-50 
The foregoing classification is made upon the basis of giving family names to the abundant kinds of the sedimentary rocks. If names were provided for kinds which are not abundant, a multitude of names would be necessary. The intermediate varieties may be provided for by compounding the various names within either the fragmental or the nonfragmental class. If the materials of each of the two classes be about equally abundant, the names may be hyphenated; if one is subordinate, this may be used in the adjective form. The following illustrates the usage: If a rock is about halfway between shale and limestone, it may be called a shale-limestone or limestone-shale. If the fingmental material be subordinate, it may be called shaly limestone. If the nonfragmental material be subordinate, it may be called a calcareous shale. In a similar mamer, if a rock be intermediate between the carbonate and siliceous rocks, one may say limestone-chert, chert-limestone, or calcareous chert, cherty limestone. If it be desired to indicate still more closely the character of the rock, geographical names may be prefixed.

It thus appears that the classification of the sedimentary rocks is comparatively simple, since, as explained on pages 555-560, the sorting of the sedimentary material, both mechanically and chemically, is along definite lines, and consequently large masses of material are produced which have comparatively narrow ranges in composition, and these abundant rocks are selected for the family names. However, the fact must not be forgotten that there are all gradations between all varieties of the sedimentary rocks. The law that gradation is the rule in nature is 110 better illustrated than by the sedimentary rocks. In biology, while gradations have once existed between various forms, in many cases the intermediate forms have been destroyed. In the early days of petrography it was not supposed that between the various igneous rocks gradation existed. But gradation varieties are known between the more important facies, although grudational varieties between all kinds lave not yet been discovered. But the fact that each kind of sedimentary rock grades into the related kinds has been recognized since the rise of geology, and thus there has been no such confusion and multiplication of names for the sedimentary rocks as for the igneous rocks. While gradations between the different varieties of the sedimentary rocks exist, it is believed that under the families above named probably 90 per cent or more of the 
material of the sedimentary rocks may be placed, and, as already explained, the remaining 10 per cent is provided for by compound names.

We are now prepared to consider the manner of formation of the various families of original sedimentary rocks, their transformation, and resultant alteration forms.

\section{NONFRAGMENTAL CLASS.}

NTTRATE ORDER.

NITER FAMILI:

Natural niter is mainly soda niter $\left(\mathrm{NaNO}_{3}\right)$, although potash niter $\left(\mathrm{KNO}_{3}\right)$ does occur in subordinate quantity. The sodiun and potassium of the niter are mainly derived from the many alkaline-bearing silicates by their decomposition in the zone of katamorphism, and chiefly in the belt of weathering, through the process of carbonation. The original source of the nitrogen of the niter is the atmosphere. This is oxidized in the zone of katamorphism, mainly in the belt of weathering and very largely in the soil, to nitric acid. (See Chapter VI, pp. 465-466.) The nitric acid unites for the most part with the alkalies, forming the nitrates. The nitrates, once formed, are dissolved fiom the soils by the circulating ground water and carried to the sea or to lakes with no outlets. In the lakes niter is chemically precipitated in consequence of continual addition of salts in solution and evaporation of water. Niter is the most readily soluble of the important natural salts, and therefore is the last of the series of chemical precipitates to separate. It forms in the final stages of desiccation of the lakes as the top deposit. Therefore niters are wholly the products of the zone of katamorphism, and mainly of the belt of weathering.

The most extensive known deposits of niter are those in the extremely arid regions of Chile. Niter deposits also occur in Bolivia, in Nevada, and in southern California.

The alterations of niter are those of recrystallization and solution. The process of recrystallization need not be dwelt upon, as it is in no way different from the recrystallization of other readily soluble compounds. Niter is so readily soluble that, muless the region be one of extreme aridity, the rock, after having been precipitated, is redissolved and transported elsewhere. Even where niter becomes buried under other rocks, it is likely to be dissolver by the ground waters and again bronght to the surface. Consequently niter as a deeply huried rock is rare. 
SULPHATE ORDER.

GIPSUM AND ANHITRITE FAMTLI.

Gypsum is hydrated calcium sulphate $\left(\mathrm{CaSO}_{4} \cdot 2 \mathrm{H}_{2} \mathrm{O}\right)$. Anhydrite is calcium sulphate $\left(\mathrm{CaSO}_{4}\right)$. The calcium for gypsum is released from other combinations, mainly silicates, in the zone of katamorphism, and especially in the belt of weathering. Sulphur, as sulphicle, and especially as pyrite, is a widespread but not abundant mineral in the original igneous rocks. In the zone of katamorphism, and especially in the belt of weathering, the sulphur is oxidized to sulphuric acid. The sulphuric acid unites with bases and forms sulphates. . Sulphates formed in the belt of weathering are transported by the underground circulating waters to the sea or to lakes without outlets. In these lakes, by the continual addition of sulphates and evaporation, supersaturation is reached, and the sulphates are thrown down as calcium sulphate, because this is the most insoluble of the sulphates of the bases which abundantly occur in such bodies of water. Where locally barium and strontium are found, these sulphates form in preference. Gypsum is less soluble than niter and sodium chloride, and more soluble than calcium carbonate; therefore it is mainly precipitated after the tufas and before the rock salts. Gypsum is now forming on a somewhat extensive scale in lakes with no outlets. In the past it has formed on a very extensive scale in such lakes and has been buried under later deposits. Some of the more important gypsum deposits of the United States are those of Grand Rapids, Michigan, and Fort Lodge, Iowa, and the widespread gypsums which occur in connection with the Red Beds (Permian and Triassic) of western America.

Gypsum, like rock salt, may by recrystallization become coarsely crystalline. In many localities, becanse of its somewhat ready solubility, it has formed crystals of great size. The most famous of the localities for large gypsum crystals is that of the Paris Basin. However, the most gigantic crystals known have recently been discovered in Utah, some of them measuring $150 \mathrm{~cm}$. in greatest dimension. ${ }^{a}$

Gypsum, like niter and rock salt, is a product of the zone of katamorphism, and mainly of the belt of weathering.

When gypsum beds become so deeply buried that pressure is dominant, and the heat is somewhat higher than at the surface, the process of dehy-

a Talmage, J. E., A remarkable occurrence of selenite: Science, vol. 21, 1893, pp. 85-86. 
dration occurs, and thus gypsum passes into anlyydrite, with a decroase of volume of 38 per cent. Anhydrite is then a result of the dehydration of gypsum, often in the zone of anamorphism. But it is to be remembered that after a deposit of gypsum has been changed to anhydrite in the lower zone, in order that it shall reach the surface by denudation it must pass through the upper zone, and under these conditions hydration occurs to a greater or less extent, and it is thus transformed to gypsum in part or in whole. At various localities the beds of calcinm sulphate are in part composed of gypsum and in part of anhydrite. Doubtless in places where the deposits are deep the change toward anhydrite is taking place, and in other places near the surface the change toward gypsnm is taking place.

CHLORIDE ORDER.

ROCK'SALT FAMILY.

Rock salt, impure sodium chloride, or simply salt, is the only abundant chloride. But potassium chloride, calcium chloride, and magnesium chloride are found as impure compounds. The sodium is derived mainly from the silicates. It is liberated from these compounds in the zone of katamorphism, mainly in the belt of weathering, by the process of carbonation. The chlorine is more difficult to account for. Of the minerals in the original rocks, only sodalite, wernerite, and apatite contain chlorine. But sodalite is abundant in the soda rocks, and the last two minerals are very widespread. Therefore these minerals are an important source of chlorine. It is well known that hydrochloric acid and other chlorine compounds are emitted in large quantities in comnection with volcanic action. In this connection it should be noted that at periods of regional volcanism the quantity of chlorine emitted is vastly greater than during periods of local volcanism, like the present. ${ }^{\circ}$ It has been supposed that emissions of chlorine during volcanism are evidence that sea waters from the surface, or the salts of underground solutions, have penetrated to the roots of volcanoes, and thus contributed chlorine to magmas. Doubtless this is true in some instances, but it can not be assumed from occasional cases of this kind that the chlorine very generally emitted in volcanic regions is thus derived from the zone of

«Van Hise, C. R., Earth movements: Trans. Wisconsin Acad. Sci., Arts, and Letters, vol. 11, 1898, pp. $496-497$. 
katamorphism. I believe that much of the chlorine emitted from volcanoes is not thus derived, but is an original constituent of the deep-seated magmas, and it follows that before the crystallization of the magmas a portion of the chlorine escapes. Consequently the quantity of chlorine in the crystallized igneons rocks is less than originally existed in the magmas. Probably the original chlorine minerals and the emissions in connection with volcanism are sufficient to account for the chlorine of the chlorides.

Sodium chloride formed in the soil is taken into solution and is transported to the sea or to lakes with no outlets, which are prevented from expansion by evaporation. As the process continues salt accumulates to the point of saturation, when further evaporation leads to chemical precipitation, precisely as with niter.

Sodium chloride ranks in solubility next to niter, and is abundantly precipitated before the latter compound is. Deposits of rock salt are forming in various desert regions at the present time by the evaporation of the waters of inclosed seas, such as the Dead Seal, Great Salt Lake, etc. Extensive deposits formed under similar conditions during past geological periods have been buried under later formations, and these are the rocksalt beds. Illustrations of such deposits are the thick rock-salt formations of Poland, of central Germany, and of Louisiana. From the foregoing it is plain that rock-salt deposits are strictly products of the zone of katamorphism, and mainly of the belt of weathering.

The alterations of rock salt are those of recrystallization and solution. In some cases the material has become coarsely crystalline, as in the case of the Polish deposits. In order that a rock-salt formation shall be preserved it is necessary that it be buried under relatively impervious formations, in order that the underground circulation shall not be so rapid as to dissolve the material and bring it to the surface. That solution of nuany ancient deposits is taking place is showi by the briny waters which are found at many localities. Where such ground waters issue at the surface we have salt springs. Such salt springs were known in America in early days as "salt licks," because the animals frequented these places in order to lick the salt which was deposited. As illustrations of deposits which are being dissolved and which are artificially abstracted from the earth in the form of brine, those of the Saginaw district of Michigan and the Syracuse district of New York may be mentioned. 
CARBONATE QRDER.

CALCIUN-MAGNESIUM CARBONATE FAMILF" AND METAMORPHOSED EQUIVALENTS.

The calcium-magnesium carbonate fanily, with its metanorphosed equivalents, comprises limestone, dolemite, marble, cherty limestone, cherty dolomite, and cherty marble, silicated marble, and silicate rocks. Each of these will be considered in turn.

LHESTONES.

Limestones comprise all those rocks which are mainly composed of calcium carbonate $\left(\mathrm{CaCO}_{3}\right)$.

SOURCE OF MATERial OF Limestones.

The original dominant source of the calcium and magnesium of the calcium-magnesium carbonates is mainly the many alkaline earth-bearing silicates. The silicates are decomposed in the zone of katamorphism, and very largely in the belt of weathering, by the processes of carbonation, bydration, and oxidation. So far as the process is due to carbonation the carbonates are formed directly. In so far as the bases are set free by other reactions they may later unite with the carbon dioxide. The carbon dioxide immediately concerned in the process of carbonation is mainly derived directly from the atmosphere, from that produced by the oxidation of the organic compounds, by the liberation from rocks during their decomposition of irclosed carbon dioxide, and from the deep-seated waters rising from the zone of anamorphism. (See pp. 461-465, 473-475, 608-610, 667, 677-678.) The relations of these sources of carbon dioxide to one another and the replenishment of the supplies in order to carry on the process of carbonation are fully discussed in Chapter XI, under the heading "Carbon."

The calcium and magnesium unite with the carbonic acid formed and form carbonates. The original carbonates are solely produced by the reactions of the zone of katamorphism, and chiefly by reactions of the belt of weathering.

The calcium carbonate formed as above describerl, after transportation to the sea or to lakes with no outlets, is thrown down as organic precipitates and as chemical precipitates, and thus limestone is formed. 
ORGANIC PRECIPITATES.

Animals of the ocean and lakes abstract calcium carbonate from solution and build it into their liard parts. The number of kinds of organisms which are doing this work is great. Of these the more important classes are the corals, mollusks, and crinoids, the relative importance probably being in the order given. In each class are many species, and the number of individuals of each species is beyond computation. In order that a great quantity of material may be abstracted from the water by organisms it is necessary that abundant material shall be fimished to it, and also that the conditions shall be favorable for the existence of abundant animal life of the right kind. The material for the building of limestone is furnished to the ocean mainly by the streams. Therefore, adjacent to great bodies of land from which large rivers enter into the sea there is a contimmous and abundant supply of calcium carbonate. Sluggish rivers which have meandered through limestone regions furnish an especially abundant supply. An essential condition for abundant animal life in the sea is a warm climate, and lience the limestones are likely to be formed most plentifully in the tropical or subtropical regions. Tropical and subtropical regions are favorable for limestone building for the further reason that evaporation is great and concentration of calcium carbonate is thus producerl. This is of great importance in shallow, nearly inclosed seas, and lagoons. The areas which combine the two conditions-abundance of material and abundance of life-are those in which the great limestone building of the present time is going on. Such regions are illustrated by Florida and the Bahamas, the sea adjacent to which is constantly fed by the currents from the Gulf of Mexico, which receives the great contributions of calcium carbonate of the Mississippi and many other rivers; and by the regions adjacent to the Yellow Sea, which receives the contributions of the Yangtze, Hoangho, and many other important rivers. But the immediate contributions of great rivers are not necessary for extensive limestone formations, for the ocean currents distribute material throughout the seas, and the water contains a sufficient amount of calcimm carbonate, so that where other conditions are favorable extensive limestone formations may be built. This is illustrated by the Great Barrer Reef of Australia and the numerous coral reefs about the tropical islands of the Pacific. 
The material deposited by animals may be amorphous or crystalline aragonite or calcite. The material deposited by corals and crinoids is crystalline, and is in the form of aragonite; the material deposited by the mollusks is in the form of calcite, and to a less extent of aragonite. The continuous precipitation of calcium carbonate of the sea by organisms, and the building up of organic deposits throngh geological periods, combined with mechanical rearrangement and with recrystallization (see pp. 795-797), result in the great limestone formations.

CHEMICAL PRECIPITATES.

Chemical precipitates of calcium carbonate include the deposits of springs and streams; inland seas witl no outlets, like the Dead Sea, Great Salt Lake, etc.; and possibly chemical precipitates in the ocean or in seas connected with the ocean.

springs and streams.-Tufa deposits are frequently formed by streams just after issuing from underground, and they are formed from water in caves as it issues from the confined passages into the open caverns. In both these cases the canses of the supersaturation and precipitation are the same-release of pressure, with eseape of carbon dioxide, and evaporation. Spring and stream deposits of tufa are usually small and unimportant.

Inland seas with no outlets.- In inland seas with no outlets the calcium carbonate contributed by the streams steadily accumulates. On the average, evaporation balances the additions of water. Concentration of the calcium carbonate is the result, until supersaturation follows, and finally precipitation. These deposits have generally been called tufa, and they are finely illustrated by the deposits of the ancient lakes Lahontan and Bonneville. Such deposits are forming at the present time in Salt Lake, Pyramid Lake, Walker Lake, and Winnemucca Lake. ${ }^{\alpha}$ The tufa forming in lakes and inclosed seas is likely to be rather impure in consequence of the simultaneous precipitation of other compounds, especially sodium chloride and gypsum.

Possible chemical precipitates in the ocean or in seas connected with the ocean.-Willis holds it to be extremely probable that extensive limestone formations have been chemically precipitated in the sea. ${ }^{b}$ At the present time the ocean and the

a Russell, I. C., The geological history of Lake Lahontan: Mon. U. S. Geol. Survey, vol. 11, 1885 pp. 188-223. Gilbert, G. K., Lake Bonneville: Mon. U. S. Geol. Survey, vol. 1, 1890, pp. 167-169.

$b$ Willis, Bailey, Condition of sedimentary deposition: Jour. Geol., vol. 1, 1893, pp. 519-520. 
connected seas are not saturated with calcium, or even approximately so. According to Mendeléeff, ${ }^{a} 1 \mathrm{~kg}$. of water saturated with carbon dioxide will dissolve 3 grams of calcium carbonate. The amount of calcium carbonate in the ocean at the present time, per kilogram of water, is .11869 gran, or 3.956 per cent of the above amount $;^{b}$ but since sea water is not saturated with $\mathrm{CO}_{2}$, the amount of calcium carbonate which could be held is less than 3 grams per kilogram. It is certain that under present conditions the precipitation of calcinm carbonate from the ocean is mainly accomplisled by organisms, as explained on pages 792-793. But in early geological periods, before life was abundant and great quantities of calcium carbonate were extracted from the sea by animals, it is barely possible that supersaturation occurred and chemical precipitation resulted. Supersaturation conld have been brought about by two factors: First, steady additions of calcium carbonate from the land in comnection with evaporation from the sea produced concentration. Second, it is possible that the amount of carbon dioxide in the atmosphere, and therefore in the ocean, was greater then than at present. 'As the carbon dioxide in the atmosphere was nsed up by the processes of carbonation, carbon dioxide would pass from the ocean to the atmosphere, and a decrease in the amount of this compound in solution would result in chemical precipitation of the calcium carbonate. ${ }^{\circ}$

The two causes for precipitation considered apply to the entire body of the ocean. Precipitation cansed by them alone would be very widespread, if not universal. The theory of chemical precipitation in the ocean has greater plausibility if there be combined with the two previous causes the existence of partly inclosed tropical mediterranean seas, which received great contributions of materials from large rivers and lost great quantities of water by evaporation. Under these circumstances chemical precipitation might occur without premising saturation of the entire ocean. It is therefore theoretically possible that extensive limestone deposits were produced by chemical precipitation in early geological ages. But if the ocean as a whole did at any time contain enongh calcium carbonate to saturate it, or even enongh to nearly saturate it, the subsequent process of limestone building by

\footnotetext{
a Mendeléeff, D., The principles of chemistry, trans. by Geo. Kamensky, Longmans, Green \& Co., London, 1897, vol. 1, p. 592.

$b$ Dittmar, William, The composition of ocean water: Report of the Scientific Results of the Exploring Voyage of H. M. S. Challenger, 1873-76; vol. 1, Physics and Chemistry, 1884, p]. 2, 204.

c Mendeléeff, cit., vol. 1, p. 592.
} 
organic precipitation must have more than equaled the additions of calcium carbonate from the land, and thus have reduced the total amount in solution.

In the present state of knowledge it must be said that the precipitation by chemical means of great limestone formations in the ocean, or in mediterranean seas connected with the ocean, is a speculation based upon the premised inadequacy of life in early times to precipitate such amounts of materials, and is required to explain only the limestones of pre-Paleozoic times, the rocks of which contain very scanty fossils. But even these limestones may have been precipitated by organisms and the fossils destroyed by the processes of recrystallization and metamorphism subsequently described, just as they have been in many later fornations.

METAYORPHISM OF ORGANIC AND CHEMICAL CALOIUM CARBONATE DEPOSITS.

During the time that the varions forees and agents are abstracting the calcium carbonate from the sea the mechanical and chemical forces are at work. No sooner is a deposit formed than the waves may break it into detritus. All the organic and chemical deposits within the reach of the waves and currents are handled by them. Thus the material may be widely distributed according to the laws of the distribution of mechanical deposits. (See Chapter VI, pp. 555-560.) To illustrate: The débris of the coral reefs is carried seaward until the water reaches such a depth that the undertow has lost its power. Thus conglomerate, sand, and silt composed of limestone may be deposited in concentric belts. (Pl. IV, A.) Any of the shore deposits described by Gilbert maly be built up. ${ }^{*}$ But the mechanical work does not go on alone. The moment an animal dies the calcium carbonate is subjected to the action of solution and deposition by the sea. When the material is exposed to the open sea, or when there are continuous currents, the water is not saturated with calcium carbonate, and there is continual solution of the material at the rock surface. Within the body of the rock the particles may be cemented by deposition. (Pl. IV, B.) In inclosed or nearly inclosed areas, as, for instance, locally between the islands and reefs encireling Australia, the evaporation may more than conpensate for the influx of fresh water, and thus the tendency, on the whole, be to precipitate additional material from the sea, rather than to dissolve material.

At the same time limestone is forming there may be a substitution of magnesinm for calcium. The processes of solution and redeposition and of

a Gilbert, G. K.. Lake Bumneville: Mon. U. S. Geol. Survey, vol. 1, 1890, pp. 23-89. 
substitution are fully considered below, in treating of "Recrystallization" and "Dolomitization." The amount and speed of the recrystallization depend, of course, upon many factors. Rather ancient limestones may have been only partially recrystallized. On the other hand, the limestones now forming may locally be coarsely crystalline.

Commonly the mechanical and chemical forces work together in the rearrangement of the rock. This is finely illustrated among the lagoous of Florida and Australia. In these regions abundant life is building up calciumcarbonate deposits. The deposits are being broken up by the waves; they are being taken into solution by the sea; evaporation is going on; and redeposition is occurring within the deposits. Thus in these regious, while the first precipitation takes place as a consequence of the action of the animals, the mechanical and chemical forces immediately begin to rearrange the calcium carbonate into a detrital rock cemented by calcite, or into coarsely crystalline rocks entirely dissolved and redeposited by means of the chemical forces, or into a combination of these.

Saville-Kent describes the main mass of the material upon which the Australian corals are at present building their deposits as limestone conglomerates, largely built up of the cemented débris of corals and mollusks. ${ }^{a}$ (Pl. IV , A.) The breaking of the Barrier Reef is due to the waves; the cementing of the material he attributes to evaporation during the low tide, when the surface is above water, at which times the sun evaporates a large amount of the interstitial water, and thus deposits material. It may be supposed that this process is coutinuous, material being added to the solutions at each time of high water and deposited at each time of low water. But it may be doubted whether it is necessary for the reefs to be exposed in order that consolidation shall occur. It seems highly probable that in the ocean menstruum the limestone débris are consolidated by the chemical processes of solution and deposition, even if the material remains continually below the surface of the water.

The process of recrystallization does not cease when the limestone formations are raised above the sea. When these formations constitute land, recrystallization continues under both mass-static and mass-mechanical conditions. This is accomplished by the action of the underground waters It has been fully explained that in its movement water is continually taking material into solution and is continually depositing material fiom solution.

a Saville-Kent, W., The Great Barrier Reef of Anstralia, London, 1893, pp. 52-54. 

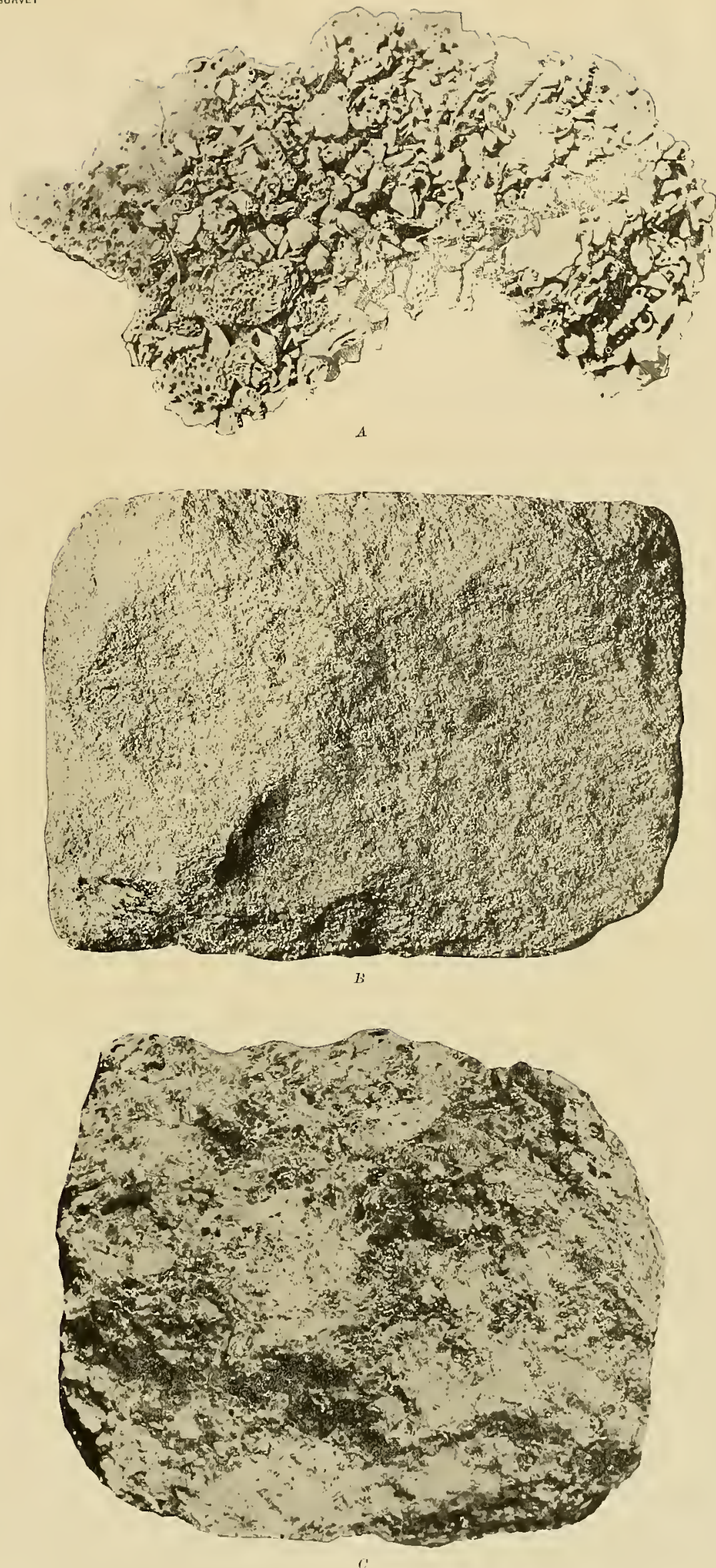

TEXTURES OF LIMESTONES AND MARBLE. 

Further, it has been explained that in the belt of weathering solution is the rule, and that in the belt of cementation solntion does not so far surpass deposition but that cementation is the rule. No other rock so well illustrates these principles as limestone, for it is the most readily soluble of the extensive formations. Under the law of dominant solution in the belt of weathering the openings are enlarged, and thus the very mumerous cracks, crevices, and cares, great and small, so characteristic of limestone, are formed. But while solution dominates in the belt of weathering, as shown by these openings, deposition is, as explained on page 487, an invariably accompanying process. Thus are made the stalactites, stalagmites, and travertine deposits. These deposits may be either aragonite or calcite.

In the belt of cementation below the level of ground water in limestones the openings formed in varions ways are as generally decreased in size by deposition as they are enlarged in the belt of weathering. The material here deposited is generally in the stable form of calcite.

But the process of solution and deposition in the belt of weathering and the belt of cementation does not affect the walls of the openings only. Solution and deposition are going on continuonsly throughout the entire mass of limestone formations in the zone of katamorphism. As a consequence of this the rock is continnously recrystallized. This process, even under mass-static conditions, may advance so far as to transform a limestone into a uniformly crystalline rock, to which the term marble is applicable. However, where the recrystallization goes so far as to transform the rock to a marble, there has usually been more or less mechanical action. But the consideration of the marbles is deferred. (See pp. 808-816.)

In modern limestones fossils are likely to be abundant; in ancient limestones they are comparatively sparse. In general it may be said that they are less abundant as the rocks are old. Also, in proportion as the rocks are old they are likely to be well crystallized. "The increased sparseness of fossil remains and the crystalline character of the limestone may both be regarded as evidence that recrystallization has taken place. Also they might be interpreted as evidence that life was not so abundant in the past and that the material had been deposited as a chemical precipitate. But certainly the latter argument does not apply to rocks later than the Algonkian. Since fossils so commonly constitute but a small fraction of the present mass of limestones, it is concluded that recrystallization has extensively occurred in Paleozoic and post-Palenzoic limestones. (See Pl. VI, A.) 
DOLOMITE.

ORIGIN OF DOLOMITE.

Dolomite is calcium-magnesium carbonate $\left(\mathrm{CaCO}_{3} \cdot \mathrm{M}\left[\mathrm{gCO}_{3}\right)\right.$. In considering the origin of dolomite the questions immediately arise: Are magnesian limestones and dolomites originally deposited as such, or are they the results of replacement of calcium by magnesium? and, if the latter, how and when did the process take place?

Dolomite due to replacement of calcium by magnesium.-That the magnesium carbonates are due to replacement of magnesium for calcium, and therefore to dolomitization, seems to be conclusively shown by the following considerations:

(1) The first of the various lines of evidence in favor of dolomitization is the composition of the hard parts of sea animals. IV e do not know any sea animals which deposit more than a small amount of magnesiun carbonate in their hard parts. Forchhammer analyzed a large number of corals and shells of marine animals. In bivalves he found the amount of magnesium to vary from 0.5 to 1 per cent; in ceplraloporls he found it to be less than 0.5 per cent. In most corals the amount of manesium is less than 0.5 per cent, although in one species it is 2 per cent and in another species 6.4 per cent. $^{a}$ Sharples analyzed seven species of corals, ${ }^{b}$ and does not report magnesium carbonate, although it is to be supposed that a small amount of that compound is present. Forchhammer found ${ }^{c}$ in a number of late deposits, which are mainly composed of the remains of animals, that the amount of magnesium is less than 1 per cent. From these results, if it be supposed that formations now dolomitic limestone were originally organic precipitates, it must be concluded either that the magnesium is mainly introduced by a secondary process or that sea animals in early periods used a larger proportion of magnesium for their hard parts than do the present animals. 'The latter conclusion would be a pure unverified assumption.

(2) Some of those who hold that dolomites are original deposits, in order to escape the difficulty involved in the supposition that animals have

a Forchhammer, Georg, Birlrag til Dolomitens-dannelshistorie: Oversigt over det Kongelige Danske Videnskab. Forhandlingar, Copenhagen, 1849, p. 89. See also Bischof, Gustav, Chemical and physical geology, London, 1855 , vol. 2, pp. 48-49.

$b$ Sharples, S. P., On some rocks and other drengings from the Gulf Stream: Am. Jour. Sci., $3 d$ ger., vol. 1, 187l, p. 169.

Forchhammer, eit., p. 89 . Also, Bischof, cit., p. 48. 
at some past time secreted magnesium in greater quantities than at present, have held that magnesium limestones and dolomites as such are original chemical precipitates. While the sea is not now saturated with calcium and magnesium salts, it is held that this might have been the case before life became abundant, and that consequently magnesim limestone and dolomite formed directly. This is again a pure, nuverified assumption, which seems to be negatived by the following considerations: (a) Since the living animals extract so little magnesium, on this hypothesis it is difficult to explain why the sea is not now saturated or nearly saturated with magnesium salts; (b) Bischof ${ }^{a}$ found by experiment that when solutions become saturated with carbonates of magnesium and calcium the calcium carbonate is largely precipitated before the magnesinm carbonate begins to be thrown down in appreciable quantity. Hence, by chemical precipitation, there would be produced separate layers composed mainly of carbonate of calcium and carbonate of magnesium, rather than calcium-magnesium carbonate. According with Bischof's experiment, the alkaline earth carbonates precipitated in Lakes Lahontan and Bommeville are essentially calcium carbonate, containing not more than 2.14 per cent of magnesium. ${ }^{b}$ The deposits of inland lakes in which the salts accumulate until precipitation occurs should be analogous to those of the ocean in ancient times, on the supposition that before life existed abmdantly chemical pereipitates formed. The fact that tufas deposited in such lakes contain so little magnesia seems to bear against the hypothesis that the dolomites are original chemical precipitates.

(3) But perhaps the most decisive of the various lines of evidence in favor of secondary dolomitization are observed facts of occurence which seem to be explicable only upon the basis of replacement. While, as already noted, coral is nearly pure calcium carbonate, Dana found that the limestone of the elevated coral island Metia is heavily magnesian, one specimen containing as much as 38 per cent of magnesium carbonate. Prestwich states that in the Carboniferous limestones of Kilkenny and Cork the upper surface and parts of the rock along the berding and joint planes

"Bischoi, Guslav, Elements of chemical and physical geology, trans. by B. H. Paul: Cavendish Society, London, vol. 3, 1859, pp. 169-170.

$b$ Russell. I. C., Geological hisiory of Lake Lahontan: Mon. U. S. Geol. Survey, vol. 11, 1885, 1. 203. Gillert, G. K., Lake Bomneville: Mon. U. S. Geol. Survey, vol. 1, 1890, p. 168.

$c$ Dana, Jas. D., Corals and Coral Islands, 3d ed., Dodd, Mear \& Co., New York, 1890, 1p. 39:3-394. 
are often dolomite. Where the rock is dolomite the fossils and the stratification are obscured or destroyed. The deeper lying rock, as well as the rock remote from the joints, is ordinary limestone. ${ }^{a}$ Geikie says that essentially the same facts are true on a large scale in the Carboniferous limestone in the north of England. ${ }^{b}$

Spurr describes the limestone of Aspen Mountain, Colorado, as dolomite near the faults. The magnesium becomes less and less plentiful as the distance from the fractures increases. He further states that dolomite almost invariably accompanies the ore. ${ }^{c}$. Bain describes precisely similar phenomena in the limestone carrying lead and zinc ore in Iowa. ${ }^{d}$ Spurr further finds in the limestone of Glenwood Springs, Colo., old water channels and zones of fracture; and adjacent to these he finds the rock to approach dolomite. Adjacent to the fractures and the underground water channels there is a gradation of the dolomite to the ordinary limestone. $^{e}$ Bain states that the Carboniferous limestones of Missouri bearing lead and zinc ore are dolomite in the vicinity of the ore deposits, and elsewhere are largely limestone. He further finds that dolomite is a most important gangue mineral in the openings of the rocks. The fissures connect with the magnesium-bearing Cambro-Silurian limestones below, and lie infers that rising waters have transported the magnesium and dolomitized the Carboniferous limestone adjacent to the water channels. ${ }^{f}$ Other instances of rapid gradation in the amount of dolomite are furnished by limestones where cut by intrusives. Finally, there are gradual variations in the amount of magnesium in great limestone formations; as, for instance, the great Cambro-Silurian limestone of North America. The Appalachian Valley Cambro-Silurian limestone is a true dolomite, while at various places in the Mississippi Valley the limestone contains so little magnesium as to be merely a magnesian limestone.

The different cases of occurrence of magnesian limestone above given

a Prestwich, Joseph, Geology-chemical, physical, and stratigraphical, Oxford, 1886, vol., 1, pp. $113-114$

$b$ Geikie, Archibald, Textbook of Geology, 3d ed., Macmillan \& Co., London, 1893, p. 321.

$c$ Spurr, J. E., Geology of the Aspen mining district, Colorado: Mon. U. S. Geol. Survey, vol. 31, 1898, pp. 210-211.

a Calvin, Samuel, and Bain, H. F., Geology of Dubuque County: Iowa Geol. Survey, vol. 10, 1900, pp. $492-498,572-575$.

e Spurr, cit., pp. 212-216.

$f$ Bain, H. F., with Van Hise, C. R., and Adams, G. I., Preliminary report on the lead and zinc deposits of the Ozark region: Twenty-second Ann. Rept. U. S. Geol. Survey, pt. 2, 1901, pp. 208-210. 
may be gathered together under a general principle, viz: On the arerage, limestones in regions of strong orogenic movements, and consequent fracturing, are more strongly magnesian than limestones of equivalent age in less disturbed regions. To illustrate, the Tertiary limestones of the Coast Range of California and of the Alps are more strongly magnesian than the undisturbed limestones of the same age. When the cases of variable magnesium are brought together under this rule, the reason for the variation is plain. Limestones are likely to be magnesian in proportion as there were favorable conditions for the entrance of solntions bearing magnesium, and these conditions are of course fumished by orogenic movements and fractures causing openings. The rariations in magnesium content, rapid and slow, above cited, and other similar instances, can apparently be explained only on the theory of secondary replacement.

(4) Taking the world as a whole, the older a limestone formation is the further advanced is dolomitization. Thus the ancient limestones, especially those of Cambrian and Silurian age, are very generally strongly magnesian, and the pre-Cambrian limestones are usually completely dolomitized. This is partly a direct consequence of (3). For in proportion as formations are old they are likely to have been subjected to orogenic movement and to fracture. Also in proportion as they are old sufficient time has elapsed for the other favorable conditions to have occurrerl. But the principle of increase in dolomitization with age must be broadly applied, for, as already seen, a young formation may be strongly dolomitic in one region, and a much older formation be only slightly dolomitized in another region; also, in various districts heavily magnesian formations occur above limestones containing little magnesium.

(5) It has been shown on page 239 that the change of calcite to dolomite involves a contraction of 12.30 per cent. It is a well-known fact that dolomites which have not been subjected to strong orogenie movement, deep below the surface, are very porous. This is beautifully illustrated by the dolomites of the Mississippi Valley, especially the so-called magnesian limestone series. In this respect the dolomites contrast strongly with the pure limestones. The natural explanation is that the porosity is due to the contraction of the rolume as a result of dolomitization. Where the change has taken place in the zone of anamorphism, or where the dolomite has been in the lower zone since the change, mashing and recrystallization have closed the openings.

MON XLVII-O4-51 
conclusion.-From the foregoing facts it is concluded that the major part of the magnesinn in dolomitic limestones and dolomites is due to replacement. In the instances of rapid local variation in the amount of magnesium in the limestones of coral islands and in the limestones of England, Ireland, and Anerica, where the amount of magnesium is greatest near the surface or adjacent to fractures, there seems to be no other conclusion. And there is no reason to doubt that the magnesian character of the great dolomite formations is due to replacement.

HOW AXD WHY DOLONITIZATION OCCURS.

The magnesium for dolomitization is prinarily derived from magnesiumbearing minerals of the original igneons rocks. The more inportant of these are the micas, pyroxenes, amphiboles, and olivines. But at the present time a large part of the magnesium for dolomitization is derived from secondary minerals, such as garnet, staurolite, tourmaline, chondrodite, chlorite, the zeolites, and even from previously formed dolomite. Indeed, the magnesium concentrated in earlier dolonite is one of the most important sources for present dolomitization. From these various sources the processes of alteration of the zone of katamorphism, and especially of the belt of weathering; prodnce sohuble magnesinm compounds, such as carbonate, hydrate, snlphate, etc. The magnesium compounds formed or dissolved in the belt of weathering are transported in part to the belt of cementation and in part to the sea, either before or after an underground journey. This process has been continuous since the continents were divided from the seas, consequently the amount of magnesium in the sea has probably continnously increased since early geological times, for it can not be supposed that, on the average, more magnesium las been precipitated from the sea than has been added to it during any geological period. It is seen in Chapter $X$ that the anount of magnesium now in the sea is more than three times as great as the amount of calciun.

The process of dolomitization may take place while the limestone is still in the sea or after it has been raised above the sea and constitutes a part of the land.

Dolomitization before limestone emerges from the sea.-The carbonate originally deposited by animals is almost wholly calcimn carbonate. The sea contains abundant magnesium salts. Thus we lave in the sea a heterogeneous 
system (see Clapter IIT, pp. 90-91), the sea not being saturater with either magnesinm or calcium salts, but containing more than three times as much magnesium as calcium, and having below it in various regions solid calcium carbonate. Under these circumstances there is a tendency for some of the calcium of the solid carbonate to change places with the magnesium in solution, and thus dolomitization may take place beneath the sea.

If the sea were saturated with magnesium salts it is probable that the replacement would go on rapidly. Since, however, the sea is far from saturated with such compounds, and since, as already shown (pp. 798-799), it can not be supposed that the sea has ever been richer i! magnesium salts than at present, the elange las taken place slowly. But the substitution is continuous; for, in conseqnence of the currents, the water depleted in maguesium is replaced by water containing a normal amount of that element. But the solutions of the ocean also contain calcium. Therefore the conditions are approximately as if one ran magnesinm-calcium solutions like those of the ocean through solid calcinm carbonate until equilibrimm under the laws of chemistry (see Chapter III, p. 90) had been reached. But in the ocean equilibrimm is probably but rarely reached on an extensive scale because of the slow and imperfect manner in which the solutions make their way through the calcium-carbonate deposits at the bottom of the sea. Occasionally in the arms or shut-off portions of the sea, where the conditions are favorable for unusual concentration, the amount of magnesium in the water may be even greater-than that in the normal waters, and under these circumstances the reaction wonld go on more rapidly: This is illustrated by the coral reefs of Metia, which are heavily magnesian. This case furnishes positive evidence that dolmitization may locally, under favorable circumstances, go very far while a limestone is below the sea. Dana's explanation of the unusual amount of magnesium is that "the sand or mud may have been that of a contracting and evaporating lagoon, in which magnesian and other salts of the ocean were in a concentrated state." a Dana compares concentration of magnesinm in lagoons mainly shut off from the sea to concentration in salt pans. ${ }^{b}$

While it is clear that dolomitization below the sea may locally go far, the usual facts of observation correspond with the conclusion above

a Dana, Jas. D., Corals and coral islands, New York, Dodd, Mead \& Co., 3d ed., 1890, p. 394.

b Dana, Jas. D., Manual of geology, American Book Company, 4th ed., 1895, p. 133. 
given, that dolomitization below the sea is usually very partial, and that the Metia instance is exceptional. It lias already been seen that Forchhammer found that late limestone deposits mainly composed of the remains of animals usually contain less than 1 per cent of magnesium, ${ }^{a}$ and that a small content of magnesinm is the ordinary thing for late limestones which have not been greatly disturbed by orogenic movements. In view of these facts the question naturally arises as to the time when the dolomitization mainly took place in those extensive dolomite formations in which the magnesinm is moderately uniform for a given district, although slowly varying as a whole. The typical formations of this kind in America are the great Cambro-Silurian limestones of the United States, which in the Appalachian region, where deformation is great, are nearly pure dolomites, and which in the Mississippi Valley are often heavily magnesian but rarely dolomite, and show, moreover, rather sharp variations in the amount of magnesium. The hypothesis which one naturally farors, because of its simplicity, is that such formations as these were mainly dolomitized below the sea. But the more closely the facts are examined the less certain does the conclusion appear to be. It is entirely possible that locally tle Cambro-Silurian limestone was dolomitized more extensively below the sea than is the case, on the average, for the later limestone formations. Indeed, it has been supposed that this limestone was deposited in a mediterrmean sea, and this entire sea may have had to some extent the concentrated conditions at Metia described by Dana. But it appears certain to me, even if the dolomitization was further advanced in the case of some of these formations while below the sea than can be paralleled by recent extensive formations, that they lave subsequently been much further dolomitized and the magnesium extensively rearranged since the limestones emerged from the sea.

Dolomitization after timestone emerges from the sea. - While it is clear that the process of dolomitization may take place below the sea, often it is there only initiated. Frequently dolomitization takes place in the main after the limestone becomes a part of the land area and is subject to the forces of metamorphism beneath the air. It is believed that dolomitization in land areas largely occurs in the zone of katamorphism rather than in the zone of anamorphism. The basis of this belief is furnished by the conclusion, fully

a Forchhammer, Georg, Bidrag til Dolonitens-dannelshistorie: Oversigt over der Kongelige Danske Videnskab., Forhandlingar, Copenhagen, 1849, p. 89. See also, Bischof, Gustav, Chemical and physical geology, London, 1855, vol. 2, pp. $48-49$. 
DOLOMITIZATION AFTER LIMESTONE EMERGES FROM SEA. 805

explained on pages $655-656,764-766$, that transfer of material and change in chemical composition are extensive and great in the zone of katamorphism and are trivial and small in the zone of anamorphism. Further, in the zone of katamorphism it is believed that dolomitization mainly occurs in the belt of cementation rather than in the belt of weathering, although the process undoubtedly takes place in both belts.

We have seen that rocks contain magnesium mainly as a silicate or carbonate. If above the level of ground water the magnesimm be as silicate, the process of carbonation changes it to a carbonate or other compound, and as such it is taken into solution and carried downward to the sea of gromnd waters. If the magnesinm be as carbonate, the process of carbouation is not necessary. In any case the waters of the belt of weathering steadily carry downward magnesium and calcium carbonate and other salts to the belt of cementation. These solutions pass into limestones and other formations.

When the solutions pass into limestones which contain little magnesium, the process of replacement begins. The substitution of magnesium for calcium is controlled by rarious factors, among which time, the absolute and relative amounts of calcium and magnesium in the solutions and in the rocks, the change in rolume in consequence of the reactions, and the direction of the movement of the solutions are important.

It is certain that time is an important factor. The underground solutions are continually circulating, and there are ever-renewer supplies of magnesium to carry on the process in the solutions which join the belt of cementation. At the outset calcium is greatly predominant in the limestone; but as the substitution goes on, magnesium becomes more and more important, and may finally become molecularly equivalent to calcium. But to accomplish this must require much time, for the solutions at any moment occupy but a small percentage of the volume of the rock, and they contain but a rery small amonnt of magnesium. Therefore the magnesium held at any one time by the solutions is but an inappreciable fraction of the total amount which is finally introduced into the rock.

The absolute and relative amounts of calcium and magnesium in the solutions and the limestones is a matter of the greatest consequence in dolomitization. The law of mass action requires that where solid calcium. carbonate is in contact with magnesium- and calcium-bearing solutions a 
part of the calcinm of the solid be replaced by the magnesium. In a limestone which has been slightly dolonitized the conditions are particularly farorable for dolomitization, for under such circumstances under chemical laws substitution goes on rapidly. But the further the process continues and the nearer equilibrium is approached the slower it becomes. Since, on the whole, calcinm is a more abundant base in the sedimentary formations, and also in the ground solutions, than magnesium, and since it is a more energetic base, it follows that at low pressure one could not expect that one-half of the calcium would be replaced by the magnesium, for when the substitution had gone to a certain stage calcium would replace the deposited magnesium as fast as the magnesium replaced the calcium. This stage would usually be reached before the magnesium was molecularly equal to the calcinm. In the foregoing we have the explanation of the fact that but very rarely is the magnesium so abundant in extensive formations as to have the precise composition of dolomite.

In determining the stage at which the static condition of affairs is reacherd pressure is very important. It has been seen that as a result of the substitution of magnesium for one-half the calcium in calcium carbonate there is a contraction in volume of 12.30 per cent: hence pressure tends to promote the change. But pressure increases with depth; therefore the deeper a rock is, the greater is the tendency for magnesium to replace the calcinm. Hence in the deeper buried rock, there is a strong force which tends to substitute magnesium for calcium. But the complete substitution is resisted, under the law of mass action, by the greater abundance of calcium, and by the more energetic character of that base. Further, as already pointed out, where the pressure is very great, as in the zone of anamorphism, circulation is very slow, and it is not possible for the solutions to supply sufficient magnesium to accomplish this, and probably in most cases not even enough to change the rock to dolomite. Usually these factors prevent the substitution from going so far as to produce equimolecular quantities of the two elements; but in the case of the pure dolomites this occur's. In such instances it may be that pressure is an important factor. Since few carbunates contain more than an equimolecular amount of magnesium as compared with the calcinm, it may be supposed that this - confound gives the limiting effect of such pressures as have obtained in the rocks which are within the zone of observation. As a corollary from the 
foregoing, one would expect to find dolonites among those rocks which have been deeply huried and strongly deformed, but at the time of dolomitization not so deeply buried as to prevent deformation from producing fractures for circulation, for there, if anywhere, the process of dolomitization would have been nearly completed. With this expectation the facts of occurrence of dolomite as given on pages $79 \varepsilon-802$ fully correspond.

As to whether dolomitization takes place more rapidly while the solntions are descending or ascending no definite answer can be given without experimental work. It is believed that the process probably aceurs throughout the journey of the mnderground water, as explained on pages 636-639. Doubtless in many cases where there is local dolomitization adjacent to the main underground circulation clamnels, the proeess has taken place while the waters were ascending, for, as shown on page 583, the trunk channels of underground waters are more often ascending than descending. Excellent illustrations of local dolomitization by ascending waters are those already referred to at Glenwood Springs, Colo., described by Spurr, ${ }^{a}$ and in the Carboniferons limestones of Missonri, adjacent to the lead and zinc areas deseribed by Bain." But in many cases of dolomitization along joints and other fractures the water was doubtless descending. The process may have been accomplished by waters which were ascending at one time and descending at another time. For instance, when the rock was somewhat deeply buried, a channel may have been occupied by ascending waters, and when brought nearer to the surface by erosion this same channel may have been occupied by descending waters, and dolomitization continued throughout the process.

Various regions conld be mentioned which illustrate the abovementioned conditions for dolonitization. One of the best of these is that portion of the limestones of the Mississippi Valley which is in the belt of cementation. It is well known that these limestones bave been broken at various times so as to produce joint fractures and local faults, and thus furnish channels for ready circulation. In the belt of weathering the great Cambro-Silurian limestone, which contains magnesium, and the magnesium of the other rocks is contimuously being dissolved and carried downward

aSpurr, J. E., Geology of the Aspen mining district, Colorado: Mon. C. S. Geol. Survey, vol. 31, 1898, pp. 212-216.

$b$ Bain, H. F., Van Hise, C. R., and Adans, G. I., Prelininary report on the leal and zinc deposits of the Ozark region: Twenty-second Ann. Rept. U. S. Geol. Survey, pt. 2, 1901, pp. $208-210$. 
into the openings of the belt of cementation. After a given period of deformation the process of dolomitization continnes until the openings are closed and circulation is checked, to begin again as soon as new openings are formed by earth movements. The process goes on with intermittent speed mutil a state of equilibrium is approximately reached between the calsium-magnesium solutions and the adjacent rock.

Other excellent illustrations of areas in which the conditions are favorable for dolomitization are furnished by various districts in the Cordilleras. Here in many areas recent orogenic movements and intrusion and extrusion of magma have taken place. The movements open new cracks and crevices in the limestones. The volcanic rocks, intruded or extruded, raise the temperature of the rocks and promote the activity of the solutions. Furthermore, the increase in temperature promotes the process of carbonation in the belt of weathering. In areas where there are limestones, recent volcanism, and orogenic movement, the conditions are especially farorable for the transfer of magnesium from the belt of weathering to the belt of cementation, with resultant dolomitization.

\section{MARBLE.}

In describing the processes of recrystallization and dolomitization in limestones, marbles lave been accounted for in the main. Marble is the term which is applied to evenly granular, finely or coarsely interlocking calcite, dolonite, or intermediate minerals. (Pl. IV C.) In the process of recrystallization it is common for a change to take place in the color of the rocks, as a result of which marbles are ordinarily white or pinkish white, rather than blue or gray, although marbles may, of course, have various other colors.

As already mentioned, marble results mainly from limestone in consequence of recrystallization or dolonitization, or the two combined. The absolutely conclusive evidence on this point is the increase of size of the mineral particles in marbles as compared with limestones. (See Pl. VI, A and B.) The formation of one mineral particle of marble of average size required a multitude of particles of the limestones, probably thousands; and in those cases where the grains of marble are coarse and the original limestone was fine perhaps many thousands were required. There is no mechanical process which alone can merge a great number of mineral 
particles into a single mineral. This can be done only by solution and deposition, or recrystallization. It is notable in this connection, as explained below, that in proportion as the rocks were deep seated and as orogenic movements were severe the marbles are likely to be coarse grained, and were therefore thoroughly recrystallized. If the deformation were mechanical, the greater the severity of the movement the greater would be the strain effects mentioned below.

The development of marble is frequently assisted by the intrusion of igneous rocks. If the masses be large they may furnish the conditions of heat necessary for the solutions to be able to recrystallize the limestone for a considerable distance about the intrusive. Of course, in many regions orographic movements and volcanism are synchronous, and in such cases the conditions furnished by the movements and those furnished by the intrusive combined are particularly favorable to the process of recrystallization. Reerystallization may have been completed in regions of comparatively little disturbance, and thus occasionally in unfolded regions calcareous rocks are locally found to which the term narble is applicable. But the great belts of marble occur in regions in which orographic movements have taken place, and especially in rocks which have been so deeply buried as to be in the zone of anamorphism. This is shown by the association of the marbles with slates, schists, and gneisses-locks which have been metamorphosed in the lower zone. Where the forces and agents were sufficiently potent to recrystallize the more refiactory minerals, the recrystallization of the caleite and dolomite is probable, even if the marbles do not give such clear evidence of the fact as does slate, schist, or gneiss. Calcite and dolomite are most ready to respond to stresses by solution and deposition, and therefore to recrystallize, and also mechanically by development of twinning structures, by novement along gliding and cleavage planes, and by granulation. ${ }^{a}$ (See Pl. Vl, $C$ and D.) Indeed, they are the most mobile of all the minerals which make up large masses of rocks. The minerals, halite, niter, ete., are even more mobile, but their rock masses are relatively small.

In consequence of the great mobility of calcite and dolomite, marbles generally differ in structure from the associated metamorphosed slaty,

a See Adams, F. D., and Nicolson, J T., An experimental investigation into the flow of marble: Philos. Trans. Royal Soc., London, ser. A, vol. 195, 1901, pp. 363-401. 
schistose, or gneissose rocks, in that they are massive and evenly granular, although the mineral particles commonly show other strain effects mentioned below. The explanation of the general lack of slaty and schistose structures is believed to lie largely in the fact that the process of recrystallization under farorable conditions goes on almost pari passu with the deformation, and thus at any given moment the minerals lack but little of adjustment to their environment. In so far as the calcite and dolomite are left with residual strain there is a tendency to recrystallize. Their mobility is such that this tendency often prevails, and the minerals are largely released from strain. But in many instances release from strain is not perfect, for when thin sections are examined in many of the apparently completely crystalline marbles strain effects remain. Cataclastic structures recur in variable amounts; strain shadows are nsual; twinning bands are

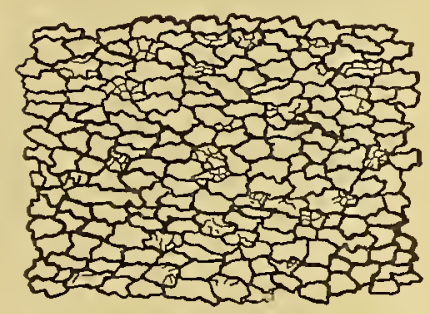

Fir. 22.-Sketch of oval irregular grains of ealcite with longer diameters parallel. From schistose marble, Talla dega Mountain, Alabana. After Leith. very abundant, often are exceedingly fine, and frequently the lamellix are curved, in such instances showing conchusively the existence of residnal strain effects. And it is not always true that during the development of marble the process of crystallization so nearly keeps pace with novement as to prevent the formation of a secondary structure. In such cases the marbles may have a well-dereloped cleavage. This is well illustrated in some of the pre-Cambrian cleavable marbles of the Laurentian Mountains, by the clearable CambroSilurian marbles of western Massachusetts, described by Dale, ${ }^{a}$ and in the marbles of Alabama at Talladega Mountain. (See fig. 22 and PI. Y, A.) At this latter locality the marble cleaves as evenly and smoothly as a slate. Where marbles have a cleavage it is found to conform to the cleavage of the surrounding rock. The cleavage is found to be wholly due to a dimensional arrangement of the mineral particles. (See Chapter VIII, p. 760.) The fact that the cleavage of the mineral particles has nothing to do with the cleavage of the rock is explained by the rhombohedral clearage of calcite resulting in fracture with equal ease in three directions. In this respect calcite and dolomite contrast strongly with the minerals

a Pumpelly, Raphael, Wolff, J. E, and Dale, T. Nelson, Geology of the Green Mountains in Massachusetts: Mon. U. S. Geol. Survey, vol. 23, 1894, pp. 181-182. 

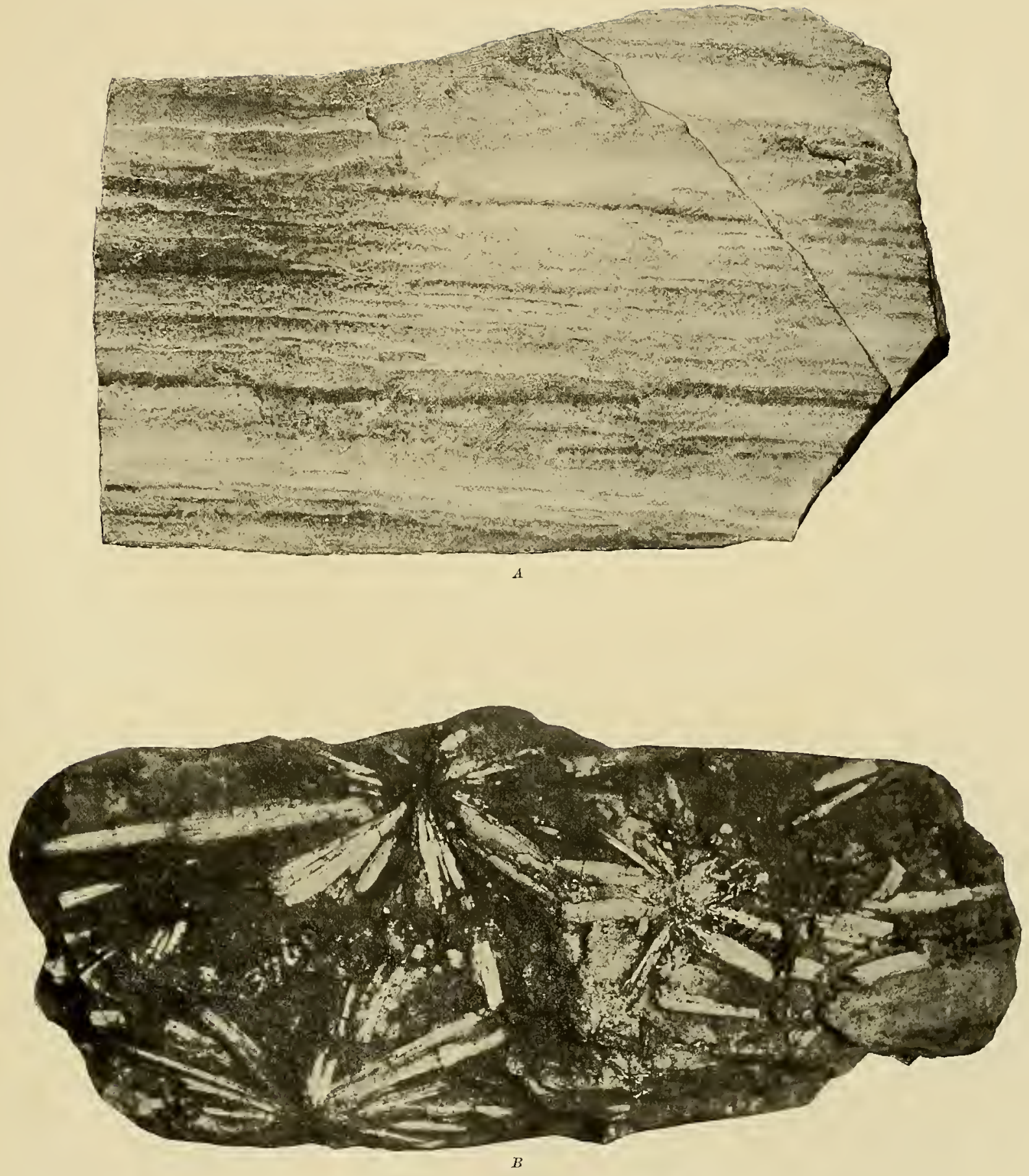

TEXTURES OF METAMORPHOSED MARBLES.

A. Schistose marble from, Talladega Mountain, Alabama. B. Tremolitic marble from Canaan, Conn. After Hobbs, 

such as mica, the clearage of which often controls the cleavage of rocks. The rare existence of cleavable narbles in connection with marble formations, the larger parts of which lack cleavage, as in the case of the marbles of the Appalachian regions just mentioned, seems to be conchnsive evidence that the gramular character of ordinary marbles is due mainly to the processes of ready solution and deposition, or recrystallization, as above explained.

Adams and Nicolson have experimentally deformed Carrara marble." Anong the varions reasons for selecting this marble was its evenly granular cluaracter and absence of strain effects. The deformation was accomplished under the conditions of pressure of the zone of anamorphism. Cylinders of marble confined on their sides by strong steel bands were shortened by pressure, and under these circumstances the shape of the marble was changed without perceptible uracks being produced. The process was carried on under various conditions.

First, the dry marble was deformed at ordinary temperatures. The rock thus deformed was foum to be weaker than the original rock, but sufficiently strong to show that the particles were partially welded. The thin sections of the marhle showed a cataclastic structure "identical with that seen in the feldspars and many gneisses." Many of the grains were flattened, and these grains showed strain shadows and fibrous structures due to minute polysynthetic twinning:

Second, the dry marble was very slowly deformed during a period of about four months at a temperature of $300^{\circ} \mathrm{C}$. The deformed marble was found to be strong, but not quite so strong as the original rock, showing a nearer approach to perfect welding than in the ase of the marble deformed at ordinary temperatures. The thin sections showed a tendency toward rock clearage. "Cataclastic structure is absent, but almost every grain shows an exceedingly fine fibrous structure. When examined under a ligh porver this fibrous structure resolves itself into an extremely narrow polysynthetic twimning-the whole grain consisting of slightly sinnous twin lamella, extinguishing in alternate sets. Each individual is usually twimed throughout, the lamella passing from end to end, althongh a single lamella often varies somewhat in width from place to place. The

a Adams, F. D. and Nicolson, J. T., An experimental investigation into the flow of marbles: Philos. Trans. Roya Soc. London, ser. A. vul. 195, 1901, pp. 363-101.

$b$ Adams and Yicolson, cit., p. 375 . 
calcite grains, which in the original rock are practically equidimensional, are now often distinctly flattened, some of them being three or even four times as long as they are wide. Some grains can be seen to have been bent around other's adjacent to them, the twin lamella and the extinction curving with the twisted grain. In other twisted individuals the twin lamelle only extend in to a certain distance from the margin of the grain, leaving a clear untwinned portion in the center; and other crystals again show not only the fibrous structure due to twinning in one direction, but broader lamella crossing this obliquely. As the twinning in all cases is probably parallel to- ${ }_{2}^{1} \mathrm{R}$ - , this is due to the appearance of a set of twin lines parallel to a second face of the rhombohedron." a. . . . "There has been no breaking-the rock has not been crushed in the ordinary sense of the term. The movement has been brought about partly by twinning, but ehiefly by a deformation of the grains due to a slipping on their gliding planes." ${ }^{\circ}$ (Pl. VI, C.)

Third, the dry marble was deformed during eight and one-fourth hours-much more rapidly than in the second case-at a temperature of $400^{\circ} \mathrm{C}$. The result in this case was very similar to that in the previous case. From this experiment it was concluded that "quick deformation at a high temperature shows therefore that calcite has freer movement in its gliding planes at a high temperature and breaks less readily than when cold." c (Pl. VI, D.)

Fourth, the marble was slowly deformed during a period of fifty-four days, at a temperature of $300^{\circ} \mathrm{C}$., in the presence of water gas. This rock after deformation "is not weaker, but actually stronger, than the original rock." "The thin sections of the rock showed substantially the same textures and structures as in the case of the dry marbles deformed at $300^{\circ}$ or $400^{\circ} \mathrm{C}$. The "granulated material is so trivial in amount that the deformation may be said to be due exclusively to movements on the gliding planes of the calcite, accompanied by polysynthetic twinning. It is thus identical in character with that seen in the case of the marble when deformed while dry, either at $300^{\circ}$ C. or $400^{\circ}$ C." . . . "There are no signs of solution and redeposition of calcirm carbonate even in this iron-stained portion of the rock. The presence of water, therefore, did not influence the character of the deformation. It is just possible, however,

a Adams and Nicolson, eit., p. $379 . \quad$ Op. cit., p. $380 . \quad$ Op. cit., p. $382 . \quad$ ap. cit., p. 385. 


\section{PLATE VI}




\section{PLA TE VI.}

\section{PHOTOMICROGRAPHS OF LIMESTONE AND MARBLES.}

A. Limestone from Wanwatosa, Wis, showing the evenly gramular character of a compact limestone. After Buckley.

B. Marble from Cockeysville, Md. After Diller.

C. Carrara marble after having been slowly deformed iluring 124 days at a temperature of $300^{\circ} \mathrm{C}$. The calcite has yielder by gliding. After Adams.

D. Carrara marble deformed at $400^{\circ} \mathrm{C}$. The slirle shows a uniform mosaic of somewhat flattened grains free from all fracturing or cataclastic structure. After Adams. 

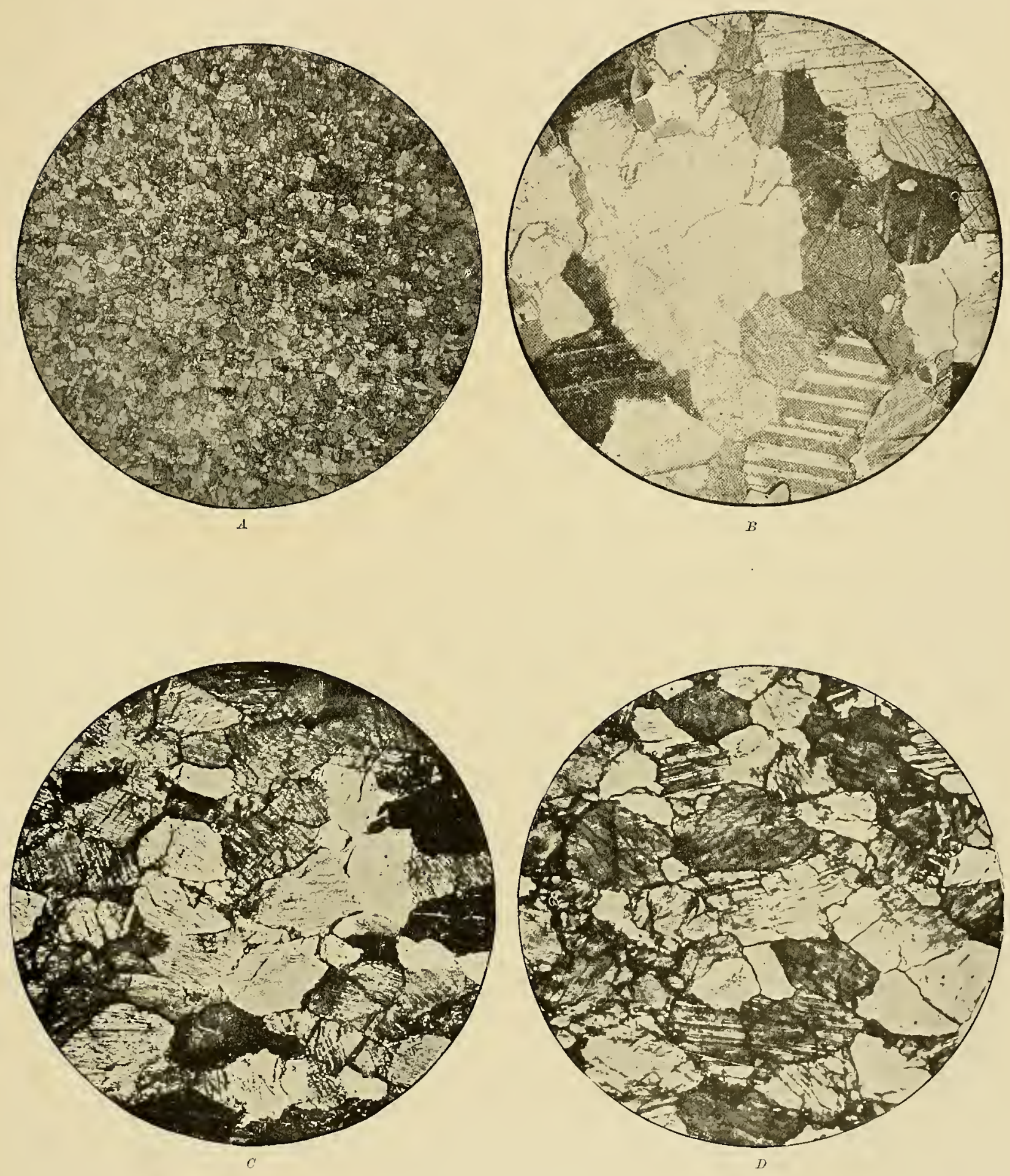

PHOTOMICROGRAPHS OF LIMESTONE AND MARBLES. 

that there may have been a deposition of infinitesimal amounts of calcium carbonate along very minute cracks or fissures, thus contributing to maintain the strength of the rock. No signs of such deposition, however, are visible." a

It has been pointed out in another place (see pp. 747-748) that the greater strength of this sample, as compared with those in which water was not present, is almost conclusive proof that solution and deposition, or recrystallization, did take place to some extent.

Adans and Nicolson compare the structures produced in the Carrara marble artificially deformed with limestones and marbles in various regions where the rocks have been metanorphosed under deep-seated conditions. In 21 rocks from different regions, 10 of which are marble and 11 of which are limestones, they find all the structures which they have artificially produced to be paralleled. ${ }^{b}$ But an equal number of rocks from other regions, only 3 of which are limestones, 2 dolomites, and 16 marbles, ${ }^{e}$ which, as shown by the greater number of narbles, have undergone more profound metamorphism, they say "do not present any undoubted evidence of morement under pressure. Their structure is that of a mosaic, apparently resulting in each case from the recrystallization of a previously existing finer-grained limestone. This process, as described by Lepsins in the Attic; marbles, ${ }^{d}$ consists of the enlargement or growth of certain of the constituent grains at the expense of others until finally a coarse-grained mosaic is produced." " In these instances it is apparent that recrystallization is the dominant process, for only by this process can large individuals be produced by the merging of small ones. (See Chapter VIII, pp. 690-696.) Adams and Nicolson conclude: "While, therefore, recrystallization undoubtedly plays an important, and in many cases probably a chief part, in the great. movements which are observed to have taken place in the limestones of contorted districts, this process is by no means the only one by which such movements are brought about. Many limestones under pressure in the earth's crust flow precisely as metals do, by deformation of the com-

a Adams and Nicolson, cit., p. 385.

$b$ Op. cit., pp. $38 ;-390$.

Op. cit., p1. 389-390; Nos. 22-42.

a Lepsius, R., Geologie von Attika; ein Beitrage zur Lehre vom Metamorphismus der Gesteine. Dietrich Riemer, Berlin, 1896, p. 186.

'Adams and Nicolson, cit., p. 397. 
pressed grains, and without the intervention of water or any other solvent." If this last sentence were written with the word may before "flow", no exception to the conclusion would be taken. While the process of flattening by movement along gliding planes undoubtedly occurs in marbles, it by no means follows, even in the 21 rocks in which the residual strain effects are described, that this was the chief process in their metamorphism. Indeed, in the production of the marbles from the original limestones, in order that the rocks conld change from the very fine-grained condition of limestone to that of marble, recrystallization must have occurred, as explained on pages 808-809. Therefore to explain the metamorphism of the 21 rocks showing residual strain effects, we must place recrystallization as the chief process. During or after this, mechanical deformation supplemented recrystallization and gave the various strain effects described. Indeed, the history of these 21 rocks is very nearly analogous to the complete history of the Carrara marble experimentally deformed by Adams and Nicolson. Nature, in producing the Carrara marble free from strain effects, utilized recrystallization as the chief process. Later Adams supplemented this process by mechanical deformation. This later artificial deformation was an umimportant episode as compared with the recrystallization by nature.

Therefore, while I have no doubt that during the deformation of marble all the mechanical movements which Adams and Nicolson have described occurred, I hold that these, in the case of the production of marble from limestone, are entirely subordinate to, although they assist, the dominant process of solution and deposition, or recrystallization. And if this be true for marbles it can not be doubted that for those rocks composed of minerals which are less mobile than calcite and dolomite, and which do not have ready gliding planes in various directions, recrystallization was the process of paramonnt importance. It is certainly yet to be proved that, in such rocks as the slates, schists, and gneisses, movement along gliding planes is a process of consequence in their metamorphism.

CHERTY LHESTONES, CHERTY DOLOMTES, AND CHERTY MARBLES.

Chert is a term used to include all forms of finely crystalline nonfragmental silica, including opaline, semicrystalline, and completely crystalline varieties. It differs from quartzite and novaculite in being nonfragmental. 
It is well known that in many limestones, dolomites, and marbles are nodnles and belts of opal, semicrystalline opal, chalcedony, finely crystalline quartz, or coarsely crystalline quartz, or various combinations of these materials. Such rocks are called cherty limestones, cherty dolomites, and eherty marbles. The siliceons material may constitute separate nodules. The nodules may unite at their ends so as to form layers of varying thickness within the limestone. The chert may be in bands with no evidence of a nodular character. Bands of chert usually have a lenticular form. The lateral extent of the lenses is likely to be in direct proportion to their thickness. The layers, which are a few centimeters in thickness, are nsually only a few meters in lateral extent. The less numerous layers, which are several meter's in thickness, may have a lateral extent of a number of kilometers. At the horizon at which one lens dies out others may appear, and thus the large lenticular bands at a definite horizon be analogous in their relations to magnified nodules. Rarely the masses of chert are many meters thick and many kilometers in length, constituting considerable formations. So far as such formations occur, they are treated on a subsequent page. The limestone or marble formations containing 'nodules or' thin layer's or bands of chert as subordinate members, and nsually having no great lateral extent, are known as cherty limestones or cherty marbles.

The majority of those who have worked on chert in the cherty limestones, including Wallich, Sorby, Sollas, and Hinde, regard the silica of the chert as having been deposited by organisms sinultaneonsly with the limestone. Of these organisms siliceous sponges appear to be the most important, although radiolaria and diatoms are of much consequence. All these aninals live under essentially the same conditions as the limestonebuilding animals. On the whole, in proportion as rocks are old, the evidence of the organic origin of the silica becomes less and less. Oftentimes in the Paleozoic and pre-Paleozoic cherty limestones no remuants of sponge, diatom, or radiolarian can be found. But this does not show that organisms were not as important in these formations as in the later formations, since there has been a longer time for their obliteration through reerystallization. On the whole; I incline to the belief that the silica of the cherty limestones and marbles is mainly dne to organic precipitation, althongh this source is supplemented by contributions furnished by ground water's, as explained below.

$$
\text { MON XLVII- } 04-52
$$


The question now arises why the chert occurs so generally segregated in ngdules, thin layers, and bands in the limestone. The silica as deposited by organisms is in the amorphous, and therefore readily soluble, form. It has been explained on pages 120-123 that during the rearrangement of minerals by solution and deposition there is a marked tendency for those of the same kind to segregate, and this tendency is strong in proportion as the minerals are readily soluble. At a point where there is more than an average amount of silica, especially large grains of quartz, this silica draws to it silica from the surrounding rocks through the solutions, under the principle expounded on pages $74-76$, that large masses and grains grow at the expense of smaller ones. In this principle we have the explanation not only of the segregation, but of the lenticular character which is so characteristic of the masses. The principle under which larger masses or grains grow at the expense of smaller ones is that the change tends to give the total mass the smallest surface area. This would be ideally accomplished by the spherical form of the masses; but since openings are numerous and circulation is comparatively easy along the beds, the lenticular masses, especially those which are more than a few centimeters in diameter, have a greater lateral than vertical extent. But in proportion as the chert masses are small they are likely to approach the spherical form, and this gives proof of the correctness of the principle. It is therefore believed that the segregation and form of nodules and thin lenticular layers of chert in limestones are adequately explained by concentration through solution and deposition.

Where, however, there are bands of chert of considerable thickness, so as to constitute definite members of a formation, and especially where there are formations of chert, the above explanation is not adequate. It is probable that many such deposits were originally dominantly siliceous. The principle of the natural groupings of animals of like kind into a colony is well known. Where there was a colony of silica-secreting organisms a major band or formation of silica would form. Modern deposits composed of nearly pure silica formed by siliceous organisms show how lenticular bands of chert may have originated. For instance, the wellknown diatom deposit of chert used as tripoli at Richmond, Va., is about 10 meters thick. ${ }^{a}$ Such deposits may have been enlargerl by segregations

a Merrill, George P., The nonmetallic minerals of the U. S. National Museum: Rept. Smithsonian Inst. for 1899, Washington, 1901, p. 219. 
from the surrounding limestone, for in regions in which there are local colonies of silica-secreting organisms there are sure to be sinilar organisms among the limestone-secreting organisms.

Therefore I hold that the nodules and minor bands of chert in the limestones are mainly due to segregations by-solution and deposition, but that many of the larger and more persistent bands of chert are at places where the silica was originally deposited in large part by the siliceous organisms, although the silica of such bands has msually been rearrangerl. Both original and secondary masses of ehert may occur in the same formation. For instance, in the lead and zine district of soutluwestern Missouri, in the Carboniferous limestone are one or more large and continuous bands of chert which can be mapped as separate members of a formation, and these are believed to be chiefly original. But in this limestone are innmmerable minute bands and lentils, from a fraction of a centimeter to several centimeters in thickness, and extending from a few centimeters to a few meters, to which the colonization theory can not be fully applied, and which were doubtless largely segregated as above described. Bands of intermediate width are doubtless due in varying degrees to original deposition and to secondary segregation. Where limestone containing chert reaches the surface, it is well known that the amount of the cherty material in the belt of weathering is relatively great This is largely due to the more ready solubility of the limestone than of the chert, in consequence of which the percentage of chert is increased. At or near the surface the removal of the limestone may be almost or quite complete, and thus produce a partly coherent or even incoherent belt of almost pure chert along the surface. In many cherty limestone regions, where the soil is residual, one might think that nearly the entire rock was chert, so prominent does this material appear in the soil and in the rock near the surface.

The silica originally present in a given mass of limestone in consequence of organic precipitation is not the only source of silica for nodules and bands of chert. The silica of the limestone in the belt of cementation may be greatly increased. This may be done in two ways. First, where the limestones reach the surface, and the segregation above mentioned takes place in the belt of weathering, a part of this siliea is being continuously dissolved and transported downward into the belt of eementation This process is especially active where the silica las not hecome wholly. 
crystallized. Second, limestones in the belt of cementation may receive important additions of silica even where they do not reach the surface but are overlain by other rocks. It has been explained that the process of carbonation of the silicates liberates colloidal silicic acid. This is taken into solntion, and passes downward into the belt of cementation. The material transported to this belt, either from another part of the limestone or from the silicates, is selectively precipitated as explained on pages 63t-636, the limestone being simultaneously dissolved, and thus silicification takes place.

This process of segregation of silica, both within the belt of weathering of the limestones and in the belt of cementation, is steadily cumulative. Therefore it is possible for limestones which originally were not especially siliceous to contain considerable amomnts of silica. However, it is supposed that usmally those limestones which are heavily siliceous contained originally a considerable quantity of silica as an organic precipitate.

SILCATEI) MARBLES.

The silicated marbles are products intermediate between marbles and the silicate rocks. The processes by which they are formed are a combination of those producing marble and those resulting in silication of the carbonates. These processes will not be described in detail here, since they are given under the immediately preceding and sncceeding headings. The conditions for their formation are intermediate between those ruling in the production of evenly granular pure marble and those ruling in the complete replacement of the carlon dioxide by silica.

Like the marbles and the silicate rocks, the silicated marbles form in the zone of anamorphism, and especially in connection with meehanical action or igneous intrusion. The most abundant silicate minerals of the marbles are pyroxene and amphibole, but many other silicates may form. Of these, olivine, chondrodite, vesuvianite, tourmaline, and mica are the most important. In any given case one or two silicates may be the preponderant ones, and under such circumstances a more definite name may be given to an individual rock or formation. For instance, if tremolite is the dominant silicate it may be called a tremolitic marble (Pl. V, B); if diopside is the dominant silicate it may be called a diopsidic marble. If two silicates occur together, as, for instance, diopside and olivine, the rock 
may be called a diopsidic and olivinitic marble. In a similar mamer, other appropriate names may be given to individual formations, more accmately defining their character than the general term silicated marbles.

Of the two most prevalent gronps of minerals, pyroxene and amplibole, calcium is more abundant in the former. Therefore from the nearly pure calcium carbonate rocks the pyroxenes are likely to develop, rather than the ampliboles. Thus from the rocks which lave not been strongly dolomitized wollastonite and diopside form, rather than tremolite, becanse the latter mineral requires a larger proportion of magnesium. Where the rocks have been dolonitized before silication the amphibole tremolite is especially likely to devolop

In the calcareons rocks in which there is a considerable amount of fragmental material mingled, and consequently aluminum is plentiful, the aluminous pyroxenes and amphiboles are likely to form.

In so far as the process of silication takes place by the combination of solid silica with the carbonate, and the liberated carbon dioxide escapes, the volume of the rock is decreased. The decrease in volume varies from a very small percentage to very considerable amounts as they approach the silicated rocks, which have a decrease in volume varying from 20 to 40 per cent.

The silicated marbles grade into the pure marbles on the one hand and into the silicate rocks on the other. The term silicated marble is properly applied to rocks which lange from those in which the silicate minerals are umimportant to those in which the carbonates are subordinate. Those rocks in which the silicates are not abundant should be classified with the marbles, and those in which the carbonates are not abmidant should be classified with the silicate rocks Thus limited, the silicated marbles occur at very numerous localities among the rocks profoundly netamorplosed under deep-seated conditions. This state of affairs naturally exists to a greater extent among the old than among the new formations, and therefore this class of rocks is especially abundant among the Paleozoic and prePaleozoic sedimentary rocks. Illustrative localities of the silicated marbles occur in almost every country. The best representatives in this comntry are found in the pre-Cambrian formations of Lake Snperior and Canada. and in the Paleozoic formations of the Appalachian region. 


\section{SILICATE ROGKS.}

In certain localities the limestones and dolomites may be wholly replaced by silicates. Of these silicates the most important are the pyroxenes and amphiboles. Of the pyroxenes the most common are wollastonite, diopside, and salılite. Of the amphiboles the most important are tremolite and actinolite. Of course other pyroxenes and amphiboles may be present, such as the augites and hornblende. Other silicates which rather frequently replace limestones are olivine, mica (including muscovite, biotite, and phlogopite), chondrodite, vesuvianite, and toumnaline. In fact, almost any of the dense silicates may develop. The limestones are transformed to silicate rocks only in the zone of anamorphism. The silicates are the nltimate products of alteration under the conditions there obtaining. The process is one of simple silication ; the silica originally present in the limestone, or contributed to it by ground waters, replaces the carbon dioxide and forms the silicate.

If the rock be pure limestone, wollastonite forms, according to the following reaction:

$$
\mathrm{CaCO}_{3}+\mathrm{SiO}_{2}+\mathrm{nH}_{2} \mathrm{O}=\mathrm{CaSiO}_{3}+\mathrm{CO}_{2}+\mathrm{nH}_{2} \mathrm{O},
$$

with a decrease in volume of 31 per cent, provided the silica is a solid and the carbon dioxide escapes.

If the rock be magnesian, diopside or tremolite forms, according to the following reactions, respectively:

$$
\begin{aligned}
& \mathrm{CaIIg}\left(\mathrm{CO}_{3}\right)_{2}+2 \mathrm{SiO}_{2}=\mathrm{CaMgSi}_{2} \mathrm{O}_{6}+2 \mathrm{CO}_{2}, \\
& 3 \mathrm{Ca} I \mathrm{Ig}\left(\mathrm{CO}_{3}\right)_{2}+4 \mathrm{SiO}_{2}=\mathrm{CaIIg}_{3} \mathrm{Si}_{4} \mathrm{O}_{12}+2 \mathrm{CaCO}_{3}+4 \mathrm{CO}_{2},
\end{aligned}
$$

with a decrease in volume of 40.11 and 25.20 per cent, respectively, provided the silica is a solid, the calcium carbonate remains as a solid when tremolite forms, and the liberated carbon dioxide escapes.

If the limestone be one which contains many bases in important amounts, other more complex silicates develop, with variable decreases in volume; and thus we have the explanation of subordinate amounts of angite, hornblende, mica, chondrodite, vesuvianite, tourmaline, etc., which are so common as replacement products of marble.

The localities in which the calcimm-carbonate formations liave been completely changed to silicate formations are comparatively few, and at 
such localities the formations are usually not extensive. These deposits are well illustrated by the kalk-silikat-hornfelse of the Harz Mountains, described by Lossen and Rosenbusch. ${ }^{a}$

\section{QENERAL STATEMLNTS.}

The processes of crystallization, dolomitization, silicification, and silication of the limestones and the resultant rocks have been separately described as if each occurred alone. As a matter of fact; in the field all the processes may occur together in various proportions, and hence we may have all gradations between limestone and dolomite, between limestone and marble, between pure limestones, dolomites, and marbles and siliceous limestones, dolomites, and marbles, and between these rocks and those in which the process of silicification is complete. Finally, we may have all gradations between the various forms above mentioned and those in which the silicates have developed in subordinate, important, or dominant amounts. Therefore, within the limestone series there are complete gradations between the various rocks of the series.

IRON-BEARING CARBONATE FAMILY AND METAMORPHOSED EQUIVALENTS.

The iron-bearing carbonate family and metamorphosed equivalents comprise siderite, ankerite, and parankerite; ferruginous shales, ferruginous cherts, and jaspilites; actinolitic and griuneritic marbles; and actinolitic quartz rocks and grïneritic quartz rocks.

\section{SIDERITE, ANKERITE, AND PARANKERITE.}

The original forms of the iron-bearing carbonates include siderite, ankerite, parankerite, and gradations between them. (Pl. VII, A.) With these carbonates, as with the less ferriferous carbonates, chert is an almost universal associate. It varies in amount from a minute quantity to an important amount, and occasionally to dominance. The alterations of the above carbonate compounds as minerals have been considered on pages 242-245. As rock masses they may be considered under the terms siderite and ferrodolomite, including under the latter term all gradations between siderite on the one hand and dolomite on the other.

The iron-bearing carbonates occur mainly in layers in the stratified rocks, and are therefore of sedimentary origin. 
The bedded iron-bearing carbonates vary from nearly pure carbonate material through siliceous and clayey iron-bearing carbonates to carbonaceous, siliceous, and argillaceous rocks. The most widespread of the ironbearing carbonates are of Carboniferous age. Other extensive deposits of iron-bearing carbonates are those of Algonkian age in the Lake Superior region. A subordinate amonnt of the iron-bearing carbonates occurs as veins, but so far as this is true the material will not be here considered.

OFIGIN OF RIDERITE, ANEERITE, AND PARANKERITE.

So far as siderite, ankerite, and parankerite are composed of calcium, magnesium, and carbonic acid, the sources of the materials are the same as for the same materials in the calcium-magnesinm carbonate family just considered. But we must aceount for the iron. As the iron-bearing carbonates are aqueous sedimentary rocks, the iron must have been deposited from water. The formations containing iron carbonate plentifully are generally local. Often they are associated with carhonaceons rocks. Many of them are closely associated with the coals which are known to have formed in lagoons and estuaries, sone of which possibly were only imperfectly commected with the sea. Deposits from which coal is derived are formed at times of very luxuriant vegetation near the level of the sea, where the soil is very moist. It is believed that the physiographic conditions for the deposition of iron-carbonate deposits are similar to those which obtain in flat-lying areas near water level, where vegetation is very luxuriant. It nay be recalled that under such conditions carbonation of the silicates goes on very rapidly. (See Chapter VI, pp. 476-477.) The iron silicates are decomposed precisely as are the others. It has been fully explained on pages 470-471 that where vegetation is very abundant, in very humid areas, the oxygen of the soil is not sufficient for the oxidation of the regetation. It was seen that under such conditions ferric oxide oxidizes some of the residual regetation, and is thereby reduced to the ferrous oxide. The oxidation of the organic componnds produced abundant carbon dioxide. The ferrous oxide originally present and that formed by reduction unites with the carbon dioxide and produces iron carbonate.

Where soluble ferrous compounds are formed abundantly, as above described, it is probable that the rocks which are being destroyed in the 
belt of weathering are rather rieh in iron; for instance, intermediate or basic igneous rocks. If rock of this favorable composition were scoriaceous volcanic rocks, the conditions would be exceptionally favorable to the production of such salts by the process of carbonation of the silicates, the partial reduction of the ferric iron, and its union with carbonic or sulphuric acirs.

Such conditions are illustrated by the Lake Superior region, where the iron for the iron-bearing formations was largely derived from basic volcanic rocks. In that region in each of the important iron-bearing districts below the iron-bearing series are found greenstones, often ellipsoidal, in many places porous and amygdaloidal, in many places sehistose, all rich in iron. Below the Mesabi, Penokee, Marquette, and Menominee series are great masses of basic voleanic rocks. In the Penokee and Crystal Falls distriets basic volcanic ontflows were contemporaneous with or immediately preceded the deposition of the iron-bearing formation. In the Vermilion distriet of Mimnesota and in varions districts of Canada, including the Michipicoten district, the iron-bearing formations immediately overlie enormous masses of ellipsoiclal and often amygdaloidal basic volcanic formations.

The ground waters take iron compounds abundantly into solution wherever the rocks are of a composition and texture favorable to furnishing iron. The waters take a longer or shorter jonrney before issuing at the surface. The issuing waters, aside from the iron eompounds, contain, among other abundant compounds, the calcium and magnesium carbonates. Where extensive iron-carbonate deposits lave formed, it is probable that the sonrees of supply were adjacent to shallow standing bodies of water, such as arms of seas, lagoons, estuaries, etc. Under such circumstances the ground waters usually issue at the lower places a short distance above or below the level of the water. As has been explained, such bodies of water are generally rieh in vegetation. In these bodies the iron salts are preeipitated.

As to the form in which the iron salts enter the seas, we can judge only by analogy, but if the present be a guide to the past, the iron was chiefly as a carbonate and to a subordinate extent as a sulphate, although it might have been in part in the form of other salts. When the iron salts reach the lagoon, they are preeipitated under favorable eonditions as ferrie liydrate or 
possibly in part as basic ferric sulphate. Supposing the iron salt to be carbonate, it would be precipitated according to the following reaction:

$$
4 \mathrm{FeCO}_{3}+3 \mathrm{H}_{2} \mathrm{O}+2 \mathrm{O}=2 \mathrm{Fe}_{2} \mathrm{O}_{3} \cdot 3 \mathrm{H}_{2} \mathrm{O}+4 \mathrm{CO}_{2} \text {. }
$$

Where this process goes on, on an extensive seale, limonite bodies (considered on pages $842-843$ ) are built up.

It was formerly supposed that this reaction took place as a result of the work of oxygen and moisture alone, and this is true to some extent. But recent observation has shown that where in lagoons iron carbonate is abundant the oxidation is largely performed throngh the agency of a class of bacteria called the iron bacteria. It has been found that these bacteria are mable to exist withont the presence of iron carbonate or manganese carbonate, but the iron carbonate is the chief compound used. This material they absorb into their cells. There the iron carbonate is oxidized and the limonite is precipitated. Says Lafar:

The decomposing power of these organisms is very great, the amount of ferrons oxide oxidized by the cells being a high multiple of their own weight. This high chemical energy on the one hand, and the inexacting demands in the shape of food on the other, secure to these bacteria an important part in the economy of Nature; the enormons deposits of ferrnginous ochre and bog iron ore, and probably certain manganese ores as well, being the result of the activity of the iron bacteria. $^{a}$

Evidence is furnished of the precipitation of the limonite of bog ironore deposits in this manner by the discovery in some of them of large numbers of the sheaths of the iron bacteria. ${ }^{b}$ Further evidence of the importance and activity of these bacteria is furnished by their partly or completely closing water pipes of cities where the water contains a considerable amount of iron carbonate.

The iron part of the salts carried down to the sea as a.sulphate would be likely to be thrown down as basic ferric sulphate, ${ }^{a}$ according to the following reaction:

$$
12 \mathrm{FeSO}_{4}+6 \mathrm{O}+(\mathrm{x}+9) \mathrm{H}_{2} \mathrm{O}=\mathrm{Fe}_{2}\left(\mathrm{SO}_{4}\right)_{3} \cdot 5 \mathrm{Fe}_{2} \mathrm{O}_{3} \cdot \mathrm{xH}_{2} \mathrm{O}+9 \mathrm{H}_{2} \mathrm{SO}_{4} .
$$

a Lafar, F., Technical mycology, Lippincott \& Co., 1898, vol. 1, p. 361.

$b$ Fischer, A., The structure and functions of bacteria, trans. by A. Coppen Jones, Clarendon Press, Oxford, 1900, p. 69 .

c Lafar, cit., p. 361.

a Pickering, S. P. U., On the constitution of molecular compounds; the molecular weight of basic ferric sulphate: Jour. Chem. Soc. London, vol. 43, 1883, p. 182. 
The material thrown down as a hydrated ferric oxide and basic ferric sulphate is mingled with more or less of organic material, and a deposit of considerable thickness may thus be built up. This deposit is below the level of ground water, and is therefore in the zone of incomplete oxidation, or is under the conditions of the belt of cementation. The oxygen required for the partial oxidation of the organic material is derived in part from the ferric oxide, and the iron is reduced to the ferrous form; butprobably this reaction does not take place on an important scale at the surface. The reducing agent may be regarded as carbon, carbon monoxide, or some of the carburetted hydrogens, such as methane. The result is the same in any case. The oxygen and the carbon produce carbon dioxide, and thus the conditions are reproduced for the production of iron carbonate. A representative reaction may have been as follows:

$$
2 \mathrm{Fe}_{2} \mathrm{O}_{3} \cdot 3 \mathrm{H}_{2} \mathrm{O}+3 \mathrm{CO}_{2}+\mathrm{C}=4 \mathrm{FeCO}_{3}+3 \mathrm{H}_{2} \mathrm{O} .
$$

In the Mesabi district of Minnesota Leith has shown that a compound, which he has called greenalite, exists on an extensive scale as an important original mineral of the iron-bearing formation. ${ }^{a}$ (Pl. VII, B.) The exact composition of greenalite has not yet been determined, but according to Clarke it appears to be either

$$
\mathrm{Fe}^{\prime \prime \prime}{ }_{2} \mathrm{Fe}_{3}{ }_{3}\left(\mathrm{SiO}_{4}\right)_{3} \cdot 3 \mathrm{H}_{2} \mathrm{O} \text { or else } \mathrm{FeSiO}_{3} \cdot \mathrm{nH}_{2} \mathrm{O} \text {, }
$$

with the probability somewhat in favor of the latter composition. ${ }^{b}$ Where silica in a colloidal form is especially abundant, with limonite produced as explained above, and with organic matter to serve as a reducing agent, the silica may unite with the ferrous oxide produced by the reduction of the ferric oxide to ferrous oxide through the organic matter, and thus with hydration produce hydrous ferrous silicate. The formation of the hydrous silicate under such circumstances, rather than the carbonate, may have been dependent upon the law of mass action.

The principles are illustrated by the conditions under which the oxidized compounds of zine occur in the Wisconsin and southwestern Missouri districts. In the Wisconsin district silica is not especially abundant, and where zinc sulphide is oxidized the zine oxide unites with carbon dioxide

$a$ Leith, C. K., The Mesabi iron-bearing district of Minnesota: Mon. U. S. Geol. Survey, vol. 43, 1903, pp. 100-I68.

${ }^{b}$ Leith, cit., p. 246 . 
and forms smithsonite $\left(\mathrm{ZnCO}_{3}\right)$. But in Missouri silica, partly in the amorphous form, is very abtindant; and there, when the zinc sulphide is oxidized, the oxide of zinc largely unites with the silica, forming calamine $\left[(\mathrm{ZnOH})_{2} \mathrm{SiO}_{3}\right]$. Both smitlssonite and calamine oecur in both clistricts, but calamine occurs abundantly only where silica is abundant. Similarly, where in lagoons the iron is reduced to the ferrous form, it would unite with the silica on a large scale, provided that compound were abundantly present in a form suitable for union. Hence the hydrated ferrous silicate of the Mesabi district is regarded as a product of the chemical reactions of the zone of katamorphism.

Another iron compound, besides ferrous silicate, which is associated with iron-bearing carbonates is iron sulphide. It is believed that this compound results from the reduction of the basic ferric sulphate. It has been pointed out that, so far as the iron goes into lagoons as a sulphate, it is thrown down as basic ferric sulphate $\left[\mathrm{Fe}_{2}\left(\mathrm{SO}_{4}\right)_{3} \cdot 5 \mathrm{Fe}_{2} \mathrm{O}_{3} \cdot \mathrm{xH}_{2} \mathrm{O}\right]$. This compound in the belt of cementation in the presence of organic matter which strongly demands oxygen is reduced, the oxygen being abstracted from the sulphur, and so far as possible from the iron, thus producing bisulphide of iron. The excess of ferrous iron unites with the carbon dioxide, or exceptionally in part with the silica, forming ferrous carbonate or ferrous silicate. Supposing ferrous carbonate were formed, and the reducing agent to be $\mathrm{CO}$, the reaction may be written:

$$
2\left[\mathrm{Fe}_{2}\left(\mathrm{SO}_{4}\right)_{3} \cdot 5 \mathrm{Fe}_{2} \mathrm{O}_{3} \cdot \mathrm{xH}_{2} \mathrm{O}\right]+33 \mathrm{CO}=3 \mathrm{FeS}_{2}+21 \mathrm{FeCO}_{3}+12 \mathrm{CO}_{2}+2 \mathrm{xH}_{2} \mathrm{O} .
$$

In an analogous manner the reaction may be written for ferrous silicate as follows:

$$
2\left[\mathrm{Fe}_{2}\left(\mathrm{SO}_{4}\right)_{3} \cdot 5 \mathrm{Fe}_{2} \mathrm{O}_{3} \cdot \mathrm{xH}_{2} \mathrm{O}\right]+33 \mathrm{CO}+21 \mathrm{SiO}_{2}=3 \mathrm{FeS}_{2}+21 \mathrm{FeSiO}_{3}+33 \mathrm{CO}_{2}+2 \mathrm{xH}_{2} \mathrm{O} .
$$

So far as there is water in the silica or the ferrous silicate, this may be added to both sides of the equation. The reducing agent may be supposed to be $\mathrm{C}$ or $\mathrm{H}$ or some combination of the two. This would modify the equation, but would not change the principle involved.

Perhaps the formation of the compounds, ferrous silicate and bisulphide of iron, can not logically come nuder the caption "iron-bearing carbonates;" but since they occur with the iron-bearing carbonates as subordinate constitnents, and only in a few districts in sufficient masses to be regarded as independent formations, they are here considered. 
It is concluded from the foregoing that the main sources of the ironbearing carbonates are the iron-bearing silicates of various rocks, and especially intermediate and basic igneous rocks which are porous. From these, iron carbonate and other soluble iron salts are produced by the reactions of the belt of weathering. They are transported to inclosed or partly inclosed bodies of standing water by the underground solutions. The material is there thrown down, mainly as ferric hydrate. By the action of the organic natter upon the ferric iron it is reduced to ferrous oxide and unites with the carbon dioxirle simultaneously produced, or with silicic acid, forming iron carbonate or iron silicate. So far as the iron is a sulphate it is reduced wholly or in part to sulphide.

In what mamer the calcium and magnesium are thrown down with the iron is uncertain. In the inclosed lagoons, which must have been of exceptional character, as shown by the precipitation of the iron itself, it is possible that calcium and magnesium might so accumulate as to be precipitated chemically, and thus the carbonate be originally an iron-bearing calcium-magnesium carbonate, in which the iron varies fiom a subordinate to a dominant constituent. This suggestion is the more plausible because where iron is abundantly precipitated as hydroxide and remains in that form life is usually somewhat sparse. While this may be a partial explanation of the precipitation of the calcium and magnesium, the calcium may have been mainly thrown down through the instrumentality of life, in the same manner as were the ordinary limestones, and the substitution of magnesium for calcinm may have occurred subsequently, precisely as in the case of the limestones, thus forming the ferrodolomite.

FERRUGIXOUS SHALES, FELRUGIXOCS CHERTS, AND JASPILITES.

In the zone of katamorphism ferruginous shales or ferruginous cherts are produced from the iron-bearing carbonates, and by modifications of these in the zone of anamorphism jaspilites are formed. By ferruginous shales are meant rocks which bave a bodded structure and are composed mainly of oxide of iron, but which include a greater or less quantity of finely disseminated quartz. By ferruginous cherts are meant those rocks which consist of two sets of bands, one of which is composed nainly of iron oxide and the other mainly of chert. 
FERRUGINOUS SHALES.

The ferruginous shales are produced from siliceous siderite, ankerite, or parankerite, by the decomposition of the iron carbonate and the partial or complete oxidation and lydration of the ferrous oxide, combined with the rearrangement of the particles, and fiequently the introduction of silica. In the zone of katamorphism the first alteration is the oxidation and partial or complete hydration of the ferrous oxide, with the liberation of carbon dioxide, thus producing limonitic and hematitic slate and various gradations between them. The reaction for hematite is as follows:

$$
2 \mathrm{FeCO}_{3}+\mathrm{O}=\mathrm{Fe}_{2} \mathrm{O}_{3}+2 \mathrm{CO}_{2} \text {. }
$$

For limonite it is:

$4 \mathrm{FeCO}_{3}+3 \mathrm{H}_{2} \mathrm{O}+2 \mathrm{O}=2 \mathrm{Fe}_{2} \mathrm{O}_{3} \cdot 3 \mathrm{H}_{2} \mathrm{O}+4 \mathrm{CO}_{2}$.

Where the constituents of the rock are not extensively rearranged the original regular stratiform arrangement of the siderite is preserved, and the rock is called a ferruginous shale. Where the iron oxide is mainly hematite the rock may properly be called hematitic shale; where mainly limonite, a limonitic shale; and where both are abundant, lematitic and limonitic shale. Simultaneously with the oxidation of the iron carbonate, calcium and magnesium carbonate, so far as they are present, may be partially or completely dissolved.

FERRUGINOUS CHERTS.

At the same time the iron carbonate is altered the silica, which is usually present in greater or less quantity, may become concentrated in layers by exactly the same process as it becomes concentrated in layers in limestones, and thus there may be produced a hematitic and limonitic chert. The rock may be somewhat regularly banded, or the bands may be very irregular and broken. As the rearrangement goes further, oxide of iron is apt to become concentrated is bands, alternating with bands which are predominantly chert. Also in this stage a concretionary nodular or geodal character is apt to be developed, and then the material may be called banded iron oxide and chert, or chert with bands and shots of iron oxide. (Pl. VII, C.) In the earlier stages frequently the silica, as in the original rock, is partly opaline, and as the rearrangement becomes more nearly complete the silica takes the form of finely crystalline, interlocking 
quartz. Each grain may become coated with a film of hematite, thus giving it a red color. Some of the more irregularly banded rocks have been called cherts with bands and shots of ore. In these rocks minute openings exist between the particles, and minor geodal cavities are very common, thus giving the rock a porous character. 'This porosity results in part from the diminution in volume in the change from iron carbonate to hematite or limonite. Also it is partially caused by the solution of the calcium and magnesium carbonates and silica more rapidly than iron oxide is substituted for these materials. During the process the dissolved iron carbonate may be transported a greater or less distance. In openings precipitation may take place, and thus veins of hematite or limonite be produced. Under favorable conditions, which are more fully discussed in Chapter XII, on "Ore deposits," the excess of silica and other material may be dissolved and nearly pure hematite or limonite bodies be formed. Thus from the iron carbonate large iron-ore deposits are produced. The details of the process of transformation I have fully discussed elsewhere. ${ }^{a}$

In closing this part of the subject it may be noted that to the stage where the ferruginous shales and ferruginous cherts are prodnced the iron has been twice in the form of the carbonate, or once as a carbonate and once as a silicate, and twice in the form of an iron oxide, and, therefore, that at least four chemical transformations have occured to that time. These were: (1) When the material was first taken into solution as carbonate, (2) when it was precipitated in the sea as hydroxide, (3) when it was transformed to an iron carbonate or hydrous iron silicate, and (4) when by the underground waters it was again chemically changed to limonite or hematite.

\section{JASPILITES.}

The jaspilites are banded rocks, the bands being composed of hematite and chert in varions proportions. The jaspilites differ from the feruginous cherts in that the siliceous bands have a bright-red color, due to the fact that each granule of quartz is coated with and includes innumerable minnte flakes of blood-red hematite. The bands in which the iron oxide is predominant are composed chiefly of specular hematite.

a Irving, R. D., and Van Hise, C. R., The Penokee iron-bearing series of Michigan and Wisconsin: Mon. U. S. Geol. Survey, vol. 19, 1892, pp. 268-295. Van Hise, C. R., The iron-ore deposits of the Lake Superior region: Twenty-first Ann. Rept. U. S. Geol. Survey, pt. 3, 1901, pp. 326-328. 
The hematitic and limonitic shales produced in the zone of katamorphism, and especially in the belt of weathering, are so unlike the original rocks from which they were derived that one would not be inclined to believe that they were derived from ferriferous carbonates if the actual transitions had not been traced at many localities. ${ }^{a}$

After the ferruginous shales and ferruginous cherts have developed they may undergo still further alterations. For instance, the hematitic and limonitic shales may, after having been formed, become deeply buried, and thus pass into the zone of anamorphism. In this position they are in the zone of dehydration, and this process will occur, especially if mass. mechanical action takes place. Thus there are produced the banded hematitic siliceous rocks known as jaspilites, which are merely banded hematite and quartz rocks. In some of the bands the quartz is dominant, in others the hematite is dominant, and in still others both are abundant. In the quartz bands innumerable minute grains of quartz are stained by still more numerous microscopic flakes of red oxide of iron. The iron oxide bands usually include nucl quartz. In proportion as mass-mechanical action is severe the rocks take on a strongly developed schistose structure, due to the similar dimensional arrangement of the hematite flakes. From the nearly pure iron-oxide bands, bands of hematite-schist are produced, the hematite being in brilliant parallel flakes resembling' flakes of mica. 'These bands of hematite are similar to the solid specular ore bodies.

Excellent illustrations of hematitic schists and jaspilites are furnished by the upper horizon of the Lower Huronian of the Lake Superior region, especially in the Marquette district. In this district, after the original iron carbonate had formed, the upper part of the formation was subjected to alteration in the belt of weathering on an extensive scale, and thus was transformed to hematitic and limonitic shales. It was afterwards buried under the great mass of deposits of the Upper Huronian, and thus passed into the zone of anamorphism. Later with that series the ferruginous

a Irving, R. D., and Van Hise, C. R., The Penokee iron-bearing series of Hichigan and Wisconsin: Ilon. U. S. Geol. Survey, vol. 19, 1892, pp. 193, 201-202, 205, 253, 294. Clements, J. Morgan, and Smyth, H. L., with W. S. Bayley and C. R. Van Hise, The Crystal Falls iron-bearing district of Michigan: Mon. U. S. Geol. Survey, vol. 36, 1899, p. 62. Van Hise, C. R., with Bayley, W. S., and Smyth, H. L., The Marquette iron-bearing district of Michigan: Mon. U. S. Geol. Survey, vol. 28, 1897, pp. 336-375. Bayley, W. S., The Menominee iron-bearing district of Michigan: Mon. U. S. Geol. Surrey, rol. 46, 1904, pp. 397, 466-468. 
shales were subjected to profound mass-mechanical action and then were transformed to jaspilites. Simultaneously with the process of jaspilitization of the upper part of the iron-bearing formation the basal conglomerate of the Upper Marquette series, largely composed of the weathered material of the iron-bearing formation, was transformed to a jasper-conglomerate. It has been noted that the formation of the ferruginous shales and ferruginous cherts required four chemical transformations. Where jaspilites occur a fifth chemical change luas taken place-dehydration.

\section{ACTINOLITIC AND GRÜNERITIC MARBLES.}

In the zone of anamorphism the alterations of the iron-bearing carbonates are entirely different in character from those in the zone of katamorphism. In the lower zone the iron carbonates go through a set of transformations which are aralogous to those of limestones under similar conditions. Furthermore, magnetite forms. 'Therefore the rocks which are first produced are actinolitic or grüneritic magnetitic marbles. In these rocks the chief constituents are dolomite, magnetite, and actinolite or griuerite, often also quartz.

The development of the dolomite is the same as in the marbles. By the silication of the carbonate either actinolite or grinerite is produced, with diminntion of volume-the former in case the bases present are calcium, magnesium, and iron, and the latter in case the carbonate was originally siderite or the original rock was greenalite (hydrous silicate of iron). Where some iron sulplide or oxygen is available a part of the ferrous iron may change to magnetite; and rarely a very little luematite may form. Very frequently there is greater or less rearrangement and concentration of the silica, so that bands or nodules of this material are formed. If the metanorphism takes place under mass-static conditions, there is little tendency for parallel orientation of the actinolite and grünerite. In proportion as the alteration occurs under mass-mechanical conditions there is a tendency for parallel orientation of the developing amphibole. Since actinolite-magnetite rocks or griunerite-magnetite rocks, the end products of the alteration of the siderites, ferrodolomites, and greenalite rocks are mnch more common than the intermediate rocks treated under this heading, the reactions producing the silicates are more fully discussed under the next heading.

MON XLVII-04-53 
ACTINOLITE-HAGETITE-QUARTZ ROCKS AND GRÜNERITE-MAGNETITE-QUARTZ ROCKS.

The actinolite-magnetite-quartz rocks consist of interlocking actinolite, magnetite, and quartz, with or without other iron oxides, and accessories of varions kinds. (Pl. VII, D.) The griinerite-magnetite-quartz rocks consist of interlocking grünerite, magnetite, and quartz, with or without other iron oxides, and accessories of varions kinds. In a given case the magnetite or actinolite or griinerite may drop ont, or nearly so. Where the magnetite becomes subordinate the rocks are actinolite-quartz rocks and grïneritequartz rocks; where the actinolite or grïnerite drops out the rocks become magnetite-quartz rocks.

The conditions under which these rocks form are those of the zone of anamorphism. In 'many cases the actinolite and grinerite have a random or radial fibrous arrangement to their bands, but in other cases they are arranged with their longer axes in a common direction, with a marked tendency toward crystallographic orientation. Where the parallel arrangement of the amphibole occurs the quartz and magnetite also have a tendency to have their longer dimensions in the same direction as that of the actinolite and magnetite. Where this arrangement is marked-and this is very common-the term gneiss is properly applicable to the rocks; and thus we may have actinolite-quartz-gneiss, magnetite-quartz-gneiss, etc. The amount of parallel arrangement of the particles is a measure of the amount of orogenic movement during the process of recrystallization. Where there is little tendency to parallelism the rocks were probably crystallized by metasomatism under mass-static conditions. Where the arrangement is well developed the recrystallization occurred during powerful orogenic movement.

This relation is well illustrated by the Marquette district of Michigan. In the central part of the district the folding is only moderately close, and there the parallel arrangement of the mineral particles is very imperfect. At the west end of the district the folding is of the closest and most intense character, and there are beantiful coarse actinolitic and grïneritic gneisses, many of the mineral particles of which are arranged with almost perfect parallelism.

The most important change of the iron carbonate is to a silicate. Where the carbonate is nearly pure siderite, grïnerite is produced, according to the following reaction:

$$
\mathrm{FeCO}_{3}+\mathrm{SiO}_{2}=\mathrm{FeSiO}_{3}+\mathrm{CO}_{2} \text {, }
$$




\section{PLATE VII}




\section{PLA TE VII.}

\section{PHOTOMICROGRAPHS OF IRON-BEARING ROCKS.}

t. Sideritic rock from Penokee-Gogebic district of Michigan and Wisconsin.

B. Greenalite or ferrous silicate rock from Mesabi district of Minnesota. After Leith.

c. Concretionary ehert resulting from the alteration of iron carbonate. From Penokee-Gogebic distriet of Michigan and Wisconsin.

D. Actinolite-magnetite-quartz rock resulting from the alteration of iron carbonate. From PenokeeGogebic district of Michigan and Wisconsin. 

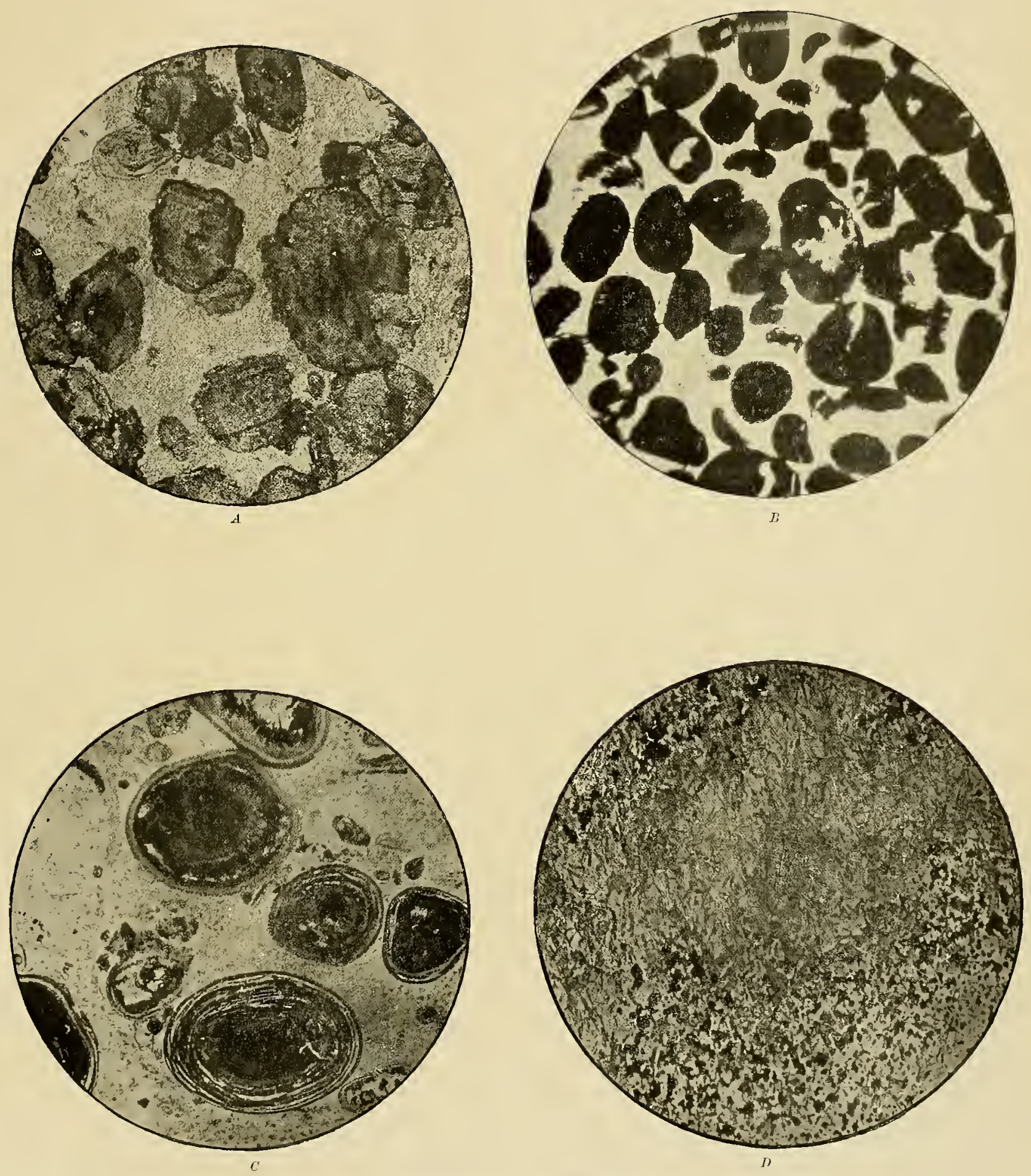

PHOTOMICROGRAPHS OF IRON-BEARING ROCKS. 
with a decrease of volume of 32 per cent, provided the silica be a solid and the carbon dioxide escape. Where the original material was hydrous ferrons silicate, greenalite, simple dehydration only is necessary to form the grimerite.

Where the iron-bearing carbonate bears calcium and magnesium in considerable quantity, instead of griinerite being produced sahlite or actinolite may be formed. Supposing the carbonate to be normal ankerite, sahlite is prodnced, according to the following reaction:

$$
\mathrm{CaFeC}_{2} \mathrm{O}_{6} \cdot \mathrm{CaMgC}_{2} \mathrm{O}_{6}+4 \mathrm{SiO}_{2}=\mathrm{Ca}_{2} \mathrm{MgFeSi}_{4} \mathrm{O}_{12}+4 \mathrm{CO}_{2},
$$

with a decrease in volume of 37 per cent, provided the silica be solid and the carbon dioxide escape.

From ankerite actinolite may be produced, according to the following reaction:

$$
3\left(\mathrm{CaFeC}_{2} \mathrm{O}_{6} \cdot \mathrm{Ca} \lambda\left[\mathrm{ggC} \mathrm{O}_{6}\right)+8 \mathrm{SiO}_{2}=\mathrm{Ca}_{2} \mathrm{Ig}_{3} \mathrm{Fe}_{3} \mathrm{Si}_{8} \mathrm{O}_{24}+8 \mathrm{CO}_{2}+4 \mathrm{CaCO}_{3},\right.
$$

with a decrease in volume of 23 per cent, provided the silica be a solid, the $\mathrm{CaCO}_{3}$ formed remain as a solid, and the carbon dioxide escape.

If a more ferriferous and less calcareous iron-bearing carbonate be taken, it would not be necessary to suppose any calcinm carbonate to have separated.

The iron-bearing carbonates may be very impure, just as limestones may be impure; and in this case there may develop various other minerals. In proportion as impurities are mingled with the carbonates, other amphiboles and the pyroxenes, micas, garmets, and other heavy minerals such as olivine, may abundantly derelop; and thus there may be produced a great variety of rocks, such as garmetiferous magnetite rocks, micaceous grinerite rocks, etc. As the impurities become abundant and the silicates other than griinerite, sahlite, and actimolite more prominent, the alterations become nearly those of the fragmental rocks, considered on page 853 et seq. Between the two there are of course all gradations.

But as a matter of fact, the two silicates which most extensively form by the alterations of the iron-bearing carbonates in the zone of ananorphism are actinolite and grimerite. Where these reactions are complete we may lave, in place of the iro:l-bearing carbonate, actinolite rocks, grinerite rocks, and all gradations between them. 
With the grïnerite, actinolite, sahlite, or other silicates, magnetite usually develops to some extent, probably as follows:

$2 \mathrm{FeCO}_{3}+\mathrm{FeS}_{2}+2 \mathrm{H}_{2} \mathrm{O}=\mathrm{Fe}_{3} \mathrm{O}_{4}+2 \mathrm{H}_{2} \mathrm{~S}+2 \mathrm{CO}_{2}$.

The following reactions are also possible:

$3 \mathrm{FeCO}_{3}=\mathrm{Fe}_{3} \mathrm{O}_{4}+\mathrm{CO}+2 \mathrm{CO}_{2} ;$

or where there is sufficient oxygen:

$3 \mathrm{FeCO}_{3}+\mathrm{O}=\mathrm{Fe}_{3} \mathrm{O}_{4}+3 \mathrm{CO}_{2}$.

The first reaction produces a decrease in volume of 47 per cent, and the second and third a decrease of 50 per cent, provided the hydrogen sulphide, oxygen, carbon monoxide, and carbon dioxide be ignored.

Observation in the field shows beyond question that the change from iron carbonate to magnetite takes place on an extensive scale. Which of the above reactions is the more important may be an open question. Since the change takes place in the zone of anamorphism, where the conditions are redncing instead of oxidizing, and since, as has already been explained (p. 828), pyrite is a rery common associate of iron carbonate, I think it probable that the first of the three reactions written is the dominant one. The reactions of the second and third equations are identical with those which take place when iron earbonate is heated in a closed tube in the laboratory where oxygen is absent or deficient in amount. It is explained below that the development of nagnetite from iron carbonate takes place on the most extensive scale where igneous rocks have been intruded. This suggests at furst that the reactions may be those of dry heat, but this idea is probably not warranted, for the magnetite which forms from carbonate is usually segregated into crystals or clusters of crystals, and this leads me to believe that the change is accomplished through the agency of water, with heat as a promoting force and iron sulphide as one of the active agents.

In the group of rocks under consideration the relative proportions of the silicates, of magnetite, and of quartz are very variable. In some instances the actinolite or the grimerite is predominant, with quartz as a subordinate constituent, and we have a quartzose actinolite or quartzose griulerite rock. In other instances the predominant constituents are magnetite and quartz, and in still other cases quartz is subordinate in amount; hence we may have a magnetite-quartz rock, or a quartzose magnetite 
rock. In still other instances all three classes of minerals are abundantly present, and we have actinolite-magnetite-quartz rocks or grïneritemagnetite-quartz rocks. Each of these different combinations of minerals may be of sufficient extent to constitute a member of a formation, or even an entire formation.

Which of the above rocks develops at a given place depends not only upon the original composition of the rocks, but upon the nature of the alteration. For instance, where in the original rock silica is subordinate and nearly pure siderite abundant, a quartzose-magnetite may develop, as at various places in the Lake Superior region. Where the conditions are such that the silicates form, the development of the actinolite or griunerite uses up both the iron carbonate and the silica, and an actinolite rock or a griinerite rock nay be produced. Where silica was originally an abundant constituent both magnetite and the silicates are likely to develop. Thus we lave various proportions of all the minerals, producing the magnetitequartz rocks, the actinolite-magnetite-quartz rocks, the grünerite-magnetitequartz rocks, the actinolite-quartz rocks and the grünerite-quartz rocks.

Usually a given formation, or member, does not show a perfectly homogeneous arrangement of the mineral particles. The original sedimentary rock is banded, and the different bands have different compositions. Naturally the transformation of these bands produces different combinations of minerals. Moreover, during the recrystallization there is a tendency, as explained in Chapter III (pp. 120-123), for minerals of the same kind to segregate. Hence, in any of the above cases, where as a whole a certain set of minerals are dominant within a rock, a single mineral, or two combined, may be largely segregated in bands; and in the alternate bands the other minerals be largely segregated. Thus a banded rock, consisting mainly of magnetite and quartz, may have a banded appearance as the result either of the segregation of the quartz and magnetite in separate bands or, more commonly, the segregation of more quartz and less magnetite in one band and less quartz and more magnetite in another band. In a similar mamner alternate bands may be made up of actinolite or grünerite with quartz in varions proportions, and of actinolite or grünerite with magnetite in various proportions. In still other instances the banding may be due to the combining of actinolite or grünerite, magnetite, and quartz in various proportions. In general, therefore, the alterations of the rock do 
not destroy the original sedimentary banding, but, on the contrary, emphasize it. The striking banded appearance of actinolitic and grïneritic rocks is one of their most characteristic features.

The development of the actinolitic and griineritic marbles and of the actinolitic, grüneritic, and magnetitic quartz-rocks is very greatly promoted by the presence of igneous rocks. Indeed, in the Lake Superior region, where iron silicates have been produced in large amounts from the ironbearing carbonates and hydrous iron silicates over extensive areas, intrusive rocks, in large masses, seem to be invariably present. At the west end of the Penokee range in Wisconsin, and at the east end of the Mesabi district in Ninnesota, ${ }^{a}$ the entire iron-bearing formations lave been changed to silicate-bearing rocks, and directly in contact with them-indeed, intrusive in them in a complex manner-are great batholithic masses of the basal gabbro of the Keweenawan. Also in the Mesabi district granite has been intruded in great quantities. In the Marquette district of Michigan, east of Negaunee, dolerite is a very abundant intrusive within the iron-bearing formation, and there in the iron-bearing formation the silicate rocks are again found, although not so abundantly as in the Mesabi and Penokee districts. ${ }^{b}$ Not only do the great areas of the silicated rocks occur where there are great masses of intrusives, but intrusives are sure to be found where the silicated rocks appear locally abundant, as, for instance, adjacent to Humboldt, Mich., in the Marquette district. Apparently in the Lake Superior region the iron-bearing formations were not sufficiently deeply buried, or subjected to sufficiently strong orogenic movements to cause the silication of the carbonates to take place on an extensive scale for those reasons alone; but where these metamorphic conditions were reenforced and intensified by intrusive rocks, there the transformation took place. If any case of metamorphism ought to be called contact metamorphism, the development of the silicated rocks from the iron-bearing carbonates should

aVan Hise, C. R., and Irving, R. D., The Penokee iron-bearing series of Michigan and Wisconsin: Mon. U. S. Geol. Survey, vol. 19, 1892, pp. 257-260. Grant, U. S., Sketch of the geology of the eastern end of the Mesabi iron range in Minnesota: Eng. Year Book, Univ. of Minnesota, 189s, p. 58. Tan Hise, C. R., and Leith, C. K., The iron-ore deposits of the Lake Superior region; section on the Mesabi district: Twenty-first Ann. Rept., U. S. Geol. Survey, pt. 3, 1901, pp. 359-360. Leith, C. K., The Mesabi iron-bearin; district of Minnesota: Mon. U. S. Geol. Survey, vol. 43, 1903, pp. 159-164, $182-188$.

$b$ Van Hise, C. R., and Bayley, W. S., The Marquette iron-bearing district of Michigan: Mon. I. A. Geol. Survey, vol. 28, 1897, pp. 380-381. 
be so designated, since in the Lake Superior region the presence of the igneous rocks seems to have been an essential condition for the process to take place on an extensive scale.

After the griineritic or actinolitic rocks have developed in the zone of anamorphism, in consequence of denudation they may pass into the zone of katamorphisin, or even into the belt of weathering. Then there will begin the processes of oxidation, hydration, and carbonation, as a result of which the magnetite is changed to hematite or limonite, and the actinolite and grinerite decompose into carbonate. However, since magnetite and the iron-bearing anphiboles are very refractory, this process is exceedingly slow, and usually has affected only comparatively thin layers of material adjacent to the surface or adjacent to openings in the rock. Indeed, the reagents of the belt of weathering and the upper part of the belt of cementation, which, as pointed out (pp. 830-831), may produce large iron-ore bodies where they have the original iron-bearing carbonates or the hychous ferrous silicates to work upon, have nowhere in the Lake Superior region formed large ore bodies where they are working upon the grineritic and actinolitic rocks. This follows directly from their refractory character, since the average amount of iron of the iron-bearing formation is essentially the same in both cases. In the refractory character of these rocks we have the explanation of the absence of rich workable iron-ore deposits for extensive areas in each of the iron-bearing districts of the Lake Superior region where the alterations of the original rocks in the zone of anamorphism leveloped actinolitic or griineritic magnetite rocks.

GENERAL STATEHENTS.

From the foregoing pages it is apparent that the iron-bearing carbonates and the hydrous iron silicates are metamorphosed along two main lines, depending upon whether they are in the zone of katamorphism or the zone of anauorphisur. Where they are altered in the zone of katamorphism, and especially in the belt of weathering, the ferruginous shales, ferruginous cherts, and ores result. Where they are altered in the zone of anamorphism the actinolitic and griineritic marbles, or the actinolitic rocks and griineritic rocks, are produced. Further, where the metamorphosed rocks produced from the iron-bearing carbouates and lyydrous iron silicates change from one zone to another they are further 
altered. The ferruginous shales and ferruginous cherts, products of the zone of katamorphism, when transferred to the zone of anamorphism are transformed to jaspilites. The actinolitic and grüneritic rocks transferred to the zone of katamorphism are altered to ferruginous shales and ferruginous cherts, but this change takes place so very slowly that these products have not been thus produced on a very large scale.

OXIDE ORDER.

IRON-OXIDE FAMILY:

The iron-oxide family comprises a number of oxides-anhydrous and hydrons. Of these limonite, hematite, and magnetite occur in sufficient masses to entitle them to consideration as rocks. Limonite is hydrated ferric oxide $\left(2 \mathrm{Fe}_{2} \mathrm{O}_{3} \cdot 3 \mathrm{H}_{2} \mathrm{O}\right)$. Hematite is ferric oxide $\left(\mathrm{Fe}_{2} \mathrm{O}_{3}\right)$. Magnetite is ferrosoferric oxide $\left(\mathrm{Fe}_{3} \mathrm{O}_{4}\right)$. Many of the larger formations are intermediate between limonite and hematite. Sone are partly hematite and partly magnetite. Usually subordinate minerals are associated with the iron oxides. Of these, quartz is almost universal. But all the carbonates, many of the hydroxides and silicates, and some of the sulphides are often associated. The carbonates and hydroxides other than of iron are apt to be associated with the limonites, and less commonly with the liematites. The silicates and sulphides are usually associated with the magnetites, and often with the specular hematites.

LIMONITE.

Limonite may compose considerable rock deposits. Ordinarily such deposits are not very thick, although they may lave considerable extent. The deposits are commonly of very irregular thickness, or bunchy, being locally perhaps 3, 6, or 10 meters thick, and within a short distance almost disappearing.

Recent deposits of limonite are extensive. These occnr in marshes and bogs. They have been worked to a greater or less extent as iron ores throughout the civilized world. Probably the most extensive deposits of limonite known are those of the Lower Silurian, which have been worked for ore in many countries.

The Silurian limonites and the limonites of many other horizons are largely replacement and concentration products of limestones, being therefore a result of metamorphism. In some districts the limestones originally 
contained a small amount of iron carbonate. This carbonate has a history identical with that of the iron of the iron-bearing carbonates, discussed on pages 824-829. Locally the iron carbonate of the limestones has been picked up by the percolating waters. At various places these waters have been converged at localities favorably situated. At such localities the iron is precipitated from the carbonate according to the reaction:

$$
4 \mathrm{FeCO}_{3}+2 \mathrm{O}+3 \mathrm{H}_{2} \mathrm{O}=2 \mathrm{Fe}_{2} \mathrm{O}_{3} \cdot 3 \mathrm{H}_{2} \mathrm{O}+4 \mathrm{CO}_{2} \text {. }
$$

Often simultaneously with this process calcium carbonate has been dissolved. Thus, at the surface of a limestone formation there may be produced a layer of limonite which passes downward into the limestone.

In still other cases the iron of limonites associated with limestones has been in large part derived from adjacent formations. In such cases the association is, in part at least, a consequence of the ready solution of the limestone, which makes it easy for the substitution to take place. Such substitution is likely to occur where underground waters from different sources unite, as, for instance, where the limestones are fractured, so as to be open and porous; where there are impervious basements, etc.

HEMATITE.

Hematite occurs in much larger nasses than limonite. The hematite is not wholly anhydrous, but contains a variable amount of water. For instance, in the Mesabi hematite, the most extensive deposits of this oxide known, the combined water varies from 2.09 to 8.23 per cent. ${ }^{a}$ Thus, there are all gradations between limonite and hematite, and the majority of the great soft iron-ore deposits contain limonite, hematite, the intermediate oxides, and various combinations of them. The more extensive iron-ore deposits of the United States, which are largely hematite, are those of the Algonkian and Archean of the Lake Superior region and the Clinton ore horizon of the Silurian. These masses of limonite and hematite were partly deposited in place as original sediments, but to a larger extent are due to subsequent segregations.

The limonitic hematites which occur as original sediments in place are identical in their development with the oxides of iron which are the original source of the iron carbonates. (See pp. 824-826.) In summary, iron salts,

a Leith, C. K., The Mesabi iron-bearing district of Minnesota: Mon. U. S. Geoi. Survey, vol. 43, 1903, pp. 214-217. 
as iron carbonate mainly, but subordinately iron sulphate and other compounds, are brought by underground solutions to shallow bodies of water, such as lagoons. By oxidation and hydration the material is thrown down as hydrated hematite or limonite, with a greater or less amount of basic ferric sulphate. But the larger masses of limonite and hematite are usually mainly produced by segregation subsequent to the formation of the original sediments. These, like the limonites, are largely replacement deposits of limestone or of some other carbonate rock. The Clinton liematite ore deposits are partly replacements of limestone which may have contained a small amount of iron carbonate, but according to various authors the hematites, as such, in large measure were deposited with the associated limestones. But the most extensive deposits of hematite known, those of the Lake Superior region, are segregations in formations which were originally in large measure iron-bearing carbonate or hydrous ferrons silicate. For these deposits the iron as carbonate has been transported to the places of deposition; there it meets other solutions bearing oxygen, and in consequence of the mingling of such solutions the iron is thrown down as a partially hydrated hematite, the reaction being:

$$
2 \mathrm{FeCO}_{3}+\mathrm{O}+\mathrm{nH}_{2} \mathrm{O}=\mathrm{Fe}_{2} \mathrm{O}_{3}+\mathrm{nH}_{2} \mathrm{O}+2 \mathrm{CO}_{2} .
$$

It may be said, therefore, that limonitic hematite is either a direct chemical precipitate in the zone of katamorphism or is due to aqueous concentration in that zone.

Ordinarily, so long as limonite and limonitic hematite remain in the horizon in which they form, they are not further altered, since they are end products of metamorphism for the zone of katamorphism. But at or near the surface in arid regions, or in times of dronght in humid regions, the more hydrous forms of the oxide may be delydrated and thus pass into hematite.

The more important alterations of limonite and liydrated hematite take place when these ores pass into the zone of anamorphism. In that zone dehydration occurs. The limonites and more hydrated hematites are gradually decreased in amount, and where dehydration is complete hematite is formed. Where the clange is from pure limonite to pure hematite a decrease in volume of 38 per cent is involved.

Where the rock is subjected to strong orogenic movements, not only does dehydration occur, but the iron becomes specular, and a- laminated 
texture is produced. Thus are formed the specular hematites. Where the movements are of extrene intensity the little flakelets of hematite may become flat and parallel, and thus resemble mica. Such a rock is a hematite-schist. Where more or less of a reducing agent is present at the time of the delydration, magnetite may form and be associated with the lıemátite.

NAGNETITE.

Magnetite, with quartz and various silicates as subordinate constituents, may compose considerable rock bodies. Such material occurs as important nember's of the iron-bearing formations of the Lake Superior region, and in the gneisses of the eastern metamorphic region of the United States-in the Adirondacks, in the lighlands of New York and New Jersey, and in the southern Appalachians, notably at Cranberry, N. C. But the greatest of the eastern magnetite deposits is that of Cornwall, Pa., in limesfone of Lower Silurian age, underlain by Triassio intrusive trap. It is uncertain whether or not the gneisses with which many of these magnetitic rocks are associated are of sedimentary origin, but presumably many of them are. If these rocks be sedimentary it is more than probable that the magnetite members are also sedimentary. The most natural hypothesis as to the origin of these rocks is that they rere iron-bearing carbonates nuetamorphosed as described on pages 834-841. The deep-seated metamorphism changed the original iron-bearing carbonates to magnetite, with the simultaneons development of quartz and silicates.

The production of magnetite from siderite may be supposed to be that of imperfect oxidation, the reaction being:

$$
3 \mathrm{FeCO}_{3}+\mathrm{O}=\mathrm{Fe}_{3} \mathrm{O}_{4}+3 \mathrm{CO}_{2} \text {. }
$$

But it has been seen (p. 828) that where iron carbonate is produced iron sulphide also is often found. Magnetite and pyrite, also, are often associated. In the deep-seated zone of anamorphism it can not be supposed that oxygen is usually present. It therefore appears to me that the more frequent reaction is that producing magnetite from siderite and pyrite. The change may be written thus:

$$
2 \mathrm{FeCO}_{3}+\mathrm{FeS}_{2}+2 \mathrm{H}_{2} \mathrm{O}=\mathrm{Fe}_{3} \mathrm{O}_{4}+2 \mathrm{H}_{2} \mathrm{~S}+2 \mathrm{CO}_{2} .
$$

These changes would result in a decrease of volume of 50.32 per cent for siderite to magnetite, or of 46.67 per cent for siderite and pyrite. 
This dimunition of yolume furnishes an entirely adequate cause for the transformation.

Also magnetite may be produced under conditions of partial oxidation of iron sulphide, such as pyrite and pyrrhotite, according to the following reactions:

$$
\begin{aligned}
& 3 \mathrm{FeS}_{22}+4 \mathrm{H}_{2} \mathrm{O}+4 \mathrm{O}=\mathrm{Fe}_{3} \mathrm{O}_{4}+4 \mathrm{H}_{2} \mathrm{~S}+2 \mathrm{SO}_{2} . \\
& 3 \mathrm{Fe}_{11} \mathrm{~S}_{12}+36 \mathrm{H}_{2} \mathrm{O}+8 \mathrm{O}=11 \mathrm{Fe}_{3} \mathrm{O}_{4}+36 \mathrm{H}_{2} \mathrm{~S} .
\end{aligned}
$$

Le Conte describes the formation of magnetite by the imperfect oxidation of iron sulphide at Sulphur Bank, California. ${ }^{a}$

Some magnetites are undoubtedly formed by the alterations of limonite or hematite or intermediate compounds. The change of these oxides of iron into maguetite is likely to take place in the deep-seated zone where organic or other material is present which can take away the oxygen. At the same time dehydration occurs. The reaction may be written as follows:

$$
3\left(\mathrm{Fe}_{2} \mathrm{O}_{3}\right) \cdot \mathrm{nH}_{2} \mathrm{O}-\mathrm{O}=2 \mathrm{Fe}_{3} \mathrm{O}_{4}+3 \mathrm{nH}_{2} \mathrm{O} .
$$

The oxygen abstracted unites with the carbon to form carbon dioxide, or with bydrogen to form water. Where the limonite or hematite is associated with iron sulphide it is not necessary that organic matter be present in order that the change shall take place; the sulphide may serve as the reducing agent. In this case the reaction may be written:

$$
22\left(\mathrm{Fe}_{2} \mathrm{O}_{3} \cdot \mathrm{nH}_{2} \mathrm{O}\right)+\mathrm{FeS}_{2}+2 \mathrm{H}_{2} \mathrm{O}=15 \mathrm{Fe}_{3} \mathrm{O}_{4}+2 \mathrm{H}_{2} \mathrm{SO}_{4}+22 \mathrm{nH}_{2} \mathrm{O} .
$$

Supposing the original oxide were hematite, the volume of the magnetite is 3.58 per cent less than that of the hematite and pyrite. So far as water was present dehychration took place and the percentage of decrease in volume is greater than given. Where the amount of the reducing agent is not sufficient to change all of the limonite or hydrated hematite to magnetite, dehydration only takes place for the remainder of the material, and consequently with the magnetite a variable amount of hematite is often associated. The segregation of iron oxide into rich deposits is further considered in Chapter XII, on "Ore rleposits."

\footnotetext{
${ }^{a}$ Le Conte, Joseph, and Rising, W. B., The phenomena of metalliferous vein formation now in progress at Sulphur Bank, California: Am. Jour. Sci., 3d ser., vol. 24, 1882, p. 33.
} 
CHERT.

The silica deposits are all included under the general term chert. This term, as here applied to siliceous layers and formations, includes amorphous, partly amorphous, and crystallized silica. Often in the same mass may be seen very minutely spotted quartz grains separated by partly amorphous material, cryptocrystalline silica of varions kinds, such as chalcedony, and completely crystalline quartz. In almost every extensive chert formation all these varieties are mingled in the most complex manner. Chert comprises both organic and chemical deposits.

The most extensive deposits of chert are those of organic origin, the silica being taken by certain animals and built into their. hard parts, precisely as is calcium carbonate by other animals. The animals which absorb the greatest amount of silica are sponges of a certain class. Other than the sponges, radiolaria and diatoms appear to be the more important. These and other animals may build up considerable deposits of chert. As illustrations of chert formations of organic origin may be mentioned the Cretaceous flints described by Wallich, ${ }^{a}$ the flints of the Trimmingham chalks described by Sollas, ${ }^{b}$ and extensive deposits of chert in Ireland, England, Wales, Spitzbergen, and Axels Island, deseribed by Hinde." Hinde says that the chert beds in Yorkshire have an estimated thickness of about 30 meters, and in North Wales of 100 meters, and these, he says, can be proved to be due to sponge remains. ${ }^{d}$

But probably the most extensive formation of chert which is known to be of organic origin is that of Axels Island, where the beds of cherty material, according to Hinde, aggregate 260 meters in thickness. ${ }^{e}$ This is not a continuous mass of chert, but consists of a number of beds interstratified with limestone.

a Wallich, G. C., A contribution to the physical history of the Cretaceous flints: Quart. Jour. Geol. Soc. London, vol. 36,1880 , pp. 68-91.

$b$ Annals Mag. Nat. Hist., 5th ser., vol. 6, 1860, p. 438. See also Wralcott, C. D., Fossil medusæ: Mon. U. S. Geol. Survey, vol. 30, 1898, p. 18.

$c$ Hinde, G. J., On the organic origin of the chert in the Carboniferous limestone series of Ireland, and its similarity to that in the corresponding strata in North Wales and Yorkshire: Geol. Mag., London, new ser., dec. 3, vol. 4, 1887, pp. 435, 436. Hinde, G. J., On the chert and siliceous schists of the Permo-Carboniferous strata of Spitzbergen, and on the character of the sponges therefrom, which have been described by Dr. E. von Dunikowski: Ibid., vol. 5, pp. 241-251.

d Hinde, cit., vol. 4, pp. 435-446.

e Hinde, cit., vol. 5, p. 243. 
The source of the silica for organisms is probably in part that dissolved in sea water. Since, however, when filtered the pure sea water contains only one part in 250,000, Murray and Renard "consider the probability of the pelagic organisms which secrete silica obtaining it from the hydrated silicate of alumina or clay held in suspension as well as the silica held in solution. This might explain the fact that these organisms abound in brackish waters, and waters of low salinity and low temperature, where the clay is more abundant than in the warmest and saltest waters of the ocean. In the case of siliceous sponges, which are rooted for the most part in the oozes and elays, Messrs. Murray and Renard think that the silica of their skeletons may be derived from the silica in solution in sea water, or from the colloid silica set free during the decomposition of the feldspathic rock fragments and minerals in the deposits." ${ }^{a}$

Chemical deposits of silica may be formed when underground solutions, especially hot solutions, reach the surface. The silica, in consequence of the decrease in pressure and temperature, is precipitated. Such deposits are known as siliceous sinter. The best known examples are the geyserite formations of the Yellowstone Park.

The silica for chemical deposits is believed to be mainly derived from that contributed to the underground waters by the process of carbonation in the zone of katamorphism, and especially in the belt of weathering, as fully explained in Chapter VI (pp. 475-480). But it is certain that a portion of the silica of the underground waters is directly derived by solution of amorphous and semicrystalline silica of organic deposits and by the solution of quartz itself. It is frequently supposed that crystallized quartz is not dissolved by the ground waters, but, as shown by Hayes, ${ }^{b}$ quartz crystals at the surface are dissolved and corroded, and observations in many mines show that the solutions have dissolved quartz in large quantities from the wall rocks. This is illustrated by the granite of the Portland mine, at Cripple Creek, Colo., where the quartz and mica are dissolved and the feldspar is comparatively untouched. While, therefore, silica for chemical precipitation is derived directly from the solution of quartz, a vastly greater amount is the colloidal silicic acid liberated by the process of

a Walcott, C. D., Fossil meduse: Mon. U. S. Geol. Survey, vol. 30, 1898, p. 20.

${ }^{b}$ Hayes, C. W., Solution of silica under atmospheric conditions: Bull. Geol. Soc. America, vol. 8, 1897, pp. 213-220. 
carbonation of the silicates and that furnished by the solution of amorphous and semicrystalline quartz.

Rearrangement of chert.-Chert, as deposited by organisms or chenically, may be hydrous and amorphous, semnicrystalline, or completely crystalline. In proportion as it is amorphous or semicrystalline, it is likely to be easily and extensively dissolved and rearranged. Usually the opaline, semicrystalline, and completely crystalline materials, are mingled in an intricate manner. Very often a single thin section shows all varieties of material. In many sections the opaline or amorphous silica constitutes a background in. which there are inmumerable polarizing spots of chalcedony and quartz. The process of rearrangement may go on until the material, whether of organic or chemical origin, becomes wholly crystalline quartz.

If erystallization be complete, there may be produced a finely crystalline rock composed of closely fitting, minute particles of quartz, many of them with crystal outlines, which average only a small fraction of a millimeter in diameter. Such rocks may be called finely crystalline quartz rocks. Representatives of them are the whetstones of Arkansas and the quartz rock of the Penokee district of Wisconsin. In many cases such rocks are stained by oxide of iron, and these are often called jasper.

The crystallization may go further, so as to produce coarsely crystalline quartz rock. This process of crystallization of the amorphous material so as to produce first, chert; next, finely crystalline quartz; and next, coarsely crystalline quartz, occurs under the laws of physical chemistry. In so far as the silica passes from a hydrous to an anhydrous condition the volume is lessened. In so far as it passes from an amorphous to a crystalline condition the volume is lessened. The change in rolume in the passage of one of the ordinary opals to quartz has been calculated on page 221 to be 22.81 per cent. All these processes may occur at any depth, precisely the same as the process of dolomitization. But they are promoted by depth of burying and by high temperature, and therefore the finely crystalline and coarsely crystalline quartz rocks derived from organic silica or siliceous sinter have usually been buried to a very considerable depth.

If in addition to depth of burying there be profound orogenic movement, the rock may be further recrystallized and mechanically sliced, and MON XLVII-04-5t 
thus the quartz particles be so rearranged that their maximum and mean diameters are in a common plane, producing quartz-schist.

It has already been explained (pp. 818-819) that where silica is rearranged it is sure to be segregated, because any area of chert attracts materials of like kind to itself, and large masses grow at the expense of small ones. Even in the cases where the cherts are undoubted replacements the source of the silica may largely have been sponge spicules, diatoms, etc., which were disseminated through the limestones. This material can not be discriminated from that furnished by the ground waters coming from some other formation. The essential fact is that such a deposit is a replacement deposit, whether the silica be derived from the decomposition of silicate, by the solution of sponge spicules, or in some other mamner.

In order that the silica may be concentrated, it is of course necessary that the material previously occupying the place shall be dissolved. Such concentration and solution are especially likely to occur in those formations which originally contained a considerable amount of cherty material, and which were readily soluble. The best representatives of rocks of this class are the carbonates-calcareous, magnesian, and ferruginous. At the time the chert is segregated the carbonate is dissolved. It therefore follows that in the calcium-magnesium carbonate family and the iron-bearing carbonate family the most extensive deposits of chert should be expected; and with this the facts correspond.

Observation shows that many carbonate formations have been extensively silicified. Positive evidence of the replacement of carbonates by chert is furnished by formations which contain numerous silicified fossils which were originally calcareous, such as the mollusks and corals. Where fossils of this kind, now chert, are contained in a mass of chert, it is natural to suppose that the formation was in the main originally calcareous. A good illustration of extensive replacement of calcareous formation by silica is that of the Tampa Bay chalcedony pseudomorphous after coral.

Where replacement has been extensive, the average compositions of considerable masses of rocks have been greatly changed-indeed, where pure limestone is replaced by chert, entirely changed. There is no means by which one can estimate the amount of silica that has been introduced from an outside source in the silicification of great carbonate formations. Doubtless the amount of such material is great, but probably in most 
instances the process of silicification of the carbonate formations is largely that of segregation of the originally dispersed silica of the limestone formations themselves.

To better illustrations of extensive cherts are known to me than those furnisher by the iron-bearing formations of the Lake Superior region. Here silica in its various forms and iron oxide constitute ahmost the entire weatlered belt of the cherty iron-carbonate formations. Locally in this region the chert is segregated almost entirely free from iron oxide. Such occurrences are illustrated by the chert near Amasa, in the Crystal Falls district of Michigan. ${ }^{\alpha}$ IVithin the limestones extensive chert berls are also found at many localities. Some of the best known in this country are those of the Boone chert formation, of Lower Carboniferous age, in the lower Mississippi Valley, and the thick bed of chert in the Carboniferous limestone of southwesteru Missouri. ${ }^{b}$

In none of these formations are organic remains found from which the chert is derived. Where the rearrangement has gone so far that the siliceous organisms, if they once existed, would have been destroyed, it becomes difficult or impossible to certainly discriminate between chert deposits which are mainly organic and those which are mainly chemical. It is natural to suppose that where chert beds are somewhat persistent they are largely organic, although doubtless they may have been extensively rearranged and have had great additions of silica. On the other hand, where the chert masses are small, nodular, and bumchy, and especially where they are exceedingly irregular, it may be supposed that they are mainly substitution products. But reasoning along either of these lines is of very doubtful value.

For instance, the rather persistent nature of the chert formations above mentioned in the Lake Superior region might be taken as evidence that they were mainly organic deposits in their present position. Howerer, a close study of this district leads to the conchsion that these formations by substitution for carbonate now occupy the place of cherty iron-bearing carbonates and silicates, and that they are mainly explained by segregation

a Clements, J. Morgan, and Smyth, H. L., with Bayley, W. S., and Van Hise, C. R., The Crystal Falls iron-bearing district of Michigan: Mon. U. S. Geol. Survey, vol. 36, I899, pp. 62, 177 .

"Bain, H. F., Van Hise, C. R., and Adams, Geo. I., Preliminary report on the lead and zinc deposits of the Ozark region: Twenty-second Ann. Rept. U. S. Geol. Survey, pt. 2, 1901, pp. 86-87, 129. 
from the parts of the formation once above the plane of denudation. The eherty formations of the Lake Superior region are usually steeply inclined, and therefore descending water rapidly and easily segregates silica on a large scale from material widely disseminated. Where such substitution occurs throughout the outcrop of a tilted formation it does not at all follow that it has taken plaee throughout the formation. Indeed, in the majority of the districts of the Lake Superior region it is probable that the segregation of chert extends to only a very limiterl depth. Where the chert is thus segregated by descending waters the source of the material may still be mainly ehert of organic origin originally dissominated through the carbonate.

Where there are rather extensive formatious of ehert in a lorizontal position, or nearly so, interstratified with beds of limestone or shale, the transportation of silica from material onee above the plane of denndation by deseending water's is not so likely to have been important. This is especially true of those cherts which are interstratified. with shales, and therefore are protected from the surface waters by impervious formations. Hence sueh formations are more likely to be in large part the direct produets of organie preeipitation. While bunchy deposits of chert having no great lateral extent may often be produeed by ehemical preeipitation, it is eertain that such deposits may also be produced by direct organic precipitation.

This is illustrated by the chert deposits of the Francisean series of California. These are regularly bedded deposits, locally of considerable thickness. They are lentienlar and have an extremely narrow lateral extent. Often a deposit haring considerable thickness disappears within a short distance. If a bunchy eharacter be regarded as evidence of ehemieal origin it would be coneluded that the Franciscan cherts are ehemical deposits, and this was Lawson's conelusion. ${ }^{n}$ Yet Lawson states that these cherts eontain rery numerous radiolaria; but this fact does not prevent him from suggesting that they are mainly due to local preeipitation, in the bed of the ocean, of silica from silica-bearing springs. Lawson explains the abundant radiolaria as a eoineidence. He says, in these deposits "radiolaria remains became embedded as they dropped to the bottom." It

a Lawson, A. C., Sketch of the geology of the San Francisco Peninsula: Fifteenth Ann. Rept. U. S. Geol. Survey, 1895, pp. $\pm 20-426$.

b Lawson, cit., p. 426. 
seems to me that this is hardly a satisfactory explanation of the very abundant radiolaria which compose a considerable proportion of the deposits. If Hinde's argument as to the organic origin of the cherts which contain sponge spicules be correct, it probably follows that the radiolarian cleets of the Franciscan series of California are also organic deposits.

Another very interesting occurrence of chert is that of the whetstones of Arkansas. These are associated with clay shales a rather than limestones. They were regarded by Griswold as fragmental, ${ }^{b}$ and therefore not belonging to the class of cherts at all, but to the novaculites. But Rutley has shown that these rocks contain no evidence of clastic origin, and have-all the characteristics of cherts. ${ }^{\circ}$ He regards them as replacement deposits of dolonite or dolomitic limestones. As this chert formation is somewhat persistent, and is between shale beds which are rather impervious, I am inclined to believe that it may be largely an organic precipitate, although now completely recrystallized, so as to be composed of perfectly fitting granules of quartz.

\section{FRAGMENTAL CLASS.}

PSEPHITE ORDER.

The pseplite order includes pebble, gravel, and bowlder deposits, conglomerates, schist-conglomerates, and gneiss-psephites. (Pl. VIII.)

\section{PEBBLE, GRAVEL, AND BOWLDER DEPOSTTS.}

The psephites form below bodies of water and also on the land. The chief body of water which deposits psephites is, of course, the ocean, although lakes and inland seas are by no means unimportant. The psephites in standing bodies of water are mainly formed along shores, where the wave action is vigorous, but to some extent they occur at the moutlis of streams which are rapid until they reach the standing bodies of water. The psephites formed on the land are the till deposits of glaciers, especially the extensive formations of continental glaciers, and the coarse

a Griswold, L. S., Whetstones and the novaculites of Arkansas: Ann. Rept. Geol. Snrv. Arkansas for 1890 , vol. 3,1892 , pp. 205-206.

$b$ Griswold, cit., pp. 168-194.

c Rutley, Frank, On the origin of certain novaculites and quartzites: Qnart. Jour. Geol. Soc. London, vol. 50, 1894, pp. 377-392. 
deposits of streams. These stream deposits are especially well illustrated in semiarid regions. For instance, at the present time large masses of psephites are found at the months of canyons adjacent to the mountains of the Great Basin, sonthern California, etc.; and Davis, Emmons, and Cross regard it as probable that other extensive psephite formations of the Cordilleras are fluriate. ${ }^{a}$

The material composing the psephites is not at all, or but roughly, assorted. Consequently, with the coarse naterial, there is a consideralle amount of rather fine material to which the term psammite is applicable, and of still finer clayey material belonging to the pelite order. Commonly, however, the major part of the pelitic material is abstracted from the psephitic material by the water. This takes place to a greater degree in those deposits laid down under water than in those laid down under air.

The material of the psephites is but poorly sorted mineralogically. This is a necessary consequence of the large size of the fragments. The majority of the larger fragments are composed of two or more minerals. If the rock against which the waves are beating: is granite, the pebbles contain all the minerals of the granite. The same statement is true in reference to all other classes of igneous and sedimentary rocks which are not readily broken into fine débris. But in some instances the majority of the pebbles may be composed of a single mineral. The most frequent illustration of this is furnished by quartz. Finally, any of the original igneous or sedimentury rocks may be in any stage of alteration, and such complex mineral material constitnte the pebbles, provided the alteration is not of suclı kind that the material breaks down into its individual mineral particles.

It follows from the foregoing that the psephites have the greatest possible variation in mineral and chemical composition. An organic or chemical precipitate or an indurated clastic rock may be a chief constitnent, quartz may be a chief constitnent, any igneons rock may be a chief constitnent, any metamorphic rock may be a chief constiment, or any of these various materials may be united in any proportion.

As rock masses, individual deposits of psephites are very common. Ordinarily these masses are not extensive in area, although sometimes they

"Davis, W. M. (with discussion by S. F. Emmons and Whitman Cross), Continental deposits of the Rocky Mountain region: Bnll. Geol. Soc. America, vol. 11, 1900, pp. 596-60t. 
are. Generally they are of but moderate thickness. The pseplite deposits made by standing bodies of water are usually in narrow bands adjacent to the shore, and, noreover; occur only locally along the shore. Where, however, a body of water steadily transgresses over the land, as, for instance, the ocean, a continnous formation of psephite over an extensive area may be deposited. Such a formation, while continuous, is not of the same age throughout. The earlier portion of a formation is usually buried under other serliments by the time the later part of the formation is deposited. Usually such psephites are not very thick formations-that is, hundreds of meters-for, as the land subsides and the sea transgresses, the wares can not transport the coarse material back to the areas where earlier psephites were deposited; consequently they are buried under finer material. The psephite deposits of continental glacieis may be very extensive and of considerable thickness. But psephite deposits of this class found annong the older rocks are not very mumerous. This may be partly due to their destruction by later geological action. The psephite deposits of fluviate origin, while usually of rather local extent, may be of considerable thickness, often from one hundred to several hundred meters. How far deposits of this origin are represented among the older formations which have been buried by later deposits it is difficult to say.

CONGLOMERATES.

Pebble, gravel, and bowlder deposits, by consolidation, cementation, and metasomatism, are transformed to conglomerates. (Pl. VIII, A.) These processes take place in the belt of cementation. The rocks here considered are so coarse that consolidation due to pressure in the belt of cementation produces comparatively little effect, since the coarse fragments have comparatively few points of contact. The process of cementation is identical with that of the psammites, described below. Since the psammites are more important than the psephites, the process of cementation is more fully discussed under that head. Because of the very great variety of material composing the psephites upon which the ground waters are acting, there may be a great variety of minerals deposited in the interstices. But the most abundant cement is usually quartz. Next in importance to quartz are iron oxide and the carbonates. In some cases hornblende, feldspar, etc., may be of consequence. 
The amount of material required to cement the psephites is nsually not nearly so great as that required to transform pure quartzose sands to quartzite. The reason for this is that the material is of such rarying sizes that the spaces between the larger blocks are largely filled by finer materials. Also the fine material raries greatly in size. Consequently the amount of original pore space is frequently but a fraction of that of the even-grained sandstones. But in some instances the amount of fine material is not great, and the pore space is correspondingly large. Such deposits are illustrated by the psephites at the mouths of canyons of the West, which are so porous as to permit the absorption and transmission of vast quantities of water.

During the process of cementation metasomatism may take place. As already noted, there is great variety in the compasition of the psephites, and any rock-making mineral may be present. From these there may be produced a great variety of secondary minerals-in fact, any of the minerals mentioned as characteristic of the belt of cementation. (See pp. 621-627). These minerals may be mingled with secondary minerals formed before the material was built into a psephite. It is frequently difficult or impossible to discriminate the alterations which occurred while the minerals were in the primary rock from those which took place after the minerals were in the secoudary rock.

The question now arises as to where the processes of transformation of pebble, sand, and bowlder deposits to conglomerates take place. May a considerable part of the work be done for those rocks which are deposited below water before they emerge from it, or is the work in all cases mainly accomplished when the rocks are below land areas? It is, of course, possible, and indeed probable, that cementation and metasomatism, the important processes in induration, take place to some extent below the sea. However, it is not thought that these processes are there important. One reason for this belief is the certainty that circulation of the waters of the ocean must be comparatively slow through the sediments at the bottom; and it has been explained on pages 571-572, 866-868, that to dissolve and transport a large quantity of mineral material requires a vigorous circulation. A second reason for this belief is that while psephite deposits are still below the sea they have above them no belt in which weathering is taking place, and therefore no belt from which solutions steadily supply material for 
cementation. But it should be stated that the psephites are the most favorable of all mechanical deposits for alteration below the water. This follows, first, from their coarseness, which is ordinarily such as to furnish openings of supercapillary size in which the resistance to water circulation is comparatively small; and, second, from the great variety of readily alterable minerals which they contain. The alteration of these minerals by oxidation, hydration, and carbonation, resulting in increase of rolume, might supply considerable quantities of material to cement the interstices of the rocks without additions of any material from an outside source, and therefore not require vigorous circulation for its accomplishment. But, as already stated, it is believed that the main work of induration is accomplished after the rocks liave emerged from the sea and erosion has begun. After arising from the sea, with differences of elevation, a vigorous underground circulation is set up; material is steadily contributed from the belt of weathering; consequently the processes of cementation and metasomatism take place with comparative rapidity, and thus transform the unconsolidated pebbles, gravels, and bowlders to conglomerates.

Where indurated conglomerates pass into the zone of anamorphism they may be further altered by the reactions of that zone. Where the conditions are mass-static the alterations do not obliterate previous textures and structures, and therefore the rocks remain conglomerates. Bnt recrystallization of matrix and pebbles alike may take place on an extensive seale by silication and dehydration, with the production of the heavy anhydrous minerals characteristic of the zone of anamorphism.

SCHIST-CONGLOMERATE ANI GNEISS-PSEPHITE, OR CONGLOMERATE-SCHIST AND PSEPHITE-GNEISS.

Where any of the previously described psephites-i. e., pebble, gravel, and bowlder deposits, or conglomerates-pass into the zone of anamorphism and are there subjected to mass-mechanical action, recrystallization and granulation, and the development of a schistose structure, take place under the principles described in Chapter VIII. (See pp.685-696.) Because of the great variety of minerals which may be present in the psephites, all the minerals which develop in the lower zone under mass-dynamic action may form, and they may be most intimately intermingled. In general, the process of recrystallization and grannlation is complete for the matrix at a stage when the pebbles are still very distinct, althongì, of course, in such 
cases they are usually flattened and more or less gramnlated and recrystallized. At the same time a schistose structure develops in the matrix, and a schist-conglomerate or conglomerate-schist is thus produced. (PI. VIII, B.)

Where the mass-mechanical movement is very severe the pebbles may be flattened into lamina. Since material does not readily migrate in the zone of rock flowage, each pebble passes into minerals which may be derived from it. If 'there are different kinds of pebbles, it follows that there are various layers composed of different combinations, or at least different proportions, of the same minerals. Large bowlders may be observed in different stages, from oval forms, through greatly elongated and widened fragments, to forms in which the greatest diameters are several times the normal. (PI. VIII, $A$ and $B$.) Such a rock, when broken parallel to the direction of greatest flattening, appears to be a perfect schist or gneiss, but at right angles to this direction still plainly shows its conglomeratic character. As the process goes on the pebbles and bowlders are flattened more and more, until they become thin, lenticular masses, perhaps scarcely thicker than cardboard, or even like sheets of paper of great size. Wherever there was a quartz pebble there is apt to be a lamina composed of a quartz aggregate. Wherever there was a granite pebble there is usually a lamina in which mica has abundantly developed, and therefore one composed of mica, quartz, and feldspar. In many cases in which the process of transformation is mearly complete one may fail altogether to recognize the lamine as pebbles in masses split parallel to the direction of greatest elongation; but when a specimen is cut in a direction transverse to this the pebbles distinctly appear. When the process has gone as far as this the material of the pebbles becomes so mingled with that of the matrix that it is difficult to exactly define the outlines of the fragments. Finally, as the process continues, no evidence of the pebbles and bowlders is left. In their places are thin lamine of material of a mineralogical character different from that of the adjacent laminx.

At the same time the bowlders are being transformed the matrix is also being recrystallized. At various steps of the process the matrix may be, in turn, slate, schist, and foliated schist. Before the pebbles are destroyed the folia of the matrix wind in and out, remaining approximately parallel to the nearest pebble, which acts as a transmitter of force. In proportion as the process continues, and the pebbles and bowlders approach oblitera- 


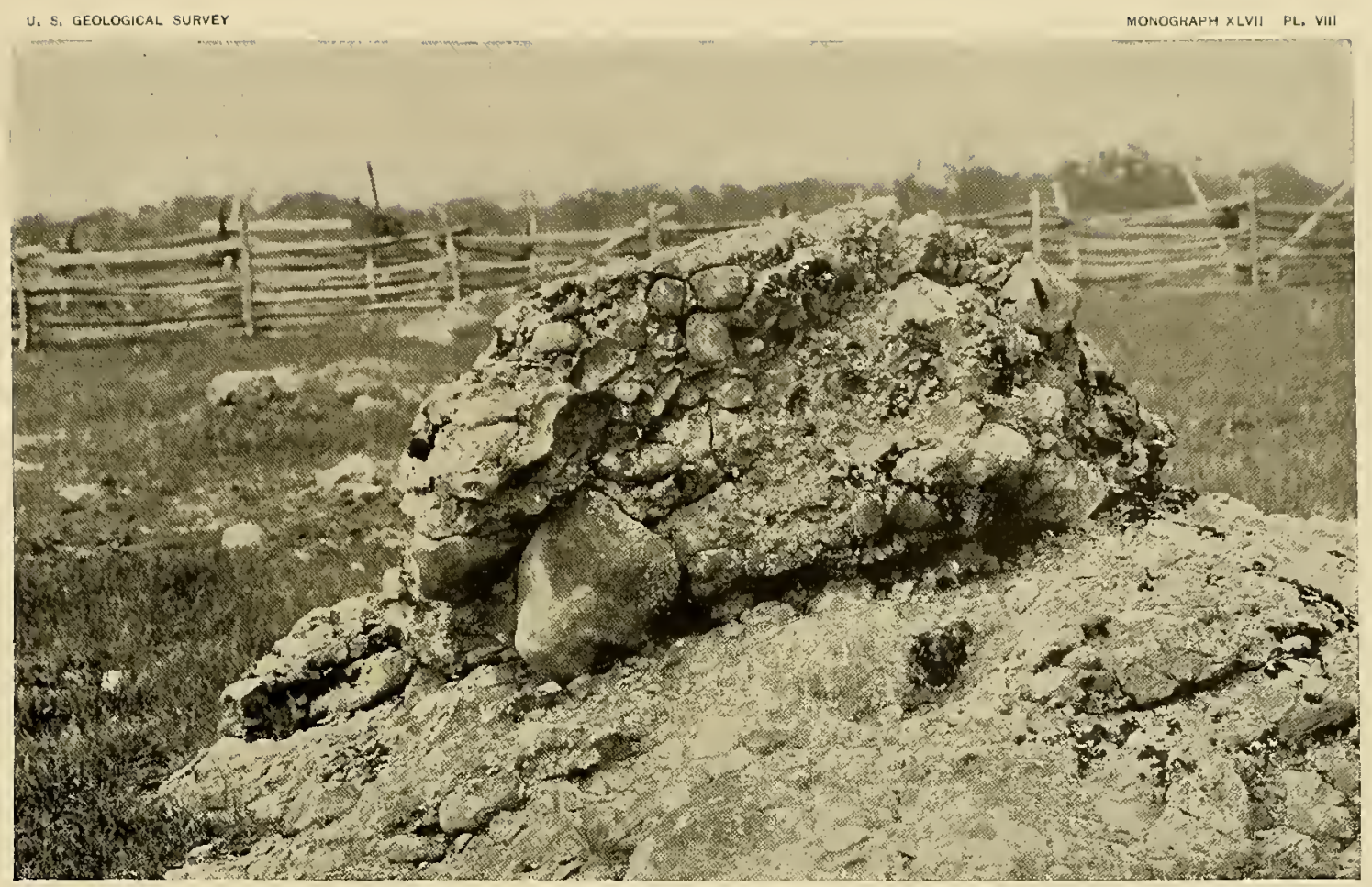

d. UNALTERED NEWARK CONGLOMERATE FROM VIRGINIA. AFTER KEITH.

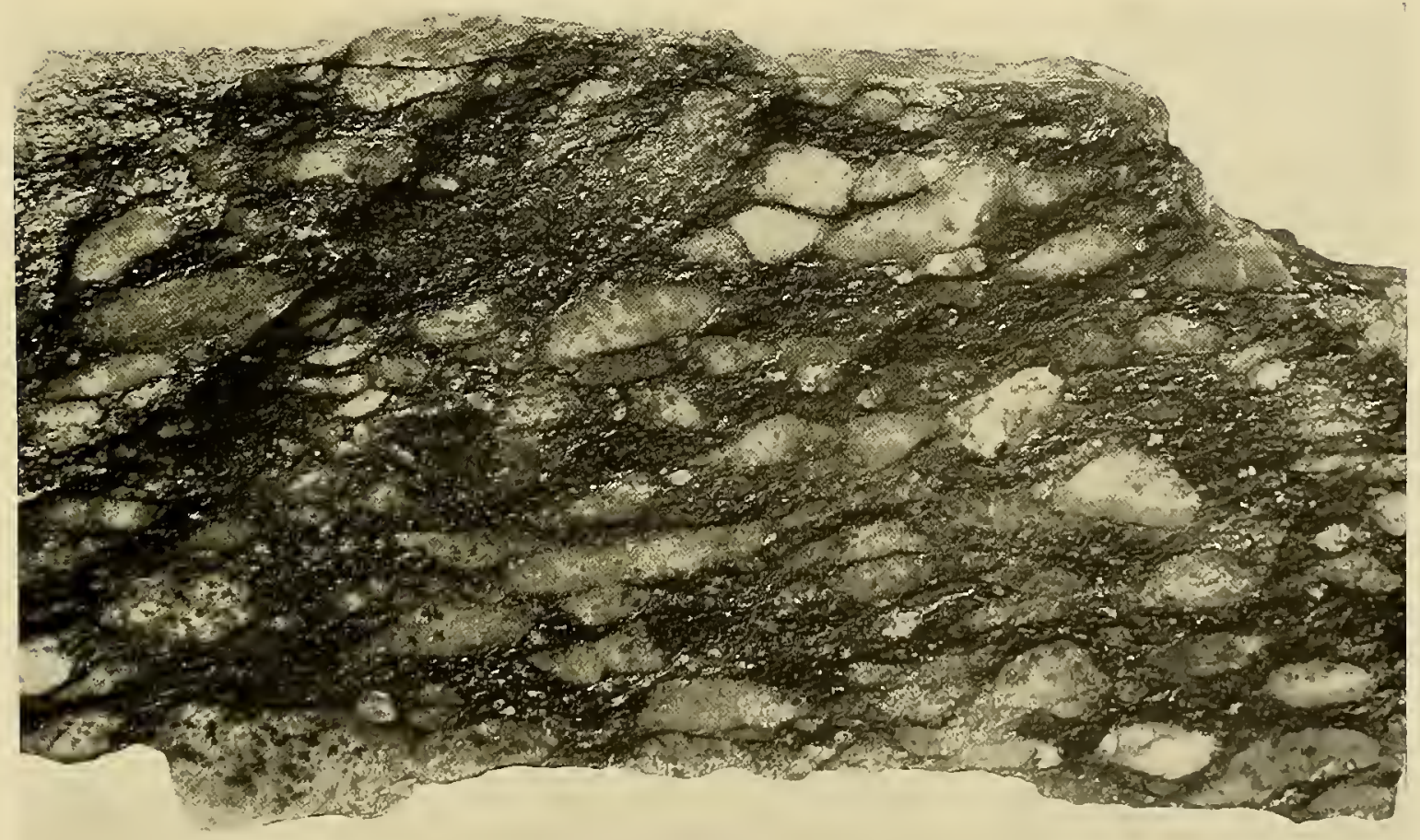



tion, the mineral particles more nearly approach a parallel orientation, instead of a part of them winding in and ont about the more refractory particles. (See pp. 760-762.) Thus, by the granulation and recrystallization of the pebbles and matrix alike, with the consequent developnient of sehistose and banded structures, a rock is produced to which the term gneiss-psephite or psephite-gneiss is applicable. (See pp. 782-783.)

Snch a rock may be composed in rarious proportions of any of the minerals which form in the zone of anamorplism, as listed in Chapter ${ }^{T}$ (pp. 363-364). This follows from the fact that the matrix and the pebbles of the psephites may be derived from all kinds of rocks, from the most basic to the most acid, from the volcanies and the plutonics, and from all varieties of metamorphic rocks. Therefore the rocks nay have chemical compositions which vary from those of the original igneous rocks to those of mud, in which certain elements, and especially alkalies and alkaline earths, have been depleted. From the great variety of chemical compositions of the psephites it follows that any of the minerals may develop in them which are subsequently spoken of as forming in the schists and gneisses which belong to the psammite and pelite orders. While there is a rery great variety of secondary minerals in the schists and gneisses of the psephites, in any given case two or three of these minerals are apt to be preponderant; and a given psephite-gneiss may be exactly designated by prefixing the names of the chief mineral constituents, as explained on page 783 .

$\Lambda$ very characteristic feature of the gneiss-pseplites is the parallel orientation of the mineral particles, which gives the rocks cleavage. This characteristic is almost, if not quite, universal with the schists and gneisses which are derived by the metamorphism of sedimentary rocks, and thus serves in many cases as a criterion by which one may separate the original gneisses of igneous origin from those produced by metamorphism.

Some of the best known illustrations of schist-conglomerates and gneiss-psephites are those described by Hitchcock many years ago, those of the Hastings district of Canada, those of various places in the Lake

a Hitchcock, Edward, Hitchcock, Edward, jr., Hager, A. D., and Hitcheock, Charles H., Report on the geology of Vermont, vol. 1, 1861, pp. 28-45. Whittle, C. L., The occurrence of Algonkian rocks in Vermont, and the evidence for their subdivision: Jour. Geol., vol. 2, 1894, pp. 422-429.

$\checkmark$ Adams, F. D., and Barlow, A. E., On the origin and relations of the Grenville and Hasting: series in the Canadian Laurentian, with remarks by R. W. Ells: Am. Jour. Sci., 4th ser., vol. 3, 18:7, pp. $173-180$. 
Superior region, ${ }^{a}$ and those of Hoosac Mountain, western Massachusetts. ${ }^{b}$ In each of these localities, where the mashing was not so severe as the arerage for the fornation, the rocks are not metamorphosed beyond the stage of schist-conglomerate, and thus give evidence that the gneisspsephite continuations of these rocks have been produced from sediments.

One of the very best illustrative localities is that of the Vermont formation of Hoosac Mountain, described by Wolffe In this formation every stage of gradation from a distinet and unmistakable schist-conglomerate to gneiss may be seen. Another excellent illustration which shows intermediate stages between the conglomerate and the gneiss is that of the Sturgeon River tongne of the Crystal Falls iron-bearing district of Michigan. ${ }^{d}$ Here the matrix is completely recrystallized, and if it were not for the pebbles would be unhesitatingly called a gneiss. But the pebbles are in an intermediate stage of destruction, being considerably flattened, though still rery distinct. The upward continnation of this formation, in which the fragments were small, shows no evidence whatever, by texture or structure, of its original clastic character, either in the field or under the microscope. It is a completely recrystallized quartz-feldspar sand which has become a psammite-gneiss. (See pp. 875-876.)

PSAMMITE ORDER.

QUARTZ-SATD FAMILY.

The quartz-sand family (Pl. IX) includes quartz-sand rock, sandstone, quartzite, and schist-quartzite.

QUARTZ-SAND ROCK.

Quartz-sand rock is an unconsolidated deposit or formation composed mainly of grains of quartz. Quartzose sands are one of the most common and widespread of the mechanical sediments. The origin of such sands is so well understood that little need be stated as to this part of the subject.

a Tan Hise, C. R., and Bayley, W. S., The Marquette iron-bearing district of Michigan, with a chapter on the Republic Trough, by H. L. Smyth: Mon. U. S. Geol. Survey, vol. 28, 1897, pp. 294-298, 434-437, 477-479. Clements, J. Morgan, and Smyth, H. L., with Bayley, W. S., and Van Hise, C. R., The Crystal Falls iron-bearing district of Michigan: Mon. U. S. Geol. Survey, vol. 36, 1899, pp. $474-476$.

$b$ Pumpelly, Raphael, Wolff, J. E., and Dale, T. Nelson, Geology of the Green Mountains in Massachusetts: Mon. U. S. Geol. Survey, vol. 23, 1894, pp. 48-59.

$c$ Wolff, cit., pp. 48-59.

a Mon. U. S. Geol. Survey, vol. 36, eit., pp. 474-176. 
Wherever coarse mechanical sediments are contributed to the sea by streams, quartz-sand grains are present. Wherever the sea is at work upon the shore, quartz sand is one of the products. At all places where the bodies of water are of a large enough size to produce waves of considerable powerthat is, in large bays and along the border of the open ocean-the process of mechanical sorting takes place, by means of which the quartz-sand grains are separated from other minerals. This follows from the difference in specific gravity, size, and shape between the grains of quartz and those of other minerals. Not only are the quartz-sand grains sorted from feldspar, hornblende, and similar minerals, but the quartz sands are sorted according to size, as a result of which in one place the grains of sand are rather large, perhaps averaging 1 to 5 millimeters in diameter, while in other places they are very small, areraging as low as 0.1 to 0.05 millimeter. Of course there are all gradations between deposits of different coarseness, and also between pure quartzose sand deposits and those in which other minerals are important or dominant.

However, the frequent almost perfect sorting of the quartz grains from other material, and the arranging of the quartz grains of nearly uniform size together, is a matter of constant surprise. Great formations of sand rock are produced which have not more than 2 or 3 per cent of other minerals besides quartz, and some which have not so much as 1 per cent of any other mineral. Moreover, in some formations, the ratios of the diameters of but few of the grains is as great as 1 to 2 , and the majority of the grains do not vary by as much as a third of a dianeter. Both the advanced condition of the sorting and the uniformity of the size of the grains are well illustrated by the St. Peter sandstone of Wisconsin. Specimens of this sandstone show but few particles of any other mineral than quartz.

Mr. Sydney II. Ball made for me a considerable number of measurements of the grains of this sandstone from two different localities. From one locality 25 graius were measured, which gave as the average greatest diameter $0.3388 \mathrm{~mm}$., and as the average least diameter $0.2964 \mathrm{~mm}$. Of these grains 21 have major diameters ranging between 0.20 and $0.50 \mathrm{~mm}$., of which 14 are between 0.25 and $0.45 \mathrm{~mm}$. Of the grains measured, 21 have minimum diameters between 0.20 and $0.50 \mathrm{~mm}$., and of these, 14 are between 0.25 and $0.45 \mathrm{~mm}$. The maximum and minimum lengths and breadtlis for indiridual grains are 0.54 and $0.16 \mathrm{~mm}$., and 0.50 and $0.14 \mathrm{~mm}$., 
respectively. From another locality 11 measurements of sandstone grains gave an average greatest diameter of $0.2009 \mathrm{~mm}$., and an average least diameter of $0.1463 \mathrm{~mm}$. At this locality all but 2 of the major diameters are between 0.15 and $0.37 \mathrm{~mm}$., and all but 2 of the minor diameters are between 0.16 and $0.23 \mathrm{~mm}$. The maximum and minimum lengths and breadths of any individual grain are 0.37 and $0.10 \mathrm{~mm}$, and 0.32 and 0.08 $\mathrm{mm}$. The above measurements for each of these rocks show a remarkable approximation to a spherical form for most of the grains, and an almost astonishing uniformity of size for the great majority of the grains, although an occasional grain varies considerably from the average in size.

Besides sand formations which are deposited below the water, sand formations are built up below the air. The most important of these are dunes, the material of which is derived from the sands sorted by the water along the shore. The wind picks up this sand, carries it inland, and thus builds up along large bodies of water, especially such bodies as the Great Lakes and the ocean, very considerable deposits which are similar in material and arrangement to the sands deposited by water. Such sand formations are, however, nore variable in thickness and more limited in extent than sands deposited under the water. In the interior, especially in desert regions, formations of quartz sands may occasionally be built up independently of water, but, in general, interior wind-depositer sands are not well sorter, and consequently contain as abundant constituents other materials than quartz. Therefore such deposits ordinarily do not belong in the quartzsand fanily, and they are considered on pages 877-878.

Since quartz is second in abundance only to feldspar as a constitnent of the original igneous rocks, since it is extensively manufactured from the silicates by the processes of metamorphism, and since, unlike many other minerals, it does not readily dissolve or unite as a solid with other minerals, one would expect that very extensive formations of quartz sand would be produced; and to such expectation the facts correspond. Almost every inland lake is building up a belt of quartz sand of greater or less width along the shore. The width of this belt is, of course, dependent upon the size of the lake and upon the depth of the water. The greater the lake the wider is the sand belt, the coarser sands being near the shore and the finer ones farther from the shore. Gradual deepening of the water also is 
favorable to a broan belt, for in that case the undertow is effective farther from shore than where the waters are deep. The rule as to gradual increase in depth applies to the ocean where the shore is swept by the full force of the waves. In bays the building up of quartzose sands is largely dependent upon the amomnt of material contributed to it. lf, for instance, a great river flows into a bay of moderate size, the amount of material of all kinds is so great that the wave action is not sufficiently vigorous to sort the material, and pure quartz-sand deposits are not formed. It appear's probable that in the past the most extensive quartz-sand formations have been the deposits of moderately shallow waters in great mediteranean seas, as, for instance, the Cambrian sands of the interior basins of the United States. These sands constituted thick deposits in the Appalachian Mountain system, the sonther'n part of Canada, and throughout the entire northern part of the United States. In the western part of the United States almost equally extensive sand formations have been produced $I_{n}$ order that thick sand formations slall be built up below the water, it is, of course, necessary that subsidence shall take place concurrently with the deposition. In this respect one rock formation does not differ from another.

If the sand grains be supposed to be of uniform size and spherical, and to be arranged in the most compact system geometrically possible, the space occupied by the sand grains is 74 per cent, and the space between the grains is 26 per cent, of the entire space occupied by the formation. (See Chapter III, p. 125.) As shown by Buckley, ${ }^{\circ}$ in the Dunnville sand rocks, which have been partially indurated, the space is found to be as great as 28 per cent. The explanation of this lies in the fact, discovered by Professor Slichter, that under natural conditions sand grains are never arranged in the most compact manner possible. Ordinarily this fact more than compensates for the varying size of the grains and their imperfect spherical shape (see p. 126); and it may be regarded as certain that the. quartz grains of well-sorted pure-sand formations, such as the St. Peter sandstone of Wisconsin (see p. 861), occupy not more than two-thirds to three-fourths of the space.

"Buckley, E. R., Building and ornamental stones of Wisconsin: Bull. Wisconsin Geol. and Nat. Hist. Surv. No. 4, 1898, p. 225. 
Sandstone is indurated quartz-sand rock. The induration is sufficient to make the grains of sand rather strongly coherent, but not so great that the grains break across when the rock is fractured; on the contrary, the fiactures follow the cement around the grains. The change of a sand formation to a sandstone is lue to consolidation and cementation. These processes are characteristic of the belt of cementation. The process of consolidation by pressure is of relatively little inportance in sandstones. Slichter has shown that sands as naturally deposited by water are likely to have a tolerably compact arrangement, ${ }^{a}$ and that mechanical disturbance of such sands is likely to result in a less compact arrangement. Sand grains, while having many more points of contact than psephites, have few as compared with the finer grained sediments. Doubtless the superincumbent pressure does bring these grains into juxtaposition, and may possibly weld them to some extent at the points of contact, but sands in which this process alone has occurred are sure to be very weak.

The main process of induration is that of cementation. (See Pl. IX, A.) Silica is dissolved in the belt of weathering, either by the decomposition of silicates or by the solution of silica, either amorphous or crystallized. The solutions join the sea of ground waters, and there the silica is deposited upon the sand grains, usually in optical orientation with them. The result of this process is to partially fill the spaces between the sand grains. 'These filling materials after' a time interfere and thus cement the sand grains together. In so far as they do not interfere, the added material is likely to develop crystal faces, and thus there are produced crystal-faceted sand grains, which together make up the sandstone. Sandstones the world over are mainly thus indurated, and ordinarily show innumerable crystal faces when a specimen is held so that the light of the sun may be reflected. While quartz is the dominant cement, iron oxide and calcite are often important cements, and many other minerals are unimportant supplementary cements. Rocks indurated by cementation are usually called sandstones from the time the cementation is sufficient to make the grains weakly cohere to the stage in which the cementation is far enough advanced to cause the rock to break across the sand grains lather than around them. At this later stage they become quartzite.

a Slichter, C. S., Theoretical investigation of the motion of ground waters: Nineteenth Ann. Rept. U. S. Geol. Survey, pt. 2, 1899, p. 305. 
The question as to where the process of cementation from sand to sandstone takes place is discussed under the next heading, "Quartzite," since the problem is precisely the same with both, and it can be better understood after the facts relating to the cementation of quartzites have been considered.

QUARTZITE.

One of the most i.rportant rocks produced by the cementation process is quartzite. (PI. IX.) The term "quartzite" is here restricted to quartzose sand rocks which have been so firmly indurated by the cenenting processes that when broken the fractires pass through the original grains and not around thenr. The process of cementation continues, until the enlarged sand grains or the independent quartz deposited interfere and interlock so as to nearly or quite fill the interspaces. (Pl. IX, B.) In the production of indurated sandstone and quartzite the quartz nay be deposited either as enlargements of old grains or as independent interstitial material. In either case the induration may be so nearly perfect that a vitreous quartzite is produced. If composed of very fine graius of sand, so that the indurated rock may serve as a whetstone, the rock has been called noraculite. Novaculite is therefore no more than an even-and fine-grained quartzite. In general, there is a strong tendency for the quartz to deposit upon the old grains rather than as independent mineral particles. 'The reason for the deposition of the quartz from the solutions and the optical orientation of this quartz with the original sand grains has beeu discussed on pages 75-76, 121-123. It may here be said in summary that the explanation lies in the power of a mineral to abstract from solutions material like itself, for large particles to grow rather than new ones to develop, and to the fact that silica is one of the most abundant of the materials which are transported by ground waters. Many of the cemented quartzites show little or no evidence of strain, which proves that mechanical action has not been potent in the induration. Neither is there any evidence that a high degree of heat is requisite to dissolve the silica or to deposit it as quartz upon or between the old grains. The sands from which quartzites develop contain various impurities. During the transformation of the sands to quartzite these impurities are rearranged to a greater or less extent by netasomatic chinges and new ninerals develop, as described in the cases of the minerals in the feldspathic sands and the grits. (See p. 870 et seq.) As with sandHON XLTII-04-55 
stones, so in quartzites, iron oxides and calcite are subordinate cements, and frequently other minerals to some extent perform a similar function. In many parts of the continents the process of cementation has transformed sandstone to quartzite for extensive areas, many such formations of widely differing geological ages covering hundreds of thousands of square kilometers. These quartzite formations vary in thickness in different places from a few meters to as much as 3 or 4 kilometers.

It has been seen under "Quartz-sand rock" (p. 863) that ordinarily the material of well-sorted, pure sand formations does not occupy more than two-thirds to three-fourths of the space. This requires that in the cementation of a sand to a quartzite from one-fourth to one-third of the formation be added by the ground waters. It is therefore certain that the amount of secondary silica required to indurate such great quartzite formations as occur in the Paleozoic and pre-Paleozoic of the continent is enormous. That required for vein fillings, while vast, is probably inconsiderable as compared with this.

For instance, if a quartzite formation were supposed to have a volume of 100 cubic kilometers, to change this rock from a sand to a quartzite would require the addition of from 25 to $33 \mathrm{or}$ more cubic kilometers of quartz. It would be very interesting to make an estimate as to the amount of quartz which has been added by the gromnd circulation to the quartzites which are now known to exist, but the descriptions of quartzite formations are not sufficiently accurate to admit of even an approximate estimate of their volume. However, certainly many thousands, and probably hundreds of thousands, of cubic kilometers of quartz must have been added by the ground solutions in order to indurate these formations. It has been fully explained on pages 480,516-517 that the silica liberated from the silicates by the process of carbonation in the belt of weathering is entirely adequate to account for much or all of the silica supplied by the ground waters.

There remains to be considered the question where the process of cementation of sand to sandstone and quartzite takes place. If the argument given on pages $856-857$ in reference to the minor importance of the cementation of psephites below the sea be correct, it is still more applicable to the cementation of sands. Murray and Renard have estimated that sea water contains in solution, on the average, only one part of silica in 250,000 
parts of water. ${ }^{a}$ The openings between sand grains are of capillary size. The circulation of the sea water through sandstone formations below the sea where there is hydrostatic equilibrium must bo exceedingly slow; indeed, is probably negligible. In the case of sandstones there is no way by which recrystallization may cement the material, as with the psephites, which contain minerals capable of expansion reactions. The sand grains are composed of quartz, and quartz is required for cenentation. There is no belt of weathering, the material of which is being continuonsly dissolved and transported to the belt of cementation below. For the above reasons it is thought that the cementation of sandstones, while still below the waters in which they were deposited, is negligible. If this be true, the cementation of sands must take place after they have been raised above the sea and an underground circulation has been established. Even after these conditions exist, and the conditions are favorable to a vigorous underground circulation which steadily derives from the belt of weathering large quantities of silica, cementation is still very slow.

It lias been seen that the amount of silica required to indurate the great quartzite formations is enormous. The vastness of the geological work of this kind probably gives us the best measure of the extent to which ground waters have circulated and the enormous amount of water which must have passed through these formations before the cementation is complete.

The mumerous analyses of mineral spring waters, more than ordinarily rich in soluble compounds, show that such waters do not contain, on the average, more than one part by weight of silica in 100,000 to one part in 10,000. This latter amount is exceeded by only a few wells or springs, such as the Humboldt salt well. " Supposing that the underground water which passes into the belt of cementation steadily carries one part in 50,000 of silica by weight, and that all of it is deposited, the filling of a pore space anounting to one cubic kilometer would require the circulation of 50,000 times 2.6, or 130,000, cubic kilometers of water.

Even for the cementation of a single formation, such as that of the quartzite of the Penokee-Gogebic iron-bearing district of Michigan and

aMurray, John, and Renard, A. F., Deep-sea deposits: Report on the scientific results of the voyage of H. M. S. Challenger, 1873-1876, London, 1891, pp. 286-288.

$b$ Peale, A. C., Lists and analyses of the mineral springs of the United States: Bull. U. S. Geol. Survey, No. 32, 1886, p. 159. 
Wisconsin, where there is a quartzite formation 130 kilometers long and 120 meters wide, the amount would be enormous. Supposing the induration to have extended only to the depth of 2 kilometers along the dip, the amount of water which must have passed through this formation in order to have cemented it would be $4,056,000$ cubic kilometers. Thus the cementation of this single formation required the circulation of almost incredible quantitios of ground water; and the addition of the almost indefinitely greater quantity of quartz cementing the quartzite formations now existing would require a correspondingly greater amount of water.

Even this point of view does not give a conception of the amount of ground circulation required to cement the quartzites; for during geological history probably a great many more quartzite formations than now exist have been produced and destroyed by the processes of erosion. And in the quartzites we lave but a single plase of the work of ground water. It therefore follows that the amount of ground water required to cement a single formation is infinitesimal as compared with the amount which has circulated through the rocks during geological ages. Indeed, it is probably not too much to say that the same water has circulated through the ground more than once, for it is doubtful whether the entire volume of the water of the ocean is sufficient to have done the work of cementation and metasomatism by use a single time.

SCHIST-QUARTZITE OR QUARTZITE-SCHIST.

A schist-quartzite or quartzite-schist is a quartzose rock derived from a sandstone or quartzite which has a more or less well-developed schistose structure. These rocks are produced in the zone of anamorphism under mass-mechanical conditions. Granulation or recrystallization, or both, are the dominant processes, but with these, welding and cementation are at work. In order to produce a schist-qnartzite it is not necessary to suppose that cementation lias filled the entire spaces between the sand grains; for mashing, resulting in granulation, recrystallization, and welding may so rearrange the material as to close the openings and lessen the volume of the rock, with no adder material from an outside source. Therefore it can not be assumed that any considerable amount of material has been added to schist-quartzites, unless evidence remains in the enlargements of the quartz grains. Not infrequently in the schist-quartzites such evidence may be seen. In the least mashed phases of schistose quartzites the quartz 
grains may be but slightly fractured. In passing to more mashed varieties regular lines of fracture occasionally appear at right angles to each other. As the mashing becomes more advanced, granulation begins. This first affects the exteriors of the grains, but as the process continues the grains may be granulated throughout. (PI. IX, D.) Generally, however, before granulation is fur arlvanced recrystallization begins. As a result of this, in the interstices new quartz and mica develop (the latter from the impurities) and the recrystallization of the old grains of quartz occurs, as described on page 865. Recrystallization cliecks, and finally reverses, the tendency of gianulation to produce finer and finer particles. Where recrystallization becomes important, and especially where it becomes dominant, the mineral particles may grow to a relatively large size. In proportion as a mass is deep seated and the mashing is extreme there is a marked tendency to a parallel dimensional arrangenent of the newly crystallized particles (see pp. 688-689, 760), and the final process is a schist-quartzite or quartziteschist which shows no sign of fragmental origin. In many instances the coarser quartzite-schists have particles averaging $7 \mathrm{~mm}$. in length and $4 \mathrm{~mm}$. in breadth. The common ratio between minor and major diameters, as ascertained by Leith, varies from 20:100 to 100:100, with an average of perhaps $50: 100 .^{a}$

The schist-quartzites and quartzite-schists which are largely readjusted by recrystallization beantifully illustrate the principle that this process lags behind mechanical deformation. (See Chapter VIII, pp. 696-698.) Residual strain effects, as shown by strain shadows, are very general. Occasionally, however; the entire rock has largely recrystallized under static conditions after mashing ceased, and there has been produced an interlocking granular quartz rock in which the quartz particles lave no similar dimensional orientation and in which there is little residual strain effect. This peculiar variety is beautifully ilhustrated by the quartz rocks of Rib and Mosinee hills, near Wansau, Wis. (Pl. IX, C.) After complete recrystallization has taken place, producing a granular quartz rock, when the rock is again deformed granulation may occur. This furthor change has locally taken place at Rib Hill. (See Pl. IX, D.)

In proportion as the sands, sandstones, and quartzites are impure the schist-quartzites and quartzite-schists forming from them will be impure. 
From the impurities are apt to derelop some of the heary minerals of the zone of anamorphism. Of these minerals mica is by far of the greatest consequence, and of the micas muscovite is the most abundant. The secondary mica always shows a weil-developed parallel arrangement, with its greater dimensions and readiest cleavage parallel to the greater dimensions of the quartz. These mica-bearing rocks are schistose, micaceons quartzites and micaceous quartzite-schists. While mica is the most frequent of the minerals which form in connection with the schist-quartzites, other minerals, snch as toumaline, actinolite, etc., may form, and if they become important they may give mineralogical qualifiers to the names schistquartzite and quartzite-schist

In some districts all stages of gradation from quartzites, through schistquartzites and quartzite-schists, may be seen. These stages may be best observed in a region not too strongly folded on the crests and in the tronghs of the folds. At such places there is comparatively little readjustment, while on the limbs of the folds, especially between the beds, the differential movements are much more marked. Therefore on the crests and in the tronghs of the folds and in the center of the beds the less changed rocks are found, while at the outer parts of the beds and on the limbs of the folds schists may be formed.

QUARTZ-FELDSPAR-SAND FAMILY.

The quartz-feldspar-sand fanily includes quartz-feldspar sands, arkose, and schist-arkose or gneiss-arkose.

QUARTZ-FELDSPAR SAND.

Some fragmental formations are composed mainly of feldspar and quartz, and sucl deposits may be called quartz-feldspar sands. The most favorable conditions for their formation are those of disintegration of acid feldspathic rocks, with comparatively little decomposition, and contiguity to the sea. (See Chapter VI, pp. 496-501.) The more prominent rocks furnishing material for the quartz-feldspar sands are the granite and syenite families among the igneons rocks, and the acid gneisses and sehists among the metamorphic rocks. The volume of these rocks is very considerable, and the acid feldspars, which are among their essential constituents, are slow to decompose. It follows that the quartz-feldspar sands occur in considerable volume. Feldspars from intermediate and basic rocks are in 


\section{PLATE IX}




\section{PLA T E IX.}

\section{PHOTOMICROGRAPHS OF SANDSTONE AND QUARTZITES.}

A. Sandstone from Arlington, Columbia County, Wis., showing enlargement of quartz grains in optical continuity, and crystal facets so common in sandstones which have been partly cemented.

$B$. Quartzite from Penokee-Gogebic district of Michigan and Wisconsin. The grains have been thoroughly cemented by enlargement, having grown by adding new quartz material to themselves in optical continuity until they met adjacent grains growing out in a similar manner. The rock is a thoroughly crystalline quartzite.

C. Completely lecrystallized quartzite in which all trace of rounded grains is lost. From Rib Hill, Wis. The rock has been so thoroughly recrystallized that the quartz grains form an irregular mosaic, like vein quartz or recrystallized chert.

D. The same, granulated. In the field, in hand specimens, and under the microscope all stages of the mashing of the rock are to he observed. Each of the granules is a minute part of the quartz individual from which it was derived. 

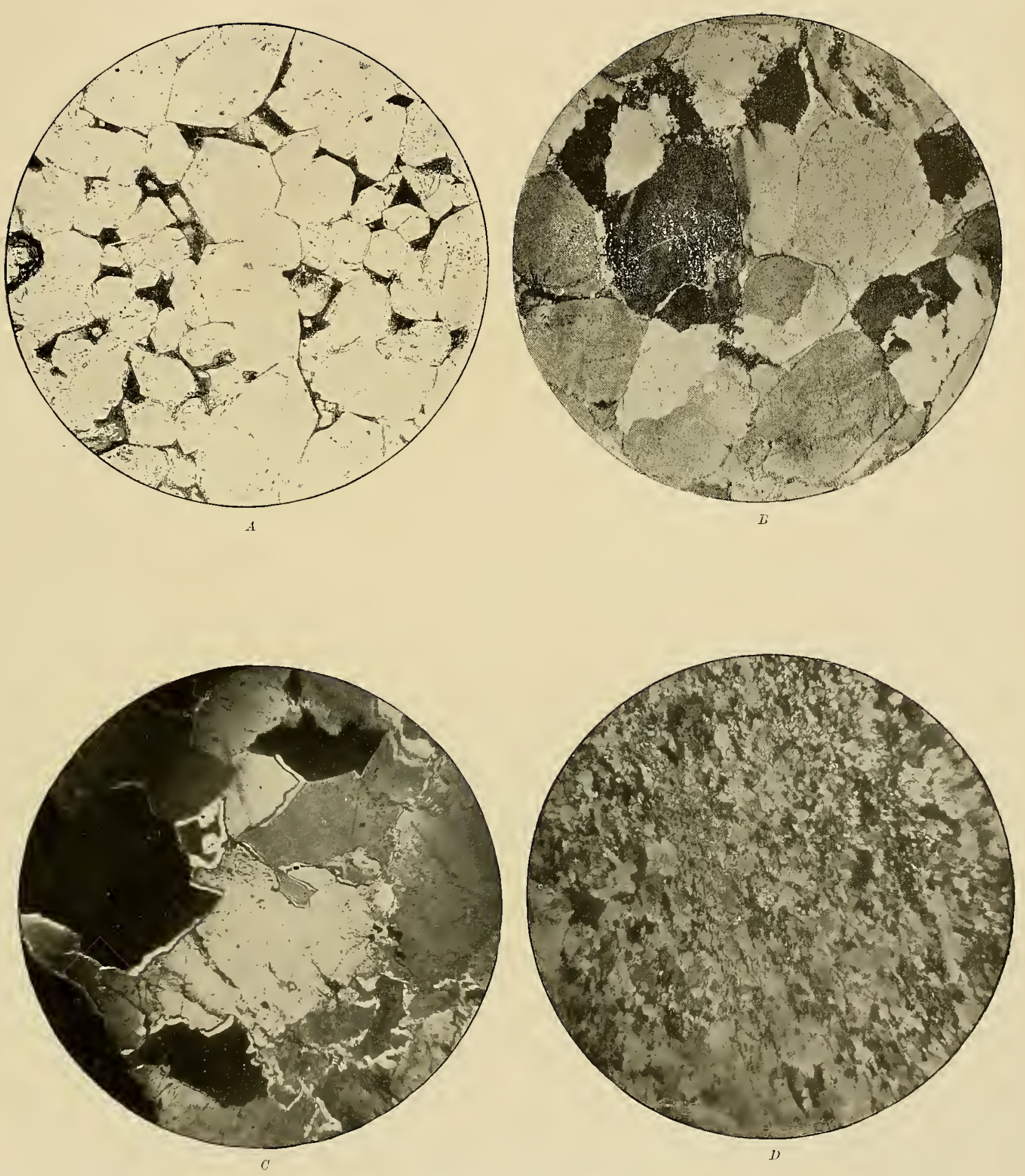

PHOTOMICROGRAPHS OF SANDSTONES AND QUARTZITES. 

some instances important supplementary sources of material. Quartz and acid feldspars have very nearly the same specific gravity, and unless such material be gradually contributed to the water, so that it can be handled by strong waves and currents for a long time before final deposition, quartz and acid feldspar will not be separated. The basic feldspar is more apt to be separated. These conditions for imperfect separation especially prevail in bays and gulfs where the full power of the ocean is not felt. The only other important constituent of ordinary granite and of many of the acid schists and gneisses, beside quartz and feldspar', is mica. 'This mineral, because in flakes, is carried farther than, the quartz and feldspar, and thus is easily and rapidly separated from them and transported to deeper water. Consequently, in the comparatively shallow waters along the shore many nearly pure quartz-feldspar sands may be built up.

One of the best illustrations of the deposition of quartz-feldspar sands at the present time is that in the Gulf of California, described by McGee." The rocks of this region consist largely of granites and granitoid schists and gneisses, although mingled with them are various igneous rocks and tuffs. The region is one of great aridity and rapidly varying temperature. The small amount of rainfall is concentrated in thunder storms, in some cases of exceptional violence. The result is that the rocks which are disintegrated but not decomposed are transported by the process which NcGee has called sheet-flood erosion. (See Chapter VI, p. 497.) The undecomposed material is piled up in the ravines of the mountains or is transported to the gulf by storms of exceptional violence. The waves of the gulf are at work upon such disintegrated material and the salients of the solid rock. Thus a large amount of material is furnished by the waves and streams, to be distributed by the shore currents and undertow. The final result is that the quartz and feldspar, with some mica, are deposited as a quartz-feldsparsand formation. MeGee notes that where there are proninent salients the quartz-feldspar sand is coarsest and cleanest, and that where there are reentrants there is mingled with the coarse quartz and feldspar a considerable proportion of finely comminuted materials. ${ }^{b}$

Doubtless this case of the formation of quartz-feldspar sands in the Gulf of Califonia points to the conditions under which similar sands were

"McGee, IV J, The formation of arkose: Science, new ser., vol. 4,1896, pp. 962-963.

b IIcGee, cit., pp. 962-963. 
deposited in the past, althongh other combinations of conditions may have producerl similar results. For instance, where the sea has rapidly transgressed over a region of granitic rocks the material may be broken down by wave action and incompletely assorted, thus producing quartz-féldspar sands. Or great deposits formed in an interior basin may be overridden. Thus if by subsidence the sea should advance over the Great Basin of western United States (see Cliapter VI, p. 559) at various places stratifier feldspathic sands similar in character to those of the Gulf of California would be buried, since in this region there are varions granitic and acid sclistic, gneissic, and granitic nowntain ranges about which the fieldspar and quartz débris of the mountains is being built np as stratified rocks by the streams and ephemeral lakes and by sheet flood erosion. But from such deposits neither mica nor any other mineral is more than imperfectly separated. Therefore, unless the original rocks were enormously rich in quartz and feldspar, such deposits are likely to contain with the quartzfeldspar sands considerable quantities of ferromagnesian sands, considered on pages $877-879$.

ARKOSE.

Arkose is cemented quartz-feldspar sands. The arkoses are formed in the belt of cementation. The cementing material is largely quartz, just as with the quartz sands. Other cementing materials are calcite, ferrite, etc., and in some cases the cementing material is largely feldspar. This is well illustrated by the arkoses of the Keweenawan of the Lake Superior region. The rocks from which these arkoses were derived were the volcanic rocks of the Lower Keweenawan. In the Keweenawan arkoses the cementing material is mainly quartz, but this is occasionally supplemented by feldspar, and in some instances where the arkose is a nearly pure feldspar rock the feldspar interstitial material is the main cement. 'This feldspar is largely added to the feldspar grains in optical continuity, precisely as is the quartz to the quartz grains, thus enlarging them. Where the feldspars are twinned plagioclases, the enlargements are twinned in similar fashion. ${ }^{a}$ (See fig. 14, p. 626.) These arkoses give one of the best illustrations of the capacity of mineral particles to abstract from the solntions material like themselves and add it to themselves. (See pp. 121-123.)

\footnotetext{
a Irving, R. D., and Van Hise, C. R., On secondary enlargements of mineral fragments: Bull. U. S. Geol. Survey, No. 8,1884 , p. 46 .
} 
The process of cementation may be partial, as with the sandstones, or may continue until the material has practically fillectall the interspaces, as with quartzites, when the rock becomes completely indurated arkose. Where cementation is very partial, the rock fractures around the grains rather than across them, just as in a sandstone. Where cementation is complete or nearly so, the fractures are across the grains rather than around them, just as in quartzite, to which the rock is then analogous.

During cementation the feldspar's in the arkoses may undergo metasomatic changes. The dominant feldspars are orthoclase, microcline, and the acid plagioclases. Any of the alteration products of these minerals characteristic of the belt of cementation may form, but the most abundant products of their alteration are quartz, chlorite, the zeolites, and the epidotes.

Where by deep burying the arkoses pass into the zone of anamorphism, the original feldspars or their alteration products are likely to recrystallize, producing heavy anhydrous minerals. Under such circumstances the acid feldspars are most likely to pass into quartz and mica. The alteration products of the feldspars produced in the belt of cementation may reproduce feldspar or may unite to form quartz and mica. In proportion as the quartz-feldspar sands were impure, the heavy minerals are likely to form. So long as the conditions are mass-static the original textures and structures of the rock are likely to be preserved; but if in the deep-seated zone the conditions are mass-mechanical, schist-arkoses or gneiss-arkoses, considered under the next heading, are likely to form.

The induration of the arkoses is believed to be mainly accomplished while the deposits are land areas. The reasons for this belief are the same as in the case of the sandstones. (See pp. 866-867.)

SCIIST-ARKOSE AND GNEISS-ARKOSE, OR ARKOSE-SCFIST AND ARKOSE-GNEISS.

After the arkoses are formed and have become buried deep enough to be in the zone of anamorphism, mass-mechanical action may take place. In consequence of this a schistose or gneissose structure is developed, and the rocks become schist-arkose and gneiss arkose, or arkose-schist and arkoseg'neiss. There are, of course, all gradations between the rocks here considered and the arkoses. Where the mechanical action is rather weak, a schistose structure is not marked. Where mass-mechanical action is 
profound, a schistose structure is strongly developed. Where the original sands were of the same general character, schists are likely to be produced; where the sands were in alternate bands, some of which were mainly quartzose and others strongly feldspathic, a gneiss is likely to form. Such a gneiss is beautifully illustrated in the Sturgeon River tongue of the Crystal Falls district of Michigan, adjacent to the conglomerate-gneiss already mentioned. ${ }^{\alpha}$ (See p. 860.)

During the transformation the quartz is granulated and recrystallized, precisely as in the schistose quartzites. Since the feldspars of the arkoses dominanty belong to the acid end of the series, they usually break up into mica and quartz. So far as the feldspar is ortloclase or microcline, muscovite and quartz form. Where the arkose is impure, and magnesium and iron are present in considerable quantity, biotite is likely to develop. At the stage $i$ wilich the alteration of the feldspar is partial there is an interlocking sixture of quartz, feldspar, and mica. In other words, at this stage the rocks have a composition which, under the German usage of the ierm, would be called mica-gneiss. Where among the feldspars interme. diate varieties, such as labradorite and bytownite, are present, simultaneously with the development of the other minerals, albite, oligoclase, and andesine may form, but of these albite is by far the most prevalent. Thus out of the old feldspar a great deal of new and usually acid feldspar is produced. The development of new feldspar is particularly likely to take place when adjacent igneous intrusions have occured, especially granitic intrusions. Doubtless the hot mass of granite promotes the formation of solutions which cary abundant feldspathic material, and out of this, in part at least, the new feldspar develops. (See pp.713-715.) In the schist-arkoses the nicas have well-developed parallel orientation, with their longer axes anr, cleavages in a common plane. The new feldspars may also have a sizilar orientation. Such an arrangement is beantifully illustrated in the Hoosac schist, described by Wolff. ${ }^{b}$ In this rock, mainly composerl of quartz, mica, and feldspar, the latter mineral, mainly albite, is wholly recrystallized and locally shows a very marked parallel orientation.

a Clements, J. Mcrgan, and Smyth, H. L., with Bayley, W. S., and Van Hise, C. R., The Crystal Falls iron-bearing district of Michigan: Mon. U. S. Geol. Survey, vol. 36, 1899, pp. 463-464.

$b$ Pumpelly, Raphael, Wolff, J. E., and Dale, T. Nelson, Geology of the Green Monntains in Massachusetts: Mon. U. S. Geol. Survey, vol. 23, 1894, pp. 59-63. 
FERROYAGNESIANSAND FAYTLY:

The ferromagnesian-sand family includes the ferromagnesian sands, grits, graywacke, and slate-graywacke, schist-graywacke, or gneissgraywacke.

FERROMAGNESIAN SANDS.

At many localities ferromagnesian sancls are built up which are mainly composed of quartz, the feldspars, and the ferromagnesian minerals. With these dominant minerals there are subordinate quantities of various other minerals-in fact, any of the minerals which are important as rock constituents, with the possible exception of such readily decomposable soda-bearing minerals as sodalite, nephelite, etc.

The conditions for the deposition of the ferromagnesian sands are those of disintegration, with little decomposition. These conditions are fully discussed on pages $496-501$. It is here only necessary to say that the conditions are substantially the same as those for the formation of the feldspar-quartz sands, except that the rocks from which the minerals are derived contain the ferromagnesian minerals abundantly. In proportion as the climate is arid, in proportion as the material has to be transported only a short distance, in proportion as it is coarse, in proportion as there is great change of temperature by insolation in the warm regions and freezing and thawing in the cold regions, the various igneous rocks are broken down. 'Thus, sands composed of individual grains or aggregates of grains of the same or unlike mineral composition are formed. The rocks from which the ferromagnesian sands are derived must contain abundantly the ferromagnesian minerals. These ferromagnesian sands are deposited under physical conditions very similar to those under which the quartz-feldspar sands are deposited.

The formations may be built up on land or below water. Where built on land in arid regions, thick deposits are likely to result, especially where there is no drainage to the sea. Such deposits are illustrated in the Sahara and in the Great Basin of western United States. The conditions for the formation of sands in such districts have been fully discussed by Walther, ${ }^{a}$

a Walther, Johannes, Die Denudation in der Wüste und ihre geologische Bedeutung, S. Hirzel, Leipzig, 1891, pp. 445-161. Walther, Johannes, Das Gesetz der Wüstenbildung in Gegenwart und Torzeit, Dietrich Riemer, Berlin, 1900, pp. 31-52. 
and have been alluded to in this treatise. (See Chapter VI, pp. 496-497.) Nothing further will be said upon their manner of formation. The essential point in this connection is that such sands are likely to be not at all, or very slightly, sorted; therefore they contain practically all the minerals of the original rocks from which they are derived, and hence include the ferromagnesian minerals. While such formations are of very great thickness in various parts of the world, and doubtless are now being indurated in their lower parts, as described below, it is difficult to ascertain how far the ferromagnesian sands, and their altered equivalents thus formed, have been preserved among the rocks of past geological ages.

Ferromagnesian sands are being extensively deposited below the waters of inland seas and of the ocean, where the sorting is very imperfect. This is bikely to be the case in the estuaries or near the mouths of strong rivers which are rapid to their mouths. All these conditions are well illustrated by some of the rivers which flow into the estuaries of the Atlantic, such as the Susquehanna. The conditions for the deposit of ferromagnesian sands are still more nearly perfect along the Pacific coast. The rapid streams of the Coast Range carry the extremely varied material of the mountains to the bays, such as San Diego, San Francisco, and Puget Sound, or to the ocean. But in the open ocean the ferromagnesian sands are likely to be sorted into their constituent minerals.

While the perfect conditions for the formation of the ferromagnesian sands are those of disintegration with no decomposition, of course decomposition does everywhere occur to a greater or lesss degree. In the case of the rivers of the Piedmont platean, which are emptying into estuaries, the decomposition of the sands is considerably advanced. But the decomposition of the sands of the Coast Range is not nearly so far advanced.

Since decomposition everywhere occurs to some extent, the ferromaguesian minerals and the feldspars have been changed more or less to minerals into which they commonly alter in the belts of weathering and cementation. The feldspars may have been changed in part to kaolin, mica, quartz, zeolites, etc. The pyroxenes, amphiboles, and biotite may have been changed to a greater or less extent to chlorite, epidote, serpentine, talc, etc. Thus in the sands under consideration there may be present not only original minerals, but any of their alteration products in various proportions. In so far as alterations have taken place the proportion of the 
elements in the secondary rocks as compared with the original rocks is likely to be changed. For instance, alumina may be relatively increased in amount, and sodium greatly depleted, as compared with the potassium, ete., as explained on page 507 et seq. This process of alteration is likely to have proceeded far, in proportion as the material is fine grained. $\mathrm{By}$ increase in anount of decomposition and decrease in size of grains, the group of sands under consideration passes by gradation into the muds or pelites. By decrease of the ferromagnesian minerals they pass into the arkose sands. By decrease of the ferromangesian and feldspathic minerals they pass into the quartz sands. Therefore there are all gradations between the ferromagnesian sands and the pelites, the quartz-feldspar sands, and the quartz sands.

$$
\text { GRITS. }
$$

In the belt of cementation, by consolidation, cementation, and metasomatism the ferromagnesian sands pass into grits. The grits occupy the same place in the fanily that sandstone and arkose bear in the quartzsand and quartz-feldspar-sand families, respectively. In the induration of the grits consolidation by pressure and welding is comparatively unimportant. The principles of cementation applicable are identical with those of the sandstones and arkoses. A much greater number of cementing minerals are inportant in the grits than in either the sandstones or the arkoses. Where a ferromagnesian sand formation extends to the surface in the belt of weathering there may be contributed to the underground waters all the important elements which make up the great masses of the rocks. Also in the belt of eementation like diversified material may be added to the solutions by alteration of the minerals. Therefore, from the waters percolating through the ferromagnesian sands almost any of the common rock-making minerals which develop in the belt of cementation may be deposited. While this is true, the fact remains that the most abundant cement is quartz. Next in importance to this, in all probability, is calcite, and occupying a third place are the iron oxides. However, feldspar, hornblende, and other silicate minerals may be enlarged by each mineral selecting from the solutions appropriate materials for this purpose, preeisely as with quartz. Also there may be deposited in the interstices such minerals as the zeolites, epidote, and ehlorite, precisely as in the vacuoles of lavas, which have an equal variety of materials. 
During cementation of the grits, metasomatism in the feldspars, ferromagnesian minerals, and constituents other than quartz is taking place. This process is precisely the same as in the metasomatism of the graywackes, next taken up; and since in these rocks the process is of greater consequence, it will not be here considered further than to remark that the expansion reactions which take place contribute material to the solutions for cementation.

It is believed that the change of the ferromagnesian sands to grits is mainly accomplisherl on the land areas. The argument is the same as with the graywackes. Since it can better be given after these rocks have been considered, the statement on this point is deferred. (See p. 882.)

Grits of Carboniferous age are rather extensive formations in varions parts of the world. This is natural, since coal is known to have formed in lagoons and partly inclosed seas, and it has already been noted that such places, where the sorting power of the waves is small, are favorable ones for the building up of the ferromagnesian sands. But the grits are not by any means confined to the Carboniferous system; they occur extensively in the Cretaceous, Tertiary, and other systems.

GRAYTACKE.

Graywackes are produced from grits in the belt of cementation. Where the cementation is adranced so far that the rock when fractured breaks across the original grains rather than around them the rock is a graywacke. (Pl. X, A.) Graywacke, therefore, occupies the same position in the fanily under consideration that quartzite and completely indurated arkose oceupy in the quartz-sand and quartz-feldspar-sand families. Nothing further need be said of the process of cementation, since it is mainly the completion of the work which cements a ferronagnesian sand into a grit. While the process of cementation is going on metasomatic changes mar also be occurring in the body of the rock. (See Chapter VII, pp. 640-646.) The clastic particles may alter in many ways. To describe them in detail wonld be to give a treatment of the alteration of minerals. The final result of the alteration is a consolirlated rock which may have a very great variety of mineral constituents. One of the most characteristic features of the grayrackes is, however (as indicater by the name), their gray color: While the new minerals may have something of a tendency 
to similar orientation, they usually do not become regularly parallel. The slight tendency toward a parallel arrangement usually accords with bedding, but in some cases it may not do so. The banded character of the original rock is ordinarily preserved, even if all of the decomposable detrital minerals are altered into new ones. Each mineral may change into any of the products which form in the belt of cementation, as listed. (See pp. 621-627.) To illustrate, the feldspars may alter into quartz, chlorite, the zeolites, and the epidotes; the pyroxenes and amphiboles may alter into quartz, serpentine, calcite, dolomite, magnesite, magnetite, and the epidotes; the micas may alter into serpentine, chlorite, and quartz. These secondary minerals vary from a subordinate to a dominant amount, and in some instances but little if any of the original feldspars, pyroxenes, amphiboles, and micas remain. But in general it is difficult to discriminate the metasomatic changes which take place in grits and graywackes from the partial alterations of the minerals before the material was deposited as a ferromagnesian sand. Where a ferromagnesian mineral of a certain kind is very abundant the alteration products from such a mineral are correspondingly plentiful.

Secondary minerals which form from several important primary minerals are likely to be especially abundant; as, for instance, serpentine. This mineral very often develops on a considerable scale in the graywackes. Indeed, it sometimes becomes so prominent that the metamorphism of graywackes has been called serpentinization. The secondary serpentine acts in a manner similar to that of silica. It may occupy the crevices and cracks, the spaces between the constituent minerals, and, finally, the place once taken by other minerals. Exactly as in the case of silica, material for the serpentine may be furnished in part or in whole by the minerals present, or the material of the serpentine may come from an extraneous source, especially from the belt of weathering. Widespread formations may be extensively serpentinized, so as to give for considerable areas almost solid masses of serpentine. The serpentinized graywackes are especially well illustrated in the Coast Range of California. ${ }^{a}$ (Fig. 23.)

Excellent illustrations of the graywackes may be found in the Huronian of the Lake Superior region, and perhaps the best illustrations of all are

$a$ Becker, G. F., Geology of the quicksilver deposits of the Pacific Slope: Mon. U. S. Geol. Survey, vol. 13, 1888, pp. 120-128.

MON XLVII-04- 56 
the so-called slate-conglomerates of Logan in the Original Huronian area on the north shore of Lake Huron. ${ }^{a}$ Here there are extensive formations the matrix of which is typical graywacke, and in which are scattered fragments, great and small, of the various rocks from which the finer débris was derived. By an increase in the amount and size of the coarse material, the graywackes pass into psephite-conglomerates. Almost equally good illustrations of graywackes are locally found in the great slate formation of the Penokee and Animikie series, although they are here not nearly so extensive as north of Lake Huron. Geikie describes graywacke as a rather common rock in Great Britain. ${ }^{b}$

The change from ferromagnesian sands to grits and graywackes is believed to take place in an important degree only when the deposits are below land areas. The argument in this connection is essentially the same as that applicable to the transformation of sands to sandstone and quartzite. The openings of the rocks are capillary, and it can

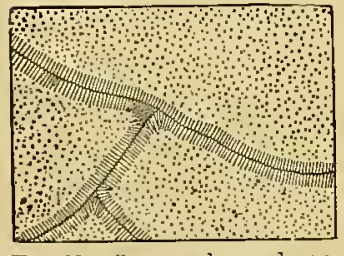

FIG. 23.-Graywacke undergoing serpentinization along cracks, After Becker. not be presumed that in the rocks while below the water there is any rapid circulation by which material may be introduced. Indeed, there is no belt of weathering available which can furnish such material. But there is one difference between quartzose sand and the ferromagnesian sands. In the latter expansion reactions may occur while the rocks are below the water. So far as metasomatism there takes place, the processes of hydration, carbonation, and oxidation, all producing increase of volume, would provide material which could be deposited between the grains and thus cement the rocks. To what extent this process has actually taken place below the water must, for the present at least, be a matter of conjecture. But, as first stated, it is believed that the major part of the cementation and metasomatism of the graywackes occurred while the rocks were parts of land areas, for there the conditions are favorable for cementation, viz, vigorous circulation of the ground water and steady contribution of material to the belt of cementation from the belt of weathering.

After the graywackes have become cemented by deep burying they may pass into the zone of anamorphism. There metasomatic changes may take place in the rocks, in consequence of which the heavy 
minerals characteristic of that zone are formed. These minerals and their mảnmer of development are, however, identical with those of the graywackeschists and graywacke-gneisses next to be considered, and they will therefore not be here discussed.

SLATE-GRAYWACKE, SCHIST-GRAYWACKE, AND GNEISA-GRAYWACKE; OR GRAYWACKE-SLATE, GRAYWACKESCHIST, AND GRAYWACKE-GNEISS.

Where graywackes are buried deep enough to be in the zone of anamorphism and are subjected to mass-mechanical action, a schistose or banded rock is prodnced, to which the terms slate-graywacke, schistgraywacke, and gneiss-graywacke, or graywacke-slate, graywacke-schist, and graywacke-gneiss, are applicable. Where the movement is moderate the slate-graywackes or graywacke-slates are likely to form, but where the mass-mechanical movements are severe schists and gneisses develop.

The rearrangement of the minerals under mass-mechanical conditions combines the processes of recrystallization and gramulation fully described in Chapter VIII (pp. 673-675, 690-696). The minerals which form are of course the heavy anhydrous minerals characteristic of the zone of anamorphism. The average composition of the minerals in a given case approximates that of the chemical composition of the original ferromagnesian sands, except so far as they have been ehanged in composition in the belt of anamorphism by dehydration and decarbonation or by injection.

Since one of the essential conditions for the formation of the ferromagnesian sands is disintegration with but little decomposition, within these rocks the various elements, including the alkalies and alkaline earths and iron, are likely to approximate the average original proportions of the rocks from which the sands were derived. It therefore follows that the ferromagnesian sands are likely to be richer in alkalies, alkaline earths, and iron than the quartz sands or even the quartz-feldspar sands. Since the rocks may contain nearly a full quota of all the elements, almost auy of the minerals may form which are characteristic of the deep-seated zome, with the exception of the ninerals rich in soda, such as sodalite, nephelite, etc., and the heavy almminum silicate minerals. Apparently there has always been sufficient depletion in soda to prevent the development of the former. As pointed out on page 900, the latter are likely to derelop only where there is an excess of aluminum beyond that required for the formation of the minerals containing the alkalies and alkaline earths. 
The original quartz is grannlated and recrystallized, as in the other varieties of sands. As the feldspars recrystallize, the micas are likely to form abundantly, especially biotite, since iron and magnesium are plentiful. (Pl. X, B.) But while the feldspar may in part pass into other minerals, it in large part recrystallizes as feldspar, with perhaps a change in species. Such new feldspar is apt to be an abundant constituent in the recrystallized rocks. Frequently the ferromagnesian minerals are so plentiful that the amphiboles develop extensively. In the abundance of amphibole these rocks differ from the schists and gneisses of the quartz-sand and quartzfeldspar-sand families. The particular amphibole which develops in a given formation depends, of course, upon the composition of the rock, but actinolite and common hornblende are very abundant. (Pl. X, Cand D.) Rarely, where the metamorphism is of a very extreme nature, the pyroxenes may also develop to some extent, but any considerable quantity of these minerals is rather unusual. It is probable that the greater abundance of amphibole is due, in part at least, to the fact that in this group of minerals the ratio between the calcium and the magnesium is $1: 1$, whereas in the pyroxenes it is $3: 1$. So far as decomposition has taken place in the original sands, the calcium is likely to lave been extracted in greater proportion than the magnesium (see pp. 515-516); therefore many of the ferromagnesian sands may have been so depleted in calcium that pyroxenes can not readily form. Associated with the more abundant minerals, the heavy metamorphic minerals, such as garnet, staurolite, and tourmaline, may appear: However, these minerals are not likely to form so abundantly as in the pelite family, and the aluminum-silicate group of minerals, so common in the pelites, is rarely found. So far as hydrous minerals have been produced in the belt of cementation, they are decomposed. The material of the chlorites may largely go into the micas, amphiboles, garnets, staurolite, and other minerals. The zeolites may pass into the feldspars, especially into albite or oligoclase. In short, any of the combinations of hydrous minerals which have been formed by the alteration of a heavy original mineral may recombine to reproduce the original heavy mineral; for instance, serpentine, gibbsite, and kaolin may unite to produce biotite; kaolin and quartz, or gibbsite and quartz, with sodium-bearing minerals, may unite to produce albite; serpentine and quartz to produce enstatite, ete. 
The newly developed minérals show a narked tendency to similar dimensional arrangement. This tendency is very strongly marked with the micas, is important with the hornblendes, and applies to a considerable extent to quartz and the feldspars. Corresponding with the dimensional arrangement of the mica there is an eminent cleavage. There may be a cleavage corresponding to the dimensional arrangement of the hornblendes and the feldspars. This dimensional arrangement and mineral cleavage combined give the rocks a slaty or schistose structure, depending upon the coarseness of the mineral particles. (See pp. 778-779.)

Where the original ferromagnesian sands were banded in consequence of alternation of coarse and fine material, or of alternation of different combinations of the mineral constituents, this banding may be preserved and thus a gneissic structure be produced in the recrystallized rocks. Where there was a band in which quartz was very abundant, the laminæe are composed largely of quartz; where there was a quartz-feldspar band there is likely to be a lamina composed of quartz, feldspar, and mica; where there was a band in which were abundant ferromagnesian minerals there are likely to be lamine in which hornblende, feldspar, mica, and quartz are all plentiful. Of course, the bands are not sharply separated from one another, and there is likely to be subordinate amounts of all the minerals which occur in the rock in each of the bands. The preservation of the bauded structure is due to the fact, fully explained in Chapter VIII (pp. 764-766), that during the alterations which take place in the zone of anamorphism migration of large quantities of material does not take place for more than exceedingly short distances.

It will be seen later that the gneisses of igneous origin ustally contain hornblende. The sedimentary gneisses belonging to the fannily under consideration nsually contain hornblende, and therefore are more likely to be confused with the gneisses of igneous origin than with the gneisses of the quartz-sand or quartz-feldspar-sand families. (Pl. X, C.) However, in many cases the average chemical composition of the rocks and the arrangement and structures of minerals enable one to discriminate gneisses of the family here considered from those derived from the igneous rocks. But, apparently, where the sedimentary rocks are adjacent to great intrusive igneous masses of hornblende-granite the sedimentary rocks may 
gain hornblende in consequence of the exomorphic effect, and in that way produce a graywacke-schist containing much hornblende and very similar to hornblendic-schists of igneous origin. (See Pl. X, D.)

The graywacke-slates, graywacke-schists, and graywacke-gneisses, of course, grade into the graywackes from which they are derived. Further, they grade on the one hand into the arkose-schists and arkose-gneisses, and on the other land into the pelite-schists and pelite-gneisses.

PELTTE ORDER.

MUD FAMILY.

Mud is the finest of the mechanical sediments. The greatest deposits of mud form at the months of large rivers. Where very great rivers empty into the sea deltas of immense thickness and size are built up of mud, as, for instance, the delta of the Mississippi. Great deposits of muds are also forming in the estuaries into which the rivers enter, such as the estuaries of the Atlantic. These delta and estuary deposits, besides being extensive, are of immense thickness. In mediterranean seas great deposits of mud may be built up as the products of many rivers. Thus Willis explains the Hamilton shale of the Devonian of the Appalachian region, a formation extending from New York to Maryland, and haring a thickness of from 350 to 420 meters. ${ }^{a}$ Also in the open sea, as a result of the process of sorting, the muds are carried beyond the psammites, and so extensive formations of mud of moderate thickness are built up.

Muds deposited in mediterranean seas or in the open ocean very frequently are interstratified with or grade into the psammites toward the shore. Seaward they frequently are interstratified, intermingled, or grade into the calcareous deposits. To a less extent similar transitions are found associated with delta and estuary deposits. Consequently we have deposits intermediate between muds and sandstones, and between muds and limestones. From the foregoing it follows that muds vary in composition from that of the various psammites to that of the carbonates. The rocks intermediate between the muds and the carbonates usually contain a large percentage of calcium, magnesium, and̀ carbon dioxide.

On the average the material of which mud is composed has been

a Willis, Bailey, Paleozoic Appalachia, or the history of Maryland during Paleozoic time: Maryland Geol. Survey, vol. 4, pt. 1, 1900, pp. 57-61. 
PLATE $X$ 


\section{PLA TE X. \\ PHOTOMICROGRAPHS OF GRAYWACKES.}

A. Graywacke from Penokee-Gogebic district of Michigan and Wisconsin. The orthoclase is in most cases separable from the quartz, in that it lacks the perfect cleamess and uniformity of color which each grain of that mineral shows. The striated feldspars are nicely shown.

$B$. Biotite-graywacke from Mesabi district of Minnesota. This is the normal phase of Lower Huronian gray wacke, consisting of quartz and feldspar grains, mainly the former, very imperfectly rounded, and a considerable amount of secondary biotite and muscovite or sericite. All the constituents have a dimensional parallelism, and the nicas have also a crystallographic parallelism. After Leith.

C. The same, showing development of new hornblende near contact with intrusive granite. A iter Leith.

D. The same, showing development of new hornblende to the practical excinsion of mica at contact with intrusive granite. After Leith.

888 

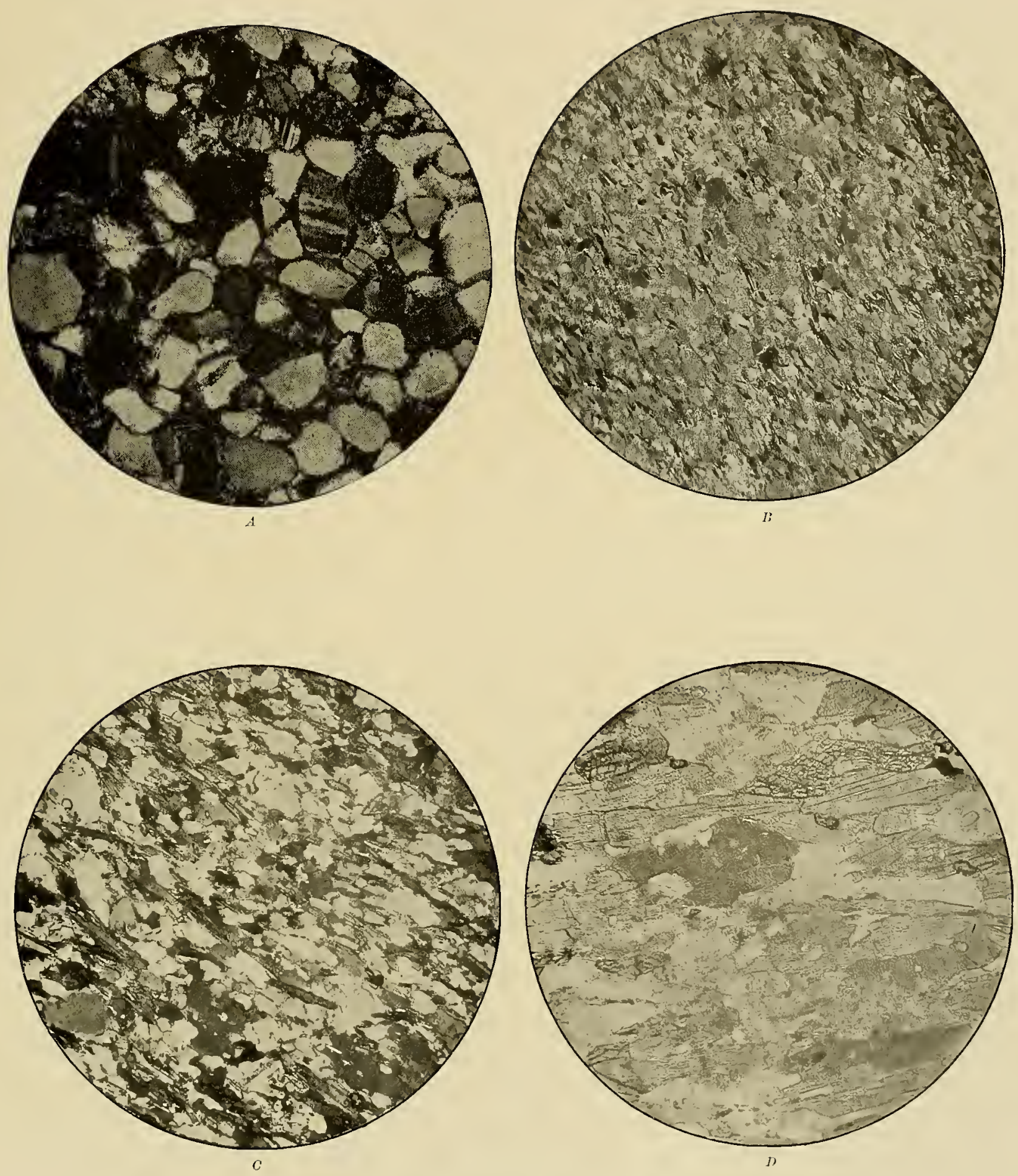

PHOTOMICROGRAPHS OF GRAYWACKES 

exposed to the weathering processes under more favorable circumstances than any other mechanical deposit. Consequently mud is material in which decomposition is farther advanced than in any of the previously considered classes of mechanical sediments. It follows from this that muds are likely to be rleficient in the more readily solnble compounds. Of these the alkalies stand first, and of the alkalies sodium is more largely dissolved, since a large proportion of sodium in the original igneous rocks occurs in minerals which are more readily decomposed than the minerals which bear potassium-that is, sodium occurs largely in the nephelites, sodalites, and basic feldspars, which, as shown on pages 252, 260, 292, 295-299, are readily soluble; whereas the great sources of potassium are orthoclase and microcline, difficultly decomposable minerals. The materials are also apt to be depleted in calcium and magnesium, since the alkaline earths are so readily soluble. (See analyses A, B, C, of shales in Chapter XI, under "Composite analyses of "sedimentary rocks." The depletion in calcium usually has gone farther than the depletion in magnesium, since in the belt of weathering much of the magnesia is retained in the serpentines and tales. The material may or may not be depleted in iron. While alumimm and silica also have been dissolved in the belt of weathering, the solution of these substances is less rapid than of the others, and thus there is usually an increase in the relative amounts of these elements. The relative rate of solution of the elements is more fully considered on pages 507-518.

The processes which lead to the solution are those of carbonation, hydration, and oxidation, so frequently mentioned. From the muds the carbonates are mainly removed in solution, the hydroxides are removed to some extent, and the highly oxidized iron largely remains. All the foregoing facts clearly appear when the analyses of original igneous rocks are compared with those of muds. I reproduce from Clarke the first column of a table giving the average of analyses of igneous and crystalline rocks, made up from 830 analyses from various parts of the world, which may be regarded as elosely approximating the composition of the original material from which the muds must have been derived, except that a considerable number of the 830 analyses are from metamorphic rocks, a portion of which may be metamorphic sedimentary rocks. So far as there was 
depletion in any of the elements of such metamorphic sedimentary rocks, this would somewhat reduce the amount of these elements and correspondingly increase the amounts of the other elements.

Average of analyses of 830 igneous and crystalline rocks."

\begin{tabular}{|c|c|c|c|}
\hline & Per cent. & & Рет cent. \\
\hline $\mathrm{SiO}_{2} \ldots \ldots$ & 59. 71 & $\mathrm{~K}_{2} \mathrm{O} \ldots \ldots \ldots \ldots$ & 02.80 \\
\hline $\mathrm{Al}_{2} \mathrm{O}_{3} \ldots \ldots$ & $15.4 \mathrm{I}$ & $\mathrm{H}_{2} \mathrm{O} \ldots \ldots \ldots$ & 1.52 \\
\hline $\mathrm{Fe}_{2} \mathrm{O}_{3} \ldots \ldots$ & 2.63 & $\mathrm{TiO}_{2} \ldots \ldots$ & .60 \\
\hline $\mathrm{FeO} \ldots \ldots \ldots \ldots$ & 3.52 & $\mathrm{P}_{2} \mathrm{O}_{5} \ldots \ldots$ & .22 \\
\hline MgO . . . . . . . . . & 4.36 & Total & 99.22 \\
\hline $\mathrm{CaO} \ldots \ldots \ldots$ & 4.90 & & \\
\hline $\mathrm{Na}_{2} \mathrm{O} \ldots \ldots \ldots$ & 3.55 & & \\
\hline
\end{tabular}

Probably the best obtainable estimate of the composition of the muds is the average of analyses of 78 Cenozoic, Mesozoic, and Paleozoic shales given by Clarke. The individual shales are given weight proportional to the mass of the formation, as nearly as this could be done. His results, by combining the two composite analyses, one for 27 Mesozoic and Cenozoic shales and the other for 51 Paleozoic shales, are as follows:

Average of analyses of 78 shales. ${ }^{b}$

\begin{tabular}{|c|c|c|c|}
\hline & Per cent. & & Per cent. \\
\hline $\mathrm{SiO}_{2} \ldots \ldots$ & 58.38 & $\mathrm{P}_{2} \mathrm{O}_{5}$ & 0.17 \\
\hline $\mathrm{Al}_{2} \mathrm{O}_{3} \ldots$ & 15.47 & $\mathrm{SO}_{3} \ldots \ldots$ & .65 \\
\hline $\mathrm{Fe}_{2} \mathrm{O}_{3} \ldots \ldots$ & 4.03 & Cl.......... & \\
\hline $\mathrm{FeO} \ldots \ldots \ldots$ & 2. 46 & S $\ldots . . .$. & $\ldots . .$. \\
\hline $\mathrm{MgO} \ldots . . . .$. & 2.45 & $\mathrm{MnO} \ldots \ldots \ldots$ & Trace. \\
\hline $\mathrm{CaO} . . . .$. & 3.12 & $\mathrm{BaO} \ldots . .$. & .05 \\
\hline $\mathrm{Na}_{2} \mathrm{O} \ldots \ldots$. & 1.31 & $\mathrm{SrO} \ldots .$. & None. \\
\hline$K_{2} \mathrm{O} \ldots \ldots \ldots$ & 3.25 & $\mathrm{Li}_{2} \mathrm{O} \ldots$ & Trace. \\
\hline $\mathrm{H}_{2} \mathrm{O}$ at $110^{\circ} \ldots$ & 1.34 & Carbon (of organic origin) & .81 \\
\hline $\mathrm{H}_{2} \mathrm{O}$ above $110^{\circ}$ & 3.68 & Total .. & $100+6$ \\
\hline $\mathrm{TiO}_{2} \ldots \ldots . .$. & .65 & & \\
\hline $\mathrm{CO}_{2} \ldots \ldots \ldots$ & $2.6 \pm$ & & \\
\hline
\end{tabular}

a Clarke, F. W., Analyses of rocks, laboratory of the U. S. Geol. Survey, 1880-1899: Bu11. U. S. Geol. Survey No. 168, 1900, p. 14.

${ }^{b}$ Clarke, cit., Bull. 165, p. 17. 
Probably the chief respect in which these shales differ in composition from muds is that water is less abundant in them. To compare the above analyses with the analyses of the original rocks, the water onght to be omitted. Omitting the water, and increasing the other elements in proportion, the analysis of shales would be as follows:

Analysis of shales on basis of 100 per cent excluding the water.

\begin{tabular}{|c|c|c|c|}
\hline & Per cent. & & Per cent. \\
\hline $\mathrm{SiO}_{2} \ldots \ldots$ & 61.45 & $\mathrm{SO}_{3}$ & 0.68 \\
\hline $\mathrm{Al}_{2} \mathrm{O}_{3} \ldots$ & 16.29 & $\mathrm{Cl} .$. & . . . . \\
\hline $\mathrm{Fe}_{2} \mathrm{O}_{3} \ldots \ldots \ldots \ldots \ldots$ & 4.24 & s.. & $\cdots$ \\
\hline $\mathrm{FeO} \ldots \ldots$ & 2. 59 & $\mathrm{M} \operatorname{\mathrm {n}O} \ldots$ & Trace. \\
\hline MgO $\ldots$ & 2.58 & BaO...... & $: 052$ \\
\hline $\mathrm{CaO} \ldots \ldots \ldots$ & 3.29 & $\mathrm{SrO} \ldots \ldots \ldots \ldots$ & None. \\
\hline $\mathrm{Na}_{2} \mathrm{O} \ldots \ldots$ & 1.38 & $\mathrm{Li}_{2} \mathrm{O} \ldots \ldots \ldots$ & Trace. \\
\hline $\mathrm{K}_{2} \mathrm{O} \ldots$ & 3.42 & \multirow{4}{*}{ Total } & .85 \\
\hline $\mathrm{TiO}_{2} \ldots \ldots$ & .68 & & 100.460 \\
\hline $\mathrm{CO}_{2} \ldots \ldots \ldots \ldots$ & 2.78 & & \\
\hline $\mathrm{P}_{2} \mathrm{O}_{5} \ldots$ & .178 & & \\
\hline
\end{tabular}

For comparison there is inserted the average of 12 analyses of clays and soils from Illinois, Iowa, Minnesota, and Wisconsin.

Average of 12 analyses of clays and soils. ${ }^{a}$

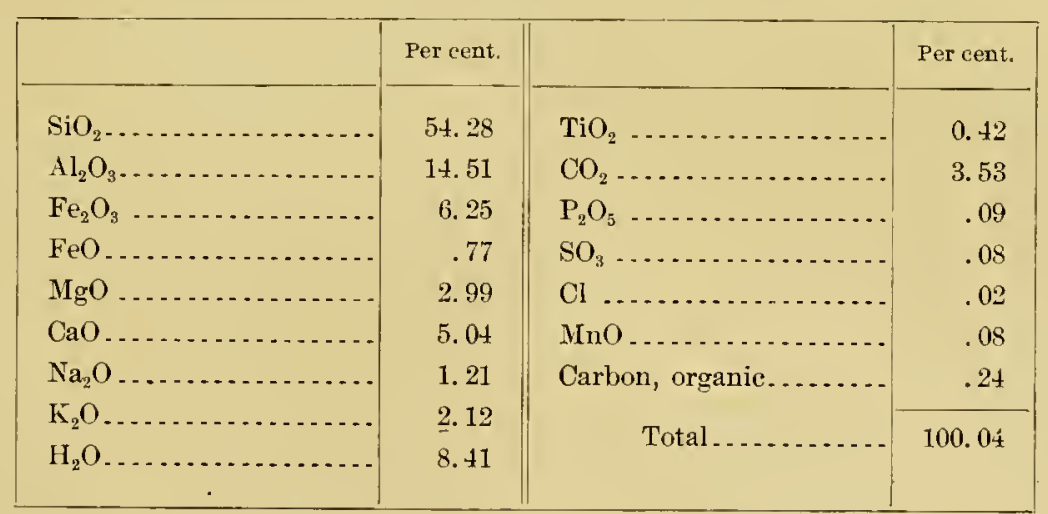

a Clarke, F. W., Analyses of rocks, laboratory of the U. S. Geol. Survey, 1880-1899: Bull. U. S. Geol. Survey No. 168, 1900, pp. 296-297. 
The secondary minerals are important constituents or the muds. Of these the most abundant are those which especially form in the belt of weathering, as given on pages 518-521. With these there are, of course, almost all the minerals which form in the belt of cementation, as given on pages 621-627, and finally with both of these classes are residual unaltered minerals, especially refractory ones, such as quartz, orthoclase and microcline, albite, etc., and the heavy refractory minerals. Not infrequently the quartz and feldspar constitute the major portion of the material. From the foregoing it is clear that in proportion as alteration is advanced the minerals forming the muds tend toward the very end products of alterationquartz, kaolin, talc, ferric oxide, and gibbsite. (See p. 520.) Some of the clayey muds are composed almost wholly of quartz and kaolin, with some talc and ferric oxide. It therefore appears that the muds have a wide variety of composition, both chemical and mineral.

SHALE FAMILY.

By consolidation, metasomatism, and cementation in the belt of cementation the muds pass into shales. Shale stands, in the pelite order, in the same place in which sandstone, arkose, and grit stand in the psammite order: The processes of alteration are the same in all, bnt their relative importance is very different in the pelites and psammites. In the induration of the psammites consolidation is of subordinate importance, and cementation by material derived from an outside source is of the first importance. In induration of the muds consolidation due to pressure is of the first importance. The particles are very small. According to Whitney, the finer soils, which in reference to subdivision may be taken as approximately the same as mud, contain from 10,000,000,000 to 20,000,000,000 particles per gram. ${ }^{a}$ In a fine sand, such as the St. Peter sandstone of Wisconsin, the number of particles per gram, as determined by Mr. S. H. Ball, are about 115,000 , and in a somewhat fine grained and better sorted beach sand about 167,000 particles per gram. Therefore in a mud, after the steady pressure has squeezed out the water so as to bring the particles in contact with one another, the number of points of contact are from 87,000 to 174,000 times as great as in such a sandstone as the St. Peter, and from 60,000 to 120,000

a Whitney, Milton, Some physical properties of soils in their relation to moisture and crop distribution: U. S. Dept. Agric., Weather Burean Bull. No. 4, 1892, pp. 73-74. 
times as great as in the beach sand. Consequently, where the pressure is sufficient to bring the particles, or a fair proportion of them, so close together that they are within the limits of molecular attraction, welding is an important factor in the coherence of the rock. It is well known that when mud is subjected to very moderate pressure and the water can escape, this is sufficient to make the particles cohere. There is therefore every reason to believe that the weight of the superincumbent material accomplishes the same thing for mud formations.

Metasomatic processes are important in the induration of the muds. The mechanical water within the interstices of the muds and that liberated by dehydration are agents through which changes may be made within the mineral particles and between the adjacent mineral particles. That dehydration occurs is shown by comparison of the analyses of slates and shales with those of muds. It has been seen on pages 742-744 that the water of the slates and shales is, on the average, about 50 per cent of that of the muds.

Where rocks are so strongly liydrated as are the shales, some of the water is combined with the hydrous minerals which most readily part with it, such as the zeolites. Under such conditions the moderate pressures and temperatures which produce the shales are sufficient forces to begin dehydration.

Where organic matter is present in muds-and this is very commonthe process of deoxidation is likely to begin. This is shown by the relative proportions of the ferric and ferrous oxides in the muds and shales, as exhibited in the analyses given on pages 890-891. It is seen that the ferric oxide in the clays and soils averages 6.25 per cent, and in the shales is reduced to 4.03 per cent; whereas the ferrous oxide in the clays and soils is 0.77 per cent and in the shales is increased to 2.46 per cent. These facts accord with the statement in Chapter IV (p. 165; also see Chapter VII, pp. 607-608) that deoxidation, while especially characteristic of the zone of anamorphism, takes place in the belt of cementation where the conditions are favorable. It thus appears that in the change from muds to shales we have the beginning of reactions which for most rocks are not important until they are deeply buried. Of the three reactions, hydration, oxidation, and carbonation, which are characteristic of the zone of katamorphism for the majority of rocks, two begin to be reversed for the pelites in the helt of 
cementation. This simply means that the pelites begin to pass into the zone of anamorphism at less depth than do other rocks.

Cementation is of consequence for the pelites, but not of such dominant importance as in the psammites. The muds are practically impervious to percolating waters, because the openings between the particles are subcapillary. (See Chapter III, p. 143.) Hence very little material can be bronght in from an ontside source to fill the minnte interspaces of the particles of mud; but by the metasomatic processes within the minute mineral particles the solutions obtain material which may be deposited between the grains. As the water is squeezed out by pressure, not only are the particles brought closer together, but as the water moves torvard the place of escape the pressure lessens and material from solution is precipitated, and thus cements the particles. (See p. 114.),

The change of mud to shale is therefore largely a mechanical process of consolidation, resulting in welding; but the chemical processes of metasomatism and cementation also are important.

Where the shales pass into the zone of anamorphism and the conditions are mass-static, the processes of that zone are inangurated. Dehydration may be carried far. The silication of the subordinate amounts of carbonates which are so generally present in the shales may take place. In the shales there is very frequently organic material, and this results in deoxidation. By metasomatism the heary minerals develop. The rocks thus altered may become compact, strong rocks, composed of anhydrous minerals. The reactions for shales in the zone of anamorphism are those which produce the rocks next to be considered.

SLATE-PELITE, SCHIST-PELITE, AND GNEISS-PELTTE; OR PELITE-SLATE, PELITE-SCHIST, AND PELITE-GNEISS.

Where shales are buried so deep as to pass into the zone of anamorphism and mass-mechanical action takes place, slate-pelites, schist-pelites, and gneiss-pelites, or pelite-slates, pelite-schists, and pelite-gneisses are produced. Where the depth is not great and the mass-mechanical action is not very severe slates are likely to form. Where the depth is greater and the mass-mechanical action is severe schists or gneisses are likely to derelop. As the shales are very weak rocks, the depth at which the reactions of the zone of anamorphism are inangurated is not great. It is certainly less, on the arerage, than for any of the previous families. 
The rearrangement of the mineral particles under mass-mechanical conditions is mainly that of recrystallization. The process of granulation, which is so important in connection with recrystallization of the psephites and psammites, is of relatively less consequence in the deep-seated metamorphism of slate, although by no means mnimportant. The particles of the original rocks are so small that they can readily slip over one another without being broken finer, so that granulation is mainly restricted to the large particles. The dominance of recrystallization is shown by the fact that the moment the change from shale to slate, schist, or gneiss commenced the small particles begin to merge and a coarser-grained rock is prodnced. (Pl. XI.)

The alterations which take place of course come under the general classes so frequently mentioned as characteristic of the zone of anamorphism-dehydration, silication, and_deoxidation.

In order to get a better idea of the chemical change from mud to shale and then to slate and schist, analyses of slates and schists are here inserted. The average of 12 analyses of clays and soils is given on page 891. The average of composite analyses of 78 shales is given on page 890 . The following is an average of the analyses of 9 slates from Vermont:

Average of andlyses of 9 slutes from Vermont. ${ }^{a}$

\begin{tabular}{|c|c|c|c|}
\hline & Per cent. & & Per cent. \\
\hline $\mathrm{SiO}_{2} \ldots \ldots \ldots$ & 61.25 & $\mathrm{TiO}_{2} \ldots$ & 0.83 \\
\hline $\mathrm{Al}_{2} \mathrm{O}_{3} \ldots \ldots$ & 16. 61 & $\mathrm{CO}_{2} \ldots$ & .82 \\
\hline $\mathrm{Fe}_{2} \mathrm{O}_{3} \ldots \ldots$ & 2.01 & $\mathrm{P}_{2} \mathrm{O}_{5} \ldots$ & .12 \\
\hline $\mathrm{FeO} \ldots \ldots \ldots$ & 4.83 & $\mathrm{MnO}$. & .14 \\
\hline $\operatorname{Ig} O \ldots \ldots \ldots$ & 2. 80 & $\mathrm{BaO} .$. & .06 \\
\hline $\mathrm{CaO} \ldots . . . . .$. & .83 & $\mathrm{FeS}_{2} \ldots \ldots$ & .22 \\
\hline $\mathrm{Na}_{2} \mathrm{O} \ldots \ldots$ & 1.42 & Carbon ........ & .05 \\
\hline $\mathrm{K}_{2} \mathrm{O} \ldots \ldots .$. & 4.24 & \multirow{3}{*}{ Total } & \multirow{3}{*}{100.07} \\
\hline $\mathrm{H}_{2} \mathrm{O}$ at $100^{\circ}$. & .27 & & \\
\hline $\mathrm{H}_{2} \mathrm{O}$ above $100^{\circ}$ & 3.57 & & \\
\hline
\end{tabular}

The following is the average of 22 analyses of pelite-slates from various localities in the United States, taken from the publications of

a Clarke, F. W., and Hillebrand, W. F., Analyses of rocks and analytical methods, U. S. Geol. Survey, 1880-1896: Bull. U. S. Geol. Survey No. 148, 1897, pp. 277-278. 
the United States Geological Survey. Analyses were taken only from specimens which were clearly of pelitic origin.

Average of analyses of 22 pelite-slates.

\begin{tabular}{|c|c|c|c|}
\hline & Per cent. & & Per cent. \\
\hline $\mathrm{SiO}_{2-}$ & 61.90 & $\mathrm{P}_{2} \mathrm{O}_{5}$ & 0.044 \\
\hline $\mathrm{Al}_{2} \mathrm{O}_{3}$ & 16.538 & $\mathrm{SO}_{3} \ldots .$. & 025 \\
\hline $\mathrm{Fe}_{2} \mathrm{O}_{3} \ldots$ & 2.726 & Cl... & Trace. \\
\hline FeO... & 3.634 & F.. & Trace. \\
\hline $\mathrm{MgO}$ & 2.988 & S... & None. \\
\hline $\mathrm{CaO} \ldots$ & 1.066 & $\mathrm{MnO}$ & Trace. \\
\hline $\mathrm{Na}_{2} \mathrm{O} \ldots \ldots \ldots$ & 2.566 & $\mathrm{BaO} \ldots \ldots \ldots$ & .01 \\
\hline $\mathrm{K}_{2} \mathrm{O} \ldots \ldots$ & 3. 146 & $\mathrm{SrO} \ldots . . .$. & Trace. \\
\hline $\mathrm{H}_{2} \mathrm{O}$ at $110^{\circ}$. & .533 & $\mathrm{Li}_{2} \mathrm{O} \ldots \ldots$. & Trace. \\
\hline $\mathrm{H}_{2} \mathrm{O}$ above $110^{\circ} \ldots$ & 3.311 & $\mathrm{FeS}_{2} \ldots \ldots \ldots$ & .112 \\
\hline $\mathrm{TiO}_{2} \ldots \ldots \ldots$ & .82 & C $\ldots \ldots \ldots$ & .222 \\
\hline $\mathrm{CO}_{2} \ldots \ldots$ & .590 & Totaî... & 100.231 \\
\hline
\end{tabular}

The following is the average of 5 analyses of pelite-schists from various localities in the United States, taken from the publications of the United States Geological Survey. Analyses were taken only from specimens which were clearly of pelitic origin.

Average of analyses of 5 pelite-schists.

\begin{tabular}{|c|c|c|c|}
\hline & Per cent. & & Per cent. \\
\hline $\mathrm{SiO}_{2} \ldots$ & 65.740 & $\mathrm{P}_{22} \mathrm{O}_{5}$ & 0.122 \\
\hline $\mathrm{Al}_{2} \mathrm{O}_{3}-\ldots$ & 17.348 & $\mathrm{SO}_{3}$ & .032 \\
\hline $\mathrm{Fe}_{2} \mathrm{O}_{3} \ldots \ldots \ldots$ & 1.896 & $\mathrm{Cl} \ldots \ldots$ & Trace. \\
\hline $\mathrm{FeO} \ldots . . . . . . . .$. & $3.3 \pm 8$ & F .. & .068 \\
\hline $\mathrm{MgO} \ldots$ & 1. 896 & S ... & ...... \\
\hline $\mathrm{CaO} \ldots \ldots$ & 1.252 & MnO .... & .034 \\
\hline $\mathrm{Na}_{2} \mathrm{O} \ldots \ldots$ & 1.784 & $\mathrm{BaO} \ldots . . . . . . . .$. & .046 \\
\hline $\mathrm{K}_{2} \mathrm{O} \ldots \ldots$ & 3.280 & SrO .................. & Trace. \\
\hline $\mathrm{H}_{2} \mathrm{O}$ at $110^{\circ} \ldots \ldots \ldots$ & .195 & $\mathrm{Li}_{2} \mathrm{O} \ldots \ldots$ & Trace. \\
\hline $\mathrm{H}_{2} \mathrm{O}$ above $110^{\circ} \ldots \ldots$. & 1.815 & C $\ldots . .$. & .582 \\
\hline $\mathrm{TiO}_{2} \ldots$. & .554 & Total .. & 99.992 \\
\hline $\mathrm{CO}_{2} \ldots \ldots$ & None. & & \\
\hline
\end{tabular}


By comparing the analyses of the shales, slates, and schists it is seen that the chief chemical changes are those of loss of water and of carbon dioxide, and transformation of the ferric iron to the ferrous form. The first of these changes is evidence of the process of dehydration, so characteristic of the zone of anamorphism. It is notable, as pointed out in Chapter VIII (p. 744), that in the change from clays and soils, which certainly do not contain more water than muds, to shales and slates the combined water is reduced by one-half, and that in the further transformation to schists the combined water is again reduced by one-half or one-third. The disappearance of the carbon dioxide of the carbonates is due, of course, to the process of silication, the silica uniting with the bases of the carbonates and forming silicates, and the carbon dioxide slowly escaping with the squeezed-out water. It has already been noted that deoxidation begins in the change from muds to shales. The average amount of ferric iron is further decreased as the process of metamorphism goes on, as shown by the fact that in the shales the ferric oxide is 4.03 per cent, in the slates is $2.726 \mathrm{per}$ cent, and in the schists is 1.896 per cent. Correlative with this process is increase of ferrous oxide from 2.46 per cent in the shales to 3.634 per cent in the slates and 3.348 per cent in the schists. (See pp. 890, 896.) In the analyses of shales from eight different States, given in the publications of the United States Geological Survey, carbon is reported in six of them. The carbon in the shales is an adequate reducing agent for this work. While the amount of carbon in the shales is not great, it is persistently present. The average amount of carbon in 78 shales is 0.81 per cent. $^{a}$ (See p. 890.) It is to be remembered that this amount of carbon is much more than sufficient to reduce all of the ferric iron to the ferrous state, as is shown by the following equation:

$$
2 \mathrm{Fe}_{2} \mathrm{O}_{3}+\mathrm{C}=4 \mathrm{FeO}+\mathrm{CO}_{2} \text {. }
$$

Since the molecular weight of two molecules of $\mathrm{Fe}_{2} \mathrm{O}_{3}$ is 320 , and the atomic weight of carbon is 12, this equation means that 12 parts of carbon is theoretically sufficient to reduce 320 parts of the ferric oxide to ferrous oxide. It follows, therefore, that 0.81 per cent of carbon would theoretically reduce 20 per cent of ferric iron to the ferrous state. Since the total

"Clarke, F. W., Analyses of rocks, laboratory of the U. S. Geol. Survey, 1880-1899: Bull. U. S. Geol. Surrey No. 168, 1900, p. 17, col. C.

ION XLVII- $04-57$ 
amount of ferric oxide is 6.25 per cent in clays and soils and 4.03 per cent in the shales, ${ }^{a}$ it is clear that the small amount of carbon in the shales furnishes, by its reducing action, an entirely adequate cause for the partial change of the ferric to ferrous iron as metamorphism of the pelites continues from muds to shales, slates, schists, and gneisses.

The fact that, with the exceptions of the chemical changes mentioned, the compositions of the pelitic gneisses, schists, and slates, where unmodified by igneous intrusions, correspond with those of the shales and muds is positive evidence of the general conclision given on pages $145,764-766$, that circulating ground waters are unable to transport material from an cutside somce through rocks the particles of which are so small as to furnish only subcapillary openings. Of this principle the pelite family affords the best illustration.

The development of the minerals will first be considered at the stage where the rocks are slates, and second where they have been transformed to schists or gueisses.

Development of minerals of slates. - Out of the constituents which are present in the irresolvable backgromul of the shales, innumerable flakes of mica and small particles of quartz develop. The feldspar, with the addition of other constituents, also largely alters into quartz and mica. (Pl. XI, A.) From a single fragmental grain of feldspar are produced many individuals of interlocking quartz and mica. (Pl. XI, B.) The minerals formed in the interstices interlock with one another and with those produced from the feldspar grains, so that an approximately uniform interlocking groundmass of quartz and mica is prodnced. If fragmental grains of quartz are not present to indicate the clastic character of the rock, the secondary interlocking quartz and mica do not betray this. The most abundant mica is usually biotite. Frequently muscovite accompanies the biotite. The sources of the material for the micas of the slates are the same as for the micas of the schists and gneisses. (See pp. 899-900.)

While in the ordinary slates the process of recrystallization as above described is inangurated, it is far from complete, and many of the original mineral particles of the mud usually remain partly changed or wholly unchanged. 
Development of minerals of schists and gneisses. - The processes which result in the formation of pelite-slate from shale when carried to completion produce pelite-schist (Pl. XI, C) or pelite-gneiss. All stages of the change may be seen. We see, besides the replacement of the feldspar by quartz and mica, the granulation and recrystallization of the quartz and the feldspar. The process is essentially the same as the development of slate, except that the destruction of the clastic quartz and feldspar grains is greatly promoted by mashing. The process takes place in perfection in proportion as the rock is fine grainer. Thus a shale may completely change to pelite-schist, while an interbedded coarse-grained grit may still reveal evirlence of its fragmental origin. In the same way a conglomerate may have its matrix completely changed to a schist and the resistant pebbles be merely deformed; but in the case of extreme alteration the most resistant and largest pebbles and bowlders are entirely destroyed. (See pp. 858-859.)

In the typical schist-pelites and gneiss-pelites the chief minerals present are quartz, muscovite, and biotite. (Pl. XI, C.) This is a natural consequence of the composition of the shales. The orthochase and microcline feldspars, with the probable addition of alumina from the background, in most cases recombine into quartz and muscovite. (See pp. 254-255.) This uses up much of the potassa, alumina, and silica. Where magnesium and iron are also available biotite is formed. (See p. 25.5.) Usually some residual feldspar remains or is produced by recrystallization, and the amount of this material is likely to be great in proportion as soda was present in undecomposed plagioclase.

Since silica and alumina are abundant, an acid plagioclase is most likely to form. Consequently albite is the most frequent plagioclase of the schist-pelites and gneiss-pelites. If the anount of soda be considerable, the albite nay be so abundant as to be a chief constituent. Such an albitepelite-gneiss is beautifully illustrated by the Hoosac formation of Hoosac Mountain, Massachusetts, described by Wolff. ${ }^{a}$ (Pl. XI, D.) In some cases where the soda is unusually plentiful, a part of the soda with alumina may pass into the soda-mica paragonite. Indeed, soda may more frequently go into paragonite in the schist-pelites and gneiss-pelites than has been supposed, for the close microscopical and chemical examinations of recent

"Pumpelly, Raphael, Wolff, J. E., and Dale, T. Nelson, (ieology of the Green Momtains in Massachusetts: Mon. I. S. Genl. Survey, vol. 23, 1894, pp. 59-64. 
years have shown that the sericite of many of the so-called sericite-schists is probably paragonite rather than muscovite; but the paragonite-schists in many cases are not pelite-schists, but are derived from the alteration of igneous rocks. As already seen, analyses of original muds show that, on the average, the potassa is several times more abundant than soda, and this fact explains why muscovite is so much more common in the slate-pelites, schist-pelites, and gneiss-pelites than is paragonite.

While the greater part of the potassium probably passes into muscovite, where the potassa is abundant a portion of it in many cases undoubtedly passes into feldspar, producing orthoclase and microcline, since these minerals are rather abundant in many of the schist-pelites and gneisspelites. All the important elements which go to make up the muds are fully accounted for in the minerals quartz, biotite, muscovite, paragonite, albite, orthoclase, and microcline.

Where there is an excess of alumina beyond that required for the formation of the minerals already mentioned, since silica is always in excess, aluminum-silicate minerals form, and thus is produced the andalusitesillinanite-cyanite series. The development of these minerals accounts for a part of the material of the kaolin, which by dehydration and separation of silica may pass directly into any of the aluninum-silicate minerals, according to the reaction:

$$
\mathrm{H}_{4} \mathrm{Al}_{2} \mathrm{Si}_{2} \mathrm{O}_{9}=\mathrm{Al}_{2} \mathrm{SiO}_{5}+\mathrm{SiO}_{2}+2 \mathrm{H}_{2} \mathrm{O},
$$

with a decrease in volume of the quartz and aluminum-silicate mineral of from 25.40 to 26.28 to 31.61 per cent, depending upon whether andalusite, sillimanite, or cyanite, respectively, be formed. Ordinarily the andalusite, having the lowest specific gravity, forms when the metanorphism is moderate, as in the slates. Sillimanite, haviug a higher specific gravity, is likely to form where the metamorphism is more intense; and where the metamorphism is most intense the heaviest of the aluminum-silicate minerals, cyanite, may develop. This fully conforms to the principle explained on pages 363-365, 683-685, that in proportion as a rock is deeply buried and metamorphism is profound, minerals of high specific gravity form. These three ninerals in the inverse order mentioned are described by Emerson as occuring peripherally to great batholiths of granite in western Massachusetts. (See pp. 717-718.) 
PLATE XI 


\section{PLATE XI.}

\section{PHOTOLICROGRAPHS OF PEIITES.}

1. Slate from Mesabi district of Minnesota. This is the normal, fine-grained Virginia slate, consisting of quartz and feldspar, chlorite, muscovite, biotite, and iron oxide, all the constituents arranged with their longer diameters roughly parallel, though the chlorite and iron oxide are arranged to a less extent than the other constituents. After Leith.

R. Biotite-slate from Penokee-Gogebic district of Michigan and Wisconsin. Shows the alteration of the feldspars to the micas. The crystalline character of the developing rock is well shown. There remain, however, areas of feldspar which act as a unit, although they are ent in every direction by the alteration products, quartz and mica.

C. Muscovite-biotite-quartz-schist, showing uniformity of texture. Black Hills, South Dakota.

D. Albite-gneiss from Hoosac Mountain, Massachusetts. Shows no trace of clastic origin. After Wolff.

902 

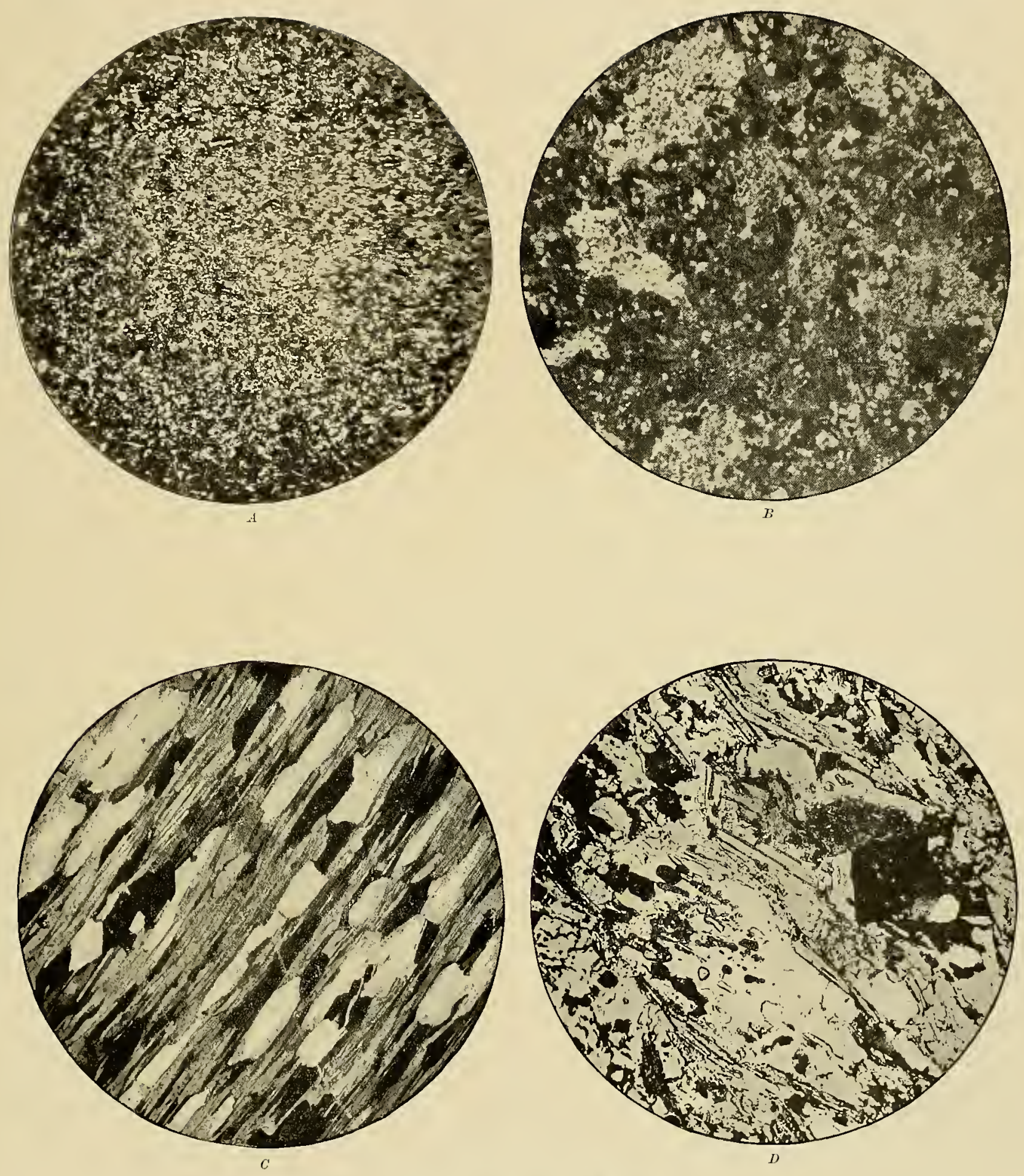

PHOTOMICROGRAPHS OF PELITES. 

Simultaneously with the development of the aluminum-silicate series, garnets and staurolites may be produced. The garnet usually marks a stage of alteration less advanced than the staurolite, and thus it is that very often schist-pelites and gneiss-pelites are garnetiferons and not stmurolitic, but in almost every case staurolitic schists and gneisses are garnetiferous. The development of the garnets may use parts of any of the constitnents, calcium, magnesium, alnminum, iron, depending on the kind of garnet. Common garnet, as explained in Chapter V (p. 302), is usually an isomorphous mixture of grossularite, pyrope, and almandite, and occasionally melanite. The particular garnet which develops in a given case largely depends upon the elements which are present in the original rock. In case iron is rather plentiful and the metamorphism is intense, staurolite is also likely to form. The development of these minerals disposes of a large amount of iron and alpmina, iron being derived from the oxide, and alumina in many cases being derived from the kaolin or from gibbsite or diaspore. If exceptional elements are present, as, for instance, boracic acid, tonrmaline and other exceptional minerals may form.

While in the majority of the schist-pelites and gneiss-pelites feldspar is rather subordinate, in certain of them, as already noted, it is plentiful. In proportion as the feldspar becomes abundant, the material from which the rock was derived grades toward the quartz-feldspar-sand family of the psammite order:

During the metamorphism of the shales to slates, schists, and gneisses the new mineral particles which develop have a very strong tendency to dimensional arrangement. Indeed, the pelite order is the one which shows this dimensional arrangement to the best advantage. The rocks here belonging are the types of rocks of this class. The mineral of most fundamental importance showing the dimensional arrangement is, of course, mica, although some of the other minerals which derelop show a marked dimensional arrangement. That the eminent cleavage of mica corresponds with its dimensional arrangement has been frequently mentioned heretofore, and is dealt with in detail by Leith. ${ }^{a}$ Consequent upon the correspondence of the dimensional arrangement and cleavage of the newly crystallized mica, the eminent cleavage of the slates, schists, and 
gneisses of the pelite order results, thus affording the best examples of rock cleavage.

Where the shales are rather homogeneous in texture, slates and schists form. Where, however, the original muds had alternations of coarse and fine material, or alternations of bands of material of different chemical compositions, these differences are apt to be maintained, to some extent at least, in the metamorphosed rocks, and thus a banded gneissic structure be prodnced. Each band of such a gneiss corresponds approximately in chemical composition to that of the original rock, and is mainly composed of the particular minerals, in the approximate proportions, which may be produced from the band of mud.

Since the muds are the most extensive of mechanical sediments, it naturally follows that there are great formations composed of their metamorphosed equivalents - slate-pelites, schist-pelites, and gneiss-pelites. As illustrations of coarse pelite-schists having a very widespread occurrence may be mentioned the Hudson schists of New England and New York, of Silurian age. ${ }^{a}$ Other equally good illustrations of very extensive schistpelite formations are those of the Upper Huronian formation of the Lake Superior region. ${ }^{b}$ Many other illustrations might be mentioned, but it is hardly necessary to take the space to do this.

\section{IGNEOUS ROCKS.}

As yet we have no classification of the igneous rocks to which there is general agreement. In this respect the igneous rocks stand on a basis different from that of the sediments. As no classification of the igneous rocks is agreed upon, since petrographers themselves have not decided as to which rocks shall have specific names, and as it is agreed that there are

" Merrill, F. J. H., Metamorphic crystalline rocks in New York City district: Geologic Atlas U. S., folio 83 , U. S. Geol. Survey, 1902, p. 4.

$b$ Irving, R. D., and Van Hise, C. R., The Penokee iron-bearing series of Michigan and Wisconsin: Mon. U. S. Geol. Survey, rol. 19, 1892, pp. 296-345. Van Hise, C. R., and Bayley, IT. S., with H. L. Smyth, The Marqnette iron-bearing district of Michigan: Mon. U. S. Geol. Survey, vol. 28, 1897, pp. 44-459. Clements, J. Morgan, and Smyth, H. L., with W. S. Bayley and C. R. Van Hise, The Crystal Falls iron-bearing district of Michigan: Mon. U. S. Geol. Survey, vol. 36, 1899, pp. 164-174. Bayley, W. S., The Menominee iron-bearing district of Michigan: Mon. U. S. Geol. Survey, vol. 46 , 1903, pp. 320-321, 462-488. Leith, C. K., The Mesabi iron-bearing district of Minnesota: Mon. U. S. Geol. Survey, rol. 43, 1903, pp. 168-177. Clements, J. Morgan, The Vermilion iron-bearing district of Minnesota: Mon. U. S. Geol. Survey, vol. 45, 1903, pp. 391-396. 
gradations between many kinds of rocks to which names have been assigned, it is evident that it is impossible at the present time to trace out the stages of alteration of the rarious rock species. All that is now possible is to indicate how metamorphic igneous rocks may be handled in order to lead at some future time to a systematic treatment similar to that applied in the present treatise to the sedimentary rocks.

A series of names has been proposed (pp. 776-784) to designate the different kinds of alterations to which rocks are subjected, and their nsage pointed out. But it seems desirable here to apply these usages to the igneous rocks, even at the risk of repetition. If it is desirable only to express the general fact of alteration, withont indicating its character, the term "meta" is prefixed. If the alterations have taken place under mass-static conditions, so that textures and structures are preserved, the term "apo" is prefixed. If the alterations have taken place under mass-mechanical conditions, so that a slaty, schistose, or gneissose structure is produced, the terms schistic or gneissic may be prefixed. If it is desired to emphasize the structure rather than the kind of rock, the name of the rock may be placed before the structural name, as gabbro-schist. Finally, the dominant metamorphic minerals not implied by the name of the rock may be prefixed, as, for instance, chlorite meta-dolerite. Another illustration is hornblende-dolerite. This is the proper name for rocks which were originally dolerite but in which the pyroxene has changed to amphibole. Such rocks occur extensively in the Lake Superior region, where they have been generally called diorite. But they do not ordinarily have the same chemical composition as the diorites, in which the hornblende is original, nor is the feldspar usually the same. If accompanying the alteration a secondary structure is produced, the altered dolerite may become hornblende-schist-dolerite or horublende-dolerite-schist.

Each of the igneous rocks has a certain range in chemical composition and is composed of certain important minerals. The alterations to which the constituent minerals of rocks are subject in the zones of katamorphism and anamorphism and in the belts of weathering and cementation of the former zone have been fully given (see Chapter V), and the variations in the alterations in each of these zones and belts have been fully discusserl. (Chapters IV, VI, VII, and VIII.) Supposing the zone and conditions to 
be definite for a given rock, one can specify what alterations are likely to occur, so far as each mineral is concerned, and also the alterations which are likely to take place from a particnlar combination of minerals. It is believed that this information will be of great service in a future systematic study of the metamorphism of the varions igneous rocks in the different belts and zones of metamorphism, for it is a great advantage to have definite suggestions as to what may occur. Such snggestions in effect ask the question, when one is making observations, whether or not the facts of alteration for each rock in the different zones and belts correspond to the expectation. If they do the suggestions are confirmed, if not, advauce has still been made upon the problem as to the physical conditions under which the alterations observed actnally took place.

Once a fair degree of agreement is reached as to the orders, families, and species of the original igueous rocks, it will be possible to trace out their alterations in the various zones and belts in a manner somewhat similar to that in which the alterations of the sedimentary rocks have been imperfectly traced out. This, however, is plainly a work which will not be accomplished for many years. In the meantime this chapter furnishes guideboards telling how a great territory of petrography, only peered into from the borders, may be occupied. 


\section{CHAPTER X.}

\section{THE RELATIONS OF METAMORPHISM TO STRATIGRAPHY. INTRODUCTORY.}

It is sufficiently evident from the previons chapter that rocks which have very similar lithological characters may have had ver'y different origins. This point can probably best be appreciated with the aid of a few illustrations.

(a) It is well known that often it is difficult or impossible to discriminate limestones of organic and chemical origin.

(b) Sometimes true water-deposited conglomerates and volcanic tuffs closely resemble each other, and often they grade into each other. This last occurs wherever volcanoes are adjacent to the sea and the fragmental material falls partly upon the land and partly in the water.

(c) A disintegrated and partly decomposed granite or other massire rock in sitn is often very similar to an arkose which is formed from it. For instance, it has been pointed out that the arkoses which are forming in the Gulf of California are practically identical in mineral and chemical character with the rocks from which they are formed. In western United States at various places, even where there is very little alteration, in the field it is difficnlt to delimit sharply the massive rocks, such as granite, from the arkoses built up from and resting upon them.

(d) It is frequently difficult to determine whether igneous rocks are tuffs or are lavas broken during flowage. Gradations between these two classes of rocks occur where tuffaceous material falls upon unconsolidated lavas.

If rocks comparatively little modified and of different origin may so closely resemble one another that they are difficult to discriminate, it is plain that after profound metamorphism they may be still nearer alike. In 
fact, in many cases rocks of diverse origins have become so similar that as yet no criteria have been devised by which they can be discriminated from one another.

It has been fully explained that many of the minerals prodnced by metamorphic processes are the same as those produced by crystallization from a magma and have identical characters. It has further been seen that during metamorphism secondary textures and structures are formed in rocks of all kinds. Some of the secondary textures are enlargement, cataclastic, laminated, porphyritic. Some of the secondary structures are jointing, faulting, bedding partings, cleavage, fissility, schistosity, gneissosity. At the time these textures and structures are producerl the original textures and structures are usually obscured, and they are not infrequently obliterated. And even if the original textures and structures are not greatly modified they are often overlooked because of the prominence of the secondary textures and structures.

Finally, where rocks of different origin but similar chemical composition are strongly metamorphosed with the production of secondary textures and structures, it is scarcely possible to discriminate them, for, as has been fully shown, upon the original chemical composition of the rocks and upon the conditions of their alterations depends the character of the resultant product. Two metamorphosed rocks of different origin but sinilar chemical composition may have practically identical mineralogical, textural, and structural characters.

\section{DISCRIMNATION BETWEEN METAMORPHOSED SEDIMENTARY AND METAMORPHOSED IGNEOUS ROCKS.}

For the purposes of stratigraphy, it is very desirable that, so far as possible, the criteria be given by which metamorphosed sedimentary rocks may be discriminated from metamorphosed igneous rocks. So long as the sedimentary rocks retain little modified clastic textures, either macroscopical or microscopical, they can be discriminated as such. So long as the igneous rocks retain the igneous textures, these may readily be recognized in thin sections. Also, it has been fully explained on pages 644-645, 689-690, that, in so far as the alterations are those of mass-static conditions, the textures and structures are not rapidly destroyed, so that it is ordinarily easy to recognize with the microscope the original textures of such rocks, even if complete 
recrystallization has taken place. A very good illustration of this is the ready recognition of the aporhyolites as volcanic rocks by the presence of spherulitic and other igneous textures. Further, it has been pointed out that where the conditions are mass-mechanical for rocks in the zone of fracture, they are merely broken up into blocks or slices and that the textures in the integral masses are preserved. Therefore, the origin of rocks altered under mass-mechanical conditions in the zone of fracture may usually be determined. Stated in another way, one may say that when the alterations are of a kind to which the prefix apo is applicable, under the significance given to it on pages $776-777$, it is easy to discriminate between altered igneous and altered sedimentary rocks.

In contrast with the above, it has been explained that where the rocks are mashed in the zone of anamorphism previous textures and structures are rapidly destroyed. This may go so far as to obliterate not only the textures and minor structures, but even the major structures of the sedimentary and igneous rocks, such as bedding and differentiation. Naturally there are all grades of this process of destruction. It is only when the mashing has gone so far as to have granulated and recrystallized the rocks in the zone of anamorphism, and has thereby transformed them to schists or gneisses, that original textures and structures are wholly destroyed.

\section{CASES OF CONFUSION.}

The following are some of the classes of igneous and sedimentary rocks which are most likely to be confused:

(1) The schistose and gneissic sedimentary rocks are particularly likely to be confused with the schistose and gneissic tuffs. Both classes of these rocks in their original form may have a lamination or banding which is roughly similar; and if the alteratious go far enough to destroy the textures, the rocks frequently assume a very similar aspect.

(2) Metamorphosed sedimentary rocks derived from arkoses and graywackes-i. e., derived from material in which the original minerals have been but little sorted-are likely to be with difficulty discriminated from metamorphosed igneous rocks. This follows, first, from the fact that the chenical composition of such rocks does not necessarily vary from that of some igneous rocks; and, second, from the fact that arkoses and graywackes are frequently very coarsely banded or even massive, so that the 
sediments have somewhat the same homogeneity of structure that igneous rocks possess. Where there is any considerable sorting of the sedimentary materials, so that they are arranged in layers of different composition, this fact tends to prevent their change to forms which appear similar or identical with metamorphosed igneous rocks.

(3) A third case which has oceasioned difficulty is that of an igneous rock which has been intruded by another igneons rock in a very complicated fashion, so that the intrusive contains very many fragments of the intruded rock. These fragments are oftentimes partly absorbed, and thus take on a psendo-conglomeratic aspect. While it is comparatively easy in most cases to separate such a rock from a true conglomerate when in the unalterated condition, the difficulty of the discrimination increases in proportion as the metamorphism is advanced. The difficulty may be appreciated from the fact that cases are known where ummetamorphosed pseudo-conglomerates of intrusion and true conglomerates which happen to be side by side have been confused by geologists. In varions cases inclucled blocks in gneissoid granites have been taken as evidence of the sedimentary character of these rocks. This mistake has been nade in reference to the Cottonwood granite of the Wasatch, which contains rounded finagments, or else segregations in situ, which have distinctly the aspects of bowlders. Similar phenomena lave led to like conclusions in the Lake Superior region. In some instances the intruded rock and included blocks are schist. In such cases parallel injections are also likely to occur. Thus we have a pseudo-conglomerate, below which are altermating layers of different kinds. These phenomena in the Lake Superior region have led certain geologists to the conclusion that the explanation of the phenomenta is downward progressive metamorphism; but it has been shown that the phenomena are due to intrusion. These difficulties are greatly increased where the rocks have been mashed subsequent to the intrusions.

(4) Another case in which it may be difficult to determine the origin of the metamorphosed rocks is that of the porphyritic schists. By the mashing of a porphyritic igneous rock the matrix may become schistose. The phenocrysts may become rounded by the interior movement, and closely resemble residual fragmental material. In many eases the porphyritic schists of sedimentary origin are derived from material which contains large grains or crystals in a fine-grainerl matrix. The matrix may be 


\section{METAMORPHOSED SEDIMENTARY AND IGNEOUS ROCKS. 911}

recrystallized and the larger particles, being more resistant, only flattened. Thus schists derived from porphyritic igneous rocks and from sediments containing materials of varying coarseness may closely resemble each other.

Another way in which close resemblance between porphyritic schists of sedimentary and of igneous origin may arise is the development of porphyritic constituents during metamorphism. The new porphyritic minerals may show random orientation if formed under mass-static conditions, or parallel orientation if formed under conditions of mashing. The angen-gneisses are cases of this kind. For instance, the angen of one gneiss may be the partly mashed original porphyritic feldspars of an igneous rock, while those of another gneiss may be newly developed porphyritic constituents in a metamorphosed sediment. In such cases it is difficult or impossible to determine from the appearance of the rock whether an augen-gneiss is of igneous or of sedimentary origin.

(5) After igneous rocks have been deformed in the zone of fracture the openings may be filled by cementation. Subsequent mashing may break the fillings into fragments, and shearing may give them roundish forms which very closely simulate pebbles. This happeus in more instances with quartz veins than with other minerals. Such metamorphosed schists bear numerous apparent pebbles of quartz, and are very difficult indeed to discriminate from metamorphosed sedimentary rocks which contain true waterworu pebbles of quartz.

(6) A final class of cases in which it is very difficult to determine what part of a rock mass is igneous and what part is sedimentary is that in which a sedimentary rock has been injected in a complicated fashion by one or more igneous rocks, and later the combined mass is metamorphosed. Such a schist is derived partly from a sedimentary and partly from an igneous rock. Some cases are as follows:

A metamorphosed fissile sedimentary rock, such as mica-schist or micagneiss, may be injected in a complicated way parallel to the schistosity, and thus produce a banded gneiss, part of which is igneous and part sedimentary. The rock may be predominantly of either one of these materials. If the injected sedimentary rock be subsequently folder, this will produce differential movements parallel to the banding, and the iguenus and aqueous bands may be merged into one another and have structures so similar that it is impossible to determine what part of the rock is ignenus and what part 
aqueous. The Hudson schists and gneisses of southeastern New York, especially near Long Island Sound, are a perfect illustration of rocks produced by the extreme metamorphism of a pelite and the subsequent parallel and cross injection of granitic material.

Another case is that in which an intrusive rock enters a fractured sedimentary rock in such a manner as to give the intrusive masses roundish forms. When later metamorphosed the roumdish forms are dissevered, and they may resemble bowlders. The frequent inference is that the rock is a metamorphosed conglomerate, whereas it is a metamorphosed sediment in which the pseudo-bowlders are introduced igneons material.

From the foregoing it is clear that an inseparable schist or gneiss formation may be produced from altered intrnsive rocks, from altered lavas, from altered tuffs, from altered sediments, and from any possible combination of two or more of these. Donbtless in many regions in which the schists and gneisses are of a very complex character a number of the processes mentioned in the previous pages, and possibly others unknown, must be united in order to explain all of the phenomena.

While similar schists or gneisses may be derived from sedimentary rocks or from igneous rocks, or partly from each, one who has had much experience in the field is apt to have a bias toward the one or the other origin in a particular instance. But if a given schist or gneiss formation can at no place be traced into a form characteristic either of a sedimentary rock or of an igneous rock, it is extremely hazardous to make positive assertions as to its origin.

\section{CRITERIA FOR DISCRIMINATION.}

While the schistose igneous rocks may have foliations, bandings, and lithological characters which very closely simulate those of metamorphosed sedimentary rocks, it is still true of the rocks belonging to the Algonkian and later periods that in many districts the majority of the metamorphosed igneous rocks can be discriminated from the metamorphosed sedimentary rocks.

The more important criteria for discrimination between the metamorphosed sedimentary and igneous rocks are as follows:

(1) The much-mashed igneous rocks are apt to have a very regular, fine foliation and great uniformity of lithological character. If an igneons 
METAMORPHOSED SEDIMENTARY AND IGNEOUS ROCKS. 913

mass gradually varies in composition in its different parts, as is so often the case with differentiated magmas, the mashed varieties grade into one another. The complete absence of minor plications, indicating the absenceof a parallel structure before the schistosity was produced, is most striking. It is therefore concluded that the finely, regularly laminated, homogeneous schists are usually of igneous origin. It should perliaps be remarked that this is a reversal of the iuterpretation frequently made at the present time, and which was almost universally made a few years ago.

The converse proposition, that the banded and heterogeneous schists and gneisses are of sedimentary origin, can not be made; for the igneous rocks, intrusive and extrusive, in a given area may have liad an original banded character, or may have had great complexity in their parts, as a result of which their mashed equivalents show a banding. This is particularly likely to be true of lavas and tuffs, and may be true even for intrusive masses. Further, it has been seen that the mashed, originally homogeneous, igneous rocks may have become cleaved or fissile, and that along the secondary structure impregnations or injections may occur and the rock thus become banded. If a new mashing now takes place which develops a tertiary structure cutting the secondary one, the minor plications of the secondary structure may simulate similar plications of sedimentary strata.

(2) The metamorphosed sedimentary rocks are not usually so changed as to obliterate all evidence of their original condition. This is true even of the metamorphosed pelites. Minute variations in the coarseness of the lamina are usually sufficient to produce minor plications which somewhere will be found to intersect the secondary structure. Moreover, in a larger way, thick pelite formations are apt to contain some beds of grit, sandstone, or limestone. These give schists of different kinds, and each of these is different from the metamorphosed mudstone.

Variations in original lithological character are still more prominent when great formations are considered. It has been seen that a sandstone formation may be transformed into a quartz-schist or a nicaceous quartzschist. Limestone may be transformed into marble, bearing greater or less quantities of silicates, depending largely upon its original purity. The arkoses and shales may be transformed into schists and guneisses. Widely disseminated graphite and the presence of ferruginous beds have been regarded as indicating a sedimentary origin. There is no evidence MON XLVII-0t-5S 
that any transformations through which sedimentary rocks go are sufficient to obliterate the original differences in thick formations of greatly varying lithological character.

These principles are well illustrated by the Paleozoic metamorphosed sedimentary rocks of the Green Mountains of New England. In this area the Paleozoic rocks have almost completely lost all interior evidence of clastic characters. It is only very rarely, where the rocks were conglomeratic, that any particles can be recogniized as fragmental. However, the shales and grits are transformed to mica-schists and mica-gneisses, the sandstones to quartz-schists, and the limestones to marbles. The schists are not evenly homogeneous and regularly schistose with a secondary structure in a single direction, as is so characteristic of metamorphosed igneons rocks. Each formation is composed of minor beds, these beds of minor laminæ. Notwithstanding the metamorphism, these retain to a greater or less degree their integrity. At many places the bedded structures intersect the secondary schistose structures. In a larger way the relations of the formations to one another are those of sedimentary rather than igneons rocks. No one skilled in work in the metamorphic rocks would fail to recognize this Paleozoic series as of sedimentary origin. For the most part these formations can be discriminated from the pre-Paleozoic gneissoid granites.

In regions of extreme metamorphism, where both igneous and aqueous rocks have had long and complex histories, including the development of secondary and perhaps tertiary structures, and sometimes impregnations and injections, no criterion as to texture or minor plication or regular banding is sufficient to discriminate the two. Even in regions in which the great formations may indicate with a high degree of probability that a considerable portion of the material is of sedimentary origin, it may be true that another considerable portion is igneons and can not be discriminaterl from the aqueons part of the series.

(3) A third criterion of great importance in the discrimination of metamorphosed sedimentary and igneous rocks is chemical composition. It has been shown on pages $555-558$ that the materials for sedimentary rocks are sorted, that in general there is depletion in certain of the elements as compared with the igneous rocks, and that the proportions of the elements in the sedimentary rocks are therefore different from those in the igneous. 
rocks. Furthermore, it has been shown that in the zone of andmorphism the chemical composition of rocks is not greatly changed during the process of metamorphism, and it has already been seen that this is the only zone in which metamorphism is likely to result in the confusion of the two classes of rocks. 'Therefore the metamorphosed sedimentary and igneous rocks which are likely to be confused have the compositions which are characteristic of their class: the metamorphosed sedimentary rocks, with minor modifications, have the chemical composition of muds, grits, sandstones, etc.; the metamorphosed igneous rocks have the compositions of granites, diorites, etc. For both sedimentary and igneous rocks there are wide variations in chemical composition, but in general the proportions of the elements are markedly different, in the two classes, as may be seen by comparison of the composition of the metamorphosed sedimentary rocks and that of the metamorphosed igneous rocks. The criterion has great value in some cases where the criterion of banding fails, for instance, in discriminating between metamorphosed sedimentary rocks and metamorphosed tuffs. The metamorplosed sediments have their characteristic compositions, while the metamorpliosed tuffs, notwithstanding the fact that they may show banding, and thus closely resemble metamorphosed sediments, have the composition of igneous rocks. This criterion has been successfully used by Adams in discriminating between the Grenville gneisses of the Original Laurentian area and the lower granitoid gneiss. The former have the composition, as he has shown, of pelites, whereas the lower gneisses have the composition of granites

While this criterion of chemical composition is one of the most important and has a wide application, it is not infallible. It has already been seen on pages 497, 870-874 that in such places as the Gulf of California, and certain other localities, the sediments are little decomposed or sorter, and thus there is produced a sedimentary rock which has essentially the same composition as the original igneous rocks from which it was derived.

(4) Closely comnected with (3), in fact dependent npon it, is a fourth criterion, that of mineral composition. On account of the difference in chemical composition which has already been mentioned, when the rocks are metamorphosed there resnlts different nineral compositions. It has been seen that the depletion of certain elements in the serlinents and the sorting of the material produce comparatively few kinds of original 
mechanical sediments. The alterations of these sediments have already been traced out, and it has been seen that from them the common characteristic rocks produced are quartzites, quartz-schists, mica-schists, and micagueisses, which are occasionally more or less pyroxenic or amphibolitic, but with these latter materials there is apt to be a considerable quantity of calcareous material. Also, staurolite and andalusite, sillimanite and cyanite are very characteristic minerals. Therefore, where certain single minerals are dominant in the schists and gneisses it seems to be a fairly safe conclusion that the rocks are sedimentary in origin. Thus, where great rock formations are composed chiefly of quartz, chiefly of calcite or other carbonate, or, with these, silicates which may readily develop by the process of silication, it is comparatively safe to assume that the materials from which the schists are derived are of sedimentary origin. Also, schists composed almost wholly of mica and quartz are likely to be of sedimentary origin.

Just as there are mineral combinations which are generally characteristic of sedimentary rocks, so there are others which are generally characteristic of the igneous rocks. From the tuffs and other rocks which develop structures similar to those in the metamorphosed sediments, and are therefore likely to be mistaken for metamorphosed sedimentary rocks, hornblende is likely to develop instead of biotite and muscovite, and thus hornblende-schists and hornblende-gneisses are produced from the metamorphism of the tuff's instead of mica-schists and mica-gneisses. In the igneous rocks with the hornblende, feldspar is apt to be abundantly present, and frequently this feldspar may be near the orthosilicate end of the series. In such rocks, also, there is likely to be present a considerable quantity of titanium, which passes into menaccanite, lencoxene, or titanite. In the igneous schists and gneisses there is likely also to be formed large amounts of epidote and zoisite. The prominence of the various minerals mentioned is due to the fact that the igneous rocks have not been depleted in allalies and alkaline eartlis.

Bat it can not be positively asserted that a metamorphic rock containing metamorphic minerals especially characteristic of igneous rocks may not be of sedimentary origin, for, as already noted, sediments exceptionally contain the unsorted constitnents of the original igneous rocks.

In discriminating between the metamorphosed sedimentary and meta- 
morphosed igneous rocks it is plain that all the eriteria above mentioner should be applied. But where there are intricate mixtmes of metamorphosed igneous and sedimentary rocks, as a result of injection, all these criteria may fail to a greater or less extent, for the rocks are not wholly sedimentary or igneous, but a combination of the two.

It is therefore clear that there is frequently very great difficulty in determining the origin of the schists and gueisses, and that the criteria which are at present available are inadequate. However, it is believed that a close study of the character of the changes in each of the wellrecognized igneous and sedimentary rocks will in the future furnish other important guides which may be used to discriminate between the two great classes of metamorphosed rocks.

RELATIONS OF METAMORPHIC SEDMENTARY ROCKS TO STRATIGRAPHY.

VARIATION IN METAMORPHISM.

In working out the stratigraphy of a metamorphosed region the fact that the metamorphism varies in degree under different conditions is of the utmost importance.

UPON WHAT VARIATIONS ARE DEPENDENT.

The variation in the amount and kind of metamorphism is dependent upon many factors (see pp. 39-44), but from the point of view of structure it is necessary to consider only variations depending upon the amount of orogenic movement, upon the character of the rock, and upon the depth of burying.

That the degree of metamorphism is largely dependent upon orogenic movement has been sufficiently shown on previous pages.

It has been seen on pages $760-762$ that where rocks consist of alternate layers of different character, these are slow to be obliterated, and especially is this so if the formations be'thick. To illustrate, it may be said that it is very difficult, and perhaps impossible, to completely destroy a great limestone or quartzite formation by metamorphism. Also, coarse and strong sedimentary formations are likely to retain their original features to a recognizable degree unless the metamorphism he extreme. The existence of such formations enables one to determine the sedimentary character of 
the rocks and often the true strike and dip. In a metamorphosed series the contacts between formations of different character are the most reliable criteria for correet structural observations.

It has been explained (Chapter IV, p. 187) that a formation in the zone of katamorphism is merely fractured, instead of being mashed throughout, and therefore if rocks are deformed under conditions of moderate burying it is usually easy to determine the origin of the rocks with which one is dealing. However, where rocks are deformed at a small depth, faulting is likely to oceur, and thus while the problem of stratigraphy is made easier, in that the formations are not so greatly altered, it is made more difficult in that faulting is always a possibility which has to be taken into account.

Rocks which were deeply buried when deformed are mashed, and therefore under these conditions the profoundest kind of metamorphism oceurs and all the difficulties which result from extreme metamorphism are introduced. On the other hand, where mashing is the typical kind of deformation faulting is not likely to oceur. But it is to be remembered that a series which is mashed before it reaches the surface must pass through the upper zone, and during this passage may again be subjected to dynamic movements and thus be broken and faulted. Consequently, combined with extreme metamorphism we may have also displacement, and in such cases the difficulties of stratigraphy are at a maximum.

\section{RESULTING VARIATIONS.}

In handling the various difficulties in stratigraphy which result from metamorphism the variations in amount and kind are of great assistance. Such changes in the nature of metamorphism are to be considered both (1) along the strike, and (2) across the strike.

(1) A series or formation which is profoundly metamorphosed in one part of a district or region may be but slightly metamorphosed in another part. The change in metamorphism is likely to be gradual along the strike. Consequently, by following a formation along the strike, one mar solve the problem of the origin of completely metamorphosed formations, for somewhere he may find a locality where it is so little metamorphosed that its original character may be determined. In the less altered area the tree succession may be made out, and thus it may be possible to interpret an 
extremely metamorphosed district or area by connecting it with areas which are less metamorphosed.

These principles are well illustrated at various places. The Penokee series of the Lake Superior region is very little metamo phosed in the eastern part, but is much more metamorphosed in the western part. A still more striking illustration is found in the Marquette district. In the easteru and central part of the district the rocks are so little metamorphosed that there is no difficulty whatever in determining the origin of the formations. But in the westem part of the district, especially in the closely mashed Republic tongue, the three unconformable series there existing-the Archean, the Lower Huronian, and the Upper Huronian-are so mashed and metamorphosed as to appear completely conformable, and one might conclude that here is an inseparable series. However, by tracing the formations along the strike until they connect with the less metamorphosed portions in the central and eastern parts of the district, one is certain that in this tongue there exist three unconformable series.

A third excellent illustration of the change of metamorphism along. the strike is furnished by the Ocoee series, which in its northeastern part, in east Temnessee, is but semimetamorphosed, and there it is easy to recognize the original character of the formations. As these formations are traced to the sontliwest they become more and more metamorphosed, until they are schists and gneisses, and then it is difficnlt to discriminate between the sedimentary and igneous parts of the series and to separate the Ocoee series from the older series unconformably below.

(2) Rapid change in metamorphism across the strike is frequently as characteristic as is gradual change along the strike. Of course in some cases the change across the strike is gradual, but in many cases it is very abrupt. Thus the rocks on the crown of an arch or at the bottom of a trough may be only partly metamorphosed, while the same formations on the limbs of the folds may be profoundly metamorphosed. This is due to difference in the amount of shearing in different parts of the folds. ${ }^{a}$ In other cases the abrupt change in amount of metamorphism is due to the fact that orogenic movement may die out rapidly across the strike or change in its character. As a consequence, rocks on a hill may be folded

"Van Hise, C. R., Principles of North American pre-Cambrian geolngy: Sixteenth Ann. Rept. U. \&. Geol. Survey, pt. 1, 1896, pp. 598-600. 
and in the next valley be unfolded. They may be very closely folded in a valley and on the mountain beyond be in a horizontal position. The rocks exposed may be strongly metamorphosed by mashing in a mountain mass, because deeply buried during the movement, and along the adjacent area merely be fractured, because in the zone of katamorphism during the movement. Since the amount and kind of metamorphism are so directly a function of the deformation and the depth, the rocks where greatly deformed or deeply buried may be profoundly metamorphosed, and those which are little deformed or near the surface may be comparatively little altered. Failure to understand these principles has led to many mistakes in stratigraphy. Some illustrations of the rapid change across the strike, and of the mistakes in stratigraphy which have resulted, are as follows:

(a) The Taconic Mfountains are immediately adjacent, across the strike, to the Hudson River series of New York and Connecticut. The latter formations are little metamorphosed. The rocks in the Taconic Mountains are schists and gneisses. It was therefore conchuded by Emmons and by others that the rocks of the Taconic Mountains were metamorphosed before the Hndson River rocks were deposited, and are therefore much older. Hence Emmons gave the Taconic rocks the name Taconic series. The entire Taconic controversy, which has cut such a figure in America, arose from this mistake. It was only when Dana, followed by Pumpelly and those who worked with him, appreciated that there might be very rapid changes in metamorphism across the strike that it was ascertained that the unmetamorphosed Hudson River rocks immediately to the west of the completely metamorphosed schists and gneisses of Greylock and the other Taconic Mnuntains are parts of the same sedimentary formations.

(b) Another region which very well illustrates the rapid change in metamorphism across the strike is that of the Great Valley and the Unaka Mountains, in the southern Appalachians. The Unaka Momntains are largely composed of the Ocoee series, which is of lower Paleozoic age, and which in the sonthern part of the region is completely metamorphosed. The metanorphism is mneh greater than in the rocks of the Great Valley immerliately adjacent, also Paleozoic. In the sonthern part of the region the much metamorphosed Ucoee is thrust over the little altered rocks of the Great Valley. 
It is plain from the foregoing that a series of rocks may be profoundly metamorphosed locally and that its metamorphism in an adjacent area may be unimportant. Not only is this so, but different parts of the same fold are often metamorphosed differently, depending upon their positions within the fold. Still further, one set of beds may be more readily metamorphosed than another, so that one formation may be a perfect schist while the adjacent formation may still be plainly fragmental; for instance, a shale may be changed to a mica-schist and an interbedded quartzite be but little affected by any process except cementation. As pegmatization is so frequently dependent upou the presence of an intrusive rock, an extreme phase of metamorphism engendered by volcanism, combined with other processes, may have a very local character.

Notwithstanding the variations of metamorphism, the amonnt and character of the metamorphism of a series of formations may be an important guide in structnral work. It may serve to separate one series from another and assist in determining the structure within a series. The criterion has limitations, which are readily deducible from the facts as to the variation in metamorphism just considered. But if a set of formations be superimposed upon another set and the lower has become schistose throughont, while the upper shows little or no change, it is probable that the lower series underwent a period of metamorphism before the upper series was deposited. In order to make this conclusion at all certain, however, the superior formations should be of kinds which are equally likely to be metamorphosed, further faulting must be excluded, and it must be certain that it is a case of superposition, for laterally the metamorphosing forces may die out rapidly and the altered rocks pass quickly into those but little changed. Still further, if the netamorphism be due to pegmatization as a consequence of the intrusion of great batholiths, the process may die out rapidly in a vertical direction, so that the extremely metamorphosed lower formations gradually pass into the unmetamorphosed beds higher up, with no structural break. Also, it has been seen that metamorphism is a direct function of depth of burying. But probably the change in metamorphism as a result of varying depth of burial is so slow that it ordinarily involves no practical difficulty in separating series. 


\section{RELATIONS OF IGNEOUS ROCIS TO STRATIGRAPIIY.}

Before considering the relations of igneons rocks to stratigraphy it is necessary to recall the forms which they usually take and the manner in which they may be expected to die out. The intrusives are ordinarily known as batholiths, bosses, laccoliths, sills, and dikes. The extrusives are either lavas or tuffs. Frequently dikes radiate from a batholithic or laccolithic mass, become less and less abundant in passing arvay from the igneous mass, and finally disappear. Not infrequently the intrusives and extrusives are elosely associated, intrusives being in one part of a region or district and equivalent extrusives in another part. But whether the rocks are intrusive or extrusive, if the quantity of igneous material be large and in varions forms the igneons rocks usually do not die out at once, but gradually. Ordinarily the distance required for their disappearance is considerable, but in certain cases there are exceptions to this.

For the most part the ordinary masses of rolcanic rocks do not profoundly affect the beds with which they are associated. On the other hand, large intrusive masses may metamorphose surrounding sediments for miles.

As a conseqnence of the gradnal disappearance of emptives under ordinary circumstances, the abundance of eruptives in one horizon and their absence in an adjacent horizon indicate that a structural break probably exists between the two, or that a fanlt has displaced the strata. The absence of phenomena which indicate faulting renders the first alternative probable. The sudden disappearance of eruptives is a particularly valuable criterion in separating adjacent series in cases in which jearallel secondary structures have been indnced in botl. These secondary structures may have obliterated or nearly obliterated the original bedding, so that there may be none of the ordinary evidences of structural breaks; but if a set of dikes passes to a certain horizon and is suddenly cut off, this is very suggestive of an erosion interval between the two series. In cases of this kind the eruptives themselves are likely to lave been extensively altered by the forces which prodnced the secondary structures in the sedimentary rocks; they may have been changed from their original condition to schists, and then may be shown to be dikes or intrusives by their structural behavior, by microscopical examination, or by chemical analysis. 
When a series is cut by intrusives it sometimes happens that there is a difference in the erodibility of the dike and of the containing rock. In case the dike be more resistant, and the two were subjected to eroding agencies, it protrudes from the underlying formation, while in the opposite case there is a hollow. The latter is the condition of affairs described by Pumpelly at Hoosac Mountain, where an ancient dike cuts throngh the gneissoid granite. After a hollow of differential erosion was formed a sedimentary series was deposited. In approaching the dike the members of the sediments thicken somewhat and pass into the depression. The greater thickness of the lower beds at the loollow finally compensates for it, and the thickened beds gradually pass up into ordinary regularly stratiform beds. (Fig. 24.) In this case later orogenic movements produced consonaut secondary structures both in the granite and in the overlying formations, and this relation of the dike to the two series was the first evidence found

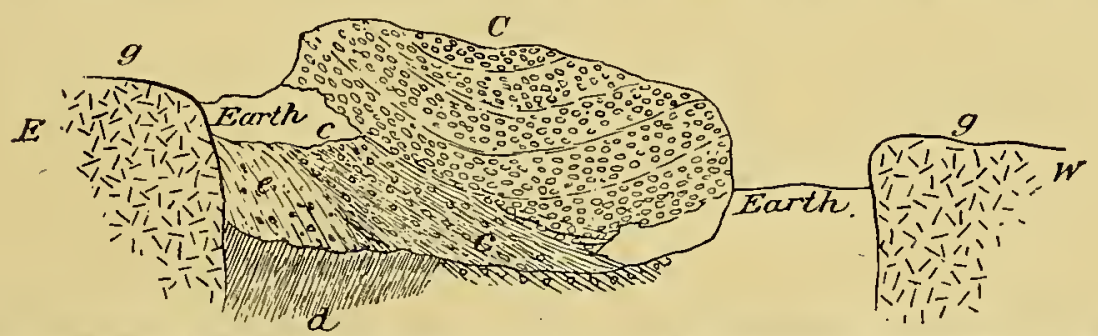

FIG. 24.-Conglomerate deposited in depression produced hy erosion of basic dike through gneiss, After Pumpelly. $c$, conglomerate; $c_{1}$ lower layers of conglomerate rendered schistose by admixture of material from the altered $d i k e ; ~ d$, diahase of the dike rendered schistose by metamorphism; $e$, altered dike material; $g$, pre-Camhrian granitoid gneiss.

of a structural break between them. They had hitherto been considered as conformable, although a very close study had been made of them. Later other evidence confirmed this inferred unconformity.

In a different case the contacts between two unconformable series may not be found, but one series may be cut through and through by dikes and contain bosses of igneous material and interstratified intrusives or extrusives, with perhaps also voleanic fragmentals, while the adjacent set of formations may be wholly free from igneous rocks. Relations of this kind have force in proportion to the extensiveness of the phenomena. If one series is rich in igneous rocks for many miles, while another contiguons series is entirely free from them, and the irregular distribution of the two is such as not to be explained by faulting, the evidence of a structural break between the series is very strong.

In any of the above cases the time break between the two series must have been long enough for a full cycle of igneous activity. 
In proportion as the igneous rocks are metanorphosed it is difficult to apply the above criteria. Where they are no longer distinguishable from the sedimentary rocks the criteria given for deternining structural relations are not available.

\section{RELATIONS OF ROCK FLOWAGF TO MOUNTAIN MAKING.}

The principles of metanorphism worked out in the previous chapters have an important bearing upon theories of mountain making. Various authors have adrocated expansion theories of mountain making. Probably the most notable of these is Reade. His explanation of the rise of mountains is that the volume of the thick deposits of sediments increases in consequence of the rise of the isogeotherms. ${ }^{n}$ It is perfectly clear from the previous chapters that the alterations of the zone of anamorphism result in very important contraction. Not only is this true of the deepseated zone, but in the zone of katamorphism the volume of one great class of sediments, the pelites, is certainly decreased both by consolidation and by dehydration. It may perhaps be conceded that the reactions of metamorphism, if all of geological time be taken into account, have somewhat expanded the volume of a very superficial belt of the earth. But in the deep-seated zone, where pressure is dominant, the reactions are taking place in a reverse sense, and as these have prevailed throughout geological time and to mknown depths, it can hardly be douloted that the contraction due to these deep-seated reactions is of vastly greater importance than the sum total of expansion due to superficial causes.

Perhaps it will be well to recall the facts bearing on the amount of contraction which takes place in conseqnence of the reactions of the zone of anamorphism.

It has been seen on page 364 that the average specific gravity of the minerals formed in the zone of anamorphism is about 18 per cent greater than that of those which develop in the zone of katamorphism; but for the rocks of the zone of auamorphism not all the minerals have passed to the products characteristic of that zone. Therefore, one can not premise that in the metamorphism of sedimentary rocks there is a diminution of volume as great as this. However, it is probable that the average of the chemical reactions of dehydration and silication and mechanical consolida- 
tion give a decrease in volume of at least 10 to 15 per cent for the majority of the sediments. This is not believed to be an overestimate for the average of the pelites, psephites, and limestones, but the decrease in volume for the sandstones is probably not so great as this. It is therefore certain that the decrease in volume in consequence of reactions controlled by compression in the deep-seated zone is vastly greater than any expansion which can result from rise in temperature. And it is certain that from the top of the zone of anamorphism to the greatest depth to which observation extends the reactions of metamorphism tend to produce ninerals of higher specific gravity. However, the entire zone of obserration is very narrow as compared with the distance to the center of the eartll. If the law observed continnes to great depth, it wonld follow that deeper within the earth than observation extends minerals of specific gravity higher than any known are produced. There is every reason to believe that the density of the most densely crystallized minerals with which we are familiar is far from the maximmm possible density. Hence, as pointed out on pages 364-365, deep within the earth, where the pressures are vastly greater than any with which we are familiar, it is certainly possible, and perhaps probable, that there exists a class of heavy minerals of complex molecules with which we are entirely unfamiliar.

but whether this speculation be well founded or not, there is every reason to believe that during geological time there has been steady condensation of the volume of the earth as a result of crystallization and recrystallization. For eras at least the earth has steadily lost heat, and magma has changed to crystallized rock, which has less rolume. Probably also the pressures within the earth hare increased in amount in consequence of decreasing rotation period, and increasing pressure promotes recrystallization, with the formation of heavy minerals. It seems to me highly probable that the decrease in volume due to the erystallization and recrystallization of rocks, with the production of minerals of high specific gravity, is probably one of the most potent of the processes which have resulted in diminished rolume. " If this be so, it appears that the sum total of metamorphic processes is subordinate to the general law of gravity which steadily demands decreasing volume for the earth. Recognizing this law, I hare elsewhere leld that it can not be maintained that masses of the earth locally rise

"Van Hise, C. R., Estimates and causes of crustal shortening: Jour. Geol., vol. 6, 1898, pp. 59-60. 
unless an equal or a larger mass elsewhere subsides - in short, that the center of gravity of the moved mass is nearer the center of the earth after the movement than before. ${ }^{a}$ The expansion theory of mountain making is wholly controverted by the facts of metamorphism.

But mountain systems have been formed in some way, and during their building the material of the mountains has been uplifted even if material elsewhere has subsided. The uplifted areas are local. Indeed, it is because of localization that mplift can be recognized. As the geoid responds to the stresses within it, at least near the surface, the folding and faulting is largely concentrated in certain belts. It follows that the onter crust of the earth must have moved in some way over the interior. This fact of the localization of momntain masses and the resultant necessity that the crust shonld shear over the interior is one of the reasons which led the early geologists to adhere strongly to the existence of a liquid substratum. However, the physicists who have studied the earth with reference to tidal deformation insist that its interior is rigid; that if it were a liquid the attraction of the moon and sum would result in tides which wonld be shown in the crust of the earth.

It appears to me that the explanation of rock flowage offered on pages $748-759$ shows how mountain masses may be segregater, the upper crust of the earth shearing over the deeper seated material for a long way without a liquid substratum. It has been explained that in the zone of anamorphism, under the deforming stresses of the earth, rocks flow by recrystallization. They are solid at the beginning of the process, throughout the process, and at the end of the process; and yet they have accommodated themselves to the form demanded by continnous solution and redeposition. It has further been somewhat fully explained (pp. 769-774) that the energy required for such deformation in the zone of flowage is not nearly so great as that required for deformation of an equal mass producing a similar form in the zone of fracture. In other words, the onter shell of the earth, the zone of fracture, is more rigid under slow deforming stresses than is a deeper seated zone which may be deformed by recrystallization. If this be so, we are able to see how the outer part of the lithosphere may shear over the zone below, as if it were a plastic

$a$ Van Hise, C. R., Earth movements: Trans. Wisconsin Acad. Sci., Arts, and Letters, vol. 11, 1898, pp. $512-514$. 
stratum, and thus the necessary crustal shortening demanded for a large segment of the earth may be concentrated in a single monntain mass. This theory of the deformation of the zone of flowage by recrystallization meets the needs of the geologist who demands a substratum sufficiently plastic to be deformed under long-continned moderate stresses, and at the same time meets the demands of the physicist for a material so strong as to resist sudden stresses.

But it may be said that this hypothesis is a mere speculation, unsupported by any observation and with no possibility of support by observation. This is true if we consider the existing mountains, the last uplift of many and perhaps the majority of which occurred in Tertiary time. But before these mountains existed more ancient monntains existed, and denndation since early geological time has exposed many parts of the lithosphere over vast regions which were once thousands of meters below the surface. For instance, the Appalachian system of the United States, from Maine to Georgia, including the New England and Piedmont plateans, has undergone deep erosion since Paleozoic time. Vạst regions in Canada and in northern Europe lave been subject to enormons, althongh perhaps interrupted, erosion since Cambrian time. In such regions observations show that there now exist at the surface extensive areas of rock which were deformed in the zone of rock flow.

Is there any evidence in such regions, from the character of the deformation and the structures which have been produced, that shearing has taken place in the same direction for considerable areas? Such evidence would support the view that equivalent shearing may have taken place in the present zone of rock flow, and thus have segregated the existing mountains. In another place I have shown that monoclinal cleavage may result from shearing motion in rocks parallel to the surface of the earth, there being no elongation or shortening in consequence of it. ${ }^{a}$ This is illustrated by fig. 25, where a mass represented by abcd in the diagram at the left is sheared into the form shown in the diagram at the right, the lines $a-b, c-d$ in both diagrams being supposed to be parallel to the surface of the earth. The position of the cleavage is indicated by the longer diameters of the flattened ellipsoids. If this sort of deformation should take place over an extensive area in the zone of flow, it might

\footnotetext{
$a$ Van Hise, C. R., Estimates and causes of crustal shortening: Jour. Geol., vol. 6. 1898, pp. 29-31.
} 
transport the superjacent material of the zone of fracture with it, and thus carry forward the mpper crnst of the earth toward the mountain mass and allow the segregation of all of the superficial deformation in one belt.

It is to be noted that in the theoretical case illustrated by the diagram there is no crustal shortening of the belt in the zone of fractnre or of the material of the zone of flowage. The material has merely changed its position with reference to the surface of the earth

From the foregoing it is not to be supposed that monoclinal cleavage has generally been prodnced withont any plications or crustal shortenings. Indeed, in areas in which monoclinal cleavages are prevalent there may be numerous folds, as, for instance, in the New England region and in the Bhe Ridge area. No donbt in cases where the deformation is consider-

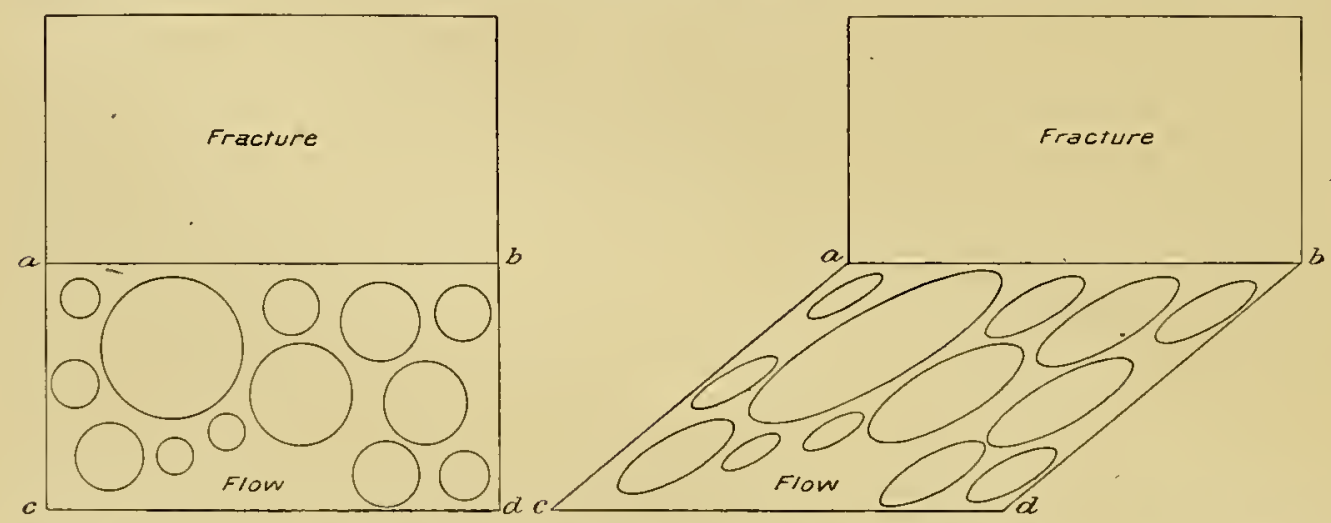

Fig. 25.-Diagraws illustrating the manner in which deformation in the zone of flowage may concentrate crustal shortening in the zone of fracture.

able there are all gradations, from very little or no crustal deformation of the superjacent rocks to that of the complex kind which is characteristic of the local zones of intense deformation. And even if the suggestion be true in general, it is believed that in any instance there is likely to be more or less of monoclinal folding in comection with the monoclinal cleavage, and cousequently more or less of crustal shortening. Howerer, it is thought that the hypothesis affords a possible explanation of the concentration of the greater part of the crustal shortening in local zones.

The question now arises whether, in the regions of the earth in which the past zone of flowage is now at the surface, monoclinal clearage exists. That such clearage does exist for some extensive regions is well known. For instance, the crystalline area of the Appalachian system from Maine to Georgia shows a dominant easterly dipping clearage. 
Where mountain systems exist with monoclinal folds or with thrust faults the segregations may be explained by shearing motion in the zone of flow over an extensive adjacent area to the east of the mountain mass in case the monoclinal folds have eastward-dipping axial planes, and to the west of the mountain mass in case the monoclinal folds have westwarddipping axial planes. (Fig. 25.) Where the folds of a mountain system are symmetrical it would be necessary to suppose that the shearing motion toward the mountain mass occurred on both sides of it.

To illustrate, we may consider one of the large, simple anticlinoria, such as those of the Park Ranges. We may suppose that such an anticlinorium was raised mainly in consequence of deep-seated flow toward the mountain mass from either side. In this case the cleavage on either side of the mountain would dip away from it. It is well known that the present Park Ranges are comparatively recent uplifts along axes of old uplifts. Some of the recent uplifts are partly or wholly covered by Paleozoic and later strata. In the cases of these simple anticlinoria of the West the cleavages of the old rocks on both sides of the anticlinal masses dip away from the cores. Indeed, because of this fact, in the days when cleavage was not discriminated from primary structures the cleavage was supposed to be bedding, and upon the basis of this structure the mountains were described as anticlinal. The present mountains we may properly describe as anticlinal with reference to the Paleozoic and post-Paleozoic rocks which rest upon their flanks. But since we know that mountains rise again and again along the old belts, the cleavage, dipping away from the cores of these mountain masses, is very suggestive that when the aucient higher mountains were developed the material was segregated in consequence of deep-seated flow by recrystallization toward the mountain masses, there being produced at this time the divergent cleavage existing in the preCambrian rocks which are now at the surface, but which were well below the surface when the cleavage was produced.

The cores now exposed were covered by rocks deformed in the zone of fracture and showed the deformation of joints, joint folds, faults, etc., characteristic of the superficial zone. The deep-seated flowage extended for an unknown distance on either side of the mountains, and thus brought to the place of uplift the necessary material. The covering rocks belonging to the zone of fracture on either side of the mountain range nay be MON XLVII $-04-59$ 
conceived as riding quietly forward toward the uplift without marked deformation.

Applying this theory, we may imagine that the Kaibab Plateau, for instance, on either side flanked by a monocline, represents an uplift which is produced by deep-seated shear from either side toward the plateau, prodncing simultaneonsly a cleavage or a tendency toward a cleavage in the zone of flowage. Such cleavage would dip away from the platean on each side of it. The joint and fault deformations exhibited by the monoclines in the zone of fracture represent the equivalent necessary superficial deformation.

Where the folds of a mountain range are symmetrical and upright it would be necessary to suppose that there was an equal amount of deepseated shearing on each side toward the mountain mass. Where the axial planes of the structures of the mountain masses tend to dip in one direction more than in another it is to be supposed that the preponderant movement came from the direction in which the axial planes dip.

Possibly the suggestion of recrystallization shearing in the zone of rock flowage also has a bearing upon the importance of the tidal forces in producing deformation. It has been noted that in America the eastwarddipping monochinal cleavage tenrls to preponderate over the westwarddipping cleavage. The same is true for monoclinal folding. This is especially marked for the eastern United States and Canada. How far it is true over the extensive areas of pre-Cambrian rocks of central Canada is uncertain. Thether in other continents there is a preponderance of eastward-dipping cleavage over westward, and of monoclinal folding with eastward-dipping axial planes over the reverse, I do not know and have been unable to ascertain; but it is interesting to note that if these easterly structures are preponderant they are in the right direction to be genetically comected with tidal friction. The earth in its rotation upon its axis from west to east produces a westward-moving tide. The same force which acts upon the water acts upon the rocks below, or, in other words, tends to slip the outer shell of the earth over the deeper shells. Such slipping, if it takes place through the processes of recrystallization in the zone of rock flowage, would produce an eastward-dipping monoclinal cleavage and monoclinal folds with eastward-dipping axial planes. 
If Darwin and Peirce are correct in thinking that the moon was once very close to the earth, and that at this early time the earth had a much briefer rotation period than at present, the tidal force tending to produce such monoclinal structures in the zone of flow would be vastly greater than at present. It is worthy of note that the preponderant easterly structures which have been noted are among the Paleozoic and pre-Paleozoic rocks which in post-Paleozoic time have been brought to the surface in consequence of denudation. If more extended and closer geological studies of cleavage and monoclinal folding lead to the conclusion that easterly structures do preponderate over westerly structures for the earth as a whole, it may be plausibly argued that these phenomena in the old rocks are geological evidence of the correctness of Darwin's general theory in reference to the earth-monn couple, and that the tidal forces in the past wert vastly greater than those which now exist. ${ }^{a}$

I am aware that the foregoing pages upon the relations of rock flowage to mountain making are speculative, but the speculations accord, so far as I know, with the facts of the field. They are here published in the hope that they may lead to more accurate observations of the relations of primary and secondary structures to each other, and of the positions of secondary structures in varions mountain regions. Concerning these points I have found the published literature upon the metamorphic rocks woefully lacking.

a Darwin, G. H., On the precession of a viscous spheroid and on the remote history of the earth: Philos. Trans. Royal Soc., vol. 170, pt. 2, 1879, pp. 530-538. 


\section{CHAPTER XI.}

\section{RELATIONS OF METAMORPHISM, TO THE DISTRIBUTION OF THE CHEMICAL ELEMENTS.}

In consequence of metamorphism the chemical elements are redistributed on the face of the earth. This redistribution concerns many large questions of geological theory. At the present time our knowledge of metamorphism is not sufficiently advanced to treat the redistribution of the elements except in a very imperfect manner. In the following pages an attempt is made to consider the original source of each of the important chemical elements composing the outer part of the earth, and the effect which the metamorphic processes have had on its redistribution and on the character of the secondary rocks. So far as practicable redistribution is dealt with in a quantitative way, but a quantitative treatment is necessarily subject to the very imperfect hypotheses upon which it is based. Indeed, for the most part the quantitative estimates are the roughest sort of approximations, made more with a view of stating the various problems which in the future will undoubtedly be satisfactorily treated quantitatively rather than with the belief that the calculations given even approach accuracy. They are all purely provisional, and it is hoped that they will be considered from this point of view. Indeed, this chapter is 110 more than an attempt to blaze a trail in the wilderness. It will require the work of many men for many year's to conquer the wilderness.

\section{COMPOSITION OF THE LITHOSPIIERE.}

The term lithosphere as nsed in this chapter is rigidly restricted to that part of the solid crust of the earth of which we have observational knowledge, and whicl, following Clarke, is assumed to extend to a depth of only 10 miles (16.1 kilometers) below the level of the sea. According to R. S. Woodward, the volume of the part of the earth that is above the sea and that extends to a depth of 10 miles (16.1 kilometers) below the level of the 
sea is $1,935,000,000$ cubic miles ( $8,075,000,000$ cubic kilometers). Of this amount $302,000,000$ cubic miles $(1,260,000,000$ cubic kilometer's) are ocean and 1,633,000,000 (6,815,000,000 cubic kilometers) are solid matter. The mass of the atmosphere is equivalent to that of $1,268,000$ cubic miles $(5,292,000$ cubic kilometer's) of water, the unit of density. "To sea water we may assign a density of 1.03 , which is a trifle too high, and to the solid rocks a specific gravity not lower in average than 2.5 , nor much higher than 2.7. With these valnes we can get the following expression for the percentage composition of the known matter of the globe:

Relative masses of air, sea, and eartl's crust.

\begin{tabular}{|c|c|c|}
\hline Per cent. & $\begin{array}{l}\text { Density of } \\
\text { crust } 2.5 \text {. }\end{array}$ & $\begin{array}{l}\text { Density of } \\
\text { crust 2.7. }\end{array}$ \\
\hline Atmosphere & 0.03 & 0.03 \\
\hline Ocean & 7.08 & 6.58 \\
\hline \multirow[t]{2}{*}{ Solid crust. } & 92.89 & 93.39 \\
\hline & 100.00 & 100.00 \\
\hline
\end{tabular}

In short, we may regard the earth's crust, 10 a depth of 10 miles [16.1 kilometers], as composed essentially of 93 per cent solid and 7 per cent liquid matter, treating the atmosphere as a small correction." a

A large number of elements have been discovered on the earth, but of these, according to Clarke, only 21 each constitute as much as 0.01 per cent of the onter part of the lithosphere, and need be considered in this chapter. Those elements which compose more than 1 per cent may be regarded as abundant and those which form less than 1 per cent as subordinate. Of the former class there are only eight, viz: Oxygen, silicon, aluminum, iron, calcium, magnesium, sodium, and potassium. Between the least plentiful of the abundant class and the most plentiful of the subordinate class there is a very considerable break, for potassium, the least plentiful of the abundant elements, makes up abont 2.3 per cent of the lithosphere, while titanium, the most abundant of the subordinate elements, composes only about 0.4 per cent of the lithosphere.

In the chenical laboratory of the United States Geological Survey a very large number of analyses of rocks liave been made. Clarke has

\footnotetext{
"Clarke, F. W., The relative abundance of the chemical elements: Bull. U. S. Geol. Survey, No. 78,1891 , pp. $34-35$.
} 
compiled these and other analyses, with the purpose of obtaining an approximate idea of the composition of the lithospliere. In his computations Clarke has considered only the "igneous and crystalline rocks." As these terms are used there are exchnded from consideration the unmetamorphosed sediments and the metamorphosed sediments so far as they are recognized as sediments. In the following table are found the analyses of various groups of 880 igneous and crystalline rocks, and the mean of the whole:

Analyses of igneous and crystalline rocks. ${ }^{a}$

\begin{tabular}{|c|c|c|c|c|c|c|c|c|}
\hline & A. & B. & c. & D. & E. & F. & G. & $\mathrm{H}$. \\
\hline $\mathrm{SiO}_{2}$ & $\begin{array}{r}\text { Per cent. } \\
61.89\end{array}$ & $\begin{array}{r}\text { Per cent. } \\
61.89\end{array}$ & $\begin{array}{c}\text { Per cent. } \\
60.49\end{array}$ & $\begin{array}{r}\text { Per cent } \\
60.66\end{array}$ & $\begin{array}{r}\text { Per cent. } \\
60.50\end{array}$ & $\begin{array}{r}\text { Per cent. } \\
59.80\end{array}$ & $\begin{array}{r}\text { Per cent. } \\
56.75\end{array}$ & $\begin{array}{r}\text { Per cent. } \\
58.59\end{array}$ \\
\hline $\mathrm{Al}_{2} \mathrm{O}_{3} \ldots$ & 15.71 & 15.73 & 16.08 & 15.46 & 14.30 & 14.65 & 14.90 & 15.04 \\
\hline $\mathrm{Fe}_{2} \mathrm{O}_{3}-$ & 1.81 & 3.18 & 2.47 & 2.74 & 3.35 & 4. 99 & 4.58 & 3.94 \\
\hline $\mathrm{FeO} \ldots . . .$. & 3.65 & 2.40 & 2.86 & 2.27 & 4.31 & 2.92 & 3.71 & 3.48 \\
\hline CaO.. & 4.51 & 4.58 & 6.15 & 4.71 & 3.52 & 5.19 & 5.79 & 5.29 \\
\hline $\mathrm{MgO}$ - & 2.40 & 3.08 & 4.31 & 3.35 & 5.00 & 3.45 & 5.22 & 4. 49 \\
\hline $\mathrm{K}_{2} \mathrm{O} \ldots \ldots$ & 3.54 & 2.70 & 1.80 & 3.97 & 2.52 & 3.06 & 2.90 & 2.90 \\
\hline $\mathrm{Na}_{2} \mathrm{O} \ldots \ldots$ & 3.28 & 3.70 & 3.31 & 3.54 & 2.49 & 2.98 & 3.24 & 3.20 \\
\hline $\mathrm{H}_{2} \mathrm{O} \ldots \ldots$ & 1.69 & 1.59 & 1.12 & .97 & 2.53 & 2. 09 & 2.12 & 1.96 \\
\hline Total.. & 98.48 & 98.85 & 98.5 .9 & 97.67 & 98.52 & 99.13 & 99.21 & 98.89 \\
\hline
\end{tabular}

ELEMENTARY SUBSTANCES

\begin{tabular}{|c|c|c|c|c|c|c|c|c|}
\hline $\mathrm{Si}$ & 28.88 & 28.88 & 28.23 & 28.31 & 28.23 & 27.91 & $26.50^{\prime}$ & 27.34 \\
\hline Al & 8.31 & 8.32 & 8.51 & 8.18 & 7.57 & 7.75 & 7.89 & 7.96 \\
\hline $\mathrm{Fe}$ & 4.11 & 4.09 & 3.96 & 3.68 & 5.71 & 5.77 & 6.09 & 5.47 \\
\hline $\mathrm{Ca}$ & 3.22 & 3. 27 & 4.39 & 3.37 & 2.51 & 3.71 & 4.13 & 3.78 \\
\hline $\operatorname{Mg} . \ldots \ldots$ & 1.44 & 1.85 & 2.58 & 2.01 & 3.00 & 2.07 & 3.13 & 2.69 \\
\hline $\mathrm{K} \ldots$ & 2.94 & 2.24 & 1. 49 & 3. 29 & 2.09 & 2.54 & 2.41 & 2. 41 \\
\hline $\mathrm{Na}$ & 2. 43 & 2. 74 & 2.46 & 2.63 & 1.85 & 2.21 & 2.56 & 2.37 \\
\hline $\mathrm{H}$. & .19 & .18 & .12 & .11 & .28 & .23 & .24 & .22 \\
\hline$O \ldots$ & 46.96 & 47.28 & 46.85 & 46.09 & 47.28 & 46.94 & 46.26 & 46.65 \\
\hline Total _. & 98.48 & 98.85 & 98.59 & 97.67 & 98.52 & 99.13 & 99.21 & 98.89 \\
\hline
\end{tabular}

${ }^{a}$ Clarke, F. IV., The relative abundance of the chemical elements: Bull. U.S. Geol. Survey No. 78, 1891. pp. 36-37. 
A. The mean of 82 analyses of voleanic rocks from the Western Territories of the United States, published in Clarence King's Survey of the Fortieth Parallel.

B. 64 analyses of rocks from the Yellowstone Park, taken from the laboratory records of the United States Geological Survey.

C. $5 t$ analyses of volcanic rocks collected in northern Califomia; also from the Snrvey records.

D. 39 analyses of eruptive rocks from various localities in the Western United States, taken from the Snrvey records.

E. 80 crystalline and Archean rocks from all parts of the United States. Of these analyses 50 were taken from the Survey records, 23 from the Fortieth Parallel Report, and 7 from the report of the New Hampshire Survey, rol. 3.

F. 75 analyses of European voleanic and erystalline rocks, taken at random from five recent rolnmes of the Neues Jahrbuch.

G. 186 miscellaneous plutonic rocks, analyzed between 1879 and 1883, and collected hy Roth in his "Beiträge zur Petrographie der plutonischen Gesteine."

H. The mean of the foregoing 880 analyses.

Clarke remarks that the columns $\mathrm{A}$ to $\mathrm{F}$ are remarkably accordant, and further says: "The thesis that the crust of the earth is fairly homogeneous in composition is thns sustained by positive evidence. The variations in the foregoing table are as small as could reasonably be expected." a

Clarke, in 1891, made an estimate of the composition of the lithosphere, of the ocean, and of the mean of the lithosphere, ocean, and air, but many of the analyses upon which this first estimate of the composition of the lithosphere was based were "incomplete regarded from a modern point of view." In 1900 Clarke therefore reestimated the composition of the lithosphere, basing the estimate upon 830 complete analyses of rocks and 400 partial analyses. Also, he computed the ten most important elements as oxides both for his first and second estimates of the lithosphere. His results are given in the following tables. 
Symbols, atomic weights, "and proportions of the twenty-there most abundant elements in the outer 10 miles of the carth. ${ }^{b}$

\begin{tabular}{|c|c|c|c|c|c|c|}
\hline \multirow{2}{*}{ Name. } & \multirow{2}{*}{ Symbol. } & \multirow{2}{*}{$\begin{array}{l}\text { Atomic } \\
\text { weight. }\end{array}$} & \multicolumn{3}{|c|}{ Estimate in 1891.} & \multirow{2}{*}{$\begin{array}{l}\begin{array}{c}\text { Estimate in } \\
1900 .\end{array} \\
\text { Solid crust. }\end{array}$} \\
\hline & & & $\begin{array}{l}\text { Solid crust, } \\
93 \text { per cent. }\end{array}$ & $\begin{array}{c}\text { Ceean, } 7 \text { per } \\
\text { cent. }\end{array}$ & $\begin{array}{l}\text { Mean, in- } \\
\text { cluding air. }\end{array}$ & \\
\hline Oxygen ............ & $\mathrm{O}$ & 16.00 & 47.29 & 85.79 & 49.98 & 47.02 \\
\hline Silicon . . . . . . . & $\mathrm{Si}$ & 28.4 & 27.21 & ......... & 25.30 & 28.06 \\
\hline Aluminum ........ & Al & 27.1 & 7.81 & - . . . . . . & 7.26 & 8. 16 \\
\hline Iron $\ldots \ldots \ldots$ & $\mathrm{Fe}$ & 56.00 & 5. 46 & $\ldots \ldots$ & 5.08 & 4.64 \\
\hline Calcium . . . . . . . . & $\mathrm{Ca}$ & 40.00 & 3.77 & .05 & 3.51 & 3. 50 \\
\hline Magnesium . . . . . . . & $M \mathrm{Ig}$ & 24.36 & 2.68 & .14 & 2.50 & 2. 62 \\
\hline Sodium & $\mathrm{Na}$ & 23.05 & 2.36 & 1. 14 & 2.28 & 9.63 \\
\hline Potassium ............ & $\bar{K}$ & 39.15 & 2. 40 & .04 & 2.23 & 2.32 \\
\hline Titanium . .......... & $\mathrm{Ti}$ & t8. 1 & .33 & $\ldots \ldots$ & .30 & .41 \\
\hline Hydrogen . . . . . . . . & $\mathrm{H}$ & 1.01 & .21 & 10.67 & 1.94 & .17 \\
\hline Carbo11 _. . . . . . . . & $\mathrm{C}$ & 12.00 & .22 & .002 & .21 & .12 \\
\hline Phosphorus ...... & $\mathbf{P}$ & 31.00 & .10 & ....... & .09 & .09 \\
\hline Manganese ........ - & Mn & 55.00 & .08 & $\ldots \ldots \ldots$ & .07 & .07 \\
\hline Sulpliur ............ & $S$ & 32.06 & $.03+$ & .09 & $.0 t+$ & .07 \\
\hline Barium .......... & $\mathrm{Ba}$ & 137.4 & .03 & $\ldots \ldots \ldots$ & .03 & .05 \\
\hline Strontium ........ & $\mathrm{Sr}$ & 87.6 & ............ & $\ldots \ldots \ldots$ & $\ldots \ldots$ & .02 \\
\hline Chromium . . . . . . . & $\mathrm{Cr}$ & 52.1 & .01 & $\ldots \ldots$ & .01 & .01 \\
\hline Nickel ............. & $\mathrm{Ni}$ & 58.7 & - & - & 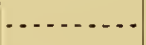 & .01 \\
\hline Lithium _. . . . . . . . . & $\mathrm{Li}$ & 7.03 & $\ldots$ & $\ldots . .$. & - $\ldots \ldots$ & .01 \\
\hline Chlorine .......... & $\mathrm{CI}$ & 35.45 & .01 & 2.07 & i. 15 & .01 \\
\hline Fluorine . . . . . . . . . & $\mathrm{F}$ & 19.00 & $\ldots \ldots$ & - . . . . . & - - - - - - - & .01 \\
\hline Bromine.... & $\mathrm{Br}$ & 79.96 & . . . & .008 & $\ldots \ldots$ & ....... \\
\hline Nitrogen ......... & $N$ & 14.04 & $\cdots$ & - n & .02 & $\ldots \ldots$ \\
\hline Total. . & & & 100.00 & 100.00 & 100.00 & 100.00 \\
\hline
\end{tabular}

a In Chapter $Y$, page 193, the list of atomic weights is given on the basis of hydrogen as 1 . The table of rock-making minerals is also constructed on this basis. However, so far as the results of increase and decrease in volume of the minerals are concerned, it makes no difierence whether bydrogen be taken as 1 and oxygen as 15.88, or whether oxygen be taken as 16 and hydrogen as 1.01 . As the more common practice of the chemists is to use oxygen as 16 , the table of atomic weights here given is on that basis. See Wiechmann, F. G., Atomic weights: Science, vol. 9, 1899, p. 23.

$b$ Clarke, F. W., Report of work done in the Division of Chemistry and Physics, 1889-90: Bull. U. S. Geol. Survey No. 78, 1891, p. 35. Clarke, F. W., Analyses of rocks, laboratory of the U. S. Geological Survey, 1880-1899: Bull. U. S. Geol. Survey No. 168, 19j0, 1. 15.

c WVith bromine. 
Amounts of the deven most important oxides of the tithosphere, as estimated in 1891 and $19000^{a}$

\begin{tabular}{|c|c|c|c|c|c|}
\hline & old mean. & New mean. & & old mean. & New mean. \\
\hline $\mathrm{SiO}_{2} \ldots \ldots \ldots$ & 58.59 & 59.71 & $\mathrm{~K}_{2} \mathrm{O} \ldots$. & 2.90 & 2.80 \\
\hline $\mathrm{Al}_{2} \mathrm{O}_{3} \ldots \ldots \ldots$ & 15.04 & 15.41 & $\mathrm{H}_{2} \mathrm{O} \ldots$ & $* 1.96$ & 1.52 \\
\hline $\mathrm{Fe}_{2} \mathrm{O}_{3} \ldots \ldots$ & 3.94 & 2.63 & $\mathrm{TiO}_{2} \ldots \ldots \ldots$ & .55 & .60 \\
\hline $\mathrm{FeO} \ldots . . .$. & 3.48 & 3.52 & $\mathrm{P}_{2} \mathrm{O}_{5}$ & .22 & .22 \\
\hline $\mathrm{MIgO} \ldots .$. & 4. 49 & 4.36 & Total & 99.66 & 99.22 \\
\hline $\mathrm{CaO} \ldots \ldots$ & 5.29 & 4.90 & & & \\
\hline $\mathrm{Na}_{2} \mathrm{O} \ldots . .$. & 3.20 & 3.55 & & & \\
\hline
\end{tabular}

* Including hygroscopic water; probably 0.40 per cent.

Clarke further made a rough approximation of the proportion of the more important minerals in 500 igneous rocks, as follows : ${ }^{b}$

Important minerals in 500 igneous rocks.

\begin{tabular}{|c|c|}
\hline & Per cent. \\
\hline Quartz ...... & 12.0 \\
\hline Felrlspars. . . . . . . . . & 60.0 \\
\hline Pyroxenes and amphiboles & 18.0 \\
\hline Micas . . . . . . . . . & 4.0 \\
\hline Total. & 94.0 \\
\hline
\end{tabular}

The foregoing estimates are wholly based upon the analyses of "eruptive and crystalline" locks, and represent, according to Clarke's point of view, the average composition of the "primitive crust of the earth." In these analyses all of the unmetamorphosed and metamorphosed sediments, so far as they are recognized as such, are excluded. As we shall see later, the unmetamorphosed sediments probably compose as much as one-thirtieth and the unmetamorphosed and metamorphosed sediments may together comprise as much as one-fifteenth of the lithosphere. The average composition of the sediments is of the utmost importance in reference to a redistribution of the elements. Clarke has had mule six composite analyses of groups of

${ }^{a}$ Clarke, F. W., Analyses of rocks, laboratory of the U. S. Geol. Survey, 1880-1899: Bull. U. S. Geol. Survey No. 168, 1900, p. 14.

$b$ Clarke, cit., p. 16. 
sedimentary rocks, in which 1,545 rocks were taken into consideration. The table below gives his results.

Composite analyses of sedimentamy rocks."

\begin{tabular}{|c|c|c|c|c|c|c|c|c|c|}
\hline & A. & B. & C. & D. & E. & F. & G. & H. & I. \\
\hline $\mathrm{SiO}_{2}-$ & 55.43 & 60.15 & 58.38 & 78.66 & 84.86 & 81.76 & 5.19 & 14.09 & 9.64 \\
\hline $\mathrm{Al}_{2} \mathrm{O}_{3} \ldots \ldots$ & 13.84 & 16.45 & 15.47 & 4.78 & 5.96 & 5.37 & .81 & 1.75 & 1.28 \\
\hline $\mathrm{Fe}_{2} \mathrm{O}_{3} \ldots$ & 4. 00 & 4.04 & 4.03 & 1.08 & 1.39 & 1. 24 & .54 & .77 & .66 \\
\hline $\mathrm{FeO} \ldots . . .$. & 1. 74 & 2. 90 & 2. 46 & .30 & $.8 \pm$ & .57 & Undet. & Undet. & Undet. \\
\hline $\mathrm{MgO}$ & 2.67 & 2.32 & 2. 45 & 1.17 & .52 & .85 & 7.90 & 4. 49 & 6.20 \\
\hline $\mathrm{CaO}=$ & 5.96 & 1.41 & 3.12 & 5.52 & 1.05 & 3. 29 & 42.61 & 40.60 & 41.60 \\
\hline $\mathrm{Na}_{2} \mathrm{O} \ldots$ & 1. 80 & 1.01 & 1.31 & .45 & .76 & .61 & .05 & .62 & .34 \\
\hline $\mathrm{K}_{2} \mathrm{O} \ldots$ & 2.67 & 3.60 & 3.25 & 1.32 & 1. 16 & 1. 24 & .33 & .58 & .46 \\
\hline $\mathrm{H}_{2} \mathrm{O}$ at $110^{\circ}$. & 2.11 & .89 & 1.34 & .31 & .27 & .29 & .21 & .30 & .26 \\
\hline $\begin{array}{c}\mathrm{H}_{2} \mathrm{O} \text { above } \\
110^{\circ} \ldots \ldots\end{array}$ & 3. 45 & 3.82 & 3.68 & b1. 33 & 61.47 & 1.40 & b. 56 & 0.88 & .72 \\
\hline $\mathrm{TiO}_{2} \ldots$ & .46 & .76 & .65 & .25 & .41 & .33 & .06 & .08 & .07 \\
\hline $\mathrm{CO}_{2} \ldots$. & 4. 62 & 1.46 & 2.64 & 5.04 & 1.01 & 3.03 & 41.58 & 35.58 & 38.58 \\
\hline $\mathrm{P}_{2} \mathrm{O}_{5} \ldots \ldots$ & .20 & .15 & .17 & .08 & .06 & .07 & .04 & .42 & .23 \\
\hline $\mathrm{SO}_{3} \ldots \ldots \ldots$ & .78 & .58 & .65 & .07 & .09 & .08 & .05 & .07 & .06 \\
\hline $\mathrm{Cl} \ldots$ & $\ldots$. & $\cdots$ & ........ & Trace. & Trace. & Trace. & .02 & .01 & .01 \\
\hline$s \ldots$. & $\ldots$ & . & - - & . & $\cdots$ & . & .09 & .07 & .08 \\
\hline \multirow{5}{*}{$\begin{array}{l}\mathrm{M} \mathrm{InO} \\
\mathrm{BaO} \ldots . . . \\
\mathrm{SrO}\end{array}$} & Trace. & Trace. & Trace. & Trace. & Trace. & Trace. & .05 & .03 & .04 \\
\hline & .06 & .04 & .05 & .05 & .01 & .03 & None. & None. & None. \\
\hline & None. & None. & None. & Trace. & None. & Trace. & None. & None. & None. \\
\hline & $\begin{array}{r}\text { Trace. } \\
.69\end{array}$ & $\begin{array}{r}\text { Trace. } \\
.88\end{array}$ & $\begin{array}{r}\text { Trace. } \\
.81\end{array}$ & $\begin{array}{l}\text { Trace. } \\
\text {. }\end{array}$ & Trace. & Trace. & Trace. & Trace. & Trace. \\
\hline & 100.48 & 100. 46 & 100. 46 & 100.41 & 99.86 & 100.16 & 100.09 & 100.34 & 100.23 \\
\hline
\end{tabular}

A. Composite analysis of 27 Mesozoic and Cenozoic shales. Each individual shale was taken in amount roughly proportional to the mass of the formation which it represented.

B. Composite analysis of 51 Paleozoic shales, weighted as in the former case.

C. General average of $\mathrm{A}$ and $\mathrm{B}$, giving them respectively weights as 3 to 5 . This average represents 78 rocks.

D. Composite analysis of 253 sandstones, about 1 gram of each being taken in preparing the average sample.

E. Composite analysis of 371 sandstones used for building purposes, equal weights taken.

F. Average of $\mathrm{D}$ and $\mathrm{E}$, total of $62 t$ sandstones. The sandstones selected at random and those used for building purposes are given equal weights.

G. Composite analysis of 345 limestones, equal weights being taken.

H. Composite analysis of 498 limestones used for building purposes, equal weights taken.

I. Arerage of $G$ and $I I$, total of 843 limestones. The limestones selected at random and those used for building purposes are giren equal weights.

a Clarke, F. W., Analyses of rocks, laboratory of the U. S. Geol. Survey, 1880-1899: Bull. U. S. Geol. Survey No. 168, 1900, pp. 16-17.

${ }^{b}$ Includes organic matter.

cof organic origin. 
Varions estimates, which are little more than guesses, have been made of the thickness of the sedimentary rocks upon the eartll. Dana in 1875 stated that the mean thickness of the sediments for the continental areas will not exceed 5 miles (8.05 kilometers). ${ }^{a} \quad$ T. Mellard Reade states that an estimate of 10 miles ( 16.1 kilometers) is a moderate one for the thickness of the sedimentary crust of the earth throughont. ${ }^{b}$ Later he greatly reduces this estimate, saying: "I think we may with safety provisionally assume that the actual average thickness of the sedimentary crust of the globe is not less than 1 mile (1.61 kilometers)." This average is for the globe as a whole, and not for the continental areas, and therefore is not greatly below Dana's estimate of 8 kilometers for the continents alone. It appears to me that even Reade's revised estimate is much too great. At only a very few localities can it be shown that the thickness of the sediments approximates 8 kilometers. For the great plains and platean areas where there are deep borings or deep gorges, as, for instance, in the Grand Canyon, the sediments frequently do not exceed 1 kilometer, and in general are less than 2 kilometers. For great areas of the continents, such as extensive Archean areas of Canada, there are no known sediments. For the greater part of the ocean, aside from the continental shelves, all the evidence available points toward very slow deposition, and over such areas, composing about two-thirds of the surface of the globe, the sediments are probably of inconsiderable thickness.

The area of the globe is approximately $500,000,000$ square kilometers, of which somewhat more than one-fourth belongs to the continents and continental shelves. If it were supposed that the sediments which have not been within the zone of anamorphism, but have always remained in the zone of katamorphism, are upon an average 2 kilometers thick for the continents, this would give $250,000,000$ cubic kilometers of sediments. This estimate is, of course, little more than a gness, made in order that a number of problems in the distribution of the elements may be quantitatively stated. In comparing this estimate with that of Dana or Reade it should also be noted that mine includes only sediments of the zone of katamorphism-not those which have been metamorphosed in the zone of anamorphism-while Reade's estimate inclndes both.

a Dana, James D., Manual of Geology, second edition, 1875, p. 657.

$b$ Reade, T. Mellard, Chemical denudation in relation to geological time, p. 29

${ }^{c}$ Loc. cit., p. 52 . 
On the supposition that the sediments of the zone of katamorphism are 2 kilometers thick, they compose about 3.668 per cent of the volume of the lithosphere to a depth of 16.1 kilometers (10 miles) below the level of the sea $(6,815,000,000$ cubic kilometers). With a specific gravity of 2.7 the weight of the sediments would be $675,000,000,000,000,000$ metric tons.

In suggesting the above figures the aim has been to underestimate rather than to overestimate the total amount of the sediments. It is thought better to have the calculated amount of elements required for certain clianges smaller than the real amounts rather than larger. For instance, it will be explained on the following pages that the cliange of ferrous to ferric oxide in the sediments has required a vast amount of oxygen-indeed, an amount so great as to be a large percentage of the total oxygen now present in the atmosphere. If an overestimate of the total mass of sediments were made, this would lead to an overestimate of the amount of oxygen required for this change. But the purpose is to make the estimate of the amount of oxygen and of the other elements required for this and for other changes less than the real amounts rather than more.

In making the first rough approximation of the weight of the sediments, they will all be supposed to have a specific gravity of 2.7. While the specific gravity of sediments varies, and doubtless upon the arerage is somewhat less than 2.7 (the average of the igneous and crystalline rocks), the error in placing it at 2.7 is small compared with the errors in the estimates of the amount of sediments and their relative proportion. Therefore, for convenience in the present provisional calculations, a uniform specific gravity for the rocks of the lithosphere is assumed. If the sediments of the zone of katamorphism were supposed to be 0.65 shales and other rocks largely composed of silicates (pelites and psephites), 0.30 sandstones, and 0.05 limestones, this would give $162,500,000$ cubic kilometers of shales, weighing 438,750,000,000,000,000 metric tons, 75,000,000 cubic kilometers of sandstones, weighing 202,500,000,000,000,000 metric tons, and 12,500,000 cubic kilometers of limestones, weighing $33,750,000,000,000,000$ metric tons. In the following pages the term shale will be understood to include all the clastic sedimentary rocks rich in silicates.

So far as I know there has been no attempt to estimate accurately the relative quantities of shales, sandstones, and limestones. The above partition of the sediments is the ronghest sort of a guess. The only computation 
which I am arvare of on the subject is in reference to limestone. T. Mellard Reade, by comparing the amount of calcium carbonate and calcium sulphate in solution in river's with the sediments mechanically carried by rivers, concluded that one-eighth to one-ninth of the transported material is composed of the carbonate and sulphate of calcium. Using his estimate of a thickness of 1 mile for the sedimentary rocks, and supposing that the mass of limestone is one-tenth of the whole mass of the rock, he says: "This gives us the equivalent of a zone of limestone rock 528 feet (160.9 meters) thick, enveloping the globe, as a very rude approximation to the absolute quantity of carbonate and sulphate of lime in the sedimentary crust of the earth." a Of the two compounds calcium carbonate so dominates over calcium sulphate that the latter will be neglected and the whole will be considered as calcium carbonate.

If the amount of calcium carbonate carried by the streams at present is not an accurate measure of the average carried by streams through geological time, the error is likely to be an overestimate rather than an underestimate, since early in geological times, before the calcareous sediments had accumulated, it can not be supposed that the streams carried as much calcium carbonate as at present. Further, the method of computation used by Reade for estimating the volume of the limestones is rather unsatisfactory, since it is certain that a considerable portion of the calcium carbonate passes into shales and sandstones, as is shown by the analyses (p. 938).

The shales contain 2.64 per cent of carbon dioxide and the sandstones 3.03 per cent. If most of this carbon dioxide is united with calcium. oxide, as is probable, this would give about 5 per cent, or one-twentieth, of calcium carbonate in the shales and sandstones. Therefore, if the shales and sandstones were supposed to be nineteen times as abundant as the limestones, these rocks would require one-half of the calcium carbonate, and the proportion of limestone instead of being one-tenth, as estimated by Reade, would be one-twentieth of the total mass of the sediments. This ratio of 19:1 between the sandstones and shales together and the limestones is accond with the relative amounts of the rocks as calculated upon the basis of depletion of calcium oxide in the sandstones and shales as compared with the original rocks (see pp. 990-991). It thus appears that the estimate of one-twentieth, or 0.05 , of the mass of sediments for limestone, is probably as near the truth as can be made from data at the present time.

a Reade, T. Mellard, Chemical clenudation in relation to geological time, p. 53. 
As a result of the work of the Challenger expedition, the ocean is estimated to have a volume of $1,283,840,000$ cubic kilometers. ${ }^{a}$ This estimate, equivaleut to $307,000,000$ cubic miles, is somewhat in excess of Woodward's estimate of $302,000,000$ cubic miles, given on page 933 . The weight of $1,283,840,000$ cubic kilometers of the ocean, with a specific gravity of 1.03 (see p. 933), is $1,322,355,000,000,000,000$ metric tons. Of this 85.79 per cent, or $1,134,448,354,500,000,000$ metric tons, is oxygen, and 10.67 per cent, or $141,095,278,500,000,000$ metric tons, is hydrogen. Taking the maximum salinity of sea water as given by Dittmar, ${ }^{6} 37.37$ grams of salts per kilogram of water, sea water is 96.263 per cent water and 3.737 per cent salts. The 3.737 per cent salts is made up of the following compounds:

Composition of salts in sea water. ${ }^{c}$

\begin{tabular}{|c|c|}
\hline & Per cent. \\
\hline Chlorine....... & 55.292 \\
\hline Bromine $\ldots \ldots$ & .1884 \\
\hline Sulphuric oxide $\left(\mathrm{SO}_{3}\right) \ldots \ldots \ldots \ldots$ & 6.410 \\
\hline Carbon dioxide $\left(\mathrm{CO}_{2}\right) \ldots \ldots \ldots$ & .152 \\
\hline Lime $(\mathrm{CaO}) \ldots$ & 1. 676 \\
\hline Magnesia (MgO) ......... & 6.209 \\
\hline Potash $\left(\mathrm{K}_{2} \mathrm{O}\right) \ldots \ldots \ldots$ & 1.332 \\
\hline Soda $\left(\mathrm{Na}_{2} \mathrm{O}\right), \ldots \ldots \ldots \ldots \ldots$ & 41.234 \\
\hline Oxygen equivalent of halogen........... & -12.493 \\
\hline Total. & 100.000 \\
\hline
\end{tabular}

a Dittmar, William, Composition of ocean-water salts: Narrative of the cruise of H. M.S. Challenger, rol. 1 , pt. 2, 1885, pp. 951, 980 .

$\checkmark$ Dittmar, William, Report of the scientific results of the exploring voyage of H. M. S. Challenger, 1873-1876: Vol. I, Physies and Chemistry, London, 1884, p. 201.

$c$ Dittmar, Narrative of the cruise, ete., p. 954 . 
Combining acids and bases, we have the following average composition of sea salt: ${ }^{a}$

Percentages of salts in sec water.

\begin{tabular}{|c|c|}
\hline & Per cent. \\
\hline Chloride of sodium.. & 77.758 \\
\hline Chloride of magnesium ....... & 10. 878 \\
\hline Sulphate of magnesium............. & 4.737 \\
\hline Sulphate of lime ....... & 3.600 \\
\hline Sulphate of potash ...... & 2.465 \\
\hline Bromide of magnesinm ... & .217 \\
\hline Carbonate of lime...... & .345 \\
\hline Total. & 100.000 \\
\hline
\end{tabular}

From the above table the percentages of the different elements in the ocean salts are calculated as follows:

Percentages of elements in sea sult.

\begin{tabular}{|c|c|c|c|}
\hline & Per cent. & & Per cent. \\
\hline Cl................. & 55.217 & K . . . . & 1. 107 \\
\hline Na................ & 30.637 & $\mathrm{Br} \ldots$ & .188 \\
\hline $\mathrm{O} \ldots$ & 5.283 & $\mathrm{C} \ldots \ldots \ldots$ & .041 \\
\hline $\operatorname{Mg} . . .$. & 3.769 & \multirow[t]{3}{*}{ Total. } & 100.000 \\
\hline s & 2.562 & & \\
\hline $\mathrm{Ca} \ldots \ldots$ & 1. 196 & & \\
\hline
\end{tabular}

The total amount of these compounds as calculated by Dittmar is $46,283,000,000,000,000$ tons, or $46,283\left(10^{12} \times 1,000\right)$ kilograms. The amounts of the different compounds are given in the table below. ${ }^{b}$

Total amounts of salts in the oceun.

$$
\text { [Unit }=10^{22} \text { metric tons.] }
$$

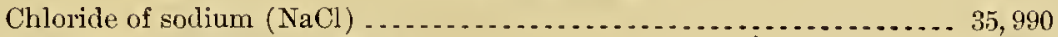

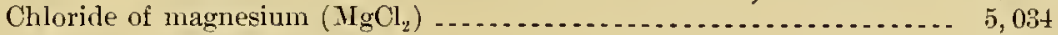

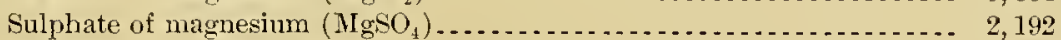

Sulphate of calcium $\left(\mathrm{CaSO}_{4}\right) \ldots \ldots \ldots \ldots \ldots \ldots$

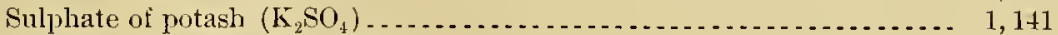

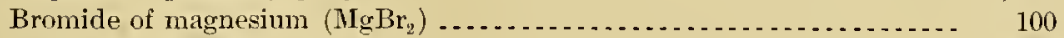

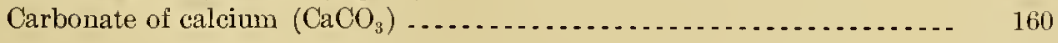

46,283

a Dittmar, Narrative of the cruise, eit., p. 954. $\quad b$ Dittmar, cit., y. 980. 
Taking the above estimates, the amounts of the different elements of the ocean salts are given in the following table:

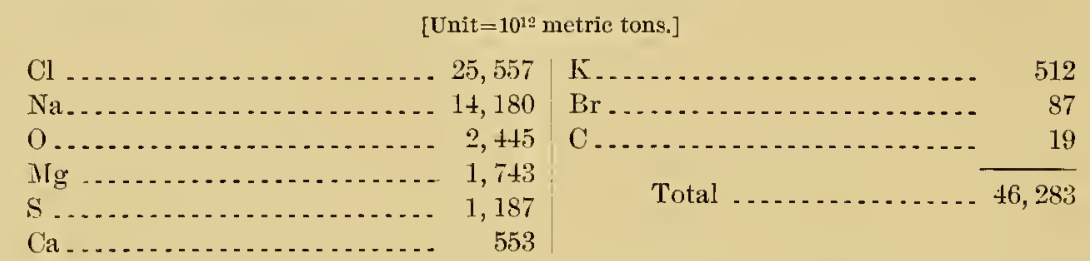

Clarke, using the above results of Dittmar, computes the elemental composition of the ocean, as already given (p. 936); but for convenience his results are here repented: ${ }^{a}$

Composition of ocean.

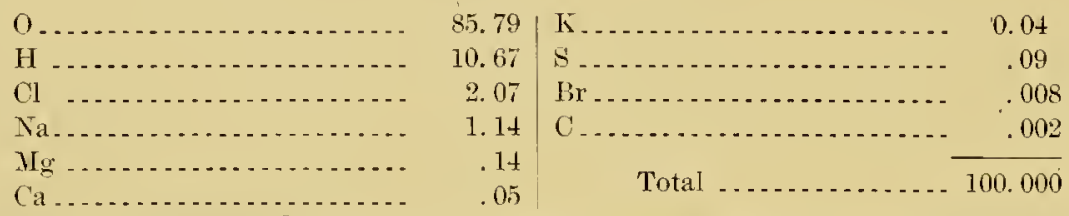

Excluding the subordinate constituents, air has the following composition:

Composition of air.

\begin{tabular}{|c|c|c|}
\hline & By volume. & By weight. \\
\hline Nitrogen & $\begin{array}{r}\text { Per cont. } \\
79.08\end{array}$ & $\begin{array}{l}\text { Per cent. } \\
76.88\end{array}$ \\
\hline Oxygen - & 20.92 & 23.12 \\
\hline
\end{tabular}

The amount of carbon dioxide in the air is 0.03 per cent by volume and 0.045 per cent by weight. ${ }^{b}$ There are also in the air minnte proportions of water vapor, ammonia $\left(\mathrm{NH}_{3}\right)$, argon, etc.

According to Woodward (see p. 933) the mass of the atmosphere is equivalent to that of $5,292,000$ cubic kilometers $(1,268,000$ cubic miles) of water of unit density. 'This is equal to a weight of $5,292,000,000,000,000$ metric tons. Disregarding the subordinate elements, the weight of the nitrogen would be $4,068,489,600,000,000$ metric tons, and of the oxygen $1,223,510,400,000,000$ metric tons.

a Clarke, F. W., Relative abundance of the chemical elements: Bull. U. S. Geol. Survey No. 78, 1891 , p. 35.

$\checkmark$ Mendeléeff, D., The principles of chemistry, translated by George Kamensky: Longmans, Green, \& Co., London, 6th ed., vol. 1, 1897, pp. 235, 236, and 238. 
The above data give the approximate composition of the lithosphere as now constituted; but not of the earth as a whole. As pointed out by Farrington, ${ }^{a}$ we can probably get a rough approximation to the composition of the earth by considering the nature of meteoric falls, as they are supposed to furnish the best basis for estimating the composition of the material out of which the world las segregated. Meteoric falls rather than meteoric finds are chosen because "the iron meteorites are much more likely to be known and preserved than the stony." ${ }^{b}$ The average specific gravity of meteoric falls, as determined by Farrington, is 3.69. ${ }^{\circ}$ No attempt lias been made to estimate quantitatively the proportions of the elements which compose such meteorites, taking into account both their masses and compositions. However, Farrington ${ }^{d}$ recently considered the mineral and chemical compositions of various classes of meteorites, including both falls and finds, and in some cases gave the relative proportions of a few of the elements in these, and the percentages of a few of the minerals in some of the meteorites considererl. From his article the following table is made:

Constituénts of meteorites.

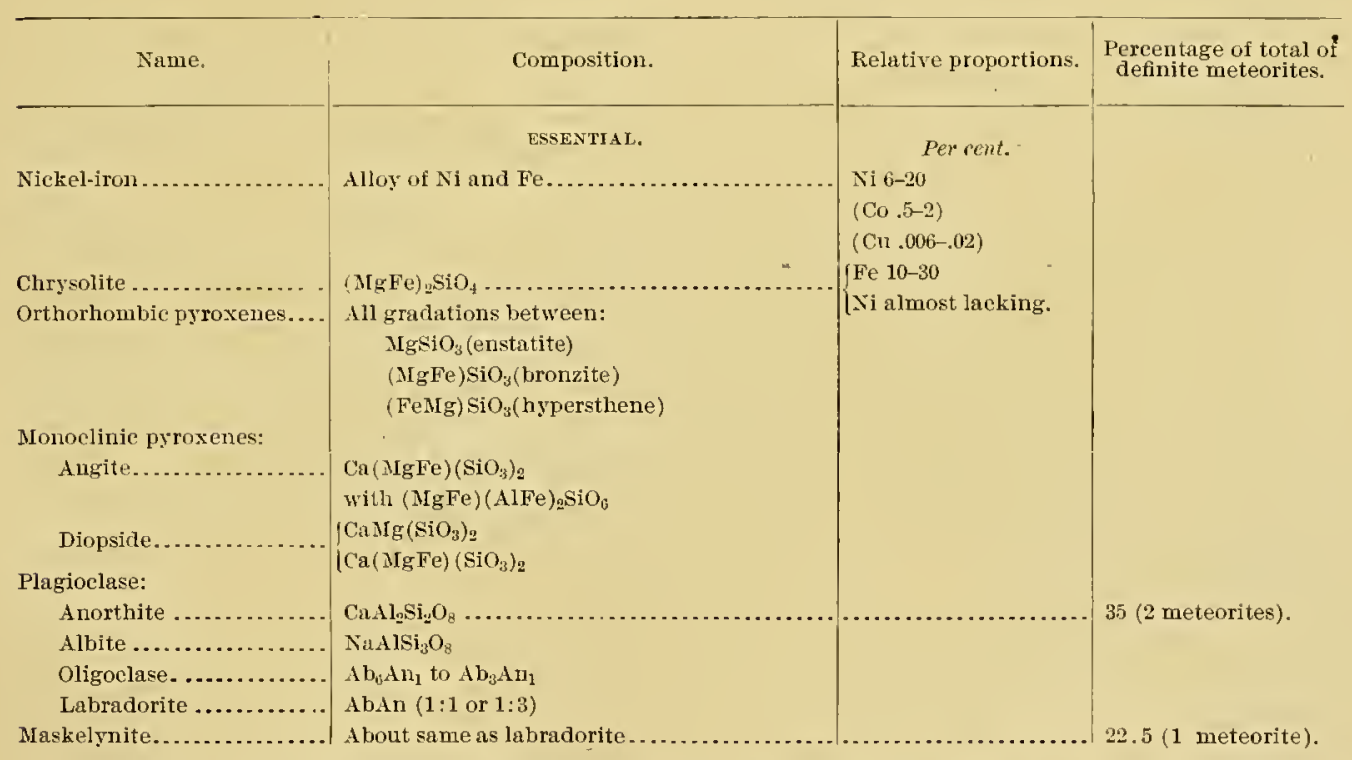

a Farrington, O. C., The average specific gravity of meteorites: Jonr. Geol., vol. 5, 1897, pp. 127-128.

$\delta$ Farrington, The constituents of meteorites: Jour. Geol., vol. 9, 1901, p. 394.

${ }^{c}$ Farrington, The average specific gravity of meteorites: Jour. Geol., vol. 5, 1897, p. 130.

a Farrington, The constituents of meteorites: Jour. Geol., vol. 9, 1901, pp. 393-408, 522-532. IION XLVII-0t- 60 
A TREATISE ON METAMIORPHISM.

Constituents of meteorites-Continued.

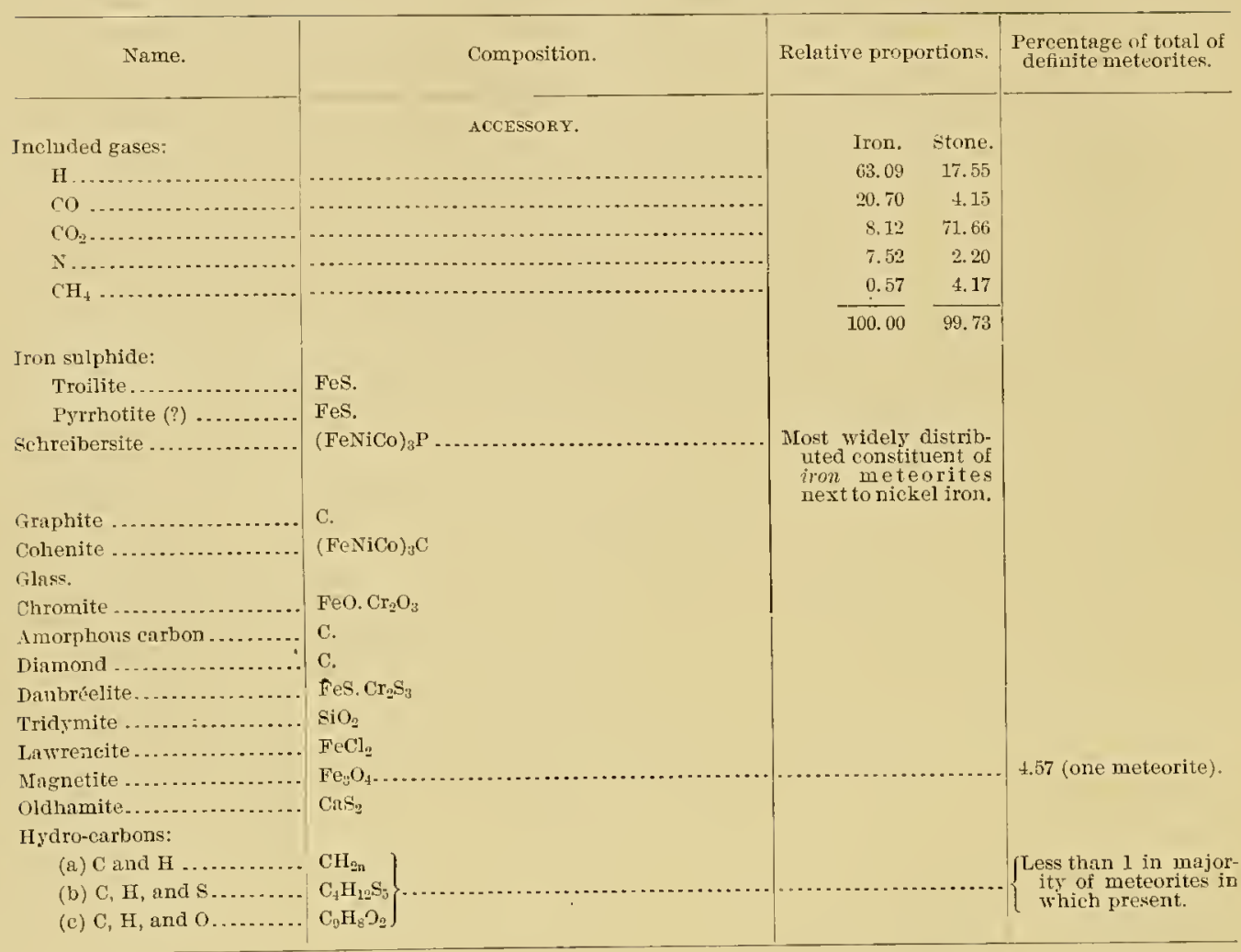

The list of elements in meteorites given by Farrington ${ }^{a}$ includes all those, except fluorine, which compose as much as 0.01 per cent of the outer part of the earth and a number of others. Farrington has given also a list of the eight chief elements in meteorites, including both falls and finds, in order of their abundance (column 1). ${ }^{b}$ For comparative purposes there are placed opposite these, in order of abundance, the eight elements which, according to Clarke, are most plentiful in the outer part of the earth (colnmu 2). 
Order of abundunce of etenents in meteorites and in the outer rocks of the enth.

\begin{tabular}{ll}
\multicolumn{1}{c}{ Meteorites. } & Onter crust of earth. \\
1. Iron. & Oxygen. \\
2. Oxygen. & Silicon. \\
3. Silicon. & Aluminum. \\
4. Magnesium. & Iron. \\
5. Nickel. & Calcium. \\
6. Sulphur. & Sodium. \\
7. Caicium. & Magnesium. \\
8. Aluminum. & Potassium.
\end{tabular}

Nickel and sulphur are found in column 1 and not in column 2, but in the latter sodium and potassinm appear. Farrington suggests that because iron meteorites are preserved longer than stony meteorites, and are therefore more likely to be found, iron probably occupies a higher place than it would if meteoric falls only were considered. He further suggests: "The relative excess of magnesimm and nickel and scarcity of aluminum and calcium in meteoric as compared with terrestrial matter may be dne to the same canse."

\section{REDISTRIBUTION OF THE CHEMICAL ELEMENTS.}

We are now prepared to consider the redistribution of the important chemical elements as a joint result of the forces and agents of metamorphism, inchuding therein for this purpose the forces and agents of denudation. In order to appreciate the results it is perhaps well to state the point of view from which the redistribution is considered. If the distribution of any element in the igneous and sedimentary rocks be compared it will be found that in the latter class certain formations are defieient in a given element, and correlative with this deficiency there is a surph in some other formation or formations. In other words, for any element some sedimentary formations, as compared with the igneous rocks, are likely to show marked deficiencies and some formations marked segregations. Where the material segregated has a value to man, either in the form in which it exists in nature or as furnishing the source of one of the elements, it becomes an economic prodnct. Thus in tracing out the redistribution of the elements we are arriving at the genesis of various economic products. In this chapter only the abundant elements are considered, but where an abundant element may be an ore we are to that extent dealing with the genesis of ore 
deposits, as for instance in the case of iron. The development of the gréter number of ore deposits involves the segregation of the rarer elements, and this aspect of the subject is especially considered in the following chapter.

\section{OXYGEN.}

Oxygen is the most abundant of the elements, both in the lithosphere and in the hydrosphere. Aceording to Clarke's estimate of 1891 oxygen composes 49.98 per cent of the lithosphere, hydrosphere, and atmosphere together, or only 0.04 per cent short of the total amount of all the other elements. According to Clarke's estimate of 1891 it composes 47.29 per cent of the lithosphere, and according to his estimate of 1900, 47.02 per cent. $^{a}$ Of the hydrosphere it composes 85.79 per cent, and of the atmosphere 23.12 per cent. While the percentage of oxygen in the hydrosphere is greater than in the lithosphere, by far the greater proportion of the oxygen is in the lithosphere, on account of its enormous mass, although an immense quantity is in the hydrosphere. The oxygen of the lithosplhere and hydrosphere is combined, while that of the atmosphere is free. Oxygen differs from all of the other abundant elements in that a large quantity of it is in the free state. The only other abundant element which occurs partly in the free state is iron, and the amount of free iron in the lithosphere is exceedingly small. One other element, nitrogen, near the bottom of the list of the 23 more plentiful elements, also occurs in the free state and in even greater quantity than oxygen. Oxygen is the element second in abundance in the meteorites. Among the gases of the meteorites free oxygen is not included in the list given by Farrington, but Wright reports oxygen as occluded. ${ }^{b}$ Even if oxygen exists as a gas in meteorites, this is not eridence that this oxygen was bronght from the outer space. It may have been absorbed there or while the meteors were passing through the atmosphere, or partly in both'ways.

The source of oxygen for the atmosphere is a matter of great consequence, since in the process of oxidation, one of the fundamental processes of the zone of katamorphism, the oxygen is derived directly or indirectly from the atmosphere. So far as known, the vast quantity of free oxygen

a Clarke, cit., Bull. 78 , p. 39: Bull. 168, p. 15.

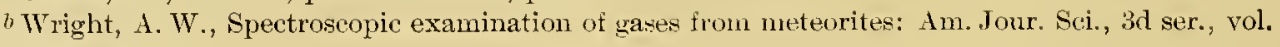
9, $18 \pi 5$, p. 301. 
within the lithosphere is combined, and there is no evidence that this is not true of the centrosphere also.

It might be supposed, as has been suggested by varions men in reference to carbon dioxide, that oxygen has been attracted to the earth by the force of gravity from the interplanetary spaces. To what extent this has occurred, if at all, must long, and perhaps forever, be a matter of conjecture.

The chief certain source of oxygen for the atmosphere is the reducing action of organic material upon carbon dioxide. As plants grow they decompose carbon dioxide of the atmosphere, thereby liberating oxygen, and build the carbon into their bodies. Animals take their carbon compounds directly or indirectly from plants. So far as the plants and animals decompose, the carbon is again oxidized to carbon dioxide by the oxygen of the atmosphere, thus consuming an amount of oxygen equivalent to that originally liberated. Therefore, so far as life products decompose there is no permanent gain of oxygen to the atmosphere by the cycle. But a portion of the organic compounds do not completely decompose, and in so far as this is true and they remain in the rocks in carbonaceous shale, graphitic slates, schists, or gneisses, in peat, in coal, and other rocks, the oxygen liberated by the reduction of the carbon dioxide is a permanent gain to the atmosphere. It will be seen under carbon, pp. 962-974, that the quantity of carbon which is thus locked up in the earth is enormons. Since no quantitative estimate has ever been made of the amount of such carbon, there is no way in which one can ascertain to what extent the air las gained in oxygen in consequence of the reduction of carbon dioxide. But it is suspected that a considerable percentage of the oxygen now in the atmosphere conld be thus accounted for. Indeed the reduction of carbon dioxide by plants and the liberation of oxygen to the atmosphere in consequence of the formation of the rock coals, peats, etc., has so impressed Koene and Plipson as to make them think that originally the relations of carbon dioxide and oxygen in the atmosphere were probably reversed, but that as a result of the continnous reducing action of vegetation and the decay of only a part of it the atmosphere las become one in which carbon dioxide is very subordinate and oxygen one of the chief constitnents. ${ }^{a}$ 
But the oxidation of carbon and deoxidation through life take into account only one aspect of the question. The inorganic carbon compounds of the original earth stuff shonld also be considered, and Koene and Plipson ignore this side of the question. It will be seen, nuder carbon, that this element in rarious forms is a constituent of the original igneous rocks, and it las been seen that carbon componds are also constituents of meteorites. So far as elemental carbon, carbon monoxide, carbnreted hydrogren, or other carbon compounds are present in the original igneous rocks and have been oxidized to carbon dioxide, demands have been made upon the oxygen of the atmosphere. These demands have certainly been large. No data are at hand to make even an approximate estimate as to how large a quantity of oxygen has thus been abstracted from the atmosphere during geological ages. But, as explained under carbon, the oxidation of carbon compounds of the original igneons rocks is believed to be one of the chief sources of carbon dioxide. In so far as this reaction has taken place it is a reversal of that of vegetation. Which of these opposing processes is preponderant is a question of great importance, but one upon which not even a qualitative guess is warranted. Therefore no statement can be made as to whether the atmosphere has permanently gained or lost oxygen as a consequence of the oxidation and deoxidation of carbon compounds throughout geological time.

A second very important reaction which depletes the atmosphere in oxygen is the oxidation of the ferrons iron of the original rocks. It has been pointed out (Chapters VI and VIII) that oxidation of the ferrous oxide to the ferric axide is characteristic of the belt of weathering and that the reduction of the ferric oxide to the ferrous oxide may occur in the belt of cementation and is characteristic of the zone of anamorphism. But the oxidation of ferrous iron to the ferric form clearly preponderates over the reduction of ferric oxide to ferrons oxide, and hence oxygen is consumed. This is shown by the following facts:

In 78 shales the percentage ratio between the ferrous oxide and the ferric oxide is $2.46: 4.03$; in 624 sandstones the ratio is $0.57: 1.24$; in 843 limestones the ferrous oxide is so small that it is undetermined, but the ferric oxide is 0.66 . Giving these sets of numbers the respective weights of $0.65,0.30$, and 0.05 (the estimated proportions of these different kinds of sediments), the ratio between the ferrons oxide and ferric oxide in the 
sediments as a whole is $1.77: 3.025$. The amount of ferrous oxide is about one-half of that of the original igneous rocks, 3.52 per cent. The amonnt of ferric oxide somewhat exceeds that in the original rocks, 2.63 per cent, but this excess falls far short of the amount required to compensate for the deficiency of ferrous iron in the secondary rocks, for the total amount of iron in 1.77 per cent of ferrons oxide and 3.025 per cent of ferric oxide is 3.49, whereas the total amount of metallic iron existing in the oxidized form in the original rocks is 4.58 , the remainder of the 4.64 total iron, as given by Clarke, probably being largely accounted for by the iron united with sulphur. It therefore appears that a large amount of the iron of the original rocks is not accounted for in the sediments which are ordinarily analyzed, and this difference amounts to one-fourth of the total amount of iron in the original rocks. This vast deficiency in iron oxide is probably largely accomnted for by the segregation of iron in the iron-bearing formations and in the iron-ore deposits such as those in the Lake Superior region. The iron in these formations is dominantly in the ferric form. Certainly the ratio of ferric oxide to ferrous oxide in them is as great as among the sediments.

Supposing, therefore, that the ratio of ferrous oxide and ferric oxide in the iron-bearing formations is the same as in the sediments analyzed, and increasing the amounts of ferrous oxide and ferric oxide in the shales, sandstones, and limestones together in the same ratio, so that they contain an amount of iron equivalent to that in the original igneous rocks, thereby inchuling the iron-bearing formations, this would give 2.35 per cent of ferrous oxide and 4.02 per cent of ferric oxide. Upon this hypothesis the difference between the amount of ferrous oxide present in the original rocks, 2.35 per cent, and that now found upon the average in the secondary rocks, 1.77 per cent, is 0.58 per cent. To change this percentage of ferrous oxide to ferric oxide for the $675,000,000,000,000,000$ metric tons of sediments of the zome of katamorphism would require $435,000,000,000.000$ metric tons of oxygen, or $35.55 \mathrm{per}$ cent of the oxygen now in the atmosphere. (See p. 944.) This shows how enormous has been the draft of oxygen from the atmosphere in consequence of the oxidation of ferrous oxide alone. (See p. 1003.)

Another very large demand upon oxygen is made by the oxidation of the metals and the sulphur united as sulphides in the original rocks. Of the 
netals united with sulphur, iron of course dominates over all others combined. We may therefore use $\mathrm{FeS}_{2}$, the most common sulphide, to illustrate the process. If the iron were changed to the ferric oxide and the sulphtur to sulphuric acid, the reaction may be represented by the equation-

$2 \mathrm{FeS}_{2}+15 \mathrm{O}+4 \mathrm{H}_{2} \mathrm{O}=\mathrm{Fe}_{2} \mathrm{O}_{3}+4 \mathrm{H}_{2} \mathrm{SO}_{4}$.

Since sulphates are not known in the original igneous rocks, nor in meteorites, it is to be presumed that practically all the sulphates which now exist are a result of the oxidation of the sulphur of the sulphides by oxygen. The total amount of sulphates in the ocean is vast. The amount of sulphur present as sulphates in the ocean is estimated by Dittmar to be $1,187,000,000,000,000$ metric tons. The oxygen derived from the atmosphere to unite with this stlphur in order to produce sulphuric acid is $1,777,200,000,000,000$ metric tons, or 145.25 per cent of that now in the atmosphere. If the sulphur in the sulphate deposits be estimated as equal to one-tenth that in the ocean, the amount of oxygen required for the production of all the supphates would be 159.77 per cent of that now in the atmosphere. As shown by the above equation, to oxidize the iron of sulphides to the ferric oxide requires one-fourth as much oxygen as the oxidation of the sulphur to sulphuric acid. Thus for this part of the process 39.94 per cent of the amount of oxygen in the atmosphere would be required. Summing all these amounts we find that for the oxidation of the sulphides $2,443,473,000,000,000$ metric tons of oxygen, or 199.91 per cent (i. e., twice), that now in the atmosphere, has been consumed. (See p. 1003 for possible modification.)

It is shown elsewhere that sulphates produced by oxidation of the sulphides are extensively reduced to sulphides by carbonaceous material, and this cycle of reproduction of sulphates and sulphides for some of the material doubtless has been repeated many times. The above is a first attempt to roughly estimate the amount of oxygen required to produce the present existing sulphates, not the total amount of oxygen which has been consumed in the oxidation of the sulphides to sulphates through geological time. So far as the sulphides have been changed to sulphates and reduced again to sulphides by organic matter, a consideration of the amount of oxygen which is drawn from the atmosphere by this process has already been accounted for in considering the relations of oxygen and carbon. 
Metallic iron is known as a rare constitnent of certain very basic igneous rocks. When such material reaches the zone of katamorphism the iron is oxidized to ferrous oxide or ferric oxide, and thus oxygen is consmmed. At the present time the consumption of oxygen by metallic iron is so small as to be insignificant, but it is possible tlat earlier in the history of the earth, before the segregation of the oxidized products at the surface, not only iron, but possibly other metals, may have been oxidized in great quantity, and thus enormous quantities of oxygen abstracted from the atmosphere. The quantity of oxygen which has thus been consumed must, so far as one can see, ever be a matter of conjecture.

The source of the water of the hydrosphere is uncertain. It may be supposed that early in the history of the earth a large part of the elements composing water was in a free state, although doubtless a part was also combined. If any cousiderable proportion of the water of the hydrosphere was produced by the oxidation of lydrogen during the time the sedimentary rocks were deposited, the amount of oxygen thus consumed would have been enormonsly greater than that required for the processes which have heretofore been considered, indeed, many times greater than the amount of oxygen now in the atmosphere. However, it is useless to speculate as to the extent to which the oxidation of hydrogen took place in early geological time. It is probable that during the deposition of the sedimentary rocks, and even at the present time, hydrogen is being oxidized on a small scale. It is seen (pj. 945-946) that hydrogen and carbureted hydrogen are constituents of meteorites, and further that liydrogen occurs occluded in varions rocks. Hydrogen is met also in connection with fumarolic and solfataric action. As already explained (p. 492), this hydrogen is supposed to be prodnced by the reaction of the ferrous oxide upon water, according to the equation

$$
\mathrm{H}_{2} \mathrm{O}+2 \mathrm{FeO}=2 \mathrm{H}+\mathrm{Fe}_{2} \mathrm{O}_{3} \text {. }
$$

So far as water is produced by the oxidation of hydrogen free or combined oxygen is abstracted from the atmosphere. This abstraction certainly occurs to some extent in volcanic districts. Phipson also holds that hydrogen, so far as it is present in the atmosphere, may be oxidized by the nascent oxygen freed by plants. He grew certain plants in an atmosphere of hydrogen and was thus able, as lie claims, to completely oxidize all of it. ${ }^{a}$ 
It might be supposed that in counting the oxygen consumed in the oxidation of hydrogen to produce water, that formed by the decomposition of water through the agency of ferrous oxide should be disregarded, since the amount of oxygen required for the change of ferrous oxide to ferric oxide in the change from the original to the altered sediments has already been estimated. But the lavas are original igneous rocks and the ferric oxide which they contain may be in part produced by the oxidation of ferrous oxide throngh water in accordance with the equation above given, and therefore the oxygen required to oxidize the ferrous oxide to the ferric oxide as calculated (p.951) does not inchude that required by the reaction above.

Since there is so little hydrogen in the air, it might be argned that the oxidation of hydrogen has taken place upon the earth on a great scale, and therefore that large quantities of oxygen have been thus consumed. But Chamberlin has shown that it is doubtful if hydrogen can be permanently held in the atmosphere by the attraction of the earth." If free hydrogen can escape from the earth it can not be assumed that the amount of oxygen required to oxidize hydrogen is important, at least during later geological time.

Another way in which oxygen has been consumed by metamorphism is in the oxidation of nitrogen. It has been explained (pp. 465-466) that in various ways, but chiefly by means of the bacteria and leguminose plants, free nitrogen is oxidized to nitric acid, and in consequence the nitrates are formed. Since the nitrates are not known in the original igneous rocks, nor in meteorites, it is to be presumed that all of the nitrogen compounds upon the earth have been produced by the oxidation of nitrogen. At the present time it is wholly impracticable to make any estimate of the amount of nitrates upon the earth. In arid regions, as is well known, there are large deposits of nitrates. (See p. 787.) In some hummid regions, as for instance at places in the Orinoco Basin of South America, the nitrates compose a large percentage of the soil. As explainer (pp. 505-506), nitrates are essential constituents of all fertile soils. Hence, while no quantitative statement can be made, the quantity of oxygen which must have been consumed in the oxidation of nitrogen munst have been very large.

a Chamberlin, T. C., A groul of hypotheses hearing on climatic changes: Jour. Geol., vol. 5, 1897, pp. 666-667. 
Besides the compounds already considered there are various rarer substances which have been oxidized, such as manganous oxide. Doubtless, however, the consumption of oxygen by the rarer compounds is inconsiderable.

The above calculations may be only roughly approximate, but they seem to show that the amount of oxygen which has been abstracter from the atmosphere during geological time in the oxidation of iron and sulphur is enormous-apparently about twice that now free in the atmosphere. If these results be correct, omitting any consicleration of the amount which has been required for the oxidation of hydrogen, nitrogen, and other substances, the original atmosphere must have been much more voluminous than at present, or else during geological time there has been some source of oxygen from which the atmosplere has been replenished.

In the previous pages only the sediments of the zone of katamorphism are considered. While in the zone of katamorphism oxygen has been added to the lithosphere and abstracted from the atmosphere, it is equally certain that in the zone of anamorphism and in the belt of cementation deoxidation takes place to some extent. Reduction is usually accomplished through vegetation, carbon being oxidized at the same time and largely retumed to the atmosphere as carbon dioxide. So far as this is the case it involves no correction beyond that alrearly considered, since the end result is the sanie as if this carbon had been oxidized by the process of decomposition at the surface of the earth, and thus to that extent balanced the process of liberation of oxygen when the organic carbon componnds were originally formed. On the whole there is no reason to believe that the sedimentary rocks metamorphosed in the zone of anamorphism contain more ferric oxide than the original rocks. Until the relative amounts of ferrous and ferric oxides in the sedimentary rocks of the zone of anamorphism are compared with the amounts of these compounds in the original rocks, it can not be asserted whether the sum total of the reactions of the sedimentary rocks in the zone of anamorphism is in the direction of the consumption or liberation of oxygen.

The oxygen added to the zone of katamorphism is not uniformly distributed, but is segregated to a very large extent. The most important segregation is that occurring in connection with iron. There are rast quantities of ferric oxide in the red sandstones, and the adderl oxygen is 
therefore distributed through these. A much greater concentration of the added oxygen is, however, found in the rich and lean iron-ore formations, from the Archean to the Pleistocene. Such segregation is well illustrated by the Clinton iron ores, and is shown on a magnificent scale by the ferruginous formations of the Lake Superior region. The gypsum and nitrate deposits, aside from the iron, are those in which the oxygen abstracted from the atmosphere is segregated to the greatest extent.

In summary it appears that the chief certain source of oxygen for the atmosphere is the reduction of carbon dioxide by vegetation and the burial of a part of this vegetation in the earth. This source is vast in amount.

On the other hand, oxygen las boen consumed by the oxidation of the carbon compounds of various kinds in the original igneous rocks and in the meteorites; by the oxidation of ferrons oxide to ferric oxide in the zone of katamorphism; by the oxidation of iron in the metallic form and as a sulphide; by the oxidation of sulphur, nitrogen, and liydrogen; and in some small measure by the oxidation of rarer compounds, such as manganous axide. The sum of these gives the amounts of oxygen consumed during geological time. Until estimates have been made of the varions amounts of the oxidized compounds, it is wholly out of the question to make any quantitative estimate of the total amount of oxygen which has been abstracted from the atmosphere by the process of oxidation since the beginning of geological time, but it is certain that the amount of oxygen thus consumed has been enormous. It probably vastly exceeds the amount of oxygen which has been liberated to the atmosphere by the reduction of carbonic acid through plants.

If this conclusion be correct such wild guesses as those of Koene and Phipson (see p. 949), that the carbon dioxide of the original atmosphere greatly exceeded the oxygen and that the proportions of these element; have been reversed in consequence of the reduction of carbon dioxide by organic matter, are wholly unwarranted. This case illustrates the danger of drawing a conclusion from the consideration of only one factor of a complex problem. 
SULPHUR.

According to Clarke's estimate of 1891 sulphur forms 0.04 per cent of the outer 10 miles (16.1 kilometer's) of the earth, including the original rocks, hydrosphere, and atmosphere, 0.09 per' cent of the ocean, and 0.03 per cent of the original rocks. However, in his estimate of 1900 the amount in the original rocks is increased to 0.07 per cent. Sulphur thus has fourteenth place in the scale of abundance. ${ }^{a}$ If the sulphur were reckoned as contained in $\mathrm{SO}_{3}$ Clarke's estimates for 1891 and 1900 for the original rocks would be 0.0749 and 0.1748 , respectively.

It is well known that sulplides are constituents of the original igneous rocks. Sulphur occurs in these rocks as pyrite and pyrrhotite certainly. Sulphur is found also in the meteorites in the form of troilite (FeS), possibly as pyrrhotite $\left(\mathrm{Fe}_{\mathrm{n}} \mathrm{S}_{\mathrm{n}+1}\right)$, as oldhamite $\left(\mathrm{CaS}_{2}\right)$, and also in the hydrocarbon $\left(\mathrm{C}_{4} \mathrm{H}_{12} \mathrm{~S}_{5}\right)$. It thus appears that there are various sources of sulphur in the material of which the earth is formed.

Sulphur occurs in the shales, sandstones, and limestones as sulphates and sulphides. The amount of $\mathrm{SO}_{3}$ reported by Clarke in 78 shales is 0.65 per cent; in 624 sandstones, 0.08 per cent. No sulphur as sulphide is reported, but Clarke writes that the above determinations include probably both the sulphur as sulphate and as sulphide. The amount of $\mathrm{SO}_{3}$ in 843 limestones is 0.06 per cent, and the amount of sulphur as sulphides in these limestones is 0.08 . The latter amount corresponds to 0.20 per cent $\mathrm{SO}_{3}$, and thus if all of the sulphur of the limestones were reckoned as $\mathrm{SO}_{3}$ the amount would be 0.26 per cent.

It thus appear's that, taking into account the molecular weights of sulphur and $\mathrm{SO}_{3}$, sulphur is about four times as abundant in the shales as in the original rocks, is redneed by about one-half in the sandstones, and is increased by about one-half in the limestones. Since the volume of the shales is so great, the amount of $\mathrm{SO}_{3}$ in the shales is much more than sufficient to compensate for the deficiency in the sandstones even if the excess in the limestones were ignored. If one were to combine amounts of sediments and percentage of $\mathrm{SO}_{3}$ in these rocks, and thus make an estimate of the amount of the compound there should be in the original rocks, he would have the following equation:

$.65 \times .65+.08 \times .30+.26 \times .05=.4595$ 
Clarke's average for the original rocks is 0.1748 . It thus appears as if there were an excess of sulphur in the secondary rocks amounting to 0.2847 per cent. To this excess, upon the theory that the salts of the ocean lave been derived from the original rocks, should be adrled the vast amount of $\mathrm{SO}_{3}$ in the ocean. Reckoned as sulphur, from Dittmar's estimates this is $1,187,000,000,000,000$ metric tons, which corresponds to 2,964,000,000,000,000 metric tons of $\mathrm{SO}_{3}$. But this is only .439 per cent of the total mass of the sediments.

The above calculations as to the amount of $\mathrm{SO}_{3}$ in the sediments take no account of gypsum deposits. If these be supposed to contain one-tenth as much $\mathrm{SO}_{3}$ as the ocean, namely, .0439 per cent of the total amount of sediments, there is in the sediments and the ocean together an excess of .7676 per cent beyond the amount calculated in the original rockśs.

These facts show that there is a great discrepancy between Clarke's estimate of 0.1748 per cent of $\mathrm{SO}_{3}$ in the original igneous rocks and the amount of sulphur in the secondary rocks. It is thought highly probable that this discrepancy is largely explained by the actual escape of much sulphur as a gas during periods of voleanism, as hydrogen sulphide, which is oxidized during volcanic action, or by the direct oxidation of the sulphur to $\mathrm{SO}_{2}$ or $\mathrm{SO}_{3}$. It is certain that the amount of sulphur may be greater in the secondary than in the original rocks, as is shown by analyses, becanse the original rocks contain only the residual sulphur which separated as a sulphide when the magma crystallized. While the igneous rocks may lose a considerable portion of their sulphur before crystallization, this may not fully explain the discrepancy. It is possible of course that Clarke's estimate of sulphur in the original igneous rocks may be somewhat too small, since this element is in such subordinate amount, and selections for analysis were made upon the basis of other elements rather than to get an average sample for sulphur:

As to the geological processes through which the redistribution of the sulphur takes place, the following summary statement may be made: In the alteration of the original rocks in the belt of weathering, the sulphides are largely oxidized to sulphates, which are for the most part taken into solution by the underground waters. Some of this dissolved material is carried down into the belt of cementation, and a portion is there precipitated as sulphate in the form of barite, celestite, and gypsun; another part is again 
reducer to sulphide by organic matter and other reducing agents, and in this form is precipitated. These precipitates are mainly those of the heavy metals, especially of iron. A considerable portion of the sulphates which form in the belt of weathering and are caried to the belt of cementation is brought to the surface by solutions which join the overground circulation. By this circulation sulphates are transported to the sea. It has already been noted that a large amount of sulphur is found in the sea as sulphate. The amount now present in solution is not necessarily any measure of the amount which has been contributed to the ocean. Indeed the relatively large amount of sulphates in the shales suggests that where immense masses of unt have become mingled with the sea water, as at the mouths of great rivers, reactions take place which result in the precipitation of the sulphates, and these salts thereby become mingled with the muds which later are transformed to shales. While by far the larger portion of the sulphates of the overground circulation are carried to the sea, in areas such as the Great Basin calcium sulphate is thrown down in the lakes and gypsum deposits are built up. Such deposits are of very considerable magnitude. So far as these gypsum deposits formed in the zone of katamorphism pass into the zone of anamorphism they may become dehydrated and anhydrite be formed.

Gypsum and barite are of very considerable economic importance in various ways. In these products a very large amount of sulphur is concentrated. The segregated sulphur, which, combined with the other elements, makes these products of value, has been brought together in the condensed form from the fraction of 1 per cent of the sulphur in the original rocks. Thus we have another illustration of the manner in which processes of metanorphism segregate elements, and result in the formation of deposits which are of service to man.

SILICON.

Silicon stands second in abundance among the elements of the earth. According to Clarke's estimate of 1891 silicon forms 25.30 per cent of the lithosphere, hydrosphere, and atmosphere together, and of the lithosphere alone 27.21 per cent, a little more than one-fourth of the total. According . to Clarke's estimate of 1900 silicon composes 28.06 per cent of the lithosphere. ${ }^{a}$ All of this silicon is combined. In analyses silicon is usually 
reported with its combined oxygen as silica. Stated as silica, Clarke's estimates of 1891 and 1900 are 58.59 and 59.71 per cent, respectively. ${ }^{a}$ This is the arerage, and in the original rocks the silica rarely falls below 50 per" cent and rarely rises above 75. Of the elements present in meteorites it has been seen that silicon is third in aburdance. Much the larger portion of the silicon in the original rocks ocenrs as silicates, although a large amount oceurs as silica in quartz.

The amount of silica in 78 shales is 58.38 per cent, in 624 sandstones is 81.76 per cent, and in 843 limestones is 9.64 per cent. (See p. 938).

It is plain from the foregoing that within the lithosphere metamorphism, denudation, and sedimentation have redistributed the silica to a very important extent. In the shales the amount renains about the same as the average for the original rocks. In the limestones the amount of silica has been very greatly reduced; indeed, to less than one-sixth of that in the original rocks. Complementary to this depletion of silica in the limestores is its segregation in the sandstones. In these rocks the silica is a little more than one-third greater than the average for the original rocks. This small difference is dne to the fact that the silica in the sandstones is mainly in the form of quartz; while in the original rocks, as already noted, the larger part is in the silicates, of which it composes about two-thirds. Therefore, while the percentage of silica in the lithosphere as a whole is two-thirds as great as in the sandstones, the amount of silica as quartz in the lithosphere, 12 per cent (see p. 937), is only about one-sixth as great as in the sandstones, for the majority of sandstones contain 75 per cent or more of silica.

Considering the zone of katamorphism, there is constant solution of silica in the belt of weatlrering and steady additions of silica in the belt of cementation, already fully explained. (See pp. 473-480, 516-5117, 621623,634-636.) Carbonation in the belt of weathering destroys tile silicates and liberates silica as colloidal silicic acid. This is largely carried downward into the belt of cementation and is there deposited in enormons quantities. (See p. 618.) Hence we lrave constant subtraction of silica from the belt of weathering and its steady addition to the belt of cementation. In the belt of weathering the proportion of silica may be increased or decreased according to the rate of solution of the other elements. (See pp. 507 et seq.). 
By erosion the belt of cementation, enriched in silica, rises into the belt of weathering and the rocks rich in quartz are broken down. The larger part of the quartz is not chemically modified, but mechanically disintegrated, contributed to the streams, and by them earried to the sea. It there joins the quartz liberated from the rocks of the shore by the action of the waves, and the whole is segregated in sandstone formations. Many of the sandstone formations thus produced in early geological time later became land areas. During later geological time streams running over sandstone areas contributed to the sea more than an average amount of quartz. Thus the combined processes of metamorphism and denudation have resulted in segregating sufficient quantities of quartzose sands to produce the quartzsand formations and their metamorphosed equivalents, the quartzites and quartz-schists.

In the deep-seated zone of anamorphism silica is neither added nor subtracted in any considerable quantity, but the form of the compound is often extensively changed. As fully explained (pp. 677-679), silica unites with the bases, especially those of the carbonates, to produce silicates. Whether at the present time the destruction of the silicates in the zone of katamorphism, and especially in the belt of weathering, or the development of the silicates and the destruction of the carbonates in the zone of anamorphism is more important is considered under the heading "Carbon." (See pp. 962-974.)

The proportion of silica in the different classes of sediments gives a criterion by which the estimates of the relative amounts of the sediments (see pp. 940-941) may be very ronghly tested. If the shales, sandstones, and limestones compose $0.65,0.30$, and 0.05 of the sediments, respectively, and contain the percentages of silica above given, the sum of the multiples of the percentage of silica in each of the sediments by the quantities of the sediments should equal the average percentage of silica in the original rocks. Thus

$$
58.38 \times .65+81.76 \times .30+9.64 \times .05=62.957 .
$$

But this equation shows an excess of 3.247 per cent of silica over that determined by analysis, 59.71 per cent.

Practically all of the silicon occurs in the lithosphere. If all classes of sedimentary rocks were taken into account, inchuding both their composition and mass, an estimate of the percentage of silica based upon the sediments MON XLVII $-04-61$ 
onght to correspond with the percentage found in the original igneous rocks. Therefore the discrepancy above noted indicates that there are factors left out of and errors in the above equation. In reference to the similar equations of most of the other elements it will be seen that the determination of the amount of the element as made from the sediments usually shows a deficiency as compared with the original rock. It will be explained that one of the reasons for this is that determinations of the average composition of the sedimentary rocks based upon analyses of the shales, sandstones, and limestones neglect the particular formations in which an element is segregated to the largest extent. In the case of silica the reverse is the case. The sandstones in which silica is concentrated are included; whereas other exceptional compounds in which there is depletion of silica are not included. Consequently we should expect in the case of this compound that the estimates made upon the basis of the sediments should be in excess of the amount found in the original igneons rocks. While the discrepancy is thus partly explained, I suspect that it is due more largely to an enror in the determination of the amount of silica in the shales. Ferr analyses have been made of this class of compounds. It will be seen on subsequent pages (see pp. 984-986) that alumina shows a discrepancy just the reverse of that of silica. It appears to me probable that when we have better representative analyses of the shales, taking into account their composition and masses, the silica will be lower and the alnmina higher than in the analyses given.

\section{CARBON.}

AMIOUNT OF CARBON.

In 1891 Clarke estimated the carbon as 0.21 per cent of the lithosphere, hydrosphere, and atmosphere together: This corresponds to 0.22 per cent of the original rocks, 0.002 per cent of the hydrosphere, and only .0127 per cent by weight of the atmosphere. In 1900 his estimate for the lithosphere was reduced to 0.12 per cent. Recently Letts and Blake, ${ }^{a}$ as a result of careful consideration of all the data and new work, conclude that carbon dioxide is present in the atmosphere to the amount of three volumes in 10,000 , which corresponds to about 0.045 per cent by weight. ${ }^{b}$

a Letts, E. A., and Blake, R. F., The carbonic anhydride of the atmosphere: Sci. Proc. Royal Dublin Society, vol. 9, new series, pt. 2, 1900, p. 172.

$b$ Mendeléeff, D., The principles of chemistry, translated by (ieorge Kamensky: Longmans, Green \& Co., London, 6th ed., 1897, vol. 1, p. 238. 
Reckoned as an oxide, 0.12 and 0.22 per cent of carbon would correspond to 0.44 and 0.81 per cent of carbon dioxide, respectively. This places carbon dioxide tenth among the oxides, and carbon eleventh in abundance, making it less plentiful than either hydrogen or titanium. In Clarke's estimate of 1900 the carbon in limestones is excluded from consideration. $^{a}$ In his estimate for 1891 is included the carbon in a layer of limestone 528 feet thick enveloping the globe, the amount of limestone estimated by Reade. ${ }^{b}$

When Clarke made his estimate in 1891 he thought the analyses of volcanic and crystalline rocks probably showed too high a percentage of carbon dioxide, since the rocks analyzed were not perfectly fresh. But he regards this error as offset by the undeterminable amount of carbon in coals, shales, and petroleuns, which were not considered. ${ }^{b}$ He thinks his resultant estimate, 0.22 per cent for the lithosphere, can hardly be too low. However, it is possible that this estimate is too small, since it is practically impossible to make more than the roughest sort of a guess as to the amount of carbon contained as graphite, anthracite, and hydrocarbons in the crust of the earth. The quantity of carbon in the coal of the earth has never been estimated, and doubtless the quantity present in workable beds is less than that present in nonworkable, widely extended, small, and thin seams. Furthermore, in the carbonaceous shales associated with the coals there is a vast amount of carbon, possibly more than in the coals. Shales as old as the Algonkian in some places contain nearly 20 per cent carbon. Graphitic gneisses have a widespread occurrence among the older metamorphosed sediments. It 'seems to me that the carbon present in the above forms in the lithosphere is likely to much more than compensate for the excess of carbon dioxide due to alteration in the igneous and crystalline rocks analyzed, since rocks which are as fresh as can be obtained are always selected for analysis. But, on the other hand, the estimated amount of carbon in limestone is probably too high, for it is very probable that Reade's estimate of the quantity of limestone is too great. While it is possible that the amount of carbon in the lithosphere is somewhat greater than the larger amount estimated by Clarke, even interpreting all doubtful points in favor

${ }^{a}$ Clarke, F. W., Bull. U. S. Geol. Survey, No. 168, p. 15.

${ }^{b}$ Clarke, Bull. U. S. Geol. Survey, No. 78, p. 38. 
of carbon, the amount wonld still be small, certainly but a fraction of 1 per cent.

Farrington's analyses of meteorites show that carbon is present in these bodies in various forms. As a solid it occurs as amorphous carbon, as graphite, and as diamond. As solid hydrocarbons it is found as $\mathrm{CH}_{2 n}$, as $\mathrm{C}_{4} \mathrm{H}_{12} \mathrm{~S}_{5}$, and as $\mathrm{C}_{9} \mathrm{H}_{8} \mathrm{O}_{2}$. As gases included in the meteorites it occurs as carbon monoxide $(\mathrm{CO})$, carbon dioxide $\left(\mathrm{CO}_{2}\right)$, and carbureted hydrogen $\left(\mathrm{CH}_{4}\right)$. The total quantity of all of these compounds in any one meteorite is small, usually less than 1 per cent, and corresponds very well with the amount in the outer 10 miles of the earth.

The importance of carbon compounds to the lithosphere is out of all proportion to the abundance of this element. As is well known, the carbon compounds are the basis of all forms of life, and it has been seen that life is one of the most potent factors concerned in the decomposition of rocks. Hence the small percentage of carbon in the lithosphere, hydrosphere, and atmosphere is of first importance among the elements concerned in the metamorphisin of rocks.

SEGREGATION OF CARBON.

It is evident from what has been said in considering the amount of carbon in the lithosphere that this element has been segregated in various ways. Carbon is segregated (1) by the process of carbonation, and (2) in the carbonaceous deposits. It has been seen (pp. 473-474) that the carbon now being segregated is directly derived from the carbon dioxide of the atmosphere. The amount of $\mathrm{CO}_{2}$ in the atmosphere, calculated upon the basis of 0.045 per cent by weight, is $2,381,400,000,000$ metric tons. This figure is very close to that of Dittmar, who estimates the amount to be $2,277,000,000,000$ metric tons. ${ }^{b} \quad$ Each of the processes of segregation and the sources of supply of carbon dioxide to the atmosphere will be considered.

segregation by carbonation.--Many years ago Hunt ${ }^{c}$ stated "that the carbonic acid absorbed in the process of rock-decay during the long geologic ages, and now represented in the form of carbonates in the earth's crust, must have equalled probably two hundred times the entire rolume of the present

\footnotetext{
Farrington, cit., pp. 395-408, 522-532.

${ }^{6}$ Dittmar, William, Narrative of the cruise of H. M. S. Challenger, 1873-1876, vol. 1, pt. 2, 1885, pp. 954-955.

- Hunt, T. Sterry, The geological relations of the atmosphere: Rept. British Assoc. Adr. Science, $1878, \mathrm{p} .544$.
} 
atmosphere of our eat th." The data upon which this calculation is made are not given, and it may be a great overestimate, but that any calculation conld have given such a result shows how trivial is the amonnt of carbon dioxide at present in the atmosphere as compared with that which has been abstracted by carbonation.

In 78 shales the amount of carbon dioxide is 2.64 per cent, in 624 sandstones it is 3.03 per cent, and in 843 limestones it is 38.58 per cent.

While segregation of the carbonates is therefore the rule for all the rocks produced by the processes of denudation, this segregation takes place to the least extent in the shales, to a greater extent in the sandstones, and to the greatest extent in the limestones.

If carbon dioside composes but 0.81 per cent of the original rocks, it appears that as compared with the average of the original rocks about three times as much carbon dioxide is concentrated in the shales where it is lowest, and forty-seven times in the limestones. This shows how enormonsly the carbon in the secondary rocks has been increased, as compared with the original rocks, by the process of carbonation in the zone of katamorphism.

Combining the above figures with the masses of the sediments given on page 940 , it follows that the amonnt of carbon dioxide in the shales is $11,583,000,000,000,000$ metric tons, in the sandstones is $6,135,750,000$,000,000 metric tons, and in the limestones is $13,020,750,000,000,000$ metric tons; total, 30,739,500,000,000,000 metric tons. From the foregoing figures it appears that the fixed $\mathrm{CO}_{2}$ in the shales, sandstones, and limestones is 12,900 times the amount now in the atmosphere, and is 1,970 times the amount of free $\mathrm{CO}_{2}$ in both atmosphere and hydrosphere, upon the basis of 0.001 per cent in the hydrosphere, and is 660 times the total free carbon dioxide of the atmosphere and the hydrosphere together, npon the basis of Dittmar's figures. ${ }^{\text {}}$

It appears from the foregoing that in the great limestone deposits a large quantity of carbon dioxide, 38.58 per cent, has been segregated from the exceedingly small amount of carbon in the original igneous rocks and from the atmosphere and hydrosphere. As already seen there is 47 times as much carbon in the linestone formations as in the original igneons rocks. The importance of this process of segregation, considered from an econonic point of view, is not generally appreciated. In order to realize 
this it is necessary to consider the relations of man to agriculture. The limestone soils of the United States, and of many other parts of the world, are of surprising fertility. The historian tells low settlement followed the limestone soils of the Great Valley, of the Blue Frass region of Kentucky and Tennessee, and of the Upper Mississippi Valley. The world over, limestone soils have unsurpassed fertility. Since the products of the soil are the materials of most importance to man, the greatest geologic formation from an economic point of view is limestone produced by the segregation of carbon and calcium.

Segregation in carbonaceous deposits.-Besides the carbon which is segregater as carbon dioxide in the lithosphere by carbonation, vast quantities lave been buried in the rocks in forms varying from nearly pure carbon, as graphite and anthracite, to cellulose. Various estimates have been made of the amount of carbon in the better-known coal berk, but so far as I know no attempt has been made to estimate the amount of carbon in all the coals, good and poor, in the carbonaceous shales associated with them, and in the shales and other rocks not associated with coal beds. The fact that carbon as hydrocurbons exists in shales las been usually overlooked. Carbon forms 0.81 per cent of 78 rocks analyzed. (See p. 938.). This quantity seems small, but when the enormous mass of the shales is considered, $438,750,000,000,000,000$ metric tons, it is seen that this percentage amounts to $3,553,875,000,000,000$ metric tons. If this amount of carbon were oxidized to $\mathrm{CO}_{2}$ it would represent 5,470 times the amount of carbon dioxide in the atmosplere, as calculated above. If it could be consumed at. the rate of $1,000,000,000$ metric tons per year, which is more rapid than the present rate of combustion of coal, it would last over 3,500,000 years. This great amount of carbon, in these, as well as in some other rocks, is ordinarily overlooked. It is therefore certain that the total amount of carbon contained as lyydrocarbons in rocks of all kinds, from the great coal seams to the sediments containing but a very small percentage, is enormous.

Next to the limestones the economic product of vastly greater importance than any other is coal. Coal contains on an average 80 per cent carbon, or 364 times the amount in the original igneous rocks, in which the carbon amounts to only $0.22 \mathrm{per}$ cent. The inestimable economic value of coal is so fully appreciater that it need not be emphasized. The point to be understood is that the forces and agents of greology have segregated this inmeasurably valuable material from a fraction of 1 per cent of 
carbon in the original rocks and from the atmosphere and hydrosphere. Furthermore, the segregation of carbon from widely dispersed naterial is essential to life, and life has profoundly modified many geological processes. The segregation of carbon by the various geological processes in limestone, in organisms, and in coal explains the great importance of this sparse element in the genesis of the earth.

SOURCES OF SEGREGATED CARBON.

It has been seen that fixed carbon exists in the salts of the ocean and in the lithosphere as a carbonate and as hydrocarbons. The important processes now producing these various carbon compounds are those involved in the interaction of the carbon dioxide of the atmosphere, of organic bodies, and of the rocks. If we apply the fundamental hypothesis of geology that the processes now at work explain past results, we must assume that the carbon dioxide for carbonation and that for the carbonaceous deposits is derived indirectly from the atmosphere. It has been seen that the amount of carbon required for this work is many thousands of times the amount of carbon dioxide now free in the atmosphere, and many hundred times the amount free or potentially free in the lydrosphere. The amount of carbou dioxide in the atmosphere may have been originally vastly greater than at present, but even if this were so the demands upon carbon have been so great that it is probable that the atmosphere has been replenished in that compound. There are several possible sources of carbon dioxide for the replenishment of the atmosphere.

An important inmediate source of carbon dioxide is the ocean. The amount of carbon dioxide in the hydrosphere, computed on the basis of a content of 0.002 per cent of carbon (Clarke's estimate), is $96,531,915,000,000$ metric tons. Dittmar's estimate of the entire carbon dioxide of the ocean is 70,350,160,000,000 metric tons, or considerably less than Clarke's. Of Dittnar's total he estimates the loose carbon dioxide (i. e., the excess of carbon dioxide of bicarbonates above that required for normal carbonates and the free carbon dioxide together) of the ocean to lie between 35,200 ,$000,000,000$ and $52,800,000,000,000$ metric tons. Supposing the true amount to be the average of these, this would give $44,000,000,000,000$ metric tons or 19.3 times the amount of carbon dioxide in the atmosphere as calculater by Dittmar. ${ }^{a}$ According to Schloesing the carbon dioxide

"Dittmar, William, Report of voyage of H. M. S. Challenger, 1873-76; Narrative of the cruise, rol. 1, pt. 2, 1885, pp. 954-955. 
in the bicarbonates of the ocean beyond that required to balance the bases as normal carbonates is about ten times the amount in the atmosphere. It thus appears that the potentially free carbon dioxide of the ocean is in much greater amount than the actual free carbon dioxide in the atmosphere. According to Schloesing ${ }^{a}$ there is a very delicate adjustment between the amount of carbon dioxide in the atmosphere and the hydrosphere. Great additions to the amount in the atmosphere would result in absorption by the lydrosphere. Depletion in the amount in the atmosphere is compensated by additions from the hydrosphere. This idea of the balance between the amount of carbon dioxide in the atmosphere and that contained as bicarbonate in the ocean has been elaborated by Chamberlin and Tolman. ${ }^{b}$ They note that under the laws of physical chemistry, when the amounts of free carbon dioxide in the atmosphere and in the ocean are in equilibrium and this equilibrinm is disturbed by a decrease of the carbon dioxide of the amosphere, this compound will pass from the ocean to the atmosphere until the equilibrium is restored. Chamberlin has also emphasized the fact that when the calcium bicarbonate of the ocean is precipitated by organisms, one-half of the carbon dioxide is thereby liberated. Consequently at periods of limestone building the amount of free carbon dioxide in the ocean, and therefore the amount in the atmosphere, would be greatly increased. These considerations lead to the conclusion that at various times in the history of the world the atmosphere has been replenished in carbon dioxide at the expense of the ocean.

Petrographic work of recent years shows that graphite and diamond are original constituents of some of the igneous rocks, especially the basalts. Further, Tilden, ${ }^{\circ}$ by chemical analyses, has shown that the plutonic igneous rocks granite and gabbro, and also the volcanic igneous rock basalt, at certain localities contain considerable quantities of carbon monoxide and methane.

$a$ Letts, E. A., and Blake, R. F., The carbonic anhydride of the atmosphere: Sci. Proc. Royal Dublin Society, vol. 9, new series, pt. 2, 1900, pp. 160-161.

${ }^{b}$ Chamberlin, T. C., A group of hypotheses bearing on climatic changes: Jour. Geol., rol. 5, 1897, pp. 653-683. Chamberlin, T. C., The influence of great epochs of limestone formation upon the constitution of the atmosphere: Jour. Geol., vol. 6, 1898, vp. 609-621. Chamberlin, T. C., An attempt to frame a working hypothesis of the cause of glacial periods on an atmospheric basis: Jour. Geol., vol. 7 , 1899, pp. 545-584. Tolman, C. F., The carbon dioxide of the ocean and its relations to the carbon dioxide of the atmosphere: Jour. Geol., vol. 7, 1899, pp. 585-618.

cTilden, IV. A., On the gases inclosed in crystalline rocks and minerals: The Chemical News, vol. 75,1897 , pp. 169-170. 
The igneous rocks containing the carbon compounds may flow ont in the belt of weathering, or, if deep seated, may reach it by denudation. In either ease, under favorable conditions, oxygen may slowly oxidize the amorphous carbon, graphite and diamond, carbon monoxide, and the carbon of methane, to carbon dioxide. If the theory be correct which regards high temperature and volcanism as much more prevalent in the early stages of the earth than at the present time, the oxidation of these compounds may have gone on more rapidly than at present, but even now when lavas containing carbon compounds are poured out over the surface their high temperature in the belt of weathering affords conditions very favorable for the oxidation of the carbon.

In this connection it should be recalled that carbon dioxide is given off in great quantities by volcanoes. "Cotopaxi, according to Boussingault, evolves more carbonic anhydride annually than a whole city like Paris." " Cotopaxi is, of course, only a single volcano, and many other voleanoes are giving off large amounts. Moreover, at times of regional volcanism it is to be presumed that vastly more carbon dioxide is given off than at times of local volcanism like the present. It is probable that some, perhaps much, or even a large part of the carbon dioxide extruded by volcanoes is that resulting from the oxidation of the various carbon compounds present in the original magmas, although a part of it may be oceluded carbon dioxide and some or much of it may be derived from carbonate formations representing previous segregations.

It is to the oxidation of the carbon of the original rocks that we must look for one important primal source of carbon dioxide.

Tilden found that in a number of rocks, including gneiss, granite, gabbro, and basalt, the volume of occluded gases varied from one to eighteen times the volume of the rock, and of these gases carbon dioxide was the most abundant, varying in five cases from 23 to 78 per cent, but in one case being as low as 5.5 per cent. ${ }^{b}$ Occlusions occur even to a greater extent in the sedimentary rocks which have been metamorphosed under deep-seated conditions by the process of silication of the carbonates. When the rocks occluding carbon dioxide are disintegrated and decom-

$a$ Letts, E. A., and Blake, R. F., The carbonic anhydride of the atmosphere: Sci. Proc. Royal Dublin Society, vol. 9, new series, pt. 2, 1900, p. 159.

$b$ Tilden, W. A., On the gases inclosed in crystalline rocks and minerals: The Chemical News, vol. 75,1897 , pp. $169-170$. 
posed in the belt of weathering this carbon dioxide escapes. Since the volume of the original and sedimentary rocks which have been broken up into fine particles or decomposed so as to allow the major portion of the gases to escape is very great, the amount of carbon dioxide given off to the atmosphere from this source must be vast.

In order to obtain any idea of the net gain to the atmosphere from carbon dioxide liberated from occhusion, much more work must be done. First, an estinate must be made as to the mass of the original igneous rocks which have been broken down, and it must be ascertained how much occluded carbon dioxide there is upon an average in these rocks in order to compute the amount of carbon dioxide liberated. In the second place it must be ascertained how much occluded carbon dioxide is in the secondary rocks. Locally the sedimentary rocks are very rich in oceluded carbon dioxide in consequence of the process of silication and of the partial escape of the liberated carbon dioxide. This carbon dioxide is indirectly derived from the atmosphere. Third, a part of the enormous quantity of carbon dioxide given off by volcanoes may be that originally occluded in the centrosphere. The quantity of carbon dioxide of this origin must apparently long, if not forever, remain a matter of conjecture. The total gain of the atmosphere in carbon dioxide from occlusions is the sum of that liberated from the original igneous rocks and that derived from magma, less that held in the secondary rocks.

It has been seen that varions forms of carbon are subordinate original constituents of meteorites. (See pp. 945-946.) Hence, another source of carbon dioxide may lave been the oxidation of the carbon contained in meteorites and the exhalation from meteorities of carbon dioxide originally contained in them in that form. However, the additions of carbon dioxide derived from meteorites can lardly have been important since the beginning of Algonkian time. Consequently this means of restoring carbon dioxide to the atmosphere is of little consequence for the period which we are considering, that in which the sedimentary rocks were built up.

Another important source of carbon dioxide is the water ascending from the zone of anamorphism. The amount of this carbon dioxide is incalculable, but certainly it is very large. The gases included in hot springs and in deep waters rising from mines are dominantly composed 
of earbon dioxide. This fact has been noted again and again sinee the days of Bischof. "Lecoq has calculated that of the mineral springs those of Auvergne alone give off in the same time [one year] $7,000,000,000$ cubic meters of the gas, an amount rather less than one-tenth of the volume produced by the annual combustion of the coal employed throughout the whole of Europe." ${ }^{a}$ It is to be remembered that Auvergne is but a single region, and while the amount of carbon dioxide emitted is exceptional, it is approximated in other regions where there are hot carbonated springs. The total amount of carbon dioxide emitted in the few areas where it is exceptionally abundant is probably small as compared with the quantity carried by the vastly larger amount of water of the great mass of springs of the world.

If the argument given on pages $176-177,677-679$ be correct, the carbon dioxide furnished by deep-seated springs is largely that liberated by the process of silication of carbonates, although some part of it may be derived from the carbon dioxide originally occluded in the earth.

The segregation of carbon as carbonates in the sedimentary rocks is a consequence of the reaction of carbonation, and chiefly of carbonation of the silicates. These carbonates, as already seen, are mainly concentrated in the carbonate formations, but to a considerable extent are found as accessory minerals in the shales and in the sandstones. When the rocks of the zone of katamorphism are buried so deeply as to pass into the zone of anamorphism the silication of the carbonates occurs with the liberation of the carbon dioxide. That this process has taken place almost completely in the pelites thus buried is shown by the very small percentage of carbonates in the schists, which are the metamorphosed equivalents of ancient muds. The silication of the limestones which have passed into the zone of anamorphism is in various stages, ranging from slight to complete. It is certain that this process is going on at the present time on a very great scale. Indeed, it is not impossible that the process of silication in the zone of anamorphism is taking place with a close approximation to the speed of the process of carbonation in the belt of weathering.

In so far as the process of silication with decarbonation is taking place in the deep-seated zone, and the liberated carbon dioxide is carried by the ground water to the atmosphere or to the hydrosphere, the depletion of the 
atmosphere and the hydrosphere in carbon dioxide by carbonation is compensated.

In the early eras of the deposition of the sedimentary rocks, before carbonates existed in important quantity, it is certain that carbonation far outclassed silication; for before the latter process became important, carbonates were necessarily formed in large amounts and buried to a considerable depth. The existence of the rast amounts of carbonates in the sediments is evidence that carbonation has greatly exceeded silication.

The further carbouation advances the more abundant become the carbonate formations, many of which in due time are buried to a great depth, and thus the more important becomes silication. And finally, in the natural conrse of events, the two processes will approach each other in quantitative value. The carbono-silicic cycle will approach a balance. But that silication is now keeping pace with carbonation is not asserted. Only conjecture can be offered on that point. While silication of carbonates may not yet equal carbonation in amount, it is believed that the former process directly or indirectly returis to the atmosphere a large percentage of the carbon dioxide abstracted from it by carbonation.

Another obvious source of carbon dioxide for the atmosphere is the oxidation of the carbonaceous materials of the earth. It has been pointed out that nearly as fast as organisms are produced they are decomposed. In so far as both processes occur there is neither loss nor gain of carbon dioxide to the atmosphere. But continuously during a large part of geological time a residual portion of the organic material has not decomposed, and thus the carbonaceous deposits have been built up, abstracting carbon dioxide from the atmosphere. (See pp. 949, 966-967.) In so far as the processes of the belt of katumorphism result in the storing of carbon in the various hydrocarbons within the earth there is continuous depletion of the carbon dioxide of the atmosphere, and during much of geological time this has been a steady, cumulative process. But recently man has begun artificially to oxidize these carbonaceous materials. Until the last lalf of the nineteenth century this was unimportant, but in recent years the oxidation of carbonaceous material once buried within the earth has been carried on on an enormous scale. As calcnlated on page 464 , the combustion of $1,000,000,000$ metric tons of coal turns into the atmosphere 2,933,333,000 metric tons of carbon dioxide. Thus, at this amual rate of combustion of 
coal, in 812 years the amount of carbon dioxide added by this process would be equal to the total carbon dioxide of the atmosphere.

Possibly carbou dioxide may be steadily gathered to the earth from the interplanetary or interstellar spaces by the force of gravity. According to Hunt, this idea was first suggested by Sir William Grove in 1843. This source of carbon dioxide Hunt regards as the chief one. The possibility of se oregation of carbon clioxide from the stellar spaces has been recently brought forward again by Chamberlin. ${ }^{b}$

If we write an equation representing the amount of carbon dioxide in the sedimentary rocks we have the following:

$$
(2.64+.81 \times+4 / 12) \times .65+(3.03 \times .30)+(38.58 \times .05)=6.4585 .
$$

In the above equation 2.64 is the $\mathrm{CO}_{2}$ in shales and 0.81 is the carbon contained as carbonaceous material in shales, which must be multiplied by $44 / 12 \mathrm{in}$ order to find the equivalent amount of $\mathrm{CO}_{2}$. The above equation does not take into account coal and other especially carbonaceous deposits, which would increase the quantity. Even omitting the coal deposits, the average amount of carbon in the sedimentary rocks is 8 times greater than Clarke's estimate of the amount of carbon dioxide in the original igneous rocks, 0.81 per cent. As in the case of sulphur, it is not necessary to suppose that these two amounts should balance, for there may have been originally a large amount of carbon dioxide in the atmosphere and hydrosphere not derived from the crystallized rocks. Also, as has been pointed out, it is little short of certain that the carbon originally in magma, either as carbon, hydrocarbons, or carbon dioxide, largely escapes as carbon dioxide at the time of the crystallization of the rocks. At this time of escape the hydrocarbons and carbon are largely oxidized to $\mathrm{CO}_{2}$. However, the above equation shows it to be certain that the original crystallized igneous rocks do not constitute the sole, or even the chief, source of the carbon which has taken such an important part in the economy of the earth.

In stmmary it appears that the carbon of the lithosphere was originally widely dispersed in small quantities. The operations of metamorphism concentrate carbon in the carbonates and carbonaceous deposits, and to a

\footnotetext{
" Hunt, T. Starry, The geological relations of the atmosphere: Rept. Brit. Assn. Adv. Sci., 1878, p. 544 .

${ }^{b}$ Chąmberlin, T. C., A group of hypotheses bearing on climatic changes: Jour. Geol., vol. 5 , 1897 , pp. 653-683.
} 
less extent in the carbonaceous shales. The direct source of the carbon for this concentration is the atmosphere, which has been continuously replenished in various ways.

The certain original sources of carbon dioxide for the replenishment of the atmosphere were the magraas and meteorites. Silication, the oxidation of organic material, and the ocean return to the atmosphere carbon dioxide which lias been taken from it. But all of the above supplies of carbon dioxide are available to replenish the atmosphere. Concluding, the chief processes which abstract carbon dioxide from the atmosphere are those of carbonation and the building up of carbonaceous deposits. All of the replenishing processes, including the reversing processes of silication and the oxidation of buried carbon compounds, have been barely able to keep a minute portion of carbon dioxide in the atmosphere- 0.030 per cent by volume, or 0.045 per cent by weight. It is probable, however, that the work of man, especially during the last half century, has returned a great volume of curbon dioxide to the atmosphere by the artificial oxidation of carbonaceons material, and thus has reversed the average of the processes of nature, which plainly appear to have caused depletion of the carbon dioxide in the atmosphere. In consequence, at the present time the amount of carbon dioxide in the atmosphere may be increasing rather than decreasing.

TITANIUM.

According to Clarke's estimate of 1891 titanium comprises 0.30 per cent of the original rocks, the lithosphere, and the atmosphere together. All of the titanium is in the original rocks, of which it composes 0.33 per cent. In 1900 Clarke increased his estimate of titanium in the original rocks to 0.41 per cent, thus giving it ninth place in the scale of abundance next to potassium. In passing from sodium to titanium we go from the elements which may be called abundant to those which are subordinate. Reckoned as an oxide $\left(\mathrm{TiO}_{2}\right)$ Clarke's estimate of the amount in the original rocks for 1891 is 0.55 per cent and for 1900 is 0.60 per cent.

In the original rocks titanium occurs both as an oxide and as a titanite. As an oxide it is found in ilmenite and in the rutile gronp. As a titanite it is found in titanite and perovskite. The amount of these minerals in the rocks is not usually large, but they are very widespread. The 
original magnetite of many rocks is strongly titaniferous, and because of its abundance may be the chief home of titanimm.

Titanium forms 0.65 per cent of 78 shales; 0.33 per cent of 624 sandstones, and 0.07 per cent of 843 limestones. It thus appears that as compared with the original rocks the amonnt of titanium is somewhat increased in the shales, is rednced to a little more than one-half in the sandstones; and is less than one-eighth in the limestones. If one were to estimate the amount of titanium in the original igneous rocks by the amount in the sedimentary rocks we would have the following equation:

$.65 \times .65+.33 \times .30+.07 \times .05=.525$.

This accords very well with the actual amount as estimated by analyses in the original igneous rocks, 0.55 to 0.60 per cent. The minerals produced by metamorphism are the same as those of the original rocks. The details of the transformations with reference to the different zones and belts of metamorphism have not been worked out. Titaninm minerals have been especially observed in the metamorphosed pelites and psephites, and to this observation the analyses above given correspond.

\section{PHOSPHORUS.}

According to Clarke's estimate of 1891 phosphorus forms 0.09 per cent of the outer 10 miles of the crust of the earth, including the original rocks, hydrosphere, and atmosphere. All of it is in the lithosphere, of which it composes 0.10 per cent. In his estimate of 1900 Clarke reduces this amount to 0.09 per cent.

Phosphorus is thus twelfth in the scale of abundance, ranking next to carbon, an element of vastly greater importance. Reckoner as an oxide Clarke's estimates of 1891 and 1900 are both 0.22 per cent. ${ }^{\sigma}$ This gives phosphorus oxide eleventh place in the table of oxides. In the original rocks phosphorus is known to occur only in the mineral apatite, of which it composes 18.47 per cent. This mineral, while usually subordinate in amount, is rery widespread. In the meteorites phosphorus is found in schreibersite $\left(\mathrm{FeNiCoI}_{3} \mathrm{P}\right.$ ). (See p. 946.) The amount of $\mathrm{P}_{2} \mathrm{O}_{5}$ in 78 shales is 0.17 per cent; in 624 sandstones 0.07 per cent; in 345 limestones not used for building purposes is 0.04 per cent, while in 498 limestones used for building purposes it is 0.42 per cent. ${ }^{b}$

\footnotetext{
aClarke, cit., Bull. 78, p. 39; Bull. 168, p. $15 . \quad$ b Clarke, cit., Bull. 168, p. 14.
} 
The amount of $\mathrm{P}_{2} \mathrm{O}_{5}$ in the limestones used for building purposes rather than the average of all limestones is taken, as probably more nearly representing the average amount of phosphorns in these rocks, since it is well known that in the belt of weathering the phosphorns is leached out.

Therefore it appears that the amount of $\mathrm{P}_{2} \mathrm{O}_{5}$ in the shales is about three-fourths of that present in the original rocks; in the sandstones is about one-third; and in the limestones is nearly doubler. If one multiplies the amount of $\mathrm{P}_{2} \mathrm{O}_{5}$ in each of the sediments by their estimated quantities, and adds them together, we have the following equation:

$.17 \times .65+.07 \times .30+.42 \times .05=.1525$.

This shows a deficiency of about one-third of $\mathrm{P}_{2} \mathrm{O}_{5}$, as compared witl the original rocks. A portion of this deficiency is undonbtedly accounted for by the phosphate rock deposits, such as those of South Carolina, Florida, and Tennessee, and by the guano deposits. These represent the economic products of segregating processes which have increased the proportional amount of phosphorus many fold.

All agree that the first stage of the segregation of phosphates in the sedimentary rocks is accomplished throngl the agency of animals. For the guanos this first concentration is made by sea birds. For the more extensive phosphate deposits the first concentration of phosphorus was by invertebrate animals, such as brachiopods and crustaceans, and by rertebrates, such as sharks and sanrians. Very commonly this first concentration is in limestones. The further concentration of the phosphorus of guanos and that of phosphatic limestones and other rocks is by mderground water. The circulations producing the concentration and the forms of the resultant deposits are multifarious, but the general principle applicable to most cases appears to be that the phosphates are dissolved by descending waters in the belt of weathering and thrown down on reaching the belt of cementation. $^{a}$ Usually the latter reaction takes place in the upper part of the belt of cementation, so that the phosphates are segregated at or just below the level of ground water. The precipitation of the plosplates is especially

a Penrose, R.A. F., jr., Nature and origin of deposits of phosphate of lime: Bull. U. S. Geol. Survey No. 46, 1888, pp. 1-143. Dall, W. H., and Harris, G. D., Correlation papers-Neocene; fhosphatic deposits of Florida: Bull. U. S. Geol. Survey No. 84, 1892, pp. 134-140. Eldridge, Geo. H., A preliminary sketch of the phosphates of Florida: Trans. Am. Inst. Min. Eng., vol. 21, 1893, pp. 196-231. Hayes, C. W., The Temessee phosphates: Seventeenth Ann. Rept. U. S. Geol. Survey, 1895-96, pt. 2, 1896, pp. 513-550. 
likely to occur in limestone. Eldridge suggests that under such circumstances the precipitation is brought abont "by the simple interchange of bases between the phosphate and carbonate of lime thus brought together, or by the lowering of the solvent power of the waters through loss of carbonic acid. 'The latter would happen whenever the acid was required for the solution of additional carbonate of lime, or when, through aeration, it should escape from the water. The zone of phosphate deposition was apparently one of double concentration, resulting from the removal of the soluble carbonate thus raising the percentage of the less soluble phosphate, and from the acquirement of additional phosphates of lime froin the overlying portions of the deposit." a

The precipitated phosphate is likely to be deposited in nodules. This material is more resistant than the containing limestone. Through erosion by streams or ocean there may be a further concentration of the phosphates due to the greater resistance of the phosphate to both solution and mechanical wear as compared with limestone.

The bedded Devonian phosphates of Tennessee are in part, according to Hayes, an important exception to the above, the phosphatic material of the beds being regarded by him as largely concentrated when originally laid downı. ${ }^{b}$

Whether or not the sedimentary rocks rich in phosphates not considered in the analyses of shales, sandstones, and limestones are sufficient to account for the deficiency in these rocks in phosphorus is undetermined. In this comnection it should be remembered that the vein phosphates of Canada, Norway, and similar phosphatic rocks, in which a large amount of phosphortus is concentrated probably in consequence of original igneons or pegmatitic processes, are also excluded from the original rocks, and in so far as these deposits occur they offset the concentrations of the sedimentary phosphatic deposits.

The redistribution of phosphorus by the ordinary metamorphic processes has as yet been little studied. In the iron-ore deposits in which phosphorus is a very important economic compound such studies have been begun, but as yet no general conclusions have been reached.

a Eldridge, Geo. H., cit., p. 216.

${ }^{b}$ Hayes, C. W., and Ulrich, E. O., Description of the Columbia [Tennessee] quarlrangle: Geologic Atlas U. S., folio 95, U. S. Geol. Survey, 1903, pp. 4-6.

HON XLVII-0t- 62 
CHLORINE.

According to Clarke's estimate of 1891 chlorine, including bromine, forms 0.15 per cent of the original rocks, the hydrosphere, and the atmosphere. Of the ocean it composes 2.07 per cent. His estimate for the original rocks in 1891 and 1900 is the same, 0.01 per cent.

As to the source of chlorine the only minerals of the original igneons rocks in which it is found are apatite, sodalite, and the marialite molecule of the wernerites. Chlor-apatite and marialite are very unimportant original minerals, and therefore the chief mineral in which it is found is sodalite, of which it constitutes 7.3 per cent. ${ }^{a}$

It has already been explained (pp. 789-790) that chlorine is emitted from rolcanoes as hydrochloric acid and to a less extent as chlorine. It has been further noted that a part of this chlorine may possibly have been derived from sea water; but there is reason to suppose that much of it is that of the original magmas. So far as this is true we have an original sonrce for chlorine. And when it is considered that at periods of regional volcanism the amount of chlorine which probably issned from volcanoes was vastly greater than at the present time of local volcanism, it follows as a possibility that volcanism is the most important source of that element.

In the meteorites chlorine occurs in lawrencite $\left(\mathrm{FeCl}_{2}\right)$. Lawrencite is a volatile and readily decomposable mineral. If at the time the earth stuff segregated chlorine was contribnted as lawrencite, it is certain that the action of water in the magmas upon this compound would produce hydrochloric acid; this suggests a source of a part of the hydrochloric acid of rolcanoes.

In the secondary rocks the amount of chlorine is very small. In the mechanical sediments it is so small that it can not be estimated. It is not mentioned in the analyses of the shales, and only a trace is reported in the sandstones. In 843 limestones chlorine composes 0.01 per cent. The sea water which was originally between the pores of the mechanical sediments must lave contained considerable chlorine. The absence of chlorine from the mechanical sediments shows how thoronghly the sea water has been squeezed or leached ont in the transformations of the rocks from their original forms to shales, sandstones, etc. The presence of

a Dana, E. S., A system of mineralogy, Wiley \& Sons, New York, 6th ed., 1892, p. 429. 
an amount of cllorine in the limestones somewhat greater than the average for the original rocks is not easy to understand. The explanation may lie in the fact that limestones are the home of the phosphates and that the phosphate apatite is a chlorine-bearing mineral.

A large part of the chlorine which was present in the original igneous rocks and which has escaped into the atmosphere through volcanoes has passed into the hydrosphere. Under ordinary conditions, after the clilorine is once taken into solution apparently rery little of it is again redeposited. It continnes in the circulating water's until it reaches the sea, in which it appears to have been segregating during geological time. Of all the elements of the salts of the sea it is by far the most abundant. According to Dittmar's estimates it composes 55.292 per cent of the total salts, or more than half of all the componnds held in solution in the sea. This would amount to $25,557,000,000,000,000$ metric tons.

While a large part of the chlorine which has been subjected to metamorphic processes has been carried to the sea, at places where there are inclosed basins, as for instance the Great Basin, the Dead Sea, etc., chloride deposits have been built up. Locally these are of considerable magnitude. Moreover, during geological ages chloride deposits, mainly of sodium, have accumulated in abundance, so that considerable becls containing variable percentages of chlorine have been buried below later sediments. Such material furmishes the rock salt of the salt mines, for instance, of Poland, and the brines of many salt-prodncing districts, such as those of New York and Michigan.

As yet it is entirely impracticable to estimate the amount of chlorine which is locked up in the rocks as sodium chloride. It has been the common impression that the major portion of the sodium chloride is in the sea rather than in such deposits. It is subsequently suggested that this impression may be erroneous (see pp. 997-998), and that the great amount of segregated sodium is in the salt deposits rather than in the sea. If this be true for that element, it would also be true for chlorine.

The chlorine concentrated with sodium in the salt deposits and the sea is the great economic product resulting from the segregation of this element in large proportions from material originally rery sparsely disseminated. The great importance of sodium-chloride to man and to animal life in general is so well known that it need not be emphasized. 
NITROGEN.

Nitrogen forms 0.02 per cent of the outer 10 miles of the crust of the earth including the lithosphere, hydrosphere, and atmosphere. ${ }^{\alpha}$ All but an inestimably small quantity of this is in the atmosphere, of which it composes 76.88 per cent by weight. (See p. 944.) It stands sixteenth in the scale of abundance. Nitrogen is among the gases which are occluder in meteorites; but what portion of this nitrogen is absorbed by the meteorites while passing through the atmosphere and what portion has been brought in from the interplanetary spaces is meertain. The amount of nitrogen in the average sedimentary rocks, such as shales, sandstones, and limestones, is so small as to be inestimable.

It has been explained that in consequence of the action of bacteria and leguminous plants nitrogen is fixed in the belt of weathering, and nitrates are formed. These nitrates in arid regions are locally segregated in the belt of weathering in considerable amounts, forming the nitrate deposits. The bases with which the nitrogen is combined are almost exclusively sodium and potassium. Since the nitrates are now forming in large quantities (see pp. 452-453,465-466) the total amount of the compounds which have been produced through geological time must have been large. But the nitrates readily break up into their original elements, and the liberated nitrogen and oxygen rejoin the atmosphere. Thus there is a continuous cycle by which nitrogen, oxygen, and carbon are united by means of the leguminous plants and bacteria; and by decomposition reduced to the original elements and carbon dioxide.

While the total quantity of nitrates is inconsiderable, as compared with the majority of the other important elements concerned in metamorphism, nitrogen is essential for the growth of plants and animals. Hence nitrogen is one of the necessary elements in the sequence of events by which carbon is abstracted from the atmosphere, passes into the plants, and thence by oxidation is concentrated so as to cary on the process of carbonation. Therefore a chief importance of nitrogen in metamorphism is as one of the aids in the chain of reactions in connection with carbon.

The nitrates in the soil and the nitrate deposits represent the economic products resulting from the abstraction of nitrogen from the air and its segregation in solids. 
HYDROGEN.

According to Clarke hydrogen composes 0.94 per cent of the outer 10 miles of the crust of the earth, including the litlosphere, hydrosphere, and atmosphere. The larger part of the hydrogen is in the hydrosphere, of which it composes 10.67 per cent. According to Clarke's estimates of 1891 and 1900 it constitutes, respectively, 0.21 and 0.17 per cent of the litlosphere. ${ }^{a}$ The hydrogen of the atmosphere is inappreciable. It thus appears that 0.8 or more of the hydrogen is concentrated in the hydrosphere, although the volume of the lithosphere is five times as great. Hydrogen has the tently place in the scale of abundance. Practically all of the hydrogen is combined. In so far as hydrogen enters into the processes of metamorphism it is in conjunction with oxygen as water. The source of the water is very largely conjectural. It may be supposed that hydrogen and oxygen, united as water, at the time the earth segregated, were with the other ingredients in great volume. As magma crystallized the water separated. This process has continued to the present time. By it some explain the ocean, and hold to its continuous growth in magnitude. It is possible that a considerable amount of the hydrogen for the water was originally in the free state or in the form of carbureted liyrogen. This is suggested by the fact that hydrogen and carbureted hydrogen are both occluded in meteorites. If the water of the hydrosphere was produced in any large measure by the oxidation of hydrogen an enormons quantity of hydrogen was thus consumed.

Probably the most characteristic reaction of the zoue of katamorphism is that of hydration. 'This process, while taking' place most rapidly in the belt of weathering, occurs continuously throughout the vast volume of the belt of cementation. According to Clarke ${ }^{b}$ the combined water in the igneous and crystalline rocks liberated at $110^{\circ} \mathrm{C}$. is 0.40 per cent, and above $110^{\circ}$ C. 1.52 per cent; total, 1.92 per cent. In 78 shales the water liberated at $110^{\circ} \mathrm{C}$. is 1.34 , and above $110^{\circ}$ is 3.68 per cent; total, 5.02 per cent. In 624 sandstones at $110^{\circ}$ it is 0.29 per cent, and above $110^{\circ}$ is 1.40 per cent; total, 1.69 per cent. In 843 limestones at $110^{\circ}$ it is 0.26 per cent, and above $110^{\circ}$ is 0.72 per cent; total, 0.98 per cent. (See p. 938.) It therefore appears that the amount of water in the shales is more than double and in

a Clarke, cit., Bull. 78, p. 39; Bull. 168, p. $15 . \quad$ bClarke, cit., Bull. 168, p. 14. 
the sandstones and limestones is less than the average for the original rocks. The increase in the amount of combined water in hydrating the materials of the shales, 0.65 of the secliments, $438,750,000,000,000,000$ metric tons, from 1.92 to 5.02 per cent, is $13,601,250,000,000,000$ metric tons. The decrease in the combined water in the sandstones, 0.30 of the sediments, $202,500,000,000,000,000$ cubic kilometers, from 1.92 to 1.69 per cent, is $465,750,000,000,000$ metric tons. The decrease of the water in the limestones, 0.05 of the sediments, 33,750,000,000,000,000 metric tons, from 1.92 to 0.98 per cent, is $317,250,000,000,000$ metric tons. The total decrease in the sandstones and limestones is 783,000,000,000,000 metric tons, which sum, subtracted from the increase in the amount of water in the shales, leaves a net increase in the water of hydration of the zone of katamorphism of $12,818,250,000,000,000$ metric tons, and an equivalent loss of water to the hydrosphere.

This estimated amount is probably too small, for the following reasons:

Throughout the immense thickness of the zone of katamorphism, hydration is the rule. A very large portion of this zone is composed of igneous rocks, and the minerals of these rocks have been hydrated to a varying extent. In the plutonic rocks which have not been fractured in a complex way the process has nsually not. gone far, but in the rolcanic rocks, and especially the porous ones, such as basalts, hyclration has taken place upon a vast scale. For instance, in rarious parts of the world, such as in the Lake Superior region and in the Deceau, hydration las gone so far in the basic amygdaloidal lavas as in many eases to have completely destroyed the original minerals. One of the results of such alterations is the filling of the pores of the vesicular rocks with various minerals of which hydrous silicates, such as the chlorites, zeolites, etc., are especially abundant. 'The process of hydration of the zone of katamorphism has continued during' geological time. So far as I can see there is no way to estimate the amount of water thus absorbed, but I suspect that the amount abstracted from the hydrosphere by the process is probably greater than that used in the hydration of the sedimentary rocks.

In consequence of the hydration of the original rocks of the zone of katamorphism, it is certain that the amonnt of combined water in the igneous and erystalline rocks analyzed in order to determine the composition of the lithosphere is greater than in the recent igneous rocks. The 
analyses of the freshest moder'u rocks usnally show less than 1 per cent of combined water. It follows that, in regarding the original rocks as containing 1.92 per cent of water, the ealeulated amount of water for the hydration of the sediments is too small.

In the zone of anamorphism the dehydration of the rocks which have been hydrated in the zone of katamorphism and passed into the zone of anamorphism, is not complete. Even the coarsest schists and gneisses ordinarily contain from 1.5 to 2 per cent of water. In so far as the process of dehydration of the rocks, which have passed into the zone of anamorphism is inconplete, water has been abstracted from the hydrosphere.

But even if the total of all the above could be estimated this would give no idea of the amount of water which has been added temporarily to the rocks by hydration during geological time. From the earliest time to the present hydrated sedimentary rocks formed in the zone of katanorphism have passed continuously into the zone of anamorphism, and have been steadily delrydrated. No data are available to estimate the amount of water which has been added by hydration and liberated by dehydration.

The question naturally arises as to what extent at the present time the process of dehydration is reversing that of hydration. It seems certain that hydration is taking place nore rapidly than dehydration. While an estimate of the amount by which liydration exceeds dehydration would be very desirable, I see no way in which a quantitative result on this point can be even approximated.

While the amount of water abstracted from the hydrosphere by hydration is large, it does not follow that the ocean is decreasing in magnitude; for the water continnously added to the hydrosphere by the liberation of oceluded water through voleanism and the crystallization of magma may more than compensate for the losses due to hydration.

\section{ALUMINUM.}

Aluminum is the most abundant of the metals of the lithosphere. Clarke's original estimate in 1891 was that aluminum constituted 7.26 per' cent of the lithosphere, hydrosphere, and atmosphere, all of this being in the rocks, of which it composed 7.81 per cent. Clarke's estimate of 1900 increases the amount in the original rocks to 8.16 per cent. ${ }^{a}$ It therefore 
appears that aluminum, the most abundaut of metals, is only about onethird as abundant as silicon, and only about one-sixth as abundant as oxygen. The metal takes third place among the elements. Reckoned as an oxide, in 1891 Clarke estimated the aluminum as 15.04 , and in 1900 as 15.41 per cent. As an oxide it stands second only to silicon.

Aluminum has its chief source in the silicates, which occur very abundantly in the original rocks. The aluminons silicates occur also in the meteorites. By far the most important of the silicates bearing aluminum are the feldspars, which, as Clarke calculates, compose about 60 per cent of the mass of the original rocks. A large part of the remainder of the aluminum is in the pyroxenes and amphiboles, which, as Clarke estimates, compose 18 per cent of the original rocks. A smaller amount of the aluminum is in the micas, which, as Clarke calculates, compose 4 per cent of the original rocks. ${ }^{a}$ Very subordinate amounts of alumina occur in other silicates, the more important of which are nephelite, lencite, and sodalite. Alumina occur's also in sufficient amount in corundum, gibbsite, and other oxides to deserve mention.

In 78 shales the alumina amounts to 15.47 per cent, ${ }^{b}$ in 624 sandstones to $5.37 \mathrm{per}$ cent, and in 843 limestones to 1.28 per cent. From the analyses given by Clarke it appears that as a result of the denuding and metamorphic processes alumina accumulates slightly in the slales, as compared with the amount present in the original rocks, and in the sandstones diminishes to about one-third, and in the limestones to a small fraction. According to Clarke's figures, the increase in the amount of alumina in the shales over that in the original rocks is trivial. This increase in the shales is sufficient to account for' only a small part of the deficiency in the sandstones and limestones. The equation

$15.47 \times .65+5.37 \times .30+1.28 \times .05=11.7305$

gires us the average of the alumina for the sediments. Therefore the analyses give a deficiency of 3.68 per cent of alumina, or nearly onefourth, as compared with the original rocks. When it is remembered that aluninum is by far the most abundant of the metals, it will be appreciated that this deficiency is enormous. 
T'o some extent this deficiency is accounted for by the. bauxite and gibbsite deposits, which serve as ores of aluminum. Rather extensive deposits of this lind are known in France and in the United States, in Georgia, Alabama, and Arkansas. The French deposits are ascribed "by Coquand and Augé to mineral springs or geysers, which brought the material of which they are composed to the surface and supplied it to lakes, where it was depositer aloug with other sediments." ${ }^{a}$

Hayes has discussed the Georgia-Alabama and the Arkansas deposits. The source of the Georgia-Alabama bauxite he regards as shales which underlie limestones. These shales contain pyrite.

It is believed that surface waters carrying oxygen in solution gained access to these shales and by oxidizing the pyrites set free sulphuric acid. This, under the conditions present, decomposed the aluminous shales, forning alum and sulphate of aluminum. Ascending currents carried these salts in solution to the surface, and. coming in contact with the limestone during their upward passage, they were deconposed, forming sulphate of lime and aluminum hydroxide, together with basic sulphate of aluminum, which was subsequently changed to aluminum hydroxide on exposure to the air. The aluminum hydroxide thus produced formed a gelatinous precipitate which collected about vents of springs. It was kept in motion by the ascending water and thus formed concentric stiuctures. ${ }^{b}$

The Arkansas deposits are regarded as produced by an underground circulation in a manner somewhat similar to those of Georgia and Alabama; but the source from which the alumina is derived is syenite, and the springs, instead of issuing on the land, issue under water, and thus the deposits are somewhat more widely distributed. Many of the springs issue directly abore the syenite, and therefore the bauxite deposits overlie the undulating syenite surface. Other springs issue through the adjacent Tertiary sediments, which in such eases are overlain by the bauxite deposits."

Bauxite deposits of character somewhat similar to those of France and the United States are known in other parts of the world, but probably the total amount of alumina segregated in all the known batxite deposits is but an insignificant fraction of the deficiency above calculated for the ordinary sediments.

${ }^{a}$ Hayes, C. W., Bauxite: Sixteenth Ann. Rept. U. S. Geol. Survey, pt. 3, 1895, p. 548.

$b$ Hayes, C. W., The Arkansas bauxite deposits: Twenty-first Ann. Rept. U. S. Geol. Survey, pt. 3,1900, p. 461 .

c Hayes, cit., pp. $46 \pm-466$. 
It therefore appears to me that we must look somewhere else to explain the greater part of the discrepancy. It is certain that when the shales (the sedimentary rocks into which the aluminous minerals mainly pass) are metamorphosed in the zone of anamorphism, the secondary minerals show an excess of alumina. All of the chief original aluminous minerals, viz, feldspar, pyroxene, amphibole, and mica, may be reproduced; but there also develop other aluminous minerals which are not known in the original rocks. Of these, garnets, staurolite, and the aluminum-silicate minerals-andalusite, sillimanite, and cyanite-are by far of the greatest consequence. The latter minerals are especially characteristic of rocks of the approximate composition of the pelites metamorphosed in the zone of anamorphism. They clearly mark an excess of ahminum and furnish almost conclusive evidence of the segregation to a considerable extent of the aluminum in the pelites beyond the amount which is present in the original rocks.

This argument has such weight that I believe more careful analyses of shales with reference to their mass and chemical composition will show that the alumina ought to be considerably higher than in the analyses given. It has already been noted (p. 962) that correlative witl the deficiency of alumina there is apparent excess of silica in the shales, and the deficiencies and excesses are remarkably accordant. It lias just been seen that the apparent deficiency in alumina is 3.68 per cent. A stnall fraction of a per cent can be accounted for by the bauxite deposits. The excess of silica as shown by the calculations (p. 961) is 3.247 per cent. Consequently the two nearly balance. I venture to predict that when more satisfactory average analyses are available the shales will be found to contain several per cent more alumina and several per cent less silica than is given in the average analyses of shales on page 938 .

IRON.

According to Clarke's estimate of 1891 iron composes 5.08 per cent of the outer 10 miles (16.1 kilometers) of the crust of the earth, including the lithosphere, hydrosphere, and atmosphere, and 5.46 per cent of the original rocks alone. In his estimate of 1900 Clarke estimates that the iron forms only 4.64 per cent of the original rocks. ${ }^{a}$ This gives iron fourth place among the elements, it being surpassed only by oxygen, silicon, and aluminum. Reckoned as an oxide, according to Clarke's estimate of 1891, 
the amount of ferric oxide is 3.94 per cent and of ferrous oxide is 3.48 per cent, and in his estimate of 1900 the ferric oxide is 2.63 per cent and the ferrous oxide 3.52 per cent. Reckoned as an oxide, iron thus has the third place in abundance, being surpassed only by silica and alumina.

Iron occurs as an original constituent of the igneous rocks in perhaps more numerous forms than any other element. It is found as a sulphide as pyrite, pyrrhotite, etc.; and as an oxide as hematite, magnetite, and ilmenite. It occurs in many silicates. Of these, the pyroxenes and amphiboles, the olivines, and the micas are the more important. In the meteorites jron is the most abundant constituent, occurring alloyed with nickel and cobalt, and in sulphides, oxides, silicates, etc.

In 78 shales the ferric oxide is 4.03 per cent of the rock, the ferrous oxide 2.46 per cent; in 624 sandstones the ferric oxide is 1.24 per cent, and the ferrous oxide 0.57 per cent; in 843 limestones the ferric oxide is 0.66 per cent, the ferrous oxide being undetermined. ${ }^{a}$

The 4.03 per cent of ferric oxide and the $2.46 \mathrm{per}$ cent of ferrous oxide in the shales is equivalent to $4.73 \mathrm{per}$ cent metallic iron. The $1.24 \mathrm{per}$ cent of ferric oxide and the 0.57 per cent of ferrous oxide in the sandstones is equivalent to 1.31 per cent metallic iron. The 0.66 per cent of ferric oxide in the limestones is equivalent to 0.462 per cent metallic iron. It thus appear's that there is a slight increase, less than 0.1 per cent, in the amount of iron in the shales as compared with the original rocks. There is great depletion of iron in the sandstones-which contain between one-third and one-fourth of the amount in the original rocks. The depletion of the iron in the limestones is very great-there being about one-tenth the amount in the original rocks. The slight increase in the shales is by no means sufficient to account for the depletion of the sandstones and limestones. If we multiply the percentage of iron present in the different kinds of sediments by the estimated quantity of those sediments, and add the three together, we have the following equation:

$4.73 \times .65+1.31 \times .30+.462 \times .05=3.491$ per cent.

Since the amount of iron present in the original rocks is 4.64 per cent, this shows a deficiency of 1.149 per cent for the entire mass of sediments. This difference seems small, but it amounts to $7,155,750,000,000,000$ 
metric tons of metallic iron. The question naturally arises, What has become of this enormons amount of iron? The processes of metamorphism have segregated from 30 to 70 per cent of iron in the various iron-bearing formations and in the iron-ore deposits. (See pp. 842-846, 1193-1198.)

While the iron-ore deposits themselves contain much the larger percentage of iron, the main mass of the segregated iron is in the iron-bearing. formations rather than in the iron ores. Indeed, the amonnt in the iron ores is probably insignificant as compared with the amount in the ironbearing formation. For instance, in the Mesabi district of Minnesota, where the iron-ore deposits are larger than in any other region, Doctor Leith has calculated that in the part of the iron-bearing formation which is exposed at the surface, including no part which passes below the overlying slate, the amount of disseminated iron is probably one hundred times as great as that contained in. the ore deposits. And the amount of this formation below the slates, in which there are no known ore deposits, is certainly many times, probably hundreds of times, that exposed. This calculation in reference to the Mesabi range shows how trivial is the amount of iron in the ore deposits as compared with the more widely distributed lower-grade products of the iron-bearing formations Such formations are illustrated by the great pre-Cambrian iron-bearing formations of varions parts of the world, such as those occurring in the Lake Superior region; by the very extensive iron-bearing member and the ores of the Clinton horizon of the Silurian; by the great iron-bearing horizons of the Carboniferous, and by the bog deposits of the Pleistocene. It is believed that if the iron-bearing formations and the iron ores associated with them were represented in the above equation in proportion to their mass and percentage of iron, the excess of iron in them beyond that of the original rocks would be nearly or quite sufficient to account for the great deficit of iron shown by the ordinary sediments. The segregation of the iron in the iron-bearing formations and the ores is treated on pages 102-130, 823-846, 1193-1198.

In the zone of katamorphism many minerals are produced by the alteration of the original iron-bearing minerals. Of these the lrydrated oxides of iron, especially limonite, and the silicates, such as the chlorites and the epidotes, are important. Where the rocks pass into the deep-seated zone any of the minerals in which the iron originally occurred may be reproduced. 
Other iron-bearing minerals also are formed. Among them garnet and staurolite are important; but various other heavy iron-bearing silicates develop, among which may be mentioned ilmenite, humite, clinolumite, ottrelite, and chloritoid.

\section{MANGANESE.}

According to Clarke's estimate of 1891 manganese forms 0.07 per cent of the outer 10 miles of the crust of the earth, including the lithosphere, hydrosphere, and atmosphere. In the lithosphere alone the amount estimated is 0.08 per cent. In lis estimate of 1900 he reduces this amount to 0.07 per cent." By this estimate manganese is thirteenth in the scale of abundance. If these amounts of 0.08 and 0.07 per cent were reckoned as $\mathrm{MnO}_{2}$ they would be respectively 0.1265 and 0.1107 per cent.

Very small percentages of manganese are reported in the following silicates: låvenite, arfvedsonite, spessartite, piedmontite, and astrophyllite. The amount in no case is large enongh to make the element an essential one. Manganese is reported among the subordinate constituents of the meteorites. A trace of it is reported in the shales and sandstones, and in 843 limestones manganese oxide composes 0.04 per cent of the rock. Since the mass of the limestones is so small as compared with the shales and sandstones, manganese in the limestones is trivial compared with that which is present in the original rocks. The probable explanation of the deficiency of manganese in the common secondary rocks is that the manganese is segregated in manganese ore deposits precisely as the iron, the reactions for segregation being analogous throughout. (See pp. 1198-1199.) Thus the manganese reported in the sedimentary rocks is found in limestones-that is, in carbonate rocks. Iron is, in a similar manner, to a large extent segregated in comnection with carbonate deposits.

The relative masses of the segregated manganese ore and iron ore are interesting, since these two compounds go through analogous transformations, producing ore bodies under similar conditions, and in very numerous cases being associated in the same ore deposits. But subject to the law of mass action the abundant element iron produces ore deposits of enormously greater size than does the rarer element manganese. The amounts of iron and manganese in the original rocks are 4.64 and 0.07 per cent respectively. Thus if the two elements were segregated in the 
same proportion by the processes of metamorphism the iron-ore deposits should be 66.3 times as great in magnitude as the manganese deposits, and this ratio is certainly approximated by the facts. There can be no better illustration of the importance of the chemical law of mass action in geological processes.

\section{CALCIUM.}

According to Clarke's estimate of 1891 calcium composes 3.51 per cent of the outer 10 miles of the crust of the earth, including the original rocks, hydrosphere, and atmosphere; of the original rocks alone 3.77 per cent, and of the ocean alone 0.05 per cent. According to his estimate of 1900 the amount of calcium in the original rocks is 3.50 per cent. ${ }^{a}$ Calcium is fifth in abundance among the elements. Reckoned as an oxide Clarke's estimate of the amount in the original rocks was 5.29 per cent in 1891, and 4.90 per cent in 1900. This gives lime fourth place in the table of oxides.

Calcium is an abundant constituent of many of the minerals of the original rocks. It occurs in all of the feldspars except the acid end of the series. It is an essential constituent of nearly all of the pyroxenes and amphiboles, being, however, more abundant in the former than in the latter. For instance in diopside the ratio between the calcium and magnesium is $1: 1$, whereas in tremolite the ratio is $1: 3$. It is an essential constituent of the scapolites, meionite and wernerite, which, however, do not form an especially important group of minerals in the igneous rocks. While calcium occurs in fewer minerals than magnesinm and is less abuudant than magnesium in the pyroxenes and amphiboles the fact that calcium is, an essential constituent of so many feldspars which, according to Clarke's estimate, compose 60 per cent of the minerals of the original rocks, makes calcium a more abundant element than magnesium. In the meteorites calcium occurs abundantly in the feldspars and pyroxenes, and as calcium sulphide in the mineral oldhamite.

In 78 shales the calcium oxide amounts to 3.12 per cent of the rock; ${ }^{b}$ in 624 sandstones to 3.29 per cent, and in 843 limestones to 41.60 per cent. (See p. 938.) These numbers show that the amount of calcium oxide, as compared with the original rocks, is reduced by more than one-third in the shales and about one-third in the sandstones, and is increased more than 
eightfold in the limestones. It therefore appears that the very considerable deficiency of calcium in the abundant shales and sandstones is to be accounted for by the great concentration of calcium in the limestones. On the hypothesis that the sum of the deficiencies should equal the excess in the limestones, we have another case by which we may test the correctness of the estimates of the relative quantities of the sediments. For if the above supposition be true, the percentage of $\mathrm{CaO}$ in each of the kinds of sediments, multiplied by the mass of the sediments, should, added together, equal the percentage in the original rocks. Putting this in the form of an equation we have:

$$
3.12 \times .65+3.29 \times .30+41.60 \times .05=5.095 .
$$

The sum, 5.095 per cent, is about halfway between Clarke's estinate of 1891 of the amount of $\mathrm{CaO}$ in the original rocks and his estimate of 1900 , being slightly less than the former and slightly greater than the latter: Therefore, so far as the criterion of analyses is applicable, the determinations of calcium seem to furnish a confirmation of the estimates of the relative masses of the shales, sandstones, and limestones.

In the above computation the amount of $\mathrm{CaO}$ in solution in the ocean is not considered. According to Dittnar's estimates this amount is $553,000,000,000,000$ metric tons of calcium, which would correspond to $774,200,000,000,000$ metric tons of $\mathrm{CaO}$. The total amount in the sediments on the basis of the above malyses and estimates of relative volumes would be $34,391,250,000,000,000$ metric tons. Therefore the amount in the ocean is 2.25 per cent of the estimated amount in the sediments. While the $\mathrm{CaO}$ in the ocean is to be regarded as derived from the destruction of the original rocks, this amount is so small as to be negligible in comparing the amount of $\mathrm{CaO}$ in the original and the secondary rocks.

The segregation of the calcium, with the greater segregation of carbon, in the limestones, is one of the most interesting and important results of chemical, physical, and organic processes. (See pp. 964-966). It has been pointed out that the process of carbonation in the zone of katamorphism is made effective by the concentration of carbon dioxide by plants in the belt of weathering. The carbonates produced are largely transported to the sea. In the sea the carbonates are thrown down by animals, and thus the lime- 
stones are formed. While much of the $\mathrm{CaCO}_{3}$ produced by carbonation is transported to the sea, a considerable part of it is transported to the belt of cementation, and enough of this is precipitated to make $\mathrm{CaCO}_{3}$ a cementing agent second in importance to silica. (See pp. 624-625.) A very subordinate part of the $\mathrm{CaCO}_{3}$ in the belt of cementation enters into combination with silica, forming the zeolites and epidotes.

From the foregoing it appears that the calcium in the secondary minerals of the zone of katamorphism is largely in the form of carbonate, often not a simple carbonate, but a calcium-magnesium carbonate. In this zone also are found other secondary calcium-bearing ninerals, such as the zeolites and epidotes.

When the rocks containing these secondary calcium-bearing minerals pass into the zone of anamorphism, the minerals are decomposed, the carbonates by silication and the zeolites and epidotes by dehydration. In the nearly pure calcium-magnesinm carbonate rocks the silicates which form most plentifully are wollastonite, diopside, tremolite, and actinolite, Naturally, where the limestones are nearly pure calcium carbonate, by silication the pure calcimm silicate, wollastonite, forms. If magnesium is not very abundant, there is likely to be developed the pyroxene, diopside, in which the calcium-magnesium ratio is $1: 1$. Where the carbonate rocks are strongly magnesian, tremolite forms; and where they also bear iron, actinolite develops. In the rocks in which there is a considerable number of bases, such as the impure linestones, the shales, and the sandstones, other silicates form. Any of the calcium-bearing silicates occurring in the original rocks may be reprodnced, and part of the calcium usually passes into heavy minerals not commonly found in the original rocks, such as garnets, melilite, the scapolites, etc.

MAGNESIUM.

According to Clarke's estimace of 1891, magnesium forms 2.50 per cent of the outer 10 miles (16.1 kilometers) of the crust of the earth, including the original rocks, the ocean, and the atmosphere. Of the ocean it comprises 0.14 per cent, and of the original rocks 2.68 per cent. In his estimate of 1900 , Clarke reduces the amount for the original rocks to 2.62 per cent. ${ }^{a}$ Magnesium thus stands seventh in the scale of abundance. It is about five-sevenths as abundant as calcium, the element with which it is 
most intimately associated and most elosely allied. Reckoned as an oxide, Clarke's estimate of 1891 is 4.49 per cent, and of 1900 is 4.36 per cent. This gives magnesia fifth place among the oxides. Magnesium occurs as a constitnent of the original igneous rocks in a number of ninerals. Of these, the pyroxenes, amphiboles, micas, and olivines are the more important. It is only rarely present in any considerable proportion in the feldspars, the most abundant group of minerals. Thus, while occurring in more minerals than calcium, it is not so abundant as calcium, because of the great rôle of the feldspars." In the secondary rocks magnesia composes 2.45 per cent of 78 shales, 0.85 per cent of 624 sandstones, and 6.20 per cent of 843 limestones. It thus appear's that as compared with the original rocks the amount of magnesia in the shales is reduced to about three-fifths, in the sandstones to about one-fiftl, and in the limestones is increased by more than one-third. The sum of the products of the percentage of each class of sediments by their proportional amounts gives the average percentage of magnesia in the sediments, thus:

$2.45 \times .65+.85 \times .30+6.20 \times .05=2.1575$.

Subtracting this 2.1575 from 4.36 , the amount in the original rocks, we have a deficiency of 2.2025 per cent. The total amount of sediments multiplied by this latter percentage gives $14,866,875,000,000,000$ metric tons.

The question now arises as to the explanation of this apparent rast deficiency of magnesia in the sedimentary rocks. The question is not easily answered. Possibly some part of the calculated deficiency is only apparent. Probably the composite analyses of 345 limestones, taken at random, in which the magnesia is 7.90 (see p. 938) is nearer the average for the limestones than this amount averaged with the quantity of magnesia, 4.49 in the building stones (see p. .938), since it is well known that the magnesian limestones are likely to be porous and brecciated, and therefore not so suitable for building purposes. If the average amount of magnesia in the limestone were taken as 7.90 instead of 6.20 , as given in the above equation, we have:

$7.90 \times .05-6.20 \times .05=.085$.

But 0.085 per cent is only abont one twenty-sixtl of the calculated deficiency, and therefore we must look somewhere else for the explanation 
of the major part of it. The natural direction to which we first turn to account for the deficiency is the ocean. According to Dittmar's estimates the amount of magnesium in the ocean is $1,743,000,000,000,000$ metric tons, which corresponds to $2,887,800,000,000,000$ metric tons of magnesia. It is at once seen that the total amount in the ocean is vast, the magnesia being between three and four times as abundant as lime. But this enormous amount accounts for only 19.45 per cent of the deficiency.

Another large portion of the deficiency is probably accounted for by magnesium in classes of the sedimentary rocks not considered-that is, the saline deposits. In all salt deposits magnesium salts are important impurities. In the water of Great Salt Lake the magnesium varies from 0.3 to 2.6 per cent of the total solids in solution; ${ }^{a}$ in the water of the Dead Sea it is given as 14.41 per cent of the total solids. ${ }^{b}$ In the salt deposits of New York and Michigan the magnesium in the brines varies from .034 to .454 per cent. $^{e}$ In the rock salts of Louisiana the magnesium varies from 0.003 to 0.06 per cent. ${ }^{d}$ These figures may be taken as representative of ordinary salt deposits, but in certain exceptional salt deposits, as those of Stassfurt, the magnesium salts are much more abundant. In such deposits a great portion of the magnesium salts with the accompanying potassium salts is likely to be found in a more or less distinct bed above the rock salts. As illustrating the abundance of these compounds Precht states that at Stassfurt, from 1876 to 1880 , there were mined 699,136 metric tons of carnallite $\left(\mathrm{KMgCl}_{3} \cdot 6 \mathrm{H}_{2} \mathrm{O}\right)$, kieserite $\left(\mathrm{MgSO}_{4}+\mathrm{H}_{2} \mathrm{O}\right)$, and kainite $\left(\mathrm{MgSO}_{4} \cdot \mathrm{KCl}+\right.$ $3 \mathrm{H}_{2} \mathrm{O}$ ) and only 96,856 tons of rock salt. A considerable amount of magnesium occurs also, in accompanying polylualite. ${ }^{e}$ It is plain that the total quantity of the magnesium in saline deposits is great, but what portion of the deficiency is thus accounted for can not be stated until very careful studies have been made of the volumes and compositions of the salt deposits of the world.

It is believed that the explanation of a larger part of the deficiency is to be found in the concentration of magnesia in the zone of katamorphism in consequence of the alterations of that belt, the magnesia as is explained

"Gilbert, G. K., Lake Bonneville: Mon. U. S. Geol. Survey, vol. 1, 1890, p. 253.

${ }^{b}$ Encyclopedia Britannica, 9th ed., 1877.

e Tenth Census, vol. 2, p. 1017.

aineral Resources, 1883-84, p. 841.

ePrecht, H., Die Salz-Industrie von Stassfurt und Ungegend, 1889, p. 12. 
below, being much more largely retained in the belt of weathering and in the belt of cementation than is calcimm. But as yet no data are available to enable us to make any statement as to the quantitative importance of this concentration.

To what extent the magnesium in the ocean, in the saline deposits, and segregated in the zone of katamorplism will explain the deficiency in the ordinary sedimentary rocks can not be stated. This can be determined only after a careful quantitative estiunate has been made of these various supplies of magnesium. The redistribution of magnesium by metamorphism, while in many respects analogons to that of calcium, is in many respects also different. It has been seen that by the process of carbonation of the silicates by far the larger part of the calcium is released from silica and changed to carbonates. The major part of the calcium carbonate and other carbonates, such as sodium carbonate, find their way to the sea in solntion. While the process of carbonation also changes a considerable portion of the magnesium of the silicates to magnesium carbonate, a very large part remains in the silicates: The olivines change to serpentine. The nonaluminous pyroxenes and amphiboles alter to talc on an extensive scale. The aluninous pyroxenes and amphiboles pass into chlorite, a magnesium aluminous silicate. The pyroxenes extensively change to amphibole, and this involves a partial substitution of magnesium for calcium, or else a subtraction of calcium and partial carbonation, or both. Thus, the magnesium is concentrater in the zone of katamorphism, and especially in the belt of weathering. But this concentration is largely dne to the abstraction of other elements rather than the addition of magnesia.

The magnesium of the original silicates, which is changed to carbonate in the zone of katamorphism, goes throngh the same processes of distribution as the calcium carbonate. A part of it passes down into the belt of cementation, and is there precipitated in dolomite, ankerite, parankerite, and hydrous magnesium silicates. Bnt a large part of the magnesinm salts, before or after an underground journey, join the surface streams and find their.way to the ocean. Maguesimm is there precipitated on a great scale as carbonate, not by the reaction of organisms, but by the reaction of magnesium salts in solution upon the calcium carbonate previously precipitated by organisms. This process inaugurated in the sea is continued in the carbonate formations on the land. 'This involves a substitution of mag'- 
nesium for calcium, or else abstraction of much calcium, or both. It is plain that the magnesium which occur's in the sedimentary rocks as magnesium carbonate is largely introduced by the substitution of magnesium for previously precipitated calcium.

When the sedimentary rocks and the altered original rocks of the zone of katamorphism containing the secondary magnesinm ninerals pass into the zone of anamorphism the original magnesium minerals, viz, the pyroxenes, amphiboles, micas, and olivines, may be produced; but a part of the magnesium goes into other minerals. Of these the garners appear to be the most important, and some of the subordinate minerals are chondrodite, humite, clinohumite, tourmaline, and melilite.

It is a well-known fact that in mechanical sedimentary rocks metamorphosed in the zone of anamorphism the ampliboles are developed upon a mucl greater scale than the pyroxenes, and that the magnesinm-bearing mica, biotite, forms very abundantly. This is a natural consequence of the depletion of the merhanical sediments in ealcium as compared with the original rocks. The ampliboles are much more heavily magnesian tham the pyroxenes. For instance, in trenolite the magnesinm-calcium ratio is $3: 1$, whereas in diopside it is $1: 1$. Consequently from the mechanical products in which the magnesium is somewhat concentrated and the calcium depleted there is a tendency to produce the magnesian minerals, ampliibole, and biotite. But in the derelopment of amphiboles and pyroxenes the pressure and the specific gravities of these minerals are also concerned. (See pp. 278-280.)

SODIUM.

Sodium, according to Clarke's estimate of 1891, composes 2.28 per cent of the outer 10 miles (16.1 kilometers) of the crust of the earth, inchuding the original rocks, the hydrosphere, and the atmosphere. According to this estinate it composes 1.14 per cent of the liydrosplrere and 2.36 per cent of the lithosphere. In lis estimate of 1900 the amount of sodinm in the original rocks is increased to 2.63 per cent. Sodinm thus has sixth place anong the elements. Reckoned as an oxide Clarke's estimate for 1891 is 3.20 per cent and for 1900 it is 3.55 per cent, and of oxides it stands sixth. ${ }^{a}$ 
Sodium is a constitnent of many of the minerals of the original igneous rocks. These minerals comprise the feldspars, the nephelites, eancrinite, sodalite, haiiynite, noselite, and mirialite. In the meteorites sodium is reported only in the feldspars. Becanse of the dominating importance of the feldspars ${ }^{a}$ the larger part of the sodium occurs in then, although the sodalite and nephelite groups of minerals are important sources of the element. Sodium is so abundant in the acid plagioclases as to give them the name of sodit feldspars.

In 78 shales soda conposes 1.31 per cent; in 624 sandstones, 0.61 per cent, and in 843 limestones, 0.34 per cent. It thus appears that in the shales the amount of soda is reduced to only about one-third of that in the original rocks, in the sandstones to about one-sixtl, in 345 limestones not used for building purposes ${ }^{b}$ to a minute fraction, but in 498 limestones used for building purposes to about one-sixth. (See p. 938.)

Multiplying the percentages of soda in each of the elasses of sediments by their masses and taking their sums we have the average percentage of soda in the serliments, thus:

$$
1.31 \times .65+.61 \times .30+.34 \times .05=1.0515 .
$$

Since the soda in the original rocks is 3.55 per cent, the defieiency in the sediments is 2.4985 per cent. It thus appears that the deficiency in the sediments considered is about 70.38 per cent of the total amount of soda in the original rocks. For the entire weight of the sediments this gives a deficiency of $475,065,000,000,000,000$ metric tons.

It is possible that when more analyses have been marle of sedimentary rocks the estimates of soda in them may be somewhat increased, but since the analyses show the amount of potassium to accord fairly well with that of the original rocks (see p. 1000), it does not seem probable that much of the deficiency in soda can he explained by insufficient analyses.

The natural souree to which one immediately turns to aecount for this vast deficieney is the ocean. The actual amount of sodium in the ocean, as determined from Dittmar's estimates, is $14,180,000,000,000,000$ metric tons, which, reckoned as an oxide, would be 19,101,000,000,000,000 metric tons. While sodium is the most abundant element in the ocean with the exception of ehlorine, and is more than five times as abundant as the magnesium, 
potassium, and calcium together, it is seen that this amount is trivial as compared with the total deficiency in the sedimentary rocks, being indeed only 4.02 per cent of this amount. It is therefore plain that, as in the case of magnesium, we must turn to some other direction to account for the great deficiency of sodium in the ordinary sedimentary rocks. The natural direction to which to turn is to the salt deposits of the world. Many great salt deposits have been discovered in the United States, Europe, and other parts of the world; such deposits are illustrated by those of Poland, New York, and Louisiana. Doubtless many other salt deposits exist which have not been discovered. Moreover it is known that there are extensive salt deposits below lakes such as Great Salt Lake and the Dead Sea. No attempt has been made to quantitatively determine the mass of the salt deposits. Until this is done no statement can be made as to the proportion of the deficiency of sodium in the ordinary sedimentary rocks which such sediments will account for.

Finally, as is shown on pages 541-543, in arid regions sodium salts are largely retained in the deposits of the belt of weathering. Since sodium-bearing deposits are known to be very thick in various arid regions, such, for instance, as those in the western part of the United States, the amount of sodium thus accounted for is rery great, but as yet our knowledge is not sufficiently advanced to make any quantitative estimate of it.

From the foregoing it appears highly probable that we must look to the salt deposits and to the alkaline deposits of arid regions to explain the great deficiency of sodium in the ordinary sediments rather than to the ocean. If this conclusion be correct, calculations upon the age of the earth have no value which are based upon the derivation of salt from the land through weathering processes and its accumulation in the sea, and which ignore or place as relatively unimportant the salt deposits of the land. Such calculations furnish but another illustration of the danger of considering a single factor in a series of complex geological processes, and neglecting to ask the question whether there are other equally or more important factors concerned.

When the original rocks containing sortium-bearing minerals are decomposed in the zone of katamorphism, the langer part of the sodium passes into solution, contrasting in this respect, as will be seen, in a marked 
degree with potassium. During the nuderground journey of a part of the solutions a small portion of this sodium. is deposited in the belt of cementation. The sodium-bearing minerals formed by direct alteration in the zone of katamorphism, and those there deposited as cementing minerals, are snbstantially the same and are mainly the zeolites. The more important of these zeolites containing sodium in notable quantities are thomsonite, hydronephelite, natrolite, mesolite, analcite, stilbite, and gmelinite.

So far as rocks containing sodium in the zeolites pass into the zone of anamorphism. some of the original minerals of which sodium is a constituent may be reproduced, but manifestly the amount of such minerals will be small as compared with the amount of the original sodium-bearing minerals in the rocks. Corresponding with this fact the rich sodium minerals, nephelite, cancrinite, sodalite, haüynite, and noselite, have never been reported as anamorphic minerals of the sedimentary rocks. Most of the sodium present passes into the feldspars; but where the rocks have been so far decomposed as not to leave a large quantity of the original sodiumbearing minerals, the amount of sodium is not sufficient to produce any considerable proportion of the feldspars. In consequence, as pointed out on pages 899-904, the schists and gneisses which form from pelites only exceptionally contain any considerable quantity of soda feldspars. The dominant secondary minerals which are produced are, quartz and mica. However, in the psephites, in which the processes of decomposition are not far advanced, and in which the sodium is therefore relatively abundant, considerable quantities of soda feldspars are produced during recrystallization. But as already noted, even in those sedimentary rocks in which residual soda is present in the undecomposed original minerals, it appears that it is not known to have been anywhere so abundant that the peculiar minerals known as the soda-bearing minerals, such as nephelite, sodalite, etc., are produced.

\section{POTASSIUM.}

According to Clarke's estimate of 1891 potassium composes 2.23 per. cent of the outer 10 miles (16.1 kilometers) of the crust of the earth, inchnding the original rocks, hydrosphere, and atmosphere. Of the ocean it composes 0.04 per cent, and of the original rocks 2.40 per cent. In his estimate of 1900 Clarke reduces the figure for the original rocks to 2.32 
per cent. This gives potassium eighth place in abundance among the elements. Reckoned as an oxide the amount in the original rocks, arcording to Clarke's estimates of 1891 and 1900 , is 2.90 and 2.80 per rent, respectively." As an oxide, potassium thus las seventh place.

Potassium is an abundant constituent of a number of the silicates of the original rocks. The more important of these are the feldspars and the leucites. Since the feldspars probably compose more than laalf of all the original rocks (see p. 937), the chief original sources of the potassium are the feldspars. Of the feldspars the content of potassium is so great in orthoclase and microcline as to gire them the distinctive name potash feldspars, thus discriminating them from the acid end of the plagioclase series in which soda is the dominant alkali.

Considering the secondary rocks, the amount of potassa in 78 shales in 3.25 per cent, ${ }^{b}$ in 624 sandstones 1.24 per cent, and in 843 limestones 0.46 per cent. It thus appears that as compared with the original rocks, the amount of potassa in the shales is increased by abont one-fifth, in the sandstones is reduced to less than one-half, and in the limestones to less thim one-fifth. Irultiplying the percentage of potassa in each class of sediment. by the rolume of those sediments, and taking their sum, we have the a verage amount of potassa for the sediments considered, thus:

$$
3.25 \times .65+1.24 \times .30+.46 \times .05=2.5075 .
$$

Since the amount of potassa in the original rocks as given by Clarke in his latest estimate is 2.80 per cent, we have a deficiency of potassa in the sediments of 0.2925 per cent, or $1,974,375,000,000,000$ metric tons.

According to Ditmar's estimates the actual amount of potassium in the ocean is $512,000,000,000,000$ metric tons, which, reckoned as potassa, is $616,600,000,000,000$ metric tons, or 31.23 per cent, i. e. abont one-third of the total deficiency. Potassium compounds are also important accessories in salt deposits. For instance, analyses show that the potassium composes from 1.1 to 7.4 per cent of the total solids of Great Salt Lake ${ }^{c}$ and 1.478 per cent of the total solids in the Dead Sea. ${ }^{d}$

As is well known, above beds of rock salt there are not infrequently overlying beds rich in potassium and magnesium. This class of salts is well

"Clarke, cit., Bull. 78, p. 39; Bull. 168, pp. 14-15.

Clarke, cit., Bull. 168, p. 17.
"Mon. U. S. Geol. Survey, vol. 1, pp. 253.

"Encyclopedia Brittanira, 9th ed., 1877. 
illustrated at Stassfurt, where, as already noted (p. 994), from 1876 to 1880 the amount of carnallite $\left(\mathrm{KM}_{\mathrm{gCl}} \cdot 6 \mathrm{H}_{2} \mathrm{O}\right)$, kieserite $\left(\mathrm{MgSO}_{4}+\mathrm{H}_{2} \mathrm{O}\right)$, and kainite $\left(\mathrm{MgSO}_{4} \cdot \mathrm{KCl}+3 \mathrm{H}_{2} \mathrm{O}\right)$ mined was 699,136 metric tons, whereas the amount of rock salt was for the same years only 96,856 metric tons. Since the salt deposits are so important, it follows that the total amount of potassium in such deposits is large.

It seems probable that the potassium in the salts of inland seas and in the saline deposits is sufficient to accomnt largely and perhaps fully for the remaining two-thinds of the deficiency of potassinm in the sediments.

Where the rocks which contain potassimm are altered in the zone of katamorphism, the potassimm-bearing minerals do not decompose to the saine extent as the sodiun-bearing minerals. So far as the potassinm is in lencite, it readily alter's; but, as already noted, the greater part of the potassium is in orthoclase and microcline, and these are the most difficultly decomposable of the feldspars. These minerals disintegrated and only partially decomposed are carried in great quantities to the sea. But eren where the potassinm feldspar's are decomposed, it seems that the potassium is held in an insoluble form to a large extent. Prestwich ${ }^{a}$ attributes the retained potassium to the action of alumina, although he does not explain the reaction by which it is held. Mendeléeff ${ }^{b}$ emphasizes the absorptive power of the soil, and especially of the vegetable mold, for potassium. It is known that potassinm compounds are used by plants to a much greater extent than sodium compounds. But the influence of plants in retaining. potassinm can not be cited to explain the apparent concentration of potassium in the muds. It appears to me that where the feldspars have decomposed and the potassium largely remains in the silts and muds, it is likely that this element has passed into the zeolites, especially apophyllite.

When the rocks formed in the zone of katamorphism are buried in the zone of anamorphism, the original minerals which contain the potassium may be produced, but it has already been seen that the chief minerals originally holding the potassium are orthoclase and microcline. It has further been pointed out that the soda minerals are much more readily decomposed and that much less of the sodium is left in the sedimentary

\footnotetext{
"Prestwich, Joseph, Geology-chemical, physical, and stratigraphical, vol. 1, 1886, p. 54 .

${ }^{b}$ Mendeléeff, D., The principles of chemistry, translated by Geo. Kamensky, Longman;, (ireen \& Co., London, vol. 1, 1897, pp. 546-5 47 .
} 
rocks. Thus it is that orthoclase and microcline are the chief feldspar minerals which develop by the deep-seated metamorphism of the pelitesrocks in which decomposition has been carried further than in the other mechanical sediments. To a less extent orthoclase is likely to be the doninant feldspar in the other sediments. However, since complete decomposition for the mechanical sediments is very rare, the potassinm for much of the orthoclase and microcline which develop by metamorphism is derived from the undecomposed original minerals.

BARIUM, STRONTIUM, CHROMIUM, NICKEL, LITHIUM, FLUORINE, BROMINE.

In Clarke's estimate of 1900 of the lithosphere barium is put down as composing 0.05 per cent, strontinm as 0.02 per cent, chromium, nickel, lithium, and fluorine as 0.01 per cent each and bromine as less than 0.01 per cent. The quantities of these elements are so small and so little is known about the transformations through which they go that no attempt is here made to consider the influence of metamorphism upon their distribution.

\section{GENERAL STATEMENTS.}

At the beginning of this chapter it is stated that the attempt to apply quantitative methods to the redistribution of the chemical elements is made more with the idea of laying out problems to be solver than with the belief that the calculations approach accuracy. However, when all of the equations which compare the average composition of the sediments with the original rocks are taken into account the impression is gained that the calculaterl relative proportions of the three classes of sediments discussed-that is, the shales (including all silicate rocks), the sandstones, and the limestones-can not be far from the truth. The percentages of each of the elements in the sediments and in the original rocks are matters of quantitative determination, by imperfect methods, it is true, and so far as absolute masses are concerned the estimates given for the sediments are but roughly approximate, but the relative proportions stated are probably nearer the truth. Other proportions of the sediments than those used might be selected which would answer in the equations for a single element, and possibly some other proportions than those used might be selected which would accord better with the facts; but it seems certain that such proportions could not differ 
greatly from those given- 0.65 for the shales, 0.30 for the sandstones, and 0.05 for the limestones. While with the numbers used discrepancies have appeared, for the most part they are of a kind which throw light upon the processes of segregation of compounds in materials other than shales, sandstones, and limestones.

In conclusion it is to be remembered that the equations are indejendent of the estimates of the absolute masses of the sediments, and therefore they can not be said to give any support to the estimates of the average thickness of the sediments for the continental areas, nor to the absolute amounts of the elements which have been calculated to be abstracted from certain of the sediments and segregated in certain others of them.

Certain of the results set fortl in the previous pages indicate the possibility that the estimate of the mass of the sediments as 2 kilometers thick for the eontinental areas is too large, but it will be noted that this estimate is very conservative as compared with estimates made by others. (See p. 939.) If one were to estimate the mass of the sediments as 1 kilometer thick for the continental areas, while the calculated percentages of the deficiencies and excesses of the various elements in the sediments as compared with the original rocks would not be changed, the calculated absolute amounts would be reduced one-half. This would reduce by one-half the calculated percentage of oxygen of the atmosphere required to oxidize ferrous iron (see p. 951), and to oxidize iron sulplide (see p. 952); would divide by 2 the numbers comparing the amount of carbon in the sediments with that in the atmosplere and hydrosphere (see pp. 965-966); and would divide by 2 all absolute estimates of the surpluses and deficiencies of the various elements in the ordinary sediments, as, for instance, the calculated deficiency in iron. (See pp. 987-988.) Other similar changes would be made in the calculations. These facts may be regarded by some geologists as evidence that even the moderate estimate for the sediments of 2 kilometers thick for the continental areas is too great, and with this view I am inclined to agree. 


\title{
CHAPTER XII.
}

\section{THE RELATIONS OF METAMORPHISM TO ORE DEPOSITS. ${ }^{a}$}

\author{
PART I. GENERAL PRINCIPLES.
}

\section{INTRODUCTORY.}

The principles of metamorplism, discussed somewhat fully in the previous chapters, have a direct bearing upon ore deposits, as it will be shown in this chapter that the deposition of most ores is but a special case of metamorphism of exceptional interest to man. Through the preceding chapter's are scattered the principles applicable to ore deposits; but as many persons interested in ores may not care to study in detail all the principles which concern metamorphism, it seems advisable to give here a brief summary of the more important principles and conclusions directly applicable to ore deposits. In order not to make the extension too great, only the principles will be repeated; for evidence showing their correctness the reader may turn to the previous chapters.

From this discussion are excluded all the nonmetallic economic products which are used without reduction to the metallic form, as apatite, clay, salt, etc., and the very rare and unimportant metals. Thus the treatment is confined to those important ores the metals of which are commonly used in the metallic rather than in the combined form. Thins circumscribed, the chapter is chiefly restricted to ores of iron, aluminnm, cobalt, nickel, manganese, lead, zinc, copper, tin, mercury, silver, gold, and platinum. Arsenic, antimony, bismuth, chromium, molybdenum, and tungsten are not considered at all, or are only incidentally mentioned.

\footnotetext{
a This chapter in a less nature form was published in time for distribution at the Washington meeting of the American Institute of 11ining Engineers in February, 1900, as a pamphlet of 126 frages. A revised pamphlet edition of 151 lages was pullished during the summer of 1900 . This edition appears as pages 27 to 177 of Volume $\mathrm{XXX}$ of the Transactions of the Anerican Institute of Mining lingineers. This paper was republished in $190^{\circ}$ by the Institute in the special volume upon the Genesis of ore deposits, pages 282-432, which volume contains also a closing discussion under the same title, pages $763-781$. 
CLASSIFICATION OF ORE DEPOSITS.

Ore deposits may be divided into three classes upon the same basis as are the three great divisions of rocks:

(1) Ores produced by the processes of sedimentation, or sedimentary ores.

(2) Ores produced by igneons processes, or igneous ores.

(3) Ores produced by the processes of metamorphism, or metamorphic ores.

Since this volume is a treatise upon metamorphism and not upon physical geology in general, only the third class of ores, those produced by metamorphism, coine within its scope. But ores formed by processes of sedimentation and by igneous processes will be briefly considered, mainly in order to point ont their relations to ores prodnced by processes of metamorphism.

Before taking up the ores it is necessary, as already stated, to summarize certain parts of the previous chapters. The three great divisions of the processes of modifications of rocks which most intimately concern ore deposits, and therefore need to be summarized, are:

The deformation of the lithosphere.

Volcanism.

The circulation and work of solutions.

DEFORMATION OF THE LITHOSPHERE.

In another place I have shown that the onter part of the crust of the earth may be divided into three zones, depending upon the character of the deformation-(1) an upper zone of rock fracture, (2) a middle zone of combined rock fractnre and flowage, and (3) a lower zone of rock flowage. ${ }^{a}$ In Chapter IV it has been shown that the zone of fracture corresponds to the zone of katamorphism and that the zone of flowage corresponds to the zone of anamorphism.

\section{ZONE OF FRACTURE, OR ZONE OF KATAMORPHISM.}

The zone of fractnre is that near the surface and in it the rocks are deformed mainly by macroscopic fracture. The ruptures are those of fanlting, jointing, bedding larting, fissility, and brecciation. The rocks

"Van Hise, C. R., Principles of North American pre-Cambrian geology: Sixteenth Ann. Rept. I. S. Geol. Survey, pt. 1, 1896, p. 589. 
are adjusted to their new positions mainly by differential movements between the separated parts. The so-called folds in the zone of fracture are largely the result of numerous parallel joint fractures across the strata with small angular displacements at the joints, giving each block a slightly different position from those on either side, and thus as a whole making joint folds. For instance, the folds of the rigid rocks in the Alleghenies are not in the main true flexures, but a series of slightly displaced blocks.

It is shown on pages 189-190 that, making all the assumptions in favor of as great a thickness as possible, the maximum thickness of the zone of fracture can not be greater than 10,000 or 12,000 meters. In many cases, even for the strongest rocks, deformation frequently takes place by flowage at depths not greater than one-third to one-half of 10,000 meters. For the weaker rocks deformation by flowage may take place at very moderate depths. If the conclusions above given be correct, it follows that all open fissures must disappear at moderate depths, and that the maximum depth at which they can exist is the depth of the zone of fracture for the strongest rocks. Illustrations of the disappearance of fissures with depth are known at various places. In the gold belt of the Sierra Nevada, as Lindgren says, it is "an incontestable fact that many small veins close up in depth."

The dying out of fissures below is insisted upon in order to exclude the lyypothesis of filling of fissures from the bottom. If fissures gradually decrease in size and finally die out, the streams which make their way into the fissure must enter from the sides or from above. For further development of this point see pages 1069-1072.

OPENINGS OF ZONE OF FRACTURE.

It has been shown that the zone of fracture is characterized by openings. It will be seen that the nature of the openings in the rocks is of the greatest inportance in the formation of ore deposits. It is therefore niecessary to summarize the material giren in Chapter III upon this subject.

It is there shown that the openings of rocks deserve consideration from three points of view: The form and continuity of the openings; the size of the openings; and the volume of the openings, or the pore space. 
FORM ANJ CONTINUITY OF OPENINGS.

The openings in rocks include those which are of great length-and depth, as compared with their width, and thus are essentially flat parallelopipeds; those in which the dimensions of the cross sections of the openings are approximately the same, and therefore resemble tubes of various kinds; and those which are irregular.

The openings which have great length and depth as compared with their width are those of faults, of joints, of bedding partings, and of fissility. The order mentioned is that of continuity. As to position, bedding partings are parallel to previous structures; while faults, joints, and fissility are at various angles with the bedding parting, and therefore intercept the layers. Because of this fact, these forms of openings may comnect separated porons strata. This is more likely to be true of faults than of joints, and of joints than of fissility.

The openings in which the dimensions of the cross section are approximately the same are those in mechanical deposits, such as conglomerates, tuffs, sandstones, and shales. From the point of view of ore deposits the most important characteristic of the openings of this class is that they are continnous, and therefore any part of a coarse, uncemented mechanical deposit is connected with all other parts by openings.

Irregular openings are those of the vesicular lavas, and the irregular fractures of rocks The openings of the lavas are usually variable in magnitude, and are discoutinuous. Usually single irregular fractures are of limited extent, but many fractures may be concentrated along a zone, and a composite zone may be contimnons for long distances.

Openings of any of the above classes, whether prodnced by deformation, by original sedimentation, or by volcanic action, may be enlarged by solution. This will be the case wherever the processes of solution more than counterbalance the processes of deposition, and, as later explained, is more likely to occur with dowuward-moving water than with upward-moving water. Since downward-moving waters are dominant above the level of ground water, and are prominent in the upper part of the belt of cementation, it is in this area that openings are most frequently enlarged by solution.

It has been argued by Posepny that openings serving as channels for ground water may be produced wholly by solution. That openings may be somewhat prolonged and adjacent opening connected by solution, 
thus helping underground circulation, is more than probable, but that long and inportant passages are producer wholly by solution is an assumption which $\mathrm{I}$ think has not been verified.

SIZE OF OPENINGS.

Openings in rocks may be divided, upon the basis of size, into those larger than capillary size, or supercapillary openings; capillary openings; and those smaller than capillary size, or snbcapillary openings. The magnitudes of these openings are given on pages 134-137. The openings of bediling parting, of faults, of joints, of conglomerates, and of tuffs are frequently of supereapillary size. Many of these openings, and also many of those of the sandstones, are of capillary size. All classes of openings may be somewhere of subcapillary size, but many rocks, such as massive igneous rocks and shales, may contain only subcapillary openings.

YOLUME OF OPENINGS.

The total volume of the openings is dependent upon the number and the size. The amonnt of pore space in rocks raries from less than 1 per cent to more than 50 per cent. The total volume of the openings in a rock in which they are so small as to be almost imperceptible and all subcapillary may be as great as in a rock in which many openings are seen. For instance, the pore space of a chalk may be as great or greater than that of a sandstone or of a massive rock containing numerous continuous fracture openings of large size. (See pp. 124-125.) In such cases the small size of the openings is compensated by their vast numbers.

CHEMICAI, REACTIONS.

As explained in the preceding chapters, especially in Chapter IV and more fully in Chapters VII and VIII, the reactions of the zone of fracture, or katamorphism, are those of oxidation, carbonation, hydration, solution, and deposition. All are of great importance in comnection with ore deposits. In the belt of weathering all of these reactions, with the exception of deposition, are vigorous. The sulphides, including the metals and the sulphur, are likely to be oxidized. Oxides may be further oxidized. The metals may be carbonated and hydrated and are likely to be dissolved upon an extensive scale. While all of these reactions take place in the belt of 
cementation, oxidation is frequently confined to those parts of the belt in which the waters come somewhat directly from the surface; whereas deeper, especially where the percolating water's have come into contact with organic compounds or sulphides, the waters may become reducing, and partial or complete deoxidation of the valuable metals take place. Furthermore, while solution probably occurs to a greater extent than deposition in the belt of cementation, as explained on pages 629-640, material is continually deposited in the openings of the belt, and the rocks are cemented in consequence of the expansion reactions of oxidation, carbonation, and hydration, and in consequence of selective precipitation, of intrusion, and of other phenomena.

ZONE OF COMBINED FRACTURE AND FLOWAGE.

Deformation by combined fracture and flowage takes place in a middle zone becanse the rocks of a given part of the lithosphere vary in character, temperature, moistmre, speed of deformation, etc. (See pp. 766-768.) Of these factors prodncing combined fracture and flowage, the effect of the character of the rocks is most obvions. While very considerable rock masses, such as the limestones and quartzites, may be homogeneons, heterogeneity is the rule. The sedimentary rocks are composed of laminx, layers, beds, and formations, no one of which is exactly like the adjacent one. The massive igneous rocks contain minerals of different resisting power, the particles of which are of different sizes. In consequence there is a broad zone in which the deformation may be by combined frecture and flowage. For instance, in an interbanded slate and graywacke the slate bands may be deformed by flowage and the more rigid grayracke bands be deformed largely by fracture. In an interbedded limestone and clastic series the limestones may be deformed mainly by flowage and the clastic material mainly by fracture. In many cases the change fiom one kind of deformation to the other is amazingly sharp, the more resistant bands being intersected by innumerable fractures which stop abruptly at the bands where the rock is deformed by flowage. The deformation of a massive rock mainly by flowage, but in a subordinate way by fracture, is finely illustrated by the Berlin rhyolite-gneiss described by Weidman. ${ }^{a}$ The deformation of this rock was mainly by recrystallization, but many of the

a Weidman, S., A contribution to the geology of the pre-Cambrian igneous rocks of the Fox River Valley, Wisconsin: Bull. Wis. Geol. Nat. Hist. Survey, No. 3, 1595, pp. 32-47.

MON XLVII-0t-6t 
mineral particles were fractured into several pieces, or even granulated. Between the langer pieces of the feldspar minute openings formed. Many minute joints and crevices also were produced and were subsequently filled by cementations.

The marked effect which the character of the rock may have upon the nature of the fractures is well illustrated in the Cripple Creek district, where, according to Pemrose, in the hard rocks the fissures are sharp, clean-cut breaks, while in the soft rocks they are ordinarily a series of very small cracks, constituting a displacement of a kind which I call a distributive fault. Mines which are partly in hard and partly in soft rock illustrate this, as the following extract from Penrose will show: ${ }^{a}$

The rein on which the Buena Vista, Lee, Smuggler, and Victor mines are located occupies a sharp, clean-cut fissure, partly in the massive rock and partly in the bard breccia; but when it passes into the soft, tufaceous breceia on the east slope of Bull Hill the fissure is represented only by faint cracks occupied by no vein of importance. In this case the force which caused the fissure orercame the cohesion of the harder rock sufficiently to make a clean break, but in the more plastic rock it overcame cohesion only to the extent of causing a series of faint fractures withont any one well-clefined break.

It follows fiom the above that displacement may disappear at variable depths. Where there are fractures witl large displacement they are likely to extend to very considerable depths, and in proportion as the displacement is small they are likely to disappear at less depths. Thus the depths to which displacements extend depend largely upon the character of the rocks. For instance, in a region in which there is a shale formation at moderate depth underlying brittle rocks, strong fissures in the higher formations may disappear as they encounter the shale, being there replaced by flexures. Where formations of shale are between brittle formations fissures may cease at the top of the shale and other fissures appear below it. Thus may fissures not only die out below, but may disappear above, the fault along the fissures being replaced by a flexme in the shale, which yields by flowage. This is beautifully illustrated by the Enterprise mine, of Rico, Colo., described by Rickard and Ransome (see fig. 29, p. 1208), where faulted fissures in sandstone and limestone disappear at the place where shale is encountered, the shale accommodating itself to the fractures below by monoclinal flexures. (See p. 1204.)

"Cross, Whitman, and Penrose, R. A. F., Geology and mining indnstries of the Cripple Creek district, Colorado: Sixteenth Ann. Rept. U. S. Geol. Snrvey, pt. 2, 1895, p. 144. 
From the above it appears that openings of the zone of the combined fracture and flowage comprise all of the classes of openings characteristic of the zone of fracture. There is, however, the great difference that upon the average the supercapillary openings are smaller, less continuous, and less numerous than in the zone of fracture.

Since there is such a great variation in the strength of the rocks and in other factors, the belt of combined fracture and flowage may be of considerable thickness, possibly as thick as 5,000 meters. In this zone we have all combinations of the phenomena of fracture in the various ways above mentioned, and of flowage by granulation and recrystallization.

\section{ZONE OF FLOWAGE, OR ZONE OF ANAMORPHISM.}

In the zone of rock flowage deformation is chiefly by granulation and recrystallization, few openings being produced, except those of microscopic size. (See pp. 658-659, 673-675, 685 et seq.) This conclusion rests upon arguments which can not here be fully repeated. ${ }^{a}$ However, it may be said in passing that the conclusion that a zone of rock flowage exists at moderate depth is based, first, upon deduction from known physical principles as to the behavior of solid bodies under pressure; and, second, upon observation. It is well known that when a rigid body, such as a rock, is subjected to unequal stresses in various directions and the difference in the stresses is greater than its ultimate strength under the conditions in which it exists, it must rupture or flow. If a rock be subjected to a stress in a single direction greater than its nltimate strength in that direction, and the rock is not under pressure in other directions, rupture occurs. However, if we suppose that the rock be subjected to stresses greater than the ultimate strength of the rock in all directions, and that the difference in the stresses in different directions is greater than the ultimate strength of the rock under the conditions in which it exists, then if openings could be produced by rupture, they would be closed by pressure. In other words, at a certain depth below the surface of the earth, if we could suppose that cracks and crevices are formed by the deformation to which the rocks are subjected, the pressures in all directions being greater than the ultimate strength of the rock, these cracks and

“Van Hise, C. R., Principles of North American pre-Cambrian geology: Sixteenth Ann. Rept. U. S. Geol. Survey, pt. 1, 1896, p. 594 et seq. 
crevices would be closed. The rate of elosing would depend upon many factors. (See pp. 766-768.)

Since this conclusion was reached, Adams and Nicolson ${ }^{a}$ have actually deformed marble under the conditions supposed to exist at moderate depth, with the result that the rock changed its form with no perceptible openings.

Before the above inductive reasoning or Adams and Nicolson's experiments were made, I had become convinced from observation that at moderate depth rocks are deformed witl fracture and differential movements between the solid particles (granulation), and by continuous solution and redeposition by underground water (recrystallization).

It has been explained (pp. 189-190) that the maximum possible depth of the zone of fracture for the strongest rocks under quiescent conditions is not greater than 10,000 or 12,000 meters, and that for the majority of rocks, and especially under conditions of movement, the zone of flowage is probably reached at depths much less than this.

OPENINGS OF ZONE OF FLOWAGE.

The openings of the zone of flowage are dominantly subcapillary. Capillary openings are numerous, but they are not usually continuous for any considerable distance. Supercapillary openings may exceptionally exist in the upper part of the zone of flowage in consequence of very rapid deformation, but such openings are likely to be temporary, for when rapid deformation ceases they are closed by flowage.

REACTIONS OF ZONE OF FLOWAGE.

The chemical reactions of the zone of anamorphism, as fully explained in Chapters IY and VIII, are dominantly those of silication, dehydration, deoxidation so taking place as to decrease rolume.

RELATIONS BETWEEN ZONES OF DEFORMATION.

From the preceding pages it is clear that the zones of fracture, of combined fracture and flowage, and of flowage are not sharply separated from one another.

a Adams, F. D., and Nicolson, J. T., An experimental investigation into the flow of marble: Phil. Trans. Roy. Soc. London, ser. A, rol. 195, 1901, pp. 363-401. 
It is lighly probable that upon the average the openings of the zone of fracture gradually decrease in number and size as depth increases, until in the zone of flowage the openings are, as already explained, microscopic or nonexistent. If such a gradation exists, it is a necessary corollary that the deformations of the zone of fracture must have their equivalents in the deeper-seated zone of flowage. This point is fully discussed elsewhere. ${ }^{n}$ It is explained that with depth, faults are replaced by flexures, and that any deformation of a large mass of a given rock from one form to another by fracturing may be imitated by similar changes of form in the zone of flowage, the result being there accomplished by granulation of the mineral particles or by their recrystallization, or by both.

Where rocks have been deformed in the zone of flowage and are now at the surface there is superimposed upon the effects of the deep-seated deformation the deformation by fracture resulting from earth movements during the time the rock was slowly migrating through the zone of fracture to the surface.

EFFECTS OF DEFORMATION AND CHEMICAL CHANGES UPON TEMPERATURE.

It has been pointed out in previous chapters that deformation results in the liberation of heat which may considerably raise the temperature of the rocks. Indeed, Mallett holds (see pp. 99-160) that deformation may actually produce enough heat to fuse the rocks. While I dissent from this conclusion, this view illustrates the importance of the rise of temperature which may follow from mechanical action.

It has been shown further that a moderate rise in temperature may increase the activity of the solutions to an amazing extent. Indeed, in a chemical laboratory a slight rise in temperature is often sufficient to inaugurate a reaction which otherwise would not take place, and to increase the speed of the reaction many fold. It is therefore clear that deformation is favorable to the segregation of ore deposits in two different ways, first, by forming openings for a vigorous circulation, and second, by heating the solutions and thereby greatly increasing their activity.

In the zone of katamorphism the chemical reactions liberate heat, cause an increase of temperature in the zone in which the ores are mainly segre-

a See Chapter VIII (pp. 766 et seq). See also Principles of North American pre-Cambrian geology, cit., pp. 674-676, 694-698. 
gated, and therefore help to develop the ores. Thus, in this zone, deformation and chemical reactions both favor the concentration of ores. In the zone of anamorphism the chemical reactions absorb heat, and to that extent work against the effect of deformation.

In the western portion of the United States there have been recent orogenic movements and also recent development of ore deposits. But correlative with orogenic movements is volcanism, and it is pointed out in the following section that volcanism also, for various reasons, is favorable to the segregation of ores. It is therefore exceedingly difficult in any given region to determine the relative quantitative importance of orogenic movements and volcanism in the development of the ores. Until this study is seriously taken up for extensive regions the relative importance of the two must remain largely a matter of speculation.

\section{TOLCANISM.}

The great importance of voleanism in reference to metamorphism has been fully dealt with in the previous chapters. The rast extent and great thickness of the Tertiary volcanic rocks afford evidence of the prodigions quantities of material which may be extruded in a single geologic period. It has been explained that correlative with and below these extrusions probably occurred intrusions on an even vaster scale. It has also been seen that important rolcanism and extensive orogenic movements are usually simultaneous in the same regions. The relation between the two is that of cause-effect. Orogenic movements produce numerous openings, which extend deeper than those that exist under quiescent conditions. These are taken advantage of by the intrusive rocks which are being forced toward the surface. The enormous hydrostatic pressure of the upwelling lava is also one of the factors in further fracturing. Consequently there is action and reaction between orogenic moveménts and volcanism, each advancing the other.

Volcanism may promote the development of ore deposits in varions ways.

First. The igneous rocks may furnish metals for the ores. In the case of a given ore deposit the metal may be almost wholly derived from the recent igneous rocks, almost wholly from earlier rocks surrounding the later intrusion, or partly from the two sources. Illustrations will be given later. 
Second. The igneous rocks may furnish aqueous and gaseous solutions which transport the metals to their places of deposition. It is very difficult to determine the quantitative amount of the solutions of this sort. Where the igneous rocks are intruded in the zone of fracture, or appear at the surface in the ordinary forms characteristic of volcanism, it is impossible to discriminate the gaseous and aqueous material which has always been within the magma from the solutions which have derived their water from metenric sources or from the sea. It is certain that vast quantities of water of meteoric origin pass into the zone of fracture. In comnection with the water phenomena of volcanic action it may perhaps be doubted if the water from the sea is important; but there can be no question concerning the effect of water of meteoric origin. Where voluminous hot springs issue in comnection with present or past rolcanic action all the evidence indicates that the major portion of this water is of meteoric origin (pp. 1065-1069). However, it has been pointed out (pp. 661-668) that in the zone of anamorphism the conditions are very different. It can not be assumed that there the water is abundantly derived from meteoric sources. In comnection with batholitic action it has been shown that there is complete gradation between strictly igneous material and material which is apparently deposited from solutions. It has been explained that the water which does this work is probably in considerable part derived from the magina itself, although some is donbtless included between the mineral particles and some is produced by processes of dehydration. But even for this zone it is impossible to make any quantitative statement as to the relative amounts of water concerned in the segregation of ores which is derived fron emanation of original magmas and from other sources.

Third. The heat of the igneous rocks may render the solutions vastly more active in segregating the metals from the intruderl rocks. The amazing increase in the power of solntions to dissolve material in consequence of rise of temperature has been emphasized (pp. 79-81). The meteoric solutions adjacent to the igneous rocks must be at a much higher temperature than normal; therefore their activity is increased many fold. It follows that where the solutions in sedimentary, metamorphic, or ancient igneous rocks may not be sufficiently active to segregate the ores even where the metal exists in sufficient quantity, they may so gain in their segregating power in consequence of igneous intrusions that ore deposits 
develop. This heating of solutions in the surrounding strata by igneous rocks is believed to be a factor of the most pronounced importance in the segregation of many ore deposits.

Fourth. The introduction of the igneous rocks may promote fracturing and thus open channels for circulation. Also, after an igneous rock has crystallized it continues to cool and to contract. In consequence of its contraction trunk channels may be opened along the contact of the intrusive and intruded rock and within the igneous mass. The production of openings is very farorable to the segregation of ores.

Fifth. Another important function of the igneous rocks is to furnish inpervious basements which control the trunk channels of circulation, as, for instance, in the Lake Superior region, in the Leadville and Tenmile districts of Colorado, and in the ILercur district of Utah.

The formation of a given ore deposit with the aid of igneous rocks may be a consequence of any combination of the above factors, and the relative importance of each factor is variable in different cases. In a given district the determination of the quantitative importance of each of these factors is a problem of great difficulty, but one of great economic importance and scientific interest.

The effect of igneous rocks in the production of ore deposits is different in the zone of fracture and the zone of flowage. In the zone of fracture, as has been fully pointed out, the igneous rocks follow the openings toward the surface, and when they finally reach the surface are spread out over it.

In the zone of fracture the effects of igneous rocks in the belt of weathering and in the belt of cementation need separate consideration. In the belt of weathering, above the level of ground water, intruded rocks are baked or calcined. They are steamed by the gaseous solutions. It is possible that in this belt ore deposits may be segregated through the influence of voleanism, but positive evidence that this is a fact is lacking.

In the belt of cementation the igneous rocks are of great consequence. There is here the direct effect of heating the intruded rocks, but far more important than this is the indirect effect in heating the solutions. Where the temperature rises above the critical temperature of water the solutions are gaseous. It is, however, believed that the gaseous solutions are probably closely confined to the borders of the intrusive masses. The chief effect is believed to be in reference to the aqueous solutions. It will be 
seen that if gaseous solutions are produced in the belt of cementation, where the openings are numerous and the rocks are saturated, there is a strong tendency for the gaseous solutions to condense (see pp. 1019-1020). In this we doubtless have the partial explanation of the dominance in the belt of cementation of ore deposits, which show all the evidence of having been deposited by aqueous solutions, although many such ore deposits are contiguous to igneous rocks.

In the zone of flowage the conditions for intrusions and their effects upon ore deposits are very different from those in the zone of fracture. It has been pointed out that in the zone of flowage the igneous rocks make their way by elevating and thrusting the intruded rocks aside, by actually mashing them so as to shorten their dianeters at right angles to the intrusives, and finally by breaking across their structures. The effect of the igneous rocks is both direct and indirect, as in the zone of fracture. The direct effect is the heating of the surrounding rocks, their absorption to some extent, and occasionally even their local fusion. The indirect effect is of far greater conseqnence. In this deep-seated zone, where the amount of water is small and the openings are usually small and discontinuons, it is highly probable that the solutions are largely gaseous. In all but the upper parts of this zone the natural increase of temperature, dne to depth alone, is sufficient to raise the solutions above the critical temperature of water, and thus produce gaseous solutions. Where igneous rocks are present in large quantity and'contribute heat it is little short of certain that gaseous solutions are abundant. Therefore it is believed that gaseous solutions, comparatively unimportant in the zone of fracture, are of great importance in the zone of flowage (see pp. 1020-1021).

\section{CIRCULATION AND WORK OF SOLUTIONS.}

Solutions in rocks occur in two forms, gaseons solutions and aqueous solutions. Where the underground solutions are referred to without qualification there is no implication as to their state, and they may be as either one or the other, or partly both. Oftentimes for aqueous solutions the term water is used, but in such usage it is not meant to imply that the water is pure. It has been shown (pp. 146-152) that the general forces producing circulation of solutions are gravity, heat, mechanical action, and molecular attraction. These forces act very differently and do not have the same 
relative importance in gaseous and aqueous solutions. Therefore the two classes are considered separately. It will be seen that in the belt of cementation aqueous solutions are probably of predominating importance and gaseous solutions very subordinate, and that in the zone of anamorphism gaseous solutions are of dominating importance and aqueous solutions subordinate or unimportant.

\section{CIRCULATION OF GASEOUS SOLUTIONS.}

The general circulation of gaseous solutions is a function of the amount of gaseous solutions; of the absolute temperature of the gaseous solutions, of the amount of aqueous solutions adjacent, of gravity, and of the form, continuity, size, and amount of the openings.

The general principle which controls the movement of gaseous solutions is that the gases move from places of high pressure to places of low pressure. The expansive force of a given amount of gas in a given volume is directly proportional to its absolute temperature. Other things being equal, gaseous solutions tend to pass from places of high temperature to places of low temperature. The higher the temperature the greater its expansive power, and the more forceful its movement toward places of low temperature. Therefore lieat is a fundamental force in the circulation of the gaseous solutions. Gravity, of the very greatest importance for aqueous solutions, is of importance also for gaseous solutions. So far as gravity is concemed, the same principles apply to gaseous solutions and aqueous solutions. The heavier column of gas puiled by gravity descends and the lighter column is forced to rise. Where the columns are of equal length that of lower temperature descencis and that of higher temperature rises.

The circulation of gaseous solutions in the zone of fracture and in the zone of flowage is very different. Moreover, the circulation in the belt of weathering is different from that in the belt of cementation.

CIRCULATION IN BELT OF WEATHERING.

In the belt of weathering the law of gravity practically controls the circulation. Where the temperature of the gases is higher than normal they rise, being driven up by the greater pressure of the adjacent cooler air. Thus, above the level of the ground water, wherever heated gaseous solutions are produced they rise in columns of steam, as in the case of fumaroles and solfataras and in connection with volcanic action. 
CIRCULATION IN BELT OF CEMENTATION.

In the belt of cementation the conditions are very different. Here the openings in the rocks are normally occupied by aqueous solutions. However, adjacent to igneous masses gaseous solutions may be produced either as emanations from the igneous rocks or by the heating of the solntions of the intruded rocks above their critical temperature, or by both combined. The surromding rocks, being occupied by aqueons solntions, serve the purpose of condensers. The conditions are those which would obtain between steam generated in a boiler connected by many openings with condensers containing water. Almost as fast as the steam is developed it is liquefied in the condensers, thus lieating the contained water. Thus gaseous solutions are condensed to liquids almost as rapidly as formed. It is possible that in the zone of fracture immediately adjacent to a great mass of intrusive igneous rocks there may be a narrow border area in which the water may be maintained as a gas and rise toward the surface, because it is driven by its expansive force from places of high temperature to places of low temperature, but evidence is necessary upon this point.

In attempting to arrive at the probability of the importance of gaseous solutions in the zone of fracture it is necessary to consider the mamer in which igneous rocks solidify. It is well known that in this zone the intrusive igneous rocks ordinarily show salılbands, giving evidence of quick chilling and solidification along their borders. From the exteriors crystallization extends inward. It is therefore plain that the surface of crystallization is ever a changing one. It should also be remembered that rocks are poor conductors of heat. It has further been pointed out that as crystallization and condensation continue openings are likely to form along the contacts, and thus give ready passages for water. The question is whether in the zone of fracture, along the borders of the intrusive masses, where there is free circulation, the temperature would be long maintained above the critical temperature of water. It seems to me that the probability is strongly against this. This probability is confirmed by observation, which shows that minerals prodnced along the contacts of igneous rocks in the zone of fracture are those characteristic of the belt of cementation, and therefore the same as those knowu to be produced by aqueous solutions. There is therefore no good reason for supposing that ores adjacent to the igneous rocks in the belt of cementation are commonly precipitated from 
gaseous solutions. But it would not follow that the aqueous solutions precipitating the ores do not receive contributions of gases, water, and metals from the contiguous igneous rock as it crystallizes and continues to cool after crystallization.

CIRCULATION IN ZONE OF ANAMORPHISM.

In the zone of anamorphism the conditions are very different. Here the openings are normally minute and disconnected, although locally and for a brief time of active intrusion they may be large and continuous. The amount of water in the surrounding rocks is very small, and the openings are so minute that it can not make its way readily toward the igneous masses. Consequently there is in this zone no condenser available to transform the gaseons solutions to the liquid condition. The temperature is certainly high, probably often above the critical temperature of water, because of the normal increase of temperature due to depth, and becanse of the ligh heat of the igneous rocks. Under these conditions it is natural to suppose that adjacent to the igneous rocks gaseous solutions are produced in considerable quantity, probably largely as emanations from the igneous rocks, but also to an important extent by transformation to the gaseons condition of the free water of the adjacent rocks and of the water liberated by the process of dehydration. Gaseous solutions would utilize the large openings temporarily formed to the fullest possible extent. It has been explained that the gaseous solutions, having very little viscosity and under the great pressure of this zone, make their way through the minute openings of the rocks and even between the individual mineral particles. The gaseous solutions emanating from the igneous rocks and produced from the surrounding rocks may contain metallic material in considerable quantity. Such gaseous solutions from various sources would deposit minerals in the larger openings precisely as do aqueous solutions under similar circumstances. Ores would probably be deposited even more extensively as impregnations in the minute openings of the adjacent rocks. The places where precipitation occurred would be controlled in part by the strength of the rocks, rigid rocks furnishing openings of a larger size than those which are more plastic. The localization would be very largely controlled also by the composition of the rocks. If they were able to take part in a reaction which would result in a precipitation, this would 
influence the result. For instance, it will be seen (pp. 1086-1087) that calcium carbonate may be very influential in precipitating the sulphides from aqueous solutions. It is supposed that the same reactions may take place with dense gaseous solutions at high temperatures; indeed, it might be argued that the calcium carbonate would be even more active with gaseous solutions than with aqueous solutions. In this connection the very frequent occurrence of the disseminated ores and deposits with irregular boundaries, with garnet, pyroxene, tommaline, and other heavy anhydrous minerals as simultaneously developed gangue minerals in limestone is to be noted. (See pp. 1052-1056.)

\section{CIRCULATION OF AQUEOUS SOLUTIONS.}

The general circulation of aqueons solutions is a function of the amount of water in the rocks, of the form, continuity, size, and amount of the openings in the rocks and of difference in head, difference in temperature, and mechanical action.

As to the amount of water in openings, in some cases the openings are not full and in some they are full, or the rock is saturated. Where the rocks are not saturated the chief forces producing circulation are gravity and molecular attraction. Grarity tends always to carry the water downward. Iolecular attraction, or what is ordinarily called capillarity, tends to diaw the water to places where the pore spaces have little water. It therefore is an effective force only where the rocks are not saturated with water. In the saturated rocks the forces producing movement are gravity, heat, and mechanical action. Where the rocks are saturated lydrostatic pressure is active, and therefore under these conditions flowage is usially much more rapid than where the rocks are not saturated. The flowage is also rapid in proportion as there is mequal head and unequal temperature in the two columns. 'The movement of water caused by gravity is due to the unequal weights of the columns of moving water. 'The unequal weight may be due to difference in the lengths or in the temperatures of the vertical columns or the two combined. That difference in length gives difference in weight is obvious. Where two connected columns of water hare unequal temperature, the cooler colnm is the denser of the two, and therefore under these circumstances gravity in comnection with heat prodnces circulation. In regions where the increment of heat is normal, there may be 
movement due to difference in temperature, but probably it is of great consequence only where the heat increment of one column is more than normal on account of mechanical action or of igneous rocks, or both. Mechanical action. may squeeze ont the water in the openings of rocks or possibly even some of the combined water and thus produce circulation. (See pp. 149, 661-665.)

Where the rocks are saturated, whatever the cause of the flow of underground water, the direction of movement is from places of greater pressure to places of less pressure. A current going in any direction is evidence of an excess of pressure in the rear of the current. Thus, water which enters by seepage or through capillary tubes into a larger opening, such as a fissure, must be under greater pressure than the column of water into which it makes its way. Whether the motive force in the movement of the water be difference in gravitative stress, of deformation, or any other cause, the excess of pressure resulting in movement is behind the current. In proportion as the opening approaches a circular form the flow increases becanse the friction between the moving water and the film of fixed water upon the walls is less per unit volume. The more continuous the openings, the more rapid is the flowage. Flowage increases as the size of the openings increases. In super-capillary openings the ordinary laws of hydrostatics apply, and therefore the flowage may be very rapid. In capillary openings the laws of capillary flow apply, and the movement of water is slow. Where the openings are subcapillary, the attraction of the mineral particles extends from wall to wall, the water films are glued to the rocks, and flowage is inappreciable. Flowage increases as the amount of openings or the pore space increases.

'So much for the laws controlling the general circulation of aqueous solutions. The combinations of the varions factors are so fundamentally different in their effects in the zone of fracture and zone of combined fracture aud flowage that further statement is necessary in reference to them

CIRCULATION IN ZONE OF FRACTURE, OR ZONE OF KATAMIORPHISI.

In the zone of fracture a great many openings are of super-capillary and capillary size, and many of them are continuous. It is clear that in this zone the conditions are very different in the belt of weathering above the level of ground water where the rocks are commonly not saturated and in the belt of cementation below the ground water where the rocks are saturated. Each belt requires consideration. 
BELT OF WEATHERING.

The belt of weathering comprises the belt at the surface of the earth in which the rocks are not continuously saturated with water. Its thickness is ordinarily between 0 and 300 meters; it is commonly less than 100 meters, but in the arid regions it may be exceptionally $1,000^{\circ}$ meters. In the belt of weathering the openings in rocks are upon the average more numerous, and larger than in any other belt. The amount of water present may vary from a very minute fraction of the amount required to fill the pore spaces to saturation. Therefore there is greater variation in the amount of water in the belt of weathering than in any other belt. The water is derived from rainfall and from the belt of saturation. At a given place, the rainfall varies greatly from time to time and there is much variation in the amount of water. It is shown (see pp. 416-423) that the forces which control the movement of aqueous solutions in this belt are gravity and molecular attraction and that these work directly and also through plant roots and mechanical morements.

So far as ore deposits are concerned, the direct actions only are important. Gravity steadily tends to carry the water downward. Molecular attraction ever tends to carry the water from places of more abundance to places of less abundance. The movements of the water due to these two factors are very complex in the upper portion of the belt of weathering, but for the middle and lower portions the movement of the ground water is mainly controlled by gravity. Therefore in these parts of the belt the water usually steadily descends. In considering ore deposits this is the fundamental point in connection with the belt of weathering, as the lateral movements and the ascending movements are unimportant.

The level of ground water for a given area is not fixed, and in consequence of its variation a certain layer near the boundary between the belt of weathering and the belt of cementation, may altemately be in one belt and in the other. There are various causes for this fluctuation, of which changes in amount of rainfall, orogenic movements, and denudation are important. Where uplift and denudation are the rule, the belt of weathering migrates steadily downward and consequently encroaches on the belt of cementation. Where there is subsidence and valley filling it is not uncommon for the belt of weathering to be encroached upon by the belt of cementation. These transfers from one belt to another will be seen to be of considerable importance in the genesis of ore deposits. 
BELT OF CEMENTATION.

The belt of cementation is the belt between the bottom of the belt of weathering and the top of the zone of flowage. Since in places the rocks are saturated to the surface of the gronnd, and since in the strongest rocks the depth of the zone of flowage under the most favorable conditions may reach 10,000 to 12,000 meters, the possible maximum thickness of the belt of cementation is 10,000 to 12,000 meters. The average thickness of the belt of cementation is probably less than 5,000 meters. Since the temperature increases $1^{\circ} \mathrm{C}$. for 30 meters, the water in the lower part of the belt of cementation is above the boiling point for atmospheric pressure. Indeed, if the belt of cementation extends to a depth of 10,950 meters, the water at this rate of increase would have a temperature of $365^{\circ}$, or the critical temperature of water. But it has been shown (pp. 5(i6-569) that, notwithstanding the high temperature of the water up to the critical point, the pressure is sufficient to hold it in the form of a liquid. Where mechan ical morements or igneons intrusions have taken place the increase of temperature may be higher than $1^{\circ} \mathrm{C}$. for 30 meters. But it the critical temperature be not reached, the increment of temperature must be very much greater than this amount in order that the water shall be changed to the form of a gas. (See pp. 566-569, 659-660.) Igneous intrusions at various times and places have doubtless raised the water above the critical temperature, but such water does not come under the subject now being considered.

The circulation of aqueous solutions in the belt of cementation is vigorons and extensive. The evidence for this is abundant. First, it is known that a considerable percentage of all meteoric water reaches the belt of cementation. All of this water except the inappreciable portion which enters into combination, after a longer or shorter journey in this belt, must somewhere again issue from it, unless a part of it makes its way downward into the zone of anamorphism, and there is no evidence to show that it does this. (See pp. 665-667.) The vigor of the circulation in the belt of cementation is further shown by the almost incredible number of springs carrying a vast volume of water, all of which are supplied by water from this belt. The water issuing from the belt of cementation in springs is probably only a small fraction of that which passes to the overground circulation by seepage through many small widely dispersed openings. (See pp. 413-423, $571-589$.) 
The strongest evidence of the vigorous and extensive character of the circulation in the belt of cementation is the fact, so strongly emphasized on pages 562-565, that cementation is universal in it. Wherever porous rocks have long remained in the belt of cementation an enormous amount of material has been deposited by underground aqueous solutions. In most cases where the porous rocks have been deeply buried in this belt for geological ages cementation is nearly or quite complete. Thus great sandstone formations have been transformed to quartzite by deposition of interstitial silica. In the San Juan district of Colorado great tuff formations of Tertiary age have been completely cemented. In order to get an idea of the original porosity of this formation it should be compared with the very recent porous cinder cones made up of bombs and lapilli, such as occur at many places in the West, as for instance near Flagstaff, Ariz. These cinder cones are so porons that rain water, however great its anount may be, passes into them as it would into a sieve, and therefore performs no work of erosion. Indeed, it seems as if the process of erosion of such deposits could scarcely begin until the openings had been partly filled by the process of cementation. Yet in the San Juan district of Colorado thousands of meters of tuffs originally as porous as these have been so perfectly cemented that the microscope scarcely discovers an opening except those which have been produced by recent fracture since cementation. The fillings of the major and minor openings are continuous physically and are composed of the same kind of material. No one who has studied such a formation as this can doubt that the general cementation and the filling of the fractures were performed by the same agent.

In general, in the rocks which have been long within the belt of cementation, the innumerable bedding partings, faults, joints, fissility and brecciation openings have been closed. The complete cementation of the more porous sandstone and tuff's requires the deposition of mineral material to the extent of 30 to 40 per cent of the volume of the rock. It has been shown (pp. 571-572) that to have accomplished this work the amount of water which circulated through the rocks probably in most cases must have been 100,000 or more times as great as the material deposited. Further, in case of the San Juan tnffs, the enormons amount of water required to deposit the inmense mass of cementing material passed through the rocks since early Tertiary time.

MON XLVII $-04-65$ 
Wherever rocks are exposed which once possessed numerous and large openings and which have been in the belt of cementation for a long time, their general cementation gives cenclusive evidence of a vigorous past circulation. In consequence of the process itself the openings become smaller and smaller; consequently the circulation less and less vigorons mntil, when the process of cementation is complete or nearly so, the circulation becomes very feeble. Thus in many regions, humid and arid alike, where there has been rigorons underground circulation, and where great quantities of material have been deposited by the aqueous solutions, the circnlation now may be relatively unimportant. At many mining districts these conditions now exist. At the time of rapid deposition of the ores there was a pervasive and vigorons circulation which, as cementation continned, gradually became less and less, and finally practically ceased. But after the gromnd-water circulation becomes feeble or practically stops, in consequence of cementation, earth movements may again fracture the rocks, and thus a new circulation be inaugurated which results in further cementation and perhaps in further concentration of ore.

In such cases the amount of the present circnlation is proportional to the fracturing which has taken place so recently that the openings formed have not had time to be filled again. In contrast with the circnlation in formations containing numerous large openings is that in rocks which contain few openings larger than subcapillary size-such as shales and the massive igneous rocks. In rocks such as these, unless orogenic movements produce capillary or super-capillary openings, the circulation may never be vigorons. The existence of impervions formations, either original or produced by the processes of cementation themselves, will be shown later to be very important factors in the general circnlation of underground waters and in the localization of ore deposits.

The aqueous circulation of the belt of cementation for homogeneous mediums is fully discussed on pages 571-589. It is there seen that the movement of the water may be resolved into two components-horizontal or lateral movements and vertical movements. In simple cases these components are usually combined in such a way that the lateral component is continuonsly in the same general direction, and the vertical component of the curved path is first downward and later upward. (See figs. 7 to 11.) But in areas of marked topographic relief a part of the water may 
move contimuonsly downward from the place where it enters the rock to where it issues from it. The form of the curved path is influenced by many factors of which the increase in temperature with depth, limiting formations, the preferential use of large channels, the relative lengths of the vertical and horizontal components are the more important.

The greater the temperature the less the viscosity of water. At $90^{\circ} \mathrm{C}$. the viscosity is only one-fifth as great as at $0^{\circ} \mathrm{C}$., and at $300^{\circ} \mathrm{C}$. the viscosity may not be more than one-twentieth of the amount at $0^{\circ} \mathrm{C}$. Since the flowage in capillary openings, which is the prevalent abundant kind in rocks, is inversely as the viscosity, the increase of temperature with depth is plainly favorable to deep penetration.

The movement of any aqueous circulation is practically stopped by strata in which all or nearly all of the openings are subcapillary. In the most favorable case for depth this would be the bottom of the zone of fracture. In many cases, lowever, limiting strata are found at very moderate depths, and there may be several limiting strata bounding pervious strata. (See fig. 12.) In all such cases a given circulation is stopped by the limiting strata, and the lines of flow are thus severely confined. The influence of limiting impervious strata upon the ground-water circulation is well illustrated by many of the artesian systems. Of the various combinations which result in artesian flow a limiting impervious stratum above a pervious stratum is the most common.

In general it may be said for a system of circulation that the entire available cross section is utilized, but not uniformly. Other things being equal, the more direct route is used to a greater extent than a less direct one, and therefore the remoter corners of a water system may have relatively small circulations.

Since the vertical movement of ground water is at a maximum confined to the zone of fracture, it can not exceed 10,000 or 12,000 meters, and commonly is much less than this. Indeed, in many systems of circulation the greater part of the water does not reach a depth as great as 1,000 meters.

There is no assignable limit to the extent of the lateral movement, but conmonly it is.longer than the vertical movement, in many cases hundreds or thousands of times longer. For instance, in the artesian circulation of the Dakota sandstone the horizontal journey of the water is at least from the 
Black Hills to the James River Valley, about 400 kilometers, whereas the vertical cireulation is limited to a depth less than 1,000 meters. In this case the vertical journey is insignificant in magnitnde as compared with the horizontal jouney. While this is an extreme case, in general the horizontal journey is several to many times longer than the vertical journey.

Large channels are utilized to a much greater extent than small channels. This preference for large channels frequently amounts to dominance, particularly for the latter part of the journey. Large chamnels may be called the trunk channels of circulation. The importance of trunk chamnels is due to the fact that (1) large chamels are likely to be more direct than smaller channels, and (2) the friction along the walls per unit of water is very much less than in capillary and in subcapillary channels. In the belt of cementation, as a rule the channels are larger and more numerous in its upper part, and steadily diminish in number and in size with depth. Therefore large channels tend to produce a shallow cireulation, and thus comteract the influence of lessened viscosity with depth and the effect of gravity, which tends to produce a deep circulation. (See pp. 578-582.) The preferential use of trunk-chamels leads to the conchusion that fault, joint, and bedding-parting openings, and those of conglomerates, all of which are likely to be of supercapillary size, are largely utilized by the ground-water circulation.

As a matter of observation, it is well known that the water which joins the belt of cementation is distributed throughout the belt, and that it enters at an infinite number of points. It is further known that at least a large part of the water issuing from the belt of cementation emerges from trunk chamels. Combining these facts with the principles controlling the circulation, it follows that the circulation of the belt of cementation is analogous to that of a tree, the twigs and branches of which have an important downward component, the medium branches of which are approximately horizontal, and the trunk chamnel of which usually has an upward component.

CIRCULATION IN ZONE OF COMBINED FRACTURE AND FLOWAGE.

Circulation in the zone of combined fracture and flowage is intermediate in its nature between that of the zone of fiacture and the zone of flowage. It has been pointed out (pp. 766-768) that as the bottom of the zone of fracture is approached probably the openings decrease in size, until 
they approach those of subcapillary size which are characteristic of tho zone of flowage. But because of variations in the nature of the rocks this change does not take place miformly, but irregularly. Hence one would expect that in formations where the deformation is mainly by fracture the movement of the water would be similar to that of the zone of fracture, but less vigorous, and that where the deformation is mainly by flowage the movement of the water would be unimportant.

CIRCULATION IN ZONE OF FLOWAGE, OR ZONE OF ANAMORPHISH.

In the zone of flowage, which corresponds to the zone of anamorphism, the circulation of water is very different from that in the belt of cementation. While much of the water in the upper parts of this zone is probably liquid, in the deeper parts of it, and in those parts where recent orogenic movements or great batholithic intrusions have occurred the solutions probably reach a temperature higher than $365^{\circ}$, and therefore are in the gaseous condition.

The openings of the zone of anamorphism are for the most part subcapillary and discontinnous. They are not only small in size, but small in total volume. In the zone of anamorphism, therefore, the quantity of free water at any one time is very small as compared with the zone of fracture. So far as the solutions in the zone of anamorphism are aqueous they are mainly glued to the walls of the subcapillary openings, and the circulation under conditions of quiescence is extremely slow. If there were no additions to the free water, doubtless the circulation would be mimportant so far as ores are concerned. But it is shown (pp. 662, 679-680) that one of the most characteristic reactions of the metamolphism of this zone is liberation of the combined water by dehydration, thus continually adding to the amount of free water. It is certain that this excess of free water is squeezed out of the zone of anamorphism, and it is shown (pp. 665-667) to be higlly probable that the major movement of this liberated water is upward into the zone of fracture rather than downward into the centrosphere. 'This highly heated water carries with it carbon dioxide liberated by the process of silication and as much mineral naterial as it is able to transport.

This upward movement may be largely as gaseous rather than as liquid solutions. So far as this is true the laws of these solutions apply rather than those of aqueous solutions. 
The nature of the rocks which contribute the metallic salts has been much diseussed. With Sandberger, ${ }^{,}$I have little doubt that the metallic constituents of ores are in large part derived from the igneous rocks which have been intruded into or extruded upon the lithosphere. In my paper on "Some principles controlling the deposition of ores," as originally published, I strongly advocated the idea that igneous rocks are the direct source of some ores, that they are the ultimate source of all ores, and that the heat of the igneous rocks is of fundamental importance in the segregation of the ores. The igneous rocks as a source of metallic ores are especially important at periods of exceptional rolcanism. At such times there rise from the lower parts of the lithosphere, and possibly to some extent from the centrosphere, enormous masses of igneous rocks which are injected into the zone of fracture or bronght to the surface. While, during the middle and later portions of geological time the magmas which came into the zone of fracture or were spread over the surface of the earth were derived from unknown depth, it is entirely possible that, during the early stages of the earth's history, magma very generally existed near or at the surface, and that such magma may have furnished a portion of the metals which now occur in ore deposits, although in such cases doubtless the metals have been distributed and redistributed again and again. From the earliest geological time the, igneous rocks have been the original source of the sedimentary rocks, although their immediate source may have been other sedimentary rocks. From the sedimentary and igneous rocks metamorphic rocks are produced. Therefore the original source of all ore deposits is believed to be magma.

I have further held that there is every gradation between igneous action and aqueous action, or, as I have stated it "under proper conditions water and liquid rock are miscible in all proportions." " I believe that there are complete gradations between purely igneous pegmatitic dikes and purely aqueous vein material. (See pp. 720-728.) Moreover, in previous papers ${ }^{d}$

"Sandherger, F., Untersuchungen über Erzgïnge, Wiesbaden, 1885, 2d Heft, pp. 159-431.

"Trans. Am. Inst. Hin. Eng, vol. 30, 1901, pp. 27-177.

c Van Hise, C. R., Principles of North American pre-Cambrian geology: Sixteenth Ann. Rept. U. S. Geol. Survey, pt. 1, 1896, p. 68T.

"Tan Hise, C. R., Metamorphism of rocks and rock flowage: Bull. Geol. Soc. Am., vol. 9, 1898,

. 299. Also this monograph, Chapter VII, pp. 566-569; Chapter VIII, pp. 659-660. 
and in this monograph I have emphasized the point that if at any time the temperature of the solutions exceed $365^{\circ} \mathrm{C}$. they are necessarily gaseous. I have also held that there is every gradation from ore deposits produced by pure magmatic differentiation through those deposited by gaseous solutions to ores produced by the work of nuderground water at ordinary temperature. ${ }^{a}$

But it has been explained (see pp. 1014-1016) that igneous rocks influence the segregation of ores in other important ways than by contributing the metals, viz, by heating the solutions of the surounding rocks and furnishing hot solutions to them, by producing clannels for circulation, and by furnishing impervious formations so as to converge solutions into tiunk chammels.

Le Conte pointed out many years ago that the undoubted frequent occurrence of workable ore deposits in regions of volcanisin may be explained by the heat furnished by the igneous rocks, thus promoting the work of underground solutions. ${ }^{b}$ That the heat furnished by the igneous rocks is a very important factor in the production of the ore deposits, I have no doubt. Since it is often difficult to prove that the metallic content of an igneous rock is original, it is impossible to make any general statement as to whether the metallic content or the heat furnished by the igneous rocks is the more important in the production of the ore deposits. It seems clear to me that both are very important; and equally clear that in many cases both work together. That is to say, an igneous rock may furuish all or a part of the metal which appears in an ore deposit, and the heat of the same igneous rock may greatly assist its concentration by underground waters of meteoric origin.

While the later igneous rocks are the undoubted source of some, perhaps many, ore deposits, it is also equally certain that another large part is derived from the sedimentary rocks and the metamorphosed, or partly metamorphosed, igneous and sedimentary rocks. As a case clearly illustrating the importance of igneous rocks in increasing the activity of solutions and enabling them to derive a large amount of material from the adjacent sedimentary rocks, there may be mentioned the Mammoth Hot

a Van Hise, C. R., Some principles controlling the deposition of ores: Am. Inst. Min. Eng., vol. 30,1901, pp. 174-175.

$b$ Le Conte, Jos., On the genesis of metalliferous veins: Am. Jonr. Sci., 3d series, vol. 26, 1883, p. 10. 
Springs of Yellowstone National Park. At this place there issues a vast amount of water, and great, brilliant travertine deposits, consisting of almost pure calcium carbonate, have been built up. ${ }^{\sigma}$ In this vicinity are Tertiary sediments which include limestones. There can be no doubt in this case that the waters are heated by the igneous rocks, and that the source of the material which is dissolved by the heated waters is the intruded sediments and not the igneous rocks. The case is particularly conclusive, because the geyserite deposits in the adjacent basins where sedimentary rocks are not close at hand consist of silica. If the heat of the igneous rocks can be so effective in promoting the solutions of vast quantities of calcium carbonate in the adjacent sedimentary rocks, may it not be equally effective in dissolving a sufficient amount of gold, silver, and copper, so that in a deposit a fraction of an ounce of gold, a few ounces of silver, or a fer per cent of copper may be found?

It is also certain that many ore deposits derive their metalliferons content in part from the intrusive and in part from the intruded rocks. Probably this is the most frequent of all cases. To give an estimate of the relative amounts of metalliferons metals derived from the original igneous rocks and from the secondary rocks is quite impossible.

Recently there has been a strong tendency among many geologists to maintain that the metals in ore deposits are mainly or wholly derived from almost immediately adjacent igneons rocks. As already intimated, this is undoubtedly true in many cases. For instance, where there is a great complex of aqneous and igneous rocks of many different kinds and the ores are always intimately associated with one particular: kind of igneous rock and no other, it is very probable that the source of the metal is the intimately associated igneous rock. Such cases are rather numerous. An excellent illustration is furnished by the copper-nickel deposits of Sudbury, which are invariably associated with norite. Another ease in which it. is believed that the ore is mainly derived from the igneous rocks is that of the copper deposits of the Lake Superior region, which occur in amygdaloids and conglomerates, but a portion of the copper was probably leached from the conglomerates. This belief is not based upon the fact that these ores occur to a considerable extent within openings of the amygdaloids,

a Hague, Arnold, Weed, W. H., Iddings, J. P., Yellowstone National Park: Geol. Atlas U. S., folio 30 , U. S. Geol. Survey, 1896. 
for the conglomerate deposits are even more important, but it is based upon the fact that copper, both in the native form and to a less extent as a sulphide, is sparsely disseminated throughout the basic Keweenawan lavas of the entire Lake Superior Basin. This broad relation has much greater significance to me with reference to the source of the metal than does the association of the ore with an igneous deposit at a particular mine.

Spurr notes substantially the same relations between the ore bodies of the Monte Cristo district of Washington and the associated tonalite. He says that metallic sulphides are everywhere noticeable thronghout the tonalite; that scarcely a cross fracture accurs through which there has been water circulation and not some concentration of sulphides; and that in the solid tonalite itself there are local segregations of sulphides. Furthermore, he says there are all gradations from these bunches of sulphide in the fractured rocks through a slight dissemination of sulphides to the ore deposits along the major fractures, such as those of the Mystery and Pride mines. Accepting this statement of fact, there is strong warrant for the suggestion of Spurr that the ores are derived "directly by concentration from the tonalite in which they lie." ${ }^{a}$

While in many instances it is therefore believed that a contiguous igneous rock is the main source of the metal for ore bodies, by some this comnection is over-emphasized, and the cases in which this is not true are often ignored. Doubtless this is a consequence of the fact that gold and silver are usually in mind when ore deposits are considered. Gold and silver ores may rather frequently be derived largely from recognizable igneous rocks, but to a very large extent, even for gold and silver, the immediate source of the metal in the deposits heretofore exploited was not the original igneous rocks. For instance, placers, which have yielded more gold to the world than any other form of deposit, have derived their metals from veins, from previous placers, and from the widely dispersed gold in many kinds of rocks. Much of the gold of many placers has been worked over by the processes of nature several times.

If we turn to iron, a metal of vastly greater importance than gold and silver combined, in few or no deposits now exploited can the metals be said to be derived directly from igneous rocks. Again, the deposits of lead and

aSpurr, J. E., The ore deposits of Monte Cristo, Washington: Twenty-second Ann. Rept. U. S. Geol. Survey, pt. 2, 1901, pp. 828-829. 
zinc of the Mississippi Valley, from which 90 per cent of the zinc and more than 20 per cent of the lead of the United States are mined, have certainly not derived their metals directly from igneous rocks. It is rather probable that the metals for these deposits, originally in rocks of unknown origin, have been taken into solntion in the belt of weathering, have been transported to the sea, and there precipitated in mimute quantities at the time the magnesian limestone formations of the Mississippi Valley were built up. The immediate sonrce of the metals for the present deposits is agreed by all who have closely studied them to be the Cambro-Silurian limestones.

The conclusion is reached that these rocks are really the source of the lead and zine, because almost everywhere through the great Cambro-Silurian limestones small amounts of these metals are found. In cracks and crevices at imnumerable localities there are very minor segregations of galena and blende, but not in snfficient amount to constitute ore deposits. Furthermore, Robertson has made analyses of the fresh solid Cambro-Silurian limestone where it showed no galena or blende to the eye, and very small amounts of lead and zinc were found. ${ }^{a}$

Thus the reasons leading to the conclusion that the Cambro-Silurian limestone is the source of the lead and zinc ores of the Mississippi Valley are precisely the same as those leading to the conclusion that the Keweenawan lava is the main source of the copper deposits of the Lake Superior region.

If these ore deposits in limestones are derived from the sediments, why should it be assumed, in cases of ore deposits in sedimentary rocks, especially in limestones cut by igneous rocks-as in the copper districts of Arizona and New Mexico, in the Leadville, Tenmile, and Aspen districts of Colorado, in the Mereur district of Utah, in rery many other places in the United States, and at a greater number in other parts of the world-that the associated igneous rocks, frequently subordinate in volume, constitute the sole somrce of the metals lead, copper, gold, zinc, and iron?

The foregoing facts show that the source of the metal for an individual district is not to be ascribed a priori to igneous, sedimentary, or metamorphic rocks, but can be determined only after an inductive investigation of the facts. The metal of a district may be derired from the late igneous

"Winslow, Arthur, Lead and zinc of Missouri: Missouri Geol. Survey, rol. 7, 1894, p. 480. 
rocks, from ancient igneous rocks, from selliments, from metamorphosed rocks, or from any combination of the above. When the important economic districts of the world are inductively studied, and certain knowledge obtained, I believe that it will be discovered that a great number, if not the majority, of ore deposits are not the result of a single segregation, but are the accumulated fruits of a great interrupted process of segregation, a part of the metals for the deposits having been worked over many times by the metamorphic processes.

According to this view, it has been shown in Chapter XI, on the redistribution of the elements, that a general result of metamorphism and accompanying processes is that many of the secondary rocks are depleted in reference to each metal, and that correlative with such depletion other deposits are formed in which each metal is segregated. Since these processes result in deposits in which each of the common metals is segregated, why should we hold that the metal of a present deposit of gold or silver or copper is derived solely from an immediately adjacent igneous rock unless evidence for this be conclusive? The natural view is that the metallic ore deposits of the world are, broadly, the accumulated results of the processes of segregation carried on throughout geological time.

While it is held that the metals for very mumerous and important ore deposits do not have their immediate source in igneous rocks, it is recognized, as stated at the ontset, that ultimately the metals for all ore deposits are probably to be traced back to igneous rocks. Since leaving their original positions the metals for many ore deposits have been transferred and segregated here and there until they reached the places where they are now found.

It is recognized that this general statement as to the sources of metals for ore deposits will be unsatisfactory to many persons, as every one is more or less influenced in his view by his own personal experience and by the particular metals which he has studied, but it is not the purpose of this chapter to consider individual districts, except as they illustrate principles. It is properly the part of the geologist or mining engineer who studies an individual district to find the source of the metals. In many cases careful investigations can undoubtedly determine this point, as, for instance, in the Lake Superior iron region. In other districts, however, the most exhaustive 
study may not enable the investigator to determine the source of the metals. This is especially likely to be true of ore deposits produced by ascending. waters from a somewhat deep circulation. The underground waters may have their sources of supply in rocks which do not reach the surface, and have not been penetrated by the mine workings.

In concluding this part of the subject it may be suggested that in many instances mistakes have been made in assuming that some one formation, sedimentary or igneous, is the sole sonrce of the valuable metals. Such an assumption is particularly prevalent in papers descriptive of gold and silver deposits. In many districts where there are a number of sedimentary and igneous rocks I have no doubt that the silver and gold are partly derived from two or several formations.

\section{PART II. SEGREGATION OF ORES.}

\section{GENERAL STATEMENTS.}

We are now prepared to consider each of the divisions of ores. It will be seen that the different divisions, groups, classes, and subclasses of ores are based upon the last dominant genetic process concerned in their production. It has just been explained that there has been a steady redistribution of the metals, each of them being taken away from some of the formations, and, corresponding with this, segregated elsewhere. Looked at from this point of view, an existing ore deposit may represent the result of segregations by many processes throughout geological time. Thus, if the full history of a metal in a given ore deposit were known it might be found that at different times parts of it had been segregated by various sedimentary, igneous, and metamorphic processes. Not only is this so, but the segregations by these varions processes may have occurred and recurred. It is therefore manifestly impossible to give the full history of ores, or to apply a genetic classification to them which does not restrict itself to the later dominant processes which resulted in the segregation of the ores at the particular places where they now are. Even thus restricted it will be found that some ore deposits placed in one division or class could, with almost equal plansibility, be placed in another. 


\section{DIYISION A. ORES PRODUCED BY PROCESSES OF SEDIMENTATION.}

Since ores produced by processes of sedimentation do not properly fall within the scope of a treatise on metamorphism, they will be considered only to the extent necessary to show their relation to the division of ores somerhat fully discussed-that produced by processes of metamorphism.

The ores produced by processes of sedimentation may be divided into two groups-those formed by chemical precipitation, and those formed by mechanical concentration.

ORES FORMED BY CHEMICAL PRECIPITATION.

Ores produced by chemical precipitation comprise some of the iron, manganese, and alminum deposits.

Bog deposits of iron ore, of recent origin and doubtless in some cases within older rocks, are the direct results of chemical precipitation. The processes by which these develop-the leaching of the metal from the land areas, and its transportation and precipitation as limonite in shallow bodies of watel-have all been fully treated in connection with the development of iron carbonate and limonite (see pp. 824-829, 842-845), therefore the process will not be here again described. Some manganese deposits are, in part at least, the direct result of chemical precipitation, the lines of development being the same as those of limonite.

Hayes holds that certain bauxite deposits also are the result of chemical precipitation. According to his views the almminum for some of the banxite deposits of Arkansas was taken into solution by underground water, was brought to the surface by springs which issued into a shallow sea, where the aluminum and iron oxides were chemically precipitated. (See Chapter XI, p. 985.) Since these deposits are considered in the chapter on the redistribution of the elements nothing further will be said here in reference to them.

Aluminim and iron are the most abundant of the metals, while manganese is rather plentiful. Again the law of mass action applies. The abundant metals are those whicl are likely to be thrown down as chemical sediments in sufficient amount to constitute ore deposits. 


\section{ORES FORMED BY MECHANICAL CONCENTRATION.}

Mechanical concentrates may be divided into residual deposits, stream deposits, and beach deposits. The term placer, originally used for stream deposits, has been, in some cases, exteuded to seabeach deposits. ${ }^{a}$ The principles which result in the production of residual deposits, stream deposits, and seabeach deposits are the same.

The valuable materials segregated have a high specific gravity and are relatively indestructible. In consequence of their capacity to resist mechanical wear and chemical solution they are segregated in alluvial deposits, in the sands and gravels of streams, and on beaches of lakes and oceans, because the other constituents are transported, worn, or dissolved more readily than is the resistant valuable product. In the production of residual deposits the capacity of the valuable material to resist solution is of dominating importance, and in the production of beach and stream deposits the valuable material must lave power to resist both solution and wear.

The ores produced by mechanical concentration comprise both metals and oxides. The important metals belonging to this gromp are gold, platinum, iridium, and osmium. Practically all of the last three metals which have been exploited have been derived from placers. But of the metals produced by processes of sedimentation gold is the one of dominating importance. To the end of the nineteenth century a very large fraction of all the gold extracted from the earth by man was derived from placers.

The oxides which occur as mechanical concentrates are those of tin (cassiterite) and iron (magnetite). For the first of these compounds the placer deposits are of great importance, but for the iron oxides are relatively unimportant. Although much cassiterite has been taken from veins, for many years the chief supplies of tin ore have come from the East Indiesthe so-called Straits tin-and all except a relatively insignificant amount of this cassiterite has been derived from mechanical concentrates. ${ }^{b}$ The Malay Peninsula now produces almost 50 per cent of the tin of the world;

aschrader, F. C., and Brooks, A. H., Some notes on the Nome gold region of Alaska: Trans. Am. Inst. Min. Eng., rol. 30, 1901, pp. 236-247.

${ }^{b}$ Rolker, C. Al., The production of tin in various parts of the world: Sixteenth Ann. Rept. U. S. Geol. Survey, pt. 3, 1895, pp. $458-192$. 
the adjacent islands, Banca and Billiton, produce about 25 per cent. Doubtless this tin is of the same origin as that of the Malay Peninsula. Thus it appears probable that substantially 75 per cent of the tin of the world is derived from mechanical concentrates. ${ }^{a}$

In a small way magnetite beach sands have been utilized. Those of New Zealand are best known. ${ }^{b}$

An excellent illustration of an iron-ore deposit prodicerl by mechanical concentration was that of Iron Mountain, Missouri, where considerable masses consisting of well-rounded bowlder's of hematite ${ }^{c}$ were found scattered over the mountain as a residual deposit and buried in pre-Cambrian ravines under Cambrian and Silurian deposits.

\section{METAMORPHIC ALTERATIONS OF SEDIMENTARY ORES.}

No sooner are ore deposits produced by processes of sedimentation than they are subject to the metamorphie proeesses, and thus are modified to a variable extent. Sedimentary deposits, whether originally formed in the belt of weathering or in the belt of cementation, later may be in the belt of weathering, in the belt of cementation, in the zone of anamorphism, or partly in one and partly in another. In each case the deposit is subject to the metamorphic processes of the horizon in which it may be. Where a deposit is in the belt of weathering, the material may be dissolved to some extent and the metal carried downward into the belt of cementation. If a deposit is in the belt of cementation valuable minerals may be added to or taken away from it as a consequence of the work of underground water. If the material is partly in the belt of weathering and partly in the belt of cementation a portion of the material dissolved in the belt of weathering may be carried downward and deposited in the belt of cementation, and thus the lower part of the deposit enriched at the expense of the upper part. If the material reaches the zone of anamorphism it may there undergo the alterations of that zone. After having been subject to the metamorphic effect of a certain belt or zone a deposit may be transferred to another belt or zone and thms the alterations of this zone be

a Penrose, R. A. F., jr., The tin deposits of the Malay Peninsula, with special reference to the Kinta district: Jour. Geol., vol. 11, 1903, pp. 135-154.

$b$ Birkinbine, John, The production of iron ores in various parts of the world: Sixteenth Ann. Rept. U. S. Geol. Survey, pt. 3, pp. 29-186, 186.

c Nason, F. L., Iron ores of Missouri: Geol. Survey Missouri, vol. 11, 1892, ]p. $27-3$ 
superimposed upon the previous alterations. These later alterations by metanorphism, like the earlier ones, may greatly diminish or greatly increase the value of the original sedimentary deposit. In consequence of the varying action of the secondary metamorphic processes an ore deposit may be chiefly due to the direct processes of sedimentation or chiefly due to metanorphic processes. There are therefore all gradations between cleposits produced solely by the processes of sedimentation and those formed entirely by the processes of metamorphism.

This is especially well illustrated by the gold placers. Many of these deposits are in large part in the belt of weathering, but extend downward into the belt of cementation. It has been repeatedly, explained that in the belt of weathering ferric and cupric sulphates and chlorides are produced. These are capable of dissolving gold. Doubtless other solutions are formed which have similar power. Wherever these solutions traverse placers it is little short of certain that the gold is dissolved to some extent. The material may be dissolved in the belt of weathering, transported downward to the belt of cementation, and there precipitated; and thus one part of the deposit may be enriched at the expense of another; or sohtion may take place throughout a deposit and, in consequence, a placer be impoverished; but the abstricted material may be precipitated in another deposit, so that correlative with the depletion of some deposits there may be enrichment of others.

The formation of placer deposits has not been restricted to the present geological period. It is highly probable that throughout geological time placer deposits of greater or less richness have been produced, although it is likely that those in early geological times were comparatively small. In many cases as denudation continnes the material of placers is largely transported to the sea, and so forms beach deposits. It at first might be thought surprising that so few ancient beach deposits of gold have been found, but this is partly explained by the fact that gold is undoubtedly dissolved in sea water, since the ocean contains compounds capable of dissolving this metal. When the gold is transported to the seabeach, it is in a very favorable position to be finely ground by attrition, and in this fine condition is especially subject to the solvent action of the sulphates and chlorides of the sea. It has been estimated that in sea water there is a greater amount of gold than has been extracted from the earth by man. 
While some of this gold was undoubtedly transferred to the sea in solution by the streams, it is believed to be probable that a major part of it was transferred to the sea by the streams meclianically, and by the action of the sea upon the beach deposits the gold was dissolved.

River deposits and beach deposits may in consequence of pluysical changes be buried under later deposits, and thus pass far down into the belt of cementation or even into the zone of anamorphism. They are then subject to all the metamorphosing processes of the belts in which they occur. In the belt of cementation the circulating underground water will superimpose its work. As illustrating this principle may be mentioned the difference of opinion which exists as to the great gold deposits of the Rand. These deposits, according to Becker, are dominantly narine beach deposits, ${ }^{a}$ although he agrees that the gold has been rearranged to some extent by underground water, ${ }^{b}$ thus explaining the crystallized character of portions of the gold and the existence of gold in cracks within the quartz pebbles. ${ }^{c}$ But Becker holds that not more than a minute fraction of 1 per cent of the gold has been introduced from an extraneous source. Others have held that the Rand deposits are of alluvial origin, i. e., stream placers; and still others believe that the gold was deposited from solution at the time the gravels accumulated. $^{a}$ Upon the other hand, Curtis ${ }^{e}$ and Hammond ${ }^{f}$ both insist that all of the gold was deposited by underground water, and therefore the deposits belong to the class produced by processes of metamorphism.

Recently an excellent statement of facts in reference to these deposits has been made by de Lamnay. ${ }^{g}$ According to this author the gold exists in pyrite contained in the siliceous cement, together with other metamorphic minerals, such as chlorite and muscovite. Inch of the pyrite is rounded like rolled grains, but a larger part is well crystallized and presents sharp angles. De Lamay is mable to decide between the hypotheses (1) of

\footnotetext{
"Becker, Geo. F., The Witwatersrand banket, with notes on other gold-bearing pudding stones: Eighteenth Ani. Rept. U. S. Geol. Survey, pt. 5, 1897, pp. 160-177.

${ }^{b}$ Becker, cit., p. 171.

Becker, eit., p. 176.

a Becker, cit., pp. 169-170. $200-201$.

e Curtis, J. S., The banket deposits of the Witwatersrand: Eng. and Min. Jour., vol. 49, 1890, pp.

$f$ Hammond, John Hays, Gold mining in the Transvaal, South Africa: Trans. Am. Inst. Min. Eng., vol. 31,1902, pp. $841-845$.

"De Launay, L., Observations on the Rand conglomerate: Eng. and Min. Jour., vol. 75, No. 14, 1903, pp. 519-521.
}

$$
\text { MON XLVII- } 0 \pm-66
$$


placer deposits, (2) of simultaneous chemical precipitation with mechanical accumulation of the gravel, and (3) of introduction of the gold into the conglomerate by underground waters since its formation. He rejects the idea of a combination of these, saying that "this would only uselessly complicate the hypothesis." It seems to me that the only hypothesis which explains the facts is a combination of the placer and metamorphic processes.

Where two men differ so radically as do Becker and Hammond, the truth may lie between, as is so often the case. Each is possibly partly right and partly wrong. It is natural to think that a given ore deposit can not be produced partly by the processes of sedimentation and partly by underground water. These two classes of deposits are automatically assumed not to grade into each other, whereas it is perfectly clear that such gradation may and probably does exist. It may therefore be suggested that a closer study of the Rand deposits will show that they are partly in the nature of mechanical sediments and partly in the nature of deposits segregated by underground water. If this be the fact, study should be directed to determine the quantitative importance of each.

The placers of California and New Zealand furnish an instance in which it is certain that both mechanical concentration and later chemical modification by underground water have played a part.o In these placer deposits, and especially in the deep placers, crystallized gold occurs not infrequently, and it must be held that at least the rearrangement of this gold has been due to the work of the underground water since the formation of the placers. If this be admitted, the question at once arises as to what extent gold has been added by the circulating waters since the placers were formed. The added gold may have been derived from the leaner upper portion of the placers, from the surrounding rocks, including the reins, or in part from both sources.

It is clear from the foregoing that mechanical concentration or secondary metamorphic action may be the dominant factor in producing a sufficient amount of segregation to make an ore deposit, or botl may be necessary in order to accomplish this work.

The chemical and mechanical ore deposits particularly well illustrate the principle that ores can be classified only upon the basis of the last

Gordon, H. A., Hysteromorphous auriferous deposits of the Tertiary and Cretaceous periods in New Zealand: Trans. Am. Inst. Min. Eng., vol. 25, 1896, pp. 292-301. 
process which is concerned in their segregation. Almost any one of these deposits illustrates the idea. For instance, a sedimentary deposit of bog iron or manganese is finally concentrated by precipitation of these materials in a marsh or lagoon. But the earlier stages of the work of segregation are by underground water, and if this part of the work were considered the ores would be classified as metanorphic. Again, the mechanical concentrates. are not mainly segregated from the sparsely dispersed metal in the original rocks, but are segregated from previous segregations, which may be the result of igneous, sedimentary, or metamorphic processes, or some combination of the two or three. To illustrate, the gold placers of the Sierra Nevada chiefly derived their gold from the vein deposits of the same mountain system. The segregation of the gold within these veins is the most important part of the process and it will be considered under the work of underground water, but the last process-mechanical concentration-produced the placers and it must be taken as the basis of classification. Similar statements could be made with reference to the residual cassiterite of the Malay Peninsula or the residual iron ore of Iron Mountain, Missonri.

DIVISION B. ORES PRODUCED BY IGNEOUS PROCESSES.

Ores produced by igneous processes, like those produced by processes of sedimentation, do not properly come within the scope of this treatise upon metamorphism. 'They will, therefore, be considered only so far' as necessary to show their relation to the ores produced by processes of motamorphism.

Ores directly produced by igneous processes are regarded as a small division by those who have most closely studied them. The recent advocates for a direct igneous origin for certain ore deposits include Togt, Beck, Kemp, Spurr, and others. Emmons ${ }^{a}$ has also favored the idea of at least a first concentration of the metallic contents of ores by processes of differentiation of igneons rocks, more particularly the basic rocks. Spurr has recently well summarized the principles which result in the segregation of ores by magmatic processes. ${ }^{b}$

"Emmons, S. F., Geological dištribution of the usefnl metals in the United States: Trans. Am. Inst. Min. Eng., vol. 22, 1894, pp. 53-95. The mines of Custer County, Colo.: Serenteenth Am. Rent. U. S. Geol. Survey, pt. 2, 1896, pp. 470-472.

$\checkmark$ Spurr, J. E., $A$ consideration of igneous rocks and their segregation and differentiation as related to the occurrences of ores: Trans. Am. Inst. Min. Eng., vol. 33, 1903, Ip. 288-341. 
Since upon the whole Vogt has most closely studied ores produced by magmatic segregation, and has been the most vigorous advocate for the existence of such, I quote from him a paragraph giving a list of deposits which he believes to be of igneous origin:

Ore deposits formed by simple magmatic differentiation are confessedly infrequent, and therefore relatively subordinate in importance to othcr classes. Under this head may be named: (1) The occurrences of titanic iron ores in basic and intermediate eruptives, perhaps also of iron ores in acid eruptires; (2) those of chromite in peridotites and their sccondary serpentines (and also according to J. H. Pratt, those of corundum in the peridotites of North Carolina); (3) a number of deposits of sulphide ores, particularly the nickeliferous pyrrhotites occurring in gabbro (at Sudbury, Canada, Lancaster Gap, Pennsylvania, many places in Norway and Sweden, and Varallo, in Piedmont); (4) according to some authorities, the auriferous pyrites of Rossland, British Columbia; (5) according to B. Lotti, the high-grade copper ores occurring in serpentinized peridotites in Tuscany and Liguria, Northcru Italy (for instance at Monte Catini), and analogous occurrences in other regions; (6) the occurrences of metallic nickel-iron (without economic valuc) in ernptive rocks; (7) those of the platinum metals in highly basic eruptive rocks, etc.

It may be pretty safely assumed that the foregoing list will be enlarged by future investigations, thongh it can never become very extensive. ${ }^{a}$

Of these classes the first mentioned, the titanic iron ores, is probably the largest. This class of ore deposits has been elaborately considered by Vogt, and a full list of illustrative localities is given by him. ${ }^{b}$ Of such ore deposits the only ones with which I an familiar are the titaniferons magnetites at the base of the Duluth gabbro in the Lake Superior region. While I have not studied these deposits closely I have no reason to dissent from Togt's belief that they are differentiation products of the gabbro magma. Recently Lindgren has described a very large titanic iron ore deposit at Iron Momtain, Wyoming, which I mnderstand him to believe to be derived by magmatic segregation from an igneous rock. ${ }^{\circ}$ The total mass of titaniferons iron ores is large, but much of this material is of low grade. It is for the most part high in titanium, averaging about 12 to 20 per cent of titanium oxide, but occasionally having as little as 3 per cent. ${ }^{d}$

a Vogt, J. H. L., Problems in the geology of ore deposits: Genesis of ore deposits, 2d ed., published by Am. Inst. Nin. Eng. 1902, pp. 642-643.

6 Togt, J. H. L., Weitere Untersuchungen über die Ausscheidungen von Titaneisenerzen in basischen Exuptirgesteinen: Zeit. für prak. Geol., Jahrgang 1900, pp. 233-242, 370-382; Jahrgang 1901, pp. 9-19, 180-186, 289-296, 327-340.

c Lindgren, Waldemar, A deposit of titanic iron ore in Wyoming [a paper presented to the Geological Society of Trashington]: Science, new ser., vol. 16, 1902, pp. 984-985.

a Kemp, J. F., Titaniferous iron ores of the Adirondacks: Nineteenth Ann. Rept. U. S. Geol. Survey, pt. 3, 1899, pp. 387-388. 
In consequence of their low grade and the difficulty of smelting them, titanium ores are at present of little or no economic importance. In the future, when high-grade nontitaniferous ores are exhausted, or nearly exlausted, it is possible that such ores will be an important future resoure for iron.

In connection with iron ores produced by magmatic segregation the question naturally arises as to why they are titaniferous. The answer is substantially that they are titaniferous because they are magmatic segregations. The magnetite in diabase, gabbro, and other basic rockis is almost universally titaniferons. This being true, it naturally follows that where this magnetite is segregated in sufficient quantity to be an ore such ore is titaniferous.

So far as I know, all of the iron ores which have been shown to be magmatic segregations are titaniferous. The majority of the great iron-ore deposits which are at present worked are known to have been produced by the action of aqueous solutions. (See pp. 1193-1197.) In view of this fact and the listory of titaniferous magnetites, it seems to me highly probable that none of the nontitaniferous ores of iron are magmatic segregations. -

Certain corundum deposits are the result of direct igneous processes. For instance, the corundum syenite of eastern Ontario, Canada, is to all appearances, as shown by its textnres and structures, a coarse igneous rock. $^{a}$ Apparently the magma was so very aluminous that at the time of crystallization not all of the alumina was able to combine with the various acids, and hence a part of it separated as an oxide, or cormundun, precisely as iron oxide, which does not wnite with the acids.

As to the production of titunic magnetite and corundum ores by magmatic processes there is no difference of opinion. But it appears to me that a point which should be emphasized in this comnection is that aluminum and iron are the two most abundaut metals of nature, and therefore they are the ones which are most likely during crystallization of magmas to segregate as oxides to such an extent as to produce ores.

The extent to which magmatic segregation must take place in order to produce an igneous ore of iron or aluminum is compantively small. To illustrate, the average amount of metallic iron in original igneous rocks is 4.64 per cent, ${ }^{b}$ and in the basic rocks in which magmatic iron ores occur it

" Niller, W. G., Economic geology of eastern Ontario; corundum and other minerals: Rept. Bureau of Mines, vol. 7 , pt. 3,1898 , pp. 210-213.

b Clarke, F. W., Analyses of rocks, laboratory of the U. S. Geol. Survey, 1880-1899: Bull. L. S. Geol. Survey No. 168, 1900, I. 15. 
is more than this, being 8.66 per cent in the Duluth gabbro of Minnesota. ${ }^{*}$ Therefore to produce an ore body by magmatic segregation in such a rock as this the iron need be increased only about seven times. The production of ores of the less common metals by direct magmatic segregation is an entirely different matter. In the original igneous rocks the amounts of copper, nickel, cobalt, gold, silver, etc, are ustrally so small as not to be detected by assay. In order to produce ores of these metals segregation must take place many fold, probably in all cases more than a hundredfold, and in many cases probably a thousand or many thousand fold. Those who maintain that an ore deposit of any of these less common metals is prodnced wholly by magmatic segregation should determine the ratios between the amount of metal in the original igneous rock and in the ore, and show that the igneons processes have segregated the metal to that extent.

These considerations apply to the other cases of ore deposits held by Vogt to be due to magmatic segregation and to the gold-ore deposits referred by Sptur to the same processes. Thus to segregate chromite from peridotite and the sulphides of the less common metals from igneous rocks by magmatic processes alone would require an amount of segregation which is yet to be proved. Of the sulphides ores that of nickel is the one which has most strenuously been held to be due to magmatic segregation. Of nickeliferous pyrrhotites, I have seen deposits at only one locality, newr Sudbury, Canada, where they are associated with norite. I shall not deny that a first segregation of these deposits along the border of the norites may have taken place in part as a consequence of magmatic differentiation. Walker ${ }^{b}$ states that in certain cases near the center of the norite masses there is comparatively little pyrrhotite, and that in passing toward the border's the amount steadily increases nutil the ore deposits are reached. But so far as I have seen the deposits there is a great difference between the nickeliferous norite and the deposits which are mined, a difference between a comparatively small and a high percentage of sulphide. It is these high-grade products which I hold were eertainly to a large extent precipitated from circulating solutions. The increase in the amount

"Winchell, A. N., Gabbroid rocks of Minnesota: Am. Geol., vol. 26, 1900, p. 374.

$b$ Walker, T. L., Geological and petrographical studies of the Sudbury nickel district, Canada: Quart. Jour. Geol. Soc. London, vol. 53, 1897, p. 52. 
of sulphide in passing from the center to the border of a norite area is just what one would expect, even if the material had been segregated by circulating solutions, since the trunk channels for circulation are frequently along the borders of intrusive masses, and at such places solutions from the igneous and adjacent rocks extensively mingle. At Sudbury almost conclusive evidence of segregations by solutions is furnished by distinct veins of pure sulphides, evidently formed in openings in the norite. Both walls of some of the veins are impreguated with ore in varying degrees. The impregnation is greatest at the walls, and in passing from them the amount of sulphide gradually lessens until none is visible. ${ }^{a}$ Ln short, the phenomena are absolutely identical with those which Lindgren has described as especially characteristic of metasomatic processes along the walls of fissure veins.

It may be suspected that a close study of some of the other nickeliferous deposits will show somewhat similar phenomena. To what extent circulating underground solutions have concentrated the nickeliferous deposits of Norway and of Varallo in Piedmont I do not venture to say. Nor do I express any opinion as to the part which magmatic segregation has played in the prodnction of the auriferous pyrites of Rossland, British Columbia, and the high-grade copper ores described by Lotti; but Lindgren, as the result of careful studies by himself and previous studies by King and Raymond, states that the Rossland deposits are metasomatic replacements rather than magmatic differentiations ${ }^{b}$ It is to be noted that the copper ores described by Lotti and that chromite ores described by Pratt $^{c}$ are in serpentinized peridotites.

In those cases in which the ores are in much altered rocks the question certainly should be asked as to what extent the ores have been modified by the processes of alteration. In the other cases, in which no evidence of secondary action is mentioned by Vogt, it certainly is a proper subject of

a While this volume is going through the press a paper by Dickson on the ore deposits of Sudbury has appeared (Ore deposits of Sudbury, by Charles W. Dickson: Trans. Am. Inst. Min. Eng., vol. 34), which gives a full summary of the views that others bave held in reference to the genesis of the Sudbury ores and contains an elaborate discussion of the facts of occurrence of these ores. As a consequence of his elaborate study, Dickson concludes that "while magmatic differentiation has gone on to some extent, the sulphides are not the result of it." He says further: "It might be safely stated that at present the whole weight of the evidence points to the secondary formation of the Sudbury ore bodies as replacements along crushed and faulted zones, with only minor indications of open cavities."

$b$ Genesis of ore-deposits: Am. Inst. Min. Eng., 2(l ed., 1902, pp. 56t-565.

$c$ Pratt, J. H., Occurrence, origin, and composition of chromite: Trans. Am. Inst. Min. Eng., vol. 29,1900 , pp. 22-24. 
inquiry as to what extent magmatic segregation has produced the deposits and to what extent subsequent metamorphic action has been influential. I suspect it will be ascertained, as is so frequently true of ore deposits, that in some of the cases cited the ores, instead of being due to a single process at one period, are due to a combination of processes. Even if a first segregation were made by direct igueous action, as maintained by Vogt, such deposits may have been further enriched by metamorphic processes after the first concentration. (See pp. 1235-1236.)

Concerning the occurrence of metallic nickel-iron in eruptive rocks, wnd platium in highly basic rocks, it may be merely remarked that such deposits are not ores. It is well known that not only these, but varions other metals, such as copper, occur widely distributed in igneous rocks, and, indeed, it has been shown that in such rocks, directly or indirectly, all ores have their" ultimate source. But before the term "ore" can be properly applied to such rocks it should be shown that there is at least a reasonable chance that the economic conditions will be such that some metal may sometime be exploited with profit. It follows that the occurrence of sparsely disseminated metals of various kinds through igneous rocks has no bearing upon the question of the segregation of ores by igneons processes alone.

Spurr, holding that pyrrotite veins are due to magmatic segregation, has applied the same explanation to the gold-quartz veins of the Yukon. ${ }^{\alpha}$ He says the pure quartz veins are produced at the final stage of crystallization in comnection with igneous rocks when the residne "is little more than hot siliceous water, which contains, besides siliea, small quantities of many other rock elements which have not been taken np by the rock-forming minerals." Later, but with no further field study or additional evidence, Spurr goes somewhat further in his views toward magmatic segregation. Explaining the origin of the Yukon and other gold-bearing quartz veins, he says:

Therefore it has been concluded that certain quartz reins in the Yukon district (part, at least, of which are auriferous) have originated by a process of magmatic segregation, which has separated them from other materials while in the state of aqueo-igneous fusion (the condition of molten rock in general), and that they represent the siliceous extreme of that process. From this standpoint, they are a variety of the igneous rocks. But it has been shown that as magmas become more siliceous

aspurr, J. E., Geology of the Yukon gold district, Alaska: Eighteenth Ann. Rept. U. S. Geol. Survey, pt. 3, 1898, pp. 311-316.

b Spurr, cit., p. 312. 
they also contain more water; so, when the stage of quartz reins is reached, the magma is beliered to be so attenuated that it may best be described as water highly beated and heavily charged with minerál matter in solution. ${ }^{\prime}$

He further states that there is no great difference between veins originating in this manner and those having other origins. On this point he says: "A quartz vein originating" by magmatic segregation often might not be distinguishable from one formed in the many other ways which are possible." ${ }^{b}$ 'The only difference which he suggests between gold-quartz veins of magmatic origin and those deposited by aqueous solutions is that the gold ores supposed to be produced by magmatic segregations are "without the admixture of so great proportions of the conmoner metals as is nsual in ore deposits." Spurr, howerer, gives no reasons showing the applicability of this criterion. From my own point of view, I should regard it as applying in the reverse direction. That is to say, if the exceedingly rare metal, gold, be segregated by magmatic processes to such an amazing extent as to produce an ore deposit, it seems to me to be exceedingly likely that other metals would be segregated in comection with the gold ores so as to be present in greater amounts than usual.

Since Spur gives no certain criteria by which gold-quartz veins supposed to be produced by magmatic segregation are to be discriminated from those formed by solutions, I take the conservative view that gold-quartz veins have their origin in solutions, and I ask for positive evidence from those who assert that such quartz veins are produced by magmatic segregation alone.

In general, concerning the production of ores of the metals other than those of iron and aluminum by magmatic segregation alone, I repeat that it seems to me that the enormous amount of segregation required should be taken into account, and that it should be most conclusively shown that this process alone produces the ores before the conclusion be accepted that during the crystallization of the magma segregation took place to the necessary extent.

While Vogt, ${ }^{c}$ Beck, ${ }^{d}$ Lindgren, ${ }^{e}$ and others believe in a direct igneous

a Spurr, J. E., A consideration of igneous rocks and their segregation or differentiation as related to the occurrence of ores: Trans. Am. Inst. Min. Eng., vol. 33, 1903, p. 311.

bSpurr, cit., p. 311.

c Vogt, J. H. L., Problems in the geology of ore deposits: Trans. Am. Inst. Min. Eng., vol. 31, 1902, pp. 131-147.

¿ Beck, R., Lehre ron der Erzlagerstätten, Berlin, 1901, pp. 700.

e Lindgren, Waldemar, Character and genesis of certain contact deposits: Trans. Am. Inst. Min. Eng., vol. 31, 1902, pp. 242-244. 
origin of certain ore deposits, they hold that far more numerons and important ore deposits ${ }^{a}$ are of contact-metamorphic origin instead of the result of direct igneous action. This view is an old one supported by von Cotta, ${ }^{6}$ ron Groddeck, ${ }^{\circ}$ de Launay, ${ }^{d}$ and many others. Still others have used the word "contact after-action" apparently as marking a grade of deposit between contact metamorphic deposits and deposits laid down by aqueous solutions.

Lindgren, considering the phenomena of pegmatitization under the principle already mentioned, that liquid rock and water are miscible in all proportions, has suggested a relation between pegmatite veins and ore deposits; but he is careful to say that the relation between the pegmatites and quartz veins must be proved, and that this has not yet been done. He further says that the California, Idaho, and. Oregon gold-quartz veins show no relation whatever to pegmatitic dikes. He also calls attention to the auriferous quartz veins of North Carolina, described by Pratt, which occur together with barren lenses of pegmatitic quartz. ${ }^{e}$

Thus Lindgren, who has stndied the gold-quartz reins of the United States more extensively than any other geologist, recognizes the fact that so far as his observations go the productive auriferous gold-quartz veins, even if associated with and possibly dependent upon pegmatitic action, are not the deposits which have ordinarily been referred to as pegmatites. Although strongly holding that the majority of fissure veins are "genetically connected with bodies of intrusive rocks, ${ }^{f}$ Lindgren states that in those great fissure veins which he has studied in the West he has not been able as yet to identify the igneons rocks with which the veins are comnected genetically. Further, he says that the waters which deposited gangue minerals of the gold-quartz veins and gold "are chiefly sufface waters, which, after a circuitous underground ronte, have found in a fissure an easy path on which to return."

a Vogt, J. H. L., Problems in the geology of ore deposits: Trans. Am. Inst. Min. Éng., vol. 31, 1902, pp. 13i -140 .

3 Cotta, B. von, Erzlagerstätten im Banat und in Serbien, Wien, 1864. '

$c$ Groddeck, A. von, Die Lehre von den Lagerstätten der Erze, Leipzig, 1879, p. 260.

d Lannay, L. de, Traité des gîtes minèraux et métallifères, Paris, vol. 2, 1893, pp. 245-258.

$e$ Lindgren, Waldemar, Character and genesis of certain contact deposits: Trans. Am. Inst. Min. Eng., rol. 31, 1902, pp. 243-24t.

$f$ Lindgren, Waldemar, Metasomatic processes in fissure veins: Trans. Am. Inst. Min. Eng., vol. 30 , 1901 , p. 691 .

g Lindgren, cit., p. 691. 
Vogt, althongh so strong an advoceste for igneous action, does not include among ore deposits formed by eruptive after-action in connection with pegmatite veins any gold, silver, copper, lead, zinc, or iron deposits. There is therefore agreement between Vogt, Lindgren, and myself upon the fundamental point that the great class of ore deposits which have been known as contact metamorphic deposits were deposited by underground solutions. There is also agreement that the igneous rocks in various instances constituted the partial or chief source from which the metals are derived. There is further agreement that the waters which deposited the materials were hot, and derived their heat largely from the igueons rocks. It follows from this that we agree that the ores were mainly put into their present places during the time in which the igneous rocks were able to produce a contact effect through hot solutions. There is also agreement that the water depositing the ores was derived from two sources, the ordinary circulating underground waters and water derived from the crystallization of the magmas themselves. So far as the waters were derived from the latter source, it is further agreed that in many cases they were rich in metalliferous material, and therefore unusually effective. Probably in some cases solutions from the igneous rock were more important than those of the meteoric origin.

In a genetic classification of ores upon the basis of agency there is no place for the contact deposits. It does not follow that no ore deposits are produced in connection with contact metamorphism. Contact metamorphic ores must be produced by direct magmatic processes and therefore be igneous ore deposits, by gaseons solutions, by aqueous solutions, or by some combination of the three. In other words, the terms contact metamorphism and eruptive after-action are too vague to give any precise meaning with reference to the deposition of ores. That this is so is shown by the very different usages of the words "contact metamorphism" and "eruptive after-action" by different authors. It is perfectly clear that different deposits, or even the same deposit, produced in connection with contact metamorphism or eruptive after-action may belong partly to igneous ores, gaseous ores, and aqueous ores. Shortly after intrusion there may be magmatic segregation along the border of the igneons rocks; later, in the process of cooling, additions may be made to the ore deposits by gaseous 
solutions; and still later, when the rocks have further cooled, further additions may be made by aqueous solutions. Indeed, I suspect that a considerable number of. ores have had such a composite history, viz, first, segregation by magmatic processes, further segregations by gaseous solutions, and finally segregations by aqueous solutions. I hold this latter stage to be commonly the one in which occurs the final concentration necessary to make a deposit of value, and therefore entitler to the name of ore. In the field the general terms "contact-action," to cover all of these three kinds of work, and "contact metamorphic ores," to cover the total result, may be useful; but one can not make a classification of ore deposits in which he introduces at the same time contact metamorphic ores and the classes of igneous ores, gaseous solution ores, and aqueous solution ores.

\section{DIVISION C. ORES PRODUCED BY PROCESSES OF MLTAMORPHISAR.}

It is believed that ore deposits produced by processes of metamorphism are of dominant importance. While ore deposits produced by processes of sedimentation and by igneous processes are of great consequence, they together are subordinate in importance to those produced by processes of. metamorphism.

Ores produced by processes of metamorphism may theoretically be divided into two groups-those deposited in their present positions by gaseouss solutions and those deposited in their present positions by aqueous solutions.

The second group is believed to be more important than all other ore deposits. I hold, therefore, that the dominant agents which deposited ores in their present positions are aqueous solutions. How important is the group of ores deposited by gaseous solutions is uncertain, as the criteria have not been fully worked out by which these deposits can certainly be discriminated from those precipitated from aqueous solutions.

GROUP A. ORES DEPOSITED BY GASEOUS SOLUTIONS.

Ores deposited from gaseous solutions comprise all those ores which are precipitated from gaseous mixtures of all kinds. They therefore include all deposits actually formed by pneumatolytic, fumarolic, and solfataric action. That ore deposits have been precipitated from gaseous solutions 
has been a farorite hypothesis ever since ores were a serious subject for investigation. The idea goes back as far as Eklie de Beaumont, ${ }^{a}$ who supposed that the majority of ore deposits were thus produced. "This theor'y has been especially applied to ores of mercury and tin. During the last ten years the idea has again been taken up and emphasized by a considerable number of vigorons advocates, of whom Vogt, Beck, Lindgren, Weed, and Kemp are well known.

Recently Weed ${ }^{b}$ gave a classification of ores in which he separates pneumatolytic deposits, fumarolic deposits, and gas-aqueous deposits, giving each as one of the major classes. The deposits here placed by Weed together comprise a very large proportion of ore deposits. Spurr ${ }^{b}$ also has given a classification of ore deposits in which contact metamorphic deposits, deep-seated gaseons deposits, fumarolic deposits, and solfataric deposits are recognized as classes. Weed divides his pneumatolytic, fumarolic, and gas-aqueous deposits into subclasses and groups. Moreover, the ores of gold, silver, and copper of many well-known districts are assigned to each of these classes and to the various subdivisions of the classes. However, neither Weed nor Spurr gives the eriteria by which he distributes the various ores among the pneumatolytic, fumarolic, solfataric, and gasaqueous deposits. Nor are the criteria even given by which deposits are known to be formed by gaseous solntions. It has been shown that the heavy anhydrous minerals of the zone of anamorphism probably develop at temperatures above that of the critical temperature of water. (See pp. 182-185, 685.) This has led me to hold that where such minerals have developed with ores formed from solutions, such solutions are gaseous. But I am unable to formulate any criteria, except purely theoretical ones, which subdivide the deposits of gaseons solutions into pneumatolytic, fumarolic, and solfataric. Indeed, I hold that the entire class of ore deposits produced by gaseous solutions, while important, is small as compared with ores deposited from aqueous solutions.

Ores deposited from gaseous solutions above the critical temperature of water may conceivably be produced in the zone of anamorphism in con-

\footnotetext{
a Bull. Soc. géol. de France, $2 d$ ser., vol. 4, 1846-17, p. 1249.

$b$ The genetic classification of ore bodies, a proposal and a discussion (including papers by W. $\mathrm{H}$. Weed and J. E. Spurr): Eng. and Min. Jour., vol. 75, 1903, pp. 256-258.
} 
sequence of the normal increase of temperature with depth. But probably ore deposits belonging here are more commonly produced in connection with eruptive rocks or orogenic morements, or both; that is to say, the eruptive rocks and earth movements are inportant factors in raising the water above its critical temperature. It has already been seen that ores may grade from those deposited by igneous agencies to those deposited by aqueous agencies. At one end the ores are the result of magmatic processes; at the other end the ores are deposited by water. At an intermediate stage it is to be supposed that ores may be deposited from gaseous solutions above the critical temperature of water, viz, $365^{\circ}$.

Lindgren says: "We may assume with great confidence that at the contacts of intrusive rocks with a sedimentary series the temperature usually exceeded $365^{\circ}$ C., and the pressure 200 atmospheres." " Theoretically one would expect that rather frequently in connection with great intrusive masses, and especially in connection with batholitic masses, the water in the surrounding rocks would be raised above its critical temperature, and therefore that its action is pneumatolytic. But the practical question is concerning the importance of gaseous solutions in comection with the ores. What are the ores which were thus deposited? What are the criteria by which they may be identified? The only metallic deposits which Vogt regards as produced by eruptive after-action in the sense of pneumatolytic action, are cassiterite veins." Beck agrees in regarding the tin deposits of Zinnwald, in Saxony, as due to pneumatolytic action. ${ }^{c}$

While it may be possible that some tin deposits may be produced by magmatic segregation or pneumatolytic action, it by no means follows that all of the tin or even a greater part of it is of this origin. Recently Penrose has visited and studied the deposits of the Malay Peninsula. ${ }^{d}$ Here, as is well known, the greater portion of the tin is actually obtained from the allurium; but Penrose's studies have shown that the tin of the alluvium has its original source in reins in the granite axis of the peninsula and in the limestones flanking this axis. The ore in these rocks is associated with sulphides, such as bornite and chalcocite, and occurs in veins which have

\footnotetext{
a Lindgren, Character and genesis of certain contact deposits, Trans. Am. Inst. Min. Eng., vol. 31, p. 238.

$b$ Togt, eit., pp. 132-137.

'The origin of ore deposits (discussion by R. Beck): Trans. Am. Inst. Min. Eng., vol. 31, 1902, p. 945.

(d Penrose, jr., R. A. F., The tin cleposits of the Malay Peninsula, with special reference to those of the Kinta district: Jour. Geol., vol. 11, 1903, pp. 135-15t.
} 
all the characters of ordinary water-deposited reins, and which are substantially alike both in the granite and in the limestones. Were it not for the cassiterite there would be no reason to suggest that these deposits differ in any way from other vein deposits produced by underground water. (See pp. 1058-1065.) As already pointed out, abont 75 per cent of the tin of the world is produced in the Malay Peninsula and from Banca and Billiton. The product is mainly a mechanical concentrate, but the cassiterite for this concentrate is derived from the veins in the limestone and granite. Therefore probably 75 per cent of the present product of tin was deposited from aqueous solutions.

Lindgren finds from his study of metasomatic processes in fissure veins that topaz, garnet, tommaline, and biotite occur as important metasomatic minerals in connection with certain ore deposits. But the metasomatic minerals which are found in an overwhelming preponderance in ore deposits are those which are produced by water action in the belt of cementation, viz., hydrous silicates, carbonates, oxides, etc.

The metallic ore deposits which contain anhydrous minerals Lindgren divides into three classes, (1) topaz-cassiterite veins, (2) tourmalinic goldcopper veins, and (3) biotitic gold-copper veins. ${ }^{\alpha}$ Lindgren's description of these veins shows that usually they are not in the igneous rocks, but are largely replacement deposits in adjacent rocks. Pyrrhotite and chalcopyrite carrying gold are found as replacement products in feldspar, and by gradual extension of the processes finally replace the whole rock. The process of formation of the biotitic gold-copper veins is "more characteristic of dynamic metamorphism than of ordinary fissure veins." $b$ Lindgren describes the ores between Signal Peak and Meadow Lake as consisting of pyrite, pyrrhotite, and sphalerite, with some galena, with a gangue consisting of quartz, epidote, and tourmaline, with some mica. He says "the ores occur intimately intergrown with this gangue." " Lindgren divides the copper deposits of the gold belt of the Blue Mountains of Oregon into various "types." The Seven Devils type, he says, is a contact deposit of chalcopyrite and bornite between limestone and diorite, which has a gangue of garnet, epidote, and other contact minerals. The tommaline type has

a Lindgren, Walclemar, Metasomatic processes in fissure veins: Trans. Am. Inst. Min. Eng., vol. 30,1901 , pp. 619-645.

${ }^{b}$ Lindgren, cit., p. 645.

c Lindgren, Waldemar, The auriferous veins of Meadow Lake, California: Am. Jour. Sci., 3d series, vol. 46,1893, p. 205. 
an ore consisting of chaleopyrite and pyrite associated with the gangue of quartz and tourmaline. He here places the Copperopolis mine and Jessie vein. The ores are intergrown with quartz and toumaline. At the Jessie vein the other gangue materials are calcite, dolomite, and specularite. $^{a}$ Lindgren says the copper deposits of the Seven Devils and tourmaline types "are of rare occurrence."

In the South Mountain district of Idaho, an argentiferous galena, with some zinc blende and copper minerals, occurs in crystalline limestone and in schist. The gangue minerals are quartz, calcite, actinolite, brown garnet, and ilvaite, the gangue ninerals and ores being intergrown. ${ }^{\circ}$

Weed states that the Jimenez copper deposits of Mexico follow a line of contact between limestone and granite, the limestone being largely converted into massive garnet. ${ }^{d}$ He further states that the Porvenir goldcopper vein in the Sierra Azul mining district of Mexico occurs in granite, and has tourmaline as an abundant gangue mineral.

Yung and McCaffery describe the copper deposits of San Pedro, in New Mexico, as contact deposits in limestone. The limestone has been largely replaced by garnet. Chalcopyrite is intimately associated with the garnet, and with subordinate amounts of specular hematite, epidote, vesuvianite, wollastonite, quartz, and calcite. They say "the ore is always accompanied by garnet, althongh the garnet does not in all places carry ore. When the garnet carries the ore the chalcopyrite is disseminated throughout its mass, and appears to be of synchronous origin." $f$

In those instances in which it is clearly shown that heavy anhydrous minerals, such as topaz, tourmaline, garnet, and biotite, develop simultaneously with the deposition of the ores by metamorphic processes, it seems highly probable that they formed under the conditions of the zone of anamorphisin and that the temperature at the time of the deposition was above the eritical temperature of water.

a Lindgren, Waldemar, The gold belt of the Blue Mountains of Oregon: Twenty-second Ann. Rept. U. S. Geol. Survey, pt. 2, 1901, pp. 629-630.

bLoc, cit., p. 629.

Linilgren, Waldemar, The gold and silver veins of Silver City, De Lamar, and other mining districts in Idaho: Twentieth Ann. Rept. U. S. Geol. Survey, pt. 3, 1900, p. 189.

a Weed, Walter Harvey, Notes on certain mines in the States of Chihuahua, Sinaloa, and Sonora, Mexico: Trans. Am. Inst. Min. Eng., vol. 32, 1902, p. 404.

e Loc eit., P. 440.

$f$ Yung, Morrison B., and McCaffery, Richard S., The ore deposits of the San Pedro district, New Mexico: Traus. Am. Inst. Min. Eng., vol. 33, 1903, p. 355. 
In this connection it may be recalled that beautiful crystals of the variety of garnet known as spessartite, fayalite, and topaz occur in lithophysæ in recent volcanic rocks, especially in the openings in them. 'The formation of these openings in the lavas and the development in them of these minerals naturally suggest the action of gaseons solutions. It has also been pointed out (p. 685) that so far as the heavy anliydrous minerals have been reproduced artificially under conditions where water is present high temperature and pressure have been necessary. For instance, Chrustschoff obtained from water solutions heated to a temperature of $550^{\circ} \mathrm{C}$. amphibole, pyroxene, quartz, and adularia. ${ }^{a}$

It thus appears that both observation and experiment strongly favor the idea that such minerals as topaz, garnet, and amphibole, so far as separated from solutions, are deposited by gaseous solutions above the critical temperature of water. If this be so, it follows that those sulphides which were deposited simultaneously with the development of the heavy anhydrous minerals were precipitated from gaseous solutions.

It is evident that it is difficult to make a certain case in favor of gaseous solutions. It nust be shown, where the ores oceur in connection with the heavy minerals supposed to be formed under conditions of gaseous solutions, that the metals have not been introducerd at a subsequent stage when aqueous solutions were the active agent. There should be excluded also the possibility that the ores were deposited by aqueous solutions in the belt of cementation and were later transferred to the zone of anamorphism, where the heavy minerals developed by later alterations in that zone. Apparently in some of the cases above cited the latter possibility is excluded, as all the evidence seems to be in favor of denndation since deposition rather than deeper burial.

Under normal conditions it might be supposed that ore deposits would be produced by gaseous solutions in the deep-seated zone above the critical temperature of water; that above this zone in the belt of cementation ores would be deposited by aqueous solutions, and that above the level of ground water other ore deposits would be produced in the belt of weathering by gaseous solutions. The latter ores would be those to which the terms fumarolic and solfataric are naturally applicable; but, so far as I know, the actual development of ore deposits by gaseous solutions above the

"Chrustschoff, K. von, Ueber künstliche Hornblende: Neues Jahrb., 1891, Bıl. II, pp. 86-90. MON XLVII-04-67 
level of ground water is only a liypothesis. If such deposits exist, I know of no criteria which have been worked out by which they may be discriminated from deposits of aqueous solutions.

The hypothesis that the vapors of the metals rise with the vapors of water from an unknown source and deposit ore in the openings of the rocks is exceedingly attractive, but it has been seen that where openings occur in rocks below the level of ground water, the rocks are saturated with aqueous solutions, therefore the locus of the deposition of ores from vapors would be in the belt of weathering. The view that fumarolic and solfataric vapors have deposited ores has been especially prevalent in reference to cinnabar and such easily sublimed deposits. Daubrée has maintained that tin ores are formed by the sublimation of stannic chloride and stamic fluoride and their reaction upon water. ${ }^{a}$ For the production of any ore deposit by sublimation in this sense I know no scrap of evidence. ${ }^{b}$ In Chapter VI, on "The belt of weathering," it has been seen that where there is fumarolic or solfataric action the rocks are rapidly carbonated, hydrated, and oxidized, the mechanical result being softening and disintegration. The products are colored yellow or brown by oxide of iron. 'That metallic ore deposits have been produced in comnection with such action remains to be proved.

It has already been seen that in varions recent classifications of ore deposits, which are made mainly upon the basis of agent, there are also introduced contact action and eruptive after-action. In so far as deposits are precipitated from gaseous solutions, whether the solutions be derived partly from the intruded and partly from the intrnsive rock, or partly from both, they belong in this class rather than in an independent class erected on an entirely different basis and therefore an incongrnous element in a scientific classification.

GROUP B. ORES DEPOSITED BY AQUEOUS SOLUTIONS.

It has been stated that ores deposited by aqueous solutions are believed to be more important than all others combined. The evidence in faror of this view will not be presented in detail, but a few of the more salient points bearing upon it will be summarized.

a Daubrée, A., Memoir sur le gisement, la constitution, et l'origine des amas de minerai d'étain: Ann. des Mines, 3 d series, vol. 20, 1841, p. 65.

${ }^{b}$ This statement is restricted to the metallic ore deposits; it does not apply to deposits of sulphur and similar compounds made in connection with volcanic action, in reference to which I express no opinion. 
First, it has been shown (pp. 571-572, 612-640) that the general cementation of the belt so named is due to the work of underground water. The evidence upon this point is briefly summarized in this chapter. (See pp. 1024-1028.) If general cementation is correctly attributed to deposition by underground water, it can hardly be doubted that many ore deposits are due to the same agency, since in general the majority of ore deposits differ in no essential respect from the ordinary cementation products, except that they contain an unusual amomnt of certain metals of importance to man. If underground water carried and deposited the material in the openings of sand, transforming them to sandstones and quartzites, in the larger openings of conglomerates and great tuff formations, thus indurating them, and in the innumerable openings produced by joint, fault, bedding parting, and brecciation fractures, it follows that similar deposits containing a minute fraction of a per cent of gold or silver, a small amount of copper, or a large quantity of iron-in other words, ores-are also the results of aqueous deposition. However, evidence that the majority of ores are deposited by underground waters does not rest alone upon the general argument of cementation.

The second argument in favor of the deposition of the majority of ores by aqueous solution is the nature of the accompanying gangue minerals and their relations to the ores. The gangue minerals which accompany the great majority of veins are the hydrons silicates, including kaolinite, sericite, the zeolites, and chlorites; the carbonates, such as calcite, dolomite, and siderite; and the oxides, such as quartz and hematite. In other words, the dominant gangue minerals are the identical ones produced on an extensive scale by metasomatic processes within the belt of cementation, and deposited upon a grand scale in the openings of that belt, thus cementing the rocks.

But the conclusion that such minerals are deposited from aqueous solutions does not depend upon their likeness to the minerals of the belt of cementation. Actual observations show that these minerals are now being deposited by aqueous solutions. This has been observed at various places. In this country the most famous localities are Sulphur Bank, California, Steamboat Springs, Nevada, and the Yellowstone Park. Perhaps the best-studied instance of all is that of Boulder Hot Springs, Montana, where the vein deposits and the alterations of the accompanying rock have been recently very closely examined and well described by 
Weed. ${ }^{a}$ The spring issues through a granite. This granite has been extensively altered into sericite, kaolinite, and zeolite. The filling of the vein consists of quartz, zeolite, and calcite. Weed finds that the vein filling contains a very small amount of gold and silver, and also that the altered granite contains a smaller amount of silver and a trace of gold. The thin sections show the presence of pyrite and hematite. Thus there is actual mineralization of this vein. ${ }^{b}$ Substantially the same phenomena as those at Boulder Hot Springs have been long known to exist at Steamboat Springs and Sulphur Bank. It is therefore certain that at those localities, where ore material is accompanied by the minerals characteristic of secondary action in the belt of cementation, the ores were deposited by aqueous solutions. If this be so, it is little short of a certainty that in general the ores associated with similar gangue minerals in the belt of cementation are deposited from aqueous solutions. At any rate, one who maintains that ores so intimately associated with the ninerals mentioned as to show contemporaneous deposition are not deposited by aqueous solutions must furnish evidence upon which he reaches a conchusion adverse to all observed facts.

It is to be observed that this reasoning is in accord with the fundamental hypothesis of geology mentioned at the outset of this treatise, viz, that when a certain set of complex forces and agents is observed to produce complex phenomena, and no other combination of forces and agents has been observed to cause such phenomena, the conclusion is that the phenomena are to be referred to the forces and agents now at work.

A third argument showing the direct connection between the recognized work of underground water and deposits of ores has been fully stated by Posepny. For the banded structure so characteristic of fillings of openings in rocks, whether these contain metals in sufficient quantity to be recognized as ores or not, Posepny proposes the term crustification." That crustified or banded or comb veins are usually preeipitates from underground waters no one doubts. It has yet to be shown that regular erustification, so general a phenomenon in ore deposits, is produced by any other agent than aqueous solutions.

a Weed, Walter Harvey, Mineral vein formation at Boulder Hot Springs, Montana: Twenty-first Ann. Rept. U. S. Geol. Survey, pt. 2, 1900, pp. 227-255.

$b$ Weed, cit., pp. 248-249.

c Posepny, F., Genesis of ore deposits: Am. Inst. Min. Eng., 2d ed., 1902, p. 12. 
As further evidence of the deposition of ores from aqueous solutions we may now pass to illustrations of ore deposits that exhibit phenomena identical with those which are known to be produced as a consequence of the action of aqueons solutions.

Upon the point that the iron ores are dominantly produced by the circulation of ordinary meteoric waters, there is no difference of opinion; there is general agreement also that these waters are mostly descending waters at ordinary temperatures. (See pp. 1193-1197.) The importance of waters of meteoric origin at ordinary temperatures in the genesis of ores should perhaps be emphasized. Probably the iron ores preponderate in volume over all other metallic ores. In the United States, 'Great Britain, and Germany $66,000,000$ tons of iron ore were mined in the year 1902. It is not probable that this amount is approached by the remaining metallic ores. Not only do the iron ores occur in largest quantity, but iron is a metal of dominant importance. There is no question that the world could spare all the other metals better than it conld spare iron. If it be agreed that iron is more important to the advancement of the race than all other metals, and that iron ore occurs in greater quantity than all other ores and is dominantly deposited by meteoric water's at ordinary temperatures, it follows, disregarding the manner of the deposition of any other metals, that the work of meteoric waters at ordinary temperatures is the most important factor in metallic ore deposition.

Other metals also are dominantly deposited by aqueous solutions. Many ore deposits are so associated with the general process and the belt of cementation that one must hold that the work of cementation and the deposition of ores were simultaneously cansed by the same agent. For instance, the San Jnan tuff of Colorado, a Tertiary volcanic formation, at the time of its deposition inust have been exceedingly porous. It is now so thoronghly cemented by quartz and other gangue minerals that the microscope can discover no openings. In the cementation of this tuff formation an immeasmably greater quantity of material was deposited between the fragments than is now found in the veins. The filling of the intersecting veins contains the same gangue minerals as those which cement the tuffs. It is perfectly clear that the formation of these veins was an incident in the general process of cementation. In some of the veins, and to a variable extent in the same vein, a sufficient amount of mineral was 
deposited to make the material an ore. The gangue of such veins, the barren reins, and the cement of the tuff are commected physically and are similar mineralogically. Thus it is certain that they are the result of like processes, and few can doubt that the general cement and rein filling were deposited through aqueous solution.

The conglomerates and amygdaloids of Lake Superior furnish conclusive evidence that the deposition of the copper was a mere incident in the general process of cementation. Throughout the Lake Superior region the Keweenawan amygdaloids, sandstones, and conglomerates have been cemented by the minerals which developed in the belt of cementation. Throughont this region, coincident with this process, there was deposited sparsely disseminated copper. Scarcely a Keweenawan district has been studied in which such disseminated copper, associated with the cementation minerals, may not be seen, and in many cases it is sufficiently abundant to warrant exploration with the hope of finding ore deposits. In only a single district, howerer, that of Keweenaw Point, has copper been discovered in sufficient quantity in veins, amygdaloids, and conglomerates to constitute ore deposits. In every respect these copper deposits are like the remaining great rolume of the Keweenawan greenstones, sandstones, and conglomerates, being, cemented in substantially the same manner and with the same minerals. At various places on Kerweenaw Point from 1 to 4 per cent of metallic copper was deposited simultaneonsly with the other cementing minerals. There can be no escape from the conclusion that the general cementation of the Keweenawan rocks and the deposition of the copper were performed by the same agent and at the same time. I do not know that any one has ever held that this general cementation is the result of other than aqueons solutions. If this general belief be true it is conclusively shown that the copper was also deposited by aqueous solutions. Other districts similar to those mentioned could be cited.

Passing to veins of lead, zinc, gold, and silver it is found that all but a comparatively small number of such veins exhibit the cementation minerals which lave been mentioned. The ores are so intimately associated with these gangue minerals that they must have been simultaneously deposited. In many cases it can be shown that the filling of the veins was contemporaneous with extensive alterations of the walls within which developed like minerals, and with the general cementation of the belt of cementation. 
Generalizing in reference to districts, it may be said that, exclnding sedimentary deposits, probably all of the great mining camps of the world show the phenomena which indicate deposition by aqueous solutions. Certainly this is true for America. The ore deposits which have been shown to be formed by gaseous solutions, or by magmatic segregation, are at comparatively small and little known camps.

Objection has been raised to the above general statements as to the importance of aqueous solutions, on the ground that in many ore-bearing districts there is not now a vigorous aqueous underground circulation. ${ }^{a}$ This may be true of deposits either in humid or in arid regions. Many important humid districts could be mentioned in which the circulation is at present very feeble. For instance, in the deep copper deposits of the Lake Superior region there is little water. The same is true of the San Juan districts of Colorado, of the deep mines of Przibram, and of many other places in the world. Another instance in which deep workings have shown very little circulating water is that of the Newhouse tumel, at Idaho Springs, Colo. This tumnel, more than 4,000 meters long, in a granitegneiss-schist complex of rocks, shows but an insignificant amount of water. A small amount percolates in at different places, but the quantity is so small that it is ignored in the drifting arrangements. For arid regions with small circulation the copper mines of New Mexico and Arizona furnish admirable illustrations. Indeed it not infrequently happens that in such regions, after one reaches a moderate depth, the levels are dry, or even dusty.

But from the above facts it is a mistake to infer that when the ores were deposited there was not a vigorous circulation. As has been so fully explained in various places, the very process of cementation lessens the size and number of the openings, and when the process nears completion the openings all become subcapillary and circulation practically ceases. $\mathrm{We}_{\mathrm{e}}$ have already seen that such are the facts in reference to the Lake Superior conglomerates, the San Juan tuffs, and to the rocks of varions other regions. The original openings, and the deformation cracks and crevices have been so thoroughly cemented, and since that time so few new fractures have been formed, that but little water can find access from the surface.

a Kemp, J. F., The rôle of the igneous rocks in the formation of veins: Trans. Am. Inst. Min. Eng., vol. 31, 1902, pp. 184-198. Rickard, T. A., Water in veins, a theory: Eng. and Min. Jour., vol. 75, 1903, pp. $402-403$. 
Under present conditions mines may be dry even when the openings have not been closed by cementation. For example, very recently in New Mexico and Arizona there have been important climatic changes. It is well known that these districts were humid in the Quaternary period, during at least two different epochs. During these times the level of underground water was probably as near the surface as it is in the humid districts of the west at the present time. Therefore in these districts in late geological time there was a vigorous underground circulation at those places where cementation was not complete.

The dryness of mines which at the time of the vein filling had a vigorous circulation may be due either to cessation of circulation by cementation or to cessation of circulation in arid regions in consequence of change from humid to arid conditions.

It seems to me that where the gangue minerals are those known to be deposited by aqueous solutions, and the relations of the vein fillings are such as to show that they were deposited contemporaneously with the general cementation material, these facts are decisively in favor of action of aqueous solutions notwithstanding absence of vigorous circulation at the present time. Those who argue that the ores were not deposited by aqueans solutions because there is not now a vigorous aqueons circulation have equally good or better ground for stating that the ores were not deposited by gaseous solutions; for certainly in regions of ore deposits where there is not now a vigorous aqueous circulation there is still more notably a deficiency in gaseous circulation. By a strange inconsistency some of the men who have held that the main class of ores is not deposited by aqueous solutions, and have used as an argument for this belief the absence of a present rigorms circulation, have jumped to the conclusion that such ores were therefore deposited by gaseous solutions, not taking the trouble to ask whether the same argument applied in this case.

In this connection it is to be recalled that in those cases where actual vein filling is now known to be going on, as at Steamboat Springs, Sulphur Bank, Boulder Hot Springs, and varions other localities, there is now a vigorous aqueous circulation. Also in some cases of very recent vein formation, as at the Comstock lode and Cripple Creek, where the openings were not fully elosed by cementation, an enormous amount of water is landled in mining. The Portland mine at Cripple Creek, Colo., from 1898 
to 1902, pumped between 300 and 900 gallons per minute, with maxima for short periods much higher than this. ${ }^{a}$ Could there be more decisive evidence that here the circulation is one of extraordinary vigor?

Therefore, I hold, the fact that in many ore-producing districts there is not now a vigorous circulation is no evidence of the nonexistence of such a circulation at the time the deposits were formed.

Finally, while comparatively little stress is to be placed on authority, it is certain that there has been general agreement among the majority of the great workers upon ore deposits as to their deposition by aqneons solutions. Upon this point Bischof, von Groddeck, von Cotta, Daubrée, and Posepny all agree. Posepny differs from some of the authors mentioned in such particulars as the source of the ores and the depth from which the waters rose. Between the authors mentioned there is difference as to whether the waters depositing the ores are mainly ascending or descending, as to the somrce of the material for deposition, and as to the canse of the circulation of the water. 'There is no difference between them upon the fumdamental point that the great majority of ores are precipitated from aqueous solutions in the positions where they are now found.

My first main conchusion in reference to ores deposited by aqueous solutions is that they form the dominant class.

\section{THE SOURCE OF AQUEOUS SOLUTIONS.}

Since it has been shown that considerable circulation of underground water in the zone of rock flowage can not be assumed, it follows that we can not suppose that the water of the zone of fracture passes into or is derived from the zone of rock flowage on any large scale. Doubtless this transfer does take place to some extent. Also hydration and dehydration of the rocks are constantly taking place, and these processes at any given place to a small extent subtract water from or add it to the circulation. Further, through volcanism water originally occluded in magma is transferred from the zone of rock flowage, or possibly even from the centrosphere, to the zone of rock fracture, and by the crystallization of the magma is there liberated and thus becomes a part of circulating mnder- 
ground water. But the water of meteoric origin is held to be dominant. It has already been noted that the great iron-ore deposits have been concentrated by waters of meteoric origin. It is further believed that the waters from which were deposited many other ores, the association of which show they were precipitated from aqueous solutions, are also dominantly of meteoric origin. It has been shown already that in order to produce aqueons ore deposits the amount of water required was probably many thousands of times the volume of the minerals deposited. If this be so, even if all the water exuded-from magmas at their time of crystallization could be supposed to be converged into the trunk channels holding the ore deposits, this would be but a fraction of that required for the segregation of the ores.

It is impossible to make an exact quantitative estimate of the relative proportions of the waters of meteoric origin and igneous origin concerned in the production of aqueous deposits. But I have no donbt whatever that water of meteoric origin forms more than 95 per cent of such waters, and I think it probable that it constitutes more than 99 per cent, if all ore deposits produced by underground water are taken into account. Mistaken conceptions upon this point frequently have been due to the fact that anthors in considering this matter often take into account only ores of a part of the metals, such as those of gold or silver, whereas a general statement with reference to the proportion of water of meteoric origin should take into consideration deposits of iron ore and of the other base metals. Even in the case of ore deposits closely associated with igneous rocks, it is believed that the water is dominantly of meteoric origin. For instance, at the present time, ore deposits are known to be in the course of formation at Steamboat Springs, Sulphur Bank, the Comstock lode and Boulder Hot Springs, Mont., described by Weed." The same is probably also true of the numerous hot springs of Yellowstone Park. The quantity of water which issues from these hot springs is enormons. These springs, in volume of water and in their relation to the topography and precipitation, are in all respects like the vastly. more numerous and more important springs which have ordinary temperatures. The study of underground circulation with reference to artesian waters has shown beyond question that the waters discharged from the great majority of springs is of meteoric

a Twenty-first Amn. Rept. U. S. Geol. Survey, pt. 2, 1900, p. 227-255. 
origiu. Numerons large springs are found both in regions in which there has been 110 igneons action for a long time and in regions in which volcanism is now or has been recently prominent. No one wonld claim that in regions of the former class the water is of other than meteoric origin. For instance, no one wonld hold that the waters of the great springs of the Appalachians and the Mississippi Valley are derived from any other source. Why then should this be held in reference to the Cordilleran region of the West? He who maintains that the water for these springs is largely derived from igneous rocks must show that the amount which issues is greater than could be expected upon the meteoric theory, taking into account the precipitation, the climate, the character of the rocks and the topography. The only way to find the effect of an agent, snch as igneous rocks, with reference to the water is to compare regions in which these rocks occm with others in which they are absent. Making this comparison, observation has as yet not shown a difference of volume, but in regions of volcanism the waters issuing from springs are frequently hot, and are depositing more than an average amount of mineral material. This difference is therefore logically referred to the igneons rocks. During its underground jomrney the water comes into contact with or comes near to hot rocks, and thereby becomes heated. In consequence of this it becomes a far more potent chemical agent, and takes into solution a large amount of mineral matter. When gathered into and rising in trunk channels a considerable portion of this mineral matter is depositerl. This effect may be accentnated in volcanic regions by mechanical action. As has been pointed ont in other places, the deposited material is derived from all the rocks with which the molerground water comes into contact during its journey, but in many cases the material is dominantly derived from a single formation or series through which the water jonrneyed.

While it is held that the water is dominantly of meteoric origin, in regions of volcanism where magmas are crystallizing the heated solutions have doubtless had accretions from this source. But those who hold that the enormons quantities of water issuing from lot springs are mainly derived from crystallizing magmas must furnish the evidence in favor of excepting them from the general rule. The fact that cold springs issue adjacent to hot springs has no bearing on the case, for often trunk chamnels which issne close together have entirely different feeding areas. Nor is the 
fact that hot waters deposit more minerals and different minerals an evidence that the hot waters are derived from crystallizing igneous rocks, although it is possible, and rather probable, that in many instances igneous rocks have contributed materials to the solutions. The high mineral content of waters is adequately explained as a function of high temperature. That this is certainly true for Mammoth Hot Springs has already been shown. (See pp. 1031-1032.) The view that the waters of Boulder Hot Springs and of the Yellowstone Park Springs are of meteoric origin was held by Weed at the time he studied and reported upon these thermal regions. ${ }^{a}$

Adjacent to great intrusive igneous masses the contributions of water from erystallizing magma may be important. Since in many cases the ores are deposited during periods of volcanism, the exuding waters are hot, and may be charged with mineral material to an unusual extent. In such cases the waters derived from igneous sources are proportionately far more active than ordinary underground water's. In many instances the water liberated by the magma during solidification has donbtless acted as a potent agent in segregating the ores, but after solidification waters of meteoric origin continue the work. Often to a large extent the solution of the metal and its deposition takes place after the magma has crystallized, but while the rocks are still hot. After an igneous rock has solidified and continues to cool the ordinary process of shrinkage tends to form openings within it, and especially to form openings along its contact with the contiguous deposits. Orogenic movements also find that the contacts between the igneous and the adjacent rocks are planes of weakness, and are likely there to form openings. This being the fact, it is entirely natural, indeed inevitable, that the hot circulating waters during the time that the rock is cooling are most active in the segregation of the deposits. The extreme activity of hot water in general metamorphism and in the production of ore deposits has been repeatedly emphasized. Thus in various instances the water liberated by the magma at solidification may have played an appreciable part in the segregation of ores, but very often the importance of this part has been overemphasized because it has not been appreciated that after solidification takes place the solutions continue the work of segregation of the ores under most favorable cireumstances.

"Weed, Walter Harvey, Mineral vein formation at Boulder Hot Springs, Mont. : Twenty-first Ann. Rept. U. S. Geol. Survey, pt. 2, 1900, pp. 249-252. 
Summarizing, the conclusion is reached that so far as the main work of aqueous ore deposition is concerned the water is that of meteoric origin, which makes its way from the surface into the ground, there performs its work, and issues to the surface again. The amount of water coming from the deep-seated zone of rock flowage, emanating from crystallizing lava and contributed by dehydration, is believed to be relatively small upon the average, although exceptionally important in proportion to its mass. It is held that, at any given time, the meteoric water entering the crust substantially balances that issuing from it, although there may be a slight continuous surplus in favor of the latter.

My second main conclusion concerning ores deposited by aqueous solutions is that the major part of the water performing the work is meteoric.

\section{SOLRCE OF METALS FOR ORES DEPOSITED FROM AQUEOUS SOLUTIONS.}

It is believed that the greater part of the metals for ores deposited by water is derived from the zone of fracture. If the reasoning thus far be correct, viz, that ores deposited from aqueous solutions are transported to their present positions by underground waters, that in order to transport this material an abundant cirenlation is required, and that in the deep-seated zone of anamorphism the circulation is a minimum, it follows that the waters derive their metals from the rocks of the zone of fracture. If any one asserts that the metalliferous materials of mineral veins are derived by water circulation from the centrosphere, or are derived from the lithosphere below the zone of rock fracture, I hold this to be a pure unverified assumption, for which there has not as yet been addnced one particle of evidence, and opposed to which stand well-known 'principles of physics concerning the movement of water in minute openings, and the condition of water in the deep-seated zone.

The conclusion that the waters derive their metals from the zone of fracture was reached as outlined on the foregoing pages, but since the publication of this conchision the observational work of Lindgren upon metasomatic processes in fissure reins has fully confirmed it. Lingdren has made a careful study of the metasomatic changes in the wall rocks while ores and gangues are being deposited. He finds that the abundant minerals produced by metasomatic processes are quartz, fluorite, calcite, magnesite, dolomite, siderite, muscovite, chlorite, kaolinite, zeolites, and the sulphides. 
He does not include epidote among the abundant metasomatic minerals of fissure veins, but it is certain that this mineral is important in certain deposits which are essentially the same as fissure veins so far as the circulating water is concerned. For instance, epidote is very important in connection with the Lake Superior copper. All of these minerals are shown (Chapters VI and VII) to be characteristic of alterations in the zone of katamorphism and especially of the belt of cementation. The carbonates are produced by the process of carbonation of the silicates, and the separation of quartz is the correlative process. The hydrous silicates are prodnced from the anhydrous silicates by a process of carbonation and hydration. For instance, Lindgren" says the muscovite is produced from orthoclase and microcline, and he thus writes the reaction:

$$
3 \mathrm{KAlSi}_{3} \mathrm{O}_{8}+\mathrm{H}_{2} \mathrm{O}+\mathrm{CO}_{2}=\mathrm{KH}_{2} \mathrm{Al}_{3}\left(\mathrm{SiO}_{4}\right)_{3}+\mathrm{K}_{2} \mathrm{CO}_{3}+6 \mathrm{SiO}_{2}
$$

It therefore appears that this reaction is one of hydration and carbonation, and at the time the muscovite is formed silica is liberated, to be deposited in the walls or in the veins.

According to Lindgren the kaolin is mainly formed by the alteration of feldspars, and especially the potassium and sodium feldspars. For potassimm feldspar Lindgren writes the reaction: ${ }^{b}$

$$
6 \mathrm{KAl}_{\mathrm{A}} \mathrm{Si}_{3} \mathrm{O}_{8}+6 \mathrm{H}_{2} \mathrm{O}+3 \mathrm{CO}_{2}=3 \mathrm{H}_{4} \mathrm{Al}_{2} \mathrm{Si}_{2} \mathrm{O}_{9}+3 \mathrm{~K}_{2} \mathrm{CO}_{3}+12 \mathrm{SiO}_{2}
$$

Thus this reaction, like that of muscovite, is one of hydration and carbonation, but takes place to a greater extent, the resultant minerals being kaolin and quartz. It is not necessary to write here reactions for the zeolites, chlorites, and other hydrous minerals, for these may be found in Chapter V. An examination will show that the reactions producing them are those of hydration and carbonation of anhydrons silicates with the liberation of silica.

Lindgren mentions also, as subordinate minerals which form by metasomatic processes, rutile, anatase, garnet, orthoclase, albite, tourmaline, topaz, scapolite, and apatite. These minerals are those which commonly form in the zone of anamorphism. It has already been seen that in those cases in which it is shown that these minerals liave developed at the same

a Lindgren, Waldemar, Metasomatic processes in fissure veins: Trans. Am. Inst. Min. Eng., vol. 30,1901, p. 608 .

${ }^{b}$ Lindgren, cit., p. 614 . 
time the ores were deposited as the domninant metasomatic minerals, the ores were probably formed in the zone of anamorphism or rock flowage, probably through the influence of gaseous solutions. The ore deposits which show these minerals as accompanying metasomatic products are few in number and unimportant in amount as compared with the ore deposits in which the metasomatic minerals are those of the first group mentroned. The point to be enforced at present is that the great mass of metasomatic minerals formed at the time the ore deposits are produced shows that these ores were deposited within the zone of fracture, or the zone of katamorphism.

This conclusion is confirmed by the close relations of the gangue minerals to the country rock. Where a vein runs through a quartzite or very siliceous rock, the gangue mineral is likely to be dominantly quartz. Where a vein runs through basic igueous rocks, the gangue minerals are likely to be largely zeolites and other hydrous silicates, carbonates, and quartz, all decomposition products of such rocks. Where the veins run through limestone the gangue material is likely to be mainly carbonate. It is therefore clear that the gangue minerals are largely segregated from the immediately adjacent rocks trarersed by the reins. If this be so for the dominant minerals, there is every reason to believe that the same conclusion applies to the very subordinate amounts of raluable metals which constitute a small or almost an inappreciable part of the filling of an ore deposit. Numerous examples could be given illustrative of this principle. One of the best known to me is that of the Lake vein in the San Juan district. This vein, ruming through the volcanic breccias, extended into the limestone below, and from this into sandstone still lower down. Where the vein was in the breccia it was a quartzose vein carrying metals; when followed into the limestone it was seen to become a calcite vein, and when followed into the sandstone it gradually changed again into a quartz vein. In the limestone and sandstone the vein was barren. In this case it seens little short of certain that the vein filling was dominantly derived from the adjacent rock, and there is no reason to doubt that in the San Juan tuff the metalliferons material and the quartz alike were derived from the breccias.

While it is held that the waters derive the metals, as their immediate source, from the zone of fracture, it does not follow that the metal for the ores deposited from aqueous solutions mat not have been derived from 
greater depths; for; as fully explained (pp. 1030-1036), magma, carrying various metals with it, does rise from unknown depths into the zone of fracture upon an enormous scale, and there yields its metallic contents to circulating waters.

My third main conclusion is that the metals for ores deposited by aqueons solutions are derived from rocks within the zone of fracture.

\section{WORK OF AQUEOUS SOLUTIONS IN SEGREGATING ORES.}

The work of aqueous solutions in segregating ores is most complex. The ores produced by aqueous solutions may be divided into three subclasses-(1) ores precipitated from aqueous solutions by ascending waters, (2) ores precipitated from aqueous solutions by ascending and descending waters combined, and (3) ores produced by precipitation from descending waters. As the processes of segregation of each of these classes of ores are distinctive, each elass will be considered in turn. In order to produce any of the ores of all these subclasses three stages of work need to be considered-the solution of the valuable metals, the transportation of them to the places where they are deposited, and their precipitation.

SUbCLASS 1. ORES PRECIPITATED Fron ascending AQUeOUS solutions.

There have been endless discussions as to whether ore deposits are produced by descending, lateral-secreting, or ascending waters. It is believed to be a corollary from what has gone before that the first concentration of many ore deposits is the result of descending, lateral-moving, and ascending waters. I say first concentration, for it will subsequently appear that many, if not the majority, of the workable ore deposits precipitated from aqueous solutions have undergone a second concentration. If the waters which deposit ores are mainly meteoric, such waters at the outset are descending. In most cases before they again issue at the surface they must ascend. During the journey they have a lateral movement.

Thus, the larger, more complete idea of the genesis of aqueous ore deposits comprises all of the old ideas, and shows that instead of being contradictory, as supposed by many, they are mutually supporting. Combined, they furnish a much more satisfactory theory than any one of them alone. How true these statements are will appear more clearly later. 
While the subclass is named "Ores precipitated by ascending aqueous solutions," possibly a more exact heading would be either "Ores precipitated from solutions deficient in oxygen," or "Ores precipitated from deep solutions." From the chemical point of view the fundamental fact is that the solntions are deficient in oxygen. It follows from this that the solutions must be sufficiently deep or sufficiently protected from the surface to be free from oxidizing effects. Thus the subclass corresponds rather closely to Posepny's "Ores of the deep circulation." ${ }^{a}$ But since the great majority of ores belonging to the subclass under discussion are deposited from solutions, the vertical element of which at the time of precipitation is ascending rather than descending, the heading chosen is given as the name of the subclass.

SOLUTION OF THE METALS.

In the first stage of the concentration of many deposits the waters are descending. They move slowly downward, are widely dispersed in small passages, have an exceedingly large surface of contact with rocks, and are subject to increasing temperature and increasing pressure. All of these conditions favor solution to the point of saturation. The various metalliferous elements present in exceedingly small quantities in the rocks, as well as many other compounds, are picked up. This follows from the law of physical chemistry, that a solution holds some part of all the elements with which it is in contact.

In the work of solution of the material for the ores, and in the deposition of it by the water, the two physical factors, temperature and pressure, are of great consequence. It is shown (Chapter III) that increase of temperature increases the activity of the water in two ways-first, the speed of the solution is very greatly increased by rise of temperature, and at temperatures of $100^{\circ} \mathrm{C}$., and especially at a temperature of $185^{\circ} \mathrm{C}$. and above, the activity of water is no less than amazing (p. 79). The effect of increase in temperature upon the activity of underground solutions can not be too strongly emplasized. It is also shown that as the temperature rises in general a larger quantity of material may be held in solution, at least for moderate increases of temperature, probably as ligh as $100^{\circ} \mathrm{C}$. (pp. 79-81).

" Posepny, F., The genesis of ore deposits: Am. Inst. Min. Eng., 2d ed., 1902, pp. 1-72. MiGN XIVII-04- 04 
Under normal conditions of increase of temperature of one degree for 30 meters, the temperature would be $100^{\circ} \mathrm{C}$. at a depth of 3,000 meters; therefore, where the circulation is deep, increase in temperature with depth, even under normal conditions, is of great consequence. But in many regions, during the segregation of ore deposits, igneons rocks have been intruded or extruded, or important orogenic movements have taken place, or botl. Wherever igneous rocks have been intruded in the upper part of the lithosphere, or poured ont upon the lithosphere during the time when ore deposits are forming, the temperature of the underground water is higher, and may be much higher than normal, so that even where ore deposits have been produced by a relatively shallow circulation the waters may have had the advantage of a high temperature. The temperature may increase with more than normal rapidity in consequence of mechanical and chemical action. Where there is no evidence of igneous intrusion during the time of ore deposition, but mechanical or chemical action has taken place upon a great scale, the temperature of the underground water may be raised considerably, and thus the deposition of the ores even in such cases be accomplished by solutions at higher temperatures than normal. For the underground solutious which occur in nature, pressure usually promotes solution. (See Chapter III.)

The particular metals and the amounts of them which are taken into solution also depend greatly upon the nature of solutions. To illustrate, where the solutions contain strong acids they are likely to dissolve the metals; where oxygen is abundant the sulphides are likely to be oxydized into sulphates and taken into solution; abundant carbonic acid forms carbonates; where alkaline sulphides and carbonates are present and the solutions come into contact with sulphides, these are somewhat readily dissolved as such.

While all of these compounds favor solutions, in the early part of the journey the most important single factor in the process of solution of the valuable metals is the presence of oxygen in the water. This is of great consequence, because many of the valuable metals, both as original compounds in the igneous rocks and as secondary products, are as sulphides. Where oxidizing waters come into contact with sulphides they are transformed to sulphates, and thus sulphates of most of the valuable metals may be formed, as, for instance, those of silver, copper, mercury, lead, zinc, iron, 
arsenic, and antimony. All of these compounds are readily, or somewhat readily, soluble, with the exception of lead sulphate, which is soluble only to the extent of one part in 31,500 parts of water at $15^{\circ} \mathrm{C} .^{a}$ But even this degree of solubility is entirely adequate to account for the transportation of the lead as a sulphate.

While the effect of the oxygen is to transform the sulphides to sulphates, it is not supposed that the metals necessarily travel as such salts. The well-known principles of physical chemistry make it certain that each of the metals present in solution is combined in part with each of the acids. For instance, if silver sulphide be oxidized to sulphate, and sodium carbonate be present in the underground solutions, as is sure to be the case, then a part of the silver will be transformed to silver carbonate and the sodium will travel in part as sodium sulphate. In this connection the point is that the sulphides get transformed through the agency of oxygen to compounds which are much more readily soluble.

It is further to be remembered that in the upper part of the course of descending water, where oxygen is abundant, $i c$ salts are produced. Of these the sulphates are most abundant, but with them are chlorides also. Of these $i c$ salts, ferric sulphate and chloride are very prevalent.

In salts of this class metallic gold and silver are dissolved. The solution is controlled by the law of mass action and by the temperature. The greater the amount of the salts present, and the higher the temperature, with a given amount of salts, the more gold and silver may be dissolved. Thus, descending solutions are those in which $i c$ salts are abundantly formed and in which the temperature is increasing. Both the abundance and the increasing temperature are favorable to the solution of gold and silver.

Therefore we conchude that the solutions which perform the first work in the genesis of ore deposits, the dissolving of the metals, are descending.

TRANSPORTATION OF THE METALS.

Superimposed upon the downward movement of the waters is a lateral one which, combined with the vertical movement, carries water sooner or later to the trunk ehamnels. The amount of water' taking part in the lateral movement is greatest near the surface of ground water, and from that 
surface on the average decreases to the bottom of the zone of fracture. It has been explained that all fissures and other openings gradually die out below as the zone of rock flowage is neared. (See pp. 187-191, 766-768.) Therefore, for a given fissure, the waters enter it mainly from the side or top, not from the bottom. Furthermore, the water does not enter the fissure at a single place, but at numberless points all the way along its

- course, from the deepest parts to the surface. Somewhere, however, the water which enters a fissure must flow from it. This place may be at the

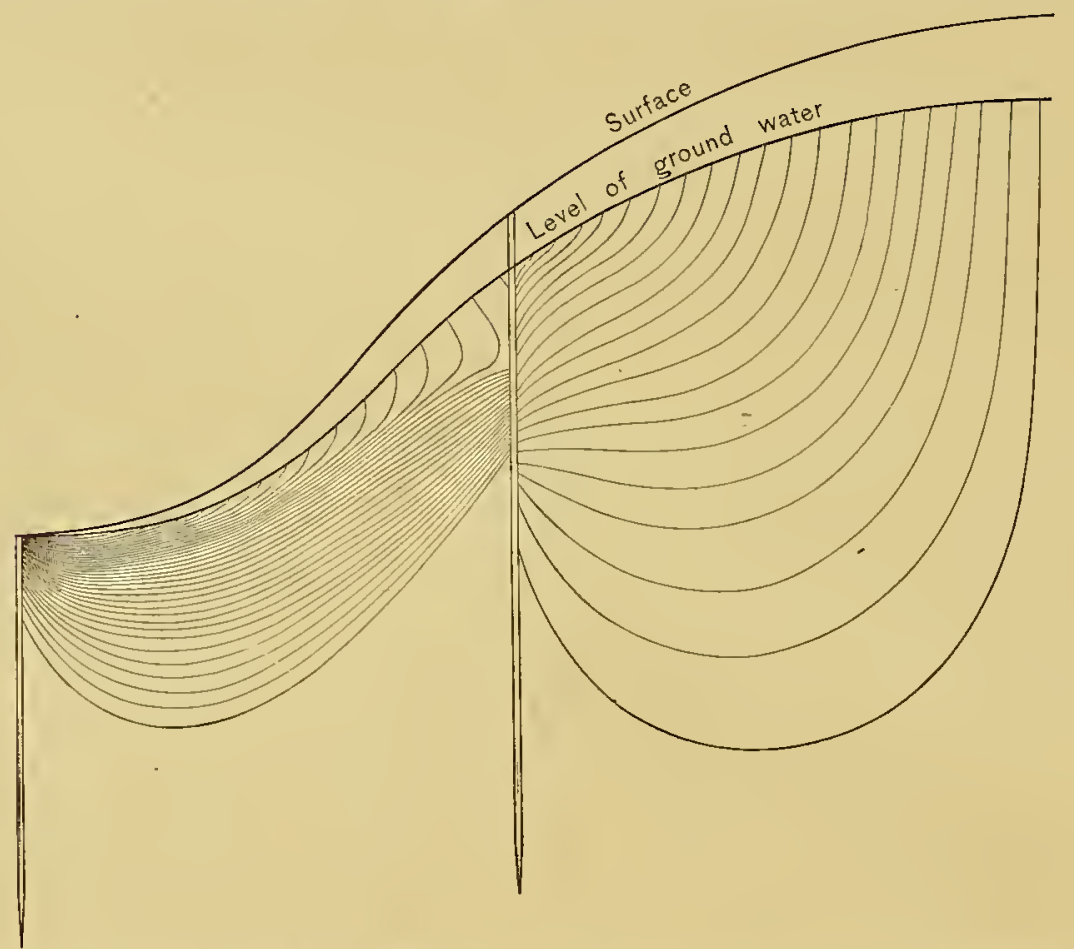

FIG. 2t;.- Ideal vertical section of the flow of water entering at a number of points on a slope and passing to a valley below throngh a homogeneous medium intermpted by two open vertical channels, one on the slope and one in the valley.

surface or at a considerable depth below the level of ground water. (See fig. 26.) The streams entering the fissure at high levels may have a downward movement and contribute water abundantly. Below the level at which water escapes laterally from a channel of given size the water contributed to it decreases on the average with increase of depth, until in the deeper part of the zone of fracture the contributions are very small. Posepny ${ }^{a}$

«Posepny, F., Genesis of ore deposits: Trans. Am. Inst. Min. Eng., vol. 24, 1875, p. 971 . Also Posepny, F., The genesis of ore deposits, Am. Inst. Min. Eng., 2d ed., 1902, pp. 242-243. 
calls attention to the frequently observed fact of the decreasing amount of water contributed laterally as depth increases. As a specific instance of this, he mentioned the Przibram district, in which the amount of water entering the fissures below a depth of 300 meters is so small as to be insignificant, but this may not have been the fact at the time the lode was forming. (See pp. 1063-1065.)

While the amount of water laterally entering a fissure decreases from near its top to the bottom, the amount of mineral material per unit volume in all probability increases on the average; for the waters entering at a low level take a longer jounney through smaller openings and at higher temperatures and pressures than the waters entering at a high level. Therefore it is clear, if the rocks with which the deeper water comes in contact can furnish metalliferous materials, that such water will be heavily loaded. It follows from this, even if the amount of water which is furnished in a short time to a fissure be small, that such water may furnish from the country rock mineral material in solution much more than sufficient to entirely fill a fissure during its long life.

We now understand that, on the average, the amount of water entering a fissure decreases from the level of ground water to its bottom, but that the amount of mineral matter brought into the fissure by the water (but not necessarily deposited) increases per unit volume from top to bottom. It is, therefore, impossible to make a general statement as to whether more mineral material is contributed to a trunk channel in its upper portion or in. its lower portion. Doubtless this varies in different cases. Other conditions than amount of water or depth may be controlling factors. For instance, if igneous rocks be intruded at high or low levels only, such rocks may furnish conditions which determine the amount of metalliferous material contributed by the waters.

While the foregoing paragraphs imply that the lateral moving waters are also downward moving, this is meant only as a general rule. The lateral movement may be accompanied by no downward movement. Not only this, hut lateral movement may be accompanied by an upward component. Indeed, this is believed to be very frequently the case, especially so far as the main branch streams in the deeper parts of the zone of fracture are concemed. In so far as there is an upward component in these branch streams, the reactions which obtain are the same as those of the trunk chamnels to be considered below. 
During the lateral journey of the water, before trunk channels are reached, the transported metals may be largely precipitated. Frequently such precipitates are very widely dispersed and are not sufficiently rich to coustitute ore deposits. Exceptionally the amounts of precipitated material during the lateral movements in the dispersed channels may result in the formation of a product of sufficient richness to constitute an ore. Precipitation may result from any of the canses or combinations of canses which are spoken of (pp. 1081-1088; see also pp. 113-123) as producing precipitation from ascending waters in trunk chamels. For the purpose of illustration, one class of compounds nay here be mentioned. Salts traveling as sulplates may be reduced to sulphides and precipitated by the direct reactions of carbonaceous materials, by the reaction of previonsly precipitated sulphides, or, in the case of copper, silver, etc, by the reaction of abmulant ferrous compounds. The Crystal Falls rolcanics ${ }^{a}$ furnish an illustrative case where rocks have been so profoundly altered by metasomatic changes as to leare scarcely an original mineral present. In them there are sparse, widely disseminated secondary sulphides. In this formation there is no organic material, and the natural cause to assign for the precipitation is the reducing action of the ferrous compounds which are abundantly present. The possible reactions are given on pages 1111-1112.

From the foregoing it appears that ores are carried to trunk channels by laterally moving waters. Lateral secretion is, therefore, an essential step in the first concentration of ore deposits, althongh I use the term lateral secretion in a broader sense than did Sandberger.

The places where the ore deposits themselres are found will now be considered. As already noted, these occur mainly in or adjacent to the more continuous larger openings. These openings are occupied by the trunk streams of circulating waters, and therefore the water is in the latter part of its conrse. Hence these trunk streams, as has already been shown (p.583), have in general an mprard rather than a downward rertical movement. The waters reaching the trunk channel at any point immediately begin their ascent. At any given cross section of a channel there must pass all of the water contributed below. At great depth this amount has already been seen to be small. From a small amount the waters steadily increase in

a Clements, J. Morgan, and Smyth, H. L., with IV. S. Bayley, The Crystal Falls iron-bearing district of Michigan: Mon. U. S. Geol. Survey, vol. 36, 1899, pp. 73-154. 
volume to the point where they begin to escape laterally. (See fig. 26.) Hence in a trunk chamnel of a definite size the circnlation is slow below and increases in speed above. Near the bases of the chamels from which the Mammoth Hot Springs and geysers of the Yellowstone Park issue the amount of water contributed may be small and the movement of the water may be exceedingly slow. Even if true, as held by some, that rapid movement of water is unfavorable to deposition of ores, it is wholly possible that at moderate depth, especially in the deeper parts of a channel from which the flow at the surface is rapid, the conditions are those of slow movement and rapid precipitation of ore deposits.

As the water passes upward the variety of solutions as well as the amount increases, for each stream differs in its salts from every other, since no two streams can possibly have had exactly similar listories. Moreover, the character of the wall rock may vary from place to place. The pressure and the temperature also lessen. These conditions are favorable to precipitation. Therefore many ores in their first concentration are precipitated by ascending waters.

It is now clear that a satisfactory account of the genesis of ores includes ascending waters. Many ores in their first concentration are actually precipitated from the ascending waters, and therefore emphasis has been placed upon this part of the work of circulating waters.

The broader statement of the genesis of a great class of ore deposits is that the water after penetrating the earth is widely scattered in contact with rocks in innumerable minor openings. These waters travel downward with. steadily increasing pressure and temperature. They take up the constitnents of the ore deposits. The downward movement of the waters has superimposed upon it a lateral component, as a result of which the waters are carried to the larger openings. During this process also the waters continue to take material into solution. In the larger openings where the waters are congregated they are upon the average ascending with decreasing temperature and pressure, and the ores are precipitater.

While it is believed that in the great majority of instances the journey of the undergronnd water involves first a descending and later an ascending movement, it is recognized that this is not invariably the case. Upon the descending movement may be superimposed a lateral movement which brings the water to the surface again at a lower level, there being at no 
time an important ascending movement. This is especially likely to occur in districts of great topographic relief, where the descending waters strike an inclined impervions plane dipping toward a valley. (See fig. 27.) In the case illustrated the water falling on the monntains percolates downward through the rocks until it comes into contact with an impervious stratum, which it follows toward the valley until it issues above the stream, having nowhere during its journey an ascending component.

While it is held, as explained above, that upon the whole the descending waters are dissolving material and the ascending waters are depositing

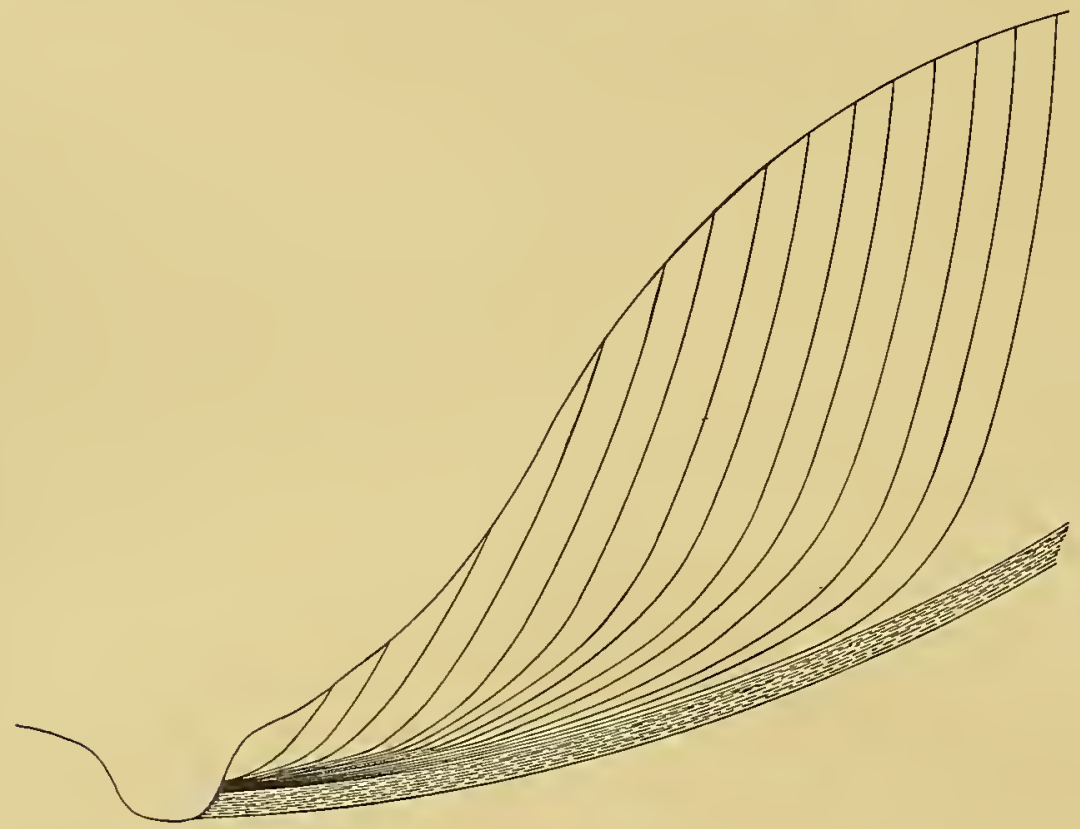

FIG. 27.-Ideal section showing underground circulation in whicb no water anywhere ascends before issuing at the surface.

material, it is not meant to imply that materials are not deposited by descending and lateral-moving waters, nor that materials are not dissolved by ascending waters. Indeed, it is certain that solution and precipitation are taking place at all times throughout the entire course of all the branches of the underground circulation. This is a necessary consequence of the laws of physical chemistry. It is meant only to imply that in the first concentration of one class of ore deposits, solution so far as the ores are concerned is the rule for the descent and deposition for the ascent, although there is no doubt that there are many local exceptions to this. 
It is, of course, mnderstood that the underground circulation in any actual instance is much more complex than that given in the simple ideal case which has been considered. For instance, it is certain that, in the same mineral-bearing area, immediately adjacent trunk chamels may have had very different histories. This is especially well shown by the deposits at Butte, Mont.; where there are two parallel main zones of mineralization, only a short distance apart, the mineral wealth of one of which is mainly copper, while that of the other is mainly silver: ${ }^{a}$ Nany of the other special factors which modify the simple general statement above given are discussed on pages $1199-1222$.

\section{PRECIPITATION OF THE METALS.}

The precipitation of metals in the trunk channels by ascending waters is of so much importance in the concentration of ores that this process needs further consideration.

Precipitation may take place (1) by change in temperature and pressure, (2) by mingling of solutions, and (3) by reactions between solutions and solids. (See pp. 113-123.)

\section{PRECIPITATION BY DECREASE OF TEMPERATURE AND PRESSURE.}

The general relations of solution and precipitation as a consequence of varying temperature and pressure have been already considered. (See pp. 114-116.) Where the increase of temperature with depth is normal, it has been seen that decreasing temperature and pressure due to the ascension of waters from a depth of at least 3,000 meters are favorable to precipitation. Furthermore, the same statement holds even if the increment of temperature be greater than normal, provided the temperature does not greatly exceed $100^{\circ} \mathrm{C}$. Cases in which water issues at the surface at such temperatures are very rare. The probably decreasing pressure and temperature of solntions rising from depths greater than 3,000 meter's are also favorable to precipitation. Since it las just been shown that ascending waters are likely to be in trunk chamels, lessening temperature and pressure are likely to prodnce precipitates in the openings of faults, joints, and bedding partings, and the more open places in sandstones, conglomerates, and amygdaloids.

Since upon the average ascending solutions are those in which the pressure and temperature are decreasing, precipitation is more likely to

a Emmons, S. F., Notes on the geology of Butte, Mont.: Trans. Am. Inst. Min. Eng., vol. 16, 1888, p. $5 \pm$. 
occur from them in consequence of change of temperature and pressure than from descending solutions.

When one attempts to apply these general statements to specific metals, experimental data are lacking. It is undoubtedly true that decreasing temperature and pressure are much inore influential in the precipitation of some metals than of others. Until experimental work has determined how the various economic metals respond to clianging temperature and pressure, it is impracticable to specify the ores in which precipitation is more strongly favored by decrease of temperature and pressure. One would expect that precipitation as a consequence of changing temperature and pressure would tend to give a somewhat orderly vertical distribution of the various metalliferous ores.

As an illustration of the influence of a decrease of temperature we may take the cases of gold and silver. It is well known that gold is precipitated by cuprous chloride, according to the following reaction:

$\mathrm{AnCl}_{3}+3 \mathrm{CuCl}=\mathrm{Au}+3 \mathrm{CuCl}_{2}$

Silver is precipitated by ferrous sulphate according to the following reaction:

$$
\mathrm{Ag}_{2} \mathrm{SO}_{4}+2 \mathrm{FeSO}_{4}=2 \mathrm{Ag}+\mathrm{Fe}_{2}\left(\mathrm{SO}_{4}\right)_{3}
$$

Under given conditions, if a sufficient amount of time be allowed, these reactions will proceed until equilibrium is reached. Stokes has shown that if the temperature is decreased, after equilibrium is reached, these reactions will proceed further, but if the temperature is increased the reactions reverse and the gold and silver are dissolved. Therefore, where for' a given temperature these solutions are saturated with silver and gold, and the temperature is decreased, precipitation of the metals will result.

PRECIPITATION BY MITGLING OF SOLUTIONS.

Precipitation in the trunk channels is produced by reactions caused by the mingling of varions solutions. The mingled solutions may be gaseous and aqueous, or all aqueous. Precipitation by reactions between aqueous solutions and gases is especially likely to take place near the level of ground water, where gases from the belt of weathering mingle with the solutions of the belt of cementation.

Precipitation by reactions between aqueous solutions is especially likely to take place at the intersections of trunk channels, where aqueous solutions 
from different sources meet. Such precipitation takes place under the general law that when solutions of two or more kinds are mingled, if a substance can form which is iusoluble in the liquids present, this compound will be produced and precipitation take place. This ningling of solutions is probably the most important of the causes of precipitation of ores.

It is evident that solutions from different sources enter a given trunk channel at many places and thus a multitude of streams with different composition mingle in a trunk channel. Each of the incoming streams is different from any of the others, although in many cases the difference may be slight. As a case of certain considerable difference may be mentioned ascending and descending streams. (See pp. 1175-1177.) If in a chemical laboratory a multitude of solutions be taken at random and thrown together precipitates will be almost certain to form, and in an underground channel the same effect is likely to be produced when the various solutions come together. This mingling of solutions is one of the most important of all the factors which results in the deposition of the ores. I have little question that the wide variety of solutions which enter a given channel explain in a large measure the exceedingly irregular richiness of ore deposits. Where a metal is found abundantly in a fissure the explanation in many cases is certainly that at or near that place there entered a stream which carried either the precipitated metal or an agent capable of precipitating it from a solution already in the trunk channel. For instance, it is believed that at or near the place where the great bonanza of the Comstock lode was found, there entered either solutions rich in gold and silver, or a solution having a compound which precipitated the gold and silver already traveling upward within the lode. Perhaps the former hypothesis is the more probable.

Ore shoots, or chimneys of ore of exceptional richness, occur very frequently in veins. They are sometimes parallel with the dip and at other times pitch to the right or left of it. The locations of these ore shoots in many instances I believe were controlled by cross fractures or joints through which entered waters, carrying either metalliferous material or solutions capable of precipitating the metalliferous mineral in the trunk chamel at the place where the lateral streams of water entered.

The lead and zinc deposits of the Mississippi Valley, according to Jenney, are larger at the crossings of two sets of fissures than elsewhere. This may be explained partly by the greater abundance of the solutions 
furnished by two sets of fissures, but, as suggested by Jenney, partly by the mingling of two different kinds of waters, thus giving conditions favorable for precipitation.

In the Enterprise mine, at Rico, Colo., described by Rickard, ${ }^{b}$ the ore bodies are in vertical veins and in flats under shales. While a set of cross veins is barren, "the rich ore bodies overlie them in the contact zone." Below the shale it is common to find ores of more than average grade in the pay veins where they are broken by the cross veins. It is believed the explanation of these relations is the reactions resulting from the mingling of the solutions of the "verticals" with the inclined cross veins. With this Ransome's recent sturlies accord. He says: "Large bodies of workable sulphide ore occur only where the solutions in the lode fissures have had opportmity to mingle with laterally moving solutions in the blanket" ${ }^{\prime}$

The silver-lead deposits of the Aspen district of Colorado, described by Spurr, fumish an instance of very probable precipitation of rich ore shoots by the mingling of solutions. Spurr states that generally an ore body is "found at the intersection of two faults, one of these fanlts usually dipping steeply, while the other is much flatter." For this "the explanation is offered that by the mingling of solutions which had previously flowed along different channels the precipitation of metallic sulphides was bronght about."

Probably the rich shoots of gold ore in the Sierra Nevada, which, according to Lindgren, pitch to the left as one looks down the rein, further illustrate the principle of precipitation by mingled solutions. For the most part, Lindgren makes no statement as to the relations of ore shoots and lateral seams. However, on Canada Hill vein there are "occasional rich bunches at the intersections" of the two systems of veins. ${ }^{f}$

a Jenney, W. P., The lead and zinc deposits of the Mississippi Valley: Trans. Am. Inst. Min. Eng., vol. 22, 1894, pp. 189-190, 224.

$b$ Rickard, T. A., The Enterprise mine, Rico, Colo.: Trans. Am. Inst. Min. Eng., vol. 26, 1897, pp. 906-980.

$c$ Rickard, cit., p. $97 \%$.

a Ransome, F. L., The ore deposits of the Rico Mountains, Colorado: Twenty-second Ann. Rept. U. S. Geol. Survey, pt. 2, 1901, p. 301.

$e$ Spurr, J. E., Geology of the Aspen mining district, Colorado: Mon. U. S. Geol. Survey, vol. 31, 1898, p. 234.

$f$ Lindgren, Waldemar, The gold-quartz veins of Nevada City and Grass Valley, California: Seventeenth Ann. Rept. U. S. Geol. Survey, pt. 2, 1896, p. 195. 
It is believed that the Cripple Creek deposits likewise illustrate this principle. Peurose ${ }^{a}$ notes that many of the rich ore shoots necur at cross fissures. It is thought probable that the main cause for the formation of ore shoots at such places is the reaction of solutions furnished by one set of fissures upon those furnished by the other set. It is but fair to say, however, that Penrose makes the explanation, the "mechanical one, in deflecting the course of the ore-bearing solutions."

What are the reactions which result in precipitation from the mingling of solutions? It has been pointed out (p. 1075) that in the upper part of the journey of descending waters $i c$ salts are likely to be present. In the deeper parts of the belt of cementation, where organic matter and ferrous compounds are abundant, these $i c$ salts are commonly changed to ous salts, and such salts are abundant. Such solutions are likely to make their way into the trunk chamels. If they there meet salts of gold, silver, or copper, these compounds may be thrown down. This is likely to take place if the reducing solutions are abundant. That is, the reaction is under the law of mass action. It has already been seen that this reaction is promoted by decreasing temperature. Another reaction frequently resulting in the precipitation of sulphides follows from the mingling of solutions, one of which bears hydrogen sulphide and the other sulphates or other oxidized salts. In trunk chammels the mingling of solutions of these kinds must be very common, the oxidized solutions coming perhaps somewhat directly from the surface, whereas the hydrogen-sulphide solutions have usually taken a longer journey in the belt of cementation, and thus have taken on a reducing character.

While the above explanation may in many cases account for apparent irregularities in the kinds and percentages of metals, other principles are needed to explain the fact that metals occur in a definite order from the surface downward and that many valuable metalliferous ores grow poorer at a depth of 1,000 meters or less. Varying temperature and pressure are important in this connection; but more influential in many instances, as will be shown subsequently, is a second concentration produced by descending waters.

" Penrose, R. A. F., jr., Mining geology of Cripple Creek, Colorado: Sixteenth Ann. Rept. U. S. Geol. Survey, pt. 2, 1895, pp. 164-165. 
PRECIPITATYON BY REACTIONS BETWEEX SOLUTHONS AND SOLIOS.

Precipitating reactions between the solutions and solids with which they are in contact often take place. The solid wall rock frequently produces precipitations of metalliferous ores from the solutions in the trunk chamels in the following ways: (1) It las already been explained that a solid, when placed in contact with a liquid, may precipitate some compound previonsly held in solution, some part of the solid going into solution at the same time. Thus, the wall rock may precipitate ores. (2) The wall rock furnishes the trunk solutions with precipitating solutions, which may precipitate metals already in solution within the trunk channels. (3) The wall rock itself may supply the ore deposit with metalliferous material, which, when it reaches the trunk channel, may be precipitated by the solutions there contained. Where the wall rock is easily soluble, enlargements of the openings occur readily and afford places for the deposition of the metalliferons material. (See pp. 1212-1216.)

The reactions dne to the country rock are likely to be effective in proportion as it is porous and soluble and therefore allows solutions to permeate and to dissolve it. Thus the comtry rock is likely to be especially effective in its reactions where the trunk chamnel is a complex one and gives a large surface of action. It is believed that the effect of the wall rock in these various ways is of great importance in the production of many ore deposits.

As an illustration, may be cited the very general association of lead, zinc, and copper ores, and the accompanying gold and silver, with limestone. It is well known that in many cases ore deposits in limestone are large and rich, and in the associated rocks are small and barren. This is illustrated by the lead and zine deposits of the Mississippi Valley, which occur almost exclusively in limestones, although these rocks are interstratified with sandstones. Where the openings pass into sandstones the ore deposits become small and poor or die out altogether. Precisely the same relation is illustrated in the copper deposits of the Southwest. Here the ores are very largely in the limestone, and when they pass into the acid associated rocks, either sediments or porphyries, become small, and often fail. ${ }^{a}$

a Douglas, James, The Copper Queen mine, Arizona: Trans. Am. Inst. Min. Eng., vol. 29, 1900, pp. 512-513. Ransome, F. L., The copper deposits of Bisbee, Arizona: Eng. and Min. Jour., vol. 75, 1903, pp. 444-445. 
Many other similar illustrations could be given. It is recognized that these relations are explained in part by the ready solubility of the linestones as compared with the acid rocks, thus giving openings for the deposition of ores, but also largely, it is believed, by the reaction of limestone, or its solutions, upon the solutions which contributed the metals. This conclusion, already announced from the geological relations, without reference to experimental work, has been confirmed by laboratory work by Mr. H. N. Stokes. Mr. Stokes has shown that when soluble zinc, lead, copper, or silver salts are heated with iron bisulphide, in the presence of an alkaline carbonate, the metals are thrown down as sulphides. The reactions are given on p. 1117. It was suggested that calcinm carbonate might be substituted for the sodinum carbonate and similar reactions take place, and this Mr. Stokes found to be the fact. It is therefore certain that where limestone is the wall rock it often has a very important influence in the precipitation of the ores.

The supposition that the limestones are a canse of precipitation does not preclude the possibility that they may not also contribute the metals, as in the case of the lead of the Mississippi Valley. But in such cases the precipitation is probably due more to the mingling of solutions in trunk chamnels than to the effect of the wall rock. Of course, in some cases, the association of ore with limestone may be due to more than one of the factors mentioned-the ready solubility of the limestone, its power to canse direct precipitation, to furnish precipitating solntions, and to supply the metals or some part of them.

Another case of precipitation resulting from the influence of the wall rock is the well-known occurrence of metallic copper in the openings of sandstones, conglomerates, and amygdaloids of Keweenaw Point. ${ }^{a}$ The metallic copper between the particles was doubtless precipitated by ferrons solutions furnished by the wall rocks, which in many cases are basic voleanics.

A particularly clear illustration of the effect of wall rock is furnished by ores in which the sulphides are confined to strata containing organic matter, as in some copper deposits ${ }^{b}$ and some of the gold reefs of Australia.

$a$ Irving, R. D., The copper-bearing rocks of Lake Superior: MIon. U. S. Geol. Surv., vol. 5, 1883, pp. $419-430$.

b Posepny, F., The genesis of ore deposits, and Cazin, F. M. F., discussion of same: Trans. Am. Inst. Min. Eug., vol. 23, 1894, pp. 316, 606-607. 
In the case of the copper deposits the organic matter has in all probability rednced sulphites or sulphates to sulphides. The function of the organic matter in the case of the gold may hare been to reduce it to metallic gold, or to produce aus salts, for instance, ferrous sulphate, which reduced the gold. (See pp. 1093-1095.)

GENERAL STATEMEXTS.

In conclusion, it may be said that the precipitation of metallic ores by the mingling of various solutions is probably the most important single factor which results in the first concentration of ores. Probably next in importance to this are the reactions upon the trunk streams, due to the wall rocks. As lateral streams from beyond the wall rocks must pass through the latter, many of these streams produce an effect due partly to materials more remote than the wall rocks and partly to the wall rocks. Thus in many cases the effect of solutions originating beyond the wall rocks and that of solutions furnished by the wall rocks may not be discriminated. Diminishing temperature and pressure, while probably subordinate in their effect to the mingling of streams and reactions due to the wall rocks, are in many instances undonbtedly important, and in some instances dominant, factors. In general, the tendency of writers has been to emphasize the effect of diminishing temperature and pressure, and to minimize or even disregard altogether the effects of mingling solutions or the wall rocks, or both.

Precipitation in many cases is not produced by a single one of the factors, but by two or three of them. For instance, precipitation may be produced by the joint effect of a change in pressure and temperature, by the reaction between gases, solutions, and solids, and by the combination of change in pressure, change in temperature, and the mingling of solutions. In short, all possible combinations of the various canses of precipitation may and do occur in comnection with ore deposits.

COMPOUNDS DEPOSITED BY ASCENDING SOLUTTONS.

Of the metallic ores those of iron, copper, lead, zinc, nickel, silver, gold, and mercury are the more important. These metals vary greatly in the forms in which they are precipitated. The deposits formed by ascending water occur in the metallic form, as sulphides, tellurides, oxides, carbonates, and silicates. The metals deposited in the metallic form in impor- 
tant amounts by ascending water at the first concentration are silver, gold, and copper. Metallic gold, copper, and silver are also produced in conncetion with the reactions of descending water, but such deposits are not here considered. Their derelopment is treated on pages 1158-1174. All of the metals mentioned, with the exception of gold, occur in the form of sulphides. 'The sulphides are either simple binary salts or' are ternary salts, such as sulpharsenites, snlpharsenates, sulphantimonites, and snlphantimonates. The sulpharsenical and sulphantinonical compounds will not be considered separately from the simple sulphides. The important tellurides are those of silver and gold. An important oxide deposited by ascending water is magnetite, and possibly fianklinite and zincite belong here. Of the carbonates that of iron is of the greatest consequence. Of the silicates that of zinc may belong here. Of conrse many other oxides, carbonates, and silicates are found in ore bodies; but so far as these are in sufficient abundance to constitute workable ore deposits, it is believed, as will be fully explained later, that these compounds do not belong to the class of ores deposited by ascending water.

Why compounds deposited by ascending waters are, for the nost part, not oxidized compounds, but metallic compounds, sulphides or tellurides, is easily explained. The widely disseminated, downward-moving water, bearing oxygen, is robbed of this constituent early in its conrse. Ferrous compounds are abundantly present in the rocks in the forms of magnetite and silicates. Iron is a strong base; and where ferrous compounds are present they continue to abstract the oxygen of the downward-moving waters until it has practically disappeared. Moreover, buried organic matter takes oxygen from underground waters. Hence oxidizing conpounds do not exist in the deep-seated ascending water.

METALS.

GOLD.

Solution.-It has been stated that gold is deposited by ascending waters in important amounts. The manner in which gold is dissolved and transported to the greatest extent in underground solutions is not well known. As a matter of experiment it has been long known that gold is soluble in ferric chloride and in cupric chloride. Doelter has shown that gold is somewhat readily soluble in a 10 per cent solution of sodic carbonate, and also MON XLVII-04-69 
in an 8 per cent solution of sodic carbonate containing an excess of carbonic acid and containing sodic silicate. ${ }^{\alpha}$ Becker has shown that gold is easily soluble in sodic sulphide and in sodic sulphydrate. ${ }^{b}$ It las also been held that gold is soluble in ferric sulphate. Recently Stokes has experimentally investigated the solubility of gold. He finds that gold is somewlat readily soluble at a temperature of $200^{\circ} \mathrm{C}$. in solutions of ferric chloride and cupric chloride according to the following reactions:

$$
\begin{aligned}
& \mathrm{Au}+3 \mathrm{FeCl}_{3} \rightleftarrows \mathrm{AuCl}_{3}+3 \mathrm{FeCl}_{2} \\
& \mathrm{Au}+3 \mathrm{CuCl}_{2} \rightleftarrows \mathrm{AuCl}_{3}+3 \mathrm{CuCl}
\end{aligned}
$$

It thus appears that when gold is dissolved by ferric chloride or cuprie chloride it is transformed to a chloride. The greater the amount of these chlorides and the stronger the solutions the more gold may be dissolved. With a given amount of ferric chloride or cupric chloride, with constant temperature, the reactions cease when equilibrium has been reached. Stokes's work las further shown that when this condition exists a rise in temperature causes the reaction to continue. That is to say, with increasing temperature a given amount of ferric or cupric chloride in a given solution is capable of taking an increasing amount of gold into solution.

Stokes finds that gold is not appreciably dissolved in ferric sulphate unless chlorides are present at the same time, thus furnishing ferric chloride and making the solution really that by the reaction already given. His experiments have not been carried to sufficient refinement to prove that ferric sulphate may not dissolve gold to an extent to be of consequence in the segregation of the metals under natural conditions.

Lenher, in advance of publication, las kindly given me the results of experiments which show that gold is soluble in sulphuric acid, phosphoric acid, and various other acids, if a compound be present which liberates oxygen, as, for instance, manganese dioxide. The reaction takes place at $0^{\circ}$ C., but is greatly accelerated by heat. This principle' may be of considerable importance in the solution of gold, since all of those compounds occur rather plentifully under natural conditions. The frequent association of gold ores with manganese minerals strengthens this suggestion.

" Doelter, C., Einige Versuche über die Lüslichkeit der Mineralien: Tschermaks Mineral. Mittheil., vol., 11, 1890, p. 329.

$b$ Becker, G. F., Geology of the quicksilver deposits of the Pacific slope: Mon. U. S. Geol. Survey, vol. 13,1888 , p. 433 . 
The conclusion that gold is soluble in ferric and cupric chlorides, in acids where oxygen is liberated, and is possibly soluble in ferric sulphate, and that these processes are promoter by increasing temperature, is of the greatest importance in reference to the segregation of gold. It has been pointed out that the $i c$ salts are those which are extensively produced in the belt of weathering by descending solutions. Iron sulphide is the most abundant sulphide. By the reaction of oxygen upon it ferric sulplate is prodnced, and by its decomposition sulphuric acid. Ferric chloride would form wherever chlorine is present. If copper sulphides occur, these would be transformed to similar salts. Thus in the belt of weathering considerable quantities of the solvents of gold are formed. In comnection with the production of a large amount of these reagents where the solutions are descending, the law of mass action leads to the conclusion that the gold will be dissolved somewhat in proportion to the mass of these compounds produced. Furthermore, where the solutions are descending there is a rise in their temperature, and the work of Stokes shows that this further increases their activity. Hence, under normal conditions in a region of mineralization where there are sulphides and where gold exists, one would expect that the dispersed descending solutions would dissolve gold in considerable quantity.

Precipitation.-In whatever form gold is carried it is known to be precipitated in the first concentration as metallic gold or as a telluride. Whether it is also precipitated as a sulplide is uncertain.

It is easy to suggest various causes for the precipitation of metallic gold from its solutions. First, it is well known that gold solutions are immediately precipitated by the more basic metals. Of these metals there is likely to occur underground those of copper, silver, and tellurium. Occa. sionally also iron may occur. The rapid precipitation of gold from its solutions by contact with iron, copper, and silver are well known.

Recently Hall and Lenher have shown that tellurium completely precipitates gold from its solutions according to the following reactions: ${ }^{a}$

$4 \mathrm{AnCl}_{3}+3 \mathrm{Te}=4 \mathrm{Au}+3 \mathrm{TeCl}_{4}$

They state: "Time is a considerable factor in bringing about complete precipitation, from two to three hours being necessary with continued

a Hall, R. D., and Lenher, Victor, Action of tellurium and selenium on gold and silver salts: Jour. Am. Chem. Soc., vol. 24, 1902, p. 919. 
leating, or several days at room temperatures. The only conditions to be observed, in order to obtain quantitative precipitation of the gold by the tellurium, are sufficient time and the direct contact of all the tellurium with the gold solution." a Hall and Lenher have also shown that selenium precipitates gold fron its solutions in a similar manner according to the reaction:

$$
4 \mathrm{AuCl}_{3}+3 \mathrm{Se}=4 \mathrm{Au}+3 \mathrm{SeCl}_{4}
$$

They say: "From six to eight hours of continued boiling are necessary to insure complete precipitation, or better, from two' to three days at a temperature of $70^{\circ}$ to $80^{\circ}$."

Not only is gold precipitated from its solutions by various metals, but it is precipitated by many ous salts and oxides; for instance, it is well known that ferrous sulphate readily reduces gold to the metallic condition. Stokes has recently shown also that ferrous salts in silicates are sufficient to precipitate copper from its solutions, and if this be so, it is certain that gold may be precipitated in like manner. There is little doubt, also, that ferrous oxide in magnetite is adequate to precipitate gold from its solutions. It is to be noted that Stokes writes the equations

$$
\begin{aligned}
& \mathrm{AuCl}_{3}+3 \mathrm{FeCl}_{2} \rightleftarrows \mathrm{Au}+3 \mathrm{FeCl}_{3} \\
& \mathrm{AuCl}_{3}+3 \mathrm{CuCl} \rightleftarrows \mathrm{Au}+3 \mathrm{CuCl}_{2}
\end{aligned}
$$

as reversible reactions. He states that "with rising temperature the equilibrium moves from left to right, with falling temperature from right to left." ${ }^{\circ}$

It follows that where there is lessening temperature and pressure, ferrous chloride and cuprous chloride reduce gold solntions, throwing down the metallic gold. Normally, the conditions for falling temperature are those for ascending solutions, and therefore, so far as gold is precipitated by these reactions, it is more likely to take place where the waters are ascending.

So far as I know, experiments have not been made in the precipitation of gold by cuprous oxide and cuprous salts other than cuprous chloride; but in general it may be stated with a considerable degree of certainty that any of the ferrous and cuprous componnds which occur in nature are adequate precipitating agents for gold solutions. From the descriptions of

\footnotetext{
${ }^{a}$ Hall and Lenher, cit., p. $920 . \quad b$ Hall and Lenher, cit., p.921. $\quad c$ Stokes, manuscript, p. 7.
} 
varions gold deposits it seems to me very probable that in many instances the ferrous salts have been important reducing agents, and the same may be true of cuprous compounds.

It has been seen on a previous page that the $i c$ compounds capable of dissolving gold are produced extensively in the early part of the journey of underground water. It has further been fully explained (p. 1085), that deep in the belt of cementation, where organic matter and sulphides are abundant, $i c$ salts are clanged to ous salts, which are the prevalent compounds deep within the belt. Therefore the trunk channels which carry the gold in solution are likely to receive contributions from other solutions which carry ous salts in large amount. Here the conditions are just the reverse of hose existing in the early part of the water's journey. The law of mass action now demands the reduction of the gold to its metallic condition. For instance, if the gold were a chloride, and ferrous sulphate were present, the following reaction would take place:

$$
2 \mathrm{AuCl}_{3}+6 \mathrm{FeSO}_{4}=2 \mathrm{Au}+2 \mathrm{Fe}_{2}\left(\mathrm{SO}_{4}\right)_{3}+2 \mathrm{FeCl}_{3}
$$

Similar reactions are written for ferrous chloride and cuprous chloride on the preceding page. It is also to be remembered that in trunk channels the solutions are likely to be ascending. Therefore the temperature is falling, and as pointed out by Stokes all of these reactions are promoted by this condition. Thus an abundance of reducing' solutions and the temperature both work together to produce precipitation in the trunk channels.

In comnection with these reactions the question naturally arises as to which of the ous salts is probably the most important. Since iron is the most abundant of all the metals carried in underground solutions, such sulphates would be more likely to be sulphates of iron than any other. If the salts formed in the belt of weathering were ferric sulplates, they would be likely to be reduced to the ferrous condition at depth by organic matter or by sulphides. Indeed, analyses of mineral waters which bear sulphates also ordinarily show ferrous iron. ${ }^{a}$ Therefore ascending waters bearing ferrons sulphate or other ous salt might be brought into a lode by side streams and there precipitate the gold. Such side channels entering through lateral cracks may, in many cases, cause the extreme irregularity in the distribution of the gold.

a Peale, A. C., Mineral waters of the United States: Bull. U. S. Geol. Survey No. 32, 1886. 
Although Lindgren argues to the contrary with regard to the Sierra Nevada, ${ }^{a}$ the suggestion that a part of the gold there has been reduced by ferrous sulphate has extreme plausibility. The gold associated with the pyrite is native. From that district are given two analyses of the waters of feeding streams (the only analyses reported) entering the lodes at a depth of 125 meters. Both of these analyses show that sulphates and iron are present. $^{b}$ According to the analyses the iron is reported as ferric; but apparently no precautions were taken, when the waters were collected, to prevent the oxidation of ferrous to ferric iron. Indeed, the precipitates of yellow material, which is partly ferric oxide, made by underground springs renders it highly probable that ferrous salts were contained in them before oxygen came into contact with the solutions. The clean vein quartz itself, which holds a large number of fluid inclusions, contains sulphates, ${ }^{c}$ showing that sulphate-bearing water's were present at the time the lodes formed.

'The ore shoots have great irregularities in richness, for which Lindgren offers no explanation. The suggestion above made that the gold is precipitated in the metallic form by the reducing action of ferrous sulphate explains all of these facts. The deposits are rich where the side springs issued from cross fissures and furnished the ascending waters with ferrous sulphate. The gold is in the metallic form becamse reduced by the ferrous sulphate.

Organic material is capable of precipitating gold from its solutions. At many places the precipitation of the gold has been ascribed, in part at least, to the influence of the organic matter. Rickard ${ }^{d}$ calls attention to the frequent association of metallic gold with sedimentary rocks bearing organic matter in California, New Zealand, Australia, and Tasmania. 'The most remarkable case is the concentration of gold in veins where they cross strata of carbonaceous shale, called indicators. Says Don, "Away from the indicator", the greater part of the vein quartz is absolutely barren; but at the intersection with the indicator large

a Lindgren, Waldemar, The gold-quartz veins of Nevarla City and Grass Valley, California: Seventeenth Ann. Rept. U. S. Geol. Survey, pt. 2, 1896, p. 181. See also Pl. V, p. 134.

$\checkmark$ Lindgren, op. cit., pp. 121-123.

"Lindgren, cit., pp. 130-131, 260, 261.

$a$ Rickard, T. A., The origin of the gold-bearing quartz of Bendigo Reefs: Trans. Am. Inst. Min. Eng., vol. 22, 1894, pp. 314-315. Rickard, T. A., The indicator veins of Ballarat, Australia: Eng. and Min. Jour., vol. 60, 1895, pp. 561-562.

$e$ Don, J. R., The genesis of certain auriferous lodes: Trans. Am. Inst. Min. Eng., vol. 27, 1898, [1. 569. 
masses of gold (often more than 100 ounces in one piece) have been obtained, and the greater part of the gold extracted from this belt has come from those parts of the quartz veins near some one of the indicators." Furthermore, Rickard ${ }^{a}$ describes experiments in which the black carbonaceous shale of Rico was placed in silver solutions and in solutions containing Cripple Creek gold ore. Both metallic silver and gold were abundantly precipitated upon the shale in a short time. In the instances above mentioned it can hardly be doubted that the organic material was an important or controlling factor in the reduction and precipitation of gold.

The argillite with which many of the gold ores of the Sierra Nevada are associated is carbonaceons, ${ }^{b}$ but the chief influence of this carbonaceons material may have been to assist in the production of the ous salts which ultimately reached the trunk channels. But in some places, as for instance where the pyrite occurs in a carbonaceous argillite, but not in quartz, ${ }^{c}$ the gold may have been precipitated directly by the carbonaceous material. But since the gold in the Sierra Nevada is mainly deposited in open fissures, ${ }^{d}$ the suggestion already made of direct reduction of the major portion of the gold by ous salts, and especially ferrous sulphate, is thought to be the more plausible, although if the formation of the ferrous sulphate be due to carbonaceous material in the country rock, the precipitation is indirectly due to organic matter.

The sulphides of the base metals also precipitate gold from its solutions. Below the level of ground water the rocks most commonly associated with gold are the sulphides of the base metals. Thus gold occurs on a great scale associated with pyrite. Very often it is found also with sulphides of the other metals, especially copper. In such occurrences, where the sulphides are abundant, the gold is likely to be plentiful; where the sulphides are present in small quantity, the gold also is likely to be deficient. This relation is illustrated in both California and Australasia,

a Rickard, T. A., The Enterprise mine, Rico, Colo.: Trans. Am. Inst. Min. Eng., vol. 26, 1897, pp. $978-979$.

${ }^{b}$ Linlgren, Waddemar, The gold-quartz veins of Nevada City and Grass Valley, California: Seventeenth Ann. Rept. U. S. Geol. Survey, pt. 2, 1896, p. 81.

$c$ lindgren, op. cit., p. 140, Pl. V1II.

"Lindgren, op. cit., p. 259.

e Lindgren, Waldemal, The gold-quartz veins of Nevada City and Grass Valley, California: Seventeenth Ann. Rept. U. S. Geol. Survey, pt. 2, 1896, pp. 124-126. Don, J. R., The genesis of certain aurilerous lodes: Trans. Am. Inst. Min. Eng., vol. 27, 1898, p. 567. 
and suggests that the original solution and deposition of native gold and the sulphides are frequently connected; therefore it is reasonable to infer that the conditions which produced sulphides may also have resulted in the precipitation of gold. ${ }^{a}$

Liversidge has shown experimentally that pyrite, galena, arsenopyrite, and nearly all other sulphide minerals will precipitate gold completely from solutions of anric chloride. ${ }^{b}$ The frequency with which gold occurs associated with or inclosed by pyrite suggests that this is a very important reaction. This relation is well illustrated by the gold-quartz veins of the Sierra Nevada described by Lindgren, where in the deeper parts of the lodes beyond the belt of surface oxidation the pyrite and the gold are intimately associated. Lindgren says that the intimate commection of the gold with the sulphicles was very likely caused by the tendeney of gold solutions to be precipitated by particles of sulphides.

In certain cases gold occurs associated with both carbonaceous material and the base sulphides. This is well illustrated by the argillite of the gold-quartz veins of the Banner mine described by Lindgren, ${ }^{d}$ and by the Bencligo reefs of Australia. In such cases the question may arise as to which of the two is the precipitating agent; but the more intimate association of the gold with the pyrite suggests that the pyrite is the precipitating agent for the gold (see Pl. XI, A), and this agrees with the experimental work of Liversidge, which shows that the metallic sulphides precipitate gold from solutions more readily than organic matter: ${ }^{f}$

Recently Lenher and Hall ${ }^{g}$ have shown that the natural tellurides of gold, silver, and mercury are capable of rapidly and completely precipitating metallic gold from its solutions. This they have accomplished with calaverite (AuAgTe ${ }_{2}$; Au 39.5, Ag 3.1, Te 57.4) (Au 41.76, Ag.80, Te 56.64,

" Lindgren, cit., p. 184.

bLindgren, Waldemar, Gold-quartz veins of Nevada City and Grass Valley: Seventeenth Ann. Rept. U. S. Geol. Survey, pt 2, 1896, p. 182. Liversidge, A., On the origin of gold nuggets: Proc. Roy. Soc. New Sonth Wales, vol., 27, 1893, p. 303.

c Lindgren, cit., p. 184, Pl. V1I, p. 138, and PI. VIII, p. I40.

¿Lindgren, cit., Pl. VIIl, fig. c, p. 140, and p. 156.

e Rickard, T. A., Origin of gold-bearing quartz of Bendigo reefs, Australia: Trans. Am. Inst. Min. Eng., vol. 22, 1894, pp. 314-317.

$f$ Liversidge, A., On the origin of moss gold: Proc. Roy. Soc. New South Wales, vol. 27, 1893, p. 287.

g Lenher, Victor, Naturally occurring telluride of gold: Jour. Am. Chem. Soc, vol. 24, 1902, pp. 355-360. Lenher, Victor, and Hal], R. D., Aetion of tellurium and selenium on gold and silver salts: Ibid., pp. 918-927. 
from Kalgoorlie), ${ }^{\prime}$ krennerite (AuAg $\mathrm{Te}_{2} ; \mathrm{An}$ 35.5, $\mathrm{Ag}$ 19.4, Te 45.1, uncertain), sylvanite ( $\mathrm{AuAg} \mathrm{Te}_{2} ; \mathrm{Au} 24.5, \mathrm{Ag}$ 13.4, Te 62.1), hessite (Ag Te), kalgoorlite ( $\left.\mathrm{Hg}_{\mathrm{A}} \mathrm{u}_{2} \mathrm{Ag}_{6} \mathrm{Te}_{1}\right)$, nagyagite $\left(\mathrm{Au}_{2} \mathrm{~Pb}_{14} \mathrm{Sb}_{3} \mathrm{Te}_{7} \mathrm{~S}_{17}\right)$, and coloradoite ( $\left.\mathrm{Hg}_{\mathrm{g}} \mathrm{Te}\right)$. It thus appears that whether these minerals are largely tellurides of gold, as calaverite; of gold and silver; as krennerite, sylvanite, etc.; of silver, as hessite, or of mercury, as coloradoite, when brought into contact with chloride of gold solutions metallic gold is precipitated. This experimental work of Lenher and Hall is of very great importance, probably largely explaining the intimate association of free gold with the tellurides at various places.

It will be explained (pp. 1170-1171) that in many places the association of free gold with tellurides is partly due to the reconcentrating action of descending water, the tellurides being the precipitating agent. Doubtless in many cases this process of reconcentration is also combined with that of direct oxidation of the tellurium of the tellurides, leaving gold behind. The spongy gold pseudomorphous after telluride, such as that which occurs at Cripple Creek, is almost certain evidence of one or both of the above processes. But in many cases the free gold associated with tellurides may be due to a first precipitation from ascending waters, the precipitating agent being the telluride. This possibility is illustrated by the Kalgoorlie district of Australia, described by Bancroft, who says: "The ore is very slightly altered comntry rock containing iron pyrites and tellurides of gold. . . . One of the interesting phenomena of the ore is the occurrence, once in a while, of small particles of crystalline gold surrounded by crystals of tellurides low in gold."

The conclusion that the Kalgoorlie gold may be precipitated by the tellurides is confirmed by observations made by Rickard. He states that "free gold at Cripple Creek has invariably that appearance which charac. terizes the metal when it has originated from the disintegration of tellurides; but at Kalgoorlie ordinary gold, in a bright and crystalline condition, also occurs."

$a$ Rickard, T. A., The telluride ores of Cripple Creek and Kalgoorlie: Trans. Am. Inst. Min. Eng., vol. 30,1901, p. 711 .

${ }^{b}$ Baneroft, Geo. J., Kalgoorlie, Western Australia, and its surroundings: Trans. Am. Inst. Hin. Eng., vol. 28, 1899, pp. 93-94.

$c$ Rickard, T. A., Telluride ores of Cripple Creek and Kalgoorlie: Trans. Am. Inst. Min. Eng., vol. 30,1901, p. 714 . 
Bearing in the same direction are facts given by Kemp: "From Mr. Bancroft the writer learns that the actual ore at Kalgoorlie consists of calaverite and native gold. In a specimen kindly given the writer there is a yellow telluride and a silvery one. In the midst of the latter a bit of wire gold is embedded. There is no sign of alteration, and the native metal and the telluride must have crystallized together." ${ }^{a}$

The very general occurrence of tellurides in gold deposits leads me to the belief that the precipitation of gold by tellurides is probably an important reaction in the first concentration by ascending waters. The work of Hall and Lenher shows conclusively that where gold-bearing solutions enter deposits containing tellurides, whatever their origin, the gold will be rapidly precipitated by the tellurides. In this comnection the manner in which the tellurium travels and is precipitated is important, and is discussed with the tellurides. (See pp. 1119-1125.)

Hall and Leuher ${ }^{b}$ have shown that silver selenide also reduces gold to the metallic form almost as rapidly as selenium does. The reaction takes place only slightly in the cold, but readily on warning. Whether or not this has any importance with reference to ore deposits is uncertain.

In many cases the precipitation of gold is not produced by a single one of the causes given, but by some combination of them. For instance, it has already been pointed out that the abundance of ous solutions and diminishing temperature work together. Again, the reducing action of organic material and that of base sulphides or tellurides, or both, may work together. In still other cases all of the above farorable conditions may occur simultaneously. The combination of organic matter' with sulphides or tellurides is believed to be very common.

Such a combination is probably illustrated by the deposits of New South Wales, in which the gold is associated both with organic matter and with pyrite. In this case the organic matter was probably the chief agent in precipitating the base sulphides from the sulphates. In consequence of this reaction there are two compounds present capable of precipitating the gold, both the pyrite and the carbonaceous material. Since the work of Liversidge shows that the sulphides precipitate gold more readily than

a Kemp, J. F., Geological occurrence and associates of the telluride gold ores: Mineral Industry, 1898, p. 319.

${ }^{b}$ Hall anı Lenher, Aetion of tellurium and selenium on gold and silver salts: Jour. Am. Chem. Soc., vol. 24 , 1902, p. 927 . 
organic material, and since the gold is more intimately associated with the sulphides, it seems probable that, in proportion to its mass, pyrite is a more important precipitating agent than the organic matter; but undoubtedly both are effective.

In many cases it is probable that the precipitation is due fundamentally to carbonaceous material, but that the influence of the organic matter is one step removed. That is to say, the organic matter first precipitated the baser sulphides by reducing them from sulphates, as explained under the succeeding section, and then the base sulphides precipitated the gold. This would seem to be the natural explanation which accounts for the close connection of the gold of some deposits with both carbonaceous materials and pyrite and other base sulphides. ${ }^{a}$

SILVER.

Metallic silver as a product of the first concentration by ascending waters is not an abundant source of the metal. One of the most notable occurrences of metallic silver of this origin is that of the Keweenawan of Lake Superior, where the silver, in subordinate amounts, is closely associated with copper.

solution-CThe form in which silver most extensively occurs is sulphide. It is well known that oxidizing waters change silver sulphide to a sulphate which is a readily soluble compound. It is therefore probable that the silver is very largely transported as a sulphate. It is also certain that silver is transported as a chloride, which may be produced either by the direct action of the chlorides or of hydrochloric acid on the sulphides of the metal, or by the interaction of the chlorides and sulphates. Silver carbonate is also somewhat readily soluble in carbonated solutions. Silver also occurs as a netal. It is well known that metallic silver is soluble in ferric sulphate, the reaction being:

$$
2 \mathrm{Ag}+\mathrm{Fe}_{2}\left(\mathrm{SO}_{4}\right)_{3}=\mathrm{Ag}_{2} \mathrm{SO}_{4}+2 \mathrm{FeSO}_{4}
$$

This reaction takes place in proportion as the ferric sulphate is abundant, and it has already been pointed out that such sulphates are likely to be abundant in the early part of the journey of the nnderground waters where they are descending. Stokes has shown that after this reaction has

" Don, J. R., The genesis of certain auriferous lodes: Trans. Am. Inst. Min. Eng., vol. 27, 1898, pp. 569,612 . 
extended to equilibrium it will continue farther where the temperature is rising, and thus descending solutions with increasing temperature are favorable to solution of metallic silver. Doubtless silver is soluble to some extent in all the strong acids which occur underground and also in their salts. When, however, the silver becomes a salt, the form in which it would subsequently travel depends on the amount of acids in the solutions and their strength. It is well known that silver sulphide is soluble in alkaline carbonates and in lyydrosulphuric acid, but probably silver thus transported is not an important source of metallic silver of the first concentration by ascending waters. From such compounds the silver is likely to be thrown down as a sulphide.

Precipitation.-The precipitation of silver in the metallic form from its solutions follows to a certain extent the same lines as that of gold; but silver is not nearly so readily reducible as gold, and therefore is not thrown down in the metallic form by so many compounds. Silver is precipitated by metallic iron, by metallic copper, by cuprous compounds, readily by ferrous sulphate, and probably slowly by all other ferrous compounds. Of the ous salts, ferrous sulphate is doubtless the most important. The precipitation of the silver by ferrous sulphate is commonly written-

$$
\mathrm{Ag}_{2} \mathrm{SO}_{4}+2 \mathrm{FeSO}_{4}=2 \mathrm{Ag}+\mathrm{Fe}_{2}\left(\mathrm{SO}_{4}\right)_{3}
$$

The reduction is a function of the abundance of the reducing agent. Where the ferrous sulphate is abundant, and the temperature moderate it is believed that the more probable reaction for the precipitation of silver from its solutions is represented by the following equation:

$$
\mathrm{Ag}_{2} \mathrm{SO}_{4}+3 \mathrm{FeSO}_{4}+4 \mathrm{H}_{2} \mathrm{O}=2 \mathrm{Ag}+\mathrm{Fe}_{3} \mathrm{O}_{4}+4 \mathrm{H}_{2} \mathrm{SO}_{4}
$$

Since ferric sulphate will dissolve silver, and ferrous sulphate will reduce silver, the relations of these two componnds are, as Stokes notes, reversible according to the following expression:

$$
2 \mathrm{Ag}+\mathrm{Fe}_{2}\left(\mathrm{SO}_{4}\right)_{3} \rightleftarrows \mathrm{Ag}_{2} \mathrm{SO}_{4}+2 \mathrm{FeSO}_{4}
$$

Stokes says that the reaction moves in the direction of solution when the temperature is rising, and in the direction of precipitation when the temperature is falling. Thus, in ascending solutions, where the temperature is falling, silver is especially likely to be tlirown down by the ferrons salts.

Silver may be also precipitated by ferrous compounds in a solid form, as in magnetite and the silicates. That this is certain follows from the fact 
that such compounds are capable of reducing copper to a metallic condition from its solutions, and this element is more difficult to reduce than silver. That such reduction has actually taken place by the ferrous iron of silicates has been maintained by Vogt for the native silver at Kongsberg, Norway. ${ }^{a}$

COPPER.

solution.-Copper in underground solutions is doubtless carried in many forms, probably more largely as copper sulphate, but as a chloride to an important extent. It may be transported also as copper carbonate in carbonate solutions carrying excess of carbonic acid. Copper as a sulphicle is soluble in the alkaline sulphides, especially acid sodium sulphide (NaHs), and is soluble in considerable quantity in alkali sulpharsenates and sulphantimonates.

Precipitation.-Copper as a metallic compound is precipitated by metallic iron and by ferrous componnds. The precipitation by metallic iron is probably unimportant, but that by ferrous compounds is of great consequence. Copper occurs most extensively in the metallic form as precipitate of a first concentration in the Lake Superior region. Many years ago Pumpelly ${ }^{b}$ noted the fact that in this region there is an intimate comnection between the native copper and the iron-bearing minerals carrying ferrous iron. On this subject Pumpelly says:

Throughout its deposits the copper exhibits a decidedly intimate connection with delessite, epidote, and green-earth silicates, containing a considerable pereentage of peroxide of iron as a more or less essential constitnent; while among the other silicates, riz, analcite, laumontite, datolite, prehnite, only the last named, which alone seems subject to a considerable replacement of its alumina by ferric oxide, is especially favored by copper. This association is so invariable * * * that there exists a close genetie relation between the metallie state of the copper and the ferric conclition of the iron oxide in the associated silicates; that the higher oxidation of the iron was effected through the reduction of the oxide of copper and at the expense of the oxygen of the latter. ${ }^{c}$

Now, may we not consider the presence of iron in prehnite generally to be due to a beginning ehange, and the deposition of native copper in the Lake Superior prehnites to be partially or wholly correlated with the higher oxidation of the iron? "

"Yogt, J. H. L., Ueber die Bildung des gediegenen Silbers, ete.: Zeitschr. i. prak. (ieol., April, 1899 , p. 118.

b Pumpelly, Raphael, The paragenesis and derivation of copper and its associates on Lake Superior: Am. Jour. Sci., 3d series, vol. 2, 18ī, p1. 353-354.

$c$ Puripelly, cit., p. 353.

a Pumpelly, cit., p. 354. 
These observations of Pumpelly convinced me some years ago that the copper was reduced by the ferrous compounds. These conclusions have been later confirmed by experimental work. Biddle, in a thick-walled flask, reduced both cupric and cuprous ehlorides by ferrous chloride in a saturated solution of potassium bicarbonate. ${ }^{a}$ More recently Stokes, by heating an acidified solution of cupric sulphate and ferrous sulphate in a closed tube, has produced metallic copper at the cold end of the tube and pure hematite at the hot end of the tube. The reactions involved are as follows: ${ }^{b}$

$$
2 \mathrm{CuSO}_{4}+2 \mathrm{FeSO}_{4} \rightleftarrows \mathrm{Cu}_{2} \mathrm{SO}_{4}+\mathrm{Fe}_{2}\left(\mathrm{SO}_{4}\right)_{3}
$$

The $\mathrm{Cu}_{2} \mathrm{SO}_{4}$ is decomposed on cooling to $\mathrm{Cu}$ and $\mathrm{CuSO}_{4}$, while $\mathrm{Fe}_{2}$ $\left(\mathrm{SO}_{4}\right)_{3}$ decomposes on heating, thus:

$$
\mathrm{Fe}_{2}\left(\mathrm{SO}_{4}\right)_{3}+3 \mathrm{H}_{2} \mathrm{O}=\mathrm{Fe}_{2} \mathrm{O}_{3}+3 \mathrm{H}_{2} \mathrm{SO}_{4}
$$

Stokes further was able to reduce cupric sulphate to metallic copper by heating with hornblende in a closed tube to a temperature of $200^{\circ} \mathrm{C}$. The reduction of the copper he attributes to the ferrous iron silicate of the hornblende. Thus experimental work completely confirms the conclusion that under natural conditions copper may be reduced from its salts by ferrous compounds, and that the metallic copper of the Lake Superior region was probably reduced both by ferrous solutions and by the ferrous iron of the solid compounds.

In the reactions written above it is supposed that where the copper salts are reduced by ferrous salts, ferric sulphate or hematite is produced. However, this is not necessary, nor where the ferrous salts are in excess is it believed to be probable that these are the common reactions. The natural reaction under such circumstances would be to produce magnetite, a compound not oxidized to the extent of ferric salts. The reaction may be represented as follows:

$$
\mathrm{CuSO}_{4}+3 \mathrm{FeSO}_{4}+4 \mathrm{H}_{2} \mathrm{O}=\mathrm{Cu}+\mathrm{Fe}_{3} \mathrm{O}_{4}+4 \mathrm{H}_{2} \mathrm{SO}_{4}
$$

By this reaction three molecules of the ferrous salts are required to produce one molecule of metallic copper, whereas if ferric salts be produced only two molecules of ferrous compound are needed. It is needless

$a$ Biddle, H. C., The deposition of copper by solutions of ferrous salts: Jour. Geol., vol. 9, 1901, pp. $430-436$.

$b$ Stokes, manuscript. 
to say that where the ferrous salts are very abundant well-known chemical principles lead to the conclusion that a partial oxidation of the ferrous compound is far more probable, since by the reduction of the copper an amount of oxygen is liberated sufficient to transform only a small part of the iron to the ferric state. In this connection it is to be remarked that in the Lake Superior native copper deposits ferrous compounds are very abundant, and magnetite is a very common mineral, both in the anygdaloid and conglomerate deposits. For example, Irving illustrates the intimate association of the native copper and the magnetite in the cupriferous sandstones of the Nonesuch mine, the copper frequently surrounding grains of magnetite. ${ }^{a}$ My first interpretation of this relation was that the magnetite was probably the reducing agent which threw down the copper, but if this were so it.should be transformed to hematite. My present view is that the native copper and the magnetite were both precipitated as a result of the reaction of ferrous salts upon copper salts. According to Stokes's work these would not be simultaneously precipitated at the same place. The magnetite would form where the temperature is higher and the copper where the temperature is lower. To explain the existence of both at the same place one is obliged to suppose that the magnetite formed first, and that later when the temperature was lower the copper was thrown down. It is notable that in the illustrative case mentioned, the copper does surronnd the grains of magnetite, and thus corresponds with Stokes's experimental work.

It is hardly necessary to say that in one district the cliief reaction precipitating the copper nay prodnce ferric salt and in another district may produce magnetite, while in still other districts the precipitation of the copper may be due to the. combination of both reactions.

The Lake Superior copper deposits are believed to be an ideal case of ores deposited by ascending waters, the sources of which are the igneous rocks of the Keweenawan. In this region the only locality at which the ore has been found in paying quantities is at Keweenaw Point, and the productive district is at present confined to a very small area about Calnmet and Houghton. Notwithstanding this fact, there is scarcely a locality in the Lake Superior region where the Keweenawan basic lavas occur in

"Irving, R. D., The copper-bearing rocks of Lake Superior: Mon. U. S. Geol. Survey, vol. 5, 1883, fig. 1, Pl. XVI, p. 127. (Description of same pp. 131-132.) 
which small amounts of copper are not found. Almost every porous amygdaloid shows flakes of it. In many localities it is so abundant that extensive exploration has been undertaken, with the hope of finding large ore bodies, as, for instance, in Douglas County, Wis., Isle Royale, and Mamainse. But all of these explorations have resulted in failure. To me the almost universal association of small quantities of copper with the Keweenaman lavas is the most conclusive evidence that these lavas are the source of the metal.

While copper commonly occurs in many of the igneons rocks in its native state, especially in those which are porous, it is found in the less porous and therefore less altered rocks in minute quantities in the form of a sulphide, and this is thought to be the original form of the metal. That is to say, at the time the lavas crystallized the copper separated as copper sulphide or copper-iron sulphide. When the lavas were upturned by the formation of the Lake Superior syncline, and denudation began truncating them, the segregation of the copper deposits was inaugurated. 'The descending oxidizing waters transformed the copper sulphides into copper sulphates and took them into solution. The underground water was finally converged into trunk channels, and there met solutions bearing ferrons salts or came into contact with ferrous compounds. At such places reduction and precipitation took place. Where there were good trunk channels, as in the upper surfaces of many of the anygdaloids, there was sufficient segregration to encourage widespread exploration, as has already been noted. But only a few of the amygdaloids were open and scoriaceous enough to become the centering points of a sufficiently extended circulation to produce workable ore deposits. The greatest trunk channels were in the conglomerates. Where these conglomerates were interstratified with abundant lavas bearing a sufficient amount of copper, and there existed other necessary favorable conditions, the rising circulation has fortumately segregated the metal in great quantity. The most notable of these deposits is in the conglomerate upon which the Calumet and Hecla and the Tamarack mines are located

SUIPHIDES.

It has been stated that metals which occur as sulphides comprise iron, copper, lead, zinc, nickel, arsenic, antimony, mercury, and silver. Of these sulphides iron is the most abundant. Indeed, the sulphides of iron- 
pyrite, mareasite, pyrrhotite, and other forms-exeeed in quantity many fold all other sulphides. Standing next in amount is the group of zinc, lead, and copper sulphides, the order of abundance probably being that named. Nickel, arsenic, and antimony sulphides, also occur in important amounts. Mercury and silver sulphides, while important ores of these metals, are insignificant as compared with those previously mentioned so far as absolute quantity is concerned. As to the original source of the sulphides, it is well known that sulphide of iron occurs as an original constituent of igneous rocks. Probably the same is true of the other sulphides, but as their quantity is very much less they have been little noticed. Even if sulphides had not been observed to be original constituents of the igneous rocks, the large amount of sulphur compounds issuing from the interior of the earth, in comnection with volcanism, would lead to the conclusion that sulphides must exist in the igneous rocks. This makes it highly probable that sulphur as sulphide is or was present in sufficient quantity in the original rocks to fully account for all of the sulphur compounds of the ore deposits.

While it is doubtless true that the original sources of all the sulphide ores are the sulphides of the igneous rocks, it does not follow that the igneous rocks are the immediate somrce of existing sulphide deposits. Indeed, in many instances this is not the case. For instance, it will be seen (p. 1146) that the sulphides of the lead and zine deposits of the Mississippi Valley are segregated from sulphides in limestones. These sulphides were derived from the sulphides of earlier rocks which were probably transformed to sulphates, transported to the sea, and in the sea, as shown by Chamberlin, precipitated as sulphides at the same time the limestone was formed. In other cases, the sulphides of a particular ore deposit may be derived from a metamorphic rock. In many instances the sulphides of an ore deposit have their immediate source very largely in sulphides which have undergone one or more cycles of segregation by the processes which are given below. In many cases the sulphides of a given ore deposit are not derived from any single sonrce or rock, but from the various sulphides in all the rocks through which the particular system of underground cirenlation prodncing the ore deposit passed.

MON XLYII-04-70 
SOLUTION OF SULPHIDES.

It is well known that the sulphides of copper, mercury, iron, nickel, lead, zinc, arsenic, and antimony are soluble in alkaline sulphides. Illustrating this general statement, Becker ${ }^{a}$ has shown experimentally that the natural sulphide of mercury, ciunabar, the natural sulphide of iron, pyrite, the sulphide of copper, and the sulphide of zinc are soluble in sodic sulphide. Along the same line as Becker's work Doelter has shown that pyrite, stibnite, sphalerite, arsenopyrite, chalcopyryite, boumonite, and galena are all soluble in sodic sulphide. ${ }^{b}$

Becker has further shown that the sulphides of iron, copper, zinc, arsenic, and antimony are also soluble in alkaline carbonates containing, but not saturated with, hydrosulphuric acid.e This is partly equivalent to saying that they are soluble in sodium sulphide; for if hydrogen sulphide be introduced in sodium-carbonate solution, the following reaction immediately takes place:

$$
\mathrm{Na}_{2} \mathrm{CO}_{3}+\mathrm{H}_{2} \mathrm{~S}=\mathrm{Na}_{2} \mathrm{~S}+\mathrm{H}_{2} \mathrm{O}+\mathrm{CO}_{2}
$$

But the observation by Becker is important, since it gives a method by which sodium sulphide, a solvent for the sulphides of the heavy metals, may be produced. In this connection it should be recalled that the carbonates of the alkalies are among the most abundant compounds carried by underground solutions, and hydrogen sulphide is known to be very common in such solutions. Therefore it is certain that considerable quantities of sodium sulphide will be produced where these two classes of solutions come together, as they are often sure to do. The formation of sodium sulphicle in consequence of the mixture of sodium carbonate and hydrogen sulphide is probably of great importance in the genesis of ores.

Confirming the conclusions of Becker and Doelter, observation has shown that at Steamboat Springs, Nevada, and Sulphur Bank, California, mercuric sulphide and iron sulphide are transported in solutions containing sorlic sulphide, lydrogen sulphide, sodium carbonate, and carbon dioxide.

$a$ Becker, G. F., Quicksilver deposits of the Pacific coast: Mon. U. S. Geol. Survey, vol. 13, 1888, pp. 428-435.

${ }^{b}$ Doelter, C., Einige Versuche über die Löslichkeit der Mineralien: Tschermaks Mineral. Mittheil., Bd. XI, 1890, pp. 323-324.

$c$ Becker, cit., pp. $432-135$. 
At Sulphur Bank boric acid is also present. ${ }^{a}$ Hydrogen sulphide has also been observed by Lindgren in the ascending waters of the Federal Loan mine of the Sierra Nevada. He says that at the Federal Loan mine "an unmistakable odor of sulphureted hydrogen was noted in the vicinity of the spring." ${ }^{\prime}$

Finally, Doelter has shown tnat the sulphides are soluble in pure water, to some extent. He has thus dissolved measureable quantities of pyrite, galena, stibnite, splalerite, chalcopyrite, arsenopyrite, and bournonite. ${ }^{c}$

Since sodic carbonate, sodic sulphide, and hydrogen sulphide are probably so important in the transportation of the sulphides of the metals, it is advisable to consider the possible sources of these compounds. This subject is of further importance, becanse it will be seen that hydrogen sulphide is also an important precipitating agent.

It has been fully explained in other places (pp. 176-177, 609-610, 677-679) that carbon dioxide is liberated on a great scale in the zone of anamorphism, and that most of this carbon dioxide joins the deep circulation. It has been seen also that the process of carbonation of the silicates is perhaps the most fundamental reaction of the zone of katamorphism-that in which aqueous ore deposits occur. Of the elements which the silicates contain, the most easily carbonated is sodium. It should follow that sodium carbonate is an abundant salt in the ground water. This theoretical conclusion is fully confirmed by observation.

We shall now see that abundant sodium carbonate results in the formation of the other compound most frequently present where sulphides of the valuable metals are in solution.

Stokes has shown recentiy that by the reaction of sodic carbonate alone upon pyrite or marcasite sodic sulphide is produced. His reaction is as follows:

$8 \mathrm{FeS}_{2}+15 \mathrm{Na}_{2} \mathrm{CO}_{3}=4 \mathrm{Fe}_{2} \mathrm{O}_{3}+14 \mathrm{Na}_{2} \mathrm{~S}+\mathrm{Na}_{2} \mathrm{~S}_{2} \mathrm{O}_{3}+15 \mathrm{CO}_{2}$

a Le Conte, Joseph, and Rising, W. B., The phenomena of metalliferons vein formation now in progress at Sulphnr Bank, California: Am. Jour. Sci., 3d ser., vol. 24, 1882, pp. 23-33. Le Conte, Joseph, On the mineral vein formation now in progress at Steamboat Springs, compared with the same at Snlphnr Bank: Am. Jonr. Sci., 3d ser., vol. 25, 1883, pp. 424-128.

$b$ Lindgren, Waldemar, The gold-quartz veins of Nevada City and Grass Valley districts, California: Seventeenth Ann. Rept. U. S. Geol. Survey, pt. 2, 1896, pp. 121-122.

c Doelter, cit., pp. 321-323. 
It is therefore evident that, since iron sulphide is the most common of the sulphides in nature and sodium carbonate an abundant carbonate, the reaction given is likely to take place on a considerable scale, and therefore that sodic sulphide, which is available to dissolve the sulphides of the other metals, is probably produced under natural conditions in large quantities.

Since experiment has shown the solubility of the sulphides in sodium sulphide and sodium carbonate, and observation has shown the frequent presence of these compounds, especially sodium carbonate, in undergronnd water, there can be little doubt that the sulphides as such are transported on an extensive scale in the ground waters.

While the sulphides are somewhat readily soluble by various compounds, it is not believed that the material of the sulphide ores is carried to the openings in the rocks to be deposited by the ascending waters in the form of sulphide only. It has been fully explained that the sulphides in the belt of weathering are largely oxidized to sulphites and to sulphates, mainly the latter, and taken into solution by the descending waters. In this connection it is to be noted that the sulphates of iron, copper, zinc, nickel, mercury, and silver are all readily soluble; and even the sulphate of lead is dissolved to the extent of one part in 31,500 parts of water at $15^{\circ} \mathrm{C}$, ${ }^{a}$ which is probably entirely adequate for the purposes of underground transportation. While the sulphur compounds of these metals are very largely transported as sulphates, they may also to some extent be transported as sulphites. Of these metals the sulphites of iron, copper, zinc, and silver are rather readily soluble.

PRECIPITATION OF SULPHIDES.

We have now seen that the metals which may be deposited as sulphides in the ore bodies may be transported as sulplides in solution or as sulphates. Tho question now arises as to the conditions which will result in their precipitation. It will be necessary to consider separately the precipitation of compounds transported as sulphides and as sulphates.

The more important metais which are known to be precipitated as sulphides in sufficient quantities to constitute ore are those of iron, lead, zinc, nickel, cobalt, copper, silver, mercury, arsenic, and antimony. As to 
whether or not gold is also precipitated as a sulphide no definite statement can be made. The majority of those who have most closely studied gold deposits hold that the gold occur's either as free gold or as telluride. In evidence of this they cite the fact that where gold occurs with prrite, as it so generally does, the microscopical study of the sulphides shows flakes of free gold within the sulphide. Admitting these facts, it does not at all follow that another portion of the gold is not present in the pyrite as a sulphide. Indeed, sinee gold sulphide is known to be a definite compound, which can easily be produced in the laboratory, and is produced by a metallurgical process, it seems to me highly probable that some of the gold is precipitated as a sulphide and in this form is associated with the sulphides of the other metals.

Precipitation of sulphides transported as such.-The precipitation of transported sulphides in the form in which they are found in the ore bodies may be accomplished either by simple dilution of the compounds, as pointed out by Becker ${ }^{a}$ for mercury sulphide, by decreasing pressure and temperature, or by both. These are the conditions in ascending solutions, hence the transported sulphides are likely to be precipitated where the water is rising in trunk channels. The precipitation of the sulphides may result also from mingling of solutions. If, for instance, an acid, such as boric or sulphuric acid, be added to the solutions of the sulphides carried in alkaline carbonates and alkaline sulphides, the simple nentralization will result in the precipitation of many of the sulphides. By such nentralization the alkaline sulphide, the solvent, is destroyed. For instance, if sulphuric acid be added to a sodium snlphide solution the following reaction takes place:

$$
\mathrm{Na}_{2} \mathrm{~S}+\mathrm{H}_{2} \mathrm{SO}_{4}=\mathrm{Na}_{2} \mathrm{SO}_{4}+\mathrm{H}_{2} \mathrm{~S}
$$

This equation shows that not ouly is the solvent destroyed, but a precipitating agent for the sulphides is produced. Under such conditions, there can be no donbt that the sulphides will be rapidly precipitated. Also, where the sulphicles are transported in solutions of sodinm sulphide and sodium carbonate, the addition of hydrogen sulphide in excess will result in the precipitation of many of the metals. 
Very frequently the mingling of alkaline solutions of sulphides with acid solutions is at the points where descending and ascending waters meet. This is very well illustrated by the conditions at Steamboat Springs and Sulphur Bank, described by Le Conte, ${ }^{a}$ where the surface descending waters are strongly acid, largely resulting from the oxidation of sulphides to sulphates, whereas the waters rising from the deep sources are strongly alkaline and bear sulp.ides in solution.

Precipitation of sulphides a ansported as oxidized salts.-Wherever below the level of ground water in the belt of cementation the sulphates and sulphites come in contact with buried organic material, or with solutions carrying organic compounds, the sulphates and sulphites may be reduced to sulphides. By such reduction ores may be directly produced. Where the salts of the metals are transported as sulphates the organic matter has merely to take away the oxygen of the sulphate in order to transform it to a sulphide. For instance, if the compound be lead sulphate $\left(\mathrm{PbSO}_{4}\right)$ the abstraction of the four atoms of oxygen produces galena (PbS). But in order that such compound be formed it is not necessary to suppose that the metals precipitated are transported as sulphates. It is only necessary to suppose that oxidized compounds of the metals and sulphates, with a reducing compound, are present. 'To illustrate, if silver be transported as a chloride with sodium sulphate in the solutions and oxygen be taken away from the sodium sulphate, this would be transformed to sodium sulphide, which would immediately precipitate the silver as silver sulplide. Again, supposing copper to be traveling mainly as carbonate, sodium sulphate to be present, and the reducing agent to be carbon, the end result is represented by the following reaction :

$$
\mathrm{CuCO}_{3}+\mathrm{Na}_{2} \mathrm{SO}_{4}+2 \mathrm{C}=\mathrm{CuS}+\mathrm{Na}_{2} \mathrm{CO}_{3}+2 \mathrm{CO}_{2}
$$

Of course the actual process would be as in the previous case. The compound containing the sulphur would be reduced to sulphide. This would react npon any of the compounds present which could produce insoluble sulphides.

Many ore deposits give evidence that the reducing action has been caused by organic material. Such cases are illustrated by disseminated sulphides occurring through carbonaceous material, as the graphite schist

\footnotetext{
"Le Conte, Joseph, Genesis of metalliferons veins: Am. Jour. Sci., 3d ser., vol. 26, 1883, p. 9.
} 
of the Vermont copper mine described by Cazin. ${ }^{a}$ The direct effect of the carbonaceous material in the production of the sulphides is also illustrated by the indicator veins of the Bendigo reef of Australia ${ }^{b}$ and by the pyrite in the argillite described by Lindgren. ${ }^{c}$ Another clear case of the direct reduction of oxidized salts by organic matter is that of the lead and zinc deposits of the Mississippi Valley. In Wisconsin, as shown by Blake, ${ }^{d}$ lead and zinc are precipitated by the organic matter of the oil rock, and in Missouri, as shown by Bain, ${ }^{e}$ by the organic matter of the Devonian shales. More frequently, however, the direct action of organic material upon the sulphates and sulphites is to form sparsely disseminated sulphides, which must be further worked over in order to produce ore deposits.

Recently Jemney has brought together a large number of instances in which there is a close association of ores with organic compounds, and these suggest that the organic material has directly or indirectly reduced sulphates to sulphides, and thus resulted in their precipitation. ${ }^{f}$

Probably sulphites and sulphates also may be reduced to sulphide by ferrous iron in the rocks. In the case of silver sulphate the reaction may be supposed to be as follows:

$$
\mathrm{Ag}_{2} \mathrm{SO}_{4}+12 \mathrm{FeSO}_{4}+12 \mathrm{H}_{2} \mathrm{O}=\mathrm{Ag}_{2} \mathrm{~S}+4 \mathrm{Fe}_{3} \mathrm{O}_{4}+12 \mathrm{H}_{2} \mathrm{SO}_{4}
$$

The reaction for the production of chalcocite from cuprous sulphate is:

$$
\mathrm{Cu}_{2} \mathrm{SO}_{4}+12 \mathrm{FeSO}_{4}+12 \mathrm{H}_{2} \mathrm{O}=\mathrm{Cu}_{2} \mathrm{~S}+4 \mathrm{Fe}_{3} \mathrm{O}_{4}+12 \mathrm{H}_{2} \mathrm{SO}_{4}
$$

and for cupric sulphate is:

$$
2 \mathrm{CuSO}_{4}+15 \mathrm{FeSO}_{4}+16 \mathrm{H}_{2} \mathrm{O}=\mathrm{Cu}_{2} \mathrm{~S}+5 \mathrm{Fe}_{3} \mathrm{O}_{4}+16 \mathrm{H}_{2} \mathrm{SO}_{4}
$$

It is to be noted that in these reactions magnetite is formed simultaneously with the production of the sulphides, and in order that the reactions

\footnotetext{
$b$ Rickard, T. A., The origin of the gold-bearing quartz of Bendigo reefs, Australia: Trans. Am. Inst. Min. Eng., vol. 22, 1894, p. 314.

$c$ Lindgren, Waldemar, Gold-quartz veins of Nevada City and Grass Valley : Seventeenth Ann. Rept. U. S. Geol. Survey, pt. 2, 1896, Pl. VIII, C, pp. 140, 156.

d Blake, Wm. P., Lead and zine deposits of the Mississippi Valley: Trans. Am. Inst. Min. Eng., vol. 22, 1894, pp. 630-631.

$e$ Bain, H. F., Van Hise, C. R., and Adams, Geo. I., Preliminary report on the lead and zinc deposits of the Ozark region : Twenty-second Ann. Rept. U. S. Geol. Survey, pt. 2, 1901, pp. 128-129.

$f$ Jenney, W. P., The chemistry of ore deposition: Trans. Am. Inst. Min. Eng., vol. 33, 1903, pp. $445-148$.
}

$a$ Cazin, F. M. F., Discussion of genesis of ores: Trans. Am. Inst. Min. Eng., vol. 24, 1894, pp. 604-608. 
shall take place a very large amount of ferrous salt is necessary. Similar reactions may be written with the ferrous reducing salt in other forms than sulphate.

The class of reactions represented by the above equations has not been confirmed by experimental work in the laboratory. It was suggested by geological facts. In the basic voleanic rocks which have been profoundly altered by metasomatic changes in the belt of cementation secondary sulphides and nagnetite are very generally present in close association. Such oceurrences are very well illustrated by the ancient voleanics of the Lake Superior region--as, for instance, the Hemlock volcanic formation of the Crystal Falls district of Michigan. ${ }^{a}$ For these rocks it can hardly be assumed that organic material or reducing agents other than the ferrous salts are present. But ferrous silicates, and, therefore, ferrous compounds, are very abundant; hence the suggestion that they are the agents which have resulted in the reprecipitation as sulphide of the sulphate compounds which have come down from the belt of weathering. The widely disseminated association of pyrite and magnetite in these rocks suggests that even the following reaction may possibly take place:

$$
22 \mathrm{FeSO}_{4}+20 \mathrm{H}_{2} \mathrm{O}=\mathrm{FeS}_{2}+7 \mathrm{Fe}_{3} \mathrm{O}_{4}+20 \mathrm{H}_{2} \mathrm{SO}_{4}
$$

If heat be liberated by this change, there is good chemical reason for its occurrence. But it must be admitted that this reaction is highly speculative and needs confirmation by experimental work.

At those places where the sulphates enter trunk channels, mingling of the solutions may cause precipitation when one of the solutions bears reducing agents. It is believed, however, that the precipitation of sulphates as sulphides in the trunk channels of circulation is far more frequently accomplished by hydrogen sulphide.

An important source of hydrogen sulphide is the reaction of organic matter upon the sulphides. Of such sulphides, that of iron is, of course, of the greatest consequence. Confirming the conclusion that the reaction of organic matter upon the sulphides may produce hydrogen sulphide is the fact that artesian waters held in sediments containing organic material are frequently marked by the presence of hydrosulphuric acid. This is

a Clements, J. Morgan, and Smyth, H. L., The Crystal Falls iron-bearing district of Michigan: Mon. U. S. Geol. Survey, vol. 36, 1899, pp. 73-15t. 
illustrated by the artesian waters of Wisconsin, ${ }^{a}$ which are contained in a series comprising limestones and shales that are rich in organic matter. The influence of organic matter in producing hydrogen sulphide is further strongly suggested by the conditions at Sulphur Bank, where hydrogen sulphide is especially abundant in the solutions and the circulation of the ground water is through sedimentary rocks bearing abundant organic material.

Another source of lydrogen sulphide is the action of the dilute strong acids upon the sulphides. For instance, the reaction of sulphnric acid npon many of the base sulphides liberates hydrosulphuric acid.

Even the weak acid, carbonic, where abundant, produces hydrogen sulphide by reaction upon the alkaline sulphides, such as sodium sulphide. As already noted, Stokes has shown that the earbonates of the alkalies, by reaction upon the sulphides of the base metals, such as pyrite, form alkaline sulphides. If the sodium sulphide thus produced comes into contact with streams bearing earbonic acid, hydrogen sulphide will be produced. When it is remembered that in the solutions sodium carbonate is an abundant salt, that pyrite is the most plentiful "sulphide, and that carbonic acid is the most abundant acid, it will be realized that the conditions must frequently arise which result in the production of hydrogen sulphide on a considerable scale.

Another way in which hydrogen sulphide can be formed is by the partial oxidation of the sulphides, especially the abundant iron bisulphide and pyrrhotite. On page 214 it was seen that the following reactions may take place:

$$
\begin{aligned}
& 3 \mathrm{FeS}_{2}+4 \mathrm{H}_{2} \mathrm{O}+4 \mathrm{O}=\mathrm{Fe}_{3} \mathrm{O}_{4}+4 \mathrm{H}_{2} \mathrm{~S}+2 \mathrm{SO}_{2} \\
& 3 \mathrm{Fe}_{11} \mathrm{~S}_{12}+36 \mathrm{H}_{2} \mathrm{O}+8 \mathrm{O}=11 \mathrm{Fe}_{3} \mathrm{O}_{4}+36 \mathrm{H}_{2} \mathrm{~S}
\end{aligned}
$$

The frequent association of magnetite with iron snlphide where the conditions have been favorable for partial oxidation suggests that this reaction may have taken place upon a considerable seale.

The hydrogen sulphide from any of the above sonrces may join the circulating waters bearing oxidized salts in solution and precipitate copper, zinc, lead, silver, and other metals as sulphides in the veins.

In this comeetion it is very interesting to note that Doelter, by treating metallic salts of the metals by liydrogen sulphide in somewhat dilute solu-

a Chamberlin, T. C., The ore deposits of southwestern Wisconsin: Geol. of Wisconsin, vol. 4,1882, p. 547 . 
tions at temperatures of $100^{\circ}$ or somewhat higher, has actually succeeded in producing artificially the following sulphicle minerals: Pyrite, chalcopyrite, bornite, chalcocite, covellite, galena, bournonite, miargyrite, jamesonite, and pyrrhotite. ${ }^{a}$

Doubtless in many instances the precipitation of the oxidized salts is accomplished by an alkaline sulphide instead of by hydrogen sulphide. It has already been pointed out that the action of alkaline carbonates upon salts such as iron sulphide produces alkaline sulphides. For instance, sodium carbonate reacts upon iron sulphide, producing sodium sulphide. Where this sulphide comes into contact with any of the oxidized salts, $\mathrm{or}^{\circ}$ other soluble sulphates, the metals may be thrown down as sulphides.

A particularly good case of precipitation due to mingling of solutions is that of the lead and zinc deposits of the Missouri-Kansas district, described by Bain, ${ }^{b}$ where waters rise through the Carboniferous limestone and come into contact with precipitating solutions derived from it. It is uncertain whether the precipitating solutions are alkaline sulphides, hydrogen sulphide, or reducing agents derived from organic matter, but probably hydrogen sulphide produced by reactions upon base sulphides is the more important precipitating agent.

Of the greatest importance in the precipitation of sulphides from ascending waters, the metals of which have been transported in the form of oxidized salts, is the reaction upon the solutions of previously precipitated sulphides. The sulphides of the less valuable but more abundant metals are important agents in the precipitation of the sulphides of the more valuable metals from the solutions of their oxidized salts. That such precipitation occurs was shown by Anthon in 1837. In 1888 the same subject was investigated by Schümann, whose results are but slightly different from those of Anthon. Schiirmann gives the following series of metals, the order being increasing strength of affinity for sulphur: Manganese, thallium, arsenic, iron, cobalt, nickel, zinc, lead, tin, antimony, cadmiun, bismuth, copper, silver, mercury, palladium. He shows that the sulphide of the first mem-

$a$ Tschermaks Min. u. Petrog. Mitth. vol. 7, 1886, p. 535 et seq.

$b$ Bain, H. F., Van Hise, C. R., and Adams, G. I., Preliminary report on the lead and zinc deposits of the Ozark region: Twenty-second Anu. Rept. U. S. Geol. Survey, pt. 2, 1901, pp. 212-214.

${ }^{c}$ Anthon, E. F., Ueber die Anwendung der anf nassem wege dargestellten Schwefelmetalle bei der chemischen Analyse: Journ. f. Prak. Chemie, 1st series, vol. 10, 1837, p. 353.

$a$ Schürmann, Liebig's Annalen der Chemie, vol. 249, 1888, p. 342. 
ber of the series, manganese, reacts upon the oxidized salts of the following metals and precipitates them as sulphides, the precipitating agent at the same time going into solution as an oxidized salt. In a similar manner the sulphide of any other member reacts upon the oxidized salts of all the following members, precipitating the sulphides of them and going into solution as an oxidized salt. Thus the sulphide of iron is a precipitating agent for the oxidized solutions of zinc, lead, copper, and silver, throwing them down from their solutions as sulphides. Similarly the sulphides of copper throw down silver as sulphide from oxidized silver solutions. It is to be noted that the base metals, manganese, iron, and arsenic, as sulphides, are capable of precipitating practically all of the higher-priced metals; and that these compounds and zinc, lead, and copper sulphides are capable of precipitating silver. It is thus shown by experiment that the abundant sulphides of the baser metals are capable of precipitating, as sulphides, the more valuable metals from their oxidized salts.

In this connection the widespread occurrence of rhodochrosite and rhodonite in connection with ore deposits is very interesting. One or both of these minerals are found in almost every Western camp. They have been especially observed at the Butte and Little Belt Mountains districts of Montana, and the San Juan, Cripple Creek, Rico, and Aspen districts of Colorado. If manganese should be present in the veins as a sulphide, for instance, as alabandite (MnS), and oxidized solutions of any of the other metals come in, the sulphides of these other metals would be formed and the manganese would pass to the oxidized condition, and it is found as a carbonate or silicate in the deposits of the first concentration and frequently as a hydrated oxide in the deposits which have been affected by secondary alterations by descending waters. The oxidized manganese is precipitater as a carbonate or silicate because carbonic and silicic acids are the two abundant rock-making acids, and because these acids, with manganese, make insoluble compounds. When later the rhodochrosite and rhodonite in the belt of weathering are affected by secondary alterations, hydrated oxide of manganese, so prevalent in the upper parts of deposits, is produced. It at least is a suggestive coincidence that the rich gold streaks in the Canp Bird mine, Colorado, ${ }^{,}$are closely associated with impure

" Purington, C. W., Woods, T. H., and Doveton, G. D., The Camp Bird mine, Onray, Colo.: Trans. An. Inst. Min. Eng., vol. 33, 1903, p. 570. 
rhodonite, and that in the Golden Fleece vein rhodochrosite "forms with quartz the gangue of the rich free gold ore." ${ }^{a}$ At Rico also, according to Ransome, rhodochrosite "is important in these mines as a rough indication of good ore."

Since manganese is not a very abundant metal, and since as a sulphide it has precedence over all other sulphides in its reactions upon oxidized salts of the other metals, being at the same time transformed to an oxidized product, it is natural to expect that manganese as rhodochrosite and rhodonite wonld be the dominating forms of manganese minerals in ore veins, and that manganese sulphide would be very rare, and such are the facts.

While manganese sulphide in many veins has doubtless been an important agent in the precipitation of ores of the first concentration by ascending water, it is probable that the much more abundant iron sulphide is of even greater importance in this comnection. Just as oxidized salts of manganese are produced by the precipitation of the valuable metals by manganese sulphide, so the precipitation of such metals by iron sulphide produces oxidized salts of iron. Siderite is an even more important gangue in ores of the first concentration than rhodochrosite or rhodonite, thus indicating that the reaction suggested has taken place. Since, however, iron is so much more common than manganese, ordinarily not all of the irow sulphide has thus been oxidized, and hence in the veins pyrite is a very common gangue.

The reactions which cansed the precipitation of the sulphides of the various metals from their oxidized solutions by the sulphides of other metals were not written out by Anthon and Schumann, but recently Stokes has investigated the reaction in the case of iron sulphide with some of the solutions. Thus he has shown that pyrite and marcasite precipitate copper sulphide from cupric sulphate according to the following reaction:

$5 \mathrm{FeS}_{2}+14 \mathrm{CuSO}_{4}+12 \mathrm{H}_{2} \mathrm{O}=7 \mathrm{Cu}_{2} \mathrm{~S}+5 \mathrm{FeSO}_{4}+12 \mathrm{H}_{2} \mathrm{SO}_{4}$.

This reaction took place at $100^{\circ} \mathrm{C}$. and above. Stokes has showi also that where sodium carbonate or potassium bicarbonate is present with the sulphide of iron and carbonates of various metals at $180^{\circ} \mathrm{C}$., sulphides are

$a$ Ransome, F. L., A report on the economic geology of the Silverton quadrangle, Colorado: Bull. U. S. Geol. Survey, No. 182, 1901, p. 73.

$b$ Ransome, F. L., The ore rleposit of the Rico Mountains, Colorado: Twenty-second Ann. Rept. U. S. Geol. Survey, part 2, 1901, 1. 252. 
precipitated in a different manner. For instance, in the case of lead carbonate with pyrite and mareasite, the reaction is as follows:

$$
8 \mathrm{FeS}_{2}+14 \mathrm{PbCO}_{3}+\mathrm{Na}_{2} \mathrm{CO}_{3}=14 \mathrm{PbS}+4 \mathrm{Fe}_{2} \mathrm{O}_{3}+\mathrm{Na}_{2} \mathrm{~S}_{2} \mathrm{O}_{3}+15 \mathrm{CO}_{3}
$$

An interesting point in connection with this reaction is the production of hematite and sodium thiosulphate. Stokes shows also that zine, copper, and silver are precipitated as sulphides by iron as sulphide in an analogous manner, the reactions being:

and

$$
\begin{aligned}
& 8 \mathrm{FeS}_{2}+15 \mathrm{ZnCO}_{3}+\mathrm{Na}_{2} \mathrm{CO}_{3}=15 \mathrm{ZnS}+4 \mathrm{Fe}_{2} \mathrm{O}_{3}+\mathrm{Na}_{2} \mathrm{SO}_{4}+16 \mathrm{CO}_{2} \\
& 8 \mathrm{FeS}_{2}+15 \mathrm{Ag}_{2} \mathrm{CO}_{3}+\mathrm{Na}_{2} \mathrm{CO}_{3}=15 \mathrm{Ag}_{2} \mathrm{~S}+4 \mathrm{Fe}_{2} \mathrm{O}_{3}+\mathrm{Na}_{2} \mathrm{SO}_{4}+16 \mathrm{CO}_{2} .
\end{aligned}
$$

While Stokes in the laboratory used temperatures of $100^{\circ}$ C. and $180^{\circ}$ C., it does not follow that the above reactions do not take place at lower temperatures but more slowly.

The above reactions in the presence of an alkaline carbonate are very suggestive, since they possibly explain in large part the association of lead, zinc, copper, and silver ores with limestone; for if calcium carbonate be substituted for sodium carbonate, similar reactions take place. It is not necessary to rewrite the equations, but the character of the reactions may be seen by substituting for $\mathrm{Na}_{2} \mathrm{CO}_{3}$ on the left-hand side the equations $\mathrm{CaCO}_{3}$, and for $\mathrm{Na}_{2} \mathrm{~S}_{2} \mathrm{O}_{3}$ and $\mathrm{Na}_{2} \mathrm{SO}_{4}$ on the right-hand side the equation $\mathrm{CaS}_{2} \mathrm{O}_{3}$ and $\mathrm{CaSO}_{4}$. Since these reactions are confirmed by experiment, we probably have the clue to the world-wide preference of many ores of lead, zinc, copper, and silver for the limestones. (See pp. 1086-1087.)

GENERAL STATEMENTS.

From the foregoing it appears that at the trunk channels of circulation the sulphur may enter in sulphides or in oxidized compounds in the forms of sulphites, sulphates, or other oxidized salts. If present as sulphides in alkatine solutions, the sulphides may be precipitated in consequence of the neutralization of the solution by an acid. They may be thrown down also in the ascending solutions in conseqnence of diminishing temperature and pressure. However, where the oxidized sulphur-bearing solutions reach trunk channels, as they frequently do, in order to precipitate the metals as sulphides they must become mingled with solntions bearing rerlueing agents, hydrogen sulplide, or alkaline sulphides, or must come into contact 
with other sulphides previously precipitated or with other reducing agents. Any of these factors, or any combination of them, may cause the precipitation of the sulphides.

A case due to the combination of these factors is the precipitation of sulphides which later may react to precipitate the metal of the oxidized salts. For instance, in the early stage of the development of a deposit, the sulphides of iron and other base metals may be precipitated by hydrogen sulphide or some other compound, and later these previously precipitated sulphides take part in the precipitation of the sulphides of copper, silver, and mercury from the oxidized solutions of these compounds, such as sulphates.

While it is believed that sulphides are generally segregated in the first concentration by upward-moving waters, this is not supposed to be universal. Nature's processes are always too complex to be coverd by a single general statement. As a result of ningling solutions at various places, and of reactions between solutions and walls, many lateral-moving and down wardmoving streams doubtless deposit rather than dissolve sulphides. Indeed, in the frequent case where in downward-moring waters sulphites or sulphates are reduced by organic matter to sulphides, precipitation of a portion of the sulphide is usual. Still the statement would hold true that upon the average more sulphides are dissolved than deposited by descending waters, and more sulphides are deposited than dissolved by ascending waters.

I conchnde, therefore, that sulphide ores, whatever their source, as first concentrates are generally deposited by ascending waters in the trunt channels.

It appears that whether sulphur-bearing compounds reach trunk channels as sulphides or as oxidized salts, they are likely to be precipitated in such channels because solutions from various sources mingle there and come into contact with previously precipitated sulphides. The sulphides thus produced in the trunk channels may by denudation again reach the belt of weathering when the cycle is complete. These sulphides may be again oxidized to sulphate, and so on. It is therefore clear that sulphur, as sulphide and sulphate, may again and again take part in the deposition of ores, ${ }^{a}$ but the first chief source of the sulphur is probably the sulphides of the original crystallized rocks and of magmas.

$a$ Le Conte, Joseph, Genesis of metalliferous veins: Am. Jour. Sci., 3d ser., vol. 26, 1883, p. 13. 
TELUURIDES.

The only important telluride ores are those of gold and silver. These compounds, until comparatively recently, were regarded as somewhat exceptional, and for the uost part rather as mineralogical rarities than as ores. The earliest gold and silver tellurium ores to be mined were those of Nagyag, in Transylvania.. Gold mining in Colorado has added other and much more important localities where the tellurides are produced in important amounts. About 1872 the tellurides of Boulder County became of consequence. But of more importance than all of the previously known tellurides are those of Cripple Creek, Colorado, which began to be exploited in $1891 .^{b}$ Here the various tellurides are found, but the greater part of the gold is believed to occur in calaverite."

Close mineralogical studies of ore deposits in recent years have shown that subordinate and usually unimportant amounts of tellurides, from an economic point of view, occur very generally associated with gold. Indeed, it appears that the presence of the tellurides with the gold ores of the first concentration is scarcely less prevalent than the association of pyrite witl gold ores. The widespread occurrence of tellurides in comnection with gold ores is illustrated by the Kalgoorlie district of West Australia, described by Bancroft; ${ }_{f}^{d}$ by the Sierra Nevada gold deposits, described by Lindgren $;^{e}$ by the Judith Mountains and Little Rocky Mountains, Montana, deseribed by Weed and Pirsson; $f$ by the Potsdam gold ores of the Black Hills, described by Smith and Irving; ${ }^{g}$ by the mines of Custer County, Colo., and by the Appalachian gold deposits, described by S. F. Emmons. ${ }^{h}$

a Kemp, J. F., Geological occurrence and associates of the telluride gold ores: Mineral Industry, vol. 6,1898 , p. 295.

${ }^{b}$ Penrose, R. A. F., jr., Mining geology of the Cripple Creek rlistrict: Sixteenth Ann. Rept. U. S. Geol. Suvey, pt. 2, p. 118.

$c$ Penrose, cit., p. 121.

a Bancroft, Geo. J., Kalgoorlie, Western Australia, and its surroundings: Trans. Am. Inst. Min. Eng., vol. 28, 1899, pp. 88-100.

$e$ Lindgren, Waldemar, The gold-quartz veins of Nevada City and Grass Valley, California: Seventeenth Ann. Rept. U. S. Geol. Survey, pt. 2, 1896, p. 117.

$f$ Weed, W. H., and Pirsson, L. V., Geology and mineral resources of the Judith Mountains, Montana: Eighteenth Ann. Rept. U. S. Geol. Survey, pt. 3, 1898, pp. 589-592. Weed, W. H., and Pirsson, L. V., Geology of the Little Rocky Mountains, Montana: Jour. Geol., vol. 4, 1896, pp. 426-428.

$g$ Smith, F. C., The Potsdam gold ores of the Black Hills of South Dakota: Trans. Am. Inst. Min. Eng., vol. 27, 1898, pp. 414-420. Irving, J. D., A contribution to the geology of the northern Black Hills: Annals New York Acad. Sci., vol. 11, 1899, pp. 297-311.

$h$ Emmons, S. F., The mines of Custer County, Colorarlo: Seventeenth Ann. Rept. U. S. Geol. Survey, pt. 2, 1896, p. 433. Emmons, S. F., Notes on the gold deposits of Montgomery County, Maryland: Trans. Am. Inst. Min. Eng., vol. 18, 1890, p. 407. 
Since the tellurides are very generally associated with gold ores and the free gold deposited by the deep circulation is almost universally associater with pyrite and other sulphides, it follows that the tellurides deposited by the deep circulation are usually associated with sulphides. This is not only true of those localities in which the telluricles are unimportant as ores, but is equally true of the great telluride camps. Of Cripple Creek Penrose says: "The close association of tellurides with sulphides, especiaily iron pyrites, which themselves often carry gold, is also a point worthy of note. Not only are auriferous tellurium and sulphur compounds often thus mechanically associated in different minerals, but sometimes they replace each other in the same minerals, such as tetradymite, nagyagite, and tellur-sulphur." a

The tellurides are also very generally associated with fluorite, and Penrose notes that where the gold is mainly in sulphides fluorite has not often been observed.

It seems to me certain that the widespread association of the tellurides with gold and silver ores, especially with gold ores, has a genetic significance probably less important only than that of the base sulphides, especially iron sulphide. As to the source of the tellurium, nothing is positively known. In all of the above-mentioned districts in which tellurium is especially abundant, with the possible exception of the Kalgoorlie district, which has not yet been thoroughly studied and in which the age of the mineralizing dikes has not been established, are found comparatively recent igneous rocks, in which doubtless the tellurium largely had its origin. At first thought one might conclude that the gold, silver, and tellurium were transported as tellurides and deposited as such without chemical change, but the recent work of Lenher and $\mathrm{Hall}^{b}$ is decidedly against this view. They have found no solvent whatever for tellurides of gold without breaking up these compounds and producing salts of tellurium, the gold usually being left in the metallic form. Moreover, as has already been noted, they have shown that metallic tellurimm and seven of the nore common mineral tellurides of gold and silver rapidly reduce gold from

a Penrose, R. A. F., jr., Mining geology of the Cripple Creek district, Colorado: Sixteenth Ann. Rept. U. S. Geol. Survey, pt. 2, 1895, p. 157.

${ }^{b}$ Lenher, Victor, Naturally occurring telluride of gold: Jour. Am. Chem. Soc, vol. 24, 1902, pp. 355-360.

Hall, R. D., and Lenher, Victor, Action of tellurium and selenium on gold and silver salts: Ibid., pp. 918-927. 
its solutions, forming metallic gold, the tellurium at the same time going into solution. Further, they have proved that the presence of any of the soluble tellurides, including hydrogen telluride, is sufficient not only to throw the gold out of solution, but to prevent it from getting into solution. Other soluble salts, where tellnrium acts as an acid, are the tellurites and tellurates. Tellurous oxide or acid is also sparingly soluble. All of these compounds, like tellurides, precipitate gold from its solutions in a metallic form, not as telluride. From the foregoing it appears that if tellurium compounds in which tellurium is a part of the acid are essential for the formation of the tellurides of gold, these tellurium salts and the gold have come into the trunk channel from separate sources. They could not have traveled together; else the gold would have been thrown from the solutions before reaching the trunk chamnels.

It is to be remembered that tellurium, besides acting in an acid, also acts as a metal to the halogens (chlorine, bromine, and iodine). The telluric compounds of this class, such as telluric chloride $\left(\mathrm{TeCl}_{4}\right)$, being completely saturated, so far as tellurium is concerned, have no reducing power, and they may therefore travel with gold solutions. But the tellurous combinations with the halogens, such as tellurous chloride $\left(\mathrm{TeCl}_{2}\right)$, can not travel with gold, for Lenher has shown that such tellurous salts in the presence of water and its compounds react upon the water, producing metallic tellurium and telluric chloride according to the following equation:

$2 \mathrm{TeCl}_{2}+\mathrm{H}_{2} \mathrm{O}=\mathrm{Te}+\mathrm{TeCl}_{4}+\mathrm{H}_{2} \mathrm{O}$

The metallic tellurium would then reduce the gold, which would therefore be precipitated before reaching the trunk channels.

The almost invariable association of tellurides with sulphides, already noted, naturally leads to the suggestion that the same conditions were favorable to the deposition of the sulphides and the tellurides. In this connection the occurrence at Cripple Creek is especially interesting. Mr. Moore, consulting engineer of the Portland mine, informs me that in this district near the surface the values are found in the oxidized zone as native gold; that deeper, the values are mainly in the tellurides, the associated sulphides being very lean; and that still deeper the values are found both in the tellurides and in the sulphides of iron. The depth at which the sulphides at the Portland mine begin to have value is about 200 meter's. HON XLVII-04- 71 
These facts strongly favor the precipitation of the gold as a first concentrate simultaneously in the sulphides and the tellurides. It is believed (see pp. 1172-1174) that the abundant native gold at the surface and in the tellurides at intermediate zones to the exclusion of the sulphides is due to secondary reaction by descending water.

It may be that the key to the problem of the deposition of the tellurides lies in their association with sulphides. We have already seen that telluric salts of the type of $\mathrm{TeCl}_{4}$ may travel with gold in solutions. It has already been pointed out that gold, in most cases, probably also travels as a chloride, and thus solutions of auric chloride and telluric chloride may together enter trunk channels which contain sulphides. In such trunk channels the reaction of the sulphides might reduce both the gold and the tellurium simultaneonsly and thus produce tellurides of gold; or, by the reaction of the sulphides upon the telluric salts, these may be reduced to tellurous salts, which, as already explained, would decompose into metallic tellurium and telluric salts, and the tellurium would precipitate the gold. Under these or some other conditions, the gold and tellurium go down together, with a definite composition, and thus form the tellurides.

The invariable association of silver with the tellurides of gold suggests the possibility that the presence of silrer salts is essential for the formation of the tellurides of gold. But in some cases the silver is very low in the tellurides, although rarely as low as 0.8 , as in the case of one specimen of calaverite from Kalgoorlie ${ }^{a}$ which makes it improbable that the presence of silver salts is essential for the precipitation of the tellurides.

The association of the tellurides with fluorite las already been mentioned, and this association suggests a genetic relation between the two; but bearing in the opposite direction are the observations made by Penrose at Cripple Creek, where the abundance of fluorite has no definite relation to the abundance of tellurides. ${ }^{b}$ Possibly pointing in the same direction is the experimental work of Lenher, ${ }^{\circ}$ who has shown that gold and gold oxide are absolutely insoluble in hydrofluoric acid. Not only is this the case, but when any gold salt is brought into contact with a soluble fluoride the gold is immediately precipitated as a hydrate. T'his is true

a Rickard, T. A., Telluride ores of Cripple Creek and Kalgoorlie: Trans. Am. Inst. Min. Eng., vol. 30,1901, p. 711 .

b Penrose, cit., pp. 158-159.

${ }^{c}$ Lenher, Victor, Fluoride of gold: Jour. Am. Chem. Soc., vol. 25, 1903, pp. 1136-1138. 
even for silver fluoride, which, according to Lenher, acts upon gold chloride. as follows:

$$
\mathrm{AnCl}_{3}+-3 \mathrm{AgF}+3 \mathrm{H}_{2} \mathrm{O}=3 \mathrm{AgCl}+\mathrm{Au}(\mathrm{OH})_{3}+3 \mathrm{HF}
$$

Lenlier's work suggests the advisability of experimenting as to the effect of the soluble fluorides and of hydrofluoric acid upon solutions bearing chlorides of both gold and tellurium. In this or some other combination of the three elements gold, tellurium, and fluorine with perhaps other compounds may lie the key to the problem of the precipitation of the gold tellurides.

The abundant fluorite associated with the tellurides has frequently been cited as evidence of pneumatolitic action in connection with such deposits. But Penrose's description of the Cripple Creek ores gives no support to this hypothesis. All his descriptions show the phenomena to be those which, in many other districts, are well known to be dne to water solutions. For instance, the most abundant gangue mineral of the district is silica in quartzose, chalcedonic, and amorphous forms. It is well known that these compounds are the most abundant ones deposited by underground water. Others of the more abundant gangue minerals are oxides of manganese, calcite, gypsum, barite and kaolin."

Furthermore, in some of the mines, as the Gold Coin mine, the ore of which is in granite, there has been solution of biotite, quartz, and feldspar, and this can not be attributed to pnemmatolitic action. ${ }^{b}$

I therefore find no evidence of pneumatolitic action in comnection with the genesis of the telluride ores. It is uncertain what conditions produce a somewhat homogeneons compound consisting of definite proportions of silver, gold, and tellurium, as in the telluride minerals. Doctor Lenher has heen at work on this problem for some time, but as yet witlout determinative results. He las treated gold solntions with hydrogen telluride and has worked on the various tellurium compounds, such as the ehloride, bromide, flnoride, and alkaline tellurites, all experiments being made in the presence of a recheing agent, such as sulphurous acid; yet in no case has he been able to get homogeneous compounds of gold and tellninm, but, on the contrary, has obtained metallic gold and tellurium salts, or mixtures of gold and teilurium of imational composition. While the problems of the

a Penrose, cit., pp. 123-129.

Penrose, R. A. F., jr., Mining geology of the Cripple Creek district: Sixteenth Ann. Rept. U. S. Geol. Survey, pt. 2, 1895, pp. 159-161. 
transportation of the compounds resulting in the tellurides and of the precipitation of the tellurides have not yet been solved, there is little doubt that careful chemical work will solve them.

In riew of all the foregoing facts, the most plausible suggestion which I am able to make as to the development of the tellurides is as follows: The gold is taken into solntion by descending waters in the early part of the jommey in the form of a chloride, as explainerl on pages 1089-1091. The tellurium is widely dispersed, possibly to some extent as metallic tellurium, but more largely as a telluride, and is oxidized in the belt of weathering. It there unites with an acid and travels as a soluble salt, perhaps, also, in large part, as telluric chloride. That reactions of this kind take place with reference to the tellurides in the belt of weathering are certain, as shown by the abundant spongy gold at Cripple Creek, psendomorphous after the various tellurides, showing that snch reactions have taken place there on an extensive scale. The auric chlorides and telluric salts, such as telluric chloride, may travel together without reaction, or they may come together in the trunk channels. There they become ningled with reducing compounds in solution, or, as has been suggested, come into contact with reducing solids, such as the sulphides. It is believed the tellurium and gold are simultaneously reduced under such conditions that they unite in definite compositions, and thins produce the telluride minerals.

Hall and Lenher were more successful in the production of telluride of silver. An ammoniacal solution of silver chloride in contact with tellurium at room temperatures resulted in the production of silver telluride according to the following reaction:

$4 \mathrm{AgCl}+3 \mathrm{Te}=2 \mathrm{Ag}_{2} \mathrm{Te}+\mathrm{TeCl}_{4}$

When the nitrate of silver was used "a greater range of temperature was possible, and the solution was either boiled continuously or kept at a temperature of about $80^{\circ} \mathrm{C}$. for a long time." ${ }^{a}$ The reaction in this case as given by them is:

$$
4 \mathrm{AgNO}_{3}+3 \mathrm{Te}=2 \mathrm{Ag}_{2} \mathrm{Te}+\mathrm{Te}\left(\mathrm{NO}_{3}\right)_{4}
$$

Since, however, it is difficult to understand how metallic tellurium can be carried in solution, there is a passibility that the silver tellurides are

a Hall, R. D., and Lenher, Victor, Action of telluriuu and selenium on gold and silver salts: Jour. Am. Chem. Soc., vol. 24, 1902, p. 922. 
prodnced in nature not by the reaction of metallic tellurinu but by tellurous salts which, according to Lenher, precipitate silver by the following reactions:

(a) $2 \mathrm{TeCl}_{2}+\mathrm{H}_{2} \mathrm{O}=\mathrm{Te}+\mathrm{TeCl}_{4}+\mathrm{H}_{2} \mathrm{O}$

(b) $4 \mathrm{AgNO}_{3}+3 \mathrm{Te}=2 \mathrm{Ag}_{2} \mathrm{Te}+\mathrm{Te}\left(\mathrm{NO}_{3}\right)_{4}$

While the reactions given may possibly explain the formation of a part of the silver telluride in the rare mineral hessite, it is to be remembered that pure silver tellnide is very exceptional.

Commonly, so far as silver occurs with tellurium, it is in minerals in which there is also telhuide of gold, and frequently telluride of lead, mercury, and antimony. It therefore follows that the conditions under which the telluride of silver is precipitated must be the same in most cases as those which cause the formation of the telluride of gold. Hence the solution of the problem of the precipitation of tellurides of gold will probably also be the solntion of the problem of the precipitation of the telluride of silver.

oxIDES.

The oxide ores that are deposited by ascending water below the belt in which the effect of descending waters is evident are dominantly hematite $\left(\mathrm{Fe}_{2} \mathrm{O}_{3}\right)$ and magnetite $\left(\mathrm{FeO} \cdot \mathrm{Fe}_{2} \mathrm{O}_{3}\right)$, and possibly zincite $(\mathrm{ZnO})$, franklinite $\left((\mathrm{FeZnNn}) \mathrm{O} \cdot\left(\mathrm{Fe} \mathrm{In}_{2}\right)_{2} \mathrm{O}_{3}\right)$, and cassiterite $\left(\mathrm{SnO}_{2}\right)$.

The association of hematite and magnetite with the sulphides of the first concentration far below the belt where oxidizing waters can act is so well known that it is not necessary to amplify by giving illustrations.

So far as I know the chief occurrences of zincite and franklinite in deep-seated deposits with no evidence of superficial oxidation are in New Jersey, especially at the famons localities of Franklin Furnace and Sterling ${ }^{a}$ It is notable that here magnetite also occurs associated with the zincite and franklinite. Magnetite associated with pyrite and mareasite occurs very extensively in the Lake Superior region, especially in Canada, although these nninerals are found together on the south shore of Lake Superior, as at the Republic trough. The question at once arises whether the metals were transported to their present positions in solution and deposited by ascending waters, or, on the contrary, were produced by alterations of solid

a Kemp, J. F., The ore deposits of Franklin Furnace and Ogdensburg, New Jersey: Trans. New York Acad. Sci., vol. 13, 1893-94, pp. 76-96. 
compounds in the zone of anamorphism by the processes of dehydration, decarbonation and deoxidation.

Magnetite. The formation of magnetite in the zone of anamorphism is fully discussed on pages 845-846, and will not again be described here. The reactions producing magnetite are believed to be as follows:

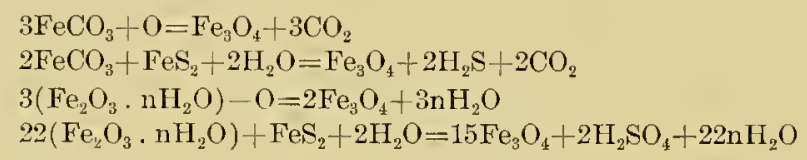

zincite.-In order to produce zincite in the deep-seated zone from smithsonite, it is only necessary that the water and the carbon dioxide be driven off, thus:

$$
\mathrm{ZnCO}_{3} \cdot \mathrm{H}_{2} \mathrm{O}=\mathrm{ZnO}+\mathrm{H}_{2} \mathrm{O}+\mathrm{CO}_{2}
$$

If smithsonite were formed in the belt of weathering, as explained on pages 1144-1145, 1147-1148, and later by burial transferred to the zone of anamorphism, the above reaction would almost certainly take place.

Franklinite. - In the case of franklinite it is necessary only to suppose that with the smithsonite there was a certain amount of hydrous oxide of iron and manganese. It is well known that the smithsonite produced in the belt of weathering almost universally contains hydrous oxide of iron. Not infrequently it is also associated with hydrous manganese oxide. If smithsonite, hydrous oxide of iron, and hydrous oxide of manganese be taken in the proper proportions, and subjected to dehydration, decarbonation, and deoxidation, franklinite may be produced. For simplicity suppose that the iron, zine, and manganese in the resultant franklinite are equally abundant as ferrous oxide, and iron and manganese equally abundant as ferric oxide. The reaction may then be written as follows:

$$
\begin{gathered}
2\left(\mathrm{ZnCO}_{3} \cdot \mathrm{H}_{2} \mathrm{O}\right)+4\left(\mathrm{Fe}_{2} \mathrm{O}_{3} \cdot 11_{2}^{1} \mathrm{H}_{2} \mathrm{O}\right)+4\left(\mathrm{Mn}_{2} \mathrm{O}_{3} \cdot \mathrm{H}_{2} \mathrm{O}\right)-4 \mathrm{O}= \\
6\left[(\mathrm{FeZnMn}) \mathrm{O} .(\mathrm{FeMn})_{2} \mathrm{O}_{3}\right]+12 \mathrm{H}_{2} \mathrm{O}+2 \mathrm{CO}_{2}
\end{gathered}
$$

Hematite- - It is well known that hematite occurs as a gangue mineral in connection with the sulphides in veins, although so far as I know there is no case in which such hematite occurs in sufficient amount to be called an ore. In this connection the recent work of Stokes is interesting. ${ }^{a}$ He has shown that $\mathrm{FeS}_{2}$ as pyrite and marcasite is a ferric iron; and further, that 
from this ferric iron hematite can be produced by the action of certain carbonates and alkaline carbonates withont oxidation. By reactions of zinc, lead, and silver carbonates with an excess of alkaline bicarbonate, he has produced hematite according to the following reactions:

$$
\begin{aligned}
& 8 \mathrm{FeS}_{2}+14 \mathrm{ZnCO}_{3}+\mathrm{Na}_{2} \mathrm{CO}_{3}=4 \mathrm{Fe}_{2} \mathrm{O}_{3}+14 \mathrm{ZnS}+\mathrm{Na}_{2} \mathrm{~S}_{2} \mathrm{O}_{3}+15 \mathrm{CO}_{2} \\
& 8 \mathrm{FeS}_{2}+14 \mathrm{PbCO}_{3}+\mathrm{Na}_{2} \mathrm{CO}_{3}=4 \mathrm{Fe}_{2} \mathrm{O}_{3}+14 \mathrm{PbS}+\mathrm{Na}_{2} \mathrm{~S}_{2} \mathrm{O}_{3}+15 \mathrm{CO}_{2} \\
& 8 \mathrm{FeS}_{2}+15 \mathrm{Ag}_{2} \mathrm{CO}_{3}+\mathrm{Na}_{2} \mathrm{CO}_{3}=4 \mathrm{Fe}_{2} \mathrm{O}_{3}+15 \mathrm{Ag}_{2} \mathrm{~S}+\mathrm{Na}_{2} \mathrm{SO}_{4}+16 \mathrm{CO}_{2}
\end{aligned}
$$

He has also produced hematite fiom the sulphide through the reaction of the alkaline carbonate alone at temperatures of $100^{\circ} \mathrm{C}$. and $190^{\circ} \mathrm{C}$., thus:

$$
8 \mathrm{FeS}_{2}+15 \mathrm{Na}_{2} \mathrm{CO}_{3} \rightleftarrows 4 \mathrm{Fe}_{2} \mathrm{O}_{3}+14 \mathrm{Na}_{2} \mathrm{~S}+\mathrm{Na}_{2} \mathrm{~S}_{2} \mathrm{O}_{3}+15 \mathrm{CO}_{2}
$$

This last reaction is reversible, but Stokes remarks it will proceed to an end if the sulphide and thiosulphate be carried away, as by a circulating solution, or if there be present a metallic salt capable of precipitating the alkaline sulphide as fast as it is formed, as in the first three reactions above given.

Cassiterite.-In reference to cassiterite $\left(\mathrm{SnO}_{2}\right)$ Lindgren calls attention to the work of Winkler, Sandberger, and Verbeek, which shows that tin "may be held in solution and deposited at ordinary pressure by thermal waters." However, in this connection it is to be remembered that both Vogt and Beck strongly insist that cassiterite is formed, to use the words of Vogt, "by eruptive after-action." Vogt says of the cassiterite veins that their "material contents were extracted from the not yet fully congealed granite." Further, Vogt and Beck, if I understand them correctly, following Elie de Beaumont and Daubrée, regard the extraction from the "not yet fully congealed granite" as accomplished by pneumatolytic processes. Upon the point that tin ore may be thus formed I express no opinion.

I do not doubt that tin, like other metals, has been transported by underground waters, and from such solutions precipitated as cassiterite. As is well known, tin may be readily carried by water as the sulphate, nitrate, or chloride, and doubtless is also transported in other forms. From stannic solutions at ordinary temperatures hydrated stannic oxide is thrown down by the alkaline carbonates. It may be that at the relatively high

$\alpha$ Lindgren, Waldemar, Metasomatic processes in fissure veins: Trans. Am. Inst. Min. Eng., vol. 30,1901, p. 625 .

$b$ Vogt, J. H. L., Problems in the geology of ore deposits: Trans. Am. Inst. Min. Lng., vol. 31, 1902, p. 135. 
temperatures and pressures which exist in the deeper parts of fissure veins, this reagent would result in auhydrous stannic oxide, or cassiterite; but this is a mere suggestion. The conditions under which anlyydrous stannic oxide is precipitated from its solutions should be experimentally investigated.

In conclusion it may be said that one oxide which very probably is deposited by ascending waters as an ore is cassiterite.

Carbovates.

Aside from hydrosulphuric acid, the acid of great importance in the deposition of ores is carbonic acid. This, as is well known, is indeed the dominant acid contained in issuing underground waters. This point both Le Conte ${ }^{a}$ and Posepny ${ }^{b}$ strongly emphasize. I have already pointed out sources for the excess of carbon dioxide held in the underground waters. (See p. 678.)

A very interesting confirmation of the theory given on the pages referred to regarding the liberation of silica by the process of carbonation near the surface and the liberation of carbon dioxide probably by the process of silication at depth is furnished by the Geyser mine of Custer County, Colo., described by Emmons. ${ }^{\circ}$ Here waters were analyzed from the 154-meter and the 615-meter levels. The surficial waters contain ten times as much silica as the deep-seated waters, and the deep waters hold a greater quantity of carbonic acid than the radose circulation.

The carbonates which are most exteusively deposited in the veins of the first concentration are those of calcium and magnesium as calcite $\left(\mathrm{CaCO}_{3}\right)$ and dolomite $\left(\mathrm{CaCO}_{3} . \mathrm{MgCO}_{3}\right)$. While calcite and dolomite are the dominant carbonates in the gangne, the carbonates of the other alkaline earths, strontianite $\left(\mathrm{SrCO}_{3}\right)$ and witherite $\left(\mathrm{BaCO}_{3}\right)$, are also well known. The other important carbonates are those of iron-siderite $\left(\mathrm{FeCO}_{3}\right)$-and of manganese-rhodochrosite $\left(\mathrm{InCO}_{3}\right)$. Of cotrse, it is well known that carbonate of zinc (smithsonite) and carbonates of copper (azurite and malachite) occur abundantly as ores; but these are mainly secondary products of descending waters and do not come under the subject now being consid-

a Le Conte, Joseph, Genesis of metalliferous veins: Am. Jour. Sci., 3d ser., vol, 26, 1883, p. 11.

$b$ Posepny, F., The genesis of ore deposits: Trans. Am. Inst. Hin. Eng., vol. 23, 1894, p. 237.

cEmmons, S. F., The mines of Custer County, Colo.: Seventeenth Ann. Rept. U. S. Geol. Survey, pt. 2, 1896, pp. $460-464$. 
ered, the deposits of a first concentration by ascending waters. It has been explained in various parts of this treatise that the two great rock-making acids are carbonic acid and silicic acid, and further it has just been explained that in the deep-seated zone carbonic acid is extensively produced. Thus it is entirely natural that so far as the metals are somewhat soluble and can travel as carbonates, they will do so. This applies especially to the alkalies and the alkaline earths, and to iron and manganese. When carbonate solutions containing these various metals rise in the trunk channels of circulation with diminishing temperature and pressure, it naturally follows that the less soluble of the carbonates are thrown down in large amounts. These less soluble carbonates are calcite, dolomite, siderite, and rhodochrosite. The carbonates of sodium and potassium are not thrown down, becanse these compounds are so readily soluble.

In conclusion it may be said that the carbonates, as original deposits by ascending waters, are essentially gangue minerals, not ores. So far as I know none of them are mined as ores within the United States, although in some places siderite and rhodochrosite, as deposits of the first concentration by ascending waters, may be an unimportant source of iron and manganese ores.

Excellent illustrations of rhodochrosite as a gangue mineral are furnished by the San Juan district, Colorado. This carbonate is generally found in that area, but is an especially important and abundant gangue mineral at the Smuggler Union mine.

siLicates.

The silicates are well known to be important gangue minerals deposited by the deep circulation. If one were to give a list of the silicates which have been found as gangue in veins in various parts of the world, it would comprise a large proportion of the entire list of silicates. This is an inevitable consequence of the facts that, first, the dominant acid of nature is silicic acid, and second, the silicates for the most part are rather insoluble, many of them extremely so. It has been explained at various places that silica as colloidal silicic acid travels in great quantities through the rocks, being produced on an enormons scale in the belt of weathering by the process of carbonation. (See pp. 173-177, 480.) Silicic acid formed in this manner and released by other reactions thins enters the belt of cementation and finds its way to the trunk chamels of circulation, to 
which come also metals in various combination. Where silicic acid and the salts of the metals thus meet it is certain that the silicates form extensively, according to the law of mass action that the most abundant compounds are most likely to be precipitated, and in consequence of the law that the most insoluble compounds are likely to be thrown down.

Of the silicates in fissure veins Lindgren regards the following of sufficient importance to be cited: Muscovite, biotite, chlorite, pyroxene, amphibole, gannet, epidote, orthoclase, albite, tourmaline, topaz, kaolinite, and zeolites. ${ }^{a}$

Lindgren's description of the occurrence of these minerals shows that the hydrous silicates are dominant. While a considerable number of the anhydrous silicates form, they are very subordinate in amount. The significance of these facts is discussed on pages 1055-1060. The abundance and prevalence of the hydrons silicates are beautifully illustrated by the copper deposits of the Lake Superior region. Here there lias been scarcely any discoverable effect of descending waters, as recent glacial erosion has entirely removed the belt of weathering of pre-Glacial time. Pumpelly gives the following list of hydrous silicates as occurring in this region: Analcite, apophyllite, chlorite, datolite, delessite, epidote, laumontite, prehnite. This list has since been supplemented by Hubbard, the following being added: Chabazite, chlorastrolite, chrysocolla, harmotome, henlandite, leunhardite, mesotype, natrolite, pectolite, saponite, stilbite, thomsonite. ${ }^{\circ}$ While in the Lake Superior copper deposits the dominance of the hydrous silicates is clear, the gangue minerals are not restricted to them, but comprise anhydrous minerals-orthoclase and wollastonite being mentioned.

It is to be noted that the silicate gangue minerals retain even some of the alkalies, i. e., sodium and potassium. Sodimn is found in analeite, chabazite, chlorastrolite, mesotype, natrolite, pectolite, stilbite, and thomsonite; and potassium is found in apophyllite, chabazite, harmotome, and orthoclase. By the mion of the alkalies with other bases and with silica it is possible to produce compounds insoluble in the liquids present, and where this could take place as demanded by the laws of chemistry, it has occmred,

$a$ Lindgren, Waldemar, Metasomatic processes in fissure veins: Trans. Am. Inst. Min. Eng., vol. 30, 1901, pp. 607-615.

$\checkmark$ Pumpelly, Raphael, The paragenesis and derivation of copper and its associates on Lake Superior: Am. Jour. Sci., 3d series, wol. 2, 1871, pp. 254-255.

c Hubbard, L. L., Macroscopic minerals of Michigan: Rept. State Board Geol. Survey Michigan, 1891-92, p. 176. 
and thus even the most soluble of the abundant elements have been fixed in the veins to some extent.

While the silicates are dominantly gangue minerals, silicates of zinc, manganese, and nickel occur as ores. Silicate of zinc occurs botle as willemite $\left(2 \mathrm{ZnO} . \mathrm{SiO}_{2}\right)$ and as calamine $\left(\mathrm{H}_{2} \mathrm{O} \cdot 2 \mathrm{ZnO}\right.$. $\left.\mathrm{SiO}_{2}\right)$. The most notable occurrence of willemite is in the New Jersey zinc deposits. ${ }^{a}$ In reference to this mineral the question arises whether it was formed as an original precipitate from the deep circulation or was produced by dehydration of calamine in the zone of anamorphism, the calamine having been formed originally in the belt of weathering in the same mamer as in the Mississippi Valley. Whether calamine occurs as zine ore as an original deposit by ascending waters I do not know. The abundant development of calamine in consequence of the reactions of the belt of weathering is very well known, as explained on pages $1144,1147-1148$.

Manganese silicate occurs rather abundautly as rhodonite ( $\mathrm{MnO}$. $\left.\mathrm{SiO}_{2}\right)$. For the most part, however, this is a gangue mineral rather than an ore, its occurrence being well illustrated at Butte, Mont., and in the Smuggler Union mine and other places in the San Juan district, Colorado. Although sometimes found in considerable quantities, it is not now used in the United States as a source of manganese on account of its ligh percentage of silica. ${ }^{b}$

The most notable occurrence of nickel as a silicate is in New Caledonia. Packard says: "The nickel ore of New Caledonia is a liydrated silicate of nickel and magnesium (garnierite) which occurs intimately associated with serpentine. ... The field observations showed that the nickel silicate is clearly an alteration product of the serpentine. ... Hot springs have played a conspicnous part in furthering the decomposition of the nickelbearing serpentine into garnierite and the other products." " Packard also notes the occurrence of nickel silicate at Riddles, Oreg., in North Carolina, in the Urals, and in Silesia. In all cases it is a secondary alteration product nsually derived from a serpentine which itself was derived from a nickeliferons olivine. From Packard's descriptions it appears probable that the nickel silicate mined is an oxidized product formed by the reaction of

a Kemp, J. F., The ore deposits at Franklin Furnace and Ogdensburg, New Jersey: Trans. New York Acad. Sci., vol. 13, 1893-94, p. 90.

${ }^{b}$ Penrose, R. A. F., jr., Manganese, its nses, ores, and deposits: Ann. Rept. Geol. Survey Arkansas for 1890 , vol. 1, 1891, p. 85 .

${ }^{c}$ Packard, R. L., Genesis of nickel ores: Hineral Resources, 1893, pp. 170-171. 
descending waters upon a sulphide of nickel, the latter being deposited by the deep circulation.

In conchusion, it appears that the silicates deposited by ascending water's, like the carbonates, are essentially gangue minerals. The only silicates deposited by ascending waters which may be ores are those of zinc, manganese, and nickel. It yet remains to be shown that any of these compounds are sufficiently abundant as first concentrates by ascending waters to serve as important ores.

CRITERIA FOR DISCRIYINATING DEPOSITS OF THE DEEP CIRCULATION.

The ascending waters depositing ores are necessarily those of the deep circulation. The criteria by which ores may be determined to have been deposited by ascending waters from a deep circulation have not yet been fully worked out, but certain suggestions may be made.

The first and most conclusive criterion discriminating ores produced by deep waters is that at the present time the waters are observed to be ascending. Locally, as in the Comstock lode, great rolumes of hot water are rising, and cloubtless ores are still being deposited. In such cases the evidence in favor of deposition from ascending waters is complete. A characteristic of ascending streams of the deep circulation is their independence of rainfall and other local conditions. The volume and the temperature of the water remains nearly constant from one year's end to the other. The best illustration of such an occurrence known to me is that furnished by the Comstock lode, already mentioned. An almost equally good case is that in the Smuggler Union mine at Telluride, Colo., where, about 600 meters below the surface, in the Pennsylvania shaft, a stream of water at a definite temperature rises with uniform flow entirely maffected by the seasons. The regularity of the temperature and volume of this water have led to the use of the stream for mine purposes. Equally good instances of an extended rising circulation independent of local precipitation are found in the Joplin district of Missouri. Here in practically all of the sulphide mines below a very moderate depth there is unanimons agreement among the miners that the volume of water which rises is not influenced in the slightest degree by precipitation. Whether the season be dry or wet the steady flow of rising water must be handled. Where for some reason the process of concentration of the ores has ceased, as is doubtless the case in many regions, we do not find 
evidence of the ascending waters. One of the common causes for the cessation of a, vigorous underground circulation is the nearly complete cementation of the openings by the circulation. When the openings become subcapillary the circulation necessarily ceases.

Where there exist underground streams with steady flow the channels which they occupy are usually clean and fresh. They are lined witl beautiful clear crystals without a stain. Along the channels there may be openings or even caves lined with crystals of various sizes, some of them reaching a foot or more in diameter. Such vugs, openings, and caves are superbly illustrated in the Joplin district of Missouri, where, in consequence of the lowering of the level of ground water by mining, such openings may be visited. When first freed from water the crystals lining the cavities are as untarnished as polished plate glass. The same thing may be seen at the Enterprise mine at Platteville, Wis., in the Upper Mississippi Valley. At this locality, as well as many in Missouri, the ores are clearly associated with the trunk channels of circulation. The miners in their operations follow the channels as guides, working against the streams. At places along a channel the water is concentrated into a single stream, and at such places there is likely to be comparatively narrow belts of very rich material along the walls. In other places the stream is subdivided among many small openings, and at such places the ore is dispersed.

Probably this criterion of ascending waters and freshness of the deposited material furnishes the best single line of evidence in favor of a deep circulation. But one must not conclude that the deposits of the ascending water's extend, unaffected by descending waters, to the very surface. For instance, while the present mining in the Joplin lead and zinc district of Missouri is in the belt in which descending waters have produced comparatively little effect, i. e., from 30 to 60 meters deep, at the surface and for a few meters below the surface descending and ascending waters mingled. Together they moved off laterally, and in consequence of their joint action the oxidized products and the galena deposits mentioned on pages 14441446 were produced. In this particular area the distance to which the descending water produced an effect is rery small, but such is not universally the case. Where the rertical elements are greater and the relief is steeper, the descending water's working against the ascending currents may produce an effect to a very considerable deptli. 
The very marked difference between deposits made by deep waters and those made by shallow waters is beautifully illustrated by the Missouri district. Thus in Joplin, where pumping has lowered the level of ground water by 30 to 45 meters, the once clean openings, formerly below the ground-water level, are now in the belt where waters are descending. The caves which when first entered showed crystals fresh and untarnished are now coated with oxide of iron and other products carried by the descending waters. Still more striking is the contrast between the clean mines in which waters are ascending and the dirty ones in other areas in which descending waters have produced an important effect to a cousiderable depth. The latter mines are on smithsonite and calamine, and are muddy and dirty to the last degree. Thick, sticky, iron-stained clay is everywhere, adhering thickly to one's boots. The amazing contrast between the conditions of the two classes of deposits is illustrated by the sulphide mines of the Joplin camp and the oxidized product mines of the Aurora camp About 2 kilometers distant from Aurora is Sand Ridge, where the capping Carboniferous impervious shale still remains. Here the descending waters have not had a chance to enter, and the deep-seated waters are still rising, and in this mine, which is only a short distance from the dirty oxidized mines, are found the same clean sulphides and beautiful crystal-lined cavities so characteristic of the mines of Joplin.

In many cases, where currents are still rising, the ores are still being deposited. This is believed to be true in the lead and zinc distrist of sonthrvestern Missouri, in the Comstock lode, and is known to be the case at Steamboat Springs and Sulphur Bank. Where, in mines, streams of clear water are found, with a uniforn flow, unaffected by the seasons, and deficient in oxygen, the evidence seems conclnsive that the ore deposits associated with such a circulation are the products of the deep circulation. But in many districts the conditions of circulation which resulted in the first concentration have ceased, the openings having been perliaps fully cemented at the time of concentration, thus causing the circulation to die out. In such cases the present circnlation may be of an entirely different character, even if the first main concentration was that of deep waters.

A second criterion indicating that ores are deposited from the deep circulation is the phenomenon of erustification, so strongly emphasized by Posepny. (Fig. 28.) Posepiny argues that the regular laminar arrangement 
of different minerals or different combinations of minerals along the walls of a vein or along one wall is evidence that the waters have risen from a deep-seated source, the mineral solntions changing from time to time and so resulting in the banded or comb structure. ${ }^{a}$ I follow P'osepny in the belief that, in most cases, such regular crustification is especially characteristic of ores deposited by ascending waters. But undoubtedly, in many cases there are superimposed upon the primary crustification later similar minerals deposited by descending waters, as fully explained on subsequent pages. (See pp. 1146, 1151, 1152, 1154-1157.) Such secondanry sulphides have been described at many localities, but so far as I know no one has claimed that such descending waters have added definite continuous secondary crusts, one above the other. Certainly it has never been shown that an ore deposit produced solely by descending waters shows a definite

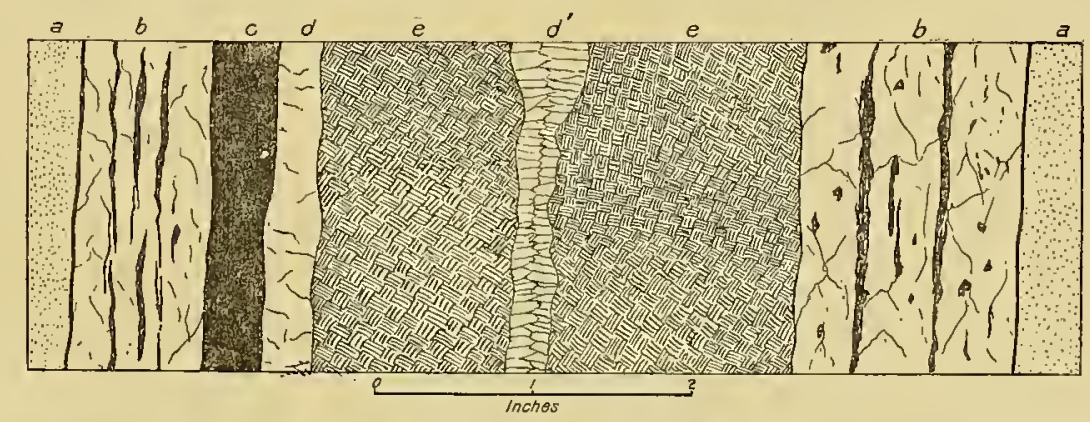

FIG. 28.-Cross section of banded vein near the London shait, Mineral Point, Colo. u, country rock; $\delta$, quartz and chalcopyrite; $c$, tetrahedrite; $d d^{\prime}$, quartz; $e$, galena. After Ransome.

crustification. It must be remembered that the existence of crustification is no evidence that the alternating minerals contaned in the veins have not been modified and enriched by descending waters. Indeed, this is very fiequently the case. Therefore crustification is an evidence of a first concentration by ascending waters, but is not evidence that descending waters have not since greatly modified the character of the deposit.

A third criterion which is of great importance in showing that ores are deposited from the deep circulation is the somewhat even tenor of values vertically. It is explained (pp. 1139-1143) that a special characteristic of descending waters is to produce a rich upper belt which diminishes in value with depth. It is shown, also, that one of the most characteristic effects of

a Posepny, F., The genesis of ore deposits: Trans. Am. Inst. Min. Eng., vol. 23, 1894, pp. $254-262$. 
descending waters is to produce a differentiation of the products, in a vertical sense, one mineral or one combination of minerals being at one horizon and another mineral or combination of minerals being at another horizon. Commonly these horizons hare a depth varying from a few meters to many or even hundreds of meters. This is very different from the phenomena of crustification, in which the change of minerals is lateral within very short distances at right angles to the walls.

It is certain that for various reasons, as fully explained under "Oreshoots," there are great variations vertically in the richness of deposits produced by cleep waters. A case of such extreme variation is that of the Comstock lode of Nevada, where there were numerous great bonanzas separated from one another by comparatively lean material; and yet in this vein the evidence of water ascending under pressure is most conclusive, with no evidence of descending water; but the variations in tenor in deposits of the deep circulation are in both directions. The bonauzas may be found lower than the poorer material, and vice versa. In contrast with this, descending waters produce an upper rich belt which is not again dnplicated below. While the deposits of the deep circulation may vary greatly in values, in many cases there is remarkably even tenor for great vertical depths. The best illustration of this known to me is the copper deposits of the Lake Superior region which are known to extend from the surface to a rertical depth of 1,600 meters, equivalent to 2,066 meters along the dip, $40^{\circ}$, with values sufficient to warrant working thronghout the distance.

As already explained, the copper was in all probability reduced and precipitated directly as metallic copper from upward-moving cupriferous solutions. The reducing agents were ferrous solutions derived from the iron-bearing silicates, and ferrous compounds in the solid form, magnetite and silicate. It is well known that metallic copper once formed is but slowly affected by the oxidizing action. Oxidation has in fact occurred in the Lake Snperior region, but not to an important extent. An oxidized belt may have formed in pre-Glacial time, but if so it was swept away by glacial erosion, and a sufficient interval has not elapsed to form another. The ore deposits now worked have apparently remained practically unchanged since their first concentration. In this fact we have the explanation of the extraordinary depths to which these deposits extend. 
Lindgren cites the gold veins of Nevada City and Grass Valley, California, as another case of constant tenor. According to him, "It can be confidently stated that there is no gradual diminution of the tenor of the ore in the pay shoots below the zone of surface decomposition," although within the same shoot there are many and great variations in richness. This statement is applicable to deposits which reach a vertical depth of 500 or 600 meters. If Lindgren is correct in thinking that the gold-quartz veins of the Sierra Nevada do not diminish in depth below an extremely superficial upper zone, this would be a case in which sulphuret ores were sufficiently concentrated by ascending waters alone to afford workable ore deposits.

In conclusion, it may be said that even tenors, in a vertical direction for any considerable depth, is very strong evidence of a concentration by ascending waters; but the reverse can not be said, that variability in a vertical direction is evidence that the deposits were not deposited by ascending waters.

Fourth. The absence of oxidized products in deposits, especially of limonite, favors the view that the ores were deposited by the deep circulation and were unaffected by secondary concentration; but this criterion is severely limited by the fact that enrichment of the sulphides takes place below the level of ground water in consequence of secondary descending solutions. An excess of base sulphides prevents the formation of the more palpable evidence of oxidizing waters.

Another difficulty in reference to using oxides as a criterion is that, in consequence of denudation, the ores deposited by the deep circulations rise into the belt of oxidation and are modified by the oxidizing waters to a variable extent. Very early in the process such oxidized products as hematite and limonite form. The ores are still essentially those of the deep circulation. From this stage to that in which the secondary action of oxidizing waters is of such consequence as to produce abundant hydrated hematite and limonite there are all gradations; but in many cases the secondary effect of descending, oxidizing waters can be allowed for and a judgment reached as to the nature of the deposit before it was modified by descending waters.

$u$ Lindgren, Waldemar, The gold-quartz veins of Nevada City and Grass Valley, California: Seventeenth Ann. Rept. U. S. Geol. Survey, pt. 2, 1896, p. 163.

MON XIVII-OH- 72 
In the case of a given ore deposit, by wise combination of the criteria given, it is in general possible to make a somewhat reliable judgment as to whether or not the ore was produced solely by ascending waters.

GENERAL STATEUENTS,

The foregoing statements explain to some extent the source, nature, and manner of deposition of the compounds deposited by ascending waters. But it is not the intention here to discuss their application to the known districts. This I do not attempt; because I lack the necessary accurate observations upon which such a discussion should be based. To tell in what manner the deposits of an individual district are formed requires very detailed investigation of that district.

While it is not the purpose here to take up the solution and deposition of the compounds which occur in individual ore deposits, it is well again to recall the law of mass action. Other things being equal, those compounds which are abundant will be dissolved in larger degree during the downward course of the waters, and will be most abundantly precipitated in the trunk channels. It is well known that, with the exception of aluminum, which does not form a sulphide, iron is the most plentiful of all the metallic compounds in the crust of the earth, and therefore iron sulphide occurs in greater abundance than the sulphide of any other metal. It is well known that in many cases the deeper a mine goes below the level of ground water the greater becomes the proportion of iron sulphide and the less that of the other metals. As a result of this, combined with increased cost of working, it frequently does not pay to mine a deposit beyond a certain depth. The law of mass action explains the abundance of the iron sulphide; it does not explain the frequent relative increase of the iron sulphide and the decrease of more valuable sulphides as one passes from the level of ground water into deeper workings. To explain this we must take into account the effect of the downward-moving waters, discussed under the succeeding heading.

We have now seen that the zone of fracture is traversed by the percolating waters; that metalliferons materials taken into solution by the downward and lateral moving waters are carried to the trunk channels of underground circulation, and that in these trunk channels the metalliferous materials are precipitated in various ways. Thus a first concentration by ascending waters, giving sulphurets, tellurides, and metals of some of the elements, is fully accounted for. 
In some cases the deposits thus produced are rich enongh to be of economic importance. In these cases, which undonbtedly exist, but which perhaps are less numerous than one might at first think, a first concentration by deep waters has been sufficient.

SUBCLASS 2. ORES PRECIPITATED FROM ASCENDING AND DESCENDING AQUEOUS SOLUTIONS.

Thus far ores precipitated by ascending waters alone have been considered. However, many of the ores thus prodnced have been profoundly modified by the action of descending waters.

Where the point of exit of the ascending waters of the trunk chamnels is in a valley or near the level of surface drainage the waters may reach the surface. However, where the openings are below slopes, ascending waters ordinarily do not continue to the surface, but make their way laterally from the trunk chamnels at and below the level of ground water. (See fig. 26.) Above the level of ground water, and frequently for a certain distance below it, the movement is downward in the openings. The water thus moving downward inchudes not only that which directly passes into the trunk openings at the surface, but a much larger quantity which converges into them from the smaller openings on all sides.

In regions in which mining is going on denudation has ordinarily truncated the reins for considerable depths, in many cases to hundreds or even thousands of meters. It is therefore clear that, in a majority of cases, the upper portions of the fissures in which the waters are now descending were in all probability much deeper below the surface, and therefore the water's in many of the larger fissures were once ascending. During the time the water was ascending the first concentration of sulphurets and other products took place. But as a result of the downward migration of the belt of weathering and the downward movement of water in that belt alteration and secondary concentration of ore deposits have taken place. This second concentration of ore deposits is of the greatest consequence, and I believe largely explains the frequent greater richness of the upper 50, or 100, or 500 meters, and in some cases 1,000 meters, as compared with lower levels.

As soon as denudation results in the transfer of the sulphides, tellurides, and metals of the first concentration into the belt of weathering they are subjected to the action of the descending waters bearing oxygen 
and carbon dioxide. As denudation continues the belt of weathering continues to migrate downward. As a consequence of the reactious of the belt of weathering, combined with denudation, the character of the upper part of the lode is greatly changed, there being produced in the upper part of it a second concentration. If this process continues long enough under favorable conditions, the deposits formed may be divided into three belts: (1) Above the level of ground water, and in some instances extending somewhat below it, is a belt largely composed of oxides of manganese, iron, and copper; carbonates of lead, zinc, and copper; hydrated silicates of nickel and zine; chloride of silver; metallic gold, silver; and copper; and residual emiched sulphides and tellurides; all with the associated gangue minerals. (2) At and below the level of ground water, and in some cases extending somewhat above it, is a transition belt composed of rich sulphides of silver, mercury, copper, lead, zinc, nickel, etc.; tellurides of gold and silver; and free gold, silver, and copper; with these are subordinate amounts of oxidized products and of course the associated gangue minerals. (3) Deeper down is a belt in which iron sulphides, pyrite, and pyrrhotite preponderate; but in which are considerable amounts of the more valuable sulphurets, the tellurides of gold and silver, and free gold, silver, and copper. Between the three classes of material there are gradations. The oxidized belt passes gradually into the rich sulphide and telhuride belt; the rich sulphide and telluride belt passes gradually into the lean sulphide belt. It is not to be supposed that all of the above products are to be found in a single lode. The development of the belts is due to a complicated set of reactions caused by descending waters. These reactions will be more fully appreciated when individual combinations of metals are considered. Here only a brief general statement will be made.

In the belt of weathering the reactions which transform the original products-sulphides, tollurides, and metals-are oxidation, hydration, and carbonation, the fundamental reactions of the belt. In this belt the formation of the materials mentioned is but the result of the application of these general processes to the exceptional geological products, ore deposits. Before hydration and carbonation can take place oxidation must occur. If the sulphides be equally abundant, the sulphide which is most easily oxidized is the first to disappear. The order of disappearance for the metals in 
this liypothetical case, as shown by the work of Anthon ${ }^{a}$ and Schiirmann, ${ }^{b}$ omitting the less important elements, is therefore manganese, arsenic, iron, cobalt, nickel, zine, lead, tin, antimony, copper', silver, mercury. It is, howerer, understood that the oxidation of an easily destroyed sulphide is not complete before the oxidation of a more refractory sulphide has begun. All of the sulphides are being oxidized all the time, but the more readily a sulphide is oxidized the more rapidly it is destroyed.

The sulphur of a sulphide may be oxidized withont the oxidation of the metal, in which case a metal is produced by the process of oxidation. At the same time the sulphur is oxidized, or subsequently, the metal may also be oxidized, and thus oxides be formed. As soon as the oxides are produced they may unite with carbon dioxide and form carbonates, or with silicic acid and form silicates. If water also unites with the compounds the carbonates and silicates are hydrated. But the carbonates and silicates may also be produced in a different manner. The sulphides as originally oxidized may be tranformed to sulphates. If thus changed, the sulphates may immediately react upon carbonates or silicic acid, producing carbonates or silicates, at the same time forming sulphates of other elements, such as barium, strontium, or calcium. The evidence that reactions of this kind have taken place upon an extensive scale in veins is perfectly clear. In mine waters sulphates of copper, zinc, and iron occur very frequently. In some cases the amount of sulphate of copper in such water is so great that it is worth while to run it over iron and thus precipitate the copper. Further evidence of the formation of the sulphates is shown by the frequent. precipitation of basic ferric sulphates in the veins, as, for instance, at Cripple Creek. ${ }^{c}$ That the sulphates produced by oxidation of the sulphides. react upon the other elements is shown by the frequent development in the upper part of the veins of such gangue minerals as barite, celestite, gypsum, and occasionally even magnesium sulphate.

An admirable case illustrating this principle is described by James Douglas. In speaking of the Arizona mines lie says that gypsum is abun-

a Anthon, E. F., Ueber die Anwendung der auf nassem wege dargestellten Schwefelmetalle bei der chemischer Analyse: Jour. f. Prak. Chem., vol. 10, 1837, pp. 353-356.

$b$ Schürmann, E., Ueber die Terwandtschaft der Schwermetalle zum Schwefel: Liebig's Ann. d. Chem., vol. 249, 18s8, pp. 326-350.

c Penrose, R. A. F., jr., Mining geology of the Cripple Creek district: Sixteenth Ann. Rept. U. S. Geol. Survey, pt. 2, 1895, p. 130. 
dantly present in the driest mines of the Southwest, but at Bisbee, a more humid area, it is absent.. ${ }^{a}$ Probably the reaction producing the sulphate has taken place extensively in both areas, but in the driest area there was not sufficient amount of water to dissolve the calcium sulphate formed and hence it was precipitated as gypsum. The sulphates may even react upon the aluminum salts and form hydrous sulphate of aluminum. This occurs in the gold veins of California. ${ }^{b}$

The oxidized belt in some cases may be altogether above the level of ground water, but in other cases where the descending oxidizing solutions are strong may extend somewhat into the belt of cementation. An excellent case illustrating the almost perfect coincidence of the oxidized belt with the belt of weathering is furnished by the Monte Cristo district, deseribed by Spurr. He says, "the zone between the surface of the ground and the lowest level of the ground-water surface is practically coincident with the zone of oxidation." c

It has been shown how the upper oxidized belt is produced, and next the manner of formation of the rich sulphide and telluride belt will be considered. The oxidized products, oxides, carbonates, and sulphates, may either in situ react upon the unaltered sulphides, or the carbonates, sulphates, and other oxidized compounds may be transported downward in solution and there react upon the sulphurets. In either case the result is to produce a richer sulphuret. The reactions may be between an oxide or a salt of a metal and its sulphide, for instance between the oxide or sulphate of copper and the sulphide of copper, as shown by the following equations:

and

$$
6 \mathrm{CuS}+2 \mathrm{Cu}_{2} \mathrm{O}=5 \mathrm{Cn}_{2} \mathrm{~S}+\mathrm{SO}_{2}
$$

$$
6 \mathrm{CuS}+2 \mathrm{Cu}_{2} \mathrm{SO}_{4}+3 \mathrm{H}_{2} \mathrm{O}=5 \mathrm{Cu}_{2} \mathrm{~S}+2 \mathrm{H}_{2} \mathrm{SO}_{4}+\mathrm{H}_{2} \mathrm{SO}_{3}
$$

The reaction, however, may be between the oxide or salt of one metal and the sulphide of a second, as for instance, between zinc oxide, sulphate, or carbonate and iron sulphide. In this case a sulphide of the first metal is

a Douglas, James, The Copper Queen mine, Arizona: Trans. Am. Inst. Min. Eng., vol. 29, 1900, p. 535 .

${ }^{b}$ Lindgren, Waldemar, The gold-quartz veins of Nevada City and Grass Valley, California: Sevententh Ann. Rept. U. S. Geol. Survey, pt. 2, 1896, p. 120.

${ }^{c}$ Spurr, J. E., The ore deposits of Monte Cristo, Washington: Twenty-second Ann. Rept. U. S. Geol. Survey, pt. 2, 1901, p. 859. 
prodnced. Thus Stokes has shown that zine carbonate and sodium carbonate together react upon iron sulphide as follows:

$$
8 \mathrm{FeS}_{2}+1+\mathrm{ZnCO}_{3}+\mathrm{Na}_{2} \mathrm{CO}_{3}=14 \mathrm{ZnS}+4 \mathrm{Fe}_{2} \mathrm{O}_{3}+\mathrm{Na}_{2} \mathrm{~S}_{2} \mathrm{O}_{3}+15 \mathrm{CO}_{2}
$$

The particnlar reactions in an individual case depend upon the relative proportions and solubilities of the compounds present, upou the existing conditions of pressure and temperature, the amount of oxygen, etc. This will more clearly appear upon subsequent pages.

The deep belt in which the sulphides of iron are preponderant is that of the first concentration alrearly considered on previous pages.

The concentrations by ascending and descending waters have been spoken of as if they were successive. In some instances this may be the case; but frequently it is much more probable that ascending and descending waters are at work upon the same fissure at the same time, and that their products are, to a certain extent, simultaneously deposited. For instance, under the conditions represented by fig. 26 there is taking place in the lower part of the fissure a first concentration by ascending waters and, in the upper part, a second concentration by descending waters. Between the two there is a belt in which both ascending and descending waters are at work. In an individual case the rich upper part of an ore deposit which is worked may now be in the place where ascending waters alone were first acting, where later, as a consequence of denudation, both ascending and descending waters were at work, and still later, where descending waters alone were at work. 'The more accurate statement for this class of ore deposits, therefore, is that deep or ascending waters are likely to be potent in an early stage of the process, that both ascending and descending water's may work together at an intermediate stage, and that descending water's are likely to be important in the closing stage.

The above general statement may perhaps be better understood if supplemented by a consideration of specific associations of the metals. The associations which are chosen for illustrative purposes are as follows: Associations (1) of lead, zinc, and iron; (2) of copper and iron; (3) of silver and gold with the base metals. 
In order to understand the relations of the lead, zine, and iron compounds where they occur together in ore deposits, it seems advisable to consider an individual region rather than to make a general statement. An excellent illustration of the association of these metals is furnished by the deposits of the Mississippi Valley, and this region will therefore be considered.

FACTS OF OCCURRENCE.

In the Mississippi Valley, as is well known, in openings in limestones, lead and zinc minerals are associated with marcasite, pyrite, and some chalcopyrite. $^{.}$Calcite and dolomite are abundant gangue minerals, as would be expected. Barite is also a common gangue mineral and locally is very plentiful. There are other gangue minerals which will not be taken into account. Since chalcopyrite is very subordinate, it will not again be alluded to.

The vertical order of occurrence in the region is commonly as follows: Above the level of ground water in the belt of weathering the dominant raluable minerals are galena and the oxidized ores-smithsonite, calamine, cerussite, and anglesite. Other oxidized ores occur in subordinate amount, but they will be ignored. The cerussite and anglesite frequently incrust the galena or are in crystals upon it. With the smithsonite and calamine there is some sphalerite. The smithsonite and calamine may extend 5 or 10 meters below the level of ground water, but deeper the oxidized products almost wholly disappear. The presence of oxidized products below the level of ground water is due in some cases to the occurrence of the material along a main channel of downward-percolating waters or to the well-known general downward morement of oxidizing water somewhat below the level of ground water; in other cases probably is due to a present ligher level of ground water than in pre-Glacial time, as a result of depression and valley filling at the close of the Glacial epoch; and in still other cases is probably due to reactions between oxidized lead salts and sphalerite. (See p. 1150.) Below the galena and the oxidized ores are sphalerite and galena together, the former being dominant except in the Southeastern district of Missouri. ${ }^{b}$

"Chamberlin, T. C., The ore deposits of southwestern Wisconsin: Geol, of Wisconsin, vol. 4 , 1882, pp. $350-393$.

$b$ Chamberlin emphasizes the inferior position of the zinc as compared with the lead and the association of the zinc and iron, but he does not consider the positions of these compounds with reference to the level of ground water. Loc. cit., pp. $488-491$. 
Associated with the sphalerite and galena are large amounts of marcasite and pyrite. For much of the region the workings have not extended far below the level of ground water, but in certain districts they have reached a considerable depth. In some places, as at Granby, Mo., ${ }^{a}$ deep exploration has shown pyrite and mareasite to dominate at the lowest level reached.

Under the present heading a full consideration of the concentration by ascending waters is excluded; but in order to consider the secondary work of descending waters it is necessary to outline the work of the first concentration by ascending waters.

In the Upper Mississippi Valley the order of occurrence of the minerals at many openings from the wall to the center of the veins or to the druses is marcasite, ferriferous sphalerite, galena in cubic crystals; or is sphalerite, galena. In some cases the order is marcasite, blende, these two being repeated perhaps several times. Not infrequently the galena of the first succession is followed by mareasite and (very subordinate in quantity) galena in octahedral crystals. Occasionally between the galena and the second marcasite is ferriferons sphalerite in small amount. If the druses are not fully closed by the sulphides there usually follows calcite, and occasionally barite on the calcite. Thus if there were a full succession at any one place, it would be (1) marcasite, (2) ferriferous splaalerite, (3) galena in cubic crystals, (4) ferriferous sphalerite, (5) marcasite, (6) galena in octahedral crystals, (7) calcite, (8) barite.

In the Lower Mississippi Valley sequences similar to those in the Upper Mississippi Valley occur in certain places, but in the best known and most productive district, that of southwestern Missouri, there seems to be no regular sequence for the supphides. According to Bain, the general order of deposition for this district, within the openings, was dolomite, metallic sulphides, and chert. "To some extent these processes were contemporaneous or recurrent, but as a whole they occur" successively in the order named." As to the relations of the sulphides to one another, Bain says: "Blende rests on galena and galena on blende indiscriminately, and both cover and in turn are covered by iron sulphide." $b$ Also blende and galena are in many cases intimately intermingled.

a Bain, H. F., with Van Hise, C. R., and Adams, G. I., Preliminary report on the lead and zinc deposits of the Ozark region: Twenty-second Ann. Rept. U. S. Geol. Survey, pt. 2, 1901, p. 162.

b Bain, H. F., cit., pp. 151-152. 
I know of no clearer illustration of the phenomenon of crustification described by Posepny, aud indeed of the general principles of ore deposition by underground water's, than that fumished by the Upper Mississippi Valley district. The larger parts of the crustified sulphide products are believed to be the work of ascending waters. In many cases it appears that there were two or more cycles of precipitation, so far at least as the sphalerite and galena are concerned, but the first cycle was by far the more important. As explained below, it is thought to be probable that the galena in octahedral crystals (No. 6 of the general succession), and in many cases the sphalerite (No.4) and the marcasite (No. 5), are due to a second concentration.

As to the manner of transportation of the metals which in the Mississippi Valley were precipitated as sulphides at the first concentration, it is believed that the lead and zinc travelled mainly as oxidized salts, and probably largely as sulphates. All the evidence goes to show that in this region the concentration took place under physical conditions substantially the same as those which exist at the present time. There is no proof that the solutions went to any great depth, or that musual temperatures prevailed. Nor is there any evidence that abundant alkaline sulphides and carbonates of the alkalies were present. Therefore, it can not be supposed that the sulphides were transported as such. Probably they were originally disseminated through the limestones as sulphides, were oxidized to sulphates and transported in that form, or as carbonates.

The first precipitation of the ascending salts is believed to have been accomplished through the agency, direct or indirect, of organic matter. There is abundant organic material in the shales associated with the ores, and a less amount in the limestones. While the precipitation of the sulphides disseminated through the shales may have been largely accomplished by the direct reaction of the solid carbonaceous material, the more common precipitation within the openings was probably accomplished through the reducing solutions which were produced by the contact of the water with the organic compounds. Water's which have been in contact with such compounds, which also bear sulphides, are very likely to contain lyydrogen sulphide. This substance is a direct precipitant of the sulphates as sulphides, but it is probable that dissolved organic compounds also act as reducing agents at the point of precipitation in the crevices. 
SECONI GONGENTATIOX.

It is highly probable that the regular vertical distribution of the minerals is due to a second concentration mainly controlled by downwardmoving watel's combined with denudation.

OXIDIZED ORES.

The oxidized ores include those above or near the ground-water level. As already noted, the important ones comprise smithsonite, calamine, cerussite, and anglesite. These ore bodies have been formed from the sulphides by oxidation, carbonation, and hydration. The beginning of these processes is coincident with the appearance of the sulphides above the level of ground water in consequence of progressive denudation. Lead sulplide (PbS) and zinc sulphide ( $\mathrm{ZnS}$ ), by simple oxidation are changed to lead sulphate $\left(\mathrm{PbSO}_{4}\right)$ and zinc sulphate $\left(\mathrm{ZnSO}_{4}\right)$. 'The lead sulphate constitutes the mineral anglesite. If this sulphate in solution reacts upon calcium carbonate, lead carbonate and hydrated calcium sulphate are produced according to the following equation:

$$
\mathrm{PbSO}_{4}+\mathrm{CaCO}_{3}+2 \mathrm{H}_{2} \mathrm{O}=\mathrm{PbCO}_{3}+\mathrm{CaSO}_{4} \cdot 2 \mathrm{H}_{2} \mathrm{O} .
$$

If zinc sulphate reacts on calcium carbonate, smithsonite is produced according to the following equation:

$$
\mathrm{ZnSO}_{4}+\mathrm{CaCO}_{3}+2 \mathrm{H}_{2} \mathrm{O}=\mathrm{ZnCO}_{3}+\mathrm{CaSO}_{4} \cdot 2 \mathrm{H}_{2} \mathrm{O} .
$$

In this connection it is interesting to note that in Wisconsin the smithsonite often occurs in beautiful pseudomorplis after the various forms of calcite characteristic of the district. In many cases when these psendomorphs are broken they are found to be partly hollow, showing not only that the calcite was replaced, but that solution of the calcium carbonate went on faster than the deposition of the smithsonite. In many other instances the smithsonite is in plates of greater or less thickness over calcite or limestone, the latter showing solution by nuequal etching.

Where the zinc sulphate finds abundant annorphous silica in chert the reaction may be between this compound and the zine salt in the presence of water, the equation being as follows:

$$
\mathrm{SiO}_{2}+2 \mathrm{ZnSO}_{4}+3 \mathrm{H}_{2} \mathrm{O}=(\mathrm{ZnOH})_{2} \mathrm{SiO}_{3}+2 \mathrm{H}_{2} \mathrm{SO}_{4} .
$$


In the Upper Mississippi Valley chert is not abundant and in that district the chief oxidized zinc ore is smithsonite. In the southwestern district of Missouri chert is very abundant, and the dominant oxidized ore is calamine, although smithsonite is also there present in important amounts.

The oxidized ores are often very rich and frequently they are concentrated in large irregular masses. These features, exceptional as compared with the sulphides of the first concentration, are due to two processes: First, through downward transportation by the solutions there may be segregated in a small vertical distance a large part of the materials which had a wider vertical distribution as sulphides; and second, residual concentration takes place-that is, the carbonates and sulphates of lead and zine are much more insoluble and heavier than the country rock with which they are associatated-the limestone. As the limestone is eroded the oxidized deposits sink down and thus accumulate.

SLLPHIDE ORES.

Galena.-If it be premised that the ascending waters evenly distributed the sulphides, at least so far as the vertical element is concerned, although across the vein these sulphides may or may not be arranged in a definite order, it is certain that downward-moving waters, combined with denudation, may concentrate the galena at high levels and the sphalerite at lower levels. (See pp. 1144-1145.)

Galena is the most difficultly oxidizible of the sulphides of lead, zinc, and iron. (See p.1140-1141.) Moreover, this compound is immeasureably more insoluble than the limestone. By the solution and mechanical erosion of the limestone and by the oxidation and solution of the sphalerite and iron sulphide above the level of ground water, the galena is concentrated. Whitney estimates that to make one-third meter of residual clay in the lead and zinc district of Wisconsin requires 10 to 12 meters of limestone and shale. $^{a}$ Since in this district the residual material is often several meters thick, it follows that at and near the surface there may be concentrated as a residual product an amount of galena which was originally distributed through several or many meters of limestone. That these processes of erosion of the limestone and the removal of the sphalerite, and marcasite by oxidation have taken place upon an extensive scale is shown by the

$a$ Hall, James, and Whitney, J. D., Geology of Wisconsin; vol. 1, 1862, pp. 121-125. 
occurrence of many detached fallen crystals and masses of galena in the openings above the level of ground water, and also at the bottoms of the wider openings and caves a short distance below it. Indeed, a considerable portion of the lead which has been mined was taken above or within a short distance below the level of ground water. This strongly corroborates the idea that concentration resulted from the solution of the other sulphides which held the galena to the walls and from the erosion of the limestone, thus permitting the material to drop to lower positions in the crevices.

While the concentration of the galena was partly as above stated, it may have been caused in part by chemical reactions between the various compounds. In the belt of weathering part of the galena, as already noted, is being oxidized, as is shown by the incrustations and superimposed crystals of cerrussite and anglesite. During the formation of the carbonates and sulphates a certain amount of these salts is taken into solution and carried downward. These carbonates and sulphates react upon the other sulphides present and reprecipitate the lead as galena. These reactions may take place to some extent above the level of ground water, but are especially likely to occur below it. As a result of the downward migration of the belt of weathering, there is in the downward-moving waters a continual supply of the sulphates and carbonates of lead. The chief reaction is that between the lead salts and the dominant iron sulphide. Supposing the iron were in the form of FeS, the reactions may be written as follows:

$$
\begin{aligned}
& \mathrm{PbSO}_{4}+\mathrm{FeS}=\mathrm{PbS}+\mathrm{FeSO}_{4} . \\
& \mathrm{PbCO}_{3}+\mathrm{FeS}=\mathrm{PbS}+\mathrm{FeCO}_{3} .
\end{aligned}
$$

If the iron be supposed to be in the form of $\mathrm{FeS}_{2}$, as is most likely, and oxygen were present, the reactions may be-

$$
\mathrm{PbSO}_{4}+\mathrm{FeS}_{2}+\mathrm{O}_{2}=\mathrm{PbS}+\mathrm{FeSO}_{4}+\mathrm{SO}_{2} \text {. }
$$$$
\mathrm{PbCO}_{3}+\mathrm{FeS}_{2}+\mathrm{O}_{2}=\mathrm{PbS}+\mathrm{FeCO}_{3}+\mathrm{SO}_{2} .
$$

Stokes has also shown that the precipitation of lead as a sulphide from its oxidized solutions may be accomplished by the bisulphide of iron without the presence of oxygen. The reaction by which this takes place is as follows, with learl sulphate:

$$
7 \mathrm{PbSO}_{4}+4 \mathrm{FeS}_{2}+4 \mathrm{H}_{2} \mathrm{O}=7 \mathrm{PbS}+4 \mathrm{FeSO}_{4}+4 \mathrm{H}_{2} \mathrm{SO}_{4} .
$$


A similar reaction takes place with lead carbonate and bisnlphide of iron where sodium carbonate is present. Stokes writes the reaction as follows:

$$
\text { I. } 4 \mathrm{PbCO}_{3}+8 \mathrm{FeS}_{2}+\mathrm{Na}_{2} \mathrm{CO}_{3}=14 \mathrm{PbS}+4 \mathrm{Fe}_{2} \mathrm{O}_{3}+\mathrm{Na}_{2} \mathrm{~S}_{2} \mathrm{O}_{3}+15 \mathrm{CO}_{2} \text {. }
$$

Subsequent experiment has shown that calcinm carbonate may be substitnted for the sodium carbonate. The last two reactions were performed at temperatures of $100^{\circ}$ and in the absence of oxygen. Since in the upper part of ore deposits such temperatures are seldom found, and there is no reason whatever to suppose that they existed during the development of the lead and zinc ores of the Mississippi Valley, and as oxygen is likely to be present, it is probable that the precipitation of the sulphide of lead by the bisulphide of iron in the upper part of veins was by the reactions written with oxygen rather than by the reactions withont oxygen.

However, it has been stated that zinc sulphide is present with the original sulphides, and this may also react upon the lead salts, according to the following equations:

$$
\begin{aligned}
& \mathrm{PbCO}_{3}+\mathrm{ZnS}=\mathrm{PbS}+\mathrm{ZnCO}_{3} . \\
& \mathrm{PbSO}_{4}+\mathrm{ZnS}=\mathrm{PbS}+\mathrm{ZnSO}_{4} .
\end{aligned}
$$

In the case of the former reaction, smithsonite would be formed. In this connection it is notable that frequently smithsonite is associated with the galena for some distance below the level of ground water. While a part of the smithsonite below ground water is of this origin, doubtless the larger portion of it is differently explained. (See p. 1147.)

To the foregoing reactions, partly explaining the concentration of galena, objection may be made on account of the slight solubility of lead carbonate and lead sulphate. It is true that these substances are very sparingly soluble in pure water; however, they are sufficiently soluble in waters bearing carbon dioxide to account for the phenomenon. But some of the lead may have been carried downward as a chloride. Independently of chemical theory, we know that much of the galena has been changed to some soluble form upon an extensive scale. As evidence for this inference, galena crystals above the level of ground water are much corroded, and the amount of cerussite and anglesite associated with them is so small as not to account for the corrosion, therefore the lead has been transformed to a soluble salt which has been transported below in important amounts. In the deposits of sonthwestern Missouri, and in those of Wisconsin adjacent to 
the oil rock, which have by denudation passed into the belt of weathering, numerous partially dissolved crystals of galena in openings and many cubical openings once evidently occupied by galena but now wholly vacant show abundant evidence of oxidation and solution of lead sulphide.

Whether or not the reactions written above express the exact chemical changes, it is certain that oxidized lead salts are precipitated by the sulphide of iron and by the sulphide of zinc as lead sulphide, as was shown by the experimental work of Anthon and Schiirman already referred to. (See Pp. 1114-1115.)

So far as my argument is concermed, it is of no consequence whether the lear be transported as a sulphate, carbonate, chloride, or other salt. However, it is believed that these are the forms in which the lead was transferred on the most extensive scale. I regard the cerussite and anglesite as evidence of the partial transfer of the lead as sulphate and carbonate. A large amount of sulphate and carbonate probably formed, but the compounds are so insoluble that a part of the salts produced was not carried downward, but precipitated near the places of formation.

In the upper Mississippi Valley for a short distance above and below the level of ground water there are cubic erystals of galena of very large size as compared with those disseminated through the sphalerite at lower levels. The crystals at this upper horizon are commonly from 5 to 8 centimeters in diameter, and a considerable proportion have diameters of 10 centimeters and some of 15 to 20 centimeters. In contrast with this, the galena intimately associated with the sphalerite at the lower levels is very rarely in crystals larger than 5 centimeters in dianeter, while a large part of it is in smaller particles. It is thought probable that the large size of the crystals at the upper horizons is the result of additions made by descending water to the smaller crystals of the first concentration. Below the level of ground water octahedral crystals of galena are frequently superimposed upon the cubic crystals of this compound.

sphalerite.-Evidence of the oxidation of sphalerite ant the transportation of the material elsewhere is as clear as in the case of galena, both in the upper and lower Mississippi Valley. At many places in southwestern Missouri sphalerite crystals may be seen in the chert in various stages of oxidation, and the porous rocks contain numerous easts of the sphalerite crystals, now vacant or occupied by a film of iron oxide. Precisely the 
same thing may be seen in Wisconsin, only that the matrix holding the partly dissolved sphalerite crystals or casts is limestone instead of chert.

The sphalerite oxidized to sulphate is carried downward. Zine holds sulphur less strongly than lead, but much more strongly than iron. 'Therefore, the sulphate is reduced to sulphide below the galena, the reactions being similar to those producing the galena. They may be written as follows:

$$
\begin{aligned}
& \mathrm{ZnSO}_{4}+\mathrm{FeS}=\mathrm{ZnS}+\mathrm{FeSO}_{4}, \\
& \mathrm{ZnCO}_{3}+\mathrm{FeS}=\mathrm{ZnS}+\mathrm{FeCO}_{3}, \\
& \\
& \mathrm{ZnSO}_{4}+\mathrm{FeS}_{2}+\mathrm{O}_{2}=\mathrm{ZnS}+\mathrm{FeSO}_{4}+\mathrm{SO}_{2}, \\
& \mathrm{ZnCO}_{3}+\mathrm{FeS}_{2}+\mathrm{O}_{4}=\mathrm{ZnS}+\mathrm{FeCO}_{3}+\mathrm{SO}_{2} .
\end{aligned}
$$

While these, and especially the last two, are regarded as probable reactions, Stokes has shown that at temperatures from $100^{\circ}$ to $180^{\circ} \mathrm{C}$. precipitation may take place without the presence of oxygen, thus:

$$
1+\mathrm{ZnCO}_{3}+8 \mathrm{FeS}_{2}+\mathrm{Na}_{2} \mathrm{CO}_{3}=1+\mathrm{ZnS}+4 \mathrm{Fe}_{2} \mathrm{O}_{3}+\mathrm{Na}_{2} \mathrm{~S}_{2} \mathrm{O}_{3}+15 \mathrm{CO}_{2}
$$

Under the conditions accompanying this reaction, calcinm carbonate may be substituted for sodium carbonate, but the reaction is slower. While it has not been shown by experiment, it is probable that, in analogy with the reaction of copper sulphate and lead sulphate, zine sulphate may at these higher temperatures react upon $\mathrm{FeS}_{2}$ as follows:

$$
7 \mathrm{ZnSO}_{4}+4 \mathrm{FeS}_{2}+4 \mathrm{H}_{2} \mathrm{O}=7 \mathrm{ZnS}+4 \mathrm{FeSO}_{4}+4 \mathrm{H}_{2} \mathrm{SO}_{4}
$$

As confirmatory of the deposition of secondary sphalerite by the reactions above written or by other reactions which produce the same result, Bain has found in the Joplin district ${ }^{a}$ of Missouri at various places rubycolored crystals of sphalerite superimposed upon the main mass of sphalerite attributed to the first concentration.

Marcasite and pyrite. - At a certain depth in the openings below the level of ground water nearly all of the salts of lead and zinc descending from the belt of weathering would be precipitated by reactions between them and the iron sulphide, as above explained. In veins in which the first concentration extends to a depth greater than that to which downward-moving: waters are effective, only the sulphurets of the first concentration would be

a Bain, H. F., Van Hise, C. R., and Adams, Geo. I., Preliminary report on the lead and zine deposits of the Ozark region: Twenty-second Ann. Rept. U. S. Geol. Survey, pt. 2, 1901, p. 161. 
found below this level. These sulphurets might consist mainly of marcasite and pyrite, with subordinate amounts of sphalerite and galena. However, even in this deep belt, concentration of galena and sphalerite may occur to some extent, although it receives no contribution from the lead and zine salts from above; for even after the salts of lead and zinc traveling downward from the belt of weathering are all precipitated, the waters may still hold oxygen. This oxygen wonld, to the largest extent, act on the marcasite, producing to some extent soluble salts which would be abstracted, and thus reduce the quantity of this material, and relatively enrich the deposits in lead and zinc, although not increasing the absolute amount of lead and zinc present in a given rertical distance. So far as the zinc and lead salts were oxidized by the oxygen-bearing water, these would react on the iron sulphide again, and they would be precipitated according to the reactions given above.

The above paragraph can not be said to apply generally to the deposits of the Mississippi Valley. These deposits are usually of very limited vertical extent. Many of them are apparently cut off by impervions strata within short distances of the surface, but drilling at the Granby area, Missouri, has developed a large amount of pyrite at depth, and thus, so far as information goes, this area appears to conform to the general rule. In the upper Mississippi Valley area, while information is not very full, apparently below the galena horizon the iron sulphide is rather more abundant at high than at low horizons. As a consequence the zine sulphides become less impure with depth. This has been noted at Shullsburg, at Platteville, at Benton, at Dubuque, and at Mineral Point. But this is in the belt in which marcasite and sphalerite altemate in the crustified ores, and both are apparently for the most part the products of ascending water. If this vertical distribution be regarded as chiefly due to the primary concentration by ascending water, the order is as it should be, for at first the zinc sulphide should be thrown down to a greater extent than the iron sulphide.

GENERAL STATEMENTS.

It is believed that concentration by ascending waters largely explains the crustified sulphide deposits of zinc and lead of the upper Mississippi Valley, at least so far as their main masses are concerned, although, as has been explained, superimposed upon the sulphides of the first concentration MON XIVII-04-73 
are subordinate amounts of sulphides of the second concentration. It is believed also that the intimately intermingled sulphides at the lower horizons in southwestern Missouri and the great disseminated deposits in the massive linnestone of southeastern Missouri are results of the first concentration. It is thought that a second concentration by descending waters explains through the reactions given the orderly distribution of the ores in a vertical direction, i. e., the oxidized products and the enriched galena above and near the ground water and the sphalerite deposits below the level of ground water. The intermingled sphalerite and galena below the level of ground water, while largely of the first concentration, are modified to a variable extent by the second concentration. Further, it is believed that the second concentration was a determinative factor in the production of many of the rich deposits, especially their upper portions. The process of concentration by descending waters is primarily chemical, but is also to some extent mechanical. The latter is especially true of the galena loosened by solution from the walls and of the oxidized products mixed with galena which lave accumulated as residual material in consequence of erosion of the limestone.

The above conclusions were reached from a study of the facts in the field, without any knowledge of the experimental work in the laboratory showing that iron sulphide precipitates zine and lead as sulphides from their oxidized salts, and that zinc sulphide precipitates lead as a sulphide from its oxidized salts. It is thus seen that the facts in the field and the experimental work of the laboratory supplement each other and strongly confirm the correctness of the conclusions as to the manner in which the vertical distribution of the ores is explained.

Thus the above theory fully explains and harmonizes the following:

(1) The galena and sphalerite crystals are frequently corroded and partly dissolved, and very numerous casts of them are found in the chert and limestone. These facts slow conclusively that the sulphides have been dissolved above the level of ground water.

(2) Upon the ealcite, and frequently pseudomorphous after its crystals, smithsonite is found, the calcite at these places showing corrosion and solution. This fumishes strong evidence that the oxidized salt of zinc, probably zine sulphate, has reacted upon the calcite. 


\section{PLATE XII.}




\section{PLATE XII.}

A. Vein quartz, Banner mine, California. Showing shattering of black argillite by quartz seams; pyrite developing in the argillite but not in the quartz; further, brownish (weathered) carbonate deposited next to the argillite in the seams. Beginning of metasomatic alteration apparent by bleaching of the black argillite. After Lindgren.

$B$. Secondary galena and blende in ores from Missouri. After Bain. 


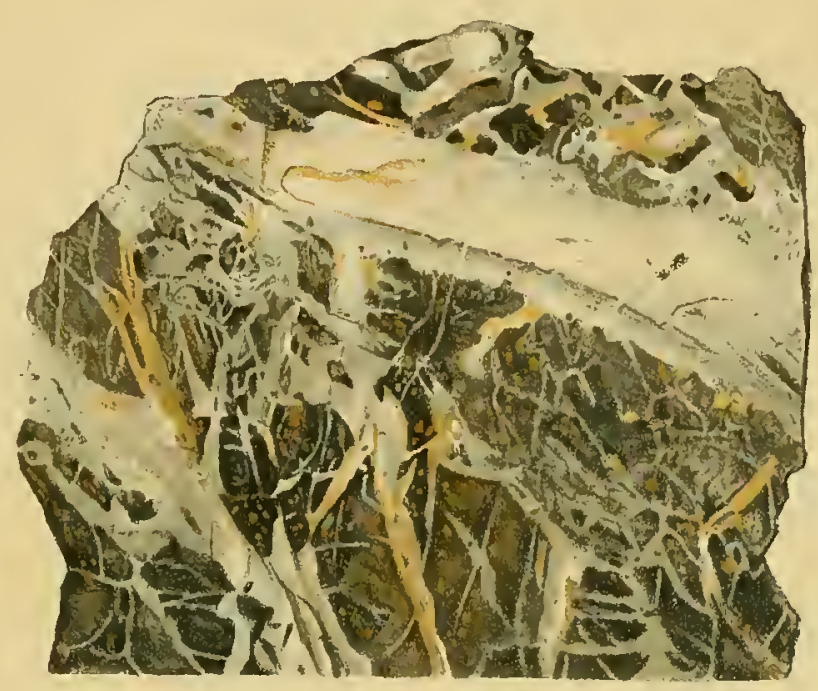

(A)

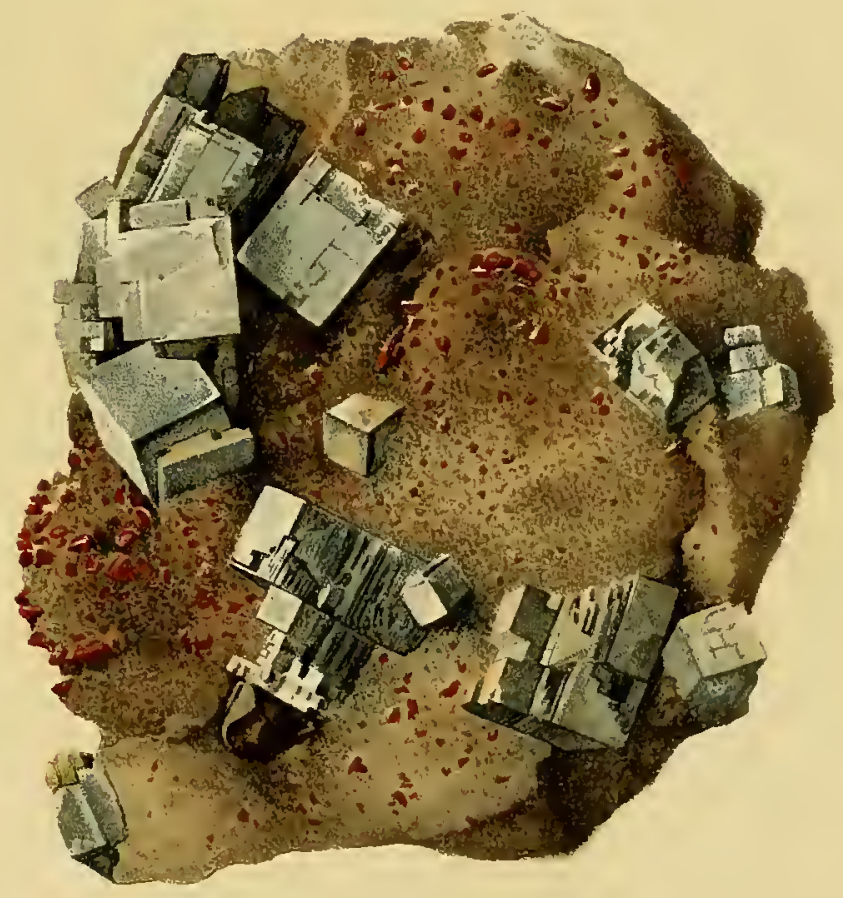

(B)

(A) VEIN QUARTZ, BANNER MINE, CALIFORNIA

( $B$ ) SECONDARY GALENA AND BLENDEIN ORES FROM MISSOURI. 

(3) With the oxidized products of lead and zine are associated barite and gypsum. These are the by-products which should be formed by the reactions of the sulphates of lead and zine upon the alkaline earth carbonates.

(4) At and near the level of ground water are very large crystals of galena as compared with those deeper in the deposits. These crystals are fully explained by secondary growths of galena deposited by descending waters.

(5) The products have a vertical order; the oxides, carbonates, and silicates lie mainly above the level of ground water, the galena largely above but extending below it, and the sulphide of zinc with the iron sulphides mainly below it. This vertical order is that which should be produced by the reactions of the descending oxidized salts of lead and zine on the sulphides of zine and iron.

(6) Superimposed upon the crustified sulphides of the first concentration are later erystals of galena and sphalerite, often different in character from the earlier sulphides. For instance, in Wisconsin the later galena is usually in octahedral crystals, and in Missomi the sphalerite is pure and ruby colored (See Pl. XII, B.) The exceptional appearances of these products are fully explained by the reactions between the oxidized products of lead and zinc and the sulphides deposited by the first concentration.

While the precipitation at the second concentration of downward-moving sulphates is partly accomplished, as has been explained, by the reaction upon them of the low-grade sulphurets, thus producing rich sulphides, the reduction and precipitation of these oxidized products is partly accomplished by the direct and indirect action of the organic matter, precisely as in the case of the original precipitation. The power which organie matter has for the reduction and precipitation of the oxidized products has been recognized by several others who have written upon the lead and zine of the Mississippi Valley. Among these are Chamberlin, ${ }^{a}$ Blake, ${ }^{b}$ Bain, ${ }^{\circ}$ and Grant. ${ }^{d}$

a Chamberlin, T. C., The ore deposits of southwestern Wisconsin: Geol. of Wisconsin, vol. 4, 1882, pp. 544,546 .

$b$ Blake, Wm. P., Lead and zine deposits of the Mississippi Valley: Trans. Am. Inst. Min. Eng., vol. 22, 1894, pp. 630-631. Also, Wisconsin lead and zine deposits: Bull. Geol. Soc. America, vol. 5. 189t, pp. 28-29.

$c$ Bain, H. F., with C. R. Van Hise and G. I. Adams, Preliminary report on the lead and zine deposits of the Ozark region: Twenty-second Ann. Rept. U. S. Geol. Survey, pt. 2, 1901, p. 213.

$d$ Grant, U. S.; Preliminary report on the lead and zine deposits of sonthwestern Wisconsin: Bull. Wis. Geol. and Nat. Hist. Survey, No. 9, 1903, p. 83. 
Chamberlin states that organic matter from the surface may have made its way down through the openings of the limestone, and thus assisted in the reduction of the descending oxidized products. ${ }^{a}$ As pointed out by Blake, the effect of the organic matter is especially clear in the case of the large sphalerite deposits of Wisconsin which rest upon the oil rock at the base of the Galena.

While the above statement concerning concentrations of the lead and zinc ores by ascending and descending waters combined is made with reference to the Mississippi Valley, it is believed that many of the lead and zine districts of other parts of the world have had a substantially similar history.

ASSOCLATION OF COPPER AND IRON COMPOLADS.

Another very general association of metals is that of copper and iron. Where this association occurs it is well known that above the level of ground water metallic copper, cuprite $\left(\mathrm{Cu}_{2} \mathrm{O}\right)$, tenorite $(\mathrm{CuO})$, malachite $\left(\mathrm{CnCO}_{3} \cdot \mathrm{Cu}(\mathrm{OH})_{2}\right)$, and azurite $\left(2 \mathrm{CuCO}_{3} \cdot \mathrm{Cu}(\mathrm{OH})_{2}\right)$ are very frequently found.

These compounds may be produced from any of the sulphides. It is not worth while to attempt to write out the reactions showing their formation from all of the sulphides, but to make the principles clearer it may be well to consider one illustrative case. For this purpose chalcocite is taken, since this is the richest sulphide and the one which, as shown below, is likely to be developed in the upper part of the belt of cementation and pass in large quantity into the belt of weathering. By simple oxidation of the sulphur of chalcocite, metallic copper is produced, according to the following reaction:

$$
\mathrm{Cu}_{2} \mathrm{~S}+2 \mathrm{O}=2 \mathrm{Cu}+\mathrm{SO}_{2}
$$

Simultaneously, or later, the metallic copper thus formed may be oxidized to enprite, according to the equation:

$$
2 \mathrm{Cu}+\mathrm{O}=\mathrm{Cu}_{2} \mathrm{O}
$$

By further oxidation the cuprite may pass into tenorite, according to the reaction:

$$
\mathrm{Cu}_{22} \mathrm{O}+\mathrm{O}=2 \mathrm{CuO}
$$


When the oxidation has gone far enough to produce tenorite, carbonation and hydration may take place, and malachite be produced, according to the following reaction:

$$
2 \mathrm{CuO}+\mathrm{CO}_{2}+\mathrm{H}_{2} \mathrm{O}=\mathrm{CuCO}_{3} \cdot \mathrm{Cu}(\mathrm{OH})_{2}
$$

Or if the carbonation goes further as compared with hydration, azurite may be proanced, according to the following reaction:

$$
6 \mathrm{CuO}+4 \mathrm{CO}_{2}+2 \mathrm{H}_{2} \mathrm{O}=2\left[2 \mathrm{CuCO}_{3} \cdot \mathrm{Cu}(\mathrm{OH})_{2}\right]
$$

T'he product represented by any stage in this process may be regarded as formed directly by a combination of two or more of the preceding reactions. But in the southwestern portion of the United States it is certain that the reactions frequently if not usually occur step by step, as is shown by numerous specimens In a single specimen I have seen a core of chalcocite surrounded by metallic copper, ontside of which is cuprite; beyond this lies tenorite, and beyond the tenorite hydrated carbonate. While it is rather rare to find this full succession, it is easy to get specimens of metallic copper interlaced or surrounded by cuprite, the latter being: surrounded by at least a film of tenorite, beyond which occur the carbonates. In this connection it may be recalled that cuprite is a rather abundant oxide and that tenorite is rare. The reason which may be suggested for this is that as soon as tenorite is formed this oxide may unite with carbon dioxide and water and produce malachite or azurite. This process goes on almost as fast as the tenorite develops, and thus rery little of this oxide is found in the mines. The oxidized copper products, instead of being formed from chalcocite, may be produced from any of the leaner sulphides of copper; but in such cases the associated iron forms iron compounds which may largely remain in situ as oxides or be carried away as sulphates.

The oxidized ores of copper occur extensively in arid regions. The precipitation is small, but there is enough moisture underground to carry on the work with the assistance of oxygen and carbon dioxide. In such a region the level of ground water is far below the surface and erosion is exceedingly slow, so that there is ample room and sufficient time for a large amount of material to accumulate above the level of ground water. In humid regions, while water is more abundant and the conditions to that 
extent are more favorable to the development of the oxidized products, denudation is frequently so rapid that time is not given for the transformation of the sulphides to such products, for a given part of the belt of weathering is above the level of ground water only a short time before the inaterial of that portion is removed by erosion. Also the belt above the level of ground water is narrow, and thus there is comparatively little room for the oxidized deposits.

While under favorable conditions oxidized products are very common above the leyel of ground water, it is well known that below it the oxidized and carbonated products occur in greatly diminished quantity, and there are frequently present rich sulphurets, such as chalcocite $\left(\mathrm{Cu}_{2} \mathrm{~S}\right)$, bornite $\left(\mathrm{Cu}_{3} \mathrm{FeS}_{3}\right)$, chalcopyrite $\left(\mathrm{CuFeS}_{2}\right)$, and sometimes covellite $(\mathrm{CuS})$. Sornewhat deeper below the level of ground water the oxides and carbonates are not found. Furthermore, the chalcocite, covellite, and bornite are very generally restricted to the upper part of the belt of cementation; deeper; the places of these minerals are largely occupied by chalcopyrite. Not only is this true, but still deeper in many instances the chalcopyrite is less prominent, and the iron sulphides more so. In the lower working's of many of the deeper mines the only metalliferous product found is cupriferous iron sulphide, the chalcopyrite having wholly disappeared. But in some places where the dominant sulphide of the deeper levels is pyrite or pyrihotite fracture openings within these sulphides are filled with the rich copper sulphides.

Whether or not this general statement is correct for a particular area, each mining engineer can julge from his own knowledge. There may be exceptions to it, dne to various causes, one of which has been alluded to in explaining bonanzas. Thus below cupriferous pyrites there may again be found richer copper sulphides. Indeed, as before stated, ore deposits vary greatly in their richness both horizontally and vertically, and the above statement can only be considered as a general average. ${ }^{a}$

The above order is believed to be explained by the work of downwardmoving waters. The combinations of lead, zinc, and iron were followed from above downward. The reactions which occur in the case of the copperiron deposits may perhaps be followed, to vary the treatment, from the base

"See Raymond, R. W., Discussion of "Genesis of ore deposits," by F. Posepny: Trans. Am. Inst. Jin. Eng., vol. 24, 1895, pp. 991-992. 
upward. At greater or less depths below the level of ground water the ores are often dominantly cupriferous pyrites or pyrrhotite, the direct deposit of the ascending waters. At a little higher level oxygen from above may have oxidized a portion of the iron and transported it elsewhere, relatively enriching the deposit in copper; at a still higher level there is a contribution of soluble copper salts from above. Since copper sulphate is certainly the most common salt, for convenience all the soluble salts will be regarded as sulphates. Reactions similar to those given below may easily be written for other salts.

At the level where salts of copper appear from above, the action of the copper salt on iron sulphide may produce chalcopyrite, the reactions resulting from the greater affinity of sulphur for copper as compared with iron, and from the law of mass action. With cupric sulphate the reaction may be written, for ferrous sulphide:

(1) $2 \mathrm{FeS}+\mathrm{CuSO}_{4}=\mathrm{CuFeS}_{2}+\mathrm{FeSO}_{4}$

For bisulphide of iron, in the presence of oxygen, the reaction may be:

(2) $2 \mathrm{FeS}_{2}+\mathrm{CuSO}_{4}+\mathrm{O}_{4}=\mathrm{CuFeS}_{2}+\mathrm{FeSO}_{4}+2 \mathrm{SO}_{2}$

or, if oxygen be absent,

(3) $7 \mathrm{CuSO}_{4}+8 \mathrm{FeS}_{2}+8 \mathrm{H}_{2} \mathrm{O}=7 \mathrm{CuFeS}_{2}+\mathrm{FeSO}_{4}+8 \mathrm{H}_{2} \mathrm{SO}_{4}$

Where the iron sulphide is pyrrhotite, intermediate between $\mathrm{FeS}$ and $\mathrm{FeS}_{2}$, the reactions may be written by combining the equations (1) and (3) in proper proportions.

The chalcopyrite may also be produced by the reaction of cuprous sulphate on pyrite or mareasite. In the presence of oxygen the reaction is as follows:

$$
3 \mathrm{FeS}_{2}+\mathrm{Cu}_{2} \mathrm{SO}_{4}+40=2 \mathrm{CuFeS}_{2}+\mathrm{FeSO}_{4}+2 \mathrm{SO}_{2}
$$

and in the absence of oxygen:

$15 \mathrm{FeS}_{2}+7 \mathrm{Cu}_{2} \mathrm{SO}_{4}+8 \mathrm{H}_{2} \mathrm{O}=14 \mathrm{CuFeS}_{2}+\mathrm{FeSO}_{4}+8 \mathrm{H}_{2} \mathrm{SO}_{4}$

In passing upward from the lowest level at which the chalcopyrite appears, this mineral may steadily increase in quantity until it becomes an important constitnent, and finally the iron sulphide may become subordinate. Under these circumstances bornite is likely to appear also. The produc- 
tion of bornite by the direct reactions of the cupric salts may be supposed to be as follows:

For ferrous sulphide in the presence of oxygen the reaction is:

(1) $4 \mathrm{FeS}+3 \mathrm{CuSO}_{4}+2 \mathrm{O}=\mathrm{Cu}_{3} \mathrm{FeS}_{3}+3 \mathrm{FeSO}_{4}+\mathrm{SO}_{2}$

For iron bisulphide the reaction is:

(2) $3 \mathrm{FeS}_{2}+3 \mathrm{CuSO}_{4}+4 \mathrm{O}=\mathrm{Cu}_{3} \mathrm{FeS}_{3}+2 \mathrm{FeSO}_{4}+4 \mathrm{SO}_{2}$

or, if oxygen be supposed to be absent, the reaction for cupric salt may be:

(3) $13 \mathrm{FeS}_{2}+21 \mathrm{CuSO}_{4}+20 \mathrm{H}_{2} \mathrm{O}=7 \mathrm{Cu}_{3} \mathrm{FeS}_{3}+6 \mathrm{FeSO}_{4}+20 \mathrm{H}_{2} \mathrm{SO}_{4}$

The production of bornite by the direct reaction of cuprous sulphate on the bisulphide of iron in the presence of oxygen may be written:

(t) $5 \mathrm{FeS}_{2}+3 \mathrm{Cu}_{2} \mathrm{SO}_{4}+8 \mathrm{O}=2 \mathrm{Cu}_{3} \mathrm{FeS}_{3}+3 \mathrm{FeSO}_{4}+4 \mathrm{SO}_{2}$

or, if no oxygen be present, the reaction is:

(5) $23 \mathrm{FeS}_{2}+21 \mathrm{Cu}_{4} \mathrm{SO}_{4}+16 \mathrm{H}_{2} \mathrm{O}=14 \mathrm{Cu}_{3} \mathrm{FeS}_{3}+9 \mathrm{FeSO}_{4}+16 \mathrm{H}_{2} \mathrm{SO}_{4}$

However, the bornite may also be produced by the reaction of the cupric salt on the chalcopyrite itself. For instance, in the presence of oxygen, for eupric sulphate, the reaction might be:

(6) $2 \mathrm{CuFeS}_{2}+\mathrm{CuSO}_{4}+2 \mathrm{O}=\mathrm{Cu}_{8} \mathrm{FeS}_{3}+\mathrm{FeSO}_{4}+\mathrm{SO}_{2}$

If oxygen be absent the reaction for cupric sulphate would be:

(i) $13 \mathrm{CuFeS}_{2}+11 \mathrm{CuSO}_{4}+8 \mathrm{H}_{2} \mathrm{O}=8 \mathrm{Cu}_{3} \mathrm{FeS}_{3}+5 \mathrm{FeSO}_{4}+8 \mathrm{H}_{2} \mathrm{SO}_{4}$

The reaction for cuprous sulphate in the presence of oxygen may be written :

(8) $4 \mathrm{CuFeS}_{2}+\mathrm{Cu}_{2} \mathrm{SO}_{4}+6 \mathrm{O}=2 \mathrm{Cu}_{3} \mathrm{FeS}_{3}+2 \mathrm{FeSO}_{4}+\mathrm{SO}_{2}$

and in the presence of oxygen:

(9) $23 \mathrm{CuFeS}_{2}+11 \mathrm{Cu}_{2} \mathrm{SO}_{4}+4 \mathrm{H}_{2} \mathrm{O}=15 \mathrm{Cu}_{3} \mathrm{FeS}_{3}+8 \mathrm{FeSO}_{4}+4 \mathrm{H}_{2} \mathrm{SO}_{4}$

Further reacions might be written by combining corresponding equations for cupric and cuprous salts, as a result of which the bornite is produced by the reaction of both cuprous and cupric compounds. Reactions might also be written by which the bornite is partly produced from bisulphide of iron and partly from chalcopyrite. These reactions would be merely the combination of corresponding equations, and it seems hardly necessary to write them out, since no new principle is illustrated. 
Still higher up, chalcocite may appear with the chalcopyrite and bornite. For a short distance below the level of ground water this mineral in some mines is the dominant sulphide and may be produced by the reaction of cupric sulphate on the iron sulphide. For ferrous sulphide the reaction in the presence of oxygen would be:

(1) $2 \mathrm{FeS}+2 \mathrm{CuSO}_{4}+2 \mathrm{O}=\mathrm{Cu}_{2} \mathrm{~S}+2 \mathrm{FeSO}_{4}+\mathrm{SO}_{2}$

For iron bisulphide in the presence of oxygen, the reaction would be:

(2) $2 \mathrm{FeS}_{2}+2 \mathrm{CuSO}_{4}+60=\mathrm{Cu}_{2} \mathrm{~S}+2 \mathrm{FeSO}_{4}+3 \mathrm{SO}_{2}$

or, if oxygen be absent, the reaction is:

(3) $5 \mathrm{FeS}_{2}+1+\mathrm{CuSO}_{4}+12 \mathrm{H}_{2} \mathrm{O}=7 \mathrm{Cu}_{2} \mathrm{~S}+5 \mathrm{FeSO}_{4}+12 \mathrm{H}_{2} \mathrm{SO}_{4}$

Chalcocite may be produced also by the reaction of cuprous salts on iron sulphide. For ferrous sulphide in the presence of oxygen the reaction is:

(4) $\mathrm{FeS}+\mathrm{Cu}_{2} \mathrm{SO}_{4}=\mathrm{Cu}_{2} \mathrm{~S}+\mathrm{FeSO}_{4}$

for iron bisulphide in presence of oxygen:

(5) $\mathrm{FeS}_{2}+\mathrm{Cu}_{2} \mathrm{SO}_{4}+2 \mathrm{O}=\mathrm{Cu}_{2} \mathrm{~S}+\mathrm{FeSO}_{4}+\mathrm{SO}_{2}$

or, if oxygen be absent,

(6) $4 \mathrm{FeS}_{2}+7 \mathrm{Cn}_{2} \mathrm{SO}_{4}+4 \mathrm{H}_{2} \mathrm{O}=7 \mathrm{Cu}_{2} \mathrm{~S}+4 \mathrm{FeSO}_{4}+4 \mathrm{H}_{2} \mathrm{SO}_{4}$

Furthermore, the chalcocite may be produced by reactions of the sulphates either on the chalcopyrite or on the bornite. In the case of cupric sulphate upon clialcopyrite in the presence of oxygen, the reaction may be written as follows:

(7) $\mathrm{CuFeS}_{2}+\mathrm{CuSO}_{4}+2 \mathrm{O}=\mathrm{Cu}_{2} \mathrm{~S}+\mathrm{FeSO}_{4}+\mathrm{SO}_{2}$

or, if oxygen be not present, the reaction may be as follows:

(8) $5 \mathrm{CuFeS}_{2}+11 \mathrm{CuSO}_{4}+8 \mathrm{H}_{2} \mathrm{O}=8 \mathrm{Cu}_{2} \mathrm{~S}+5 \mathrm{FeSO}_{4}+8 \mathrm{H}_{2} \mathrm{SO}_{4}$

For cuprous sulphate upon chalcopyrite, in the presence of oxygen, the reaction is:

(9) $2 \mathrm{CuFeS}_{2}+\mathrm{Cu}_{2} \mathrm{SO}_{4}+6 \mathrm{O}=2 \mathrm{Cu}_{2} \mathrm{~S}+2 \mathrm{FeSO}_{4}+\mathrm{SO}_{2}$

and in the absence of oxygen is:

(10) $\mathrm{SCuFeS}_{2}+11 \mathrm{Cu}_{2} \mathrm{SO}_{4}+4 \mathrm{H}_{2} \mathrm{O}=15 \mathrm{Cu}_{2} \mathrm{~S}+8 \mathrm{FeSO}_{4}+4 \mathrm{H}_{2} \mathrm{SO}_{4}$ 
In the production of the chalcocite from the bornite the reaction for cupric salts in the presence of oxygen may be as follows:

(11) $\mathrm{Cu}_{3} \mathrm{FeS}_{3}+\mathrm{CuSO}_{4}+2 \mathrm{O}=2 \mathrm{Cu}_{2} \mathrm{~S}+\mathrm{FeSO}_{4}+\mathrm{SO}_{2}$

or, if oxygen be not present, the reaction may be:

(12) $5 \mathrm{Cu}_{3} \mathrm{FeS}_{3}+11 \mathrm{CuSO}_{4}+8 \mathrm{H}_{2} \mathrm{O}=13 \mathrm{Cu}_{2} \mathrm{~S}+5 \mathrm{FeSO}_{4}+8 \mathrm{H}_{2} \mathrm{SO}_{4}$

For cuprous salt in the presence of oxygen the reaction is:

(13) $2 \mathrm{Cu}_{3} \mathrm{FeS}_{3}+2 \mathrm{Cn}_{2} \mathrm{SO}_{4}+2 \mathrm{O}=5 \mathrm{Cu}_{2} \mathrm{~S}+2 \mathrm{FeSO}_{4}+\mathrm{SO}_{2}$

or, in the absence of oxygen:

(14) $8 \mathrm{Cu}_{3} \mathrm{FeS}_{3}+11 \mathrm{Cu}_{2} \mathrm{SO}_{4}+4 \mathrm{H}_{2} \mathrm{O}=23 \mathrm{Cu}_{2} \mathrm{~S}+8 \mathrm{FeSO}_{4}+4 \mathrm{H}_{2} \mathrm{SO}_{4}$

In all of the foregoing reactions the fundamental principle, so far as iron and copper are concerned, is the same. In every case the acid radical of the oxidized copper salt passes to the iron, and the sulphur in the iron unites with the copper, forming copper sulphide, thus producing a greater proportion of copper sulphide in the ore than before the reaction.

'Too much stress must not be laid on the particular chemical reactions written. They are designed to show the nature of the reactions which may occur rather than to assert that the particular reactions written do occur exactly. It is believed that the reactions written are possible, but much experimental work must be done in the laboratory in order to ascertain which of the reactions is most common in an individual case. It is believed that the reactions for the production of rich sulphides of copper by descending waters are often those in which oxygen is present, but doubtless reactions without oxygen also take place frequently.

In all cases where $\mathrm{SO}_{2}$ is regarded as produced by the reactions it may be that instead of this compound sulphuric acid is formed. Indeed, it is well known that $\mathrm{SO}_{2}$ in the presence of ferric sulphate is oxidized to sulphuric oxide. In order to modify the equations in which $\mathrm{SO}_{2}$ appears so as to produce sulphuric acid it is merely necessary to substitute $\mathrm{H}_{2} \mathrm{SO}_{4}$ for each $\mathrm{SO}_{2}$ on the right side of the equation, and add $\mathrm{H}_{2} \mathrm{O}+\mathrm{O}$ on the left side. Probably the reactions in which oxygen is absent also occur in the first concentration of copper in consequence of the reactions of ascending copper solutions upon previously precipitated lower-grade materials. 
While in some cases the sulphides were precipitated by reactions in which oxygen is present and in other cases by those in which it was absent, in still other cases I have no doubt that the reactions utilized some oxygen, but not as much as indicated by the equations as written. In such instances the real changes when precipitation took place are represented by equations which combine in varions proportions those in which oxygen is represented as present and those in which it is absent. Moreover, for a certain part of a deposit the conditions may for a time have been those in which the reactions were without oxygen, later those in which it was insufficient, and finally those in which it was sufficient. Thus, all combinations of the reactions with and without oxygen may. have taken place in the production of a single deposit.

The vertical relations of the richer sulphides which appear in passing from deptl to the surface are very different in various regions. In some districts there may be somewhat regular gradations from the poor sulphurets at depth to the very rich sulphurets at or near the level of ground water. In other cases this change may be very abrupt. For instance, at Ducktown, Tenn., the lean cupriferous pyrrhotite changes rapidly into a zone of very rich sulphuret at and near the level of ground water. At Butte, Mont., the rich sulphurets are found at a much greater depth, and in the deeper workings of some of the mines secondary fracture openings in the lean sulphurets now contain small veins of rich sulphides of varions kinds, even bornite or chalcocite, which have evidently- been reduced by the leau sulphides adjacent. These illustrations slow that the varions sulphides overlap one another. In passing upward from the poor material, bornite may appear before the iron sulphide has been replaced largely by chalcopyrite, and at the place where bornite has become reasonably abundant chalcocite may be found. If the dominating material be iron sulphide, the copper mineral which is present is likely to be chalcopyrite rather than the richer sulphurets. Chalcopyrite is likely to be associated on the one hand with pyrite or pyrrhotite and on the other hand with bornite, or even chalcocite. Bornite and chalcocite are likely to be associated with each other and with chalcopyrite.

At still higher levels in a mine, a moderate distance below the level of ground water, oxidized and carbonated products may appear with the sulphurets. These mixed products, sometines called oxysul- 
phurets, are well illustrated in the Appalachian, Arizona, and Montana deposits. ${ }^{a}$ Still higher, and especially above the level of ground water, the oxidized and hydrated products may become dominant, for there the rich sulphurets which have emerged from the ground water have been directly acted upon by the oxygen, carbon dioxide, and water. A series of transformations now take place which may result in metallic copper, cuprite, tenorite, azurite, and malachite, as already described. (See pp. 1158-1159.) The oxidized products may largely remain in place, furnishing rich ores, or they may be almost wholly dissolved and carried to lower levels, to react on the sulphides, as already explained.

Therefore rich sulphurets are first formed largely by the oxidation and the reaction of the oxidized products on lean sulphurets. Later, when in consequence of denudation, these rich sulphurets pass into the belt of weathering, rich oxidized compounds are produced. Thus in' the upper few hundred meters of a vein there may be concentrated a large part of the copper produced by a first concentration in a much greater distance.

I do not mean to imply that each rich copper sulphide deposit has gone through the entire history above detailed, or that other factors have not been concerned in the development of the rich ore. Indeed, it will be seen that the general process outlined is much modified in many instances. (See pp. 1182-1189). However, it is held that processes of secondary concentration, due to descending water, have been very important factors in the production of rich copper deposits at many localities.

ASSOCIATION OF SILVER AND GOLD WTTH BASE METALS.

The association of lead, zinc, and iron, and of copper and iron-two common cases-have now been considered. A similar set of transformatious can be traced ont in either of these classes of deposits when they contain silver and gold.

SILVER.

In the case of silver it is well known that the original forms are generally sulphides, sulphantimonites, sulphantimonates, sulpharsenites, sulpharsenates, and silver replacing a part of the iron, lead, zinc, or copper in the sulphides of these metals. Silver is one of the compounds which holds

$a$ Douglas, James, The copper resources of the United States: Trans. Am. Inst. Min. Eng., vol. 19,1891 , p. $688-695$. 
strongly to sulphur. Ordinarily it is not sufficiently abundant to constitute the main mass of an ore deposit. Since silver holds so strongly to its sulphur, the silver salts are likely to be found, in the case of lead-zinc-iron compounds, most abundantly with the lead, less abundantly with the zinc, and least abundantly with the iron; and in the ease of the copper-iron compounds, most abundantly with the copper and less abundantly with the iron. Native silver and the rich silver compounds-cerargyrite $(\mathrm{AgCl})$, argentite $\left(\mathrm{Ag}_{2} \mathrm{~S}\right)$, proustite $\left(\mathrm{Ag}_{3} \mathrm{AsS}_{3}\right)$, pyrargyrite $\left(\mathrm{Ag}_{3} \mathrm{SbS}_{3}\right)$, and stephanite $\left(\mathrm{Ag}_{5} \mathrm{SbS}_{4}\right)-$-may be found abundantly in the upper parts of mines, but frequently decrease in anount in passing from the surface to the zone of sulphides, and at sufficient depth in this zone may entirely disappear, the products being wholly argentiferous lead, zinc, copper, and iron sulphides. In many instances independent silver minerals do not occur at all, all of the silver being in the lead, zinc, copper, and iron compounds. In the argentiferous lead, zinc, and iron deposits, the ores are likely to contain less silver as they become poorer in lead and zinc. As the argentiferous copper deposits become poorer in copper with depth, the silver also ordinarily decreases in amount. Therefore the plumbiferons and zinciferous pyrites and cupriferous pyrites deep in the mines ordinarily contain less silver than the deposits above, which are richer in the base metals.

In the belt of weathering above the level of ground water native silver and silver chloride, cerargyrite, are likely to be found. The native silver is produced by the direct oxidation of the sulphur, antimony, or arsenic united with the sulphur. For instance, if the silver compound be $\mathrm{Ag}_{2} \mathrm{~S}$, metallic silver is produced by simple oxidation of the sulphur as follows:

$$
\mathrm{Ag}_{2} \mathrm{~S}+\mathrm{O}_{2}=2 \mathrm{Ag}+\mathrm{SO}_{2},
$$

This reaction is very common, because silver is very slowly oxidized. But argentite may be directly oxidized to sulphate, according to the following reaction:

$$
\mathrm{Ag}_{2} \mathrm{~S}+2 \mathrm{O}_{2}=\mathrm{Ag}_{2} \mathrm{SO}_{4} \text {. }
$$

This compound is a very readily soluble one, and therefore does not remain in situ, but if chlorides are present they react upon this salt and produce cerargyrite, according to the following reaction:

$$
\mathrm{Ag}_{2} \mathrm{SO}_{4}+2 \mathrm{NaCl}=2 \mathrm{AgCl}+\mathrm{Na}_{2} \mathrm{SO}_{4} .
$$


It is well known that in arid regions, native silver and cerargyrite are especially abundant in the belt of weathering. These compounds are produced in the same manner as native copper and its oxidized products, with, however, one additional factor. In arid regions the alkaline salts, such as sodium chloride and similar compounds, are segregated. (See pp. 542-543.) Therefore in such regions the ground waters are particularly likely to contain chlorides in solution which react upon the sulplates and thus produce the chloride of silver. Water is not sufficiently abundant to dissolve the chloride and hence cerargyrite accumulates.

Not all the silver which is oxidized to the soluble form of sulphate is precipitated as chloride, and even the chloride is somewhat readily soluble, so that if the silver be thus transformed a part of it may be held in solution. Therefore silver sulphate, and some silver chloride passes downward from the belt of weathering to the belt of sulphides. Since silver holds to its sulphur more tenaciously than any of the base metals with which it is associated, the first of the sulphides of these metals which is met in mass is reacted on by such silver salts. Where they may come into contact with chalcocite, for instance, argentite is precipitated according to the following reactions:

$$
\begin{aligned}
& \mathrm{Cu}_{2} \mathrm{~S}+\mathrm{Ag}_{2} \mathrm{SO}_{4}=\mathrm{Ag}_{2} \mathrm{~S}+\mathrm{Cu}_{2} \mathrm{SO}_{4} . \\
& \mathrm{Cu}_{2} \mathrm{~S}+2 \mathrm{AgCl}=\mathrm{Ag}_{2} \mathrm{~S}+2 \mathrm{CuCl} .
\end{aligned}
$$

While it would be easy to write equations representing the reactions of the soluble silver salts upon the various sulphides of the base metals, producing silver sulphurets, it hardly seems worth while to do so until experimental work has determined the reactions which actually take place in the different cases. For the present purpose it is necessary only to understand that when soluble silver salts are brought into contact with base sulphides the silver certainly will be precipitated as independent silver sulphides or as rich sulphides in which the silver replaces a part of the base metals.

As an instance in which silver is concentrated in a base sulphide rather than in the carbonate of the base netal may be mentioned the Leadville ores. Here, according to Emmons, the galena is much richer in silver than the associated cerussite. Not only is this so in general, but there are some very interesting special cases. For instance, five assays of galena nodules which had carbonate crusts showed "six times as much silver in the galena 
as in the cerussite." a Essentially the same phenomenou has been observed by Spurr in the Monte Cristo district of Washington. He says that here "the very richest ores in the district are the bunches of sulphides which are residual in the oxidized ores." ${ }^{\circ}$ Such cases as these may be partly explained by the abstraction of the silver as sulphate from the lead carbonate, but I suspect it to be mainly explained by the reaction of the oxidized silver salts upon the galena, producing a galena richer in silver than originally existed.

Where the silver is largely changed to the sulphate and chloride, and is not largely precipitated as cerargyrite, the upper part of tlie silver veins in the belt of weatliering may be greatly depleted in silver as a result of this leaching process. 'That the silver is not thrown down as cerargyrite may be due to a deficiency of chlorine in the descending solutions, or to the fact that the solutions are of such a character or so abundant that they are capable of dissolving the silver chloride. Illustrations of this process of depletion may probably be found in the Cripple Creek district, where the upper parts of the veins which carry free gold are deficient in silver, while the original telluride contains a certain amonnt of the latter metal, indicating that it has been leached out. ${ }^{c}$

GOLD.

It has already been fully explained (see pp. 1088-1089, 1139-1140) that gold occurs extensively (1) in the native form free from sulphides and tellurides; (2) in the native form closely associated witl sulphides and tellurides; and (3) as a telluride. In the belt of weathering gold is very largely found in the metallic form, associated with the oxidized products of the base metals, especially with oxide of iron. Much of such gold was originally associated with the sulphides or the tellurides, or was united with tellurium as a telluride.

If the gold is in the metallic state, and merely inclosed in sulphides of iron or other sulphides, it is freed by the oxidation of these sulphides. Where it is united with tellurium it is necessary that this element be

a Emmons, S. F., Geology and mining industry of Leadville, Colo.: Mon. U. S. Geol. Survey, rol. 12,1886, p. 553.

b Spurr, J. E., The ore deposits of Monte Cristo, Washington: Twenty-second Ann. Rept. U. S. Geol. Survey, pt. 2, 1901, p. 851.

c Penrose, R. A. F., jr., Mining geology of the Cripple Creek district, Colo.: Sixteenth Ann. Rept. U. S. Geol. Survey, pt. 2, 1895, pp. 131-132.

MON XLVII-04-74 
oxidized in order that the free gold may be produced. This may take place first by the oxidation of tellurium to an oxide, and then the solution of the oxide by acids. Or the sum total of all the changes may be represented in a given case as follows:

$$
\mathrm{Au}_{4} \mathrm{Te}_{3}+12 \mathrm{NaCl}+6 \mathrm{CO}_{2}+6 \mathrm{O}=4 \mathrm{An}+3 \mathrm{TeCl}_{4}+6 \mathrm{Na}_{2} \mathrm{CO}_{3}
$$

That this or some similar process of the oxidation of the tellurium, leaving gold behind, has taken place upon an extensive scale at Cripple Creek, is shown by the very frequent pseudomorphs of spongy gold after the various tellurides.

The free-gold ores thus formed in the belt of weathering are commonly very much richer than the downward extensions of the deposits, in which the gold is associated with sulphides or tellurides, or occurs as a telluride. This exceptional richness of the upper part of the gold deposits is so well known that it is umnecessary to give many cases illustrative of it. However, one or two of the more important districts may be mentioned. In Australia, Don says, "for ounces per ton above the ground-water level, only pennyweights per ton have been formd below it." " In the Sierra Nevada deposits, according to Lindgren, near the surface the values are from $\$ 80$ to $\$ 300$ per tou, whereas deeper they are somewhat uniform for the given vein, and run from $\$ 20$ to $\$ 30$ per ton. ${ }^{b}$ In many instances the decrease in values is so great, in passing from the belt of weathering to the deeper workings, that while the belt of weathering and the upper part of the belt of cementation may be very profitable, the deeper portions of the deposits are so lean as not to warrant working.

These facts seem to me to be conclusive evidence that, in some way, the downward-moving waters have concentrated in a comparatively narrow belt an amount of gold which originally had a much wider vertical extent. That is to say, in some way, as denudation continued downward, the gold deposited in one of the original forms has been taken into solution by the descending waters and has been reprecipitated, thus producing the enriched upper part of the veins. As this process continues the belt of weathering becomes richer and richer, there being segregated within a comparatively p. 596

$a$ Don, J. R., The genesis of certain auriferous lodes: Trans. Am. Inst. Min. Eng., vol. 27, 1898,

${ }^{b}$ Lindgren, Waldemar: The gold-quartz veins of Nevada City and Grass Valley, California: Seventeenth Ann. Rept. U. S. Geol. Survey, pt. 2, 1896, p. 128. 
small vertical distance (from a few meters to 100 meters or more) a large part of the gold which, as a first concentration, may have had a vertical extent of 1,000 to several thousand meters.

It has been seen that gold is solnble in ferric chloride, cupric chloride, sodic carbonate, alkaline sulphides, and in other compounds. There are likely to be present in descending waters ferric chloride and ferric sulphate, and, in case the lode is a copper-bearing one, also cupric chloride. It is therefore believed that in the rpper part of the belt of weathering these reagents or others take the gold in solution. As the solutions pass below the belt of weathering and into the belt of cementation they come into contact with sulphides of the base metals, tellurides, or organic materials, or are mingled with reducing solutions. It has already been seen that any of these conditions results in the precipitation of gold from its solutions, and therefore the gold is thrown down by these compounds in the upper part of the belt of cementation. Probably in the majority of instances the sulphides are the chief reducing compounds, although the others are not unimportant. The reduction of gold by sulphides is somewhat different from the reduction of any of the metals previously considered. Zinc, lead, copper, and silver are thrown down from their salts as sulplides by the baser sulplides. The gold is thrown down from its salts by those sulphides not as a sulphide but as metallic gold, because gold and sulphur have such weak affinity and gold is so easily reduced to the metallic form.

As denudation goes on the enriched upper portion rises into the belt of weathering. The sulphides and tellurides are there again oxidized, the gold is again partly dissolved and transported downward to be again precipitated, and thus an horizon of steadily increasing richness and breadth is formed below the belt of weathering in the belt of cementation, the gold commonly being largely free, but associated with sulphides.

During the mrocess not all the gold which rises into the belt of weathering is dissolved, and the richer the sulphide zone which rises into the belt of weathering the greater the amount of gold left behind. 'This process of chemical concentration in the belt of weathering is supplemented to an important degree in many districts by residual concentration. As denudation continues the rocks are disintegrated, dissolved, and transported to the streams to a greater extent than is the gold, and thus the gold in the 
upper parts of the veins is segregated. Segregation by this method is especially important at and near the surface. It thus appears that the production of the free gold of the upper parts of lodes is largely a chemical process, but is partly a process of residual concentration The two together continned for a sufficient length of time are believed to adequately explain the rich free gold ores of the upper parts of lodes.

Cripple Creek furnishes an excellent illustration of rich free gold at and near the surface. Near the surface numerous deposits in this district were exceptionally rich, containing a large amount of free gold above and near the level of ground water. Usually much of this fiee gold was in spongy pseudomorphs after tellurides, showing its formation in large measure by the direct oxidation of the tellurium of the tellurides, the gold being left behind. For some years it has been well known that below the upper belt of rich material in many of the veins the deposits were very much poorer. Indeed, many of the deposits were found to be so poor below the upper narrow belt of rich ores as to lead to their abandonment.

In reference to this poor ground Mr. Moore says:

"It is undoubtedly true that some mines have entered poor ground in the veins at depths of 250 feet [75 meters] to 400 feet [120 meter's] below the surface, and have sumk down to depths of 400 feet [120 meters] to 500 feet $[150$ meters] deeper without finding payable ore bodies again." But this was by no means true of all the deposits. Mr. Moore further says, "It is a fact that in a greater number of mines the values luave been carried down to more than 1,200 feet [360 meters] below the surface continuonsly, and in at least two mines the values have greatly increased from 1,100 feet [330 meters] downward." a A most interesting feature in reference to the Cripple Creek district has been developed recently. Deep in some of the mines which showed a depleted horizon there has been discovered a lower horizon of very rich ores, partly sulphides and tellurides, but also in large part free gold.

According to Mr. Hills: "The original ground-water level at Cripple Creek is about altitude 9,500 feet [2,850 meters] for the west side of the district and considerably higher for the Bull Cliff region." ${ }^{b}$ The upper part

"The Daily News, Denver; Colo., Jan. 1, 1903, p. 3.

$b$ Ninth Ann. Rept., Portland Gold Miuing Co., Victor, Colo.; Report ol Victor G. Hills, Consulting Fngineer, 1903, p. 87. 
of these rich deposits appeared upon an average at least 120 meters below ground-water level. Mr. Moore ${ }^{a}$ states that the depths of the deepest shafts in the Cripple Creek district vary from 240 to 450 meters. On Battle Mountain are the Portland, Granite, Burns, Ajax, Stratton's Independence, Strong, Gold Coin, and Modoc. At Bull Hill are the Last Dollar, Blue Bird, Logan, American Eagles, Wild Horse, Isabella. At East Spur Bull Hill are the Independence T. \& M. Co., Vindicator, Lillie, and Golden Cycle. He says in reference to these deposits: "All but one of these shafts have good bodies of ore and excellent indications for the future at the lowest levels to which they have thus far attained. Certain of these shafts, to wit, the Last Dollar and Blue Bird, show some of the richest ore ever mined in the district at their lowest levels." Mr. Moore regards these deep, rich deposits as due to the secondary action of descending waters. It has already been noted that in the Cripple Creek districts the values in the upper part of the veins near the ground-water level are very largely in native gold; deeper they are largely in the tellurides, the sulphides being comparatively poor; while still deeper they are to a large extent in the sulphides.

If these are facts they seem to be evidence that the ores of the Cripple Creek district have undergone two concentrations. The first concentration was by ascending waters, and the ores were originally deposited in some measure as tellurides, but perhaps more largely as free gold associated with sulphides. In consequence of later denudation, with action by descending waters, secondary segregation may have taken place and produced two rich upper horizons, that of free gold largely above the level of ground water and that of the rich tellurides and associated free gold, mostly below it.

Exceptionally the Cripple Creek mines have a deep horizon of rich tellurides. In most districts where rich ores occur at some depth below the level of ground water the reduction of the gold to its free state is believed to be largely the work of the base sulphides. As already noted, in the deeper workings of the Cripple Creek district the values are largely in the sulphides, and the tellurides are subordinate. The natural explanation of the rich tellurides is that as the original sulphides and tellurides rose above the level of ground water the gold and tellurium were both 
oxidized and traveled down, the first as gold chloride or a similar salt, and the tellurium as telluric chloride or a similar salt. Below the level of ground water these two compounds would both be reduced where they came into contact with the base sulphides. At the moment of reduction they may have united, and thus the rich tellurides of gold may lave been formed. It is thought possible that precipitation was cansed in this manner rather than by previously existing lean tellurides of the first concentration, because in the deeper workings of some of the mines the tellurides seem to be very subordinate to the sulphides, and the values are mainly in the sulphides. If the above suggestion proves correct, in the Cripple Creek district the deep, rich tellurides represent a concentration of tellurium as well as of gold. If the amount of tellurium for the upper 500 meters or more of the lodes was not originally greater than in the deeper workings, the tellurium now found in the deep rich horizon must have had a much wider original vertical distribution. ${ }^{a}$

The formation of the rich free gold near and above the level of ground water in the Cripple Creek district is not materially different from the formation of sucl products elsewhere. As denudation continued the enriched sulphides and tellurides rose above the level of ground water, the sulphur and tellurium were there oxidized, and some of the free gold was left behind. This chemical process was accompanied by residnal concentration.

CONCEYTRATION BY REACTION UPON SULPHIDES COMPARED WTTH METALLURGICAL CONCENTRATION.

One of the more conmon processes of metallurgy for the separation of gold, silver, copper, and lead from iron is based upon the principle explaining the second concentration given on preceding pages, viz, that iron holds sulphur less strongly than the other elements named. The sulphureted ores are imperfectly roasted, thus partly oxidizing them to oxides and sulphates. The ores are then smelted in a furnace with a flux. The oxides of the valuable metals and the sulphates react on the remaining sulphides of all the metals, producing a matte containing the sulphides of the valuable metals. The iron gets all or nearly all of the oxygen; the iron oxide unites with the fluxes and passes into the slag.

a Since the above was in page proof I have been informed by Dr. Lindgren, who has closely studied the district, that he donbts the existence of enriched deep tellurides at Cripple Creek. If these tellurides do not exist the two preceding paragraphs need radical modification. 
OTHER REACTIONS OF DESCENDING SOLUTIONS.

In the foregoing pages the second concentration of metals by solution, downward transportation, and precipitation by reactions on the sulphides of the first concentration has been emphasized. However, it is not supposed that this is the only process which may result in enrichment by descending waters of the upper parts of vein deposits. The enrichment of this belt may be caused by reactions between the downward-moving waters carrying metallic compounds and the rocks with which they come in contact, and by reactions due to the meeting and mingling of ascending and descending waters.

The descending waters carrying metals dissolved in the upper part of the veins may be precipitated by material contained in the rocks below. This material may be organic matter, ferrous salts, ete. So far as precipitating materials are reducing agents, they are likely to change the sulphates of most of the metals to sulphides, and precipitate the metals in that form. While sulphides may thus be precipitated to some extent above the level of ground water, because of the deficiency of oxygen they are thrown down much more largely below it. The reducing solutions ordinarily precipitate gold from its solutions in the metallic form.

In a trunk channel, where ascending and descending waters meet, there is a considerable horizon in which the circulation is slow and irregular, the currents now moving slowly upward and now moving slowly downward, and at all times being disturbed by convectional movements. Doubtless this belt of slow general movement and convectional circulation reaches lower levels at times and places of abundant rainfall than at other times and places, for under such circumstances the descending currents are strong. The ascending currents, being controlled by the meteoric waters falling over wider areas, and subject to longer joumeys than the descending currents, do not so quickly feel the effect of abundant rainfall. Later, the ascending eurrents may feel the effect of the increased rainfall and cartiy the belt of upward movement to a higher level than normal. However, where the circulation is a broad one, little variations in ascending currents result from irregularities of rainfall.

In the belt where ascending and descending waters meet (see fig. 26), convectional mixing of the solutions dne to difference in temperature is an important phenomenon. The waters from above are cool and dense, and 
tend to sink downward, while those from below are warm and less dense and tend to rise; thus the waters are mingled. But even if the water were supposed to be stagnant at the neutral belt, it is probable that by diffusion the materials contributed by the descending and ascending waters would be mingled.

Ascending and descending solutions are sure to have widely different compositions, and an accelerated precipitation of metalliferous ores is a certain result of their mixture. As an illustrative case in which precipitation is likely to occur, we may recall that ascending waters contain practically no free oxygen, frequently contain hydrogen sulphide, and are often somewhat alkaline, while descending waters are usually rich in oxygen and frequently contain acids, as at, Sulphur Bank, described by Le Conte. ${ }^{a}$ The mingling of such waters as these is almost sure to result in precipitation of some kind. As illustrating the effect of the mingling of descending and ascending solutions we may suppose that the sulphides of any of the metals are rising in solutions of sodium sulphide, and that the descending waters are carrying sulphates of the metals and sulphuric acid. The sulphuric acid would destroy the sodium sulphide according to the following reaction:

$$
\mathrm{Na}_{2} \mathrm{~S}+\mathrm{H}_{2} \mathrm{SO}_{4}=\mathrm{Na}_{2} \mathrm{SO}_{4}+\mathrm{H}_{2} \mathrm{~S}
$$

The sodium sulphide being destroyed, the sulphides traveling as such in the ascending solutions would be thrown down. This reaction also produces hydrogen sulphide, which, formed in this way or originally present, would throw down metals from the descending oxidized salts. For instance, sulphate of copper would be thrown down as a sulphide by hydrogen sulphide. Another illustrative case is the mingling of descending waters bearing oxygen with ascending waters bearing iron carbonate. The result is to throw down the iron as ferric oxide, according to the following reaction:

$$
2 \mathrm{FeCO}_{3}+\mathrm{O}+\mathrm{nH}_{2} \mathrm{O}=\mathrm{Fe}_{2} \mathrm{O}_{3} \cdot \mathrm{nH}_{2} \mathrm{O}+2 \mathrm{CO}_{2}
$$

Le Conte also snggests that by the mingling of the waters from below with those from above the temperature of the ascending column is rapidly lessened, and this also may result in precipitation. The dilution may work in the same or in the reverse direction.

a Compare Le Conte, Am. Jour. Sci., 3d series, vol. 24, 1882, p. 33, and vol. 26, 1883, p. 9. 
The metals precipitated by the mingling of waters may be contributerl by the descending waters, by the ascending waters, or partly by each. In so far as more than an average anount of metallic material is precipitated from the ascending waters, this results in the relatively greater richness of the upper part of veins independently of the material carried down from above.

The aoove methods of precipitation and enrichment of the upper parts of deposits follow from the reactions of downward-moving waters. Their effect is to precipitate the metals of the ascending water to some extent, and thus assist in the first concentration. But the results of these processes can not be discriminated from the second concentration, which is cansed by an actual downward transportation of the material of the first concentration. It is believed that the pecnliar character of the upper portions of lodes is mainly owing to downward transportation of metals previonsly precipitated (see pp. 1182-1189); but whether this be so or not, it is certainly dne to descending waters.

SECOND CONCENTRATION FAVORED BY LARGE OPENINGS NEAR THE SURFACE.

The concentration of large ore bodies in the belt of weathering and in the upper part of the belt of cementation is greatly favored by the abundance and size of the openings as compared with the openings at greater depths.

The openness of the rocks above the level of ground water and the rapid lessening of the volume of the openings below it have already been alluded to as general phenomena, and an explanation has been offered that in the belt of weathering solntion is the law, and in the belt of cementation cementation is the law. (See pp. 484-487,562-565, 612-617.) Of course, it is understood that there is usually not a sudden change in the amount of pore space at the level of ground water, but at and below it the extremely open upper ground grades into the much less open lower ground. In some instances the gradation requires some distance. Thus, so far as the openings are concemed, the conditions for the formation of large ore deposits are more favorable above the level of ground water and as far below it as openings are numerous than at deeper levels.

This openness of the belt of weathering and the comparative closeness of the belt of cementation are well illustrated by many limestone regions; 
for instance, the lead and zine district of southwestern Wisconsin, already described. (See pp. 1144 et seq.) Another excellent illustration of very loose and open ground above the level of ground water and tight ground below it is furnished by the Monte Cristo district of Washington. ${ }^{a}$ Here near the surface all the minor joints are open, circulation has been free, and the larger ore deposits are found. At depth the joints are mostly tight, only a few being sufficiently open to allow of much water circulation.

But numerous and large openings may exist below the level of ground water. In various kinds of rocks-such as sandstones, conglomerates, amygdaloids, and tuffs - the openings are original, and may not have been closed by cementation. Of course, the more recent the earth movements the more numerons and larger are the openings. In some places the descending waters are not saturated when they reach the level of ground water, and solution continues for some distance below it. Furthermore, the level of ground water varies under different circumstances. Where a region is being uplifted the level of ground water, other things being equal, is descending, and where a region is subsiding it is rising. As a result of physiographic changes there may be alternate valley filling and valley erosion. These changes affect the level of ground water. In Pleistocene time there was an extensive period of valley filling instead of erosion. Consequent on this the level of drainage, and therefore the level of ground water, rose. Also there may be very considerable variations in the level of ground water as a consequence of long-continued climatic changes, sucl, for instance, as the alternating periods of humidity and aridity in the Cordilleras of the West in connection with the Pleistocene. ${ }^{b}$ To illustrate, at the present time in the mining districts of New Mexico and Arizona the level of ground water is far below the surface, but it can not be doubted that during the humid epoch evidenced by the existence of Lake Bonneville and Lake Lahontan the level of ground water was much higher. Emmons gives a specific case in which the ground water was apparently once nearer the surface than at present. According to him, at the Delamar

a Spurr, J. E., The ore deposits of Monte Cristo, Washington: Twenty-second Ann. Rept. U. S. Geol. Survey, pt. 2, 1901, p. 847.

$b$ Gilbert, G. K., Lake Bonneville: Mon. U. S. Geol. Survey, vol. 1, 1890. Russell, I. C., Geological history of Lake Lahontan, a Quaternary lake of northwestern Nevada: Mon. U. S. Geol. Survey, vol. 11, 1885. 
mine the lower levels are as dry as the upper levels. The region is arid and the mine is never wet, but the mine shows "universal evidence of a secondary enrichment that must have proceeded from the surface downwards." " This fact Emmons regards as evidence that at the comparatively recent Bonneville epoch the water level was comparatively near the surface.

Aside from secular changes in the level of ground water, due to variations in rainfall extending through geological periods, the shorter periods of varying rainfall produce some effect upon the level of ground water. Thus the annual and several-year period variations in rainfall cause slight changes in it.

All these changes favor alternate solution and deposition-solution when the level of ground water falls, precipitation when it rises. Where the ground water has been at a low level large openings to some depth are likely to be produced. Where later for some reason the level of ground water rises these openings are in a very favorable position to be filled with ore, as a result of precipitation from ascending solutions, of the reactions of descending solutions, and of the mingling of ascending and descending waters.

It might be argued that the existence of ore deposits in the large openings of the belt of weathering is evidence that the ores were not first deposited by ascending waters. However, as has been already explained, in such openings there may be concentrated mineral material originally distributed by ascending waters throngh a much greater vertical distance. Thus a very rich ore deposit in large openings, formed by the reaction of descending waters upon a first concentration produced by ascending waters, may be bounded below by a horizon in which the ground is very close, the comparatively small openings which once existed having been greatly enlarged by solution during reconcentration by descending water.

DEPTH OF EFFECT OF DESCENDING WATERS.

There can be no doubt of the importance of downward-percolating waters in the production of ore deposits in the zone in which they are active. The only question which remains open is the depth to which they are effective. This varies greatly in different districts and in the mines of

a Emmons, S. F., The Delamar and the Horn-Silver mines; twotypes of ore deposits in the deserts of Nevada and Utah: Trans. Am. Inst. Min. Eng., vol. 31, 1902, pp. 672-673. 
the same district. In general, the effect is likely to be deep seated in proportion as the lode worked is on high ground. (See p. 1181.)

In arid regions the level of ground water is far below the surface and the process of denudation is slow, so that the downward-moving waters have both a wide belt in which to work above the level of ground water and a long time in which to work upon a given horizon. In such regions the oxides and carbonates are likely to occupy a considerable horizon. This is very well illustrated by the copper mines of Arizona and New Nexico and by the "colorados" of the silver-gold deposits in various arid regions.

In humid regions, on the other hand, the level of ground water is likely to be near the surface. If this be combined with marked relief so that denudation is rapid, the processes of oxidation and carbonation may be very incomplete above the level of ground water. Indeed, in many cases erosion may be so rapid that the sulphurets do not have time for more than very partial oxidation, and they may extend nearly or quite to the surface. If the raibfall is abundant, descending waters are likely to be effective below the level of ground water; and if there are large openings and strong relief, the waters are effective to a considerable depth. Consequently even where there are no oxidized products above the level of ground water, the ores are likely to have been enriched by descending waters in the belt of cementation. It is very seldom that a deposit is found in which no effect of descending waters can be discovered.

It has already been seen that the level of ground water may vary from the surface to a depth of 300 meters or more. Hence it is certain that from the surface to a depth of 300 meters the ground waters may be a potent factor in the production of the rich ore deposits. The deposits in this belt are particularly profitable, not only because of the accessibility of the material, but because of the fact that there is no expense for pumping; furthermore, the products are commonly easily reducible. This may be illustrated by the gold and silver deposits. In the former, the native gold is free from its entanglement of sulphurets and tellurides; in the latter the silver is largely in the form of the readily extracted chloride, or in some instances as native silver. Aspen Mountain furnishes an excellent illustration of a broad belt of weathering. Here, at a depth of 250 meters, at least one great body of lead carbonate has been developed. This carbonate contains a few small crystals of galena, showing its derivation from the sulphide, and 
therefore showing that the oxidizing, carbonating waters above the level of ground water have been extremely effective.

$\mathrm{Up}_{\mathrm{p}}$ to this point there will be no disagreement on the part of anyone. The question now arises as to the deptlis below the level of ground water to which descending waters produce their effects. This is a question to be answered, not by deduction, but by observation. Even Posepny, who emphasizes the effect of ascending waters, agrees that oxidized products are the eridence of the work of vadose circnlation, or the circulation of lateral and downward-moving waters. Furthermore, Posepny agrees that the iron ores of the Lake Superior region, ${ }^{a}$ which are oxidized prodnets, have been prodnced by downward-moving waters. A number of the mines have been worked to a deptl of 500 meters or more below the level of gronnd water; and in these cases it is perfectly clear that to this depth the downward-percolating waters have produced an oxidizing effect. This is true in a region in which the level of ground water is relatively near the land surface, and which is not mountainous. In various other regions oxidized products are found also to a very considerable deptl below the level of the ground water.

In the San Juan distriet of Colorado, in the Revenne tumnel of the Virginius mine, the effect of oxidizing waters has been observed to the deptl of nearly 1,000 meters, as shown by iron-oxide stains through the sulphides. How much deeper oxidation may be effective is not known, and below this depth there may be a belt in which the sulphides may have been enriched by descending solutions from above without the actnal production of oxidized products. In the Cripple Creek district of Colorado oxidized products ase not found to a great deptlh, but if the suggestion is correct that the high-grade tellurides are dne to the effect of descending waters, such waters must have been effective to a depth of 400 meters. As yet the lowest limits of the enriched belt has not been reached, and how much deeper it extends is mnknown. Both these districts are humid and of very accentuated topography, and thus furnish exceptionally favorable conditions for descending waters to produce deep effects.

The illustrations given furnish positive evidence that the belt in which descending waters are effective in producing rich secondary concentrates under favorable conditions extends to a very considerable depth.

a Posepny, F., Genesis of ore deposits (discussion): Trans. Am. Inst. Min. Eng., vol. 24, 1895, pp. $966-967$. 
ILLUSTRATIONS OF SECONDARY ENRICHVENT AND DLUINUTION OF RICIINESS WITH DEPTH.

The processes have now been explained by means of which a rich upper belt may be produced. If the argument be correct, it is an inference from this that ore deposits which have undergone a second concentration are likely to diminish in richness with depth, provided a considerable belt be considered. It remains to give the facts which confirm the above hypothesis, and illustrate diminution of richness with depth.

At Ducktown, Temm., at the level of ground water, appeared a belt of rich black copper ore (copper glance), which varied from less than 1 to about $2 \frac{1}{2}$ meters in thickuess. Above this belt was gossan, very poor in copper; below it a very low grade cupriferous pyrrhotite. ${ }^{a}$ In this instance it can hardly be doubted that originally the lean cupriferous pyrrhotite extended not only to the present surface but probably much higher. The dowuward-moving waters transported copper to its locus near the level of ground water. Here the copper salts reacted on the iron sulphide and produced rich sulphurets.

A case which has been, perhaps, more closely studied than any other in the United States is that of the deposits of Butte, Mont. Douglas states that here rich oxysulphurets are found near the surface. On the summit of the hill "it seems as if the copper, leached out of the 400 feet (120 meters) of depleted vein, had been concentrated in the underlying ore, and had thus produced a zone of secondary ore about 200 feet (60 meters) deep, which contains, as might be expected, about thrice its normal copper content." $^{b}$ Of the Butte deposits Emmons says:

Secondary deposition, or transposition of already deposited minerals, has played an unusually important rôle. In the case of the copper veins it has not been confined to the oxidizing action of surface waters, which has resulted in an impoverishment of the ore bodies, but below the zone of oxidation it has resulted in the formation of the richer copper minerals bornite, chalcocite, and covellite, in part, at least, by the breaking up of original chalcopyrite. Unusual enrichment of the middle depths of the lodes has thus been caused. Whether the two processes of imporerishment and enrichment have been differing phases of the action of descending waters, or whether the latter may have been a later result of the rhyolite intrusion, has not yet

a Blake, W. P., The persistence of ores in lodes in depth: Eng. and Min. Jour., vol. 55, 1893, p. 3. Henrich, C., The Ducktown ore deposits and the treatment of the Ducktown copper ores: Trans. Am. Inst. Min. Eng., vol. 25, 1896, pp. 206-209.

${ }^{b}$ Douglas, James, The copper resources of the Uniterl States: Trans. Am. Inst. Min. Eng., vol. 19, 1891, p. 693. 
been definitely decided. It is, however, fairly well determined that the enrichnent of the copper deposits is so closely associated with the secondary faulting that it may be considered to be a genetic result of it."

While the larger and richer sulphide bodies were found at from 60 to 125 meters below the water level, rich sulphide bodies of smaller size are liere and there found at a depth of 450 meters below the water level, "thongh in apparently decreasing amount as compared with the immense thickness of pyritous ore." Brown states that in the same area oxidized products extend to the level of ground water. These oxidized products, according to Brown, promptly change at water level into normal sulphnrets. "There follows below a region of varying height, of valuable rock, which again slowly deteriorates in depth, this deterioration, however, being so retarded finally as to be scarcely appreciable." " He further says that above the level of ground water is gossan "carrying high values in silver, and particnlarly in gold." d Thus at Butte we have emrichment in silver and gold and depletion in copper in the belt above the level of ground water as compared with the material below it; and at and below the level of ground water we have rich sulphides of copper which grade into leaner sulphurets. In the case of the Bntte deposits it can hardly be doubted that the comparatively lean sulphides in the deeper workings represent the product of a first concentration, and that the modifications of this material found above and below the level of ground water represent the work of downwardmoving waters. To account for the high values of gold and silver above the level of ground water, one must suppose that this belt has received contributions of these metals from the upward extension of the veins which has now been removed by erosion. The great richness of the copper below the level of ground water Douglas clearly attributes to the downward transportation of the material from the depleted copper veins. However, a part of this material was doubtless derived from an upward extension of these veins, precisely as in the case of the gold and silver. For my own part, I have little doubt that the precipitation of the rich sulphides was produced by reactions upon the lean snlphurets, as given in the equations on pages $1161-1164$.

a Emmons, S. F., Economic geology of the Butte special district, Montana: Geologic Atlas U. S., folio $38,1897$.

b Emmons, S. F., The secondary enrichment of ore deposits: Genesis of ore deposits, Am. Inst. Min. Eng., 2d ed., 1902, p. 444.

c Brown, R. C., The ore deposits of Butte City: Trans. Am. Inst. Min. Eng., vol. 24, 1895, p. 556.

a Brown, eit., p. 555 . 
Penrose cites the Arizona copper deposits as instances of secondary concentration. These deposits he regards as produced by leaching of the copper from a lean copper-bearing pyrite, and its segregation at the places where the rich ores occur. In this process Penrose, however, says that the vohme of the deposit must be decreased; but he makes the point that the smaller amount of the rich product is more valuable than a larger lean deposit, becanse more easily mined and more readily reduced. ${ }^{a}$ This process of concentration is further described by Douglas, who notes, also, that the changes have resulted in the production of enriched sulphides from very lean sulphides in the Copper Queen mine. Here, according to Douglas, a large very low-grade copper-bearing pyrite deposit running from the 60 - to the 120-meter level contains rich oxysulphides and black sulphides on the outside and mainly lean pyrite in the interior. ${ }^{b}$ The original material in the Arizona locality is as plainly a lean cupriferous pyrite as in Tennessee. Here, however, on account of the peculiar climatic conditions, the alterations have been of a different kind and have not extended to a uniform depth. Instead of the rich belt being a horizontal sheet, it occurs in a zone about a large cupriferous pyrite mass; but the principles of concentration are identical, and the rich products are unquestionably in part due to reactions between the oxidized salts and the lean sulphides. The rich oxidized products of the Southwest doubtless were produced directly from the enriched sulphurets. Therefore, in the formation of the rich oxidized products there were two stages of alteration; first, the production of rich sulphurets by the reaction of oxidized products upon the lean pyritiferous material, and after that oxidation of the rich sulphurets. These oxidized ores formed partly in situ, but there has been also more or less of transfer of material from one place to another.

An excellent illustration of an enriched upper belt in the case of gold is furnished by the gold-quartz veins of Grass Valley, California, where, according to Lindgren, the decomposed belt of weathering, about 50 meters in depth, contains "from $\$ 80$ to $\$ 300$ per ton, while the average tenor in depth is from \$20 to $\$ 30 . "$ Furthermore, the rich 50 meters, which con-

"Penrose, R. A. F., jr., The superficial alteration of ore deposits: Jour. Geol., vol. 2, 1894, pp. 306-305.

${ }^{b}$ Douglas, James, The Copper Queen mine, Arizona: Trans. Am. Inst. Min. Eng., vol. 29, 1900, pp. 532-533.

c' Lindgren, Waldemar, The gold-quartz veins of Nevada City and Grass Valley, California: Seventeenth Ann. Rept. C. S. Geol. Survey, pt. 2, 1896, p. 128. 
tain from four to ten times as much gold as the sulphurets below the level of ground water, are depleted in silver. In some veins the sulphurets extend almost to the surface. Lindgren further states that the sulphurets below the level of ground water continue with undiminished richness to a depth of 500 or more meters. ${ }^{a}$ He aulds that the California region is one in which denudation has extended to a depth of 500 to 1,500 or more meters. ${ }^{b}$ From these facts it is highly probable, as suggested by Lindgren, that sulphurets similar to those below the level of ground water were deposited above the present surface. If this were the case the only possible explanation of the belt of weathering rich in gold and depleted in silver is that descending waters have abstracted a large part of the gold from the material removed by erosion, and have deposited it in the belt of weathering. Its precipitation there was, doubtless, mainly due to reduction by the sulphides, producing sulphurets richer in gold. Later, the sulphicles have been oxidized, leaving the enriched belt of free gold. The silver apparently has been transported downward to a greater extent. One would expect that correlative with the belt above the level of ground water poor in silver, there would be a belt at and below the level of ground water richer in silver. Upon this point Lindgren does not give us information.

Another very interesting case of richness of the belt of weathering in gold, as compared with the unaltered sulphides below, is furnished by the Australian gold fields, where the belt above the level of ground water is several times as rich as the unaltered tellurides and sulphides below; some mining men say ounces above to pennyweights below. ${ }^{e}$ This rich belt is from $\mathbf{1 5}$ to $\mathbf{1 2 0}$ meters wide. In a portion of the mines of some districtsfor example, the Kalgoorlie district-when the bottom of the oxidized zone is reached, the ores are so lean as to be valueless, so that mines which were profitable in the weathered zone did not pay below it. ${ }^{d}$ Many of the mines of that district, however, are profitable below the weathered horizon. If it had not been for the secondary enrichment by denudation and downward transportation of material, many of the mines would not have been exploited,

a Lindgren, cit., pp. 161-163.

$b$ Lindgren, cit., pp. 182-183.

${ }^{c}$ Don, J. R., The genesis of certain auriferous lodes: Trans. Am. Inst. Min. Eng., vol. 27, 1898, p. 596.

$d$ Hoover, H. C., The superficial alteration of western Anstralian ore deposits: Trans. Am. Inst. Min. Eng., vol. 28, 1899, pp. 762-764.

MON XLVII-04- 75 
although Hoover thinks that in this strange country the downward concentration is more mechanical than chemical. Thus the secondary concentration by descending waters is no less an important part of the genesis of the gold ores of Australia than the first concentration by ascending waters.

It has already been fully explained (p. 1144 et seq.) that the lead and zinc deposits of the Mississippi Valley furnish clear cases of the importance of the action of descending waters in enriching ores first concentrated by ascending waters.

The Lead ville deposits furnish an instance of the decrease of "the richness in silver with depth. Einmons says: "There is a fair foundation for the generalization that in the deposits, as developed at the time of this investigation, the ores were growing poorer in silver as exploration extended farther from the surface." ${ }^{a}$

The ores early mined contained scarcely any zinc. Emmons states of the ores of the deeper levels later mined that the "sulphide ores consisted of mixtures of pyrite, galena, and zinc blende, the latter in fairly equal amounts." The sulphide bodies immediately below the belt of oxidation are richer in zinc blende than the ore at greater depth. The material rich in zine below correlates with the ores low in zine near the surface, the zinc sulphide of that horizon having been oxidized, and the zinc carried down and redeposited. ${ }^{b}$

Another case of the diminution of the richness of sulphurets with depth is furmished by the nickel mines of Lancaster Gap, Pennsylvania, which were not worked beyond a depth of about 75 meters, presumably becanse "the ore decreased in richness as depth was attained."

The San Juan district of Colorado gives excellent illustrations of decrease of values with depth. The upper parts of the lodes were usually very rich in silver, not infrequently ores ruming 300 ounces or more per ton. In the deeper workings of the veins the valnes in silver usually ran down, in many cases very rapidly, so that, at a depth of a few hundred meters the amount of silver became so low that work upon many of the

a Emmons, S. F., The geology and mining industry of Leadville, Colo.: Mon. U. S. Geol. Survey, vol. 12,1886 , pp. $554-555$.

$b$ Emmons, S. F., The secondary enrichment of ore deposits: Genesis of ore deposits, Am. Inst. Min. Fing., 2d ed., 1902, pp. 439-440.

c Kemp, J. F., The nickel mine at Lancaster Gap, Pennsylvania: Trans. Am. Inst. Min. Eng., vol. 24,1895, p. 626 . Discussion by E. E. Olcott, p. 884 . 
lodes ceased comparatively early in the history of the district. Regarding these ores Ransome says:

In spite of the diversity shown by the different ore bodies, there is after all remarkable uniformity to be found in the change at very moderate depths-nsually less than 300 feet [91 meters] - from an ore consisting chiefly of argentiferous galena to highly argentiferons silver-copper ores, and then a gradual diminution of value downward through the increasing proportion of low-grade pyrite in the ore bodies. These changes are best recorded in the Yankee Girl, Guston, and Silver Bell mines. ${ }^{a}$

In some of the deeper lodes of the district the values have become so low that they do not warrant working. While in some lodes there has also been a decrease in the amount of gold with depth, the gold values in general have held up very much better than the silver, and in some of the mines at a depth of 500 or more meters below the surface, as at the Camp Bird, the values are still very high in gold. Possibly the explanation of the difference between the two metals is that from the descending solutions the silver was thrown down more rapidly than the gold. Since silver is precipitated as a sulphide, it is very quickly thrown down from its soluble salts in consequence of the reaction of the sulphides of the base metals, such as galena, sphalerite, and pyrite; whereas by these compounds the gold is thrown down from its solutions in metallic forms, and is therefore probably more slowly precipitated, and consequently secondary enrichment extends much deeper.

The Monte Cristo district of Washington, described by Spurr, gives a most excellent illustration of the principle of decreasing richness with depth. In that district there is a definite arrangement of the ores vertically, which arrangement has a very marked relation to the topography. The order downward is, (1) oxidized ores; (2) upper sulphide belt, eharacterized by galena, blende, and chalcopyrite, carrying the highest valnes in gold and silver and extending not more than 100 meters below the surface; (3) intermediate sulphide zone, having reduced amounts of galena, blende, and chalcopyrite, and with these realgar; arsenopyrite, pyrite, and pyrrhotite; and (4) lower sulphide zone, low in gold and silver, and consisting of pyrite, pyrrhotite, and arsenopyrite, and in which galena and blende are subordinate or absent. ${ }^{b}$ In the upper sulphide belt the "galena

" Ransome, F. L., A report on the economic geology of the Silverton quarlrangle, Colorado: Bull. U. S. Geol. Survey No. 182, 1901, pp. 111-112.

${ }_{b}^{b}$ Spurr, J. E., The ore deposits of Monte Cristo, Washington: Twenty-second Aun. Rept. U. S. Geol. Survey, pt. 2, 1901, pp. 841-857. 
zone is shallowest and is overlapped by the blende zone, and this by the chalcopyrite zone." ${ }^{a}$ Thus in this upper belt there is a definite order of prominence of these three minerals-galena, blende, and chalcopyrite.

In addition to these specific instances of the production of a rich upper belt, some general statements have been made which need to be referred to. One of these is made by Douglas in reference to sulphuret mines as a whole. Says he, in the conclusion of his discussion as to the copper resources of the United States, with reference to the various Appalachian deposits, "Like all sulphuret mines, they became poorer as depth was attained." $"$

With the exception of the San Juan and Monte Cristo districts, the above illustrations of secondary enrichment and diminution of richness with depth are the same as originally published by me. $\quad$ Recent articles by other authors have given many other instances of secondary enrichment which fall in line with the above illustrations, but which in this treatment of principles need not be repeated. Some of the more notable contributions upon this subject are those by Emmons, ${ }^{d}$ Weed, ${ }^{e}$ Ransome ${ }^{f}$ and Bain. ${ }^{g}$

Upon the hypothesis that the rich ores of the upper parts of deposits usually result from secondary action of descending solutions upon material no richer than the deeper parts of the deposits, the extent and richness of such deposits may give an approximate idea of the minimun denudation which a district has suffered. For example, at Ducktown, Temn., to produce the rich oxidized products of copper above the level of ground water, and the very rich sulphides at and near it, from the lean, cupriferous pyrrhotite below, which bears about 2 per cent of metallic copper,

$a$ Spurr, cit., p. 841

${ }^{b}$ Douglas, James, The copper resources of the United States: Trans. Am. Inst. Min. Eng., vol. 19, 1891, p. 694 .

c Van Hise, C. R., Some principles controlling the deposition of ores: Trans. Am. Inst. Min. Eng., vol. 30, 1901, PP. 128-134.

d Emmons, S. F., Secondary enrichment of ore deposits: Trans. Am. Inst. Min. Eng., vol. 30, 1901, pp. 177-217.

$e$ Weer, W. H., Enrichment of mineral veins by later metallic sulphides: Bull. Geol. Soc. Am., vol. 11, 1900, pp. 179-206.

$f$ Ransome, F. L., Ore deposits of the Rico Mountains, Colorado: Twenty-second Ann. Rept. U.S. Geol. Survey, pt. 2, 1901, pp. 229-397. Report on the economic geology of the Silverton quadrangle, Colorado; Bull. U.S. Geol. Survey No. 182, 1901, pp. 265.

$g$ Bain, H. F., with Van Hise, C. R., and Adams, Geo. I., Preliminary report on the lead and zinc deposits of the Ozark region: Twenty-second Ann. Rept. U. S. Geol. Survey, pt. 2, 1901, pp. 23-227. 
there must have concentrated in the shallow deposits at the surface an amount of copper which was originally distributed through a vertical distance of humdreds of meters. At Butte, Mont., the prodnction of the rich sulphide deposits characteristic of that district must also have required enormous denudation. In this case where the belt of weathering is depleted in copper, it may be supposed that during the secondary concentration the major part of the copper originally distributed through a great rertical distance was carried downward and reprecipitated; and that the losses in consequence of denudation were not great. But in other cases, where geological studies show that great denndation must have taken place, the amount of enriched material is comparatively small. For example, in the Sierra Nevada gold belt, the enriched product has a thickness of not more than 30 meters and is not more than five times as rich upon the average as the sulphides of the first concentration below. It would therefore follow that the gold distributed through 150 meters of the first concentration would be sufficient to account for all of the enriched product, but Lindgren places the extent of the denndation in this district as about 3,000 meters. Hence in this case but a small part of the gold has been taken into solution by descending waters and transported below and reprecipitater. It therefore follows that the larger part of the gold produced by the original concentration has been carried away from the fissures by the processes of denudation, and correlative with these great losses to the veins are the placer deposits of California. While the material was mainly carried away from the veins, it was in great measure segregated in the beds of streams, past and present, from which deposits it is being extracted.

These instances of the relation of depth of denudation and amount of enriched deposits, where the evidence seems to be particularly clear, are mentioned with a view of suggesting an interesting line of study with reference to ore deposits rather than with an idea of giving exact or comprehensive data upon the subject.

GENERAL STATEMENTS.

It is believed to be a very general rule, if a long enough scale be used, that ore deposits diminish in richness with depth. But it is well known that above the level of ground water the valuable materials may be almost wholly dissolver and deposited at or below the level of ground water 
by the reactions above stated, as at Ducktown, Tenn., or partly dissolved and transported below, as at Butte, Mont. Thus for a certain depth the ores may increase in richness. This exception, however, does not affect the common rule as to diminution of richness with increasing depth.

Penrose, ${ }^{a}$ in 1894, in discussing the superficial alteration of ore deposits, says:

As a result of these various changes, certain materials are sometimes leached from the upper parts of ore deposits, which have become porous by alteration, and carried down to the less pervious unaltered parts. Here they are precipitated by meeting other solutions, or in other ways, and hence the richest bodies of ore in a deposit often occur between the overlying altered part and the underlying unaltered part. This is not always the case, but it is true of some copper, silver, iron, and other deposits. ${ }^{b}$

De Launay, in 1897 , emphasizes the frequent occurrence near the surface of rich deposits, which in some cases are oxidized products and in others are sulphides. He explains the richness of the deposits by the abstraction of more soluble material. This frequently results, he thinks, in transforming a low-grade product into a rich ore. By this process a poor sulphide may be changed to a rich sulphide, as, for instance, cupriferous pyrites or chalcopyrite may be transformed to covellite or chalcocite by abstraction of iron sulphide. It is a natural deduction from de Launay's explanation $^{d}$ that the volume of the material is decreased, although he does not make this point.

De Lamay further emphasized the point that the metallic material of veins may have been repeatedly transferred from one place to another, and suggests that a part of the material now found in veins may have been transferred from vein material which was once above the present surface of denudation.

Le Conte ${ }^{e}$ suggested that the rich belt may be explained by supposing that precipitation by ascending waters does not occur at great depth, because the solutions do not get saturated until comparatively near the level of underground water. But it is to be remembered that the upper

a Penrose, R. A. F., jr., The superficial alteration of ore deposits: Jour. Geol., vol. 2, 1894, pp. $288-317$.

7 Penrose, cit. p. 294.

o Launay, M. I. re, Contrilutions il l'étude des gites métallifères: Annales des Mines, 9th ser., vol. 12,1897 , pp. $151-152$.

d Launay, de cit. p. 194.

Le Conte, Jos., On the genesis of metalliferous veins: Am. Jour. Sci., 3d series, vol. 26, 1883, p. 12. 
part of a fissure receives abundant lateral waters which have been transported a comparatively short distance under conditions of low pressure and temperature; whereas the solutions lower down have taken a longer journey under conditions of high pressure and temperature. If Le Conte's explanation be satisfactory, one would expect the most insoluble constituent to be precipitated at the greatest depth. In the case of the lead-zinc-iron deposits this would make the galena abundant at depth, the sphalerite abundant at a higher level, and the iron sulphide the dominating constitnent at the highest levels. In the case of the copper-iron deposits the rich sulphides of copper would be in the lower levels and the cupriferous pyrites at the higher levels.

From the foregoing it is apparent that there has been a general understanding that a rich upper belt has been produced in many ore deposits. My explanation of a rich upper belt is, mainly, that oxidized soluble compounds are produced in the belt of weathering, and that these in situ or lower down react upon the lean sulphides and tellurides. In this way a rich belt is formed. Later, in consequence of denudation, these rich sulphides and tellurides pass into the belt of weathering. Here they are again exposed to the oxidizing forces, are largely transformed in situ to oxides, carbonates, etc., and a belt of rich oxidized products is formed above the ground water. In part, when oxidized, the materials are taken into solution, again transported downward, and again react upon the sulphides and tellurides. In arid regions, where the amount of downward-moving water is small, the oxidized products formed from the rich sulphides and tellurides are likely to remain in large part in situ; but in humid regions, where water is abundant, the metals, after oxidization, are in large measure carried downward and again react upon the sulphides and tellurides below and further broaden and emrich this belt. Thus, under different climatic conditions, we may have a rich oxidized zone, a rich sulphide and telluride zone, or both, in varying. proportion.

It is notable that the vertical distribution of the sulphirles in the rich zone is precisely that which should be expected from the affinity of the metals for sulphur In the lead-zinc-iron districts the galena is fonnd at the highest horizon, lower down is the sphalerite, and still lower the iron sulphide. In the copper-iron lodes the high-grade copper sulphides, chalcocite and bornite, are at higher levels; lower these are intermixed 
with chalcopyrite; still lower the chalcopyrite is mixed with pyrite; and in the deepest levels the pyrite is dominant. Apparently this vertical arrangement of the sulphides can not possibly be explained by precipitation by ascending waters. From such waters we would expect exactly the reverse distribution.

While the reaction between the oxidized products and the snlphides has been strongly emphasized, because it is believed to be the most fundamental of the canses producing a rich upper belt, it is understood that other factors may also help in this process. As already pointed out, reduction and precipitation of the metals of descending solutions may take place through the agency of organic matter or other reducing materials contained in the rocks, or by meeting ascending solutions carrying precipitating agents. Near the surface more than an average amount of original precipitates from ascending solntions is a possibility in some cases. (See p. 1077.)

Concluding, it appears to me that the existence of a rich upper belt in many deposits, and the frequent diminution of the ores in richness in passing from the surface to some distance below the level of ground water, can not be the work of ascending or descending waters alone, but is due to ascending and descending waters combined. Ascending waters produce a first concentration. A second concentration by descending waters produces the rich deposits. These rich products are found in the few meters or few hundred meters of the onter crust of the earth. When it is remembered that the greater part of the ores which have yet to be abstracted from the earth comes from the first 500 or 700 meters, and when it is further considered that the effect of descending waters may be felt to these depths, it becomes evident that the process of second concentration by descending waters is a very important one indeed, so far as the economic value of ore deposits is concerned. Indeed, as a result of it there is concentrated in the extreme outer shell of the crust of the earth a large portion of the products which during the first concentration may in many cases have been distributed over 1,500 or 3,000 meters or more, but which have now been largely removed by erosion. We therefore conclude that for a large class of ore deposits a second concentration by descending waters can not be said to be one whit less important in the genesis of ores than a first concentration by ascending waters. 
It follows from the foregoing that one of the most important classes of ore deposits is that produced by the joint action of ascending and descending waters. First comes the action of the downward-moving, lateral-moving waters, mainly of meteoric origin, which take into solution metalliferous material. In regions of recent volcanism these waters may be joined by subordinate amounts of water exuded during the crystallization of magmas; and such waters may be rich in metallic material. The waters, after collecting metals from any or all of the rocks with which they come into contact, are converged into trunk channels and there, while ascending, may deposit ore of the first concentration. During and after this first concentration many of the ore deposits which are worked by man have undergone a second concentration not less important than the first as a result of descending lateral-moving waters. In some cases a concentration by descending lateral-moving waters alone is sufficient to explain ore deposits. It, therefore, appears more clearly than heretofore that an adequate view of ore deposits must not be a descending-water theory, a lateral secreting water theory, or an ascending-water theory alone. The descending, lateral-moving, and ascending waters alike are driven mainly by gravity. Each performs its own work.

SUBCLASS 3. ORES PRECIPITATED FROM DESCENDING AQUEOUS SOLUTIONS.

For the sake of simplicity and continuity of exposition, the effects produced by descending waters have been applied to deposits which have been first concentrated by ascending waters. However, it is perfectly clear that a concentration by descending waters alone may be adequate to produce ore deposits. The more important ores which are produced by descending waters alone are those of iron and manganese. The ores of these metals thus formed are chiefly oxides, and so far as iron and manganese are concerned are largely hydrated oxides.

IRON ORES.

The ores of iron, unlike those of the other metals, occur in such large masses that they properly belong with the rocks, hence their general development has been already considerered in Chapters IX and XI. It remains here only to summarize the special factors which have been of consequence in their segregation. Of the ore deposits which it has been 
shown are produced by descending waters alone, those of the Lake Superior region are unquestionably of the greatest importance.

In another place I have fully discussed the segregation of these iron-ore eleposits. " Without exception the great iron-ore deposits of the Lake Superior region are found resting upon impervious formations. In the great majority of cases these impervious formations are in pitching troughs. (See Pl. XIII.) Thus the trunk channels of circulation are formed. For the most part these troughs are somewhat close and have steep pitches, but in the Mesabi district the troughs are less definite in form and have a very shallow pitch. The impervious basement for an iron ore deposit may be an impervious sediment such as a slate, may be an igneous rock, or a combination of the two. The essential thing is that the basement shall be relatively impervious to water as compared with the iron-bearing formation in which the ores occur. The source from which the iron oxide is obtained is the original rock of the iron-bearing formation, either siderite or hydrous ferrous silicate, greenalite. As the water starts on its downward journey the oxygen it contains is exhausted in the oxilation of the iron carbonate or ferrous silicate, thus producing the ferruginous slates and cherts, at the same time liberating the carbon dioxide of the carbonates. The waters from which the oxygen is exhansted and which are enriched in carbon dioxide are now able to take the ferrous carbonate and hydrated ferrous silicate into solution. Where impervious basements exist in pitching troughs, the downward-moving waters are deflected toward these, and thus are converged into such troughs. Other waters more dirertly from the surface which have not come into contact with iron carbonate and iron silicate, and therefore bear oxygen, are also converged into the troughs. The mingling of the two classes of waters in the troughs results in the precipitation of the hydrated hematite and limonite, the reaction in the case of the iron carbonate being:

$$
2 \mathrm{FeCO}_{3}+\mathrm{nH}_{2} \mathrm{O}+\mathrm{O}=\mathrm{Fe}_{2} \mathrm{O}_{3} \cdot \mathrm{nH}_{2} \mathrm{O}+2 \mathrm{CO}_{2}
$$

At the same time the abundant waters converged in the trunk channels dissolve the silica, and thus the ores are depleted in that compound. So far as there was iron carbonate or iron silicate in the pitching troughs the ferrous oxide is largely oxidized in situ. Thus, the ore depusits are the

a Van Hise, C. R., The iron-ore deposits of the Lake Superior region: Twenty-first Ann. Rept. U.S. Geol. Survey, pt. 3, 1901, pp. 305-434. 


\section{PLATE XIII.}




\section{PLATE XIII.}

\section{IRON ORE DEPOSITS IN PITCHING TROUGHS.}

(Both ore exploited and ore now in mine are represented as ore, since the purpose of this plate is to show the manner of the development of the ore rather than the present stage of exploitation.)

Fig. 1. Vertical north-sonth cross section of Chandler mine, showing relations of the ore deposit to the soap rock, Ely greenstone, and ore-bearing formation. The iron ore is in a broad U-shaped trough, bottomed by soapstone or paint rock which grades down into greenstone. It is capped by the ore-formation material. At the place where the cross section is made the ore does not extend to the surface along either limb. Therefore, at the particular place where this cross section exists, although there is a very large ore deposit below the surface, at the surtace the only rocks which are found are the greenstone, soapstone and iron-bearing formation.

Scale: 1 inch equals 250 feet.

Fig. 2. Vertical east-west longitndinal section of Chandler mine, showing the same relations as fig. 1. The figure very well illustrates how the ore body increases in size from the surface. Where the ore reaches thedrift its area is small; and this great ore deposit, which extends eastriard, where it constitutes the Pioneer mine, is below a heary capping of the ore-bearing formation.

Scale: 1 inch equals 250 feet.

1196 

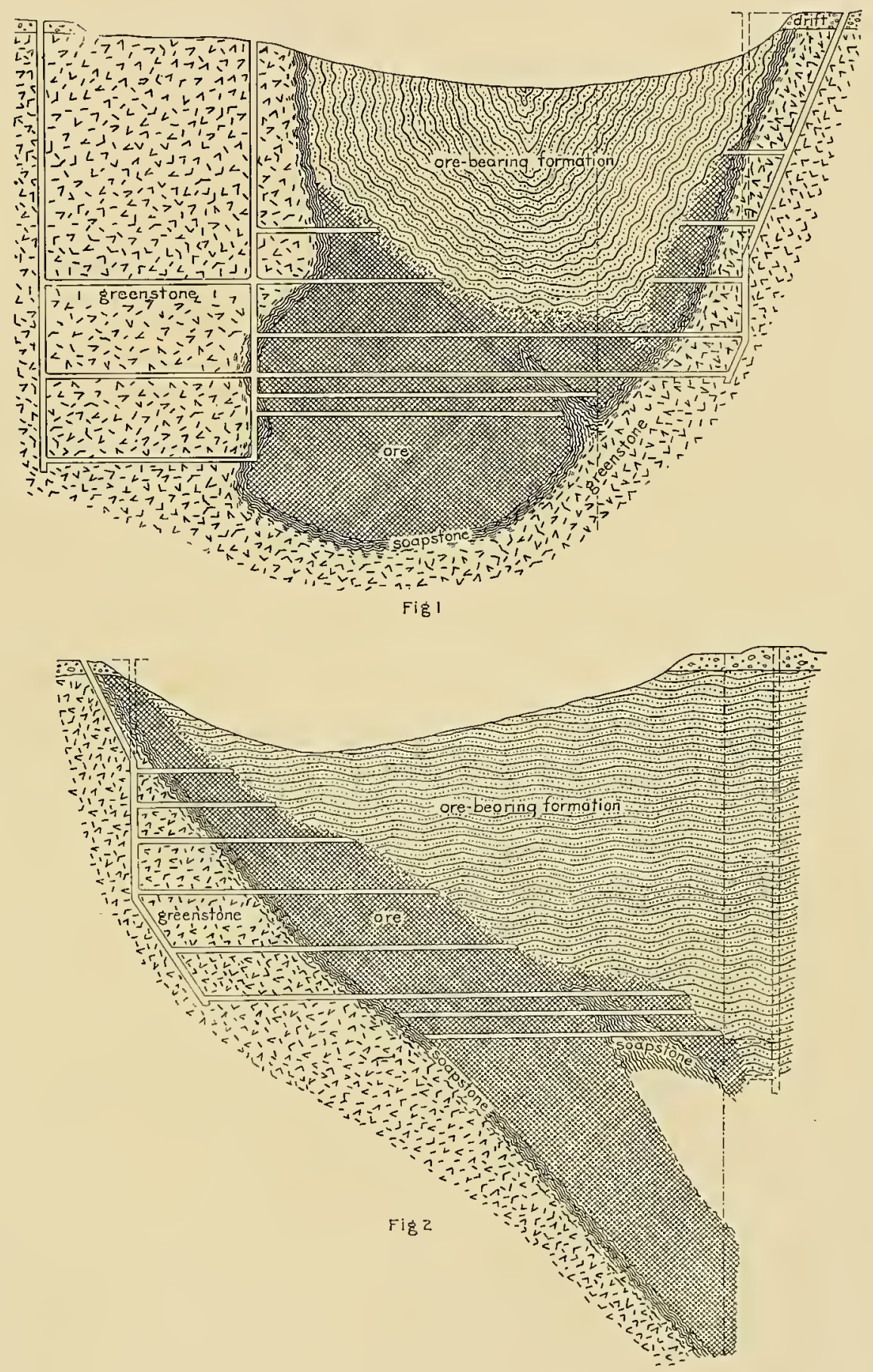

IRON-ORE DEPOSITS IN PITCHING TROUGHS. 

result largely of the transportation of iron carbonate to the pitching troughs, the iron being there precipitated, and partly of oxidation of ferrons carbonate or silicate in place. Simultaneously with these processes the silica is rlissolved and abstracted.

It is to be noted that the precipitation of iron ores by the above process is due essentially to the mingling of solutions from two different sources. The solutions from one source have taken a longer journey, or else have passed through rocks more capable of abstracting oxygen, so that they early acquired the properties of deep solutions-an excess of carbonic acid and an absence of oxygen. Under such circumstances they carry iron carbonate precisely as do the deep solutions of the first concentration in ores produced by ascending waters. The solutions from the other source pass through material in which the iron has already been oxidized to the ferric form, and therefore do not have the oxygen extracted. The course of this water is not necessarily shorter than that of the other waters, but upon the average is likely to be so. When the two solutions come together the iron oxide is precipitated, in consequence of the mingling of solutions. While for the Lake Superior iron ores apparently the solutions from both sources were descending to the point where they became mingled, in iron-ore deposits in other regions it may be found that the precipitation of the iron oxide was dne to the mingling of ascending solutions bearing iron carbonate with descending solutions bearing oxygen.

For instance, at certain localities the iron ores are magnetite instead of hydrated hematite. In Chapter IX the various ways in which magnetite may be produced are discussed, but it may be suggested that magnetites may be due to the direct precipitation of ascending solutions bearing iron carbonate and descending solutions bearing an insufficient amount of oxygen for transformation to the ferric oxide, the reaction being as follows: $3 \mathrm{FeCO}_{3}+\mathrm{O}=\mathrm{Fe}_{3} \mathrm{O}_{4}+3 \mathrm{CO}_{2}$.

Perhaps the most notable magnetite deposit in the United States is that of the Cornwall mine in Pennsylvania. Here the ore is a replacement of Silurian limestone, and rests upon a trap dike as an impervious basement. The Mesozoic rocks are fanlted against the limestone and ore. A plausible suggestion as to the origin of this deposit is that ascending waters bearing iron carbonate, moving up along the fault and through the limestone, met 
descending waters bearing oxygen and following the impervious basement, and as the oxygen was not in sufficient quantity to oxidize the iron to the ferric oxide it was thrown down as magnetite.

It has been pointed out (pp. 845-846), that magnetite may be produced in two other ways-by the reaction of siderite and pyrite upon each other, or by the partial oxidation of pyrite or pyrrhotite. In the Cornwall deposits ${ }^{a}$ sulphur is a constant associate in small percentage except at the surface, and this fact suggests the possibility that the reactions between iron carbonate and iron sulphide or between iron sulphide and oxygen may have been also instrumental in the production of the magnetite; but the amount of residual sulphur is so small that the theory of the derivation of the deposit in large measure from pyrite has seanty support.

'To what extent the principles worked out in reference to the Lake Superior ores are applicable to the iron-ore deposits of other parts of the world it is yet too early to say, but, as just suggested, the descriptions of the Cornwall deposit show that it has many features in common with the ores of the Lake Superior region. Many of the Silurian deposits of the Appalachian region are at contacts of limestones with shale or slate. In some places these latter are certainly in such positions as to furnish impervious basements, and therefore the ores present many features analogous to. those of the Lake Superior region. But a much more extended study of the iron-ore deposits of other regions must be made before any generalization can be made with reference to them.

MANGANESE ORES.

The manganese deposits, like the iron-ore deposits, are very largely secondary segregations by descending waters. Indeed, iron and manganese are very closely associated. Many of the iron-ore deposits are manganiferous, and some of them sufficiently so locally that they also become ores of manganese. For instance, in the Gogebic district of Michigan a small amount of the iron ore was sufficiently manganiferous to be sold as a manganese ore rather than an iron ore. Manganese ores are always associated with iron oxide. The amount of iron is variable, running from a smal! percentage to an amount considerably in excess of the manganese.

aLesley, J. P., and d'Invilliers, E. I., Report on the Comwall iron-ore mines, Lebanon County: Ann. Rept. Geol. Survey Pennsylvania for 1855 , p1. 533-534. 
Manganese is present in the original igneous rocks in very much smaller quantity than iron, and therefore the manganese deposits are much smallcr than those of iron; but so far as can be made ont, the segregation of manganese and iron are strictly parallel processes. Thus in the secondary rocks manganese is found only as traces in the sandstones and shales, but in the limestones-carbonate rocks-it is more than half as abundant as in the original rocks. Since the limestones are so small in mass, only a small fraction of the manganese of the original rocks is in the limestones. Apparently the great mass of the manganese of the original rocks has been segregated in the ores of manganese and iron and in the iron formations.

In view of all the foregoing facts it is thought to be extremely probable that the manganese is largely transported as a carbonate from the original rocks to lagoons, and is there precipitated as an oxide. By this process bog ores of manganese are produced just as are the bog limonites. But to a large extent the manganese oxide is reduced to the manganous form by the organic matter, reunites with carbon dioxide, forming carbonate, and in this form is built up into carbonate formations. From such carbonate formations it is segregated by underground solutions which have different sources and mingle in the trunk channels. Some solutions bear the manganese carbonate and others the oxygen. When these two meet the manganese is precipitated as hydrated oxide according to the following reaction:

$$
\mathrm{InCO}_{3}+\mathrm{O}+\mathrm{nH}_{2} \mathrm{O}=\mathrm{HnO}_{2} \cdot \mathrm{nH}_{2} \mathrm{O}+\mathrm{CO}_{2} \text {. }
$$

It is yet too early to state to what extent the manganese ores have been concentrated on impervious basements in pitching troughs.

\section{SPECIAL FACTORS AFFECTING THE CONCENTRATION OF ORES.}

Thus far the discussion of ores deposited from aqueous solutions has not taken into account a number of the special factors which affect the concentration of ores. The general discussion may need great modification to adapt it to a particular district. To illustrate my meaning, it may be well to consider some of the additional factors affecting the deposition of ores, and to point out the more obvious possible modifications of the general theory which may result from them. There will be briefly considered the effect of (1) variations in porosity and structure, (2) the character of the topography, and (3) physical revolutions. 
TARIATIONS IN POROSITY AND STRUCTURE.

It has been fully explained that a rigorous circulation is essentral for the production of aqueous ore deposits. It has been pointed out that in order to produce an ore cleposit the amount of water which must flow through the openings is many thousands of times the volume of the ores deposited. Also it has been explained that waters do not produce channels. In order to have a vigorous circulation original and continuous channels must exist. Thus initial porosity in rocks is an essential factor in the development of ore deposits. In the foregoing discussion the existence of trunk channels has been recognized, but otherwise it has been assumed that the rocks were equally porous in all directions. As a matter of fact, the rocks range between the widest extremes in porosity; from those in which the openings are subcapillary and which are substantially impervious to those which are as open as a sieve in all directions.

The different masses of sedimentary rocks, igneous rocks (especially the lavas), and metamorphosed equivalents of either sedimentary or igneous rocks may differ in porosity. ${ }^{a}$ The contacts of rocks of different kinds frequently furnish trunk channels for circulating water. Bedding partings produced by shearing stresses during deformation furnish sheet channels parallel to the strata, or openings on the anticlines or synclines. Some strata when deformed may yield by fracture, furnishing channels for water circulation, while interlaminated strata may yield by flowage, thns remaining relatively impervious. These various irregularities may combine in different ways.

All irregularities in porosity and structure require modification of the simple general statements of the present paper (see pp. 129-156, 571-589) concerning the character of underground circulation and the concentration of ore deposits. At some time it may be possible to divide the modifications of the general circulation due to variation of porosity and structure into classes, but at present this can not be done. The modifications of the general circulation which oceur in many districts must first be studied and described individually, after which generalizations may possibly be made. At present some statements may be made in reference to certain modifications of the underground circulation.

a Compare Emmons, Structural relations of ore deposits: Trans. Am. Inst. Min. Eng., vol. 16, 1888, pp. $804-839$. 
DISTRIBLTION AND SIZE OF OPENINGS.

From the foregoing general statement it is clear that one of the essential conditions for the production of large ore deposits is that openings should be of adequate size. As will be seen, these openings may be original or they may be largely secondary. A close analysis of the mamer in which the waters work shows that it is not of advantage in ore deposition to have equal porosity in all directions. Were the rocks equally porous in every direction there would be no reason for the concentration of the water in trunk channels, and therefore the conditions which have been discussed as essential for the mingling of solutions of different kinds would not exist. Oftentimes the essential condition is to have considerable masses of rocks nomporous or moderately porous adjacent to or associated with other areas which are very porous. Oftentimes where the porous belts are too numerous there is a segregation of a small amount of ore in them all, and not an adequate segregation in any one.

The most frequent combination of porous and relatively nonporous rocks favorable to the production of ore deposits is to have certain belts with openings of adequate size associated with more extensive areas in which the openings are much smaller, although they may be equally continuons. As illustrations of such combinations we may have layers of sandstene or conglomerate between igneous rocks or shale. 'The large openings may be furnished by fault fissures.

For many reasons trunk channels may vary greatly in size and contimuity. For instance, fault fissures, in consequence of the irregularity of the fractures and the displacements, may range in width from great rooms to mere seams. The effect of the dip upon fissures is of great importance. Where the dips are vertical or nearly so, the veins may be wide; whereas, where the dips are flat, the veins may be relatively narrow. This is a natural consequence of the effect of gravity. The more inclined the veins the more forcibly does gravity pull down the overhanging wall, and thus tend to close the openings. This association of wide veins with steep dips, and narrow veins with low dips, is beautifully illustrated at the Smuggler Union mine, of southwestern Colorado.

HON XLV11-04-76 
COMPLEXITY OF OPENINGS.

In the general discussion an ore deposit has been spoken of as if it were a single continuous mass formed in a large opening. An ore deposit in a single large opening is exceptional. Ore deposits show all gradations of openings from large single ones to those of 'an extraordinarily complex character. A trunk chamnel may be a set of distributive faults; a group of parallel or intersecting sets of joint openings; the minute parallel openings of fissility; a group of openings along bedding planes; the shrinkage openings formed within or aloug the border's of cooling magma; the openings in an autoclastic rock or reibungs breccia; the multitude of openings of a sandstone or a conglomerate; or the very minute openings between the mineral particles of a limestone, schist, gneiss, - or other dense rocks.

Trunk channels may vary from vertical to nearly horizontal attitudes. Ore deposits ordinarily have important vertical components, although they may be found in nearly horizontal positions. In the latter case the trunk cliannels forming the deposits probably have vertical components somewhere else.

It is hardly necessary to give illustrations of ore deposits for each of these complex conditions, but, as very excellent instances of veins of a very composite character may be mentioned the Cripple Creek deposits ${ }^{\alpha}$ and the gold-quartz veins of Nevada City and Grass Valley, Cal. ${ }^{b}$ The essential point, so far as the discussion of the foregoing pages is concernerl, is that ore deposits commonly occur at places where there are trunk channels for ascending or descending waters, or both. In order that metalliferous material shall be brought to a place and deposited in large quantity, there must be long-continued circulation. It matters not whether a truuk channel is a single passage or is composed of an indefinite number of minor passages, the principles given on the previous pages are applicable to the deposition of ores in such trunk channels.

In various regions the conditions are so exceedingly complex that ore deposits close together may differ greatly in their mineral content. This is the best evidence that, notwithstanding their continuity, the under-

a Penrose, R. A. F., jr., Mining geology of the Cripple Creek district, Colo.: Sixteenth Ann. Rept. U. S. Geol. Surrey, pt. 2, 1895, pp. 137-153.

$b$ Lindgren, Waldemar, The gold-quartz veins of Nevada City and Grass Valley, California: Seventeenth Ann. Rept. U. S. Geol. Survey, pt. 2, 1896, pp. 158-160, 259. 
ground systems of water circulation have been, if not independent, at least partly so. This is well illustrated by the ore deposits of Butte, Mont. Apparently the metallic contents of the individual feeding streams and even the trunk channels were very different within short distances. There are two main zones of mineralization. The more important product of one of these mineral zones is silver sulphide, which is associated with sulphides of lead, zine, and iron, and with silicate of manganese. 'The chief product of the other mineral zone is copper, which carries silver in important amounts. $^{a}$

PREEXISTING CHANNELS AND REPLACEMENTS.

When it is understood that ore deposits from aqueous solutions ordinarily form in trunk channels the question as to whether ores are deposited in preexisting openings or are replacements is easily answered, as a general proposition. It has been shown that such channels are not originally formed by aqueous solutions. (See pp. 1007-1008.) Original channels for underground circulation are primarily due to the structures of rocks or to the effects of deformation. It therefore follows that ores are, to some extent at least, deposited in preexisting openings. However, the conditions farning vigorous circulation are also those causing reactions on the wall rocks. It has been fully explained that solution and deposition are commonly simultaneous processes. Wherever there is a trunk channel it is certain that the walls of the openings are dissolved to some extent, and at the same time, or subsequently, metalliferous minerals are precipitated. Indeed, either enlargement by solution and subsequent precipitation of ore, or synchronous solution and precipitation by which the wall rocks are replaced in rarious degrees, molecule by molecule, by the ore, or both together, are almost universal phenomena.

I therefore believe that the large majority of ore deposits, if not all, are partly deposited in preexisting openings and are partly replacements of the wall rocks. However, in some cases the filling of the preexisting cavities is more important, and in other cases substitution for the wall rocks is the dominant process.

Other things being equal, ore deposits which are largely in preexisting cavities are more likely to occur in strong refractory rocks, such as quartzite,

a Emmons, S. F., Notes on the geology of Butte, Montana: Trans. Am. Inst. Min. Eng., rol. 16, 1888, p. 54 . 
granite, and porphyry; and ore deposits which are largely replacements are more likely to be found in easily soluble rocks, such as limestone. The gold-quartz veins of California give an excellent illustration of the deposition of ores in preexisting cavities in refractory rocks, such as siliceous argillite, diabase, diorite, and granodiorite. ${ }^{a}$ This case is all the more interesting since the wall rock itself is greatly modified, and has lost and gained various elements. The San Juan district of southwestern Colorado furnishes another excellent illustration of veins deposited in openings of hard, refractory rocks. Here great continnous lodes in preexisting openings are known to extend for a rertical distance of 1,000 meters or more; but even here there is very frequently complex fracturing or even brecciation, as a result of which the veins form either a series of sheets separated by layers of wall rock or breccia cemented by vein material. Ore deposits which are largely replacements in easily soluble rocks are well illustrated by the silver-lead deposits of Eureka, Nev., ${ }^{b}$ and Leadville ${ }^{c}$ and $A$ spen, ${ }^{d}$ Colo.

Replacements are likely to be important also in proportion as the trunk chamnels are complex rather than simple. This follows from the law of mass action. In proportion as a trunk channel is complex, the surface of action upon the wall rock for a given quantity of solution is large. As conspicuons examples where there are large surfaces of action may be mentioned sandstones and conglomerates and the reibungs breccias, or crushed rocks along fanlt zones. Where the trunk channels are very complex, the rocks, even if refractory, may be replaced to a considerable extent by the metalliferous ores. A conspicuous instance of this in a sedimentary rock is that of the copper conglomerate deposits of Lake Superior, where many grains, pebbles, and bowlders of porphyry are partly or wholly replaced by metallic copper. On some bowlders the metallic copper occurs as partial or complete skulls surrounding the fragments of porphyry; in others these skulls are thicker, and in still others the entire masses of the bowlders, as described by Pumpelly, ${ }^{e}$ are fully replaced by

a Lindgren, cit., pp. 172-257, 259, 261; also pp. 146-157.

$b$ Curtis, J. S., Silver-lead deposits of Eureka, Nev.: Mon. U. S. Geol. Survey, rol. 7, 1884, pp. 93-106.

c Emmons, S. F., Geology and mining industry of Leadville: Mon. U. S. Geol. Survey, rol. 12, 1886, pp. 565-569.

a Spurr, J. E., Geology of the Aspen mining district, Colorado: Mon. U. S. Geol. Survey, vol. 31, 1898, 1p. 231-23t.

e Pumpelly, R., Copper district: Geol. of Michigan, vol. 1, pt. 2, 1873, pp. 3i-38. Pumpelly, R., The paragenesis and derivation of copper and its associates on Lake Superior: Am. Jour. Sci., 3d series, vol. 2,1871 , pp. 348-355. 
the metallic copper. While the conglomerate deposits of Lake Superior are in part replacements, they also are in large part fillings of preexisting cavities between the clastic particles. An excellent example of replacement in igneous rocks where there is wonderfully complex distributive faulting and folding, and thus a large surface of contact for substitution, is furnished by the Cripple Creek district, in which, according to Penrose, ${ }^{a}$ ore mainly occurs replacing and blending into various igneous rocks.

By substitution a rock may be completely replaced by ore. This is particularly likely to occur where the rock is uniform in structure and composition, as limestone or dolomite. Where, on the contrary, the rock is of complex composition, such as granite or porpliyry, or where there are different kinds of rock present, as, for instance, diorite and granite, the replacement is usually largely selective. This selective replacement may apply to the mass of the wall rock, to the individual fragments of it, to clastic fragments of sandstones or conglomerate, and to the different constituent minerals in a single fragment. The particular minerals or masses which are most soluble in the solutions present are most rapidly dissolved. Where the wall rock varies greatly in the solubility of its minerals the selective replacement of the country rock may extend for some distance from the central deposits. The readily soluble minerals are dissolved, and in place of them are precipitated the metalliferous minerals. This process is ordinarily called impregnation. Selective replacement of this kind is well illustrated by the Butte, Mont., granite, in which "the basic constituents of the granite are naturally attacked first, then the feldspars, and finally the quartz itself may be removed, so that in some parts there are found large masses composerl entirely of metallic minerals." ${ }^{b}$

In regions of heterogeneous rocks the frequent occurrence of main masses of the ore deposits in the more soluble rocks is due in part to its greater solubility. For instance, where limestone occurs in intimate association with sandstone, with quartzite, with diorite, with trachyte, with porphyry, with granite, or with alnost any other rock, and ore deposits are found, the ore is likely to be largely in the limestone, partly becanse it is

a Penrose, R. A. F., jr., The mining geology of Cripple Creek, Colorado: Sirteenth Ann. Rept. U. S. Geol. Survey, pt. 2, 1895, pp. 140-141, 144-146, 161-162.

${ }^{b}$ Emmons, S. F., Notes on the geology of Butte, ALontana: Trans. Am. Inst. Min. Eng., vol. 16, 1888 , p. 57. 
more soluble than the other rocks. ${ }^{a}$ But other factors enter into the matter. It has already been explained that country rock, especially limestone, may furnish solutions which react on the mineral-bearing solntions and thus cause precipitation or furnish the metallic material. (See pp. 1086-1087.) Furthermore, where limestone and stronger rocks are deformed together, the limestone, having less strength, is more likely to be crushed and broken in a complex mamner and thus furnish trunk channels for cireulation.

Change in the level of ground water may be an important factor in opening up rooms in which ores may be deposited later. It is explained (pp. 409-411, 565-566) that for various reasons the level of ground water may vary greatly, and that above it large openings, such as caves, are formed. (See pp. 484-487.) If, later, the level of ground water for any reason rises, these openings pass into the belt of cementation and in them large ore bodies, including sulphides, may be deposited. This may be the history of the great cave-like openings, lined with gigantic geodal crystals, which are found in the lead and zinc districts of Missouri, and which were below the level of ground water before punping was begun. While the larger caves apparently have not been especially favorable places for ore deposition, in some of the smaller ones ores have been deposited. Probably this history applies to the Butte district. Emmons ${ }^{b}$ says that for this district the level of ground water was once very much lower than now, possibly as much as 300 to 600 meters. Donbtless much of the solution occurred when the water was at a lower level. Later, when the ground-water level was raised, the openings formed by solution were utilized by the ore precipitated from descending waters transporting material from higher levels. This process may have keen important in the development of the large sulphide bodies now below the level of ground water.

iil conclusion, I hold that ores deposited from aqueous solutions form where there existed original trunk channels of circulation. Ore deposits

a Wendt, Arthur F., The copper ores of the Southwest: Trans. Am. Inst. Min. Eng., vol. 15, 1887, pp. 25-77. Curtis, J. S., Silver-lead deposits of Eureka, Nevada: Mon. U. S. Geol. Surrey, rol. 7, 188t, pl. 6t-79. Emmons, S. F., Geology and mining industry of Leadville: Mon. U. S. Geol. Survey, vol. 12 , p. $540-543$.

$b$ Emmons, S. F., The secondary enrichment of ore deposits: Genesis of ore deposits, Am. Inst. Min. Eng., 2d ed., 1902, pp. 444 445. See also Weed, W. H., The enrichment of gold and silver veins: loc. cit., p. 497. 
formed along trunk eliannels occur commonly, if not universally, to some extent in preexisting openings and to some extent as a substitution for the wall rock. Where the trunk channels are simple and the rocks refractory, the ore deposits may be largely in preexisting openings. Where the trunk channels are complex and the rocks soluble, the ore deposits to a large extent are likely to be replacements.

IMPERVIOUS STRATA AT VARIOUS DEPTHS.

Slichter's theoretical investigations on the motions of ground waters show that, in order to discuss the flowage nnder any given set of conditions, it must be assumed that it is limited only by an impervious stratum."

It is, of course, understood that there are no strata which are absolutely impervious, but there are many which are practically so. Wherever there is an impervious stratum the effective underground circulation is there limited or divided, whether the stratum be at the deptl of 100 or 1,000 or more meters. The impervious stratum may be a plastic shale which yields to deformation without fracture, or it may be a rock intruded after deformation has occurred, thus making a barrier. Of course there are all gradations, from practically impervions strata to strata which merely check the circulation. It is believed that in the average case the limit of effective circulation is probably much less than the theoretical limit of 10,000 meters given by the depth of the zone of fracture:

If an impervious stratum be but 100 meters from the surface and fissures be limited to that depth or interrupted, the laws given (pp. 1021-1028) apply to the circulation above the stratum. Therefore, such a fissure may be occupied by ascending water in the lower part and by descending water in its upper part. Hence an ore deposit contained in such a shallow fissure may be the result of a single concentration by ascending or descending waters, or of two concentrations, the first by ascending and the second by descending waters.

The foregoing statement in reference to the practical limits of underground circulation for the ore deposits of a given distriet may be true even if below the impervious stratum there are other strata, fed from a distance, in which circulation is occurring. Such lower pervious strata may have

a Slichter, C. S., Theoretical investigation of the motion of ground waters: Nineteenth Ann. Pept. U. S. Geol. Survey, pt. 2, 1899, 329-357. 
circulations of their own, independent of the higher circulations, and this circulation may produce ore bodies. This is beautifully illustrated by the Enterprise mine, of Rico, Colorado (see fig. 29), described by Rickard ${ }^{a}$ and Ransome, ${ }^{b}$ in which the ore is confined to fissured and broken limestones, gypsum, and sandstone below a black shale, which, when bent, did not fracture, and therefore afforded no channels for water circulation.

In this comection it may be well to mention the Mercur district of

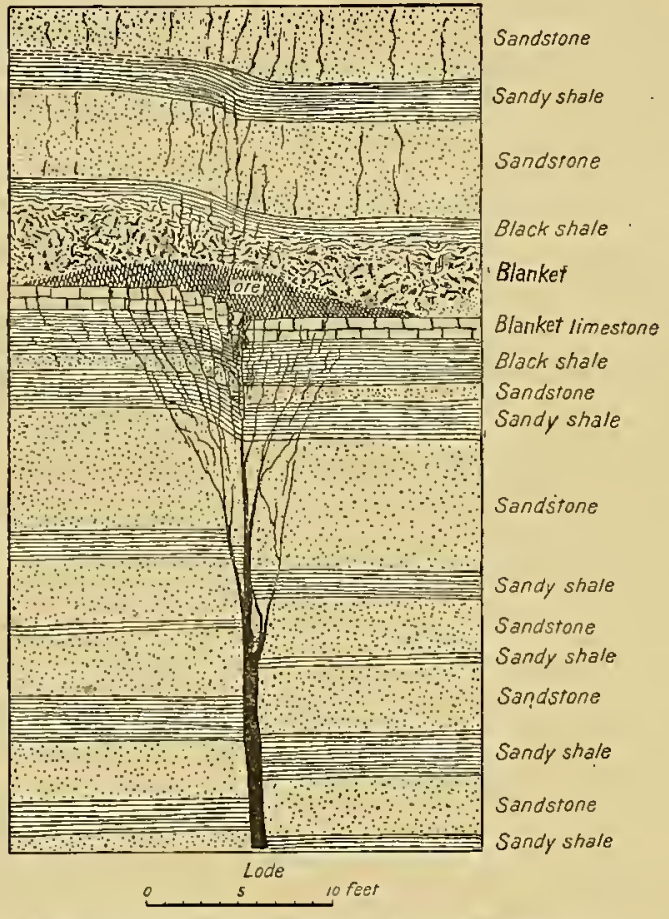

FIG. 29.-Diagrammatic section of Enterprise mine, Colorado, and its blanket pay shoot. After Ransome.
Utah (see pp. 1213-1214), where a silver ledge and a gold ledge, about 30 meters apart, occur in limestone, each below a shale-like stratum of altered porphyry. Spur regards the silver ledge as produced during an earlier mineralizing period, and the gold ledge during a later one. It may be suggested that the trine explanation of the existence of two mineral ledges so near together and of such different mineral character is that in this district there were two independent circulations separated by impervious strata-the upper one, producing the gold ledge, lying between the two impervious porphyry belts; while the lower one, forming the silver deposit, was below the lower impervions layer.

The lead and zine ores of the Mississippi Valley ${ }^{d}$ furnish another illus-

a Rickard, T. A., The Enterprise mine, Rico, Colo.: Trans. Am. Inst. Min. Eng., vol. 26, 1897, pp. 918, 960-973, 976-977.

$b$ Ransome, F. L., The ore deposits of the Rico Mountains, Colorado: Twenty-second Ann. Rept. U. S. Geol. Survey, pt. 2, 1901, pp. 299-397.

cSpurr, J. E., Economic geology of the Mercur mining district, Utah: Sixteenth Ann. Rept. U. S. Geol. Survey, pt. 2, 1895, pp. 367-369.

a Bain, H. F., with C. R. Tan Hise and G. I. Adams, Preliminary report on the lear and zinc deposits of the Ozark region: Twenty-second Ann. Rept. U. S. Geol. Survey, pt. 2, 1901, pp. 33-227. Tan Hise, C. R., Some principles controlling the deposition of ores: Trans. Am. Inst. Min. Eng., vol. 30, 1900, pp. 102-109. Van Hise, C. R., and Bain, H. F., The learl and zinc deposits of the Mississippi Valley: Trans. Federated Inst. Min. Eng., England, 1902, pp. 1-60. 
tration in which impervious layers are of the greatest importance. Taking this region as a whole, and considering only the lithology, we have the following succession in descending order: (1) Thick shale formation; (2) limestone, bearing ore bodies; (3) shale; (4) limestone, bearing ore bodies; (5) shale, often interstratified with limestone; (6) sandstone; and (7) preCambrian. As illustrating the influence of the impervious strata in the formation of the ores, we can consider more particularly two districts, the Missouri-Kansas district and the upper Mississippi Valley district.

In the Missouri-Kansas district the descending succession of strata is: (1) Undifferentiated Carboniferons sandstones and shales; (2) Lower Carboniferous (Mississippian) limestones; (3) Devono-Carboniferous shales; (4) Cambro-Silurian limestones; (5) Cambrian sandstones; (6) preCambrian. In this area there was an artesian circulation in the CambroSilurian limestones and sandstones under the Devono-Carboniferous shales, and in the Lower Carboniferous limestones under the Carboniferous

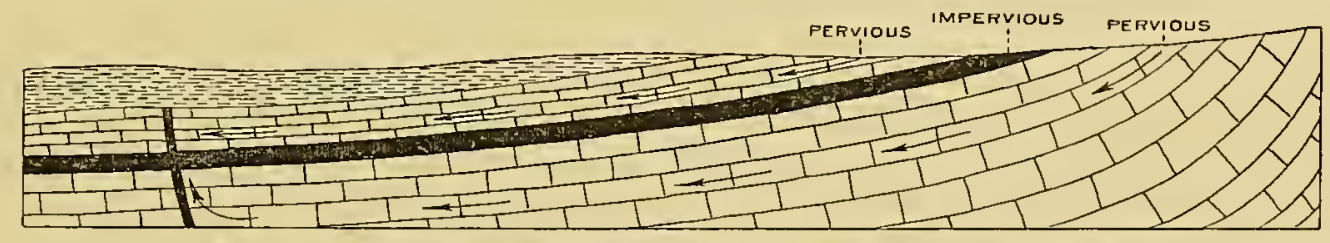

FIG. 30.-Illustrating mingling of circulations of two limestones separated by a shale.

sandstones and shales. (See fig. 30.) Probably the deposition of the ores began in consequence of a connection of the circulations of the CambroSilurian and the Carboniferons limestones by faults cutting the impervious Devono-Carboniferous shales. The ores of the district are deposited in the Carboniferons limestone, which is not dolomitic. The Cambro-Silurian limestone is strongly dolomitic. A very important gangue mineral deposited with the ores in the Carboniferons is dolomite. It is therefore believed that the metals for the ores and the dolomite alike were derived from the Cambro-Silurian limestone and were precipitated in the Lower Carboniferous limestone in consequence of the reducing action of the solutions furnished by it and by the direct action of the organic matter in the shales and limestones. At an early stage of erosion, when the Carboniferous shales and sandstones were removed, the artesian water under pressure arose along joints, faults, and other trunk channels to the surface, and thus the first concentration of the sulphides in the Carboniferous limestone took 
place. In some places in the district where the capping shale still remains, apparently little or no secondary concentration has taken place; but at many places the capping shale has been largely removed, and in such areas descending waters have produced the oxidized ores above the level of ground water, have enriched the sulphides below it, and have formed the rertical arrangement of the lead and zine ores described on pages 1144-1145.

In the upper Mississippi Valley district it is believed that the lead and zinc have undergone two concentrations, as in the Missouri-Kansas district, althongh the evidence is not quite conchsive. Here Galena limestone is overlain by the Cincinnati shale, in Iowa called the Maqnoketa shale,

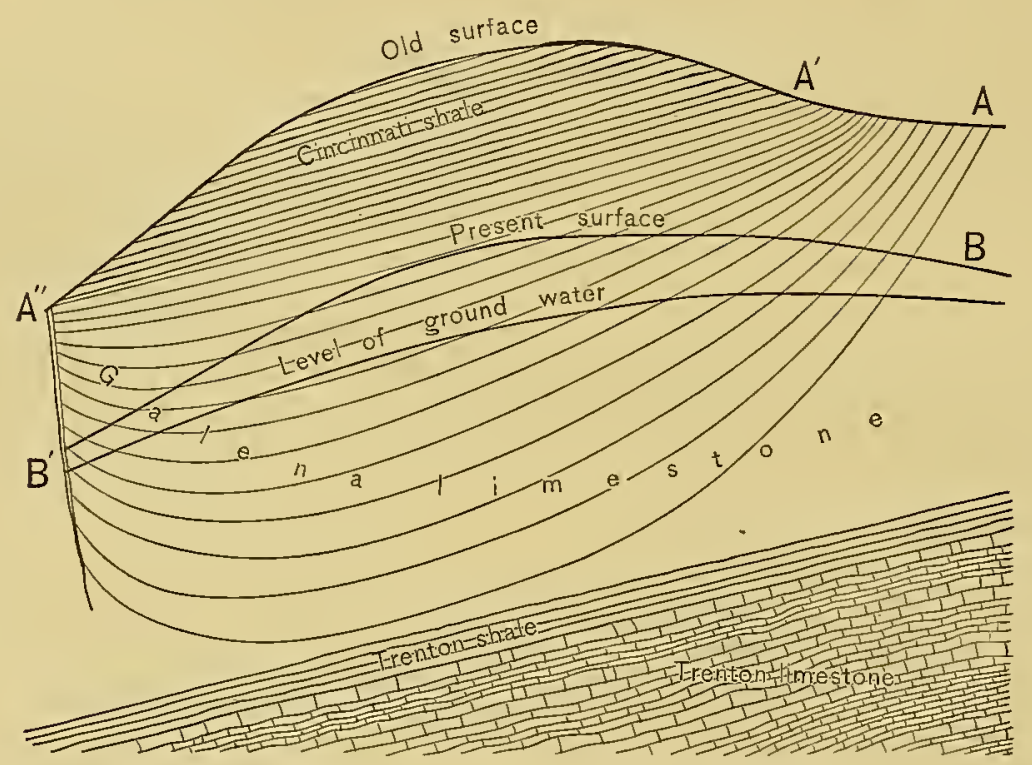

FIG. 31.-Ideal vertical section of flow of underground water in the Galena limestone of the upper Mississippi Valley. When the surface was at $A A^{\prime} A^{\prime \prime}$ the first concentration by ascending water took place; when erosion had

reduced the surface to $B B^{\prime}$ the second concentration by descending water occurred.

and is underlain by the Trenton limestone, with an oil-bearing shale between. When the impervious overlying shale was partly removed an artesian circulation was inaugurated which resulted in the first concentration. Later, when the overlying shale was largely removed, a second concentration by descending waters took place, which has continued to the present time. (See fig. 31.)

The main difference between the upper Mississippi Valley and MissouriKansas districts is that in the upper Mississippi Valley district the important metals are believed to have their chief source in the limestones in which 
the deposits are now found; whereas, as has been pointed out, in the Missouri-Kansas district the source of the ore is believed to be the Silurian dolomite and the deposits are in the overlying Carboniferous limestone. The lead and zinc deposits of central and southeastern Missouri are more nearly analogous in their history to the Upper Mississippi Valley district than to the Missomi-Kansas district.

PITCHING TROUGHS AND ARCHES.

Another interesting special case of influence of porosity and structure is that where alternately pervious and impervious layers are in a set of pitching folds. The varying porosity may follow from original difference in the porosity of the layers, or it may result from the deformation itself. The more rigid strata may be deformed by fracture, and the less rigid by flowage. The convex sides of the brittle layers are likely to be more fractured, and therefore more porous than the concave sides. For synclines this would place the more porous parts of a stratum at the bottom and for anticlines at the top.

Where strata are deformed so as to produce a set of similar or nearly similar folds, if no openings are produced at the synclines and anticlines, the layers on the limbs of the folds must be thinned and those on the arches and troughs thickened, or both. But more frequently, in the zone of fracture, instead of the layer's on the limbs being thinned and the arches and troughs thickened sufficiently to occupy all the space, openings form on the anticlines and synclines, thus furnishing trunk channels. Where the folds are large, on account of their being less weight above an arch than above the corresponding syncline, the openings of the anticlines tend to be larger; but this does not apply to anticlines and synclines which are at the same level.

Any combination of porous layers with impervious layers in folds is likely to give trunk chamnels for underground water in the troughs above impervious strata, and at the crests below impervious strata. When descending waters come into contact with an impervious stratum, they are deflected toward the synclines, and there finding trunk channels, they follow the troughs downward along the pitch. When ascending waters come into contact with an impervious stratum they are deflected torard the anticlines, and there finding trunk chammels they follow the arches upward along the pitch. Therefore, ore deposits produced by descending waters are often 
found in pitching troughs underlain by relatively impervious strata; and ore deposits produced by ascending waters are often found in pitching arches overlain by impervious strata.

If this statement be reversed we have the suggestion that where ore deposits occur in connection with pitching anticlines and synclines, their positions furnish a criteriou by which it may be decided whether their first concentration was accomplished by asceuding or descending waters. Where the ores occur in pitching arches bounded above by impervious strata, the presumption is that they were concentrated by ascending waters; where the ore deposits occur in pitching troughs bottomed by impervious strata, the inference is that they were concentrated by descending waters, for it is difficult to see how waters can be converged at such positions by moving in the reverse directions. Of course this criterion can not be too rigidly applied, for independently of the impervions strata, openings which so frequently occur on anticlines and synclines might furnish trunk channels which could be taken advantage of by asceuding or descending waters.

The Lake Superior iron ores furnish an admirable illustration of the concentration of ores by descending waters in pitching troughs which are on impervious basements. Since these ore deposits, which fully illustrate the principles of concentration of ores by descending water in pitching impervious troughs, have already been discussed, ores of this class will not be here further considered. (See Pl. XIII.)

A case in which ore is probably deposited by ascending waters in. arches, because there concentrated by impervious roofs, is furnished by the Bendigo gold district of Australia. ${ }^{a}$ The typical position for the gold in the district, according to Rickard, is immediately below a slate, on top of a sandstone. The slate is the impervious stratum and the sandstone the pervious stratum. In this district there are a large number of alternations of pervious and impervious strata, as a result of which concentrations have occurred at a number of horizons, one above the other. While Rickard does not specifically speak of the pitch of the anticlines, the longitudinal sections show that they do have a marked pitch.

It is not supposed that the location of ore deposits in pitching arches below imperrious strata is wholly controlled by the existence of the impervious roofs, for, as already explained, when a heterogeneous mass of strata is

a Rickard, T. A., The Bendigo gold field: Trans. Am. Inst. Mlin. Eng, vol. 20, 1892, pp. 463-545. 
folded, openings are likely to be formed at the anticlines and syuclines. Rickard's explanation of the location of the ores is that the apices of the anticlines furnish more open passages than the syuclines. As already explained, if it be assumed that there be less load above the anticlines than above the synclines, this would be favorable to the production of larger openings at the anticlines. This explanation may possibly be to some extent applicable, but the pitching arches concentrating the ascending solutions below impervious strata are believed to be an important factor in the localization of the ores. Varions other factors-for instance, intersecting fractures - may be very important in the process. The Bendigo gold fields are very interesting in a scientific way in that such a large number of bonanzas have been found at a deptlı of 600 to 700 meters. ${ }^{a}$ At the present time information is not available which adequately explains these bonanzas.

A pervious layer or other opening furnishing a trunk channel for circulating waters may be bounded on both sides by inpervions strata. An excellent illustration of ore deposits at the openings of anticlines between relatively impervious strata, presumably formed by ascending waters, are the gold-bearing quartz ores in the slates and quartzites of Nova Scotia, described by Faribault. ${ }^{b}$ Here are a great many parallel deposits directly at the anticlines or on some parts of the anticlinal folds, the deposits being separated by layer's of relatively impervious slate. Furthermore, the largest deposits are located on the great pitching anticlines rather than on the subordinate ones.

Another excellent illustration of ascending ore solutions concentrated by an impervious roof is furnished by the Mercur district, Utal, described by Spurr, where two ore-bearing beds, one called the silver ledge and the other the gold ledge, about 30 meters apart, occur in a limestone below seams or beds of very much altered porphyry resembling shale. The ores are especially localized where fissures reach these beds, and thus displace them, and in some cases form local arches. Moreover, the entire ore district is located upon a general anticline, furnishing a gently pitching arch.

\footnotetext{
a Rickard, T. A., The Bendigo gold field: Trans. Am. Inst. Min. Eng., vol. 20, 1892, pp. 538-539.

$\downarrow$ Faribault, F. R., The gold measures of Nova Scotia and deep mining: Paper read before the Canadian Mining Institute, March, 1899; published by the Mining Society of Nova Scotia, 1899.

cSpurr, J. E., Economic geology of the Mereur mining district, Utah: Sixteenth Amm. Rept. U. S. Geol. Survey, pt. 2, 1895, pp. 365-367, 395, 399-401, 449, 454; see also Pls. XXV and XXXIV, and figs. 44 andi 45 .
} 
No better illustration could be furnished of an impervious pitching arch than that of the Elkhorn mine described by Weed. (See fig. 32.) Here the ore is at the contact of limestone and an overlying argillaceous rock which Weed calls hornstone. The deposit is altogether below the hornstone, and extends down an irregular distance into the limestone which it replaces. ${ }^{a}$ It can hardly be doubted that this deposit received its first concentration by ascending waters.

If the criterion that ores in troughs are deposited by descending waters and ores in arches are deposited by ascending waters be applied to the Leadville ore deposits, the conclusion is that the sulphides of Leadville were originally deposited by ascending waters. These ores occur below a relatively impervious porphyry in a much-broken limestone, mainly the Blue limestone. ${ }^{b}$ Later, when the second concentration by downward-

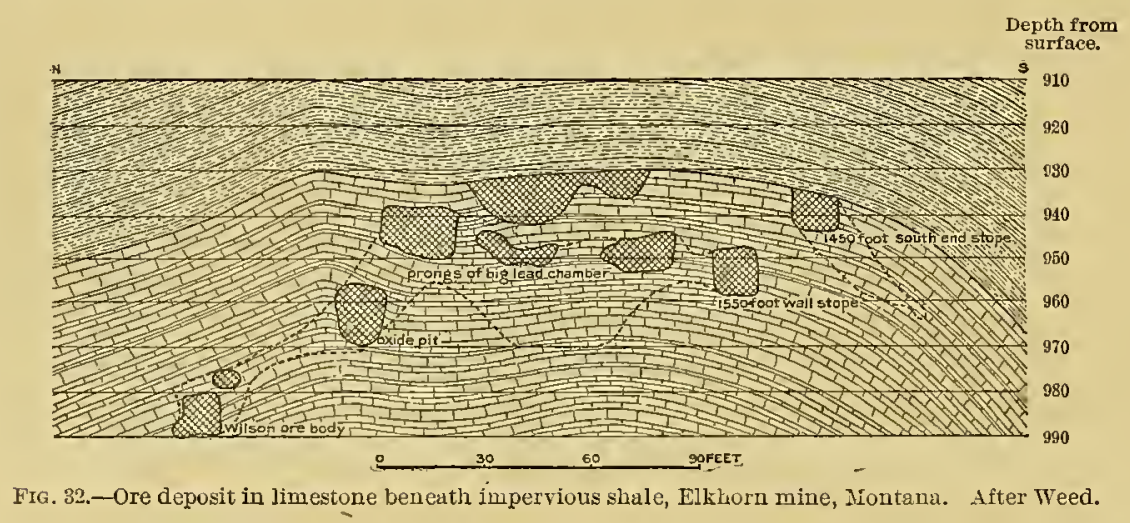

moving waters occurred, the material which in many places was on denuded anticlines was in part carried down the limbs of the folds under the porphyry into the limestone. At this time, doubtless, also, the limestone was largely dissolved, the ores rere carried down, not only along the dip but across the beds, thus producing the very great irregularities which are characteristic of the deposits. If the above explanation be correct, the Leadville ores present another case in which both ascending and descending waters were concerned. ${ }^{\circ}$

$a$ IVeed, W. H., Geology and ore deposits of the Elkhorn mining district, Jefferson County, Montana: Twenty-second Ann. Rept. U. S. Geol. Survey, pt. 2, 1901, pp. 472-483.

$b$ Emmons, S. F., Geology and mining indnstry of Leadville, Colo.: Mon. U. S. Geol. Survey, vol. 12, 1886, pp. 539-584.

$c$ Blow, A. A., Geology and ore deposits of Iron Hill, Leadville, Colo.: Trans. Am. Inst. Min. Eng., vol. 18, 1890, pp. 173-181. 
In this connection it may be suggested that the positions of the ores in reference to the limestone and porphyry in the Leadville district are remarkably similar to those of the ores in the Mercur district in reference to almost identical formations. The forms of the deposits, their irregular under surfaces in the linestone, and the regular surfaces at the porphyry are all identical. Both Emmons and Spurr agree that the ore in the Mercur district was deposited as sulphides by ascending waters. If this be true, the same explanation is probably applicable to the Leadville district.

Another exceedingly interesting illustration of the deposition of ores below an impervious stratum in pitching arches is that furnished by the Enterprise mine of Rico, Colorado, described by Rickard ${ }^{a}$ and Ransome. ${ }^{b}$ In this district above the ore bodies is an impervions shale, which is very rarely broken by the fissures. The ore occurs in two places: First, ore in nearly vertical fissures extends indefinitely downward below the shale, but not upward into it. The verticals are cut by cross fissures, and where the intersections occur the fissures are likely to be unusually rich. (See p. 1084.) Second, the larger masses of ore are in crushed or fractnred limestone below the black shale, but the rich blanket of ore replaces gypsum. ${ }^{b}$ These ore bodies are narrow laterally, some being parallel to the strike of the verticals and others parallel to the cross veins. Fig. 29 shows that they occur below anticlinal flexures of the shale made by the deformation resulting in the fracturing and faulting in the more brittle rocks. Rickard regards the deposits as the result of ascending waters, since the fissures continue downward hut do not extend upward into the shale. The anticlinal arches have a pitch. Probably the waters issining from the verticals and the cross fissures followed these arches upward until the pitch somewhere brought them to the surface, at which places the waters escaped as springs, for the waters of the ascending circulation must have somewhere escaped, and that they could not do through the impervions shale.

Porous pitching troughs below, above, or between impervious strata may have different origins from those mentioned. Very frequently such troughs are produced in part or in whole by intrusive igneons rocks. For instance, if an impervious sedimentary stratum has a monoclinal dip and a

a Rickard, T. A., The Enterprise mine, Rico, Colo.: Trans. Am. Inst. Min. Eng., vol. 26, pp. 918-973.

$b$ Ransome, F. L., The ore deposits of the Rico Mountains, Colorado: Twenty-second Ann. Rept. U. S. Geol. Survey, pt. 2, 1901, pp. 254-302. 
dike cuts across the stratum, a pitching trough may be produced, as, for instance, in the Penokee-Gogebic district of Michigan and Wisconsin. ${ }^{a}$ An intruded igneous rock may follow the contact between folded strata and thus furnish a trough or arch bounded by an impervious formation. Various other ways will occur to one in which pitching troughs or arches with imperrious basements, or roofs, or both, may be produced. A trough or areh, no matter how formed, is favorable to the concentration of ores, provided a porous stratum or an opening between the layers furnishes a trunk channel. Of course, other favorable conditions must cooperate with these in order to produce an ore deposit.

Combinations of pervions and impervious strata, united with joints, faults, and other structures which affect some impervious strata and not others, furnish extraordinarily complex sets of conditions which will undoubtedly yield interesting results when studied in special cases.

GENERAL STATEMENTS.

The importance of variation in porosity and structure is sufficiently illustrated in the foregoing pages to show that one of the first steps in studying the genesis of ore deposits formed by aqueons solutions is to investigate the underground circulation. If a geologist wishes to know whether or not adequate supplies of underground water can be obtained for a city, he should at once begin to study the strata, in order to ascertain their rarying porosity, their accessibility, the amount of water they carry, their importance as water bearers and water restrainers, and the possible sources of supply; in short, he should make a complete investigation of all of the factors which influence the underground circulation for that district. Frequently this would involve the study of the stratigraphy for extensive areas, often for entire geological provinces. From my own point of view it is equally important, in order to ascertain snccessfully the genesis of the ore deposits of a given district, to begin by studying the stratigraphy in all its bearings, especially with reference to underground systems of circulation. The problems of stratigraphy and underground circulation being solved, including both the ascending and descending currents, the geologist will have gone far toward the solution of the problem of the genesis of the ores

a Irving, R. D., and Tan Hise, C. R., The Penokee iron-bearing series of Michigan and Wiscon" sin: Mon. U. S. Geol. Survey, vol. 19, 1892, pp. 268-275. 
for that district. But for some districts not only is it necessary to solve the problem of the present circulation of the undergromnd water, but it is essential that possible past circulations should be studied. Thus, where there are impervious strata which have been largely removed by erosion, the conditions for circulation are very different before and after the removal of the impervious stratum. To illustrate, it has already been pointed out that in various districts in the lead and zinc region of the Mississippi Valley the first concentration took place under conditions of artesian circulation, the upper confining stratum being an impervious shale. Subsequent to that time this shale has been removed from most of the region and a second concentration has taken place by descending water under very different conditions of circulation.

CHARACTER OF TOPOGRAPHY.

EFFECT OF VERTICAL ELEMENT

Where the relief is marked, the underground circulation is likely to penetrate much deeper than in regions where the variations in relief are slight.

In mountainous and elevated platean regions the lithosphere is likely to have more numerous, larger, and deeper openings than low-lying areas. Elevated areas are usually those of comparatively recent orogenic or epeirogenic movement. Therefore, they are regions in which the rocks have recently been fractured, and hence the processes of cementation are less likely to have closed the openings. In regions of very steep topography the tendency for the material to glide down the slope under the stress of gravity also tends to widen openings which have been once formed. Such movements are known to be effective to the depth of hundreds of meters. It is hence clear that elevated and rough regions are those in which the underground circulation is likely to find large, numerous, and deep openings. Further, elevated and mountainous regions are those in which the underground water has the greatest difference in liead, and this is favorable to deep circulation.

Thus, in mountainous regions, like the Cordilleras, it is to be expected that the underground circulation, botl ascending and descending, is effective to greater depths upon the average than in regious of gentle topography. The Cordilleran region is well illustrated by the San Juan MoN XLVII-04-77 
district, where the topography is very rngged. It has been pointed out that oxidizing effects are here produced to a depth of a thousand meters, and it can hardly be doubted that the breadth of the belt of effective ascending circulation is great. In the lead and zinc district of southwesteru Wisconsin the topography is gentle, and here the effective circulation, ascending and descending, was confined to a vertical distance of not more than 150 meters; but this is partly due to impervious strata.

EFFECT OF HORIZONTAL ELEMENT.

The horizontal position of an ore deposit with reference to topography often has an important influence upon its richness and magnitude. If the correct theory of circulation of underground waters and the deposition of ores has been given, certain corollaries follow with reference to this point.

(1) Commonly ores deposited by ascending waters should be formed below the valleys, or at least below the lower parts of the slopes; for these are the places where waters are ascending in the trunk channels. (2) Commonly ores deposited by descending waters should be formed below the crests or below the upper slopes of elevations; for these are the places where water would be descending. Probably the upper slopes are more favorable places than the crests; for at an annular belt on the upper slope of an elevation the quantity of descending waters would be greater than at the crests. (3) Commonly ores which receive a first concentration by ascending waters and a second concentration by descending waters shonld be on the slopes, probably in many instances nearer the valleys than the crests. At such places the meteoric waters falling at the higher elevations have sufficient head to search deeply the zone of fracture for ores. Therefore, the ascending circulation in trunk channels is strong. Further, at such places the level of ground water is a considerable distance below the surface, and abundant descending waters are concentrated in the upper parts of the openings. (See fig. 26, p. 1076.) The downiward migration of the belt of weathering furnishes the final favorable condition for the accumulation of a large amount of second concentrates by descending waters.

Admirable illustrations of ore deposits corresponding to the second of the corollaries are furnished by the iron-ore deposits of the Lake Superior region. These are the products of descending waters, and the great majority of the ore deposits are found near the tops of hills or upon the slopes. 
For instance, in the Gogebic and Menominee districts of Michigan, where the drainage is across the range, the great ore deposits reach the surface on the slopes or crests, and comparatively little ore has been discovered below the strong cross drainage lines where the water's are probably ascending. All of the great iron-ore deposits reach the surface, but many of them have a pitch which carries them below the rocks. An ore deposit which at the surface starts on a slope or crest may extend below a subordinate cross valley. In such cases the water had head sufficient to carry it down and make it effective below the valley; but, so far. as I know, it has yet to be proved that any great deposit continues in force across the valley of an important stream. ${ }^{*}$

The topography in the Mesabi range of Minnesota exerts a somewhat different influence. The productive portion of this range extends from a point west of Hibbing to Embarrass Lake. Here the Giants range to the north is strongly emphasized, and there are good drainage lines to the south. West of Hibbing the Giants range is much less marked; indeed, for much of the distance to the Mississippi River is almost imperceptible. ${ }^{b}$ While ore deposits have been discovered in this part of the range, they are not nearly so numerous and extensive as in the area to the east, and the ores which have been found are sandy (indicating an imperfect removal of the silica). There is no known stratigraphic reason why the ore deposits should not have developed as extensively between Hibbing and the Mississippi River as to the east. The only suggestion which has occurred to me in reference to the matter is that because of the dying out of the Giants range and the lack of sufficiently marked elevation and good slopes to prodnce a vigorous circnlation, the groundwater circulation has not been sufficiently vigorons to concentrate the iron oxide and to remove the silica to the same extent as farther east.

An excellent illustration of the third corollary is furnished by the San Juan district of Colorado. In that district the richer parts of the lodes are generally below the middle slopes of the mountains. Nearly all of the great lodes have been opened on veins which outcropped in the so-called * "basins" at altitudes of 3,000 to 3,500 meters. Above these basins are the

$a$ Van Hise, C. R., The iron-ore deposits of the Lake Superior region: Twenty-first Ann. Rept. U.S. Geol. Survey, pt. 3, 1901, pp. 329-330.

$b$ Van Hise, cit., Section on the Mesabi district, by C. K. Leith: pp. 352-353. 
high peaks, rising to 4,000 and 4,300 meters. Below the mines are the towns at altitudes from 2,300 to 2,700 meters-that is, the ontcrops of the veins are 700 to 1,000 meters above the main valleys.

Another illustration of deposits which are on slopes and are the result of two concentrations is furnished by the lead and zine district of the upper Mississippi Valley. Chamberlin ${ }^{a}$ notes that in the valleys of the Wisconsin part of the district the waters generally ascend to the surface; therefore, at such places only a first concentration would be expected. It is the general impression among miners in this district that a lode makes better on the slope of a hill "than at the summit or at the foot of a hill." ${ }^{\prime}$ Also, it is held by the miners that the lodes which run parallel to a contour of a hill "like an eave trough" are more likely to be rich than those which run toward the summit of the lill. When considered in connection with the topography both of these practical conclusions of the miners are fully explained by the theory of a first concentration by ascending waters and a second concentration by descending waters. This case of the Wisconsin lead and zinc district must not be too strongly insisted upon, for at many places the streams have cut through the lead-bearing limestone into the St. Peters sandstone below, which is a barren formation.

In regions in which there have been recent important changes in the positions of the drainage lines and elevations, the generalizations concerning the relations of ore deposits and topography are only partly applicable. It is well known that in consequence of the varying hardness of rocks, of structure, of the unequal strength of streams and of unequal declivity, drainage lines are almost constantly shifting, in many regions somewhat rapidly. Another way in which the position of the drainage lines with reference to ore deposits may be shifted is by base leveling and subsequent uplift. After a region has been cut down to the level of the sea and is again uplifted it is well known that some of the streams are likely to be along old drainage lines, but that others will be in new positions. It follows that when the second cycle of erosion is well inaugurated an ore deposit which during the first cycle of erosion was in a valley may be on a crest, and vice versa. When it is remembered that there have been various

a Chamberlin, T. C., The ore deposits of southwestern Wisconsin: Geology of Wisconsin, vol. 4, 1882 , p. 565.

b Chamberlin, cit. p. 563 . 
epochs of extensive base leveling from pre-Cambrian to Tertiary time, it is seen that shifting of drainage lines in consequence of different cycles of topographic erosion may be of great consequence.

Doubtless in consequence of changes in drainage many ore deposits which, when below valleys, received a first concentration by ascending waters, are now well up on slopes or even at crests. A change of this kind is especially favorable to the development of ore deposits which are forned by two concentrations, the first by ascending and the second by descending waters. In an early stage of the history of a deposit it may be in a favorable place to receive a first contribution of ore. Later, if in consequence of a topographic change, it be on higher ground, it is then in a favorable place for the work of descending waters. Althongh it is difficult to prove, I have little doubt that many ore deposits have had this history.

Where a region has been base leveled it is very difficnlt to reconstruct the topographic conditions which led to the concentration of the ores. To illustrate, the Lake Superior copper deposits are believed to lave been deposited by ascending waters. The waters may have made their way down along fault fractures and through the minor pores to the sloping conglomerate beds and have risen along the beds which had their surface outcrop at a lower elevation than the feeding areas. But all this is purely hypothetical, for the region has been base leveled and the copper deposits unquestionably developed before the end of the base-leveling period. Since that time the region has been uplifted and the present topography incised in the base-leveled plateau. So far as one can see the present topograply has no recognizable relation to the ore deposits.

From the foregoing it is apparent that the relation of topography to ore deposits is an important one, and also that in many distriets its decipherment is a difficult problem.

PHYSICAL REVOLUTIONS.

The genesis of many ore deposits is mndoubtedly further complicated by physical revolutions of various kinds. After an ore deposit has partly formed, either by ascending or descending waters, or both, the region may go through a physical revolution, and after the revolution the concentration of the ores may again be taken up by nature's processes. 
After an ore deposit has been formed the country may pass below the level of the sea by denudation and subsidence, may be deeply buried under sedimentary rocks, and may be again uplifted and undergo a second cycle of reactions which affect the nature of the ore deposits. An ore deposit partly formed may be buried deep under volcanic rocks. This undoubtedly has occurred on a great scale in the great region of Tertiary volcanism in the Cordilleras of the West. The ore deposits there buried are placed in a new environment and are undergoing a second cycle of concentration or depletion. In that district it is entirely possible, indeed probable, that ore deposits formed in the pre-Tertiary volcanic rocks, and with a very complex history involving the work of both ascending and descending waters, are now receiving additions of ores from ascending waters, or, on the contrary, are being depleted, and in consequence are contributing metals to waters which are rising. Such waters may deposit the metals in openings within the volcanic rocks, thus making new ore deposits. When in the future denudation shall have stripped off these volcanics, or the upper part of them, these ore deposits will be at the surface. In this comnection it is to be remembered that in the Yellowstone Park and other areas there are extensive Tertiary volcanic tuffs in almost every respect like formations which in the San Juan district of Colorado bear important ore deposits, but the San Juan region was so elevated that denudation has thoronghly dissected the volcanic material. Indeed, the major streams have cut down through the volcanics to the sediments below. It may be suggested that when denndation of the volcanic series shall have progressed as far in various other Tertiary voleanic regions as in the San Juan region ore deposits will be exposed, but this may not occur while man occupies the earth.

It is well known that fissures are places of weakness, and that movement has again and again recurred along the old planes. Thus favorable conditions for ore concentration may recur in the same places through varions revolutions. Physical changes of varions other kinds may take place. Each of the complex changes in physical history prodnces its effect upon an ore deposit. 


\section{T. GENERAL STATEMENTS}

It is clear from the foregoing that an ore deposit may have a wonderfully complex history. It may not represent the work of a single period of ascending or of descending waters, or one cycle of ascending and one cycle of descending waters, but may be the result of a number of cycles of deposition by ascending or descending waters, or both.

Thus irregularities in certain of the ore deposits in very ancient rocks may be explained. But in many cases it appears probable that the main work in an existing ore deposit has been done by continuous concentration, first by ascending waters, second by descending waters, although in such cases part or even all of the netals may have been derived from earlier concentrations.

Any of the special and local factors above discussed and others not considered may in an individual case be so conspicuous as to appear to be a controlling factor in the formation of an ore deposit. One might say that the existence of a given trough was the canse of the production of an ore deposit. The truer statement would be that the factor' under consideration is one essential among many. The porosity of a formation, the existence of a pitching trough, favorable topography, the presence of igneons rocks furnishing heat to make the waters active, and many other special factors may, in a given case, all be essential, and withont the help of any one of them an ore deposit would not have been produced, but no combination of factors will forn an ore body if a source of the metal is not available upon which the underground waters may act. In short, each case of the development of an ore deposit requires the fortunate combination of many favorable factors, working harmoniously together, the absence of any one of which may prevent the concentration of the ore deposit.

\section{ORE SHOOTS.a}

No fact is better known concerning ore deposits than that they vary in the most remarkable fashion, both in size and richness. Moreover, these variations are both vertical and horizontal. Frequently rich deposits decrease in size or are wholly cut off with extraordinary abruptness. Other equally rich deposits may appear somewhere else on the same level or on another

$a$ For a general discussion of ore shoots in fissures, see Penrose, R. A. F., jr., The mining geology of the Cripple Creek district, Colorado: Sixteenth Ann. Rept. U. S. Geol. Survey, pt. 2, 1895, pp. $162-166$. 
level in an equally strange and apparently inexplicable manner. The ore masses of exceptional richness are generally called ore shoots. Sometimes they are spoken of as pay streaks, at other times as bonanzas, at other times as chimneys. In this paper ore shoot is used as a general term to include all deposits of exceptional richness or size, of whatever origin. At various places in this paper factors have been mentioned which prodnce ore shoots. However, because of the very great economic importance of ore shoots, it seems to me advisable to consider under one heading some of the more prominent features of ore shoots deposited from aqueous solutions, even at the risk of repetition.

Ore shoots may be grouped into those which are largely due to structural features, to the influence of the wall rocks, and to secondary concentration by descending waters.

One large class of ore shoots may be explained principally by structural features. These structural features may be the varying size of openings, varying complexity of fractures, flexures, intersections of fractures, and later orogenic movements.

A fracture through a mass of rocks is necessarily uneven. Where there are movements, it follows that the walls are not adjusted to each other. Where convex surfaces are opposite each other, a fissure may be represented by a mere seam. Where, on the other hand, two concave surfaces are opposite each other, a widening may occur which in some cases is sufficient to produce a great room. 'This is beantifully illustrated by the Comstock lode. This lode showed remarkable variations in its width, here being represented by a narrow seam of clay, there by a great bonanza. The story that tells how Fair and Mackay, with persistent courage, drove along a little seam of clay, at places almost umnoticeable, for hundreds of meters, from the 360-meter level of the Gould and Curry mine to the great bonanza, is one of the romances of mining. ${ }^{a}$ The clay seam marked a place where two pretuberances of the walls had been jammed together so that there was no opening through which circulating waters could pass, whereas the great bonanza represented a place where both walls bowed ontward and thus gave ample space for the deposition of the great deposit. Rooms may be produced also partly or largely by solution, and may be connected by comparatively large channels.

$a$ Lord, Eliot, Comstock mining and miners: Mon. U. S. Geol. Survey, vol. 4, 1883, pp. 309-314. 
It has been shown, other things being equal, that the underground circulation follows the larger openings. Thus the abundant circulation is converged wherever there are rooms, especially where they are connected with passages of considerable width. Moreover, the solutions of such a circulation are likely to be derived from varions sources. Hence, upon the average, in the large openings the ore is in greater quantity and very frequently richer than in the narrower ones, where the solutions are both less abundant and less complex.

It is evident from the above that there may be every variation in the widtl of an ore deposit due to uneven walls, from zero to many feet.

Ore shoots are frequent where the fractures, instead of being simple, are complex; that is, where there is a crushed zone, or zone of brecciation and mashing. It has been pointed out (pp. 1086-1088) that some ore deposits are largely due to reactions between the solutions and the rocks through which they pass. Such an ore deposit is most likely to be rich at a crushed zone, where the interaction between the solutions and the rocks throngh which they circulate is much greater than at a point where there is a single fracture, even if the latter furnishes a larger space than the multitude of smaller openings. (See pp. 1213-1215.)

The Cripple Creek district is an excellent illustration of a region in which the fracturing is of an extremely complex character. The ores and gangue are largely impregnation and replacement products of the rocks in which they occur, including granite, andesite, phonolite, basalt, etc. The solutions in this district evidently followed the innumerable minute fractures of all kinds and had a very large surface of contact. ${ }^{a} \quad$ A condition for the deposition of the ore and gangue was the previous enlargement of the openings by solution.

Very frequently the rich shoots of ore are located by flexures, the ore being either at the crests of anticlines or at the bottoms of synclines. As pointed out (pp. 1206-1212), this is especially likely to be the case where, in connection with the folds, there are impervious strata. Under such conditions, as has alrearly been fully explained, ore is likely to be converged from ascending solutions in the arches of pervious strata below impervious strata, and from descending waters in tronghls of pervious strata above impervious strata. In the cases cited, such as those of

" Rickard, T. A., The lodes of Cripple Creek: Trans. Am. Inst. Min. Eng., vol. 33, 1903, pp. 613-618. 
Australasian and Nova Scotian gold ores and the Lake Superior iron ores, these relations are perfectly clear. Doubtless in many mines there are minor flexures which have been overlooked, but which may be sufficient to control the movement of the circulation, and thus produce the chimneys of ore. These minor flexures may be parallel with the dip of a deposit, or they may pitch to the right or to the left as one looks down the dip.

The intersections of fractures furnish one of the most frequent explanations of ore shoots. The intersections may be those of faulted fissures, those of fissures and joints, or the intersections of joints. In many instances one set of fractures carries the larger ore deposits, and the intersecting set or sets of fractures are known as side fractures. In some instances deposits may occur in two or more sets of intersecting fractures, and in others one of the intersecting sets may be barren of deposits.

In all cases where intersecting fractures occur solutions are contributed from two or more sources. The solutions invariably have different compositions, and therefore precipitation is likely to occur at or near the junctions. In some cases metalliferous material may be furnished by more than one set of fractures, while in other cases it may be contributed by one set of fractures and the precipitating agents by the others. In those instances where the intersecting veins all carry ore it is easy to see why the deposits at the intersections are unusually large and rich. Where the side veins are small or are wholly filled with gangue material their importance in the genesis of ore deposits has been very generally overlooked. In many instances there is little cloubt that the metallic material was precipitated in a main fissure at or near the point where the side veins join, through the influence of the solutions contributed by the latter veins. A very clear case of the influence of barren side veins is that already cited of the Enterprise mine, of Rico, Colo., where the pay shoots are especially rich in the main fissures at the places where barren side veins intersect them.

Not infrequently, where a side fracture intersects a vein carrying the main deposit, the ligh values are not exactly at the intersection, but a little way from it: This is a natural consequence of the laws of circulating waters. Where two streams come together from different sources they are sure to have different heads. If the side fracture which furnishes the precipitating solution has the greater head its water will occupy the mair 
fissure for some distance on either side of it, the solutions furnished by the main fissure being excluded; but at a greater or less distance from the intersection the solutions from the two sources become mingled and precipitation takes place, thus prodncing rich ore shoots. This relation is very well illustrated at the Silver Age mine, at Idaho Springs, Colo. Here the ore shoots are connected with intersecting fractures. They are in the main vein at places near, but not directly at intersections of the subordinate fissures. Again, at the Last Dollar mine in the Cripple Creek district the main vein is cut by numerous cross veins, which upon the whole have not been very profitable; but at numerons places the very rich values are found in the main veins comparatively close to the cross veins; that is, at distances from them varying from 15 to 60 meters. Where ore shoots are found to be connected structurally with barren side veins a consideration of the minerals of the main vein and of the side veins ought to lead to more exact knowledge concerning the manner of the precipitation of the metal; for presumably the precipitation of the metals was connected with some of the compounds which occur as gangue, and in the side veins these may be different from those of the main vein.

Side fractures may be at right angles to the main fractures or incline to them. They may extend directly down the dip or pitch to the right or left along the dip. Therefore almost any curions distribution of the rich shoots may occur. All of these relations of fractures with lodes are beautifully illustrated in the San Juan district. Here some fractures strike parallel with the lodes, but dip at considerable angles with them. There are also cross fractures which differ from the lodes both in strike and dip. ${ }^{a}$

Usually side streams bearing either metals or precipitating agents or both do not issue equally all along the faults or joints, but may be largely converged into large channels, and under such circumstances strong springs enter the fissures. Where such springs empty into a room produced by the structural features, discussed on pp. 1224-1225, bonanzas may be formed, such as those of the Comstock lode.

While the relative influence of the different sets of intersecting fractures is very complex, in an individual mine a close study of the number, order, and relations of the fractures and joints, many of which are, perhaps,

a Ransome, F. L., A report on the economic geology of the Silverton quadrangle, Colorado: Bull. U. S. Geol. Survey No. 182,1901 , p. 59. 
almost imperceptible, may furnish rules which will enable one to more intelligently search for ore.

Between the two cases of trunk channels produced by flexures (described on pp. 1225-1226) and by cross fractures (described on pp. 1226-1228) there are complete gradations.

Late orogenic movements explain certain ore shoots. After openings have received a first contribution of ore, and are, perhaps, fully cemented by ore and gangue materials, orogenic movements frequently recur, which again fracture the ground and produce openings. Some parts of a deposit may escape fracture, while other parts may be broken. The fracturing of the broken parts nay be simple or complex. The latter may prodnce zones of parallel fractures, zones of intersecting fractures, brecciated zones, or eren zones in which the material is finely mashed. Between the parts of a deposit where fracturing is absent and those where it is most complex there may be all gradations. The fractures may be confined to a narrow belt of a deposit or to one side of it, and to varying limits laterally or vertically. Entirely new sets of openings may be produced in the wall rock. All of the above statements in reference to a main deposit apply equally well to intersecting deposits. Therefore an ore deposit which has received a first contribution and is subjected again to orogenic movements is in such a condition that it may again receive a contribution of ore material under the same complex laws as at first. The late fractures may be filled with new contributions of metals from the original source; they may be fed by the solution of the deposits before formed; or they may derive metal both from the original souree and from the earlier deposit.

The new ore may be distributed very irregularly through the older ore, may be superimposed upon the old material where there are openings, may be deposited as relatively small secondary veins, or any combination of these may take place. The original irregularities in the tenors of the veins, combined with the irregular deposition of the secondary material, may give extraordinary and apparently inexplicable variations in richness. Excellent examples showing how secondary fracture produces very rich subordinate veins are furnished by the San Juan district of Colorado. At the Smuggler Union, deep in the mine, in a secondary fracture adjacent to the main vein, are found extraordinarily rich deposits of free gold in quartz, having an exceedingly iregular and "pockety" distribution of values. It seems probable that in this fracture the gold has been precipi- 
tated as a result of reducing solutions furnished by the adjacent sulplides of the main vein. At the fannous Camp Bird mine there are thin black seams deep below the surface, which are extraordinarily rich in gold. ${ }^{a}$ The main part of the vein has its gold and silver values in copper sulphides, galena, blende, and other base sulplides and in tellurides, but the fine black material in the small veins apparently contains free gold, as is shown by the fact that 75 per cent of the value of the ores is collected on the plates. It seems perfectly clear that these minute seams of rich goldbearing material are the results of precipitation in secondary fractures.

Ore shoots in many cases are explained by the influence of the wall rocks. It is well known that where ore deposits intersect a complex set of rocks the pay shoots are likely to have a decided preference for one rock. For instance, if a fissure passes from granite to diorite, or from either of these to limestone, or from any of these to sandstone, the character and richness of the deposit may vary greatly as the rock changes. For this variability, due to the character of the wall rocks, different explanations apply in different cases. In some instances the restriction of the ore shoots to one rock is largely explained by its more ready solubility. This is particularly applicable to the substitution deposits, the wall rock being dissolved in advance of or pari-passu with the deposition of the ore. By the solution of , the soluble rock sufficient room is furnished for a large ore deposit. The above is undonbtedly the partial explanation in many cases of the occurrence of the ores in limestone rather than in the adjacent more insoluble rocks. Gypsum is even moro readily soluble than limestone. Of the Enterprise mine of the Rico district, Ransome ${ }^{b}$ says the rich blanket of ore is "due essentially to the removal by solution of a massive bed of gypsum which may have been from 15 to 30 feet [5 to 10 meters] in thickness." All stages of the process of replacement are seen.

In other instances the occurrence of the rich and large bodies with one wall rock rather than with another is due to the fact that the wall rock itself, by reaction upon the solutions, precipitates the ore material. This also partly explains the preference of certain ore deposits for limestone, for, as already explained (pp. 1116-1117), calcium carbonate probably accelerates

a Ransome, F. L., A report on the economic geology of the Silverton quadrangle, Colorado: Bul!. U. S. Geol. Survey, No. 182, 1901, pp. 89-90.

$b$ Ransome, F. L., The ore deposits of the Rico Mountains, Colorado: Twenty-second Ann. Rept. U. S. Geol. Survey, pt. 2, 1901, pp. 278-295. 
the precipitation of metals as sulphides from their oxidized salts by iron sulphide.

In still other instances the wall rock itself furnishes solutions containing metalliferous material which is precipitated in the trunk channels or furnishes solutions eapable of precipitating metalliferous material in the trunk channel. Either of these may be true for igneous rocks. Also igneous wall rocks may furnish heat and thus in a very important measure promote segregation, as explained on pages 1015-1016.

An excellent illustration of the influence of the wall rock is exhibited by the Lake vein of the San Juan district, near Telluride. This vein, profitable in the volcanic tuff, extends through the tuff into the limestones below, and through them into the sandstones. In passing from the tuff into the limestones the vein changes from a quartz vein to a calcite vein, and as it goes into the sandstone it gradually changed again to a quartz vein. There can be no better illustration than this of the influence of the wall rock and of the domination of the law of mass action. The rein material deposited in the limestone and sandstone has essentially the same composition as the rock through which it passes, showing that the minerals deposited in this vein were dependent mpon the solutions derived from the adjacent formations. Each formation contributed as its chief material compounds which could be derived from it. Solutions entering the vein from other sources were subordinate to those derived from the wall rock. The influence of the wall rock is further illustrated by the fact that so long as the vein remains in the tuffs it is of economic importance, and as soon as it passes into the sedimentary rocks the amounts of gold and silver become so small that it is valueless.

A third class of ore shoots are those produced by the process which has been so fully explained in this paper, viz, the secondary enrichment of deposits by descending waters, the first concentration of which was produced by ascending waters. This process produces rich ore bodies, either oxidized or sulphureted, or partly each, which are limited in depth by the distance to which the descending waters are effective.

GENERAL STATEMENTS.

Of necessity, in this analysis, the various factors which may produce ore shoots have been separately treated. In a given case it is rare, indeed, to find that the entire explanation lies in the application of a single one of 
them. To explain an ore shoot of an individual mine, ordinarily a number of the ahove causes need to be combined, and in some cases doubtless, other canses which have not been treated. No study is more important economically, more fascinating, or more difficult than to ascertain the particular combination of factors which produced the ore shoots in a given district or mine.

From the foregoing it is plain that no general statement can be made in explanation of ore sloots. In each district, in each mine, in each part of a mine, all the phenomena must be studied closely in the light of correct theories of ore deposition in order to reach an explanation applicable to the particular case.

It is well known that in the districts which are mineralized the workable ore deposits are ordinarily confined to relatively small areas, although, so far as one can see, the amount of metalliferous material furnishing ore deposits may have been the same throughout the districts. The absence of workable ore deposits for the larger parts of the districts ordinarily is due to lack of favorable combination of the varions special factors mentioned, and. doubtless many others which have not been considered. As better illustrating my meaning, I may again mention the iron and copper ores of the Lake Superior region. The iron-bearing formation has an extensive occurrence tlurongh the Lake Superior region, but the workable iron ores are confined to small areas which have been subject to ancient and recent metamorphism, and in which there are favorable structural features. The Lake Superior copper deposits equally well illustrate the principle. All of the mines now being exploited are confined to an exceedingly narrow area on Keweenaw Point, while the copper-bearing rocks occupy an extensive belt about nearly the entire Lake Superior basin. Moreover, these copper-bearing rocks are mineralized in many places, as is shown by the widely disseminated copper. But, unfortmately, in many areas a little copper is concentrated in many amygdaloid or sandstone belts, rather than in a single amygdaloid or sandstone. For instance, in certain districts scores of amygdaloidal flows lie upon one another. In each of these beds the scoriaceous upper surface bears metallic copper, but in none is it in sufficient amount to make the copper a workable deposit. Had the copper deposited in a number of these amygdaloid formations been concentrated in one of them, a workable ore deposit would have been produced. 
From the foregoing it is clear that an investigation of the local factors in a district should include both those which are favorable and unfavorable to the concentration of ores, for a study of the latter in many districts may prevent the expenditure of large sums in exploration where the mineralization is general, but the conditions are not such as to have concentrated the valuable material in sufficient quantity at any one position to warrant exploitation.

A treatise on ore deposits, including descriptions of individual districts, necessarily deals with the special factors which are important in each district. These special factors may be considered so conspicnous that the entire attention is given to them. But it is to be remembered that each of these is subordinate to the general principles controlling the deposition of ore deposits in all districts.

\section{SUMMARY AND CONCLUSION.}

I shall now make a summary statement of the genetic classification of ore deposits proposed, and consider briefly the relations of these different classes of deposits. It is proposed that ore deposits be divided into three divisions: (A) Sedimentary ores, (B) igneous ores, and (C) metamorphic ores. The sedimentary ores may be divided into two classes: (1) Chemical precipitates, and (2) mechanical concentrates. The mechanical concentrates may be divided into (a) residuary deposits, (b) stream deposits, and (c) beach deposits. As yet criteria have not been formulated by which igneous ores may be subdivided, and therefore there is only one class (1) magmatic segregations. Metamorphic ores are divided into two classes: (1) Gaseous solution ores, and (2) aqueous solution ores. The aqueous solution ores are subdivided into (a) ores depositer by ascending waters, (b) ores deposited by descending waters, and (c) ores deposited by ascending and descending waters combined. The scheme is therefore as follows:

Classification of metallic ore deposits.
(A) Sedimentary $\cdots\left\{\begin{array}{l}\text { (1) Chemical precipitates. } \\ \text { (2) Mechanical concentrates. }\left\{\begin{array}{l}\text { (a) Residnal deposits. } \\ \text { (b) Stream deposits. } \\ \text { (c) Beach deposits. }\end{array}\right.\end{array}\right.$
(B) Igneous ...... . (1) Magmatic segregations.
(C) Metamorphic.. $\left\{\begin{array}{l}\text { (1) Deposits from gaseous } \\ \text { solution. } \\ \text { (2) Deposits from aqueous } \\ \text { solution. }\end{array}\left\{\begin{array}{l}\text { (a) By ascending waters. } \\ \text { (b) By descending waters. } \\ \text { (c) By ascending and descending water. }\end{array}\right.\right.$ 
Of the sedimentary ores the important chemical precipitates are those of iron, manganese, and aluminum. Of the mechanical concentrates the residuary deposits include ores of iron and tin; the stream deposits inclnde ores of gold, of tin, and of platinum; the beach deposits include ores of gold and magnetite.

In igneous ores-magmatic segregations-we can only certainly include titaniferous iron ores and the aluminum ores which occur in corundum syenite.

In the metamorphic ores deposited from gaseous solutions are probably to be placed those impregnation deposits associated with which there have contemporaneously developed the heavy anhydrons minerals, such as garnet, wollastonite, amphibole, pyroxene, biotite, and tourmaline. Doubtless many if not all of the ores here belonging developed under the conditions of the zone of flowage or anamorphism. This class is a subordinate one, but includes a number of mines in various districts. Copper seems to be the most important metal of this class, but zinc, lead, gold, silver, etc., occur.

The class of aqueous solution ores is believed to be more important than all others combined. The criteria by which these ores are to be recognized are as follows :

(1) The major portion of the material of the ore deposits, and especially the gangue minerals, is the same as the general cementation materials which fill the openings of rocks of all kinds, from fissures to subcapillary openings. General cementation is universally recognized as the work of aqueous solutions.

(2) The gangue minerals of the ores are dominantly hydrous silicates, carbonates, and oxides, such as are now being produced by aqueous solutions in innumerable localities throughout the world, as, for instance, in the Yellowstone National Park, the Mississippi Valley, Iceland, etc.

(3) At some of these localities in which the gangue minerals are being formed on an extensive scale, metallic ores are also being deposited in small quantities by the aqueous solutions, as at Steamboat Springs, Sulphur Bank, and Boulder Hot Springs.

All of the three subclasses of ores deposited by aqueous solutions are important. Ores of the first subclass, those which at the point of precipitation are deposited by ascending waters alone, comprise ores of gold, silver, and copper, the sulphides of all of the valuable metals, and the tellurides of MON XLVII-04-7S 
gold and silver. This subclass is of very great importance. It is illustrated by the copper ores of the Lake Superior region, by all but the superficial portion of the pyritiferous gold veins of the Sierra Nevada, and by the deposits of many other regions.

The ores which are deposited by descending waters alone are the most important subclass, both as to volnme and as to importance to mankind. These ores are chiefly oxides, anhydrous and hydrous. The tominant ores here placed are those of iron. While subordinate amounts of iron ores belong in other divisions, certainly more than 90 per cent and probably more than 95 per cent of the iron ores yet exploited are in this subclass. The ores of manganese also are mainly oxides produced by descending waters.

The ores deposited by ascending and descending waters combined constitute a very important subclass. The materials of this subclass include oxides, carbonates, anhydrous and hydrous silicates, and chlorides, chiefly above the level of ground water; sulphurets and tellurides chiefly below, but often also above it, and native metals both above and below it. There is frequently a transition belt of considerable breadth between the various products. At or near the level of gromnd water all of these products are often intermingled. Important ores of copper and zinc are included in the oxides; of lead, zinc, and copper in the carbonates; of zinc, copper, and nickel in the hydrous silicates; of silver in the chlorides; of iron, zinc, lead, copper, nickel, mercury, and silver in the sulphides; of gold and silver in the tellurides. The metals include important ores of gold and silver, and subordinate anounts of copper.

It is believed that the ores deposited by ascending and descending waters combined are more numerons than those of any other subclass, even if they do not occur in such great volume and are not of the same importance to man as the ores deposited by descending water alone. I suspect that a close study of the origin of ore deposits will show that of ores formed by underground water the most numerous subclass is not made up of ores deposited by ascending waters alone, but is composed of ores which have undergone a first concentration by this process and a second concentration by descending waters. As a result of this there is found in the upper 50 to 500 , or possibly even 1,000 , meters of an ore deposit a large portion of the metalliferous material which originally had, as a result of the first concentration, a much wider vertical distribution. 
It is to be noted that the ores assigned above to the work of descending water's alone do not include any sulphicles. It is by no means asserted that sulphide ores belonging to this subclass do not exist, but I know of no sulphide deposit which can be certainly placed here. If more careful investigation shall show that no important sulphide ores are deposited by descending waters alone it will follow that all aqueous solution sulphide ores belong either to the class deposited by ascending waters or to the class produced by ascending and descending waters combined. It would therefore follow that in the production of all sulphide ores ascending waters are concerned. To my knowledge the only sulphide ores which are held to be the result of desceiding waters alone are those of the Monte Cristo district of Washington, described by Spurr. ${ }^{a}$ But Spurr's statement does not seem to me to prove the conclusion. The mining has extended to only a moderate depth in this district. So far as the facts are known, one might explain the ores as being first concentrated by ascending waters and reconcentrated by descending waters, or as produced by ascending waters alone. It seems to me more probable that the interpretation should be along the line applicable to so many other districts-a first concentration of the sulphides by ascending waters and a later concentration by descending waters.

If the conclusion be established that ascending waters are concerned in the production of all sulphide ores, to this extent the contention of Posepny, who strongly insisted that all sulphide ores are the work of ascending waters, is confirmed. His error would be that he overlooked the importance of the concentrating effect of descending waters. Since the tellurides are so closely associated with the sulphides it is highly probable that they also will be found to be produced not by descending waters alone, but by either ascending waters alone or by ascending and descending waters combined.

To the foregoing classification objections will at once occur. It may be said that there are no sharp dividing lines between the divisions, classes, and subclasses. But transitions are everywhere the law of nature. In a previous chapter (see pp. 786-787, 904-905) I have explained that there are gradations between different classes of rocks, and this statement applies equally well to ore deposits.

a Spurr, J. E., The ore deposits of Monte Cristo, Washington: Twenty-second Ann. Rept. U. S. Geol. Survey, pt. 2, 1901, p. 857. 
There may be complete gradations between ores deposited by processes of sedimentation and those produced by processes of metamorphism, and between ores apparently most widely separated. Even ores. of igneons origin and those deposited by aqueous solutions may grade into each other.

It lias been fully explained that ore deposits produced by processes of sedimentation may grade into those produced by processes of metamorphism. Illustrating this, it may be recalled that a placer deposit formed by mechanical concentration may be profoundly modified by the circulating waters of the belt of cementation. Such circulating waters may add greatly to or subtract much from the amount of gold in a mechanical concentration deposit. It is highly probable (as explained on pp. 1042-1043), that the gold conglomerates of the Rand and the deep placers of California have this composite origin. It is also conceivable that ore deposits primarily produced by sedimentation may also be modified by the actions of gaseons solutions, but this is probably much less common than the modification by aqueous solutions.

If it be agreed that ore deposits are produced by magmatic segregation, by gaseous solution, and by aqueous solution, it is certain that a deposit may be partly segregated by one of these processes, and this work supplemented by one or both of the other processes. This may be true of a deposit which is the result of continuous segregation. It is hard to see how an ore deposit produced by magmatic segregation can be formed wholly independent of the action of gaseous and aqueous sohntions. If at the time a magma solidifies, magmatic segregation of some valuable metal takes place to a certain extent, after solidification is complete the temperature is still above $365^{\circ} \mathrm{C}$. for a considerable time, and the conditions are almost certainly those favorable to the action of gaseous solutions. These may continue the process of segregation for a long time, but finally the temperature falls below $365^{\circ} \mathrm{C}$, and then when the temperature is still high and hot water potent, the aqueons solutions begin their work. This work of aqneous solutions may continue to the time the ores are exploited. Thus an ore deposit partly formed by magmatic segregation is sure to be be subsequently modified by the action of gaseous and aqueous solutions. The modification may be by addition or subtraction of the valuable material; that is, in the direction of further enrichment or in the direction of depletion. For the titanic magnetites and the corundum-syenite ores it is not 
supposed that the action of the gaseous and aqueous solutions is usually of great consequence; but for the sulphide ores and the gold ores which have been held to be produced by magmatic segregation alone, I hold the work of the solutions to be a necessary and in most instances the dominant part of the process.

Whether ore deposits produced by magnatic segregation are likely to be altered mainly by gaseous solutions or by aqueous solutions will depend largely on the zone in which the igneons rocks are intruded. If the rocks are batholiths in the zone of anamorphism the magmatic segregations which there form are likely to be modified by gaseous solutions, and so long as they remain in that zone aqueous solutions are likely to be unimportant. Where the igneous rocks are intruded into the zone of fracture the conditions are not favorable for action of gaseous solutions for any length of time, but are especially favorable for the long-continued action of aqueous solutions. Thus we would expect that magmatic-segregation ores would be especially likely to be modified by gaseous solutions in the zone of anamorphism, and by aqueous solutions in the zone of fracture.

Metamorphic ore deposits formed mainly by gaseous solutions or by aqueous solutions, or by the two combined, may form without any implication that they are partly dne to magmatic processes. Often after igneous rocks are intruded ores do not begin to form until gaseous solutions are active, or much later, when aqueous solutions are at work.

Not only are there transitions between ore deposits prodnced by sedimentary, igneous, and metamorphic processes, but there are transitions between the classes and subclasses. To illustrate, there are transitions between chemical precipitates and mechanical concentrates; between residnal, stream, and beach deposits; between the deposits prodnced by gaseous and aqueous solutions; between deposits produced by ascending waters, descending waters, and ascending and descending waters.

The chemical precipitates and mechanical concentrates are connected by the residual deposits. Very frequently chemical solution of a rock in which the ore was disseminated is of equal or greater importance than the mechanical concentration. The residual iron ore mantling Iron Mountain, Missouri, is quite as much due to the solntion of the porphyry as to its mechanical disintegration. The tin ore in the alluvinm of the Malay Peninsula is probably concentrated more extensively by chemical than by 
mechanical processes. Thus one might consider that the residual deposits which are classified as mechanical concentrates are partly chemical concentrates, and on this basis chemical deposits might be divided into chemical precipitates and residual concentrates. However, residual deposits are placed with the mechanical concentrates mainly because of their close alliance with stream and beach deposits, which are plainly mechanical concentrates. .

This leads to the transition between residual, strean, and beach deposits. It is well known that a residual deposit on a hill or slope una pass by imperceptible stages into the concentrates at the bottom of a stream. It is known also that stream deposits may extend along the stream until the ocean is reached, where a beach deposit may exist. It is therefore clear that there is every possible gradation between residual, stream, and beach deposits.

An ore deposit which is formed mainly by gaseous solutions nay be modified by aqueous solutions, for when the temperature has fallen so that the water is below its critical temperature, it is little short of certain that the processes of segregation may and usually will be continued by aqueous solutions, just as in the case of magmatic ores. Thus ore deposits are probably seldom formed solely by gaseous solutions withont any subsequent modification by aqueous solutions. Probably very often ore deposits, perhaps inaugurated by precipitation from gaseous solutions, have been profoundly modified by aqueous solutions. Like the ore deposits first segregated by magmatic segregation, the later water action may be in the direction of addition or subtraction. As to the importance of subsequent action by aqueous solutions upon ore deposits partly former by gaseous solutions, there may be difference of opinion. It is possible that rocks which do not freely permit the circulation of underground water may be more pervious to gaseous solutions, and that in very dense rocks deep within the earth gaseous solutions may segregate ore deposits-such as those associated with heavy anhydrous silicates or gangue minerals-which while in that position are not materially modified by the subsequent action of aqueous solutions. But ore deposits which are formed in the zone of anamorphism must pass well up into the zone of fracture, if not to the surface, before they are accessible to man. They are now in the zone in 
which aqueons solutions are active, and while migrating they may be profoundly modified. The amount of subsequent modification, while migrating from the deep zone to the surface, depends upon the conditions of fracture, water circulation, and all the other factors which have been discussed in connection with the deposition of ore deposits by aqueous solutions. The modifications in the zone of fracture of an ore deposit the concentration of which was begun in the zone of flowage, may be, therefore, inappreciable or of dominating importance.

Ore deposits formed by aqueous solutions are not nearly so likely to be modified by gaseous solutions as are the latter by aqueous solutions. Under normal conditions an aqueous ore deposit would not be modified by gaseous solutions, but if there were sufficiently powerful orogenic movements or great igneous intrusions adjacent to an ore deposit partly formed or primarily produced by aqueous solutions, it is conceivable that the water might be raised above its critical temperature and thus a further concentration take place as a result of the work of gaseous solutions. It might be supposed also that an ore deposit partly formed by aqueous solutions might become so deeply buried as to pass into the zone of anamorphism and there be modified by gaseous solutions. Thus, while it is admitted that modification of aqueous solution deposits by gaseous solutions is possible, it is believed that it is exceptional.

Ore deposits which are precipitated almost solely by ascending waters often grade into those in which descending waters have produced an important effect. Thus there is transition between the ores deposited by ascending waters and those deposited by ascending and descending waters. Similarly there is every gradation between ore deposits formed by ascending waters and those produced by descending waters, and between ore deposits formed by descending waters and those precipitated from ascending and descending waters. It may not infrequently happen that a single fissure may fall partly in one subclass and partly in another. Thus a single ore deposit may belong partly in the subclass of ores formed by ascending waters, and partly in the subclass of ores produced by ascending and descending waters. However, most aqueous deposits belong chiefly to one of the three subclasses.

Finally, not only are there gradations between different varieties of the ore deposits among themselves, but there are gradations between the ore 
deposits and the rocks, for the ore deposits in many cases are not sharply separated from the country rocks, but grade into them in various ways.

Therefore it appears that not only are there no hard and fast lines between ore deposits of different modes of origin, but that a single ore deposit may be produced by various combinations of most widely diverse processes. Indeed, it is certain that many ore deposits are not produced by a single process, but by several processes, one following another, or even by more than one cycle of processes. Thus, ore deposits which receive the first concentration by magmatic segregation may be concentrated further by gaseous solutions, still further by aqueous solutions, still further by sedimentary processes, and again by aqueous solution. It is clear that there may be every gradation between ore deposits produced solely by magmatic segregation and solely by aqueous solutions.

For the production of many ore deposits in their present condition there have been many stages of concentration by various processes. One cycle of concentration may have followed another through a large part of geological time in accordance with the general law for the segregation of each of the metals in certain formations. (See pp. 947-948.) Many iron-ore deposits have certainly, and many deposits of other metals have probably, been produced as the result of the work of several cycles.

While a part of the metals for many and perhaps most of the ore deposits have an exceedingly composite history, in the majority of cases a final process is dominant, and ore deposits may therefore be fairly classified on the basis of the last permanent process. For instance, there is no question that the Lake Superior iron ores were deposited by descending aqueous solutions; the copper deposits of the same region by ascending aqueous solutions, and the lead and zinc deposits of the Mississippi Valley by ascending and descending aqueous solutions.

Looked at broadly from the above point of view, the total mass of existing ore deposits of all kinds taken together represents the accumulation of the valuable metals of all previous processes of concentration. The processes of segregation are continuous. We eatch the series of cycles at a certain stage, and upon the basis of the existing facts we classify them. In coming geological periods existing ore deposits will be sources from which, by varions processes of segregation, the ore deposits of that distant time will derive a portion of their material. Another source of 
material for such ores will be the igneous rocks which in the future enter the upper part of the lithosphere from the centrosphere.

In conclusion the merits of the classification proposed may be summarized as follows:

First, the classification is strictly genetic, and is based upon a consistent plan.

Second, the primary divisions of metallic ore deposits are parallel with those of rocks. Just as there are sedinentary, igneous, and metamorphic rocks, so there are sedimentary, igneous, and metamorphic ores. If this division of rocks be logical the division of ore deposits is equally logical.

Third, the classification recognizes the gradation and connection between different classes of deposits, one of the most fundaniental laws of geology. Recognizing that many ore deposits have a long complex history in which many processes have been concerned, it makes the basis of the classification the last process which resulted in the deposition of the ores where they are now found.

Fourth, it is believed that the classification offered, being strictly genetic and recognizing gradation, is enlightening from a scientific point of view and gives a better idea of the relations of various ore deposits to one another than classifications heretofore proposerl.

Fifth, it is believed that the classification will assist mining engineers and geologists in accurately describing deposits, and will give rules to guide them in the exploration and exploitation of ore deposits.

As an illustration of the practical usefulness of the classification is the comection between genesis and depth for those ore deposits in which descending waters were an important factor in concentration. Ores deposited by ascending waters alone are likely to continue to great depth. Therefore, where a given ore deposit has been shown to belong to this class, the expenditure of money for deep exploration may be warranted. Where a deposit is produced by descending waters alone the extent in depth is probably much more limited. In such cases, when the bottom of the oxidized product is reached, it would be folly to expend money in deep exploration with the expectation of finding other rich oxidized masses. Where the ore deposit belongs to the third class, that prodncer by ascending and descending waters combined, there is a rich upper belt which we can not hope will be duplicated at depth. However, this class of deposit 
may grade into the first class, and after the transition the deposit may be rich enough to warrant exploitation at depth. If such work be undertaken, it must be understood that the rich upper products peculiar to the belt of weathering and to the belt of sulphide and telluride emrichment will not be duplicated at depth. It therefore appears to me that the determination to which of the classes of ore deposits produced by underground waters a given deposit belongs has a direct practical bearing upon its exploration and exploitation.

Again it has been seen that the ores produced by magmatic segregation and those which are produced by gaseous solutions form a relatively small class, and not only so, but that the ore deposits themselves are usually rather circumscribed. When, therefore, deposits have either of these origins, experience does not justify the belief that they will be of great importance. For instance, if a copper deposit is associated with heavy anhydrous gangue minerals, and has irregular boundaries, it can not be expected to prove comparable in richness and extent to the great copper deposits produced by aqueous solutions.

It is my hope that mining engineers and geologists will study ore deposits in various regions with reference to the principles discussed in this treatise. It appears to me that he who does this will be capable of interpreting better than before the phenomena which he finds in the ore body or bodies with which he is particularly concerned.

In addition to the points specially emphasized in this volume, accurate descriptions should be made of the relations of the different minerals of ore deposits, of the occurrence of each ore mineral with reference to the wall rocks, and of the variations of the ores in composition and richness at rarious depths, reckoning both above and below the level of ground water. Moreover, such a study should include close observation of the gangue minerals in their relations to one another and to the valuable minerals, for in many instances they give important testimony as to the origin of the ore deposit. A study should be made of the stratigraphy, including the changes of country rocks and wall rocks, the pervious and impervious formations, the phenomena of deformation, such as folding, faulting, jointing, brecciation, secondary structures, etc. The volcanisin of the district should be fully investigated. Finally, the general netamorphism should be worked out. In short, my point of view is that the principles controlling the 
deposition of ores must be interpreted in the light of the general principles of geology and especially of metamorphism. It is believed that when a comprehensive study of various ore-bearing districts has been made from this point of view a more satisfactory treatise upon ore deposits may be written than has yet appeared.

Such a study of ore deposits must be a difficult one, involving as it does a working knowledge of stratigraply, of physical geology in its broadest and most intricate aspects, of petrology, including igneous, sedimentary, and metamorphic rocks, of mineralogy, and of modern physical chemistry. Undoubtedly many ore deposits will be found to be exceedingly complex and not to come fully within the scope of the principles discussed. So far as any ore deposit fails to do this, it will give data upon which to state a more nearly complete theory of ore deposits than that here proposed. 



\section{N D E X.}

A.

Absorption, capacity of rocks for, an index to power of transmission 155 Acid rocks, resistance of, to weathering .......... $532-533$ Acid salts, instance of ......................... 84 Acids, definitions of

solution of, by rock weathering ............. 536,537 strength of, dependence of, on degree of dissociation.

strong and weak, discussion of ................ work of, in ground-water solutions ............

Acmite, chemical and physical constants of ...... 195,271 occurrence of .......... 273 somr'ce and mode of origin of _. $273,280,286,289,369,378$ Actinolite, alterations and alteration products of . $290,372,375,398,399$

chemical and physical constants of 195,283 formation of, from ankerite, chemical reaction involved in.

occurrence of.

sources and mode of formation of . _... _ _.... - 243,268 $270,271,274,277,279,283-284,286-287,309$, $310,354,369,376,379,382,388,391,40 \%, 408$

Actinolite-magnetite-quartz rock, origin of . . .... 834-841 photomicrograph of ........................ 836 Actinolitic marbles, origin of ..................... 833

Adams, F. D., figures cited from . ............. 674,814

on deformation of quartz grains in rocks ....... 695 on granulation and recrystallization as affected by water content of rocks .......

on mechanical granulation of anorthosite......

on rock flowage by granulation :............ 759

Adams, F. D., and Barlow, A. E., on schist conglomerates

Adams, F. D., and Nicolson, J. T., on deformation of calcitecrystals

on deformation of marble under pressure .... 49,670, $681,696,747,77 \%, 809,811,81 \%, 814,815,816,1012$ on mobility of calcite.

Adams, G. I., on chert beds of Missouri

Adaptation of minerals to environgent, tions of .............................

Adhesion, influence of, in ground-water circulation - 150-15e

Adsorption, phenomena of Agirite, chemical and physical constants of ....... 195 Aggregation, state of, in rocks, effect of, on rate of weathering . ................... 533-534

Agricnlture, eftect of, on ground-water level...... 427 effect of, on run-offi. ............ 415 on soils

Aikman, C. M., on nitrogen compounds, decomposition of .
An nitrogen precipitated from the air, amount
on of

on oxygen in soils, amount of ................. 470 on reduction of nitrates to nitrites .............. 472 on temperature at which bacteria show maximum activity ..................... 466

Air, chemical composition of .................... 944 See also Atmosphere.

Albite, alteration of, to analcite and quartz, volume changes produced by alterations and alteration products of ....... 260-265, $366,372,375,398,400,404$

chemical and physical constants of .......... 195,259 sources and mode of formation of. $260,261,265,274,281$, $294,333,334,335,366,369,375,376,377,384,386$ $388,389,392,393,396,397,400,404,405,406,40 \div$

Albite and anorthite, alterations and alteration products of ...... . . $375,376,377,39 \%, 398$

Albite and gibbsite, alterations and alteration products of .............. 3400 Albite and halite, alterations and alteration prod ucts of . . .

Albite, anorthite, and leucite, alterations and alteration products of ........... $375,376,386,397$ Albite, anorthite, and microcline, alterations and alteration products of .............. 389 Albite, anortbite, and orthoclase, alterations and alteration products of ...... $375,377,389,404$

Albite-gneiss, photomicrograph of -

Albite-schist, thin section of ......................

Alfalfa, disintegration of rocks by ............. 445

Alkalies, decomposition of, in rock weathering, order of ............ 536 in arid regions, aceumnlation of . in soils, amount of, necessary to prevent agriculture

migration of, to surface, process of .......... 546 prevention of deposits of ............... 546 susceptibility of, to weathering ................ $\quad 632$ Alkaline rocks, susceptibility of, to weathering.- 532-533 Allanite, alterations and alteration products of .... 324 chemical and physical constants of......... 195,320 occurrence of 322

Allophane, chemical and physical constants of ... 195, 254 sources and mode of formation of .............. 369, 389

Almandite, alterationsand alteration products of , 372,375 chemical and physical constants of ........... 195, 299 occurrence of . .............................. 300-301 Almandite and pyrope, alterations and alteration products of ............ 375, 383,390,401, 404 Almandite, melanite, and pyrope, alterations and alteration products of .. $375,383,387,390,396$ 
Alteration of minerals, cbemical reactions and rolume changes involved in, table showing lassification of, with rolume changes . . . ..... 395-408 general nature of .............. $20 \%-206$ products of tables showing with addition or subtraction of material, categories and examples of . ........... 208-206

with change in chemical composition, character and conditions of

without addition or subtraction of material, categories and examples of ..........

without change in chemical composition, character and conditions of .............. 202

Alterations of rocks, general nature of ............ $31-38$ geological factors affecting ................... $40-44$ See also Metamorphism.

Aluminates, deposition of ........................... 54

Aluminum, in earth's crust, amount and percentage of .

in rocks of different kinds, proportions of . . ....- 984 minerals containing ............................ 628 decomposition of, in rock weathering, order

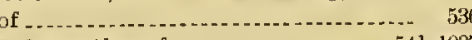

Aluminum ores, formation of ................. 541, 1037 Aluminum-silicate group of minerals, character, occurrence, formation, and alterations of .......... 316-319 Amesite, alterations and alteration products of -. 347-348 chemical and physical constants of ........... 196, 345 occur'rence of . source and mode of formation of .............. 302, $304,328,369,390,373,399,403$ Ammonia, production of, from urea, formula for reaction Amorphons componds, erystallization and conden . Amphiboles, alterations and aiteration products of _282, 354 ehemical and physical constants of (.....- 195, 197,281 formation of, from limestones................ 822 from pyroxenes ....................... 276-278 occurrence of . ........... 281-282 percentage of, in igneous rocks................ 937 peurces and mode of formation of . ........... 274 $276-278,354,380,383,394,822$

See also names of minerals of the group, Actinolite, etc.

Amphibole-gabbro, mineral composition of, and volume changes possible in ........ 692-63\%

Analcite, alterations and alteration products of . _ 333-335, $366,372,376,401$

chemical and physical constants of . . .... . . .... 195, 330 occurrence of . . . . sources and mode of formation of .......... 260,266, $267,292,293,295,296,334,335,366,369$ $375,386,388,392,39 \%, 398,400,402,404$

Analcite and quartz, alterations and alteration products of ........................ 375,407

production of, from alhite, volume change incident to -................... $632-633$

Anamorphism, propriety of use of term _......... 169 zone of, chemical ebanges and reactions in ..... 93-94, $168,171,180,181,186,590,675-707,764-766$

chemical reactions in, heat effects of . ..... 110-111 common to zone of katamorphism and. 181-182 opposed to those taking place in zone of katamorphism .............. 181,366-369 thermal and volume conditions and effects of $167,170,186$
Anamorphism, zone of, circclation of gaseous solutions in .................... 1020-102 zone of, condensation of volume of rocks in..... 169 conditions and materials in ............ 668-670 definition of . . . . deformation in . ..... . . . . . . . . . . . 1011-1012 energy required for ................. 769-774 dehydration in . . deoxidation in .................. 169,955 factors dominant in . gaseous solutions in, circulation of ...... 1020-1021 gradation between, and zone of katamorphism ........................... 191

igneous work in . ....................... 707-748 materials and conditions in . mechanical work in ....................... $600-675$ minerals formed in . ..... . . . . . . . . . . $169,363-364$ oxidation and deoxidation in, thermal and volume changes involved in.

relation of, to zones of fracture and flowage _........ 187, 190 to zone of katamor phism ..... 170-186, 766-768 rock flowage in ................. rocks formed in, character of ........ 169 silication in . . . specific gravities of minerals in ... 169, 363-364,924 temperature conditions in . thermal effects of chemical reactions in.... $\quad 170$ volume changes in . .................. 167, 182-183 water in, circulation of ........... 1:8, 129, 661-668 condition of . ....................... 659-661 quantity of .. .......... 661 work in, chomical. ............ 675-706 igneous .... $707-748$ mechanical.......................... 670-675 Anatase, alterations and alteration products of ...$231,374,388$

chemical and physical constants of .......... 199,230 occurrence of . sources and modes of formation of ............ 297 $228,230-231,355,371,385,386,393,396,405$ Andalusite, alterations and alteration products of .

chemical and physical constants of . . _...... 195,316 occur rence and mineral associates of .......... 316 Andesine, mineral composition and physical constants of .............................

occurrence, alterations, and alteration products of . Anglesite, reaction of, on calcium carbonate, equation showing - 1147 Anhydrite, alterations and alteration products of.. 357 , 372,402

chemical and physical constants of ........ 195, 357,788 sour ce and mode of formation of . . _........... $35 \%$ $358,369,384,400,788-789$ Anthophyllite, source and mode of formation of ... 310 Anhydrous minerals, order of decomposition of .... 533 Animals, abundance of, favorable to decomposition of rocks .

phospbates and nitrates produced by .......... 542-543 scarcity of, favorable to rock disintegration without decomposition............ 500

work of, in soils................. 447-451, 456-45\%, 504-50 Ankerite, alterations and alteration products of . 242-243, $372,405,408$

chemical and physical constants of ........... 195, 737 formation of actinolite from, chemical reaction involved in ........................ 837 


\section{INDEX.}

Ankerite, formation of sahlite from, chemical reaction involved in .................. 838 sources and modes of formation of $242-243,625,823-889$ Ankerite and parankerite, alterations and alteration products of ..

Ankerite and quartz, alterations and alteration products of ..................... 376,407

Ankerite, parankerite, and quartz, alt rations and alteration products of ..............

Anorthite, alteration of, to gismondite, volume change incident to

alteration of, to thomsonite, volume change incident to

\section{6}

633

alterations and alteration products of ......... 260, $261,264,367,372,376,377,402,404$

chemical and physical constants of ......... 195,259

oceurrence of . .

sources and modes of formation of ....... $260,264,367$

Anorthite, trisilicic, alterations and alteration products of ............................. 262

chemical and physical constants of

Anorthite, albite, and leucite, alterations and alteration products of ........... $375,376,386,397$

Anorthite, albite, and microcline, alterations and alteration products of ................

Anorthite, albite, and orthoclase, alterations and alteration products of ....... $375,377,389,404$

Anorthite and albite, alterations and alteration products of ............ $375,376,377,397,398$

Anorthite and calcite, alterations and alteration products of

products of products of .

Anorthite and olivine, alterations and alteration products of...................... 388,408

Anorthoclase, aiterations and alteration products of 258 $259,369,370,371,372,377,398$

chemical and physical constants of 195,253

occurrence of .........

sources and modes of formation of ........... 258

Anorthoclase and gibbsite, alterations and alteration products of ................ $377,400,401$

Anorthoclase, hematite, and calcite, alterations and alteration products of ............ 377

Anthon, E. F., on order of disappearance of the metals on oxidation. 1141

on precipitation of sulphides............... 1114,1116

Anthophyllite, alterations and alteration products of . . . . .

chemical and physical constants of ......... 195,281

occurrence of .

sources and modes of formation of ............ 268 , $270,271,282,309,310,354,369,379,382,388,399,406$

Ants, work of. on soils ..................... 448,449 Apatite, alterations and alteration products of ....

occurrence of . . . . 35.356

chemical and physical constants of .......... 195, 356

Aphrosiderite, chemical and physical constants of 195,327

sour'ces and modes of formation of .... .......... 303 , $304-305,369,376,383,390,404$

Apo, definition of term ............... $776-777$

Apophyllite, alterations and alteration product of. $\quad 333$, $334,372,378,401$

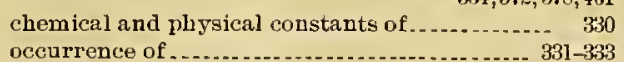
Aqueous solutions, ascending, ores precipitated from
Aqueous solutions, ascending and descending, ores precipitated from

circulation of .... descending, ores precipitated from........ 1193-1199 formation of ......... 59

metamorphic work of . $63-158$ minerals now in course of deposition by .... 1059-1060) ores deposited by ...................... 1058-1234 metals of sources of .................. 1069-1072 modification of, by gaseous solutions....... $1: 39$ precipitation of minerals by reactions between 116-119 precipitation of minerals by reactions between gases and........................... 119 source of water of work of, in segregating ores............. $1(7 \%-1199$ Aragonite, alterations and alteration products of.. 245

$246,37 \%, 378,399$ chemical and physical constants of .......... 195, 245 occurrence of . . . . . 245,79 sources and modes of formation of ........... 245 Arches in strata, influence of, on ore deposition. 1211-1216 Arctic regions, disintegration of rocks in . ........ 498-499 Arfvedsonite, alterations and alteration products of chemical and physical constants of ........... 195, 283 occurrence of . ....................... 285 Argentite, alteration of, to silver sulphite, equation showing . . ......................... $116 t$

formation of, equation showing . . Argillite, association of gold with ............ 1095, 1096 losses in, by weathering, analyses showing. $510,515,522$ Arid regions, accumulation of alkalies in . ........ 545-546 disintegration of rocks in .................. 497 ground-water level in, as affecting depth of ore deposits ................. 1180

soils of, composition of Arizona, copper deposits of, secondary enrichment of . 1184 Arkansas, limestone from, losses in, by weather-

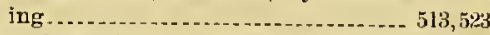
syenite from, losses in, by weathering, analyses showing ........................ 508,5\%

Arkansas River, ground water of, rate of flow of Arrhenius, Svante, on climatic effect of increased amount of carbon dioxide in atmosphere -... 464 Arkose, deposits of, origin and character of ...... 874-8i5 Arkoses, metamorphosed, discrimination of ...... 909-910 Arkose-gneiss, deposits of, origin and character of $875-876$ Arkose-schist, deposits of, origin and character of $875-876$ Artesian water, flow of, loss of head in ........... 142 Artesian wells, section showing requisite conditions for ............................ queous solutions, ores deposited by .... 10:2

See also Water, ground, ascending.

Ascending and descending aqueous solutions, ores deposited from -...... 1139-1193, 1234, 1\%35; Aspen district, Colorado, silver-lead deposits of, theory of formation of .......... 1084 Atmosphere, chemical composition of............. 944 percentage of known matter of glohe formed by A ugé, on bauxite deposits................ 985 Augite, alterations and alteration products of .... $\quad 273$ $277-280,372,378,397,399,408$ chemical and physical constants of .......... 195,271 occurrence of . ............................ 272 
l'age.

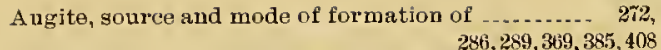
A ugite, siderite, and magnesite, alteration products of ................ $3 \pi 8,408$ Austin, L. W., and Thwing, C. B., on volume of water at different temperatures....

Australia, gold fields of, secondary enrichment in $1185-1186$

ore deposits of, infinence of organic matter of wall rock on deposition of ...... 1u8\%-1088

Axinite, chemical and physical constants of ...... 195,323 occurrence of

Azurite, formation of, from malachite ............ 1159

\section{B.}

Bacteria, work of, in disintegrating plant and animal remains.

work of, in plant growth $45 \overline{0}-450,457$

Bain, H. F., figure cited from

on chert beds of Missouri

on dolomitization of limestone by ascending waters............................... 800,807

on lead and zine ores of the Mississippi Valley -..... 1145, 1208

on precipitation of lead and zinc ores by mingring of solutions ............ 1114

on precipitation of lead and zinc ores by organic

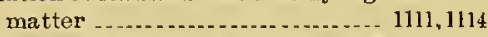

on reduction and precipitation of oxidized prod. nets by organic matter............. 1157

on secondary enrichment of ore deposits........ 1188

on secondary sphalerite in the Joplin district. .- 115

Bain, H. F., and Calvin, Samue], on dolomitization of limestone

Ball, S. H., aid rendered by, in measurement of grains of sandstone

on density of saturated solution of sodiur ride. ation of anorthosite.

on granulation

on size of grains of feldspar in original and granvlated rocks

on size of particles of sand composing sandstone -

Bancroft, G. J., on precipitation of gold by tellurides.......................................

on tellurides in the Kalgoorlie district of West Australia.............................

Banuer mine, California, vein quartz from, figure of ..................................... 1156

Barium, perceutage of, in carth's crust .......... 936,100\%

Barium oxide, percentage of, in earth's crust....... 938

Barker, G. F, on capillary and molecular attraction ............................... 150,151

on strength of surface tension of water........ 150

Barlow, A. E., on fusion of sedimentary rocks ..... 734

Barlow, A. E., and Adams, F. D., on schist-conglomerates

Barometric pressure, influence of, on ground-water level

Barus, Car 1 , on decrease of volnme of glass and hot water on solution

on miscibility of water with rock magma......

on nonaction of steam on dialase................

on potentialization of energy in strained minerals . . . . .

on solubility of glass in water ............ 79,80

$112,630,637,692,723,740,749,750$
Barus, Carl, on temperature increase with increase of depth...............................

on temperatures required for aqueo-igneous fusion ................... 729

Basalt, losses in, hy weathering, analyses showing.. 509

515,522

Bascom, Florence, on devitrification ............ 247 on use of term "apo" $\ldots \ldots \ldots \ldots 77 \%$ on weatherea dikes.

Basement complex, rocks of, hypotheses as to origin of

Bases, definition of

strength of, dependence of, on degree of dissociation

strong and weak, discussion of ................ 92

substitution of, alterations produced by ........ 408

Basic salts, instance of ............................ 84

Bastite, chemical and physical constants of ........ 195 sources and mode of formation of ........... 268, 270 , $275,278,282,285,286-287,288,290,369$ $375,378,379,381,382,391,398,399,404$

Bauxite deposits, formation of .................... 1037

Bayley, W. S., on arkose-gneiss deposits of Lake

Supertor region. .................. 876 on biotite and chlorite, mutual replacement of 179-180 on fusion of racks on Pigeon Point, Minn..... 732, 733 on schist-conglomerates ............... 860 on schists of Lake Superior region .............. 904 on water content of rocks as affecting granulation and recrystallization

Berumont, Élie de, on ore production hy gaseous solutions .................. 1053

\section{$\tau 13$} on origin of pegmatites _..................... term "agents minéralisateurs" first used hy ... $\quad 59$ Beck, R., on formation of cassiterite ............. 1127 on igneous origin of certain ore deposits ...- 1049-1050 on ores deposited from gaseous solutions....... 1054

Becke, F., chemical reactions given by ........... 261,264 on aiteration of olivine to anthophyllite ....... $\quad 310$ un alteration of orthoclase and plagioclase to alkite and other minerals ........... 264 alhite and other minerals .............
on enlargement of mineral particles.......... 644 Becker, G. F., figures cited from ................. 643,889 on bowlder-like masses produced by weathering. on consolidation of rocks. on contact metamor phism .................. $\$ 15$ on precipitation of mercury sulphide.......... 1109 on serpentinization . ........... 219,646,881 on solubility of gold ................. 1090 on solubility of sulphides _............ 1106 on strain, flow, and rupture of rocks . . ...... 600,753 on Witwatersrand banket . ................ 1041 Bedding partings, size of ........................... 138 Bedding planes, importance of, in ground-water circulation ............................

Bell, Robert, on rolume changes in rocks by weathering .................................

Belt of cementation, weathering. See Cementation; Weathering.

Belt, Thomas, on rock decomposition in tropical regions .................... 476,530-531 Bendigo gold district of Anstralia, ores formed heneath impervious arches in . . .... 1212-1213

Berea sandstone, strain in, show $n$ by quarrying... 598 Berlanite, source and mode of formation of .- $347,369,380$ Berthelot, Marcellin, on production of heat in chemical changes ................... 106-10 
Beta-spodumene, alterations and alteration products

$$
\text { of }
$$

chemical and physical constants of $\ldots \ldots-280$ sources and mode of formation of . $250-281,369,392,408$ Biddle, H. C., on precipitation of copper ......... 1102 Bingley, C. W., on devitrification ............... $\quad \mathbf{2 4 8}$ Biotite, alterations and alteration products of ... $339-343$, $354,72,378,379,396, \therefore 97,399,402$

chemical and physical constants of _..._._... 195,336 occurrence of .............................. 339 sources and modes of formation of .... $255,25 \%, 278,280$, $286,312,354,369,377,578,355,387$, $389,393,394,597,: 99,400,401,405$ Biotite and hematite, alterations and alteration products of .............. $379,396,398,401$ Biotite-chlorite, chemical and physical constants of. $\quad 195$ source of .

Biotite-graywacke, photomicrographs of .......... 888

Biotite-slat $\theta$, photomicrograph of ............... 902

Birkinbine, John, on magnetite beach sands of New Zealand ...... 1039

Bischof, Gustav, on carbonation of silicates _ _ _ 175-176 on carbon dioxide in earth's crist.............. 474 on carbonic acid in ground waters _.......... 610 on carbono-silicic cycle of metamor phism. 176-1\% , 181 on decomposition of silicates by alkaline carbonates..

on interchange of carbon dioxide and silica in chemical reactions at different temperatures .-

on magnesium content of corals and marine she1ls

on oxygen contained in ground waters, amount of

on penetration of basalt by water. on precipitation of calcium and magnesium car bonates, order of

on replacement of carbonic acid by gilicic acid on sea water, density of

Biake, R. F., on effect of work of burrowing animals on soils ............................

Blake, R. F., and Letts, E. A., on amount of oxygen in soils

on bicarbonates in zone of weathering ........ on carbon dioxide in the atmosphere............ on carbon dioxide in soils.---5

Blake, W. P., on ore deposits at Ducktown on organic matter, action of, in reducing and precipitating oxidized products $115 \pi, 1158$

on precipitation of lead and zinc by organic matter .

Blende, secondary, figure showing .............. 1156

Blow, A. A., on ore deposits of Leadville, Colo..... 1214 Blue Mountains, Oreg., copper deposits of ..... 1055-1056 Bog iron ore, formation of deposits of. ............ 550

Bohemia, basalt from, losses in, by weathering ... 509, 592 phonolite from, lasses in, by weathering ....... 512 Boration, definition of ................. 206

Bornite, production of, reactions showing ........-. 1162 zone of deposition of .

Bornstein, Hans, and Landolt, Richard, on viscosity of water at different temperatures.. $\quad 141$

Boulder Hot Springs, Mont., mineral vein formation at . . . . . 1059-1060, 1064, 1066, 1068 sources of water of

Boussingault, $J$. B., on amount of carbon dioxide emitted by volcanoos 10

MON XLVII-04- 79
Bonssingault, J. B., and Lewy, B., on carbon dioxide Page. Bowlder, in soils. ............... 4 it Bowlders of disintegration, production of Branner, J. C., on ants and termites, burrowing wo1.lr of ............... $448,449,456$ on bowlders and mountains of disintegration in Brazil -......

on carbon dioxide brought down by rain, amount of

on disintegration of rocks by changes in temperature ......................... on diurnal change of temperature in Brazil..... $\quad 436$ Brauns, R., on formation of webskyite........... उद्. Breccias, pore space in .......................... 127 Rrecciation. See Fracture.

Breunnerite, sources and mode of formation of .. 309,369 Brewster, David, on devitrification of glass. ........ Briggs, L. J., on absorbent power of soil for carbon dioxide.

Brögger, W. C., on alteration of arfredsonite to acmite......... 286

on pegmatization. Bromide of magnesium. See Magnesium bromide.

Bromine, in earth's crust, amount and percentage of in ocean, amount and percentage of . . $936,94 t, 978$ in sea salt, percentage of . .................... 942,943 Bronzite, alterations and alteration produets of - 268-271, $372,379,399,404,405$

chemical an 1 physical constants of .......... 196, 267 occurience of . Bronzite, calcite, and quartz, alteration products of ........... $379,40 \%$

Brookite, alterations and alteration products of ... 230 $\quad 231,372,3 \% 9$ chemical and physical constauts of ........... 196, 230 occurrence of ................................ 2330 sources and mode of formation of .............. $\quad 231$ Brown, R. C., on ore deposits of Butte, Mont. ..... 1183 Brucite, alterations and alteration products of.... 235, $372,379,396$ chemical and physica1 constants of .......... 196,234 occurience of sources and mode of formation of, ........... 325 , $349,369,380,385,391,396,403,404$

Bnckley, E. R., figure cited from ............ 814 on crushing strength of Berlin rhyolite-gneiss and Niagara limestone............ 534 on effect of freezing on rocks, as influenced by pore space ...................... 441 on pore space in sandstones. .......... 124, 126,569, 863 Burrowing animals, work of, on soils ......... $447-451,456$ Butte, Mont., copper ores at, secondaryenrichment of .

miñeralized zones at, copper and silver ores separately borne by .............. 1081 ore cieposits of, contiguous mineral zones in, bearing different ores.--... 1303 Bytownite, character, occurrence, frrmation, and alterations of . . . . C.

Cacti, disintegrating effects of, on rocks......... $\quad 415$ Calamine, formation of ......................... 898 Calcite, alterations and alteration prodncts of ... 235-240, $373,379,380,407,408$ 
Page. chemical and physical constant J of . .......... 196,237 mobility of . occurrence of sources and modes of formation of ... 216,237-238, 241 $245-246,273,274,282,285,286,298,312$, $322,358,369,375,376,377,378,379,381$ $382,383,384,385,387,390,391,393,394$ $396,397,398,399,402,407,408,624-625$

Calcite and anorthite, alterations and alteration products of ......................... 377,400

Calcite and quartz, alterations and alteration products of .

Calcite, anorthoclase, and hematite, alterations and alteration products of . .............

Calcite, bronzite, and quartz, alterations and alteration products of ................. 37,

Calcite, diaspore, and quartz, alterations and alteration products of . . ..........

Calcite, forsterite, and quartz, alterations and alteration products of

Calcite, gibbsite, and quartz, alterations anci alteration products of .

Caicite, hematite, and microcline, alterations and alteration products of . ............ 389, 401

Calcite, hematite, and orthoclase, alterations and alteration products of ............... 359,401

Calcite, hypersthene, and quartz, alterations and alteration products of . ............. 379,407

Calcite, ilmenite, and quartz, alterations and alteration products of...................... 385, 408

Calcite, olivine, and quartz, alterations and alteration products of.

Calcite, quartz, and corundum, alterations and alteration products of .............. 381,408

Calcite, quartz, and rutile, alterations and altereation products of ................ 391,407

Calcium, agricultural benefits of, in soils .......... 92 in earth's crust, amount and percentage of ..... 934,

in acean amount of $\quad 956,990$

in sea salt, percentage of

occurrence and combinations of -

Calcium-bearing minerals, deposition of ........... 627

Calcium carbonate, amount of, annually removed

from soil ................... 486

deposition of . deposits of, metamorphism of _... _.......... $795-797$

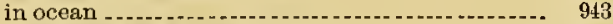

in salts of sea water .......... 943

solution and precipitation of ........... 119, 539,557-558

Calcium-magnesium-carbonate family of rocks, deposits composing -.................791-823

Calcium oxide, percentage of, in earth's crust.. 934,937, 938 See also Lime.

Calcium sulphate, amount of, annually removed

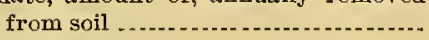

amount of, in ocean

in salt of sea water ..........................

production of, equation showing reaction for.--

solubility of, in salt water. ...................

California, depth of disintegration of rocks in

ground water in, rate of flow of ................ 585

Calvin, Samuel, and Bain, H. F., on dolomitization of limestone

Cameron, F. K., on absolption of carbon dioxide by soils

Cameron, F. K., on adsorption.

Page.

on alkaline reaction of sodium silicate in solu-

tion

on hydrolysis in case of aluminatesand ferrates. on osmotic pressure on precipitation of alumina and ferric oxides... on solubility of gypsum and calcium carbonate in salt water.

on solutions . ................................... 58

Camp Bird mine, Colorado, ore seams in secondary fractures at

Cancrinite, alterations and alteration products of.- 294 295373.379 .402

chemical and physical constants of ...._._... 196, 292 occurrence of ....... 294

Capillarity, definition of .......................... 152

effect of, on level of ground water.............. 412 influence of, in ground-water circulation ..... 151-15? upward transfer of material by ............... $\quad 549$ Capillary openings in rocks, flow of water in ..... 138-143 Capillary, subcapillary, and supereapillary openings in rocks, sizes of ......... 135-136, 138, 145-146

Carbon, chemical relations of, to silicon, discussion of .................................. 173-17\% in atmosphere . in earth's crust . . .................... 936,938,962-97t in igneous rocks . . in meteorites. . . ............... 964 in ocean ........................ 944,969,965, 967-968 in sea salt . . . . . . . oxidation of, in belt of weatbering ........... 461-465 replacement of, by silicon, discussion of _.... 175-177 segregation of, modes and extent of......... 964-967 Carbon-bearing minerals, deposition of ............ 698

Carbon compounds, specific volumes of, compared with volumes of similar silicon com-

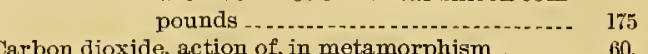

\section{6} 87 73

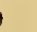
.

.

dioxide, action of, in metamorphism ....... 60 ,

action of solutions of, on minerals. ........ $475-476$ appropriation of, by plants, effects of .......... 452 emitted by fumaroles and solfataras, sources of. $\quad 492$ gravitational gatbering of, from interstellar space

in atmosphere, amount of $\quad 472,474,962-963$ increase of, by buman agencies . ....... 457,463-465 now and formerly, amount and proportion

of ........................... 949-950,956, 864-965 in earth's crust, percentage of ............ 938 in rain water, amount of . in rocks, as liquid........................... $746-747$ in salts of sea water, percentage of ............ 942 ' in sedimentary rocks...... . . ............ $965,966,973$

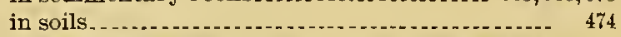
increasing amount of, thrown into atmosphere, results of . influence of pressure on action of liberation of, by erosion.................... $969-970$ pressure of, at earth's surface production of, conditions favoring ............ 609 by combustion of coal replacement of, by silicon dioxide............ 173-177 replacement of silicates by segregation of, by gravity from interstellar space ....... 973 sources of, in metamorphism .. $164,609,610,950,967-974$ work of, in metamorphism ........ $60,61,62,71,165$ 

tion of quartz veins with. ....... 1094-1095 tion of quartz veins with....

Carbonate order of rocks, deposits of . Carbonates, cement-forming, in helt of cementa tion, enumeration of ..................

character, occurrence, formation, and alterntions of

chemical relations of, to silicates .

$236-245$

decomposition of, by silica

deposition of, conditions of $173-177$ $176-177$

formation of, extent of $971-979$

in belt of cementation

angue-forming, depcsition of............. 1128-1129

in waters of mineral springs, content of '..... 611

solubility of, increase of, by pressure _.......... 78

Carbonation, alteration produced by ........... 396

definition of ............ 204-205

depth and pressure at which silication re-

places ............................ 180-181

discussion of . ....... $473-480,608-612$ extent of . . . . . . . . . . .

as compared with extent of silication .... 971-972

in belt of weathering . .................. 163,479

in belt of cementation..................... 164

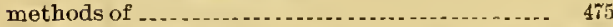

method and extent of, in zone of katamorphism. 161 $163,164-165$

of silicates, discussion of $175-176$

relations of, to vegetation

source of carhon dioxide for, in zone of kata-

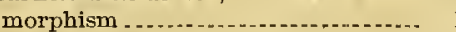

volume changes incident to .......... $478-479$

Carbonation and defluoridation, alteration pioduced by ...................................

Carbonation and dehydration, alterations pro-
duced by

Carbonation and dehydration, alterations pro
duced by Carbonation and deoxidation, alterations produced hy

Carbonation and desilication, alterations prodnced and hydration, alterations produced

Carbonation and hydration, alterations produced deoxidation, and dehydration, altera-

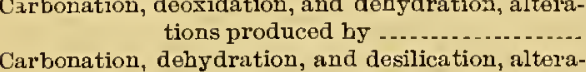
tions produced by :-

Carbonation, dehydration, and desulphation, alterations produced by .

Carbonation, hydration, and dechloridation, alterations produced by -...............

Carbonation, hydration, and desilication, alterations produced by -...

Carbonation, hydration, oxidation, and desilication, alterations produced by .......-

Carbonation, hydration, and desulphation, alterations produced by

Carhonation, hydration, and silication, alteration

produced by ......................... of

Carbonation, oxidation, dehydration, and desilication, alterations produced by

Carbonic acid, acids replaced by -

dissociation of, equation showing ...............

importance of, in metamorphism.
Carbic " Page. in ground-water solutions, work of ............ in salts of sea water, percentrgo of ............. 942 replacement of, by silicic acid ............. 94 replacemeut of, by silicic acid, rolume changes resulting from See also Carbon dioxide.

Carra1'a marhle, deformation of, experiments in - 811-816 deformation of, photographs showing effects of - 814 Casehardening of locks, an illustration of chemical action hetween solids................. 56 discussion of .....

Cassiterite, deposition of, from gaseous solutions... 1054 formation of . .

Caves in lead and zine district of Missouri, features of

Cavities containing liquid, eut showing ................ 746

Cazin, F. M. F., on ore deposition................. 1111

Cellulose, composition and geological effects of .... 452 oxidation of, acids produced by .............. . $461-46$ ?

Cementation, belt of, aqueous solutions in, circulation of . . . . . . . . 1024-1028 belt of, houndaries of . belt of weathering contrasted with . ...... 166-167

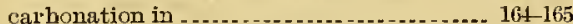
chemical changes in, variation of amount of, with varying porosity

chemical leactions in . . . . . . ... 161-167, 608-604 thermal effects of . . ................... 590 circulation in, aqueous solutions. 571-593, 1024-1028 gaseous solu tious . . . .................. 1019-1020 water ................................. 571-598 conditions and materials in, variability of .. 594 definition of ...................... 162, 164,562-565 deoxidation in ....... 164-165 gaseous solutions in, circulation of...... 1019-1020 hydration in . ...... 164-165, 612 igneous work in . ............. 646-652 limits of . . materials and conditions in. variability of .- $\quad 594$ metamorphic agents in.................... 64 name of, reasons for choosing .............. 563

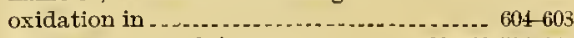
processes at work in . ............... 568-563,594-652 silicification in, dominance of . . transfer of material from belt of weathering to ........ 538 transition from belt of weathering to.... $560-56 \mathrm{l}$ variable materials and conditions of ........ 591 water in, amount of ............... $569-571$ circulation of . . . . . . . condition of $-566-569$

work in, chemical .............. $602-646$

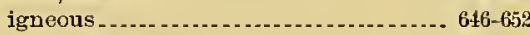

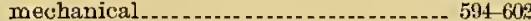
causes of . . ................... 699640 discussion of . .................................... $617-640$ in zone of anamorphism, discussion of ....... 681-68 methods of . 619-621 methods and materials of ............... $563-564$ operation of, hy igneous injections............ 634

in conjunction with metasomatism ........- 654

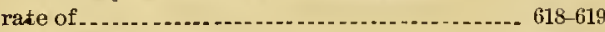
relations of diffusion to time necessary for Cementing materials in belt of cementation, discussion of.................... $621-627$ 
Page. bution of . 628 distribution of elements in . . precipitation of, principles of................ 689 similarity of, to rocks cemented........... 628 Centrosphere, definition of ter'm .................. 31, 658 Cephalonia, sea mills of, canse of water power of... 149 Cerargyrite, production of, equation showing -..... 116\% Chabazite, alterations and alteration products of .. 334 , $373,380,401$

chemical and physical constants of . . . . . . .... 196,331 occurrence of . ... . . . . . ........................ 331-333 sources and mode of formation of . ... . . . . . . $\quad 262$ $298,299,369,375,377,384,398,399$

Chalcedony, alterations and alteration products

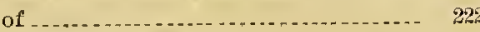
sources and mode of formation of ............. 222, $273,369,389,400$

Chalcedony and chert, alterations and alteration products of ............................

Chalcocite, alteration of, to metallic copper, equation showing - ........................ 115 production of copper from, equation showing.- 1158 production of, from cuprous and cupric sulphates, equations showing reactions for ................................. 1111

reactions involving ................... 1162,1163,116 zone of deposition of . ...................... 1160

Chalcopyrite, reactions involving . ........ 1161,116:, 1163 zon $\theta$ of deposition of ........................ 1160

Chalk, pore space in, amount of . . . . .

Challenger expedition, citations of scientific results of....... $794,942,943,944,964,967,974,991,997$

Chamberlin, T. C., on carbon dioxide drawn from interstellar spaces by gravitation ...

on carbon dioxide in air and in the ocean, bal ance between

cimatic effect of increase dioxide in atmosphere caused by use of coal...

ground water, systems of

on hydrogen in atmosphere................ 95

on hydrogen sulphide in artesian waters issuing near Lake Michican

on hydrosulphuric acid in artesian waters.. 1112-1113

on loess of Mississippi Valley ................. 501

on minerals associated with lead and zinc ores.. 1144

on ore deposits of southwestern Wisconsin ...... 1920

on organic matter as an agent in reducing and precipitating oxidized products - $115 \%, 1158$

section cited from, showing requisito conditions for artesian wells.................... 577

Chamberlin, T. C., and Salisbury, R. D., on size of particles of loess ......................

on thickness of residual clay in upper Mississippi Valley.

Chandler iron mine, Lake Superior region, figures showing occurrence of ores at . ...... 1196

Chapman, R. M., aid by, in mathematical computa-

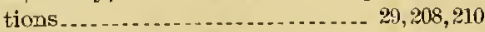

Chemical action, importance of heat in . . . ....... 105-110 metamorphic effects of . ............ . . . . production of beat by ......................... 54 relation of, to mecharical action and heat... 110-113 through solutions, definition of ................ 66

Chemical changes in ear'th's crust, temperaturo effects of ....................... 1013-1014
Page.

Chemical composition of rocks, changes in $507-518,764-766^{2}$ changes in, variation of, with porosity ........ $655-656$ effect of, on rate of weathering . ...... . . . . ... 532-533 importance of, in metamorphism ............... $\quad 359$ use of, as criterion for discriminating metamorphosed sedimentary and igneous rocks ............................. $914-915$

Chemical composition of ear'th's crust, discussion of . . Chemical compounds, heat of formation of ......... 106 Chemical effects of heat, discussion of .............. 56 Chemical elements, distribution of, as affected by metamorphism ................. 932-100: in earth's crust, percentages of, tahles showing. 984. 936,938 redistribution of . . . . . . . . . . relative abundance of .................... 192-193 Chemical energy, metamorphic effects of........... 45-46 Chemical precipitation, ore formation by ......... $103 \pi$ Chemical reactions, categories of, in zone of katamorphism - complementary, examples of . ............... 204,206 effect of pressure on .......... 100-104, 168 heat involved in ............................ 106 jeversibility of ........ . . . $87-90,110-111$ equations illus rating . ..................... 88,110 speed of increase in, with increase of temperature $-=--20 \%$ stoppage of, by pressure and heat generated by the reactions themselves............. 89

ther-mal aspects of, in zones of metamorphism .. $\quad 189$ rolume changes consequent on, energy factors involved in ........................ 170-171

principle applicable to ..................... 29:

table showing, as applied to minerals ..... 375-394 Chemical solutions, increase of solubility of, with increase of heat......................

Chemical work, combination of, with mechanical work, in metamorphism ............. $49 \bar{\jmath}-49$ i

in belt of cementation, discussion of ......... $602-641$ in belt of weathering, agents and their work in -.......... $451-488$ in metamorphism, combinations and relations of, to mechanical and igneous work_ 653

in zone of anamorphism, discussion of ....... 675-706 Chemical-physical factors on which natur' of alter tions depends . - - $359-36$

Chemical-physical principles applicable to action of ground water ................... 65-1:3 Chert, alterations and alteration products of ....... 222 concretionary, photomicrograph of ............ 836

definition of ........................... 816 deposits of, origin and features of . ............ $847-853$

ferruginous, origin of . ............ . ......... $899,830-831$ sources of .......... Chert and chalcedony, alterations and alteration products of ....................... 380

Cherty limestones, weathered forms of ........... 529 Cherty limestones, dolomites, and marbles, features and origin of ............ $816-820$

Chicago, artesian wells at, conclusions drawn from flow of, as to friction of water flow in Potsdam sandstone................. $58 \%$

loss of head of artesian waters at.............. 142 Chicago, University of, aid hy students of́........ Chile, nitrate deposits in .......................... 543 
lage.

Chloridation, alterations produced by definition of.

Cbloride of maguesium. See Magnesium chloride. Chloride of sodium. See Sodinm chloride.

Chloride order of rocks, deposits composing ...... $789-790$ Chlorine, emission of, during volcanic eruptions, ohservations on in earth's crust and in the ocean, amount of .. 978-979 in earth's crust, percentage of . in ocean, amount of .

in sea salt, percemtare of -

Chlorophyllite, chemical and physical constants of -.

- 196,291

source and mode of formation of $291,370,386,40^{\circ}$ Chlorites, alterations and alteration products of ... $34 i-$ $348,3 \pi 3,380$

chemical and pliysical constants of ........ 196,345-346 occurrence of . sources and modes of formation of ....... 273,275-276, $278,285,287,290,302,303,304,322,324$ $326,327,328,339,340,341,342,343,347$, $353,354,369,375,378,381,382,384,386$ $389,390,391,393,398,402,403,404,625$

See also names of minerals of the group, Amesite, etc.

Chloritoid, alterations and alteration products of .- $\quad 345$ chemical and physical constants of . ......... 196,344

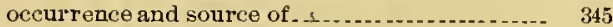
porplyyritic, thin section of ................ 704 sources and modes of formation of ..........

Chondrodite, alterations and alteration products of . 325 $3 \pi 3,380,403$

chemical and physical constants of . .......... 196,325 occurrence of 325

Chromite, occurrence of ........... . . . . 228, 229-230 chemical and physical constants of . . ......... 196, 228 source and mode of formation of . . . . . . . . . 309,370

Chrominm in earth's crust, percentage of . 936, 1002

Chrustschoff, $K$. Fon, on laboratory production of certain ininerals................... 685

on minerals obtainable from water solutions at high temperature and pressure..... $105 \%$

Chrysolites, alterations and alteration products of .......... 308-311

chemical and physical constants of ......... 199,308 occurrence of . Cimolite, chemical and physical constants of ..... 196.254 sources of

Circulation of ground water, canses of, summary.- $\quad 152$ factor opposing......................... 153-154 forces and movements involved in .... 146-152,416-423 influence of size and continuity of rock openings on speed of . . $154-155$ rapidity of factors determining ............. 154-15̃5 Sre also Ground water; Water.

Clarke, F. W., on alterations of albite and anorthite_ $\quad 264$ on atmosphere, hydrosphere, and litrosphere, chemical composition of

on carbon in earth's crust.

on carhon in shales

on chemical action in solutions, throry of

on chlorophyllite, formation of, from iolite....

on clays and soils, average chemical composition of

on "crust of the ear th," definition of terni on depth limit of observation of earth"s structure
Clarke, F. W., on earth's crust, chemical composi-

tion of . $192-193,934-938,959,974,975,981,9833$,

$984,986,987,989,990,992,993,999,1000,100 \%$

on feldspar minerals, abundance of .......... relations of, to zeolites ................. 261 on ferric oxide in clays and shales, amount of.- 898 on igneous and crystalline rocks, average chemjeal composition of ............. 889,890 on iron (metallic) in original igneous rocks, amount of . on lithosphere, limits of on mesolite...................... 262 on ocean, chemical composition of .............. 944 on oxygen in earth's crust, percentage of...... 948 on penninite, composition of ................. 344 on quartz, abundance of ................. 217 on shales, a verage chemical composition of... 890,891 on silicates, alkaline reaction of . . ............. 86,87 on tourmaline, constitution of ............... 326 on water combined in rocks, amount of........ 162 on zeolites, alterations of composition of ........... 329

Clarke, F. W., and Hillebrand, W. F., on chemical action in solutions, theory of ........ 68

on rock analyses .................. 693 on rocks of Pigeon Point, Minn, composition of . on slate, chemical composition of on water content of rocks, relation of, to recrystallization . .

Clay, chemical composition of . ............. 891

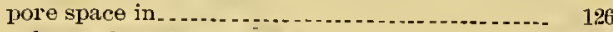
volume changes requisite to produce.......... 523-5i24 Clay soils, effect of freezing on . .................... 443 Clearage, display of, by weathering ............. $52^{2}$ meaning of . . monoclinal, existence of, over extensiveareas. 9:28-931 Clements, J. M., on cementing material and rock cemented, similarity of.............. 628 or chert rocks of Lake Superior region ........ 851 on contact metamorphism _.................. 650 on Crystal Falls folcanics.................... 1078 on devitrification on schists of Lake Superior region ............ 904 on secondary sulphides and magnetite, association of ....... 1112 Cleopatra's Needle, Central Park, New York, effect of freezing and thawing on........ 441-442 Climate, effect of, on metamorphism............. 41 Climatic changes, infuence of, on lerel of ground water..................................

Clinochlore, alterations and alteration products of . $347-348$ chemical and physical constants of .......... 196,346 occurrence of ...................... 346-34 sourees and modes of formation of . . . . ... 344,370,390 Clinohnmite, alterations and alteration products of . . . . . . . . . . . . . . . $35,373,380,403$

chemical and physical constants of .......... 196,3\% occurrence of .............. 325 Clintonites, alteration aud alteration products of... chemical and physical constants of .............. 344 occurrence, sources, and modes of formation of

Clin tonite group of minerals, character, occurrence, formation, and alterations of . .... 344-345 see also Chloritoid; Margarite; Ottrelite. 
Coal, earbon in, l'age. carbon dioxide produced by combustion of amount of

Coal beds, formation of

Coarse-grained rocks, rate of weathering of, as compared with that of fine-grained rocks . $533-534$

Cohesion, influence of, in ground-water circula-

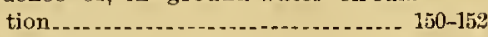

Colloidal silica, silicification by $\ldots \ldots \ldots \ldots$............ 510,517

Colorado, Aspen district of, silver-lead deposits of _ 1081 San Juan district of. See San Juan district.

Comey, A. M., on solubility of the sulphates..... 10\%, 1108

Comminution, effect of, on amount of soluble raa. terial in soils.......................... 495

Complementary reactions, examples of ........ 204, 206 Composition, chemical, importance of, in motamor-

$\begin{array}{rrr}\text { phism } & 359 \\ \text { Comstock lode, history of exploitation of } \ldots \ldots \ldots & 1224\end{array}$ precipitation of metals at, hypothesis concerning 1083

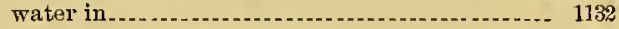
width of, variations in .................... 1221

Concentration, second, conditions favoring. .... 117\%-1179 See also Second concentration; Secondary enricbment.

Concentration of soluble material by ground water, discussion of ..................... 543-551

Concretionary ehert photomicrograph of $\ldots . . . . . .-836$

Condensation with recrystallization and mineral changes, features of ............ 102-103

Conductivity of rocks as regards heat, degree of ..- $\quad 53$

Consolidation of rocks, methods of . . . . . . . . . . .... 595-597

Contact metamorphism, direct contact effect of. - 489-490 exumorphic and endomorphic effects of ....... 488

extent of, conditions governing ............. 649-652

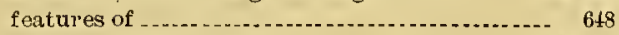

indirect contact, effect of .......... $490-494$

Conglomerate, original structure in, preservatiou of, after weathering.............. 526

Conglomerates, origin and character of . ......... 855-857 Conglomerates an\} pseudo-conglomerates, discrimination between, criteria for......... 910

Conglomerate-schist, origin and character of . Conn, H. W., on nitrogen compounds, decomposition of

on nitrogen in soils, loss of, by manufacture of

explosive powders.................. 466

Copper and iron compounds, association of..... 1158-1163 Copper ores, formation of . . . . . . . . . .... 1062, 1158-1166 of Lake Superior region, features of . . . ..... 1204-1205 origin of . . . of Oregon, types of secondary enrichment of...................... 1184 Copper Queen mine, Arizona, secondary enrichment at Coquand, Henri, cited on bauxite deposits .......... 985 Coral limestones, dolomitization of ................. $799-800$ Corals, magnesium content of .............. . .... 798 Coldierite, alterations and alteration products of:- 291 , $373,386,402$ chemical and physical constants of ....... ...... 198,291 occurrence of . Cornwall, Pa., iron o1e deposits at .............. 1198 Corundophilite, alterations and alteration products of ................ 34i 34 chemical and physical constants of $\ldots$
Page. Corundophilite, occurrence of .................. $346-347$
sources and mode of formation of ........... 318,347 Corundum, alterations and alteration products of ............ 223-225, 373,380,381,402,408

chemical formula of, physical constants of, and other data concerning ............. 196, 223

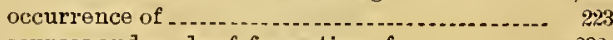
sources and mode of formation of ........... 232, $235-236,318,328,367,370,331,383,400,624$ Corundum and magnesite, alterations and altoration products of ................... 381,40) Cornndum and quartz, alterations and alteration products of - calcite, alterations and alCorundum, quartz, and calcite, altelations and alteration products of .............. 381, 408 Corundum, quartz, and potassium carbonate, alterations and alteration products of .. 381,408 Corundum-syenite, deposits of Cottr, B. von, on contact metamorphic origin of

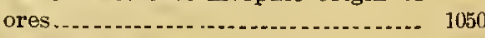
Covellite, zone of deposition of .............. 1160 Cramer, Frank, on strain in rocks Credner, H., on origin of pegmatites ........... Cripple Creek mining district, Colorado, fracturing in, complex character of

gold ores of . . ore deposits at, origin of ...................... 1085 ore sboots near, intersecting fractures in ...... 1227 oxidation in, depth of ........................... 1181

replacement of igneous rocks by ores in ........ 1205 Crosby, W. F., and Crosby, W. O., on cause of water

power of sea mills of Cephalonia --.-
Crosby, W. O., on induration of Pikes Peak granite along joints

031 red color of soils, cause of Crosby, W. O, and Fuller, M. L., on origin of pegmatites ............... 722,72 Cross, Whitman, on fluviate origin of pseplites of Cordilleras . ..........................

Cross, Whitman, Iddings, J. P., Pirsson, L. V., and Wasbington, H.S., on mineral composition of a mphibole-gabbro

Crustification, examples of .................... 1146 Crystalline rocks, average chemical composition of

Crystalline and igneous rocks, analyses of ....... 934-935 Crystalline form, symmetry of, influence of, on stability of minelals. ............... $360-361$

Crystallization, alteration of rocks by ............. 203

effect of pressure on .............. 103

effect of temperature on ....................... 78

importance of, in metamorphism ............. it

methods of ........ $i 4-i 6$

Culver, G. E., and Hobbs, W. H., on decomposition of olivine-diabase in South Dakota .. 560

cummingtonite, alterations and alteration products of.

chemical aud physical constants of ............ 196,283 occurrence of - 28 Cupric salts, reactions in rolving. ...... 1161,1162, 1163,1164 Cupric sulphate, production of chalcocite from, eqnation showing reaction for ....... 1111

reactions involving . . - . . . . . . . . reversible reaction of, with ferlous sulphate... 1102 Cuprite, production of, equation showing........... 1158 Cuprous chloride, precipitation of gold by, equation showing .................. 192, 1082 
INDEX.

Cuprous gulphate, production of chalcocite from, equation showing reaction for....... 1111 reactions involving Curtis, J. S., on genesis of ore deposits ............. 1206 on ore deposits of Eureka, Ner . .............. 1204 on Witwatersiand banket...................... 1041 Cushing, H. P., on effects of freezing and thawing on rocks in Alasket Cyanite, alterations and alteration products of... 318-319, $373,381,402$ chemical and physical constants of ............ 196,316 occurrence and associations of. sources and modes of formation of. $223,224,225,232,236$, $317,318,319,370,376,381,382,383,399,406,407$

Cymatolite, source of.

\section{D.}

Dale, T. N., on cleavable marbles .

Dale, T. N., Pumpelly, Raphael, and Wolff, J. E., on crystallographic orientation of porphyritic feldspars .....................

Dall, W. H., and Haxris, G. D., on phosphates ......

Dalmar, K., on zonal arrangement of metamorphic minerals peripheral to intrusive

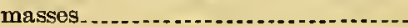
Damourite, sources and modes of formation of..... 223, $224,225,255,318,319,327,328,353,370$, See also Muscovite. $376,381,389,398,400,402,403,406,408$

Dana, E. S., on chlorine in sodalite.

Dana, J. D., on composition of dolomitic coral lime stone

on magnesian deposits of coral reefs ............. on red color of soils, cause of

on sedimentary rocks, thickness of on water contained in rocks.

use made of System of Mineralogy of

Dana, J. D. and E. S., on Hautefeuille's experiments producing rutile group of minerals . on garnet, products of fusion of

on scapolites

on wernerite

on zeolites.

Dana, Mount, disintegration of rock at, by freezing and thawing

Daniell, Alfred, on capillary flow

on dissipation of energy.

on friction between ground water and containing rocks

on gaseous solutions

on heat production in all transformations of energy -...-.......................... on size of rock openings available for water fiow on surface tension of water

Darton, N. H., on flow of artesian water............ on level of ground water.

Darwin, Charles, on effect of worle of earthworms on soils

Darwin, G. H., on "stress difference"

on tidal forces of the past.

Daubree, A., on combined effect of chemical and mechanical action on minerals....... on penetration of rock by water gas under pressure

on serpentine, formation of
810 on tin ores, formation of . ............. 1058

on trituration of rocks, limit of.................

on zeolites, artificial formation of............. 333

Davis, W. M., on fluviate origin of psephites of Cordilleras

Davison, Charles, on effect of work of lobworms on

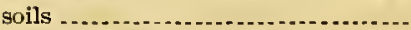

Dawson G M on peripheral structiore

Deboration, definition of ........................... 206

Deboration and decarbonation, alterations produced by ............................. 400

Decarbonation, alterations produced by ........... 400

definition of ........................................ 205

in zone of katamorpbism.................... 162

Decarbonation and deboration, alterations produced by ............................ 400

Decarbonation and bydration, alterations produced by ........................ $401-402$

Decarbonation and titanation, alterations produced by ................................... 400

Dechloridation, definition of ......................... 206

Dechloridation and hydration, alterations produced by -............ 403

Dechloridation, carbonation, and hydration, alterations produced by 398

Dechloridation, decarbonation, and hydration, alterations produced by............. 403

Decomposition of minerals in rocks, order of..... 518-521 of rocks, regions favorable to. ................. 501-506 Decomposition and solution, relations of disintegra tion to ............................. 494-507

Dedication of work

Deep circulation, deposits of, criteria for discriminating -............................ 113?-1138

Defluoridation, definition of ........ 206

Defluoridation and carbonation, alterations produced by -.............................. Deffuoridation and hydration, alterations produced
by

Deformation of minerals, relation of pressure to repidity of . ......... 141

of rocks, diagram illustrating................. 769 energy required for, in zones of katamorphism and anamorphism .................. $769-774$

lag of recrystallization behind mechanical energy a cause of _.... pressure a cause of . . . . . speed of . . .

temperature effects of ........................ 1013-1014 time relation of recrystallization to . . . . $696-698$

Dehydration, alterations produced by ............ 400

conditions and effects of .

definition of. .................................. 204

depths necessary for .

discussion of ................ 482-483

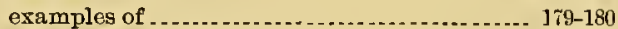

in belt of weathering .................

in zone of a namorphism................ 178,662,679-680

in zone of katamorphism............

Debydration and carbonation, alterations produced by

Dehydration, deoxidation, and carbonation, alterations produced by ............... 396

Dehydration, desilication, and carbonation, alterations produced by ......................

Dehydration, desulphation, and carbonation, alterations produced by ................... 396

\section{6




\section{INDEX.}

Dehydration, carbonation, oxidation, and desilication, alterations produced by

Debydration and decarbonation, alterations produced by.

Delamar mine, Nevada, secondary enrichment in showing former presence of circulat ing waters

Delesse, A., (?) on decrease of density by ritrification

on nonaction of dry steam on minerals .........

Demorphism, belt of, name proposed for belt of weathering

Density of minerals composing rocks, increase of with increase in depth ........... 18\%-185

with increase in depth levels by reason of . ............. 1139-1 influence of, on ground-water level .............

Deoxidation, alterations profluced by .............. definition of

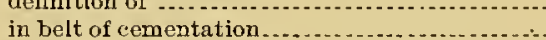

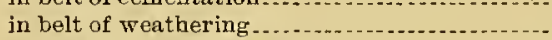

in zone of anamorphism 172,676

in zone of katamorphism....................... 162

of iron compounds in soils, examples of. ...... 471-472

Deoxidation and carbonation, alterations produced by -.......................................

Deoxidation, carbonation, and dehydration, alterations, produced by

Dephosphation, definition of

Deposition, discussion of 206 in belt of cementation, discussion of .. 165-166,612-61

Depth from earth's surface, density of minerals as determined by ..................... 18:-185

effect of, in metamor phism ............ 43-44

increase of temperature with increase of ....... $5 \pi 8$

limits of, to which rocks have been observed ...

Depth of no annual variation in temperature, probable coincidence of, with lerel of ground water............................

Derby, O. A., on hydration of rocks _............ 481

Desert raruish, reference to . ..................... 547

Descending waters, depth of effect of......... 11\%9-1181 ores precipitated from ................ 1193-1199, 1234

Desilication, agents and processes of ......... 475-476,480 alterations produced by ....................... 401 definition of .

Desilication and carbonation, alterations produced by .....................................

Desilication and hydration, alterations produced by -

Desilication, carbonation, and dehydration, alter'ations produced by

Desilication, carbonation, and hydration, alterations produced by .............. 398-399

Desilication, carbonation, hydration, and oxidation, alterations produced by

Desilication, carbonation, oxidation, and dehydration, alterations prodnced by .........

Desmine. See Stilbite.

Desulphation, definition of..

Desulphation, dehydration, and carbonation, alter ations produced by.

Desnlphation, hydration, and carbonation, alterations produced by .................

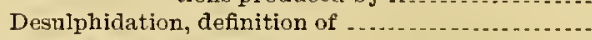
Detitanation, definition of

Deville, H. St. Claire, "agents minéralisatenrs" de fined by ..........................

Page.

Devitrification of glass, conditions governing .... 248-249 heat and $\nabla$ olume, relations of ................ 251 minerals produced by ..................... 251 scale, rate, and zonal place of . .............. 24\%-252 Diabase, losses in by weathering, analysis showing. 509 , $510-511,515,522$ Diallage, alterations and alteration products of.... 274 , 373,381

Diaspore, alterations and a]teration products of .... 232 $3 \sim 3,381,400$

chemical and physical constants of ........... 196,231 occurrence of . . ...... sources and mode of formation of . . ...... 223, 235-236, $292,296,298,299,312,318,337,343,353,370,379$, $380,383,388,390,392,397,398,400,401,402,624$

Jiaspore and magnesite, alterations and alteration prodncts of ...................... 381,401

Diaspore and quartz, alterations and alteration products of .................. 381,382,407

Diaspore group of minerals, character, occnrience, formation, and alteration of ....... 231-23t

Diaspore, quartz, and calcite, alterations and alteration products of . ................ 382,407 Diaspore, quartz, and potassium carbonate, alteration products of .................. $382,40 \pi$ Dichroite. See Tolite; Cordierite.

Dickson, C. W., on ore deposits of Sudbury, Canada. 1047 Diffusion, influence of, in cementation of rocks .. 636-639 Diffusion by solution, discussion of ................. 82-83

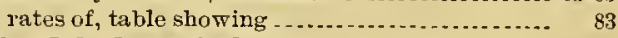
Diller, J. S., figure cited from .................. 814 Diopside, alteration of, to talc, quartz, magnetite, and calcite, rolume change incident to alterations and alteration products of ........ 273 , $274-275,277,278,373,382,398,408$ chemical and physical constants of ......... 196,271 formation of, from dolomite, chemical reaction involved in ......................... 822

occurrence of ................................. $\quad 272$ source and mode of formation of .- $241,272,370,382,407$ Diopside and magnesite, alterations and alteration prodncts of . . . ... . . . .

Diopside-augite series of minerals, character, occurrence, formation, and alterations of $272-280$

Diorite, losses in, by weathering, analyses showing. 510 ,

Dip, steepness of, effect of, on width of fissures 515,522 Disintegration of rocks, regions favorable to .... 496-501 relations of decomposition and solution to .... 494-507 temperature changes producing, examples of. $434-439$ Dissociation, theory of . . . . . .................... 84-85 Dissociation of salts in water, p'zenomena of ....... 73 Dissolved materials resulting from weathering, distribution of Disthene, alterations and alteration products of . - 318-319 chemical and physical constants of . ........... 196,316 see also Cyanite.

District of Columbia, granite from, losses of constituents in, by weathering ........ $50 \%, 5 \% 2$ Dittmar, William, on calcium in the ocean, amount of on carbon in atmosphere, amount of ........... 964 on carbon dioxide in the ocean and the air, amonnt of ......................... 967 on chlorine in the sea, amount of . ... on ocean, chemical composition of............. 944 
Dittmar, William, on ocean, Felume of

Page. on sea water, composition of .................... 79 on sodium in the ocean, amount of . . . . . . . .... 997

Deelter, C., on gold, soluhility of ............... 1089-1090 on sulphide minerals, artificial preduction of ... 1114 on sulphides, solubility of . . . . . . . . . . . .. 1106,110\% on zeolites, selubility of, in water ............. 112

Dolemite, alteratiens and alteration preducts of. 241-242, $373,38 \%, 407$ chemical and physical censtants of . . . . . . . . 197, 237 cherty, features and origin of . $816-820$ formation of, from limestone, volume change involved in ............................

formation of diopside from, chemical reaction formation of tremolite from, chemical reaction invelred in...................... 82 sources and medes of formation of ......... 238-239, $240-241,370,379,380,408,624-625,798-808$

Dolomite and quartz, alterations and alteration products of. nditions of . magnesium for, seurce of ...................... 802 occurrence of, at sea hottom . . . . . . . . . . . . . . 802-804 subaerial .

Don, J. R., on gold depesits of Australia . . . . ... 1170, 1185 on gold ores and sulphides, asseciation of .. 109j-1096,

on occurrence of gold at intersection of quartz veins and carbenaceous shales _... 1094-1095

Douglas, James, on copper deposits of Arizona .... 1086 $1183,118+, 1188$

on gypsum in Arizena mines - 1141-1142 or exysulphurets $1165-1166,1182$

Deveten, G. D., Purington, C. W., and Woeds, T.H. on occurrence of rhedonite at the Camp Bird mine, Colo ........... 1115-1116

Dry mines, mistaken inferences concerning ..... 1063-1065 Ducktown, Tenn., copper depesits at, secondary enrichment of ................ 1182,1188-1189

Dudleyite, tormation of . . . . . . source of . . .................................... 370,387 Dynamic action, metamorphic effects of ........... $42-43$ Dynamic: metamerphism, definition of ......... 47 use of term, discussion of ....................

\section{H.}

Earth, specific gravity of, discussion of facts bear-

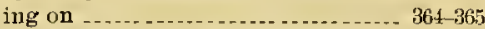
Earth mevements, effect of, ou temperature of ground water...................... 590

Earth's crust, chemical composition of ... 192-193, 933-948 deformation of ............................. 1005-1014 density of .

elements in, order of ahundance of, compared with order of abundance of elements in meteorites.

relative abundance of

movements of, in mountain making, discussion of .

percentage of known matter of glebe fermed by - 933

Earthworms, effect of work of, on seils .......... 448,456

Eldridge, G. H., on origin of phesphates ......... 976,977

Elements (chemical) in earth's crust, percentages of, tables shewing _._._. 193, 934,936,938 in earth's crust, relative abundance of ........ 192-193
Elements (native), occurrence of, as minerals Page.

Elkhorn mine, Mont., ores formed heneath imperrious arches in....................... 1214 Emez'sen, B. K., en fusion of schist by granite in

Massachusetts - 735-736 on minerals formed hy igneous intrusion ..... 717,718 on peripheral structure................ 716 on porphyritic gneisses.

Emmons, S. F., on carbenic acid in underground waters........................... 1128 on mineral veins at Butte, Mont ................ 1081 on ore deposits, genesis of ............. 1183,1200,1206 on ore depesits of Butte district, Mont .... . 1182-1183, 1203,1205 on ore depesits of Delamar mine, Ner ..... 1178-1179 on ore deposits of Leadville district, Cole .. 1168-1169, $1186,1204,1214$

on ore production from igneous rocks ........... 1043 on psephites of Cordilleras, fluviate origin of ... 854 on secondary enrichment of ore depesits ....... 1188 on tellurides associated with gold ores .......... 1119 Endomerphic effect of igneous intrusien, definition of

Endemerphism, definition of ....................... 648 Energy facter's of zones of metamerphism, censideration of . .... . Enlargement of minerals in recks hy depesition of new matter, discussion of .......... 619-621

Enophite, source of . . . . . . . . . . . . . . . . . . . . $347,370,380$ Enstatite, alterations and alteration products of ... 268, $269,373,382,397,404$ chemical and physical constants of ...... 197,267 seurces and medes of formation of .... .......... 268 $302,304-305,307,367,370,386,390$

Enter"prise mine, Rice, Celo., ore deposits at ........ 1084 $1208,1215,1229$ Environment, adaptation of minerals to ............ $33-35$ importance of, in metamorphism Epeirogenic movement, influence of, on ground water level ...................... 426 Epidote, alterations and alteration products of ... $322-323$, $373,382,383,398$

chemical and physical constants of . ......... 197,320 occurrence and associations of ............... 321 sources and modes of formation of ............ 255 $260,263,264,265,2 \% 3,2 \% 4,275-2 \% 6,285,288,303$ $305,312,313,321,339,340,341,342,353,354,370$, $377,378,379,381,382,383,384,385,387,389,390$ $391,394,396,398,399,401,402,404,405,406,625$ Epidote group of minerals, character, occurrence, formation, and alterations of ...... $320-323$ hydration of, degree of ............... 625 Epistilbite, chemical and physical constants of ... 197,330 eccurrence of ............................. . $331-333$ sources and medes of formatien of ... . . ....... 33\% $370,3 \pi 5,37 \%, 397$

Equilibrium, chemical, notes on ................. 90 Eresion, belts of ores deposited at different levels in consequence of . . . . . . ......... 1139-1140 Eucryptite, chemical and physical constants of .... 197 source and mede of fermation of . . . . $281,370,392,405$ Evaperation, influeuce of, on ground-water level ................................... 425-4:26 Exomerphic effect of igneous intrusion, definition of

Exomorphism, definition of ...................... 648 Expansion reactions, discussion of.............. $631-643$ 


\section{INDEX.}

F.

Faribault, E. R., on gold ores of Nova Scotia ....... 1213 Farrington, O. C., cited on meteorites _._. 945,946,947,964 Fassaite, source and mode of formation of .... 314,370,383 Fault openings, size of .

Fault planes, importance of, in ground-water circulation ....................................

Faults, importance of, in ground-water cireulation . . 130-131 pore space added to rocks by _............. 127

Fayalite, alterations and alteration products of .... 308 chemical and physical constants of .......... 197,308 occurrence of

Federal Loan mine, sulphureted hydrogen at .... Feldspar, alteration of, to quartz and mica, thin section showing.

fragment of, cut showing enlargement of in igneous rocks, percentage of ............... Feldspar group of minerals, character, occur rence, formation, and alterations of....- 252-265 $394,353,380,381,625-607$

Feldspar-porphyry, weathered, original structure preserved in ....................

Feldspathoid class of minerals, alterations and alteration products of............ 352-353

Ferrates, deposition of..

Ferric chloride, hydrolysis of, equation showing Fric oxide in ear'th's crust, percentage of ... 934,937,938

in sedimentary and igneous rocks, ratio of, to fer'rous oxide . .

red or yellow soils produced by ................ 469

saurces and modes of formation of ... $172,467,540-541$

Ferric sulphate, formation of, chemical reaction involved in ... $826,8: 8$

reversible reaction of, with ferric sulphate, in presence of silver................. 1100

solution of silver by, equation showing ........ 1099

Ferrodolomites, formation of ............... 242-243,625

Ferromagnesian silicates, alterations of ........... 353

Ferromagnesian sands, deposits of, character and origin of . . .

Ferrous carhonate, formation of, chemical reaction inrolved in . ..........................

origin of, from basic ferric sulphate, chemical reaction involved in .................

Ferrous chloride, precipitation of gold by, equation showing

Torrous componnds, precipitation of copper $\mathrm{by} . . . . . . . .1101$ wark of, in metamorphism ........ 165

Ferrous oxide, decomposition of, in rack weathering 536 in earth's crust, percentage of . ........... 934,937,938 in sedimentary and igneons rocks, ratio of, to ferric oxide ...................... 950-951 accurrence of ........................ $46 \%$ oxidation of.

precipitation of .

Ferrous silicate, formation of, chemical reaction involved in .................................

Ferrous sulphate, precipitation of gold by, equation showing precipitation of silver by, equation showing 1082,1100 reversible reaction of, with cupric sulphate.... 1102 reversible reaction of, with ferric sulphate, in presence of silver.................. 1100 Ferruginous cherts, origin of ................ $829,830-831$ Ferruginous slialeg, origin of . . ........ . . . . . ..... 829-830
Fine-grained rocks, rate of weathering of, as compared with that of coarse-grained rocks ...................... 533-534

Fischer, Alfred, on bacterial action in decompasition of carbolydxates .............. 463 on bacterial action in plant growth .......... 452,453 on carbon dioxide in rain water, amount of .... 474 on iron bacteria .................. 826 on nitrogen compounds, decomposition of ..... 465 Fissility, display of, hy weathering See also l'racture.

Fissility openings, importance of, in ground-water circulation ....... 131 size of 138

Fissures, width of, effect of dip on ............. 1201 Flexibility of rocks, conditions affecting ........ 188-189 Flexures, occurrence of rich ore shoots near ... 1225-1226 Flow of ground water, rate of . ................ 582-588 See also Ground water; Water.

Flow of rocks, effect of, on texturesand structures. $760-76$

Flowage, zone of, circulation of water in ......... 1029 zone of, deformation in ....... . . . . . . . ... 1011-1012 relation of zones of anamorphism and katamorphism to upper limit of

Fluid inclusions in roeks, figure showing .......... 746 sizes of cavities containing.................... 658 Fluoridation, definition of .................. 206 Fhnorides, character, occurrence, and alterations of. $\quad 216$ Fluorine, percentage of, in ear th's crust... ...... 936,1002 Fluorite, alterations and alteration product of. $373,383,396$ chemical and physical constants of ........... 197,216 occurrence and alterations of ................ 216

Foerste, A. F., Shaler, N. S., and Woodworth, J. B. on occurrence of graphitic coals...-- 212 Forces of metamolphism, consideration of. $39-40,44,45-5 r$ Forchhammer, Georg, on magnesium content of corals and marine shells forming limestone deposits ................ 798,804 on potassium silicate, dissolution of, in water .. 112 Forsterite, chemical and physical constants of ... 19i,308 occurrence and alterations of . . .... . . . . . . . .... 308,311 Forsterite, calcite, and quartz, alterations and alteration produets of

Friction, internal, of ground water, character and influence of .

Fracture, secondary, reins produced by ........... 1228 zone of circulation of aqueous solutions in _ 1022-1028 features of, and chemical reactions in . . 1005-1009 openings in ...... . . relation of zones of anamorphism and katamolphism to .

Fracture and flowage, zone of, aqueous circulation in . zone of phenomena in ... . . . . . . ........... 1009-1011

Fractures of rocks, causes and character of . ..... 599-602

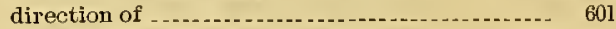
inter'sections of, or'e shoots at or near . ..... 1226-122 pore space added to rocks by ................. 127

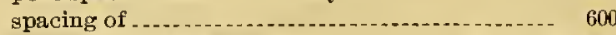

Fragmental rocks, classification of _.__ $784-78 \pi, 853-904$ deposits composing .................... . . ....... 853-904 France, basalt from, Iosses in, by weathering .... 509, 522 Franklinite, formation of .................. 1125 production of, from Smithsonite, equation showing Freezing, likeness of, to precipitation ............. 


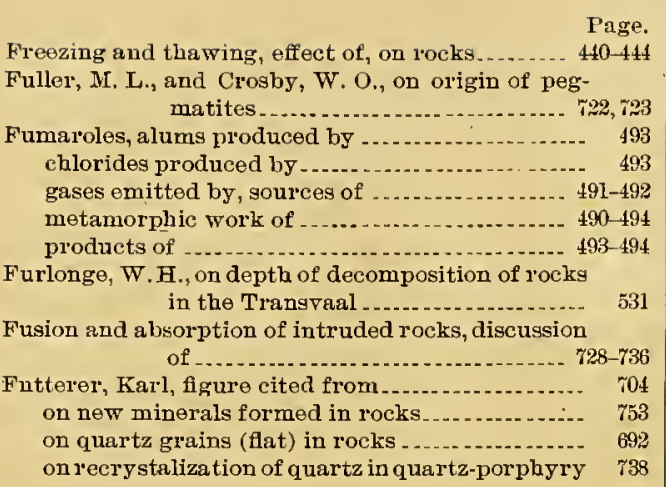
G.

Gabbro, miner:al composition of, and volnme changes possible in ........ $632-633$

Galena, occurrence and genesis of secondary, figure showing ...................... 1156

Galena limestone, strain in, shown by quarrying.-. 598

Gangue minerals of aqueous solution ores, enumeration of .................... 1233

Gangue minerals of ore deposits, citations concerning . . . 1055-1057

Gannett, Henry, on range of temperature in Alaska_ 437 Gardner, F. D., and Means, T. H., on effect of alkalies in soils 478,543

Gardner, F. D., and Stewart, John, on calcium chloride and sodium carbonate in soil at Great Salt Lake 542,543

Garnet, absorption of other minerals in rocks by :- 70 alterations and alteration produets of. $302307,373,383$ chemical and physical constants of. $19 \pi, 299$ occurrence of - $300-302,105 \%$ sources and mode of formation of ...... $300-301$ $353,370,380,393,903$

Gas, water, in zone of anamorphism, action of ...- 660-661 Gas content of rocks, effect of, on metamorphism.. Gaseous solutions, circulation of . ................ 1018-1021 formation of ....

metamorphism by ores produced by work of, in belt of cementation . . . . _._._. 648-649 Gaseous and aqueous solutions, precipitation by reactions between ...................

Gases, chemical and physical principles applicable

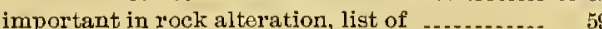
inclusions of, in rocks, figure showing ......... $6: 0$ metamorphic work of . mixtures of, properties of ................. 60 precipitation between aqueous solutions and ... 119 pressure of, importance of, in metamorphism.. 61-70 quantity of, dissolved by liquid, proportional to pressure

solubility of, as affected by temperature.......

solution of, in ground waters................. 68-72

temperature of, importance of, in metamorphism . .

Gedrite, chemical and physical constants of . .... 19\% , 281

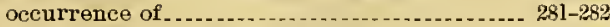
sources and mode of formation of ............. $\quad 289$ Gehlenite, alterations and alteration products of... 314,
Page.

Gelenite, chemical and physical constants of .... 197,314

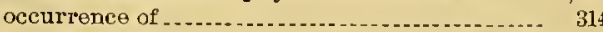
Gehlenite and quartz, alterations and alteration products of . - ........ 383,406 Geikie, Alchibald, on dolomitezation of Carbonifer ous limestones in England . ........ 800 n graywackes of Great Britain on hydrogen of volcanoes, source of............. 492 on lavas, temperatures of . . .

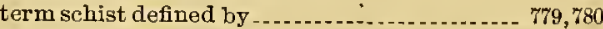
Geographic conditions, effect of, on metamorphism. 41 Geological factors affecting alteration of rocks, enumeration of .

Goological work of ground water, factor's influencing Geology, data composing great volume of . . . Georgia, depth of decomposition of rocks in ........ 530 granites from, losses in, by weathering ......... 529 Geyserite, deposits of, reference tu ................ 550 Gibbsite, alterations and alteration products of .... 235

$236,373,383,400$ chemical and physical constants of........ 197, 198,234 occurrence of . . . . . . . . . . . sources and modes of formation of $224-225,235-236,254,255,256,258,260,261,263,264$, $265,292,293,294,296,298,299,304,312,313,318,319$, $322,323,328,337,338,339,341,343,353,370,375,376$ $377,378,379,380,381,382,384,386,35 \%, 388,389,390$ $392,393,394,397,398,399,400,402,403,404,406,624$ Gibbsite and albite, alterations and alteration products of . . . . . Gibbsite and anorthoclase, alterations and alteration products of .......... $377,400,401$

Gibbsite and magnesite, alterations and alteration products of . ......................... 383,401

Gibbsite and microcline, alterations and alteration produets of .......... 359,400

Gibbsite and orthoclase, alterations and alteration products of ........... 389,400

Gibbsite and quartz, alterations and alteration products of . ...................... $383,40 \%$ Gibbsite, magnesite, microcline, and siderite, alterations and alteration products of .- 389,401 Gibbsite, magnesite, orthoclase, and siclerite, alterations and alteration products of ...- 389 Gibhsite, quartz, and calcite, alterations and alter'ation products of . . . . Gibbsite, quartz, and potassium carbonate, alterations and alteration prodncts of ... $383,40 \%$ Gibbsite. See also Hydrargillite.

Gismondite, alterations of - 335,36 chemical and physical constants of ........... 197, 231 occurrence of ........... 331-333 sources and modes of formation of .......... 262 $332,367,370,376,402,633$ Gilhert, G. K., on climatic cbanges in the Far. West in Pleistocene time............... 1178 on contact metamorpbism ......-... 651 on deposits of Lake Lahontan ........... 554 on exfoliation of rocks in Sierra Nevada (note)_ $\quad 438$ on magnesium in salts of Great Salt Lake ..... 994 on post Glacial anticlinal arches in shale and

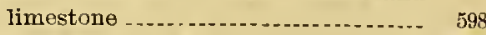
on potassium in the Dead Sea............. 1000 on shore deposits . on warm or hot springs of Cordilleran region. $591-592$ Glaciers, disintegrating work of .................. 498 

lass, alteration of, minerals produced by .........- 251 eritrification of, phenomena of $\ldots \ldots \ldots \ldots \ldots$
heat and rolume relations of natural, occurrence, and alterations of ....... 246-352 solubility of, in water. ...................... 79 $80,112,630,637,692,723,740,749,750$ strain in, example of 691 Glauconite, character, occurrence, and alterations

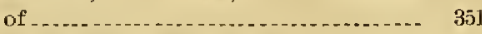
chemical and physical constants of _-_.-_-_.-. 197,35] Glaucophane, chemical and physical constants of. 197,283 occurrence, sources, and modes of formation

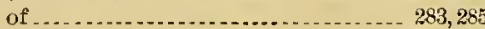

Gmelinite, character and occurrence of . . ......... 331-333

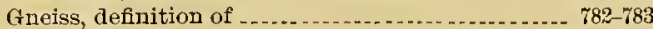
features of .

lossesin, by weathering, analysis showing .... 508,515 metamorphic, igneous, and sedimentary rocks often combined in . .............. 911-912 minerals of, derelopment of . . . ............ 899 photomicrograph of Gneiss-arkose, deposits of, origin and character of. $875-876$ Gneiss-gray wacke, deposits of, character and origin of .

Gneiss-pelite, deposits of, origin and character of- $894-904$ Gneiss psephite, origin and character of ......... 857-860 Gneissic tuffs, discrimination between sedimentary gneissic rocks and . . .......... . 909,913 Gold, association of, with argillite. .......... 1095, 1096 association of, with base metals .......... 1169-117t deposition of, by ascending solutions _. _. 1089-1099 forms of occurrence of . . . . . . . . . . . . . . ... 1169 precipitation of . . solubility of $1075,1089-1091,11 \%$

Gold-bearing quartz reins, origin of, by magmatic segregation, theory concerning.. 10:8-1049

Gold deposits, formation of, possible modes of .- 1041-1042, $1048-1049,1050$

Gold ore of Sierra Nerada, origin of . . . . . . _._._._. 1084 Gold placer deposits, formation of ............ 1040 1043 Gogebic districts of Michigan, iron ore deposits of, as affected by topography .......... 1219 Gordon, H. A., on gold deposits of New Zealand.... 1042 Grain, silica potash, soda, etc., in ................ 454 Grain of rocks, effect of, on rate of weathering .. 533-534 See also Recrystallization.

Grains and grasses, disintegration of rocks by ..... 445 Granite, induration of, along joints _... 549 injected, example of .............................. 64 . losses of constituents of, by weathering - $507,522,523$ strain in, shown by quarrying - 598

Grant, U. S., on action of organic matter in reducing and precipitating oxidized products

on agency of igneous intrusions in producing iron-silicite rocks.

on zonal arrangement of metamorphic minerals peripheral to i trusire masses

Granulation of minerals, energy factors involved in . . . . . .

relation of recrystallization to ........... 737,748 temperatures favorable to water content of rocks as affecting ........... $741-748$ Graphite, character, oceurrence, and alterations of , 212 cheraical and physical constants of -197

Grasses and grains, disintegrating effects of, on

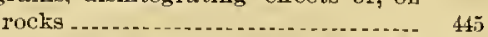

Grass Valley, Cal., gold veins of, constant tenor of _ 1137 secondary enrichment of gold ores at. ..... 1181-1185 Gravel, pebble, and bowlder deposits, discussion of Gravity, metamorphic effects of ............ $46-50$ ground-water motions as affected by .. 146-147, 148-149 Gravity, specific. See Specific gravity.

Grays Peak, Colo., disintegration of rock at, hy freezing and thawing - 43 Gray wacke, deposits of, character and origin of .- $880-883$ metamorphosed, character and origin of .....- $883-886$ diserimination of photomic1ographs of ........................ 888 serpentinized, formation of . ............. 881-882 Graywacke-gneiss, deposits of, character and origin of . Gray wacke-schist, deposits of, character and origin of . . . $883-886$

Graywacke-slate, deposits of, character and origin of . Great Basin, deposits in, reference to.......... 559 ground water of, rate of flow of streams and lakes of, soluble material transported and deposited in ........... 551-554

Great Salt Lake, calcium chloride deposits of . ..... 54 t? precipitation of salts in ....................... 552,553 Greenalite, character and occurrence of ........ 284 photomicrograph of ........................ 836 Griswold, L. S., on whetstones of Arkansas Grits, deposits of, character and origin of ........ $879-880$ Groddeck, A. von, on contact metamorphic or'igin of ores_........................... 1050

Grossularite, alterations and alteration products of . . . . . . 302, 303, 305, 367, 373, 384, 398 chemical and physical constants of ........... 197,299 occurrence and associations of ............. 301 sour'ces and modes of formation of. $301,314,370,383,406$ Grossularite and melanite, alterations and alteration products of $\ldots \ldots \ldots 3,384,38 \pi, 398$ Grossularite, pyrope, and melanite, alterations and alteration products of.. $383,384,387,390,398$ Groth, P. H., on composition of zeolites Ground water, absence of, in ore-bearing districts, mistaken inferences from ........ 1063-1065 aciis present in

channels traversed by, size of chemical and physical principles controlling action of ............................. $65-123$

circulation of - 183-158,416-429,571-593, 661-668, 1021-1029 causes of, summary of ................. 152 channels of, variations in sizeand continuity

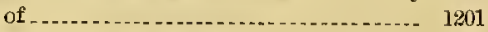
character and conditions of 129 $137,139-146,572-579$ concentration of soluble material by . . ... 543-551 conditions governing .................. 129-158 downward movements of, factors influencing ........................ $417-419$ factor's or forces influencing....... 146-156,416-417 adhesion - 150-152 friction. . . . . . . gravity ................... 146-147,578 gravity and heat.............. 148-149 heat . . .... limiting formations ............. $576-578$ mechanical action -........ 149 molecular attraction ........... 150-152 openings in rocks......... 199-146 temperature ........................... 157 regetation - . rate of..................... 154-156,583 588 
INDEX.

Page.

Ground water, circulation of, sections (diagrams)

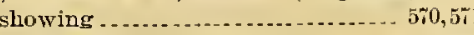
tree-like system of ........................ 583 upward morements of, factors influencing- 419-422 vigor of . compounds present in . deposition of minerals from.................. 613-617 dissolution of material by ........... . . . . . 613-617 effect of, in cases of igneous intrusion ........... 650 eraporation of, effect of cultivation on _....... 421, 422 gases present in

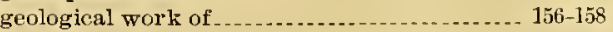
ions present in ................ 92 large channels preferred by .................. 580-552 level of, change in, influence of, on ore deposition. 1206 depth of ....... . . . . . . . factors affecting or determining . . . . . _ _. 423-429 agriculture ................................ $42 i$ barometric pressure.................. 428 eapillarity -................... 412 denudation _. $4: 26$ evaporation ......................... 425-426 man ................................... $427-428$

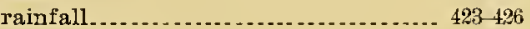
seepage tempirature _....................... 428 uplift and subsidence. ................ 426

form of - 411-413 in arid and humid regions, as affecting $01^{\circ} \theta$ deposits ..

ore deposition as affected by change in --2- 1201 relations of, to topography ........... 410,411-413 relations of, to topography .......... $410,411-413$
variation in ...... importance of, in lead and zinc regions of Mississippi Valley ........... materials added to, in belt of weathering .... $617-618$ metamorphism by .............................. 65-123 movements of $416-429,571-593,661-668,1021-1029$

in trausporting metals .............. $10 \%-1081$ speed of . . . . . .

vertical and horizontal, relative length of . 579-580 See also Ground water, circulation of. pressures, temperatures, and depths of, tahle showing relations of principles of chemical reactions applicable to _. 84-123 principles of solutions applicable to . ........... 65 - 83

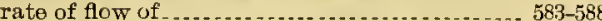
silica in, large amount of, where regetable matter is abundant . . . . . . . .

solution of gases in

solution of solids in

source of . temperature of, asaffected by earth morements. $\quad 590$

importance of 615

increase of, with depth................... 578-579 on entering and issuing from the earth ... 589-593

thermal effects of . . . . . ... . . . . . . . . . . . . . . . . . . 5 589-593

upward movements of . . ... . . . . . . . . . . . . . $419-492$

forces influencing, vegetation ............ $422-423$ molecular attraction - ............... 419-420

universal presence of $123-124$

See also Water; Ascending waters; Descending waters.

Grove, Sir William, on segregation of carbon diox ide from interstellar spaces hy gravitation ..............................
Grïnerite, alterations and alteration produc

a

373,384

chemical and physical constants of ....... 197,283,284 occurrence and associations of $-2-28$ origin of, from iron carbonate, chemical reaction inrolved in.............. 834 source and mode of formation of ................ 244 $245,284,370,392,407$

Grünerite-magnetite-quartz rocks, origin of..... 834841 Grüneritic marbles, origin of .................... 833 Gümbel, K. W. von, on use of term "epi" ........ 777 Gypsum, alterations and alteration products of .... 358 $373,384,396,400,788-78:$

ehemical and physical constants of ....... 197,35\%, 788 occurrence and associations of solubility of, in salt water . ................ 119 source and mode of formation of . ............ $35 \%-358$ H.

$370,376,402,788-789$

Hague, Arnold, on calcareous doposits in Yellowstone National Park.................. 551

Hahn, Julius, on annual range of temperature ..... 437

Halite, ehemieal and physical constants of ......... 197 Halite and albite, alterations and alteration prod. ucts of . . . . . . . 375,400 Halite and nephelite, alterations and alteration products of . ........................ 388,400

Hall, R. D., and Lenher, Victor, on precipitation of gold ................ 1091-1092, 1096-1097, 1098 on telluride of silver, artificial production of ... 1124 on tellurides, formation of ........ . .... 1120-1121,112. Hallock, william, on variations in rigidity of bodies accordant with degree of pressure ... 672

Halloysite, chemical and physical constants of . 197 sources and mode of formation of . . . . 253,254,370,389 Hambrechen, Carl, on potentialization of energy in strained metals and minerals...... 97,69

Fammond, J. H., on Witwatersrand banket....... 104

Hann, Julius, on temperatures at surface of the earth ...................................

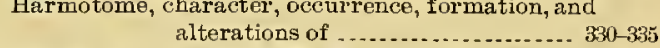

Harris, G. D., and Dall, W. H., on phusphates ...... 976 Hautefeille, Paul, experiments of, producing rutile group of minerals

Haüy, R. J., ou rock nomenclatnre................ Haüynite, alterations and alteration prodncts of. 298-299 $373,384,399$ chemical and physical constants of ........ 19\%, 295, 297 oceurrence of ..... Hayes, C. W., on bauxite deposits .............. 985, 1037 on colors of soils of Nicaragua as indicating presence of ferric or ferrous oxide..... 470,4i1 on Nicalaguan streams, lack of sediment in .... 504 on origin of phosphates ..................... $976,97 \%$ on quartz crystals, corrosion of............... 218 on solntion of silica

Heat, absorption and liberation of, by solution .... 81 chemical effects of $\ldots$ conductivity of rocks for...................... 5 derived from the sun, metamorphic effects of .. 51-53 derived from within the earth, metamorphic

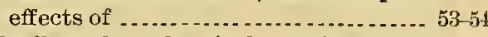
inerease of, effect of, on chemical reactions...... liberation of, dominance of reaction carasing ..- 362 mechanical effects produced by, in belt of cementation....................... 595 
Page.

Heat, metamorphic effect of production of, by mechanical action in rocks, importance of, in metamorphism _. 54, 99-100 relation of, to chemical and mechanical action. 110-113 work of, in ground-water circulation ......... 147-149 Heat toning of chemical reactions, mathematical statement of

Heat and gravity, work of, in gromnd-water circula-
tion........

Heat and gravity, work of, in gromnd-water circula-
tion.

Heat and light, metamorphic effect of ......... chemical and physical constants of _......... 197,271 Hematite, alterations and alteration products of ... 2936$227,373,37 \%, 379,384,401,402,408$ chemical and physical constants of ....... 197,223,842 formation of, chemical equations showing -. 830,1126 from cupric sulphate and ferrous sulphate solution, chemical equations showing.

from iron carbonate, chemical equations showing -..............................

from siliceous siderite, etc., chemical equations showing . . . . .

formation of magnetite from, chemical reaction involved in. ................. 846

residual deposits of........................... 1039 sources and modes of formation of . ...... 214,225-2226, $227,229,233,242,244,245,268,269,282,303$, $309,313,328,342,370,375,376,377,37 \mathrm{~S}, 379$, $384,355,386,387,390,391,398,399,400,404$, $405,467,468,623,830,843-845,846,1102,1126$

specular, origin of .

Hermatite and anorthite, alterations and alteration products of . .................... 377, 402,404

Hematite and biotite, alterations and alteration products of ............... 379,396,398,401

Hematite and meiorite, alterations and alteration products of . .................. 387,402

Hematite, anorthoclase, and calcite, alterations and alteration products of ................

Hematite, calcite, and microcline, alterations and alteration products of . .............. 389, 401

Hematite, calcite, and orthoclase, alterations and alteration products of .............. 389, 401

Hematite-schist, origin of ........................ 845

Henrich, C., on ore deposits of Ducktown, Tenn--.- 1182

Hercynite, chemical and physical constants of .... 198

source of ..........

Heterogeneous and homogeneous chemical systems, notes on ........................... 90-91

Heulandite, alterationg and alteration products of. 333 , $334,373,384,400$

chemical and physical constants of ........... 198,330 sources and modes of formation of ........... 262 , $331-333,370,375,376,397$

High lands, disintegration of rocks in ............. 499

Hilgard, E. W., on amount of soluble salts contained in soils in California ........... on decomposition of rocks in arid regions..... on decomposition of sibicates in calcareous and noncalcareous soils .-

on endurance of plants to alkalies...............

on soils of arid regions .............................

Hill, R. T., on systems of circulating underground water. 545 478
Hillebrand, W. F., and Clarke, F. W., on chemical action in solutions, theory of ....... on chemical composition of slate .............. 895 on rock analyses................................ 693 on rocks of Pigeon Point, Minn .................. 733 on water content of rocks, relation of, to crystallization. .......................... 743,744

Hills, R. C., on ground-water level in Cripple Creek district.......... $11 \%$

Hinde, G. J., on cherts of organic origin........... 847 on silicification at Spitzbergen -

Hitchcock, Edward, on schist conglomerates....... 859

Hobbs, W. H., on enlargement of mineral particles. 641 on regeneration of mineral particles ............ 705

Hobbs, W. H., and Culver, G. E., on decomposition of olivine-diabase in South Dakota .- 560

Hoff, J. H. van't, on heat of chemical reactions.... 107

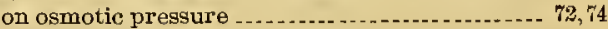
on reactions

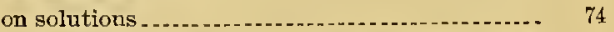
on thermal effects of chemical reactions at high and low temperatures.............. 168

Homogeneous and heterogeneous chemical systems, notes on .................... 90-91

Hoover, H. C., on ore deposits of western Australia 1185-

Horizontal movement of ground water, limits of. 5 i9-580 Horublende, alterations and alteration products of $-285-286,287,288,289,290,373,384,385,398$ chemical and physical constants of............ 198, 283 fragment of, cut showing enlargement of....... 626 occurlence of sources and modes of formation of... $274,279,285,303$, $305-306,370,3 \% 6,378,383,387,390,396,408,625-627$

Hornblende and quartz, alterations and alteration products of .................... $385,399,405$

Hoskins, L. M., on flow and fracture of rocks ...... 671

Hoskins, L.S., on shearing of rocks ................ 763

Howell, E. E., on warm or hot springs of Cordilleran region ............... 591-592

Hubbard, H. L., on hydrous silicates in the Lake Superior region...................... 1130

Hudson schists, igneous and sedimentary rocks combined in Human influences on ground-water level, character of . .

Humic acid, formation and action of, in soils. .... 462463 Humid regions, decomposition of rocks in ....... 501-502 Ievel of ground water in, as affecting depth of ore deposits ........................... 1180

Humidity, importance of, in decomposition of rocks

Humites, alterations and alteration products of.- 325 , $373,385,403$

chemical and physical constants of............ 198, 325 occurrence of Hunt, T. Sterry, on carbon dioxide formerly in atmosphere . . ................ $964-965$ on carbon dioxide of mineral springs, source of. $\quad 678$ on carbon dioxice segregated from interstellar. spaces by gravitation.............. 973 501 477 497 on silica in underground water................. 476 Huttonian principles of geology, application of, to metamorphism ................... 35-36

reversal of, as applied to metamorphism ........ 3637 578 Hyalosiderite, chemical and physical constants of.. 199 
Page.

Hydrargillite, chemical and physical constants of. 198,234 occurrence, sources, and alterations of ........ 235-236 See also Gibbsite.

Hydration, alterations produced by conditions farorable to \begin{tabular}{rr}
401 \\
\hline
\end{tabular}

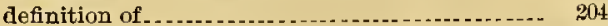
deptb and pressure required for reversal of . - 180-181 discussion of

examples of

cxtent of, in belt of cementation ...... 164, 165, 166,612 limitation of, by expansion of volume........ 481 occurrence of, in zone of katamorphism ........ 178 water fixed by, amount of . .................... 161-162

Hydration and carbonation, alterations produced

Hydration and decarbonation, alterations produced

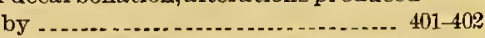

Hydration and dechloridation, alterations produced by -

Hydration and defluoridation, alterations produced by .

Hydration and desilication, alterations produced

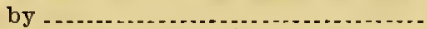

Hydration and oxidation, alterations produced by --

Hydration and silication, alterations produced by --

Hydration, carbonation, and dechloridation, altera tions produced by ................ 398

Hydration, carbonation, and desilication, alterations produced by - ... 398-399

Hydration, carbonation, and desulphation, alterations produced by - 399

Hydration, carbonation, and oxidation, discussiou of . ............... $483-481$

Hydration, carbonation, and silication, alterations prooduced $b_{\nabla}$...........................

Hydration, decarbonation, and dechloridation, alterations produced by

Hydration, dechloridation, carbonation, and desilication, alterations produced by

Hydration, desilication, and decarbonation, alterations produced by -

Hydration, oxidation, and desilication, alterations ploduced by

Hydration, oxidation, carbonation, and desilication, alterations produced by ........

Hydrobiotite, chemical and physical constants of $\ldots \ldots . . .198$ source and mode of formation of $\ldots \ldots \ldots, \quad 339$,

Hydrogen in earth's crust, amount of . .......... 981-982 in ear'th's crust, percentage of ............... 934,936 in sea water', percentage of .................. 942 occurrence and combinations of $\quad$ 981-983 of volcanoes and fumaroles, sources of ......... 492 oxiāation of, in belt of weathering .

Hydrogen sulphide, sources and importance of. 1112-1114

Hydralysis, increase of amount of, with increase of temperature ........................ importance of, possible, in metamorphism..... 108 of sodium silicate, observations on ............ 67 phenomena of .

Hydromagnesite, chemical and physical constants of 198 sources and modes of formation of .... 235, 370,379, 396

Hydromuscovite, sources and mades of formation See also Pinite.
Hydronephelite, chemical and physical constants

Page.

of .................. 198,329

occurrence and associations of ............... 331-333

sources and modes of formation of .......... . ... 202, $295,331-333,370,388,392,397,398$

Hydrophlogopite, chemical and physical constants

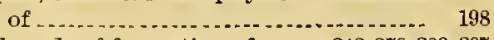
source and mode of formation of ...... $343,370,389,397$ Hydrasulphuric acid, oxidation of, by bacteria, formula for reaction................ 468 production of .

solubility of sulphides in ........................ 1106

Hydrosphere, percentage of known matter of globe

See also Ocean. formed by ....................... 933

Hydrotalcite, source and mode of formation of... 309-3\%0 Hydrous silicates, alterations and alteration products of

Hygrometric water in rocks, definition of .......... 124 Hyperstbene, alteration of, to talc, magnetite, and quartz, volume change incident to... 633 alterations and alteration products of ........ 268-271, $373,379,385,399,404,405$ chemical and physical constants of . . . . . .... 198, $26 \%$ accurience and associations of................. 268 sources and modes of formation of ..._ .......- 2668 , $302,339,342,370,375,376,379,383,390,396,401$ Hypersthene, calcite, and quartz, alterations and alteration products of . ............. 379,407

I.

Ice, change of water to. See Freezing.

Idaho, South Mountain district of, ore deposits and gangue minerals of ................ 1056

Idaho Springs, Colo., ore shoots near, inter'secting fractures at ...................... 1227

Iddings, J. P., Cross, Whitman, Pirsson, L. V., and Washington, H. S., on mineral compasition of amplioble-gabbro Igneous and crystalline rocks, analyses of . . ...... 934-935 Igneous intrusion, features of.....- 488-494,646-652, 707-736 ground-water temperature as affected by ..... 590-591 metamorphic effects of ......... 42,54, 716-736, 1014-1017 factors influencing, composition of intrusive and intruded rocks .............. 650 deptb of intrusion ...................... 652 ground water. length of time of intrusion.......... $651-652$ porasity of rocks...................... 649-650

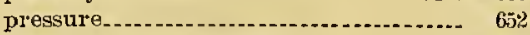
size of intrusive masses $\ldots . . . . . . . . . . . .651$ temperature of intrusive............ 652 minerals formed by .................. $717-730$ water released by, in zone of anamorphism.... 662 work of, ih belt of cementation............. $646-652$ Igneous processes, ores produced by . ...... 1043-1052,1233 Igneous rocks, chemical composition of ............ 890 classification and nomenclature of . . . . . . 904906 effects of, in metamorphism .................. 42 importance of, as sourcestof ore deposits. .. 1030-1034 metamorphosed, and metamorphosed sedimentary rocks, discrimination between, criteria for....................... 908-917 minerals in, percentages of ............ 937 ore deposition as affected by ............ 1014-1017 ore deposits in ...................... 1030-103t 
Page.

Igneous rocks, relations of stratigraphy to ....... 922-924 See also Igneous intrusion.

Igneous work, character and extent of, in belt of

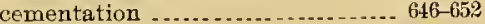

in zone of anamorphism . ..................... 707-736 relations of, to chemical and mechanical work in metamorphism ... See also Igneous intrusion.

IImenite, alterations and alteration products of _ $22 \%-\$ 28$, $373,385,386,405,408$

chemical and physical constants of .......... 198-293 occurrence of . ................................ 227 sources and modes of formation of ............ $231,355,370,389,391,400,405$ Ilmenite, calcite, and quartz, alterations and alteration products of ................... 355,408 Imbibition, capacity of rocks for, an index to power

of transmission ........................ 155

water of, definition of ..................... 124,155 Impervious strata, offect of, on ore deposition. . . 576-578,

Induration of rocks, subsurficial, by injection of molten magma................... 647 surficial, method of

Injection, igneous, in belt of cementation........ 646-652 igneous, in zone of anamorphism ........... $707-736$ Inorganic compounds, oxidation of ............ $466-469$

Insolation, conditions favorable to .................. 438 importance of topography in ................. 439 origin of term.................................... 43

resistance of rocks to, varying power of ....... 439

Insoluble compounds, precipitates formed by .... 540-541

Intruded rocks, composition of, a factor in meta-

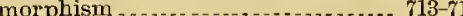

Intrusion, igneous, manuer of, in zone of anamorphism . . .

igneous, metamorphic effects of . .............. 42,54, 488-494, 646-65\%, 716-736, 1014-1017

metamorphism resulting from ............ 711 minerals formed by .................

temperatur $\theta$ effects of ...................... $\quad 712$

water present during effects of . . . . . . $712-713$

work of, in belt of cementation.............. 646-65? Intrusive rocks, composition of, a factor in metamorphism ........................ $713-715$

ground water temperature as affected by.... 590-591 Intrusive masses, size of ............................ 711-712 Invilliers, E. V. d', and Lesley, J. P., on Cornwall iron-ore mines ....................... 1198 Iolite, alterations and alteration products of. ........ 291 , $3 \pi 3,386,402$

chemical and physical constants of . . . ......... 198, 291

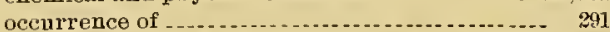
sonic theory of solutions, change of view required

$$
\text { hy . }
$$

statement of .................... 116-118

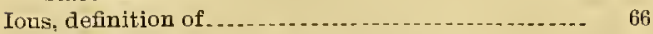

separation of acids, bases, and salts into ........ 85

Iron, amount of, dissolved from rocks in weathering

compounds of, oxidation of ..............

compounds of, oxidation of

in earth's crust, percentage of . . ............ 934,936

occurrence and combinations of .............. 986-989

oxidation of methods of $467-468$

oxygen consumed in . . . . . . . . . . 950-951,955

precipitation of copper by . ..................... 1101

Iron and copper compounds, association of . .... 1158-1166
Iron-bearing carbonate family of rocks, deposits composing .......................... 8:3-843 Iron-bearing minerals, deposition of ........... 627 Iron-bearing rocks, photomicrographs of . ......... 836 Iron bisulphide, reactious involving - . ..... 1161, 116\%, 1163 Iron carbouate, formation of, modes of . ........ 233- $\$ 34$, oxidation of $239,241,242,82 \%, 843,844,1176$ rou compounds, decomposition of, in rock weath-

deoxidation of ering - .

of

Iron Mountain, Mo., process of weathering at .... 580-521

Iron ores, bog deposits of, formation of........... 550 conditions of occurrence of, figures showing ..- 1196

formation of, by ascending solutions ........... 1089

by chemical precipitation _... _..._......... 1037

by reprecipitation and solution ............ 541

modes of . . ........ 560-561, 1044-1045, 1061,1198-1198

residual deposits of . ............................. 1039

titaniferous, deposits of $\ldots$ Iron oxides, ferric and ferrous, ratios of in sedimentary and igneous rocks . . . . . ... 950-951 formation of ............. 241-242, 282, 285, 286, 322, 540 forms of deposition of . ......................... 623 removed from soil annually, amount of ....... 486 source of .................................. 370 surface induration of rocks by $\ldots \ldots \ldots$ Iron-oxide family of rocks, deposits forming ..... 842-846 Iron sulphate, production of . . ... . . . . . . . . . . . . 468 Iron sulphides, oxidation of . ................... 468,952 reactions infolving . .- 959,1143, 1149, 1150, 1161,1162, 1163 volume changes incident to production of .... 418-469 Iron, zinc, and lead compounds, association of ................................ 1144-1158

Irrigation, migration of alkalies to surface caused Irving, A., on alterations of rocks by contact meta- 546 morphism . . . . . . . . . . . . . . . . . . . . 489-490

on classification of matmorphism . ............ 39

Irving, J. D., on tellurides associated with Potsdam gold ores of the Black Hills .......... 1119

Irving, R. D, an alterations of rocks by contact metamorphism ..................... $489-490$

on cementing materials of rocks, similarity of, to rock cemented ................... 628

on copper (native) and magnetite, association

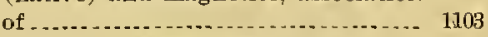
on copper deposits of Kerveenaw Point, Mich . . 1087 on metasometism in the Keweenawan series.... 641 on ore deposits of the Penokee-Gogebic district of Michigan and Wisconsin . ......... 1216

on production of openings at contact of igneous and intruded rocks ................ 655

Irving, R. D., and Van Hise, C. R., on actinolite, growth or penetration of, into quartz 219

on alteration of clastic rocks................... 184

on enlargement of mineral particles. . . on diahase from Michigan, losses in, due to weathering -......................... 511

on iron-ore deposits, origin of ................ 831 on iron silicate rocks, agency of igneous intrusions in producing .................. 840

on recementation of rocks ....................... 564

on recrystallization of quartz and development of mica in rocks. ........................

on rock textures (original), preservation of, after metasomatic alteration ........

on schists of the Lake Superior region .......... 
J.

James River Valley, S. Dak, loss of head of arte-

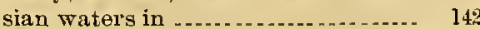

Jaspilites, origin of . ................... Lake Snperior region, metamorphic history of 38

Jenney, W. P., on chemistry of ore deposition...... 1111 on lead and zinc deposits of Mlississippi Valley ............. 1083,1084

John, C. yon, and Teller F., on zonal arrangement of metamorphic minerals peripheral to intrusive masses . . ................ 719

Johnson, S. W., on disintegration of granite by lichens

on silica, potash, soda, etc., in grain and strar Johnston, John, on spontaneons movements, dne to strain in sandstones

Jolınstone, A., on carbon dioxide solutions, action of, on micas........................ 476 Jointing, gronnd-water circulation as affected hy _. $12 \%$, See also Fracture.

Joints, ground-rvater circulation as affected hy .... 130131,138 pore space added to rocks by

Jones, H. C., on chemical reactions............. 89

Joplin district of Missouri, water in mines of ...... 1132,

Judd, J. W., on eolian action in rounding sand grains .............. 432 on Nile delta deposits . . . . . . Jadeite, chemical and physical constants of ........ 198 Julien, A. A., on hending of marble slabs by pressure

\section{K.}

$\mathbf{k}+$ and $\mathbf{k}-$, signitication of, in eqnations

Kahlenberg, Lonis, on electroly tic dissociation and chemical change................. 67,85 on osmotic pressure

Kahlenberg, Lonis, and Lincoln, A. T., on silicates in solntions.

Kaolin, alterations and alteration products of...- 31\%, 35\% chemical and physical constants of . .......... 198,352 formation of, from potassinm feldspar, equation showing - .

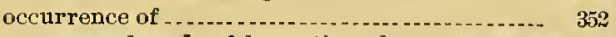
sources and mode of formation of .... $253,260,263,264$, $265,266,292,293,291,2997,312,313,314$, $318,319,322,323,339,340,35 \%, 353,370$, $375,376,377,378,381,382,386,387,388$, $389,392,393,394,397,398,399,402,403$

Kaolin and quartz, formation of, by alteration of or'thoclase, volume change incident to

Kaolinite, alterations and alteration prodncts of - 317,352 chemical and physical constants of ......... 198,352 occurrence of ................................ 352 sources and modes of formation of . . . ... 253, 260,263 , $264,265,266,292,293,294,297,312,313,314$, $353,370,375,376,377,378,381,382,386,387$. $388,389,392,393,394,397,398,399,402,403$

Katamorphic, katamorphism, propriety of use of terms.

Katamorphism, zone of, belts composing zone of, chemical reactions in . ...... . . ...... 161-162, $166-167,171,180,181,186,1008-1009$
Katamorphism, zone of, chemical reactions in, heat effects of ................. 109, 111

chemical reactions in, occurring also in zone of anamorphism ....... 181-182 reversed in zone of anamorphism .. 181, 366-369 thermal and volume effects of . ...... 186 thermal conditions of circnlation of aqneons solutions in . . .... 1022-1028 defiuition of . ........................... 43, 160, 162 deposition of silica in ..................... 176 energy required for deformation in, compared with energy required for defor. mation in zone of anamorphism ... $769-7 \pi 4$ features of, and chemical l'eactions in ... 1005-1009 gradation between, and zone of anamorphism ............................ 191 bydration in ......... 178-180 minerals of specific gravities of . . . . . . . . . . . 363,364 openings in . oxidation in, minerals or compounds affected by .................. 171-172,955-956

oxidation and deoxidation in. thermal and rolume changes involved in......... $17 \%$ phenomena occurring in . relation of zone of anamorphism to ....... 170$186,766-768$

relation of zones of fracture and flowage to _........ 187, 190

specific gravities of minerals in $\quad 363,364$ snbdivisions of . . . volnme changes consequent upon chemical reactions in .

See also Cementation, belt of; Weathering, belt of.

Kekekabic Lake, Minnesota, enlargement of hornblende crystals of volcanic tuffis at.. 62

KeIvin, Lord [William Thomson], on potential energy of certain forms of minerals.. $360-361$

Kelyphite, formation of ..-.......

Kemp, J. F., on nickel mines of Lancaster Gap, Pa $\quad 1186$

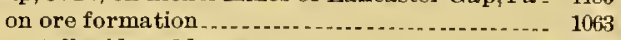
on tellnride gold ores. ......... on titaniferous iron ores . . ................ 1044 on willemite in the New Jersey zinc deposits. .. 1131 on zincite and franklinite, occurrences of...... 1125 Kerrite, formation of ......................... 343 Keweenaw Point, Mich., copper at......... 1062, 1087 Keweenatwan sandstone, cementation of, by feldspar - 626

Keweenawan series, metasomatism in ............. 641

Killinite, sources and modes of formation of ...... 392

King, F. H., diagram cited from. . ............. 410,411 on ground water .................... 413,421,428,581 on pore space in rocks . ................ on waterflow throngh capillary openings..... 140 Koene, C. J., on carhon dioxide now and formerly in atmospher $\Theta$. . . . . . . . . . . $949,950,956$ Kyanite. See Cyanite.

I.

Labradorite, character, occurrence, formation and alterations of .

Lacroix, A., on alteration of hornblende to angite.- 286 on formation of calcite from anthophyllite....- 282 on minerals produced in alterations of hornblende to chlorite................... 28

MION XLVII-04-80 
Lafar, Franz, on action of bacteria in metamorphism .

Lake Superior region, changes in rocks of.......... 35 copper deposits of ........ 1032, 1103-1104, 1204-1205, 1231 iron ore deposits of $560-561,606,1193-1198,1218-1219,1231$

Lake vein, San Juan district, Colorado, influence of wall rock on

Lakes, concentration of soluble materials in .... tufa deposits in

Lancaster Gap, Pa., diminution of richness of sulphurets with depth in nickel mines

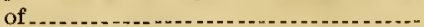

Landolt, Hans, and Bornstein, Richard, on viscosity of water at different temperatures.

Last Dollar mine, Cripple Creek mining district, ore shoots near intersecting fractures in.

Lateral secretion, importance of, in first concentration of ore deposits . . ............... 1078

Latitudes, high, disintegration of rocks in ....... 498-499 low, decomposition of rocks in ............... 502

Laumontite, alterations and alteration products of . chemical and physical constants of ........... 198, 331 occurrence of sources and modes of formation of ........ 262,376,397

Launay, L. de, on contact metamorphic origin of ores

1050

on genesis of ore deposits 1190 on Witwatersrand banket 1041-1042

Lavas, openings or pore spaces in ................ 127,13.

Jow on Franciscan cherts . . . . . on fusion of sedimentary rocks on peripheral stiucture

Lead and zinc deposits of Mississippi Valley, formation of, conditions of ... 1083-1084, 1208-1209 secondary enrichment of ..................... 1186

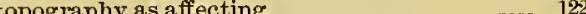

Lead and zine distriet of Mrississippi Valley, caves in. $\quad 565$ ground-water level, changes in ........... 429 silicate of zinc formed in ......................

Lead carbonate, production of, equation showing reaction for

Lead ores. associated minerals of............... 1144-114

Lead sulphates, reactions involving . . . _....... 1149-1150 soluhility of .

Lead sulphide, occurrence and genesis of .-.... 1148-1151

1154-115

Leadville, Colo., secondary enrichment of ores at _. 1186 silver ores at . ............................. 116s-1169

Lead, zinc, and iron compounds, association of. 1144-1158

Le Chatelier, Henri, on chemical reactions ..........- 89 on relation of pressure to solidification

Le Conte, Joseph, on boric acid at Sulphur Bank, Cal ........ 110 on formation of magnetite by oxidation of iron sulphide. t Sulphur Bank, Cal on ore deposits, genesis of.......... 1031,1118,1128,1190 on silication of carbonates.

Lecoq, Henri, on carbon dioxide exhaled by mineral springs of Auvergne . . . . . ..........678,971

Lehmann, Johannes, on pegmatites .............. 722,723

Leith, C. K., acknowledgments to ................ 29 figures cited from . ..... . . . . . . . ..... 704, 810, 836, 888,902 on clearage
Page.
Leith, C. K., on greenalite ..................... 284,827 on hydration, temperature of, as determined by Hampe on igneous intrusions as an agency in producing iron-silicate rocks .................. 840 $\begin{array}{rr}\text { ing iron-silicate rocks } & 840 \\ \text { on iron-ore deposits of Lake Superior region..... } & 1219\end{array}$ on quartzite-schists, diameters of particles of .. 869 on water content of hematite

Leith, C. K., and Van Hise, C. R., on agency of igneous intrusions in producing ironsilicate rocks..........................

Iember $J$ dissolution of zeolites in water by on artificial transformation of leucite to analcite. $\quad 26 \%$ Lenher, Victor, on gold, salts, and soluble fluorides, reactions between ........ 1123 on insoluhility of gold in hydrofluoric acid ....- 1122 on precipitation of silver by tellurous salts ....- 1125 on solubility of gold .......................... 1090

Lenher, Victor, and Hall, R. D., on precipitation of gold ........... 1091-1092,1096-1097,1098 on telluride of silver, artificial production of ... 1124 on tellurides, formation of ............. 1120-1121, 1124

Lepidomelane, source of ........................ 370,378 Lepsius, C. G. R., on Attic marbles, structure of ... 815 on oxygen contained in ground waters .......... 605 on recrystallization Lesley, J. P., and d'Invilliers, E. V., on Cornwall iron-ore mines . ..................... 1198

Letts, E. A., and Blake, R. F., on bicarbonates in zone of weathering .............. 536 on carhon dioxide in a tmosphere on carbon dioxide in soils . . _... _.............. 475 on oxygen in soils ............................. 470 Lencite, alterations and alteration products of .. 266-267, $373,386,402,408$

chemical and physical constants of _......... 198, 266 occurrence of .......... 266 sources and modes of formation of -........- 266

Leucite, albite, and a northite, alterations and alteration products of ............ $375,376,386,397$

Level lands, decomposition of rocks in ............ $502-503$ Leverett, Frank, on artesian waters, flow of ...... 142, 587 on underground water..................... 578 Levy, A. Michel, on pegmatization ............. 726 Lewy, B., and Boussingault, J. B., on sodium dioxide in soils

Lichens, disintegrating effects of, on rocks ...... $444-445$ Life, work of, in metamorphism .- 503-504,505-506, 5,57-558 See also Plants; Animals; Vegetation.

Light and heat, metamorphic effect of.............. 51-56

Lime, in earth's crust . . in grain and straw ........................... 454 in salts of sea water ...................... 912

Limestone, analyses of ........................... 938 cherty, features and origin of weathered forms of .......... 529 dolomitization of ................. 798-808 volume changes involved in ............... 209 formation of, mode of ............. 558, 791-795, 991-99? formation of Wallastonite from, chemical reaction involved in.................. 892 losses in, by production of clay ...... by weathering ....................... 513,523,524 material of, source of ....................... 791 metallic ores associated with . ............. 1086-1087 metamorphism of ............. 795-797,822 photomicrograph of . . ... . . . . . . 
INDEX.

Limestone, pore space in, amount of .............. Page. solution of ...... strain in, shown by quarrying................. 598 thickness or mass of, contained in eartb's erust_ $\quad 941$ transformation of, to silicate rocks ............ 822 weatbering of, features of . . . . losses by - 513,583,524 Limestone regions, solution and precipitation of calcium carbonate in .............. $539-540$ Limonite, alterations and alteration products of ... 373 $386,396,400$ chemical and physical constants of ........ 198,231,842 formation of, cbemical reactions showing ...... 826 , $830,843,846$ occurrence and character of . . ......... 232-233, 842-843 sources and modes of formation of ................ 214, $215,216,226,227,229,232-233,234,242,244$ $268,282,303,309,328,371,376,377,378,379$ $380,382,384,385,386,387,390,391,398,402$ $404,406,467,550,623,624,826,830,842-813$

Lincoln, A. T., aid by, in mathematical computations .

Lincoln, A. T., and Kahlenberg, Louis, on silicates in solutions . ...................... $67,87,115$

Lindgren, Waldemar, figure cited from ........... 1156 on calcium carbonate, solubility of ............ 78 on deposition of cassiterite..................... 1127 on gold deposits of the Sierra Nevada _ 1084 $1094,1095,1096,1137.1170,1184,1185,1202,1204$ on beat atcontact of intrusive with sedimentary rocks ............................ 105 on hydrogen sulpbide in mines of Sierra Nevada. 1107 on bydrous sulphate of aluminum in gold veins of California . on igneous origin of certain ore deposits ... 1049-1050 on metasomatic cbanges in fissure veius. $602,1069-1070$ on minerals accompanying ore deposits . _... 1055-1066 on ore deposits, genesis of ...................... 1111 on origin of ores by metasomatic replacement.- 1047 on silicates in fissure veins .... .................. 1130 on tellurides associated with gold deposits. . 1119,117 on titanic iron-ore deposit at Iron Mountain, Wyo

Lippincott, J. B., on flow of water through sands. 142-143

Liquid-filled cavities in rocks, euts showing ...... 620,746

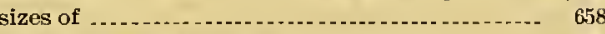

Liquid solutions, formation of . .

Liquids and solids, graduations between.--...-

Lithium, percentage of, in eartb's crust ......... 936, 100\%

Lithium oxide, percentage of, in eartb's crust..... 938

Litbosphere, chemical composition of ............. 933-947

definition of term

deformation of ................ 1005-101 Folume of ....

See also Earth's crust.

Liversidge, A., on precipitation of gold hy sulphide minerals . . . . . . . . ........... 1096-1098

Loams, pore space in ..........

Lobworms, effect of work of, on soils............... 448

Loess of Mississippi Valley, character of .......... 433,501

Logan, W. E., on graywackes of Lake Superior re-

$$
\text { gion ......................... 881-882 }
$$

London shaft, Mlineral Point, Colo., cross section of rein near...

Lord, Eliot, on the Comstock lode

on water in Comstock lode...................... 428

on weathered dikes......................... 527
Page.

Los Angeles River, ground water feeding, flow of. 142-143 Lossen, K. A., on zonal arrangement of metamorphic minerals peripheral to intrusive masses

Loughridge, R. H., on proportion of soluble material in soils to degree of comminution ... 495

Low lands, decomposition of rocks in . . . . . . . . ... 502-503

Lugwor'ms, effect of work of, on soils ............. 448

M.

MeCaffery, R. S., and Yung, M. B., on copper de posits of New Mexico....... 1056

MeGee, W J, on arkose

on quartz-feldspar sands _.

on rock disintegration by changes in tempera-

ture ........

873 water derived from .

Magmatic segregation, ores produced by ....... 1043-1052 ores produced by, alterations of . . . . . . . . ... 1237

Magnesia in earth's crust . . in grain and straw

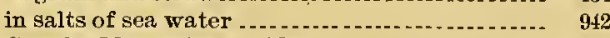
See also Magnesium oxide.

Magnesite, alterations and alteration products of ... 243244,386 cbemical and physical constants of . ......... 198,237 occurrence of sources and modes of formation of .......... 243,304 $309,349,350,366,371,378,383,384$ $387,388,390,391,396,397,398,399$

Magnesiteand corundum, alterations and alteration products of .......... 381,400

Magnesite and diaspol'e, alterations and alteration products of 381,401

Magnesite and diopside, alterations and alteration products of . . . . . . . . . .

Magnesite and gibbsite, alterations and alteration products of . . . ................ 383,401

Magnesite, gibbsite, microcline, and siderite, alterations and alteration products of ... 389.401

Magnesite, gibbsite, ortboclase, and siderite, alter ations and alteration products of.... 389

Magnesite, microcline, and siderite, alterations and alteration products of .............. 389,401

Mlagnesite, ortboclase, and siderite, alterations and aiteration products of ............. 389,401

Mlagnesite, sablite, and siderite, alterations and alteration products of .......... 391,408

Magnesium in corals and marine sbells .......... 798 in earth's crust . . . . . . . . . . . in limestones. ................. 800-801, 802 in ocean . . . in sea salt . in soils, agricultural benefits of ........... 92 occur rence and combinations of . ............. 992-996 precipitation of, in tbe sea, discussion of ..... 788-789 replacement of, by calcium, pbenomena of . - 279-280 Magnesium bromide, amount of, in the ocean and in sea salt.

943 Magnesium carbonate removed from soil annually. 486 Magnesium chloride in the ocean and in sea salt ... 94 Magnesium oxide in eartb's cr'ust. . .......... 934, 937, 938 in ocean and in salts of sea water............. 942 Magnesium sulpbate in ocean and in salts of sea

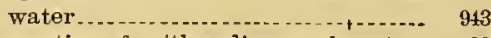
reversible reaction of, with sodium carbonate.. 88 


\section{INDEX.}

Page.

Magnesium-hearing minerals, deposition of ....... 627 Magnetite, alterations and alteration products of - 2239 , $373,386,396,404,405$ chemical and physical constants of 198, 228, 84 formation of, chemical reactions involved in .-- 838 , $845,846,1102,1112,1126,1197$ oceur rence and character of. .... 229,623-624,1197-1198 precipitation of silver by . . . . . . . . . . . . . . 1100-1101 sources and modes of formation of ..... 214,215,216, $226,227,229,242,244,245,268,269,274,286,303$ $309,336,342,371,376,378,379,381,384,385,387$ $388,390,391,392,393,399,401,404,405,406,408$ $468,623-624,838,845,846,1112,1126,1197-119$

Magnetite and rutile, alterations and alteration products of . . . . . . . . . . . . Magnetite, augite, and siderite, alterations and alteration products of . . . ........... 378,408

Magnetite beach sands, utilization of ............. 1039 Malachite, alteration of, to azurite, equation showing . ............................. 1159 formation of, from tenorite ................ 1159 Malacon, chemical and physical constants of ....... 198 source and mode of formation of ...... 315, 371, 394, 402 Malay Peninsula, tin deposits of . . . . . . . . . . ..... 1054-1055 Mallet, Robert, on liquefaction of rocks by mechanical action

on source of molten matter of volcanoes - - - 790

Iammoth Hot Springs, sources of water of ....... 1068

Man, effect of work of, on soils ................. $450-451$ influence of work of, on ground-water level _ _ 427-428

Manganese in earth's crust . . .... . .... . . . . . . .... 936-989 occurrence and combinations of ................ 989-990

Mranganese minerals, occurrence of ............... 1116

Manganese ores, genesis of . . . . . . . .......... 1037, 1198-1199

Ianganese oxide iu earth's crust ................. 938

Manganese silicate, occurrence of .................. 1131

Manganese sulphide, importance of, in precipitation

$$
\text { of ores } 1116
$$

Marcano, V, on amount of nitrates in soils of tropical

conntivies - 465-466

Marble, deformation of ................. 658-659,811-816 deformation of, photomierographs showing effects of

formation of

Marbles, actinolitic, origin of cherty, features and origin of . .............. 816,820 grüneritic, origin of

schistose, oceurrence of $\ldots$. silicated, origin of $\ldots$........................ $820-821$

Marcasite, alterations and alteration products of . . . . . . . . . . 2. 211-216,373,387,399, 406 chemical and physical constants of . . . _..... 198,213

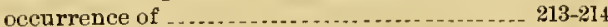
precipitation of copper sulphide from cupric sulphate by ...................... 1116 source and modes of formation of ............. 213, $214,215,226,22 \%, 3 \% 1,354,408,62 \%, 1153$ Marcasite and siderite, alterations and alteration products of . .

Marcano, A., and Müntz, V., on origin of nitrates of

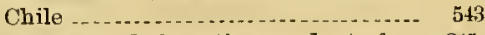
Margarite, alterations and alteration product of ... $\quad 345$,

chemical and physical constants of........... 198,344 occurrence of .......... ... sources and modes of formation of ............ $2 \% 3$, $224,295,232,236,371,381,382,383,407,408$
Page.

Marialite, alterations and alteration produets of. 312-314,

$373,38 \%, 403$

chemical and physical constants of ........... 198,311 oceurrence of .................................. 31 sources and modes of formation of $263,265,312,375,400$ Marmorosis, an example of alteration of rocks without change in chemical composition. $\quad 202$

Marsh, G. P., on effects of man's work on soil ......

Martite, formation of .............................. 46 . Mlaryland, argillite from, losses in by weathering.- 510

Mashing of rocks, discussion of . . . . . ..... $762-i 64$ Mass mechanical action, definition of ............ 47 metamorphism by Mass-static conditions, alterations of jocks under. . . . . . 698 . 706 Massachusetts, diabase from, losses in, by weathering ........................... 509,522

Means, T. H., on saline incrustation of soils .... 544 Means, T. H., and Gardner, F. D., on effect of alkalies in soils

Means, T. H., and Whitney, Milton, on endurance of plants to alkalies. . ............... 478

Mechanical action in rocks, ground-water circulation as affected by ................. 149 heat generated by .......... metamorphic effect of. ................... 46-50,95-104 relation of to chemical action and heat _. _ 110-113 Mechanical concentration, formation of ores by - 103\&-1059 Mechanical effects of heat and light on rocks, statement of .

Mechanical work in belt of cementation, discussion of ......... 594602

Mechanical work in metamorphism, combinations and relations of, to chemical and igneous work - ......... 495-496,653-655 Meionite, alterations and alteration products of ... $3 \% 3$, $387,397,406$ chemical and physical constants of ........... 198,311
occurrence of ............. 312 source and mode of formation of ............... 263, $265,302,303,312,371,37 \%, 384,396,400$ Meionite and hematite, alterations and alteration products of . Melanite, chemical and physical constants of ....- 199,299 oceurrence of ................................ 302 Melanite, almandite, and pyrope, alterations and alteration products of.. $375,383,387,390,396$ Melanite and grossularite, alterations and alteration products of ........ 383,384, 387, 390, 398 Melanite, grossularite, and pyrope, alterations and alteration products of.. $383,384,387,390,398$

Melilite, chemical and physical constants of ....... 199 sourees and mode of formation of 314 Mendeléeff, D., on carbon dioxide iu the atmosphere .............. 944,962 on dehydration of silicic acid ................. 617 on soil's ahsorptive power for potassium ........ 1001 on solution of calcium carbonate by carbonic

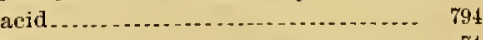
on solutions Meniscus, retarding influence of, in capillary flow - 141 Menominee district of Michigan, iron-ore deposit of, as affected by topography ........... 1219 Mercur mining district of Utah, ore deposits

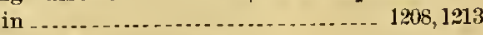
Merrill, F, J. H., on Hudson schists .. . . . . . . . . .... 904 


\section{INDEX.}

Merrill, G. P., on acids in soils -

on bacteria, increased activity of, in tropical courtries ...............................

on burrowing animals, effect of work of, on soils - .

on carbon dioxide in rain water, as determined by Fischer .

on carbon dioxide in soils, as determined by Boussingault and Leroy

on casehardening of rocks ...

deposit of chert at Richmond, Va...

disintegration of rocks, depth of ...........

by changes in temperature .................

on remoral of pressure.

on freezing as an agency in removing disintegrated-rock material . ..............

on hydration of granite rocks. .......... ..... on man's work on soil

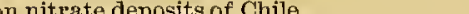

on pore space in chalk ............................

on preservation of original textures and structures in decomposed rocks . . _ . .... 5 525-5:26

on pressure as affecting character of rocks.... - 363

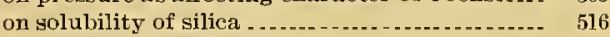

on soluble material in soils, proportion of to degree of comminution -.....-.

on uplift of overlying material by a hydrating rock

l'alge.

Metar

in belt of cementation -----

in belt of weathering . ......................... 409-561

in zone of anamorphism .............. 657-774

in zone of katamorphism ...

ores produced by . ......... 1052-123?

rate of

relations of ore deposit to .............

relations of stratigraphy to

relations of, to distribution of the chemical elements ........................ 992-1003

structures and textures produced by ... . . . . $37-38$ variations in, within one district.... ......... 917-921 variations in nature of, with depth .......... 160 zones of, definitions of . .... 159, 160,163,164, 167, 189-190

Metamorphism by jgneous intrusior, conditions governing extent of . . . . . . . . $649-652$ See also Alteration.

Metasomatism, conditions favorable to - 641-64 definition of - . extent of . growth of large mineral individuals by, with preservation of original textures _ _ 643-645 in zone of anamorphism, methods of .......... 682-683 minerals formed in ..................... $683-685$ minerals produced by . operation of, in conjunction with cementation . 654 segregation of individual minerais by . ....... - 645-646 volume change by, illustration of . ........... 633 Meteorites, constituents of ........... 945-947,970,975,978 on trituration of rocks, limit of on vegetation, effect of on motions of ground water.

on weathering, end products of .............. on weathering, losses of constituents of rock by

Mesolite, alterations and alteration products of... 333-334 $373,387,401$ chemical and physical constants of ........... 199, 329 occurrence of .............. 332 sources and modes of formation of............. 262 , $332,371,375,377,398$

Meta, definition of term. ........................ 776 Metals, occurrence of forms of precipitation of, methods of ........... 1081-1088 solution of . . sources of ..... transportation of . ................. 1075-1081

Metamorphic action of intruded magmas, discussion of ......... 648

Metamorphic ore deposits, enumeration of......... 1233 Metamorphic processes, ores produced hy ...... 1052-1232 Metamorphic textures of rocks, plate showing ..... 704 Hetamorphism, agents of _..... $33,34-35,39-40,44,58-158$ belts and zones of, definitions of

$160,163,104,10 \pi, 189-190$

chemical elements, distribution of, as affected

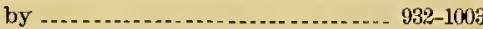
classification of contact, direct contact effect of $\ldots \ldots \ldots \ldots \ldots . .489-490$ discussion of .................... $488-494$ exomorphic and endomorphic effects of..... 488 indirect contact effect of . . definition of.

extent of, by igneous intrusion in belt of cementation. factors affecting - . for ces of . general principles of . . ... . . . . . .
Metia, island of, magnesian coral reefs at .... $799,803,804$

Micas, character, occurrence, and alterations of - 336-344 sources and modes of formation of . . ........ 228, 256 , $326,337,338,339-344,371,374$, $380,383,392,393,394,625-627$

authigenic nature of ................. . . . . . $693-694$ percentages of, in igneous rocks. Michigan, diahase from, losses in, by weathering - 510-511 Microcline, alterations and alteration products of . . . . 253-257, 373, 389, 398

chemical and physical constants of ........... 199, 253 occurrence of - 253 sources and modes of formation of - $253,281,371,392,397$ Microcline, albite, and anorthite, alterations and alteration products of ..............

Microcline and gibhsite, alterations and alteration products of ............... 389,400

Microcline and orthoclase, equation showing production of muscovite from 1070

Microcline, calcite, and hematite, alterations and alteration products of . ............. 389,401

Microcline, magnesite, and siderite, alterations and Microchne, magnesite, siderite, and gibhsite, alterations and alteration products of ... 389,40

Miller, W. G., on corundum deposits ..............

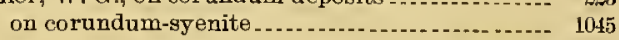
Mineral composition of earth's crust, discussion of . Sineral composition of rocks, effect of, on rate of weathering -

use of, as criterion for discriminating metamorphosed, sedimentary, and igneous rocks . .....

Mineral growth in rocks, examples of ...... . . .... . 643-645 methods of . ....................... $619-621$ alteration products of . . . . . . . . 389,401 
Mineral particles, regeneration of . Page. Mineral Point, Colo., cross section of vein near London shaft at ..................... 1135

Min $3 r a 1$ springs, carbon dioxide emitted from ...... 971 carbonates contained in, amount of ........... 611

silica in water of, amount of ................ 572 See also Springs.

Mineral stability, factors determining ........... 359-362

Mineral-vein formation, examples of, now in progress _. . . . 1059-1060

Mineralizers, or mineralizing agents, definition of .. 59-60 equivaient term used by Élie de Beaumont and H. Ste. Claire Deville............

Minerals (rock-making), adaptation of, to environment . ...................................

alterations of, chemical reactions and volume changes involved in . $375-394$ classification of, with volume changes .... 395-408 ceneral nature of aiterations and alteration products of, tabies showing ............. 372-374 accompanying ore deposits, citations concern-

ing ............ 1055-1057 ing
chemical formulas for.

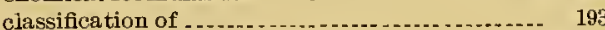
consideration of, in detail ................... 198-408 deposition of, now in progress. . . enlargement of, hy deposition of new matter

formation of, by igneous intrusion . . . . ... $717-720$

conditions affecting . . . . . . . . $33-35$

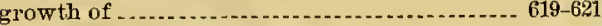

in igneous rocks, percentages of............... 987 in zone of anamorphism, enumeration of..... 363-364,

in zone of katamorphism, list of list of, showing chemical composition, specific gravity, etc .................. 195-201 loss of, by weathering, order of. ............. 518-521 table showing quantities of -516 molecular volumes and weights of ......... 195-201 solubility of, order of . . . . . . sources of, discussion of

table showing ............ 369-372 specific gravities of.

Miries, dry, mistaken inferences concerning ... 1063-1065 ground water in ......................... 1064-1065 Mining operations, influence of, on ground-water

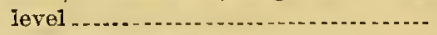

Mississippi Vailey, loess of character of zine and lead deposits of. See Lead; Zinc.

Missouri, lead and zinc district of, caves in ......... oxidation in, depth of ........................................... See also Lead; Zinc.

Molecular attraction, influence of, on ground-water circulation ......... 150-152,419-482

Molecular change and change of symmetry, alterations produced hy ................. 399

Molecular dirision, alterations produced by ........ 405

Molecular mechanical action, definition of .......... metamorphic effect of - . . . . . . . .

Molecular rearrangement, alterations in rocks by -- 202

Mroliusks, magnesium contents of shelis of .......... 798

Monocinal cleavage, existence of, over extensive areas .................. 928-981

Monoclinic amphiboles, character, occurrence, formation, and aiterations of .... . ..... 283-290
Monoclinic pyroxenes, character, occurrence, formation, and aiterations of .......... 271-281 Monson granite, strain in, shown by quarrying .... 598 Montara granite, disintegration of, extent of...... Monte Cristo district of Washington, richness of ores in, decrease of, with increase of depth in . . . . . 1187-1188 second concentration of ores in, conditions fa-

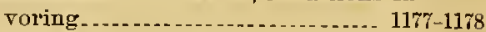
siiver ores in . ................. 1169 Moore, C. J., on ore deposits of Cripple Creek district .......... 1172, 1173 MIosses, disintegratory effects of, on rocks ........ $444-445$ Mountain making, rejations of rock flowage to ... $924-931$ Mountainous regions, disintegration in . . ........ 499-500 Mountains, limitation of height of, by disintegration............... 499,528 Mountains of disintegration, production of . . Mousson, A., on pressures required to hold water liquid at temperatures below freezing point ............. 44

Movement, metamorphic effects of . Mud family of rocks, character and origin of ....- 886-89? average chemical composition of ........... 890 Mueller, Richard, on chemical action of carbon dioxide solutions on minerais _. $61,71,475-476$ Mügge, O., on deformation of crystals ........... 695 Müntz, A., on nitrates in soils of tropical countries $465-466$ Müntz, A., and Marcano, V., on origin of nitrates of Chile................... 54 Miùntz, A., and Sehloessing, T., on bacteria, activity of, temperature favorable to..... 466

Murray, John, and Renard, A. F., on silica in sea water........ 866-867 on source of silica for marine organisms........ 848 Muscovite, aiterations and alteration products of. $337-338$, $353,374,387,388,402,403$ chemical and physical constants of .......... 199, 336 formation of, from orthoclase and microcline, equation showing . occurrence of . . . . . ........ . . . sources and modes of formation of ........ 223, 221, 225, $232,296,254,257,264,265,266,281,293,297$, $312,313,318,319,327,328,353,371,375,376$, $377,381,382,383,386,387,388,389,392,393$ See also Damourite.

$394,397,398,400,402,403,404,406,407,408$

Muscovite-biotite-quartz-schist, photomicrograph

$$
\text { of ..... }
$$

Nason, F. L., on iron ores of Missouri .............. 1039 Native elements, occurrence of, as minerals........ 212 Natrolite, aiterations and alteration product of ...- 333 chemical and physicai constants of $\begin{array}{r}334,374,388,401 \\ -199,329\end{array}$ occurrence of . . .... sources and modes of formation of ......... 261 $292,294,295,296,298,334,335,371,375,379$ $380,384,388,392,397,398,399,401,402,404$ Naumann, C. F., on rock nomenclature............. 785 Naumann, C. F., and Zirkel, Ferdinand, on formation of smaragdite.................... $\quad 274$ Nephelite, aiterations, and alteration products of. 292-294, $297,374,388,39 \%, 400,402$ chemical and physical constants of..........- 199,292 
Nephelite, occurrence of ...................... Page. sources and modes of formation of ............ 266, $967,292,3 \pi 1,386,408$ Nephelite and halite, alterations and alteration products of ..................... 388,400

Nephelite and quartz, alterations and alteration products of ..................... 388,406

Nepheline-syenite, weathered formas of . . . . . ..... 528-529 Nernst. Walter, on chemical changes produced by mechanical action ................. 49 on chemical reactions .................... $87,88,89,90$ oll chemical systems, homogeneous and heterogeneous _ on diffusion of substances in solution ........... 82,83 on electrolytic dissociation as a measure of reaction capacitios of substances -...-

on freezing and crystallization, identical char-

on freezing point of solutions, lowering of by crystallization of contained materials on heat effects connected with chemical action. $105,106,107$

on molecular attraction in gases $---1-2 \cdot---2-500$ on osmotic pressure ............................. on precipitation by reactions between solutions and solids

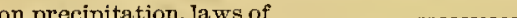

on pressure, effect of, on chemical reactions .... 100

on pressure, relations of, to solubility . . _..... 77,101

on proportion of volume of liquids occupied by their molecules

on separation of salts into their ions ...........

on solubility, increase of, by increase of temperature

Nevada, lake deposits in .

Nerada City, Cal., gold veins of, constant tenor. of ..................... 1137

New Caledonia, nickel or $\theta$ of . ............ 1131 Newell, F. H., on proportion of run-off to rainfall.. Newmaan, George, on number of bacteria in soil....

New Mexico, copper deposits of ................... 1050

New South Wales, gold deposits of .

Newtonite, chemical and physical constants of ....- 199 sources and mode of formation of . .... 253, 254,371, 389

New Zealand, magnetite beach sands of ........... 1039

Nicaragua, depth of disintegration of rocks in ..... 531

Nickel in earth's crust .....-.-. 936,1002

Nickel ores, formation of ....................... 1046-1048

Nickel silicate, occurrence of .................... 1131

Nickel sulphides, formation of ores of .......... 1046-1048

Nicolson, J. T., and Adams, F. D., on deformation of calcite crystals.................. 675 on deformátion of rocks under pressure... $49,670,681$, $696,747,772,809,811,812,814,815,816,1012$ on mobility of calcite......................... 754 Niles, W. H., on strain in rocks................. 598 Niter family of rocks, deposits composing -.......- 787 Nitrates, occurrence and origin of .......... 542 543,980

Nitrogen in atmosphere......................... 944

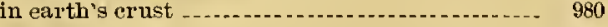
in ocean . occurrence of . . ............................... 980 oxidation of, consumption of oxygen of air by _. $\quad 954$

methods and products of .................... 465-466 sources of, for plants ............................. 452 Nonfragmental rocks, classification of .......... 784-853
Page.

Norites, nickeliferous, deposits of . ............. 1046-1047 Noselite, alterations and alteration products of - 298-299,

$374,388,399$

occurrence of ..... . .

chemical and physical constants of

Novaculite, character of .......... 865

Nova Seotia, gold ores of ...................... 121s

\section{O.}

Ocoee series, metamorphism in, variations of .... 919,920 Octahedrite, alterations and alteration product of chemical and physical constants of ............ 199, 230

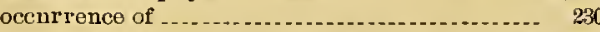
sources and modes of formation of ........... $22 \%, 228$, 230-231, 355, 371, 385, 386, 393, 396, 405

Ocean, carbon dioxide in . . chemical composition of limestone formations deposited in . ........... 793-795 salts in - 942,943,944 source of water of .......... 953-954 Oligoclase, character, occurrence, formation, and alterations of . ...................... 259-265 See also Andesine.

Olivine, alteration of, to serpentine, magnetite, and quartz, -olume change incident to ... 639

alterations and alteration products of . ...... $308-311$ $354,366,374,388,399,404,405$

chemical and physical constants of ...... . .... 199, 30 occurrence of - 308,367 sources and modes of formation of .... $308,367,380,386$ Olivine and anorthite, alterations and alteration products of ........................ 388,408

Olivine and quartz, alterations and alteration products of ............................ 388,406

Olivine, calcite, and quartz, alterations and alteration products of ..................... $388,40^{\circ}$ Omphacite, alterations and alteration products of .................................... 27

Opal, alterations and alteration products of . . ... 221-223, $388,389,400$

chemical and physical constants of ........... 199,221 occurrence of sources and moodes of formation of .............. 221 . $309,349,3 \pi 1,391,540$

Openings in rocks, character, distribution, forms, and sizes of . $143-146,155,618,658,1201,1202$ filling of ............................ 564-565 flow and work of water in _. 136-143, 154-155 second concentration of oles favored by .... 1177-1179 Ore deposits, classification of ................ 1005,1232 contiguous, difference in mineral content of. 1202-1203 derivation of, from igneous rocks . ......... 1030, 1054 from sedimentary rocks .. ................ 1033,1036 genetic classification of, table showing.......... 123: igneous, enumeration of ...... 123 raetamorphic, enumeration of ............... 1233 openings occupied by, character of .... 1078,1201,1202 position of, as affected by topography ...... 1217-1221 present formation of .......................... 1233 relations of metamorphism to . rich upper belts ot ....................... 1182-1193 sedimentary, enumeration of .................. 1233 superficial alteration of .............. 1190 
Page.

Ores concentration of special factors affecting 1199-1222 formation of, by aqueous solutions . . ..... .... 1058-1234 by ehemical precipitation................ 1037 by different processes, transition between . . by gaseous solutions, discussion of . .... 105:-1058 by igneous processes, diseussion of ...... 1043-1052 by mechanical concentration _ 1038-1059 by metamorphic processes . . . . . . . . . .... 1052-1232 by sedimentation . . ....................... 1037-1043 metals of, sources of $\quad$ 1235-1240, 1069-1072 Ore sboots, formation of, in secondary fractures _...

requency of. near complex fractures .......... 1225 influence of wall rocks on formation of . ...... 1229 location of, factors determining ........... 1083 occurrence of, near flexures. ...... . . ....... 1225-1226 origin of some, during late orogenic movements. 1228 variatious in size and richness of ........... 1223-1224 Oregon, copper deposits of . . . ................. 1055-1056

Organic matter,importance of, in ore deposition ... 1146 oxidatiou of . $461-466,606-607$ precipitation of gold by ... precipitation of ores by ........... 1110-1111

Orientation of mineral particles in recrystallized rocks, discussion of . . . . . . . . . . . 688-689 Orogenic movements, ground-water level as effected

ore shoots formed by Orthite, chemical and physical constants of ....... 195 Orthoclase, alteration of, to kaolin and quartz, rolume change produced by .......... 632 alterations and alteration products of . ........ 253-25\%, $374,389,398,404$

chemical and physical constants of _ _ $\quad 199,253$ occni'rence of . ................................... 253 sources and modes of formation of . ......... 253,266, $333,334,335,371,376,384,3 \$ 6,393,397,400,401,408$

Orthoclase, albite, and anorthite, alterations and alteration products of . . . . - $375,377,389,404$

Ortboclase and gibbsite, alterations and alteration products of .................... 369,400

Orthoclase and microcline, equation showing production of muscovite from..........

Orthoclase, calcite, and hematite, alterations and alteration products of . . . . . . . . . ... 359,401

Orthoclase, magnesite, and siderite, alterations and alteration products of .............. 389,401

Orthoclase, magnesite, siderite, and gibbsite, alterations and alteration products of .... 389

Orthorhombic pyroxenes, character, occurrence, formation, and alterations of . ..... 267-271

Osmotic pressure, character of ................. $72-74$

Osteolite, source and mode of formation of... $356,371,378$

Ostwald, W., diagram cited from, showing quantitative relations between solution and temperature

on acid reaction of solutions containing strong acid and weak base...............

on acids, character of ...................

on acids and bases

on acids and bases, strength of, as a measure of reaction capacities.................

on adsorption.

or bases, character of on carbonic acid, absence of second stage of dissociation in
Ostwald, W., on chemical reactions, nature and speed of ......................... 9$]$ on crystallization from solutions on diffinsion in solutions.......... 82,83 on gas absorption by water as affected by solids held in solution................. 72 on heat phenomena of chemical solutions.... 106,107 on hydrolysis . ............................ $86,87,108$ on osmotic pressure on precipitation ....................... 115, 117-118 on pressure in gas dissolved in liquid ........ 70 on separation of salts into their ions ... . . . .... $66-67$ on solutions . ........................ $58,77,79$ on surface tension of water. on temperature, effect of, on solubility ......... Ottrelite, chemical and physical constants of.... 199, 344 accurrence and alterations of

Oxidation, alterations produced by ................ 405 belt of, coincidence of, with belt of weatbering. 1142 compounds affected by, in zone of katamol-$$
\text { phism }
$$

definition of depth and pressure required for reversal of .. 180-181 depth of ... in belt of cementation . . .......... $164,165,166,601-608$ in belt of weathering . . . . .............. 163,461-473 materials affected by ....................... 172 method of, in zone of katamorphism........... 161 of carbonaceous matter, earbon dioxide produced by ......................... 972-974

of inorganic compounds, diseussion of . . . ... $466-469$ of organic compounds, discussion of ......... 461-466 oxygen for, source of, in zone of katamorphism -

substances affected by .................. 606 Oxidation and decarbonation, alterations produced by - . .

Oxidation and desulphidation, alterations produeed by ............................ 406 Oxidation and hydration, alterations produced by - 404 Oxidation and titanation, alterations produced by. 405 Oxidation, carbonation, and hydration, discussion of . . . . Oxidation, carbonation, dehydration, and desilication, alterations produced by ....... 399 Oxidation, carbonation, hydration, and desilication, alterations produced by...

Oxidation, decarbonation, and desulphidation, alterations produced by ............. 406 Oxidation, hydration, and decarbonation, alterations produced by ....................

Oxidation, bydration, and desulphidation, alterations produced by ............. 406 Oxide order of rocks, deposits forming ........... $842-853$ Oxide ores, genesis of . . . . . . . . . . . . Oxides, chaxacter, occurrence, formation, and alterations of ................ 217-236,520 Oxides cementing rocks in belt of cementation, forms and conditions of deposition of .... Oxygen, amount of, iu atmospher' in atmosphere, depletion of, causes of ....... 949-956 in earth's crust . . . ....................... 934,936 in earth's crust, sea, and atmospher'e ........... 948 in sea salt and sea water................... $942,943,944$

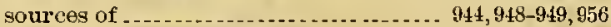
work of in metamorphism ................ $60,61,62$ 
INDEX.

$P$.

Packard, R.L., on occur'rence of nickel as a silicate. 1131 Paragonite, chemical and physical constants of ... 199 336,338 occurrence and alterations of 338 sources and modes of formation of ............ 258 $260,261,337,358,371,375,377,388,400,401,408$

Parankerite, alterations and alteration products of _. chemical and physical constants of . . . . ....... 199,237 occurrence of sources and modes of formation of ........ 242,823-829 Palankerite and ankerite, alterations and alteration products of

Parankerite and quartz, alterations, and alteration produets of .

Parankerite, ankerite, and quartz, alterations and alteration products of ................

Park Ranges, uplift of, discussion of ............ 929-930 Parker, E. W., on amount of coal mined and used.. 464 Pectolite, chemical and physical constants of .... 199,271 occurrence of . source and mode of formation of .

$280,333,334,371,3 \pi 8,401$

Peale, A. C., on carbonates in waters of mineral springs .

on chemical action taking place in solutions

on ferrous iron in sulphate-bearing mineral waters. . . .

on silica in spring water .................

Pearlash. See Potassium carhonate.

Peat beds, production of ..................... 479

Pebble, gravel, and howlder deposits, discussionof. 853-869

Pebhles, quartz, simulation of, by sherred quar'tz fragments.........................

Pecos Valley, New Mexico, prevention of alkaline deposits in, methods adopted for ... 546

Pegmatite veins, possible relation of to ore deposits. 1050 Pegmatites, production of, by contact metamorphism .......... $720-$;28

Peirce, on greater tidal forces of the past Pelite-gneiss, deposits of, origin and character of. 894-904 Pelite order of rocks, families of .............. 785 deposits composing . ........................ 886-892

Pelite-schist, deposits of, origin and character of - 894-904

Pelite-slate, deposits of, origin and character of .- 894-904

Pelites, definition of ............................... 785 photomicrographs of - 902

Penck, A.. on limitation of heights of mountains hy disintegration

Penfield, S. L., and Sperry, F. L., cited on aphrosiderite at Spurr mine

Penninite, formation, alterations and alteration products of ...... $347-348$

chemical and physical constants of ... 196,344,345,346 occur rence of . . . . . . . . sources and modes of formation of ... $343,344,371,390$

Penokee-Gogebic district, diabase from, losses in, by weathering .................. 510-511 photomicrographs of rocks from ............ 836

Penokee series of Michigan, diahase dikes in, metamorphism of .......................

Penrose, R. A. F., jr., on copper deposits of Arizona 1184 on difference in effects of displacement on different kinds of rock . ............ 1010 on ore deposits, Cripple Creek district.. 1085, 1169, 1205 on ore deposits, superficial alteration of .......- 1180

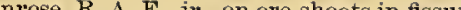
on manganese silicate ................ 1131 on phosphates, origin of . on sulphates, formation of ................. 1141 on telluride gold ores of Cripple Creek, Colo.... 1119 on tellurides and fluorite, association of .... 1122, 1123 on tellurides and sulphides, association of ...... 11*0 on tin deposits of Malay Peninsula _. ... 1039, 1054-1055 on veins of Cripple Creek district ............ 1202 Peridot, chemical and physical constants of ....... 199 Peridotites, ore deposits in . ..................... 1047 Perorskite, alterations and alteration produets of 355 , 374,389

chemical and physical constants of 199,354 occurrence of ..... 355 souree and mode of formation of . .... $355,371,393,401$

Perry, J. H., on occur'ence of graphite. ........ 212 Phillipsite, chemical and physical constants of ... 199, 330 sources and modes of formation of ..._._. 262, $332,371,375,376,386,397$

Phipson, T. L., on carbon dioxide now and formerly in atmosphere on oxidation of hydrogen hy plants . .......... 953

Phlogopite, alterations and alteration products of ....... 343-344,374,389, 390,39\%, 403 hemical and physical constants of ......... 199,336 occurrence and associations of ............. 343

Phlogopite-ehlorite, chemical and physical constants of............ 199 source and mode of formation of $\ldots \ldots \ldots \ldots$ Phonolite, losses in, by weatbering, analyses showPhosphates, character, occurrence, formation, and alterations of . . . . .... $356,542-543,976-977$

Phosphation, definition of . ..................... 206 Phosphoric acid, percentage of, in grain and straw presence of, in ground waters ............

Phosphorus, in ear'th's crust . .................... 986, 975

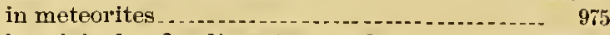
in original and sedimentary rocks. ......... $975-976$ Phosphorus pentoxide, percentage of, in earth's crust . . . Physical and chemical principles applicable to action of ground water.......... 65 -123

Physical-chemical factor's affecting rock alteration Physical revolutions, effect of, on ore deposits . 1221-1220

Physics, principles of, applicable to motions of ground water

Pickering, S. P. U., on precipitation of basic ferric sulphate....................... 826

Picotite, chemical and physical constants of....... 200 Piedmontite, character, occurrence, formation, and alterations of ............... $320,321-322$ Pinite, chemical and physical constants of......... 200 source and mode of formation of ............ 291 $393,312,371,386,397$

Pirsson, L. V., and Weed, W. H., on tellurides associated with gold ores of Judith and Little Rocky mountains, Mont ....... 1119

Pirsson, L. V., Cross, Whitman, Iddings, J. P., and Washington, H. S., on mineral composition of amphibole gabhro....... 63\% Pitching arches, influeuce of, on ore deposition _ 1211-1216 Pitching troughs, influence of, on ore deposition - 1211-1216 origin of . . ... . . . . . 
Page.

Placer deposits, metals derived from .............. 1038 séa-beach deposits so designated............... 1038 Plagioclases, alterations and alteration products of. 374 Plagioclase feldspars, character, occurrence, formation, and alterations of . ......... 259-265

Plants, abundance of, favorable to decomposition. 503-504 chemical work of, in soils . . . . . . . . . . . . . . $452-456$

disintegrating effects of, on rocks . . .......... 444-447 geological work of . ground-water circnlation affected by .... $417,422-493$ material ahstracted from soil by . . . _ . . . . . . . 537-538 sparseness of, farorable to rock disintegration without decomposition.......... 500

work of in maintaining soils . ............... $505-506$

Plateau, J, on molecular attraction between water and walls of its container

Pleonaste, chemical and physical constants of .....

Poiseuille, J., laws of water flowage formulated

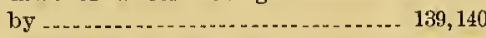

Polar regions, disintegration of rocks in ......... $498-499$

Pore space of rocks, amount of .................. 12t-128 form of openings constituting, diagrams show-

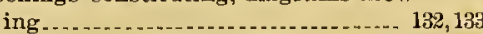

influence of amount of, on effects of freezing. .. size of openings constituting - 13t-146

prosity of rocks, effect of, as regards metamorphism -

effect of, in cases of igneous intrusions. . . . . . 649-650 influence of, on ore deposition. .......... 1201 variations in ................................. 1200-1217

Porphyritic chloritoid, thin section of _._.

Porphy ritic minerals in rocks, development of ... 699-705 occurrence of, in schists, significance of ........ 697 Porphyritic schists, dissemination of ......... 910-911

Porphyritic textures, development of . . . ......... 699-r05

Portland mine, Cripple Creek, Colo., ground water in .... 1064-1065

Posepny, F., on copper deposits of Australia ....... 1087 on crustification . ......................... 1134-1135 on ore classification on ore deposits, genesis of .................. 1060 ,

$1065,1076,1128,1160,1181,1235$

on production of sulphide ores by ascending waters.

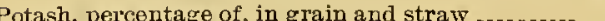
percentage of, in salts of sea water .............. 949

Potassa, amount of, in original and sedimentary rocks ..................................

See also Potassium carbonate; Potassium oxide.

Potassium, in earth's crust............. 934,936,999-1001 iu lithosphere.

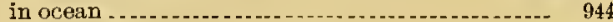

in sea salt .

minerals and rocks containing................ 1000

occurrence of $999-1009$

Potassium-bearing minerals, deposition of .........- 627

Potassium carbonate, chemican composition of and other data concerning...............

Potassium carbonate, quartz, and diaspore, alteration products of................. 382, 407

Potassium carbonate, gibbsite and quartz, alteration products of ...... 383,407

Potassium carbonate, quartz, and cor undum, alteration products of ............... 38

Potassium feldspar, equation showing production of kaolin from

Potassium minerals, order of decomposition of, in

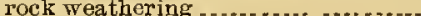

Page.

Potassium oxide, in earth's crust ............... 934,937,938 in salts of sea water ........................ 942

Potassium sulphate in the ocean ................. 943

Potassium sulphide in salts of sea water ............ 943

Potentialized energy resulting from strain, discussion of . . ......................... 96-97

Potsdam sandstone, ground water in, rate of flow

$$
\text { of .............................. 585-586,587 }
$$

Potter, W. B., on preservation of original structure in decomposed rocks................. 526

Powell, J. W., on fourfold structural character of

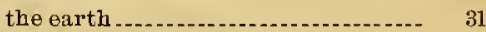
on proportion of run-off to rainfall ........... 414 on springs of Grand Canyon of the Colorado.... 411 on temperature required for aqueo-igneous fusion ................ 79

Pratt, J. H., on chromito ores.................... 1047

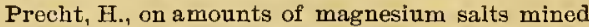
at Stassf urt . . . . . Precipitates, organic, formation of Precipitation, ascending waters farorable to . .... 115,116 by change of pressure, phenomena of....... 114-115 by change of temperatur $\theta$, phenomena of .... $79-81$, by reactions between aqueous solutions, phe$115-116$ nomena of . by reactions between aqueous solutions and gases, phenomena of ............... 119 conditions governing - ........... 116-118 cycles of, inflnence of on ground-water level ... 424 heat effect in ..................................... 105-106

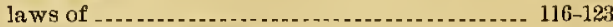
likeness of, to freezing -... of abundant compounds in a solution, law of ... $\quad 539$ of cementing material, principles of ...._....... 629 of material in belt of weathering, discussion of of metals, methods of . of minerals from solutions, causes of _........ $10 \pi 8$ ores formed by .............................. 1037 phenomena of selective, discussion of . . ................... 634630 supersaturation necessary to . ............... 113-114 Prehnite, alterations and alteration products of ... 324 ,

$374,390,404$

chemical and physical constants of ...-...-. 200,324 occurrence of . . sourcesand modes of formation of. $260,263,324,333,334$ $335,371,376,317,386,38 \%, 388,391,401,404,625$ Pressure, decrease of, precipitation of metals by effect of; on chemical reactions.......... 100-104, 168 on erystalization............................ 103 on meta mor phism by igneous intrusion..... 65 ? on ore deposition .................. 1073, 1074 on production of minerals ....... . . . . . . $363-365$ on solution importance of, in chemical work in belt of weathering . . . 460-461 increase of, effect of, on chemical reactions...- 89 of gases, importance of, in metamor phism..... $70-71$ osmotic, character of . . . . precipitation by change of .......... 114-115 range of, at which work of water solutions is done................................... relation of, to rapidity of deformation of rocks_ $\quad 741$ to solubility ......... 77-79 See also Strain; Stress. 
INDEX.

Preston, Tbomas, on pressures necessary to keep water liquid at different temperatures.

Prestwich. Joseph, on dolomitization of Carboniferous limestones in Ireland ........ $799-800$ on ground-water transmission as influenced by size of openings in rocks .............. on retention of decomposed potassium feldspars by rocks .......................... 1001

Prochlorite, chemical and physical constants of . 196,346 occurrence and alterations of................. 346-348

Przibram mining district, ground water in mines of . .

Psammite order of rocks, deposits forming - $785,860-886$

Psephite gneiss, origin and character of .... . . .... 857-860

Psephites, deposits composing ............... 785, 853-860

Pseudo-conglomerates, discrimination of, from true conglomerates .........................

Pumpelly, Raphael, figure cited from ............... on aphrosiderite at Spurr mine .............. on cementing materials, similarity of to rocks cemented ...........................

on copper deposits of the Lake Superior region .............................. 1101, 1204 on hydroussilicates in the Lake Superior region. 1130 on metasomatism in the Keweenawan series . on replacement of silica by copper iu rocks of Lake Superior region

on substitution of copper for porphyry pebhles.

Pumpelly, Rapbael, Wolff, J.E., and Dale, T. N., on crystallographic orientation of porphyritic feldspar ......................

Purington, C. W., Woods, T. H., and Doveton, G. D., on occurrence of rhodonite at the Camp Bird mine, Colo............. 1115-1116

Pyrite, alteration of, to magnetite . . . ........ 845,846,1112 alterations and alteration products of .. ...... 214-216, $374,390,406$ cbemical and physical constants of ........... 200,213 occurrence of . precipitation of copper sulpkide from cupric sulphate by, equation showing reaction for sources and modes of formation of . . ....... 213-216, $226,227,371,384,387,390,399,408,627,1153$

Pyrite and siderite, alterations and alteration products of . Pyrope, alterations and alteration products of ..... 302 , $374,3 \pi 6,390,397,399,401,402,404$

chemical and physical constants of . . .......... 200,299 occur rence of . sources and modes of formation of ..............

Pyrope, almandite, and melanite, alterations and alteration products of.. $375,383,387,390,396$

Pyrope and almandite, alterations and alteration produets of .............. $375,383,390,401,404$

Pyrope, grossnlarite, and melauite, alterations and alteration products of _. $383,384,387,390,398$

Pyrophyllite, sources and modes of formation of .. 25 , $254,371,389$

Pyroxenes, alterations and alteration prodncts of - 275-

character, occurrence, formation, and alterations of . . . percentage of, in ignoous rocks................. $93 \pi$

Pyroxenite, losses in, by weatbering, analyses showing .................... 510,515,5\&2-523
Pyrrhotite, alterations and alteration products of - . 21... $216,374,390,391,406,408,849$ chemical and physical constants of ........ 200,213 chemical reactions involving . . ............... 846,1161 occur rence of ................................. 213-214 sources and modes of formation of .......... 213-214

Q.

Quadrupeds, burrowing, effect of work of, on soils. 450 Quarry water of sandstones, surface induration caused by evaporation of ............ 549

Quartz, alterations and alteration products of ... 218-220 cementation by, preponderance of ........... 634-636 chemical and physical constants of ........ 200,217 clastic, penetrated by serpentine, figure show*

ing 648 in igneous rocks, percentage of .............. 93 i mobility of occurrence of . . ...... . . sources ind modes of formation of . .... 218, 220-221, $254,260,261,264,269,273,282,285,286,304$, $305,305,307,309,312,322,339,349,353,366$, $371,375,376,377,378,379,380,381,382,383$, $384,385,387,388,389,3 i 0,391,393,394,396$, $398,399,400,401,403,404,405,540,622-623$

rein, figure showing

Quartz and analcite, alterations and alteration products of......................... 376,407

Qnartz and ankerite, alterations and alteration products of ...................... 376,407

Quartz and calcite, alterations and alteration products of ............... $3 \$ 0,407$

Quartz and corundum, alterations and alteration products of Quartz and diaspore, alterations and alteration products of .................... 381,382, 407 Quartz and dolomite, alterations and alteration products of . ...................... 382,407 Quartz and gehlenite, alterations and alteration products of ......................... 383,406 Quartz and gibbsite, alterations and alteration products of ..................... 383,407

Qnartz and hoinblende, alterations and alteration products of .................. $385,399,405$ Quartz and nephelite, alterations and alteration products of . . ............... 388, 406

Quartz and olivine, alterations and alteration products of . ........... 388,406 Quartz and parankerite, alterations and alteration products of Quartz and siderite, alterations and alteration products of ............... 392,407

Quartz, ankerite, and parankerite, alterations and aiteration products of ............. 376 Quartz, bronzite, and calcite, alterationsand alteration products of ............. 379,407

Quartz, calcite, and corundum, alterations and alteration procucts of .............. 381,408 Quartz, calcite, and forsterite, alterations and alteration products of. .............. 383,407

Qnartz, calcite, and hypersthene, alterations and alteretion products of ............. 379,407

Quartz, calcite, and ilmenite, alterations and alteration products of .................. 385, 408 Quartz, calcito, and olivine, alterations and alteration products of .................. 388,407 Quartz, calcite, and rutile, alterations and alteration products of .................. 391,407 
Quartz, corundum, and potassium carbonate, alterations and alteratiou products of... 381,408 Quartz, diaspore, and calcite, alterations and alterition products of $\quad 382,40 \%$ Quartz, diaspore, and potassium carbonate, alterations and alteration products of ... $382,40 \%$

Quartz-feldspar sand, deposits of ................. 870-87 Quartz-feldspar sand family of rocks, deposits com posing ............................. $870-876$

Quartz, gibbsite, and calcite, alterations and alteration prodncts of .................. 383,40 \% Quartz, gibbsite, and potassium carbonate, alterations and alteration products of... 383, 407

Quartz, porphyry, mashed, thin section of, showing elongated quartzes

Quartz rocks, deposition of . 704 Quartz rocks, deposition of Quartz-schist, view of thin section of, showing liquid and gas filled cavities ............ 699

Quartzite, character and origin of ............... 865-868

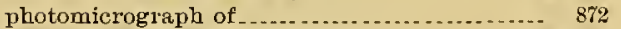
Quartzite-schist, character and origin of -.....-. $868-870$ Quincke, MI., on molecular attraction between water and walls of its container . . ........ 143-144

\section{R.}

Rainfall, amount of, in different sections . ........ $\$ 13-41$ cycles of, influence of, on ground-water level... $\quad 424$ seasons of, influence of, on ground-water level. $\quad 424$

Rain water, carbon dioxide in, amount of ......... tit

Ransome, F. L., figure cited from on ore deposits of the Enterprise mine, Rico, Colo ................... 1084, 1208, 1215, 1229

on ore deposits of the San Juan district, Colo-

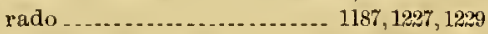
on rhodochrosite, occurrences of, in connection with gold

on seeondaris enticliment of oro der

Raoult, F. ML., on lowering of freezing point of liquids by addition of material for dissolution

Raymond, R. W., on genesis of ore deposits......... 1160

Reactions, chemical, discussion of ................. $87-90$

compounds present in, consideration of . . . . . . 91-9.

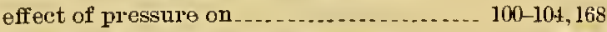

importance of, in metamorphism ... . . . . . . . 88-89

of expansion, discussion of . . .............. 631 634

nature and speed of . . ................. 91-113, 107-108

phenomena of . . . . .

reversibility of . . .... . . . . . . $87-90,110-111,360-369$

speed and nature of

speed of, increase in, with increase of temperature ............................ 107-108

stoppage of, by pressure and heat generated by the reactions themselves..............

see also Chemical reactions.

Reade, T. Mellard, mountain-making theory of, as affected by theory of increase of density of minerals with depth .........

on limestone contained in earth's crust, thickness or mass of.

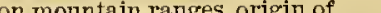

on salts abstracted from soil by solution, amount of . ....................... 485-486

on sedimentary rocks, thickness of

Recrystallization of minerals in rocks, alterations effected by

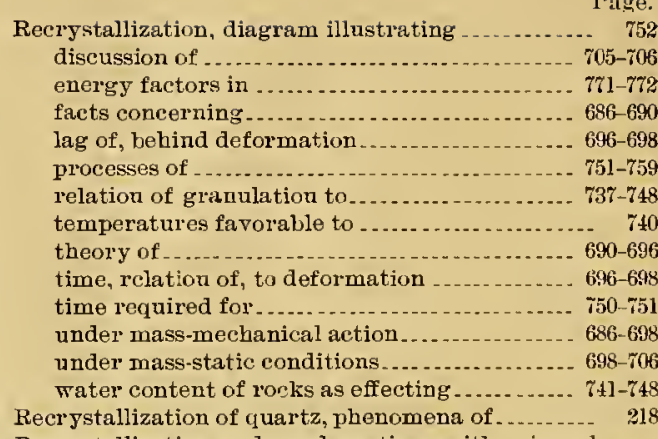

Recrystallization and condensation, with mineral changes, features of .............. 102-104

Renard, A. F., on submarine formation of phillipsite ........................... $33:$

Renard, A. F., and Murray, John, on silica in sea water

on source of silica for marine organisms........ 848 Replacement of wall rock by ores, examples of . 1203-1207 Reprecipitation of material in belt of weathering, discussion of . . .............. $539-554$

Residuary deposits, burial of, under marine deposits, example of ................... 559

reference to

Renter, M., and Treadwell, F. P., on solubility of calcium carbonate in salt water..... 119

Reversibility of chemical reactions, observations on . .............. 87-90, 110-111,366-369 Reyer, E., on origin of pegmatites................ Rhodochrosite, occurrence of, in connection with ore deposits, significance of...... 1115-1116

Rbodonite, occurrence of ............... 1131 occurrence of, in connection with ore deposits, significance of ................. 1115-1116 Rbombic pyroxenes, character, occurrence, formation, and alterations of . ............ 267-27.

Rickard, T. A., on indicator veins of Bendigo reef, Australia ........................ 1111 on lodes of the Cripple Cruek district ........... 1925 on ores of the Bendigo gold district, Australia.. 1212, 1213 1084 on precipitation of gold by organic.matter. 1094,1095 on precipitation of gold by tellurides ........ 1097 on telluride ores of Kalgoorlie................. 1122 on water in veins . ............................... 106 . Rico, Colo., ore bodies at Enterprise mine at ...... 108t, 1208,1215

Riebeckite, chemical and physical constants of.:. 200,283 occurrence of

Rock-making minerals, chemical formulas for ... 195-201 consideration of .......... 207-358 list of, showing chemical formula, specific gravity, etc .......... 195-201 molecular volumes of $\ldots \ldots \ldots$ 195-201 molecular weights of .................... 195-801 specific gravities of, logarithms of ........... 195-201 Rock-salt family of rocks, features of deposits composing . . . . . .

Rocks, alteration of, geologic factor's affecting ...... $40-44$ alterations of , general nature of . ............... 31-38 analyses of .......................... 
Rocks, eapacity of, for imbibition of water, an index to power of transmission ........ 155

deformation of, speed of . . . . . . . . . . . . ... 188-189 diminution of volume of, methods of .......... 101-104 disintegration of, by changes in tempera.

ture ...................................... 434439 expansion of, with increase of temperature, rate of .

flow of, character and conditions of..... $748-759$ effect of, on textures and structures . . ... . 760-762 mashing by ............................... 762-764 relations of, to mountain making . . ........ 924-931 igneous, analyses of ............ 934 losses of, constituents of, in belts of weather'ing 507-518 metamorphic, nomenclatur $\theta$ of ................ $776-784$ openings in, capillary, flow of water in ....... 138-143 capillary, subcapillary, and supercapillary, sizes of ................ 135-136, 138, 145-146 diagrams showing form of . ............... 132,133 due to faults, joints, and fissility, relative size of .............. 155 form and continuity of . . . . . . . . influence of, on speed of water transmission $154-155$ percentage of rock occupied by ...... 12t-129, 146 size of _. subcapillary .............................. 143-146 supercapillary, flow of water in ........... 137-138 work of water in, variable in amount with variation in size .....................

pore space in, diagrams showing form of openings constituting .................. 132,133 sedimentary, analyses of. 938

thickness, rolume, and weight of .......... 939-941 solid, penetration of, by water .............. 123 Rolker, C. M., on tin deposits ..................... 1038 Roots of plants, disintegrating effects of, on rocks. $414-447$

Rosenbusch, $H$., on alterations of chlorite ........ 347 on definition of psammites . ................ 785

on kalk-silikat-hornfelse of the Harz Mountains. 823

on zonal arrangement of metamorphic minerals peripheral to intrusive masses..... $718-719$

Rossland, British Columbia, auriferous pyrite deposits of . . ........................ 1047

Run-off, effect of agriculture on ............... 415

material abstracted from belt of weathering by .................................... 538

Rupture of rocks by strain, discussion of ........ 599-602 Russell, I. C., on cause of red color of soils ... ...... 469,482 on chemical composition of alkaline earth carbonates of Lakes Lahontan and Bonneville ......................... $\quad$ 99

on climatic changes in far West in Pleistocene time

on deposits of Lake Labontan ............. 554

on present formation of tufa deposits in salt lakes

on preservation of original textures and structures in decomposed rocks......... 526

on subtuberant mountains...................... 709

Rutile, alterations and alteration products of .... 231,374

chemical and physical constants of........... 200,230

sources and mode of formation of .............. 227 , $228,230,231,355,371,379,385,388,393,396,405$

Rutile and magnetite, alterations and alteration produets of ...... . . . . . . . . . . . 391,405 Rutile and siderite, alterations and alteration prod. ucts of .......................... 391,400
Rutile, calcite, and quartz, alterations and alteration products of .

Rutley, Frank, on Paleozoic limestone beds, dwindling and disappearance of......... 524 on whetstones of Arkansas ..................... 853

$$
\text { S. }
$$

Sahlite, alterations and alteration products of . ..... $2 \% 3$, $274,275,277,278,279,374,391,399,408$

chemical and physical constants of ........... 200,271 occurrence of .............................. 272 origin of, from ankerite, chemical reaction involved in .... $83 \%$ sources and modes of formation of .......... 242, $243,272,371,376,407$

Sahlite, siderite, and magnesite, alterations and alteration products of ........... 391,408 Salisbury, R. D., on loess of Mississippi Valley ..... 501 Salisbury, R. D., and Chamberlin, T. C., on size of particles of loess.

on thickness of residual clay in Upper Mississippi Valley. amount of annunlly removed fiom Salt, common, amount of, annually removed from

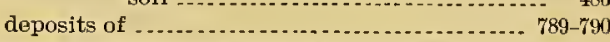
Salt Lake Valley, lands rendered alkaline in, by ir-

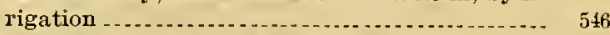
Salton Basin, Cal., soluble salts in soil of ........... 545 Salts, acid, example of .......................... 84 basic, example of ............................. 8 definition of dissociation of, iu water........... formation of, mode of ........................ 8 in ocean, total amount of . . . . . ............. 943,944 in sea water................................... 942 precipitation of, in belt of weathering.......... 542 soluble, amount of, contained in soils ........... 545 solution and abstraction of, in soils . . . . . . . .... 485-486 solutions containing, phenomena of ........... 116-119 San Bernardino spring, amount of silica in water of. $\quad 5 \% 2$ San Joaquin Valley, Cal., lands rendered alkaline in, by in'rigation.

San Juan mining district of Colorado, decrease of values with increase of depth in. 1186-1187 depth of oxidation in................... 606,1181 Lake vein in, rariations in, with variations in character of country rock ........... 1071

ore deposits of ..................... 1204 as affected by topography ............ 1219-1220 ore shoots in ............ secondary enrichment of ores in............ 1186-1187 wall rock in, influence of, on reins in .......... 1230 Sand dunes, formation of ........................ 862 Sand grains, size of smallest particles of . . . . . . $432-433$ Sandberger, F., on source of metals............ 1030 Sands, ferromagnesian. deposits of, character and

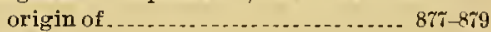
pore space in . . Sandstones, analyses of . . ........................... 938 casehardening of . . . . . . . . . . . character and origin of......................... $860-865$ induration of surface of, by iron oxide ...... 5 $48-549$ photomicrograph of ........................ 872 pore space in, amount of . ..................... 124, 126 quarried, surface induration of, caused by evaporation of quarry water............ 549 strain in, shown by quarrying. 598 
Saville-Kent, W., on composition and cementation of Bar'rier Reef of A ustralia ....... 796 Scapolites, alterationsand alteration products of. 312-314,

occurrence of sources and mode of formation of $260,263,265,353,371$ Scheerer, C. J. A. T., on origin of pegmatites._..- 722

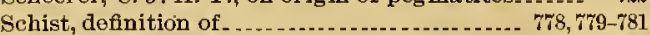
photomicrograph of Schist-arkose, deposits of, origin and character of Schist conglomerate, origin and character of.... $857-860$ Schist-graywacke, deposits of, character and origin Schist-pelite, deposits of, origin and character of $894-904$ Sehist-quartzite, character and origin of . ........ 868-870 Schistose tuffs, discrimination between sedimentary schistose rocks and .......... 909-913 Schistosity, display of, by weathering ............ 525 Schists, metamorphic, igneous and sedimentary rocks often combined in ........... 911-912 minerals of, development of . . . . porphyritic, discrimination of ................ 910-911 Schloessing, $T$, on activity of bacteria, temperaturo
favorable to Schloessing, $T$, on activity of bacteria, temperature
favorable to..... on carbon dioxide the ocean, ratio of, to that in the atmosphere -......... 967-568 Schürmann, E., on ordel of disappearance for the metals by oxidation . on precipitation of sulphides............... 1114,1116 Scolecite, alterations and alteration products of ... $3 \mathfrak{3}$,

chemical and physical constants of $\quad 334,374,391,401$

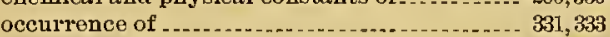
sour'ces and mode of formation of . $331-333,371,377,397$

Sea, chemical composition of .................... See also Ocean.

Sea-beach deposits of gold, term "placer" used for. 1039

Sea salt, chemical composition of

Sea water, salts contained in................. 949

Seas, inland, tufa deposits of . .............. 793

limestone formations deposited in ........... $793-795$

Seashore regions, disintegration in .............. 500-501

Secondary enlargement of minerals in rocks, discussion of . . .

Secondar.y enrichment of ore deposits, discussion of - . of ores, illustrations of ......... 1182-1189

Secondary fracture, veins produced by............. 1228

Sedimentary metamorphosed rocks, relation of stratigraphy to................. 91\%-921

Sedimentary ore deposits, enumeration of - 1233 metamorphic alterations of . ............... 1039-1043

edimentary rocks, a nalyses of ................... 938

chemical composition of materials of . ........ $556-557$

classification of .

material in solution forming ............... . 557-558

material in suspension forming . . . . . . 556-557,558

metamorphosed, and metamorphosed igneous rocks, discrimination between, criteria for ore deposits in ........................... 1033-1036 relations of belt of weathering to ... thickness, volume, and weight of ........... $989-941$ Secimentation, ores produced by Seelheim, $\mathbf{F}_{\text {., }}$ on pore space in clays
Seepage, amount of, infiuence of, on ground-water level. level .................... 425

Segregation, magmatic, ores produced by ...... 1043-1052 Segregation of individual minerals, discussion of. 645-646 Segregation of ores, discussion of . Selective precipitation, discussion of .............. 634-636 Selenite. See Gypsum.

Selenium, precipitation of gold by ................. 1092 Serpentine, alterations and alteration products of.... 349-350,353,354,367,374,391,396, 402, 404 chemical and physical constants of . .......... 200,348

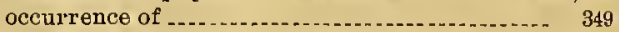
penetration of quartz by, tigure showing ....... 643 sources and modes of formation of ......... 219 , $228,268,269,273,274-275,278,285,286,288-$ $289,302,308-309,325,357,339,340,353,366$, $371,378,379,380,382,385,387,388,390,391$, $392,397,398,399,402,403,404,405,625$

Serpentinization, example of ................ 646

Serpentinized gray wacke, formation of........... 881-882

Serpentinized peridotites, ore deposits in ........ 1047

Shaler, N. S., on ants, work of, on soils............ 449

on igneous and vein material in certain New England regions, amount of ......... 127 on increase of rock volume by cementation, metasomatism, and injection ....... 65

on man's work on soil ....................... 451 on trituration of rocks, limit of ........... 432 Shaler, N. S., Woodworth, J. B., and Foerste, A.F., on occurrence of graphitic coals.... 212

Shales, carbon in ........................................ 966 chemical analyses of deposits composing . ........... 892-904 origin and character of ...... . . ferruginous, origin of ................ $829-830$ Slarples, S. P., on chemical composition of corals_. 798 Shearing, use of term, discussion of .............. 763 Shrubs, disintegrating effects of, on rocks . Siderite, alteration of, to magnetite .................. 845 alterations and alteration products of ... 244-245, 374, $378,391,392,405,406$ chemical and physical constants of .......... 200,237

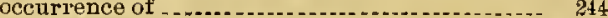
sources and modes of formation of . ...... 226, 229,233, $234,244,286,309,372,384,386,396,398,408,472$, $625,823-829$.

Siderite and marcasite, alterations and alteration products of ........................ 392,406

Siderite and pyrite, alterations and alteration products of

Siderite and quartz, alterations and alteration products of . ......... 392,407

Siderite and rutile, alterations and alteration products of . ..................... 391,400

Siderite, augite, and magnesite, alterations and alteration products of ................ 378,408

Siderite, gibbsite, magnesite, and microcline, alterations and alteration products of ... 389,401

Siderite, magnesite, and microcline, alterations and alteration products of .............. 389,401

Siderite, magnesite, and or'thoclase, alterations and alteration products of .......... 389,401 Siderite, magnesite, gibbsite, and or thoclase, alterations and alteration products of .... 389

Siderite, sahlite, and magnesite, alterations and alteration products of ............. 391,408

Sideritic rock, photomicrograph of .............. 836 
Page of gold ore of, origin of injected granite of

from soil colloidal, silicification by...................... 540,517 crystallization of, form of, dependence of, on depth...................... 185 deposition of forms of . . . . in earth's crust .................. 934,937,938,960-962 in grain and straw . .......................... 45 in mineral-spring waters. . ................... 572 in solutions, state of .

in underground water, large a mount of, where

liberation of, by action of carbon dioxide...... 480 solubility of .................................. 516-517 solution and precipitation of _.. $5 \pm 0,547,848-849,960-961$ source of, for marine organisms ............... 848 Silica family, deposits composing ................. $847-853$ See also Silicate rocks; Silica tes.

Silicate of zinc, formation of

Silicate rocks, origin of, from limestones and dolomites

$822-823$

Silicated marbles, origin of Silicates, action of carbon-dioxide solutions on ..... 475-

alkaline reactions of certain solutions of $\quad-86-87$ alterations of, summary . anhydrous, deposition of behavior of, on dissolution . . carbonation of .......... 175-176 cementation by . character, occurrence, formation, and alterations of chemical relations of, to carbonates deposition of, conditions of . ....... $625-627,1129-1132$ hydrolysis of - 86 hydrous, alterations of ......................... 519 depusition of

solubility of, increased by pressure

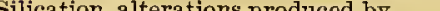
definition of ................... 168,205 depth and pressure at which carbonation replaces ........ 180-18 examples of .............. 218-219 extent of, as compared with extent of carbona tion

illustrations of

in zone of anamorphism, discussion of ....... 677-679 of carbonates, discussion of . . . . . . . . _....... 176-177 volume results of

Silication and decarbonation, alterations produced by

Silicationand dehydration, alterations prodnced by Silication and hydration, alterations produced by Silication, carbonation, and hydration, alterations produced by

Silication, dehydration, and decarbonation, altera tions produced by

Silication, hydration, and decarbonation, alterations produced by

Silication, oxidation, and decarbonation, alterations produced by ......... 408

Siliceous sinter, deposits of . ..................... 550,848

Silicic acid, acids replaced by

chemical activity of, at depths.............. 67 colloidal, dehydration of
Silicic acid oxides, niting with presence of, in ground waters ............. 93 production and deposition of -... replacement of carbonic acid by ........... 94 replacement of carbonic acid by, volumechanges resulting from .................

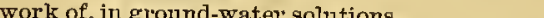

Silicification, definition of

example of ....................... 646

of calcareous formations, example of.

Silicon, chemical relations of, to carbon, discussion of . ......... 173-177

in earth's crust . . . . . . . . . . .......... 934,936,959-962

replacement of carbon by, discussion of ..... 175-177

Silicon-bearing minerals, deposition of ........... 628

Silicon compounds, specific volumes of, compared with volumes of similar carbon com-

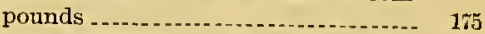

Silicon dioxide, replacement of, by carbon diox-

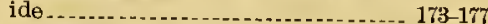

Sillimanite, alterations and alteration products of . chemical and physical constants of occurrence of . ......... 316-317 sources and modes of formation of ...... 223,221, 225, $232,317,339,342,372,379,381,383,396,406,407$

Silver, association of, with base metals native, genesis of ..... precipitation of ................... 1082, 1100-1101 salts dissolving ................. solution of -..... 1099-1100 solution of. by ferric sulphate, equation showing 1099 Silver Age mine, Idaho Springs, Colo., ore shoots near inter'secting fractures at ....... 1227

Silver-lead deposits of Aspen district of Colorado, origin of .......... 1084

Silver sulphate, reduction of, to silver sulphide,

equation showing reaction for..... 1111
Slate, definition of photomicrographs of . Slate-graywacke, deposits of, character and origin Slate-pelite, deposits of, origin and character of ......... 894-904 deposits analyses of .................... 895, 896 deposits of, origin and character of ......... 892-904 minerals of, development of . ...... 898 Slichter, C. S., diagrams cited from, showing openings in rocks . ................ 132,133 on azrangement of particles of mechanical sediments

on flow of ground waters ..... $572,576,577,582,584,1207$ on flow of water through capillary tubes.... 139-140 on most compact arrangement of molecules.... $\quad 362$ on openings in rocks .......... 125, 131-132, 137, 863,864 on pressure of underground water ......... 587 Slope, effect of, on metamorphism .............. Smaragdite, source and mode of formation of $274,372,381$ Smith, F. C., on tellurides associated with Potsdam gold ores of Black Hills. . ........ 1119

Smith, J. G, on penetration of soil by alfalfa...... Smith, W. N., acknowledgments to ............. 29 Smithsonite, occurvence and associations of .... 1147,1150 sources and modes of formation of . . Smuggler Union mine, San Juan district of Colorado, ore shoots produced by secondary fracture in...... 1228

wator in ........... 1130 
Soda in grain and straw .

Soda in rocks of various kinds

Soda in salts of sea water.

See also Sodium oxide.

Sodalite, alterations and alteration products of $\quad 295-297$, $374,392,398,403$

chemical and physical coustants of ........... 200,295 occurrence of source and mode of formation of .. $294,295,372,388,400$ Sodium, in earth's crust . . ...... . ........... 934,936,996-997 in sea salt and in the ocean ................... 943,944 minerals and rocks containing. . . . . . . . . . . 997,999 occurrence of . . ............................... 996-999

Sodium-hearing minerals, deposition of .......... 627

Sodium carbonate, hydrolysis of ................... 86

presence of, in soils.

reaction of, with zinc carbonate on iron sulphide, equation showing ..............

reversible reaction of, with magnesium snlphate.............................. 88

soluhility of sulphides in . . .

Sodium chloride, deposits of ............... $789-790,979$

in sea salt and in the ocean ... .............. 943

in soils

removed from soil annually

Sodium minerals, order of decomposition of, in rock weathering .................. 536

Sodium oxide, in earth's crust in salts of sea water ....................... 942

Sodium silicate, alkaline reaction of in solution .... hydrolysis of .

Sodium sulphide, action of sulphuric acid on, equa. tion showing ...................... 1176 solubility of sulphides in . . . . . . . . . . ...... 1106,1108

Soils, alkaline deposits in, prevention of ............ 546 alkaline deposits in, effect of on agriculture _... 543 calcinm in, agricultural henefits of ............ 92 carbon dioxide in, amount of ............... 474 chemical composition of ......................... 891 concentration of minerals in, hy ground water- 544,550 effect of agriculture on ...................... 451 effect of treezing on maintenance of, hy plants and animals ...... 441-451 $456-457,504-506$ materials ahstracted from, by plants _ _ 537-538 number and surface area of grains of .......... 496 of arid regions, composition of . . .

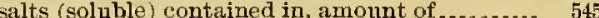
soluble material in, as effected hy comminution. 495

Solfataras, alums produced by ................... 493 chlorides produced by

gases emitted by, sources of _... metamorphic work of ........................ 490-494 products of.

Solid solutions, formation of

Solids, precipitation hy ons between solutions and .................... 120-123, 1086-1088 solution of, in ground water 72-81

Solids and liquids, gradations hetween .............

Solids held in solution, effect of on absorption of gas hy water, of solution ...............

Sollas, W. J., on cherts of organic origin ..........
Solubility, relations of, to ahsortion and liheration Solubility, relations of, to ahsortion and liheration
of heat

relations of, to pressure..... $77-79,80,101$

to temperature ......................... $79-81$ See also Solut:on.
Page.

Solution, definition of ........................... $\tau$

discussion of .... . . . . .

heat of, defined ............................... 105

extent and importance of, in belt of weather-

ing .

in belt of cementation. materjals transported in.............. 557-558 promotion of, hy pressure . . . quantitative relations between deposition and . 613 quantity of material that may be held in ....... 79-81 relations of, to absorption and liberation of heat 81

to pressure............................ $77-79,101$

to temperatme

speed of, as affected by temperatur $\theta$........... $\quad 79$

volume change resulting from ............... 78

Solution and decomposition, relations of, to disintegration ...................... 494-507

Solntion and deposition in zone of anamorphism - 680-681 Solution and suspension, materials transported in $\ldots 58$

Solutions, aqueous, circulation of . . ....... 1021-1029 aqueous, formation of ............... metamorphic worls of . precipitation by reactions between ....... 116-117 sonrce of water of $\quad$ 1065-1069 ascending, compounds deposited by ......... 1088-1132 ores precipitated from ...........10\%2-1139, 1234, 1235 ascending and descending, ores precipitated from ............................ 1193-1199 chemical action through, definition of .......... 66 chemical composition of, importance of ......... 359 chemical work of, in belt of weathering .. .... 457-461 circulation and work of . ................... 1017-1030 composition and properties of . . . . . . . . . . .... 58-59 gaseous, circulation of ..... . . . . . . . . . . . . . . . 1018-1021 formation of ................... 59

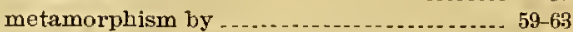
mineral spectes present in, advantages held hy - 122-123 minerals now in course of deposition by ... 1059-1060 mingling of, precipitation of metals hy ..... 1082-1085 mixture of, heat phenomena produced hy ...... 106

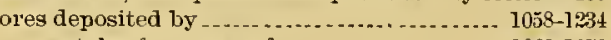
metals of, sources of .................. 1069-1072 modification of, by gaseous solutions... 1239 precipitation by reactions hetween solids and. 120-123 precipitation of abundant compounds in ....... 539 principles of, applicable to ground waters ..... 65-83 saturated, crystallization from ............... solid, formatiou of .......................... 59 sulubility of, increase of, with increase of heat.. $\quad 116$ strength of, a factor in metamorphism ........ 94-95 water of, source of . ..................... 1065-1069 Solutions and solids, precipitation by reactions between _.................. 120-123, 1086-1088 Sorhy, H. C., on enlargement of mineral particles _ 644 South Mountain district of Idaho, ore deposits and gangue minerals of ................. 1056

Spodumene, alterations and alteration products of . . . . . 280-281, 374,392,39\%, 405, 408 chemical and physical constants of ........... 200,271

occurrence of 273 Speciflc gravity of minerals, in different zones of metamol'phism, discussion of . . ... 182-185

influence of, on stability ..................... 360

of zone of anamorphism .................... 363-364

of zone of katamor phism . . .................. 363,364 
INDEX.

Spencer, J. W., on depth of decompositioll of rocks in Georgia ........................ 530 Sperry, F. L., and Penfield, S. L., on aphrosiderite at Sporr mine Spessartite, chemical and physical constants of . . 200,299 occturrence of . Spbalerite, occurrence and genesis of .......... 1151-1152 Sphene, chemical and phrsical constants of ....... 195 Spheres, compactly packed, disgram showing, to illustrate continuous openings in rocks Spine1, alterations and alteration products of - $228,374,392$ chemical and physical constants of ........... 200, 2288

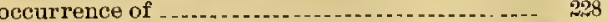
sources and modes of formation of ........... 223,224 , $225,228,232,236,302,304,307,309,341,372,375$, $376,379,381,383,388,390,396,400,401,402,408$

Spring, walther, experiments of, in compaction of clay ........... 100, 101 on production of chemical changes by mechan-

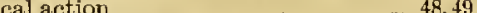

Springs, carbon dioxide exhaled by car'bonates contained in tufa deposits of . ................................. 793

Spurs, J.E., on dolomitization of limestone . ..... 800,807 on gold-quartz veins on Yukon River, Alaska_ 1048-1049 on ore deposits, genetic classification of ....... 1053 on ore deposits of Aspen mining district, Colorado on ore deposits of the Mercur mining district, Utah _ 1208,1213,1215 on ore deposits of the Monte Cristo district, Washington _. 1033,1169,1178,1187-1188, 1235 on ore production from igneous rocks........... 1043 on oxidized belt in MIonte Cristo district, coincidence of, with belt of weathering.... 1142

Stability of minerals, dependence of, on chemical composition.

dependence of, on chemical composition of ad: jacent minerals.

on chemical composition of circulating solutions $360-362$

Stable and unstable minerals, examples of ........ 359,360 Staurolite, absor ption of otber minerals in rocks by - 701 alterations and alteration products of ....... $327-329$ $3 \pi 4,393,403,406$

chemical and physical constants of .........-. 200,327 occurrence of ................... 327 sources and modes of formation of .......- 327,353,380 Steamboat Springs, Nev., mineral vein formation at. $1059,1060,1064,1066$ sulphides in solution at. teatite, See also Talc. $326,337,350-351,372,376,381,392,393,402,403$

Stevenson, J. J., on warm or hot springs of Cordilleran regions -.... 591-592 Stewart, John, and Gardner, F. D., on calcium chloride deposits near Great Salt Lake .. 542

on sodium carbonate in soil at Great Salt Lake $\quad 543$ Stilbite, alterations and alteration products of ....- 334 ,

chemical and physical constants of $\quad 364,393,400$ occurrence of . . . . . . . . .
Stilbite, sources and modes of formation of See also Desmine.

Stokes, H. N., on metals, precipitation of _. $108 \%, 1092,1102,1149$ on precipitation of sulpbides . ....... 1113,1116-1117 on production of sodic sulphide from reaction of sodic carbonate on iron sulphides, 1107 on pyrite and marcasite ..................... 1126-1127 on reaction of zinc carbonate and sodium carbonate on iron sulphide 1143 on reversible reaction of ferric and ferrous sulphates in presence of silver ......... 1100 on solubility of crold . In chemical action of plants or soils . $\quad 45$ on disintegration of rocks by plants.......... 445,454 Strain in minerals, metasomatism produced by .. 641-64 potentialization of energ 7 uy $-690-691$ Strain of rocks, discussion of ............ $46-47$ $49-50,95-98,597-602,641-642,671-675$

Strain and stress, metamor phic effect of ..... Statigraphy, igneous rocks as related to .......... $922-92$ metamorphic sedimentary rocks as related to. 917-921 metamor phism as related to ................. 907-931 Straw, percentage of potash, soda, lime, ete., in ... 454 Streams, concentration of soluble materials by .. 551-554 Stream-transported materials deposited inland, dis-

cussion of ...................... 5 metamorphic effect of See also Strain.

Stretching of rocks, use of term, discussion of ... $763-764$ Strontium, percentage of, in earth's crust. ...... 936, 1002 Strontinm oxide, per'centage of, in earth's crust Structures of rocks, category of, produced by metamoxphism . ........ 37 coarse, favorable to permanency ............... emphasis of, by weathering obliteration of, hy weathering . . ............. $526-527$ obliteration of, hy weathering . .............. $526-524$ rock flow as affecting . . .......... 760-769 variations in $1200-1217$ Struve, F. A. A., on action of earbon dioxide solutions on rocks................ $61,71,4$

Subcapillary openings in rocks, flow of water in . 143-146 Subsidence and rplift, influence of, on groundwater level................. $4: 26$

Substitution of bases, alterations produced by $-{ }_{4}$ Sudbury, Canada, nickel ores at.............. 1046-1047 Sulphate of iron, production of ................. 468 Sulphate of lime. See Calcium sulphate.

Sulphate of potash. See Potarsinm sulpbate.

Sulpbate order of rocks, features of............... 788

Sulpbates, alkaline, amount of, annually removed from soil

Sulphates, character, occurrence, formation, and alterations of .................... $357-358$ $472,952,955,957,958-9 \div 9$

Sulphation, definition of . Sulphidation, alterations produced by ........... 408 definition of Sulphidation, deoxidation, and carbonation, altera tions produced by ........ 408 Sulphide ores, occur rence and genesis of ....... 1148-1153 Sulpbides, cementing action of, in belt of cementa tion......................... 622

MON XLVII-04- -91 
Sulphides, character, occurrence, formation, and alterations of $212-216,472,622$ $627,957,9-8-859,1075,1104-1105,1108-1118$ formation of, from sulphates oxidation of, oxygen consumed in _.. 951-952,955 precipitation of gold by ............... 1095-1096

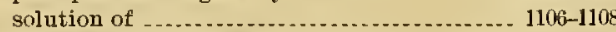
Sulphides of iron, oxidation of iron of ............ 468 volume changes incident to production of .... $468-469$ Sulphides of metals, process of extracting .......... 117 Sulphur, in earth's crust.................... 936,938,957 in ocean and sea salt. . . . . . . . . . . . . . . . . . . . . . 943-944 in rocks and meteorites . . .... . . . . . . . . . . . 957-959 oxidation of .......... Sulphur Bank, California, mineral vein formation at ....................... 1059, 1060, 1064, 106 sulphides in solution at.................... 1106 Sulphur-bearing minerals, deposition of . Sulphur compounds, oxidation of

Sulphur trioxide, percentage of, in earth's crust.

Sulphuret mines, diminution of richness in, with increase of depth

Sulphuric acid in salts of sea water $--c_{-}$

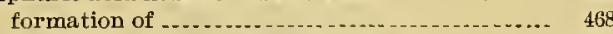

Sulphuric oxide. See Sulphur trioxide.

Sulphurous acid in ground water ..... 93 formation of . Sunlight and sun heat, metamorphic effect of ..... 51-53 Surface induratiou of rocks, discussion of ........ 546-549 Surface tension of water, strength of .............. 150 Suspension, materials transported in ............. $5006-557$ Suspension and solution, materials transported in . 558 Symmetry of crystalline forms, change of, in minerals, and molecular change, alterations produced by (1) Syenite, lossesin, by weathering, analysis showing. 508 , r.

Taconic controversy, causes of 920

Talc, chemical and physical constants of . . ...... 200,348 occurrence of $-350-351$ sources and modes of formation of ... 228, 268, 270, 273, $274,278,282,285,286,290,302,303,309,312,314$, $318,319,327,328,337,343,351,353,354,372,375$, $376,377,379,381,382,383,385,387,390,391,392$, See also Steatite. $393,394,397,398,399,402,403,404,405,406,625$

Talmage, J. E., on a remarkable occurrence of selenite ................................... 788

Teller, F., and von John, C., on zonal arrangement of metamorphic minerals periphera to intrusive masses

Telluride of gold, production of gold from, equation showing ................... 1169-1170

Tellurides, genesis of, speculations concerning - 1120-112 occurrence and associations of .............. 1119-1125 precipitation of gold by ................. 1096-1098

Tellurium, association of, with gold ................ 1170 precipitation of gold by ........................ 1091

Temperature, annual range of ................... 437 change in metamorphic effects of ...

chemical changes and deformation as affected by . chemical work in belt of weathering as affected by decrease of, precipitation of metals hy ...... 1081-1082
Temperature, gases, activity of, as affected by Page. solubility of, as affected by increase of . - granulation and recystallization as affected hy $\quad 740$ ground-water action as affected by ............. 157 ground-water level as affected by ............. 428 increase of, with increase of depth from earth's

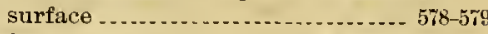
ore deposition, as affected by ..... 1015-1016, 1073-1074 precipitation by . . ......... rock disintegration as affected by ......... $434-439$ range of, at which work of water solutions is done 60

relations of, to solubility ........... $79-81$ zone of constant, in earth, depth of.......... 590 Temperature and solution, relations of . ........... 79-81 Temperature of earth at surface and helow, average ............................... 51-5: Tenorite, alteration of, to malachite, equation showing $\ldots$

formation of, equation showing ............. 1158 Tension. see Strain.

Termites, effect of work of, on soils ... ....... $448,449,456$ Textures of rocks, category of, produced by metamolphism ....... $37-38$

coarse, favorable to permanency .............

lock flow as affected by . weathering as affecting . . . . . . preservation of, after metasomatic alteration. 644-645 Tha wing and freezing, effect of, on rocks Thermal factors inrolved in chemical changes, discussion of .

Thomson, Sir William. See Kelrin.

Thomson, W., and Tait, P. G., on effects of "stress difference" ..................... 672 Thomsonite, chemical and physical constants of - 201,329 formation of, from anorthite, volume change incident to ......................... 633 occurrence of $\ldots$ sources and modes of formation of . . $292,298,295,296,372,376,388,392,402,403$ Thwing, C. B., and Austin, L. W., on volume of water at different temperatures .... 147

Tidal forces, effect of, on movements of earth's crust ............. 930 Tilden, W. A., on carbon gases inclosed in rocks . 968,969 Time as a factor in metamorphism, importance of . 41-42 Tin deposits, character of ... ......... . . . . .... 1038-1039 Tin or'es, formation of, modes of ........... 1054-1055, 1058 Titanates, character, occurrence, formation, and alteration of ...................... 354355 Titanation, definition of ......................... 205 Titanation and decarbonation, alterations produced by ......................... 400 Titaniferous iron ores, deposits of . . ............ 1044-1045 Titanite, alterations and alteration products of .... 355 , $374,393,396,401$

chemical and physical constants of .......... 201,354 occurrence of ................... 354 sources and modes of formation of ........... $2: \%$, $228,231,354,372,385,391,40 \%, 408$ Titanium, in earth's cruat and in original and sedimentaly rocks ..... ......... 933,936,974-975 Titanium dioxide, percentage of, in earth's crust. 937,938 Tolman, C. F., on balance between carhon dioxide in air and that in the ocean ........ 968 on pressure, effect of, on crystallization ........ 10: on spring's experiments in compaction of clay. 100 
Page.

Topaz, alterations aud alteration products of. 318,374,393 chemical and phrsical constants of . ......... 201,316 occurrence of - 310 Fopography, character of, effect of, on ore deposits.......................... 121\%-1221

Tourmaline, alterations and alteration products of ..................... 326-327, $374,393,400$ chemical and physical constants of . ........ 201,326 occurrence of .............................. 326 sonlees and modes of formation of .......... 396,380 Transmission of water, capacity of rocks for, determinable by capacity of imbibi-

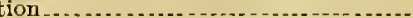

Transportation of material, agency of water solutions in

Transvaal, depth of disintegration of rocks in -.0.

Travertine, deposits of, reference to

Treadwell, F. P., and Reuter, M., on solubility of

Tree-like system, Ground-water circulation in - - - 583,58

Trees, disintegrating effects of, on rocks ........ $445-447$

Tremolite, alterations and alteration products of .- 285 , $286,290,374,393,397$

chemical and physical constants of . . .... . . .... 201, 283 formation of, from dolomite, chemical reaction involved in ....................... 822

occurrence of ..... sources and modes of formation of ......... 241,249, $274,277,279,283-284,309,354$, $372,382,383,386,40 \%, 408,822$

Tridymite, chemical and physical constants of ... 201, 220 occurrence and modifications of . . . . . . ....... 220-201 Trisilicic anorthites, chemical and physical constants of .............. 201

Tropical lands, decomposition in ............... 502

Tronghs, pitching, influence of, on ore deposition _ 1211-1216 Trunk channels of ground-water* circulation, attitudes of size and continuity of, variations in

Tschermak, Gustav, on enorphite and berlanite... 347

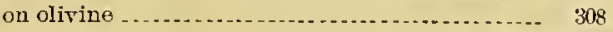

Tufa, formation of . . . .

Tuffs, cementation of .

character of . . . .

consolidation of ................. 597

gneissic, discrimination of . ................... 909

schistose, discrimination of ....... 909

U.

Unaka Mountains, 7ariable metamorphism in ..... 92 Underground circulation, variation in size and continuity of channels for .............. 1201 See also Ground water.

Uplift and subsidence,influence of, on ground-water level.

Urea, transformation of, to ammonia, formula for reaction producing

Urarorite, chemical composition of, and other data concerning ................... 201, 2019

occurrence of.$$
\text { V. }
$$

Van Hise, C. R., on alteration of clastic rocks .... on belt of cementation, depth of on cementing material, similarity of, to rock cemented
Van Hise, C. R., on chlorine, emission of, during volcanic eruptions

on clearage ................... on closure of rock openings at depths .......... 566 on crustal shortening - 7 on deformation of rocks placed in unusual positions . ............................... 188

on earth movements ......... 111, 146, 774,924,926,997 on enlargement of mineral fragments ..... $625,626,644$ on granulation and recrystallization, influence of rock character on

on igneous intrusion, periods of, coincidence of, with periods of rapid orogenic morements ...................................

on igneous intrusions, agency of, in producing iron-silica te rocks ................. 840

on gravity, domination of, in earth movements. 46 on iron-ore deposits of the Lake Stzperior region ................... 831,1194, 1216, 1219 on ore deposition . . . . . . . on ore deposits. secondary enrichment of . ..... 1188 on liquid inclusions, secondary character of .... on magnetite deposits of Michigan ............ 624 on mashing of rocks....................... $762-764$ on metals, source of .. 1030 on metamorphism, variations in, within short distances .... . . . ...

on miscibility of rock and water.......... $\% 23,1030$ on movements of ear'th's crust ............ 924,926,927 on pegmatization .......................... 727

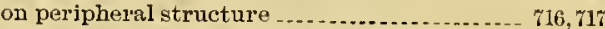
on porplyyritic crystals in scluists............. $70 \%$ on cluartz grains (flat) in rocks............... 692 on recrystallization of quartz and development of mica in rocks

on residual cores of recrystallized quartz grains of rocks. .

on replacement of quartz by iron oride ....-

on rock alteration in intermediate belt between zone of katamorphism and zone of anamorphism

on rock cleavage

on rock flowage

on schists of Lake Superior region .............. 904

on schist-conglomerates .................. 860

on secondary enrichment of ore deposits ...... 1188

on strain and fracture of rocks ............... 600

on strain in minerals, effect of ..................

on zones of fracture and flowage, subdivision of outer part of earth into ............. 187

Van Hise, C. R., and Irving, R. D., on actinolite, growth or penetration of, into quartz.......................... 218 on alteration of clastic rocks. ................... 184 on diabase from Michigan, lasses in, due to weathering -.. 511

on enlargement of mineral particles......... 644,87 on igneous intrusions, agency of, in producing iron-silicate rocks .................... 840

on iron-ore deposits, origin of ................. 831

on recementation of rocks ...................... 564

on crystallization of quartz and derelopment of mica in rocks

on rock textures (original), preservation of, after metasomatic alteartion ............. on schists of the Lake Superior region........... 187

8

(1)

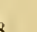

.

40

\%

6

9

8

i

4

9

7

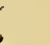

$0 \%$

94

ธ52

20

8

48

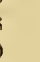

9

1


Van Hise, C. R., and Leith, C. K., on igneous intr'usions as an agency in producing ironsilicate rocks.

Valley filling, influence of, on ground-water level .

Variations in metamorphism within a single district, discussion of ................ 917-921

Varnish, desert, reference to

Vegetation, carbonation of soils promoted by ... 477 ground-water motion as affected by -.- $152,41 \%, 420-493$ rock decomposition and solution by ... $444-447,505-506$ upward transfer of material by ................. 550

Vein quartz, figure showing ...................... 1156

Venezuela, diabase from, losses in, by weathering- 508 ,

Vermiculite, alterations and alteration products

$$
\text { of }
$$

source and mode of folmation of .... $337,353,372,388$

Vertical movement of ground water, limits of ... 579-580

Vesuvianite, alterations and alteration products

$$
\text { of }
$$

chemical and physical constants of ........... 201,315

occurrence of 315

Virginia, diorite from, losses in, by weathering ...- 510 ,

gneiss from, losses in, by weathering, analyses showing .......................... 508

pyroxenite from, losses in, by weathering ...... 510

Viscosity of solutions, importance of degree of, in glound-water circulation ............ 153

Viscosity of water, decrease of, with increase of dopth from surface.......... .5 578-579

lecrease of, with increase of temperature $e_{-} 140-141,153$ table showing, for various temperatures ........ 141

Vogt, J. H. L., on cassiterite, deposition of ........ 1127 on ore deposits, production of, from igneous rocks ............... 1044,1049-1050,1051 on ores deposited from gaseous solutions . . . . . . 1054 on precipitation of silver by ferrous iron of sili-

$$
\text { cates.................................. } 1101
$$

Volcanism, effects of, on ore deposition ......... 1014-1017 Volcanoes, carbon dioxide emitted by.............. 969 vapors flom, sources of ................. 49

Volume, changes in, chemical reactions as affecting 93 , $170-171,18 ?-182,208-211,375-408,63 ?$

changes in, motasomatism as affecting .......... 63 weathering as affecting . ................. 523-524

diminution of, in rocks.................. 101-10

pressure, effects on ......................... 363-365

\section{TV.}

Wadsworth, M. E., on casehardened sandstones...- $5 \pm$ r Valcott, C. D., on source of silica for marine organisms _............................. 818

Walker, T. L., on nickel ores of Canada . . . ....... 1046 Wall rocks, ore shoot formation as affected by . 1086-1088,

Wallich, G. C., on cherts of organic origin ......... 847 Walther, Johannes, on deposits of ferromagnesian sands on disintegration of rocks by changes in temperature ........................ 437,439

Washington, H. S., Cross, Whitman, Iddings, J. P., and Pirsson, L. V, on mineral composition of amphihole-gahbro

Washington, Monte Cristo, district of. See Monte Cristo district.
Water, combined, in rocks, proportion of .......... 12 deep, deposits made in, compared with deposits made in shallow water .............. 1134

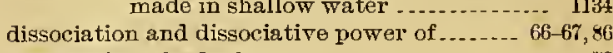
dissociation of galts $h y$........................ 73 expansion of, with increase of temperature .... $\quad 149$ flow of, through rock openings .......... 137-146 gravitative action of, metamorphism by ........ 50 ground, ascending, carbon dioxide exhaled by ascending, deposits by, eriteria for discriminating

first concentration of ores by descending, deposition of ores by ....... 1079.1080 circulation of, forces producing ........ 146-15? See also Ground water.

hot, work of, in solution and recrystallization .. 692 in minerals, granulation and recrystallization as affected by ....................... 741-748 in belt of cementation, condition of . ......... 566-569 in mines, features of . . . . . . . . . . . . . . . . . . . 1132-1134 in rocks, amount of ........... 123,934,987,938,981-983 metamorphism as affected by ............... 41 in zone of anamorphism, condition, quantity, and surfaces of . .................. $659-66$ miscibility of, with rock magma ......... 111-115, 723 movement of, below zone of anamorphism .... 668 of the ocean, source of ........... pressure necessary at different temperatures to maintain liquidity of . . . . . . . shallow, deposits made by, compared with deposits made in deep water . ......... 1134 surface, concentration of soluble materials by $551-55$ work of, in metamorphism ............. 432 viscosity of, at different depths from earth's surface........................... 578-579

at different temperatures. ............... 141, 153

Water bubhles in rocks, figure showing ........... 746

Water gas, in zone of anamorphism, action of .... $660-661$ penetration of rocks by ...................... 14t-145

Water solutions, metamorphism by .......... 602-656 pressure range at which work is done by ...... 603 temperature range at which work is done by -- 603

Watson, T. L., on losses of granites by weathering. $\quad 523$ on weathering of granitic rocks of Georgia .... $\quad 520$

Wavellite, chemical and physical constants of ..... 198

Weathering, acids going into solution during _... 536, 537 additions made to rocks in . ................... 523 belt of, alterations in, contrasted with those of

$$
\text { belt of cementation................ 166-167 }
$$

helt of oxidation coincident with .......... 1142 carbon dioxide in, amount of ............. 4 it

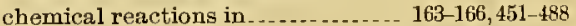
cipeulation in .............. 416-423, 1018, 1023 definition of. . . gases in, eirculation of . . . . . . . . . . . . .... 1018 limits of $\quad 43,529$ material abstract $\odot$ from, by run-off ...... 538-539 material dissolved and reprecipitated in .. 539-554 materials and conditions in . ............... 429,431 mechanical work in .... . . . . . . . . . . . . 161, $431-451$ metamorphism in . . . agencies of . . . ................... $64,430-431$ mineral concentration in. . . . . ...... . . . . 544-550 openings in, promotion of second concentration of ores by ................. 117 $7-1179$ 
Page.

Werthering, belt of, phenomena of .............. 409,56 reactions of

relations of, to sedimentary rocks....... 555-560 residual material in, distribution of . ..... 551-555 rocks produced from material of, witbout transportation to the sea ... . . . . $559-560$ temperatures in . .......................... 431 thickness of . ..................... 534535 transfer of material from, to belt of cementation............................. 538 transition from belt of cementation to.... 560-561 water in, amount and source of ........... 413-416 depth and degree of .......................... 529-533 dissolved materials resulting from, distribution of . .

effect of, on structures and textures .......... 524-526 forces and agents of ............ 539 gains and losses in . . minimum and maximum, regions of .... . .... 531-532 rate of . rock constituents lost by ........ stages of, discussion of ....................... 535 536 surfaces produced by ............. 527-528 surfaces produced by
ultimate products of $\ldots \ldots \ldots$ rolume changes in rocks by ....... ...... . . . 522-524

Webskyite, for mation and sources of $-.349,350,3 \pi 2,391,402$

Weed, W. H., figure cited from. ................ 1214 on copper deposits in Mexico . . on ore deposits of the Elkhorn mining district.. 1214 on ores, genetic classification of ................. 1053 on present mineral vein formation .... 1060, 1066, 1068 on secondary enrichment of ore deposits _._._... 1188 on travertine deposits of Mammoth Hot Springs. 1032

Weed, W. H., and Pirsson, L. V., on tellurides associated with gold ores of Judith and Little Rocky mountains, Mont....... 1119

Weidman, Samuel, on agriculture as affecting ground-water level

on deformation of rocks by combined flowage and fractur' $\Theta$............................... 1009

on devitrification

on regeneration of mineral particles ........... 705

Weight. See Specific gravity.

Welding in zone of anamorphism, extent of ..... $6 \pi 0-6$ r 1

Wells, influence of, on gronnd-water level ........ 497-428

Wells, artesian, section showing requisiteconditions for.

Wendt, Arthur F., on genesis of ore deposits ....... 1206 Wernerite, character, occurrence, formation, alterations, and alteration products of - 311-314,

Whitney, J. D., on residual clay in upper Mississippi Valley .................... 520,114

on volume changes in rocks by weathering _... 524

Whitney, Milton, on rainfall and run-off, relations of.

on sand grains and clay grains in residual jimestone subsoil, number and surface

area of ............................. 496

$$
414
$$

on soils, size of particles of . . ......

on water in arid soils. . ................. 413,418,419

Whitney, Milton, and Means, T. H., on endurance of plants to alkalies.

Whittle, C.L., on enlargement of mineral particles. 644,705 on schist conglomerates ....................... 859 Wiechmann, F. G., on atomic weights ........... 936
Willemite, deposits of Page.

Williams, G. H. dedication of monograph to

on devitrification ............................... 247

on enlargement of mineral particles............ 64

on metasomatism.......................... $68 \%$

on origin of pegmatites ............ $721-722$

on pegmatization

Willis, Bailey, on Hamilton shale, origin of ..... $886-892$

on limestone deposits in the ocean, formation of. $\quad 793$

Winchell, A. N., on Duluth gabbro, content of iron ore in . . .

Winslow, Arthur, on flexibility of rocks .......... 189 on lead and zine in limestone Wisconsin, ground water in Potsdam sandstone in, rate of flow of ................ 585,587

lead ani zinc district of, conditions in, favoring second concentration of ores.... 1177-1178

Wisconsin, University of, aid by students of ....... 29 Wolff, H. C., on capillary flow of water, retardation of, by meniseus................ 141

on water in dry soil, motion of ............. 418 Wolff, J. E., on albite crystals in Hoosac schist, orientation of ................ 876

on albite-pelite-gneiss of Hoosac Mountain..... 899

on porphyritic texture in schist .............. 687

on regeneration of mineral particles_......... 705

on schist conglomerates........................ 860

photomicrograph cited from .

Wolff, J. E., Pumpelly, Raphael, and Dale, T. N., on crystallographic orientation of porpby ritic feldspars ............ 698 Wollastonite, chemical and physical constants of . 201,271 formation of, from calcite and quartz, rolume changes involved in............... 209-210

formation of, from limestone, chemical reaction involved in 822

oceurence of

sources and modes of formation of ... $209-210,239,240$, $241,242,272-273,280,318,372,380,382,407,822$

Woods, T. H., Purington, C. W., and Doneton, G. D. on occurrence of rhodonite at the Camp Bird mine, Colo........... 1115-1116

Woodward, R. S., on mass of the atmosphere...... 944

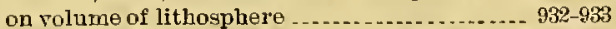
Woodworth, J. B., Shaler, N. S., and Foerste, A. F., on oceurrence of graphitic coals_.... 212

Worms, effect of work of, on soils . . .... . . ....... 448, 459

Wright, A. W., on occurrence of oxygen in meteor-

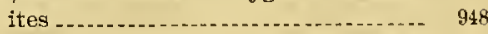

Wyatt, Francis, on precipitation of phosphates in soil f......... 541

I.

Yellowstone Park, deposits of travertine and geyserite in springs of, sources of water of Yung, M. B., and McCaffery, R. S., on copper deposits of New Mexico.............. 1056

Z.

Zeolites, alterations and alteration products of ... $333-335$ character, occurrence, formation, and alteraations of chemical and physical constants of ... 201,329-331,625 occurrence of . . ............. $331-333$ 
Zeolites, sourcesand modes of formation of - . $261-263,265,292,294,295,298,353,625$ Zine, silicate of, formation of ..................... 480 Zinc and lead regions of Mississippi Valley, cares

$$
\text { in . . }
$$

depositions in, conditions of ................. 1083, 1084 ground-water level in, effect of changes of ..... 429 Zinc blende, secondary, figure showing............. 1156 Zinc carbonate and sodium carbonate, reaction of on iron sulphide, equation showing.- 1143

Zine, lead, and iron compounds, association of - - 114t-1158

Zinc ores, associated minerals of

Zinc salts, reactions involving ................... 1151-1152

Zinc sulpbate, reaction of, on amorphons silica,

equation showing..................... $11 \pm$

reaction of, on calcium carbonate, equation showing ............................ 1147

Zinc sulphide, precipitation of, conditions govern$115+1158$

reactions involving. .......................... 1150

Zincite, occurrences of . . ......................... 11:5

production of, from smithsonite, equation show-

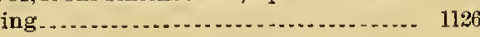

Page. Zircon, alteration and alteration product of........ 315 $374,394,402$ chemical and physical constants of ........... 201,315
hydrons, formation of ......................... 315 hydrons, formation of .......................... 315

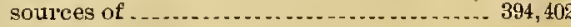
occur rence of .................................... 315 See also Malacon.

Zivkel, Ferdinand, and Naumann, C. F., on forma-

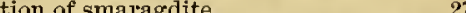

Zoisite, alterations and alteration products of ... $320-3: 3$

$374,394,399$

chemical and physical constants of ............ 201,320 occurrence of . . . . . . . . . . . . . . . . . . sources and modes of formation of . ......... 223, 225, $232,236,263,264,265,302,303,320$ $322,353,372,375,377,381,382,383$, $384,389,398,402,404,407,408,625$ Zonal arrangement of minerals consequent upon

ioneous intrusion ...... Zone. See Anamorphism; Flow age; Fracture; Katamorphism.

Zones and belts of metamorphism, definitions of... 159 $160,163,164,167,189-190$ 


\title{
PUBLICATIONS OF UNITED STATES GEOLOGICAL SURVEY.
}

\author{
[Monograph XLVI1.]
}

The serial publications of the United States Geological Survey consist of (1) Annual Reports, (2) Monographs, (3) Professional Papers, (4) Bulletins, (5) Mineral Resources, (6) Water-Supply and Irrigation Papers, (7) Topographic Atlas of the United States-folios and separate sheets thereof, (8) Geologic Atlas of the United States-folios thereof. The classes numbered 2, 7, and 8 are sold at cost of publication; the others are distributed free. A circular giving complete lists may be had on application.

\section{MONOGRAPHS.}

I. Lake Bonneville, by G. K. Gilbert. 1890. $4^{\circ} . \quad \mathrm{xx}, 438$ pp. 51 pl. 1 map. Price $\$ 1.50$. (Out of stock.)

II. Tertiary history of the Grand Cañon district, with atlas, by C. E. Dutton, Capt., U. S. A. 1882. $4^{\circ}$. xiv, $264 \mathrm{pp} .42 \mathrm{pl}$. and atlas of 24 sheets folio. Price $\$ 10$

III. Geology of the Comstock lode and the Washoe district, with atlas, by G. F. Becker. 1882. $4^{\circ}$. xv, $422 \mathrm{pp} .7 \mathrm{pl}$. and atlas of 21 sheets folio. Price $\$ 11$

IV Comstock mining and miners, by Eliot Lord. $1883.4^{\circ}$. xiv, $451 \mathrm{pp} .3 \mathrm{pl}$. Price $\$ 1.50$

$\mathrm{V}$. The copper-bearing rocks of Lake Superior, by R. D. Irving. $1883.4^{\circ}$. xvi, $464 \mathrm{pp} .15 \mathrm{l}$. $29 \mathrm{pl}$. and maps. Price $\$ 1.85$. (Ont of stock.)

VI. Contributions to the knowledge of the older Mesozoic flora of Virginia, by W. M. Fontaine. 1883. $4^{\circ}$. xi, $144 \mathrm{pp} .54 \mathrm{l}$. 5t pl. Price $\$ 1.05$.

V11. Silver-lead deposits of Eureka, Nevada, by J. S. Curtis. 188t. tº $^{\circ}$ xiii, 200 pp. 16 pl. Price $\$ 1.20$.

VIII. Paleontology of the Eureka district, by C. D. Walcott. 188t. $4^{\circ}$. xiii, 298 pp. 241.24 pl. Price $\$ 1.10$.

1X. Brachiopoda and Lamellibranchiata of the Raritan clays and greensand marls of New Jersey, by R. P. Whitfield. $1885.4^{\circ} . \quad \mathrm{xx}, 338 \mathrm{pp} .35 \mathrm{pl}$. 1 map. Price $\$ 1.15$.

X. Dinocerata A monograph of an extinct order of gigantic manmals, by 0 . C. Marsh. 1886 . $4^{\circ}$. xviii, 243 pp. 561 . 56 pl. Price $\$ 2.70$.

XI. Geological history of Lake Lahontan, a Quaternary lake of northwestern Nevada, by I. C. Russell. 1885. $4^{\circ}$. xiv, $288 \mathrm{pp}$. $46 \mathrm{pl}$. and maps. Price $\$ 1.75$.

III. Geology and mining industry of Leadville, Colorado, with atlas, by S. F. Emmons. 1886. $4^{\circ}$ xxix, $770 \mathrm{pp} .45 \mathrm{pl}$. and atlas of 35 sheets folio. Price $\$ 8.40$

XIII. Geology of the quicksilver deposits of the Pacific slope, with atlas, by G. F. Becker. 1888. $4^{\circ}$. xix, $486 \mathrm{pp} .7 \mathrm{pl}$. and atlas of 14 sheets folio. Price $\$ 2$.

XIV. Fossil fishes and fossil plants of the Triassic rocks of New Jersey and the Connecticut Valley, by J. S. Newberry. $1888.4^{\circ}$. xiv, $152 \mathrm{pp}$. $26 \mathrm{pl}$. Price $\$ 1$

XY. The Potomac ar younger Mesozoic flora, by W. M. Fontaine. $1889.4^{\circ}$. xiv, $377 \mathrm{pp} .180$ pl. Text and plates bound separately. Price \$2.50.

XVI. The Paleozoic fishes of North America, by J. S. Newberry. 1889. $t^{\circ} .340$ pp. 53 pl. Price $\$ 1$.

Xvil. The flora of the Dakota group, a posthumons work, by Leo Lesquereux. Edited by F. H. Knowlton. 1891. $t^{\circ} .400 \mathrm{pp}$. $66 \mathrm{pl}$. Price $\$ 1.10$.

xviII. Gasteropoda and Cephalopoda of the Raritan clays and greensand marls of New Jersey, by R. P. Whitfield. 1891. $4^{\circ} .402 \mathrm{pp} .50 \mathrm{pl}$. Price $\$ 1$.

IIX. The Penokee iron-bearing series of northern Wisconsin and Michigan, by R. D. Irving and C. R. Van Hise. $1892.4^{\circ}$. xix, $534 \mathrm{pp}$. Price $\$ 1.70$.

xx Geology of the Eureka district, Nevada, with an atlas, by Arnold Hague. 1892. $4^{\circ}$. xvii, 419 pp. 8 pl. Price $\$ 5.25$.

IX1. The Tertiary rhynchophorons Coleoptera of the United States, by S. H. Sculder. $1893.4^{\circ}$. xi, $206 \mathrm{pp} .12 \mathrm{pl}$. Price 90 cents.

XilI. A manual of topographic methods, by Henry Gannett, ehief topographer. 1893. $4^{\circ}$. xiv,

$300 \mathrm{pp} .18 \mathrm{pl}$. Price 81 . J. E. Wolff. 1894. 40. xiv, $206 \mathrm{pp}$. $23 \mathrm{pl}$. Price $\$ 1.30$. 
XXIV. Mollusca and Crustacea of the Miocene formations of New Jersey, by R. P. Whitfeld. 1894. $4^{\circ} .193 \mathrm{pp} .24 \mathrm{pl}$. Price 90 cents.

XXY. The Glacial Lake Agassiz, by Warren Upham. 1895. $4^{\circ} . \quad \mathrm{xxiy}, 658 \mathrm{pp} .38 \mathrm{pl}$. Price $\$ 1.70$.

XXVI. Flora of the Amboy clays, by J. S. Newberry; a posthmmous work, edited by Arthur Hollick. $1895.44^{\circ} .260 \mathrm{pp} .58 \mathrm{pl}$. Price $\$ 1$.

XY VII. Geolooy of the Denver Basin in Colorado, by S. F. Emmons, Whitman Cross, and G. H. Eldridge. $1896.44^{\circ} .556 \mathrm{pp}$. $31 \mathrm{pl}$. Price $\$ 1.50$.

XXVIII. The Marquette iron-bearing district of Michigan, with atlas, by C. R. Van Hise and W. S. Bayley, including a chapter on the Republic trough, by H. L. Smyth. 1897. $4^{\circ}$. $608 \mathrm{pp} . \quad 35 \mathrm{pl}$. and atlas of 39 sheets folio. Price $\$ 5.75$.

XXIX. Geology of old Hampshire County, Massachusetts, comprising Franklin, Hampshire, and Hampden counties, by B. K. Emerson. 1898. $4^{\circ}$. xxi, $790 \mathrm{pp}$. $35 \mathrm{pl}$. Price $\$ 1.90$.

XXX. Fossil Meduse, by C. D. Walcott. 1898. $4^{\circ}$. ix, $201 \mathrm{pp}$. $47 \mathrm{pl}$. Price $\$ 1.50$.

XXXI. Geology of the Aspen mining district, Colorado, with atlas, hy J. E. Spurr. 1898. $4^{\circ}$. $\mathrm{xxxv}, 260 \mathrm{pp}$. $43 \mathrm{pl}$. and atlas of 30 sheets folio. Price $\$ 3.60$.

YXXII Geology of the Yellowstone National Park, Part II, descriptive geology, petrography, and paleontology, by Arnold Hague, J. P. Iddings, W. H. Weed, C. D. Walcott, G. H. Girty, T. W. Stanton, and F. H. Knowlton. 1899. $4^{\circ}$. xvii, $893 \mathrm{pp} .121$ pl. Price $\$ 2.45$.

XXXIII. Geology of the Narragansett Basin, by N. S. Shaler, J. B. Woodworth, and A. F. Foerste. 1899. $4^{\circ}$. $\mathrm{xx}, 402 \mathrm{pp} .31 \mathrm{pl}$. Price $\$ 1$.

XXXIV. The glacial gravels of Miaine and their associated deposits, by G. H. Stone. 1899. $4^{\circ}$. xiii, $499 \mathrm{pp} .52 \mathrm{pl}$. Price $\$ 1.30$.

XXXV. The later extinct floras of North America, by J. S. Newberry; edited by Arthur Hollick. 1898. $4^{\circ}$. x viii, $295 \mathrm{pp} .68 \mathrm{pl}$. Price $\$ 1.25$.

XXXV1. The Crystal Falls iron-bearing district of Nichigan, by J. M. Clements and H. L. Smyth; with a chapter on the Sturgeon River tongue, by W. S. Bayley, and an introduction by C. R. Van Hise. $1899.4^{\circ}$. xxxvi, $512 \mathrm{pp}$. $53 \mathrm{pl}$. Price $\$ 2$.

XXXVII. Fossil flora of the Lower Coal Measures of Missouri, by David White. $1899 . \quad 4^{\circ} . \quad$ xi, 467 pp. $73 \mathrm{pl}$. Price $\$ 1.25$.

XXX VIII. The Illinois glacial lobe, by Frank Leverett. $1899.4^{\circ} . \quad$ xxi, 817 pp. 24 pl. Price $\$ 1.60$.

XXXIX. The Eocene and Lower Oligocene coral faunas of the United States, with descriptions of a few doubtfully Cretaceous species, by T. W. Vaughan. $1900.4^{\circ} .263 \mathrm{pp} .24 \mathrm{pl}$. Price $\$ 1.10$.

XL. Adephagous and clavicorn Coleoptera from the Tertiary deposits at Florissant, Colorado, with descriptions of a few other forms and a systematic list of the nonrhyncophorous Tertiary Coleoptera of North America, by S. H. Scudder. $1900.44^{\circ} .148 \mathrm{pp} .11 \mathrm{pls}$. Price 80 cents.

XLI. Glacial formations and drainage features of the Erie and Ohio basins, by Frank Leverett. $1902.4^{\circ} .802 \mathrm{pp} .26 \mathrm{pls}$. Price $\$ 1.75$.

XLII. Carboniferous ammonoids of America, by J. P. Smith. $1903.4^{\circ} .211$ pp. 29 pls.

Price 85 cents.
XL11I. The Mesabi iron-bearing district of Minnesota, by C. K. Leith. $1903 . \quad 4^{\circ} .316 \mathrm{pp} . \quad 33$ pls. Price $\$ 1.50$.

XLIV. Pseudoceratites of the Cretaceous, by Alpheus Hyatt, edited by T. W. Stanton. 1903. $4^{\circ} .351 \mathrm{pp} .47 \mathrm{pls}$. Price $\$ 1$.

XLV. The Vermilion iron-bearing district of Minnesota, with atlas, by J. M. Clements. 1903. $4^{\circ} .463 \mathrm{pp} .13 \mathrm{pls}$. Price $\$ 3.50$.

XLVI. The Menominee iron-bearing district of Michigan, by W. S. Bayley. 1904. $4^{\circ} .513 \mathrm{pp}$. 43 pls. Price $\$ 1.75$.

XLVII. A treatise on metamorphism, by C. R. Van Hise. 1904. $4^{\circ}$. 1286 pp. 13 pls. Price $\$ 1.50$.

All remittances must be by MONEY ORDER, made payable to the Director of the United States Geological Survey, or in curRercy - the exact amount. Checks, drafts, and postage stamps can not be accepted. Correspondence should be addressed to

The Director,

United States Geologrcal Survey,

Washington, D. C.

October, 1904. 


\section{LIBRARY CATALOGUE SLIPS.}

[Momnt each slip upon a separate card, placing the subject at the top of the second slip. The name of the series should not be repeated on the series card, but the additional numbers, as received, should be added to the first entry.]

\section{Van Hise, Charles Richard.}

... A treatise on metamorphism, by Charles Richard Van Hise. Washington, Gov't print. off., I 904.

1286, 11 p. illus., 13 pl., diagrs. $30 \frac{1}{2} \times 23^{\mathrm{cm}}$. (U. S. Geological survey. Monographs v. 47.)

Van Hise, Charles Richard.

... A treatise on metamorphism, by Charles Richard Van Hise. Washington, Gov't print. off., I904.

1286, II p. illus., 13 pl., diagrs. $30 \frac{1}{2} \times 23^{\circ m}$. (U. S. Geological survey. Monographs v. 47.)

\section{U. S. Geological survey.}

$\frac{\sin }{4}$

Monographs.

v. 47. Van Hise, C. R. A treatise on metamorphism. I 904 .

U. S. Dept. of the Interior.

see also

U. S. Geological survey. 





, 


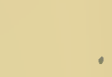$$
\text { - }
$$ 

